\title{
Testing and Data Recovery Excavations at 11 Native American Archeological Sites Along the U.S. Highway 271 Mount Pleasant Relief Route, Titus County, Texas Volume I
}

Ross C. Fields

Prewitt and Associates, Inc.

Virginia L. Hatfield

Prewitt and Associates, Inc.

Damon Burden

Prewitt and Associates, Inc.

Eloise Frances Gadus

Prewitt and Associates, Inc.

Michael C. Wilder

Prewitt and Associates, Inc.

See next page for additional authors

Follow this and additional works at: https://scholarworks.sfasu.edu/ita

Part of the American Material Culture Commons, Archaeological Anthropology Commons, Environmental Studies Commons, Other American Studies Commons, Other Arts and Humanities Commons, Other History of Art, Architecture, and Archaeology Commons, and the United States History Commons

Tell us how this article helped you.

This Article is brought to you for free and open access by the Center for Regional Heritage Research at SFA ScholarWorks. It has been accepted for inclusion in Index of Texas Archaeology: Open Access Gray Literature from the Lone Star State by an authorized editor of SFA ScholarWorks. For more information, please contact cdsscholarworks@sfasu.edu. 


\title{
Testing and Data Recovery Excavations at 11 Native American Archeological Sites Along the U.S. Highway 271 Mount Pleasant Relief Route, Titus County, Texas Volume I
}

\author{
Authors \\ Kibler \\ Creative Commons License \\ (c) $(1) \Theta \theta$
}

Ross C. Fields, Virginia L. Hatfield, Damon Burden, Eloise Frances Gadus, Michael C. Wilder, and Karl W.

This work is licensed under a Creative Commons Attribution-NonCommercial-No Derivative Works 4.0 International License. 


\title{
TESTING AND DATA RECOVERY EXCAVATIONS AT 11 NATIVE AMERICAN ARCHEOLOGICAL SITES ALONG THE U.S. HIGHWAY 271 MOUNT PLEASANT RELIEF ROUTE, TITUS COUNTY, TEXAS
}

\author{
VOLUME I \\ by \\ Ross C. Fields \\ Virginia L. Hatfield \\ Damon Burden \\ Eloise Frances Gadus \\ Michael C. Wilder \\ and \\ Karl W. Kibler
}

Principal Investigator: Ross C. Fields

REPORTS OF INVESTIGATIONS, NUMBER 168

submitted to

PTP, LP

The Woodlands, Texas

and

Titus County, Texas

by

Prewitt and Associates, Inc.

Cultural Resources Services

Austin, Texas

PAI Nos. 204042, 205010, 206053, 208001, and 209032

May 2014

TEXAS ANTIQUITIES PERMIT NOS. 3786, 4303, and 5495 


\section{VOLUME I}

CHAPTER 1: Introduction

CHAPTER 2: Testing At 41TT6, 41TT846, 41TT847, 41TT851-41TT854, 41TT858, 41TT862, 41TT865, and 41TT866

CHAPTER 3: Research Design and Field and Analysis Methods for Data Recovery Excavations

CHAPTER 4: Results of Excavations In Subarea 1 of the George Richey Site, 41TT851

CHAPTER 5: Results of Excavations in Subarea 1 of the William Ford Site, 41TT852

CHAPTER 6: Results of Excavations at the James Richey Site, 41TT853

CHAPTER 7: The Thomas B. Caldwell and A. P. Williams Cemeteries and Titus Phase Mortuary Behavior

CHAPTER 8: Interpretations and Conclusions

REFERENCES CITED

\section{VOLUME II}

APPENDIX A: Research Design for Test Excavations

APPENDIX B: Archaeogeophysical Survey

APPENDIX C: Stratigraphic Integrity Analysis for 41TT852 and 41TT853

APPENDIX D: Historic Landscape Study

APPENDIX E: Metric Data for Stone Tools (compact disk only)

APPENDIX F: Macrobotanical Plant Remains

APPENDIX G: Vertebrate Remains

APPENDIX H: Invertebrate Faunal Remains

APPENDIX I: Neutron Activation Analysis of Caddo Ceramics

APPENDIX J: Petrographic Analysis of Pottery

APPENDIX K: Analysis of the Anderson Collection 


\title{
TABLE OF CONTENTS
}

\author{
VOLUME I
}

ABSTRACT

xvii

ACKNOWLEDGMENTS

xviii

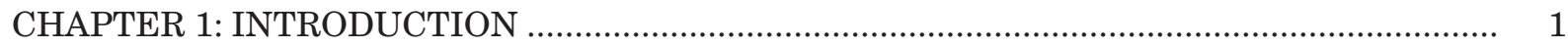

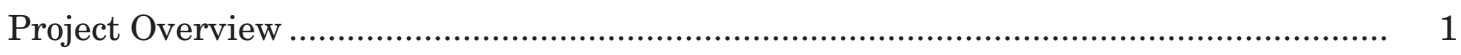

Description of the Project Area …......................................................................... 3

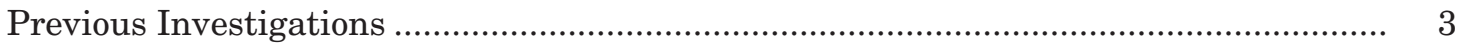

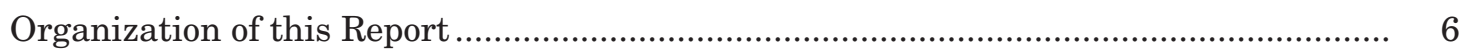

CHAPTER 2: TESTING AT 41TT6, 41TT846, 41TT847, 41TT851-41TT854, 41TT858, 41TT862, 41TT865, AND 41TT866 ........................................... 7

Project Design and Methods of Investigation................................................................. 7 Auger and Shovel Testing ............................................................................ 7

Intensive Testing ......................................................................................... 10

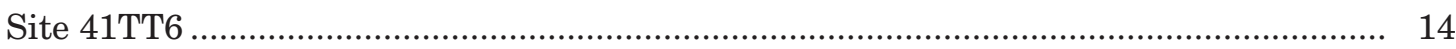

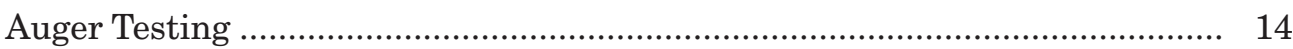

Work Accomplished in Intensive Testing .................................................... 14

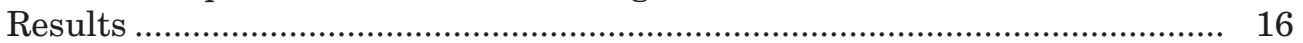

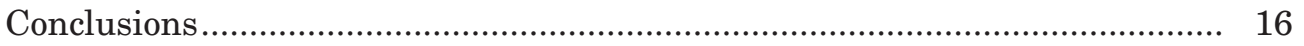

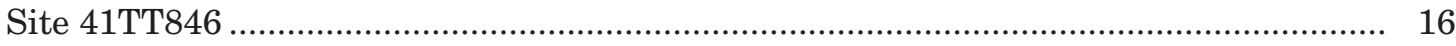

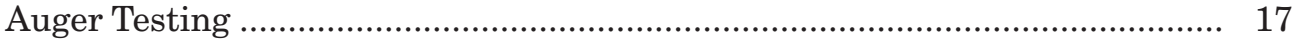

Work Accomplished in Intensive Testing .................................................... 19

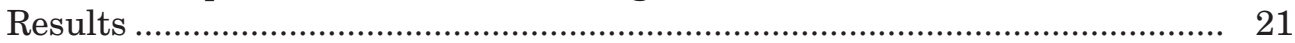

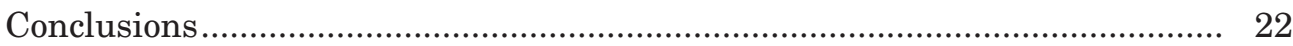

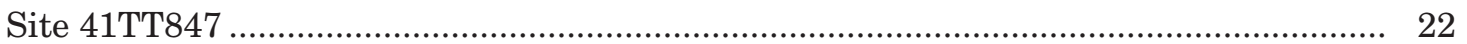

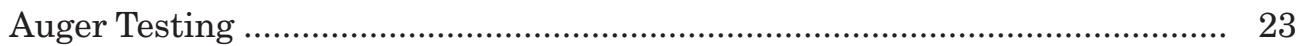

Work Accomplished in Testing................................................................. 26

Cultural Features ...................................................................................... 26

Artifact Assemblage ...................................................................................... 27

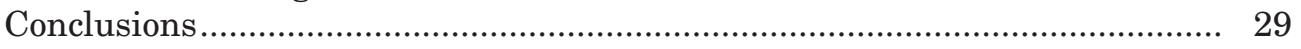

Site 41TT851

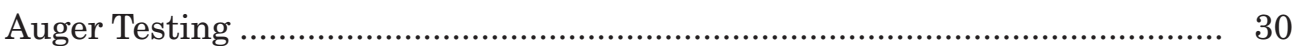

Work Accomplished in Intensive Testing ................................................... 38

Sediment Descriptions ............................................................................. 38

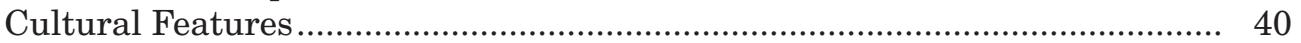

Artifact Assemblage ..................................................................................... 40

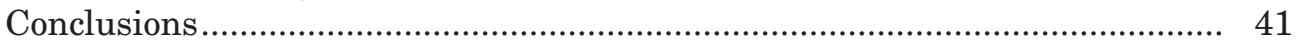

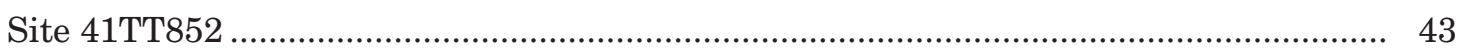

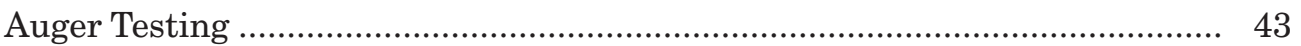

Work Accomplished in Intensive Testing ....................................................... 53

Sediment Descriptions ................................................................................. 53

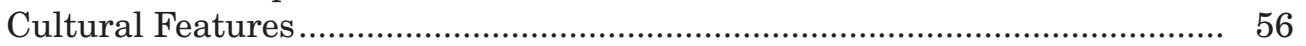




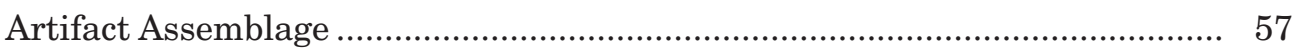

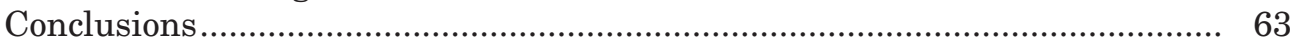

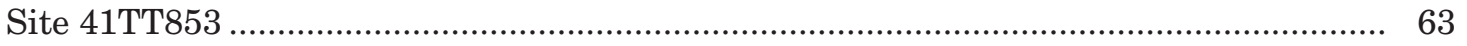

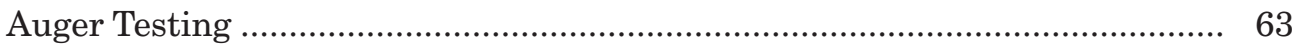

Work Accomplished in Intensive Testing ...................................................... 69

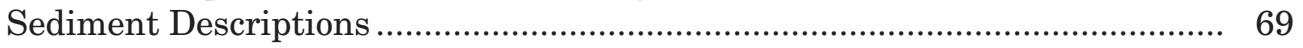

Cultural Features ......................................................................................... 71

Artifact Assemblage ............................................................................... 73

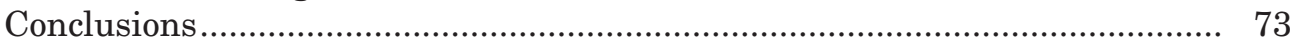

Site 41TT854

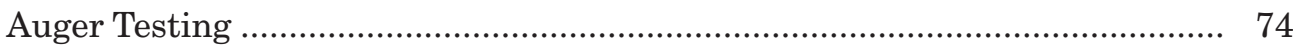

Work Accomplished in Intensive Testing ...................................................... 74

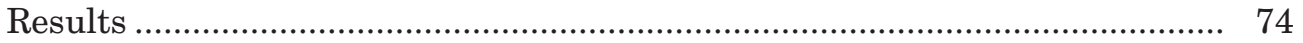

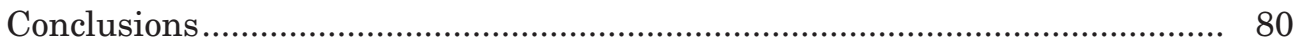

Site 41TT858

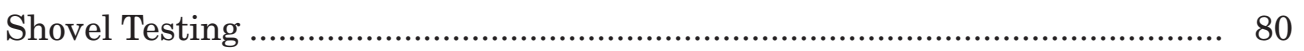

Work Accomplished in Intensive Testing ................................................ 81

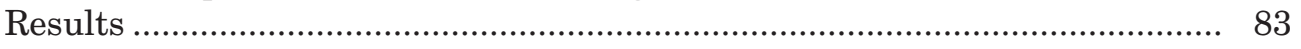

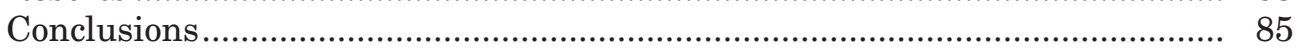

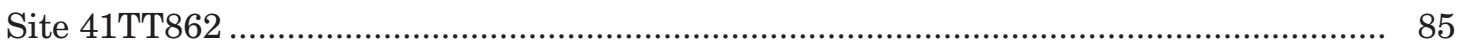

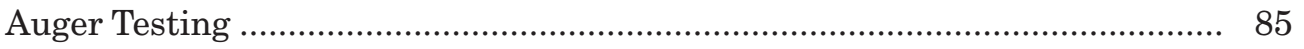

Work Accomplished in Intensive Testing ..................................................... 88

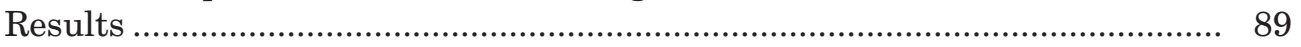

Conclusions ....................................................................................... 90

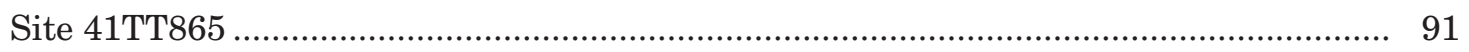

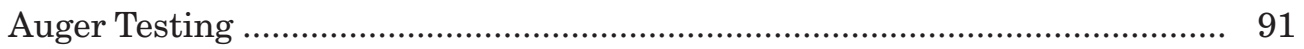

Work Accomplished in Intensive Testing ……................................................ 95

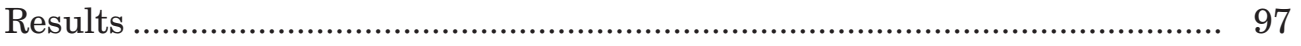

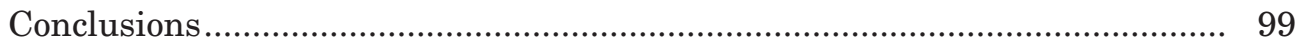

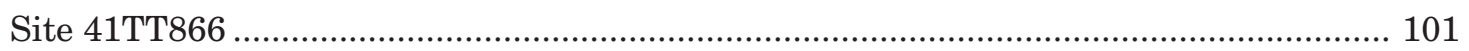

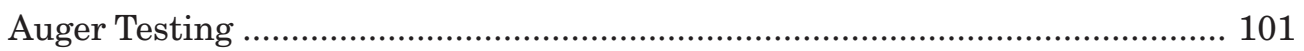

Work Accomplished in Intensive Testing ........................................................ 101

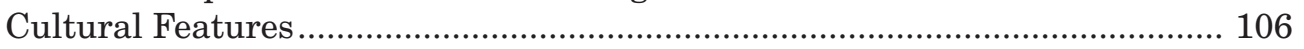

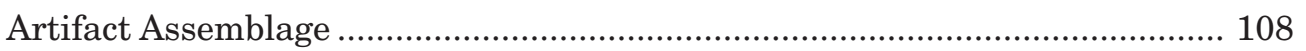

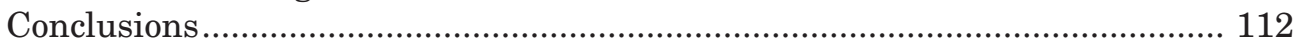

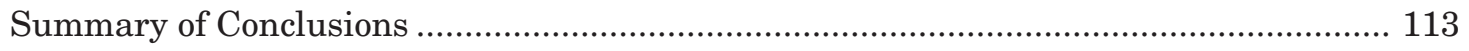

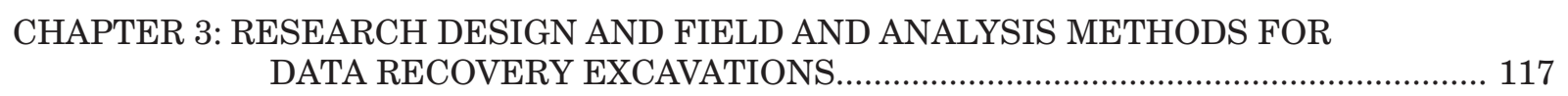

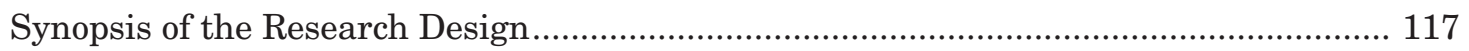

Household-Oriented Research Strategies ....................................................... 119

Community-Oriented Research Strategies .................................................. 120

Intercommunity-Oriented Research Strategies .............................................. 122

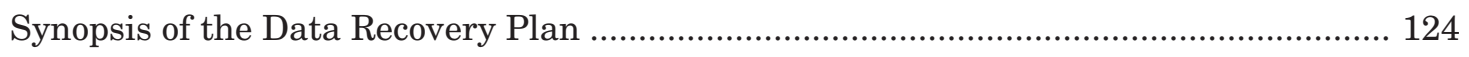

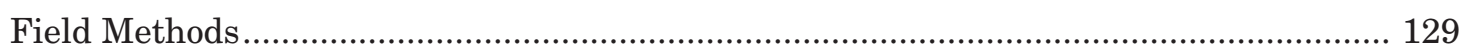

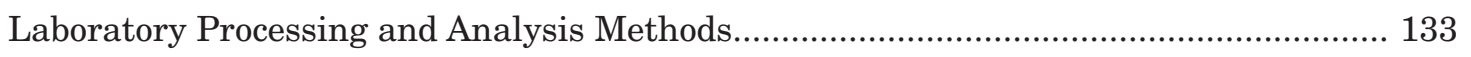

Laboratory Processing .............................................................................. 133

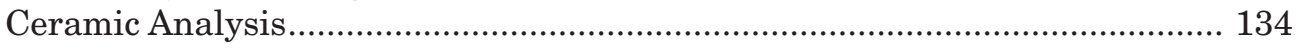




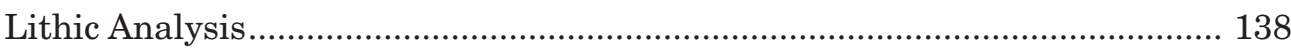

Bone Tools, Daub, Burned Clay, and Thermally Altered Rocks ....................... 144

CHAPTER 4: RESULTS OF EXCAVATIONS IN SUBAREA 1 OF THE GEORGE

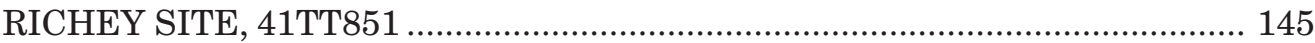

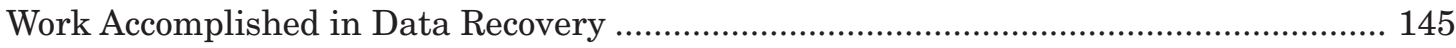

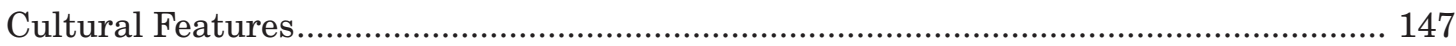

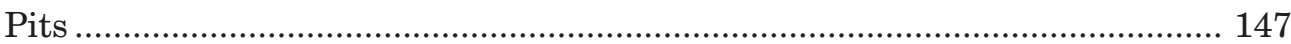

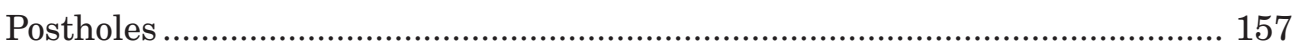

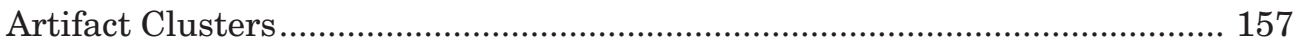

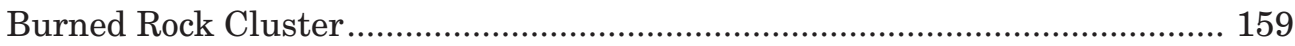

Organically Enriched Midden Sediments ....................................................... 159

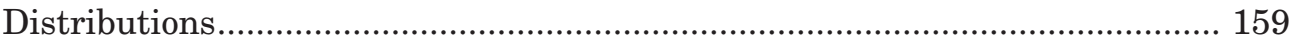

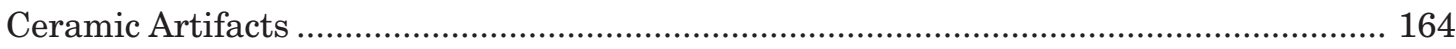

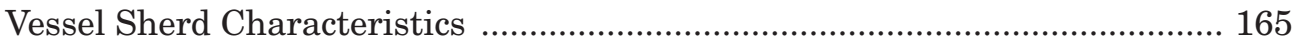

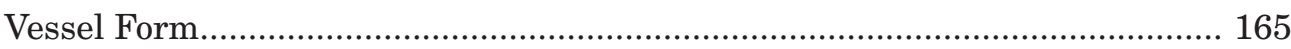

Decorative Elements, Motifs, and Ceramic Types ......................................... 167

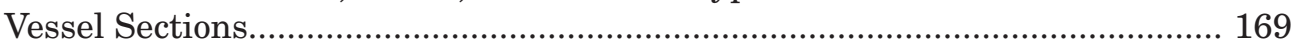

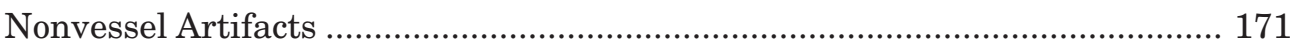

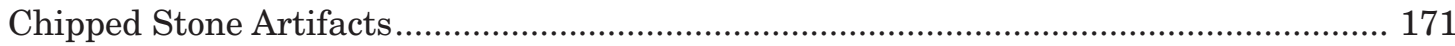

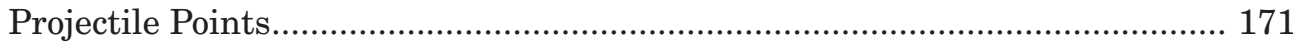

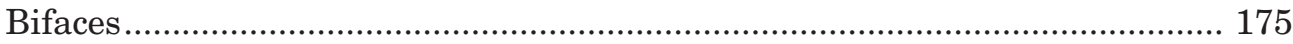

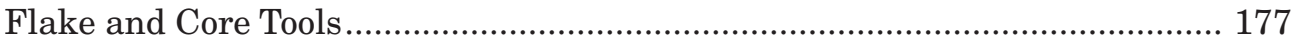

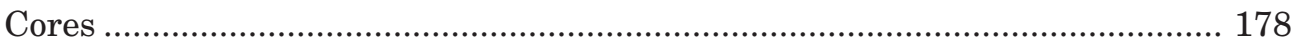

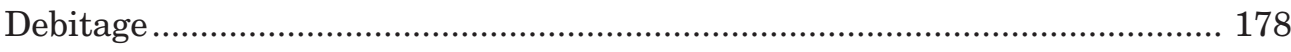

Ground, Pecked, and Battered Stone Artifacts .............................................................. 180

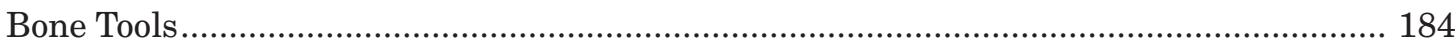

Daub, Burned Clay, and Mud Dauber Nests.............................................................. 184

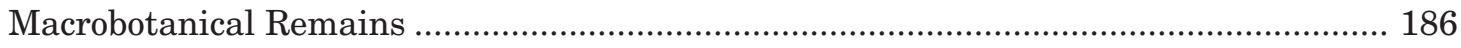

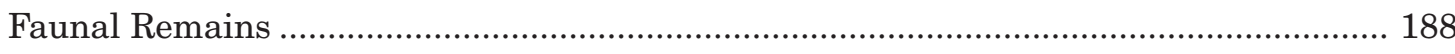

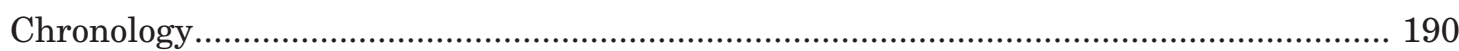

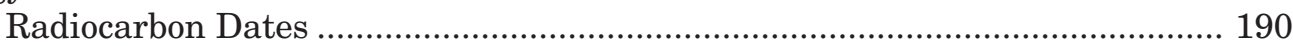

The Artifact Evidence ................................................................................. 195

Patterning in the Horizontal Distribution of Materials.................................................... 195

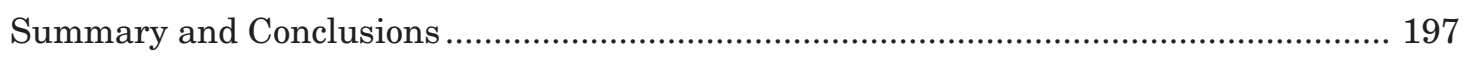

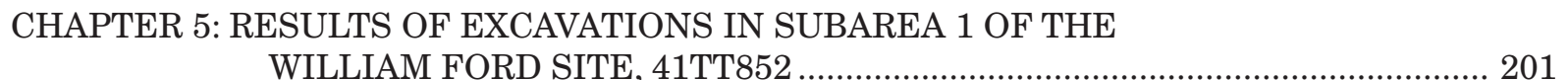

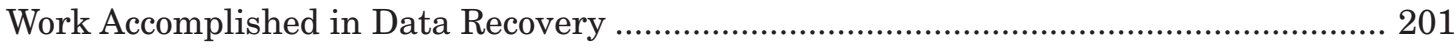

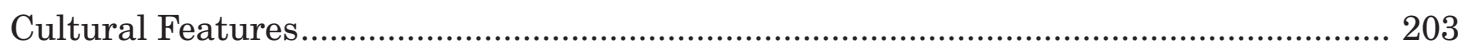

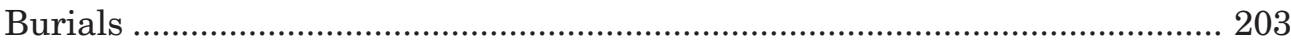

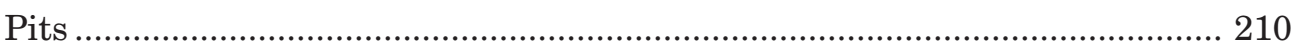

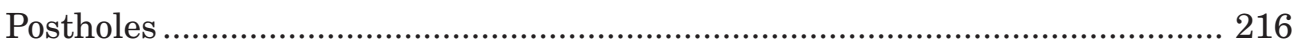

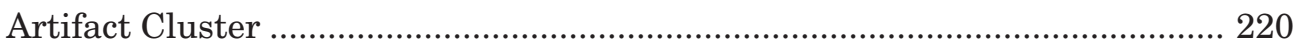

Organically Enriched Midden Sediments ....................................................... 220

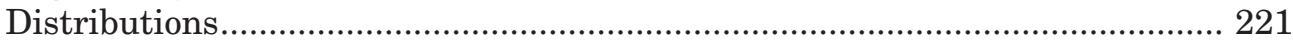

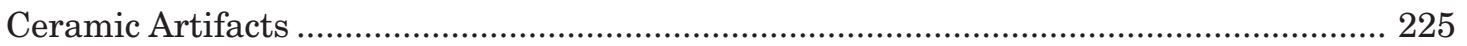




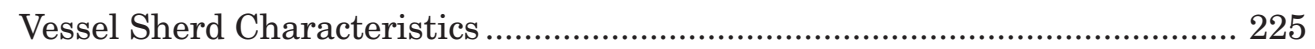

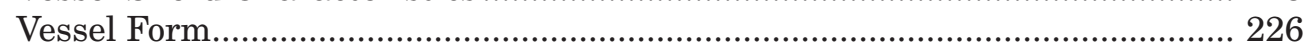

Decorative Elements, Motifs, and Ceramic Types ........................................... 226

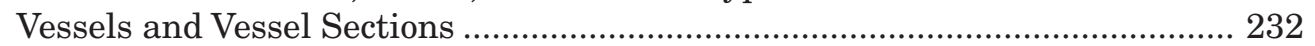

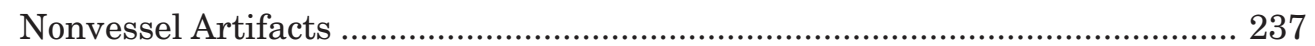

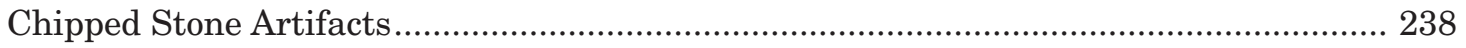

Projectile Points.............................................................................................. 238

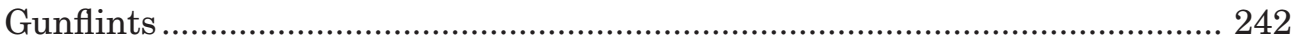

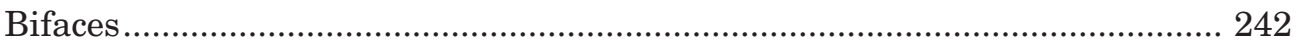

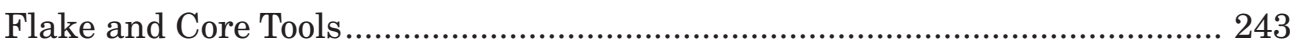

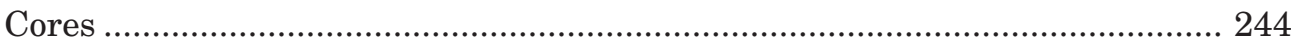

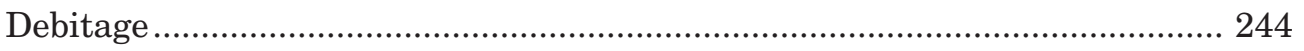

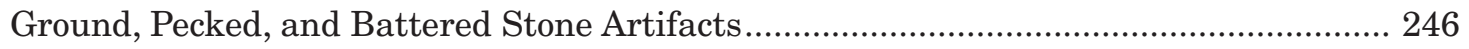

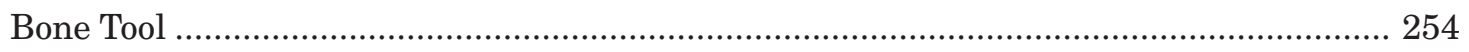

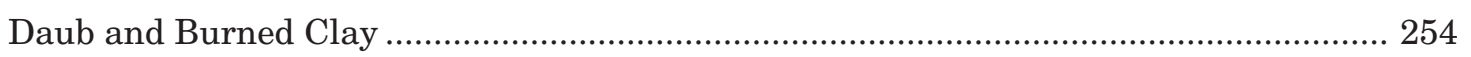

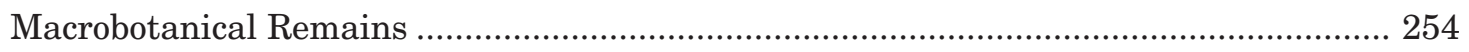

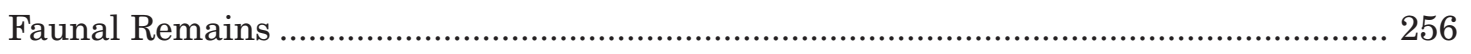

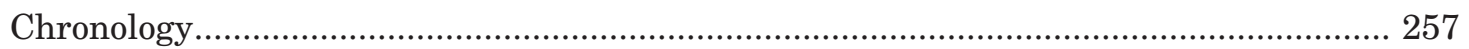

Radiocarbon Dates ...................................................................................... 257

The Artifact Evidence .................................................................................... 266

Patterning in the Horizontal Distribution of Materials................................................ 267

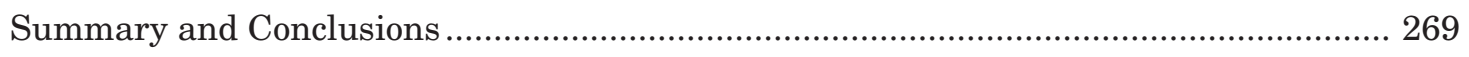

CHAPTER 6: RESULTS OF EXCAVATIONS AT THE JAMES RICHEY SITE,

Work Accomplished in Data Recovery ................................................................... 271

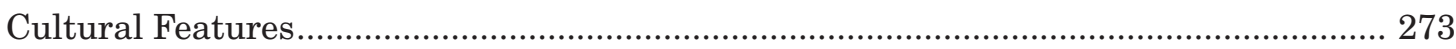

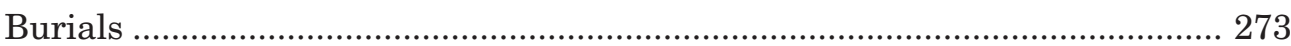

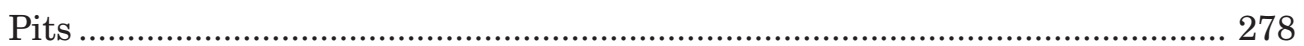

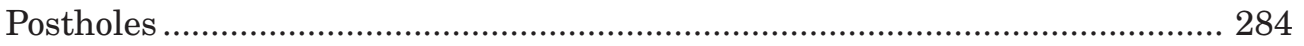

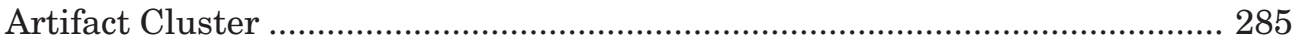

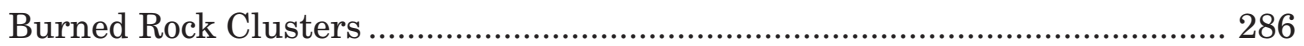

Organically Enriched Midden Sediments .................................................. 286

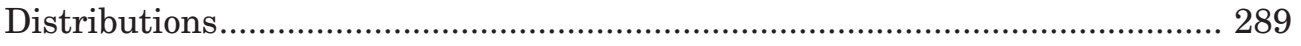

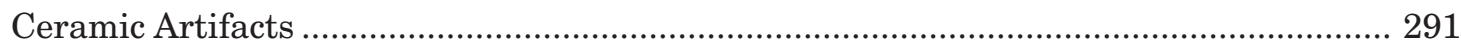

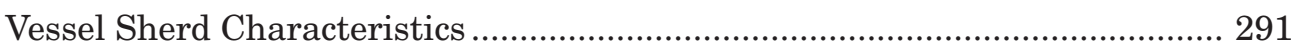

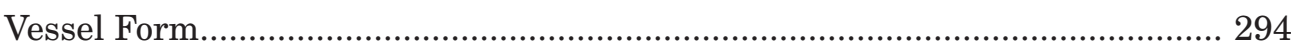

Decorative Elements, Motifs, and Ceramic Type............................................. 294

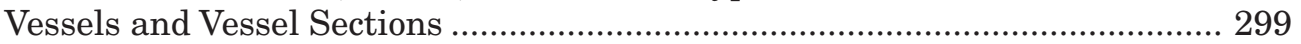

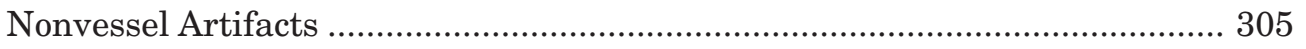

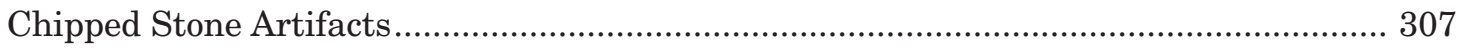

Projectile Points................................................................................. 307

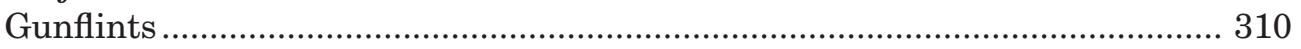

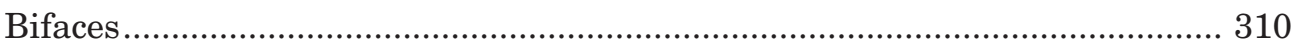

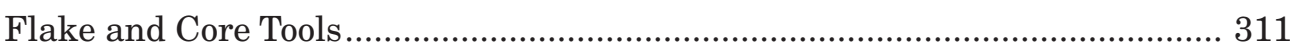

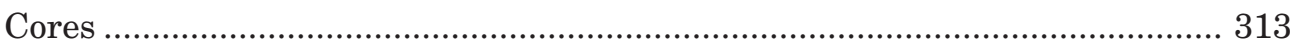

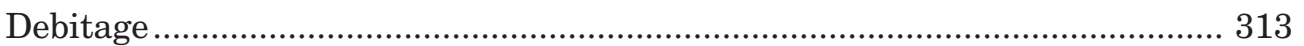




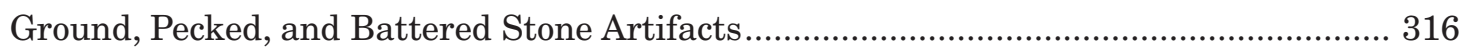

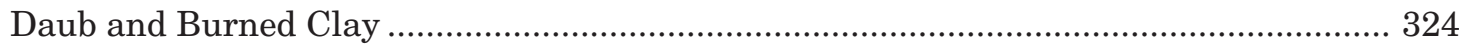

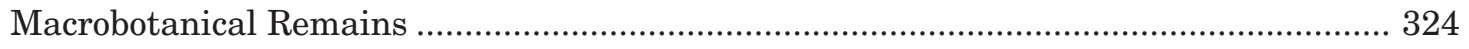

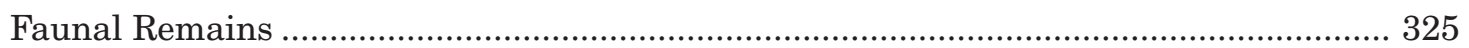

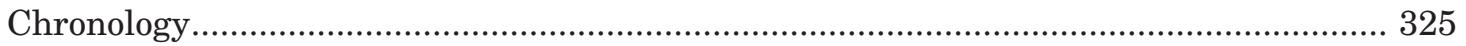

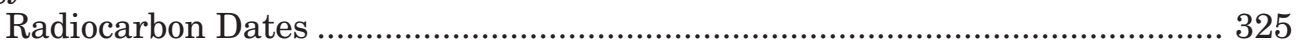

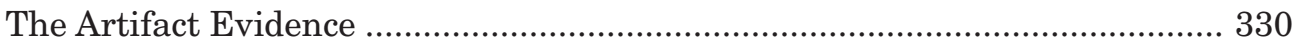

Patterning in the Horizontal Distribution of Materials.................................................. 331

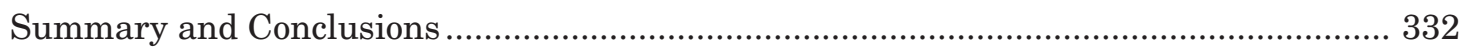

CHAPTER 7: THE THOMAS B. CALDWELL AND A. P. WILLIAMS CEMETERIES AND TITUS PHASE MORTUARY BEHAVIOR ............................................. 335

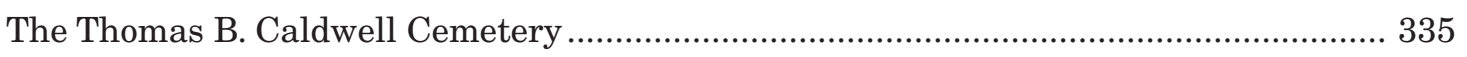

Excavation Methodology and General Results .............................................. 336

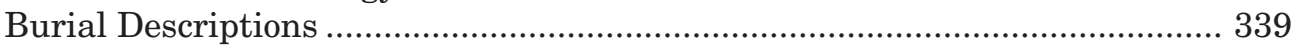

The Ceramic Assemblage ............................................................................... 345

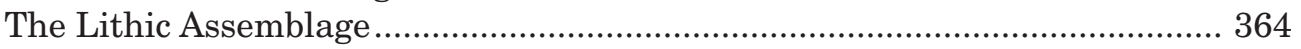

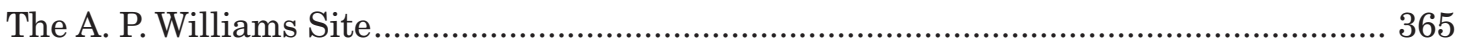

Excavation Methodology and General Results ............................................... 369

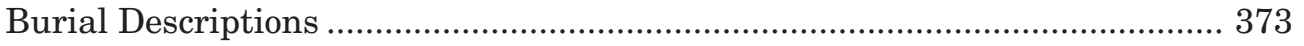

The Ceramic Assemblage ................................................................................. 378

The Lithic Assemblage ................................................................................. 398

Relationships to the George Richey, William Ford, and James Richey Sites ................... 400

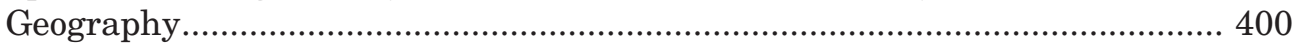

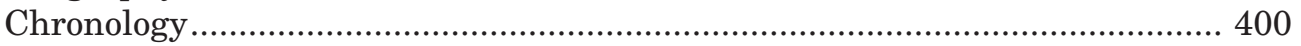

Motifs and Elements on Decorated Pottery …….............................................. 403

Titus Phase Mortuary Behavior ........................................................................ 405

CHAPTER 8: INTERPRETATIONS AND CONCLUSIONS ....................................................... 435

Native American Use of the Tankersley Creek Valley Before the

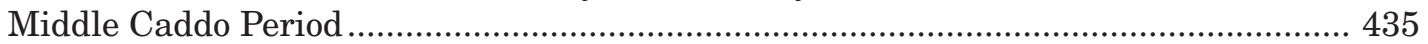

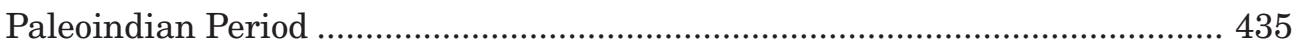

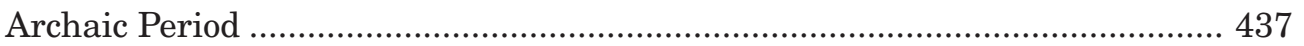

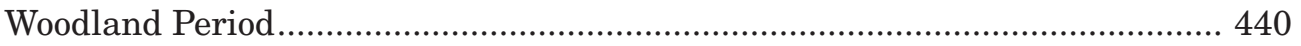

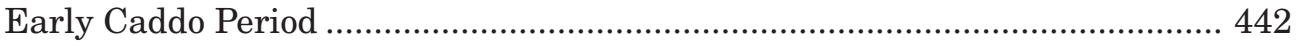

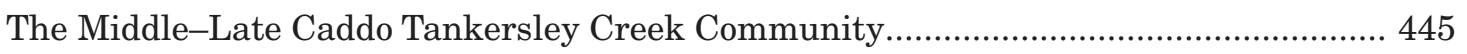

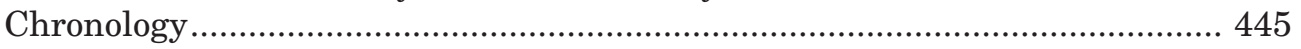

Site Layout and Function and Local Settlement Patterns ............................. 447

Use of Animals and Plants........................................................................... 450

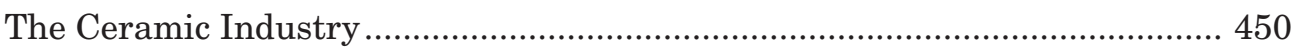

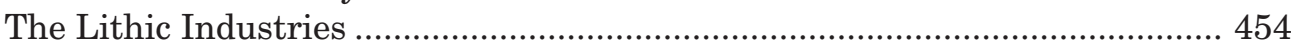

Community Organization and Extent........................................................ 455

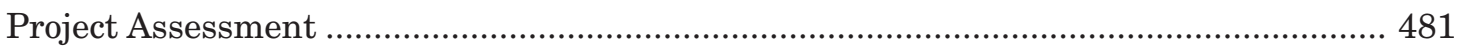

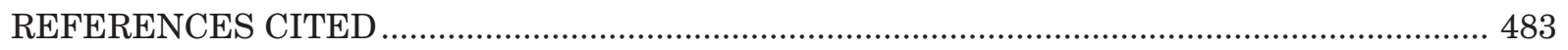




\section{LIST OF FIGURES}

1.1. Project location map

1.2. Modern aerial photograph of the U.S. Highway 271 Mount Pleasant relief route corridor

1.3. Topographic map of the project area showing site locations

2.1. Map showing the proposed relief route project area and the locations of the tested sites

2.2. Map of 41TT6 showing topography, auger test locations, and geophysical survey grid on 2005 aerial imagery

2.3. Aerial photograph of 41TT6 showing the geophysical survey grid and test excavations

2.4. Map of 41TT846 showing topography, auger test locations, and geophysical survey grids on 2005 aerial imagery.

2.5. Aerial photograph showing the 41TT846, Subarea 1 and Subarea 2 (north grid), geophysical survey grids and associated test excavations.

2.6. Aerial photograph showing the 41TT846, Subarea 2 (south grid), geophysical survey grid and associated test excavations

2.7. Map of 41TT847 showing topography, auger test locations, and geophysical survey grid on 2005 aerial imagery

2.8. Aerial photograph of 41TT847 showing geophysical survey grid and test excavations.... 26

2.9. View to the north of Features 1 and 2 in Test Units 2 and 4 at 41TT847 ...................... 27

2.10. View to the east of Feature 3 in Test Unit 11 at 41TT847 ............................................... 28

2.11. Chipped stone artifacts from $41 \mathrm{TT} 847$.....

2.12. Map of 41TT851 showing topography, auger test locations, and geophysical survey grid on 2005 aerial imagery

2.13. Aerial photograph of 41TT851 showing geophysical survey grid and test excavations

2.14. Plan showing the locations of features identified during test excavations at $41 \mathrm{TT} 851$

2.15. Map of 41TT852 showing topography, auger test locations, and geophysical survey grid on 2005 aerial imagery

2.16. Aerial photograph of 41TT852, Subarea 1, showing geophysical survey grid and test excavations.

2.17. Aerial photograph of 41TT852, Subareas 3 (south) and 4 (north), showing geophysical survey grids and test excavations

2.18. Plan of the tested area at 41TT852, Subarea 1, showing feature locations...................... 58

2.19. Plan of the tested area at 41TT852, Subarea 3, showing feature locations...................... 59

2.20. Artifacts recovered in testing in Subareas 3 and 4 at 41TT852 ................................... 61

2.21. Map of 41TT853 showing topography, auger test locations, and geophysical survey grid on 2005 aerial imagery 
2.22. Aerial photograph of $41 \mathrm{TT} 853$ showing geophysical survey grid and test excavations.

2.23. Plan of the tested area at 41TT853 showing feature locations

2.24. Map of 41TT854 showing topography, auger test locations, and geophysical survey grid on 2005 aerial imagery

2.25. Aerial photograph of 41TT854 showing geophysical survey grid and test excavations

2.26. Artifacts recovered in testing at $41 \mathrm{TT} 854$

2.27. Map of 41TT858 showing topography, auger test locations, and geophysical survey grid on 2005 aerial imagery

2.28. Aerial photograph of 41TT858 showing geophysical survey grid and test excavations....

2.29. Artifacts recovered in testing at $41 \mathrm{TT} 858$

2.30. Map of 41TT862 showing topography, auger test locations, and geophysical survey grid on 2005 aerial imagery

2.31. Aerial photograph of 41TT862 showing geophysical survey grid and test excavations

2.32. View to the north of Feature 1 exposed in Trench 12 and Test Units 6 and 9 at $41 \mathrm{TT} 862$

2.33. Stone tools recovered in testing at $41 \mathrm{TT} 862$

2.34. Map of 41TT865 showing topography, auger test locations, and geophysical survey grid on 2005 aerial imagery

2.35. Aerial photograph of 41TT865 showing geophysical survey grid and test excavations....

2.36. Artifacts recovered in testing at $41 \mathrm{TT} 865$

96

2.37. Map of 41TT866 showing topography, auger test locations, and geophysical survey grid on 2005 aerial imagery

2.38. Aerial photograph of 41TT866 showing geophysical survey grids and test excavations

2.39. Plan of the west geophysical survey grid at 41TT866 showing feature locations ............ 107

2.40. View to the east of Feature 3 exposed at the north end of Trench 35 at 41TT866. 108

2.41. View to the west of the cross section of Feature 5 in the wall of Trench 38 at $41 \mathrm{TT} 866$

2.42. View to the east of Feature 9 exposed in Trench 43 and Test Unit 8 at 41TT866.

2.43. Artifacts collected in testing at $41 \mathrm{TT} 866$

3.1. Topographic map and 2005 aerial photograph showing the locations of the George Richey, William Ford, and James Richey sites

3.2. Plan of the George Richey site, Subarea 1, showing area proposed for data recovery excavations

3.3. Plan of the William Ford site, Subarea 1, showing area proposed for data recovery excavations

3.4. Plan of the James Richey site showing area proposed for data recovery excavations ...... 
3.5. View of backhoe-excavated sample units at the George Richey site............................... 130

3.6. View of excavation of a trackhoe swath at the George Richey site ................................ 131

3.7. Views of trackhoe stripping at the George Richey and William Ford sites ..................... 132

3.8. View of the crew troweling trackhoe-stripped area at the James Richey site.................. 133

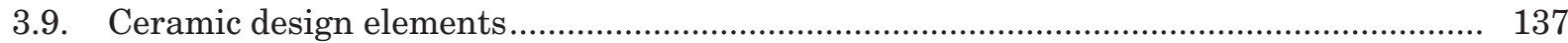

4.1. Map of Subarea 1 at the George Richey site showing the data recovery excavations ...... 146

4.2. Map of Subarea 1 at the George Richey site showing the distribution of cultural features

4.3. Cross sections of selected large pits in Subarea 1 at the George Richey site .................. 153

4.4. Cross sections of selected small pits in Subarea 1 at the George Richey site ................. 156

4.5. Cross sections of selected postholes in Subarea 1 at the George Richey site ................... 158

4.6. Photograph of burned rock cluster Feature 8 in Subarea 1 at the George Richey site....

4.7. Photograph of a section of the east wall of Trench 40 in Subarea 1 at the George Richey site showing organically enriched midden sediments in the upper part of the profile

4.8. Plan of the southern feature concentration in Subarea 1 at the George Richey site........ 162

4.9. Plan of the northern feature concentration in Subarea 1 at the George Richey site........ 164

4.10. Bowl and jar sherds with punctations, appliqué, and incising from Subarea 1 at the George Richey site

4.11. Incised jar sherds from Subarea 1 at the George Richey site ...................................... 169

4.12. Engraved bowl and bottle sherds from Subarea 1 at the George Richey site ................. 170

4.13. Vessel sections from Subarea 1 at the George Richey site

172

4.14. Arrow points recovered from Subarea 1 at the George Richey site

4.15. Dart points and point fragments from Subarea 1 at the George Richey site 176

4.16. Bifaces and flake tools recovered from Subarea 1 at $41 \mathrm{TT} 851$ 177

4.17. Full-grooved ferruginous sandstone axe from Subarea 1 at the George Richey site 181

4.18. Quartzite anvils from Subarea 1 at the George Richey site 183

4.19. Vesicular ferruginous sandstone grinding slab fragment from Subarea 1 at the George Richey site 184

4.20. Tabular abraders and grooved stone from Subarea 1 at the George Richey site 185

4.21. Bone tools from Subarea 1 at the George Richey site 186

4.22. Graph of two-sigma calibrated ranges of the 45 radiocarbon dates from Subarea 1 at the George Richey site

4.23. Distribution of ceramic sherds and total lithic artifacts across the data recovery area in Subarea 1 at the George Richey site

5.1. Map of Subarea 1 at the William Ford site showing the data recovery excavations...... 202

5.2. View to the east of excavation of the larger trackhoe swath in Subarea 1 at the William Ford site 
5.3. View to the northeast showing Feature 90, the organically enriched anthropogenic deposit, in Subarea 1 at the William Ford site

5.4. Map of Subarea 1 at the William Ford site showing the distribution of the cultural features. 205

5.5. Plan of burial Feature 164 in Subarea 1 at the William Ford site 211

5.6. Photograph of burial Feature 164 in Subarea 1 at the William Ford site 212

5.7. Plan view and profile of probable burial Feature 542A in Subarea 1 at the William Ford site.

5.8. Photograph of probable burial Feature 542A in Subarea 1 at the William Ford site ....... 214

5.9. Cross sections of selected large pits in Subarea 1 at the William Ford site .................... 215

5.10. Plans of three large pits in Subarea 1 at the William Ford site ..................................... 217

5.11. Cross sections of selected small pits in Subarea 1 at the William Ford site.................... 218

5.12. Cross sections of selected postholes in Subarea 1 at the William Ford site .................... 219

5.13. Plan of the southeastern feature concentration in Subarea 1 at the William Ford site

5.14. Plan of the northwestern feature concentration in Subarea 1 at the William Ford site

5.15. Jar sherds with punctations and incising from Subarea 1 at the William Ford site 229

5.16. Jar sherds with brushing, punctations, appliqué, and pinching from Subarea 1 at the William Ford site. 230

5.17. Engraved rim and body sherds likely representing Ripley Engraved bowls from Subarea 1 at the William Ford site 231

5.18. Engraved olla and unique bowl sherds from Subarea 1 at the William Ford site. 232

5.19. Miniature square bottle from Test Unit 9 in Subarea 1 at the William Ford site.. 233

5.20. Rim section from a large punctated jar from Feature 1 in Subarea 1 at the William Ford site

5.21. Two views of a small Ripley Engraved bowl from Feature 164 in Subarea 1 at the William Ford site

5.22. Punctated-incised jars from Subarea 1 at the William Ford site 236

5.23. Nonvessel ceramic artifacts from Subarea 1 at the William Ford site 237

5.24. Arrow points and preforms from Subarea 1 at the William Ford site 239

5.25. Dart points and preforms from Subarea 1 at the William Ford site 241

5.26. Gunflints, bifaces, and flake tools from Subarea 1 at the William Ford site 243

5.27. Celt fragments from Subarea 1 at the William Ford site 248

5.28. Mano/pitted hammerstone and anvil from Subarea 1 at the William Ford site. 250

5.29. Grinding slab/anvil from Subarea 1 at the William Ford site 251

5.30. Abrader, grooved stone, and possible unfinished stone pipe from Subarea 1 at the William Ford site 253

5.31. Modified turtle shell from Subarea 1 at the William Ford site 254 
5.32. Graph of two-sigma calibrated ranges of the 54 Middle to Late Caddo-age radiocarbon dates from Subarea 1 at the William Ford site.

5.33. Distribution of ceramic sherds and total lithic artifacts across the data recovery area in Subarea 1 at the William Ford site 268

6.1. Map of the James Richey site showing the data recovery excavations 272

6.2. Map of the James Richey site showing the distribution of cultural features 274

6.3. Plan of burial Feature 2 at the James Richey site 277

6.4. Photograph of burial Feature 2 at the James Richey site 278

6.5. Plan of burial Feature 18 at the James Richey site 279

6.6. Photograph of burial Feature 18 at the James Richey site 280

6.7. Plan of burial Feature 25 at the James Richey site 281

6.8. Photograph of burial Feature 25 at the James Richey site 282

6.9. Cross sections of large pits at the James Richey site. 283

6.10. Cross section of large pit Feature 17 at the James Richey site. 285

6.11. Photograph of large pit Feature 17 at the James Richey site 286

6.12. Cross sections of selected small pits at the James Richey site 287

6.13. Cross sections of selected postholes at the James Richey site. 288

6.14. Photograph of artifact cluster Feature 10 at the James Richey site 289

6.15. Photograph of burned rock cluster Feature 8 at the James Richey site 290

6.16. Plan showing features in the central possible house area at the James Richey site 291

6.17. Plan showing features in the possible outdoor activity area at the James Richey site.... 292

6.18. Jar rims with horizontal rows of stick and fingernail punctations from the James Richey site

6.19. Jar rims and necks with punctations and incising from the James Richey site 296

6.20. Jar sherds with brushing, punctations, and appliqué from the James Richey site. 298

6.21. Probable jar sherds with appliqué and pinching from the James Richey site 299

6.22. Ripley Engraved carinated and compound bowl sherds from the James Richey site. 300

6.23. Engraved bowl sherds with uncommon motifs and elements from the James Richey site 301

6.24. Bottle and olla sherds from the James Richey site 302

6.25. Vessels from Feature 2 at the James Richey site 303

6.26. Vessels from Feature 18 at the James Richey site 304

6.27. Vessels from Feature 25 at the James Richey site ........................................................ 306

6.28. Arrow points from the James Richey site ....................................................................... 308

6.29. Dart points from the James Richey site ........................................................................ 309

6.30. Gunflints, bifaces, and flake tools from the James Richey site....................................... 312 
6.31. Full-grooved hematite axe from the James Richey site......

6.32. Celt, adze, hammerstones, and mano/hammerstone from the James Richey site... 318

6.33. Anvil and grooved or incised stones from the James Richey site 321

6.34. Graph of two-sigma calibrated ranges of the 23 Late to Historic Caddo-age radiocarbon dates from the James Richey site.

6.35. Distribution of ceramic sherds and total lithic artifacts across the data recovery area at the James Richey site

7.1. Plan of the 1934 excavation at the Thomas B. Caldwell cemetery. 337

7.2. Plans of Burials $1-5$ at the Thomas B. Caldwell cemetery 341

7.3. Plans of Burials $6-10$ at the Thomas B. Caldwell cemetery 344

7.4. Bottles from the Thomas B. Caldwell cemetery arranged by vessel height 355

7.5. Ripley Engraved slanted scroll motifs on carinated bowls from the Thomas B. Caldwell cemetery .

7.6. Ripley Engraved straight scroll motifs on carinated bowls from the Thomas B. Caldwell cemetery 358

7.7. Ripley Engraved opposed scroll and band of alternating elements motifs on carinated bowls from the Thomas B. Caldwell cemetery

7.8. Johns Engraved and untyped carinated bowl motifs from the Thomas B. Caldwell cemetery

7.9. Decoration on Harleton Appliqué jar from the Thomas B. Caldwell cemetery 362

7.10. Decoration on untyped jar with rows of punctations on the rim and incised scroll on the body from the Thomas B. Caldwell cemetery.

7.11. Sketch map of the A. P. Williams site depicting the natural and artificial channels of Dragoo Creek and the locations of the cemetery excavation and nearby tested areas.

7.12. Plan of the 1934 excavation at the A. P. Williams cemetery. 371

7.13. Plans of Burials $1-5$ at the A. P. Williams cemetery 375

7.14. Plans of Burials $6-10$ at the A. P. Williams cemetery 376

7.15. Ripley Engraved bottles from the A. P. Williams cemetery 387

7.16. Wilder Engraved bottle from the A. P. Williams cemetery 388

7.17. Untyped bottles from the A. P. Williams cemetery 390

7.18. Ripley Engraved scroll motifs and band of alternating elements motif on carinated bowls from the A. P. Williams cemetery .... 391

7.19. Ripley Engraved motifs and untyped carinated bowl motifs from the A. P. Williams cemetery 393

7.20. Ripley Engraved motifs on compound bowls from the A. P. Williams cemetery 394

7.21. Ripley Engraved motifs on simple bowls from the A. P. Williams cemetery. 396

7.22. Map showing the locations of residential sites George Richey (41TT851), William Ford (41TT852), and James Richey (41TT853) and the cemeteries at Thomas B. Caldwell (41TT6/846), A. P. Williams (41TT4), and Duncan Anderson (41TT18). 
7.23. Graphs showing Middle-Late Caddo component chronologies indicated by radiocarbon dates from the George Richey (41TT851), William Ford (41TT852), and James Richey (41TT853) sites

7.24. Map showing the locations of the Titus phase sites with compiled burial data

7.25. Histograms showing frequency distributions for grave size, number of ceramic vessel offerings, and number of kinds of durable offerings for 238 analyzed Titus phase burials

7.26. Map of the Titus phase area showing sites with shaft graves and key sites

8.1. Map showing the locations of tested and excavated sites and important unexcavated sites in and near the Tankersley Creek drainage; only particularly notable sites are labeled

8.2. Map of the L. A. Hale site, 41TT12

8.3. Graph of the 120 radiocarbon dates (two-sigma ranges) from the U.S. Highway 271 project area that postdate A.D. 1200

8.4. Graphs showing Middle-Historic Caddo component chronologies indicated by radiocarbon dates from the George Richey, William Ford, and James Richey sites

8.5. Plans of the George Richey and William Ford sites showing farmstead layout

8.6. Map of Thurmond's (1990) Cypress cluster showing extents of hypothesized Titus phase subclusters.

8.7. Map of the extents of the key sites for the six hypothesized Titus heartland communities and Cypress subclusters

8.8. Map of the U.S. Highway 271 project vicinity showing possible integrative sites for the Tankersley Creek community

8.9. Map of the George L. Keith site 467

8.10. Map showing the locations of Titus phase cemeteries used in Ripley Engraved bowl variety comparisons

8.11. Map showing the locations of Titus phase cemeteries grouped according to frequencies of Ripley Engraved bowl varieties. 


\section{LIST OF TABLES}

2.1. Summary of work accomplished in intensive testing ...................................................

2.2. Artifacts recovered in auger and intensive testing at 41TT6 ....................................... 16

2.3. Artifacts recovered in auger and intensive testing at 41TT846 ................................... 20

2.4. Artifacts recovered in auger and intensive testing at 41TT847 ................................... 24

2.5. Artifacts recovered in auger and intensive testing at 41TT851 .................................... 32

2.6. Cultural features found in testing at 41TT851........................................................... 41

2.7. Artifacts recovered in auger and intensive testing at 41TT852 ................................... 45

2.8. Cultural features found in testing at 41TT852 ........................................................ 57

2.9. Artifacts recovered in auger and intensive testing at 41TT853 ................................... 65

2.10. Cultural features found in testing at 41TT853 ............................................................

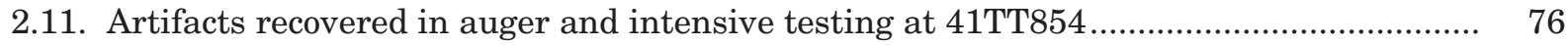

2.12. Artifacts recovered in shovel and intensive testing at 41TT858 .................................... 82

2.13. Artifacts recovered in auger and intensive testing at 41TT862 .................................... 87

2.14. Artifacts recovered in auger and intensive testing at 41TT865 ................................... 93

2.15. Artifacts recovered in auger and intensive testing at 41TT866 ................................... 102

2.16. Feature and artifact densities based on testing data................................................. 113

4.1. Summary of the cultural features in Subarea 1 at the George Richey site..................... 149

4.2. Cultural materials from pits and postholes in Subarea 1 at the George Richey site....... 154

4.3. Tempering agents in the George Richey site ceramic sherd sample............................... 165

4.4. Surface treatment and decorative attributes for the ceramic sherd sample from Subarea 1 at the George Richey site ................................................................... 166

4.5. Cores from Subarea 1 at the George Richey site........................................................ 179

4.6. Burned clay, daub, and mud dauber nests from Subarea 1 at the George Richey site ..... 187

4.7. Radiocarbon dates from Subarea 1 at the George Richey site ...................................... 191

4.8. Radiocarbon-dated contexts in Subarea 1 at the George Richey site ............................. 194

5.1. Summary of cultural features in Subarea 1 at the William Ford site ............................. 206

5.2. Cultural materials from pits and postholes in Subarea 1 at the William Ford site......... 216

5.3. Tempering agents in the ceramic sherd sample from Subarea 1 at the William Ford site

5.4. Surface treatment and decorative attributes for the ceramic vessel sample from Subarea 1 at the William Ford site 227

5.5. Cores from Subarea 1 at the William Ford site........................................................... 245

5.6. Burned clay and daub from Subarea 1 at the William Ford site.................................... 255

5.7. Radiocarbon dates from Subarea 1 at the William Ford site.......................................... 258 
5.8. Radiocarbon-dated contexts in Subarea 1 at the William Ford site............................... 263

6.1. Summary of the cultural features at the James Richey site ......................................... 275

6.2. Cultural materials from pits and postholes at the James Richey site............................. 284

6.3. Tempering agents in the ceramic sherd sample from the James Richey site.................. 292

6.4. Surface treatment and decorative attributes for the ceramic vessel sample from the James Richey site

6.5. Cores from the James Richey site .............................................................................. 314

6.6. Burned clay and daub from the James Richey site...................................................... 324

6.7. Radiocarbon dates from the James Richey site.......................................................... 326

6.8. Radiocarbon-dated contexts at the James Richey site.................................................. 329

7.1. Thomas B. Caldwell cemetery burial pit orientations and dimensions ........................... 338

7.2. Burial offerings in the Thomas B. Caldwell cemetery graves ......................................... 339

7.3. Characteristics of the ceramic vessels from the Thomas B. Caldwell cemetery............... 347

7.4. Metric data for the arrow points from the Thomas B. Caldwell cemetery....................... 366

7.5. A. P. Williams cemetery burial pit orientations and dimensions ................................... 372

7.6. Burial offerings in the A. P. Williams cemetery graves .................................................. 373

7.7. Characteristics of the ceramic vessels from the A. P. Williams cemetery …..................... 379

7.8. Metric data for the arrow points from the A.P. Williams (41TT4) cemetery.................... 399

7.9. Middle-Late Caddo ceramic types from the cemeteries at Thomas B. Caldwell, A. P. Williams, and Duncan Anderson and from residential sites George Richey, William Ford, and James Richey.....

7.10. Motifs and primary elements on Ripley Engraved bowls from the Thomas B. Caldwell, A. P. Williams, and Duncan Anderson sites.

7.11. Comparison between Pine Tree Mound site and selected other Titus phase cemeteries in terms of frequencies of offerings per grave and grave size.....

7.12. Summary of 238 burials at 14 Titus phase sites .......................................................... 408

7.13. Burials at 14 Titus phase sites grouped according to potential status indicators ........... 426

7.14. Frequencies of burials by potential status group at 14 Titus phase sites ...................... 431

8.1. Typed dart points from sites in and near the project area .......................................... 438

8.2. Breakdown of vessel forms among the ceramic sherds from the George Richey, William Ford, and James Richey sites and the vessels from the Thomas B. Caldwell, A. P. Williams, and Duncan Anderson cemeteries

8.3. Middle-Late Caddo ceramic types from the George Richey, William Ford, and James Richey sites and the Thomas B. Caldwell, A. P. Williams, and Duncan Anderson cemeteries

8.4. Summary of lithic tool assemblages from sites in and near the project area.................. 456

8.5. Summary of local vs. nonlocal materials among the lithic artifacts ............................... 458

8.6. Ripley Engraved varieties based on bowl motifs.......................................................... 473

8.7. Ripley Engraved bowl varieties in the analyzed Titus phase cemetery collections .......... 477 


\begin{abstract}
This report deals with three episodes of archeological work that began in 2005 and concluded in 2010 for the proposed U.S. Highway 271 Mount Pleasant relief route in Titus County, Texas. The early part of the work was done for the Texas Department of Transportation (TxDOT), Environmental Affairs Division. The later part was done for PTP, LP, acting on behalf of Titus County. The work was done to address the requirements of Section 16 of the National Historic Preservation Act and the Texas Antiquities Code and was governed by the terms of Texas Antiquities Permit Nos. 3786, 4303 , and 5495 .

The project involved 11 Native American archeological sites: 41TT6, 41TT846, 41TT847, 41TT851-41TT854, 41TT858, 41TT862, 41TT865, and 41TT866. The overall goal was to assess these 11 sites in terms of their eligibility for listing in the National Register of Historic Places and designation as State Antiquities Landmarks, and to conduct data recovery excavations at any that were found to be eligible. The project began with intensive auger or shovel testing at all 11 sites in July-August 2005. Formal testing was done between December 2006 and February 2008, and data recovery excavations were undertaken at three sites-George Richey (41TT851), William Ford (41TT852), and James Richey (41TT853)—between January and June 2010.

In total, the excavations consisted of the following: 1,147 auger tests at 10 sites and 31 shovel tests at the eleventh site; 386 backhoe trenches covering $2,695 \mathrm{~m}^{2}$ and $225 \mathrm{~m}^{2}$ of manual excavations at all 11 sites; and machine excavation of 215 sample units measuring $2.0 \mathrm{~m}$ long and $1.0 \mathrm{~m}$ wide on average and trackhoe stripping of about $6,875 \mathrm{~m}^{2}$ at the 3 data recovery sites.

The excavations identified 378 cultural features, mostly postholes and pits, with much smaller numbers of burials, burned rock concentrations, artifact clusters, and middens. The artifacts recovered consist mainly of 11,713 ceramic sherds and vessels and 8,729 lithic tools and debitage. Most of these remains relate to occupation of the project area during the Middle-Late Caddo periods (A.D. 1250-1700), with minor amounts resulting from earlier and later use during the Paleoindian, Archaic, Woodland, Early Caddo, and Historic Caddo periods. The primary Middle-Late Caddo components at the three fully excavated sites represent use as rural farmsteads within a dispersed local community associated with the Titus phase Caddo. At least four of the tested sites were occupied less intensively during this same interval.
\end{abstract}




\section{ACKNOWLEDGMENTS}

As this project progressed through the various phases of work, many individuals devoted time and energy to its success. Thanks go to Waldo Troell, Jim Abbott, Dennis Price, and Owen Lindauer with the Texas Department of Transportation (TxDOT), Environmental Affairs Division, for their input and assistance, particularly during the early stages, and for taking the time to make site visits. Thanks also go to Terry Plucker and Scott Young of PTP, LP, who managed the project from the latter part of testing through data recovery. Terry Plucker, in particular, was tireless in aiding our field efforts. Titus County Commissioner Mike Fields and his assistant Phillip Hoffman provided invaluable assistance as the project transitioned from TxDOT control to Titus County. Thanks also go to Jim Bruseth and Mark Denton with the Texas Historical Commission for taking the time to make site visits and for their guidance and suggestions. Dennis Cameron and machine operators John, Javier, Jose, and Steven filled all of our heavy equipment needs.

Much appreciation goes to the many individuals involved in fieldwork. In addition to being the author of the research design for the testing phase, Charles Frederick handled the geoarcheological component of the project and performed the site integrity study. Chet Walker conducted the geophysical surveys. Prewitt and Associates, Inc., personnel included the following: Ross Fields, principal investigator for all phases; Michael Wilder, project archeologist in charge of the auger testing in 2005; Karl Kibler, project archeologist for shovel testing at 41TT858 and formal testing at several sites in early 2007; Virginia Hatfield, project archeologist for testing investigations in late 2007 through early 2008 and all of the data recovery investigations in 2010; and Damon Burden, assistant project archeologist for the 2010 data recovery excavations. The field technicians who worked on various stages of this project were Roman Clem, Mark Holderby, Chris Kugler, Weldon Hammond, Greg Labudde, Marshall (Macky) MacIntosh, Matt Elverson, Ben Pollack, Ray Frye, Aaron Norment, Rob Thrift, and Jenny McWilliams.

Thanks go to those who spent the many hours involved in laboratory processing, data analysis, and report preparation. This includes all the specialists who authored the appendixes to this report, as well as Prewitt and Associates staff: Rob Thrift, who cataloged the artifacts, floated soil samples, and refitted ceramic vessels; Eloise Frances Gadus, who analyzed the ceramic artifacts; Virginia Hatfield (chipped stone) and Damon Burden (ground, pecked, and battered stone), who conducted lithic and other artifact analyses; Karen Gardner, who filled database needs and analyzed the few

shell remains recovered; Jenny McWilliams, who photographed artifacts; John Dockall, who provided consultation on lithic artifacts; Sandy Hannum and Brian Wootan, who prepared the graphics in the report; and Elaine Robbins, who copyedited this report. 


\section{INTRODUCTION}

Ross C. Fields

\section{PROJECT OVERVIEW}

This report deals with three episodes of archeological work that began in 2005 and concluded in 2010 for the proposed U.S. Highway 271 Mount Pleasant relief route in Titus County, Texas (Figure 1.1). The early part of the work was conducted for the Texas Department of Transportation (TxDOT), Environmental Affairs Division, under Work Authorization Nos. 57501SA006, 57511SA006, 57547SA006, and 57553SA006. The later part was done for PTP, LP, acting on behalf of Titus County. The work was performed to address the requirements of Section 106 of the National Historic Preservation Act and the Texas Antiquities Code and was governed by the terms of Texas Antiquities Permit Nos. 3786, 4303, and 5495.

The project involved 11 Native American archeological sites-41TT6, 41TT846, 41TT847, 41TT851-41TT854, 41TT858, 41TT862, 41TT865, and 41TT866 - that had been recorded during previous survey efforts for the relief route and that had been assessed as having the potential to contain important information. The overall goal was to assess these 11 sites in terms of their eligibility for listing in the National Register of Historic Places and designation as State Antiquities Landmarks, and to conduct data recovery excavations at any that were found to be eligible. The project began with intensive auger or shovel testing at all 11 sites in July-August 2005. In October 2005 , a research design and scope of work for formal testing were completed, and this plan was implemented between December 2006 and February 2008. The interim report on the testing, submitted in July 2008, recommended that four sites-George Richey (41TT851), William Ford (41TT852), James Richey (41TT853), and Priefert-1 (41TT866)_are eligible for National Register listing and State Antiquities Landmark designation, and a final research design and data recovery plan for these sites was submitted in May 2009. The Priefert-1 site subsequently was dropped from the list of sites needing further work because of a change in the project alignment. Data recovery at the other three sites began in January 2010 and was completed in June of that year. All of these investigations are reported in this volume.

The initial phase of work entailed the excavation of 1,147 auger tests at 10 sites and 31 shovel tests at the eleventh site. This was followed by geophysical surveys using magnetometer, resistivity meter, conductivity meter, and magnetic susceptibility meter at all 11 sites and ground-penetrating radar at 1 site; 16 grids covering almost $25,000 \mathrm{~m}^{2}$ were surveyed. Then, 386 backhoe trenches covering $2,695 \mathrm{~m}^{2}$ were spaced systematically across 15 of the survey grids at 10 of the sites, and $225 \mathrm{~m}^{2}$ of manual excavations, usually $1 \times 1-m$ test units, were placed to sample various parts of all 16 survey blocks. The data recovery excavations at the George Richey, William Ford, and James Richey sites began with the machine excavation of 215 sample units measuring $2.0 \mathrm{~m}$ long and $1.0 \mathrm{~m}$ wide on average. Then a trackhoe was used to strip about $6,875 \mathrm{~m}^{2}$ at the three sites, and the features found were excavated by hand.

The excavations identified 378 cultural features, mostly postholes and pits, with much smaller numbers of burials, burned rock concentrations, artifact clusters, and middens. The artifacts recovered consist mainly of 11,713 ceramic 


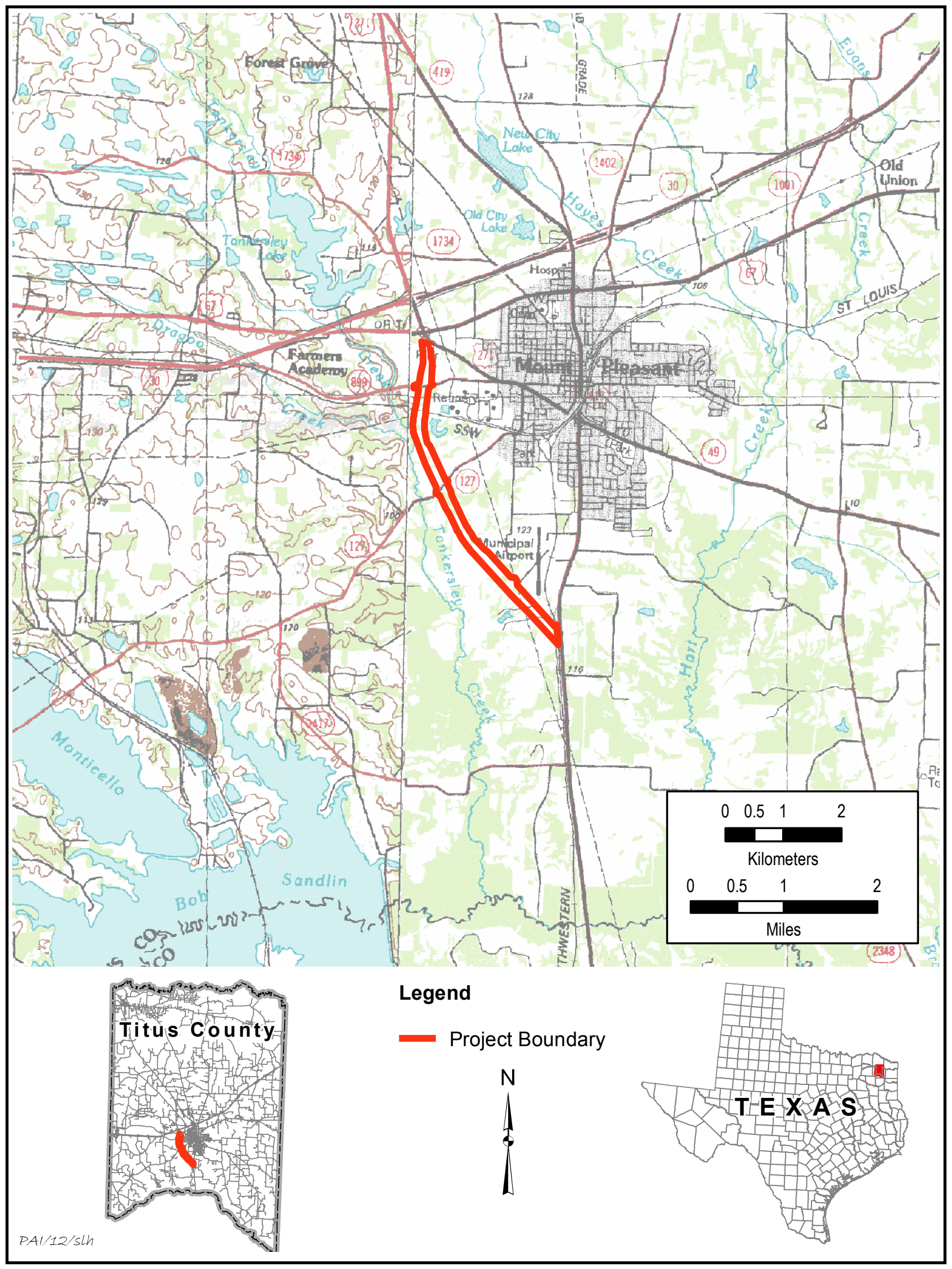

Figure 1.1. Project location map. 
sherds and vessels and 8,729 lithic tools and debitage. Most of these remains relate to occupation of the project area during the Middle-Late Caddo periods (A.D. 1250-1700), with minor amounts resulting from earlier and later use during the Paleoindian, Archaic, Woodland, Early Caddo, and Historic Caddo periods. The primary Middle-Late Caddo components at the three fully excavated sites represent use as rural farmsteads within a dispersed local community associated with the Titus phase Caddo. At least four of the tested sites were occupied less intensively during this same interval.

\section{DESCRIPTION OF THE PROJECT AREA}

The relief route for U.S. Highway 271 will swing around the southwest side of Mount Pleasant, Texas, meeting up with the current highway $4.3 \mathrm{~km}$ south and $2.7 \mathrm{~km}$ west-northwest of the center of town. The project corridor is $5.9 \mathrm{~km}$ long, varies in width from 134 to $244 \mathrm{~m}$ with an average of $189 \mathrm{~m}$, and encompasses about 275 acres of land (Figure 1.2); this excludes the $0.6-\mathrm{km}$-long northern and $3.2-\mathrm{km}$-long southern ends, which technically are part of the relief route project because the existing highway will be modified there but were not part of this archeological investigation. The relief route will be a controlled-access highway with bridges over major intersections at FM 127, FM 899, and the Union Pacific Railroad tracks.

Despite its proximity to Mount Pleasant, the project area was entirely undeveloped during fieldwork for this project. Though some parts were wooded, most of it was in improved-grass pasture used for grazing cattle. The landscape of the project corridor is dominated by a series of upland interfluves adjacent to the east side of the floodplain of Tankersley Creek, which originates $8 \mathrm{~km}$ northwest of the project area and flows south to Big Cypress Creek $4 \mathrm{~km}$ south of it (Figure 1.3). Eight tributaries of Tankersley Creek cross the project corridor northeast to southwest, but all are small and unnamed on USGS quadrangle maps; all of them appear to be spring fed. Geologically, these uplands are mapped as the Eocene Wilcox Group, with Holocene alluvium mapped for the floodplain to the west (Bureau of Economic Geology 1966). Soils are mapped chiefly as Woodtell fine sandy loam (48 percent), Wolfpen loamy fine sand (25 percent), Freestone fine sandy loam (10 percent), and Nahatche silty clay loam (10 percent); the first three are deep, moderately well drained upland soils, while the fourth is a deep, poorly drained floodplain soil (Roberts 1990).

\section{PREVIOUS INVESTIGATIONS}

Fieldwork in the current project area began in 2002, when Geo-Marine, Inc., performed an impact evaluation for the relief route project and recommended archeological survey with shovel testing and backhoe trenching in areas with deep alluvial sediments (Ahr 2002). The survey subsequently was carried out by Archeological and Environmental Consultants, LLC (AEC), and the results of this work were presented in two 2002 interim reports (Perttula and Nelson 2002a; Perttula et al. 2002) and a 2005 final report (Perttula and Nelson 2005). Based on the results of the survey, AEC recommended that 15 of the 24 sites in the project corridor as it was defined at that time warranted further investigation to determine their eligibility for National Register of Historic Places listing and State Antiquities Landmark designation. After the AEC survey investigations, the project corridor narrowed, and of the 15 sites recommended for additional work, only 11 (all or portions) were still within the project corridor as it was defined when the project reported here began. Revisions to the design subsequently removed most or all of 2 of these 11 (41TT865 and 41TT866) from the list of sites that will be impacted.

The project vicinity has been the scene of numerous archeological investigations, aside from the work in the U.S. Highway 271 relief route corridor. As of May 2013, 963 archeological sites had been recorded in Titus County, mostly as a result of lignite mining, reservoir, and transportation projects. Among the intensively investigated sites are Ear Spool, 41TT653 (Perttula and Sherman 2009); Mockingbird, 41TT550 (Perttula et al. 1998); Alex Justiss, 41TT13 (Bell 1981; Rogers et al. 2003); 41TT372 (Barnhart et al. 1997); Tankersley Creek, 41TT108 (Young 1981); A. P. Williams (Goldschmidt 1934b); and Thomas B. Caldwell, 41TT6 (Goldschmidt 1934a, 1935). The last two of these are just outside the current project area and are discussed in detail in Chapter 7. 


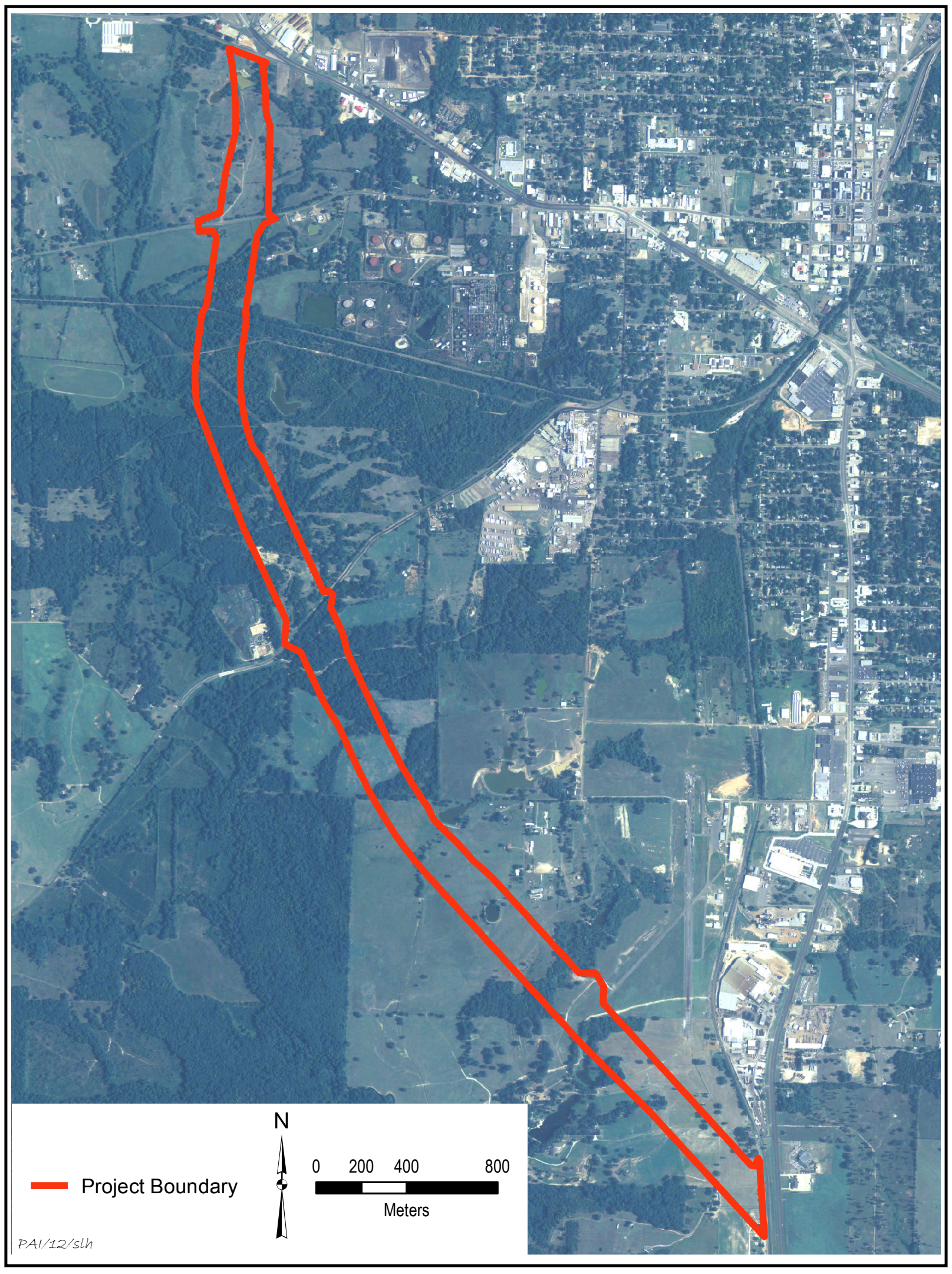

Figure 1.2. Modern aerial photograph of the U.S. Highway 271 Mount Pleasant relief route corridor. 


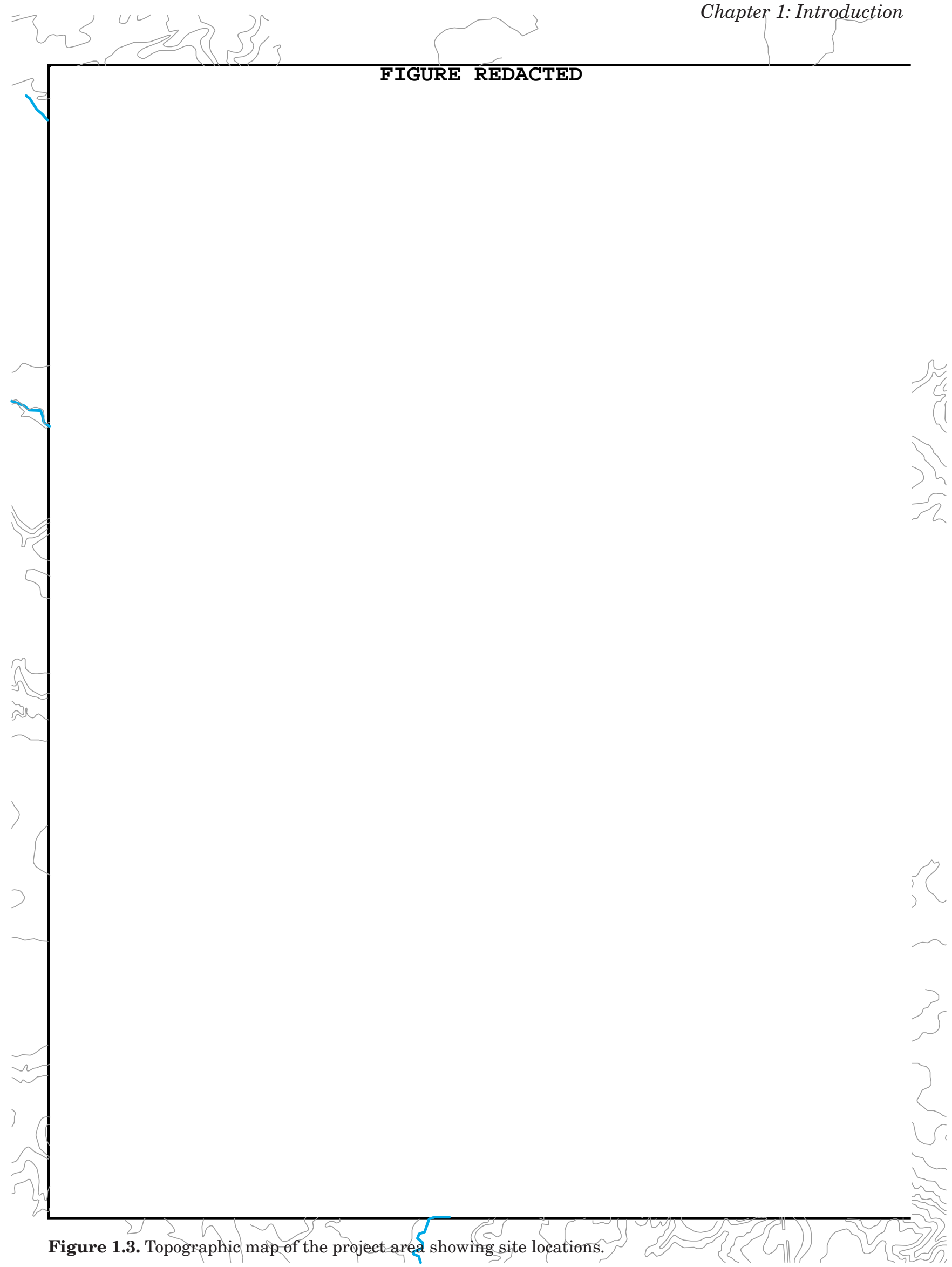




\section{ORGANIZATION OF THIS REPORT}

Chapter 2 presents the methods and results of the first two episodes of work by Prewitt and Associates on the U.S. Highway 271 Mount Pleasant relief route project-auger/ shovel testing and formal testing at all 11 sites. Chapter 3 contains the research design for the data recovery excavations at the George Richey, William Ford, and James Richey sites, along with discussions of the work accomplished at these sites and the methods used in analyzing the materials recovered in all phases of work. Chapters 4-6 present the results of the data recovery work. Chapter 7 discusses the Thomas B. Caldwell and A. P. Williams sites, two Late Caddo cemeteries just outside the project area that were excavated in the 1930s. The final chapter synthesizes previous ones and discusses how this project contributes to a better understanding of the prehistory of the area. Most of the 11 appendixes are reports of special studies performed during the testing and data recovery phases: geophysical survey (Chester P. Walker and Timothy K. Perttula), site integrity analysis (Charles D. Frederick), macrobotanical analysis (Leslie L. Bush), analyses of faunal remains (Brian S. Shaffer and Karen M. Gardner), instrumental neutron activation analysis of ceramic artifacts (Jeffrey R. Ferguson and Michael D. Glascock), and petrographic analysis of artifacts (Leslie G. Cecil). Other appendixes are the research design that guided the intensive testing part of the project, a historic landscape study done during the testing phase, a table with metric attributes of the stone tools recovered, and descriptions of artifacts in a private collection from sites across Tankersley Creek from the project area. 


\section{TESTING AT 41TT6, 41TT846, 41TT847, 41TT851-41TT854, 41TT858, 41TT862, 41TT865, AND 41TT866}

Virginia L. Hatfield, Karl W. Kibler, Ross C. Fields, Eloise Frances Gadus, Michael C. Wilder, and Damon Burden

This chapter summarizes the results of two phases of work at 41TT6, 41TT846, 41TT847, 41TT851-41TT854, 41TT858, 41TT862, 41TT865, and 41TT866 (Figure 2.1). The first consisted of intensive auger testing at 10 of these sites and shovel testing at the eleventh one (41TT858). The auger testing was done in July and August 2005 for the Texas Department of Transportation, Environmental Affairs Division, under Work Authorization No. 57511SA006 and Texas Antiquities Permit No. 3786. Auger testing was not done at 41TT858 at that time because of the lack of right of entry. That site was investigated with shovel tests in May 2007 under Work Authorization No. 57553SA006.

The second phase of work was done between March 2007 and February 2008, first under Contract No. 575XXSA006, Work Authorization No. 57553SA006, with the Texas Department of Transportation and later under a contract with PTP, LP (acting for Titus County). The Texas Historical Commission issued Texas Antiquities Permit No. 4303 for this project. The effort was designed to gather sufficient information to assess the eligibility of the 11 sites for inclusion in the National Register of Historic Places and designation as State Antiquities Landmarks, and hence address the requirements of Section 106 of the National Historic Preservation Act and the Texas Antiquities Code and their implementing regulations.

The results of these efforts are presented together here, even though they were done as separate projects under different antiquities permits, because they represent a logically connected sequence of tasks aimed at a single goal, i.e., determining which if any sites contained important information. Unlike the intensive testing, the auger testing was conceptualized as an extension of survey and was not intended to result in formal National Register and State Antiquities Landmark assessments. It did prove to be a critical step in guiding the work that would follow, though.

\section{PROJECT DESIGN AND METHODS OF INVESTIGATION}

\section{Auger and Shovel Testing}

This phase of work was intended to provide high-resolution data on the distributions and densities of artifacts across the sites to help in planning formal testing. The inspiration for this came from a thorough review of the survey data, which included plotting the locations of artifact types and frequencies within the identified site areas. Based on this review, six different site and subarea types were defined to help characterize the known resources: (1) low-density lithic scatters with no ceramics; (2) areas with middens or numerous ceramic sherds; (3) areas with moderate numbers of ceramics but no middens; (4) low-density lithic scatters with small areas having moderate lithic densities; (5) low-density lithic scatters with sparse or scattered ceramics; and (6) low-density lithic scatters with small areas having moderate lithic densities and very sparse or scattered ceramics.

This typology was not intended to constitute descriptions of formal site types, but rather to serve as a starting point for examining potential relationships between sites and parts of sites. Some of the sites and subareas within sites met expectations for Caddo hamlets or villages, while others appeared more likely to represent 


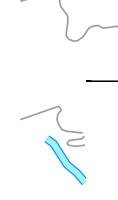

\section{FIGURE REDACTED}

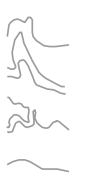

$\frac{\pi}{23}$

Figure 2.1. Map showing the proposed relief route project area and the locations of the tested sites. (Note that the right of way narrowed in some areas after testing; Figure 1.3 shows the final project limits.) 
less-intensively used residential camps and multiple types of limited-use procurement or processing areas. It was recognized, however, that the typology was based on a modicum of shovel test data, and that additional data could change both the typology and how sites and subareas fit within that typology. Hence, it was considered worthwhile to obtain more data concerning intrasite artifact distributions and frequencies.

Accordingly, a sampling plan to acquire such data quickly via intensive auger testing within previously defined site boundaries was devised. The Area of Potential Effects (APE) for this plan was considered to be a 1,000-ft-wide corridor centered on the project right of way, as then proposed, which had a normal width of 400-500 ft (see Figure 2.1); the APE was made larger than the proposed right of way to accommodate future shifts in the project alignment. In the northern part of the project area, the APE encompassed the full width of the original archeological survey area. In the southern part, substantial parts of the original survey area and four sites originally recommended for further work (41TT856, 41TT861, 41TT863, and 41TT867) were excluded from the APE.

Mechanical excavation was conducted with a 12-inch auger mounted onto a Bobcat, and auger tests were dug every $12 \mathrm{~m}$ across site areas in the project corridor, with some exceptions. A total of 1,147 tests were dug. Typically, the location of each test was established by tape and compass and marked with a pin flag, giving each auger test a unique number on a site-bysite basis. Pacing was used to mark test locations when thick vegetation prevented the use of a tape. Dense vegetation and factors such as surface topography prevented systematic $12-\mathrm{m}$ spacing of tests in some areas. In these cases, auger tests were excavated as close as possible to the intended grid position. Additionally, auger tests were not excavated in extensively disturbed or badly eroded areas. In one instance, fresh chicken sludge fertilizer dumped on the surface of a portion of a site prevented investigation of that area.

The auger testing effort was designed primarily to investigate and define horizontal variation in artifact frequencies and classes within the sites. Vertical artifact distributions and contextual integrity were issues to be examined in subsequent investigations. Therefore, each test was excavated in a single vertical increment, usually to the base of the surface sands. All excavated sediments were screened through 1/4-inch-mesh hardware cloth and examined for cultural materials. All recovered artifacts were classified by type (i.e., lithic debitage, dart point, ceramic sherd, etc.) and counted. Where allowed by landowners, all artifacts were collected. On sites where collection was not permitted (41TT852, 41TT862, 41TT866, and the northern portions of 41TT6 and 41TT846), artifacts were placed back in auger holes after they were tallied, and potentially diagnostic items were photographed. Other information recorded for each test included maximum depth, depth to clay, sediment descriptions, and presence of cultural features or other anomalies. This information was recorded on a form and later integrated with the point data collected by the GPS unit. All auger tests were backfilled immediately after recording was completed.

The 31 shovel tests excavated at $41 \mathrm{TT} 858$ also were spaced at $12-\mathrm{m}$ intervals when possible. Each test was about $35 \mathrm{~cm}$ in diameter and excavated in arbitrary $20-\mathrm{cm}$ levels until the Bt horizon was encountered. The sediments removed were screened through 1/4-inch-mesh hardware cloth and examined for cultural materials. All recovered artifacts were classified, counted, and collected. Maximum shovel test depth, depth to clay, and sediment descriptions were recorded on a form and later integrated with point data collected by the GPS unit as with the auger testing investigation. All shovel tests were backfilled.

Site boundary polygons and subareas were generated in digital format for use with ArcMap 9.1 GIS. High-resolution aerial photographs (provided by Kennedy Consulting, Inc.) were used as the base layer for field maps displaying site areas (as defined by the 2002 AEC survey), site subareas, and the project boundary. This information was downloaded into a TDS Recon PDA that was used for data collection of GPS points taken in the field. A Trimble Pathfinder Pro XRS GPS receiver unit was also used in the field. This unit provided on-site real-time data with a differential correction feature that improved horizontal locational accuracy from ca. 7-8 $\mathrm{m}$ to submeter levels (generally approximately $30 \mathrm{~cm}$ of error in horizontal location was observed in the data collected). GPS reception was generally excellent despite heavy 
tree canopy in many areas. Points could not be collected in only a few isolated instances; in those cases, a point's location was established by comparing its position to nearby collected points.

The GPS points were downloaded and corrected nightly, allowing quick field maps to be generated showing test locations. In-field access to this information helped ensure adequate coverage in investigated site areas. This method of data collection worked smoothly in the field, and the few errors that did occur were attributable to operator error. Such errors involved duplication or omission of test numbers, which were generally easily resolved through cross-checking the GPS files with the paper records. Following completion of fieldwork, the information recorded on paper forms for each auger and shovel test was entered into a Microsoft Excel spreadsheet and tabulated by site. The locational information recorded by the GPS unit was converted into a shape file (using the Pathfinder program) and imported into the GIS. The spreadsheet was then joined to the shape file using auger test (or shovel test) number as the common field. Once this task was accomplished, an integrated database for each site was created, with UTM coordinates for each test and associated data for each point. This process allowed the generation of maps depicting artifact types and densities across the sites. Depth to clay data also allowed maps to be generated depicting variation in the thickness of the surface sediments. This information proved useful in the consideration of site formation and transformation processes.

The site boundary polygons resulting from the AEC 2002 survey were generated from information provided by consultant engineers (Kennedy Consulting, Inc.) working for TxDOT's Atlanta District. During the course of fieldwork, some inaccuracies in their positioning and overall shape were noted. These inaccuracies were identified through ground-truthing field conditions and checking these findings against the original site sketch maps presented by Perttula et al. (2002). Potential sources of these inaccuracies include: (1) lack of use of GPS units to record site locations during the initial survey; (2) altering a site's location, size, or shape when original site sketch maps were transferred to the consultant engineer's CAD system; and (3) modifying a site's location, size, or shape when site boundaries were viewed on the high-resolution air photos. The same issues were responsible for inconsistencies in the locations of site subareas depicted on AEC maps and subsequent maps used in auger testing. In most cases, mapping discrepancies were minor and easily resolved, and there were no problems that could not be corrected. Further, any such inconsistencies were immaterial, since the denser and more-accurately plotted auger and shovel test data allowed more-rigorous delineation of site boundaries and subareas than was possible with the survey shovel test data.

\section{Intensive Testing}

By 2007, the design of the relief route had firmed up, with the project corridor being $5.9 \mathrm{~km}$ long and 85-296 $\mathrm{m}$ wide and encompassing about 322 acres of land (see Figure 2.1). All of the sites auger tested in 2005 except 41TT865 were still wholly or partly within the corridor and thus still required formal assessments. Site 41TT865 remained in the testing plan though, due to concerns that future alignment changes might once again include it in the project area. The research design developed for intensive testing of these sites identified the primary relevant historic context for the project as The Development of Agriculture in Northeast Texas Before A.D. 1600 (Appendix A). It concluded that significant information on all nine context study units (chronology and typology, settlement systems, subsistence systems, social and political complexity, demographic change, mortuary practices, local and extralocal trade and exchange, technological change, and material culture) might be recoverable. The overall goal was to identify and explore Caddo community structure, with an emphasis on behavior and how people interacted and organized their world at the following spatial scales: within houses, on individual house lots, within villages, between two or more contemporaneous villages, and as villages and other components of the settlement system (e.g., field houses, mounds, cemeteries, agricultural fields, ceremonial centers). Other project goals included testing the efficacy of using geophysical methods to identify cultural features; determining the integrity of the archeological deposits and assessing site significance; and performing ancillary studies to provide a broader understanding of the landscape and its recent history and compile data sets useful for detailed analyses. The eight research themes 
posited to structure the investigations were as follows: (1) finding cultural features through geophysical survey; (2) site integrity; (3) looking for structures when geophysics lets you down: the scrape and peck approach; (4) paleoenvironmental change; (5) finding Caddo agricultural/horticultural landscapes; (6) background sampling for ceramic studies; (7) background sampling for lithic studies; and (8) historic landscapes (see Appendix A).

The scope of work developed to accompany the testing research design identified a variety of tasks generally falling into two categories. The first consisted of work targeting specific areas of the 11 sites based on their perceived potential to contain important information relevant to the research themes. The second category included tasks that were not site specific, tasks apportioned to sites as the work proceeded, and efforts focused outside site boundaries or even beyond the limits of the project area.

Work at each site was to begin with geophysical survey. The results of the previous auger and shovel test sampling were used to identify geophysical survey grids focused on areas of ceramic and lithic concentration within each site; it was presumed these areas had the greatest likelihood of containing features such as Caddo houses. Fifteen grids covering a combined area of $28,600 \mathrm{~m}^{2}$ were identified. This sum included an arbitrary $3,200-\mathrm{m}^{2}$ grid at $41 \mathrm{TT} 858$, which had not yet been sampled with auger or shovel tests. Single grids were proposed for most sites, but 41TT846 and 41TT866 had two and 41TT852 had three survey grids. An unallocated contingency of $6,000 \mathrm{~m}^{2}$ of geophysical survey was proposed to provide flexibility to expand grids as interesting patterns of anomalies emerged. The survey methods proposed were magnetometer, resistivity, EM conductivity, magnetic susceptibility, and potentially ground-penetrating radar.

Hand-excavated test units were proposed to ground-truth promising anomalies identified through geophysical survey. In the absence of promising anomalies, test unit positioning would default to more-traditional modes of assessment, relying upon artifact or feature distribution patterns determined from survey, auger sampling, and mechanical trenching. The amount of proposed hand excavation generally represented between 0.5 and 1.0 percent of the area of each geophysical grid. Sites that revealed more-promising artifact patterns during auger sampling generally were scheduled for proportionally greater hand excavation. The approximate total area proposed for hand excavation was $253 \mathrm{~m}^{2}$.

Mechanical trench excavation was proposed to search for cultural features and help ground-truth geophysical anomalies. Like the hand excavations, backhoe trench locations were to be based on the results of geophysical survey or known artifact distribution patterns. Approximately $2,800 \mathrm{~m}^{2}$ was slated for mechanized stripping through trench excavation at 10 of the 11 sites, with the estimated amounts constituting 7.5-13.3 percent of the geophysical grids. In addition, $600 \mathrm{~m}^{2}$ of mechanical scraping were allocated to search for remaining traces of the Thomas B. Caldwell cemetery in the vicinity of 41TT6 and 41TT846. Trench excavation was not proposed at $41 \mathrm{TT} 865$ due to its small size and the fact that the proposed hand excavations would provide the necessary information concerning feature preservation.

The scope of work called for several forms of specialized sampling. Sampling for deposit characterization studies aimed at the issue of site integrity was proposed for profiles representative of the project area and included collection of samples for the following analyses: ${ }^{137} \mathrm{Cs},{ }^{210} \mathrm{~Pb}$, single-grain OSL, organic carbon, granulometry, magnetic susceptibility, and total phosphorus. Two kinds of sampling for paleoenvironmental studies were proposed:(1) stratigraphic examination and documentation of colluvial and alluvial sedimentary records for evidence of soil erosion; and (2) search for a suitable pollen locality on Tankersley Creek. The first would involve trenching of colluvial toe slopes and alluvial lowlands near 5 of the 11 sites and collecting single-grain OSL and radiocarbon samples for dating and sediment samples for granulometry, organic carbon, magnetic susceptibility, total phosphorus, and stable carbon isotope analyses. The second would involve scrutiny of aerial photographs followed by examination of depressions on the valley floor that might have the potential of preserving wetland deposits. If promising locations were found, coring to examine the sediments and the extraction of samples for a feasibility study of pollen preservation were proposed. Chronometric dating and the five other types of analyses listed above would accompany any coring efforts.

Additionally, soil samples would be submitted for magnetic susceptibility, total phosphorus, and stable carbon isotope analyses in 
an attempt to identify prehistoric agricultural fields. These samples would be collected at 20-m intervals across portions of sites or immediate off-site areas where agricultural fields may have been located. Sampling was proposed along 93 transects totaling $12,700 \mathrm{~m}$ in length. On floodplains and water-gathering slopes where sedimentation since prehistoric occupation is possible, sample collection would follow stratigraphic work done in nearby areas (as part of paleoenvironmental studies) in an effort to identify proximate, contemporaneous residential and agricultural surfaces. A pilot study involving thermoluminescence dating of potsherds or burned lithics recovered from possible agricultural fields was proposed as a way to help establish contemporaneity of possible upland agricultural fields and residential areas. Specialized ceramic and lithic studies also were proposed to address the issue of sourcing clays and lithic raw materials.

The final task identified in the scope of work was a historic landscape study with three goals: (1) document information about the landscape during the earliest period of Euro-American settlement; (2) determine whether available archival sources could identify locations of historic landscape features for periods subsequent to initial settlement; and (3) clarify the location of the Thomas B. Caldwell cemetery. This was to involve documentary research at The University of Texas at Austin, the Texas General Land Office, the Titus County courthouse, and the Texas State Library and Archives. Oral history research was to be limited to interviewing individuals knowledgeable about the histories of the tracts containing the possible location of the Caldwell cemetery.

Most tasks were accomplished as planned, but several avenues of investigation were set aside due to funding changes that occurred partway through fieldwork. This change, from TxDOT to Titus County as the funding source, happened at the end of December 2007 and arose from a statewide shortage of money that forced TxDOT to stop work on the project. Titus County opted to complete the work with the understanding that the ambitious research goals presented in the original research design and scope of work would be scaled back to meet normal compliance requirements. The scope was revamped in consultation with TxDOT to eliminate tasks that were not essential for assessing sites and developing data recovery plans, or that logically could be delayed until data recovery. The proposed paleoenvironmental, prehistoric agricultural field identification, and lithic sourcing studies were cancelled, and parts of the deposit characterization and ceramic sourcing studies were scaled back. Part of the historic landscape study task also was considered nonessential but had already been completed by that time.

As planned, geophysical surveys using magnetometer, resistivity meter, conductivity meter, and magnetic susceptibility meter were done at all 11 sites, and ground-penetrating radar also was used at 41 TT865. Sixteen grids were surveyed, with 3 at $41 \mathrm{TT} 846,3$ at 41TT852, 2 at 41TT866, and 1 at each of the other sites (Table 2.1). These grids, which served as the foci of the subsequent test excavations, covered almost $25,000 \mathrm{~m}^{2}$. The surveyed area was 13 percent smaller than that proposed in the scope of work, mostly because 41TT853 and 41TT858 were considerably smaller than originally estimated. The results of the geophysical surveys were consistently disappointing. While anomalies were detected at some sites, only two (at 41TT852) appeared to be possible candidates for prehistoric structures, and upon ground-truthing, few strong associations between anomalies and cultural features were identified. Preliminary analysis showed that the geophysical data were not sufficiently informative about the structure of the sites to help guide test excavations (Appendix B). Because of this, the contingency of $6,000 \mathrm{~m}^{2}$ of geophysical survey proposed in the scope of work was not implemented.

Systematically spaced backhoe trenches were excavated across 15 of the survey grids to try to find prehistoric cultural features despite the equivocal geophysical survey data (no trenching was conducted at 41TT865). Any geophysical anomalies highlighted by the geophysical specialist were examined during this part of the testing investigations. Trenches were excavated with a 1-m-wide, smooth-bladed bucket to minimize sediment disturbance on trench floors and sidewalls. Backhoe trenches were excavated to the contact between the sandy mantle and the clay subsoil (or slightly below that contact) in an effort to detect cultural features such as postholes and pits. Trenches generally ranged from 5 to $10 \mathrm{~m}$ in length and 
Table 2.1 Summary of work accomplished in intensive testing

\begin{tabular}{l|c|c|c|c|c|c}
\hline \multicolumn{1}{c|}{ Site } & \multicolumn{2}{|c|}{ Geophysical Survey } & \multicolumn{2}{c}{ Machine Stripping } & \multicolumn{2}{c}{ Test Units } \\
\hline & $\begin{array}{c}\text { No. of } \\
\text { Grids }\end{array}$ & $\mathrm{m}^{2}$ & $\begin{array}{c}\text { No. of } \\
\text { Trenches }\end{array}$ & $\mathrm{m}^{2}$ & $\mathrm{~m}^{2}$ & $\mathrm{~m}^{3}$ \\
\hline 41TT6 & 1 & 2,400 & 28 & 168 & 12 & 3.6 \\
\hline 41TT846, Subarea 1 & 1 & 1,600 & 20 & 137 & 9 & 2.5 \\
\hline 41TT846, Subarea 2 & 2 & 2,400 & 38 & 259 & 13 & 3.8 \\
\hline 41TT847 & 1 & 1,600 & 30 & 189 & 11 & 5.0 \\
\hline 41TT851 & 1 & 3,200 & 50 & 400 & 44 & 16.6 \\
\hline 41TT852, Subarea 1 & 1 & 2,400 & 51 & 328 & 26 & 10.6 \\
\hline 41TT852, Subarea 3 & 1 & 1,050 & 21 & 135 & 12 & 3.5 \\
\hline 41TT852, Subarea 4 & 1 & 800 & 15 & 100 & 8 & 2.5 \\
\hline 41TT853 & 1 & 1,600 & 29 & 259 & 22 & 11.7 \\
\hline 41TT854 & 1 & 1,600 & 16 & 106 & 8 & 4.7 \\
\hline 41TT858 & 1 & 750 & 8 & 81 & 8 & 2.4 \\
\hline 41TT862 & 1 & 1,600 & 30 & 194 & 10 & 4.1 \\
\hline 41TT865 & 1 & 1,400 & 0 & 0 & 25 & 8.4 \\
\hline 41TT866, Subarea 1 & 2 & 2,400 & 50 & 343 & 17 & 9.5 \\
\hline Totals & 16 & 24,800 & 386 & 2,695 & 225 & 88.9 \\
\hline
\end{tabular}

0.1 to $1.0 \mathrm{~m}$ in depth. Trenches were photographed, and profiles of selected trench walls were described, primarily noting soil horizons, texture, color, structure, and boundary characteristics. A total of 386 trenches were excavated during the testing investigations. Combined, these covered $2,695 \mathrm{~m}^{2}$, which is 4 percent less than the area called for in the scope of work. As with the geophysical survey coverage, the discrepancy was due to the smaller-than-anticipated sizes of 41TT853 and 41TT858, plus the fact that the $600 \mathrm{~m}^{2}$ of machine excavation set aside to search for traces of the Thomas B. Caldwell cemetery near 41TT6 and 41TT846 was not needed because research done as part of the historic landscape study determined convincingly that the cemetery location is outside the project boundary.

Manual excavations, usually in the form of $1 \times 1-m$ test units but sometimes in small blocks as large as $2 \times 2 \mathrm{~m}$, were placed to sample various parts of all 16 survey blocks. The total area encompassed by hand excavations $\left(225 \mathrm{~m}^{2}\right)$ was 11 percent smaller than the coverage area proposed in the scope, again due to the smaller than estimated sizes of 41TT853 and 41TT858. The units generally were placed adjacent to backhoe trenches to expose features or artifacts revealed in the trenches, or over anomalies de- tected by the geophysical surveys. Some of the hand-excavated units were randomly positioned within the geophysical survey grids.

The test units were excavated in arbitrary $10-\mathrm{cm}$ levels to the contact with the clay subsoil, with the ground surface of the highest corner used as a datum for vertical control. Notes for each excavation level were recorded on an Excavation Record form. All excavated matrix was dry screened through 1/4-inch-mesh hardware cloth. Artifacts were categorized by type or class (i.e., chipped stone, ceramic sherd, and ground stone), collected and bagged by level, and noted on an Artifact Frequency Distribution Summary form. Other materials, such as firecracked rocks, were counted and weighed but not collected. Each test unit was digitally photographed upon completion. Discrete cultural features typically were excavated as separate entities. Features were described and recorded on Feature Data forms, as well as photographed and mapped in plan. Sediment samples for deposit characterization studies were collected from the walls of selected trenches and test units at several sites representing the range of settings in the project area (Appendix C). Finally, all sites were mapped using a Sokkia electronic total station. 


\section{SITE 41TT6}

Site 41TT6 is on an upland slope and crest on the east side of the Tankersley Creek valley in the south-central part of the project area. As of 2005, the northern third of the site was in unimproved, partially open woodlands, and the southern part was in maintained open pasture that slopes gently downward to the south (Figure 2.2). This site is the purported location of the Thomas B. Caldwell cemetery excavated by archeologists from The University of Texas at Austin in 1934 (Goldschmidt 1934a, 1935). However, Perttula et al. (2002) note that the location does not match the description given in the original excavation report, and subsequent research determined that $41 \mathrm{TT} 846$ to the immediate west is the more likely location of the cemetery (see Appendix D). AEC recovered eight flakes and a flake tool from 7 of 11 shovel tests excavated during its 2002 investigation (Perttula et al. 2002). At that time, the site was estimated to cover approximately $20,000 \mathrm{~m}^{2}$. All of this area was within the $1,000-\mathrm{ft}-$ wide auger testing corridor; ultimately, though, highway design changes excluded the north end from the project corridor, and thus intensive testing occurred only in the southern part.

\section{Auger Testing}

A total of 129 auger tests were excavated. The tests were primarily at $12-\mathrm{m}$ intervals, though some in the northern portion were spaced less regularly due to vegetation and tree cover. No tests were placed in the vicinity of a tree-lined, east-west fence in the north-central part of the site. Additionally, a ca. $45-\mathrm{m}^{2}$ cattle-feeding area in the central portion of the site was not tested because it had been disturbed by earthmoving activities that created artificial berms and exposed clay subsoil. Only 12 tests yielded 22 artifacts (Table 2.2), with 1 other (Auger Test 31) containing a single burned rock. Five pieces of debitage were identified in two auger tests in the noncollection area in the northern part of the site (Auger Tests 110 and 115). Based on the combined auger test and survey data, the site boundary was modified slightly to encompass an area of about $19,000 \mathrm{~m}^{2}$. Most artifacts were scattered sparsely in a broad, discontinuous east-west belt across the south half of the site. No ceramics or diagnostic lithic artifacts were recovered.
The 105 tests that reached clay subsoil indicate that the surface sands are generally thin, with average and maximum basal depths of 35 and $66 \mathrm{~cm}$, respectively. The 24 tests that did not reach the subsoil were stopped by hard soils or other obstructions at depths of 18-55 cm (average $34 \mathrm{~cm})$. The sands are thinnest $(20 \mathrm{~cm}$ or less) on the west edge of the site, in the vicinity of the fence line where the surface drops into an intermittent drainage. Thin sands are also present on the eastern edge of the site, where the surface slopes into another intermittent drainage. Sands exceeding $50 \mathrm{~cm}$ in thickness are primarily along the lower part of the southern toeslope. This may reflect sediments washing downslope and accumulating near the base of the landform.

\section{Work Accomplished in Intensive Testing}

Given the spotty, low-density recovery of artifacts in auger testing, no part seemed like a more-compelling area for testing than any other. Hence, a $60 \times 40-\mathrm{m}$ area in the southeast corner that included one positive test (Auger Test 44) and that was proximate to three others (Auger Tests 31,33 , and 39) was selected for geophysical survey (see Figure 2.2). The geophysical survey did not detect any anomalies considered likely to be cultural (see Appendix B). Following the survey, 28 backhoe trenches and twelve 1x1-m test units were excavated within the grid (Figure 2.3). The trenches were $1.0 \mathrm{~m}$ wide, ranged from 5.3 to $6.8 \mathrm{~m}$ in length (mean $=6.0 \mathrm{~m})$, and had maximum depths of 27 to $82 \mathrm{~cm}$ (mean $=44 \mathrm{~cm})$. The excavated trenches encompassed an area of $168 \mathrm{~m}^{2}$. All of the test units were placed adjacent to trenches, and unit depths ranged from 10 to $40 \mathrm{~cm}$ below the surface.

The profiles of six trenches were described. All displayed A-E-Bt soil profiles. The A horizon was $6-13 \mathrm{~cm}$ thick and consisted of brown (7.5YR 5/4 and 4/3) to dark brown (7.5YR 3/2) loamy very fine sand. The $\mathrm{E}$ horizon was 11 to $30 \mathrm{~cm}$ thick and consisted of very pale brown (10YR 7/4), light brown (7.5YR 6/4), and brown (7.5YR 4/4, 4/3,5/4, and 5/3) very fine sandy loam. The Bt horizon was well structured, sometimes mottled, and comprised of red (2.5YR $4 / 6$ and 4/8), reddish brown (2.5YR 4/4), strong brown (7.5YR 5/6), or brown (7.5YR 5/3) sandy clay, sandy clay loam, or clay loam. 


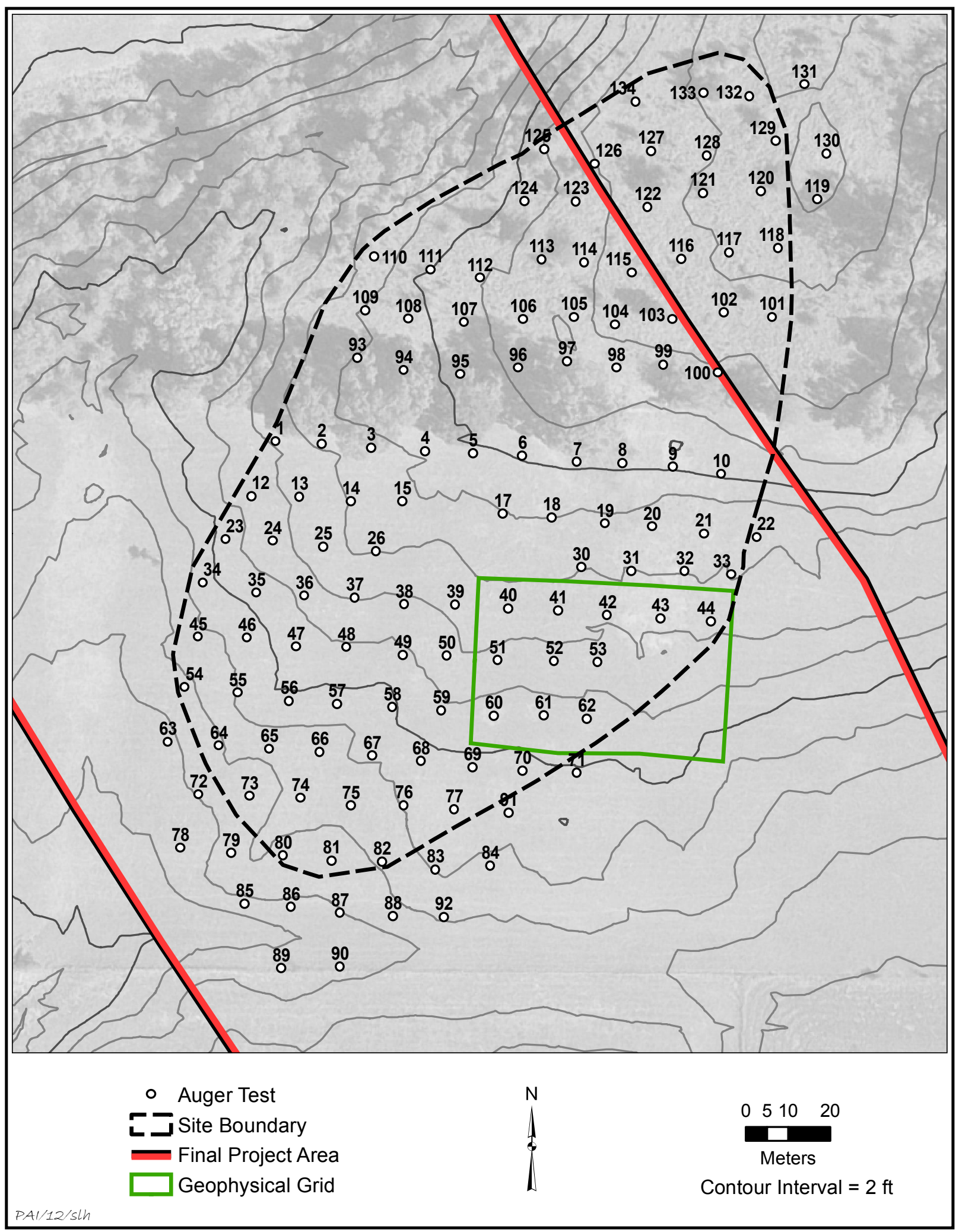

Figure 2.2. Map of 41TT6 showing topography, auger test locations, and geophysical survey grid on 2005 aerial imagery. 
Table 2.2. Artifacts recovered in auger and intensive testing at 41 TT6

\begin{tabular}{|c|c|c|c|c|}
\hline Provenience & Debitage & Core & $\begin{array}{l}\text { Ground } \\
\text { Stone }\end{array}$ & Totals \\
\hline Auger Test 14 & 1 & 0 & 0 & 1 \\
\hline Auger Test 23 & 1 & 0 & 0 & 1 \\
\hline Auger Test 26 & 0 & 1 & 0 & 1 \\
\hline Auger Test 33 & 0 & 1 & 0 & 1 \\
\hline Auger Test 39 & 1 & 0 & 0 & 1 \\
\hline Auger Test 44 & 6 & 0 & 0 & 6 \\
\hline Auger Test 45 & 1 & 0 & 2 & 3 \\
\hline Auger Test 46 & 1 & 0 & 0 & 1 \\
\hline Auger Test 55 & 1 & 0 & 0 & 1 \\
\hline Auger Test 81 & 1 & 0 & 0 & 1 \\
\hline Auger Test 110 & 2 & 0 & 0 & 2 \\
\hline Auger Test 115 & 3 & 0 & 0 & 3 \\
\hline \multicolumn{5}{|l|}{ Test Unit 2} \\
\hline $0-10 \mathrm{~cm}$ & 5 & 0 & 0 & 5 \\
\hline $10-20 \mathrm{~cm}$ & 4 & 0 & 0 & 4 \\
\hline $20-30 \mathrm{~cm}$ & 3 & 0 & 0 & 3 \\
\hline $30-39 \mathrm{~cm}$ & 0 & 0 & 0 & 0 \\
\hline \multicolumn{5}{|l|}{ Test Unit 4} \\
\hline $0-10 \mathrm{~cm}$ & 7 & 1 & 0 & 8 \\
\hline $10-20 \mathrm{~cm}$ & 4 & 0 & 0 & 4 \\
\hline $20-30 \mathrm{~cm}$ & 1 & 0 & 0 & 1 \\
\hline \multicolumn{5}{|l|}{ Test Unit 12} \\
\hline $0-10 \mathrm{~cm}$ & 2 & 0 & 0 & 2 \\
\hline $10-20 \mathrm{~cm}$ & 2 & 0 & 0 & 2 \\
\hline $20-30 \mathrm{~cm}$ & 0 & 0 & 0 & 0 \\
\hline $30-36 \mathrm{~cm}$ & 0 & 0 & 0 & 0 \\
\hline Total & 46 & 3 & 2 & 51 \\
\hline
\end{tabular}

\section{Results}

No prehistoric cultural features were identified during test excavations at 41TT6, and the meager artifact recovery was limited to 12 auger tests and Test Units 2, 4, and 12 in the central and south-central parts of the geophysical survey grid (see Table 2.2). Recovered materials consist of 46 pieces of lithic debitage, 3 tabular silicified wood cores, and 2 ground or battered stones. The debitage is predominantly silicified wood $(\mathrm{n}=37)$, with small amounts of quartzite $(n=2)$, chert $(\mathrm{n}=1)$, and ferruginous sandstone $(\mathrm{n}=1)$ (excludes 5 flakes not collected from 2 auger tests). All of these lithic materials are available locally. The size distribution of the flakes shows that 83 percent of the debitage is less than $25 \mathrm{~mm}$. The high frequency of flakes and flake fragments smaller than $25 \mathrm{~mm}$ reflects late reduction and tool production activities. However, the assemblage of debitage is very small and of limited interpretability. The 2 ground or battered stones are a hammerstone and a mano/hammerstone, both of quartzite. The hammerstone is battered on one end and on one face. Heat-derived color alteration is visible in a flake scar on one side, but flake detachment appears to be associated with recent mechanical damage. The mano/ hammerstone has one smoothed facet with visible percussion marks. Battering from use as a percussor is visible on a prominent part of the opposite face and on a margin. The size of this artifact is indicative of the fingermanipulated mullers that Ellis (2009:Table 13-1) classified as a distinct tool type in the ground stone assemblage from the Ear Spool site (41TT653).

\section{Conclusions}

The archeological deposits in the investigated portion of 41TT6 can be characterized as a low-density scatter of lithic artifacts. No ceramics or diagnostic lithic artifacts were found, and no cultural features were identified. The minimal artifact assemblage and lack of features greatly limit what can be said about 41TT6. Site age and function are unknown, though the sparseness of artifacts clearly indicates low-intensity use. The absence of carbonized macrobotanical material and diagnostic artifacts precludes any temporal assessment. The scant deposits may be derived from use by pre-Caddo hunter-gatherers (dating anywhere from the Paleoindian to Woodland periods) or later Caddo farmers, or perhaps they are a mix of materials from multiple periods. Site 41TT6 was judged ineligible for inclusion in the National Register and for designation as a State Antiquities Landmark because it does not contain isolable and interpretable archeological components. Hence, further work was considered unwarranted.

\section{SITE 41TT846}

Site $41 \mathrm{TT} 846$ is just west of $41 \mathrm{TT} 6$, on an upland crest and adjacent sideslope bordered 


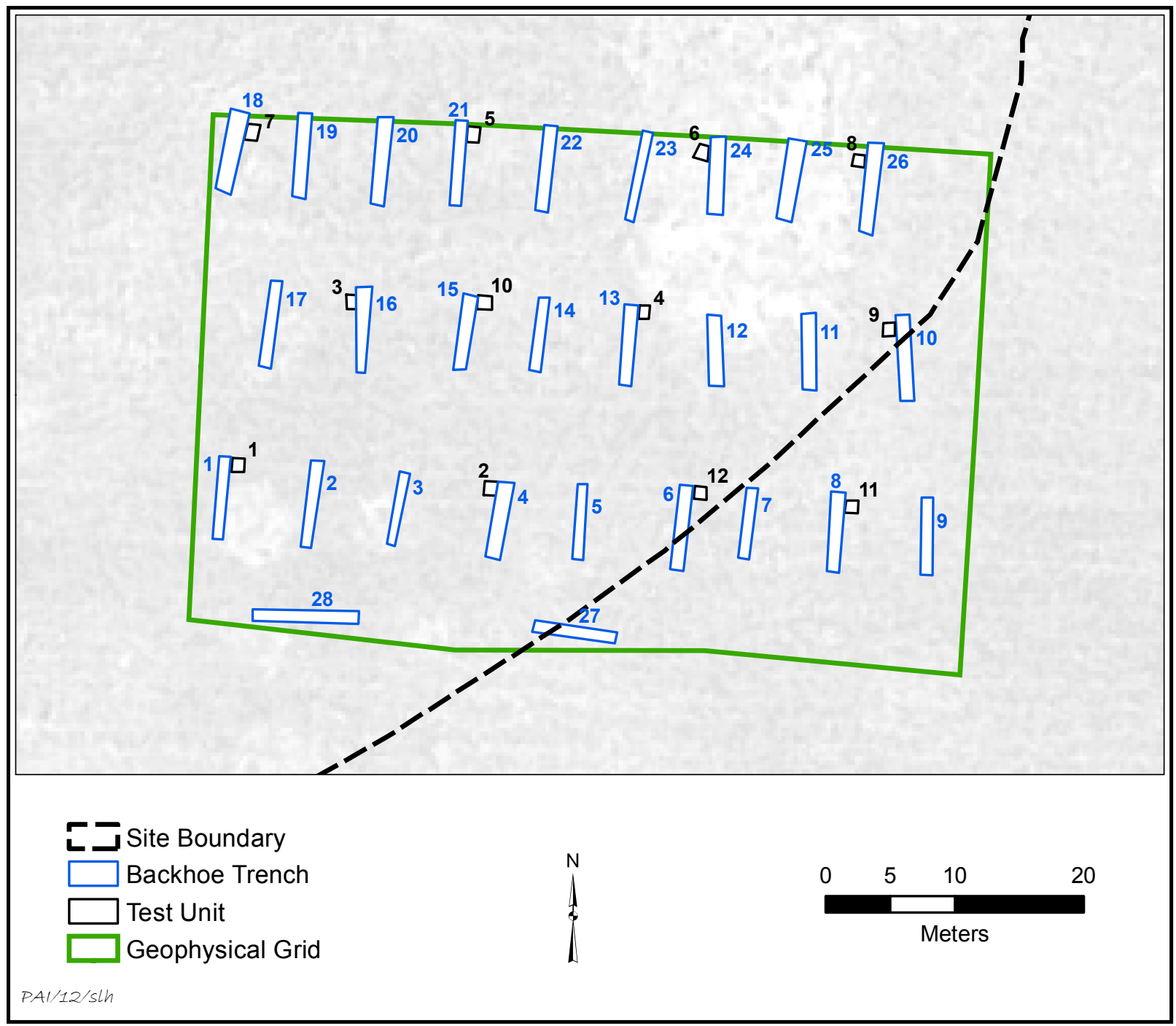

Figure 2.3. Aerial photograph of 41TT6 showing the geophysical survey grid and test excavations.

by two intermittent tributaries of Tankersley Creek (Figure 2.4). It is the most likely location of the Thomas P. Caldwell cemetery, which was excavated in 1934 (Goldschmidt 1934a, 1935; see Appendix D). When the site was investigated in 2002 by AEC, 23 shovel tests were excavated across the full extent of the site, which was then estimated to cover an area of $46,400 \mathrm{~m}^{2}$. Twenty artifacts ( 3 sherds, 13 flakes, 2 cores, and 2 flake tools) were recovered from 17 of the tests. The southwest half of the original site area (and the posited cemetery location) was eliminated from the project corridor between 2002 and 2005, and subsequent design changes excluded all but the northeast edge, including two of the three areas investigated during intensive testing.

\section{Auger Testing}

The portion of the site investigated in 2005 was in open, improved-grass pasture. A tree-lined, east-west fence divided the investigation area roughly in half. Auger tests were not excavated along the east edge of the site, since it encompassed low-lying terrain along an intermittent drainage. In addition, a deposit of chicken sludge fertilizer prevented auger testing in the northernmost part. A total of 117 

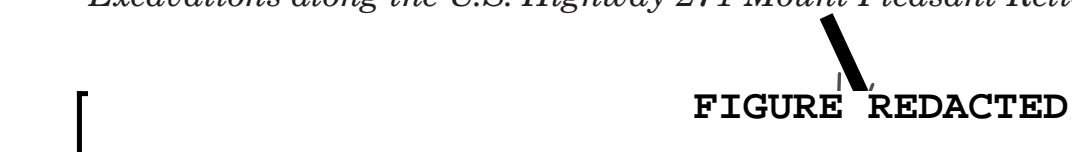

Figure 2.4. Map of 41TT846 showing topography, auger test locations, and geophysical survey grids on 2005 aerial imagery. 
auger tests were excavated across most of the remaining investigation area, primarily at $12-\mathrm{m}$ intervals. Ten tests (Auger Tests 1, 11, 21, 30, 38, $43,48,52,55$, and 63 ) were accidentally placed just outside the project corridor.

Just seven tests within the project corridor as defined in 2005 yielded artifacts, consisting of a ceramic sherd and 15 pieces of debitage (Table 2.3); an eighth test (Auger Test 19) contained a single burned rock. Auger Test 63 just outside the corridor contained a single flake. Most of the positive tests were south of the east-west fence line; only the materials south of the fence line were collected. The ceramic sherd was recovered north of the fence, in the same general location where AEC collected 3 sherds in 2002. The auger test artifact distribution, combined with survey data, was used to decrease the site area within the 1000 -ft-wide project corridor to $15,700 \mathrm{~m}^{2}$ and divide it into two subareas. Subarea 1 encompassed $1,400 \mathrm{~m}^{2}$ at the northwest edge of the tested area and included the single ceramic sherd recovered. Subarea 2 included the remainder of the revised site area and appeared to be a low-density lithic scatter.

The 115 tests that reached clay subsoil indicate that the surface sands are generally thin, with average and maximum basal depths of 31 and $90 \mathrm{~cm}$, respectively. The 2 tests that did not reach the subsoil were stopped by hard soils at depths of 18 and $37 \mathrm{~cm}$. Sands are thinnest along the central crest of the landform, while deeper deposits were encountered mainly along the sideslopes in the southern portion of the investigated site area. As with 41TT6, this pattern may reflect slopewash and erosion that moved sediments (and artifacts) downslope from topographic highs.

\section{Work Accomplished in Intensive Testing}

The spotty, low-density recovery of artifacts in auger testing provided little guidance for placement of test excavations, other than that indicated by the two subareas defined. A single T-shaped block for geophysical survey was placed to encompass much of Subarea 1, including positive Auger Test 80. This grid was $40 \times 60 \mathrm{~m}$ across on its axes (Figure 2.5); it was about 40-50 m northeast of the reconstructed location of the Thomas B. Caldwell cemetery. The two geophysical grids placed to sample Subarea
2 were a $20 \times 40-m$ rectangle on elevated ground along the northeast edge of the site (north grid; see Figure 2.5) and a 40x40-m block along the southeast site boundary (south grid; Figure 2.6). Sparse lithic artifacts were found in a few auger tests (Auger Tests 31, 36, 42, and 85) around the margins of both areas in 2005, though no positive tests were within either block. The south grid was about 70-80 m east-southeast of the proposed location of the Thomas B. Caldwell cemetery (see Appendix D).

The geophysical survey did not identify any geophysical anomalies that appeared to represent prehistoric structural remains or archeological features (see Appendix B). Twenty backhoe trenches and nine $1 \mathrm{x} 1-\mathrm{m}$ test units were excavated within the geophysical survey grid in Subarea 1, and 38 trenches and thirteen $1 \mathrm{x} 1-\mathrm{m}$ test units were excavated within the two Subarea 2 grids. In Subarea 1, trenches ranged from 6.1 to $7.3 \mathrm{~m}$ in length $($ mean $=6.9 \mathrm{~m}$ ) and had maximum depths of 19 to $52 \mathrm{~cm}$ $($ mean $=34 \mathrm{~cm})$. Subarea 2 trenches were 5.2 to $7.4 \mathrm{~m}$ long (mean $=6.5 \mathrm{~m}$ ) and had maximum depths of 22 to $65 \mathrm{~cm}$ (mean $=39 \mathrm{~cm})$. All trenches were $1.0 \mathrm{~m}$ wide, with the exception of Trench 22 in Subarea 2, which was $2.6 \mathrm{~m}$ wide. The area stripped through trenching covered $396 \mathrm{~m}^{2}$. Six of the 22 test units were placed adjacent to backhoe trenches, while the remaining 16 were excavated as isolated units away from the trenches. Test unit depths ranged from 20 to $40 \mathrm{~cm}$ below the surface in Subarea 1 and 17 to $50 \mathrm{~cm}$ below the surface in Subarea 2 .

The profiles of nine trenches in the north part of the site were described, eight of which displayed A1-A2-E-Bt soil profiles, while one trench displayed a thin A2-Bt soil profile below a distinct dark brown to black fertilizer-enriched A1 horizon, identified in all but one trench in this part of the site. The fertilizer-enriched A1 horizon is 3 to $9 \mathrm{~cm}$ thick and consists of black (10YR 2/2) loamy sand with an abrupt lower boundary. The A2 horizon is 9 to $19 \mathrm{~cm}$ thick and consists of dark yellowish brown (10YR 3/6, 4/4) to dark brown (10YR 3/3) very fine sandy loam. The E horizon is 9 to $22 \mathrm{~cm}$ thick and consists of yellowish brown (10YR 5/6) to brownish yellow (10YR 6/6) very fine sandy loam. The Bt horizon is well structured, sometimes mottled, and comprised of strong brown (7.5YR 5/8) to yellowish red (5YR 4/6) sandy clay. The profiles of four trenches in the south part of the site were de- 
Table 2.3. Artifacts recovered in auger and intensive testing at 41 TT846

\begin{tabular}{|c|c|c|c|}
\hline Provenience & Debitage & Sherd & Totals \\
\hline \multicolumn{4}{|l|}{ Subarea 1: } \\
\hline Auger Test 80 & 0 & 1 & 1 \\
\hline \multicolumn{4}{|l|}{ Test Unit 12} \\
\hline $0-10 \mathrm{~cm}$ & 0 & 0 & 0 \\
\hline $10-20 \mathrm{~cm}$ & 3 & 3 & 6 \\
\hline $20-30 \mathrm{~cm}$ & 0 & 0 & 0 \\
\hline \multicolumn{4}{|l|}{ Test Unit 13} \\
\hline $0-10 \mathrm{~cm}$ & 0 & 0 & 0 \\
\hline $10-20 \mathrm{~cm}$ & 1 & 0 & 1 \\
\hline $20-30 \mathrm{~cm}$ & 0 & 0 & 0 \\
\hline \multicolumn{4}{|l|}{ Test Unit 14} \\
\hline $0-10 \mathrm{~cm}$ & 1 & 0 & 1 \\
\hline $10-20 \mathrm{~cm}$ & 0 & 0 & 0 \\
\hline $20-30 \mathrm{~cm}$ & 0 & 0 & 0 \\
\hline \multicolumn{4}{|l|}{ Test Unit 16} \\
\hline $0-10 \mathrm{~cm}$ & 2 & 0 & 2 \\
\hline $10-20 \mathrm{~cm}$ & 0 & 0 & 0 \\
\hline \multicolumn{4}{|l|}{ Test Unit 17} \\
\hline $0-10 \mathrm{~cm}$ & 0 & 0 & 0 \\
\hline $10-20 \mathrm{~cm}$ & 0 & 1 & 1 \\
\hline $20-25 \mathrm{~cm}$ & 0 & 0 & 0 \\
\hline \multicolumn{4}{|l|}{ Test Unit 21} \\
\hline $0-10 \mathrm{~cm}$ & 0 & 0 & 0 \\
\hline $10-20 \mathrm{~cm}$ & 2 & 1 & 3 \\
\hline \multicolumn{4}{|l|}{ Test Unit 22} \\
\hline $0-10 \mathrm{~cm}$ & 0 & 0 & 0 \\
\hline $10-20 \mathrm{~cm}$ & 0 & 0 & 0 \\
\hline $20-30 \mathrm{~cm}$ & 0 & 1 & 1 \\
\hline $30-40 \mathrm{~cm}$ & 0 & 0 & 0 \\
\hline BHT 39 & 1 & 3 & 4 \\
\hline Subarea 1 Totals & 10 & 10 & 20 \\
\hline \multicolumn{4}{|l|}{ Subarea 2: } \\
\hline Auger Test 4 & 3 & 0 & 3 \\
\hline Auger Test 29 & 1 & 0 & 1 \\
\hline Auger Test 31 & 3 & 0 & 3 \\
\hline Auger Test 36 & 3 & 0 & 3 \\
\hline Auger Test 42 & 2 & 0 & 2 \\
\hline Auger Test 85 & 3 & 0 & 3 \\
\hline \multicolumn{4}{|l|}{ Test Unit 2} \\
\hline $0-10 \mathrm{~cm}$ & 2 & 0 & 2 \\
\hline $10-20 \mathrm{~cm}$ & 0 & 0 & 0 \\
\hline $20-28 \mathrm{~cm}$ & 1 & 0 & 1 \\
\hline \multicolumn{4}{|l|}{ Test Unit 3} \\
\hline $0-10 \mathrm{~cm}$ & 0 & 0 & 0 \\
\hline $10-17 \mathrm{~cm}$ & 13 & 0 & 13 \\
\hline \multicolumn{4}{|l|}{ Test Unit 5} \\
\hline $0-10 \mathrm{~cm}$ & 0 & 0 & 0 \\
\hline
\end{tabular}

\begin{tabular}{|c|c|c|c|}
\hline Provenience & Debitage & Sherd & Totals \\
\hline $10-20 \mathrm{~cm}$ & 1 & 0 & 1 \\
\hline $20-30 \mathrm{~cm}$ & 0 & 0 & 0 \\
\hline $30-40 \mathrm{~cm}$ & 0 & 0 & 0 \\
\hline \multicolumn{4}{|l|}{ Test Unit 6} \\
\hline $0-10 \mathrm{~cm}$ & 0 & 0 & 0 \\
\hline $10-20 \mathrm{~cm}$ & 1 & 0 & 1 \\
\hline $20-23 \mathrm{~cm}$ & 0 & 0 & 0 \\
\hline \multicolumn{4}{|l|}{ Test Unit 7} \\
\hline $0-10 \mathrm{~cm}$ & 0 & 0 & 0 \\
\hline $10-20 \mathrm{~cm}$ & 1 & 0 & 1 \\
\hline $20-30 \mathrm{~cm}$ & 0 & 0 & 0 \\
\hline $30-40 \mathrm{~cm}$ & 1 & 0 & 1 \\
\hline \multicolumn{4}{|l|}{ Test Unit 8} \\
\hline $0-10 \mathrm{~cm}$ & 6 & 0 & 6 \\
\hline $10-20 \mathrm{~cm}$ & 4 & 0 & 4 \\
\hline \multicolumn{4}{|l|}{ Test Unit 10} \\
\hline $0-10 \mathrm{~cm}$ & 0 & 0 & 0 \\
\hline $10-20 \mathrm{~cm}$ & 1 & 0 & 1 \\
\hline \multicolumn{4}{|l|}{ Test Unit 11} \\
\hline $0-10 \mathrm{~cm}$ & 3 & 0 & 3 \\
\hline $10-20 \mathrm{~cm}$ & 0 & 0 & 0 \\
\hline $20-30 \mathrm{~cm}$ & 0 & 0 & 0 \\
\hline $30-40 \mathrm{~cm}$ & 1 & 0 & 1 \\
\hline $40-50 \mathrm{~cm}$ & 1 & 0 & 1 \\
\hline Subarea 2 Totals & 51 & 0 & 51 \\
\hline \multicolumn{4}{|c|}{ Outside Corridor: } \\
\hline Auger Test 63 & 1 & 0 & 1 \\
\hline Site Totals & 62 & 10 & 72 \\
\hline
\end{tabular}




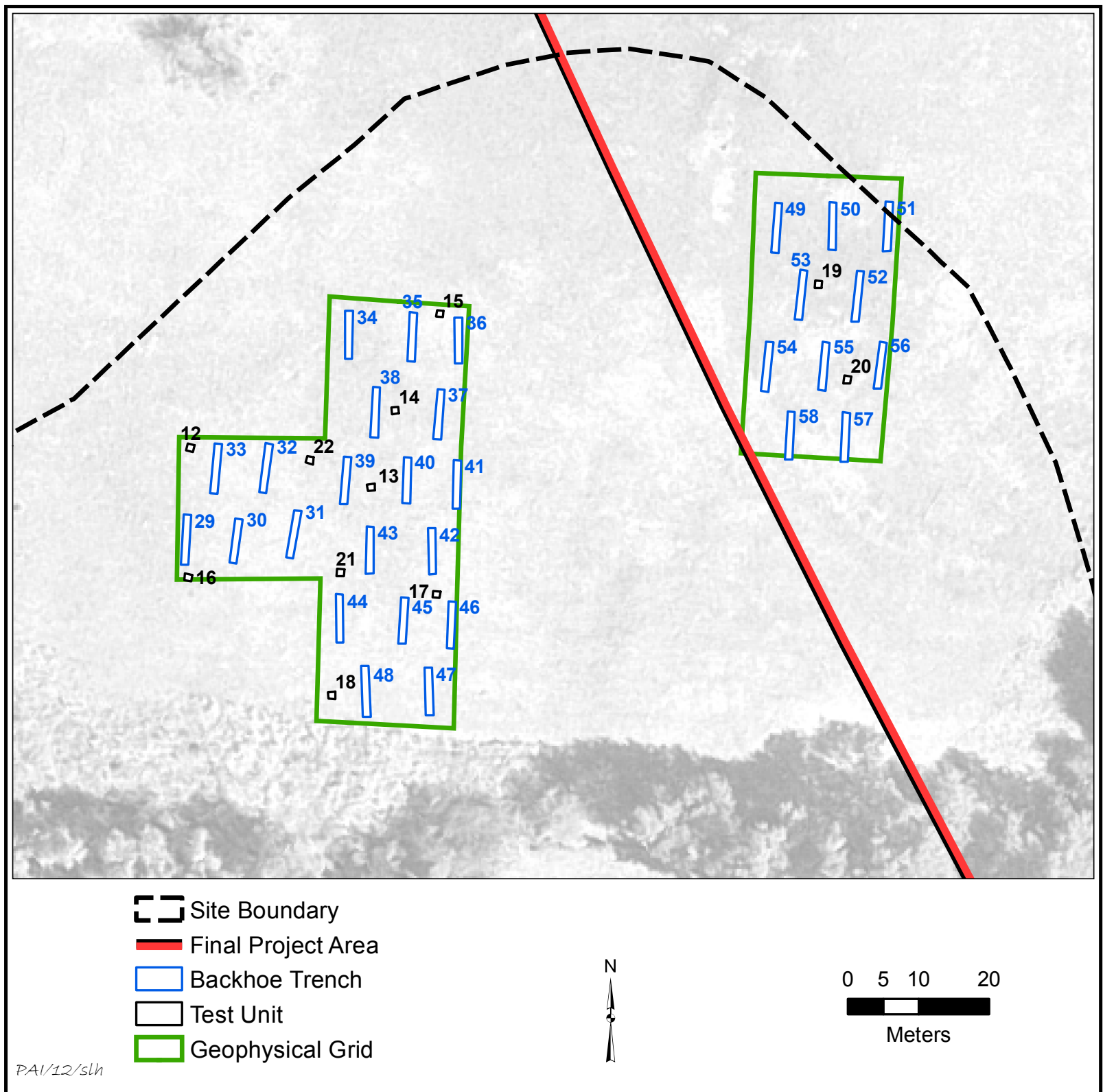

Figure 2.5. Aerial photograph showing the 41TT846, Subarea 1 and Subarea 2 (north grid), geophysical survey grids and associated test excavations.

scribed. All displayed A-E-Bt soil profiles, except for one, which had a thin A-Bt soil profile. The A horizon is 7 to $15 \mathrm{~cm}$ thick and consists of brown (7.5YR 4/3, 4/4, and 5/3) loamy very fine sand. The E horizon is 11 to $29 \mathrm{~cm}$ thick and consists of brown (7.5YR 5/4) to strong brown (7.5YR $5 / 6$ ) very fine sandy loam. The Bt horizon is well structured, sometimes mottled, and comprised of red (2.5YR 4/6 and 4/8) to dark red (2.5YR $3 / 6$ ) sandy clay.

\section{Results}

No prehistoric cultural features were identified, and just 10 ceramic sherds and 62 pieces of lithic debitage were recovered from 7 auger tests, 


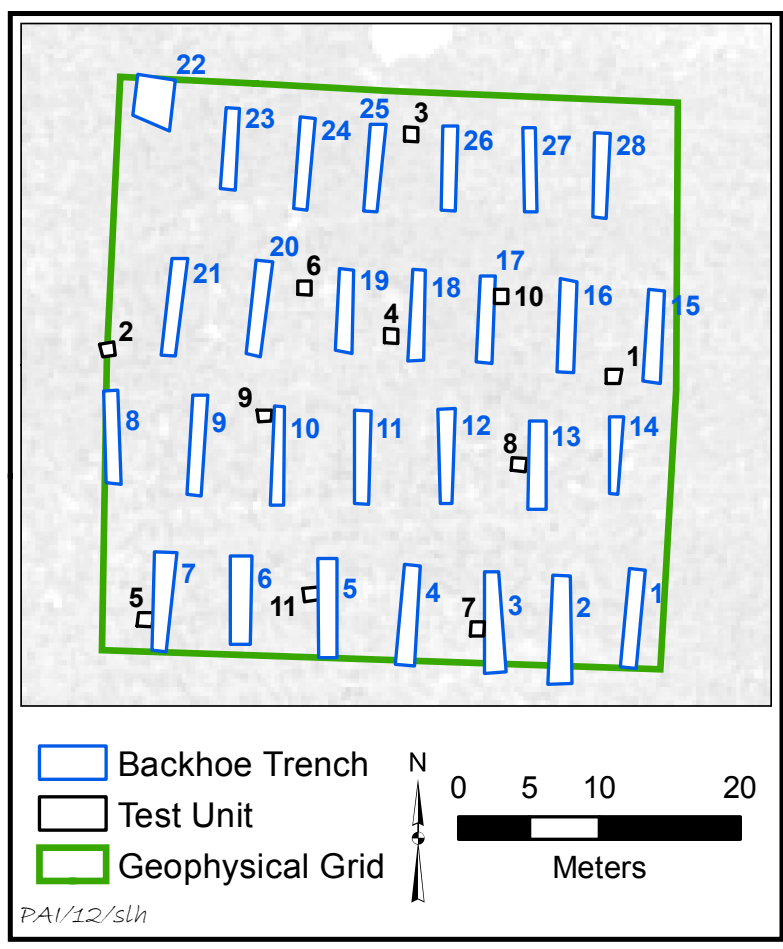

Figure 2.6. Aerial photograph showing the 41TT846, Subarea 2 (south grid), geophysical survey grid and associated test excavations.

15 test units and 1 backhoe trench (see Table 2.3). Positive test units were scattered across the Subarea 1 grid and the Subarea 2 south grid; no horizontal or vertical patterning was evident in the artifact distributions in either. No artifacts were found in the Subarea 2 north grid.

Of the 10 sherds ( $57.5 \mathrm{~g}), 9$ (56.7 g) are large enough for analysis. Seven are body sherds, 1 is a carinated body sherd, and 1 is a flat base sherd. Eight have grog temper, and 1 has grog and bone. Three sherds have brushed exteriors, and the rest are undecorated. Surfaces that are not brushed are floated or smoothed, except for one plain body sherd with a burnished exterior and smoothed interior. The carinated body sherd indicates the presence of at least one bowl, while the brushed sherds suggest that jars are also present. None of the sherds can be associated with any particular ceramic type.

The 58 pieces of debitage that were collected (excludes 4 from the north part of the site) are all of locally available materials, including silicified wood $(n=40)$, chert $(n=3)$, hematite $(\mathrm{n}=3)$, Ogallala and other quartzite $(\mathrm{n}=10)$, and indeterminate $(n=2)$. Eighty-four percent are less than $25 \mathrm{~mm}$ in size. The sample size is very small and conclusions are tenuous, but the size of the debitage reflects mostly late reduction and tool production as well as reduction from small lithic source materials.

\section{Conclusions}

As with 41TT6, interpretations about 41TT846 are limited by low artifact densities and the absence of features and datable materials in the investigated areas. The sparseness of archeological remains certainly implies low-intensity use, and the recovery of ceramics indicates that at least some of this use occurred during the Caddo period. The presence of brushed sherds in the assemblage is indicative of Middle to Late Caddo use, but the ceramic assemblage is not distinctive enough to convey more specific information. Some association with the Thomas B. Caldwell cemetery nearby is possible, but the materials found are not abundant enough to indicate that the tested parts of $41 \mathrm{TT} 846$ contain the main residential area for that cemetery. It is likely that some of the lithics represent pre-Caddo occupations as well, but the lack of diagnostic tools or datable materials prevents verification of this. Site 41TT846 was judged to be ineligible for inclusion in the National Register and for designation as a State Antiquities Landmark because it does not contain isolable and interpretable archeological components. Hence, further work was considered unwarranted.

\section{SITE 41TT847}

Site $41 \mathrm{TT} 847$ is south of $41 \mathrm{TT} 6$ and $41 \mathrm{TT} 846$ in maintained open pasture on an eroded upland hill crest with a gentle slope down to the south, east, and west (Figure 2.7). When investigated by AEC in 2002, 15 shovel tests and a $50 \times 50-\mathrm{cm}$ unit were excavated in a site area estimated to cover $30,000 \mathrm{~m}^{2}$. All but 2 of the tests were positive, and the investigators recovered 51 flakes, 2 ground stone artifacts, burned rocks, and charcoal. Most of this material came from the site's west end where a possible feature or buried midden was identified. Modification of the project corridor between 2002 and 2005 excluded the west half of the original site area from further investigation, and subsequent highway 


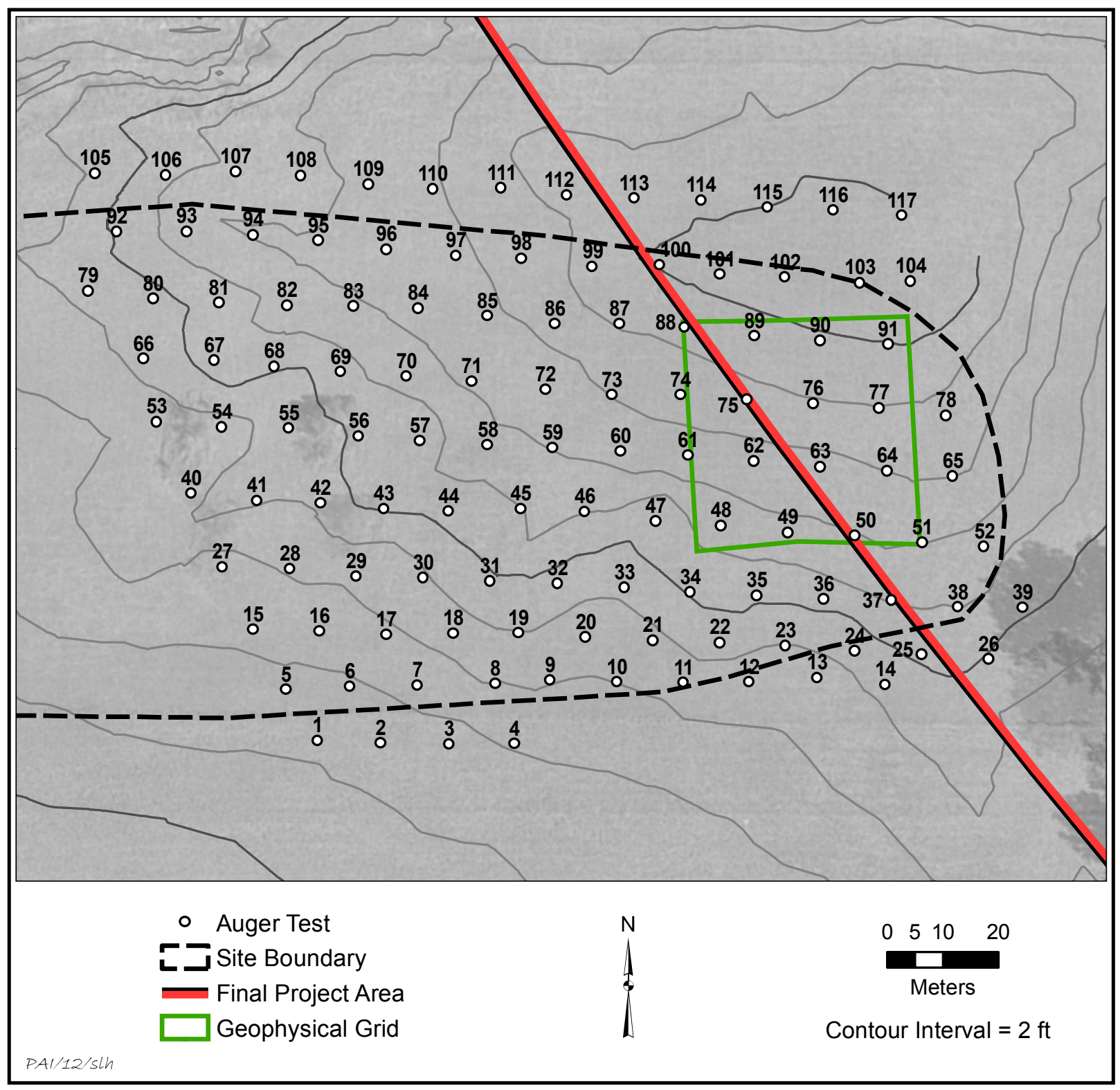

Figure 2.7. Map of 41TT847 showing topography, auger test locations, and geophysical survey grid on 2005 aerial imagery.

design changes excluded all but the east edge of the site from the project area.

\section{Auger Testing}

A total of 117 systematically spaced auger tests were dug in the east half of the site area. Fourteen of these (Auger Tests 1, 2, 5, 6, 15, $16,27,28,40,41,53,54,66$, and 79$)$ were just outside the project corridor's west edge. Nineteen tests yielded artifacts, consisting of 1 dart point fragment, 1 biface, 1 utilized flake, 28 pieces of debitage, 2 cores, and 1 ground/battered stone (Table 2.4); 2 other tests (Auger Tests 60 and 93) contained small numbers of burned rocks but no other cultural materials. Positive Auger Test 1 , containing a single flake, was just outside the project corridor. Most of the positive tests 
Table 2.4. Artifacts recovered in auger and intensive testing at 41TT847

\begin{tabular}{|c|c|c|c|c|c|c|}
\hline Provenience & $\begin{array}{c}\text { Chipped } \\
\text { Stone Tool }\end{array}$ & Debitage & Core & $\begin{array}{c}\text { Ground } \\
\text { Stone Tool }\end{array}$ & Sherd & Totals \\
\hline Auger Test 30 & 0 & 1 & 0 & 0 & 0 & 1 \\
\hline Auger Test 38 & 0 & 0 & 1 & 0 & 0 & 1 \\
\hline Auger Test 43 & 0 & 1 & 0 & 0 & 0 & 1 \\
\hline Auger Test 44 & 0 & 1 & 0 & 0 & 0 & 1 \\
\hline Auger Test 45 & 0 & 2 & 0 & 0 & 0 & 2 \\
\hline Auger Test 47 & 2 & 1 & 0 & 0 & 0 & 3 \\
\hline Auger Test 48 & 0 & 1 & 0 & 0 & 0 & 1 \\
\hline Auger Test 49 & 0 & 2 & 0 & 0 & 0 & 2 \\
\hline Auger Test 58 & 0 & 2 & 0 & 0 & 0 & 2 \\
\hline Auger Test 61 & 0 & 0 & 0 & 1 & 0 & 1 \\
\hline Auger Test 63 & 0 & 2 & 0 & 0 & 0 & 2 \\
\hline Auger Test 74 & 0 & 1 & 0 & 0 & 0 & 1 \\
\hline Auger Test 76 & 0 & 2 & 0 & 0 & 0 & 2 \\
\hline Auger Test 77 & 0 & 1 & 0 & 0 & 0 & 1 \\
\hline Auger Test 90 & 0 & 2 & 0 & 0 & 0 & 2 \\
\hline Auger Test 92 & 0 & 3 & 0 & 0 & 0 & 3 \\
\hline Auger Test 104 & 1 & 0 & 0 & 0 & 0 & 1 \\
\hline Auger Test 105 & 0 & 5 & 1 & 0 & 0 & 6 \\
\hline \multicolumn{7}{|l|}{ Test Unit 1} \\
\hline $0-10 \mathrm{~cm}$ & 0 & 0 & 0 & 0 & 0 & 0 \\
\hline $10-20 \mathrm{~cm}$ & 0 & 0 & 0 & 0 & 0 & 0 \\
\hline $20-30 \mathrm{~cm}$ & 0 & 0 & 0 & 0 & 0 & 0 \\
\hline $30-40 \mathrm{~cm}$ & 1 & 1 & 0 & 0 & 0 & 2 \\
\hline $40-50 \mathrm{~cm}$ & 1 & 1 & 0 & 0 & 0 & 2 \\
\hline $50-60 \mathrm{~cm}$ & 0 & 2 & 0 & 0 & 0 & 2 \\
\hline $60-70 \mathrm{~cm}$ & 1 & 0 & 0 & 0 & 0 & 1 \\
\hline $70-75 \mathrm{~cm}$ & 0 & 0 & 0 & 0 & 0 & 0 \\
\hline \multicolumn{7}{|l|}{ Test Unit 2} \\
\hline $0-10 \mathrm{~cm}$ & 0 & 4 & 0 & 0 & 0 & 4 \\
\hline $10-20 \mathrm{~cm}$ & 0 & 5 & 0 & 0 & 0 & 5 \\
\hline $20-30 \mathrm{~cm}$ & 0 & 3 & 0 & 0 & 0 & 3 \\
\hline $30-40 \mathrm{~cm}$ & 0 & 0 & 0 & 0 & 0 & 0 \\
\hline $40-50 \mathrm{~cm}$ & 0 & 9 & 0 & 0 & 0 & 9 \\
\hline $50-60 \mathrm{~cm}$ & 0 & 1 & 0 & 0 & 0 & 1 \\
\hline \multicolumn{7}{|l|}{ Test Unit 3} \\
\hline $0-10 \mathrm{~cm}$ & 0 & 0 & 0 & 0 & 0 & 0 \\
\hline $10-20 \mathrm{~cm}$ & 0 & 1 & 0 & 0 & 0 & 1 \\
\hline \multicolumn{7}{|l|}{ Test Unit 4} \\
\hline $0-10 \mathrm{~cm}$ & 0 & 9 & 0 & 0 & 0 & 9 \\
\hline $10-20 \mathrm{~cm}$ & 0 & 4 & 0 & 0 & 0 & 4 \\
\hline $20-30 \mathrm{~cm}$ & 0 & 5 & 0 & 0 & 0 & 5 \\
\hline $30-40 \mathrm{~cm}$ & 0 & 0 & 0 & 0 & 0 & 0 \\
\hline $40-50 \mathrm{~cm}$ & 0 & 0 & 0 & 0 & 0 & 0 \\
\hline $50-60 \mathrm{~cm}$ & 0 & 0 & 0 & 0 & 0 & 0 \\
\hline \multicolumn{7}{|l|}{ Test Unit 5} \\
\hline $0-10 \mathrm{~cm}$ & 0 & 0 & 0 & 0 & 0 & 0 \\
\hline $10-20 \mathrm{~cm}$ & 0 & 1 & 1 & 0 & 0 & 2 \\
\hline $20-25 \mathrm{~cm}$ & 0 & 0 & 0 & 0 & 0 & 0 \\
\hline
\end{tabular}


Chapter 2: Testing

Table 2.4, continued

\begin{tabular}{|c|c|c|c|c|c|c|}
\hline Provenience & $\begin{array}{c}\text { Chipped } \\
\text { Stone Tool }\end{array}$ & Debitage & Core & $\begin{array}{c}\text { Ground } \\
\text { Stone Tool }\end{array}$ & Sherd & Totals \\
\hline \multicolumn{7}{|l|}{ Test Unit 6} \\
\hline $0-10 \mathrm{~cm}$ & 0 & 1 & 0 & 0 & 0 & 1 \\
\hline $10-14 \mathrm{~cm}$ & 0 & 0 & 0 & 0 & 0 & 0 \\
\hline \multicolumn{7}{|l|}{ Test Unit 7} \\
\hline $0-10 \mathrm{~cm}$ & 0 & 0 & 0 & 0 & 0 & 0 \\
\hline $10-20 \mathrm{~cm}$ & 0 & 1 & 0 & 0 & 0 & 1 \\
\hline $20-30 \mathrm{~cm}$ & 0 & 1 & 0 & 0 & 0 & 1 \\
\hline $30-40 \mathrm{~cm}$ & 0 & 0 & 0 & 0 & 0 & 0 \\
\hline $40-50 \mathrm{~cm}$ & 0 & 1 & 0 & 0 & 0 & 1 \\
\hline $50-60 \mathrm{~cm}$ & 0 & 0 & 0 & 0 & 0 & 0 \\
\hline $60-70 \mathrm{~cm}$ & 0 & 0 & 0 & 0 & 0 & 0 \\
\hline $70-73 \mathrm{~cm}$ & 0 & 0 & 0 & 0 & 0 & 0 \\
\hline \multicolumn{7}{|l|}{ Test Unit 8} \\
\hline $0-10 \mathrm{~cm}$ & 0 & 7 & 0 & 0 & 0 & 7 \\
\hline $10-20 \mathrm{~cm}$ & 0 & 6 & 0 & 0 & 0 & 6 \\
\hline $20-30 \mathrm{~cm}$ & 0 & 3 & 0 & 1 & 0 & 4 \\
\hline $30-40 \mathrm{~cm}$ & 0 & 4 & 0 & 0 & 0 & 4 \\
\hline $40-50 \mathrm{~cm}$ & 0 & 4 & 0 & 0 & 0 & 4 \\
\hline $50-60 \mathrm{~cm}$ & 0 & 2 & 0 & 0 & 0 & 2 \\
\hline $60-70 \mathrm{~cm}$ & 0 & 2 & 0 & 0 & 0 & 2 \\
\hline \multicolumn{7}{|l|}{ Test Unit 9} \\
\hline $0-10 \mathrm{~cm}$ & 0 & 0 & 0 & 0 & 0 & 0 \\
\hline $10-20 \mathrm{~cm}$ & 0 & 2 & 0 & 0 & 0 & 2 \\
\hline $20-30 \mathrm{~cm}$ & 0 & 0 & 0 & 0 & 0 & 0 \\
\hline $30-40 \mathrm{~cm}$ & 0 & 0 & 0 & 0 & 0 & 0 \\
\hline \multicolumn{7}{|l|}{ Test Unit 10} \\
\hline $0-10 \mathrm{~cm}$ & 0 & 5 & 1 & 0 & 0 & 6 \\
\hline $10-20 \mathrm{~cm}$ & 0 & 5 & 0 & 0 & 0 & 5 \\
\hline $20-30 \mathrm{~cm}$ & 0 & 2 & 0 & 0 & 0 & 2 \\
\hline $30-36 \mathrm{~cm}$ & 0 & 0 & 0 & 0 & 0 & 0 \\
\hline \multicolumn{7}{|l|}{ Test Unit 11} \\
\hline $0-10 \mathrm{~cm}$ & 0 & 7 & 0 & 0 & 0 & 7 \\
\hline $10-20 \mathrm{~cm}$ & 0 & 11 & 0 & 0 & 0 & 11 \\
\hline $20-30 \mathrm{~cm}$ & 0 & 13 & 0 & 0 & 0 & 13 \\
\hline $30-40 \mathrm{~cm}$ & 0 & 15 & 0 & 0 & 0 & 15 \\
\hline BHT 8 & 0 & 1 & 0 & 0 & 0 & 1 \\
\hline BHT 9 & 0 & 1 & 0 & 0 & 0 & 1 \\
\hline BHT 18 & 0 & 1 & 0 & 0 & 0 & 1 \\
\hline BHT 20 & 0 & 0 & 1 & 0 & 0 & 1 \\
\hline BHT 21 & 0 & 2 & 0 & 0 & 0 & 2 \\
\hline BHT 23 & 0 & 1 & 1 & 0 & 0 & 2 \\
\hline BHT 24 & 0 & 1 & 0 & 0 & 0 & 1 \\
\hline Surface & 0 & 0 & 1 & 0 & 1 & 1 \\
\hline
\end{tabular}

Outside Corridor:

Auger Test 1

Totals

\begin{tabular}{l|l}
0 & 0 \\
\hline 7 & 2 \\
\hline
\end{tabular}


were on the southern and eastern slopes of the landform. The only other artifacts were from 3 tests in the northwest corner of the sampled area. About two-thirds of the assemblage was from 10 tests in a 50x50-m area in the east-central part of the investigation area, corresponding with a deposit of relatively deep surface sands. The site boundary within the project area as it was defined at that time was modified based on the results of auger testing to encompass $11,200 \mathrm{~m}^{2}$.

\section{Work Accomplished in Testing}

Testing investigations began with geophysical survey of a 40x40-m grid located just inside the revised project corridor at the east end of the site (Figure 2.8). A number of auger tests (Auger Tests 38, 47-49, 61, 63, 74, 76, and 77) had identified a low-density lithic scatter in and adjacent to this area. The survey identified no clear signs of archeological structures or other features within this grid (see Appendix B).

Thirty backhoe trenches and eleven 1x1-m test units were excavated within the geophysical survey grid. All of the trenches were $1.0 \mathrm{~m}$ wide, were 5.5 to $6.7 \mathrm{~m}$ long $($ mean $=6.3 \mathrm{~m})$, and had maximum depths that ranged from 14 to $80 \mathrm{~cm}$ $($ mean $=48 \mathrm{~cm})$. Excavated trenches encompassed $189 \mathrm{~m}^{2}$ of site area. Three of the test units were opened off of trenches, while the remaining units were placed away from trenches. Two test units (Test Units 2 and 4) were adjacent to one another. Test unit depths ranged from 13 to $75 \mathrm{~cm}$ below the surface.

The six recorded trench profiles displayed A-E-Bt soil columns. The A horizon is 7 to $34 \mathrm{~cm}$ thick and consists of brown (7.5YR 4/3, 4/4, and $5 / 4$ ) loamy very fine sand to very fine sandy loam. The E horizon is 7-43-cm-thick brown (7.5YR $5 / 4$ ) to strong brown ( $7.5 \mathrm{YR} 4 / 6$ and 5/6) very fine sandy loam. The Bt horizon is well structured, sometimes mottled, red (2.5YR 4/6) to strong brown (7.5YR 4/6) sandy clay loam to sandy clay.

\section{Cultural Features}

Three burned rock features were identified and documented (see Figure 2.8). Each of these probable hearths was composed of a slightly disarticulated cluster of fire-cracked ferruginous sandstone rocks that was less than $80 \mathrm{~cm}$ in diameter. Feature 1 consisted of 19 burned rocks at $20-40 \mathrm{~cm}$ below the surface in the northwest

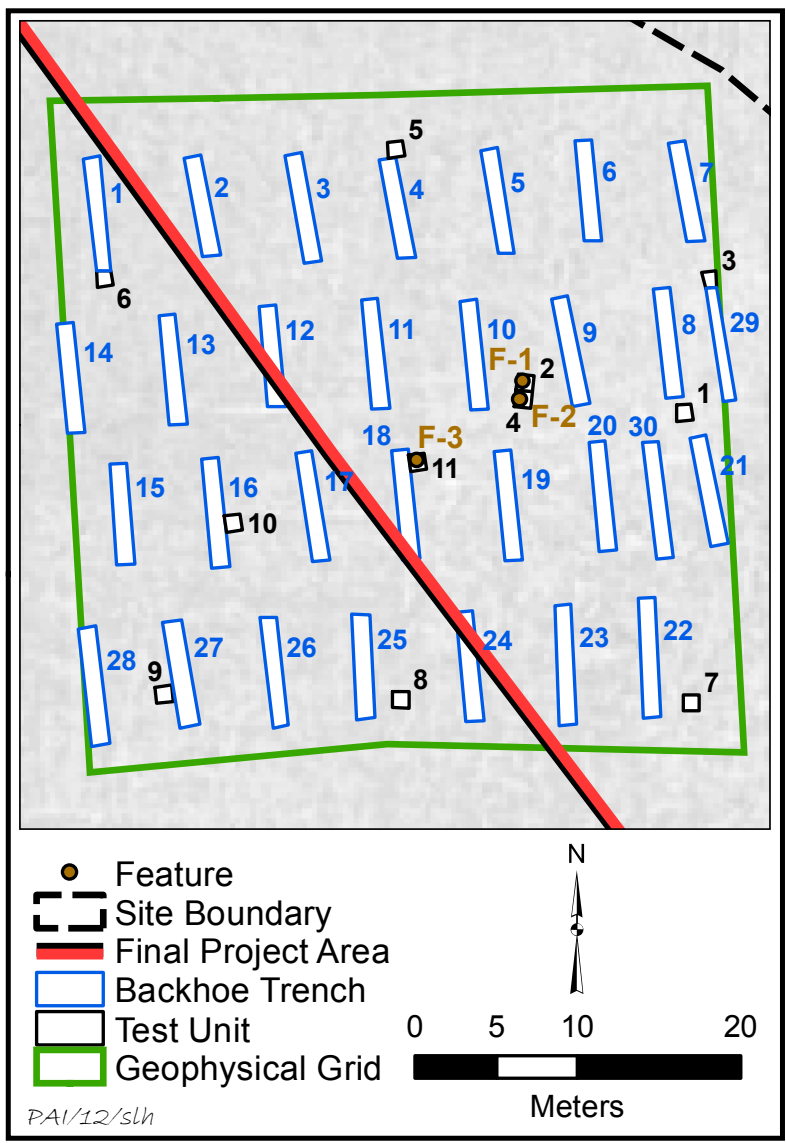

Figure 2.8. Aerial photograph of 41TT847 showing geophysical survey grid and test excavations.

quadrant of Test Unit 2 (Figure 2.9). It probably extended beyond the northern and western limits of the unit. No carbon staining, charred plant material, or associated artifacts were observed during feature excavation. The burned rocks attributed to Feature 1 had a combined weight of $2.5 \mathrm{~kg}$.

Feature 2 was south of Feature 1 in the southwest and northwest quadrants of adjacent Test Units 2 and 4 (see Figure 2.9). It likely extended beyond the western boundary of both units. Located at a depth of $23-46 \mathrm{~cm}$, Feature 2 was composed of 64 burned rocks with a combined weight of $29.6 \mathrm{~kg}$. No carbon staining was observed, but a small amount of oak (Quercus subg. Lobatae) wood charcoal was collected from the lower portion. It yielded a corrected radiocarbon age of $1330 \pm 40$ B.P. (Beta- $242371 ;{ }^{13} \mathrm{C} /{ }^{12} \mathrm{C}$ Ratio $=-26.6)$, with a calibrated two-sigma date range of A.D. $640-770$. 


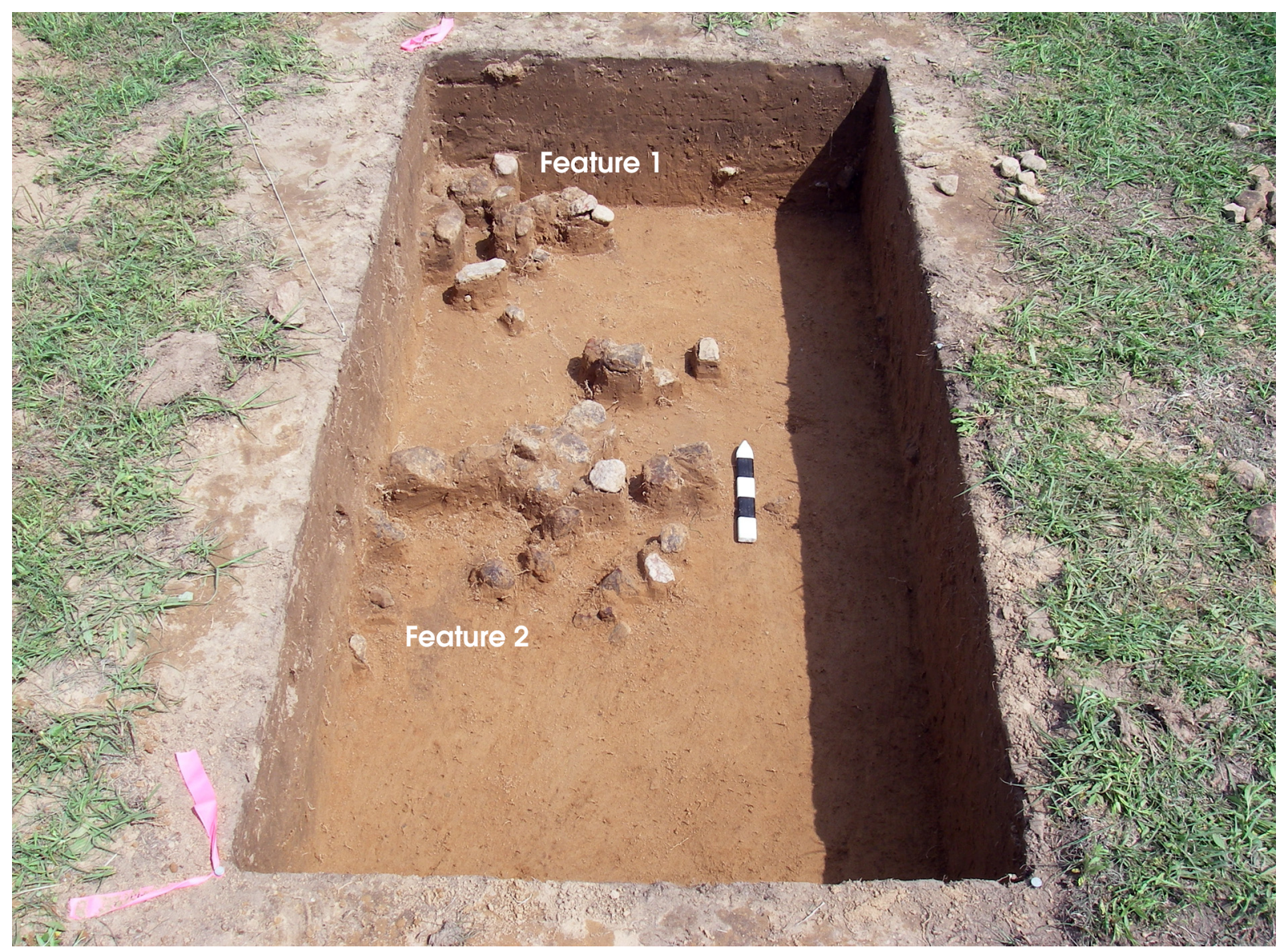

Figure 2.9. View to the north of Features 1 and 2 in Test Units 2 and 4 at 41TT847.

Feature 3 was in Test Unit 11 about 8-9 m west-southwest of Features 1 and 2. Located from 25 to $38 \mathrm{~cm}$ below the surface, it consisted of a cluster of 46 burned rocks without associated carbon-stained sediment or charred botanical material (Figure 2.10). The clasts had a combined weight of $11.0 \mathrm{~kg}$. This feature probably extended beyond the north and east walls of the unit.

Features 1 and 2 were between two magnetic susceptibility anomalies identified during the geophysical survey, and Feature 3 was just southwest of the smaller western anomaly. These features may relate to the anomalies, but such anomalies are not very diagnostic.

\section{Artifact Assemblage}

Artifacts were recovered from 19 auger tests, all of the test units, and 7 of the backhoe trenches, as well as the surface (see Table 2.4). This assemblage consists of 1 sherd, 3 dart points, 3 other chipped stone tools, 173 pieces of debitage, 7 cores, 2 ground/battered stones, and 2 pieces of intrusive metal (from Test Units 9 and 10). A plain, grog-tempered body sherd collected from the surface is the only ceramic recovered; it weighs $4.9 \mathrm{~g}$ and has floated exterior and interior surfaces. One of the dart points, from Level 4 of Test Unit 1, is typed as Gary. Made of Ogallala quartzite, it has a triangular blade, a contracting stem, and a lateral fracture on the base (Figure 2.11a). Even with the fracture, the base appears to be convex. The second dart point is a San Patrice, from Level 7 of Test Unit 1 ; it is a reworked proximal fragment made of yellowish brown, nonlocal (possibly Edwards) chert (Figure 2.11b). It has a concave base and expanding stem with basal and stem edge grind- 


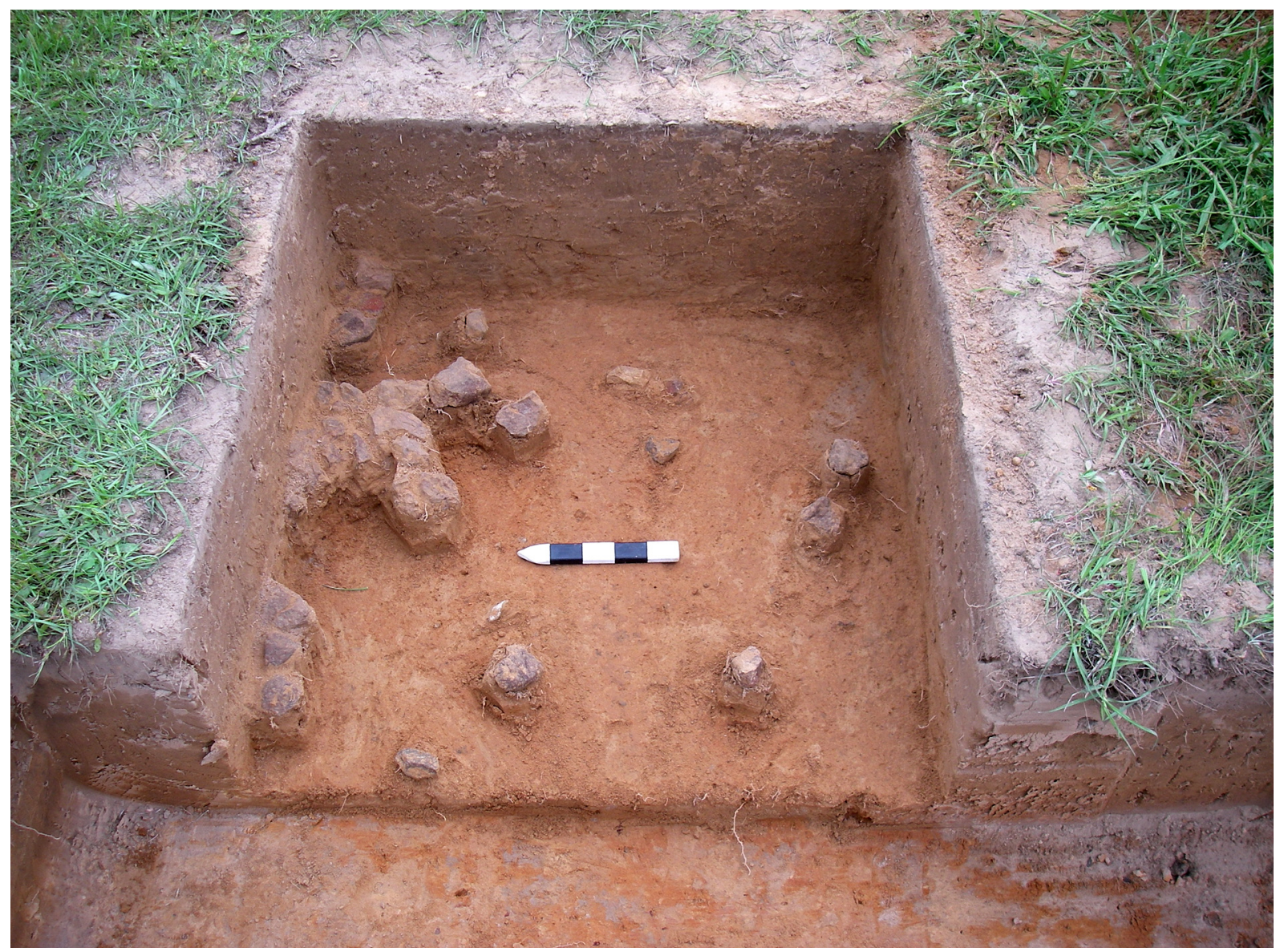

Figure 2.10. View to the east of Feature 3 in Test Unit 11 at 41 TT847.

ing. The distal end was reworked into a scraper after the tip was fractured. The third dart point, from Auger Test 47, is an untypeable, very thin, finely flaked proximal fragment made of local chert (Figure 2.11c); it has a contracting stem and a straight though slightly irregular base.

Also recovered from Auger Test 47 is a hafted bifacial scraper made of local chert (Figure 2.11d). This biface may have been used initially as a projectile point but subsequently was extensively reworked. It has steep edge retouch on the distal end and sides, and the proximal end has some retouch. The haft has parallel stem edges. The existence of the haft is suggested by a slight indentation on one lateral edge, toward the distal end, and tapering on the opposite lateral edge. Two flake tools consist of an edge-modified flake/scraper made of banded brown local chert from Level 5 of Test Unit 1 and a utilized flake of silicified wood from Auger Test 104.

Four percussion flake cores and three tested cobbles were recovered. The flake cores are all of silicified wood, and the tested cobbles are of hematite, local chert, and silicified wood. All of these materials are available locally. The 173 pieces of debitage are mostly small with 66 percent less than $19 \mathrm{~mm}$. The small specimens reflect flake fragmentation, and they support the conclusion that much of the assemblage represents late core reduction, tool production, and tool retouch using small source materials. The lithic materials are nearly entirely (98 percent) locally available and dominated by silicified wood (63 percent) and Ogallala and other quartzites (24 percent). Other local materials include chert (7 percent), ferruginous sandstone ( $<1$ percent), hematite ( 3 percent), and siltstone 

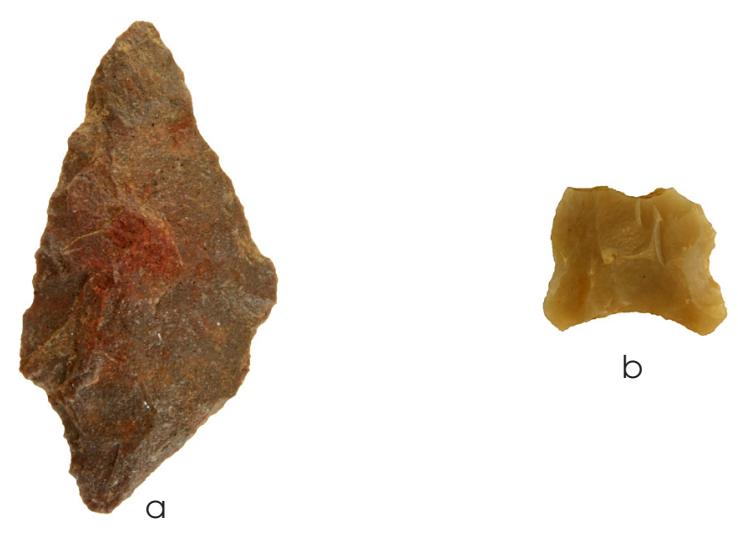

b
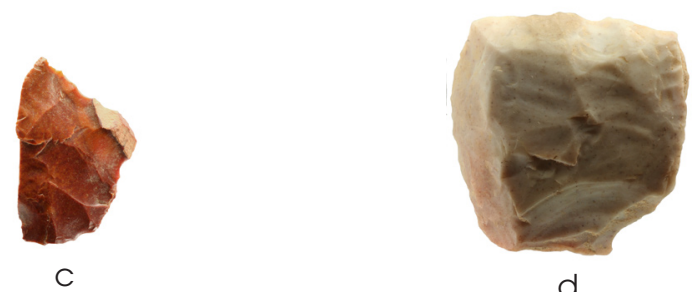

d

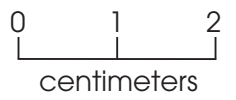

Figure 2.11. Chipped stone artifacts from 41 TT847. (a) Gary dart point; (b) San Patrice dart point; (c) untyped dart point fragment; (d) bifacial scraper.

( $<1$ percent). The nonlocal materials include only a few flakes ( 2 percent) of gray chert.

A pitted hammerstone was found in Test Unit 8. It is an irregular fragment of nonferruginous sandstone, retaining approximately 60 percent of a pitted area at the edge of one face. The surrounding surface was smoothed by crushing and pulverizing and possibly from limited grinding and abrasion. The margin adjacent to the pitted depression is clearly battered, and the opposite margin is thermally fractured. The position of the pit on the facet edge indicates that this is a fragment of a larger artifact that was utilized after initial fracture, but it is not clear if the complete pitted artifact served as an anvil or was used as a hammer in conjunction with an anvil. A mano/hammerstone was retrieved from Auger Test 61. It is battered primarily on one margin but also exhibits battering damage on one end. A facet opposite the battered margin is smoothed and somewhat flattened. This artifact's dimensions are indicative of the finger-manipulated mullers categorized by Ellis (2009:306) at the Ear Spool site.

Artifact counts were highest in Test Units 2,4 , and 11 in the central part of the grid and Test Units 8 and 10 in the south-central and west-central parts. Two of the dart points, the scraper, and several pieces of debitage were from Test Unit 1 at the east-central edge of the block, less than $10 \mathrm{~m}$ east-southeast of Features 1 and 2 . Vertically, 69 percent of the artifacts derived from controlled test unit excavation were recovered between 0 and $30 \mathrm{~cm}$ below the surface, and 94 percent were within $50 \mathrm{~cm}$ of the modern surface. Artifact counts steadily decreased below $20 \mathrm{~cm}$ : 24 percent at $0-10 \mathrm{~cm} ; 25$ percent at $10-20 \mathrm{~cm} ; 19$ percent at $20-30 \mathrm{~cm} ; 15$ percent at $30-40 \mathrm{~cm} ; 11$ percent at $40-50 \mathrm{~cm} ; 4$ percent at $50-60 \mathrm{~cm}$; and 2 percent at $60-70 \mathrm{~cm}$.

\section{Conclusions}

The tested part of 41TT847 is characterized by low feature density and a moderate density of lithics. The single sherd retrieved appears to be an incidental inclusion unrelated to most of the other materials. The presence of three burned rock features coupled with a higher lithic artifact density relative to nearby sites $41 \mathrm{TT} 6$ and $41 \mathrm{TT} 846$ suggests that this part of $41 \mathrm{TT} 847$ was used differently than the other two sites, possibly as a campsite. The radiocarbon date from one of the features and the recovery of a Gary dart point indicate that at least some of this use occurred during the Woodland period. The presence of the San Patrice dart point and the Caddo sherd also imply ephemeral earlier and later use, though the former may well represent a scavenged and recycled artifact.

The archeological deposits were within thin surface sands that retained little if any potential for stratification. Because of this, and the presence of palimpsest components, the sparseness of materials suitable for dating, and disturbance from pedogenic processes and various kinds of bioturbation, the investigated part of 41TT847 was considered to have little potential to contribute important information about prehistory. Hence, it was considered ineligible for inclusion in the National Register and for designation as a State Antiquities Landmark, and further work was judged unnecessary. 


\section{SITE 41TT851}

Site 41 TT 851 is near the middle of the project corridor, on a generally level upland ridge between two intermittent tributaries of Tankersley Creek (Figure 2.12). The site area is bisected by a shallow, south-trending drainage that feeds two stock tanks. FM 127 borders the southeast side of the site, and a large wastewater treatment facility is on the Tankersley Creek floodplain just below and west-southwest of the site. Cultural deposits in the northwestern portion of the site were removed during borrow pit excavation, and the southwestern arm of the site was disturbed by haul road construction, heavy equipment traffic to and from the borrow pit, earthmoving, and the construction of asphalt pads. Gravel, asphalt, and modern trash also had been dumped in this part of the site. Further disturbance is attributable to various activities associated with a previous residence and previous and ongoing ranching. A burned house and associated outbuildings are in the east and southeast portions of the site area, and a dilapidated barn and stock pens are on the northeastern edge. As of 2005, most of the site area consisted of open, variably wooded pasture. The valley wall that delimits the site's west edge and the drainage that cuts through the site were wooded. Almost the entire site was within the project corridor as of 2005 , and this was still largely the case in 2007 when intensive testing focused on the southwestern arm. By the 2010 data recovery excavations, the project alignment had shifted so that the southwest corner was excluded from the proposed right of way.

AEC excavated 37 shovel tests at 41TT851 during its initial 2002 investigation (Perttula et al. 2002). Twenty-five of those tests were positive. Recovered materials included 5 sherds, 24 pieces of lithic debris, a flake tool, burned rocks, and 19 historic artifacts. Three other sherds were collected from the surface in a garden north of the barn. Prehistoric lithic artifacts were recovered in subsurface contexts across the site, but subsurface recovery of prehistoric Caddo sherds was limited to shovel tests in the site's southwest arm. Most of the historic artifacts were recovered in the northern and eastern portions of the site. The historic assemblage is likely derived from previous farmstead occupation and the use of the various structures on that part of the site. Based on the findings of this investigation, 41TT851 was estimated to cover $90,000 \mathrm{~m}^{2}$.

Subsequent to borrow pit excavation and haul road construction, AEC personnel returned to the site to evaluate the archeological deposits in the vicinity of the haul road (Perttula and Nelson 2002a). This investigation focused on an 8 -acre area in the southwestern part of the site. Twenty-five shovel tests and a 50x50-cm unit were excavated, and artifacts were recovered from 14 tests and the sample unit. This assemblage included 52 ceramic sherds, an unidentified arrow point, 2 scrapers, 31 pieces of lithic debris, a ground stone artifact, numerous fragments of burned clay, charcoal, and faunal bone fragments. Most of this material was recovered from apparent midden deposits (Perttula and Nelson 2002a).

\section{Auger Testing}

A total of 188 auger tests was excavated, many of which encountered sediments disturbed by historic and recent activities. Tests were placed primarily at $12-\mathrm{m}$ intervals, but the drainage and associated wetlands, historic structures and other features, the borrow pit and associated haul road, and steep slopes sometimes prevented systematic placement of tests, particularly in the northern and eastern areas of the site. Prehistoric artifacts were retrieved from 22 tests (Table 2.5). The materials recovered consist of 18 ceramic sherds, 4 chipped stone tools, 24 pieces of debitage, 1 core, 3 ground/ battered stones, and 15 burned rocks. Most of the positive tests were in the site's southwest arm. Prehistoric ceramics and lithics in that area revealed discrete but partly overlapping loci for each artifact type, with ceramics clustered in a $60 \times 50-\mathrm{m}$ area and lithics dispersed across a $120 \times 50-\mathrm{m}$ area that trended south of the sherd concentration. The midden-stained sediments observed there in 2002 were not evident in the auger tests.

Only seven widely dispersed prehistoric artifacts were recovered from auger tests in other parts of the site. A flake and a flake tool were collected from Auger Test 62 close to the borrow pit in the northwest part of the site. Two sherds were found in two isolated tests (Auger Tests 39 and 67) in the northern part. Finally, two sherds and a ground stone artifact were recovered from adjacent Auger Tests 157 


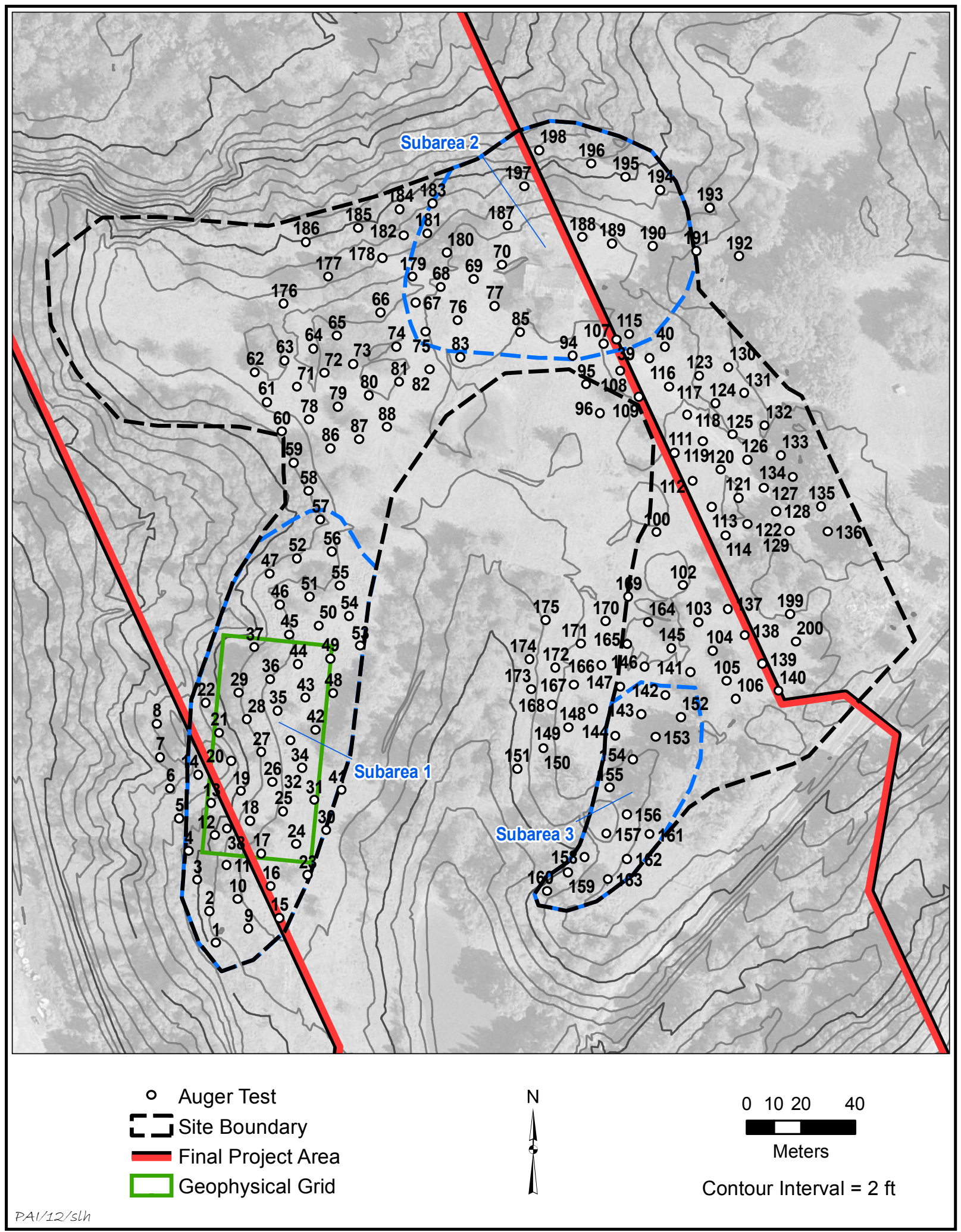

Figure 2.12. Map of 41 TT851 showing topography, auger test locations, and geophysical survey grid on 2005 aerial imagery. 
Excavations along the U.S. Highway 271 Mount Pleasant Relief Route

Table 2.5. Artifacts recovered in auger and intensive testing at 41TT851

\begin{tabular}{|c|c|c|c|c|c|c|c|}
\hline Provenience & $\begin{array}{c}\text { Chipped } \\
\text { Stone } \\
\text { Tool } \\
\end{array}$ & Debitage & Core & $\begin{array}{c}\text { Ground } \\
\text { Stone } \\
\text { Tool }\end{array}$ & Sherd & $\begin{array}{c}\text { Faunal } \\
\text { Remains }\end{array}$ & Totals \\
\hline \multicolumn{8}{|l|}{ Subarea 1: } \\
\hline Auger Test 1 & 0 & 1 & 0 & 0 & 0 & 0 & 1 \\
\hline Auger Test 3 & 0 & 1 & 0 & 0 & 0 & 0 & 1 \\
\hline Auger Test 11 & 0 & 1 & 0 & 0 & 0 & 0 & 1 \\
\hline Auger Test 12 & 0 & 1 & 0 & 0 & 1 & 0 & 2 \\
\hline Auger Test 22 & 0 & 2 & 0 & 0 & 0 & 0 & 2 \\
\hline Auger Test 24 & 0 & 1 & 0 & 0 & 0 & 0 & 1 \\
\hline Auger Test 25 & 0 & 3 & 0 & 0 & 0 & 0 & 3 \\
\hline Auger Test 26 & 1 & 2 & 0 & 1 & 0 & 0 & 4 \\
\hline Auger Test 28 & 0 & 2 & 0 & 0 & 2 & 0 & 4 \\
\hline Auger Test 29 & 0 & 0 & 0 & 0 & 1 & 0 & 1 \\
\hline Auger Test 35 & 0 & 0 & 0 & 0 & 2 & 0 & 2 \\
\hline Auger Test 37 & 1 & 0 & 1 & 1 & 4 & 0 & 7 \\
\hline Auger Test 38 & 0 & 4 & 0 & 0 & 1 & 0 & 5 \\
\hline Auger Test 44 & 0 & 4 & 0 & 0 & 1 & 0 & 5 \\
\hline Auger Test 45 & 0 & 1 & 0 & 0 & 0 & 0 & 1 \\
\hline Auger Test 47 & 1 & 0 & 0 & 1 & 2 & 0 & 4 \\
\hline Auger Test 50 & 0 & 1 & 0 & 0 & 0 & 0 & 1 \\
\hline \multicolumn{8}{|l|}{ Test Unit 1} \\
\hline $0-10 \mathrm{~cm}$ & 0 & 4 & 0 & 0 & 10 & 0 & 14 \\
\hline $10-20 \mathrm{~cm}$ & 0 & 5 & 0 & 0 & 13 & 0 & 18 \\
\hline $20-30 \mathrm{~cm}$ & 0 & 4 & 0 & 0 & 4 & 0 & 8 \\
\hline \multicolumn{8}{|l|}{ Test Unit 2} \\
\hline $0-10 \mathrm{~cm}$ & 0 & 2 & 0 & 0 & 0 & 0 & 2 \\
\hline $10-20 \mathrm{~cm}$ & 0 & 5 & 0 & 0 & 2 & 0 & 7 \\
\hline $20-30 \mathrm{~cm}$ & 1 & 3 & 0 & 0 & 2 & 0 & 6 \\
\hline $30-40 \mathrm{~cm}$ & 0 & 0 & 0 & 0 & 1 & 0 & 1 \\
\hline \multicolumn{8}{|l|}{ Test Unit 3} \\
\hline $0-10 \mathrm{~cm}$ & 1 & 4 & 0 & 0 & 15 & 2 & 22 \\
\hline $10-20 \mathrm{~cm}$ & 1 & 8 & 0 & 0 & 15 & 8 & 32 \\
\hline $20-25 \mathrm{~cm}$ & 0 & 5 & 2 & 0 & 10 & 18 & 35 \\
\hline $25-30 \mathrm{~cm}$ & 0 & 0 & 0 & 0 & 2 & 31 & 33 \\
\hline $30-35 \mathrm{~cm}$ & 0 & 1 & 0 & 0 & 7 & 4 & 12 \\
\hline \multicolumn{8}{|l|}{$\begin{array}{c}\text { Test Unit BHT } 40 \\
\text { South Extension }\end{array}$} \\
\hline $0-10 \mathrm{~cm}$ & 0 & 4 & 0 & 0 & 10 & 0 & 14 \\
\hline $10-20 \mathrm{~cm}$ & 0 & 2 & 0 & 0 & 7 & 0 & 9 \\
\hline $20-25 \mathrm{~cm}$ & 0 & 1 & 0 & 0 & 4 & 6 & 11 \\
\hline $25-30 \mathrm{~cm}$ & 0 & 0 & 0 & 0 & 3 & 6 & 9 \\
\hline $30-35 \mathrm{~cm}$ & 0 & 2 & 0 & 0 & 6 & 9 & 17 \\
\hline \multicolumn{8}{|l|}{ Test Unit 4} \\
\hline $0-10 \mathrm{~cm}$ & 0 & 0 & 0 & 0 & 0 & 0 & 0 \\
\hline $10-20 \mathrm{~cm}$ & 0 & 0 & 0 & 0 & 6 & 0 & 6 \\
\hline $20-30 \mathrm{~cm}$ & 1 & 2 & 0 & 0 & 4 & 0 & 7 \\
\hline $30-40 \mathrm{~cm}$ & 0 & 1 & 0 & 1 & 3 & 0 & 5 \\
\hline $40-50 \mathrm{~cm}$ & 0 & 1 & 0 & 0 & 0 & 0 & 1 \\
\hline $50-60 \mathrm{~cm}$ & 0 & 0 & 0 & 0 & 0 & 0 & 0 \\
\hline
\end{tabular}


Chapter 2: Testing

Table 2.5, continued

\begin{tabular}{|c|c|c|c|c|c|c|c|}
\hline Provenience & $\begin{array}{c}\text { Chipped } \\
\text { Stone } \\
\text { Tool }\end{array}$ & Debitage & Core & $\begin{array}{c}\text { Ground } \\
\text { Stone } \\
\text { Tool }\end{array}$ & Sherd & $\begin{array}{c}\text { Faunal } \\
\text { Remains }\end{array}$ & Totals \\
\hline \multicolumn{8}{|l|}{ Test Unit 5} \\
\hline $0-10 \mathrm{~cm}$ & 0 & 0 & 0 & 0 & 0 & 0 & 0 \\
\hline $10-20 \mathrm{~cm}$ & 0 & 14 & 0 & 0 & 5 & 0 & 19 \\
\hline $20-30 \mathrm{~cm}$ & 1 & 2 & 0 & 0 & 5 & 0 & 8 \\
\hline $30-40 \mathrm{~cm}$ & 0 & 4 & 0 & 1 & 10 & 0 & 15 \\
\hline \multicolumn{8}{|l|}{ Test Unit 6} \\
\hline $0-10 \mathrm{~cm}$ & 1 & 8 & 0 & 1 & 22 & 14 & 46 \\
\hline $10-20 \mathrm{~cm}$ & 1 & 3 & 0 & 0 & 21 & 9 & 34 \\
\hline $20-25 \mathrm{~cm}$ & 0 & 4 & 0 & 0 & 10 & 22 & 36 \\
\hline $25-30 \mathrm{~cm}$ & 0 & 9 & 0 & 0 & 26 & 58 & 93 \\
\hline $30-35 \mathrm{~cm}$ & 0 & 3 & 0 & 0 & 20 & 9 & 32 \\
\hline $35-43 \mathrm{~cm}$ (gopher hole) & 0 & 1 & 0 & 0 & 1 & 5 & 7 \\
\hline \multicolumn{8}{|l|}{ Test Unit 7} \\
\hline $0-10 \mathrm{~cm}$ & 0 & 2 & 0 & 0 & 3 & 0 & 5 \\
\hline $10-20 \mathrm{~cm}$ & 1 & 3 & 1 & 0 & 18 & 0 & 23 \\
\hline $20-30 \mathrm{~cm}$ & 0 & 17 & 1 & 0 & 35 & 12 & 65 \\
\hline $30-40 \mathrm{~cm}$ & 1 & 6 & 0 & 0 & 21 & 0 & 28 \\
\hline \multicolumn{8}{|l|}{ Test Unit 8} \\
\hline $0-10 \mathrm{~cm}$ & 0 & 0 & 0 & 0 & 0 & 0 & 0 \\
\hline $10-20 \mathrm{~cm}$ & 0 & 1 & 0 & 0 & 0 & 0 & 1 \\
\hline $20-30 \mathrm{~cm}$ & 0 & 0 & 0 & 0 & 1 & 0 & 1 \\
\hline $30-35 \mathrm{~cm}$ & 0 & 0 & 0 & 0 & 1 & 0 & 1 \\
\hline \multicolumn{8}{|l|}{ Test Unit 9} \\
\hline $0-10 \mathrm{~cm}$ & 0 & 0 & 0 & 0 & 0 & 0 & 0 \\
\hline $10-20 \mathrm{~cm}$ & 0 & 2 & 0 & 0 & 0 & 0 & 2 \\
\hline $20-30 \mathrm{~cm}$ & 0 & 0 & 0 & 0 & 3 & 0 & 3 \\
\hline \multicolumn{8}{|l|}{ Test Unit 10} \\
\hline $0-10 \mathrm{~cm}$ & 0 & 3 & 0 & 0 & 3 & 0 & 6 \\
\hline $10-20 \mathrm{~cm}$ & 0 & 8 & 0 & 0 & 7 & 0 & 15 \\
\hline $20-30 \mathrm{~cm}$ & 1 & 7 & 0 & 0 & 15 & 0 & 23 \\
\hline $30-39 \mathrm{~cm}$ & 0 & 3 & 0 & 0 & 7 & 1 & 11 \\
\hline \multicolumn{8}{|l|}{ Test Unit 11} \\
\hline $0-10 \mathrm{~cm}$ & 0 & 1 & 0 & 0 & 2 & 0 & 3 \\
\hline $10-20 \mathrm{~cm}$ & 1 & 1 & 0 & 0 & 3 & 0 & 5 \\
\hline $20-30 \mathrm{~cm}$ & 0 & 3 & 0 & 0 & 10 & 0 & 13 \\
\hline $30-40 \mathrm{~cm}$ & 0 & 3 & 0 & 0 & 6 & 2 & 11 \\
\hline \multicolumn{8}{|l|}{ Test Unit 12} \\
\hline $0-10 \mathrm{~cm}$ & 0 & 1 & 0 & 0 & 1 & 0 & 2 \\
\hline $10-20 \mathrm{~cm}$ & 2 & 3 & 0 & 0 & 9 & 1 & 15 \\
\hline $20-30 \mathrm{~cm}$ & 0 & 2 & 0 & 0 & 4 & 1 & 7 \\
\hline $30-40 \mathrm{~cm}$ & 0 & 2 & 0 & 0 & 2 & 0 & 4 \\
\hline \multicolumn{8}{|l|}{ Test Unit 13} \\
\hline $0-10 \mathrm{~cm}$ & 0 & 1 & 0 & 0 & 1 & 0 & 2 \\
\hline $10-20 \mathrm{~cm}$ & 1 & 8 & 0 & 1 & 4 & 2 & 16 \\
\hline $20-30 \mathrm{~cm}$ & 0 & 0 & 0 & 0 & 0 & 0 & 0 \\
\hline $30-40 \mathrm{~cm}$ & 0 & 3 & 0 & 0 & 2 & 1 & 6 \\
\hline \multicolumn{8}{|l|}{ Test Unit 14} \\
\hline $0-10 \mathrm{~cm}$ & 0 & 2 & 0 & 0 & 2 & 0 & 4 \\
\hline
\end{tabular}


Table 2.5, continued

\begin{tabular}{|c|c|c|c|c|c|c|c|}
\hline Provenience & $\begin{array}{c}\text { Chipped } \\
\text { Stone } \\
\text { Tool }\end{array}$ & Debitage & Core & $\begin{array}{c}\text { Ground } \\
\text { Stone } \\
\text { Tool }\end{array}$ & Sherd & $\begin{array}{c}\text { Faunal } \\
\text { Remains }\end{array}$ & Totals \\
\hline $10-20 \mathrm{~cm}$ & 0 & 4 & 0 & 0 & 12 & 0 & 16 \\
\hline $20-30 \mathrm{~cm}$ & 1 & 15 & 0 & 0 & 41 & 1 & 58 \\
\hline $30-40 \mathrm{~cm}$ & 1 & 2 & 0 & 0 & 14 & 0 & 17 \\
\hline \multicolumn{8}{|l|}{ Test Unit 15} \\
\hline $0-10 \mathrm{~cm}$ & 0 & 2 & 0 & 0 & 4 & 0 & 6 \\
\hline $10-20 \mathrm{~cm}$ & 0 & 1 & 0 & 0 & 6 & 0 & 7 \\
\hline $20-30 \mathrm{~cm}$ & 0 & 3 & 0 & 0 & 5 & 0 & 8 \\
\hline \multicolumn{8}{|l|}{ Test Unit 16} \\
\hline $0-10 \mathrm{~cm}$ & 0 & 7 & 0 & 0 & 3 & 0 & 10 \\
\hline $10-20 \mathrm{~cm}$ & 0 & 7 & 0 & 0 & 6 & 0 & 13 \\
\hline $20-30 \mathrm{~cm}$ & 0 & 8 & 0 & 1 & 12 & 0 & 21 \\
\hline \multicolumn{8}{|l|}{ Test Unit 17} \\
\hline $0-10 \mathrm{~cm}$ & 0 & 3 & 0 & 0 & 1 & 0 & 4 \\
\hline $10-20 \mathrm{~cm}$ & 0 & 6 & 0 & 0 & 11 & 0 & 17 \\
\hline $20-30 \mathrm{~cm}$ & 2 & 16 & 0 & 0 & 15 & 0 & 33 \\
\hline \multicolumn{8}{|l|}{ Test Unit 18} \\
\hline $0-10 \mathrm{~cm}$ & 0 & 2 & 0 & 0 & 1 & 0 & 3 \\
\hline $10-20 \mathrm{~cm}$ & 0 & 12 & 0 & 0 & 7 & 0 & 19 \\
\hline $20-30 \mathrm{~cm}$ & 0 & 28 & 0 & 0 & 11 & 0 & 39 \\
\hline $30-40 \mathrm{~cm}$ & 0 & 9 & 1 & 0 & 10 & 0 & 20 \\
\hline \multicolumn{8}{|l|}{ Test Unit 19} \\
\hline $0-10 \mathrm{~cm}$ & 0 & 12 & 0 & 0 & 0 & 0 & 12 \\
\hline $10-20 \mathrm{~cm}$ & 2 & 9 & 0 & 0 & 2 & 1 & 14 \\
\hline \multicolumn{8}{|l|}{ Test Unit 20} \\
\hline $0-10 \mathrm{~cm}$ & 0 & 6 & 0 & 0 & 6 & 0 & 12 \\
\hline $10-20 \mathrm{~cm}$ & 0 & 7 & 0 & 0 & 7 & 0 & 14 \\
\hline $20-30 \mathrm{~cm}$ & 0 & 1 & 0 & 0 & 4 & 0 & 5 \\
\hline \multicolumn{8}{|l|}{ Test Unit 21} \\
\hline $0-10 \mathrm{~cm}$ & 0 & 1 & 0 & 0 & 1 & 0 & 2 \\
\hline $10-20 \mathrm{~cm}$ & 0 & 0 & 0 & 0 & 3 & 0 & 3 \\
\hline $20-30 \mathrm{~cm}$ & 1 & 1 & 0 & 0 & 4 & 0 & 6 \\
\hline \multicolumn{8}{|l|}{ Test Unit 22} \\
\hline $0-10 \mathrm{~cm}$ & 0 & 0 & 0 & 0 & 0 & 0 & 0 \\
\hline $10-20 \mathrm{~cm}$ & 0 & 2 & 0 & 0 & 1 & 0 & 3 \\
\hline $20-30 \mathrm{~cm}$ & 0 & 7 & 0 & 0 & 7 & 0 & 14 \\
\hline $30-40 \mathrm{~cm}$ & 1 & 9 & 0 & 0 & 10 & 0 & 20 \\
\hline $40-50 \mathrm{~cm}$ & 1 & 8 & 1 & 0 & 6 & 0 & 16 \\
\hline \multicolumn{8}{|l|}{ Test Unit 23} \\
\hline $0-10 \mathrm{~cm}$ & 0 & 5 & 0 & 0 & 4 & 0 & 9 \\
\hline $10-20 \mathrm{~cm}$ & 0 & 3 & 0 & 0 & 4 & 4 & 8 \\
\hline $20-30 \mathrm{~cm}$ & 0 & 5 & 0 & 0 & 7 & 0 & 12 \\
\hline $30-40 \mathrm{~cm}$ & 0 & 2 & 0 & 0 & 7 & 0 & 9 \\
\hline $40-50 \mathrm{~cm}$ & 0 & 1 & 0 & 0 & 5 & 0 & 6 \\
\hline \multicolumn{8}{|l|}{ Test Unit 24} \\
\hline $0-10 \mathrm{~cm}$ & 0 & 2 & 0 & 0 & 0 & 0 & 2 \\
\hline $10-20 \mathrm{~cm}$ & 1 & 2 & 0 & 0 & 3 & 0 & 6 \\
\hline $20-30 \mathrm{~cm}$ & 0 & 1 & 0 & 0 & 3 & 0 & 4 \\
\hline Test Unit 25 & & & & & & & \\
\hline
\end{tabular}


Chapter 2: Testing

Table 2.5, continued

\begin{tabular}{|c|c|c|c|c|c|c|c|}
\hline Provenience & $\begin{array}{c}\text { Chipped } \\
\text { Stone } \\
\text { Tool }\end{array}$ & Debitage & Core & $\begin{array}{c}\text { Ground } \\
\text { Stone } \\
\text { Tool }\end{array}$ & Sherd & $\begin{array}{c}\text { Faunal } \\
\text { Remains }\end{array}$ & Totals \\
\hline $0-10 \mathrm{~cm}$ & 1 & 1 & 0 & 0 & 2 & 0 & 4 \\
\hline $10-20 \mathrm{~cm}$ & 0 & 1 & 0 & 0 & 4 & 1 & 6 \\
\hline $20-30 \mathrm{~cm}$ & 0 & 1 & 0 & 0 & 9 & 0 & 10 \\
\hline $30-40 \mathrm{~cm}$ & 2 & 4 & 0 & 0 & 19 & 0 & 25 \\
\hline $40-50 \mathrm{~cm}$ & 0 & 5 & 0 & 0 & 10 & 0 & 15 \\
\hline \multicolumn{8}{|l|}{ Test Unit 26} \\
\hline $0-10 \mathrm{~cm}$ & 0 & 7 & 0 & 0 & 2 & 0 & 9 \\
\hline $10-20 \mathrm{~cm}$ & 0 & 7 & 0 & 0 & 8 & 0 & 15 \\
\hline $20-30 \mathrm{~cm}$ & 0 & 14 & 0 & 0 & 33 & 0 & 47 \\
\hline $30-35 \mathrm{~cm}$ & 1 & 7 & 0 & 0 & 6 & 0 & 14 \\
\hline \multicolumn{8}{|l|}{ Test Unit 27} \\
\hline $0-10 \mathrm{~cm}$ & 0 & 0 & 0 & 0 & 0 & 0 & 0 \\
\hline $10-20 \mathrm{~cm}$ & 0 & 1 & 0 & 0 & 3 & 0 & 4 \\
\hline $20-30 \mathrm{~cm}$ & 0 & 2 & 0 & 0 & 0 & 0 & 2 \\
\hline $30-40 \mathrm{~cm}$ & 0 & 0 & 0 & 0 & 0 & 0 & 0 \\
\hline \multicolumn{8}{|l|}{ Test Unit 28} \\
\hline $0-10 \mathrm{~cm}$ & 0 & 1 & 0 & 0 & 0 & 0 & 1 \\
\hline $10-20 \mathrm{~cm}$ & 0 & 1 & 0 & 0 & 5 & 0 & 6 \\
\hline $20-30 \mathrm{~cm}$ & 0 & 0 & 0 & 0 & 4 & 0 & 4 \\
\hline $30-34 \mathrm{~cm}$ & 0 & 0 & 0 & 0 & 0 & 0 & 0 \\
\hline \multicolumn{8}{|l|}{ Test Unit 29} \\
\hline $0-10 \mathrm{~cm}$ & 1 & 3 & 0 & 0 & 9 & 0 & 13 \\
\hline $10-20 \mathrm{~cm}$ & 1 & 9 & 0 & 0 & 9 & 0 & 19 \\
\hline $20-25 \mathrm{~cm}$ & 0 & 10 & 0 & 0 & 0 & 0 & 10 \\
\hline \multicolumn{8}{|l|}{ Test Unit 30} \\
\hline $0-10 \mathrm{~cm}$ & 0 & 0 & 0 & 0 & 0 & 0 & 0 \\
\hline $10-20 \mathrm{~cm}$ & 1 & 0 & 0 & 0 & 4 & 0 & 5 \\
\hline $20-30 \mathrm{~cm}$ & 1 & 2 & 0 & 0 & 1 & 0 & 4 \\
\hline \multicolumn{8}{|l|}{ Test Unit 31} \\
\hline $0-10 \mathrm{~cm}$ & 0 & 5 & 0 & 0 & 2 & 0 & 7 \\
\hline $10-20 \mathrm{~cm}$ & 0 & 1 & 0 & 0 & 13 & 0 & 14 \\
\hline $20-30 \mathrm{~cm}$ & 0 & 6 & 0 & 0 & 31 & 1 & 38 \\
\hline $30-40 \mathrm{~cm}$ & 1 & 5 & 0 & 0 & 4 & 0 & 10 \\
\hline $40-50 \mathrm{~cm}$ & 0 & 0 & 0 & 0 & 1 & 0 & 1 \\
\hline \multicolumn{8}{|l|}{ Test Unit 32} \\
\hline $0-10 \mathrm{~cm}$ & 0 & 0 & 0 & 0 & 0 & 0 & 0 \\
\hline $10-20 \mathrm{~cm}$ & 0 & 0 & 0 & 0 & 2 & 0 & 2 \\
\hline \multicolumn{8}{|l|}{ Test Unit 33} \\
\hline $0-10 \mathrm{~cm}$ & 0 & 0 & 0 & 0 & 1 & 0 & 1 \\
\hline $10-20 \mathrm{~cm}$ & 0 & 2 & 0 & 0 & 1 & 0 & 3 \\
\hline $20-30 \mathrm{~cm}$ & 0 & 1 & 0 & 0 & 0 & 0 & 1 \\
\hline \multicolumn{8}{|l|}{ Test Unit 35} \\
\hline $0-10 \mathrm{~cm}$ & 0 & 5 & 0 & 0 & 4 & 0 & 9 \\
\hline $10-20 \mathrm{~cm}$ & 0 & 7 & 0 & 0 & 5 & 0 & 12 \\
\hline $20-30 \mathrm{~cm}$ & 0 & 3 & 0 & 0 & 8 & 0 & 11 \\
\hline $30-40 \mathrm{~cm}$ & 1 & 3 & 0 & 0 & 3 & 0 & 7 \\
\hline $40-45 \mathrm{~cm}$ & 0 & 0 & 0 & 0 & 0 & 0 & 0 \\
\hline Test Unit 36 & & & & & & & \\
\hline
\end{tabular}


Table 2.5, continued

\begin{tabular}{|c|c|c|c|c|c|c|c|}
\hline Provenience & $\begin{array}{c}\text { Chipped } \\
\text { Stone } \\
\text { Tool }\end{array}$ & Debitage & Core & $\begin{array}{c}\text { Ground } \\
\text { Stone } \\
\text { Tool }\end{array}$ & Sherd & $\begin{array}{c}\text { Faunal } \\
\text { Remains }\end{array}$ & Totals \\
\hline $0-10 \mathrm{~cm}$ & 0 & 0 & 0 & 0 & 6 & 0 & 6 \\
\hline $10-20 \mathrm{~cm}$ & 0 & 0 & 0 & 0 & 1 & 0 & 1 \\
\hline $20-30 \mathrm{~cm}$ & 0 & 0 & 0 & 0 & 0 & 0 & 0 \\
\hline $30-40 \mathrm{~cm}$ & 0 & 0 & 0 & 0 & 4 & 0 & 4 \\
\hline $40-50 \mathrm{~cm}$ & 0 & 0 & 0 & 0 & 0 & 0 & 0 \\
\hline \multicolumn{8}{|l|}{ Test Unit 37} \\
\hline $0-10 \mathrm{~cm}$ & 0 & 2 & 0 & 0 & 7 & 0 & 9 \\
\hline $10-20 \mathrm{~cm}$ & 0 & 4 & 0 & 0 & 16 & 0 & 20 \\
\hline $20-30 \mathrm{~cm}$ & 0 & 8 & 0 & 0 & 16 & 0 & 24 \\
\hline $30-40 \mathrm{~cm}$ & 0 & 3 & 0 & 0 & 12 & 1 & 16 \\
\hline $40-45 \mathrm{~cm}$ & 0 & 0 & 0 & 0 & 0 & 0 & 0 \\
\hline \multicolumn{8}{|l|}{ Test Unit 38} \\
\hline $0-10 \mathrm{~cm}$ & 0 & 1 & 0 & 0 & 10 & 0 & 11 \\
\hline $10-20 \mathrm{~cm}$ & 0 & 1 & 0 & 0 & 16 & 0 & 17 \\
\hline $20-30 \mathrm{~cm}$ & 0 & 1 & 0 & 0 & 50 & 0 & 51 \\
\hline $30-40 \mathrm{~cm}$ & 0 & 2 & 0 & 1 & 11 & 0 & 14 \\
\hline \multicolumn{8}{|l|}{ Test Unit 39} \\
\hline $0-10 \mathrm{~cm}$ & 0 & 1 & 0 & 0 & 1 & 0 & 2 \\
\hline $10-20 \mathrm{~cm}$ & 1 & 0 & 0 & 0 & 3 & 0 & 4 \\
\hline $20-30 \mathrm{~cm}$ & 0 & 1 & 0 & 0 & 1 & 0 & 2 \\
\hline $30-37 \mathrm{~cm}$ & 0 & 1 & 0 & 0 & 0 & 0 & 1 \\
\hline \multicolumn{8}{|l|}{ Test Unit 40} \\
\hline $0-10 \mathrm{~cm}$ & 0 & 0 & 0 & 0 & 1 & 0 & 1 \\
\hline $10-20 \mathrm{~cm}$ & 0 & 0 & 1 & 1 & 4 & 0 & 6 \\
\hline $20-30 \mathrm{~cm}$ & 0 & 1 & 0 & 0 & 3 & 0 & 5 \\
\hline $30-40 \mathrm{~cm}$ & 0 & 2 & 0 & 0 & 0 & 0 & 2 \\
\hline \multicolumn{8}{|l|}{ Test Unit 41} \\
\hline $0-10 \mathrm{~cm}$ & 0 & 0 & 0 & 0 & 2 & 0 & 2 \\
\hline $10-20 \mathrm{~cm}$ & 0 & 0 & 0 & 0 & 4 & 0 & 4 \\
\hline $20-30 \mathrm{~cm}$ & 0 & 0 & 0 & 0 & 0 & 0 & 0 \\
\hline \multicolumn{8}{|l|}{ Test Unit 42} \\
\hline $0-10 \mathrm{~cm}$ & 0 & 0 & 0 & 0 & 0 & 0 & 0 \\
\hline $10-20 \mathrm{~cm}$ & 0 & 9 & 0 & 0 & 6 & 0 & 15 \\
\hline $20-30 \mathrm{~cm}$ & 0 & 9 & 0 & 0 & 8 & 0 & 20 \\
\hline \multicolumn{8}{|l|}{ Test Unit 43} \\
\hline $0-10 \mathrm{~cm}$ & 0 & 2 & 0 & 0 & 1 & 0 & 3 \\
\hline $10-20 \mathrm{~cm}$ & 0 & 1 & 0 & 0 & 5 & 0 & 6 \\
\hline $20-30 \mathrm{~cm}$ & 0 & 0 & 0 & 0 & 7 & 0 & 7 \\
\hline $30-40 \mathrm{~cm}$ & 0 & 3 & 0 & 0 & 6 & 0 & 15 \\
\hline \multicolumn{8}{|l|}{ Test Unit 44} \\
\hline $0-10 \mathrm{~cm}$ & 0 & 17 & 0 & 0 & 0 & 0 & 17 \\
\hline $10-20 \mathrm{~cm}$ & 0 & 19 & 0 & 0 & 7 & 0 & 26 \\
\hline $20-30 \mathrm{~cm}$ & 0 & 5 & 1 & 0 & 10 & 0 & 16 \\
\hline $30-40 \mathrm{~cm}$ & 0 & 13 & 0 & 0 & 4 & 0 & 17 \\
\hline Feature 8 & 2 & 11 & 0 & 1 & 3 & 5 & 22 \\
\hline Feature 9 & 2 & 21 & 0 & 1 & 57 & 185 & 266 \\
\hline Feature 11 & 0 & 2 & 0 & 1 & 2 & 11 & 16 \\
\hline Feature 12 & 0 & 1 & 0 & 0 & 0 & 0 & 1 \\
\hline
\end{tabular}


Chapter 2: Testing

Table 2.5, continued

\begin{tabular}{|c|c|c|c|c|c|c|c|}
\hline Provenience & $\begin{array}{c}\text { Chipped } \\
\text { Stone } \\
\text { Tool } \\
\end{array}$ & Debitage & Core & $\begin{array}{c}\text { Ground } \\
\text { Stone } \\
\text { Tool } \\
\end{array}$ & Sherd & $\begin{array}{c}\text { Faunal } \\
\text { Remains }\end{array}$ & Totals \\
\hline Feature 13 & 0 & 1 & 0 & 0 & 0 & 0 & 1 \\
\hline Feature 16 & 0 & 4 & 0 & 0 & 8 & 38 & 50 \\
\hline Feature 17 & 1 & 18 & 1 & 0 & 35 & 250 & 305 \\
\hline Feature 19 & 0 & 2 & 0 & 0 & 5 & 30 & 37 \\
\hline Feature 20 & 0 & 2 & 0 & 0 & 1 & 0 & 3 \\
\hline BHT 1 & 1 & 3 & 2 & 1 & 19 & 0 & 26 \\
\hline BHT 2 & 0 & 1 & 0 & 0 & 0 & 0 & 1 \\
\hline BHT 4 & 0 & 0 & 0 & 0 & 1 & 0 & 1 \\
\hline BHT 9 & 0 & 0 & 0 & 0 & 1 & 0 & 1 \\
\hline BHT 10 & 0 & 0 & 0 & 0 & 1 & 0 & 1 \\
\hline BHT 11 & 0 & 1 & 0 & 0 & 0 & 0 & 1 \\
\hline BHT 12 & 1 & 4 & 0 & 0 & 8 & 0 & 13 \\
\hline BHT 13 & 1 & 0 & 0 & 0 & 5 & 0 & 6 \\
\hline BHT 15 & 0 & 0 & 0 & 0 & 5 & 0 & 5 \\
\hline BHT 16 & 0 & 3 & 0 & 0 & 14 & 0 & 17 \\
\hline BHT 17 & 1 & 1 & 2 & 0 & 8 & 0 & 12 \\
\hline BHT 18 & 0 & 0 & 0 & 0 & 13 & 0 & 13 \\
\hline BHT 19 & 0 & 1 & 0 & 0 & 13 & 0 & 14 \\
\hline BHT 20 & 0 & 0 & 0 & 0 & 1 & 0 & 1 \\
\hline BHT 22 & 1 & 0 & 0 & 0 & 0 & 0 & 1 \\
\hline BHT 24 & 0 & 0 & 2 & 0 & 3 & 0 & 5 \\
\hline BHT 25 & 0 & 0 & 0 & 0 & 6 & 0 & 6 \\
\hline BHT 26 & 0 & 0 & 0 & 1 & 3 & 0 & 4 \\
\hline BHT 31 & 0 & 0 & 0 & 0 & 6 & 0 & 6 \\
\hline BHT 32 & 2 & 4 & 1 & 0 & 14 & 0 & 21 \\
\hline BHT 33 & 1 & 2 & 0 & 0 & 17 & 0 & 20 \\
\hline BHT 34 & 0 & 0 & 0 & 0 & 7 & 0 & 7 \\
\hline BHT 36 & 0 & 0 & 0 & 0 & 3 & 0 & 3 \\
\hline BHT 38 & 0 & 1 & 0 & 0 & 0 & 0 & 1 \\
\hline BHT 40 & 0 & 0 & 2 & 0 & 3 & 0 & 5 \\
\hline BHT 41 & 1 & 0 & 0 & 0 & 0 & 0 & 1 \\
\hline BHT 45 & 1 & 0 & 1 & 0 & 0 & 0 & 2 \\
\hline BHT 47 & 0 & 0 & 0 & 0 & 1 & 0 & 1 \\
\hline BHT 48 & 0 & 0 & 0 & 0 & 4 & 0 & 4 \\
\hline BHT 49 & 0 & 1 & 0 & 0 & 0 & 0 & 1 \\
\hline BHT 50 & 0 & 0 & 0 & 0 & 1 & 0 & 1 \\
\hline Subarea 1 Totals & 53 & 720 & 20 & 14 & 1,354 & 746 & 2,907 \\
\hline \multicolumn{8}{|l|}{ Subarea 2: } \\
\hline Auger Test 39 & 0 & 0 & 0 & 0 & 1 & 0 & 1 \\
\hline Auger Test 67 & 0 & 0 & 0 & 0 & 1 & 0 & 1 \\
\hline \multicolumn{8}{|l|}{ Subarea 3: } \\
\hline Auger Test 157 & 0 & 0 & 0 & 1 & 0 & 0 & 1 \\
\hline Auger Test 161 & 0 & 0 & 0 & 0 & 2 & 0 & 2 \\
\hline \multicolumn{8}{|l|}{ Other: } \\
\hline Auger Test 62 & 1 & 1 & 0 & 0 & 0 & 0 & 2 \\
\hline Site Totals & 54 & 721 & 20 & 15 & 1,358 & 746 & 2,914 \\
\hline
\end{tabular}


and 161 at the south end of the site's east arm. Historic artifacts (ceramics, glass, metal, and brick fragments) were recovered from 29 tests, most of which were in the eastern portion of the site area.

The findings of the auger testing were used to modify the limits of 41TT851 and define three subareas within the revised site boundary. Subarea 1 encompassed a $6,000-\mathrm{m}^{2}$ area with low-density ceramics and lithics in the site's southwest arm. Subarea 2 included a $6,300-\mathrm{m}^{2}$ area with low-density ceramics in the north-central part of the site. Subarea 3 consisted of a $2,400-\mathrm{m}^{2}$ area on the southeast edge of the site that was derived from the recovery of a small number of prehistoric ceramics and a ground stone artifact.

Clay subsoil was identified at varying depths in 173 auger tests, ranging from 1 to $100 \mathrm{~cm}$ below the surface. These tests indicated that the surface sands have an average thickness of $34 \mathrm{~cm}$. Most of the 15 tests that did not reach the subsoil were stopped by hard soils or other obstructions at depths of 12-91 cm (average $=48 \mathrm{~cm}$ ), although Auger Tests 39 and 130 in the northeast part reached 110 and $100 \mathrm{~cm}$, respectively. Relatively thick sands were encountered in less-disturbed portions of the southwest arm, at a toeslope terminus in the southeastern part of the site, and on pimple mound remnants in the northern part. Areas with thin to nonexistent surface sands typically were associated with some form of recent disturbance.

\section{Work Accomplished in Intensive Testing}

Testing began with geophysical survey of a 3,200- $\mathrm{m}^{2}$ grid that encompassed an $80 \times 40-\mathrm{m}$ area covering the central part of Subarea 1, including or adjacent to positive Auger Tests 3,11 , $12,22,24-26,28,29,35,37,38,44,45$, and 50 (Figure 2.13). Magnetic susceptibility anomalies identified along the south end of the grid were interpreted as modern disturbances correlating with haul road construction (see Appendix B). An anomaly indicated at the center of the grid through magnetometer, magnetic susceptibility, and conductivity data was likely derived from modern or historic metallic debris. Several areas of positive conductivity and areas of positive resistivity appeared to correlate with variability in the thickness of the sandy mantle. None of these was considered a good candidate for a prehistoric structure.

Fifty backhoe trenches were excavated within the survey grid. The trenches were $1.0 \mathrm{~m}$ wide, ranged from 6.6 to $10.0 \mathrm{~m}$ in length $($ mean $=8.0 \mathrm{~m})$, and varied from 25 to $85 \mathrm{~cm}$ (mean $=45 \mathrm{~cm})$ in maximum depth. Mechanical trench excavation accounted for $400 \mathrm{~m}^{2}$ of site area. Thirty-nine $1 \mathrm{x} 1-\mathrm{m}$ test units and a $1.0 \times 0.35-\mathrm{m}$ test unit were excavated within the geophysical survey grid. The latter, opened in the south end of Trench 40 to expedite feature exposure, was referred to as Test Unit BHT 40 South Extension. Five additional 1x1-m units were north and south of the grid. Test unit depths ranged from 20 to $60 \mathrm{~cm}$ (mean $=37 \mathrm{~cm})$ below the ground surface. Twenty-three of the 45 test units were opened off of backhoe trenches, and the remaining units were isolated.

\section{Sediment Descriptions}

The walls of 23 trenches were profiled. Along the eastern side of the grid, evidence of the aforementioned haul road was encountered. These compact deposits covered the eastern 10 to $15 \mathrm{~m}$ of the grid. Along the southern portion of this disturbed area (Trenches 1-3, 8-10, and 14-16), introduced road gravels (2-5 cm thick) overlaid the soil profiles. In these deposits, the profiles ranged from gravels over E-Bt horizons to gravels mixed with A1 horizons over A2-E-Bt horizons. Where present, the A1 horizon was $8-10 \mathrm{~cm}$ thick and composed of firm very dark brown (10YR 2/2), very dark grayish brown (10YR 3/2), dark yellowish brown (10YR 3/4), and reddish brown (5YR 4/4) loamy sand. The A2 horizon was $10-20 \mathrm{~cm}$ thick and composed of dark yellowish brown (10YR 4/4) very fine sandy loam. The E horizon was $13-17 \mathrm{~cm}$ thick and consisted of yellowish brown (10YR 5/4, $5 / 8)$ sandy loam mottled with manganese. The Bt horizon was well-structured strong brown (7.5YR 5/8) clay with manganese mottling. Manganese mottling and ferruginous sandstone gravels occurred in most haul-road-disturbed deposits in both the $\mathrm{E}$ and Bt horizons.

Along the northern portion of this haul road, more intrusive disturbance, perhaps from road grading, was evident (Trenches 22-24, 29-31, 36-39, and 43-46). Gravels were not observed on the surface of these deposits. The A1, $\mathrm{A} 2$, and $\mathrm{E}$ horizons were similar to the horizons 


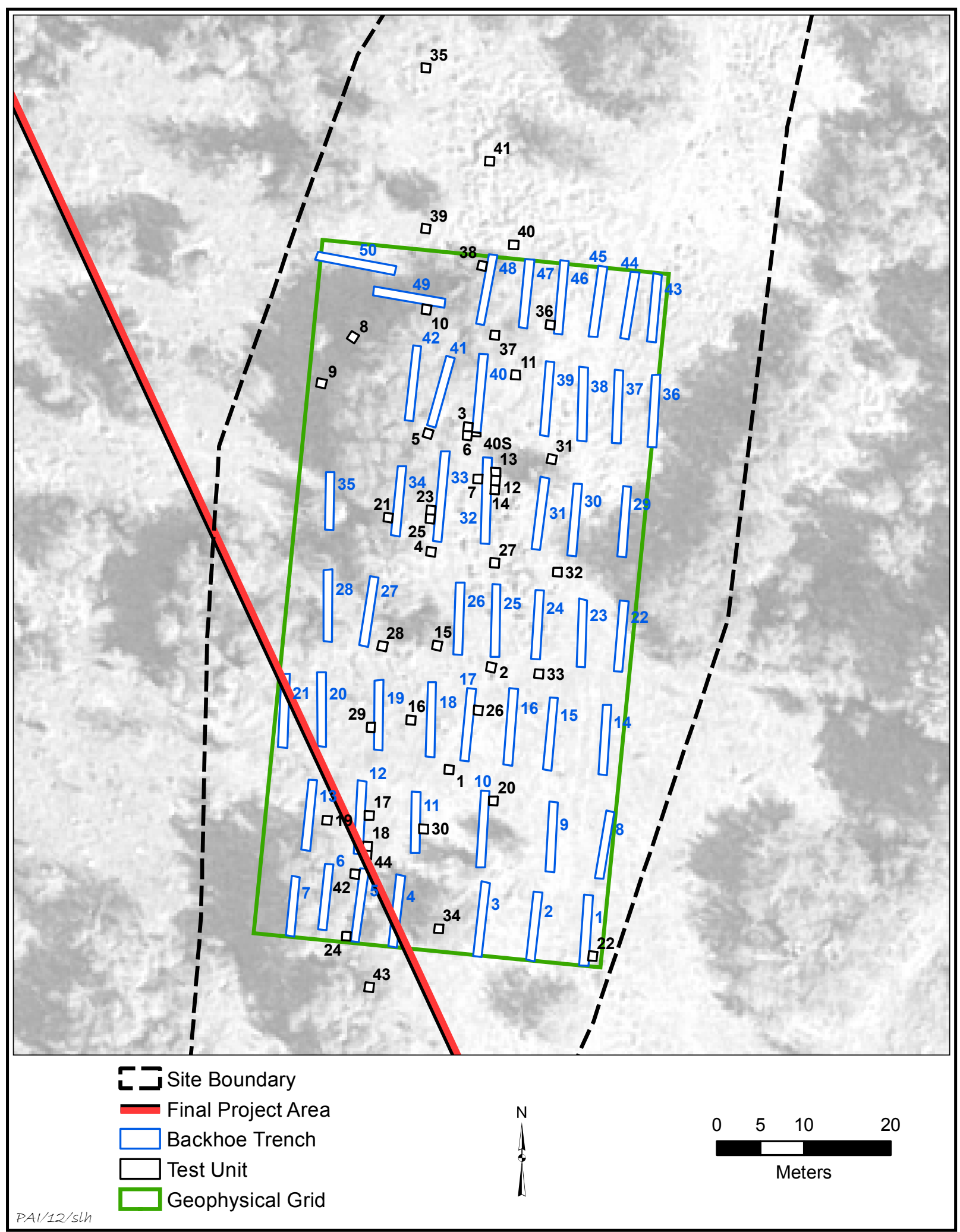

Figure 2.13. Aerial photograph of 41TT851 showing geophysical survey grid and test excavations. 
south of this area, although more often mixed. The Bt horizon consisted of extensively mottled yellowish brown (10YR 5/4, 5/6), strong brown (7.5YR 4/6), light yellowish brown (10YR 6/4), and brownish yellow (10YR 6/6) clay with manganese mottles.

In a more-confined area of disturbance in the southwest portion of the grid, degraded asphalt and road gravels were found on top of the A-E-Bt soil profiles but with little evidence of disturbance below the surface. This area included Trenches $5,11,12$, and 13 . The $\mathrm{A} 1$ horizon here was $2-5-\mathrm{cm}$-thick very dark grayish brown (10YR 3/2) loamy sand. The A2 horizon was 5-28-cm-thick dark yellowish brown (10YR 5/4, 4/4) and dark grayish brown (10YR 3/1) very fine sandy loam. The E horizon was $10-20 \mathrm{~cm}$ thick and consisted of yellowish brown (10YR 5/6, 5/8) or brownish yellow (10YR 6/6) firm sand. The Bt horizon was well-structured, sometimes mottled, strong brown $(7.5 \mathrm{YR} 5 / 6,5 / 8)$ sandy clay.

The center of the grid (Trenches 16, 17, 25, and 26) had deposits with A1-A2-A3-E-Bt profiles, with manganese mottles in the $\mathrm{A} 2$ and A3 horizons likely due to disturbance from compaction. In this area, the A1 horizon was $3-8 \mathrm{~cm}$ thick and composed of dark yellowish brown (10YR 3/4) very fine sand; the A2 horizon was $5-15 \mathrm{~cm}$ thick and consisted of dark yellowish brown (10YR 4/4) fine sand; the A3 horizon was 10-20-cm-thick dark brown (10YR 3/4) very fine sand with manganese mottles. The $\mathrm{E}$ horizon was $6-8 \mathrm{~cm}$ thick and composed of yellowish brown (10YR 5/6) firm sand with manganese mottles. The Bt horizon was well-structured, sometimes mottled, strong brown (7.5YR 5/6, 5/8) sandy clay.

The western edge of the grid had shallower deposits with A1-A2-Bt soil profiles (Trenches 20,21 , and 28). The A1 horizon was 5-cm-thick dark grayish brown (10YR 3/2) loamy sand. The A2 horizon was 20-cm-thick dark yellowish brown (10YR 4/4) very fine sand. The Bt horizon was well-structured strong brown (7.5YR 4/6) firm clay.

Soil profiles in the north-central grid area (Trenches 40 and 41 and less obviously Trenches 32 and 33) exhibited A1-A2-Bt soil sequences with the A1 and A2 horizons comprised of midden-enriched deposits. This area lacked an E horizon. A1 horizon soils were 3-6-cm-thick dark grayish brown (10YR 3/2) mottled with dark grayish brown (10YR 4/3) loamy sand. The
A2 horizon was 18-28-cm-thick dark yellowish brown (10YR 3/4) very fine loamy sand. Bt horizon soils are well-structured strong brown (7.5YR 5/8) sandy clay.

\section{Cultural Features}

Twelve cultural features were recorded in Subarea 1 during testing (Table 2.6). These consisted of a smudge pit, 3 other pits, 1 pit or large posthole, 6 possible postholes, and 1 rock hearth. Most were in the north-central and southwestern parts of the area investigated (Figure 2.14). They are discussed in more detail in Chapter 4 together with the features documented during subsequent data recovery efforts.

Four radiocarbon dates were obtained from feature contexts. Two from pit Feature 9 had corrected radiocarbon ages of $670 \pm 40$ B.P. (Beta$242374 ;{ }^{13} \mathrm{C} /{ }^{12} \mathrm{C}$ Ratio $=-26.1$ ) and $690 \pm 40$ B.P. $\left(\right.$ Beta-242375; ${ }^{13} \mathrm{C} /{ }^{12} \mathrm{C}$ Ratio $\left.=-26.2\right)$, with calibrated two-sigma date ranges of A.D. 1260 1320/1350-1390 and 1270-1330/1340/1400. A date from pit Feature 17 had a corrected age of $590 \pm 40$ B.P. $\left(\right.$ Beta- $242376 ;{ }^{13} \mathrm{C} /{ }^{12} \mathrm{C}$ Ratio $\left.=-26.1\right)$ and a two sigma-range of 1290-1420. Smudge pit Feature 20 yielded a date with a corrected age of $620 \pm 40$ B.P. $\left(\right.$ Beta- $242377 ;{ }^{13} \mathrm{C} /{ }^{12} \mathrm{C}$ Ratio $\left.=-26.7\right)$ and a two-sigma range of 1280-1410.

\section{Artifact Assemblage}

Cultural materials were recovered from 22 auger tests, all but 1 of the test units (TU 34), 31 backhoe trenches, and 9 sampled or excavated features (see Table 2.5). The assemblage includes 1,358 prehistoric ceramic sherds, 54 chipped stone tools, 721 pieces of debitage, 20 cores, $15 \mathrm{ground} / \mathrm{battered} \mathrm{stone} \mathrm{tools,} 105.3 \mathrm{~g}$ of daub, $85.1 \mathrm{~g}$ of burned clay, and $18 \mathrm{~kg}$ of burned rocks. Also recovered were 746 vertebrate faunal elements, 61 pieces of mussel shell, part of a burned mud dauber nest that weighs $72.8 \mathrm{~g}$, and $18.91 \mathrm{~g}$ of carbonized macrobotanical material. Most of these materials are from Subarea 1 and are discussed in more detail in Chapter 4 along with materials recovered in subsequent data recovery excavations.

The very scant materials not from Subarea 1 consist of four sherds, a biface, one small (12.5$19.0 \mathrm{~mm}$ ) flake of local chert, one ground stone, and one faunal element. Of the four sherds (10.2 g), only three are large enough for analy- 
Table 2.6. Cultural features found in testing at 41TT851

\begin{tabular}{c|l|l|c|c}
\hline Feature & \multicolumn{1}{|c|}{ Provenience } & \multicolumn{1}{|c|}{ Type } & Dimensions & $\begin{array}{c}\text { Depth Below Surface } \\
\text { (top and bottom) }\end{array}$ \\
\hline 1 & BHT 12 & possible posthole & $16 \times 18 \mathrm{~cm}$ & $58-74 \mathrm{~cm}$ \\
\hline 8 & BHT 32 & fire-cracked rock hearth & $220 \times 200 \mathrm{~cm}$ & $18-40 \mathrm{~cm}$ \\
\hline 9 & BHT 40,TUs 3 and 6 & pit & $88 \times 74 \mathrm{~cm}$ & $35-45 \mathrm{~cm}$ \\
\hline 10 & BHT 40 & possible posthole & $19 \times 19 \mathrm{~cm}$ & $70-79 \mathrm{~cm}$ \\
\hline 12 & BHT 12 & possible posthole & $24 \times 18 \mathrm{~cm}$ & $42-56 \mathrm{~cm}$ \\
\hline 13 & BHT 12 & possible posthole & $18 \times 18 \mathrm{~cm}$ & $45-48 \mathrm{~cm}$ \\
\hline 15 & BHT 12 & possible posthole & $14 \times 14 \mathrm{~cm}$ & $50-60 \mathrm{~cm}$ \\
\hline 16 & TU 3 & large posthole or pit & $44 \times 26 \mathrm{~cm}$ & $35-62 \mathrm{~cm}$ \\
\hline 17 & BHT 40 South Extension & pit & $40 \times 62 \mathrm{~cm}$ & $35-63 \mathrm{~cm}$ \\
\hline 18 & TU 11 & possible posthole & $24 \times 24 \mathrm{~cm}$ & $40-56 \mathrm{~cm}$ \\
\hline 19 & BHT 40 South Extension & pit & $32 \times 20 \mathrm{~cm}$ & $39-67 \mathrm{~cm}$ \\
\hline 20 & TU 27 & smudge pit & $28 \times 28 \mathrm{~cm}$ & $28-42 \mathrm{~cm}$ \\
\hline
\end{tabular}

sis. One is part of a carinated bowl, and two are body sherds. Two have grog temper, and one has voids that probably represent leached bone. One of the body sherds is brushed, while the others are undecorated. Other than the brushed one, all surfaces are smoothed. The biface is a very thin knife made of reddish brown local chert broken during manufacture. The ground stone, from Auger Test 157 in Subarea 3, is a large oblong quartzite cobble that is roughly triangular in cross section. Slight smoothing on a narrow ridge along one side indicates it was used for grinding or pulverizing. A marginally smoothed, lightly battered end suggests it also was used as a pestle. The single animal bone is a fragmented carnivore canine; it is from Auger Test 127 in the northeast part of the site.

The intensive testing indicated that artifacts were concentrated in two parts of the Subarea 1 geophysical grid. The northern concentration was sampled by Test Units $3,5-7$, 10-14, 23, 25, 31, 37, 38, and BHT 40 South Extension; these units yielded 54 percent of the ceramics and lithic artifacts collected from all test units for a density of 66 artifacts $/ \mathrm{m}^{2}$. This area yielded 99 percent of the faunal elements (mostly from pit features in that area) and (by weight) 69 percent of the wattle-impressed daub and 94 percent of the burned clay. The southern artifact concentration was sampled by Test Units 1, 16-19, 26, 30, 42, and 44. These units contained 26 percent of the ceramic and lithic artifacts collected from all test units for a den- sity of 50 artifacts $/ \mathrm{m}^{2}$. Only one faunal element was found here. All of the remaining daub and nearly all of the remaining burned clay in the assemblage was from these units.

Vertically, 98 percent of all the artifacts from the test units were recovered between 0 and $40 \mathrm{~cm}$ below the surface, which correlates with the average Bt horizon depth of $37 \mathrm{~cm}$ in the test units. Artifact returns from nonfeature contexts in test units across the site were as follows: 15 percent at $0-10 \mathrm{~cm} ; 28$ percent at $10-20 \mathrm{~cm} ; 38$ percent at $20-30 \mathrm{~cm} ; 18$ percent at $30-40 \mathrm{~cm}$; and 2 percent at $40-50 \mathrm{~cm}$. No evidence was identified to suggest that components were isolable through patterning in the vertical distributions of artifacts.

\section{Conclusions}

Auger and intensive testing revealed that only the southwest part of 41TT851, Subarea 1 , contains substantial cultural deposits. This area was characterized by high densities of ceramic artifacts and numerous cultural features. Two parts of the tested area were marked by elevated artifact frequencies, feature concentrations, and the presence of wattle-impressed daub, all factors that suggested both might contain prehistoric houses or outdoor activity areas. No features were found in the intervening $15-\mathrm{m}$ wide space, which when coupled with notably lower artifact densities there suggested that it could represent a plaza or garden plot. None of 


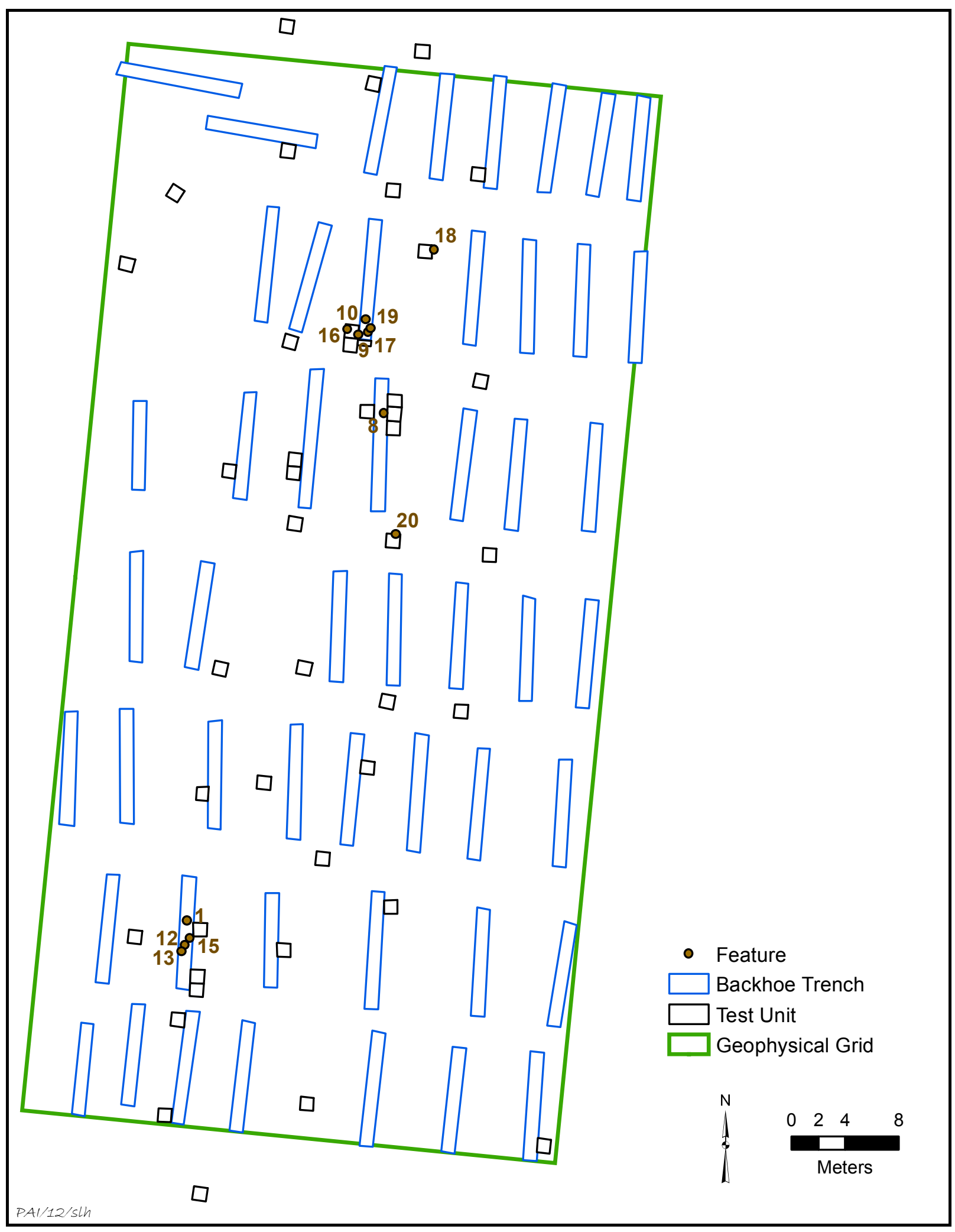

Figure 2.14. Plan showing the locations of features identified during test excavations at 41TT851. 
the possible postholes identified were confidently attributable to residential structures, but they suggested that additional investigation likely would identify one or more houses in the tested area.

Although the recovery of 7 dart points indicated some pre-Caddo occupation, the bulk of the tested archeological deposits appeared to represent a small Caddo farmstead composed of one or a few houses and associated activity areas. The 12 arrow points and many ceramics generally were consistent with both Whelan and later Titus phase occupations, with the four radiocarbon assays supporting occupation at least during the Whelan phase.

With the presence of matrix-defined features and contexts with moderately good bone preservation and ample datable carbon, the archeological deposits in Subarea 1 were judged to have sufficient integrity to allow for productive analyses. Additionally, proximity to similar residential loci at 41TT852 and 41TT853 suggested that 41TT851 was part of a larger Caddo community on this part of Tankersley Creek. Thus, the archeological deposits in Subarea 1 at 41TT851 were considered to contain information relevant to the larger prehistoric community. Given the information potential represented by the deposits, 41TT851 was considered eligible for inclusion in the National Register and designation as a State Antiquities Landmark. Since the site was not a candidate for preservation in place, data recovery excavations were recommended to mitigate the adverse impacts of the proposed project.

\section{SITE 41TT852}

Site 41TT852 is a large site on three adjacent interfluves along the dissected margin of the Tankersley Creek valley, just south of the Southern Pacific Railroad tracks in the northern part of the project area (Figure 2.15). An unnamed tributary of Tankersley Creek delimits the south end of the site. A cleared transmission line right of way trends northwest-southeast across the predominately wooded site area, and cleared pipeline rights of way cross the northern and southern ends of the site. Area vegetation is characterized by secondary-growth hardwood forest.

AEC personnel excavated 37 shovel tests in 2002. The assemblage collected from 29 of those tests consisted of 61 ceramic sherds, a Gary dart point, a biface, 73 pieces of lithic debris, fragments of burned clay and daub, and burned rocks (Perttula et al. 2002; Perttula and Nelson 2005). Most of the materials were from the southeastern portion of the site. The site was estimated to cover $146,000 \mathrm{~m}^{2}$.

All of the site was within the project corridor as of 2005. This was still largely the case in 2007 when intensive testing was done in three areas. By the 2010 data recovery excavations, the project alignment had shifted so that the east edge of the site was excluded from the proposed right of way.

\section{Auger Testing}

A total of 272 auger tests were excavated in 2005. Spacing of the tests was less regular than on most of the other sites because of dense vegetation and the presence of steep slopes and slash timber piles. Nonetheless, most of the site as it was delimited during the AEC survey was auger tested. The least-sampled area is the northern section, which had served as a staging area for a logging operation and was covered with timber piles. Where auger holes could be placed in this section, they revealed thin sediments that appeared to reflect mechanical scraping and pushing of soils associated with the logging. The area to the west of this at the north end of the site as it was defined by AEC was not tested because it consists of a series of intermittent drainages and erosional gullies. The AEC crew found only a few surface artifacts in this area, and any artifacts in this area likely have been translocated downslope by erosion.

Prehistoric archeological materials were identified in 49 auger tests (Table 2.7). As with the previous AEC investigation, most of the assemblage came from tests in the southeast part of the site, specifically from the crest of the southernmost interfluve. Twenty-two auger tests within a $90 \times 60-\mathrm{m}$ area on top of that interfluve produced 80 ceramic sherds, 2 dart points, 36 pieces of lithic debitage, a burned rock, and daub/burned clay. This artifact-rich area was in and north of the transmission line right of way. Small amounts of prehistoric ceramics and lithics were observed eroding out of the crest of the northernmost interfluve at the west-northwest edge of the site, but auger holes in this vicinity were shallow and encountered no ceramic artifacts and few lithic artifacts (7 flakes came from Auger Tests 169, 


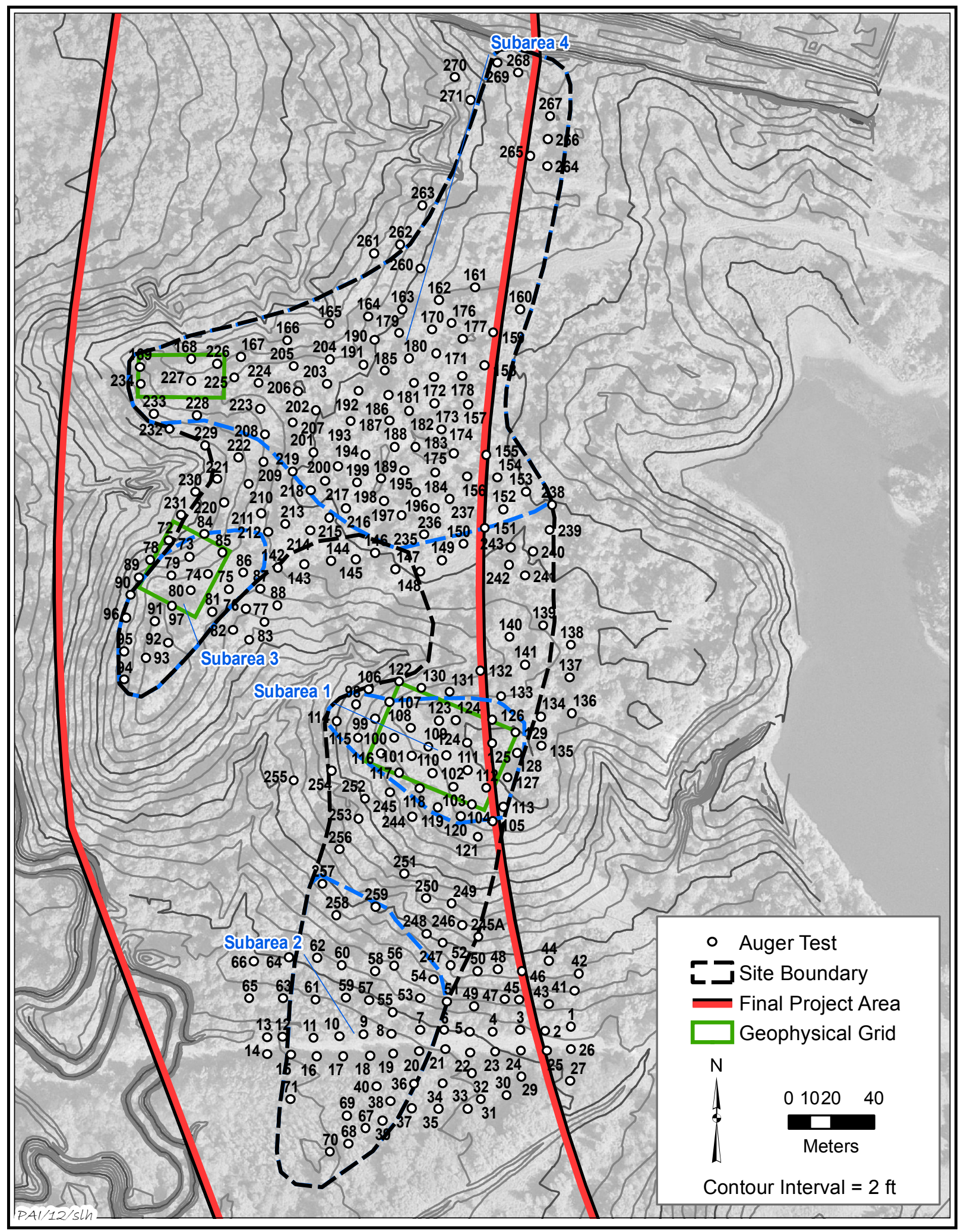

Figure 2.15. Map of 41TT852 showing topography, auger test locations, and geophysical survey grid on 2005 aerial imagery. 
Table 2.7. Artifacts recovered in auger and intensive testing at 41 TT852

\begin{tabular}{|c|c|c|c|c|c|c|c|c|}
\hline Provenience & $\begin{array}{c}\text { Chipped } \\
\text { Stone } \\
\text { Tool } \\
\end{array}$ & Debitage & Core & $\begin{array}{c}\text { Ground } \\
\text { Stone } \\
\text { Tool } \\
\end{array}$ & Sherd & Bone & Other & Totals \\
\hline \multicolumn{9}{|l|}{ Subarea 1: } \\
\hline Auger Test 99 & 0 & 2 & 0 & 0 & 1 & 0 & 0 & 3 \\
\hline Auger Test 101 & 0 & 2 & 0 & 0 & 13 & 0 & 0 & 15 \\
\hline Auger Test 102 & 0 & 2 & 0 & 0 & 0 & 0 & 0 & 2 \\
\hline Auger Test 103 & 1 & 6 & 0 & 0 & 9 & 0 & 0 & 16 \\
\hline Auger Test 104 & 0 & 8 & 0 & 0 & 6 & 0 & 0 & 14 \\
\hline Auger Test 108 & 0 & 1 & 0 & 0 & 0 & 0 & 0 & 1 \\
\hline Auger Test 109 & 0 & 1 & 0 & 0 & 1 & 0 & 0 & 2 \\
\hline Auger Test 110 & 0 & 1 & 0 & 0 & 2 & 0 & 0 & 3 \\
\hline Auger Test 113 & 0 & 0 & 0 & 0 & 4 & 0 & 0 & 4 \\
\hline Auger Test 114 & 1 & 0 & 0 & 0 & 0 & 0 & 0 & 1 \\
\hline Auger Test 116 & 0 & 0 & 0 & 0 & 1 & 0 & 0 & 1 \\
\hline Auger Test 117 & 0 & 0 & 0 & 0 & 1 & 0 & 0 & 1 \\
\hline Auger Test 118 & 0 & 3 & 0 & 0 & 8 & 0 & 0 & 11 \\
\hline Auger Test 119 & 0 & 1 & 0 & 0 & 0 & 0 & 0 & 1 \\
\hline Auger Test 120 & 0 & 3 & 0 & 0 & 1 & 0 & 0 & 4 \\
\hline Auger Test 123 & 0 & 2 & 0 & 0 & 22 & 0 & 0 & 24 \\
\hline Auger Test 124 & 0 & 0 & 0 & 0 & 2 & 0 & 0 & 2 \\
\hline Auger Test 125 & 0 & 1 & 0 & 0 & 3 & 0 & 0 & 4 \\
\hline Auger Test 126 & 0 & 3 & 0 & 0 & 0 & 0 & 0 & 3 \\
\hline Auger Test 127 & 0 & 0 & 0 & 0 & 2 & 0 & 0 & 2 \\
\hline Auger Test 128 & 0 & 0 & 0 & 0 & 2 & 0 & 0 & 2 \\
\hline Auger Test 129 & 0 & 0 & 0 & 0 & 2 & 0 & 0 & 2 \\
\hline \multicolumn{9}{|l|}{ Test Unit 1} \\
\hline $0-10 \mathrm{~cm}$ & 0 & 2 & 0 & 0 & 5 & 0 & 0 & 7 \\
\hline $10-20 \mathrm{~cm}$ & 0 & 10 & 0 & 0 & 14 & 0 & 0 & 24 \\
\hline $20-30 \mathrm{~cm}$ & 0 & 3 & 0 & 0 & 3 & 0 & 0 & 6 \\
\hline $30-40 \mathrm{~cm}$ & 0 & 5 & 0 & 0 & 0 & 0 & 0 & 5 \\
\hline $40-50 \mathrm{~cm}$ & 0 & 3 & 0 & 0 & 0 & 0 & 0 & 3 \\
\hline $50-60 \mathrm{~cm}$ & 0 & 0 & 0 & 0 & 0 & 0 & 0 & 0 \\
\hline \multicolumn{9}{|l|}{ Test Unit 2} \\
\hline $0-10 \mathrm{~cm}$ & 0 & 1 & 0 & 0 & 0 & 0 & 0 & 1 \\
\hline $10-20 \mathrm{~cm}$ & 0 & 3 & 0 & 0 & 9 & 0 & 0 & 12 \\
\hline $20-30 \mathrm{~cm}$ & 0 & 0 & 0 & 0 & 3 & 0 & 0 & 3 \\
\hline $30-40 \mathrm{~cm}$ & 0 & 0 & 0 & 0 & 0 & 0 & 0 & 0 \\
\hline $40-50 \mathrm{~cm}$ & 0 & 1 & 0 & 0 & 0 & 0 & 0 & 1 \\
\hline $50-60 \mathrm{~cm}$ & 0 & 0 & 0 & 0 & 0 & 0 & 0 & 0 \\
\hline \multicolumn{9}{|l|}{ Test Unit 3} \\
\hline $0-10 \mathrm{~cm}$ & 0 & 0 & 0 & 0 & 6 & 0 & 0 & 6 \\
\hline $10-20 \mathrm{~cm}$ & 0 & 3 & 0 & 0 & 8 & 0 & 0 & 11 \\
\hline $20-30 \mathrm{~cm}$ & 0 & 2 & 0 & 0 & 0 & 0 & 0 & 2 \\
\hline $30-40 \mathrm{~cm}$ & 0 & 3 & 0 & 0 & 1 & 0 & 0 & 4 \\
\hline $40-50 \mathrm{~cm}$ & 0 & 2 & 0 & 0 & 0 & 0 & 0 & 2 \\
\hline $50-55 \mathrm{~cm}$ & 0 & 0 & 0 & 0 & 0 & 0 & 0 & 0 \\
\hline \multicolumn{9}{|l|}{ Test Unit 4} \\
\hline $0-10 \mathrm{~cm}$ & 0 & 0 & 0 & 0 & 5 & 0 & 0 & 5 \\
\hline
\end{tabular}


Excavations along the U.S. Highway 271 Mount Pleasant Relief Route

Table 2.7, continued

\begin{tabular}{|c|c|c|c|c|c|c|c|c|}
\hline Provenience & $\begin{array}{c}\text { Chipped } \\
\text { Stone } \\
\text { Tool } \\
\end{array}$ & Debitage & Core & $\begin{array}{c}\text { Ground } \\
\text { Stone } \\
\text { Tool } \\
\end{array}$ & Sherd & Bone & Other & Totals \\
\hline $10-20 \mathrm{~cm}$ & 0 & 3 & 0 & 0 & 1 & 0 & 0 & 4 \\
\hline $20-30 \mathrm{~cm}$ & 0 & 2 & 0 & 0 & 0 & 0 & 0 & 2 \\
\hline $30-40 \mathrm{~cm}$ & 0 & 2 & 0 & 0 & 1 & 0 & 0 & 3 \\
\hline $40-50 \mathrm{~cm}$ & 0 & 2 & 0 & 0 & 1 & 0 & 0 & 3 \\
\hline $50-55 \mathrm{~cm}$ & 0 & 0 & 0 & 0 & 0 & 0 & 0 & 0 \\
\hline \multicolumn{9}{|l|}{ Test Unit 5} \\
\hline $0-10 \mathrm{~cm}$ & 0 & 0 & 0 & 0 & 3 & 0 & 0 & 3 \\
\hline $10-20 \mathrm{~cm}$ & 0 & 4 & 0 & 0 & 13 & 0 & 0 & 17 \\
\hline $20-30 \mathrm{~cm}$ & 0 & 2 & 0 & 0 & 7 & 0 & 0 & 9 \\
\hline $30-40 \mathrm{~cm}$ & 0 & 2 & 0 & 0 & 1 & 0 & 0 & 3 \\
\hline $40-50 \mathrm{~cm}$ & 0 & 0 & 0 & 0 & 0 & 0 & 0 & 0 \\
\hline \multicolumn{9}{|l|}{ Test Unit 6} \\
\hline $0-10 \mathrm{~cm}$ & 0 & 8 & 1 & 0 & 17 & 0 & 0 & 26 \\
\hline $10-20 \mathrm{~cm}$ & 2 & 5 & 1 & 0 & 27 & 0 & 0 & 35 \\
\hline $20-30 \mathrm{~cm}$ & 0 & 12 & 0 & 0 & 18 & 0 & 0 & 30 \\
\hline $30-36 \mathrm{~cm}$ & 0 & 1 & 0 & 0 & 0 & 0 & 0 & 1 \\
\hline \multicolumn{9}{|l|}{ Test Unit 7} \\
\hline $0-10 \mathrm{~cm}$ & 0 & 5 & 0 & 0 & 11 & 0 & 0 & 16 \\
\hline $10-20 \mathrm{~cm}$ & 0 & 4 & 0 & 0 & 31 & 2 & 0 & 37 \\
\hline $20-30 \mathrm{~cm}$ & 0 & 0 & 0 & 0 & 2 & 0 & 0 & 2 \\
\hline \multicolumn{9}{|l|}{ Test Unit 8} \\
\hline $0-10 \mathrm{~cm}$ & 0 & 1 & 0 & 0 & 3 & 0 & 0 & 4 \\
\hline $10-20 \mathrm{~cm}$ & 0 & 7 & 0 & 0 & 10 & 0 & 0 & 17 \\
\hline $20-30 \mathrm{~cm}$ & 0 & 8 & 0 & 0 & 9 & 0 & 0 & 17 \\
\hline $30-38 \mathrm{~cm}$ & 0 & 10 & 0 & 0 & 6 & 0 & 0 & 16 \\
\hline \multicolumn{9}{|l|}{ Test Unit 9} \\
\hline $0-10 \mathrm{~cm}$ & 0 & 6 & 0 & 0 & 26 & 0 & 0 & 32 \\
\hline $10-20 \mathrm{~cm}$ & 1 & 13 & 0 & 0 & 20 & 6 & 1 vessel & 41 \\
\hline $20-30 \mathrm{~cm}$ & 2 & 18 & 0 & 0 & 29 & 14 & 0 & 63 \\
\hline $30-36 \mathrm{~cm}$ & 0 & 1 & 0 & 0 & 4 & 0 & 0 & 5 \\
\hline \multicolumn{9}{|l|}{ Test Unit 10} \\
\hline $0-10 \mathrm{~cm}$ & 0 & 2 & 0 & 0 & 9 & 0 & 0 & 11 \\
\hline $10-20 \mathrm{~cm}$ & 0 & 4 & 0 & 0 & 15 & 0 & 0 & 19 \\
\hline $20-23 \mathrm{~cm}$ & 0 & 0 & 0 & 0 & 0 & 0 & 0 & 0 \\
\hline \multicolumn{9}{|l|}{ Test Unit 11} \\
\hline $0-10 \mathrm{~cm}$ & 0 & 6 & 0 & 0 & 2 & 0 & 0 & 8 \\
\hline $10-20 \mathrm{~cm}$ & 0 & 5 & 0 & 0 & 4 & 0 & 0 & 9 \\
\hline $20-30 \mathrm{~cm}$ & 0 & 0 & 0 & 0 & 0 & 0 & 0 & 0 \\
\hline \multicolumn{9}{|l|}{ Test Unit 12} \\
\hline $0-10 \mathrm{~cm}$ & 0 & 0 & 0 & 0 & 0 & 0 & 0 & 0 \\
\hline $10-20 \mathrm{~cm}$ & 0 & 2 & 1 & 1 & 42 & 0 & 0 & 46 \\
\hline $20-30 \mathrm{~cm}$ & 0 & 2 & 0 & 0 & 26 & 3 & 0 & 31 \\
\hline $30-40 \mathrm{~cm}$ & 0 & 2 & 0 & 0 & 19 & 4 & 0 & 25 \\
\hline $40-50 \mathrm{~cm}$ & 0 & 5 & 0 & 0 & 11 & 0 & 0 & 16 \\
\hline $50-60 \mathrm{~cm}$ & 0 & 9 & 0 & 0 & 9 & 0 & 0 & 18 \\
\hline $0-43 \mathrm{~cm}$ & 0 & 0 & 0 & 0 & 30 & 0 & 0 & 30 \\
\hline Test Unit 13 & & & & & & & & \\
\hline
\end{tabular}


Chapter 2: Testing

Table 2.7, continued

\begin{tabular}{|c|c|c|c|c|c|c|c|c|}
\hline Provenience & $\begin{array}{c}\text { Chipped } \\
\text { Stone } \\
\text { Tool } \\
\end{array}$ & Debitage & Core & $\begin{array}{c}\text { Ground } \\
\text { Stone } \\
\text { Tool } \\
\end{array}$ & Sherd & Bone & Other & Totals \\
\hline $0-10 \mathrm{~cm}$ & 0 & 5 & 0 & 0 & 8 & 0 & 0 & 13 \\
\hline $10-20 \mathrm{~cm}$ & 0 & 2 & 0 & 0 & 14 & 0 & 0 & 16 \\
\hline $20-30 \mathrm{~cm}$ & 0 & 3 & 0 & 0 & 9 & 0 & 0 & 12 \\
\hline $30-35 \mathrm{~cm}$ & 0 & 0 & 0 & 0 & 2 & 0 & 0 & 2 \\
\hline $35-40 \mathrm{~cm}$ & 0 & 3 & 0 & 0 & 2 & 0 & 0 & 5 \\
\hline $40-50 \mathrm{~cm}$ & 0 & 0 & 0 & 0 & 0 & 0 & 0 & 0 \\
\hline \multicolumn{9}{|l|}{ Test Unit 14} \\
\hline $0-10 \mathrm{~cm}$ & 0 & 3 & 0 & 0 & 24 & 0 & 0 & 27 \\
\hline $10-20 \mathrm{~cm}$ & 0 & 4 & 0 & 0 & 18 & 0 & 0 & 22 \\
\hline $20-30 \mathrm{~cm}$ & 0 & 3 & 0 & 0 & 7 & 0 & 0 & 10 \\
\hline $30-40 \mathrm{~cm}$ & 0 & 0 & 0 & 0 & 8 & 0 & 0 & 8 \\
\hline \multicolumn{9}{|l|}{ Test Unit 15} \\
\hline $0-10 \mathrm{~cm}$ & 0 & 2 & 0 & 0 & 7 & 0 & 0 & 9 \\
\hline $10-20 \mathrm{~cm}$ & 1 & 3 & 1 & 0 & 10 & 0 & 0 & 15 \\
\hline $20-30 \mathrm{~cm}$ & 0 & 16 & 0 & 0 & 16 & 0 & 0 & 32 \\
\hline $30-35 \mathrm{~cm}$ & 0 & 7 & 0 & 0 & 0 & 0 & 0 & 7 \\
\hline \multicolumn{9}{|l|}{ Test Unit 16} \\
\hline $0-10 \mathrm{~cm}$ & 0 & 11 & 0 & 0 & 8 & 0 & 0 & 19 \\
\hline $10-20 \mathrm{~cm}$ & 0 & 8 & 0 & 0 & 5 & 0 & 0 & 13 \\
\hline $20-30 \mathrm{~cm}$ & 0 & 6 & 0 & 0 & 9 & 0 & 0 & 15 \\
\hline $30-40 \mathrm{~cm}$ & 1 & 3 & 0 & 0 & 0 & 0 & 0 & 4 \\
\hline \multicolumn{9}{|l|}{ Test Unit 17} \\
\hline $0-10 \mathrm{~cm}$ & 0 & 8 & 1 & 0 & 12 & 0 & 0 & 21 \\
\hline $10-20 \mathrm{~cm}$ & 1 & 2 & 0 & 0 & 2 & 0 & 0 & 5 \\
\hline \multicolumn{9}{|l|}{ Test Unit 18} \\
\hline $0-10 \mathrm{~cm}$ & 0 & 4 & 0 & 0 & 14 & 0 & 0 & 18 \\
\hline $10-20 \mathrm{~cm}$ & 0 & 0 & 0 & 0 & 0 & 0 & 0 & 0 \\
\hline \multicolumn{9}{|l|}{ Test Unit 19} \\
\hline $0-10 \mathrm{~cm}$ & 0 & 3 & 0 & 0 & 5 & 0 & 0 & 8 \\
\hline $10-20 \mathrm{~cm}$ & 1 & 3 & 0 & 0 & 26 & 0 & 0 & 30 \\
\hline $20-30 \mathrm{~cm}$ & 0 & 5 & 0 & 0 & 9 & 0 & 0 & 14 \\
\hline $30-40 \mathrm{~cm}$ & 1 & 0 & 0 & 0 & 15 & 0 & 0 & 16 \\
\hline $40-50 \mathrm{~cm}$ & 0 & 1 & 0 & 0 & 8 & 2 & 0 & 11 \\
\hline \multicolumn{9}{|l|}{ Test Unit 20} \\
\hline $0-10 \mathrm{~cm}$ & 0 & 1 & 0 & 0 & 3 & 0 & 0 & 4 \\
\hline $10-20 \mathrm{~cm}$ & 1 & 3 & 0 & 0 & 4 & 0 & 0 & 8 \\
\hline $20-30 \mathrm{~cm}$ & 0 & 4 & 0 & 0 & 4 & 0 & 0 & 8 \\
\hline $30-40 \mathrm{~cm}$ & 2 & 1 & 0 & 0 & 0 & 0 & 0 & 3 \\
\hline \multicolumn{9}{|l|}{ Test Unit 21} \\
\hline $0-10 \mathrm{~cm}$ & 0 & 2 & 0 & 0 & 24 & 0 & 0 & 26 \\
\hline $10-20 \mathrm{~cm}$ & 1 & 2 & 0 & 0 & 21 & 0 & 0 & 24 \\
\hline $20-30 \mathrm{~cm}$ & 0 & 5 & 0 & 0 & 15 & 0 & 0 & 20 \\
\hline $30-40 \mathrm{~cm}$ & 0 & 6 & 0 & 0 & 28 & 1 & 0 & 35 \\
\hline \multicolumn{9}{|l|}{ Test Unit 22} \\
\hline $0-10 \mathrm{~cm}$ & 1 & 17 & 0 & 0 & 34 & 0 & 0 & 52 \\
\hline $10-20 \mathrm{~cm}$ & 1 & 28 & 0 & 0 & 36 & 5 & 0 & 72 \\
\hline $20-30 \mathrm{~cm}$ & 3 & 15 & 0 & 0 & 31 & 0 & 0 & 47 \\
\hline
\end{tabular}


Excavations along the U.S. Highway 271 Mount Pleasant Relief Route

Table 2.7, continued

\begin{tabular}{|c|c|c|c|c|c|c|c|c|}
\hline Provenience & $\begin{array}{c}\text { Chipped } \\
\text { Stone } \\
\text { Tool } \\
\end{array}$ & Debitage & Core & $\begin{array}{c}\text { Ground } \\
\text { Stone } \\
\text { Tool } \\
\end{array}$ & Sherd & Bone & Other & Totals \\
\hline $30-40 \mathrm{~cm}$ & 1 & 17 & 0 & 0 & 7 & 0 & 0 & 25 \\
\hline \multicolumn{9}{|l|}{ Test Unit 23} \\
\hline $0-10 \mathrm{~cm}$ & 0 & 2 & 0 & 0 & 17 & 0 & 0 & 19 \\
\hline $10-20 \mathrm{~cm}$ & 0 & 3 & 0 & 0 & 10 & 0 & 0 & 13 \\
\hline \multicolumn{9}{|l|}{ Test Unit 24} \\
\hline $0-10 \mathrm{~cm}$ & 1 & 15 & 0 & 0 & 22 & 0 & 0 & 38 \\
\hline $10-20 \mathrm{~cm}$ & 0 & 13 & 1 & 0 & 19 & 0 & 0 & 33 \\
\hline $20-28 \mathrm{~cm}$ & 0 & 4 & 1 & 0 & 5 & 0 & 0 & 10 \\
\hline \multicolumn{9}{|l|}{ Test Unit 25} \\
\hline $0-10 \mathrm{~cm}$ & 0 & 3 & 0 & 0 & 0 & 0 & 0 & 3 \\
\hline $10-20 \mathrm{~cm}$ & 0 & 6 & 0 & 0 & 6 & 0 & 0 & 12 \\
\hline $20-30 \mathrm{~cm}$ & 0 & 6 & 0 & 0 & 2 & 0 & 0 & 8 \\
\hline $30-35 \mathrm{~cm}$ & 0 & 0 & 0 & 0 & 0 & 0 & 0 & 0 \\
\hline \multicolumn{9}{|l|}{ Test Unit 46} \\
\hline $0-10 \mathrm{~cm}$ & 0 & 3 & 0 & 0 & 8 & 0 & 0 & 11 \\
\hline $10-20 \mathrm{~cm}$ & 0 & 6 & 0 & 0 & 12 & 0 & 0 & 18 \\
\hline $20-30 \mathrm{~cm}$ & 0 & 6 & 1 & 0 & 15 & 1 & 0 & 23 \\
\hline $30-40 \mathrm{~cm}$ & 0 & 3 & 0 & 0 & 14 & 1 & 0 & 18 \\
\hline $40-50 \mathrm{~cm}$ & 0 & 0 & 0 & 0 & 0 & 0 & 0 & 0 \\
\hline $50-60 \mathrm{~cm}$ & 0 & 0 & 0 & 0 & 0 & 0 & 0 & 0 \\
\hline Feature 1 & 0 & 0 & 0 & 0 & 9 & 0 & 1 vessel & 10 \\
\hline Feature 1 Pedestal & 5 & 53 & 0 & 0 & 198 & 12 & 0 & 268 \\
\hline Feature 3 & 0 & 0 & 0 & 0 & 0 & 2 & 0 & 2 \\
\hline Feature 7 & 0 & 3 & 0 & 0 & 10 & 0 & 0 & 13 \\
\hline Feature 12 & 0 & 1 & 0 & 0 & 0 & 0 & 0 & 1 \\
\hline Feature 13 & 1 & 10 & 0 & 0 & 3 & 0 & 0 & 14 \\
\hline Feature 14 & 0 & 0 & 0 & 0 & 4 & 0 & 0 & 4 \\
\hline Feature 15 & 0 & 1 & 0 & 0 & 0 & 0 & 0 & 1 \\
\hline Feature 17 & 0 & 2 & 0 & 0 & 0 & 0 & 0 & 2 \\
\hline Feature 19 & 0 & 0 & 0 & 0 & 1 & 0 & 0 & 1 \\
\hline Feature 23 & 1 & 0 & 0 & 0 & 1 & 0 & 0 & 2 \\
\hline Feature 24 & 0 & 0 & 0 & 0 & 3 & 0 & 0 & 3 \\
\hline Feature 25 & 0 & 0 & 0 & 0 & 6 & 0 & 0 & 6 \\
\hline Feature 30 & 0 & 0 & 0 & 0 & 1 & 0 & 0 & 1 \\
\hline Feature 35 & 1 & 0 & 0 & 0 & 0 & 0 & 0 & 1 \\
\hline Feature 39 & 0 & 0 & 0 & 0 & 4 & 0 & 0 & 4 \\
\hline BHT 2 & 2 & 14 & 0 & 0 & 26 & 5 & 0 & 47 \\
\hline BHT 3 & 0 & 0 & 1 & 0 & 7 & 0 & 0 & 8 \\
\hline BHT 4 & 1 & 9 & 0 & 3 & 46 & 0 & 0 & 59 \\
\hline BHT 5 & 0 & 0 & 0 & 0 & 2 & 0 & 0 & 2 \\
\hline BHT 6 & 0 & 1 & 0 & 0 & 3 & 0 & 0 & 4 \\
\hline BHT 7 & 2 & 5 & 0 & 0 & 8 & 0 & 0 & 15 \\
\hline BHT 8 & 0 & 3 & 0 & 0 & 32 & 0 & 0 & 35 \\
\hline BHT 10 & 0 & 0 & 1 & 0 & 5 & 0 & 0 & 6 \\
\hline BHT 11 & 0 & 0 & 0 & 0 & 4 & 0 & 0 & 4 \\
\hline BHT 12 & 0 & 1 & 0 & 0 & 15 & 0 & 0 & 16 \\
\hline BHT 15 & 0 & 1 & 0 & 0 & 10 & 0 & 0 & 11 \\
\hline
\end{tabular}


Chapter 2: Testing

Table 2.7, continued

\begin{tabular}{|c|c|c|c|c|c|c|c|c|}
\hline Provenience & $\begin{array}{c}\text { Chipped } \\
\text { Stone } \\
\text { Tool } \\
\end{array}$ & Debitage & Core & $\begin{array}{c}\text { Ground } \\
\text { Stone } \\
\text { Tool } \\
\end{array}$ & Sherd & Bone & Other & Totals \\
\hline BHT 16 & 0 & 1 & 0 & 1 & 13 & 0 & 0 & 15 \\
\hline BHT 18 & 0 & 1 & 0 & 0 & 8 & 0 & 0 & 9 \\
\hline BHT 19 & 1 & 0 & 0 & 0 & 6 & 0 & 0 & 7 \\
\hline BHT 21 & 0 & 0 & 0 & 0 & 1 & 0 & 0 & 1 \\
\hline BHT 22 & 0 & 1 & 0 & 0 & 1 & 0 & 0 & 2 \\
\hline BHT 23 & 0 & 1 & 1 & 0 & 1 & 0 & 0 & 3 \\
\hline BHT 24 & 0 & 0 & 1 & 0 & 0 & 0 & 0 & 1 \\
\hline BHT 26 & 0 & 0 & 0 & 0 & 2 & 0 & 0 & 2 \\
\hline BHT 27 & 0 & 0 & 0 & 0 & 6 & 0 & 0 & 6 \\
\hline BHT 28 & 0 & 0 & 0 & 0 & 1 & 0 & 0 & 1 \\
\hline BHT 30 & 0 & 0 & 0 & 0 & 2 & 0 & 0 & 2 \\
\hline BHT 31 & 0 & 0 & 0 & 0 & 1 & 0 & 0 & 1 \\
\hline BHT 34 & 0 & 0 & 0 & 0 & 1 & 0 & 0 & 1 \\
\hline BHT 35 & 0 & 0 & 0 & 0 & 2 & 0 & 0 & 2 \\
\hline BHT 36 & 0 & 0 & 1 & 0 & 2 & 0 & 0 & 3 \\
\hline BHT 38 & 0 & 0 & 0 & 0 & 6 & 0 & 0 & 6 \\
\hline BHT 39 & 0 & 0 & 0 & 0 & 1 & 0 & 0 & 1 \\
\hline BHT 40 & 0 & 0 & 0 & 0 & 1 & 0 & 0 & 1 \\
\hline BHT 43 & 0 & 0 & 0 & 0 & 2 & 0 & 0 & 2 \\
\hline BHT 46 & 0 & 0 & 0 & 0 & 1 & 0 & 0 & 1 \\
\hline BHT 47 & 0 & 1 & 0 & 0 & 6 & 0 & 0 & 7 \\
\hline BHT 49 & 2 & 4 & 2 & 0 & 7 & 0 & 0 & 15 \\
\hline BHT 50 & 2 & 7 & 0 & 0 & 8 & 0 & 0 & 17 \\
\hline BHT 51 & 0 & 2 & 0 & 0 & 4 & 0 & 0 & 6 \\
\hline Surface & 0 & 1 & 0 & 1 & 5 & 0 & 0 & 7 \\
\hline Subarea 1 Totals & 41 & 626 & 15 & 6 & 1,600 & 58 & 2 & 2,348 \\
\hline
\end{tabular}

Subarea 2:

\begin{tabular}{l|c|c|c|c|c|c|c|c}
\hline Auger Test 54 & 0 & 2 & 0 & 0 & 0 & 0 & 0 & 2 \\
\hline Auger Test 58 & 0 & 0 & 0 & 1 & 0 & 0 & 0 & 1 \\
\hline Auger Test 59 & 0 & 2 & 0 & 0 & 0 & 0 & 0 & 2 \\
\hline Auger Test 257 & 0 & 10 & 0 & 0 & 0 & 0 & 0 & 10 \\
\hline Auger Test 258 & 0 & 1 & 0 & 0 & 0 & 0 & 0 & 1 \\
\hline Subarea 2 Totals & 0 & 15 & 0 & 1 & 0 & 0 & 0 & 16 \\
\hline
\end{tabular}

\section{Subarea 3:}

\begin{tabular}{l|l|l|l|l|l|l|l|l}
\hline Auger Test 73 & 0 & 0 & 0 & 0 & 2 & 0 & 0 & 2 \\
\hline Auger Test 74 & 0 & 1 & 0 & 0 & 0 & 0 & 0 & 1 \\
\hline Auger Test 75 & 0 & 0 & 0 & 0 & 1 & 0 & 0 & 1 \\
\hline Auger Test 80 & 0 & 1 & 0 & 0 & 0 & 0 & 0 & 1 \\
\hline Auger Test 84 & 0 & 3 & 0 & 0 & 0 & 0 & 0 & 3 \\
\hline Auger Test 85 & 0 & 0 & 0 & 0 & 2 & 0 & 0 & 2 \\
\hline Auger Test 90 & 0 & 2 & 0 & 0 & 0 & 0 & 0 & 2 \\
\hline Auger Test 92 & 1 & 3 & 0 & 0 & 0 & 0 & 0 & 4 \\
\hline Auger Test 93 & 0 & 2 & 0 & 0 & 0 & 0 & 0 & 2 \\
\hline Auger Test 94 & 0 & 1 & 0 & 0 & 0 & 0 & 0 & 1 \\
\hline Auger Test 96 & 1 & 5 & 0 & 0 & 0 & 0 & 0 & 6 \\
\hline Test Unit 26 & & & & & & & & 0 \\
\hline \multicolumn{1}{c}{ 0-10 cm } & 0 & 0 & 0 & 0 & 0 & 0 & 0 & 0 \\
\hline
\end{tabular}


Excavations along the U.S. Highway 271 Mount Pleasant Relief Route

Table 2.7, continued

\begin{tabular}{|c|c|c|c|c|c|c|c|c|}
\hline Provenience & $\begin{array}{c}\text { Chipped } \\
\text { Stone } \\
\text { Tool } \\
\end{array}$ & Debitage & Core & $\begin{array}{c}\text { Ground } \\
\text { Stone } \\
\text { Tool } \\
\end{array}$ & Sherd & Bone & Other & Totals \\
\hline $10-20 \mathrm{~cm}$ & 0 & 3 & 0 & 0 & 1 & 0 & 0 & 4 \\
\hline \multicolumn{9}{|l|}{ Test Unit 27} \\
\hline $0-10 \mathrm{~cm}$ & 0 & 15 & 0 & 1 & 8 & 0 & 0 & 24 \\
\hline $10-20 \mathrm{~cm}$ & 0 & 12 & 0 & 0 & 8 & 0 & 0 & 20 \\
\hline \multicolumn{9}{|l|}{ Test Unit 28} \\
\hline $0-10 \mathrm{~cm}$ & 0 & 0 & 0 & 0 & 1 & 0 & 0 & 1 \\
\hline $10-20 \mathrm{~cm}$ & 0 & 10 & 0 & 0 & 6 & 0 & 0 & 16 \\
\hline $20-30 \mathrm{~cm}$ & 0 & 5 & 0 & 0 & 4 & 0 & 0 & 9 \\
\hline $30-40 \mathrm{~cm}$ & 0 & 0 & 0 & 0 & 0 & 0 & 0 & 0 \\
\hline $40-50 \mathrm{~cm}$ & 0 & 0 & 0 & 0 & 0 & 0 & 0 & 0 \\
\hline \multicolumn{9}{|l|}{ Test Unit 29} \\
\hline $0-10 \mathrm{~cm}$ & 0 & 8 & 0 & 0 & 0 & 0 & 0 & 8 \\
\hline $10-20 \mathrm{~cm}$ & 2 & 13 & 0 & 0 & 5 & 0 & 0 & 20 \\
\hline $20-30 \mathrm{~cm}$ & 0 & 22 & 0 & 0 & 16 & 0 & 0 & 38 \\
\hline $30-40 \mathrm{~cm}$ & 0 & 6 & 0 & 0 & 1 & 1 & 0 & 8 \\
\hline \multicolumn{9}{|l|}{ Test Unit 30} \\
\hline $0-10 \mathrm{~cm}$ & 0 & 1 & 0 & 0 & 1 & 0 & 0 & 2 \\
\hline $10-20 \mathrm{~cm}$ & 0 & 0 & 0 & 0 & 0 & 0 & 0 & 0 \\
\hline $20-25 \mathrm{~cm}$ & 0 & 0 & 0 & 0 & 0 & 0 & 0 & 0 \\
\hline \multicolumn{9}{|l|}{ Test Unit 31} \\
\hline $0-10 \mathrm{~cm}$ & 0 & 0 & 0 & 0 & 0 & 0 & 0 & 0 \\
\hline $10-20 \mathrm{~cm}$ & 0 & 1 & 0 & 0 & 0 & 0 & 0 & 1 \\
\hline $20-30 \mathrm{~cm}$ & 0 & 0 & 0 & 0 & 0 & 0 & 0 & 0 \\
\hline $30-34 \mathrm{~cm}$ & 0 & 0 & 0 & 0 & 0 & 0 & 0 & 0 \\
\hline \multicolumn{9}{|l|}{ Test Unit 32} \\
\hline $0-10 \mathrm{~cm}$ & 0 & 4 & 0 & 0 & 2 & 0 & 0 & 6 \\
\hline $10-20 \mathrm{~cm}$ & 0 & 8 & 0 & 0 & 1 & 0 & 0 & 9 \\
\hline \multicolumn{9}{|l|}{ Test Unit 33} \\
\hline $0-10 \mathrm{~cm}$ & 0 & 1 & 0 & 0 & 2 & 0 & 0 & 3 \\
\hline $10-20 \mathrm{~cm}$ & 0 & 11 & 0 & 0 & 6 & 0 & 0 & 17 \\
\hline $20-30 \mathrm{~cm}$ & 0 & 3 & 0 & 0 & 1 & 0 & 0 & 4 \\
\hline $30-40 \mathrm{~cm}$ & 0 & 0 & 0 & 0 & 0 & 0 & 0 & 0 \\
\hline \multicolumn{9}{|l|}{ Test Unit 34} \\
\hline $0-10 \mathrm{~cm}$ & 0 & 0 & 0 & 0 & 0 & 0 & 0 & 0 \\
\hline $10-20 \mathrm{~cm}$ & 0 & 1 & 0 & 0 & 1 & 0 & 0 & 2 \\
\hline $20-30 \mathrm{~cm}$ & 0 & 0 & 0 & 0 & 0 & 0 & 0 & 0 \\
\hline \multicolumn{9}{|l|}{ Test Unit 35} \\
\hline $0-10 \mathrm{~cm}$ & 0 & 5 & 0 & 0 & 3 & 0 & 0 & 8 \\
\hline $10-20 \mathrm{~cm}$ & 1 & 5 & 0 & 0 & 6 & 0 & 0 & 12 \\
\hline \multicolumn{9}{|l|}{ Test Unit 36} \\
\hline $0-10 \mathrm{~cm}$ & 0 & 6 & 0 & 0 & 1 & 0 & 0 & 7 \\
\hline $10-20 \mathrm{~cm}$ & 0 & 0 & 0 & 0 & 0 & 0 & 0 & 0 \\
\hline $20-30 \mathrm{~cm}$ & 0 & 2 & 0 & 0 & 0 & 0 & 0 & 2 \\
\hline \multicolumn{9}{|l|}{ Test Unit 37} \\
\hline $0-10 \mathrm{~cm}$ & 2 & 5 & 1 & 0 & 2 & 0 & 0 & 10 \\
\hline $10-15 \mathrm{~cm}$ & 0 & 0 & 0 & 0 & 0 & 0 & 0 & 0 \\
\hline $15-20 \mathrm{~cm}$ & 0 & 4 & 0 & 0 & 0 & 0 & 0 & 4 \\
\hline
\end{tabular}


Chapter 2: Testing

Table 2.7, continued

\begin{tabular}{|c|c|c|c|c|c|c|c|c|}
\hline Provenience & $\begin{array}{c}\text { Chipped } \\
\text { Stone } \\
\text { Tool } \\
\end{array}$ & Debitage & Core & $\begin{array}{c}\text { Ground } \\
\text { Stone } \\
\text { Tool } \\
\end{array}$ & Sherd & Bone & Other & Totals \\
\hline Feature 48 & 1 & 1 & 0 & 0 & 0 & 2 & 0 & 4 \\
\hline BHT 56 & 0 & 1 & 0 & 0 & 1 & 0 & 0 & 2 \\
\hline BHT 59 & 0 & 1 & 0 & 0 & 3 & 0 & 0 & 4 \\
\hline BHT 62 & 0 & 0 & 1 & 1 & 3 & 0 & 0 & 5 \\
\hline BHT 64 & 1 & 6 & 0 & 1 & 10 & 0 & 0 & 18 \\
\hline BHT 66 & 0 & 1 & 0 & 0 & 3 & 0 & 0 & 4 \\
\hline Subarea 3 Totals & 9 & 179 & 2 & 3 & 101 & 3 & 0 & 297 \\
\hline \multicolumn{9}{|l|}{ Subarea 4: } \\
\hline Auger Test 169 & 0 & 2 & 0 & 0 & 0 & 0 & 0 & 2 \\
\hline Auger Test 189 & 0 & 1 & 0 & 0 & 0 & 0 & 0 & 1 \\
\hline Auger Test 192 & 0 & 1 & 0 & 0 & 0 & 0 & 0 & 1 \\
\hline Auger Test 227 & 0 & 4 & 0 & 0 & 0 & 0 & 0 & 4 \\
\hline Auger Test 234 & 0 & 1 & 0 & 0 & 0 & 0 & 0 & 1 \\
\hline Auger Test 235 & 0 & 1 & 0 & 0 & 0 & 0 & 0 & 1 \\
\hline Auger Test 238 & 0 & 1 & 0 & 0 & 0 & 0 & 0 & 1 \\
\hline Auger Test 266 & 0 & 1 & 0 & 0 & 0 & 0 & 0 & 1 \\
\hline Auger Test 267 & 0 & 1 & 0 & 0 & 0 & 0 & 0 & 1 \\
\hline Auger Test 269 & 1 & 0 & 0 & 0 & 0 & 0 & 0 & 1 \\
\hline \multicolumn{9}{|l|}{ Test Unit 38} \\
\hline $0-10 \mathrm{~cm}$ & 0 & 3 & 0 & 0 & 0 & 0 & 0 & 3 \\
\hline $10-20 \mathrm{~cm}$ & 0 & 1 & 0 & 0 & 0 & 0 & 0 & 1 \\
\hline $20-30 \mathrm{~cm}$ & 0 & 2 & 0 & 0 & 0 & 0 & 0 & 2 \\
\hline \multicolumn{9}{|l|}{ Test Unit 39} \\
\hline $0-10 \mathrm{~cm}$ & 0 & 4 & 0 & 0 & 0 & 0 & 0 & 4 \\
\hline $10-20 \mathrm{~cm}$ & 0 & 13 & 1 & 0 & 0 & 0 & 0 & 14 \\
\hline $20-30 \mathrm{~cm}$ & 0 & 5 & 0 & 0 & 0 & 0 & 0 & 5 \\
\hline $30-34 \mathrm{~cm}$ & 0 & 3 & 0 & 0 & 0 & 0 & 0 & 3 \\
\hline \multicolumn{9}{|l|}{ Test Unit 40} \\
\hline $0-10 \mathrm{~cm}$ & 0 & 0 & 0 & 0 & 0 & 0 & 0 & 0 \\
\hline $10-20 \mathrm{~cm}$ & 0 & 2 & 0 & 0 & 1 & 0 & 0 & 3 \\
\hline $20-30 \mathrm{~cm}$ & 1 & 5 & 0 & 0 & 0 & 0 & 0 & 6 \\
\hline $30-40 \mathrm{~cm}$ & 1 & 1 & 0 & 0 & 0 & 0 & 0 & 2 \\
\hline \multicolumn{9}{|l|}{ Test Unit 41} \\
\hline $0-10 \mathrm{~cm}$ & 0 & 0 & 0 & 0 & 0 & 0 & 0 & 0 \\
\hline $10-20 \mathrm{~cm}$ & 1 & 1 & 0 & 0 & 0 & 0 & 0 & 2 \\
\hline $20-30 \mathrm{~cm}$ & 1 & 5 & 0 & 0 & 0 & 0 & 0 & 6 \\
\hline \multicolumn{9}{|l|}{ Test Unit 42} \\
\hline $0-10 \mathrm{~cm}$ & 0 & 0 & 0 & 0 & 0 & 0 & 0 & 0 \\
\hline $10-20 \mathrm{~cm}$ & 0 & 3 & 0 & 0 & 0 & 0 & 0 & 3 \\
\hline $20-30 \mathrm{~cm}$ & 0 & 7 & 0 & 0 & 1 & 0 & 0 & 8 \\
\hline \multicolumn{9}{|l|}{ Test Unit 43} \\
\hline $0-10 \mathrm{~cm}$ & 0 & 0 & 0 & 0 & 0 & 0 & 0 & 0 \\
\hline $10-20 \mathrm{~cm}$ & 0 & 4 & 0 & 0 & 1 & 0 & 0 & 5 \\
\hline $20-30 \mathrm{~cm}$ & 0 & 0 & 0 & 0 & 0 & 0 & 0 & 0 \\
\hline \multicolumn{9}{|l|}{ Test Unit 44} \\
\hline $0-10 \mathrm{~cm}$ & 1 & 16 & 0 & 0 & 3 & 0 & 0 & 20 \\
\hline $10-20 \mathrm{~cm}$ & 0 & 32 & 0 & 0 & 1 & 0 & 0 & 33 \\
\hline
\end{tabular}


Table 2.7, continued

\begin{tabular}{|c|c|c|c|c|c|c|c|c|}
\hline Provenience & $\begin{array}{c}\text { Chipped } \\
\text { Stone } \\
\text { Tool }\end{array}$ & Debitage & Core & $\begin{array}{c}\text { Ground } \\
\text { Stone } \\
\text { Tool }\end{array}$ & Sherd & Bone & Other & Totals \\
\hline $20-24 \mathrm{~cm}$ & 0 & 5 & 0 & 0 & 0 & 0 & 0 & 5 \\
\hline \multicolumn{9}{|l|}{ Test Unit 45} \\
\hline $0-10 \mathrm{~cm}$ & 1 & 11 & 0 & 0 & 0 & 0 & 0 & 12 \\
\hline $10-20 \mathrm{~cm}$ & 0 & 21 & 1 & 0 & 0 & 0 & 0 & 22 \\
\hline $20-27 \mathrm{~cm}$ & 0 & 3 & 0 & 0 & 0 & 0 & 0 & 3 \\
\hline BHT 73 & 0 & 2 & 0 & 0 & 0 & 0 & 0 & 2 \\
\hline BHT 77 & 1 & 0 & 1 & 0 & 0 & 0 & 0 & 2 \\
\hline BHT 78 & 0 & 3 & 0 & 0 & 0 & 0 & 0 & 3 \\
\hline BHT 82 & 0 & 1 & 0 & 0 & 0 & 0 & 0 & 1 \\
\hline BHT 83 & 0 & 0 & 0 & 1 & 0 & 0 & 0 & 1 \\
\hline BHT 84 & 0 & 1 & 0 & 0 & 0 & 0 & 0 & 1 \\
\hline BHT 87 & 0 & 1 & 0 & 0 & 2 & 0 & 0 & 3 \\
\hline BHT 88 & 0 & 0 & 1 & 0 & 0 & 0 & 0 & 1 \\
\hline Surface & 1 & 25 & 1 & 0 & 45 & 0 & 0 & 72 \\
\hline Subarea 4 Totals & 9 & 193 & 5 & 1 & 54 & 0 & 0 & 262 \\
\hline \multicolumn{9}{|l|}{ Other: } \\
\hline Auger Test 132 & 0 & 0 & 0 & 0 & 1 & 0 & 0 & 1 \\
\hline Site Totals & 59 & 1,013 & 22 & 11 & 1,756 & 61 & 2 & 2,924 \\
\hline
\end{tabular}

227, and 234). More artifacts were found south of this area on the central interfluve. Three tests contained 5 sherds, and 8 tests yielded 18 flakes and 2 chipped stone tools. However, this area had been disturbed by logging, and large slash piles hindered systematic auger testing. The southernmost area of the site as defined by AEC is a south-trending slope from the transmission line to bottomlands adjacent to a tributary to Tankersley Creek. Auger Test 257 in this area produced 10 flakes as well as 3 fire-cracked rocks. This test was on a small high area between two erosional gullies and could represent a small remnant of a larger lithic cluster that has been eroded away. Four other tests in this general area produced a limited number of lithic artifacts, but these were not spatially contiguous. Seven pieces of debitage were recovered from three tests excavated in shallow deposits on the northernmost interfluve at the northwest limit of the sampled site area. The remainder of the auger test assemblage (a biface fragment, quartzite cobble, and 5 pieces of debitage) was sparsely scattered among seven tests on the ridge top east and northeast of the central and southern interfluves.
The auger test data were used to refine the limits of $41 \mathrm{TT} 852$, reducing the overall site extent to about $41,000 \mathrm{~m}^{2}$, and define four subareas within the modified site boundary. Subarea 1 encompassed approximately $3,500 \mathrm{~m}^{2}$ and included an area with moderate-density ceramics and low-density lithics on the crest of the southernmost interfluve. Subarea 2, located on the toeslope south-southwest of Subarea 1, covered $7,700 \mathrm{~m}^{2}$ and included moderate-density lithics. Subarea 3 covered $2,700 \mathrm{~m}^{2}$ on the crest of the central interfluve and had low densities of ceramics and lithics. Subarea 4 consisted of a $17,500-\mathrm{m}^{2}$ area characterized by low-density lithics on the revised site area's north end.

Clay subsoil was exposed at varying depths in 201 auger tests, ranging from the surface to $100 \mathrm{~cm}$ below the surface. The average thickness of overlying sands in these tests was $33 \mathrm{~cm}$. The deepest surface sediments were on the toeslope of the southernmost interfluve where discontinuous pockets of sediment were separated by erosional gullies. Moderately thick surface sediments were identified in a wooded upland surface in the north-central portion of the site, where depth to clay ranged from 40 to $60 \mathrm{~cm}$ 
below the surface. A smaller area of moderately thick surface sediments was identified on the crest of the southernmost interfluve, just north of the transmission line corridor, where the sand mantle was up to $50 \mathrm{~cm}$ thick. However, the upland crests and surfaces were typically characterized by thin surface sediments, as were many segments of the upland sideslopes.

\section{Work Accomplished in Intensive Testing}

Intensive testing was done in Subareas 1 , 3 , and 4; auger testing suggested that Subarea 2 was unlikely to contain important information. Testing began with geophysical survey of a $60 \times 40-m$ grid in Subarea 1, a 35x30-m grid in Subarea 3, and a 20x40-m grid in Subarea 4 (Figures 2.16-2.17). The Subarea 1 grid focused on the area of positive Auger Tests 99, 101-104, $108-110,113,116-118,119,120$, and 123-129 and was bisected by a large cleared corridor for an overhead transmission line. The Subarea 3 grid, the placement of which was constrained some by large push piles from logging activities and was transected by the same utility corridor as Subarea 1, encompassed or was adjacent to positive Auger Tests 73-75, 80, 84, 85, and 92. The Subarea 4 grid did not contain any positive auger tests, but it was near several (Auger Tests 169, 227, and 234), and it was next to a buried pipeline corridor where artifacts were exposed on the surface. Subareas 1 and 3 were considered the most likely to have important cultural remains because the auger tests indicated well-defined concentrations of materials, as opposed to Subarea 4 where artifacts were sparser and more widely scattered. The grids in Subareas 1 and 3 were not aligned to the cardinal directions but were oriented approximately $23^{\circ}$ and $26^{\circ}$ east of north, respectively; the grid in Subarea 4 was more closely aligned with the cardinal directions.

Several magnetic anomalies were identified in Subarea 1, including an 8-m anomaly in the northeast portion of the grid and a 9-m anomaly on the southwest side that were interpreted as possible prehistoric structures (see Appendix B). One of these correlated with a high-resistance anomaly. Magnetic susceptibility data identified an anomaly in the southeast corner that was interpreted as prehistoric anthropogenically enriched sediments. In Subarea 3, one area of enhanced magnetism was deemed potentially cultural. In the Subarea 4 grid, there was one area of high magnetic susceptibility on the crest of the landform that was considered potentially cultural.

Subarea 1 test excavations included 51 backhoe trenches and twenty-six 1x1-m units (see Figure 2.16). Fifty of the trenches and 25 of the units were in or partly within the geophysical survey grid. The trenches were $1.0 \mathrm{~m}$ wide, ranged from 3.5 to $9.9 \mathrm{~m}$ in length $($ mean $=6.4 \mathrm{~m})$, and varied from 22 to $60 \mathrm{~cm}$ in depth $($ mean $=37 \mathrm{~cm})$. A total of $328 \mathrm{~m}^{2}$ of site area was stripped through mechanical trench excavation in Subarea 1. Test unit excavation revealed surface sediments (A and $\mathrm{E}$ horizons) that ranged from 20 to $60 \mathrm{~cm}$ thick (mean $=40 \mathrm{~cm}$ ). Nineteen test units were opened off of trenches, and 7 were set apart from the trenches. Isolated Test Units 1-5 were excavated in the northeast part of the grid to investigate one of two large magnetometer anomalies identified in the Subarea 1 grid. Test Unit 7 was in the area of the second magnetometer anomaly on the west side of the grid. Test Unit 46 was opened about $1 \mathrm{~m}$ east of the grid to investigate the extent of the anthropogenically enriched deposits identified in trenches and units to the west.

Testing of Subarea 3 included the excavation of 21 backhoe trenches and twelve $1 \times 1-m$ test units within the geophysical grid (see Figure 2.17). The trenches ranged from 6.0 to $7.5 \mathrm{~m}$ in length $($ mean $=6.5 \mathrm{~m})$ and were from 9 to $41 \mathrm{~cm}$ deep $($ mean $=27 \mathrm{~cm})$. Mechanical trench excavation stripped $136 \mathrm{~m}^{2}$ in Subarea 3. Eight test units were adjacent to trenches, and four were isolated units. Surface sediments in these units ranged from 20 to $50 \mathrm{~cm}$ thick $($ mean $=29 \mathrm{~cm})$.

Sixteen backhoe trenches and eight $1 \times 1-m$ test units were excavated within the geophysical grid in Subarea 4 (see Figure 2.17). The trenches ranged from 2.1 to $12.2 \mathrm{~m}$ in length $($ mean $=6.3 \mathrm{~m})$, were from 18 to $47 \mathrm{~cm}$ deep $($ mean $=30 \mathrm{~cm})$, and had a combined horizontal area of $100 \mathrm{~m}^{2}$. Surface sediments in the excavated test units ranged from 27 to $40 \mathrm{~cm}$ thick $($ mean $=30 \mathrm{~cm})$.

\section{Sediment Descriptions}

The profiles of 23 trenches in Subarea 1 were described and revealed slightly variable stratigraphy. Most displayed A1-A2-E-Bt soil 


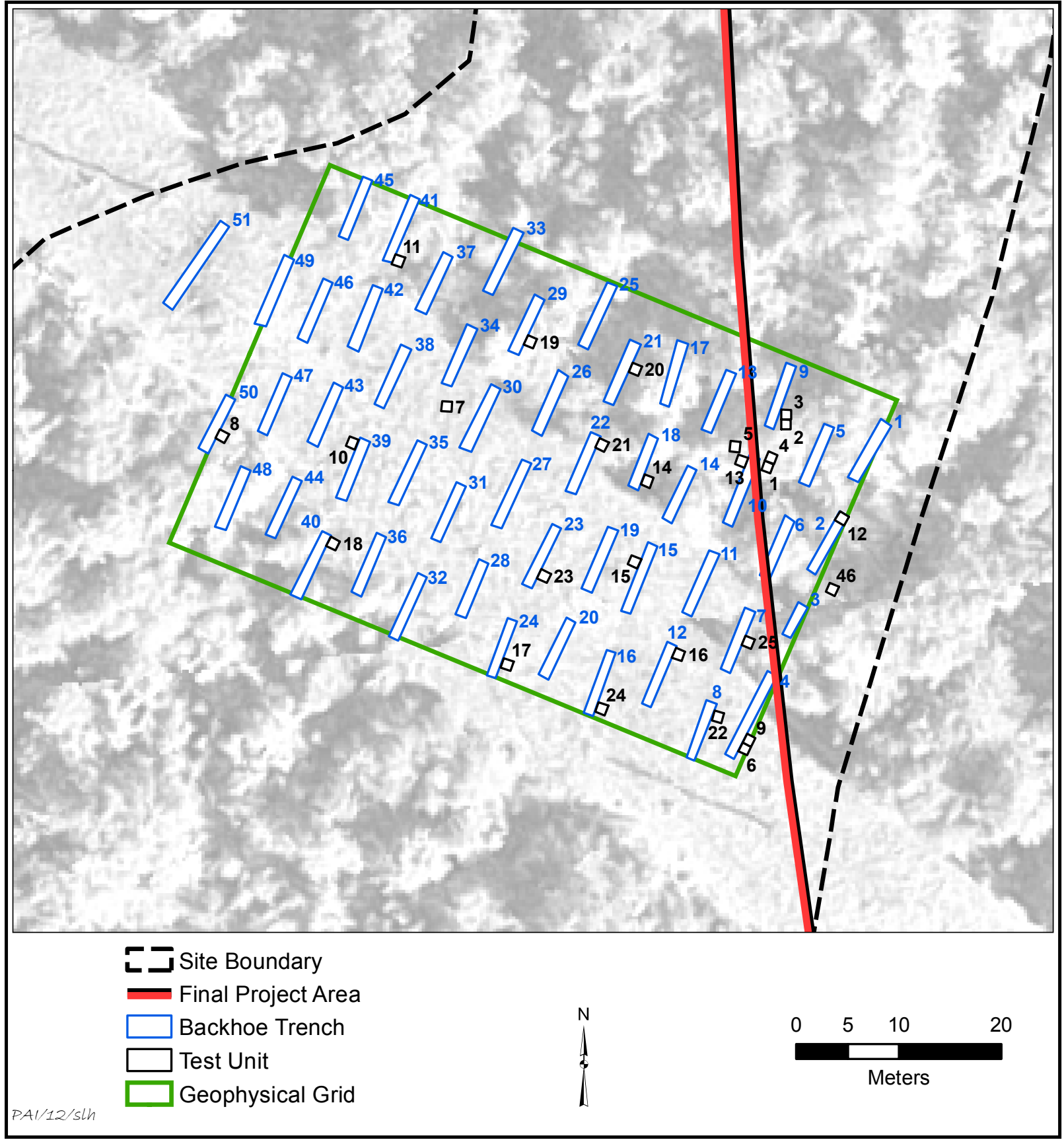

Figure 2.16. Aerial photograph of 41TT852, Subarea 1, showing geophysical survey grid and test excavations.

profiles. The A1 horizon was a $2-10$-cm-thick dark yellowish brown (10YR 3/3) very fine sand. The A2 horizon was 8-25-cm-thick dark yellowish brown (10YR 4/4,4/6) fine sand. The E horizon was 6-15-cm-thick yellowish brown (10YR 5/8) sand. The Bt horizon was firm strong brown (7.5YR 5/8) well-structured clay. Exceptions to this profile occurred along the south and southwestern edges and in the center of the west half of the grid. On the south and southwestern edges (Trenches 16, 20, 24, 28, 31, $32,40,41,44$, and 48), profiles were similar to 


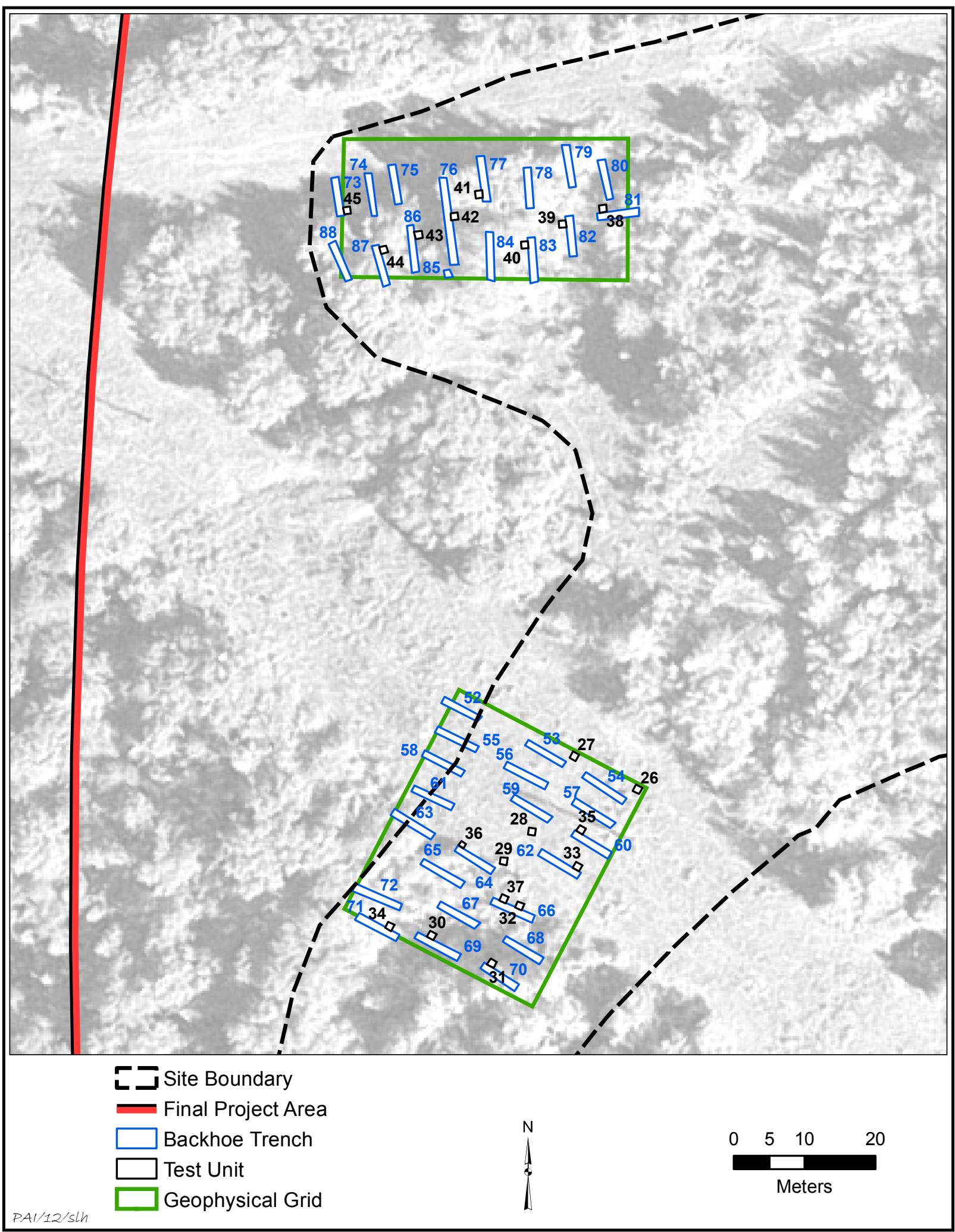

Figure 2.17. Aerial photograph of 41TT852, Subareas 3 (south) and 4 (north), showing geophysical survey grids and test excavations. 
that described above but without an E horizon. In the center western portion (Trenches 31 , $35,38,39,42-44,46,47$, and 49 and to a lesser extent Trenches 22 and 23), profiles illustrated some disturbance likely due to timber clearing and maintenance of the utility line running through the center of Subarea 1. In this area, profiles had A1-A2-Bt horizons with mottling in the $\mathrm{A} 2$ and $\mathrm{Bt}$ horizons. Here, the $\mathrm{A} 1$ horizon was 10-17-cm-thick dark brown (10YR 3/3) to dark yellowish brown (10YR 3/4) fine sand. The A2 horizon was 10-15-cm-thick dark yellowish brown (10YR 3/6) mottled with dark yellowish brown (10YR 4/4), yellowish brown (10YR 5/4), and pale brown (10YR 6/3) sand. The Bt horizon soils were well-structured strong brown (7.5YR 5/8) mottled with pale brown (10YR 7/4) clay.

The profiles of six trenches in Subarea 3 were described. Like Subarea 1, Subarea 3 had areas of shallower deposits with A-Bt or A1-A2Bt horizons and areas of thicker sandy deposits with A-E-Bt horizons. The areas of thicker sands (Trenches 59 and 64-69) correlate with a rise in the landscape at the center of the grid. Here, the A horizon was 12-15-cm-thick dark yellowish brown (10YR 4/6) fine sand. The E horizon was 12-27-cm-thick yellowish brown (10YR 5/6) fine sand. The Bt horizon was firm well-structured strong brown (7.5YR 5.8) clay. Very shallow deposits were found along the west edge of the grid where the site slopes to the northwest, and this area exhibited an A-Bt soil profile. In this area (Trenches 52, 53, 55, 58, 61, and 63), the A horizon was 5-12-cm-thick dark yellowish brown (10YR 3/4, 4/4) sand. The Bt horizon was very firm yellowish red (5YR 5/8) well-structured clay. Along the other edges of the area, the excavations portrayed A1-A2-Bt profiles. The A1 horizon was 10-12-cm-thick dark yellowish brown (10YR 3/4) very fine sand. The A2 horizon was 8-14-cm-thick dark yellowish brown (10YR $4 / 4,4 / 6)$ sand. The Bt horizon was firm strong brown (7.5YR 5/8) well-structured clay.

The profiles of seven trenches in Subarea 4 were described and were similar to Subarea 3 , with A-E-Bt profiles in the deeper sands along the crest of the ridge through the center of the grid and A-Bt soil profiles on the edges where shallower deposits occur. The A horizon was 8-22-cm-thick dark yellowish brown (10YR 3/4, $4 / 4$, or $4 / 6$ ) fine sand. Where present, the E horizon was 8-15-cm-thick yellowish brown (10YR $5 / 4,5 / 8)$ sand. The Bt horizon was well-struc- tured strong brown (7.5YR 4/6 to 5/8) clay. Soils along the northern edge of the grid were not examined since a gasoline pipeline ran along this area and limited excavations there.

\section{Cultural Features}

Investigation of the anomalies identified during geophysical survey failed to find cultural origins for them, except perhaps for anthropogenically enriched midden deposits in Subarea 1. Other than the midden deposits, 22 cultural features were found in Subarea 1 and 3 in Subarea 3 (Table 2.8). Most $(\mathrm{n}=19)$ were interpreted as postholes or possible postholes. The others consisted of a pit, a posthole or smudge pit, 2 large postholes or pits, a sherd cluster, and a fire-cracked rock scatter. Eighteen of the Subarea 1 features were in the southeast corner of the grid in Trench 4 and adjacent Test Units 6 and 9 (Figure 2.18). The others were in Trenches $12,31,43$, and 50 and were dispersed across the south half of the grid. The Subarea 1 features are discussed in more detail in Chapter 5 together with those documented during subsequent data recovery efforts.

Four radiocarbon dates were obtained from feature contexts in Subarea 1. Two from pit Feature 13 had corrected radiocarbon ages of $400 \pm 40$ B.P. (Beta-242378; ${ }^{13} \mathrm{C} /{ }^{12} \mathrm{C}$ Ratio $=-24.2$ ) and $840 \pm 40$ B.P. (Beta-242379; ${ }^{13} \mathrm{C} /{ }^{12} \mathrm{C}$ Ratio = -26.3), with calibrated two-sigma date ranges of A.D. 1430-1530/1560-1630 and 1060-1080/1150-1270. A date from posthole or smudge pit Feature 14 had a corrected age of $350 \pm 40$ B.P. $\left(\right.$ Beta $-242380 ;{ }^{13} \mathrm{C} /{ }^{12} \mathrm{C}$ Ratio $\left.=-26.7\right)$ and a two sigma-range of 1450-1650. Possible posthole Feature 15 yielded a date with a corrected age of $410 \pm 40$ B.P. (Beta-242381; ${ }^{13} \mathrm{C} /{ }^{12} \mathrm{C}$ Ratio $=-26.0$ ) and a two-sigma range of 1430-1520/1580-1630.

The three Subarea 3 features consist of possible posthole Features 42 and 43 in Test Unit 28 in the north-central part of the grid and fire-cracked rock Feature 48 in the south-central part (Figure 2.19). Features 42 and 43 were small to medium-sized circular disturbances that extended only $4-6 \mathrm{~cm}$ into the Bt horizon; their shallow depths prevented certain identification. Feature 48 was a very light scatter of fire-cracked rocks in Trench 66. It was shallowly buried in thin sands, with the rocks resting on the Bt horizon in most places. It was severely 
Table 2.8. Cultural features found in testing at 41TT852

\begin{tabular}{|c|c|c|c|c|c|}
\hline Subarea & Feature & Provenience & Type & Dimensions & $\begin{array}{l}\text { Depth Below Surface } \\
\text { (top and bottom) }\end{array}$ \\
\hline 1 & 1 & BHT 4 & sherd cluster & $40 \times 27 \mathrm{~cm}$ & $19-39 \mathrm{~cm}$ \\
\hline 1 & 4 & BHT 12 & large posthole or pit & $31 \times 33 \mathrm{~cm}$ & $36-46 \mathrm{~cm}$ \\
\hline 1 & 13 & TUs 6 and 9 & pit & $100 \times 69 \mathrm{~cm}$ & $30-37 \mathrm{~cm}$ \\
\hline 1 & 14 & TU 6 & posthole or smudge pit & $22 \times 15 \mathrm{~cm}$ & $28-40 \mathrm{~cm}$ \\
\hline 1 & 15 & BHT 31 & possible posthole & $26 \times 20 \mathrm{~cm}$ & $23-47 \mathrm{~cm}$ \\
\hline 1 & 19 & BHT 43 & possible posthole & $39 \times 26 \mathrm{~cm}$ & $5-35 \mathrm{~cm}$ \\
\hline 1 & 21 & BHT 50 & posthole & $13 \times 10 \mathrm{~cm}$ & $23-42 \mathrm{~cm}$ \\
\hline 1 & 23 & BHT 4 & posthole & $25 \times 25 \mathrm{~cm}$ & $35-43 \mathrm{~cm}$ \\
\hline 1 & 24 & TU 9 & posthole & $18 \times 25 \mathrm{~cm}$ & $30-54 \mathrm{~cm}$ \\
\hline 1 & 25 & TU 9 & large posthole or pit & $25 \times 24 \mathrm{~cm}$ & $35-43 \mathrm{~cm}$ \\
\hline 1 & 30 & TU 9 & posthole & $20 \times 20 \mathrm{~cm}$ & $37-62 \mathrm{~cm}$ \\
\hline 1 & 31 & BHT 4 & posthole & $22 \times 19 \mathrm{~cm}$ & $39-56 \mathrm{~cm}$ \\
\hline 1 & 32 & BHT 4 & posthole & $16 \times 16 \mathrm{~cm}$ & $30-42 \mathrm{~cm}$ \\
\hline 1 & 33 & BHT 4 & posthole & $23 \times 23 \mathrm{~cm}$ & $42-53 \mathrm{~cm}$ \\
\hline 1 & 34 & BHT 4 & posthole & $13 \times 13 \mathrm{~cm}$ & $43-54 \mathrm{~cm}$ \\
\hline 1 & 35 & BHT 4 & posthole & $21 \times 15 \mathrm{~cm}$ & $40-58 \mathrm{~cm}$ \\
\hline 1 & 36 & BHT 4 wall & posthole & $19 \times 14 \mathrm{~cm}$ & $40-56 \mathrm{~cm}$ \\
\hline 1 & 37 & BHT 4 & posthole & $18 \times 15 \mathrm{~cm}$ & $37-44 \mathrm{~cm}$ \\
\hline 1 & 38 & BHT 4 & posthole & $25 \times 23 \mathrm{~cm}$ & $32-47 \mathrm{~cm}$ \\
\hline 1 & 39 & BHT 4 & posthole & $21 \mathrm{x} 16 \mathrm{~cm}$ & $32-50 \mathrm{~cm}$ \\
\hline 1 & 40 & BHT 4 wall & posthole & $15 \mathrm{~cm}(\mathrm{E} / \mathrm{W})$ & $15-37 \mathrm{~cm}$ \\
\hline 1 & 41 & BHT 4 & posthole & $20 \times 20 \mathrm{~cm}$ & $42-62 \mathrm{~cm}$ \\
\hline 3 & 42 & TU 28 & possible posthole & $19 \times 18 \mathrm{~cm}$ & $38-44 \mathrm{~cm}$ \\
\hline 3 & 43 & TU 28 & possible posthole & $13 \times 11 \mathrm{~cm}$ & $38-42 \mathrm{~cm}$ \\
\hline 3 & 48 & BHT 66, TU 37 & fire-cracked rock scatter & $183 \times 160 \mathrm{~cm}$ & $7-15 \mathrm{~cm}$ \\
\hline
\end{tabular}

disarticulated and scattered with rocks spaced up to $80 \mathrm{~cm}$ apart. The only real grouping was in Test Unit 37, which was excavated to further expose the feature. In this unit, there were 13 fire-cracked rocks weighing $1.8 \mathrm{~kg}$; another 12 or so rocks were left in Trench 66 and not included in the weight.

\section{Artifact Assemblage}

\section{Subarea 1}

Cultural materials were recovered from 22 auger tests, all test units, 35 backhoe trenches, and 18 cultural features in Subarea 1 (see Table 2.7). Recovery included a complete small ceramic bottle, one reconstructed partial ceramic vessel, 1,600 prehistoric ceramic sherds, 41 chipped stone tools, 626 pieces of debitage, 15 cores, $6 \mathrm{ground} / \mathrm{battered}$ stone tools, $843.3 \mathrm{~g}$ of wat- tle-impressed daub, $139.7 \mathrm{~g}$ of burned clay, and at least $0.36 \mathrm{~kg}$ of burned rocks. Also recovered were 58 vertebrate faunal elements and $34.36 \mathrm{~g}$ of carbonized macrobotanical material. Most of these materials are discussed in more detail in Chapter 5 along with materials found in subsequent data recovery excavations, although a small number (80 sherds, 19 flakes, a Gary dart point, and a Dalton dart point) are omitted because they were not collected.

Artifacts were most frequent in the southeast quadrant of the geophysical grid. The 9 units in this area (Test Units 6, 9, 15-17, and 22-25) contained 45 percent of the ceramic and lithic artifacts recovered from the Subarea 1 test units, for a density of 78 artifacts $/ \mathrm{m}^{2}$. These units also yielded much of the wattle-impressed daub, burned clay, and faunal material retrieved from the Subarea 1 test units. Artifacts were moderately frequent in test units in the northeast and 


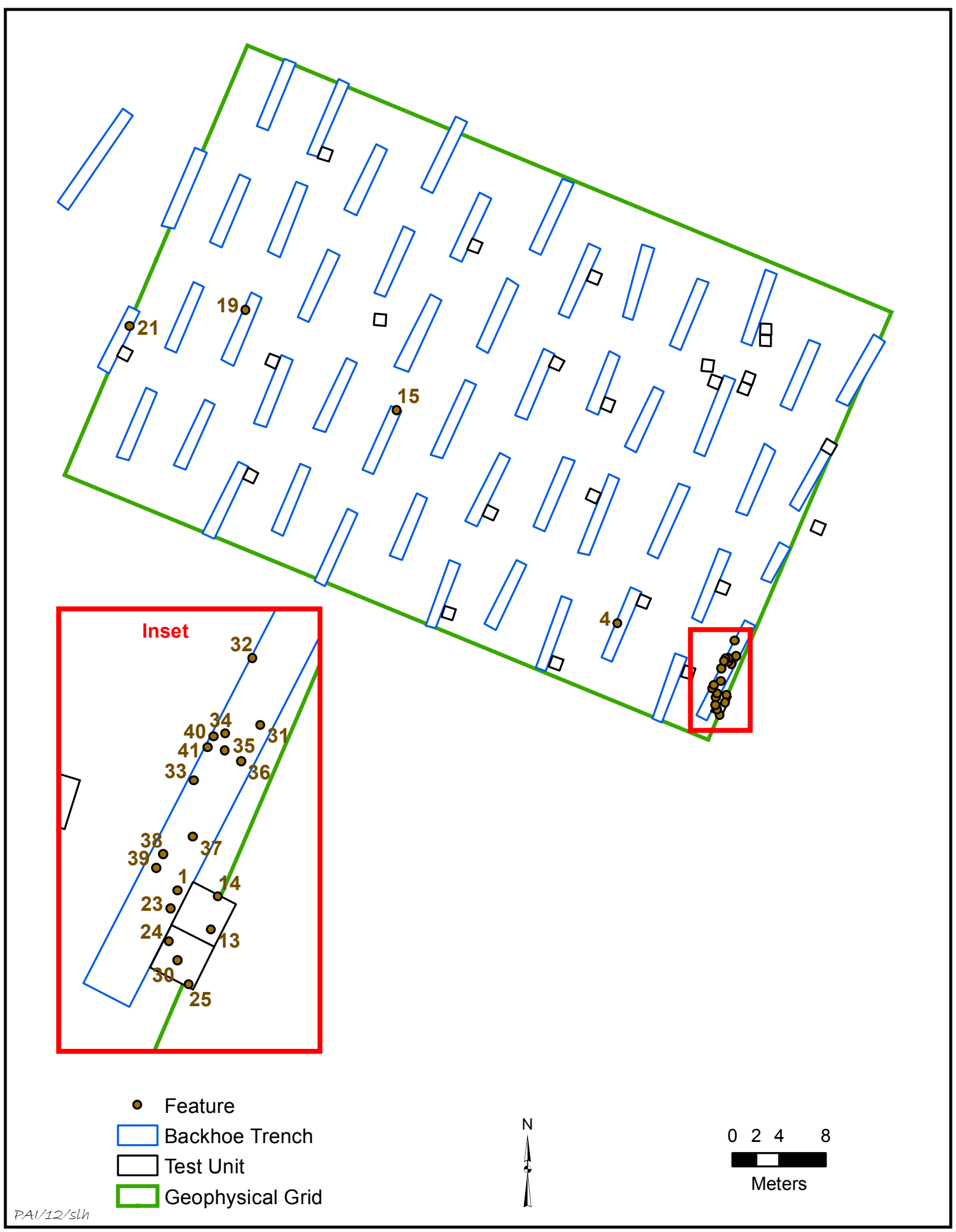

Figure 2.18. Plan of the tested area at 41TT852, Subarea 1, showing feature locations. 


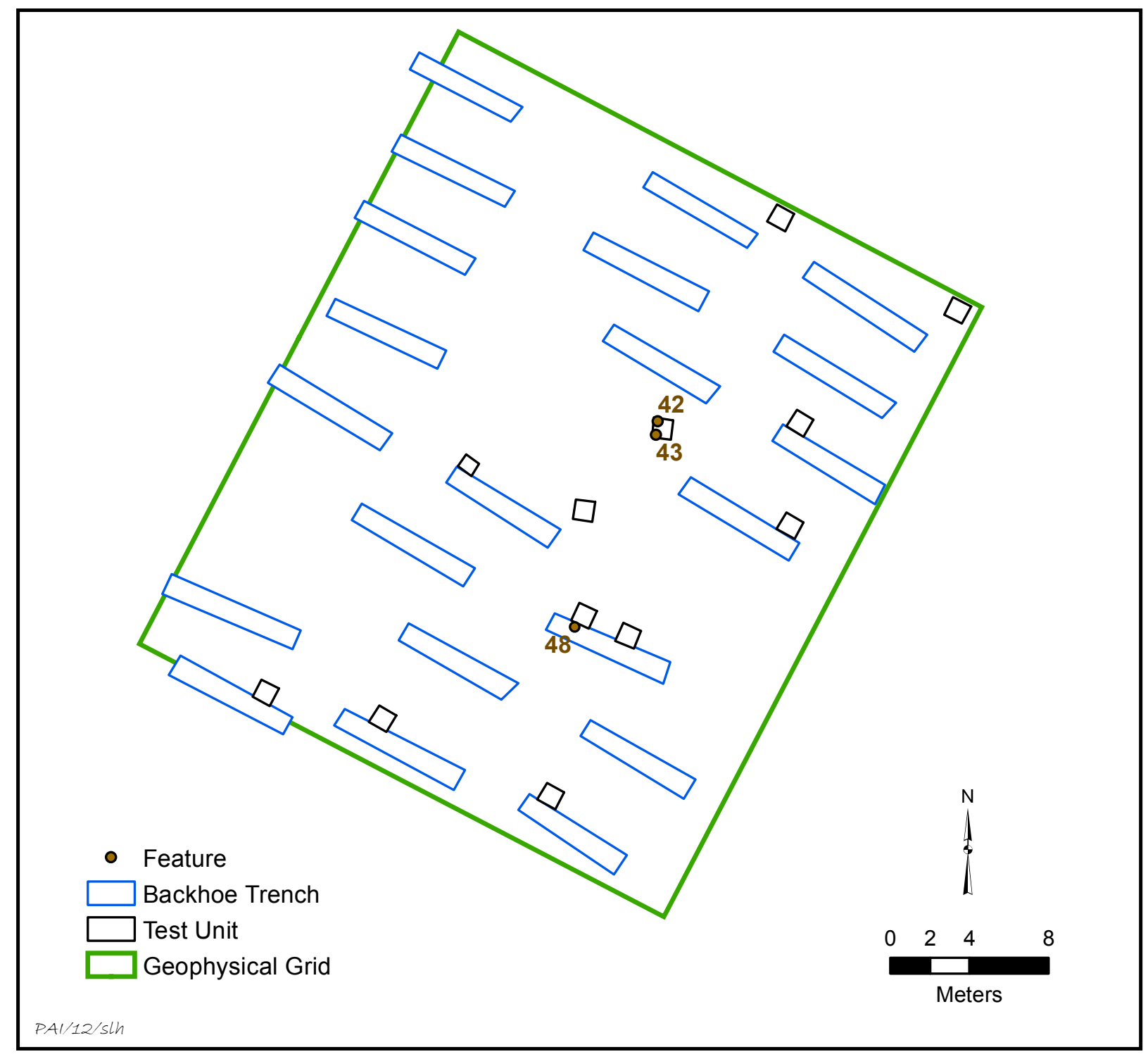

Figure 2.19. Plan of the tested area at 41TT852, Subarea 3, showing feature locations.

northwest quadrants, with the 14 units in those areas (Test Units 1-5, 7, 11-14, 19-21, and 46) having ceramic and lithic artifact densities of $55 / \mathrm{m}^{2}$. Artifacts were least frequent in the southwest quadrant; Test Units 8,10 , and 18 there had an average density of 34 artifacts $/ \mathrm{m}^{2}$.

Vertically, 97 percent of all artifacts were recovered between 0 and $40 \mathrm{~cm}$ below the surface, which correlates with the average depth to the Bt horizon in Subarea 1. Artifact recovery from nonfeature contexts in Subarea 1 test units was as follows: 25 percent at $0-10 \mathrm{~cm} ; 36$ percent at $10-20 \mathrm{~cm} ; 24$ percent at $20-30 \mathrm{~cm} ; 12$ percent at $30-40 \mathrm{~cm} ; 2$ percent at $40-50 \mathrm{~cm}$; and 1 percent at $50-60 \mathrm{~cm}$.

\section{Subarea 2}

Fifteen pieces of debitage, a ground stone fragment, and three burned rocks were recovered from five auger tests in Subarea 2. Only 4 pieces of debitage were collected; the remaining 11 pieces were left at the site. These 4 are small to medium in size and made of local materials 
( 1 chert, 2 silicified wood, and 1 quartzite). The ground stone artifact consists of several pieces of thermally fractured quartzite from Auger Test 58 that refit to form a larger specimen with a ground, smoothed surface and a second facet remnant with percussion marks; its primary function is unknown.

\section{Subarea 3}

Cultural materials were recovered from 11 auger tests, all test units, 5 trenches, and 1 cultural feature in Subarea 3 (see Table 2.7). These consist of 101 prehistoric ceramic sherds, 9 chipped stone tools, 179 pieces of debitage, 2 cores, 3 ground/battered stone tools, $9.1 \mathrm{~g}$ of burned clay, $2.76 \mathrm{~kg}$ of burned rocks, 3 faunal bone fragments, and $1.60 \mathrm{~g}$ of carbonized plant material.

Of the 96 total sherds (508 g; excluding 5 sherds not collected from auger tests), 42 (392 g) are large enough for analysis. These consist of 33 vessel body sherds, 3 carinated body sherds, 3 rim sherds, 1 neck sherd, 1 base sherd, and 1 indeterminate sherd. Thirty-one have grog temper alone, 8 have grog and bone, 2 have voids probably representing leached bone as well as grog and bone, and 1 has bone alone. Interior surfaces are generally floated $(\mathrm{n}=24)$, and exterior surfaces are commonly smoothed $(\mathrm{n}=19)$ or floated $(n=14)$. One sherd is burnished on both the interior and exterior surfaces, and 1 neck sherd has a scraped interior suggesting it is part of an olla. One body sherd has red slip on both its interior and exterior surfaces. The carinated body sherds and 1 of the rims indicate that bowls also are represented. The single bowl rim is everted with a folded lip and a rim thickness of $4.12 \mathrm{~mm}$. The other 2 rims are indeterminate as to form, but they also have folded lips and they are thicker at 6.40 and $7.60 \mathrm{~mm}$. The single neck sherd is $8.79 \mathrm{~mm}$ thick. The single base sherd is of indeterminate form and is $10.51 \mathrm{~mm}$ thick.

Fifteen sherds are decorated: 11 brushed, 2 engraved, and 2 punctated. The engraved sherds have rectilinear lines, horizontal lines, and crosshatching; 1 could be part of a slanted scroll motif but cannot be typed (Figure 2.20a). One sherd has a line of punctations but cannot be identified with any particular motif or type. This assemblage, with its high incidence of brushing (Figure 2.20b), is consistent with Middle-Late Caddo occupation, although it is too small to be very diagnostic.
The chipped stone tools are an arrow point preform, two untyped dart points, three bifaces, and a core tool/knife (excludes 2 tools not collected from auger tests). The arrow point preform, from Level 2 of Test Unit 35, is triangular and roughly shaped (Figure $2.20 \mathrm{c}$ ); it is missing a portion of the base. It is made of dark reddish brown local chert. One untyped dart point is complete, with a fracture on one side, and has a convex base and a straight stem (Figure 2.20d). It appears to have been aborted during manufacture and is of yellowish brown chert; it was recovered from Level 2 of Test Unit 29 . The second untyped dart point is a small proximal fragment with a convex base and contracting stem (Figure 2.20e); it is made of light brown chert and is from Level 1 of Test Unit 37. An early-stage proximal quartzite biface fragment from Level 1 of Test Unit 37 is very crude. A middle-stage lateral biface fragment of local chert is from Feature 48 in Test Unit 37; and a proximal fragment of an indeterminate quartzite biface is from Level 2 of Test Unit 29 (Figure 2.20f). The core tool/knife made of silicified wood is from Trench 24 .

The cores consist of an irregular flake core of silicified wood and a local chert core fragment. The 160 pieces of debitage collected (excludes 19 pieces not collected from auger tests) are dominated by local materials ( 98 percent). Fiftynine percent are quartzite, 29 percent are local chert, and 17 percent are silicified wood; quartz, ferruginous sandstone, and hematite account for 1 percent each. The ferruginous sandstone and hematite are likely from the production or use of ground stone tools. Nonlocal materials consist of 2 flakes of gray chert and 1 flake of white chert. The debitage is mostly small to medium-sized, with 68 percent less than $19.0 \mathrm{~mm}$. This indicates that late reduction and tool production activities are represented with most early-stage reduction probably occurring off-site.

The ground/battered stone tools are a hammerstone, a pitted hammerstone, and an indeterminate fragment, all of quartzite. The irregular hammerstone fragment, from Test Unit 27 , has battering damage on narrow margin remnants and a small smooth area adjacent to a battered edge that is derived from grinding/ abrasion wear. Broad, shallow percussion marks are visible in the cortical surface of the opposite face. Facet morphology suggests that this small tool was used in conjunction with an anvil to 


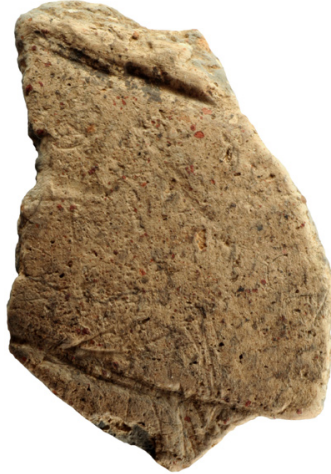

a

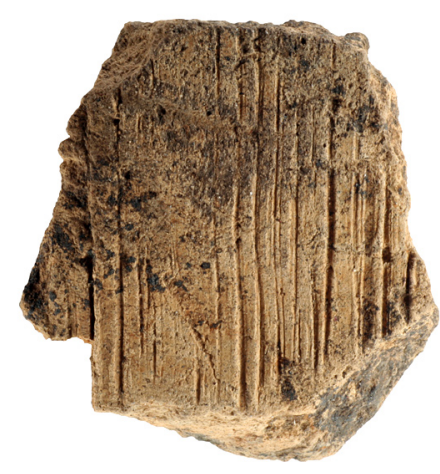

b
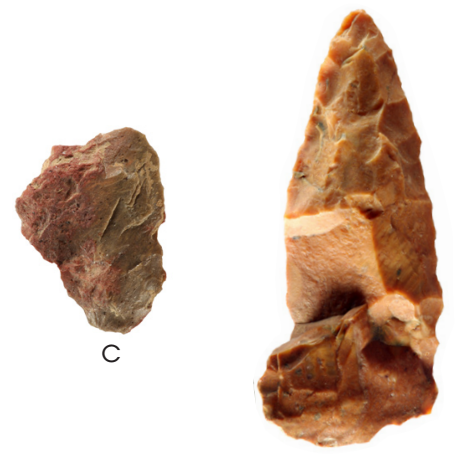

d

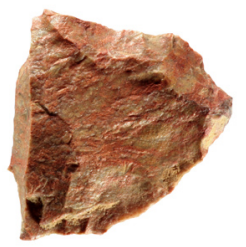

f

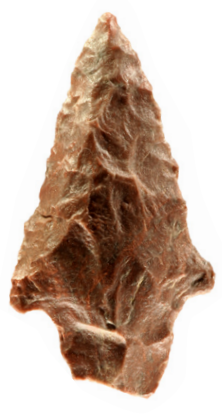

g

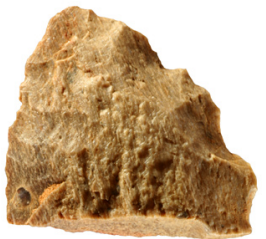

k

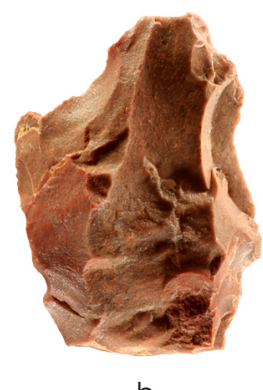

h
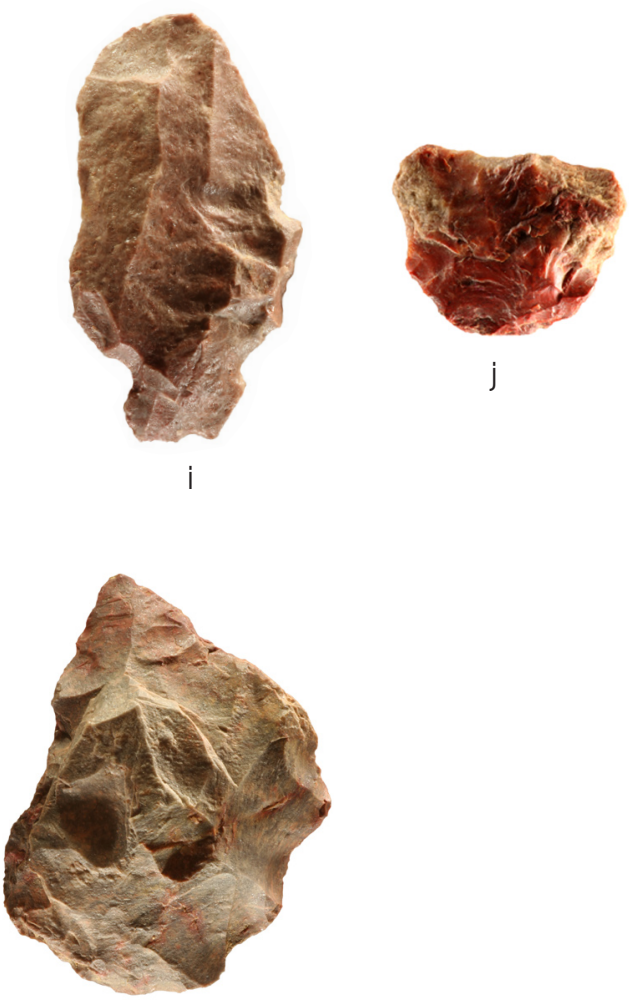

I

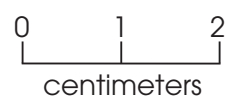

Figure 2.20. Artifacts recovered in testing in Subareas 3 and 4 at 41TT852. (a) Engraved body sherd with possible slanted scroll motif from Subarea 3; (b) brushed body sherd from Subarea 3; (c) arrow point preform from Subarea 3; (d-e) untyped dart points from Subarea 3; (f) proximal fragment of indeterminate biface from Subarea 3; (g) Gary or Kent dart point from Subarea 4; (h) Gary dart point preform from Subarea 4; (i) projectile point preform from Subarea 4; (j) possible gunflint from Subarea 4; (k-l) bifacial knives from Subarea 4. 
crush or pulverize material. The pitted hammerstone, from Trench 62 , is a roughly ovate cobble with percussion marks and battering damage at both ends. Impact-derived flake and fragment removal is apparent on one end and on the side of the cobble. Concentrated percussion marks forming incipient pitting are apparent in two places on the artifact's surface. A natural depression on the surface also may have been used for crushing/pulverizing. Variable surface smoothing is evident around each of those areas. Wear and incipient pitting on a thermally fractured fragment from Trench 64 suggest that this artifact was used in conjunction with an anvil. The smooth faces also indicate grinding/ abrasion-derived wear. The primary function of this artifact is indeterminate.

Test Unit 29 in the center of the grid and Test Unit 27 at the north edge had the highest artifact counts. Most of the other units had moderately low frequencies, with Test Units 30, 31, and 34 at the south edge having especially low counts. Apparently, whatever activities occurred in this part of 41TT852 did not extend south toward the nose of this interfluve. Vertically, 97 percent of the test unit assemblage was recovered between 0 and $30 \mathrm{~cm}$ below the surface, and 100 percent was recovered from 0 to $40 \mathrm{~cm}$. Test unit artifact recovery was as follows: 29 percent at $0-10 \mathrm{~cm} ; 45$ percent at $10-20 \mathrm{~cm} ; 23$ percent at $20-30 \mathrm{~cm}$; and 3 percent at $30-40 \mathrm{~cm}$.

\section{Subarea 4}

Cultural materials were recovered from the surface in and around the Subarea 4 grid and from 10 auger tests, all 8 test units, and 8 trenches (see Table 2.7). Recovery consisted of 54 prehistoric ceramic sherds, 9 chipped stone tools, 193 pieces of debitage, 5 cores, 1 ground/ battered stone tool, $1.8 \mathrm{~g}$ of burned clay, and at least $1.23 \mathrm{~kg}$ of burned rock.

Of the 54 total sherds (126 g), 11 (56 g) are large enough for analysis. These consist of 10 vessel body sherds and 1 carinated body sherd. Ten have grog temper alone, and 1 has grog and bone. Interior and exterior surfaces are floated or smoothed, except for 1 sherd that is burnished on both. The only identified vessel form is a bowl, based on the carinated sherd. Four sherds are decorated, 2 with brushing and 2 with engraving. The engraved sherds have curvilinear lines and crosshatching, but they are not large enough to allow motifs and types to be identified. This assemblage is too small to be very diagnostic.

The chipped stone tools are 1 Gary or Kent dart point, 1 Gary dart point preform, 1 other point preform, 1 gunflint, 2 bifacial knives, 1 late-stage biface, and 1 edge-modified knife (excludes 1 tool not collected from an auger test). The Gary or Kent dart point is missing the base but has a straight to contracting stem and a triangular blade (Figure $2.20 \mathrm{~g}$ ). It is of dark reddish brown chert and was recovered from Level 2 of Test Unit 41. The Gary preform is a proximo-medial fragment with a convex base, a contracting stem, and an irregular blade that is missing the tip (Figure 2.20h). It appears to be an aborted preform based on the break and is made of reddish brown local chert; it is from Level 3 of Test Unit 41. Another preform, that is either for an arrow or dart point, is complete with a straight base, an expanding stem, and an irregular blade (Figure 2.20i). It is made of reddish brown chert on a flake blank and was recovered from Level 1 of Test Unit 45. The gunflint is made on a flake with cortex covering most of the dorsal side and is irregular in shape (Figure 2.20j). It has bifacial retouch on two edges, unifacial retouch on the other edge, and wear indicative of use as a gunflint on one and perhaps two edges. It was recovered from the surface and is made of a local red chert. One of the bifacial knives is the distal end of a well-made tool (Figure 2.20k). It is made of silicified wood and is from Level 4 of Test Unit 40. The other bifacial knife is an irregular but complete tool with hinge fractures on the blade faces (Figure 2.201). It is made of dark brown and reddish brown local chert and is from Level 3 of Test Unit 40. A small complete late-stage biface was recovered from Level 1 of Test Unit 44. It is made of dark reddish brown chert. The single edge-modified flake knife is from Trench 77 and is made of silicified wood.

The cores consist of 4 flake cores of silicified wood and 1 tested cobble of quartzite. The 180 pieces of debitage collected (excludes 13 pieces not collected from auger tests) are dominated by local materials (98 percent), mostly quartzite and chert as well as silicified wood. A few pieces are ferruginous sandstone and hematite and probably are the byproduct of manufacturing and use of ground or battered stone tools such as hammerstones, celts, and manos. The nonlocal materials consist of 2 flakes of gray chert and 1 
flake of chalcedony. In size, the debitage ranges fairly evenly from 7 to $38 \mathrm{~mm}$, with the most (38 percent) between 12.5 and $19.0 \mathrm{~mm}$, reflecting late-stage reduction and use of somewhat small source materials.

The single ground/battered stone tool is a pitted hammerstone fragment from Trench 83. One face on this thermally fractured cobble exhibits clear pitting and battering wear. Subtle percussion marks and incipient pitting are visible on the opposite face. Wear indicates use in conjunction with an anvil.

Test Units 44 and 45 on the west side of the geophysical survey grid contained the highest artifact counts. Test Unit 39 in the east-central portion also had a relatively high chipped stone artifact count. Vertically, 97 percent of the artifacts from test units were recovered between 0 and $30 \mathrm{~cm}$ below the surface. Artifact recovery by level was as follows: 24 percent at $0-10 \mathrm{~cm}$; 52 percent at $10-20 \mathrm{~cm} ; 21$ percent at $20-30 \mathrm{~cm}$; and 3 percent at $30-40 \mathrm{~cm}$.

\section{Conclusions}

The tested parts of 41TT852 appeared to have seen varying histories of use. Caddo materials were present in all three areas where intensive testing was done but frequent only in Subarea 1. Based on the presence of midden deposits, numerous features, a sizeable ceramic assemblage, wattle-impressed daub, and the radiocarbon dates, Subarea 1 appeared to contain a Late Caddo Titus phase farmstead dating to the A.D. 1400s-1600s. It was considered likely that this farmstead was represented by several houses and associated outside activity areas. Dart points indicated some earlier occupation, but the remains of this earlier use were not isolable into interpretable components.

With the presence of matrix-defined features and ample datable carbon, the archeological deposits in Subarea 1 were judged to have sufficient integrity to allow for productive analyses. Additionally, proximity to similar residential loci at 41TT851 and 41TT853 suggested that Subarea 1 was part of a larger Caddo community on this part of Tankersley Creek. Thus, the archeological deposits here were considered to contain information relevant to the larger prehistoric community. Given the information potential represented by the deposits, Subarea 1 was considered eligible for inclusion in the
National Register and designation as a State Antiquities Landmark. Since it was not a candidate for preservation in place, data recovery excavations were recommended to mitigate the adverse impacts of the proposed project.

Testing results indicated that Subareas 3 and 4 also had pre-Caddo components, as well as components contemporaneous with the Late Caddo occupation in Subarea 1. These parts of $41 \mathrm{TT} 852$ were hard to interpret, however, because features were infrequent, artifacts were comparatively sparse, and no charcoal for radiocarbon dating was recovered. These areas were characterized by multiple components that could not be isolated from one another and represented ephemeral, probably nonresidential use. Based on these characteristics, it was concluded that these parts of 41TT852 lacked the capacity to contribute important information and were not eligible for listing in the National Register or designation as a State Antiquities Landmark. Hence, no further work was planned for these parts of the site.

\section{SITE 41TT853}

Site 41 TT 853 is on a wooded upland surface and adjacent sideslope along the dissected eastern margin of the Tankersley Creek valley (Figure 2.21). Intermittent west-flowing tributaries are north and south of the site. A stock pond is immediately northeast of it. The landform slopes down moderately to the southwest. AEC excavated six shovel tests at 41TT853 in 2002. Seventeen sherds, 19 pieces of lithic debris, a flake tool, and a core were recovered from five tests during this effort (Perttula et al. 2002). The site was estimated to cover $14,850 \mathrm{~m}^{2}$. It was entirely within the project corridor as of the 2005 auger testing and remained so throughout the project.

\section{Auger Testing}

Forty-one auger tests were excavated at 41TT853. Thick vegetation, steep slopes, and exposed subsoil in various parts of the site resulted in irregular spacing of the tests. Fifty-one ceramic sherds, 33 pieces of debitage, 2 burned rocks, and daub were collected from 18 tests (Table 2.9). The majority of this material was from a $50 \times 60-\mathrm{m}$ area in the southwest portion of the site, near the base of the upland slope. Ten 


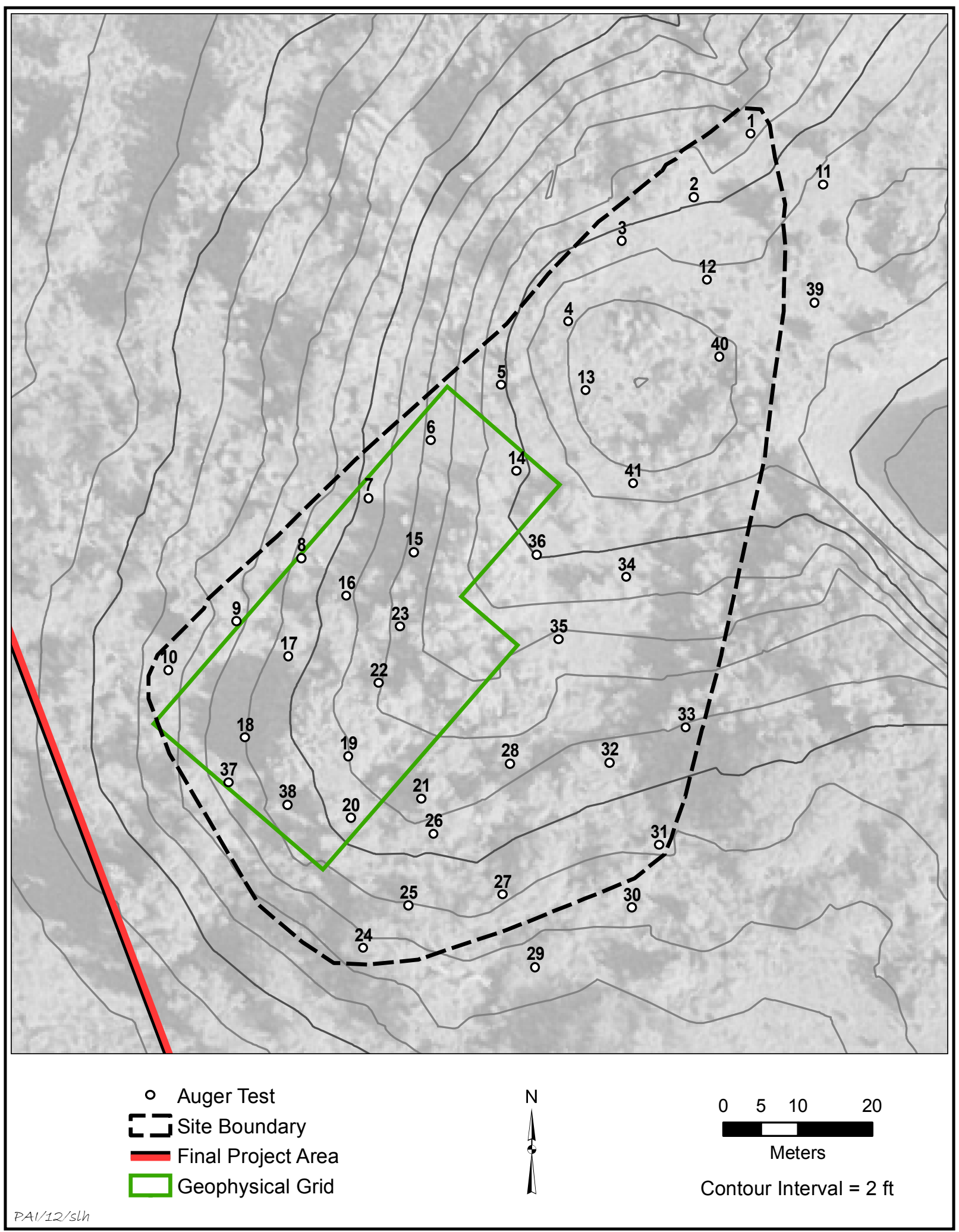

Figure 2.21. Map of 41TT853 showing topography, auger test locations, and geophysical survey grid on 2005 aerial imagery. 
Table 2.9. Artifacts recovered in auger and intensive testing at 41 TT853

\begin{tabular}{|c|c|c|c|c|c|c|c|c|}
\hline Provenience & $\begin{array}{c}\text { Chipped } \\
\text { Stone } \\
\text { Tool } \\
\end{array}$ & Debitage & Core & $\begin{array}{c}\text { Ground } \\
\text { Stone } \\
\text { Tool } \\
\end{array}$ & Sherd & Bone & Other & Totals \\
\hline Auger Test 1 & 0 & 0 & 0 & 0 & 1 & 0 & 0 & 1 \\
\hline Auger Test 4 & 0 & 1 & 0 & 0 & 2 & 0 & 0 & 3 \\
\hline Auger Test 5 & 0 & 4 & 0 & 0 & 1 & 0 & 0 & 5 \\
\hline Auger Test 8 & 0 & 1 & 0 & 0 & 2 & 0 & 0 & 3 \\
\hline Auger Test 13 & 0 & 2 & 0 & 0 & 1 & 0 & 0 & 3 \\
\hline Auger Test 15 & 0 & 0 & 0 & 0 & 1 & 0 & 0 & 1 \\
\hline Auger Test 16 & 0 & 4 & 0 & 0 & 9 & 0 & 0 & 13 \\
\hline Auger Test 17 & 0 & 1 & 0 & 0 & 2 & 0 & 0 & 3 \\
\hline Auger Test 18 & 0 & 8 & 0 & 0 & 17 & 0 & 0 & 25 \\
\hline Auger Test 19 & 0 & 2 & 0 & 0 & 1 & 0 & 0 & 3 \\
\hline Auger Test 20 & 0 & 0 & 0 & 0 & 1 & 0 & 0 & 1 \\
\hline Auger Test 21 & 0 & 2 & 0 & 0 & 7 & 0 & 0 & 9 \\
\hline Auger Test 23 & 0 & 3 & 0 & 0 & 3 & 0 & 0 & 6 \\
\hline Auger Test 24 & 0 & 3 & 0 & 0 & 1 & 0 & 0 & 4 \\
\hline Auger Test 25 & 0 & 0 & 0 & 0 & 4 & 0 & 0 & 4 \\
\hline Auger Test 28 & 0 & 1 & 0 & 0 & 0 & 0 & 0 & 1 \\
\hline Auger Test 31 & 0 & 1 & 0 & 0 & 0 & 0 & 0 & 1 \\
\hline Auger Test 40 & 0 & 0 & 0 & 0 & 1 & 0 & 0 & 1 \\
\hline \multicolumn{9}{|l|}{ Test Unit 1} \\
\hline $0-10 \mathrm{~cm}$ & 0 & 1 & 0 & 0 & 5 & 0 & 0 & 6 \\
\hline $10-20 \mathrm{~cm}$ & 0 & 6 & 0 & 0 & 10 & 0 & 0 & 16 \\
\hline $20-30 \mathrm{~cm}$ & 0 & 8 & 0 & 0 & 5 & 2 & 0 & 15 \\
\hline $30-35 \mathrm{~cm}$ & 0 & 2 & 0 & 0 & 2 & 0 & 0 & 4 \\
\hline $35-40 \mathrm{~cm}$ & 0 & 0 & 0 & 0 & 1 & 0 & 0 & 1 \\
\hline $40-50 \mathrm{~cm}$ & 0 & 7 & 0 & 0 & 11 & 0 & 0 & 18 \\
\hline $50-60 \mathrm{~cm}$ & 0 & 1 & 0 & 0 & 0 & 0 & 0 & 1 \\
\hline \multicolumn{9}{|l|}{ Test Unit 2} \\
\hline $0-10 \mathrm{~cm}$ & 0 & 12 & 0 & 0 & 7 & 0 & 0 & 19 \\
\hline $10-20 \mathrm{~cm}$ & 1 & 12 & 0 & 0 & 12 & 0 & 0 & 25 \\
\hline $20-30 \mathrm{~cm}$ & 0 & 4 & 0 & 1 & 7 & 0 & 0 & 12 \\
\hline $30-35 \mathrm{~cm}$ & 0 & 5 & 0 & 0 & 8 & 0 & 0 & 13 \\
\hline $35-40 \mathrm{~cm}$ & 1 & 2 & 0 & 0 & 1 & 0 & 0 & 4 \\
\hline $40-50 \mathrm{~cm}$ & 0 & 3 & 1 & 0 & 4 & 0 & 0 & 8 \\
\hline \multicolumn{9}{|l|}{ Test Unit 3} \\
\hline $0-10 \mathrm{~cm}$ & 0 & 3 & 0 & 0 & 4 & 0 & 0 & 7 \\
\hline $10-20 \mathrm{~cm}$ & 0 & 10 & 0 & 0 & 8 & 0 & 0 & 18 \\
\hline $20-25 \mathrm{~cm}$ & 0 & 14 & 0 & 0 & 1 & 0 & 0 & 15 \\
\hline $25-30 \mathrm{~cm}$ & 0 & 4 & 0 & 0 & 2 & 0 & 0 & 6 \\
\hline $30-40 \mathrm{~cm}$ & 2 & 10 & 1 & 0 & 10 & 0 & 0 & 23 \\
\hline $40-50 \mathrm{~cm}$ & 0 & 0 & 0 & 0 & 0 & 0 & 0 & 0 \\
\hline \multicolumn{9}{|l|}{ Test Unit 4} \\
\hline $0-10 \mathrm{~cm}$ & 0 & 1 & 0 & 0 & 0 & 0 & 0 & 1 \\
\hline $10-20 \mathrm{~cm}$ & 0 & 3 & 0 & 0 & 2 & 0 & 0 & 5 \\
\hline $20-30 \mathrm{~cm}$ & 0 & 5 & 0 & 0 & 5 & 0 & 0 & 10 \\
\hline $30-40 \mathrm{~cm}$ & 0 & 1 & 0 & 0 & 2 & 0 & 0 & 3 \\
\hline $40-50 \mathrm{~cm}$ & 0 & 2 & 0 & 0 & 0 & 0 & 0 & 2 \\
\hline
\end{tabular}


Excavations along the U.S. Highway 271 Mount Pleasant Relief Route

Table 2.9, continued

\begin{tabular}{|c|c|c|c|c|c|c|c|c|}
\hline Provenience & $\begin{array}{c}\text { Chipped } \\
\text { Stone } \\
\text { Tool } \\
\end{array}$ & Debitage & Core & $\begin{array}{c}\text { Ground } \\
\text { Stone } \\
\text { Tool } \\
\end{array}$ & Sherd & Bone & Other & Totals \\
\hline \multicolumn{9}{|l|}{ Test Unit 5} \\
\hline $0-10 \mathrm{~cm}$ & 0 & 0 & 0 & 0 & 0 & 0 & 0 & 0 \\
\hline $10-20 \mathrm{~cm}$ & 0 & 5 & 0 & 0 & 6 & 0 & 0 & 11 \\
\hline $20-30 \mathrm{~cm}$ & 0 & 0 & 0 & 0 & 2 & 0 & 0 & 2 \\
\hline $30-40 \mathrm{~cm}$ & 0 & 2 & 0 & 0 & 3 & 0 & 0 & 5 \\
\hline $40-50 \mathrm{~cm}$ & 0 & 2 & 0 & 0 & 0 & 0 & 0 & 2 \\
\hline $50-60 \mathrm{~cm}$ & 1 & 4 & 0 & 0 & 2 & 0 & 0 & 7 \\
\hline \multicolumn{9}{|l|}{ Test Unit 6} \\
\hline $0-10 \mathrm{~cm}$ & 0 & 0 & 0 & 0 & 0 & 0 & 0 & 0 \\
\hline $10-20 \mathrm{~cm}$ & 0 & 4 & 0 & 0 & 6 & 0 & 0 & 10 \\
\hline $20-30 \mathrm{~cm}$ & 0 & 6 & 0 & 0 & 12 & 0 & 0 & 18 \\
\hline $30-40 \mathrm{~cm}$ & 1 & 3 & 0 & 0 & 6 & 0 & 0 & 10 \\
\hline $40-50 \mathrm{~cm}$ & 0 & 1 & 0 & 0 & 0 & 0 & 0 & 1 \\
\hline \multicolumn{9}{|l|}{ Test Unit 7} \\
\hline $0-20 \mathrm{~cm}$ & 0 & 0 & 0 & 0 & 0 & 0 & 0 & 0 \\
\hline $20-30 \mathrm{~cm}$ & 0 & 0 & 0 & 0 & 0 & 0 & 0 & 0 \\
\hline $30-40 \mathrm{~cm}$ & 0 & 2 & 0 & 0 & 0 & 0 & 0 & 2 \\
\hline $40-50 \mathrm{~cm}$ & 0 & 0 & 0 & 0 & 1 & 0 & 0 & 1 \\
\hline \multicolumn{9}{|l|}{ Test Unit 8} \\
\hline $0-10 \mathrm{~cm}$ & 0 & 2 & 0 & 0 & 6 & 0 & 0 & 8 \\
\hline $10-20 \mathrm{~cm}$ & 1 & 10 & 0 & 0 & 14 & 0 & 0 & 25 \\
\hline $20-30 \mathrm{~cm}$ & 0 & 6 & 0 & 0 & 3 & 0 & 0 & 9 \\
\hline \multicolumn{9}{|l|}{ Test Unit 9} \\
\hline $0-10 \mathrm{~cm}$ & 0 & 5 & 0 & 0 & 3 & 0 & 0 & 8 \\
\hline $10-20 \mathrm{~cm}$ & 0 & 10 & 0 & 0 & 5 & 0 & 0 & 15 \\
\hline $20-30 \mathrm{~cm}$ & 2 & 11 & 0 & 0 & 3 & 0 & 0 & 16 \\
\hline $30-40 \mathrm{~cm}$ & 0 & 3 & 0 & 0 & 0 & 0 & 0 & 3 \\
\hline \multicolumn{9}{|l|}{ Test Unit 10} \\
\hline $0-20 \mathrm{~cm}$ & 1 & 10 & 0 & 0 & 6 & 0 & 0 & 17 \\
\hline $20-30 \mathrm{~cm}$ & 1 & 17 & 0 & 0 & 20 & 0 & 0 & 38 \\
\hline $30-40 \mathrm{~cm}$ & 0 & 18 & 0 & 0 & 8 & 0 & 0 & 26 \\
\hline $40-50 \mathrm{~cm}$ & 1 & 32 & 1 & 0 & 10 & 0 & 0 & 44 \\
\hline $50-60 \mathrm{~cm}$ & 1 & 8 & 1 & 0 & 5 & 0 & 0 & 15 \\
\hline $60-70 \mathrm{~cm}$ & 0 & 4 & 0 & 0 & 0 & 0 & 0 & 4 \\
\hline \multicolumn{9}{|l|}{ Test Unit 11} \\
\hline $0-20 \mathrm{~cm}$ & 0 & 1 & 0 & 0 & 4 & 0 & 0 & 5 \\
\hline $20-30 \mathrm{~cm}$ & 0 & 21 & 0 & 0 & 6 & 0 & 0 & 27 \\
\hline $30-40 \mathrm{~cm}$ & 0 & 16 & 0 & 0 & 10 & 0 & 0 & 26 \\
\hline $40-50 \mathrm{~cm}$ & 0 & 23 & 2 & 0 & 5 & 0 & 0 & 30 \\
\hline $50-60 \mathrm{~cm}$ & 0 & 1 & 1 & 0 & 0 & 0 & 0 & 2 \\
\hline $60-70 \mathrm{~cm}$ & 0 & 0 & 0 & 0 & 0 & 0 & 0 & 0 \\
\hline \multicolumn{9}{|l|}{ Test Unit 12} \\
\hline $0-10 \mathrm{~cm}$ & 0 & 2 & 0 & 0 & 0 & 0 & 0 & 2 \\
\hline $10-20 \mathrm{~cm}$ & 0 & 10 & 0 & 0 & 3 & 0 & 0 & 13 \\
\hline $20-30 \mathrm{~cm}$ & 0 & 8 & 0 & 0 & 7 & 0 & 0 & 15 \\
\hline $30-40 \mathrm{~cm}$ & 0 & 12 & 0 & 0 & 2 & 0 & 0 & 14 \\
\hline Test Unit 13 & & & & & & & & \\
\hline
\end{tabular}


Chapter 2: Testing

Table 2.9, continued

\begin{tabular}{|c|c|c|c|c|c|c|c|c|}
\hline Provenience & $\begin{array}{c}\text { Chipped } \\
\text { Stone } \\
\text { Tool } \\
\end{array}$ & Debitage & Core & $\begin{array}{c}\text { Ground } \\
\text { Stone } \\
\text { Tool }\end{array}$ & Sherd & Bone & Other & Totals \\
\hline $0-10 \mathrm{~cm}$ & 0 & 2 & 0 & 0 & 5 & 0 & 0 & 7 \\
\hline $10-20 \mathrm{~cm}$ & 1 & 2 & 0 & 0 & 3 & 0 & 0 & 10 \\
\hline $20-30 \mathrm{~cm}$ & 0 & 0 & 0 & 0 & 0 & 0 & 0 & 0 \\
\hline \multicolumn{9}{|l|}{ Test Unit 14} \\
\hline $0-10 \mathrm{~cm}$ & 0 & 10 & 0 & 0 & 9 & 0 & 0 & 19 \\
\hline $10-20 \mathrm{~cm}$ & 0 & 5 & 0 & 0 & 17 & 0 & 0 & 22 \\
\hline $20-30 \mathrm{~cm}$ & 1 & 8 & 0 & 0 & 26 & 0 & 0 & 35 \\
\hline $30-40 \mathrm{~cm}$ & 0 & 6 & 0 & 0 & 35 & 11 & 0 & 52 \\
\hline $40-50 \mathrm{~cm}$ & 0 & 1 & 0 & 0 & 12 & 0 & 0 & 13 \\
\hline $50-60 \mathrm{~cm}$ & 0 & 0 & 0 & 0 & 9 & 0 & 0 & 9 \\
\hline \multicolumn{9}{|l|}{ Test Unit 15} \\
\hline $0-10 \mathrm{~cm}$ & 0 & 7 & 0 & 0 & 4 & 0 & 0 & 11 \\
\hline $10-20 \mathrm{~cm}$ & 0 & 20 & 0 & 0 & 11 & 0 & 0 & 31 \\
\hline $20-30 \mathrm{~cm}$ & 0 & 3 & 0 & 0 & 4 & 0 & 0 & 7 \\
\hline $30-40 \mathrm{~cm}$ & 0 & 1 & 0 & 0 & 3 & 0 & 0 & 4 \\
\hline $40-44 \mathrm{~cm}$ & 0 & 0 & 0 & 0 & 0 & 0 & 0 & 0 \\
\hline \multicolumn{9}{|l|}{ Test Unit 16} \\
\hline $0-10 \mathrm{~cm}$ & 1 & 34 & 0 & 0 & 2 & 0 & 0 & 37 \\
\hline $10-20 \mathrm{~cm}$ & 2 & 34 & 0 & 0 & 9 & 0 & 0 & 45 \\
\hline $20-30 \mathrm{~cm}$ & 0 & 30 & 0 & 0 & 5 & 1 & 0 & 36 \\
\hline $30-40 \mathrm{~cm}$ & 1 & 17 & 0 & 0 & 0 & 0 & 0 & 18 \\
\hline $40-50 \mathrm{~cm}$ & 0 & 37 & 1 & 0 & 1 & 0 & 0 & 39 \\
\hline $50-60 \mathrm{~cm}$ & 1 & 24 & 0 & 0 & 0 & 0 & 0 & 25 \\
\hline \multicolumn{9}{|l|}{ Test Unit 17} \\
\hline $0-10 \mathrm{~cm}$ & 0 & 14 & 0 & 0 & 10 & 0 & 0 & 24 \\
\hline $10-20 \mathrm{~cm}$ & 1 & 20 & 0 & 0 & 17 & 0 & 0 & 38 \\
\hline $20-30 \mathrm{~cm}$ & 2 & 12 & 0 & 0 & 12 & 0 & 0 & 26 \\
\hline $30-40 \mathrm{~cm}$ & 1 & 9 & 0 & 0 & 5 & 0 & 0 & 15 \\
\hline $40-48 \mathrm{~cm}$ & 1 & 15 & 0 & 0 & 0 & 0 & 0 & 16 \\
\hline \multicolumn{9}{|l|}{ Test Unit 18} \\
\hline $0-10 \mathrm{~cm}$ & 0 & 7 & 0 & 0 & 4 & 0 & 0 & 11 \\
\hline $10-20 \mathrm{~cm}$ & 0 & 16 & 0 & 0 & 8 & 0 & 0 & 24 \\
\hline $20-30 \mathrm{~cm}$ & 0 & 19 & 0 & 0 & 20 & 0 & 0 & 39 \\
\hline $30-40 \mathrm{~cm}$ & 1 & 14 & 1 & 0 & 25 & 0 & 0 & 41 \\
\hline $40-50 \mathrm{~cm}$ & 2 & 7 & 0 & 0 & 33 & 1 & 0 & 43 \\
\hline $50-60 \mathrm{~cm}$ & 1 & 7 & 0 & 0 & 13 & 0 & 0 & 21 \\
\hline $60-70 \mathrm{~cm}$ & 0 & 10 & 0 & 0 & 7 & 0 & 0 & 17 \\
\hline \multicolumn{9}{|l|}{ Test Unit 19} \\
\hline $0-10 \mathrm{~cm}$ & 0 & 10 & 0 & 0 & 2 & 0 & 0 & 12 \\
\hline $10-20 \mathrm{~cm}$ & 0 & 13 & 0 & 0 & 3 & 0 & 0 & 16 \\
\hline $20-30 \mathrm{~cm}$ & 0 & 17 & 0 & 0 & 6 & 0 & 0 & 23 \\
\hline $30-40 \mathrm{~cm}$ & 1 & 6 & 0 & 0 & 11 & 0 & 0 & 18 \\
\hline $40-50 \mathrm{~cm}$ & 1 & 14 & 0 & 0 & 24 & 0 & 0 & 39 \\
\hline $50-60 \mathrm{~cm}$ & 1 & 15 & 1 & 0 & 10 & 0 & 0 & 27 \\
\hline $60-67 \mathrm{~cm}$ & 1 & 6 & 0 & 0 & 0 & 0 & 0 & 7 \\
\hline \multicolumn{9}{|l|}{ Test Unit 20} \\
\hline $0-10 \mathrm{~cm}$ & 0 & 6 & 0 & 0 & 0 & 0 & 0 & 6 \\
\hline
\end{tabular}


Excavations along the U.S. Highway 271 Mount Pleasant Relief Route

Table 2.9, continued

\begin{tabular}{|c|c|c|c|c|c|c|c|c|}
\hline Provenience & $\begin{array}{c}\text { Chipped } \\
\text { Stone } \\
\text { Tool } \\
\end{array}$ & Debitage & Core & $\begin{array}{c}\text { Ground } \\
\text { Stone } \\
\text { Tool } \\
\end{array}$ & Sherd & Bone & Other & Totals \\
\hline $10-20 \mathrm{~cm}$ & 0 & 9 & 0 & 0 & 3 & 0 & 0 & 12 \\
\hline $20-30 \mathrm{~cm}$ & 1 & 4 & 0 & 0 & 12 & 0 & 0 & 17 \\
\hline $30-40 \mathrm{~cm}$ & 0 & 1 & 0 & 0 & 4 & 0 & 0 & 5 \\
\hline \multicolumn{9}{|l|}{ Test Unit 21} \\
\hline $0-10 \mathrm{~cm}$ & 0 & 13 & 0 & 0 & 3 & 0 & 0 & 16 \\
\hline $10-20 \mathrm{~cm}$ & 0 & 15 & 0 & 0 & 9 & 0 & 0 & 20 \\
\hline $20-30 \mathrm{~cm}$ & 0 & 21 & 0 & 0 & 6 & 0 & 0 & 27 \\
\hline $30-40 \mathrm{~cm}$ & 0 & 13 & 1 & 1 & 1 & 0 & 0 & 16 \\
\hline $40-50 \mathrm{~cm}$ & 0 & 0 & 0 & 0 & 0 & 0 & 0 & 0 \\
\hline $50-60 \mathrm{~cm}$ & 0 & 0 & 0 & 0 & 0 & 0 & 0 & 0 \\
\hline \multicolumn{9}{|l|}{ Test Unit 22} \\
\hline $0-10 \mathrm{~cm}$ & 0 & 0 & 0 & 0 & 2 & 0 & 0 & 2 \\
\hline $10-20 \mathrm{~cm}$ & 0 & 1 & 0 & 0 & 2 & 0 & 0 & 3 \\
\hline $20-30 \mathrm{~cm}$ & 1 & 1 & 0 & 0 & 3 & 0 & 0 & 5 \\
\hline $30-40 \mathrm{~cm}$ & 0 & 1 & 0 & 0 & 0 & 0 & 0 & 1 \\
\hline $40-50 \mathrm{~cm}$ & 0 & 0 & 0 & 0 & 0 & 0 & 0 & 0 \\
\hline \multicolumn{9}{|l|}{ Test Unit 23} \\
\hline $0-10 \mathrm{~cm}$ & 0 & 4 & 0 & 0 & 2 & 0 & 0 & 6 \\
\hline $10-20 \mathrm{~cm}$ & 1 & 4 & 0 & 0 & 1 & 0 & 0 & 6 \\
\hline Feature 2 & 0 & 39 & 2 & 1 & 13 & 1 & 2 vessels & 58 \\
\hline Feature 4 & 2 & 106 & 0 & 0 & 3 & 0 & 0 & 111 \\
\hline Feature 5 & 0 & 4 & 0 & 0 & 0 & 0 & 0 & 4 \\
\hline Feature 6 & 0 & 1 & 0 & 0 & 2 & 23 & 0 & 26 \\
\hline Feature 8 & 0 & 11 & 0 & 0 & 5 & 0 & 0 & 16 \\
\hline Feature 10 & 0 & 1 & 0 & 0 & 37 & 0 & 0 & 38 \\
\hline Feature 12 & 0 & 3 & 0 & 0 & 9 & 0 & 0 & 12 \\
\hline Feature 14 & 0 & 1 & 0 & 1 & 1 & 0 & 0 & 3 \\
\hline Feature 15 & 0 & 1 & 0 & 0 & 0 & 0 & 0 & 1 \\
\hline Feature 16 & 0 & 5 & 0 & 0 & 2 & 0 & 0 & 7 \\
\hline Feature 17 & 5 & 63 & 0 & 0 & 63 & 0 & 0 & 131 \\
\hline Feature 18 & 0 & 3 & 0 & 0 & 3 & 0 & 3 vessels & 9 \\
\hline Feature 19 & 1 & 1 & 0 & 0 & 0 & 0 & 0 & 2 \\
\hline Feature 20 & 0 & 9 & 0 & 0 & 2 & 0 & 0 & 11 \\
\hline BHT 1 & 0 & 1 & 0 & 0 & 1 & 0 & 0 & 2 \\
\hline BHT 2 & 1 & 0 & 0 & 0 & 0 & 0 & 0 & 1 \\
\hline BHT 3 & 0 & 0 & 0 & 0 & 1 & 0 & 0 & 1 \\
\hline BHT 4 & 0 & 5 & 3 & 0 & 1 & 0 & 0 & 9 \\
\hline BHT 6 & 2 & 8 & 1 & 0 & 46 & 0 & 0 & 57 \\
\hline BHT 7 & 0 & 8 & 1 & 0 & 15 & 0 & 0 & 24 \\
\hline BHT 8 & 0 & 9 & 2 & 0 & 32 & 0 & 0 & 43 \\
\hline BHT 9 & 0 & 0 & 1 & 0 & 0 & 0 & 0 & 1 \\
\hline BHT 10 & 1 & 1 & 0 & 0 & 4 & 0 & 0 & 6 \\
\hline BHT 11 & 0 & 2 & 0 & 0 & 5 & 2 & 0 & 9 \\
\hline BHT 12 & 0 & 0 & 0 & 0 & 5 & 0 & 0 & 5 \\
\hline BHT 13 & 1 & 0 & 0 & 0 & 5 & 0 & 0 & 6 \\
\hline BHT 14 & 2 & 6 & 2 & 1 & 10 & 0 & 0 & 21 \\
\hline BHT 15 & 1 & 3 & 0 & 1 & 3 & 0 & 0 & 8 \\
\hline
\end{tabular}


Table 2.9, continued

\begin{tabular}{l|c|c|c|c|c|c|c|c}
\hline Provenience & $\begin{array}{c}\text { Chipped } \\
\text { Stone } \\
\text { Tool }\end{array}$ & Debitage & Core & $\begin{array}{c}\text { Ground } \\
\text { Stone } \\
\text { Tool }\end{array}$ & Sherd & Bone & Other & Totals \\
\hline BHT 16 & 0 & 1 & 0 & 0 & 14 & 0 & 0 & 15 \\
\hline BHT 19 & 0 & 1 & 0 & 0 & 5 & 0 & 0 & 6 \\
\hline BHT 20 & 0 & 2 & 1 & 0 & 4 & 0 & 0 & 7 \\
\hline BHT 21 & 2 & 16 & 2 & 5 & 28 & 0 & 0 & 53 \\
\hline BHT 23 & 0 & 1 & 0 & 2 & 4 & 0 & 0 & 7 \\
\hline BHT 28 & 1 & 0 & 0 & 0 & 0 & 0 & 0 & 1 \\
\hline BHT 30 & 5 & 28 & 5 & 4 & 7 & 0 & 0 & 49 \\
\hline Totals & 0 & 2 & 0 & 0 & 5 & 0 & 0 & 7 \\
\hline
\end{tabular}

tests in that area produced 92 percent of the sherds and 69 percent of the lithics. A second minor artifact concentration was identified a short distance northeast of and upslope from the primary concentration. Only 2 artifacts were recovered outside these concentrations. These artifact distributions were used to reduce the site area to $5,400 \mathrm{~m}^{2}$.

Thirty-eight auger tests exposed clay subsoil, revealing a generally thin sandy mantle with an average thickness of $31 \mathrm{~cm}$ and a maximum thickness of $95 \mathrm{~cm}$. The thinnest surface sediments ( $20 \mathrm{~cm}$ or less) were on the most elevated north end of the site and along part of the sideslope south-southwest of the stock tank. The thickest sands were near the base of the toeslope in the southeast part of the site.

\section{Work Accomplished in Intensive Testing}

Testing investigations began with geophysical survey of a $1,600-\mathrm{m}^{2}$ grid that encompassed a 60x30-m area across much of the southwest part of the site, including and adjacent to positive Auger Tests 15-21, 23-25, and 28 and extending upward from near the floodplain edge to just below the top of the interfluve. Survey was not conducted in areas around this because of dense woods and steep slopes in places. The grid was oriented with respect to the landform and not to the cardinal directions; grid north was $35^{\circ}$ east of north (Figure 2.22). The survey identified a variety of anomalies. Most interesting were three high-resistance anomalies in the southwest part, which were suggested to relate to cultural activities. The magnetic susceptibility data also revealed several potential cultural anomalies.

Thirty backhoe trenches were subsequently excavated in and around the geophysical survey grid. Trenches 1-3 were along the interface between the floodplain and the toeslope at the southwest edge of the site to assess the deposits downslope from the grid. Trench 30 was located northeast of the survey grid to examine deposits near the crest of the interfluve. The 26 remaining trenches were spaced (more or less systematically) within the grid. Trenches were $1.0 \mathrm{~m}$ wide, ranged from 6.6 to $14.9 \mathrm{~m}$ in length $($ mean $=8.6 \mathrm{~m})$, and varied from 12 to $110 \mathrm{~cm}$ $($ mean $=44 \mathrm{~cm})$ in maximum depth. Mechanical trenching stripped $259 \mathrm{~m}^{2}$ of site area.

The manual excavation of twenty-two 1x1-m test units and a 1.0x0.5-m test unit followed backhoe excavation. Twenty of these were in or on the boundary of the survey grid and off of trenches. Many of these were paired or in contiguous blocks to investigate features exposed by trench excavation. Thin to nonexistent surface sands precluded unit placement in the northern portion of the grid or along its western edge. Test Units 16 and 22 were outside the survey grid. Depth to clay subsoil in 22 of the test units ranged from 30 to $70 \mathrm{~cm}$ (mean $=52 \mathrm{~cm})$. The 1.0x0.5-m unit (Test Unit 23) was not excavated to clay subsoil.

\section{Sediment Descriptions}

The walls of 17 trenches were recorded and revealed A1-A2-E-Bt or A-E-Bt soil profiles across most of the site and A-Bt profiles where 


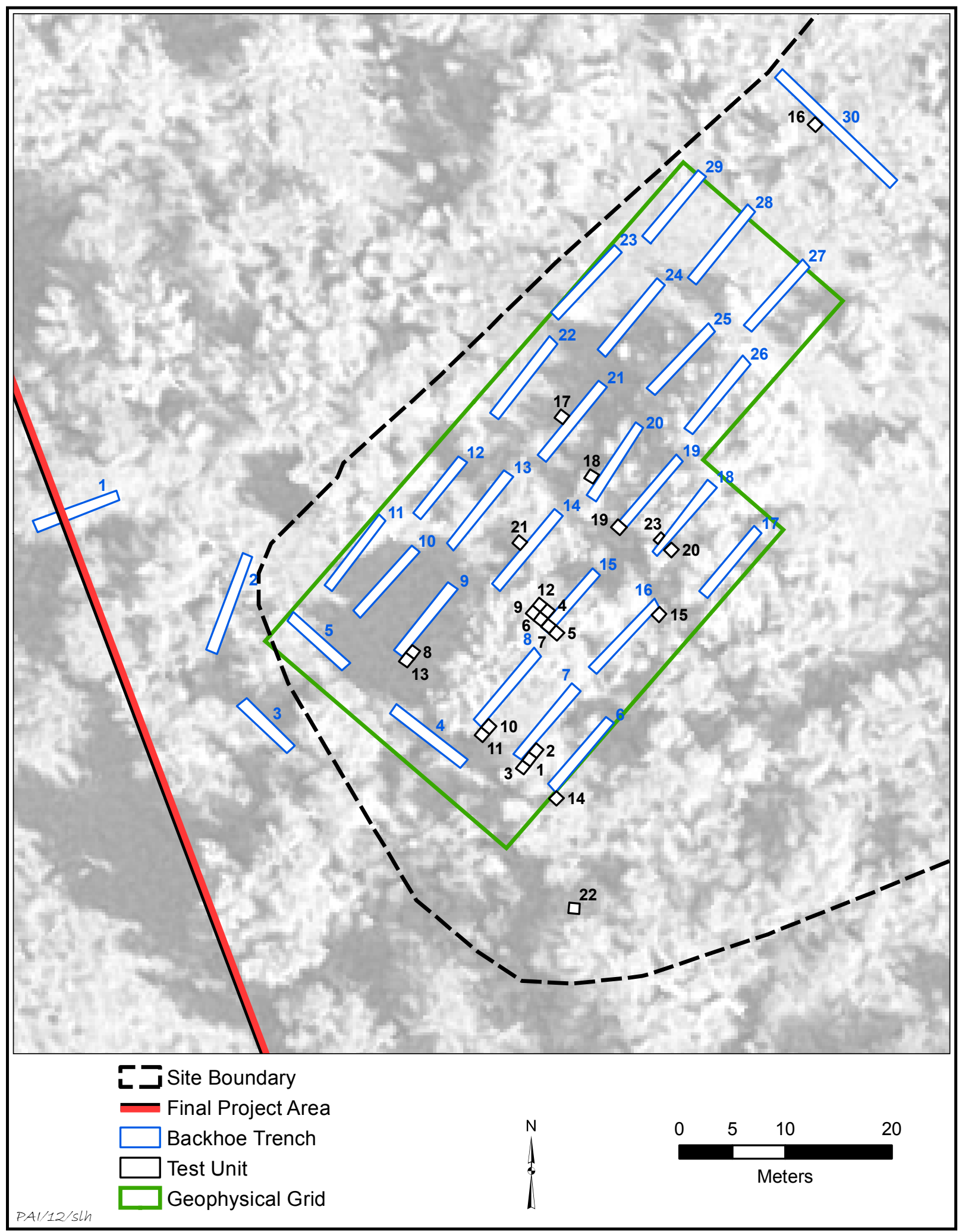

Figure 2.22. Aerial photograph of 41TT853 showing geophysical survey grid and test excavations. 
the sand mantle is thinner. Where the sands are fairly thick, A-E-Bt and A1-A2-E-Bt profiles were noted. Where present, the A1 horizon was 2-8-cm-thick very dark gray (10YR 3/1) to very dark grayish brown (10YR 3/2) to dark brown (10YR 3/3) very fine loamy sand. The A and A2 horizons were $2-40$-cm-thick brown (10YR 4/3) to dark yellowish brown (10YR 3/4, 4/4, 4/6) fine sand. The E horizon was 18-25-cm-thick yellowish brown (10YR 5/4) sand. The Bt horizon was well-structured strong brown (7.5YR 4/6, $5 / 6,5 / 8)$ firm clay. In the areas where the sandy mantle was very thin, the A horizon was $4-10$ cm-thick yellowish brown (10YR 5/4) sand, and the Bt horizon was well-structured strong brown (7.5YR 4/6) firm clay.

\section{Cultural Features}

One of the three high-resistance anomalies suspected to be of cultural derivation contained two features (Features 5 and 17). Four magnetic susceptibility anomalies were investigated with trenches; none correlated with any identifiable cultural activity.

Twenty-one cultural features were identified (Table 2.10; Figure 2.23). These consisted of 2 human burials, 7 postholes and possible postholes, 3 postholes or pits, 6 pits and possible pits of various sizes, 2 burned rock hearths, and a sherd concentration. Ten features were clustered in and around the south end of Trench 15. The features are discussed in more detail in Chapter 6 together with those documented during subsequent data recovery efforts.

Nine radiocarbon dates were obtained from feature contexts. One on charcoal from the fill of burial Feature 2 had a corrected radiocarbon age of $400 \pm 40$ B.P. (Beta- $242382 ;{ }^{13} \mathrm{C} /{ }^{12} \mathrm{C}$ Ratio $=-23.8$, with calibrated two-sigma date ranges of A.D. 1430-1520/1580-1630. Two dates from pit or large posthole Feature 6 had corrected ages of $250 \pm 40$ B.P. (Beta- $242389 ;{ }^{13} \mathrm{C} /{ }^{12} \mathrm{C}$ Ratio $=-26.9$ ) and $380 \pm 40$ B.P. (Beta-242390; ${ }^{13} \mathrm{C} /{ }^{12} \mathrm{C}$ Ratio = -24.4), with two sigma-ranges of 1520-1580/1630-1680/1770-1800/1940-1950

Table 2.10. Cultural features found in testing at 41 TT853

\begin{tabular}{c|l|l|c|c}
\hline Feature & \multicolumn{1}{|c|}{ Provenience } & \multicolumn{1}{c|}{ Type } & Dimensions & $\begin{array}{c}\text { Depth Below Surface } \\
\text { (top and bottom) }\end{array}$ \\
\hline 2 & TUs 1 and 2, BHT 7 & human burial & $180 \times 63 \mathrm{~cm}$ & $40-54 \mathrm{~cm}$ \\
\hline 4 & BHT 8, TU 10 & possible pit & $138 \times 84 \mathrm{~cm}$ & $50-77 \mathrm{~cm}$ \\
\hline 5 & BHT 9, TU 8 & pit & $60 \times 60 \mathrm{~cm}$ & $20-38 \mathrm{~cm}$ \\
\hline 6 & BHT 10 & pit or large posthole & $37 \times 37 \mathrm{~cm}$ & $10-36 \mathrm{~cm}$ \\
\hline 7 & BHT 13 & possible posthole & $9 \times 9 \mathrm{~cm}$ & $20-23 \mathrm{~cm}$ \\
\hline 8 & TU 21, BHT 14 & fire-cracked rock hearth & $190 \times 124 \mathrm{~cm}$ & $20-30 \mathrm{~cm}$ \\
\hline 9 & BHT 14 & possible posthole & $25 \times 25 \mathrm{~cm}$ & $51-66 \mathrm{~cm}$ \\
\hline 10 & BHT 15, TU 7 & sherd cluster & $17 \times 13 \mathrm{~cm}$ & $22-26 \mathrm{~cm}$ \\
\hline 11 & BHT 18 & fire-cracked rock hearth & ca. 100x80 cm & ca. 20-28 cm \\
\hline 12 & TU 15 & pit & $64 \times 41 \mathrm{~cm}$ & $18-28 \mathrm{~cm}$ \\
\hline 13 & BHT 30 & possible posthole & $20 \times 25 \mathrm{~cm}$ & $59-67 \mathrm{~cm}$ \\
\hline 14 & BHT 15, TU 7 & pit & $38 \times 20 \mathrm{~cm}$ & $37-50 \mathrm{~cm}$ \\
\hline 15 & TU 6 & posthole or pit & $30 \times 15 \mathrm{~cm}$ & $39-53 \mathrm{~cm}$ \\
\hline 16 & TU 6 & posthole or smudge pit & $36 \times 14 \mathrm{~cm}$ & $29-40 \mathrm{~cm}$ \\
\hline 17 & TUs 8 and 13 & large pit & $120 \times 68 \mathrm{~cm}$ & $29-103 \mathrm{~cm}$ \\
\hline 18 & TUs 4, 7, 9, and 12 & human burial & $98 \times 44 \mathrm{~cm}$ & $40-46 \mathrm{~cm}$ \\
\hline 19 & TU 12 & posthole & $15 \times 15 \mathrm{~cm}$ & $29-34 \mathrm{~cm}$ \\
\hline 20 & TU 9 & pit (hearth) & $40 \times 34 \mathrm{~cm}$ & $23-41 \mathrm{~cm}$ \\
\hline 22 & TU 9 6 & posthole & $18 \times 17 \mathrm{~cm}$ & $23-33 \mathrm{~cm}$ \\
\hline 23 & TU 9 wall & posthole & $39-43 \mathrm{~cm}$ \\
\hline
\end{tabular}




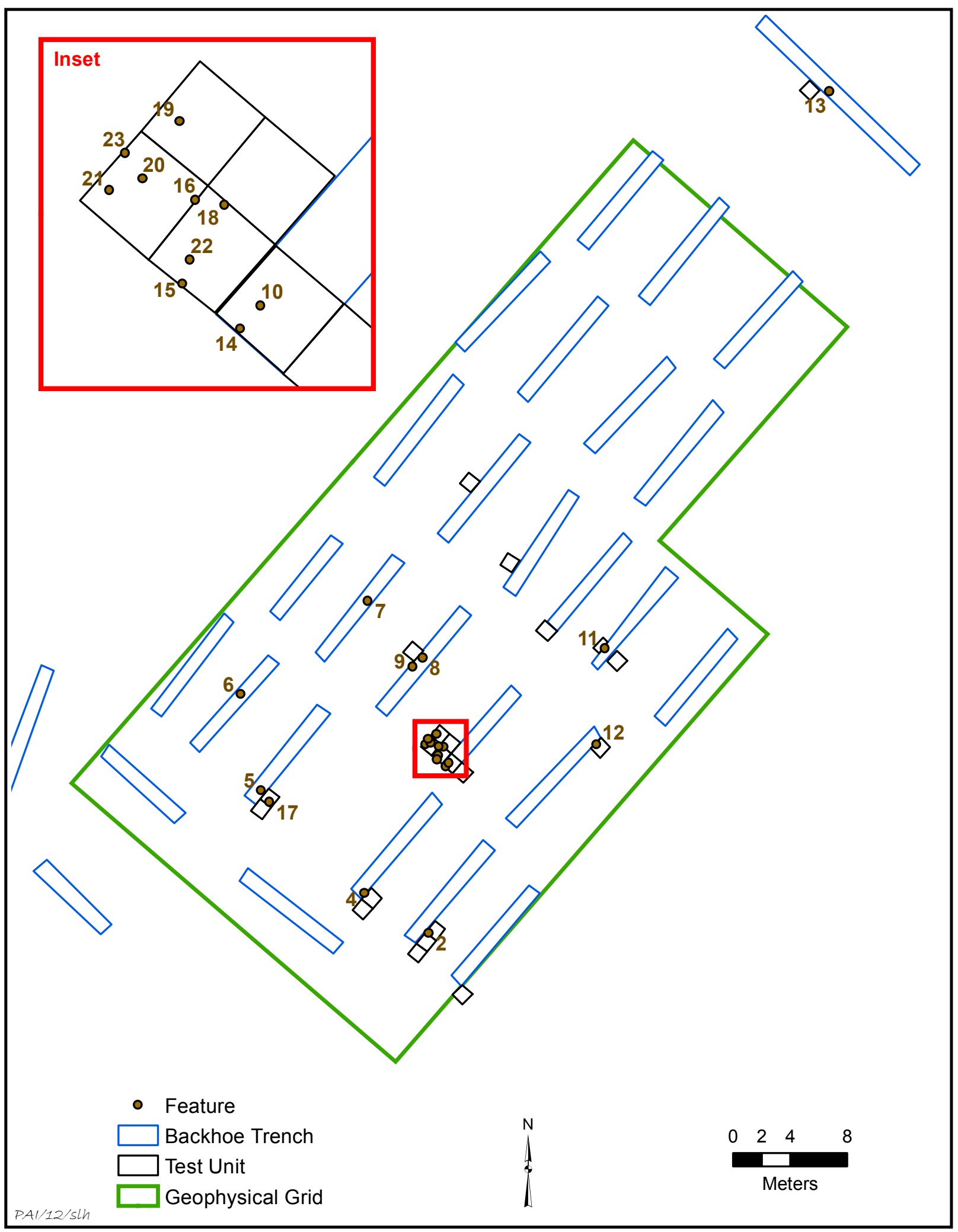

Figure 2.23. Plan of the tested area at 41 TT853 showing feature locations. 
and 1440-1640. Two dates from pit Feature 12 had corrected ages of $350 \pm 40$ B.P. (Beta$242385 ;{ }^{13} \mathrm{C} /{ }^{12} \mathrm{C}$ Ratio $\left.=-26.7\right)$ and $260 \pm 40$ B.P. $\left(\right.$ Beta-242386; ${ }^{13} \mathrm{C} /{ }^{12} \mathrm{C}$ Ratio $\left.=-26.4\right)$, with two sigma-ranges of $1450-1650$ and 1520 1590/1620-1670/1770-1800/1940-1950. Pit Feature 14 yielded a date with a corrected age of $410 \pm 40$ B.P. $\left(\right.$ Beta- $242384 ;{ }^{13} \mathrm{C} /{ }^{12} \mathrm{C}$ Ratio $=-25.3$ ) and two-sigma ranges of 1430-1520/1580-1630. Posthole or smudge pit Feature 16 had a date with a corrected age of $230 \pm 40$ B.P. (Beta-242387; ${ }^{13} \mathrm{C} /{ }^{12} \mathrm{C}$ Ratio $=-26.9$ ) and two-sigma ranges of 1630-1680/1740-1810/1930-1950. Large pit Feature 17 had a date with a corrected age of $620 \pm 40$ B.P. $\left(\right.$ Beta- $242383 ;{ }^{13} \mathrm{C} /{ }^{12} \mathrm{C}$ Ratio $\left.=-24.5\right)$ and a two-sigma range of 1280-1410. Finally, pit hearth Feature 20 yielded a date with a corrected age of $320 \pm 40$ B.P. (Beta-242388; ${ }^{13} \mathrm{C} /{ }^{12} \mathrm{C}$ Ratio $\left.=-25.1\right)$ and a two-sigma range of 1460-1660.

\section{Artifact Assemblage}

Cultural materials were recovered from 18 auger tests, all of the test units, and 21 backhoe trenches (see Table 2.9). The testing assemblage includes 5 ceramic vessels (from burials), 1,069 prehistoric ceramic sherds, 60 chipped stone tools, 1,319 pieces of debitage, 31 cores, 17 ground/battered stone tools, $87.0 \mathrm{~g}$ of daub, $13.2 \mathrm{~g}$ of burned clay, and $8.26 \mathrm{~kg}$ of burned rocks. Also collected were 41 faunal elements and about $59.10 \mathrm{~g}$ of carbonized macrobotanical material. These materials are discussed in more detail in Chapter 6 along with the materials recovered in subsequent data recovery excavations.

Artifacts were generally concentrated in areas with deeper sands, particularly in the south half of the tested area where 66 percent of the assemblage came from and the artifact density in nonfeature contexts was 57 artifacts/ $\mathrm{m}^{2}$. That part of the site contained 95 percent of the recovered faunal elements and (by weight) 67 percent of the daub and 72 percent of the burned clay. The southeast quadrant of the site contained most of the documented cultural features and half of the testing assemblage. The area north of the geophysical grid, where sands were also relatively deep (Trench 30 and Test Unit 16), contained 10 percent of the assemblage. Vertically, 77 percent of the artifacts from test units came from between 0 and $40 \mathrm{~cm}$ below the surface, and 92 percent were from between 0 and $50 \mathrm{~cm}$, which correlates with the average depth to clay of $52 \mathrm{~cm}$ in the test units. Artifact recovery by level was as follows: 13 percent at $0-10 \mathrm{~cm} ; 22$ percent at $10-20 \mathrm{~cm} ; 24$ percent at $20-30 \mathrm{~cm} ; 18$ percent at $30-40 \mathrm{~cm} ; 15$ percent at $40-50 \mathrm{~cm} ; 6$ percent at $50-60 \mathrm{~cm}$; and 2 percent at $60-70 \mathrm{~cm}$.

\section{Conclusions}

Testing indicated that 41TT853 was characterized by high ceramic and lithic artifact densities and relatively numerous cultural features. While the presence of dart points and burned rock features pointed to some use during the Archaic or Woodland periods, most of the evidence suggested that the most visible component was derived from a small Caddo farmstead comprised of one or a few houses and associated outdoor activity areas. Recovered diagnostic ceramics and projectile points and the radiocarbon dates suggested this was mostly a Late Caddo Titus phase occupation.

The presence of matrix-defined features with datable carbon demonstrated that the deposits retained sufficient integrity to allow for productive analyses. Additionally, proximity to residential loci at $41 \mathrm{TT} 851$ and $41 \mathrm{TT} 852$, overlap in radiocarbon dates obtained from these three localities, and the recovery of similar Caddo diagnostic artifacts at each locality suggested that 41TT853 was part of a larger Caddo community on this part of Tankersley Creek. Thus, the deposits at 41TT853 were considered to have the potential to contain information relevant to the larger prehistoric community. The site was judged eligible for listing in the National Register and designation as a State Antiquities Landmark, and, since it was not a candidate for preservation in place, data recovery excavations were recommended.

\section{SITE 41TT854}

Site 41TT854 is in partially wooded pasture on a small upland crest and adjacent sideslope immediately north of a Tankersley Creek tributary, not far south of 41TT853 (Figure 2.24). The terrain drops sharply from the small, discrete topographic high, falling south and east toward the tributary and west toward Tankersley Creek. Eight shovel tests were excavated here during 
the 2002 AEC survey, four along the upland crest and four on adjacent sideslopes. Recovered cultural material, which was limited to the latter group of tests, included 14 prehistoric ceramic sherds, 7 lithic artifacts, and charcoal. Survey investigations suggested that the site covered approximately $5,000 \mathrm{~m}^{2}$ (Perttula et al. 2002). It was entirely within the project corridor as of the 2005 auger testing and remained so throughout the project.

\section{Auger Testing}

Thirty-four auger tests were excavated at 41TT854. Surface topography and vegetation density affected test spacing, with no tests placed in roughly the eastern third of the original site extent because it consisted of heavily vegetated, steeply sloping terrain adjacent to the tributary. Eight auger tests yielded 23 ceramic sherds, a chipped stone drill, 3 cores, 11 pieces of debitage, and a burned rock (Table 2.11). Most of this assemblage was recovered on and just below the upland crest at the north edge of the site. Four tests in that area contained 87 percent of the ceramics and 67 percent of the chipped stone artifacts. The rest of the assemblage was from 4 tests downslope from this concentration. Based on this distribution of artifacts, the site boundary was redefined to encompass $1,600 \mathrm{~m}^{2}$.

All of the auger tests reached clay, and these demonstrated that the sands had an average basal depth of $30 \mathrm{~cm}$ across the site and a maximum basal depth of $90 \mathrm{~cm}$ at the bottom of the toeslope on the site's south end. Deeper sediments (up to $85 \mathrm{~cm}$ ) also were encountered around the primary artifact concentration in the northern portion of the sampled area. Sands were thinnest on the slopes marking the eastern and western boundaries of the modified site area.

\section{Work Accomplished in Intensive Testing}

Testing began with geophysical survey of a $40 \times 40-m$ grid that covered most of the site, including or adjacent to the area with positive Auger Tests 1, 4, 6-9, 11, and 32) (Figure 2.25). This survey did not identify any anomalies that appeared likely to be cultural. Subsequent test excavations were within the geophysical grid and just south of it. This included excavation of 16 backhoe trenches and eight $1 \mathrm{x} 1-\mathrm{m}$ test units. The trenches were $1.0 \mathrm{~m}$ wide, ranged from 6.0 to $7.5 \mathrm{~m}$ in length (mean $=6.6 \mathrm{~m}$ ), and had maximum depths ranging from 18 to $150 \mathrm{~cm}$ $($ mean $=60 \mathrm{~cm})$. Trench excavation encompassed $106 \mathrm{~m}^{2}$ of site area. The test units were isolated from the backhoe trenches. Unit depths ranged from 4 to $120 \mathrm{~cm}$ below the surface, with an average of $58 \mathrm{~cm}$.

The walls of seven trenches were described and display predominantly A-E-Bt soil profiles, except on the slope where thin A-Bt soil profiles are present. The A horizon was 13 to $49 \mathrm{~cm}$ thick and consisted of dark yellowish brown (10YR 4/4, $4 / 6$ ) to yellowish brown (10YR 5/4, 5/6, 5/8) very fine sand. The $\mathrm{E}$ horizon was 12 to $26 \mathrm{~cm}$ thick and consisted of yellowish brown (10YR 5/6, $5 / 8$ ), light yellowish brown (10YR 6/4), and very pale brown (10YR 7/6) sand. In the E horizon in Test Unit 3, a thick lamella was noted. The Bt horizon was strong brown $(7.5 \mathrm{YR} 5 / 6,5 / 8)$ firm sandy clay above firm well-structured yellowish red (5YR 4/6) clay. In areas where the sand was very thin, the Bt horizon was firm yellowish red (5YR 4/6) clay.

\section{Results}

Testing identified no cultural features. Prehistoric cultural materials were recovered from the modern surface, eight auger tests, six test units, and seven backhoe trenches (see Table 2.11). The assemblage consists of 131 ceramic sherds, 6 chipped stone tools, 166 pieces of debitage, 9 cores, 5 ground/battered stone tools, 1 burned rock, and $15.2 \mathrm{~g}$ of burned clay. Also collected were 11 faunal elements and $0.30 \mathrm{~g}$ of carbonized plant material.

Of the 131 total sherds $(749.0 \mathrm{~g}), 57$ $(622.0 \mathrm{~g})$ are large enough for analysis. These consist of 48 vessel body sherds, 2 carinated body sherds, 3 rim sherds, 2 neck sherds, and 2 base sherds. Twenty-six have grog alone as temper, 26 have grog and bone, 4 have bone alone, and 1 has grog and bone along with voids that are probably leached bone. Exterior and interior surfaces are generally floated or smoothed, with burnishing evident on just 2 sherds. One sherd has a scraped interior suggesting it was part of a bottle, and another has a red-slipped interior. Two rims are everted with flat lips, and 1 straight rim has a rounded lip; all three rims range from 6.32 to $7.57 \mathrm{~mm}$ in thickness. 


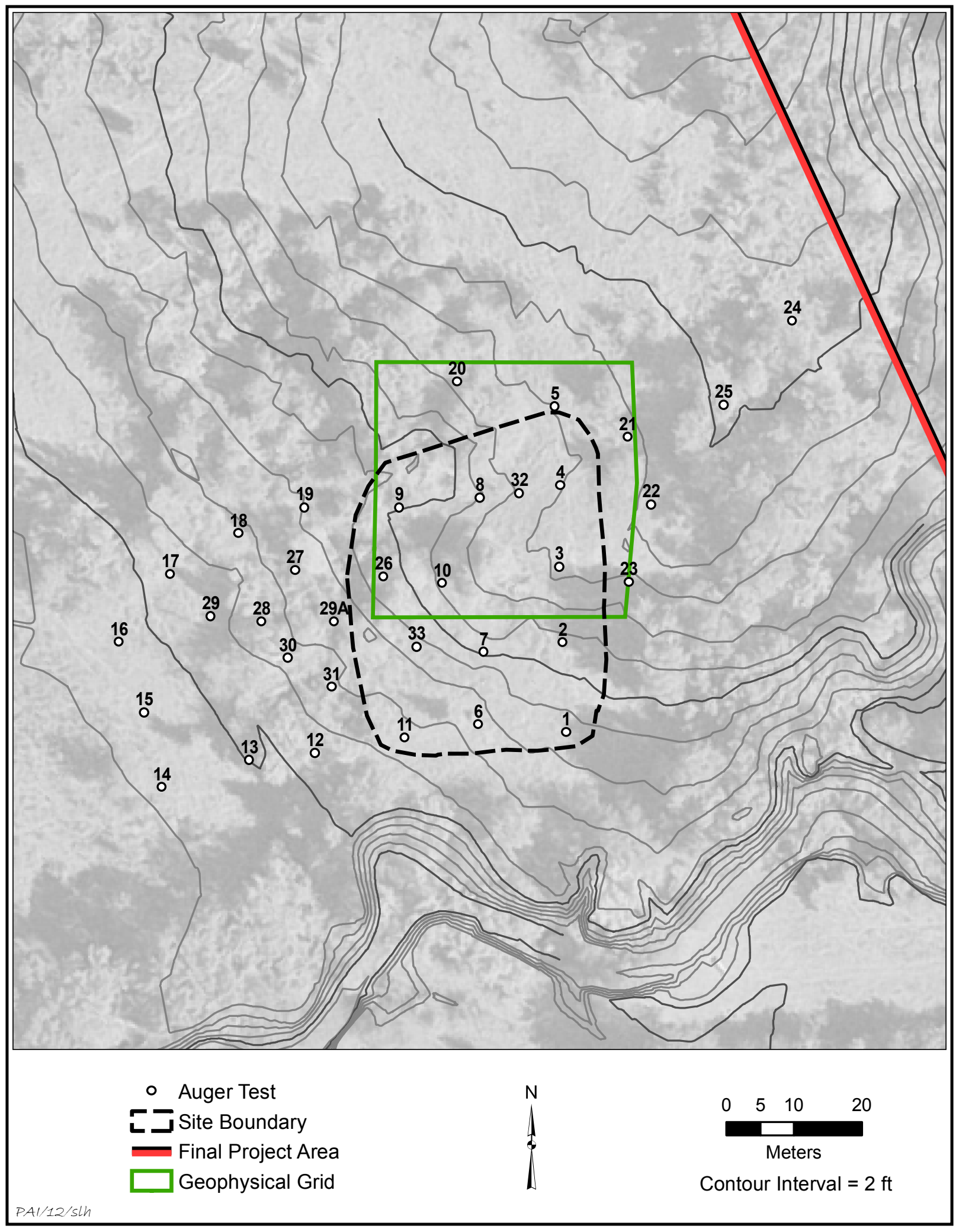

Figure 2.24. Map of 41TT854 showing topography, auger test locations, and geophysical survey grid on 2005 aerial imagery. 
Excavations along the U.S. Highway 271 Mount Pleasant Relief Route

Table 2.11. Artifacts recovered in auger and intensive testing at 41TT854

\begin{tabular}{|c|c|c|c|c|c|c|c|}
\hline Provenience & $\begin{array}{c}\text { Chipped } \\
\text { Stone Tool }\end{array}$ & Debitage & Core & $\begin{array}{c}\text { Ground } \\
\text { Stone Tool }\end{array}$ & Sherd & Bone & Totals \\
\hline Auger Test 1 & 0 & 2 & 1 & 0 & 1 & 0 & 4 \\
\hline Auger Test 4 & 0 & 2 & 1 & 0 & 0 & 0 & 3 \\
\hline Auger Test 6 & 0 & 0 & 1 & 0 & 1 & 0 & 2 \\
\hline Auger Test 7 & 0 & 1 & 0 & 0 & 0 & 0 & 1 \\
\hline Auger Test 8 & 0 & 3 & 0 & 0 & 17 & 0 & 20 \\
\hline Auger Test 9 & 0 & 1 & 0 & 0 & 0 & 0 & 1 \\
\hline Auger Test 11 & 0 & 0 & 0 & 0 & 1 & 0 & 1 \\
\hline Auger Test 32 & 1 & 2 & 0 & 0 & 3 & 0 & 6 \\
\hline \multicolumn{8}{|l|}{ Test Unit 1} \\
\hline $0-10 \mathrm{~cm}$ & 0 & 4 & 0 & 0 & 4 & 0 & 8 \\
\hline $10-20 \mathrm{~cm}$ & 0 & 10 & 0 & 0 & 1 & 0 & 11 \\
\hline $20-29 \mathrm{~cm}$ & 0 & 5 & 0 & 0 & 0 & 0 & 5 \\
\hline \multicolumn{8}{|l|}{ Test Unit 3} \\
\hline $0-10 \mathrm{~cm}$ & 0 & 0 & 0 & 0 & 1 & 0 & 1 \\
\hline $10-20 \mathrm{~cm}$ & 0 & 0 & 0 & 0 & 0 & 0 & 0 \\
\hline $20-30 \mathrm{~cm}$ & 1 & 1 & 0 & 0 & 3 & 0 & 5 \\
\hline $30-40 \mathrm{~cm}$ & 0 & 1 & 0 & 0 & 5 & 0 & 6 \\
\hline $40-50 \mathrm{~cm}$ & 0 & 0 & 0 & 0 & 1 & 0 & 1 \\
\hline $50-60 \mathrm{~cm}$ & 0 & 0 & 2 & 0 & 3 & 0 & 5 \\
\hline $60-70 \mathrm{~cm}$ & 0 & 1 & 0 & 0 & 1 & 0 & 2 \\
\hline $70-80 \mathrm{~cm}$ & 0 & 2 & 0 & 0 & 0 & 0 & 2 \\
\hline $80-90 \mathrm{~cm}$ & 0 & 0 & 0 & 0 & 0 & 0 & 0 \\
\hline $90-100 \mathrm{~cm}$ & 0 & 0 & 0 & 0 & 0 & 0 & 0 \\
\hline $100-110 \mathrm{~cm}$ & 0 & 0 & 0 & 0 & 0 & 0 & 0 \\
\hline $110-120 \mathrm{~cm}$ & 0 & 0 & 0 & 0 & 0 & 0 & 0 \\
\hline \multicolumn{8}{|l|}{ Test Unit 4} \\
\hline $0-10 \mathrm{~cm}$ & 0 & 1 & 0 & 0 & 1 & 0 & 2 \\
\hline $10-20 \mathrm{~cm}$ & 0 & 7 & 0 & 0 & 2 & 0 & 9 \\
\hline $20-30 \mathrm{~cm}$ & 0 & 7 & 0 & 0 & 1 & 0 & 8 \\
\hline $30-40 \mathrm{~cm}$ & 0 & 10 & 0 & 0 & 6 & 0 & 16 \\
\hline $40-50 \mathrm{~cm}$ & 0 & 10 & 0 & 0 & 1 & 0 & 11 \\
\hline \multicolumn{8}{|l|}{ Test Unit 5} \\
\hline $0-10 \mathrm{~cm}$ & 0 & 4 & 0 & 0 & 4 & 1 & 9 \\
\hline $10-20 \mathrm{~cm}$ & 0 & 8 & 0 & 0 & 6 & 0 & 14 \\
\hline $20-30 \mathrm{~cm}$ & 0 & 8 & 0 & 0 & 10 & 3 & 21 \\
\hline $30-40 \mathrm{~cm}$ & 0 & 7 & 0 & 0 & 1 & 0 & 8 \\
\hline $40-50 \mathrm{~cm}$ & 0 & 7 & 0 & 0 & 11 & 1 & 19 \\
\hline $50-60 \mathrm{~cm}$ & 0 & 5 & 0 & 0 & 5 & 0 & 10 \\
\hline $60-70 \mathrm{~cm}$ & 0 & 4 & 0 & 0 & 5 & 0 & 9 \\
\hline \multicolumn{8}{|l|}{ Test Unit 6} \\
\hline $0-10 \mathrm{~cm}$ & 0 & 1 & 0 & 0 & 0 & 0 & 1 \\
\hline $10-20 \mathrm{~cm}$ & 0 & 0 & 0 & 0 & 3 & 0 & 3 \\
\hline $20-30 \mathrm{~cm}$ & 0 & 1 & 0 & 0 & 2 & 0 & 3 \\
\hline $30-40 \mathrm{~cm}$ & 0 & 0 & 0 & 0 & 4 & 0 & 4 \\
\hline $40-50 \mathrm{~cm}$ & 0 & 7 & 0 & 0 & 0 & 0 & 7 \\
\hline $50-60 \mathrm{~cm}$ & 0 & 6 & 0 & 0 & 1 & 0 & 7 \\
\hline
\end{tabular}


Chapter 2: Testing

Table 2.11, continued

\begin{tabular}{l|c|c|c|c|c|c|c}
\hline Provenience & $\begin{array}{c}\text { Chipped } \\
\text { Stone Tool }\end{array}$ & Debitage & Core & $\begin{array}{c}\text { Ground } \\
\text { Stone Tool }\end{array}$ & Sherd & Bone & Totals \\
\hline Test Unit 7 & & & & & & & \\
\hline $0-10 \mathrm{~cm}$ & 0 & 3 & 0 & 0 & 4 & 0 & 7 \\
\hline $10-20 \mathrm{~cm}$ & 0 & 2 & 1 & 0 & 3 & 3 & 9 \\
\hline $20-30 \mathrm{~cm}$ & 0 & 1 & 0 & 0 & 5 & 2 & 8 \\
\hline $30-40 \mathrm{~cm}$ & 0 & 4 & 0 & 0 & 2 & 0 & 6 \\
\hline $40-50 \mathrm{~cm}$ & 0 & 8 & 0 & 0 & 2 & 0 & 10 \\
\hline $50-60 \mathrm{~cm}$ & 1 & 4 & 0 & 0 & 2 & 0 & 7 \\
\hline $60-70 \mathrm{~cm}$ & 0 & 2 & 0 & 0 & 1 & 1 & 4 \\
\hline $70-80 \mathrm{~cm}$ & 1 & 4 & 0 & 0 & 0 & 0 & 5 \\
\hline $80-90 \mathrm{~cm}$ & 0 & 3 & 0 & 0 & 0 & 0 & 3 \\
\hline $90-100 \mathrm{~cm}$ & 1 & 0 & 0 & 0 & 0 & 0 & 1 \\
\hline $100-110 \mathrm{~cm}$ & 0 & 2 & 1 & 0 & 0 & 0 & 3 \\
\hline BHT 3 & 0 & 0 & 0 & 1 & 1 & 0 & 2 \\
\hline BHT 4 & 0 & 0 & 1 & 0 & 0 & 0 & 1 \\
\hline BHT 5 & 0 & 1 & 0 & 0 & 0 & 0 & 1 \\
\hline BHT 6 & 0 & 0 & 1 & 0 & 3 & 0 & 4 \\
\hline BHT 7 & 0 & 0 & 0 & 1 & 0 & 0 & 1 \\
\hline BHT 10 & 1 & 0 & 0 & 0 & 0 & 0 & 1 \\
\hline BHT 13 & 0 & 0 & 0 & 1 & 0 & 0 & 1 \\
\hline Totals & 166 & 9 & 5 & 131 & 11 & \\
\hline
\end{tabular}

One base sherd is rounded, and the other is of indeterminate form; they are 7.20 and $10.66 \mathrm{~mm}$ thick. Vessel forms identified based on carinated sherds and neck sherds are two bowls, one jar, and one bottle.

Thirteen sherds are decorated: 5 engraved, 5 incised, 2 punctated, and 1 punctated and incised. The engraved sherds display curvilinear and rectilinear elements as well as hatching and crosshatching. Two are from bowls that likely have slanted scroll motifs, with 1 displaying enough of the motif to provide a clear association with the type Ripley Engraved (Figure 2.26a). This sherd appears to be from a small bowl decorated with a slanted scroll and bar element similar to that seen on a small bowl from Feature 18 at 41TT853 (see Chapter 6). Another engraved sherd from a bottle has a wide crosshatched element possibly within a circle or zone (Figure 2.26b). This combination of elements could be associated with a number of Caddo ceramic types, and thus this sherd remains untyped. The sherds with incising or punctations also cannot be related with certainty to a particular motif or type, though 3 of them have diagonal lines and 1 has zoned punctations, which are suggestive of Maydelle Incised. The lack of brushed sherds could suggest occupation prior to the Middle-Late Caddo period, but the presence of Ripley Engraved argues strongly against this. Instead, it seems likely that most or all of the ceramics relate to Late Caddo occupations contemporaneous with those at 41TT853 just to the north, with the lack of brushing being due to the small sample size.

The chipped stone tools consist of two projectile points, three bifaces, and one edge-modified flake. The projectile points are the distal tip of an untyped arrow point made of quartzite recovered from Level 6 of Test Unit 7 and the distal tip of an untyped dart point made of quartzite from Level 3 of Test Unit 3 (Figure 2.26c). One biface is a complete early-stage specimen made of local dark brown to reddish brown chert from Level 10 of Test Unit 7 (Figure 2.26d). The other two bifaces are middle-stage specimens; one is a lateral fragment of local reddish brown chert 


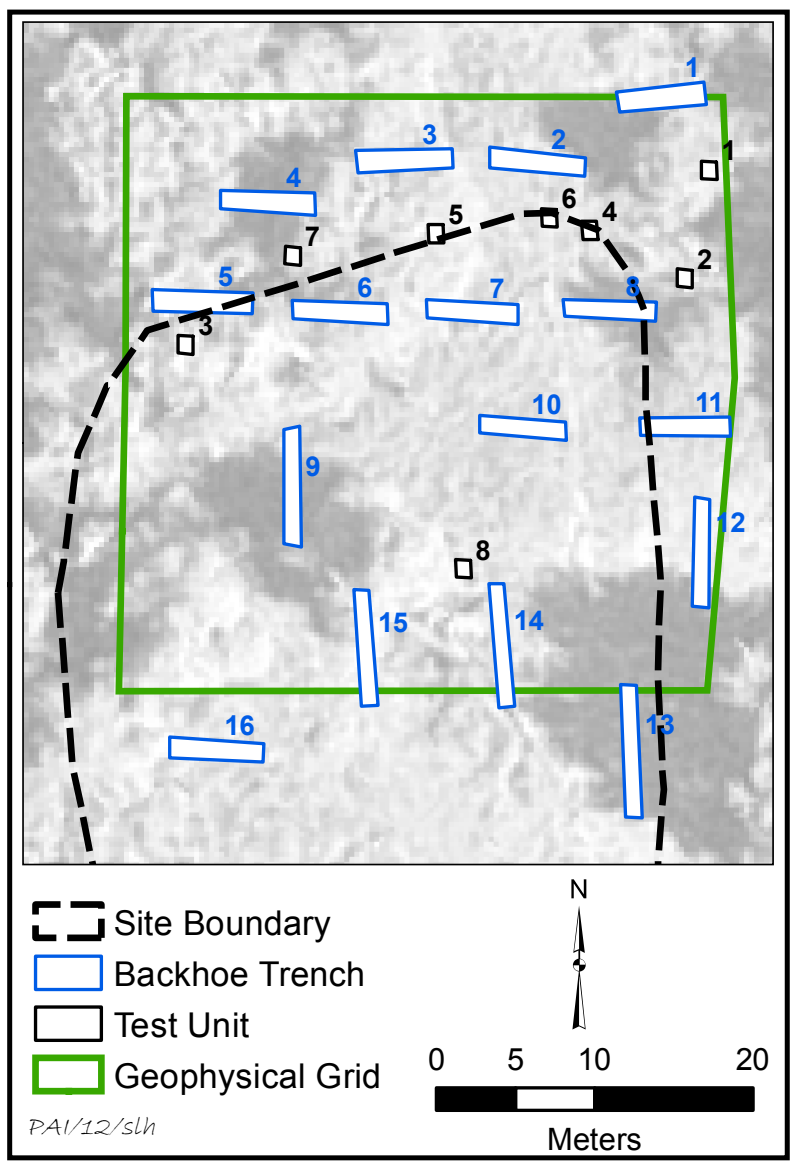

Figure 2.25. Aerial photograph of $41 \mathrm{TT} 854$ showing geophysical survey grid and test excavations.

from Level 8 of Test Unit 7, and the other is a complete biface of local hematite with cortex on both faces (Figure 2.26e) recovered from backdirt. The edge-modified flake, from Auger Test 32, is a perforator that was bilaterally retouched on one edge; it was made of local yellowish brown chert with cortex on the proximal end (Figure 2.26f).

There are five flake cores and four tested cobbles. The flake cores were reduced using hard-hammer percussion; four are silicified wood, and one is quartzite. The tested cobbles consist of one each of quartz, quartzite, silicified wood, and ferruginous sandstone. Most of the debitage is small to medium-sized with 67 percent less than $19 \mathrm{~mm}$. The lithic materials are dominated by locally available chert $(\mathrm{n}=62)$, silicified wood ( $n=40)$, and quartzite $(n=40)$, which, combined with small amounts of hematite and ferruginous sandstone, make up 90 percent of the debitage.
Nonlocal lithic materials consist of black chert $(n=1)$, white chert $(n=1)$, gray chert $(n=12)$, and Edwards chert $(n=3)$. The sandstone and hematite debitage is likely the byproduct of manufacture or use of ground or battered stone tools such as hammerstones, celts, and manos. The small size of the debitage indicates that late reduction and tool production and maintenance activities occurred on the site, though some of the debitage does reflect early reduction using small source materials such as local pebbles and cobbles.

The ground/battered stone tools consist of a polishing stone, a hammerstone, a pitted hammerstone, a pitted anvil, and an indeterminate fragment. The anvil and hammerstone are ferruginous sandstone, and the others are quartzite. The polishing stone and hammerstone are from the modern ground surface in the northwest part of the site; the others are from the backdirt of Trenches 3, 7, and 13. The polishing stone is a small, oval, well-smoothed pebble with highly polished margins. The hammerstone is a large oval pebble with battered/ crushed ends and limited battering damage on its narrow margins; use-derived fracture lines extend the length of one side of the pebble. The indeterminate fragment's cortical surface suggest it is part of a pitted anvil. The surface is variably smoothed with percussion marks and at least three incipient pits. One side of the fragment was modified to create a sharp edge. Small flake scars along that edge indicate that it was utilized, possibly for scraping or planing.

The narrow, tabular pitted hammerstone fragment has a subrectangular, extensively battered end and roughly smoothed margins (Figure $2.26 \mathrm{~g}$ ). Battering damage and percussion marks are visible on the short margin segments. The faces are relatively flat and variably smoothed, and each retains part of a shallow smoothed pit. Percussion marks are present on both faces and are densest on the face with the deeper pit. A shallow groove is cut into the face with the deeper pit, between the depression and the battered end. This feature has a maximum length and width of $30.69 \mathrm{~mm}$ and $9.36 \mathrm{~mm}$, respectively, and it is about $2 \mathrm{~mm}$ deep. Wear indicates this tool was used as a hammerstone, an abrader, and in conjunction with an anvil or grinding slab.

The small, tabular, discoidal anvil has two smoothed faces and a shallow, smooth depression in each face (Figure 2.26h). Percussion marks are present in and around the rougher 


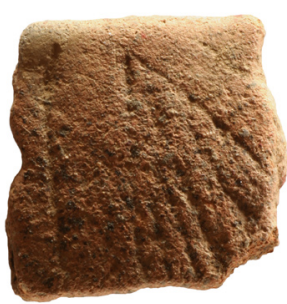

a

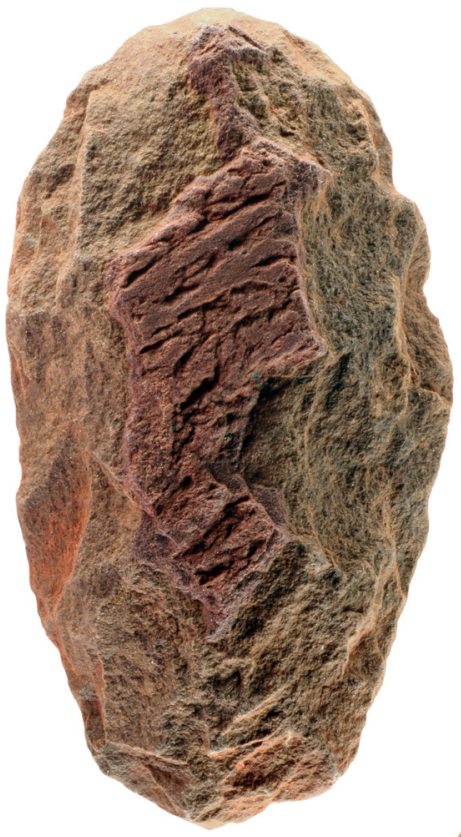

e
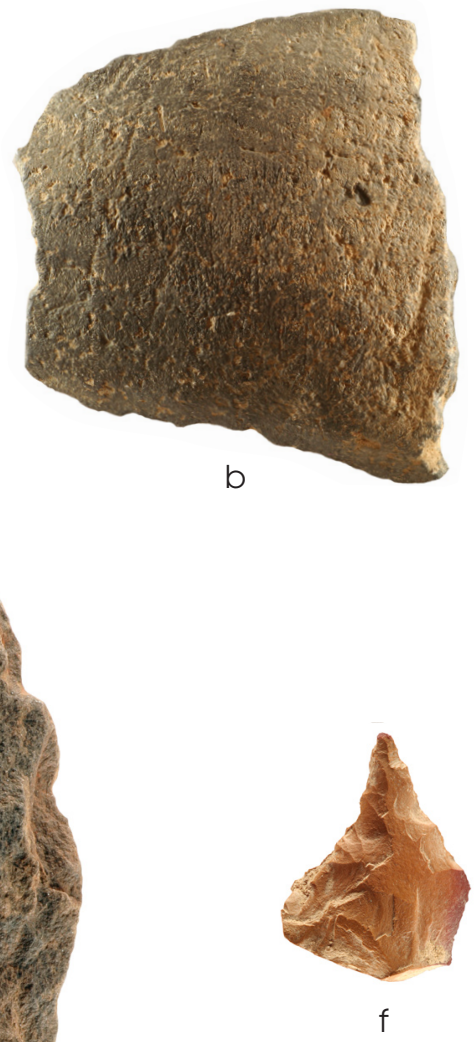

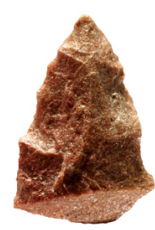

C

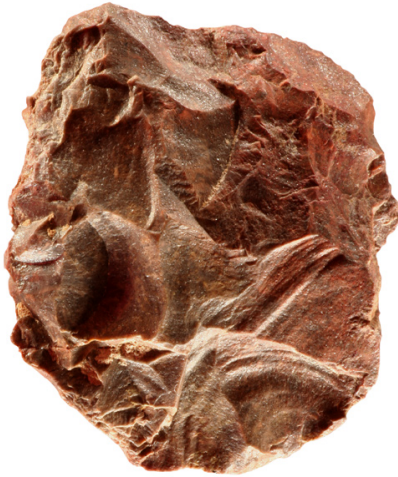

d

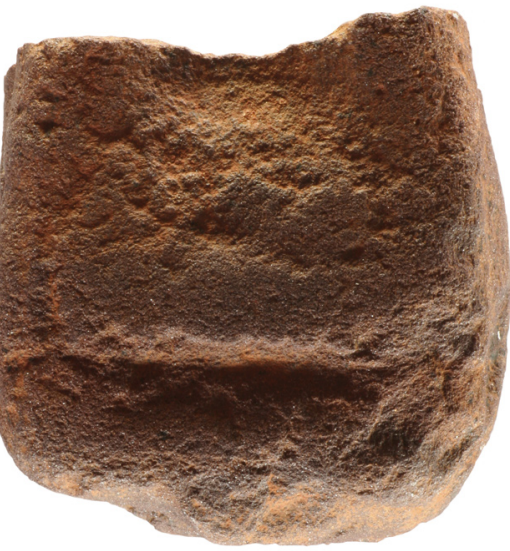

9

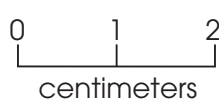

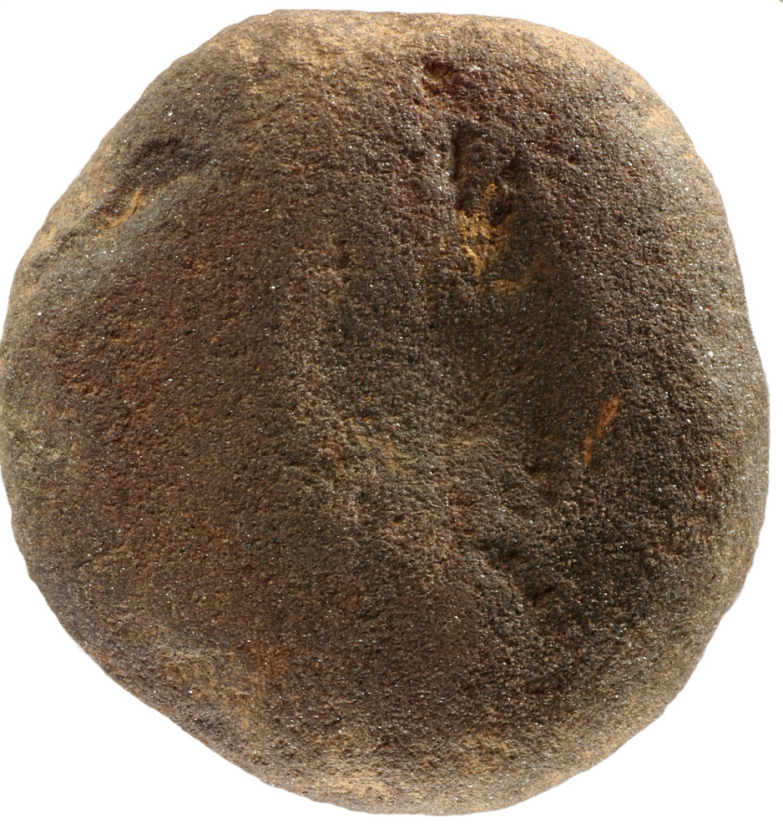

h

Figure 2.26. Artifacts recovered in testing at 41TT854. (a) Engraved bowl rim sherd with slanted scroll; (b) engraved bottle body sherd with wide crosshatching; (c) untyped dart point fragment; (d) early-stage biface; (e) complete middle-stage biface; (f) edge-modified flake perforator; (g) pitted hammerstone; (h) anvil. 
of the two pits. Surface smoothing around these depressions is consistent with abrasion wear derived from using the anvil in conjunction with a hammer for crushing/pulverizing. The degree of smoothing suggests this artifact also was used as a mano. The margins were intentionally shaped, and one short straight margin segment suggests this tool was recycled.

The very small faunal assemblage consists of 11 bone fragments. Five are identifiable only as vertebrates, and four are from canid/deersized mammals, probably deer.

Almost all of the artifacts are from the north half of the geophysical survey grid, and 73 percent are from Test Units $4-7$. Vertically, 88 percent were recovered from 0 to $60 \mathrm{~cm}$, and nearly half were from the upper $30 \mathrm{~cm}$. By level, test unit artifact recovery was as follows: 10 percent at $0-10 \mathrm{~cm} ; 17$ percent at $10-20 \mathrm{~cm}$; 18 percent at $20-30 \mathrm{~cm} ; 15$ percent at $30-40 \mathrm{~cm}$; 18 percent at $40-50 \mathrm{~cm} ; 11$ percent at $50-60 \mathrm{~cm}$; and 5 percent at $60-70 \mathrm{~cm}$. The remaining 7 percent of the assemblage was recovered between 70 and $110 \mathrm{~cm}$.

\section{Conclusions}

Site 41TT854 was characterized by a moderate density of chipped stone artifacts and a moderately low density of ceramic artifacts. The fact that no cultural features were identified may be attributable in part to the comparatively great thickness of the surface sands in much of the investigated part of the site area. The absence of features, relatively small ceramic sample, and recovery of few temporally diagnostic artifacts make 41TT854 difficult to interpret beyond its association with a Caddo occupation. The lack of brushed sherds in the ceramic assemblage implies earlier Caddo use, but this is probably a sampling problem, with the presence of Ripley Engraved clearly pointing to Middle-Late Caddo occupation. The recovery of the untyped dart point suggests pre-Caddo use of this locality, though it is possible that this item was scavenged elsewhere and brought to this site by the Caddo.

Site 41 TT 854 could be a campsite or procurement and processing locality associated with the nearby Middle to Late Caddo residential community marked by 41TT851, 41TT852, and 41TT853. However, assessment of this inference is hindered by the recovery of only small amounts of datable materials from nonfeature contexts in bioturbated surface sands. Because the deposits lack identifiable cultural features and dateable materials from secure contexts and contain few temporally diagnostic artifacts, interpretable components could not be isolated and the site was judged to lack the capacity to contribute important information. Thus, 41TT854 was considered ineligible for listing in the National Register and designation as a State Antiquities Landmark.

\section{SITE 41TT858}

Site 41 TT 858 is on a small upland projection south of an intermittent tributary of Tankersley Creek (Figure 2.27). The landform is bordered by a small erosional gully on its south side and a low-lying area that isolates it from adjacent upland terrain to the east. Located north of 41TT852, 41TT858 is between FM 899 and the Southern Pacific Railroad tracks. Area vegetation includes pines and hardwoods with open grass-covered areas. Survey investigations by AEC in 2002 included shovel test excavation that revealed cultural deposits as deep as $60 \mathrm{~cm}$ below the surface. Six of the seven tests produced 1 ceramic sherd, 15 pieces of lithic debitage, and 6 burned rocks (Perttula et al. 2002). The site was estimated to encompass $5,700 \mathrm{~m}^{2}$. The site was entirely within the project corridor.

\section{Shovel Testing}

Auger testing was not conducted at this site in 2005 because right of entry was denied, so additional shovel testing was done there in 2007. Thirty-one systematically spaced shovel tests were excavated. A small assemblage of two undecorated ceramic sherds and eight pieces of lithic debitage was recovered from six tests (Table 2.12). All of this material was retrieved at depths of $40 \mathrm{~cm}$ or less. The testing results were used to reduce the site area to $3,900 \mathrm{~m}^{2}$.

All of the shovel tests reached clay, indicating that the sands varied from less than 1 to $90 \mathrm{~cm}$ thick, with an average of $21 \mathrm{~cm}$. The characteristics of the sand mantle, with the thickest deposits on top of the landform quickly grading to thin or nonexistent sands (particularly at the west end of the redefined site area), strongly suggest that the landform and the deposits there have been impacted by slopewash and erosion. 


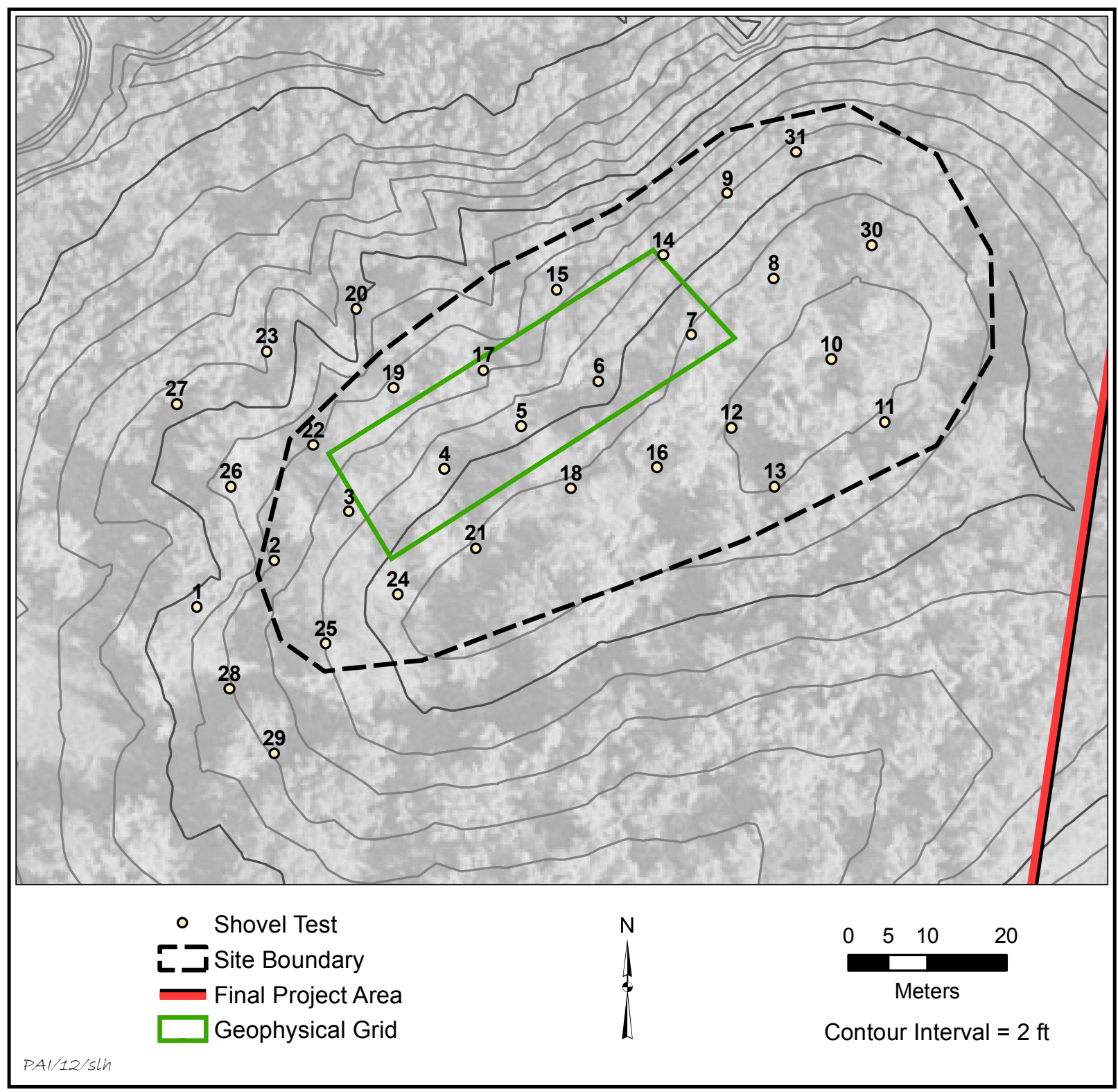

Figure 2.27. Map of 41TT858 showing topography, auger test locations, and geophysical survey grid on 2005 aerial imagery.

\section{Work Accomplished in Intensive Testing}

The testing investigation began with geophysical survey of a $15 \times 50-\mathrm{m}$ grid that was set in alignment with the landform's long axis, encompassing and adjacent to the area containing positive Shovel Tests 3, 5, 7, 8, and 21 (Figure 2.28). No clear patterning sugges- tive of archeological features was evident in the geophysical data. Eight backhoe trenches and eight $1 \times 1-m$ test units subsequently were excavated within the geophysical survey grid. The trenches were $1.0 \mathrm{~m}$ wide, ranged from 9.5 to $11.2 \mathrm{~m}$ long (mean $=10.1 \mathrm{~m}$ ), and had maximum depths ranging from 30 to $46 \mathrm{~cm}$ $($ mean $=38 \mathrm{~cm})$. Trench excavation stripped $81 \mathrm{~m}^{2}$ of site area. All of the test units were 
Excavations along the U.S. Highway 271 Mount Pleasant Relief Route

Table 2.12. Artifacts recovered in shovel and intensive testing at 41TT858

\begin{tabular}{|c|c|c|c|c|c|c|}
\hline Provenience & $\begin{array}{c}\text { Chipped } \\
\text { Stone Tool }\end{array}$ & Debitage & Core & $\begin{array}{c}\text { Ground } \\
\text { Stone Tool }\end{array}$ & Sherd & Totals \\
\hline Shovel Test 3 & 0 & 2 & 0 & 0 & 0 & 2 \\
\hline Shovel Test 5 & 0 & 1 & 0 & 0 & 1 & 2 \\
\hline Shovel Test 7 & 0 & 2 & 0 & 0 & 0 & 2 \\
\hline Shovel Test 8 & 0 & 1 & 0 & 0 & 0 & 1 \\
\hline Shovel Test 14 & 0 & 2 & 0 & 0 & 0 & 2 \\
\hline Shovel Test 21 & 0 & 0 & 0 & 0 & 1 & 1 \\
\hline \multicolumn{7}{|l|}{ Test Unit 1} \\
\hline $0-10 \mathrm{~cm}$ & 0 & 6 & 0 & 0 & 1 & 7 \\
\hline $10-20 \mathrm{~cm}$ & 0 & 8 & 0 & 0 & 0 & 8 \\
\hline $20-30 \mathrm{~cm}$ & 0 & 1 & 0 & 0 & 0 & 1 \\
\hline \multicolumn{7}{|l|}{ Test Unit 2} \\
\hline $0-10 \mathrm{~cm}$ & 0 & 2 & 0 & 0 & 2 & 4 \\
\hline $10-20 \mathrm{~cm}$ & 1 & 11 & 0 & 0 & 2 & 14 \\
\hline $20-30 \mathrm{~cm}$ & 0 & 12 & 0 & 0 & 2 & 14 \\
\hline $30-40 \mathrm{~cm}$ & 1 & 6 & 0 & 0 & 1 & 8 \\
\hline \multicolumn{7}{|l|}{ Test Unit 3} \\
\hline $0-10 \mathrm{~cm}$ & 0 & 4 & 0 & 0 & 7 & 11 \\
\hline $10-20 \mathrm{~cm}$ & 1 & 9 & 1 & 0 & 2 & 13 \\
\hline $20-24 \mathrm{~cm}$ & 0 & 0 & 0 & 0 & 0 & 0 \\
\hline \multicolumn{7}{|l|}{ Test Unit 4} \\
\hline $0-10 \mathrm{~cm}$ & 0 & 1 & 0 & 0 & 3 & 4 \\
\hline $10-20 \mathrm{~cm}$ & 0 & 1 & 0 & 0 & 1 & 2 \\
\hline $20-30 \mathrm{~cm}$ & 0 & 0 & 0 & 0 & 0 & 0 \\
\hline \multicolumn{7}{|l|}{ Test Unit 5} \\
\hline $0-10 \mathrm{~cm}$ & 0 & 3 & 1 & 0 & 1 & 5 \\
\hline $10-19 \mathrm{~cm}$ & 0 & 4 & 0 & 0 & 0 & 4 \\
\hline \multicolumn{7}{|l|}{ Test Unit 6} \\
\hline $0-10 \mathrm{~cm}$ & 0 & 6 & 0 & 0 & 5 & 11 \\
\hline $10-20 \mathrm{~cm}$ & 0 & 6 & 0 & 0 & 6 & 12 \\
\hline $20-30 \mathrm{~cm}$ & 0 & 2 & 0 & 0 & 0 & 2 \\
\hline \multicolumn{7}{|l|}{ Test Unit 7} \\
\hline $0-10 \mathrm{~cm}$ & 0 & 8 & 0 & 0 & 0 & 8 \\
\hline $10-20 \mathrm{~cm}$ & 0 & 9 & 0 & 1 & 0 & 10 \\
\hline $20-30 \mathrm{~cm}$ & 0 & 3 & 0 & 0 & 0 & 3 \\
\hline \multicolumn{7}{|l|}{ Test Unit 8} \\
\hline $0-10 \mathrm{~cm}$ & 0 & 11 & 0 & 0 & 2 & 13 \\
\hline $10-20 \mathrm{~cm}$ & 1 & 6 & 0 & 0 & 0 & 7 \\
\hline $20-28 \mathrm{~cm}$ & 0 & 2 & 0 & 0 & 0 & 2 \\
\hline BHT 1 & 0 & 1 & 0 & 0 & 0 & 1 \\
\hline BHT 2 & 0 & 0 & 0 & 0 & 1 & 1 \\
\hline BHT 3 & 0 & 1 & 0 & 0 & 0 & 1 \\
\hline BHT 8 & 1 & 0 & 0 & 0 & 0 & 1 \\
\hline Totals & 5 & 131 & 2 & 1 & 38 & 177 \\
\hline
\end{tabular}




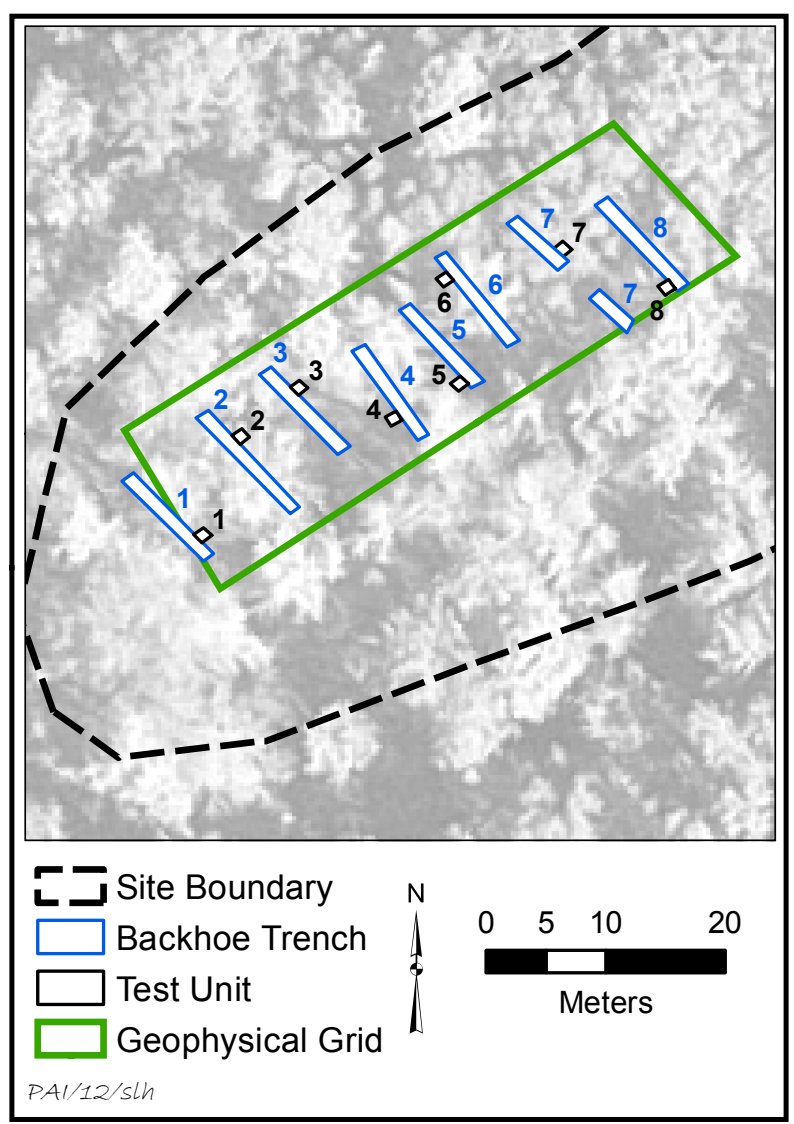

Figure 2.28. Aerial photograph of 41TT858 showing geophysical survey grid and test excavations.

opened off of trenches. Depth to clay in these units ranged from 19 to $40 \mathrm{~cm}$ (mean $=29 \mathrm{~cm})$.

The walls of six trenches were described and revealed A-E-Bt or A1-A2-E-Bt soil profiles, except for two trenches on the westernmost end of the grid that lacked $\mathrm{E}$ horizons. Where present, the A1 horizon was 8 to $12 \mathrm{~cm}$ thick and consisted of very dark grayish brown (10YR 3/2) to dark yellowish brown (10YR $3 / 4,3 / 6)$ very fine sandy loam. The A and A2 horizons were $10-22-\mathrm{cm}$ thick dark yellowish brown (10YR 3/6, 4/4, 4/6) very fine sand. The $\mathrm{E}$ horizon, where present, was 6-12-cm-thick yellowish brown (10YR 5/8) sand. The Bt horizon across the site was well-structured strong brown (7.5YR 4/6) clay.

\section{Results}

Testing identified no cultural features. Artifacts were recovered from six shovel tests, all of the test units, and four trenches (see Table 2.12). Recovery consisted of 38 ceramic sherds, 5 chipped stone tools, 131 pieces of debitage, 2 cores, 1 ground/battered stone tool, and $29.5 \mathrm{~g}$ burned clay.

Of the 38 total sherds (192.0 g), 25 (175.0 g) are large enough for analysis. Nineteen are vessel body sherds, 2 are neck sherds, 1 is a carinated body sherd, 1 is a rim, 1 is a base sherd, and 1 is of indeterminate form. Ten are tempered with grog, and 11 have grog and bone; 3 have grog and bone along with voids that probably represent leached bone, and 1 has indeterminate temper. Interior and exterior surfaces are generally floated; only 8 surfaces are smoothed and 3 are burnished. The single rim $(7.14 \mathrm{~mm}$ thick) is everted with a rolled lip, and the single base ( $8.91 \mathrm{~mm}$ thick) is flat. Most sherds do not convey information about vessel forms, but the two neck sherds may represent jars.

Nine sherds are decorated: four engraved, two incised, one punctated, and two both punctated and incised. None can be unequivocally associated with particular ceramic types. However, the engraved sherds display rectilinear and curvilinear elements (Figure 2.29a-b), and one also has what appears to be a pendant triangle element, which are suggestive of Ripley Engraved scroll motifs. The incised and punctated sherds have single examples of horizontal lines, zoned punctations, and lines of punctations, which are similar to elements on Maydelle Incised jars and untyped Caddo utility vessels. The assemblage is not very informative about chronology, though it could be mostly or entirely Middle-Late Caddo, with the lack of brushed sherds due to the sample size.

The chipped stone tools consist of an Ellis dart point, a Kent dart point, a Gary or Wells dart point, and two bifaces. The Ellis point is a small well-made point made of yellowish brown quartzite (Figure 2.29c); it is short and thick with shallow corner notching, squared barbs, an expanding stem, and a straight base. It is symmetrically reworked and was recovered from Level 2 of Test Unit 8. The Kent point, from Level 2 of Test Unit 2, is of dark reddish brown chert and was crudely worked and reworked (Figure $2.29 \mathrm{~d})$. The tip was damaged and retouched resulting in a blade shape that is somewhat rectangular. Kent points typically are asymmetrical with squared to indistinct shoulders, a straight stem (although it may be contracting or slightly 

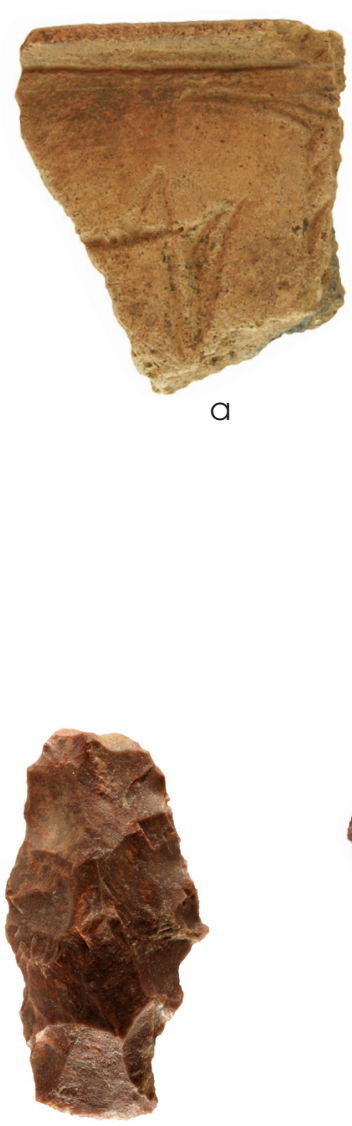

d

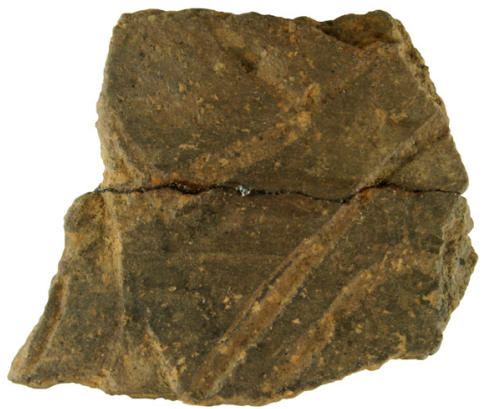

$\mathrm{b}$
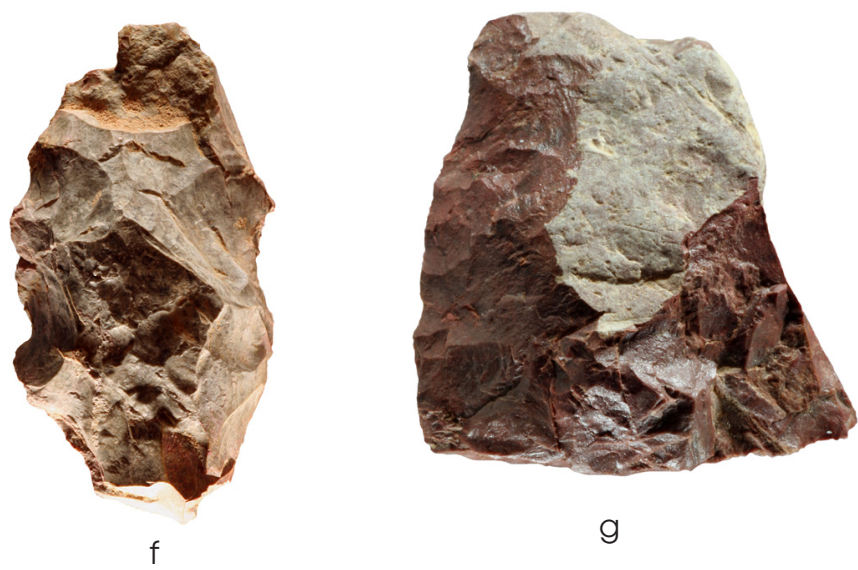

9

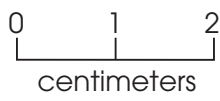

Figure 2.29. Artifacts recovered in testing at 41TT858. (a) Engraved bowl rim with rectilinear and possible pendant triangle elements; (b) engraved body sherd with rectilinear and curvilinear elements; (c) Ellis dart point; (d) Kent dart point; (e) Gary or Wells dart point; (f) early-stage biface; (g) middle-stage biface.

expanding as well), and a flat to concave base. This specimen most likely was used as a knife toward the end of its use life. The Gary or Wells point is very thick and crude with a break on the distal end (Figure 2.29e). It has a very long contracting stem (typical of Wells) and a convex base, but the absence of grinding on the stem edges suggests it is a Gary. The distal end was reworked into a scraper following a break. It is made of reddish brown chert and was recovered from Level 2 of Test Unit 3.
One of the bifaces is an early-stage specimen made of mottled tan and gray nonlocal chert (Figure 2.29f). It was recovered from backdirt. A proximal middle-stage biface fragment made of red chert has cortex on three sides and appears to be a manufacture reject (Figure $2.29 \mathrm{~g}$ ); it was recovered from Level 4 of Test Unit 2.

Both cores are tested cobbles, one of silicified wood and one of ferruginous sandstone. The vast majority of the debitage, 99 percent, is of local materials, including silicified wood $(n=47)$, 
quartzite $(\mathrm{n}=37)$, and chert $(\mathrm{n}=40)$ with a few flakes made of ferruginous sandstone and hematite. Nonlocal material consists of 1 flake of novaculite. The sandstone and hematite debitage is likely the byproduct of manufacturing and use of ground/battered stone tools such as hammerstones, celts, and manos. The debitage is small to medium-sized with 79 percent ranging from 3 to $25 \mathrm{~mm}$. This suggests later stages of reduction as well as tool production and tool maintenance. Early and middle-stage reduction on small source materials such as pebbles and cobbles is also likely.

A mano/hammerstone was recovered from Test Unit 7. This oval, nonferruginous sandstone cobble has one smoothed face. Minor battering damage is apparent on the opposite face and on portions of the margins. Slight thermal discoloration is evident. This artifact's dimensions are indicative of the finger-manipulated mullers identified at the Ear Spool site by Ellis (2009:306).

The test units with the highest artifact counts were in the eastern and western thirds of the investigated area. Test Units 1, 3, and 6-8 each contained 16-25 artifacts, and Test Unit 2 had the highest count $(n=39)$. The two centrally located units (Test Units 4 and 5) had the lowest counts (6 and 8, respectively). Ninety-five percent of the artifacts from test units were found at $0-30 \mathrm{~cm}$ below the surface, which correlates with the average depth to clay in the test units of $28 \mathrm{~cm}$. By level, recovery was as follows: 39 percent at $0-10 \mathrm{~cm} ; 43$ percent at $10-20 \mathrm{~cm} ; 13$ percent at $20-30 \mathrm{~cm}$; and 5 percent at $30-40 \mathrm{~cm}$.

\section{Conclusions}

Testing determined that 41TT858 is characterized by low to moderate chipped stone artifact densities, low ceramic densities, and a lack of cultural features. The dart points and Caddo ceramics suggest repeated use of this locality, possibly beginning in the Late Archaic period. The lack of brushed sherds could indicate earlier Caddo use, though it is more likely a function of the small sample size. Given the characteristics of the assemblage, limited number of diagnostic artifacts, absence of features, and lack of dateable material, 41TT858 is difficult to interpret beyond its association with potential Late Archaic or Woodland and Caddo occupations. It appears to be a multicomponent campsite or procurement/processing locality, but this cannot be verified without chronometric evidence and a larger ceramic sample. The absence of isolable and interpretable components indicates that the site lacks the capacity to contribute important information. Hence, it is not eligible for listing in the National Register and designation as a State Antiquities Landmark.

\section{SITE 41TT862}

Site 41TT862 is near the south end of the relief route corridor, on a gentle upland slope between intermittent drainages that border the south and west sides of the site (Figure 2.30). The west drainage was dammed and now serves as a spring-fed stock tank. Hardwoods along the drainages frame the maintained pasture that includes most of the site area. A subsurface pipeline trends across the northeast corner of the site. Although the property containing the site was investigated during a 2001 impact evaluation conducted by Geo-Marine, Inc., the site was not identified and recorded until the subsequent AEC survey (Perttula et al. 2002). Four of the eight shovel tests excavated at that time contained 13 pieces of lithic debitage and a flake tool. In addition, eight lithic artifacts were collected from eroded parts of the site surface. Survey data suggested that $41 \mathrm{TT} 862$ covered $9,320 \mathrm{~m}^{2}$. It was entirely within the relief route corridor.

\section{Auger Testing}

Sixty-five systematically spaced auger tests were excavated on open ground between the vegetated drainages. Twenty-one pieces of lithic debitage were recovered in 11 tests, and a possible burned rock feature but no artifacts was found in a twelfth test, Auger Test 59 (Table 2.13). Most of the positive tests were in the east half of the tested area, though three tests in the west part also contained flakes. The auger testing data were used to refine the site location and reduce the site area to $5,300 \mathrm{~m}^{2}$.

The 56 auger tests that reached clay subsoil indicated that the surface sands had average and maximum basal depths of 40 and $100 \mathrm{~cm}$ below surface. Relatively thick surface sediments (60 $\mathrm{cm}$ or more) were encountered in the northeastern portion of the tested area. The shallowest sands (less than $20 \mathrm{~cm}$ thick) were at the southwest end of the investigation area, on an eroded part of the toeslope. 


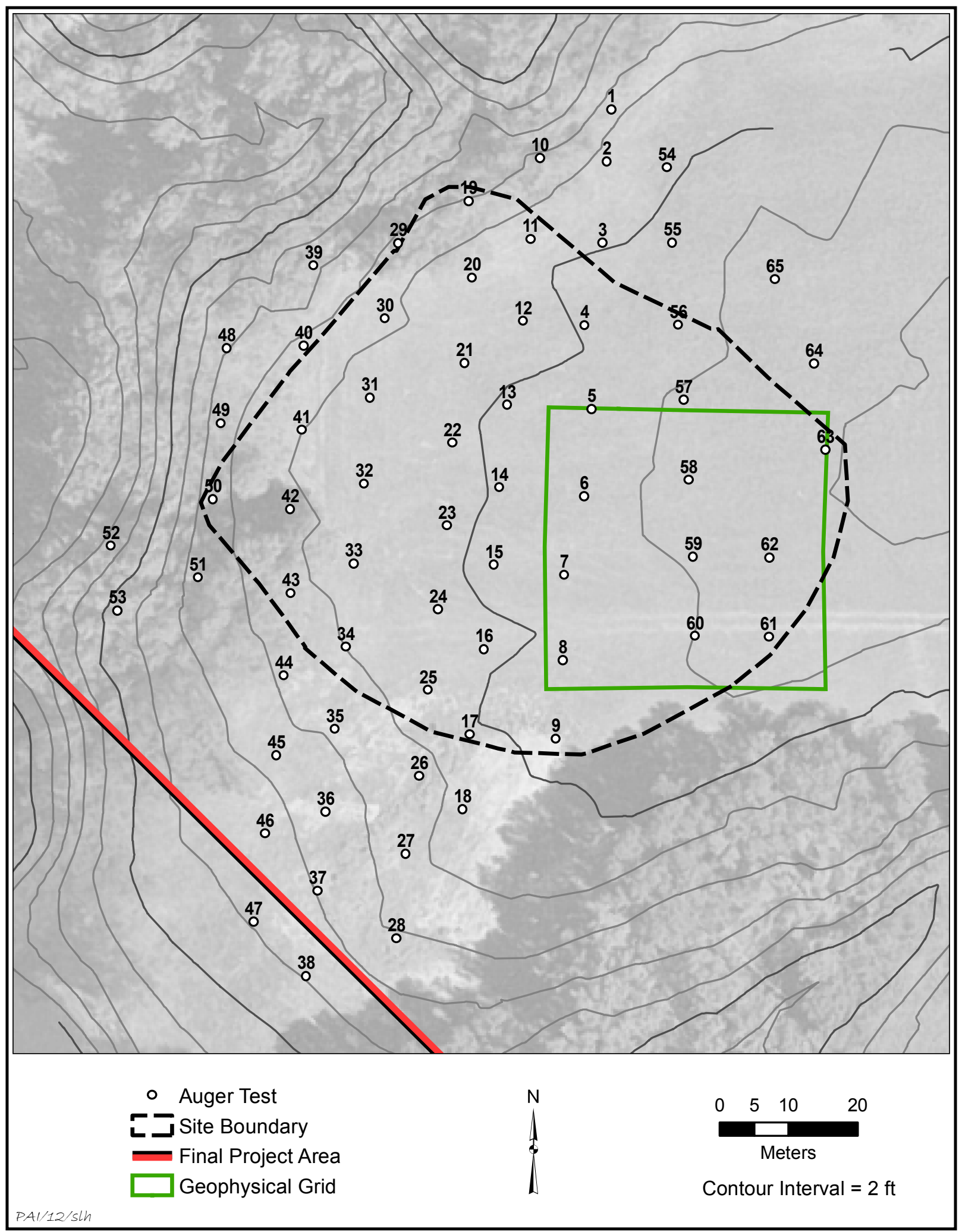

Figure 2.30. Map of 41TT862 showing topography, auger test locations, and geophysical survey grid on 2005 aerial imagery. 
Table 2.13. Artifacts recovered in auger and intensive testing at 41 TT862

\begin{tabular}{|c|c|c|c|c|c|}
\hline Provenience & $\begin{array}{c}\text { Chipped } \\
\text { Stone Tool }\end{array}$ & Debitage & Core & $\begin{array}{c}\text { Ground } \\
\text { Stone Tool }\end{array}$ & Totals \\
\hline Auger Test 5 & 0 & 1 & 0 & 0 & 1 \\
\hline Auger Test 6 & 0 & 2 & 0 & 0 & 2 \\
\hline Auger Test 8 & 0 & 4 & 0 & 0 & 4 \\
\hline Auger Test 17 & 0 & 1 & 0 & 0 & 1 \\
\hline Auger Test 19 & 0 & 2 & 0 & 0 & 2 \\
\hline Auger Test 41 & 0 & 1 & 0 & 0 & 1 \\
\hline Auger Test 50 & 0 & 1 & 0 & 0 & 1 \\
\hline Auger Test 58 & 0 & 1 & 0 & 0 & 1 \\
\hline Auger Test 61 & 0 & 2 & 0 & 0 & 2 \\
\hline Auger Test 62 & 0 & 1 & 0 & 0 & 1 \\
\hline Auger Test 63 & 0 & 5 & 0 & 0 & 5 \\
\hline \multicolumn{6}{|l|}{ Test Unit 1} \\
\hline $0-10 \mathrm{~cm}$ & 0 & 0 & 0 & 0 & 0 \\
\hline $10-20 \mathrm{~cm}$ & 0 & 1 & 0 & 0 & 1 \\
\hline \multicolumn{6}{|l|}{ Test Unit 2} \\
\hline $0-10 \mathrm{~cm}$ & 0 & 3 & 0 & 0 & 3 \\
\hline $10-20 \mathrm{~cm}$ & 0 & 3 & 0 & 0 & 3 \\
\hline $20-30 \mathrm{~cm}$ & 0 & 2 & 0 & 0 & 2 \\
\hline $30-40 \mathrm{~cm}$ & 0 & 1 & 0 & 0 & 1 \\
\hline $40-50 \mathrm{~cm}$ & 0 & 0 & 0 & 0 & 0 \\
\hline \multicolumn{6}{|l|}{ Test Unit 3} \\
\hline $0-10 \mathrm{~cm}$ & 0 & 5 & 0 & 0 & 5 \\
\hline $10-20 \mathrm{~cm}$ & 0 & 0 & 0 & 0 & 0 \\
\hline $20-30 \mathrm{~cm}$ & 0 & 2 & 0 & 0 & 2 \\
\hline $30-40 \mathrm{~cm}$ & 0 & 0 & 0 & 0 & 0 \\
\hline $40-50 \mathrm{~cm}$ & 0 & 3 & 0 & 0 & 3 \\
\hline $50-58 \mathrm{~cm}$ & 0 & 1 & 0 & 0 & 1 \\
\hline \multicolumn{6}{|l|}{ Test Unit 4} \\
\hline $0-10 \mathrm{~cm}$ & 0 & 0 & 0 & 0 & 0 \\
\hline $10-20 \mathrm{~cm}$ & 0 & 0 & 0 & 0 & 0 \\
\hline $20-30 \mathrm{~cm}$ & 0 & 0 & 0 & 0 & 0 \\
\hline $30-40 \mathrm{~cm}$ & 0 & 1 & 0 & 0 & 1 \\
\hline $40-50 \mathrm{~cm}$ & 0 & 0 & 0 & 0 & 0 \\
\hline $50-60 \mathrm{~cm}$ & 0 & 0 & 0 & 0 & 0 \\
\hline \multicolumn{6}{|l|}{ Test Unit 5} \\
\hline $0-10 \mathrm{~cm}$ & 0 & 4 & 0 & 0 & 4 \\
\hline $10-20 \mathrm{~cm}$ & 0 & 5 & 0 & 0 & 5 \\
\hline $20-30 \mathrm{~cm}$ & 0 & 3 & 0 & 0 & 3 \\
\hline $30-40 \mathrm{~cm}$ & 0 & 3 & 0 & 0 & 3 \\
\hline $40-50 \mathrm{~cm}$ & 0 & 3 & 0 & 0 & 3 \\
\hline \multicolumn{6}{|l|}{ Test Unit 6} \\
\hline $0-10 \mathrm{~cm}$ & 0 & 9 & 0 & 0 & 9 \\
\hline $10-20 \mathrm{~cm}$ & 0 & 8 & 0 & 0 & 8 \\
\hline $20-30 \mathrm{~cm}$ & 0 & 10 & 0 & 0 & 10 \\
\hline
\end{tabular}


Table 2.13, continued

\begin{tabular}{|c|c|c|c|c|c|}
\hline Provenience & $\begin{array}{c}\text { Chipped } \\
\text { Stone Tool }\end{array}$ & Debitage & Core & $\begin{array}{c}\text { Ground } \\
\text { Stone Tool }\end{array}$ & Totals \\
\hline \multicolumn{6}{|l|}{ Test Unit 7} \\
\hline $0-10 \mathrm{~cm}$ & 0 & 7 & 2 & 0 & 9 \\
\hline $10-20 \mathrm{~cm}$ & 1 & 5 & 0 & 0 & 6 \\
\hline $20-30 \mathrm{~cm}$ & 0 & 6 & 0 & 0 & 6 \\
\hline $30-40 \mathrm{~cm}$ & 0 & 4 & 0 & 0 & 4 \\
\hline \multicolumn{6}{|l|}{ Test Unit 8} \\
\hline $0-10 \mathrm{~cm}$ & 0 & 1 & 0 & 0 & 1 \\
\hline $10-20 \mathrm{~cm}$ & 0 & 1 & 0 & 0 & 1 \\
\hline $20-26 \mathrm{~cm}$ & 0 & 0 & 0 & 0 & 0 \\
\hline \multicolumn{6}{|l|}{ Test Unit 9} \\
\hline $0-10 \mathrm{~cm}$ & 0 & 2 & 0 & 0 & 2 \\
\hline $10-20 \mathrm{~cm}$ & 0 & 1 & 0 & 0 & 1 \\
\hline $20-30 \mathrm{~cm}$ & 0 & 4 & 0 & 0 & 4 \\
\hline \multicolumn{6}{|l|}{ Test Unit 10} \\
\hline $0-10 \mathrm{~cm}$ & 0 & 11 & 0 & 0 & 11 \\
\hline $10-20 \mathrm{~cm}$ & 0 & 6 & 0 & 0 & 6 \\
\hline $20-30 \mathrm{~cm}$ & 0 & 2 & 1 & 0 & 3 \\
\hline $30-40 \mathrm{~cm}$ & 0 & 0 & 0 & 0 & 0 \\
\hline Feature 1 & 0 & 4 & 0 & 0 & 4 \\
\hline BHT 3 & 1 & 0 & 0 & 0 & 1 \\
\hline BHT 6 & 0 & 1 & 0 & 0 & 1 \\
\hline BHT 8 & 1 & 0 & 0 & 0 & 1 \\
\hline BHT 11 & 0 & 0 & 0 & 1 & 1 \\
\hline BHT 12 & 2 & 0 & 0 & 0 & 2 \\
\hline BHT 16 & 0 & 1 & 0 & 0 & 1 \\
\hline BHT 19 & 0 & 0 & 1 & 0 & 1 \\
\hline BHT 21 & 0 & 2 & 0 & 0 & 2 \\
\hline BHT 22 & 1 & 0 & 0 & 0 & 1 \\
\hline Totals & 6 & 146 & 4 & 1 & 157 \\
\hline
\end{tabular}

\section{Work Accomplished in Intensive Testing}

Testing investigations began with geophysical survey of a 40x40-m grid on the southeast edge of the site, encompassing and adjacent to positive Auger Tests 6, 8, 58, 59, 61, and 62 (Figure 2.31). A variety of anomalies were identified, but none appeared to be clear candidates for prehistoric cultural features (see Appendix B). Thirty backhoe trenches and ten 1x1-m test units subsequently were excavated within the geophysical survey grid. The trenches were $1.0 \mathrm{~m}$ wide, ranged from 5.5 to 6.8 long $($ mean $=6.5 \mathrm{~m})$, and had maximum depths ranging from 25 to $76 \mathrm{~cm}($ mean $=58 \mathrm{~cm})$. The area stripped through trenching totaled $194 \mathrm{~m}^{2}$. Excavated test units were almost evenly divided between isolated units and units opened off of backhoe trenches. Unit depths ranged from 20 to $60 \mathrm{~cm}$ below the surface $($ mean $=40 \mathrm{~cm})$.

The walls of nine trenches were described and display A-E-Bt soil profiles. The A horizon was 8 to $12 \mathrm{~cm}$ thick and consisted of dark brown (10YR 3/3), dark yellowish brown (10YR $3 / 4$ ), dark grayish brown (10YR 4/2), and dark brown to brown (10YR 4/3) very fine sand. The E horizon was 6 to $31 \mathrm{~cm}$ thick and consisted of yellowish brown (10YR 5/4) and light yellowish brown (10YR 6/4) fine sand. The Bt horizon 


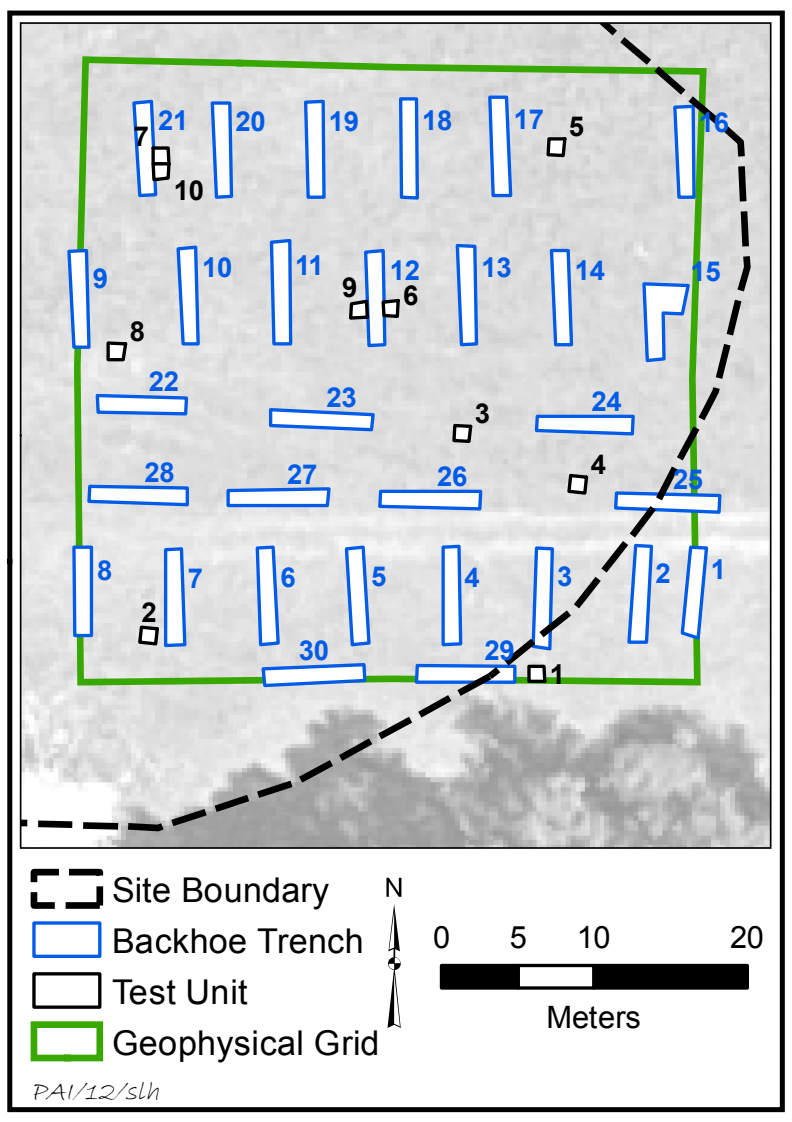

Figure 2.31. Aerial photograph of 41 TT862 showing geophysical survey grid and test excavations.

was well-structured firm dark yellowish brown (10YR4/6) and strong brown (7.5YR 5/6, 5/8) sandy clay loam to sandy clay with occasional yellowish brown (10YR 5/6) mottles.

\section{Results}

The single feature identified in the testing may correlate with one of the magnetometer and magnetic susceptibility anomalies in the center of the grid. Feature 1 was detected during the excavation of Trench 12 and fully exposed by Test Units 6 and 9 (Figure 2.32). It consisted of an oval scatter of friable fire-cracked rocks that typically was one layer thick. All of the clasts were ferruginous sandstone; most were irregular cobbles, but several tabular pieces were also present. The scatter was at $28-34 \mathrm{~cm}$ below the surface and was $170 \times 160 \mathrm{~cm}$ across. An oval,
$80 \times 50-\mathrm{cm}$ area in the central portion was devoid of rocks, suggesting that it represents a cleaned out hearth or earth oven. No charcoal-stained sediment, charred botanical material, or artifacts were observed in the fill surrounding the burned rocks during feature excavation, however, four small flakes were recovered from processed flotation samples. Feature 1 consisted of 301 fire-cracked rocks that had a combined weight of $35.5 \mathrm{~kg}$.

Artifacts were recovered from 11 auger tests, all of the test units, and 9 of the trenches (see Table 2.13). Recovered artifacts consist of 6 chipped stone tools, 146 pieces of debitage, 4 cores, and 1 ground stone tool, as well as burned rocks from Feature 1 and a few nonfeature proveniences. The chipped stone tools consist of 1 Gary dart point and 5 bifaces. The Gary point, from Level 2 of Test Unit 7, has a contracting stem with convex base and extensive retouch on the blade (Figure 2.33a); it is made of Ogallala quartzite. Of the bifaces, 4 are early stage and 1 is middle stage (Figure 2.33b-d). Three of the former are complete, and 1 is a medial fragment; 1 is of silicified wood, 2 are of quartzite, and 1 is of local red chert. The middle-stage distal biface fragment is of quartzite.

The 3 flake cores are of local materials ( 1 of chert, 1 of Ogallala quartzite, and 1 of another local quartzite), as is the tested quartzite cobble. The 121 pieces of debitage collected (excluding the 4 unanalyzed flakes from Feature 1 and 18 flakes from auger tests that were not collected) are of locally available materials with 64 percent $(\mathrm{n}=77)$ of quartzite, 26 percent $(\mathrm{n}=32)$ of chert, and the rest of silicified wood ( $\mathrm{n}=3$ ), ferruginous sandstone $(n=4)$ and hematite $(n=5)$. The debitage is mostly small with 93 percent smaller than $25 \mathrm{~mm}$. This reflects early reduction using small source materials as well as middle to late reduction and tool manufacture.

The single ground stone tool was used for several tasks (Figure 2.33e). This elongated ferruginous sandstone tabular cobble is roughly subrectangular in outline. Both faces are smooth from use as a mano. A shallow, smooth pit is in the center of one face, and concentrated percussion marks with incipient pitting are present in the center of the opposite face. These features indicate that this specimen was used as an anvil in conjunction with a hammer. Percussion marks are visible on the margins and ends as well. Some of these could be from 


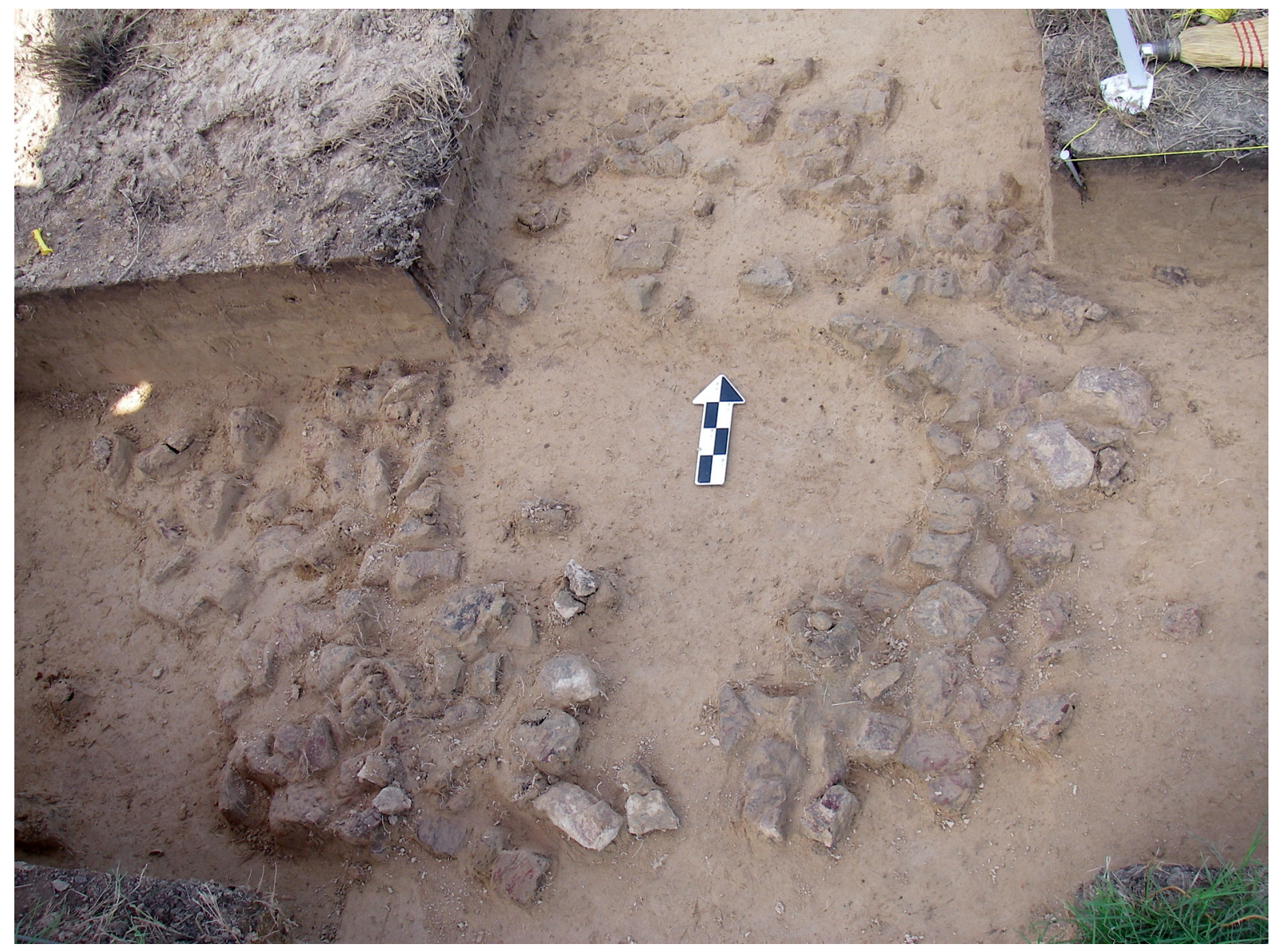

Figure 2.32. View to the north of Feature 1 exposed in Trench 12 and Test Units 6 and 9 at 41 TT862.

intentional shaping; however, concentrated battering at both ends and a flake scar on one end indicate that this artifact also was used as a hammerstone.

Artifact counts were highest in Test Units 5, 6,7 , and 10, which were in the north half of the geophysical survey grid. No significant vertical patterning was apparent. Almost 90 percent of the assemblage was found within $30 \mathrm{~cm}$ of the modern surface. The small amount of isolated burned rock documented in controlled excavation was in the top $30 \mathrm{~cm}$, with almost all of this material found in the immediate vicinity of Feature 1. By level, artifact recovery was as follows: 35 percent at $0-10 \mathrm{~cm} ; 23$ percent at $10-20 \mathrm{~cm} ; 29$ percent at $20-30 \mathrm{~cm} ; 7$ percent at $30-40 \mathrm{~cm} ; 5$ percent at $40-50 \mathrm{~cm}$; and 1 percent at $50-60 \mathrm{~cm}$.

\section{Conclusions}

Testing determined that 41 TT862 is a lowdensity lithic scatter. The presence of at least one burned rock feature and the nature of the artifact assemblage suggest low-intensity use as a campsite. The recovery of a Gary dart point and the lack of Caddo ceramics suggest use during the Woodland or Late Archaic periods. The absence of carbonized macrobotanical remains prevents a firmer chronological assessment, however, and the sparseness of cultural materials in general make this site difficult to interpret. Site 41TT862 was considered ineligible for listing in the National Register and designation as a State Antiquities Landmark because it does not contain isolable and interpretable archeological components. 


\section{SITE 41TT865}

Site $41 \mathrm{TT} 865$ is a small site on a slight rise in the narrow floodplain of an intermittent, channelized tributary of Tankersley Creek at the north end of the project area (Figure 2.34). The terrain east of the rise slopes moderately upward to an eroded hillcrest. The site is in maintained pasture with a mix of pasture and woods on the upland slope to the east and a line of trees along the drainage just to the west. According to designs in place at the time of auger testing, 41TT865 was in the path of the planned U.S. Highway 271/U.S. Highway 67 interchange. Subsequent design changes excluded the site from the highway right of way.

AEC recorded the site in 2002 and excavated 10 backhoe trenches and 5 test pits measuring $0.5 \times 0.5 \mathrm{~m}$ (Perttula et al. 2002). These efforts identified a midden on the rise and recovered 108 ceramic sherds, a Kent dart point, 2 cores, 18 pieces of lithic debris, burned clay, faunal bone, charred plant remains, and burned rocks. Ceramic analysis indicated that the midden dates to the Late Caddo Titus phase (Perttula and Nelson 2005; Perttula et al. 2003). The site was estimated to encompass $1,620 \mathrm{~m}^{2}$.

\section{Auger Testing}

Eighteen auger tests were placed across the plotted site location. The fact that all of these tests were negative indicated that the site had been misplotted, and an additional 16 tests were excavated on and around a low rise situated north of the first group of tests. Eight of the 16 additional tests contained prehistoric artifacts, confirming this as the location of the site (Table 2.14). Auger testing yielded 52 sherds, a
Gary dart point, 2 edge-modified flakes, 1 other chipped stone tool, 9 pieces of lithic debitage, and 1 core; a single ground stone tool was found on the surface. The rise was found to contain dark, organically rich midden sediments extending
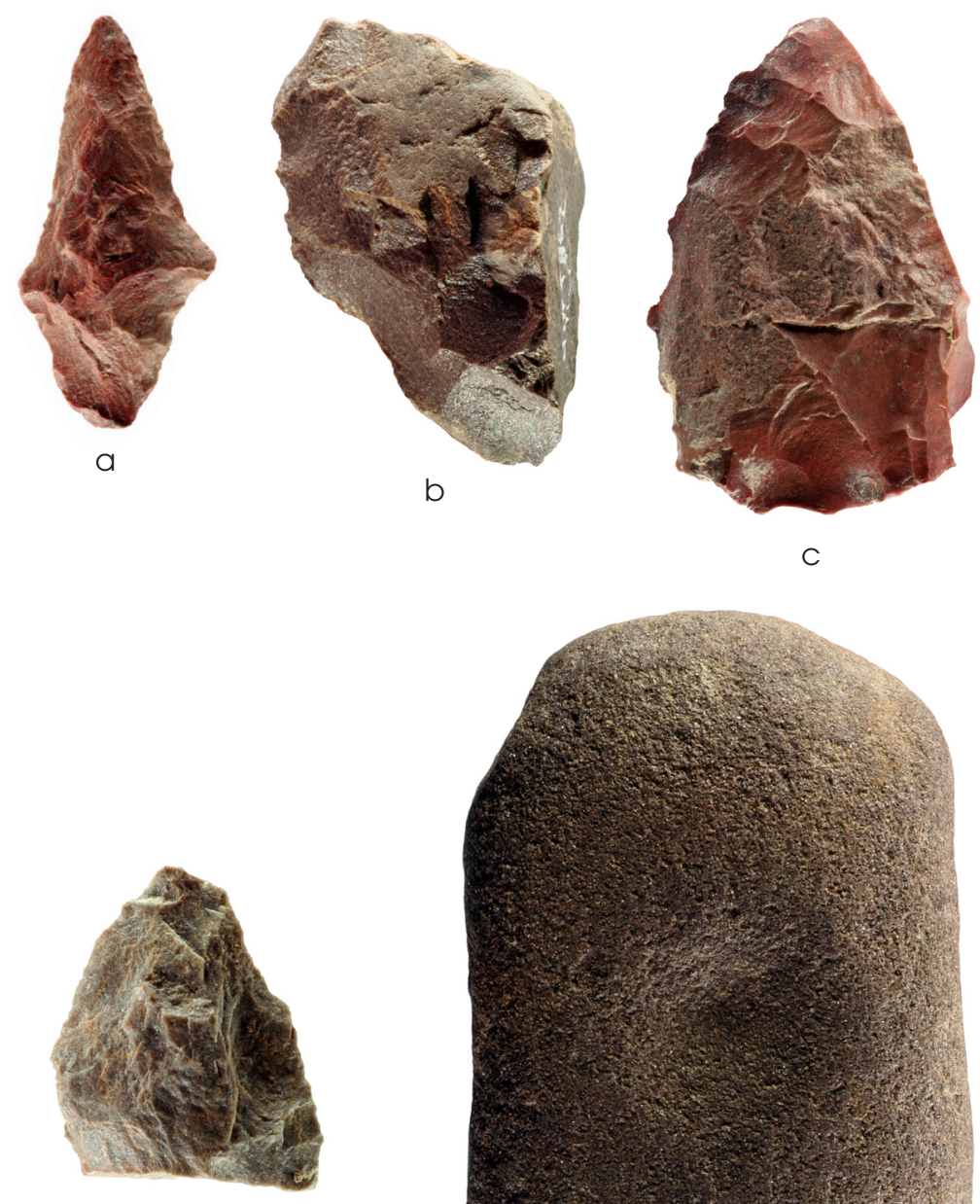

d

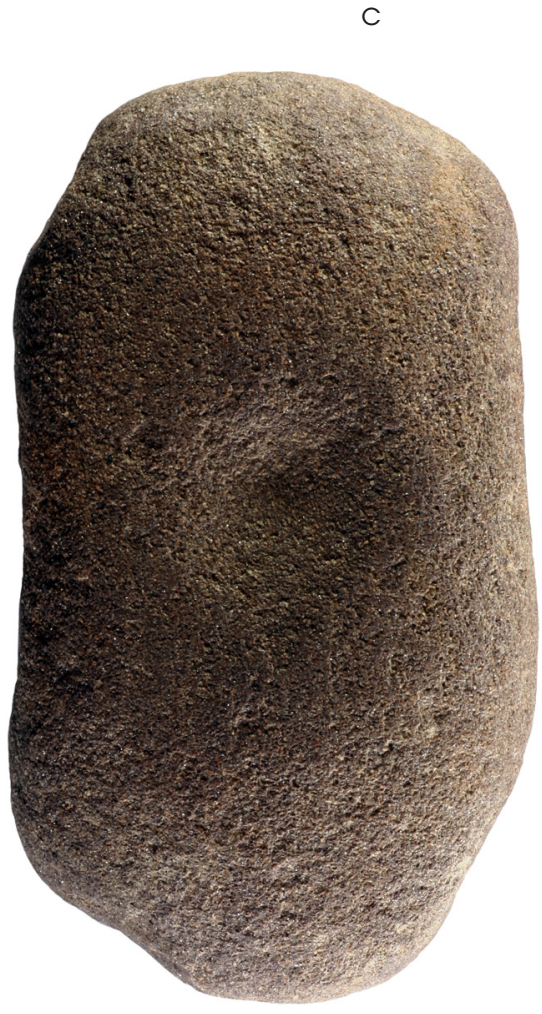

e

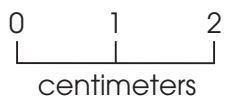

Figure 2.33. Stone tools recovered in testing at 41TT862. (a) Gary dart point; (b-c) early-stage bifaces; (d) middle-stage biface; (e) multifunctional ground stone tool. 


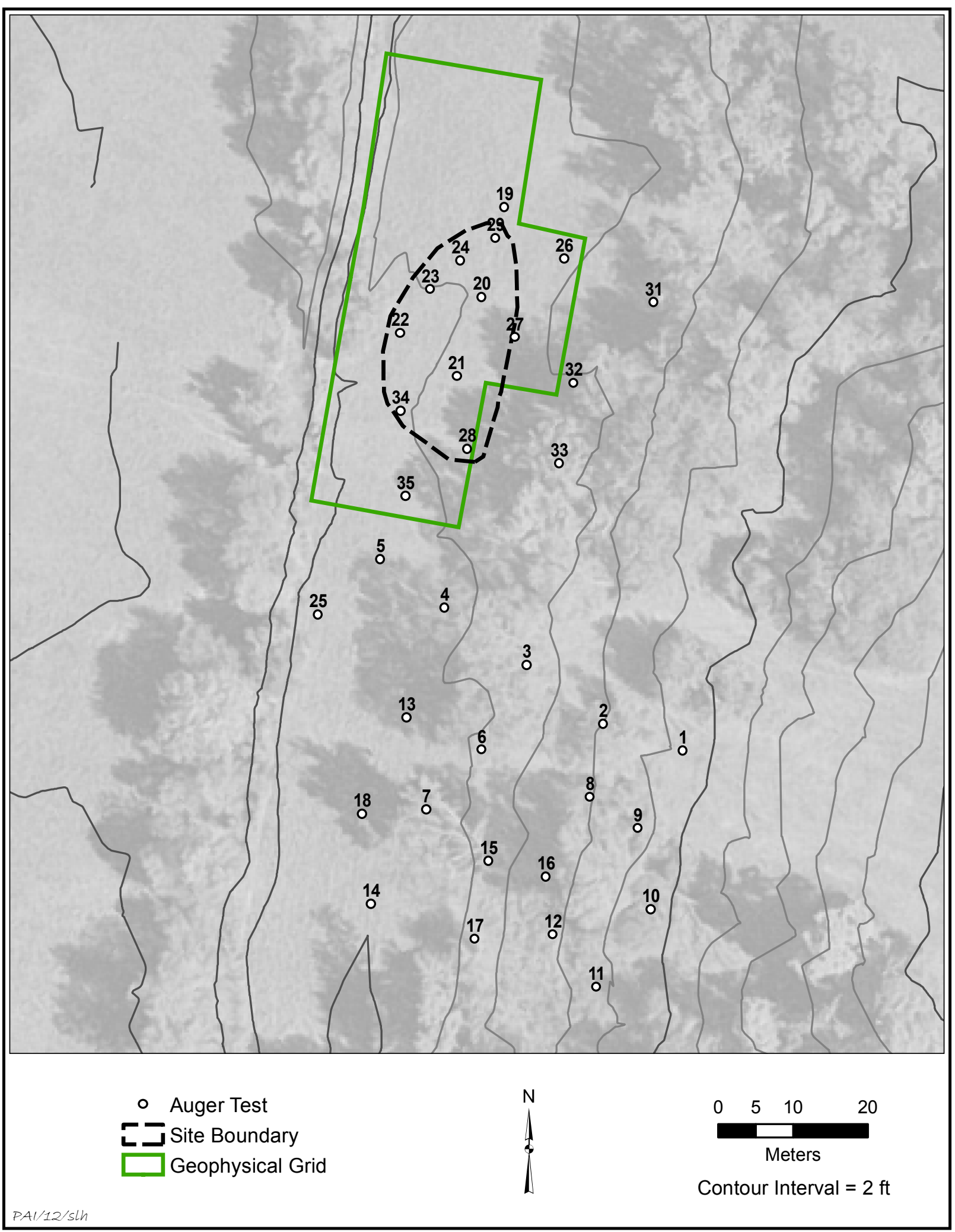

Figure 2.34. Map of 41TT865 showing topography, auger test locations, and geophysical survey grid on 2005 aerial imagery. 
Chapter 2: Testing

Table 2.14. Artifacts recovered in auger and intensive testing at 41TT865

\begin{tabular}{|c|c|c|c|c|c|c|}
\hline Provenience & $\begin{array}{c}\text { Chipped } \\
\text { Stone Tool }\end{array}$ & Debitage & Core & $\begin{array}{l}\text { Ground } \\
\text { Stone }\end{array}$ & Sherd & Totals \\
\hline Auger Test 20 & 0 & 0 & 0 & 0 & 4 & 4 \\
\hline Auger Test 22 & 0 & 2 & 0 & 0 & 6 & 8 \\
\hline Auger Test 23 & 1 & 5 & 0 & 0 & 17 & 23 \\
\hline Auger Test 24 & 0 & 0 & 0 & 0 & 20 & 20 \\
\hline Auger Test 28 & 1 & 2 & 1 & 0 & 0 & 4 \\
\hline Auger Test 29 & 0 & 0 & 0 & 0 & 2 & 2 \\
\hline Auger Test 31 & 1 & 0 & 0 & 0 & 1 & 2 \\
\hline Auger Test 34 & 1 & 0 & 0 & 0 & 2 & 3 \\
\hline \multicolumn{7}{|l|}{ Test Unit 1} \\
\hline $0-10 \mathrm{~cm}$ & 0 & 1 & 0 & 0 & 3 & 4 \\
\hline $10-20 \mathrm{~cm}$ & 0 & 0 & 0 & 0 & 3 & 3 \\
\hline $20-30 \mathrm{~cm}$ & 0 & 0 & 0 & 0 & 0 & 0 \\
\hline $30-40 \mathrm{~cm}$ & 0 & 0 & 0 & 0 & 0 & 0 \\
\hline \multicolumn{7}{|l|}{ Test Unit 2} \\
\hline $0-10 \mathrm{~cm}$ & 0 & 0 & 0 & 0 & 8 & 8 \\
\hline $10-20 \mathrm{~cm}$ & 0 & 8 & 0 & 0 & 23 & 31 \\
\hline $20-30 \mathrm{~cm}$ & 0 & 1 & 0 & 0 & 9 & 10 \\
\hline $30-40 \mathrm{~cm}$ & 0 & 0 & 0 & 0 & 1 & 1 \\
\hline \multicolumn{7}{|l|}{ Test Unit 3} \\
\hline $0-10 \mathrm{~cm}$ & 0 & 0 & 0 & 0 & 0 & 0 \\
\hline $10-20 \mathrm{~cm}$ & 0 & 0 & 0 & 0 & 8 & 8 \\
\hline $20-30 \mathrm{~cm}$ & 0 & 0 & 0 & 0 & 0 & 0 \\
\hline \multicolumn{7}{|l|}{ Test Unit 4} \\
\hline $0-10 \mathrm{~cm}$ & 0 & 7 & 0 & 0 & 18 & 24 \\
\hline $10-20 \mathrm{~cm}$ & 0 & 1 & 0 & 0 & 24 & 25 \\
\hline $20-30 \mathrm{~cm}$ & 1 & 2 & 0 & 0 & 18 & 21 \\
\hline $30-40 \mathrm{~cm}$ & 0 & 2 & 0 & 0 & 2 & 4 \\
\hline $40-50 \mathrm{~cm}$ & 0 & 0 & 0 & 0 & 0 & 0 \\
\hline \multicolumn{7}{|l|}{ Test Unit 5} \\
\hline $0-10 \mathrm{~cm}$ & 0 & 0 & 0 & 0 & 2 & 2 \\
\hline $10-20 \mathrm{~cm}$ & 0 & 1 & 0 & 0 & 12 & 13 \\
\hline $20-30 \mathrm{~cm}$ & 0 & 0 & 0 & 0 & 1 & 1 \\
\hline $30-40 \mathrm{~cm}$ & 0 & 0 & 0 & 0 & 0 & 0 \\
\hline $40-50 \mathrm{~cm}$ & 0 & 0 & 0 & 0 & 0 & 0 \\
\hline \multicolumn{7}{|l|}{ Test Unit 8} \\
\hline $0-10 \mathrm{~cm}$ & 0 & 1 & 0 & 0 & 6 & 7 \\
\hline $10-13 \mathrm{~cm}$ & 0 & 0 & 0 & 0 & 0 & 0 \\
\hline \multicolumn{7}{|l|}{ Test Unit 9} \\
\hline $0-10 \mathrm{~cm}$ & 0 & 3 & 0 & 0 & 5 & 8 \\
\hline $10-18 \mathrm{~cm}$ & 0 & 0 & 0 & 0 & 0 & 0 \\
\hline \multicolumn{7}{|l|}{ Test Unit 10} \\
\hline $0-10 \mathrm{~cm}$ & 0 & 2 & 0 & 0 & 0 & 2 \\
\hline $10-20 \mathrm{~cm}$ & 0 & 2 & 1 & 0 & 10 & 13 \\
\hline $20-30 \mathrm{~cm}$ & 0 & 2 & 0 & 0 & 6 & 8 \\
\hline $30-40 \mathrm{~cm}$ & 0 & 0 & 0 & 0 & 0 & 0 \\
\hline $40-50 \mathrm{~cm}$ & 0 & 0 & 0 & 0 & 0 & 0 \\
\hline
\end{tabular}


Excavations along the U.S. Highway 271 Mount Pleasant Relief Route

Table 2.14, continued

\begin{tabular}{|c|c|c|c|c|c|c|}
\hline Provenience & $\begin{array}{c}\text { Chipped } \\
\text { Stone Tool }\end{array}$ & Debitage & Core & $\begin{array}{l}\text { Ground } \\
\text { Stone }\end{array}$ & Sherd & Totals \\
\hline \multicolumn{7}{|l|}{ Test Unit 11} \\
\hline $0-10 \mathrm{~cm}$ & 0 & 2 & 0 & 0 & 1 & 3 \\
\hline $10-20 \mathrm{~cm}$ & 0 & 3 & 0 & 0 & 7 & 10 \\
\hline $20-30 \mathrm{~cm}$ & 0 & 0 & 0 & 0 & 0 & 0 \\
\hline $30-38 \mathrm{~cm}$ & 0 & 0 & 0 & 0 & 0 & 0 \\
\hline \multicolumn{7}{|l|}{ Test Unit 12} \\
\hline $0-10 \mathrm{~cm}$ & 0 & 0 & 0 & 0 & 1 & 1 \\
\hline $10-20 \mathrm{~cm}$ & 0 & 1 & 0 & 0 & 0 & 1 \\
\hline $20-30 \mathrm{~cm}$ & 0 & 0 & 0 & 0 & 1 & 1 \\
\hline $30-40 \mathrm{~cm}$ & 0 & 0 & 0 & 0 & 0 & 0 \\
\hline $40-44 \mathrm{~cm}$ & 0 & 0 & 0 & 0 & 0 & 0 \\
\hline \multicolumn{7}{|l|}{ Test Unit 13} \\
\hline $0-10 \mathrm{~cm}$ & 0 & 6 & 0 & 0 & 0 & 6 \\
\hline $10-20 \mathrm{~cm}$ & 0 & 2 & 0 & 0 & 0 & 2 \\
\hline $20-30 \mathrm{~cm}$ & 0 & 2 & 0 & 0 & 0 & 2 \\
\hline $30-34 \mathrm{~cm}$ & 0 & 0 & 0 & 0 & 0 & 0 \\
\hline \multicolumn{7}{|l|}{ Test Unit 14} \\
\hline $0-10 \mathrm{~cm}$ & 0 & 0 & 0 & 0 & 0 & 0 \\
\hline $10-20 \mathrm{~cm}$ & 0 & 0 & 0 & 0 & 1 & 1 \\
\hline $20-30 \mathrm{~cm}$ & 0 & 0 & 0 & 0 & 1 & 1 \\
\hline \multicolumn{7}{|l|}{ Test Unit 15} \\
\hline $0-10 \mathrm{~cm}$ & 0 & 0 & 0 & 0 & 1 & 1 \\
\hline $10-20 \mathrm{~cm}$ & 0 & 0 & 0 & 0 & 1 & 1 \\
\hline $20-30 \mathrm{~cm}$ & 0 & 0 & 0 & 0 & 0 & 0 \\
\hline $30-40 \mathrm{~cm}$ & 0 & 0 & 0 & 0 & 0 & 0 \\
\hline \multicolumn{7}{|l|}{ Test Unit 16} \\
\hline $0-10 \mathrm{~cm}$ & 0 & 0 & 0 & 0 & 0 & 0 \\
\hline $10-20 \mathrm{~cm}$ & 0 & 1 & 0 & 0 & 0 & 1 \\
\hline $20-30 \mathrm{~cm}$ & 0 & 0 & 0 & 0 & 0 & 0 \\
\hline \multicolumn{7}{|l|}{ Test Unit 17} \\
\hline $0-10 \mathrm{~cm}$ & 0 & 0 & 0 & 0 & 0 & 0 \\
\hline $10-20 \mathrm{~cm}$ & 0 & 2 & 0 & 0 & 2 & 4 \\
\hline $20-30 \mathrm{~cm}$ & 0 & 0 & 0 & 0 & 0 & 0 \\
\hline \multicolumn{7}{|l|}{ Test Unit 18} \\
\hline $0-10 \mathrm{~cm}$ & 0 & 0 & 0 & 0 & 4 & 4 \\
\hline $10-20 \mathrm{~cm}$ & 0 & 9 & 0 & 0 & 5 & 14 \\
\hline $20-30 \mathrm{~cm}$ & 0 & 2 & 0 & 0 & 3 & 5 \\
\hline $30-40 \mathrm{~cm}$ & 0 & 0 & 0 & 0 & 0 & 0 \\
\hline \multicolumn{7}{|l|}{ Test Unit 19} \\
\hline $0-10 \mathrm{~cm}$ & 0 & 4 & 0 & 0 & 1 & 5 \\
\hline $10-20 \mathrm{~cm}$ & 0 & 1 & 0 & 0 & 8 & 9 \\
\hline $20-30 \mathrm{~cm}$ & 0 & 3 & 0 & 0 & 3 & 6 \\
\hline $30-40 \mathrm{~cm}$ & 0 & 3 & 0 & 0 & 1 & 4 \\
\hline \multicolumn{7}{|l|}{ Test Unit 20} \\
\hline $0-10 \mathrm{~cm}$ & 0 & 2 & 0 & 0 & 2 & 4 \\
\hline $10-20 \mathrm{~cm}$ & 0 & 8 & 1 & 0 & 7 & 16 \\
\hline $20-30 \mathrm{~cm}$ & 0 & 14 & 0 & 0 & 9 & 23 \\
\hline
\end{tabular}


Chapter 2: Testing

Table 2.14, continued

\begin{tabular}{|c|c|c|c|c|c|c|}
\hline Provenience & $\begin{array}{c}\text { Chipped } \\
\text { Stone Tool }\end{array}$ & Debitage & Core & $\begin{array}{l}\text { Ground } \\
\text { Stone }\end{array}$ & Sherd & Totals \\
\hline $30-40 \mathrm{~cm}$ & 0 & 0 & 0 & 0 & 1 & 1 \\
\hline \multicolumn{7}{|l|}{ Test Unit 21} \\
\hline $0-10 \mathrm{~cm}$ & 0 & 2 & 0 & 0 & 2 & 4 \\
\hline $10-20 \mathrm{~cm}$ & 0 & 3 & 0 & 0 & 4 & 7 \\
\hline $20-30 \mathrm{~cm}$ & 1 & 57 & 1 & 0 & 7 & 66 \\
\hline $30-40 \mathrm{~cm}$ & 0 & 3 & 0 & 0 & 2 & 5 \\
\hline \multicolumn{7}{|l|}{ Test Unit 22} \\
\hline $0-10 \mathrm{~cm}$ & 0 & 6 & 0 & 0 & 3 & 9 \\
\hline $10-20 \mathrm{~cm}$ & 0 & 6 & 0 & 0 & 11 & 17 \\
\hline $20-30 \mathrm{~cm}$ & 0 & 0 & 0 & 0 & 0 & 0 \\
\hline $30-34 \mathrm{~cm}$ & 0 & 0 & 0 & 0 & 0 & 0 \\
\hline \multicolumn{7}{|l|}{ Test Unit 23} \\
\hline $0-10 \mathrm{~cm}$ & 0 & 1 & 0 & 0 & 3 & 4 \\
\hline $10-20 \mathrm{~cm}$ & 0 & 8 & 0 & 0 & 8 & 16 \\
\hline $20-30 \mathrm{~cm}$ & 0 & 1 & 0 & 0 & 1 & 2 \\
\hline \multicolumn{7}{|l|}{ Test Unit 24} \\
\hline $0-10 \mathrm{~cm}$ & 0 & 3 & 0 & 0 & 4 & 7 \\
\hline $10-20 \mathrm{~cm}$ & 0 & 3 & 1 & 0 & 5 & 9 \\
\hline $20-30 \mathrm{~cm}$ & 0 & 1 & 1 & 0 & 0 & 2 \\
\hline \multicolumn{7}{|l|}{ Test Unit 25} \\
\hline $0-10 \mathrm{~cm}$ & 0 & 3 & 0 & 0 & 1 & 4 \\
\hline $10-20 \mathrm{~cm}$ & 0 & 5 & 0 & 0 & 5 & 10 \\
\hline $20-30 \mathrm{~cm}$ & 0 & 0 & 0 & 0 & 0 & 0 \\
\hline Surface & 0 & 0 & 0 & 1 & 0 & 1 \\
\hline Totals & 6 & 209 & 6 & 1 & 327 & 549 \\
\hline
\end{tabular}

approximately $30 \mathrm{~m}$ north-south by $15 \mathrm{~m}$ eastwest. Auger Tests 20,22-24, and 29 on the rise contained 94 percent of the ceramic sherds and 57 percent of the chipped stone artifacts. Artifact recovery was sparse beyond the immediate perimeter of the rise. A modified flake, debitage, and a core were recovered from floodplain sediments in Auger Test 28, and a sherd and a modified flake were recovered from Auger Test 31 at the base of an eroded sideslope east of the midden. The findings of the auger testing reduced the site's size to $350 \mathrm{~m}^{2}$, including the midden deposit and the area immediately surrounding it.

Surface sand thickness corresponded well with topography. The thinnest deposits were on the upland slope, and the thickest deposits were situated in the narrow floodplain. The sand mantle had average and maximum basal depths
33 and $96 \mathrm{~cm}$ below the surface. Depths to clay on the rise ranged from 45 to almost $80 \mathrm{~cm}$.

\section{Work Accomplished in Intensive Testing}

Testing investigations began with geophysical survey of a $1,400-\mathrm{m}^{2}$ grid that encompassed the rise and adjoining floodplain to the north, south, and west, as well as a small section of the lower upland slope to the east (Figure 2.35); this grid included or was adjacent to all but one of the positive auger tests (Auger Test 31). The geophysical survey identified several anomalies that were considered to potentially have cultural origins (see Appendix B). A large (22x17 m) magnetometer anomaly was in the east-central part of the grid, a larger (30x17 m) partly overlapping resistivity anomaly was in the central portion, 


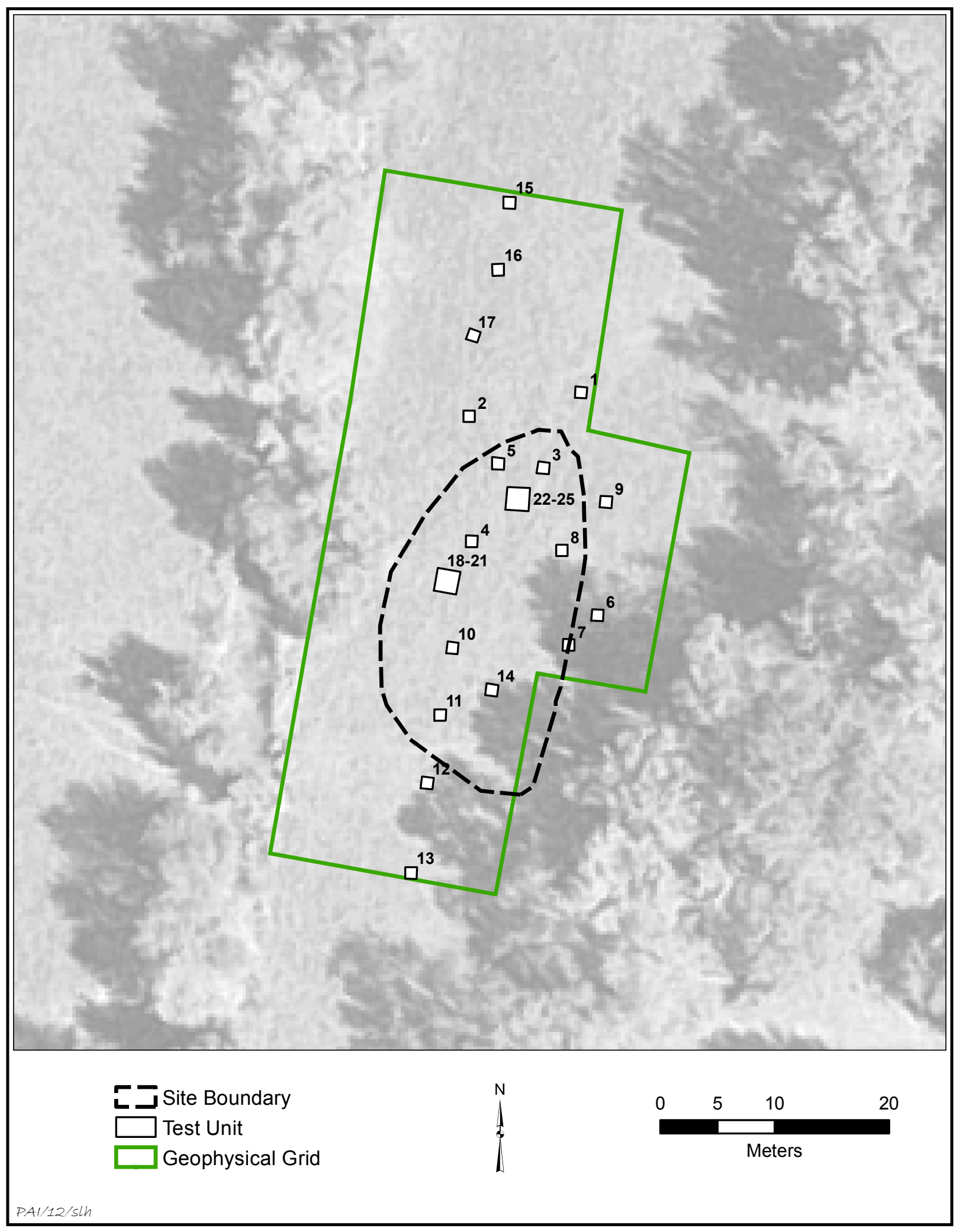

Figure 2.35. Aerial photograph of 41TT865 showing geophysical survey grid and test excavations. 
and an oval magnetic susceptibility anomaly (ca. $17 \times 9 \mathrm{~m}$ ) overlapped the central part of the resistivity anomaly; the latter two were considered to mark anthropogenic midden deposits. Two linear magnetic susceptibility anomalies crossed the southeast and east-central parts of the grid, partially overlapping the large magnetometer anomaly, and were considered possible markers of fences or other barriers.

Mechanical trench excavation was not done at this site due to its small size and because manual excavation was considered a sufficient means of assessing midden preservation. Rather, twenty-five $1 \mathrm{x} 1$-m test units were opened in the east-central portion of the grid and along its length, thus ensuring that all of the geophysical anomalies would be sampled. Most of the test units were isolated $1 \times 1-\mathrm{m}$ units, but two $2 \times 2-\mathrm{m}$ blocks (composed of Test Units 18-21 and 22-25) were on the rise. Test unit depths ranged from 5 to $50 \mathrm{~cm}$ below the surface, though the depth to the clay subsoil was at least $59 \mathrm{~cm}$ in one unit (Test Unit 20) that could not be excavated to clay due to the water table. This occurred in four other test units as well (Test Units 2, 18, 19 , and 21), where the depth of the clay subsoil ranged from 46 to $53 \mathrm{~cm}$ below the surface but the depth of excavation was limited to $40 \mathrm{~cm}$.

The profiles of five test units were described. Three of the profiles are from Test Units $3,4,18$, and 19 on the rise. Their profiles are distinctly different from the profiles of test units off the rise. Profiles from the rise display A-C$\mathrm{Ab}-\mathrm{C}-\mathrm{Bt}$ soils. The A horizon was $4-6 \mathrm{~cm}$ thick and consisted of very dark grayish brown (10YR $3 / 2$ ) to dark brown (10YR 3/3) very fine sandy loam and loamy very fine sand. The underlying $\mathrm{C}$ horizon was 13 to $15 \mathrm{~cm}$ thick and consisted of brown (7.5YR 4/3, 10YR 4/3, and 10YR 5/4) very fine sandy loam with some faint redox mottles. A dark organic-rich zone, designated an $\mathrm{Ab}$ horizon, was below the $\mathrm{C}$ horizon. It was 7 to $19 \mathrm{~cm}$ thick and consisted of dark grayish brown (10YR 4/2) or mottled very dark grayish brown (10YR 3/2) and brown (10YR 4/3) or yellowish brown (10YR 5/4) very fine sandy loam. This zone is primarily limited to the rise and is probably anthropogenic in nature. In some areas, the top of this buried soil is eroded and covered with gravelly material. The underlying $\mathrm{C}$ horizon was 7 to $20 \mathrm{~cm}$ thick and consisted of brown (7.5YR 4/4) to light yellowish brown (10YR 6/4) very fine sandy loam, with some exposures displaying distinct redox mottles. The Bt soil horizon was grayish brown (10YR 5/2) to light brownish gray (10YR 6/2) and exhibited many redox mottles and some manganese staining. Profiles of test units off the rise exhibited A-C-C2-Bt soil profiles and lacked the buried organic-rich zone observed on the rise.

\section{Results}

None of the geophysical anomalies correlated with discrete cultural features, and no features other than the midden deposit were identified in the test units. Artifacts were recovered from eight auger tests, and all test pits but Test Units 6 and 7, which were at the base of the upland slope east of the rise. The assemblage consists of 327 ceramic sherds, 6 chipped stone tools, 209 pieces of debitage, 6 cores, 1 ground/ battered stone, $3.9 \mathrm{~g}$ of burned clay, a fragmented cow/bison (Bos/Bison) tooth, and $7.87 \mathrm{~g}$ of carbonized botanical material (see Table 2.14).

Of the total 327 sherds $(1,366.0 \mathrm{~g}), 135$ $(1003.0 \mathrm{~g})$ are large enough for analysis. Of these, 109 are vessel body sherds, 7 are carinated body sherds, 5 are rim sherds, 1 is a rim/carination sherd, 8 are neck sherds, and 5 are base sherds. Eighty-six sherds have grog alone as temper, 46 have grog and bone, 2 have grog and bone along with voids that probably represent leached bone, and 1 has bone alone. Interior and exterior surfaces are mostly floated or smoothed, but 11 percent of all surfaces are burnished with 13 sherds burnished on both the interior and exterior. Two sherds have scraped interiors, suggesting they may be fragments of bottles or ollas, and 2 other sherds have red or reddish-brown slipped exteriors. The rims are either everted or of indeterminate form with rolled, tapered, rounded, or indeterminate lips. Rim thickness ranges from 5.15 to $7.68 \mathrm{~mm}$. The bases are flat or of indeterminate form with a thickness range of 9.37 to $12.63 \mathrm{~mm}$. Vessel forms identified consist of two bottles, six bowls, and one jar.

Forty-two sherds are decorated: 14 engraved, 9 incised, 16 brushed, 2 punctated, and 1 appliquéd. The engraved sherds display rectilinear and curvilinear elements along with crosshatching. Only one of these clearly shows a slanted scroll motif with a possible open circle or half circle primary element (Figure 2.36a). This sherd was part of a carinated bowl and is typed as Ripley Engraved. Another engraved carinated 

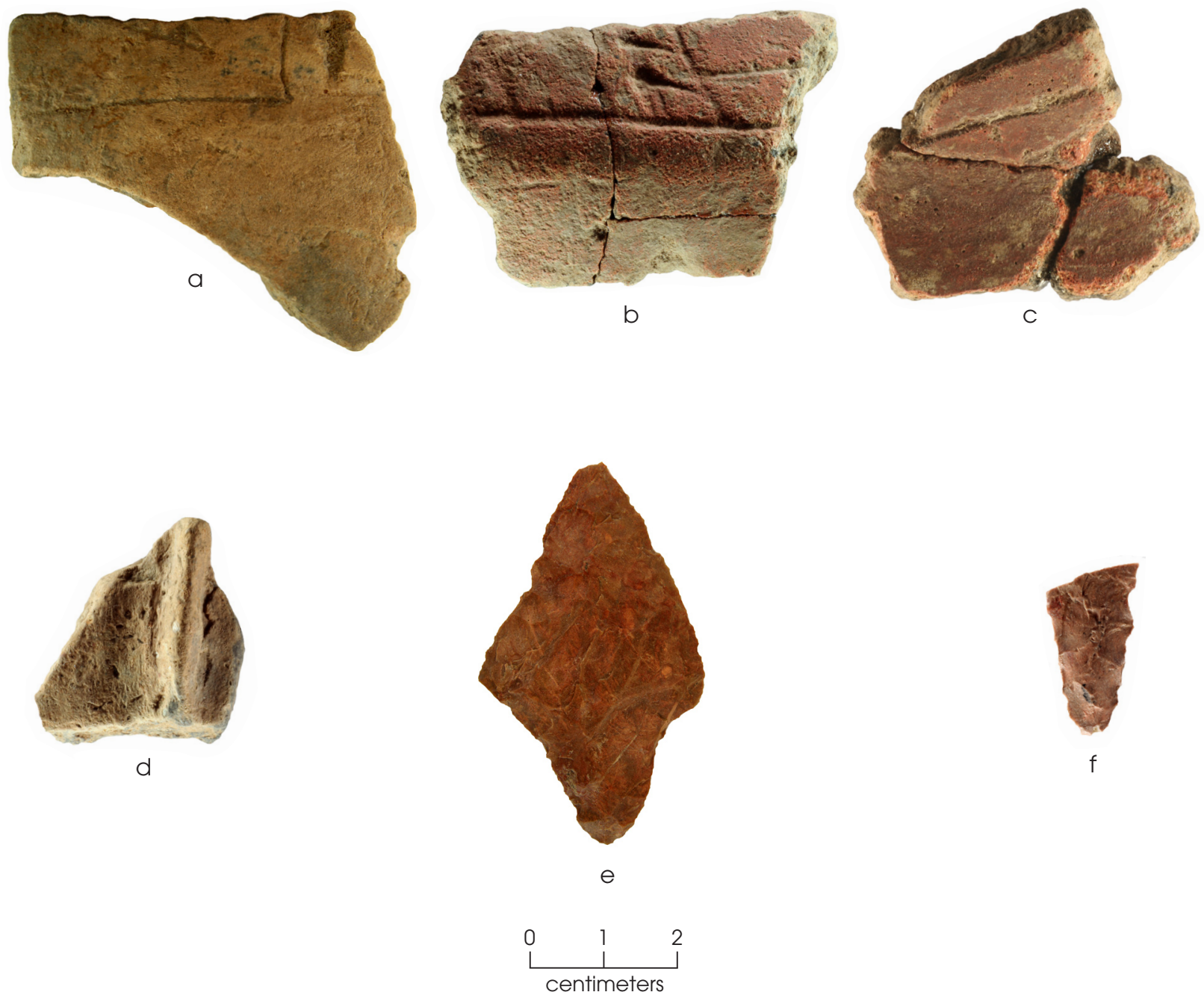

Figure 2.36. Artifacts recovered in testing at 41TT865. (a) Engraved carinated bowl sherd with slanted scroll motif; (b) engraved carinated bowl sherd with curvilinear lines and ticking; (c) jar neck sherd with incised diagonal lines; (d) body sherd with appliqué fillet; (e) Gary dart point; (f) untyped dart point.

bowl sherd has curvilinear lines and ticking, but not enough remains to define a motif or to associate it with a ceramic type (Figure 2.36b). Other sherds with incised diagonal lines or appliqué fillets suggest that Maydelle Incised and Pease Brushed-Incised are likely represented, though not enough of the sherds remain to make unequivocal identifications (Figure 2.36c-d). Ripley Engraved and probable Maydelle Incised and Pease Brushed-Incised, along with the high incidence of brushing, indicate that most or all of the assemblage relates to Middle-Late Caddo occupations.
The chipped stone tools consist of two dart points and four flake tools. One dart point is a Gary of local reddish brown chert (Figure 2.36e). It is well made with a convex base and contracting stem; it is from Auger Test 34. The other is an untyped proximal dart point fragment, from Level 3 of Test Unit 4, of local dark brown chert (Figure 2.36f). The flake tools are a unifacial drill, an edge-modified flake/knife, an edge-modified flake/scraper, and a utilized flake. The drill, of local red chert, is from Level 3 of Test Unit 21. The edge-modified flake knife has light retouch indicative of light-duty expedient cutting; it is 
from Auger Test 28 and is of local dark reddish brown chert. The edge-modified flake scraper has light retouch and wear indicative of scraping and is made of silicified wood; it is from Auger Test 31 . The utilized flake was made of silicified wood and is from Auger Test 23.

The 4 cores consist of 1 of chert and 3 of silicified wood; the 2 core fragments are quartzite and silicified wood. Most of the 209 pieces of debitage (96 percent) are of local materials with chert $(n=95)$ and silicified wood $(n=83)$ making up the majority. Other local materials include quartzite $(\mathrm{n}=21)$ and sandstone $(\mathrm{n}=1)$. Nonlocal materials consist of some Edwards chert $(n=2)$, some gray chert $(n=6)$, and another nonlocal chert $(n=1)$. The debitage is mostly small with 91 percent smaller than $25 \mathrm{~mm}$. The small to medium size of the assemblage reflects small source materials and predominantly later reduction and tool production.

A ferruginous sandstone anvil was found on the surface between Auger Tests 4 and 13. This rounded vesicular cobble is roughly oval in plan and irregular in cross section. A well-defined pit (possibly an expanded natural vesicle) is on one relatively flat face. Slight surface smoothing around the pit is consistent with abrasion wear derived from using the anvil in conjunction with a hammer for crushing/pulverizing. Incipient pitting is evident in two adjacent locations, and percussion marks and spatially associated smoothing are present elsewhere on the same face.

A fragmented cow/bison (Bos/Bison) tooth was the only faunal material found. This unburned specimen was recovered between 30 and $40 \mathrm{~cm}$ below the surface in Test Unit 20, which places it within or below the anthropogenic deposit on the rise. While its vertical provenience suggests the tooth is that of a bison (Bison bison), it could just as easily be a cow (Bos taurus) tooth that was moved downward through bioturbation or other recent disturbance.

Two samples of carbonized plant material were recovered from Test Unit 10 south of the topographic rise. Hickory (Carya spp.) wood charcoal and carbonized nutshell and nut husk fragments were retrieved from Level 3 (20-30 cm), and oak (Quercus spp.) wood charcoal was collected at $30-40 \mathrm{~cm}$. The 44 fragments of hickory had a combined weight of $6.35 \mathrm{~g}$; the 10 pieces of oak weighed $1.52 \mathrm{~g}$.

The charcoal from Level 3 in Test Unit 10 yielded a corrected radiocarbon age of
$380 \pm 40$ B.P. $\left(\right.$ Beta- $242372 ;{ }^{13} \mathrm{C} /{ }^{12} \mathrm{C}$ Ratio $\left.=-25.5\right)$, with a calibrated two-sigma date range of A.D. 1440-1640. Charcoal from Level 4 had a corrected age of $2150 \pm 40$ B.P. (Beta-242373; ${ }^{13} \mathrm{C} /{ }^{12} \mathrm{C}$ Ratio $\left.=-26.9\right)$ and two sigma-ranges of 360-280/260-60 B.C.

The test units on and about the rise (Test Units $2-5$ and 18-25) were the most productive in terms of artifacts. These units produced 176 (85 percent) of the lithic artifacts and 226 (82 percent) of the sherds, for a density of 34 artifacts $/ \mathrm{m}^{2}$. The units to the north, south, and east of the rise typically had uniformly low artifact counts, averaging just 7 artifacts $/ \mathrm{m}^{2}$. In the units on the rise, 96 percent of all artifacts were recovered between 0 and $30 \mathrm{~cm}$ below the surface, which corresponded with the buried organic-rich soil horizon (Ab) and the overlying $\mathrm{A}$ and $\mathrm{C}$ horizons. By level, artifact recovery was as follows: 19 percent at $0-10 \mathrm{~cm} ; 44$ percent at $10-20 \mathrm{~cm} ; 34$ percent at $20-30 \mathrm{~cm}$; and 4 percent at $30-40 \mathrm{~cm}$. No artifacts were collected between 40 and $50 \mathrm{~cm}$ below the surface in these units. The presence of numerous artifacts in sediments above the buried midden deposit is likely the result of vegetation clearing and plowing, which helped move material upward in the soil column.

\section{Conclusions}

Testing confirmed that 41TT865 contains organically enriched midden deposits and has moderate lithic and ceramic artifact densities. Diagnostic ceramics and a radiocarbon date indicate that the midden deposit dates to the Late Caddo Titus phase. A Late Archaic-age radiocarbon date and the recovery of a Gary point and an untyped dart point, along with a Kent point found during previous investigations, indicate the presence of earlier materials as well. The lack of occupational features suggests that the small rise, covering an area of about $150 \mathrm{~m}^{2}$, represents a disposal point for a nearby Titus phase Caddo household. The location of the posited residential locality is unknown, although the uplands immediately east of the site are the most likely place since the rise is surrounded by low-lying floodplain in the other directions. While testing provided a moderately sized artifact sample and carbon for chronometric dating, the absence of an associated residential locality greatly limited what the site might communicate relative to the important research topics for this 


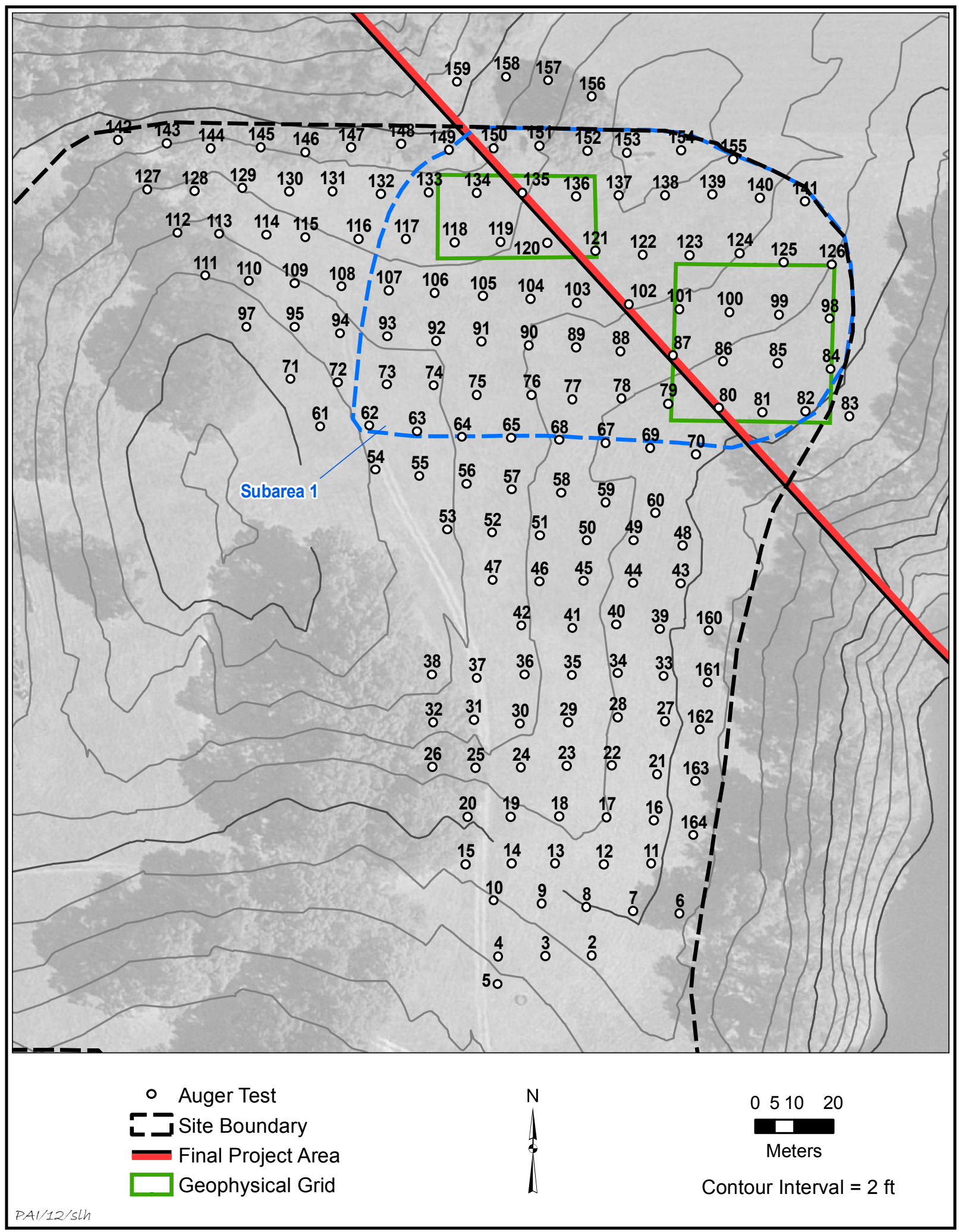

Figure 2.37. Map of 41TT866 showing topography, auger test locations, and geophysical survey grid on 2005 aerial imagery. 
project area. Consequently, 41TT865 was judged to lack the capacity to contribute important information and thus was considered ineligible for listing in the National Register and designation as a State Antiquities Landmark. Personnel with the Texas Department of Transportation and Texas Historical Commission did not concur with this assessment, but for the purposes of this project that became moot when subsequent redesign of the relief route excluded 41TT865 from the project area.

\section{SITE 41TT866}

Site 41TT866 is on a gently sloping upland surface on the dissected valley margin of Tankersley Creek, near the south end of the project area (Figure 2.37). The landform is bounded by intermittent tributaries on its north, west, and east sides. The drainage immediately east of the site holds the spring-fed stock tank that separates 41TT866 and 41TT862. Large oaks and other hardwoods fringe the drainages that border the site, with most of the site area in maintained pasture. The creation and use of two-track roads, installation of water pipelines, and fence construction had disturbed parts of the site. Only the northeast half of the site was in the project area as of the 2005 and 2007 work; subsequent design changes excluded all but the northeast edge.

Geo-Marine, Inc., surveyed this site at the landowner's request in 2001. Field efforts included shovel testing and backhoe trenching. Peter et al. (2001) described the site as a low-density prehistoric artifact scatter that covered $800 \mathrm{~m}^{2}$ on an eroding upland slope. AEC personnel formally recorded the site in 2002. Fifteen of 17 shovel tests were positive for prehistoric and historic artifacts. The assemblage consisted of 2 prehistoric ceramic sherds, an untyped dart point fragment, a flake tool, 17 flakes, a burned rock, charred nutshell fragments, and 6 historic artifacts possibly derived from a mid- to late-nineteenth-century farmstead. In addition, 5 pieces of lithic debris, 2 burned rocks, and several twentieth-century artifacts were recovered from the surface. Prehistoric artifacts were concentrated in the southeastern part of the site. Lithic artifacts and the 2 ceramic sherds were recovered between 0 and $40 \mathrm{~cm}$ below the surface in that area. Chipped stone artifacts were widely scat- tered across the remainder of the site (Perttula et al. 2002). According to the findings of the AEC survey, the site area was expanded to encompass $39,000 \mathrm{~m}^{2}$.

\section{Auger Testing}

In 2005,161 systematically spaced auger tests were placed across the site's northeast half (33 tests were excavated outside the 1000 -ft-wide project corridor accidentally). Eighteen tests within the corridor produced 5 ceramic sherds and 22 pieces of lithic debitage (Table 2.15). Auger Test 152 contained 38 burned rocks but no other artifacts; the large number of burned rocks in Auger Test 152 appeared to represent a burned rock feature. Eleven tests outside the corridor contained 7 sherds, 3 chipped stone tools, and 12 pieces of debitage. The lithic debris identified in the project corridor was more widely dispersed than the ceramics, though most was from tests on a small knoll at the eastern edge of the site. Eighteen lithic artifacts were recovered from 10 tests in a roughly $50 \times 50-\mathrm{m}$ area in that part of the site. Mostly isolated artifacts were recovered in 8 tests north and west of this concentration. Based on the auger testing results, the site extent within the project corridor was reduced to about $13,000 \mathrm{~m}^{2}$, and Subarea 1 characterized by low-density ceramics and lithics over an area of $8,400 \mathrm{~m}^{2}$ was defined to distinguish the area within the project corridor from the apparently separate scatter of materials to the south of it.

Clay subsoil, which was exposed in 130 of the tests, had average and maximum depths of 49 and $85 \mathrm{~cm}$. In the project corridor, relatively thick surface sands ( $60 \mathrm{~cm}$ or more) were encountered on the interfluve crest. Thinner surface sands in other parts of the site likely represent areas that had been impacted by erosion and various forms of human-derived disturbance.

\section{Work Accomplished in Intensive Testing}

Testing investigations began with geophysical surveys in two grids, a 40x40-m east grid and a 20x40-m west grid (Figure 2.38). These blocks were about $20 \mathrm{~m}$ apart within a dispersed low-density ceramic and lithic 
Excavations along the U.S. Highway 271 Mount Pleasant Relief Route

Table 2.15. Artifacts recovered in auger and intensive testing at 41TT866

\begin{tabular}{|c|c|c|c|c|c|c|c|}
\hline Provenience & $\begin{array}{c}\text { Chipped } \\
\text { Stone Tool }\end{array}$ & Debitage & Core & $\begin{array}{c}\text { Ground } \\
\text { Stone Tool }\end{array}$ & Sherd & Bone & Totals \\
\hline Auger Test 62 & 0 & 1 & 0 & 0 & 0 & 0 & 1 \\
\hline Auger Test 76 & 0 & 0 & 0 & 0 & 1 & 0 & 1 \\
\hline Auger Test 80 & 0 & 2 & 0 & 0 & 0 & 0 & 2 \\
\hline Auger Test 81 & 0 & 2 & 0 & 0 & 0 & 0 & 2 \\
\hline Auger Test 82 & 0 & 1 & 0 & 0 & 0 & 0 & 1 \\
\hline Auger Test 84 & 0 & 1 & 0 & 0 & 0 & 0 & 1 \\
\hline Auger Test 85 & 0 & 2 & 0 & 0 & 0 & 0 & 2 \\
\hline Auger Test 86 & 0 & 4 & 0 & 0 & 0 & 0 & 4 \\
\hline Auger Test 87 & 0 & 1 & 0 & 0 & 0 & 0 & 1 \\
\hline Auger Test 88 & 0 & 1 & 0 & 0 & 0 & 0 & 1 \\
\hline Auger Test 91 & 0 & 1 & 0 & 0 & 0 & 0 & 1 \\
\hline Auger Test 99 & 0 & 2 & 0 & 0 & 0 & 0 & 2 \\
\hline Auger Test 126 & 0 & 2 & 0 & 0 & 0 & 0 & 2 \\
\hline Auger Test 133 & 0 & 0 & 0 & 0 & 1 & 0 & 1 \\
\hline Auger Test 134 & 0 & 0 & 0 & 0 & 2 & 0 & 2 \\
\hline Auger Test 135 & 0 & 0 & 0 & 0 & 1 & 0 & 1 \\
\hline Auger Test 140 & 0 & 1 & 0 & 0 & 0 & 0 & 1 \\
\hline Auger Test 155 & 0 & 1 & 0 & 0 & 0 & 0 & 1 \\
\hline \multicolumn{8}{|l|}{ Test Unit 1} \\
\hline $0-10 \mathrm{~cm}$ & 0 & 0 & 0 & 0 & 0 & 0 & 0 \\
\hline $10-20 \mathrm{~cm}$ & 1 & 0 & 0 & 0 & 0 & 0 & 1 \\
\hline $20-30 \mathrm{~cm}$ & 0 & 0 & 0 & 0 & 0 & 0 & 0 \\
\hline $30-40 \mathrm{~cm}$ & 0 & 0 & 0 & 0 & 0 & 0 & 0 \\
\hline \multicolumn{8}{|l|}{ Test Unit 2} \\
\hline $0-10 \mathrm{~cm}$ & 0 & 0 & 0 & 0 & 0 & 0 & 0 \\
\hline $10-20 \mathrm{~cm}$ & 0 & 0 & 0 & 0 & 0 & 0 & 0 \\
\hline $20-30 \mathrm{~cm}$ & 0 & 1 & 0 & 0 & 0 & 0 & 1 \\
\hline $30-40 \mathrm{~cm}$ & 0 & 2 & 0 & 0 & 0 & 0 & 2 \\
\hline $40-50 \mathrm{~cm}$ & 0 & 0 & 0 & 0 & 0 & 0 & 0 \\
\hline \multicolumn{8}{|l|}{ Test Unit 3} \\
\hline $0-10 \mathrm{~cm}$ & 2 & 3 & 0 & 0 & 16 & 0 & 21 \\
\hline $10-20 \mathrm{~cm}$ & 2 & 10 & 0 & 0 & 23 & 1 & 36 \\
\hline $20-30 \mathrm{~cm}$ & 0 & 1 & 0 & 0 & 2 & 3 & 6 \\
\hline $30-40 \mathrm{~cm}$ & 0 & 0 & 0 & 0 & 0 & 0 & 0 \\
\hline $40-50 \mathrm{~cm}$ & 0 & 1 & 0 & 0 & 6 & 0 & 6 \\
\hline $50-55 \mathrm{~cm}$ & 0 & 0 & 0 & 0 & 0 & 0 & 0 \\
\hline \multicolumn{8}{|l|}{ Test Unit 4} \\
\hline $0-10 \mathrm{~cm}$ & 0 & 0 & 0 & 0 & 1 & 0 & 1 \\
\hline $10-20 \mathrm{~cm}$ & 0 & 0 & 0 & 0 & 4 & 0 & 4 \\
\hline $20-30 \mathrm{~cm}$ & 0 & 0 & 0 & 0 & 3 & 0 & 3 \\
\hline $30-40 \mathrm{~cm}$ & 0 & 0 & 0 & 0 & 1 & 0 & 1 \\
\hline $40-50 \mathrm{~cm}$ & 0 & 0 & 0 & 0 & 0 & 0 & 0 \\
\hline $50-60 \mathrm{~cm}$ & 0 & 0 & 0 & 0 & 0 & 0 & 0 \\
\hline \multicolumn{8}{|l|}{ Test Unit 5} \\
\hline $0-10 \mathrm{~cm}$ & 0 & 0 & 1 & 0 & 11 & 0 & 12 \\
\hline $10-20 \mathrm{~cm}$ & 0 & 0 & 0 & 0 & 6 & 0 & 6 \\
\hline
\end{tabular}


Chapter 2: Testing

Table 2.15, continued

\begin{tabular}{|c|c|c|c|c|c|c|c|}
\hline Provenience & $\begin{array}{c}\text { Chipped } \\
\text { Stone Tool }\end{array}$ & Debitage & Core & $\begin{array}{c}\text { Ground } \\
\text { Stone Tool }\end{array}$ & Sherd & Bone & Totals \\
\hline $20-30 \mathrm{~cm}$ & 0 & 0 & 0 & 0 & 4 & 0 & 4 \\
\hline $30-40 \mathrm{~cm}$ & 0 & 0 & 0 & 0 & 1 & 0 & 1 \\
\hline $40-50 \mathrm{~cm}$ & 0 & 0 & 0 & 0 & 0 & 0 & 0 \\
\hline $50-60 \mathrm{~cm}$ & 0 & 0 & 0 & 0 & 0 & 0 & 0 \\
\hline $60-70 \mathrm{~cm}$ & 0 & 0 & 0 & 0 & 0 & 0 & 0 \\
\hline \multicolumn{8}{|l|}{ Test Unit 6} \\
\hline $0-10 \mathrm{~cm}$ & 0 & 2 & 0 & 0 & 11 & 0 & 13 \\
\hline $10-20 \mathrm{~cm}$ & 0 & 1 & 0 & 0 & 21 & 1 & 23 \\
\hline $20-30 \mathrm{~cm}$ & 0 & 2 & 1 & 0 & 12 & 0 & 15 \\
\hline $30-40 \mathrm{~cm}$ & 0 & 0 & 0 & 0 & 8 & 0 & 8 \\
\hline $40-50 \mathrm{~cm}$ & 0 & 0 & 0 & 0 & 5 & 2 & 7 \\
\hline $50-60 \mathrm{~cm}$ & 0 & 0 & 0 & 0 & 4 & 0 & 4 \\
\hline \multicolumn{8}{|l|}{ Test Unit 7} \\
\hline $0-10 \mathrm{~cm}$ & 0 & 4 & 0 & 0 & 0 & 0 & 4 \\
\hline $10-20 \mathrm{~cm}$ & 0 & 0 & 0 & 0 & 0 & 0 & 0 \\
\hline $20-30 \mathrm{~cm}$ & 0 & 0 & 0 & 0 & 0 & 0 & 0 \\
\hline $30-40 \mathrm{~cm}$ & 0 & 0 & 0 & 0 & 2 & 0 & 2 \\
\hline $40-50 \mathrm{~cm}$ & 0 & 0 & 0 & 0 & 0 & 0 & 0 \\
\hline $50-60 \mathrm{~cm}$ & 0 & 0 & 1 & 0 & 0 & 0 & 1 \\
\hline $60-70 \mathrm{~cm}$ & 0 & 1 & 0 & 0 & 0 & 0 & 1 \\
\hline \multicolumn{8}{|l|}{ Test Unit 8} \\
\hline $0-10 \mathrm{~cm}$ & 0 & 0 & 0 & 0 & 0 & 0 & 0 \\
\hline $10-20 \mathrm{~cm}$ & 0 & 2 & 0 & 0 & 0 & 0 & 2 \\
\hline $20-30 \mathrm{~cm}$ & 0 & 0 & 0 & 0 & 1 & 0 & 1 \\
\hline $30-40 \mathrm{~cm}$ & 0 & 0 & 0 & 0 & 0 & 0 & 0 \\
\hline \multicolumn{8}{|l|}{ Test Unit 9} \\
\hline $0-10 \mathrm{~cm}$ & 0 & 2 & 0 & 0 & 0 & 1 & 3 \\
\hline $10-20 \mathrm{~cm}$ & 0 & 0 & 0 & 0 & 0 & 0 & 0 \\
\hline $20-30 \mathrm{~cm}$ & 0 & 0 & 0 & 0 & 0 & 0 & 0 \\
\hline $30-40 \mathrm{~cm}$ & 0 & 0 & 0 & 0 & 0 & 0 & 0 \\
\hline $40-50 \mathrm{~cm}$ & 0 & 0 & 0 & 0 & 0 & 0 & 0 \\
\hline \multicolumn{8}{|l|}{ Test Unit 10} \\
\hline $0-10 \mathrm{~cm}$ & 0 & 0 & 0 & 0 & 0 & 0 & 0 \\
\hline $10-20 \mathrm{~cm}$ & 0 & 0 & 0 & 0 & 0 & 0 & 0 \\
\hline $20-30 \mathrm{~cm}$ & 0 & 1 & 0 & 0 & 0 & 0 & 1 \\
\hline $30-40 \mathrm{~cm}$ & 0 & 0 & 0 & 0 & 0 & 0 & 0 \\
\hline $40-50 \mathrm{~cm}$ & 0 & 0 & 0 & 0 & 0 & 0 & 0 \\
\hline \multicolumn{8}{|l|}{ Test Unit 11} \\
\hline $0-10 \mathrm{~cm}$ & 0 & 6 & 0 & 0 & 0 & 0 & 6 \\
\hline $10-20 \mathrm{~cm}$ & 0 & 4 & 0 & 0 & 0 & 0 & 4 \\
\hline $20-30 \mathrm{~cm}$ & 0 & 1 & 0 & 0 & 0 & 0 & 1 \\
\hline $30-40 \mathrm{~cm}$ & 0 & 2 & 0 & 0 & 0 & 0 & 2 \\
\hline $40-50 \mathrm{~cm}$ & 0 & 0 & 0 & 0 & 0 & 0 & 0 \\
\hline \multicolumn{8}{|l|}{ Test Unit 12} \\
\hline $0-10 \mathrm{~cm}$ & 0 & 0 & 0 & 0 & 0 & 0 & 0 \\
\hline $10-20 \mathrm{~cm}$ & 0 & 1 & 0 & 0 & 0 & 0 & 1 \\
\hline $20-30 \mathrm{~cm}$ & 0 & 1 & 0 & 0 & 0 & 0 & 1 \\
\hline
\end{tabular}


Table 2.15, continued

\begin{tabular}{|c|c|c|c|c|c|c|c|}
\hline Provenience & $\begin{array}{c}\text { Chipped } \\
\text { Stone Tool }\end{array}$ & Debitage & Core & $\begin{array}{c}\text { Ground } \\
\text { Stone Tool }\end{array}$ & Sherd & Bone & Totals \\
\hline $30-40 \mathrm{~cm}$ & 0 & 0 & 1 & 0 & 0 & 0 & 1 \\
\hline $40-50 \mathrm{~cm}$ & 0 & 1 & 0 & 0 & 0 & 0 & 1 \\
\hline \multicolumn{8}{|l|}{ Test Unit 13} \\
\hline $0-10 \mathrm{~cm}$ & 0 & 0 & 0 & 0 & 0 & 0 & 0 \\
\hline $10-20 \mathrm{~cm}$ & 0 & 3 & 0 & 0 & 0 & 0 & 3 \\
\hline $20-30 \mathrm{~cm}$ & 0 & 1 & 0 & 0 & 0 & 0 & 1 \\
\hline $30-40 \mathrm{~cm}$ & 0 & 0 & 0 & 0 & 0 & 0 & 0 \\
\hline $40-50 \mathrm{~cm}$ & 0 & 0 & 0 & 0 & 0 & 0 & 0 \\
\hline \multicolumn{8}{|l|}{ Test Unit 14} \\
\hline $0-10 \mathrm{~cm}$ & 0 & 0 & 0 & 0 & 0 & 0 & 0 \\
\hline $10-20 \mathrm{~cm}$ & 0 & 0 & 0 & 0 & 0 & 0 & 0 \\
\hline $20-30 \mathrm{~cm}$ & 0 & 0 & 0 & 0 & 0 & 0 & 0 \\
\hline $30-40 \mathrm{~cm}$ & 0 & 0 & 0 & 0 & 0 & 0 & 0 \\
\hline $40-50 \mathrm{~cm}$ & 0 & 1 & 0 & 0 & 0 & 0 & 1 \\
\hline \multicolumn{8}{|l|}{ Test Unit 15} \\
\hline $0-10 \mathrm{~cm}$ & 0 & 5 & 0 & 0 & 0 & 0 & 5 \\
\hline $10-20 \mathrm{~cm}$ & 0 & 3 & 0 & 0 & 0 & 0 & 3 \\
\hline $20-30 \mathrm{~cm}$ & 0 & 2 & 0 & 0 & 0 & 0 & 2 \\
\hline $30-40 \mathrm{~cm}$ & 0 & 2 & 0 & 0 & 0 & 0 & 2 \\
\hline $40-50 \mathrm{~cm}$ & 0 & 0 & 0 & 0 & 0 & 0 & 0 \\
\hline \multicolumn{8}{|l|}{ Test Unit 16} \\
\hline $0-10 \mathrm{~cm}$ & 0 & 0 & 0 & 0 & 0 & 0 & 0 \\
\hline $10-20 \mathrm{~cm}$ & 1 & 0 & 0 & 0 & 0 & 0 & 1 \\
\hline $20-30 \mathrm{~cm}$ & 0 & 0 & 0 & 0 & 0 & 0 & 0 \\
\hline $30-40 \mathrm{~cm}$ & 0 & 0 & 0 & 0 & 0 & 0 & 0 \\
\hline $40-50 \mathrm{~cm}$ & 0 & 0 & 0 & 0 & 0 & 0 & 0 \\
\hline \multicolumn{8}{|l|}{ Test Unit 17} \\
\hline $0-10 \mathrm{~cm}$ & 0 & 1 & 0 & 0 & 0 & 0 & 1 \\
\hline $10-20 \mathrm{~cm}$ & 0 & 1 & 0 & 0 & 0 & 0 & 1 \\
\hline $20-30 \mathrm{~cm}$ & 0 & 3 & 0 & 0 & 0 & 0 & 3 \\
\hline $30-40 \mathrm{~cm}$ & 0 & 0 & 0 & 0 & 0 & 0 & 0 \\
\hline \multicolumn{8}{|l|}{ Test Unit 18} \\
\hline $0-10 \mathrm{~cm}$ & 0 & 0 & 0 & 0 & 0 & 0 & 0 \\
\hline $10-20 \mathrm{~cm}$ & 0 & 3 & 0 & 0 & 0 & 0 & 3 \\
\hline $20-30 \mathrm{~cm}$ & 0 & 2 & 0 & 0 & 0 & 0 & 2 \\
\hline $30-40 \mathrm{~cm}$ & 0 & 0 & 0 & 0 & 0 & 0 & 0 \\
\hline Feature 3 & 0 & 0 & 0 & 1 & 0 & 0 & 1 \\
\hline Feature 5 & 1 & 1 & 0 & 0 & 14 & 86 & 102 \\
\hline ВНТ 9 & 0 & 0 & 1 & 0 & 0 & 0 & 1 \\
\hline BHT 20 & 0 & 1 & 1 & 0 & 0 & 0 & 2 \\
\hline BHT 25 & 0 & 1 & 0 & 0 & 0 & 0 & 1 \\
\hline BHT 26 & 0 & 2 & 0 & 0 & 0 & 0 & 2 \\
\hline BHT 27 & 0 & 1 & 0 & 0 & 0 & 0 & 1 \\
\hline BHT 32 & 0 & 0 & 0 & 0 & 2 & 0 & 2 \\
\hline ВНT 33 & 0 & 0 & 0 & 0 & 4 & 0 & 4 \\
\hline BHT 34 & 0 & 0 & 0 & 0 & 2 & 0 & 2 \\
\hline BHT 35 & 0 & 0 & 0 & 0 & 1 & 0 & 1 \\
\hline
\end{tabular}


Chapter 2: Testing

Table 2.15, continued

\begin{tabular}{l|c|c|c|c|c|c|c}
\hline \multicolumn{1}{c|}{ Provenience } & $\begin{array}{c}\text { Chipped } \\
\text { Stone Tool }\end{array}$ & Debitage & Core & $\begin{array}{c}\text { Ground } \\
\text { Stone Tool }\end{array}$ & Sherd & Bone & Totals \\
\hline BHT 37 & 0 & 0 & 0 & 0 & 3 & 0 & 3 \\
\hline BHT 38 & 0 & 0 & 1 & 0 & 23 & 0 & 24 \\
\hline BHT 39 & 0 & 0 & 0 & 1 & 0 & 0 & 1 \\
\hline BHT 40 & 0 & 1 & 0 & 0 & 1 & 0 & 2 \\
\hline BHT 43 & 0 & 0 & 0 & 0 & 3 & 0 & 3 \\
\hline BHT 44 & 0 & 0 & 0 & 0 & 11 & 0 & 11 \\
\hline BHT 46 & 0 & 0 & 0 & 0 & 6 & 0 & 6 \\
\hline BHT 49 & 0 & 0 & 0 & 0 & 4 & 0 & 4 \\
\hline Surface & 0 & 0 & 2 & 0 & 6 & 0 & 8 \\
\hline
\end{tabular}

\section{Outside Corridor:}

\begin{tabular}{l|l|l|l|l|l|l|l}
\hline Auger Test 2 & 1 & 0 & 0 & 0 & 0 & 0 & 1 \\
\hline Auger Test 6 & 0 & 1 & 0 & 0 & 0 & 0 & 1 \\
\hline Auger Test 8 & 0 & 1 & 0 & 0 & 0 & 0 & 1 \\
\hline Auger Test 10 & 0 & 1 & 0 & 0 & 0 & 0 & 1 \\
\hline Auger Test 13 & 0 & 2 & 0 & 0 & 0 & 0 & 2 \\
\hline Auger Test 14 & 1 & 1 & 0 & 0 & 6 & 0 & 8 \\
\hline Auger Test 17 & 0 & 2 & 0 & 0 & 0 & 0 & 2 \\
\hline Auger Test 19 & 1 & 0 & 0 & 0 & 1 & 0 & 2 \\
\hline Auger Test 21 & 0 & 1 & 0 & 0 & 0 & 0 & 1 \\
\hline
\end{tabular}

artifact distribution. The east grid was on the southeast edge of the investigated part of the site where positive Auger Tests 80-82 and $84-86$ were. There were no positive auger tests within the west grid, but several were just outside it to the south (Auger Tests 88 and 91) and north (Auger Tests 134 and 135).

The geophysical survey verified the location of a known subsurface irrigation pipeline in the east grid but identified no anomalies that appeared likely to be prehistoric features. Thirty trenches and 10 test units were placed in the east grid, and 20 trenches and 9 test units were placed in and around the west grid. The trenches were $1.0 \mathrm{~m}$ wide and ranged from 4.1 to $8.5 \mathrm{~m}$ in length $($ mean $=6.9 \mathrm{~m})$. Trench excavation stripped $208 \mathrm{~m}^{2}$ in the east grid and $135 \mathrm{~m}^{2}$ in the west grid. The test units in the east grid were set apart from the trenches. In the west grid, 5 test units were opened off of trenches and the other 4 were isolated. Test unit depths ranged from 20 to $70 \mathrm{~cm}$, with an average of $50 \mathrm{~cm}$.

The walls of 16 trenches (9 in the east grid and 7 in the west grid) were described and display mostly A-E-Bt soil profiles. Trenches 16, 46, 47, 49, and 50 exhibited A-E-Ab-Bt soil profiles. Midden deposits within an A1-A2-E-Bt soil profile were described for Trench 37 and Test Unit 6, and culturally enriched midden deposits were also noted in Trenches 38, 39, 44, 45, and 48 and Test Units 3 and 7.

The A-E-Bt soil profiles had an A horizon that was 8 to $30 \mathrm{~cm}$ thick and consisted of dark yellowish brown (10YR 3/4, 3/6, 4/3, 4/4) silty sand. The E horizon was 9 to $41 \mathrm{~cm}$ thick and consisted of dark yellowish brown (10YR 4/4), yellowish brown (10YR 5/4, 5/6,5/8), light yellowish brown (10YR 6/4), and brownish yellow (10YR 6/6) sand. The Bt horizon was firm dark yellowish brown (10YR 4/6), yellowish brown (10YR 5/4,5/8), and brownish yellow (10YR 6/6) sandy clay. Where present, the Ab soil horizon was 12 to $42 \mathrm{~cm}$ thick and consisted of dark yellowish brown (10YR 3/6, 4/6) sand below the $\mathrm{E}$ horizon. In Trench 37, the A1 horizon was $8 \mathrm{~cm}$ thick and consisted of dark yellowish brown (10YR 3/4) silty sand, and the A2 horizon was $15 \mathrm{~cm}$ thick and consisted of dark yellowish brown (10YR 4/6) silty sand. 


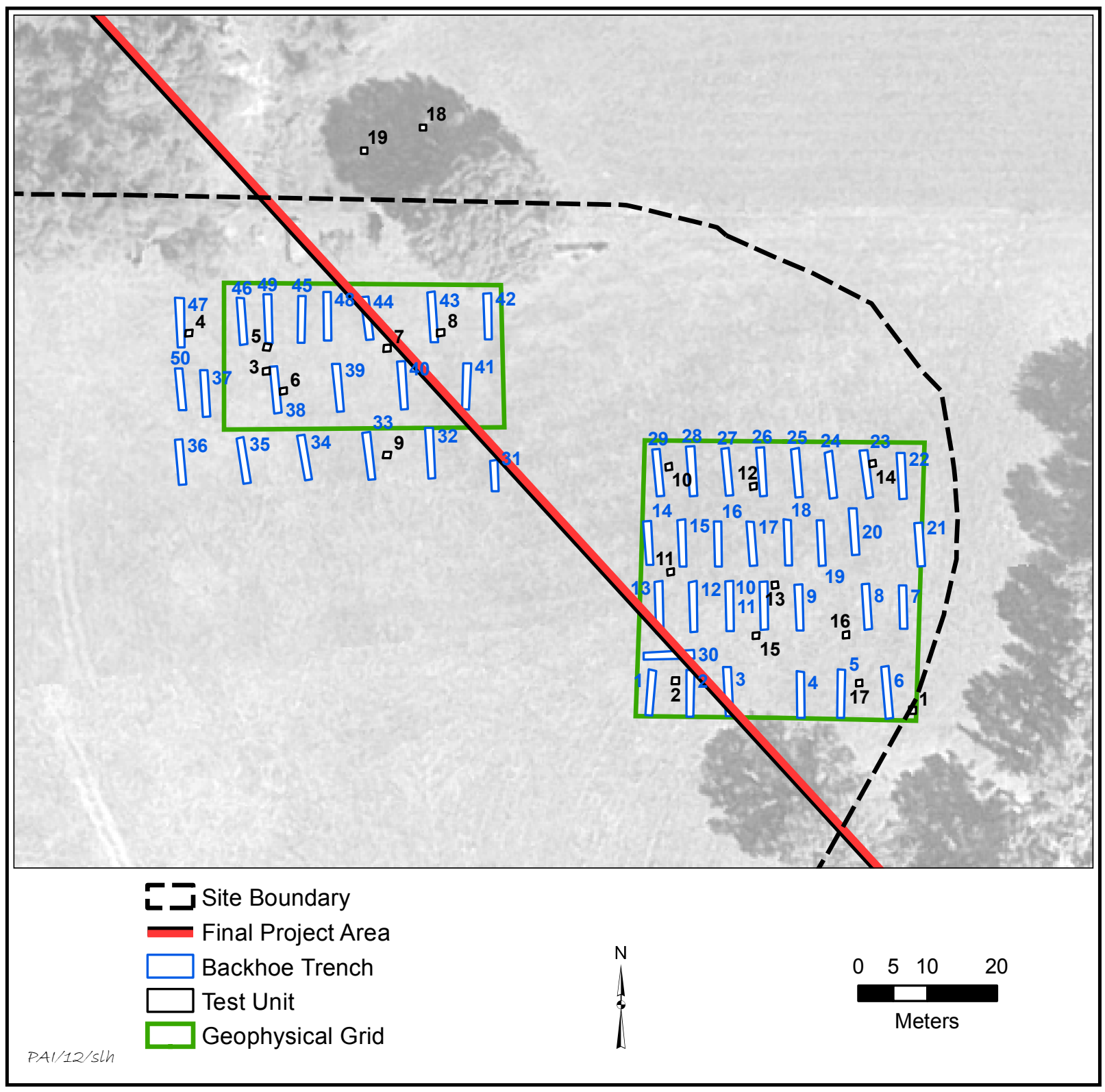

Figure 2.38. Aerial photograph of 41TT866 showing geophysical survey grids and test excavations.

\section{Cultural Features}

Twenty-two soil disturbances were identified during test excavations. Four were exposed in trenches in the east grid, and 18 were in trenches and units in the west grid. Nineteen of these were assigned feature numbers, only 1 of which was in the east grid. Ultimately, only 4 were assessed as cultural, consisting of 2 burned rock features, a pit, and a possible pit. All of these were in or around the west grid (Figure 2.39). The other disturbances were attributed to rodent activity, plant growth, and pedogenic processes. Soil disturbances originated in A2 or E horizon sediments, and most extended into the underlying Bt horizon.

Feature 3 was a dispersed scatter of burned rocks at the north end of Trench 35 (Figure 2.40). The exposed portion, extending $120 \times 100 \mathrm{~cm}$ in the trench floor at a depth of $33-43 \mathrm{~cm}$ below the surface, was a disarticulated scatter of a 


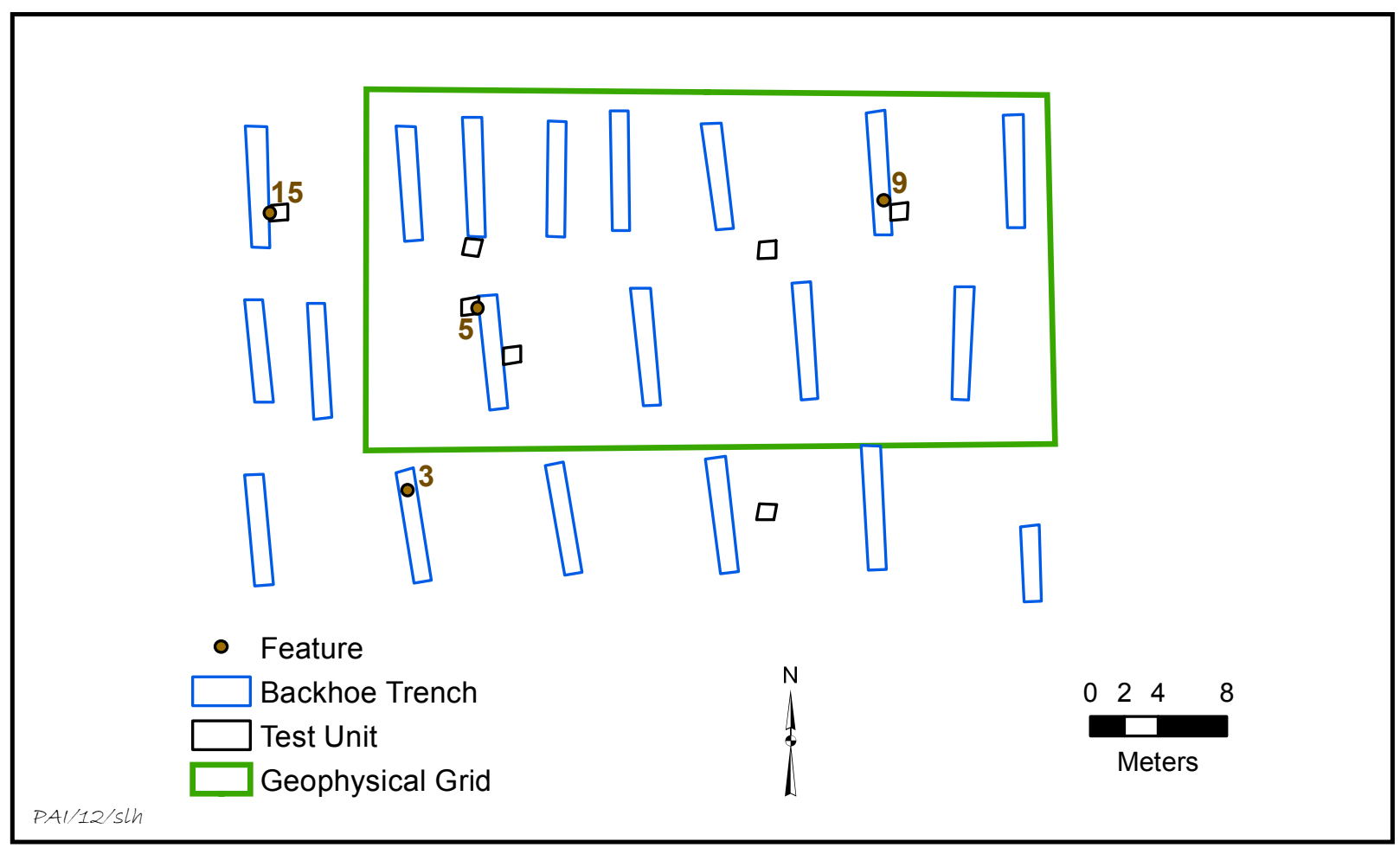

Figure 2.39. Plan of the west geophysical survey grid at 41TT866 showing feature locations.

single layer of primarily tabular ferruginous sandstone clasts. Several krotovina were present. A ground/battered stone tool fragment that likely was used as a heating element was noted, and 41 fire-cracked rocks weighing $7.3 \mathrm{~kg}$ were documented but not collected. Several rocks visible in the trench walls were left in situ. Feature 3 probably represents a hearth that had been disturbed by bioturbation and historic agricultural activity.

Feature 5 was a roughly oval, basin-shaped pit first identified at the north end of Trench 38 and fully exposed in Test Unit 3. The pit was $74 \times 62 \mathrm{~cm}$ across and $48 \mathrm{~cm}$ deep. In the test unit, the oval stain was discernible about $20 \mathrm{~cm}$ below the surface at the contact between dark yellowish brown anthropogenically enriched sediment and the yellowish brown E horizon. The feature continued through the $\mathrm{E}$ horizon into the Bt horizon (Figure 2.41). Rodent, root, and insect intrusions were noted within and around the feature. Undisturbed pit fill consisted of brown to dark brown (10YR 4/3) sandy loam with scattered charcoal flecks. Recovered cultur- al material includes 14 ceramic sherds, a Maud arrow point, a piece of lithic debitage, $3.1 \mathrm{~g}$ of daub, 86 vertebrate faunal elements, a mussel shell fragment, and $1.0 \mathrm{~g}$ of carbonized nutshell and other charred macrobotanical material. Almost all of the faunal assemblage is indeterminate vertebrate skeletal material. Identifiable elements include part of a cottontail rabbit (Sylvilagus sp.) tooth, a spirally fractured ulna fragment that is similar to turkey (cf. Meleagris gallopavo), and two long bone fragments from at least one medium-sized bird.

Feature 9 was an amorphous scatter of burned rocks partially exposed at the south end of Trench 43 and in Test Unit 8 (Figure 2.42). The uncovered part was $210 \times 185 \mathrm{~cm}$ across and extended from 41 to $56 \mathrm{~cm}$ below the surface. Although more rocks were visible in the east trench wall and the north wall of the test unit, excavation suggested that the central portion of the feature was exposed. The scatter consisted predominantly of a single layer of ferruginous sandstone cobbles and tabular fragments, but some clasts were stacked one above another. The 
dispersed scatter had an amorphous appearance overall, but the rocks generally were concentrated with respect to each other. Two small clusters of rocks at the north end suggest that some rocks were removed from the main cluster during use of the feature or were concentrated there as functional extensions of the central feature area. Intervening sediment contained scattered charcoal flecks, and all of the sediment between and below the clasts was collected as a flotation sample. A total of 136 burned rocks weighing $42.2 \mathrm{~kg}$ were documented in the excavated portion of the feature but not collected. No other artifacts were recovered. Feature 9 probably is a repeatedly used hearth or perhaps an earth oven. While some of the clast dispersal may be derivative of indigenous activities, other factors like root growth, vegetation clearing, and historic plowing likely played a role in feature disturbance.
A basin-shaped disturbance visible in the east wall of Trench 47 was tentatively classified as a pit. Designated Feature 15, it was $60 \mathrm{~cm}$ long and extended from 10 to $16 \mathrm{~cm}$ below the surface (from the Ab horizon into the E horizon). No artifacts were observed in the truncated feature fill.

\section{Artifact Assemblage}

Artifacts were recovered from the modern surface, 29 auger tests, 18 test units, and 18 trenches (see Table 2.15). The assemblage consists of 235 prehistoric ceramic sherds, 10 chipped stone tools, 116 pieces of debitage, 9 cores, 2 ground/battered stone tools, $18.60 \mathrm{~g}$ of daub, $2.9 \mathrm{~g}$ of burned clay, and $49.5 \mathrm{~kg}$ of burned rock. Also collected were 95 faunal elements and $1.90 \mathrm{~g}$ of carbonized botanical material.

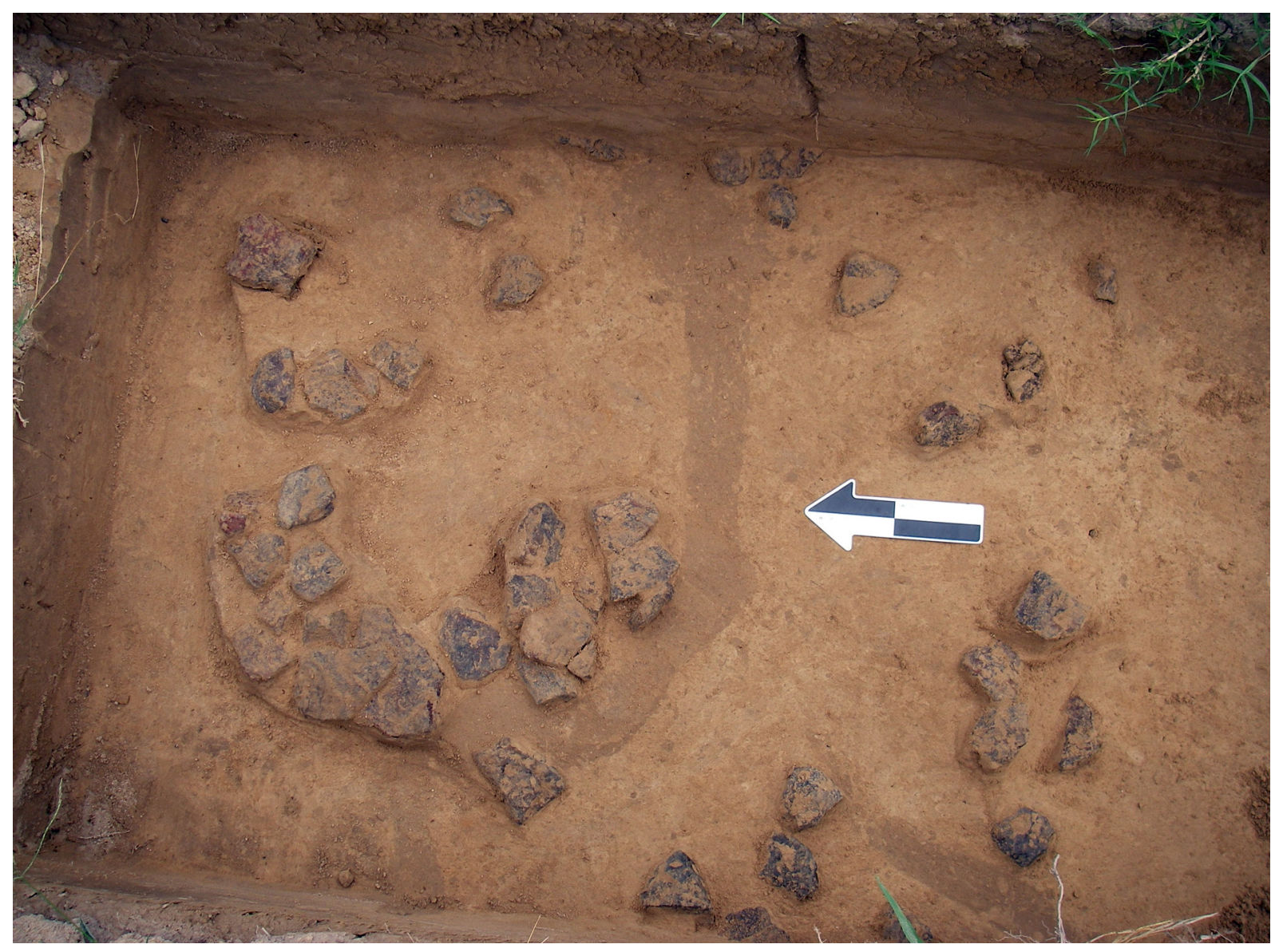

Figure 2.40. View to the east of Feature 3 exposed at the north end of Trench 35 at 41TT866. 


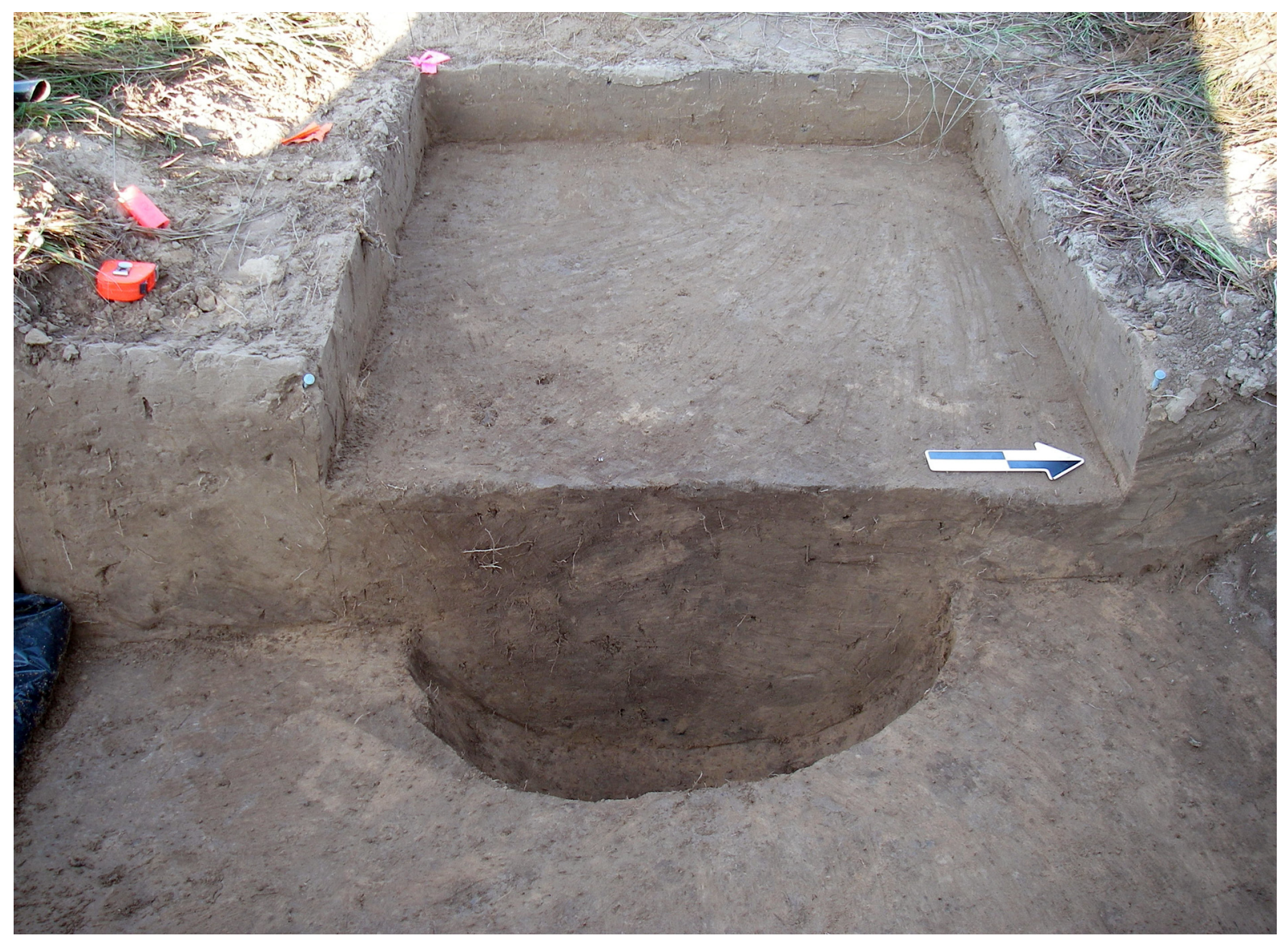

Figure 2.41. View to the west of the cross section of Feature 5 in the wall of Trench 38 at 41 TT866.

Of the total 223 sherds (1,400 g; minus 12 from auger tests, which were not collected), 141 $(1,263 \mathrm{~g})$ are large enough for analysis. Of these, 113 are vessel body sherds, 3 are carinated body sherds, 12 are rim sherds, 9 are neck sherds, and 4 are base sherds. One hundred six have grog temper alone, 31 have grog and bone, and 4 have voids probably representing leached bone along with grog and bone. Interior and exterior surfaces are mostly floated or smoothed, with burnishing on 18 percent of all surfaces and on both the interior and exterior of 15 sherds. Three sherds have scraped interiors suggesting they are parts of bottles or ollas. Two exterior surfaces have a red slip, and 1 other sherd has red pigment in its engraved decoration. Ten rims are everted, and 2 are of indeterminate form. Most everted rims have rolled lips, although 1 has a round lip and 1 has a folded lip. The rims of indeterminate form have a rolled lip and a flat lip. Rim thickness ranges from 4.77 to $9.75 \mathrm{~mm}$. Three of the base sherds are flat, 1 is of indeterminate form. Base thickness ranges form 7.71 to $14.46 \mathrm{~mm}$. Vessel forms identified are four bowls, five jars, and three bottles or ollas.

Sixty-seven sherds are decorated: 8 engraved, 9 incised, 33 brushed or brushed with appliqué or punctations, 10 punctated only, 4 punctated and incised, and 3 ridged. Elements associated with engraved sherds are mainly horizontal lines $(n=6)$, although there are also single examples of vertical lines and rectilinear lines. Some of these horizontal lines appear to be around vessel rims, but these sherds are too small for motif or type identification. Incised sherds display horizontal lines $(n=5)$, diagonal lines $(n=2)$, and vertical lines $(n=2)$. In a few instances, horizontal or diagonal lines occur in combination with lines of punctations (Figure 2.43a-b). In all, 
lines of punctations are found on 9 sherds. Rim sherds with diagonal lines, with or without punctations, suggest that Maydelle Incised vessels are represented in the sherd sample. Two small sherds with appliqué fillets have the body panels motif and support the presence of Pease Brushed-Incised. Four rim sherds with horizontal rows of punctations are indicative of a utility ware that occurs at most of the sites in the Tankersley Creek study area (Figure 2.43c). Horizontal and vertical brushing are found in combination with lines of stick punctations, which may be indicative of Maydelle Incised, Pease Brushed-Incised, or the untyped utility ware noted above. Three ridged body sherds (Figure 2.43d) may be associated with the type Belcher Ridged. In general, this assemblage is consistent with Middle-Late Caddo occupations.
The chipped stone tools (excluding three from auger tests that were not collected) consist of a Maud arrow point, two bifaces, and four flake tools. The Maud point, from Feature 5, is made of local brown chert (Figure 2.43e). It has a concave base, expanding stem, and triangular blade. The two bifaces are both late stage and broken. One is an indeterminate fragment of local brown quartzite from Level 2 of Test Unit 3. The other is a proximal fragment of local reddish brown chert from Level 2 of Test Unit 16. The flake tools consist of two edge-modified flake tool knives, one edge-modified flake tool scraper, and one utilized flake. The knives both are from Level 1 of Test Unit 3; 1 is of local red chert, and the other is of Ogallala quartzite and has bilateral retouch on one face and bifacial retouch on one edge. The scraper, of local brown and reddish brown chert, was recovered from Level 3 of Test

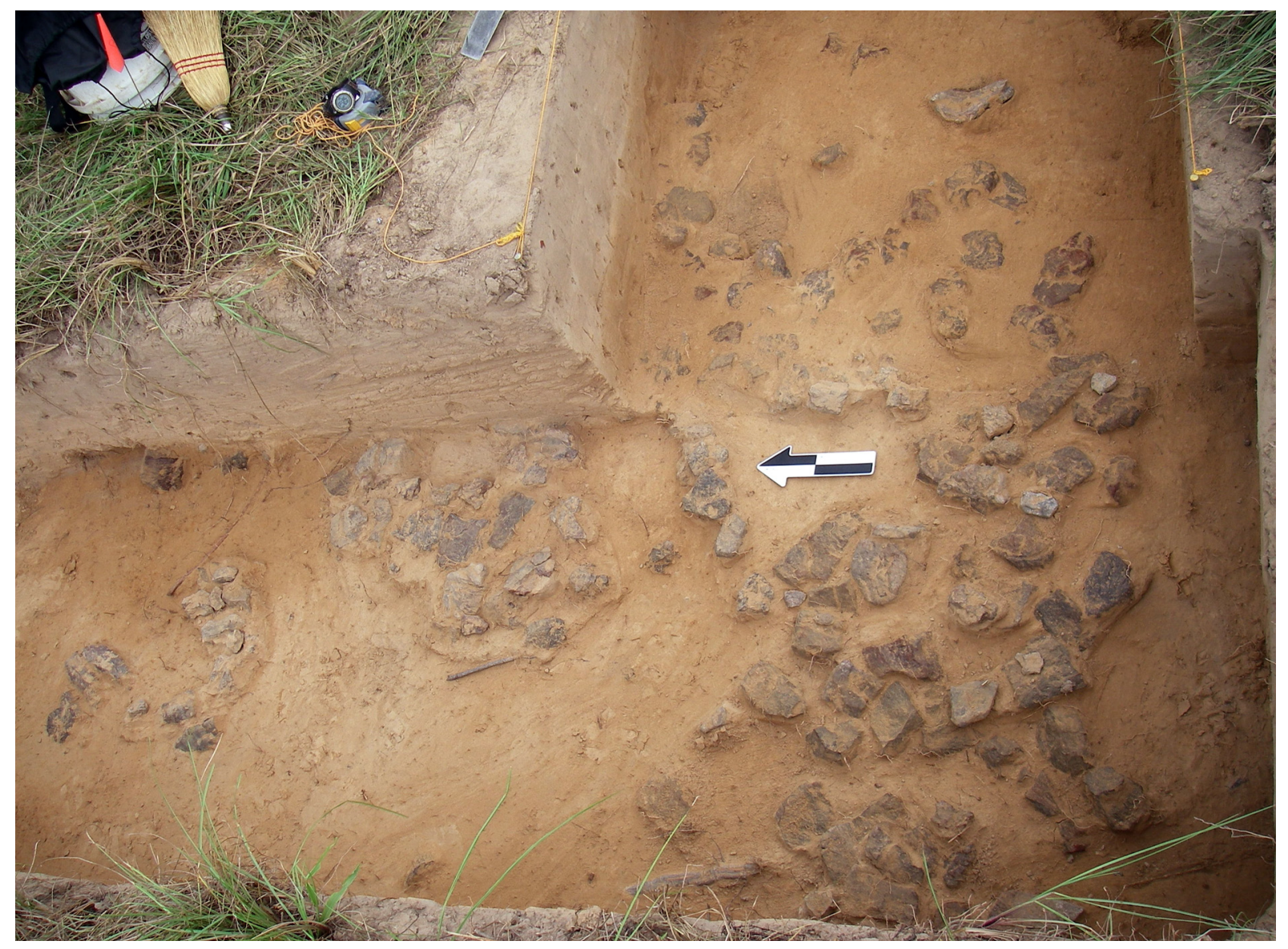

Figure 2.42. View to the east of Feature 9 exposed in Trench 43 and Test Unit 8 at $41 T T 866$. 

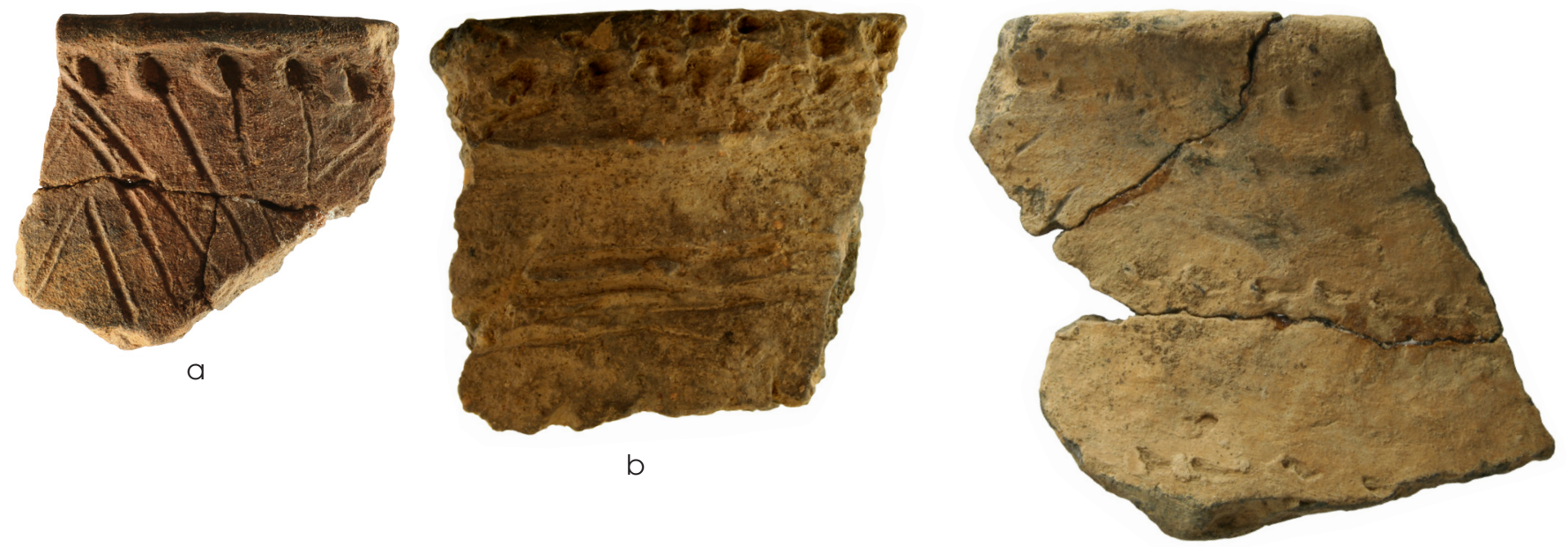

C
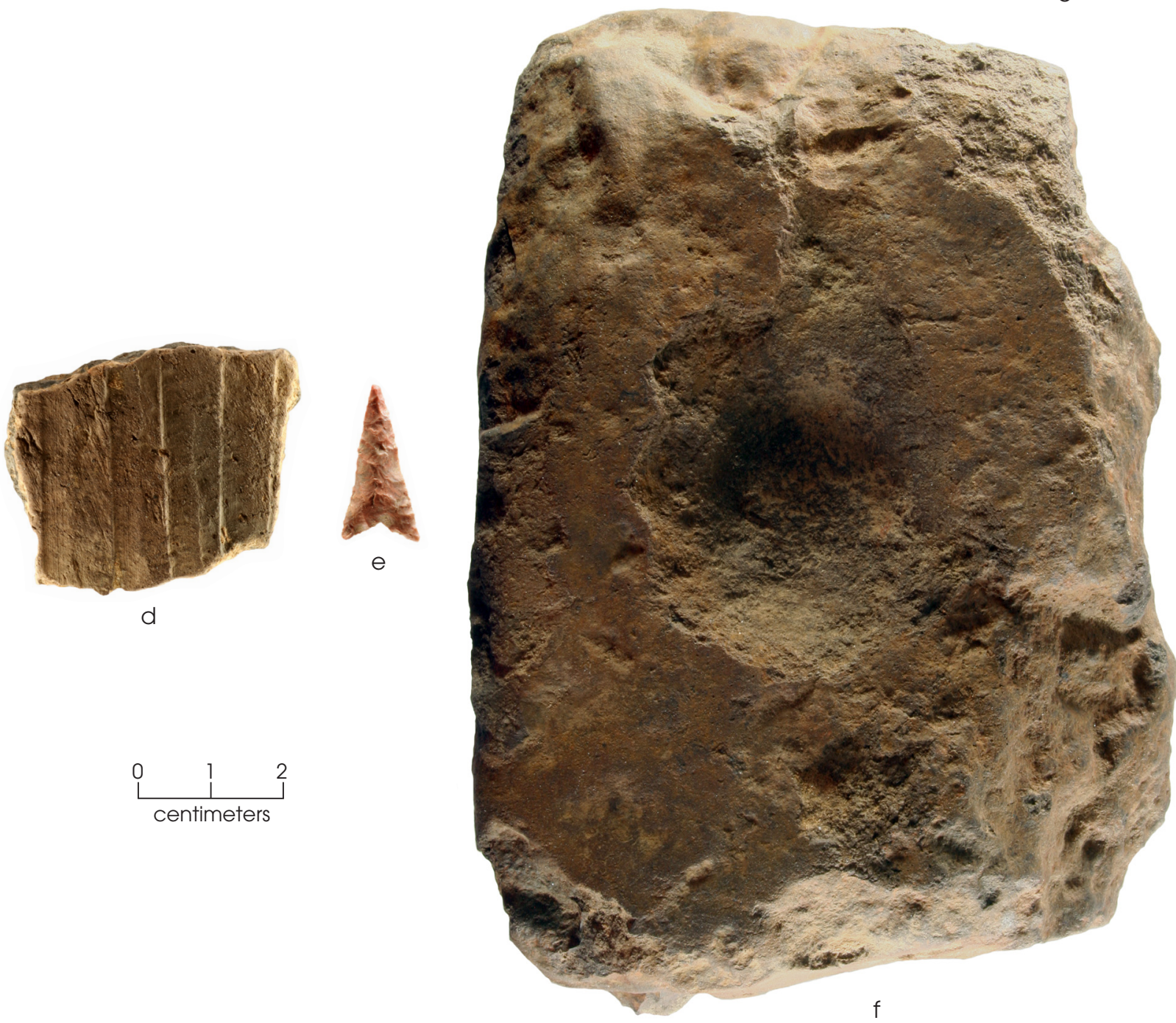

Figure 2.43. Artifacts collected in testing at 41TT866. (a) Jar rim with diagonal incised lines and horizontal row of punctations; (b) jar rim with horizontal incised lines and horizontal rows of punctations; (c) jar rim with horizontal rows of punctations; (d) ridged body sherd; (e) Maud arrow point; (f) ferruginous sandstone anvil. 
Unit 3. The utilized flake, from Level 2 of Test Unit 1 , is of reddish brown local chert.

The cores consist of one bipolar core of local chert, a bifacial core of local chert, two irregular flake cores of silicified wood, three core fragments of local chert, and two tested cobbles of local chert. The analyzed debitage (excluding flakes from auger tests, which were not collected) is dominated by locally available materials, which make up 98 percent, mostly chert $(n=49)$, quartzite $(\mathrm{n}=13)$, and silicified wood $(\mathrm{n}=11)$ as well as hematite $(n=7)$. Nonlocal lithic materials consist of single flakes of gray chert and white chert. Most of the debitage (78 percent) is smaller than $19 \mathrm{~mm}$, and 90 percent is smaller than $25 \mathrm{~mm}$. The high frequency of fairly small debitage suggests that late-stage reduction and tool production occurred on the site with a small amount of early reduction. Early reduction from medium-sized to small lithic source materials is also likely given the nature of the local materials.

The two ground/battered stone artifacts, both of ferruginous sandstone, are an anvil fragment found with other pieces of ferruginous sandstone in burned rock Feature 3 and a complete anvil from Trench 39 backdirt. The former is an irregular heat spall with a facet remnant containing a broad depressed area with percussion/battering marks. The depression is $4-5 \mathrm{~cm}$ across. The surrounding surface segments are slightly smoothed. The complete anvil is a rectangular, roughly tabular artifact with one relatively flat face with a large well-formed pit in its center (Figure 2.43f). The pit is roughly $4 \mathrm{~cm}$ in diameter. Battering damage on some margins suggest this cobble was minimally shaped.

The 94 vertebrate faunal elements were mostly from feature and nonfeature contexts in Trench 38 and adjoining Test Units 3 and 6. Ninety-three percent are identifiable only as indeterminate vertebrate. The seven elements classifiable beyond that are cottontail rabbit (Sylvilagus sp.); medium-sized artiodactyl; probably deer (Odocoileus sp.); probable turkey (cf. Meleagris gallopavo); medium-sized bird (Aves); and turtle (Testudinata) shell. A single invertebrate faunal element is an unidentifiable bivalve shell.

Artifacts were most frequent in and around the west grid. The trenches and units there yielded 93 percent of all of the cultural materials. The west grid assemblage consists of 71 percent of the chipped stone tools, 43 percent of the lithic debris, 67 percent of the cores, and 100 percent of the ceramics, ground stone tools, daub, burned clay, faunal remains, fire-cracked rocks, and carbonized plant material. Just over 80 percent of the materials from nonfeature contexts in the test units was from $0-30 \mathrm{~cm}$ below the surface, and 97 percent was from 0-50 cm. By level, artifact recovery was as follows: 28 percent at $0-10 \mathrm{~cm} ; 37$ percent at $10-20 \mathrm{~cm} ; 17$ percent at $20-30 \mathrm{~cm} ; 8$ percent at $30-40 \mathrm{~cm} ; 6$ percent at $40-50 \mathrm{~cm} ; 2$ percent at $50-60 \mathrm{~cm}$; and less than 1 percent at $60-70 \mathrm{~cm}$.

\section{Conclusions}

Site 41TT866 is difficult to interpret because much of it is outside the project area to the southwest, and previous investigations identified a clear Caddo component there. The east grid is especially hard to interpret because no features were exposed and no diagnostic artifacts were recovered in that area. The low-density lithic distribution identified in that grid is consistent with the findings of the auger sampling and indicates ephemeral use. Test excavations in the west grid expanded on the findings of the auger sampling. The recovery of a Maud point and ceramics and the identification of several features suggest that this part of the site relates to the Caddo component to the south-southwest. The moderate-density ceramic distribution suggests that this area may have functioned as a procurement or processing locality adjunct to a nearby residential locus. Alternatively, this location may have served as a repeatedly used campsite set at a distance from a residential locality.

The Maud point and ceramics indicate use during the Middle-Late Caddo period, but some chronological uncertainty is introduced by the fact that two of the four features are fire-cracked rock hearths, which may indicate that this area contains one or more pre-Caddo components. Resolving questions about the chronology of site use would be difficult because charcoal for radiocarbon dating was recovered from only one of the four features. Further, it would be hard to interpret the remains from this peripheral part of 41TT866 without knowing anything about the main body of the site. For these reasons, this part of 41TT866 was judged to have little capacity to yield important information and was considered ineligible for listing in the National Register of Historic Places and designation as a 
Table 2.16. Feature and artifact densities based on testing data

\begin{tabular}{|c|c|c|c|c|c|c|c|c|}
\hline Site & $\begin{array}{c}\text { No. of } \\
\text { Features }\end{array}$ & $\begin{array}{l}\text { Feature } \\
\text { Density }\end{array}$ & $\begin{array}{c}\text { Total } \\
\text { Ceramics }\end{array}$ & $\begin{array}{c}\text { Ceramics } \\
\text { from Test } \\
\text { Units }\end{array}$ & $\begin{array}{l}\text { Ceramic } \\
\text { Density }\end{array}$ & $\begin{array}{c}\text { Total } \\
\text { Lithics }\end{array}$ & $\begin{array}{l}\text { Lithics from } \\
\text { Test Units }\end{array}$ & $\begin{array}{c}\text { Lithic } \\
\text { Density }\end{array}$ \\
\hline 41TT6 & 0 & 0.00 & 0 & 0 & 0.0 & 35 & 35 & 2.9 \\
\hline $\begin{array}{l}\text { 41TT846, } \\
\text { Subarea } 1\end{array}$ & 0 & 0.00 & 10 & 6 & 0.7 & 10 & 9 & 0.8 \\
\hline $\begin{array}{l}41 \mathrm{TT} 846, \\
\text { Subarea } 2\end{array}$ & 0 & 0.00 & 0 & 0 & 0.0 & 41 & 41 & 3.7 \\
\hline 41TT847 & 3 & 0.01 & 1 & 0 & 0.0 & 154 & 146 & 13.3 \\
\hline $\begin{array}{l}\text { 41TT851, } \\
\text { Subarea } 1\end{array}$ & 12 & 0.03 & 1,354 & 1,125 & 25.6 & 802 & 755 & 17.0 \\
\hline $\begin{array}{l}\text { 41TT852, } \\
\text { Subarea } 1\end{array}$ & 22 & 0.06 & 1,602 & 1,051 & 40.4 & 673 & 522 & 20.1 \\
\hline $\begin{array}{l}\text { 41TT852, } \\
\text { Subarea } 3\end{array}$ & 3 & 0.02 & 101 & 76 & 6.3 & 178 & 162 & 13.5 \\
\hline $\begin{array}{l}\text { 41TT852, } \\
\text { Subarea } 4\end{array}$ & 0 & 0.00 & 54 & 7 & 0.9 & 163 & 151 & 18.9 \\
\hline $41 \mathrm{TT} 853$ & 21 & 0.07 & 1,074 & 791 & 36.0 & 1,455 & 1,283 & 57.0 \\
\hline $41 \mathrm{TT} 854$ & 0 & 0.00 & 131 & 101 & 12.6 & 187 & 164 & 20.5 \\
\hline 41TT858 & 0 & 0.00 & 38 & 35 & 4.4 & 135 & 131 & 16.4 \\
\hline 41TT862 & 1 & $<0.01$ & 0 & 0 & 0.0 & 135 & 121 & 12.1 \\
\hline 41TT865 & 0 & 0.00 & 327 & 275 & 11.0 & 207 & 207 & 8.3 \\
\hline 41TT866 & 4 & 0.01 & 235 & 152 & 8.9 & 105 & 92 & 4.8 \\
\hline
\end{tabular}

Note: Feature densities are per $\mathrm{m}^{2}$ of test units and trenches. Ceramic and lithic densities are per $\mathrm{m}^{2}$ of test units.

State Antiquities Landmark. Personnel with the Texas Department of Transportation and Texas Historical Commission did not concur with this assessment, but for the purposes of this project that became moot when subsequent redesign of the relief route excluded almost all of 41TT866 from the project area.

\section{SUMMARY OF CONCLUSIONS}

Following completion of the intensive testing, it was clear that focusing this project on the topic of Caddo use of the Tankersley Creek valley, as outlined under Project Design at the beginning of this chapter, was still appropriate. While many sites contained artifacts that probably related to pre-Caddo occupations, none of this material was isolable into components with the potential for meaningful interpretation. In contrast, the remains of Caddo occupations occurred at many sites and were especially abundant at several.

Table 2.16 provides information on some of the key attributes used in assessing the sites. Subarea 1 at 41TT851 (George Richey), Subarea 1 at 41TT852 (William Ford), and 41TT853 (James Richey) had high ceramic densities and relatively numerous cultural features. Site 41TT853 also had a high density of lithic artifacts. Recorded features included 19 postholes, 11 possible postholes, 10 pits, 1 possible pit, 7 postholes or pits, 3 fire-cracked rock hearths, 2 human burials, and 2 sherd clusters. None of the posthole groups exposed during test excavations were confidently identifiable as parts of houses, but the evidence suggested that additional work probably would be successful in finding residential structures.

Although Subarea 1 at 41TT851, Subarea 1 at $41 \mathrm{TT} 852$, and $41 \mathrm{TT} 853$ yielded some evidence of pre-Caddo occupations, most of the artifacts and almost all of the features at these sites were clearly associated with Caddo occupations. The bulk of the archeological deposits at these localities appeared to be representative of small Caddo farmsteads made up of one or a few houses with associated activity areas. The presence of matrix-defined features at each 
indicated a degree of integrity sufficient to allow productive studies of various kinds. All three locations contained dateable carbon. Most of the dates obtained from 41TT852 and 41TT853 suggested that they represent contemporaneous occupations in the A.D. $1400 \mathrm{~s}-1500$ s, with a possibility of continued use into the A.D. 1600 s. Four dates from 41TT851 suggested occupation of that locality occurred in the A.D. 1300s. The proximity of these three sites and the ages of the investigated areas suggested they held clues to the evolution of a Caddo community along this stretch of Tankersley Creek, perhaps one that evolved over a period of a hundred years or more. Given the potential for these sites to retain important information about the larger prehistoric community, data recovery excavations were considered warranted if avoidance or preservation in place were not feasible.

Site 41TT6, Subareas 1 and 2 at 41TT846, Subarea 4 at 41TT852, and 41TT862 contrasted sharply with those discussed above in that they contained few if any ceramics and typically no features. Lithic densities were low to moderate. A burned rock hearth at 41TT862 was the only feature identified at the sites in this group. The recovery of Gary dart points at 41 TT852 (Subarea 4) and 41TT862 suggested that Woodland-age occupations were represented, but the archeological deposits at these sites were almost certainly composed of a mix of cultural materials derived from several time periods. The absence of carbonized macrobotanical material at any of them prevented confident temporal assessments. The only other chronological clues were the small numbers of ceramic sherds from Subarea 1 at 41TT846 and Subarea 4 at 41TT852, which indicate use sometime during the Caddo period. However, the sherds are not numerous or distinctive enough to convey more-specific information, and it is impossible to know the occupational histories of these sites with any certainty. They were considered poor candidates for contributing important information and thus not worthy of further work.

Three other sites-41TT854, 41TT858, and 41TT865-were similar to the above group in that they lacked features and had low to moderate lithic artifact densities, though they did have higher ceramic densities. Sites 41TT854 and $41 \mathrm{TT} 858$ were difficult to interpret due to the absence of features and relatively small ceramic samples. Both sites may be small campsites or procurement or processing localities associated with the Middle to Late Caddo community represented at adjacent residential sites (41TT851, 41TT852, and 41TT853), but assessment of this inference was hindered by the lack of datable materials. Site 41TT865 was more interpretable. It is a small midden atop a low floodplain rise. The ceramics recovered and one radiocarbon date indicate that the midden dates to the Late Caddo Titus phase. A Late Archaic-age date and the recovery of dart points during this project and during survey also indicate the presence of earlier materials, though. The lack of occupational features supports the conclusion that the rise, covering an area of about $150 \mathrm{~m}^{2}$, is a disposal area for a nearby unidentified Caddo household.

The testing data indicated that 41TT854 and 41TT858 lacked the capacity to contribute important information and thus did not warrant any further work. The evidence from 41TT865 was more equivocal and led Prewitt and Associates personnel and Texas Department of Transportation and Texas Historical Commission personnel to reach different conclusions about the site's eligibility. As far as the relief route project was concerned, though, the question was rendered moot when changes in the design of the project excluded the site from disturbance.

The remaining sites and subareas-41TT847, Subarea 3 at 41TT852, and 41TT866-have low feature densities and low to moderate lithic densities. Subarea 3 at 41TT852 and 41TT866 have low to moderate ceramic densities, whereas only one sherd was recovered from 41TT847. These three are best discussed individually.

The higher lithic artifact density at 41TT847 compared to nearby sites 41TT6 and 41TT846 and the presence of three fire-cracked rock hearths suggest that it was used differently than the other two sites, and the single radiocarbon date and the recovery of a Gary dart point indicate that at least some of this use occurred during the Woodland period. The single Caddo sherd found on the surface and perhaps the reworked San Patrice dart point imply that later and earlier occupations could be represented as well. The part of 41TT847 that is within the project area was judged to have little capacity to contribute important information, and thus not warrant any further work, because of this multicomponency and the inability to isolate components for interpretation, or probably even to determine the extent of multicomponency. Sorting out the his- 
tory of use would be impossible because charcoal for radiocarbon dating is sparse and because the artifacts and features are in generally thin sands with no potential for stratification.

Subarea 3 at 41 TT 852 may be associated with the nearby Late Caddo occupation at Subarea 1 of the same site, but the low density of ceramics and few features (two possible postholes and a fire-cracked rock scatter) suggested comparatively ephemeral use. Determining that association was problematical, though, because no charcoal for radiocarbon dating was recovered. Chronological uncertainties aside, the integrity of the deposits across virtually all of that area had been compromised by construction and maintenance of an overhead power line and logging, accompanied by bulldozing and placement of debris piles. Because of the problems of determining chronology and associations and the low integrity, that part of 41TT852 was judged to lack the capacity to contribute important information and thus to not warrant further work.

Site 41TT866 was hard to interpret because the main part of the site was outside the project area. Nonetheless, the area of the eastern tested grid, with no features or diagnostic artifacts and only a low density of lithic artifacts indicating ephemeral use, clearly lacked important information and was worthy of no further work. The area of the western tested grid apparently related to the Caddo component on the main part of the site to the south, but the fact that two of the four features identified were fire-cracked rock hearths suggested that area contained one or more pre-Caddo components as well. Because of anticipated problems with resolving questions about the chronology of site use and interpreting this part of 41TT866 in isolation from the main body of the site, Prewitt and Associates personnel concluded that 41TT866 had comparatively limited capacity to contribute important information. Texas Department of Transportation and Texas Historical Commission personnel disagreed with this conclusion, but as far as the relief route project was concerned, the question became moot when redesign of the project excluded almost all of the site from disturbance. 



\section{RESEARCH DESIGN AND FIELD AND ANALYSIS METHODS FOR DATA RECOVERY EXCAVATIONS}

Virginia L. Hatfield, Ross C. Fields, Eloise Frances Gadus, and Damon Burden

As a result of the test excavations detailed in Chapter 2, five sites were found to be eligible for listing in the National Register of Historic Places and designation as State Antiquities Landmarks: 41TT851 (George Richey), 41TT852 (William Ford), 41TT853 (James Richey), 41TT865 (S. Stockade), and 41TT866 (Priefert-1). The latter two were subsequently excluded from the project area through changes to the design of the U.S. Highway 271 relief route, however, and thus data recovery was planned only for the George Richey, William Ford, and James Richey sites (Figure 3.1). Testing indicated that each of these sites had a Middle to Late Caddo component, with earlier components also present at some. The Caddo components included concentrations of ceramics, lithics, and usually daub, as well as features representing houses or outdoor activity areas, while the apparently ephemeral pre-Caddo occupations were represented by small numbers of dart points and burned rock features. The Caddo components were the main focus of the data recovery excavations, since they have far more substantial deposits and more potential for contributing to a better understanding of the prehistory of the region. These three sites are close to one another, occupying a series of interfluves on a ca. 1-km-long segment of the east wall of the Tankersley Creek valley.

\section{SYNOPSIS OF THE RESEARCH DESIGN}

The U.S. Highway 271 Mount Pleasant relief route project was seen as an opportunity to investigate household and community organization for the Middle to Late Caddo people who lived along Tankersley Creek and within the larger region. Particularly important were the following: (1) the three sites were close enough to one another and contained sufficiently similar remains that they appeared to be associated with one another and represent parts of a particular community of Caddo Indians; (2) the three sites appeared to have sufficient time depth to allow investigation of how this community evolved; (3) there had been sufficient archeological attention paid to the Late Caddo Titus phase, particularly through the synthetic works of Thurmond (1981, 1985, 1990), Perttula (1992, 2004, 2005), and Perttula and Sherman (2009), that there was ample context for phrasing relevant questions to be addressed by further work at these sites; (4) the numerous archeological investigations throughout the Cypress Creek basin and adjoining basins, including extensive work at the Monticello Mine west and north of the current project area, meant that there is a large body of comparative data to help in interpreting the sites in the current project area; and (5) the occurrence of several probably associated cemeteries near these sites (the Thomas P. Caldwell cemetery recorded as $41 \mathrm{TT} 6$ but actually on a part of 41TT846, the A. P. Williams cemetery recorded as $41 \mathrm{TT} 4$, and a reported looted cemetery on the Duncan Anderson Farm, 41TT18) but outside the project area and the potential for integrating the materials from these cemeteries into the data recovery analysis raised the possibility of exploration of a fuller and more-interesting range of behaviors than would be possible using data from residential sites alone.

The data recovery excavations were planned to focus on three interrelated scales of organization. The first and most basic concerns 


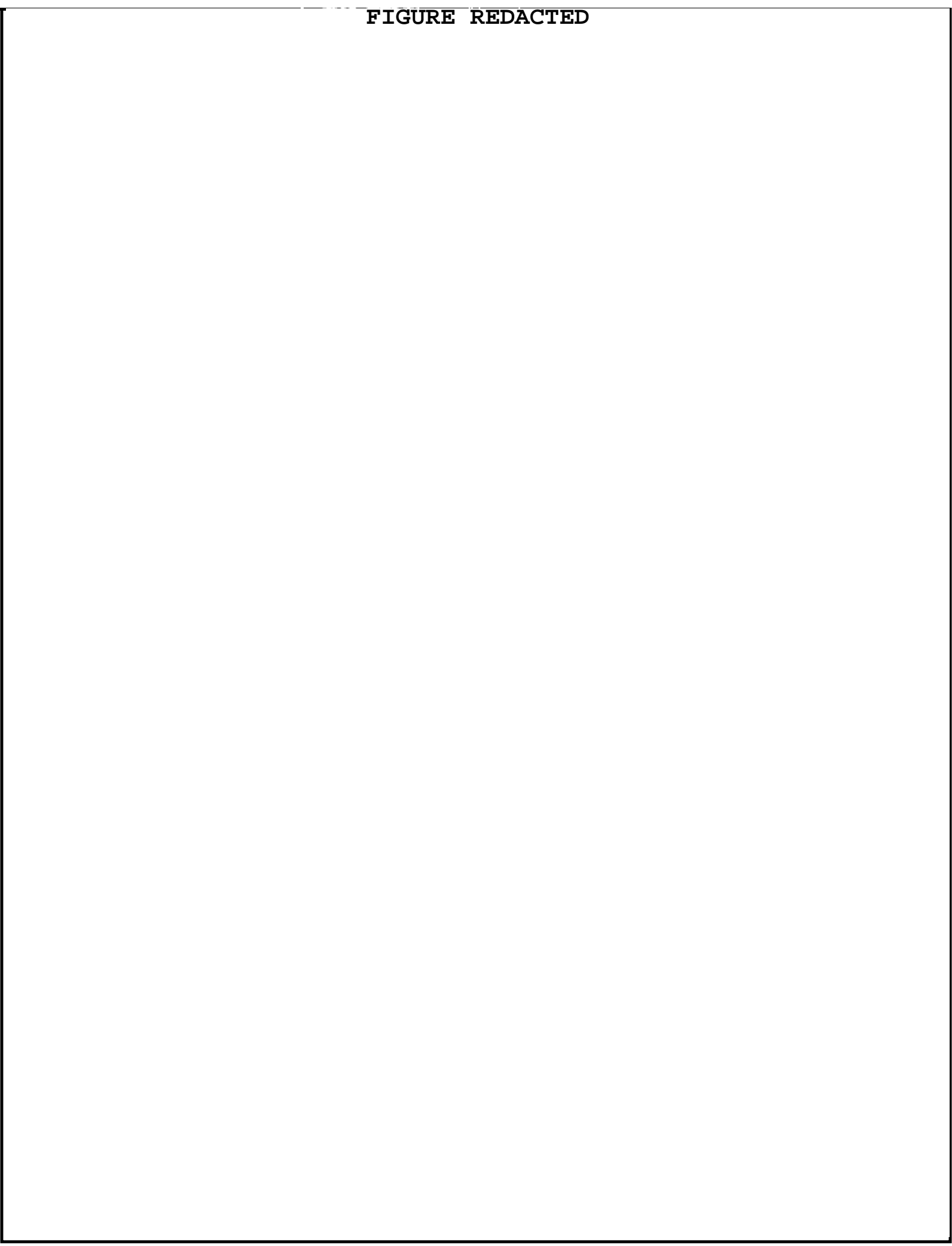

Figure 3.1. Topographic map and 2005 aerial photograph showing the locations of the George Richey, William Ford, and James Richey sites. 
the households of Caddo Indians who lived along this stretch of Tankersley Creek. By household, we mean the facilities and structures associated with the basic social, biological, and economic unit that made up the community, as it is the household that brings together a myriad of interactions that reflect the variability and viability of the community as a whole (Rogers 1995:8-10). Given the apparent nature of the archeological remains at the three sites, this level of inquiry was considered primary, underpinning all others.

Moving beyond single households, the second level of inquiry focused on the larger community of which these sites were a part. This was to include consideration of the range of nearby sites that may have been associated with this community, as known chiefly from testing and data recovery efforts on various projects in the vicinity of Mount Pleasant. The goal was to try to define some of the characteristics of this community and distinguish it from others that existed in nearby drainages or upstream or downstream on Tankersley Creek. And lastly, the larger regional context of these sites was to be considered, with an emphasis on connections to and interactions with the Titus phase heartland on Big Cypress Creek to the south and southeast and the contemporaneous Caddo groups who lived on the Red River to the north and east, the Sabine River to the southeast, and the Neches River to the south.

The directions that the research design advocated were admittedly ambitious, with optimistic hopes about the kinds of information that these three sites would yield. We recognized that we might be unable to answer or even address some of the questions posed, as pertinent data might not be recovered or be of the quality or quantity needed for serious analysis and interpretation. Starting off the project in an optimistic frame of mind was considered important, though, because it would promote an openness to possibilities about what the information obtained could tell us. In our view, it was easier to start out this way and alter plans as realities demanded than to start out thinking small.

\section{Household-Oriented Research Strategies}

The patterning reflected in the postholes, pit features, and occasional burials, as well as the artifact assemblages, found in testing 41TT851, $41 \mathrm{TT} 852$, and 41TT853 appeared to represent clusters of one or more individual households or outdoor activity areas near houses. Although a living household encompasses many strategies to "meet the social, material, and subsistence needs of its members" (Nass and Yerkes 1995:69), how such a household is reflected in the archeological record is not always clear. However, a good model for a Caddo household, as defined architecturally, can be constructed from both historic records and archeological sources.

We know based on a map of a Nasoni town drawn by Don Domingo Terán de los Ríos (ca. 1691-1692) that the early historic Caddo on the Red River to the north lived in household compounds of one to three circular houses, with exterior above-ground granaries and often rectangular ramadas (Perttula 1992:159-161; Swanton 1942:Plate 1). Henri Joutel, member of the La Salle expedition (ca. 1680), described agricultural fields surrounding the houses of the Caddo living along the Angelina and Neches Rivers (Swanton 1942:148-149). Joutel also observed that the largest "cabins" of the historic Caddo were $18 \mathrm{~m}(60 \mathrm{ft})$ across and had a central hearth with raised sleeping platforms. He estimated that these large structures might have housed 8 to 10 families. However, Swanton (1942:149) concludes, based a report by Fray Damián Massanet, founder of Spanish missions among the Caddo, that the large house Joutel observed was likely that of a chief. Massanet provides further details of the chief's house, including reference to interior shelving for storage of baskets containing corn, beans, nuts and acorns, a row of large earthen pots for making atole, and six wooden mortars to pound corn. Massanet also refers to other buildings surrounding the chief's house that were for sheltering visiting high-ranking members from other communities. Clearly, there was a difference in structure size probably based on rank; in another account Anastase Douay states that houses accommodated only 2 families. Douay does confirm, however, the presence of raised sleeping platforms and central hearths within these smaller houses.

Recent archeological investigations also are informative about Caddo households. At the Pilgrim's Pride site in Camp County 8 km southeast of the current project area, two houses-one well-defined circular house approximately $7 \mathrm{~m}$ 
in diameter and one less well-defined circular structure ca. $8.5 \mathrm{~m}$ in diameter with an extended entryway-were discovered (Perttula 2005:6570, 375). Dating to the Titus phase, both houses were surrounded by exterior features including pits and numerous postholes that may represent ramadas or other outbuildings similar to those described in the historic accounts. Even closer to the project area, the Titus phase Ear Spool site in the East Piney Creek drainage north of Mount Pleasant had four circular houses ranging from less than $5 \mathrm{~m}$ to about $7.5 \mathrm{~m}$ in diameter and a possible plaza. The houses represent two sequential occupations, with exterior pits and postholes once again pointing to outside activity areas (Perttula and Sherman 2009). Similar houses associated with distinct trash middens were found at a Titus phase site, Rookery Ridge, in Upshur County (Parsons 1998; Perttula 2005:363).

At one of the most extensively excavated Caddo sites in northeast Texas, Oak Hill Village in Rusk County, $100 \mathrm{~km}$ south of the current project area, numerous mainly circular houses ranging from 7 to $10 \mathrm{~m}$ in diameter and dating mostly to A.D. 1250 to 1450 were identified (Rogers 2004a:345-347). Floor area calculations indicate that structures of these sizes could have sheltered anywhere from 4 to 20 persons; this range would support an estimate of two or more families per house (Rogers 2004b:94-95). Structural evidence of possible exterior granaries also was discovered (Rogers 2004b:72-75). Evidence from these excavations suggests that the size of a household, its associated facilities, and the number of people it could accommodate may have varied little, with size and structural differences possibly related to differences in social status within a community.

A model Caddo household can be drawn from the above historic and archeological information. It includes a circular house $5-10 \mathrm{~m}$ in diameter, or large enough to accommodate one or two families. Larger structures may have been built to house more people, because of status differences, or possibly for other reasons. Houses would have interior central hearths and evidence of interior structures that would have served as storage shelving or bed platforms. Exterior features may include ramadas and possibly additional storage structures. Gardens would be close to or surrounding the house and its exterior features.
The data recovery investigations at the George Richey, William Ford, and James Richey sites were to focus on determining how this model applies to the households at these sites. Among the relevant research questions were the following:

- What groupings of features (posthole patterns, hearths, pits, middens, courtyards/ plazas, and burials) constitute an individual household within the middle Tankersley Creek Titus phase community?

- What activities were performed within the household? Were these related solely to mundane domiciliary activities? Did they include ritual/ceremonial activities, or were such special activities reserved for mound or community cemetery sites located elsewhere?

- Were households occupied on a seasonal basis or year-round?

- What were the sizes and structural forms of individual houses and ramadas, and how may this have been related to the sizes or statuses of the groups who utilized them?

- Who occupied the households? Was it one or more extended family or possibly a corporate group of adult males or groups of juveniles and adult women?

- If areas contain multiple houses, is it a function of serial occupancy or family growth over time?

- Were houses rebuilt within single areas over time, and if so does this reflect natural decay of building materials and house replacement? If they were not rebuilt, what does that suggest regarding mobility and community boundaries?

\section{Community-Oriented Research Strategies}

A household may be considered the basic social, biological, and economic unit of a wider community that is composed of groups of related households, and thus study directed at the household level is also pertinent to looking at community-level patterns. The structure and extent of the middle Tankersley Creek (if, indeed, that is its geographic focus) Middle-Late Caddo community was unknown at the outset of this project, but they could be explored through com- 
parison of households identified within each site and, at least at the artifact assemblage level, at nearby tested and excavated sites, and perhaps even some sites known only from survey-level data, in the Mount Pleasant area. Thus, these investigations were to focus on the community immediately around 41TT851, 41TT852, and $41 \mathrm{TT} 853$ and to attempt to define that community as it may have extended up and down Tankersley Creek and into adjoining valleys.

In addition to understanding the cultural landscape, investigations at these sites offered an opportunity to investigate how these people managed their environmental and physical landscapes. Environmental reconstructions for the Big Cypress Creek basin and larger region have identified environmental fluctuations between A.D. 1430 and 1680 (Crowley 2000; Perttula 2005). Perttula (2005:22) notes three droughty climatic episodes during this time (A.D. 1430-1476, 1525-1538, and 15731602) with warmer and wetter periods before and after. Thus, the sites distributed along Tankersley Creek offered an opportunity to investigate how individual households and the larger community of households adapted to fluctuations in rainfall. Through time, the Caddo became increasingly dependent on agricultural products, particularly maize, which increased their vulnerability to climatic fluctuations. The significance of community dynamics is heightened during such times when multiple households and even multiple communities are thought to have worked together, sharing surpluses to mitigate shortfalls. Perttula (2005:359) suggests that the dispersed settlements of the Tankersley Creek Caddo would have served to lower competition for resources in this more-marginal environment compared to the Caddo to the north and east. Settlement dispersion, therefore, may serve as an indicator for environmental conditions relating to environmental carrying capacity, locations of water sources, mitigation of droughty periods, or other factors, as well as for population growth and the need for neighbors for security or trade.

Almost 1,000 archeological sites had been recorded in Titus County as of 2009, most of which have prehistoric components. While these sites vary in age, Middle-Late Caddo components are common. Most are known only from survey-level data, but some have been tested or seen data recovery excavations. In addition to some of the other sites investigated during the U.S. Highway 271 project (41TT854, 41TT858, $41 \mathrm{TT} 865$, and 41TT866), nearby tested or excavated sites with components comparable in age to 41TT851-41TT853 include the Thomas P. Caldwell cemetery on a part of 41TT846 not far outside the proposed relief route right of way (Goldschmidt 1934a, 1935); the A. P. Williams cemetery, 41TT4, on Dragoo Creek about $1.4 \mathrm{~km}$ to the west (Goldschmidt 1934b); the cemetery at the Mockingbird site, 41 TT550, ca. $4.6 \mathrm{~km}$ north of the current project area (Perttula et al. 1998); several sites 3-5 km north-northwest of Mockingbird (Nash et al. 1995); the Ear Spool site, $41 \mathrm{TT} 653$, ca. $9 \mathrm{~km}$ north of the project area (Perttula and Sherman 2009); 41TT440, 41TT572, 41TT577, and 41TT593 near the Ear Spool site (Galan et al. 1997; Sills and Cliff 2003); 41TT672 just west of the current study area (Dixon et al. 1995); and 41TT182 ca. $8 \mathrm{~km}$ west-southwest of the current study area (Kotter et al. 1991). All of these were expected to be useful in comparative studies relating to community definition. Other potential data sources were a collection of materials in private hands from a looted cemetery at the Duncan Anderson Farm (41TT18) just west of Tankersley Creek and limited information regarding a probable mound site (41TT890) near 41TT866 (Bo Nelson, personal communication 2008).

Working with data from these and other sites, we hoped to address the following kinds of questions relating to the middle Tankersley Creek community:

- What was the geographic extent of the community?

- What kinds of sites made up the community? Did it include limited-use areas, small settlements, large settlements, and family cemeteries, consistent with Thurmond's (1990) model?

- Does this community equate to Thurmond's (1985, 1990) Tankersley Creek subcluster?

- Were some places on the landscape considered community or sacred spaces, for example, cemeteries used by multiple households or even mound centers?

- Are multiple contemporaneous households represented within each residential site? 
- How densely settled was the landscape, and is it possible to estimate the population of the community?

- Are there any apparent status differences between households?

- What was the role of tropical cultigens in the organization or support of community patterns?

- Was the community under environmental stress? How did the landscape and other environmental factors structure community patterns?

- Did communities work together to cope with environmental stress?

\section{Intercommunity-Oriented Research Strategies}

Looking beyond the middle Tankersley Creek valley and adjoining watersheds, it is appropriate to look at how the Caddo who lived there interacted with their neighbors and how local settlement patterns fit into regional systems. To understand this, comparisons to sites in other parts of the Titus phase area and in other Caddo-occupied river valleys were to be made.

Fortunately, the Titus phase is among the most-intensively and extensively researched places and times in Caddo history, with synthetic treatments by Thurmond (1985, 1990), Perttula (1992, 2004, 2005), Perttula and Sherman (2009), and Fields and Gadus (2012) providing fertile ground for developing increasingly refined interpretive frameworks. In his seminal study, completed in 1981 as part of research for an Master's thesis and printed nine years later by the Texas Archeological Research Laboratory, Thurmond (1990:232) defined the "Cypress cluster," which he saw as "a third Caddoan confederacy in addition to those of the Hasinai and Kadohadacho...centered geographically on the upper Cypress Creek, White Oak Bayou, and Lake Fork Creek basins." He used this construct to refer to the remains of Caddo groups who occupied an area extending to the eastern arm of Lake Fork Reservoir on the west, Black Cypress Bayou on the east, White Oak Creek in the Sulphur basin on the north, and the Sabine River on the south and spanning ca. A.D. 1400-1600 (Thurmond 1990:229).

In looking at burial assemblage variability across this region, which Turner (1978) previously had ascribed to changes through time (i.e., early [Whelan] and late Titus), Thurmond saw four spatial subclusters (Three Basins, Tankersley Creek, Swauano Creek, and Big Cypress Creek) within the Cypress cluster and decided that the subclusters represented contemporaneous sociopolitically integrated tribes or subtribes (Thurmond 1985:191-196). This interpretation was possible, in part, because "the geographic distributions of the components assignable to each subcluster are, with the exception of some minor overlap, mutually exclusive" (Thurmond 1990:229). Three Basins subcluster sites were in the western part of the Titus phase area in the Lake Fork Creek drainage, the uppermiddle part of the White Oak Creek basin, and the upper reaches of Big Cypress and Little Cypress Creeks. Tankersley Creek subcluster sites were mainly in the valleys of Tankersley Creek and Blundell Creek just to the west and Big Cypress Creek just downstream and upstream from Tankersley Creek. Swauano Creek subcluster sites were farther to the east along Big Cypress Creek and tributaries, and the Big Cypress Creek subcluster was downstream on Big Cypress and its tributaries (Thurmond 1985:197).

Thurmond (1990:214) was well aware of the limitations of his study, relying as it did on "archeological data collection in the Cypress basin [that] have been haphazard and variable to an extreme," such that "any analysis or interpretation of the data must remain on a tentative level." Since then, as a result of acquisition of new data and more synthetic analyses, especially those of Perttula (1992, 2004, 2005), we have gained a better understanding of the archeology of the region, particularly for the Late Prehistoric Titus phase.

Our perceptions about the geographic extent of the Titus phase have changed some over the past several decades, and recent work in the Sabine River valley at the far southeast edge of the region makes it clear that some rethinking of the extent of this construct is in order (Fields and Gadus 2012:673-677). In addition, we have a much better handle on its chronology today than Thurmond did because many more radiocarbon dates are available, with the Titus phase dated to A.D. 1430-1680 and the preceding Whelan phase, which really is nothing more than the beginnings of the Titus phase, starting by the mid A.D. 1300s (Perttula 
2004:396). As Perttula (2004:396) writes, "these Caddoan peoples lived in dispersed year-round settlements where they farmed and hunted, buried their dead in planned cemeteries, and manufactured culturally distinctive ceramics of considerable stylistic and functional diversity."

Late Caddo sites are more common in the region than sites of any other age, which could indicate relatively large populations, but these Caddo inhabited what are viewed as rural community systems, as opposed to the larger, perhaps more densely settled town systems that characterized the major river valleys to the north and east (Red, Ouachita, and Little Rivers) (Perttula 2004:398). These rural systems consisted largely, though not exclusively, of functionally equivalent farmsteads and hamlets distributed widely across the landscape, including up smaller stream valleys into the uplands (Perttula 2004:398-400). Most residential sites were occupied by no more than a few families for maybe just one generation before settlement shifted elsewhere, perhaps to take advantage of new farmlands (Perttula 2004:398).

Though the settlement pattern implies a less-complex, less-hierarchical sociopolitical system than was the case among the Caddo groups who lived on the Red, Ouachita, and Little Rivers, this is not to say that the Titus peoples lived in strictly egalitarian societies. Use of certain structures for ceremonial and ritual activities, and their subsequent destruction and burial to create mounds, continued throughout the period (Perttula 2004:398, 400), albeit in a modest way compared to larger Caddo towns on the major rivers. All 11 of the known Late Caddo mound centers that Perttula (2004:401) identifies in the Titus heartland are on Big Cypress Creek or its tributaries downstream from Hart Creek. This is the same area where 11 of the 13 known Titus phase community cemeteries are situated. Usually containing 60-70 interments and rarely up to $150-300$, these cemeteries apparently were used by multiple communities and represent "community-based participation in ceremonial and mortuary activities" (Perttula 2004:401). The mound centers and especially the community cemeteries reflect the existence of status and social differentiation among these Caddo groups, and Perttula (2004:401, 403) argues that these two kinds of sites were functionally equivalent.

Based chiefly on artifacts found in burial contexts, it is clear that the Late Caddo groups who lived in this part of northeast Texas interacted in meaningful ways with the Caddo who lived in other river valleys of the region, with farther-reaching but less intensive interaction with people of the Great Plains, the Southwest, and the Lower Mississippi Valley indicated as well (Perttula 2004:405-406). Traded vessels indicate that the strongest ties were with people of the McCurtain, Texarkana, and Belcher phases on the Red River to the north and east, with this interaction apparently intensifying in the A.D. 1500s (Perttula 2004:406). Interaction with Frankston and Allen phase groups in the Neches drainage to the south also is evident in the ceramics.

While asserting that Thurmond's four Titus subclusters may represent distinct groups or subgroups that "maintained a regional or local spatial integrity" over time, Perttula (2004:397) goes on to suggest that some of the apparent variability that distinguishes the subclusters relates to temporal changes rather than geographic differences, echoing Turner's (1978) earlier conclusions. Further, in looking at the mortuary ceramics from the Pilgrim's Pride site, he had trouble getting the assemblage to fit well with any of Thurmond's subclusters, and he concluded that "the Pilgrim's Pride site, and probably other Titus phase sites in the immediate vicinity, apparently represents part of another local but separate Titus phase community from those subsumed under the subcluster groupings proposed by Thurmond" (Perttula 2005:280-281). He reached much the same conclusion in his analysis of the ceramics from the Mockingbird site (Perttula et al. 1998:251-253).

In his synthesis of Pilgrim's Pride, Perttula scarcely mentions the four subclusters, preferring instead to talk about a string of at least seven Late Caddo communities along Big Cypress Creek, crosscutting three of the four subclusters (Perttula 2005:360-362). In looking at the ceramics from this same area, he sees two distinct traditions, an eastern one and a western one, and says "these basic differences in the two ceramic traditions...suggest a dichotomy in belief and cultural practices between the eastern and western Titus phase Caddo groups, as well as in styles of expression, that was of long standing (perhaps for 150-200 years, and 7-8 generations). That dichotomy further suggests that there were well-defined social boundaries between the different Titus phase communities 
in the Big Cypress Creek basin and that the cultural landscape across the Titus phase heartland and hinterlands was complex and dynamic" (Perttula 2005:404).

Examples of intercommunity research questions that can be derived from the preceding discussion include the following:

- What are the temporal relationships between the middle Tankersley Creek community and others investigated nearby, such as that centered around Pilgrim's Pride?

- What are the functional relationships between these sites on the periphery of the Titus phase heartland and the mound and community cemetery sites closer to Big Cypress Creek?

- Are any of the four proposed subclusters useful in interpreting these sites, or is definition of new subclusters in order?

- Do these sites fit well with the notion of eastern and western ceramic traditions in the Titus phase heartland?

- Can sufficient temporal control be gained to look at movement of communities and people through time?

- Was the intensity of interaction between communities dependent on distance, or were other natural or cultural factors at play?

- What was the nature of the interaction? Was it based on trade of material objects alone, or was it based in part on the dissemination of ideologies?

- Was interaction with Caddo groups who lived in the Red River and Neches River valleys face-to-face or down-the-line?

- How do Titus phase Caddo communities compare with other Caddo households?

- Are similarities the result of communication with these societies through down-the-line trade or from earlier historical relationships and subsequent similar responses to the cultural or natural environments?

\section{SYNOPSIS OF THE DATA RECOVERY PLAN}

The overall goal of the data recovery excavations, then, was to identify and explore Caddo community structure at various spatial scales, including within single houses, on individual house lots, within villages, between one or more contemporaneous villages, and as villages and other components of the settlement system. To achieve this goal, we needed data on the kinds and distributions of features, artifacts, and ecofacts within whatever components of the settlement system we could define. The most promising components defined through testing were at the George Richey (Subarea 1), William Ford (Subarea 1), and James Richey sites, all three of which appeared to be small residential hamlets with one or more clusters of houses and associated activity areas. To identify the areas with the greatest interpretive potential at the three sites, the distributions of cultural features in the backhoe trenches and test units were examined relative to the locations of test units with comparatively high frequencies of ceramics and lithics and the presence of wattle-impressed daub. Studies at other sites in the region have shown that these are good indicators of Caddo houses. The testing data indicated that high frequencies of ceramics and lithics tended to occur in the same places, and that this also is where the daub and all or most of the features were.

At George Richey, there were two such areas measuring $25 \times 10 \mathrm{~m}\left(200 \mathrm{~m}^{2}\right)$ and $35 \times 20 \mathrm{~m}$ $\left(550 \mathrm{~m}^{2}\right)$, separated by a ca. $15-\mathrm{m}$ swath with lower densities of materials and no features (Figure 3.2). These were considered likely to represent two clusters of one to three houses with nearby activity areas, or perhaps one house cluster and a separate activity area, with an intervening plaza or garden plot. At William Ford, there was one main concentration measuring $50 \times 30 \mathrm{~m}\left(1,180 \mathrm{~m}^{2}\right.$; Figure 3.3$)$; given its size, it was judged likely to represent multiple houses with associated activity areas, though testing yielded good feature evidence only for one house area. The James Richey site also had a single main concentration, which covered an area of $40 \times 20 \mathrm{~m}\left(630 \mathrm{~m}^{2}\right.$; Figure 3.4); based on size, it appeared to represent a single set of one to three houses with associated activity areas.

The three probable house areas at these sites were the target of the data recovery work. To ensure that we investigated their full extent, would be able to confidently identify their boundaries, and would avoid looking exclusively where the archeology is densest, we proposed to include a buffer zone around each, which would include parts of the sites shown by 


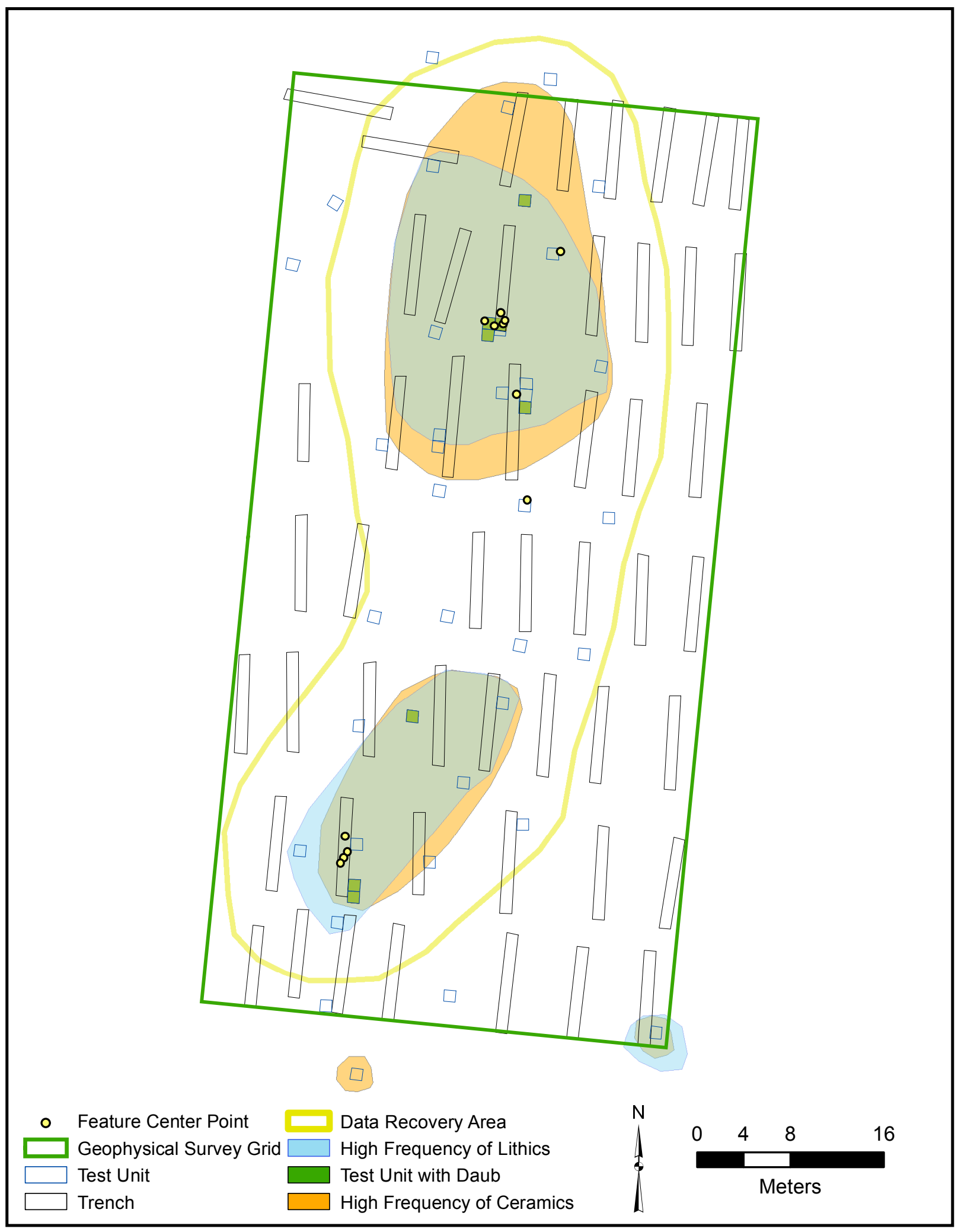

Figure 3.2. Plan of the George Richey site, Subarea 1, showing area proposed for data recovery excavations 


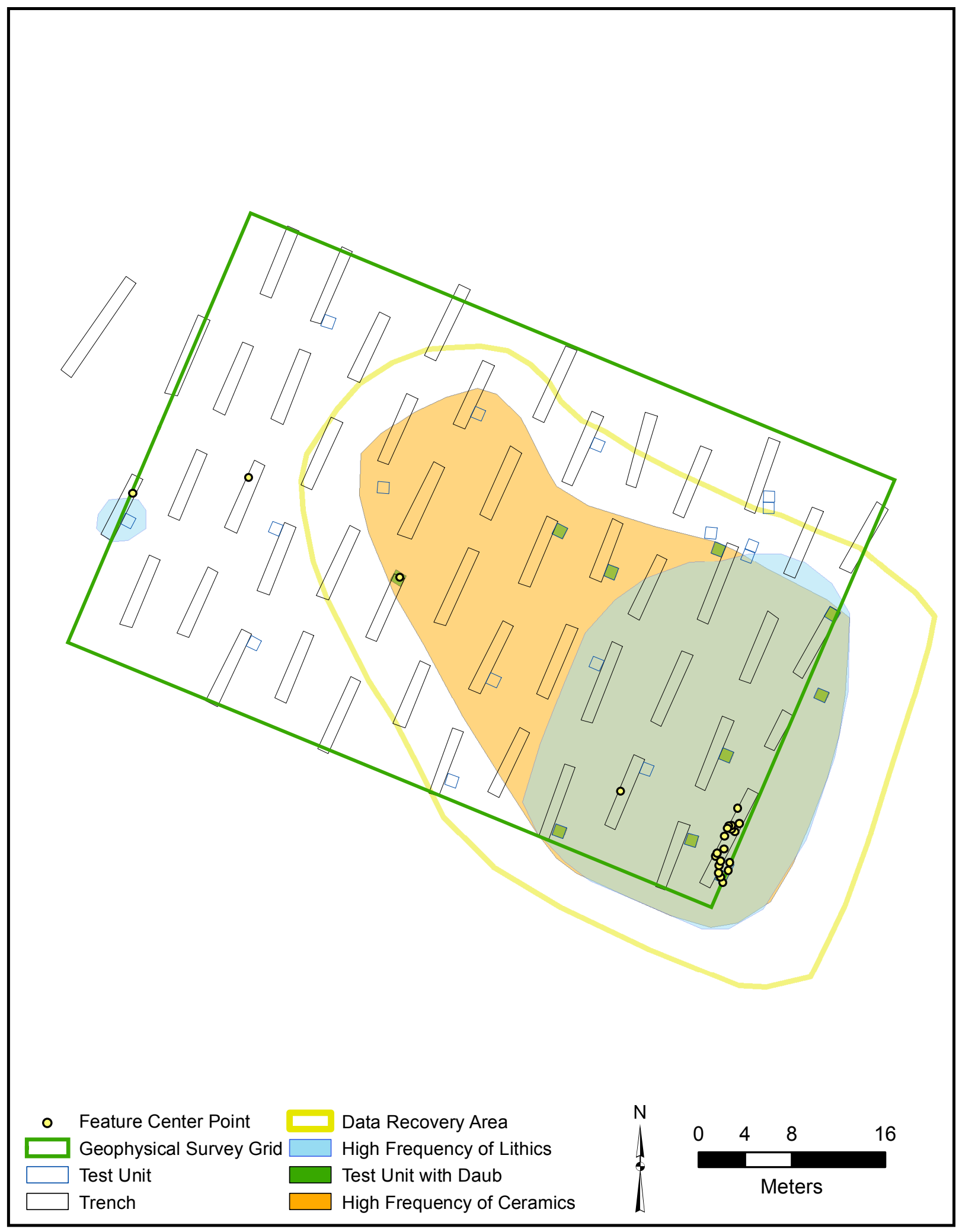

Figure 3.3. Plan of the William Ford site, Subarea 1, showing area proposed for data recovery excavations. 


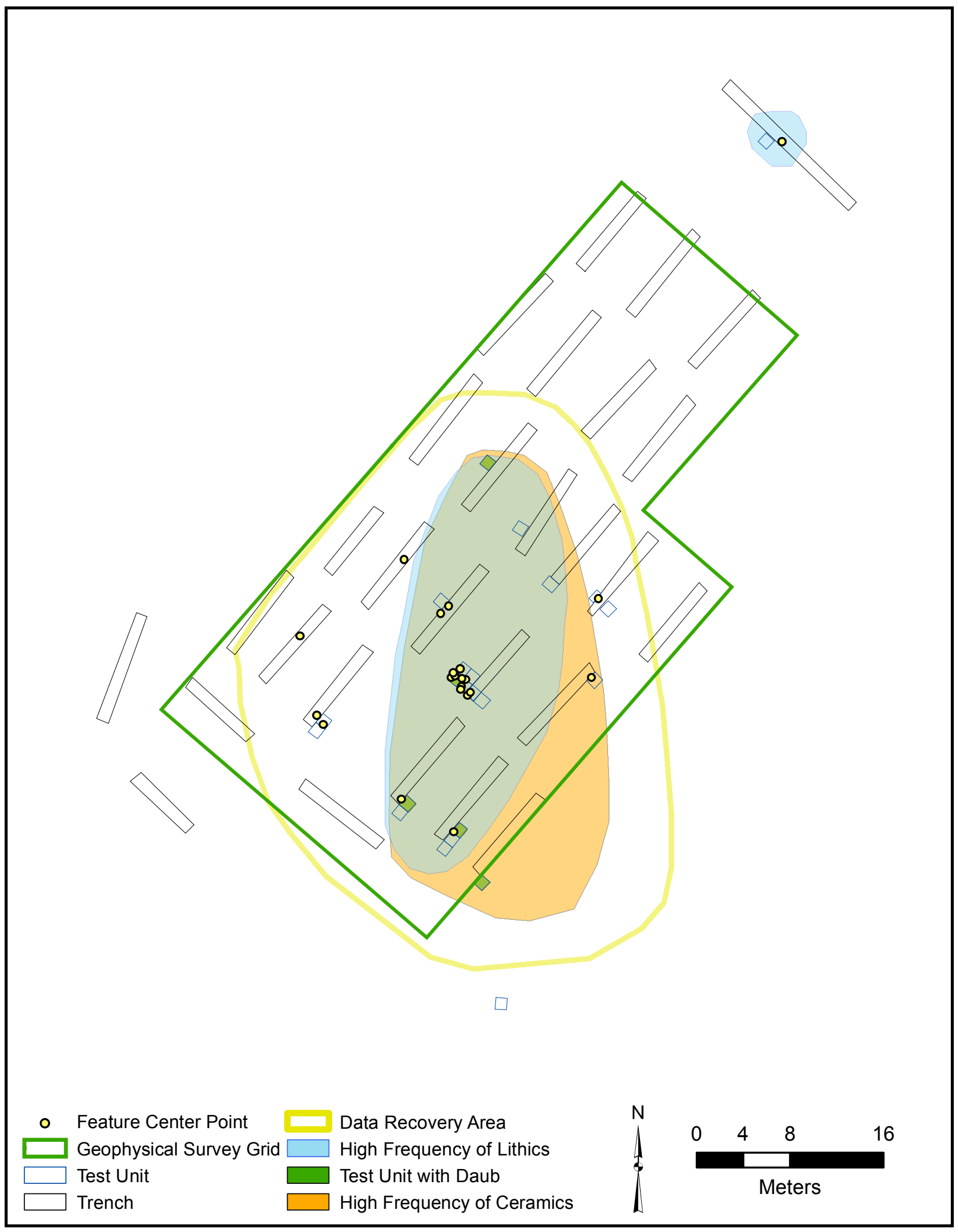

Figure 3.4. Plan of the James Richey site showing area proposed for data recovery excavations. 
testing to have relatively sparse archeological remains. Hence, at George Richey the investigated area was to extend ca. $80 \mathrm{~m}$ north-south and $20-30 \mathrm{~m}$ east-west and cover ca. $1,850 \mathrm{~m}^{2}$. At William Ford, Subarea 1, the investigated area would be ca. $60 \mathrm{~m}$ northwest-southeast by 25-40 m northeast-southwest and encompass ca. $1,900 \mathrm{~m}^{2}$. At James Richey, the investigated area was to extend west from the area where ceramics and lithics were most concentrated into an area where artifacts were less frequent, probably because erosion had removed sediments and artifacts, but where features were present; the investigated area at this site was to be $50 \mathrm{~m}$ north-south by $40 \mathrm{~m}$ east-west and encompass ca. $1,325 \mathrm{~m}^{2}$. These three areas are comparable in size $\left(1,325-1,900 \mathrm{~m}^{2}\right)$ to the areas containing concentrations of features representing houses and activity areas at some of the more-extensively excavated Caddo sites in the region, including Ear Spool in Titus County $\left(1,600 \mathrm{~m}^{2}\right)$, Area I at Pilgrim's Pride in Camp County $\left(1,500 \mathrm{~m}^{2}\right)$, and Areas 2 and 8 at Pine Tree Mound in Harrison County $\left(1,100-2,000 \mathrm{~m}^{2}\right)$. This supported the idea that the data recovery areas would be of sufficient size to contain the kinds of archeological evidence sought.

Ultimately, the full extent of each of the three areas was to be excavated by one means or another, for a total of about $5,075 \mathrm{~m}^{2}$ of excavation. This approach parallels that used in several recent data recovery projects with similar goals at Caddo sites, including Oak Hill Village, the Ear Spool site, and Pine Tree Mound. The following six-step excavation strategy was planned.

(1) A backhoe with a ca. 1-m-wide bucket was to be used to systematically sample the full extent of each of the three data recovery areas at an interval of ca. $5 \mathrm{~m}$. The objective was to acquire samples of artifacts to allow investigation of the horizontal distributions of activities, both in kind and intensity, across each area and thus contribute to an understanding of hamlet structure. Sample units were to be ca. $1 \mathrm{~m}$ wide (the width of the bucket) and $1.5 \mathrm{~m}$ long. Where the surface sands are more than $40 \mathrm{~cm}$ deep, the sample units would be excavated in at least two vertical increments to give the excavators a chance to find features above the sand-clay contact. A limited amount of manual work would be needed to square up these units and ensure comparability for vol- umetric comparisons. All sediments removed from the sample units were to be screened through 1/4-inch-mesh hardware cloth. It was expected that about 256 units would be required to cover all three areas. In 59 instances, manual units dug during testing were close enough to proposed sample unit locations that they could be substituted, leaving 197 units yet to dig during data recovery.

(2) Within each data recovery area, a track Gradall or trackhoe was to be used to remove sediments in one or two $3 \times 16-\mathrm{m}$ swaths where testing most clearly indicated houses were likely. This was to occur in the following areas:

- in the north part of George Richey, in the vicinity of Trench 40 where 1 posthole (Feature 10), 3 pits (Features 9, 17, and 19), and 1 large posthole or pit (Feature 16) had been found, with a possible posthole (Feature 18) in a test unit not far to the northeast;

- in the south part of George Richey, in the vicinity of Trench 12 where 4 postholes (Features 1, 12, 13, and 15) had been found;

- in the southeast corner of the tested grid at William Ford, in the vicinity of Trench 4 where 14 postholes (Features 23, 24, and 30-41), 1 pit (Feature 13), 2 postholes or pits (Features 14 and 25), and 1 sherd concentration (Feature 1) had been found and west toward Trench 12 where a large posthole or pit (Feature 4) had been identified;

- in the central part of James Richey, in the vicinity of the south end of Trench 15 where 4 postholes (Features 19 and 21-23), 1 pit (Feature 14), 1 pit hearth (Feature 20), 2 postholes or pits (Features 15 and 16), 1 child burial (Feature 18), and 1 sherd concentration (Feature 10) had been found and north toward Trench 14 where a rock hearth (Feature 8) and a possible posthole (Feature 9) had been identified.

The goal would be to determine if arcs of postholes representing parts of houses could be identified. The sizes of the swaths were designed to equal or exceed twice the anticipated diameter of houses at these sites $(6-8 \mathrm{~m})$ in the long dimension and to be half or less the diameter in the other dimension. This would provide exposures 
extensive enough for confident identification of houses, while at the same time leaving large parts undisturbed so they could be excavated manually if warranted. Before the Gradall excavations, approximately 22 percent of each swath was to be removed by machine in 1.0x1.5-m units and screened. The goal was to provide horizontal control for recovery of samples of artifacts along the length of each swath, with these samples potentially being useful for characterizing activities within and around houses. Half of these units would be 5 -m-interval sample units dug during Step 1; the other half would be additional sample units placed between 5 -m-interval units and units dug in testing.

(3) If houses were identified in Step 2, their remaining parts adjacent to the Gradall swaths were to be excavated manually using small horizontal and vertical subdivisions (maximally $1.0 \times 1.0 \times 0.1 \mathrm{~m}$, and perhaps smaller) to look at intrahouse use of space and arrangement of activities and the use history and postuse history of the structure.

(4) Then, a track Gradall or trackhoe would be used to completely strip all three data recovery investigation areas, covering a total area of about $5,075 \mathrm{~m}^{2}$, to examine the horizontal distributions of features across each area and thus contribute to an understanding of hamlet structure and the use of space. Where the surface sands are more than $40 \mathrm{~cm}$ deep, this stripping was to be done in at least two vertical increments to give the excavators a chance to find features above the sand-clay contact.

(5) The cultural features were to be mapped with a Total Data Station, recorded in plan view, and cross sectioned and recorded in profile. Samples of fill would be collected for flotation and recovery of charcoal for radiocarbon dating, with portions of the fill not collected for flotation screened through 1/4-inch-mesh hardware cloth for recovery of artifacts.

(6) As a final step, using heavy equipment to strip large enough areas around the three data recovery areas to make sure that no human burials or cemeteries adjacent to the residential areas remained unidentified. The extent of this final stripping was to depend on topography and landform extent.

\section{FIELD METHODS}

Data recovery excavations followed the scope of work with only minor adjustments. Investigations began with the excavation of 215 sample units at all three sites to evaluate the densities of cultural materials. The sample units were excavated using a backhoe with a 1-m-wide bucket and on average measured $2.0 \mathrm{~m}$ long, $1.0 \mathrm{~m}$ wide, and $0.36 \mathrm{~m}$ deep (Figure 3.5). The units were excavated in single levels down to the top of the Bt horizon at average depths of $0.36 \mathrm{~m}$ (41TT851), $0.32 \mathrm{~m}$ (41TT852), and $0.39 \mathrm{~m}$ (41TT853). In addition to having the thickest surface sands overall, 41TT853 also had the greatest variability in sand thickness, with some areas having essentially no sands and others having deposits almost $1 \mathrm{~m}$ deep. The excavation of sample units occurred in two phases with the first set of units spaced at an interval of ca. $5 \mathrm{~m}$, skipping places where units had been excavated during testing. The second series of sample units were excavated within the areas that potentially had house features. These areas, detailed above, were designated for the excavation of $16 \times 3$-m-wide swaths using a track Gradall or trackhoe. Three or 4 additional sample units were placed within each area marked for Gradall or trackhoe excavations to further sample the artifact densities.

Due to time constraints and other factors (particularly some units being larger than planned, resulting in unmanageable backdirt piles, and frozen backdirt that could not be screened in some cases), not all the fill from most units was passed through 1/4-inch screens. Instead, approximately half the fill from most units was visually targeted for screening, with the actual amounts processed being tallied using five-gallon buckets filled 75-80 percent full. In most cases $(n=170)$, this equated to $12-20$ buckets being screened per unit. Smaller amounts were screened from 32 units, generally because they were shallow and did not yield as much backdirt. In 4 cases, no fill was screened because essentially no sediments were present or the unit was in an area that had been excavated during testing. Seven units had 21-40 buckets screened; 4 of these, with 30-40 buckets, had all or almost all of their fill screened.

Following sample unit excavation and screening, the 16x3-m swaths were excavated using a trackhoe with a smooth-edged bucket 
(Figure 3.6). As stated in the scope of work, swaths were excavated in two areas on George Richey, in one area on William Ford, and in one area on James Richey. After each swath was excavated, these areas were shovel skimmed and troweled, the walls were cleaned, and parts of the walls were profiled (either descriptively or graphically). All of the swaths contained soil disturbances, some apparently representing postholes, but none could be associated with a definable house arc allowing us to designate areas for hand excavation.

Following trackhoe swath excavations, the trackhoe was used to strip all three data recovery investigation areas, which covered a total area of about 5,306 m $\left(2,218 \mathrm{~m}^{2}\right.$ at George Richey, 1,754 $\mathrm{m}^{2}$ at William Ford, and 1,334 $\mathrm{m}^{2}$ at James Richey) (Figure 3.7). Trackhoe stripping proved less effective at James Richey than the other two sites because of the extreme variation $(5-70 \mathrm{~cm})$ in the thickness of the $\mathrm{A} / \mathrm{E}$ horizon sands. Though an attempt was made to investigate the upper sands at this site, bioturbation and the minimal contrast between the $\mathrm{A} / \mathrm{E}$ horizon sediments and possible feature fill made it nearly impossible to identify features with confidence in areas where the sands were thick, since possible features rarely extended into the Bt horizon. Hence, it is likely that the features identified here represent a fraction of the total number once present.

After stripping, the exposed areas were troweled and, in some places, shovel skimmed, and soil disturbances were identified on the $\mathrm{Bt}$ horizon surface (Figure 3.8). Disturbances were indicated by variations in fill color and texture and occasionally by concentrations of artifacts or ecofacts. All disturbances, except those that were obviously not cultural, were mapped using

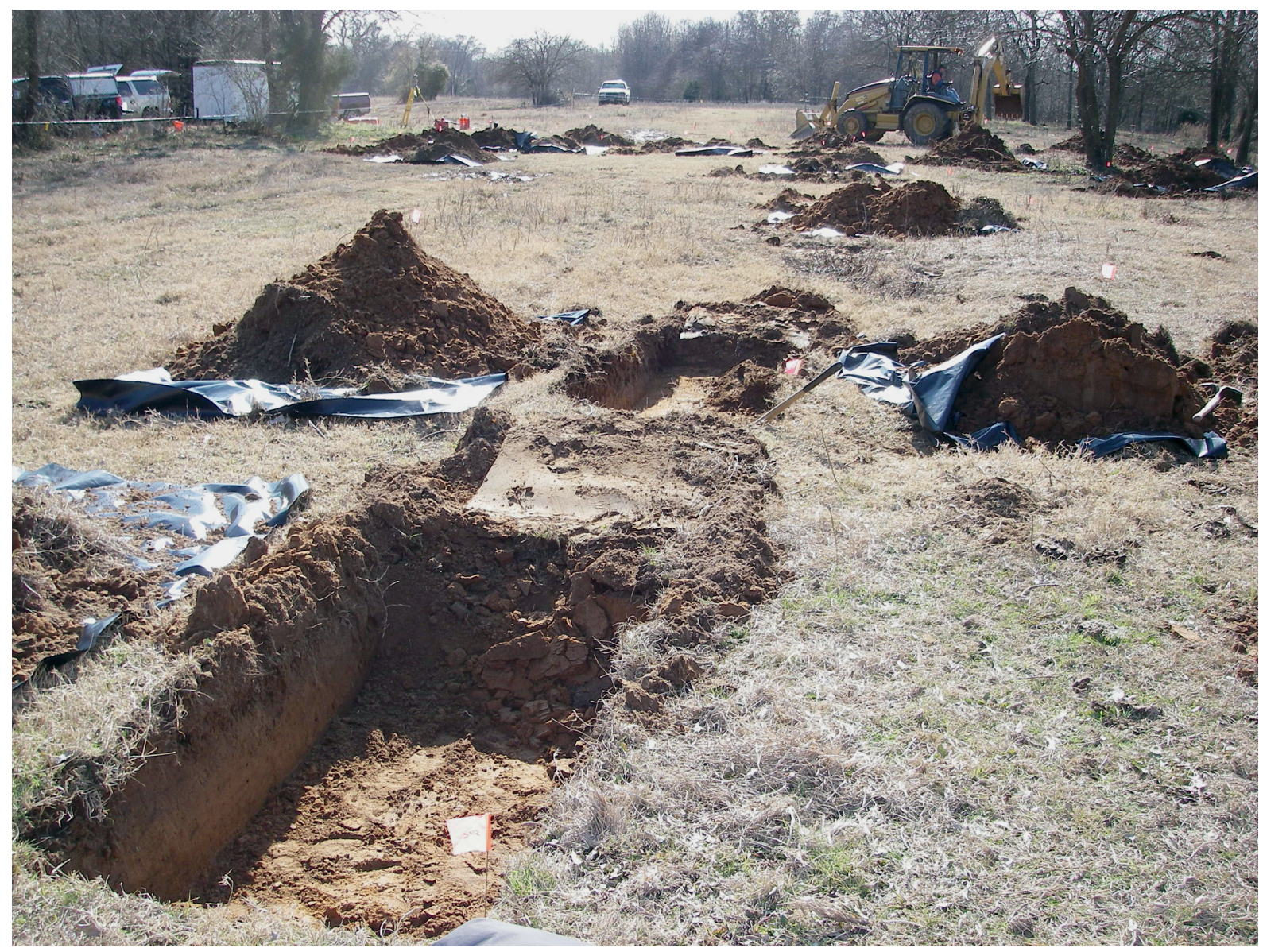

Figure 3.5. View of backhoe-excavated sample units at the George Richey site. 


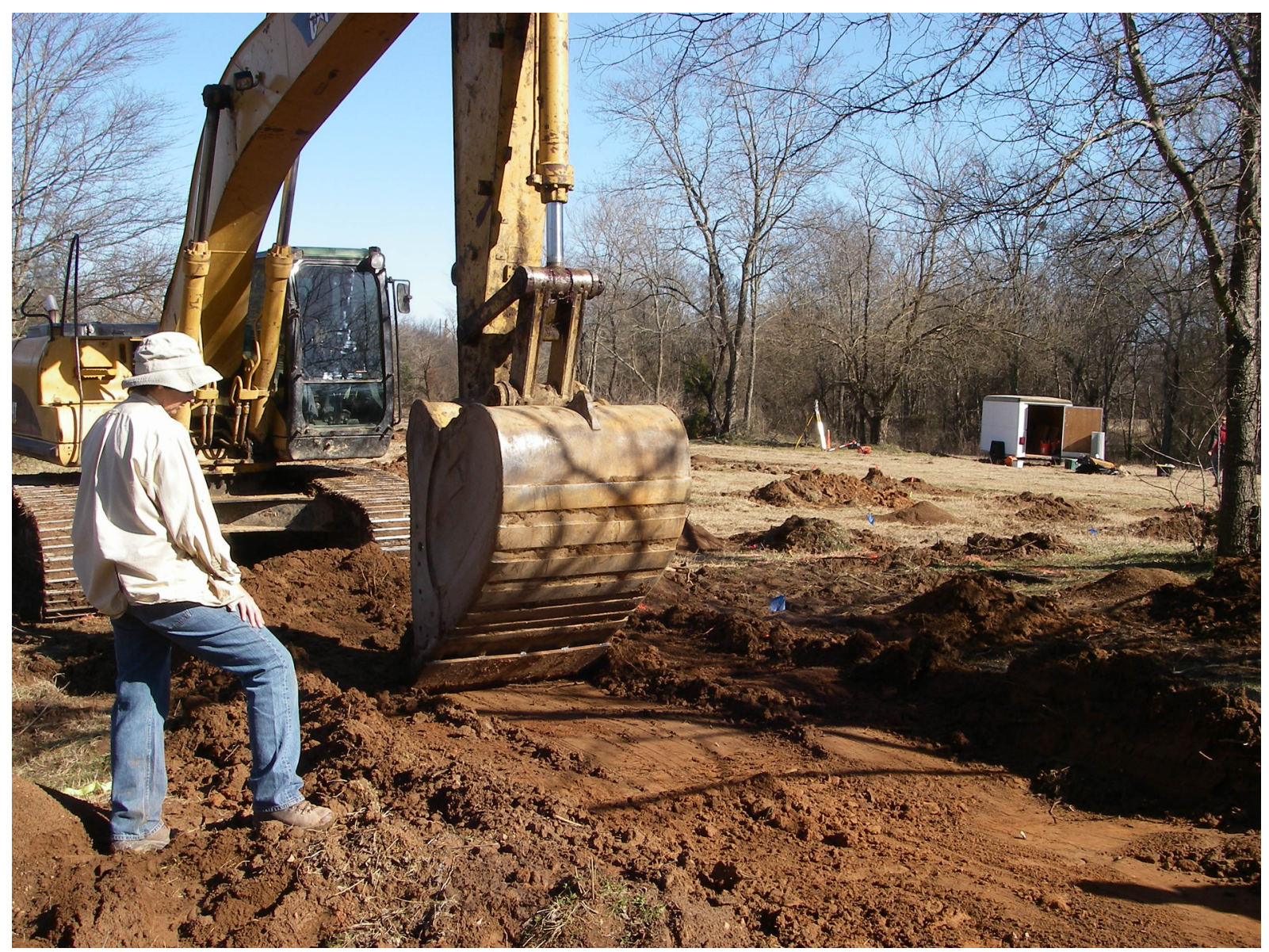

Figure 3.6. View of excavation of a trackhoe swath at the George Richey site.

a Sokkia total data station and given a feature number. Since excavation of all soil disturbances took several weeks to accomplish at each site, all unexcavated disturbances were kept under a plastic cover to retain soil moisture and protect them from rainwater and erosion (Figure 3.8). Erosion after rains still destroyed a few disturbances at each site before they could be investigated. The mapped soil disturbances were drawn and photographed in plan view and then cross sectioned and recorded. Some of the smaller ones were excavated in their entirety and were not photographed in cross section. The fill from the cultural features, and some later determined to be noncultural, was taken for flotation. A handful of features were very large, and the fill was sampled to represent the entire depth; in these cases, the remaining fill was screened through 1/4-inch mesh. Flotation sample volumes ranged from 0.25 to 139.00 liters, averaging around 9.70 liters.

A second phase of stripping followed the investigation of soil disturbances at all three sites. This stripping extended beyond the data recovery investigation areas to the edges of the landforms to ensure that no burials or other major features along the margins of the site were missed. These varied from site to site, ranging from long trenches to big block areas, and covered $428 \mathrm{~m}^{2}$ at George Richey, $606 \mathrm{~m}^{2}$ at William Ford, and $535 \mathrm{~m}^{2}$ at James Richey. No burials or any other significant cultural features were identified within these areas.

Toward the end of the project, personnel from the Texas Historical Commission (THC) visited each of the sites. Only at George Richey did the THC request further investigations. This resulted in an additional block excavation, 

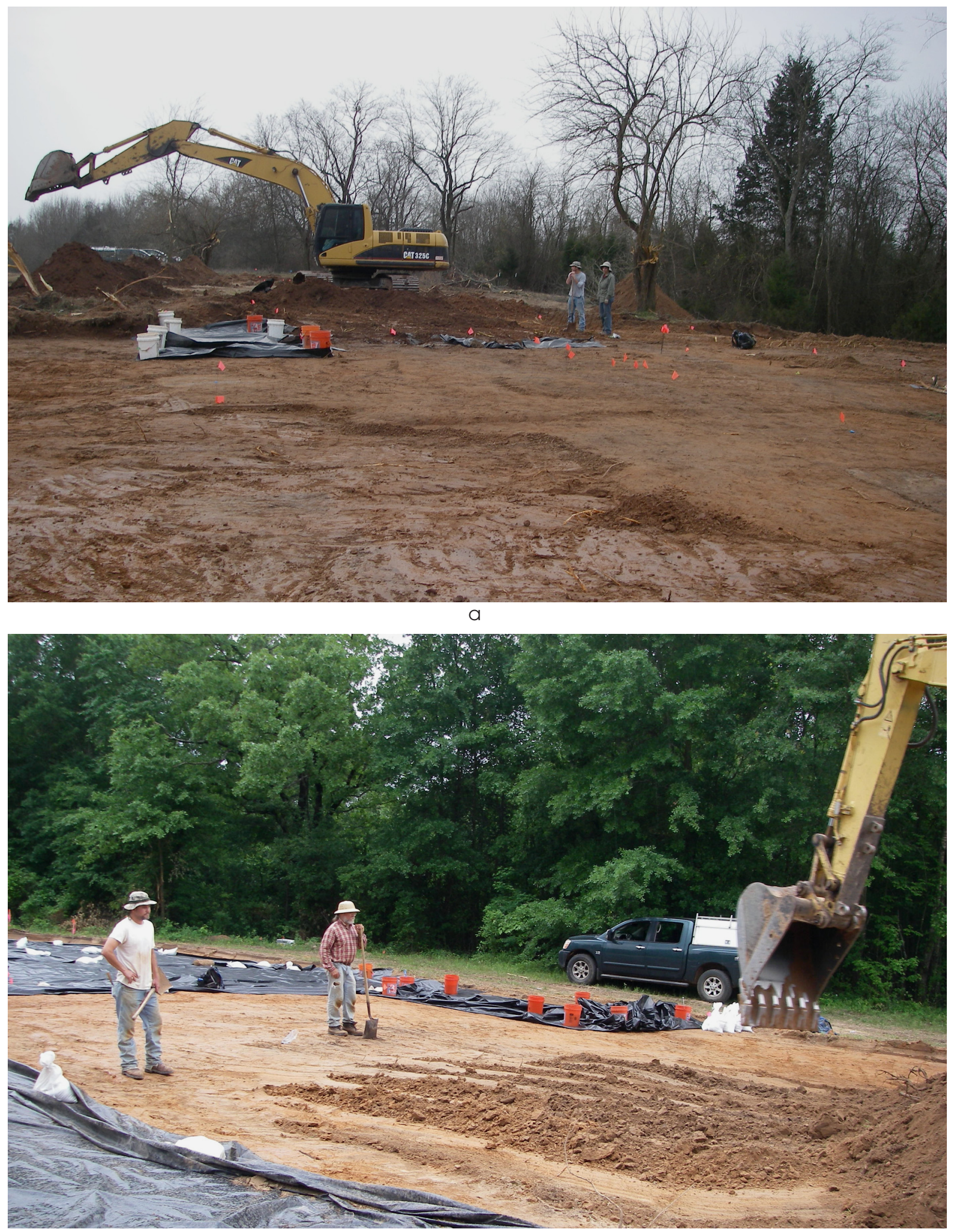

$\mathrm{b}$

Figure 3.7. Views of trackhoe stripping at the George Richey (a) and William Ford (b) sites. 
using a backhoe with a smooth-edged bucket, in an area with multiple large pit features in the north-central part of the site. Fieldwork began in January 2010 and concluded in mid June 2010.

\section{LABORATORY PROCESSING AND ANALYSIS METHODS}

\section{Laboratory Processing}

The artifacts and other materials collected were brought back to the laboratory at Prewitt and Associates in Austin for processing. Artifacts were washed and sorted, and counts done in the field were rechecked. Artifacts considered tools were labeled with the site number, their lot number, and a lot-specific specimen number so they could be tracked through the analysis process. In addition, 20-25 percent of the lithic debitage and ceramic sherds from each provenience were labeled with site and lot numbers. All artifact and item classes were recorded in a specimen inventory catalog by lot number, thereby linking them back to their provenience.

A major laboratory effort concerned the processing and sorting of 206 flotation samples from feature proveniences. Processing of the selected samples was completed using a FloteTech flotation system. Two recovery fractions were obtained for each sample: a fine fraction composed of materials that floated and were caught in a 0.32-mm screen and a coarse fraction that did not float and was recovered from a 1.0-mm screen. After processing, heavy fractions were further sorted to remove artifacts and animal bones that were reincorporated into the artifact/ecofact samples. Animal bones were sent to faunal analyst Dr. Brian S. Shaffer for iden-

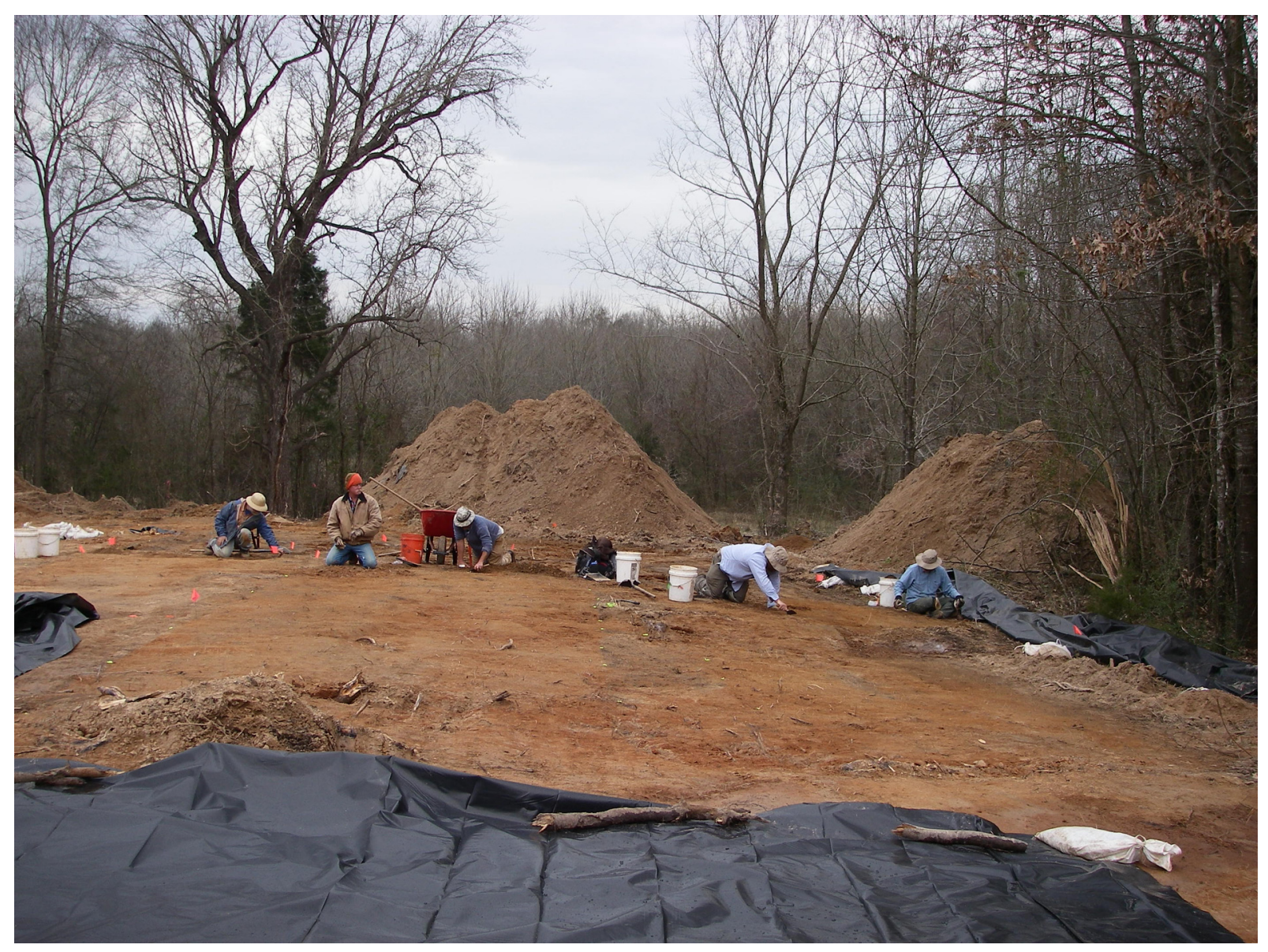

Figure 3.8. View of the crew troweling trackhoe-stripped area at the James Richey site. 
tification. Macrobotanical remains were sent to archeobotanist Dr. Leslie L. Bush for analysis. The macrobotanical analysis not only provided information on the prehistoric use of vegetal resources, but it also contributed to selection of materials for radiocarbon dating.

All artifacts and ecofacts recovered, databases, inventories, logs, field notes and journals, site maps and drawings, analysis notes, and photographs generated by this project are curated at the Texas Archeological Research Laboratory (TARL) of The University of Texas at Austin. These materials were prepared according to that facility's curatorial standards.

\section{Ceramic Analysis}

Ceramic sherds were recovered from nine sites during testing or data recovery, and vessels or vessel sections were found at all three sites investigated during data recovery. In addition to these materials, the analysis included a small collection of vessels from the Duncan Anderson Farm (41TT18), a small Caddo cemetery on private land near the U.S. Highway 271 Mount Pleasant relief route corridor (see Appendix K), and the vessels from the graves at the Thomas B. Caldwell cemetery and the A. P. Williams cemetery, also near the project area, were studied with an emphasis identifying motifs and ceramic types (see Chapter 7). The ceramics from these three cemeteries informed the analysis of the vessels and sherds from the project area by providing comparative data on morphology, decorative modes, motifs, and types. The cemetery vessel data also provide opportunities that the sherd collections from residential sites do not to address questions concerning the prehistoric Caddo community in the Tankersley Creek drainage and its place within the broader Caddo social and political organization. This discussion of analysis methods starts with morphological characteristics and then goes on to address decoration and design. These characteristics were used to identify the ceramic types represented in the samples. Type was far less discernible within the sherd collections than the vessels because most of the sherds are small.

All sherds more than 1/4 inch across were counted and weighed, though on occasion smaller sherds were included if, for example, they were recovered by flotation from a feature. Only sherds larger than 1 inch were fully analyzed, however. Many sherds with fresh breaks from excavation were reconstructed. These reconstructed sherds were counted as single sherds. Reconstruction of vessels and vessel sections also was done for the complete and mostly complete jars and bowls recovered. These were counted as single entities in the sherd database, with weight as the true indication of their contribution to the ceramic artifact density at each site.

Ceramic reconstruction, using PVA in acetone as glue, enabled collection of accurate measurements as well as more-precise graphic and photographic documentation of larger sherds and vessel sections. Digital photographs were made of selected sherds and all the vessels recovered in the excavations, as well as the vessels from the Duncan Anderson Farm site. The vessels from the Thomas B. Caldwell and the A. P. Williams cemeteries were not photographed because they are in the collections at TARL. In addition, drawings were made to provide a quick reference for recognition of similar motifs between sites. The drawings of sherds also captured rim profiles, which helped in understanding vessel forms represented. For decorated vessels, drawings where made in-the-round and, where informative, with the motif opened out.

All of the decorated bowls and bottles from the Thomas B. Caldwell cemetery were drawn with an emphasis on collecting information on motif structure. These drawings complement the photographic record, as they provide more-complete, seen-from-all-angles understanding of the structure of the vessels in relation to the decorative motifs. At the same time, the full range of morphological data collected for the vessels from the George Richey, William Ford, and James Richey sites was recorded for the Caldwell cemetery vessels. The vessels from the A. P. Williams cemetery were recorded in more-abbreviated fashion. The existing TARL catalog thumbnail drawings and vessel notes were utilized and augmented with spot checks of the vessels themselves; drawings of selected vessels were made to clarify particular motifs. Morphological data on the A. P. Williams vessels was taken from the TARL catalog as well and thus is not fully comparable to the range of attributes recorded for the other collections.

\section{Morphological Attributes}

Included under this heading are attributes relating to vessel type and paste/fabric 
characteristics, which help in interpreting the functions of the vessels used at the sites. Vessel type includes the attributes of vessel form, rim form, lip form, and base form. Vessel forms identified are bottles, bowls, jars, beakers, and ollas. Vessel form identification for sherds relied heavily on rims, necks, and carinated sherds. Neck sherds were especially important in identifying jars and ollas, as were carinated sherds for bowls. Occasionally, a large body sherd or a sherd with a specific motif could be used to identify vessel form. For instance, thick brushed body sherds are likely from jars. Rim form, vessel wall curvature, and surface treatments such as interior scraping were important in identifying bottles and ollas. Rim form was recorded as everted, inverted, straight, or indeterminate. Rim thickness was recorded as a rough indicator of vessel size, as often there was not enough of the rim remaining to determine rim diameter. Rim diameter was measured where possible, though. Lip form was recorded as flat, tapered, rounded, rolled, folded, and indeterminate. Base form, recorded as flat, rounded, or indeterminate, generally provided little help in distinguishing vessel form, though it can provide an indication of vessel size based on thickness. Rounded bases were difficult to distinguish in the sherd sample.

Paste/fabric characteristics include temper, interior and exterior surface treatment, and color. Temper, or the main constituent added to the clay body, was determined using 10x magnification on a fresh break. Temper type was recorded as grog, bone, voids (probably leached bone), sand, and indeterminate, with the first three occurring in varying combinations. No size grading or proportional determination was made for temper, since a sample of the sherds was to be more rigorously analyzed using petrographic methods.

Surface treatment is considered as the method chosen by the potter to finish the vessel body prior to the application of decoration, if any. Floating and smoothing are two of the most common ones in these collections. Floating is done with a wet hand or cloth to bring fine particles of clay to the surface, providing a uniform and somewhat impervious surface. Burnishing also helps render the vessel surface strong and less permeable, but it is not as common in the analyzed samples. Burnishing is recognized by the glossy finish or tool marks. It may be that weathering has destroyed some of this evidence. Another less common finish is scraping. Such a surface on the interior of a sherd indicates it is from a bottle or olla, since a potter cannot finish the interior of a vessel with a highly constricted rim or neck. Roughened surfaces were noted for some sherds. A roughened surface on the exterior of a vessel may be a means to give the vessel a nonslip texture, which is advantageous for large utility vessels. On the interior of vessels, roughening may be just an unfinished surface similar to scraped surfaces but without the striations of scraping. Some modifications to a vessel or surface help gauge a vessel's function or use life. The presence of burned organic encrustations on a vessel's exterior surface marks it as a cooking pot, for example, while the presence of drilled holes may indicate vessel repair. The most common ones in this analysis are eroded surfaces and modern damage, which indicate these artifacts underwent extensive postdepositional alterations.

Color of the fired clay body was recorded for vessels but not sherds. Color was recorded as the main interior color, exterior color, and core color. Color was recorded for slips and pigments in incised or engraved lines on both sherds and vessels. Color was recorded using vernacular terms that can be related to Munsell colors as follows: dark brown 7.5YR 4/3, 4/4, 4/6; brownish red, 10R 3/3, 4/4; light brown, 7.5YR 5/3, 5/4, 6/3, 6/4; yellow, 10YR 5/6, 5/8, 6/6, 6/8, 7/6, 7/8; black, 10YR 2/1, 2/2, 3/1, 3/2; gray, 10YR 4/1, $4 / 2,5 / 1,5 / 2$; red, $10 \mathrm{R} 4 / 8,5 / 6,5 / 8$; green gley, $5 / 5 \mathrm{G}$; and white gley, $8 / \mathrm{N}$. These were meant to provide a description of a vessel's general color scheme, which may have been important to the sociocultural meaning or function of the vessels. For example, a black bottle with red pigment in its engraved design may have had a different cultural significance then a plain yellow bottle. The colors are not intended to provide definitive evidence of firing technology.

Additional information recorded for a vessel includes the percentage of the pot represented, which can provide a measure of the strength of some of the observations made. Other vessel dimensions recorded include overall height along with rim, neck, base, and body diameter where possible. For carinated bowls, body diameter was measured at or just below the carination. For bowls with rim elaboration, the diameter measure was made on the inside of the lip. For those vessels with a partially intact rim, a graduated ring scale was used to determine 
diameter; for some, precise estimates could be made, but for some rim sections, only ranges could be determined. Vessels defined based on small sections obviously lack dimension data. A general size category of small, medium, or large is given for these vessels based on comparisons with more-complete vessels. Volume was recorded for vessels where possible using dry rice and a graduated measuring cup. Vessels were filled with rice to within $0.5 \mathrm{~cm}$ of their rim to obtain a measure of their volume. Jar and bowl interiors were protected from the rice with a removable plastic liner.

\section{Decoration and Design}

Decoration was recorded using a three-level approach. The first is decorative mode, which is the basic technique used. Modes include engraving, incising, brushing, appliqué, pinching, coil crimping (neck banding), and stick or fingernail punctations. These often were applied in various combinations. This basic level of decorative information is often the most useful in characterizing sherd-based ceramic samples, with analyses of samples consisting mostly of small sherds often stopping at this level.

The second level of recordation of decoration involves identification of design elements that contributed to motifs. Thirty-nine elements were identified (Figure 3.9). For most sherds in these samples, design definition stopped at the element level because the small sherds convey no additional information. Even so, certain elements such as pendant triangles and interlocking ends can provide some indication of motif and ceramic type. Where enough of the design remains, motifs were defined based on the combination of elements, their relationship to each other, and their placement on the vessel. For instance, a scroll motif could be defined based on the combination of rectilinear lines and open circle or bar elements. Where possible, an element was identified as either primary or secondary within a motif. An open circle is a good example of a primary design element, as it is known to be common at the center of Ripley Engraved scroll motifs. Secondary elements could include bars or pendant triangles, which appear in the arms of scrolls, or horizontal lines, which occur around the rim of the vessel above the scroll. When such combinations of elements occur in what is obviously a scroll motif, it is easy to identify that sherd or vessel as relating to the type Ripley Engraved.

In some instances, designation of a primary element was problematical. This was especially the case for complete or nearly complete jars that are decorated with a range of punctated, incised, brushed, and appliquéd elements. The element considered primary was the one viewed as being central to the overall design. In some instances, this determination also took into account the placement of the element on the vessel. For example, appliqué fillets on the body of a jar were considered primary because the fillets were essential for defining the body panels motif, which defines the type Pease Brushed-Incised. Brushing and lines of punctations, which can occur with the body panels motif, were considered secondary elements.

The third level of decoration recordation, motif, refers to "a complex unit of design consisting of a configuration or pattern of configurations that retains its identity across a number of vessels and/or design contexts within a particular style repertory" (Jernigan 1986:10-11). Twenty-four main motifs were identified across all the analyzed ceramics, including the three cemetery assemblages from outside the project area proper. Because motif definitions needed to be useful for analysis of both sherds and vessels, some motifs were simplified. An example of this involves the multiple motifs that were used to define Maydelle Incised jars. A complete Maydelle Incised jar from the James Richey site was considered to display the band of alternating elements motif. However, most sherds thought to be Maydelle Incised have diagonal lines at the rim or alternating parallel lines motifs. The motif association based on sherds focuses more narrowly on the configuration of elements, whereas the vessel provides a total configuration.

The main motifs are organized here by vessel form. Simplified motifs that occur mainly with jar sherds are also included. The few motifs defined for ollas follow those for bottles, and the motifs on the few beakers from the Thomas B. Caldwell and A. P. Williams sites follow the motifs for jars. Bottle and olla motifs include the following: concentric circles, concentric circles/ diamonds, concentric bands, medallions, swirl, and unique. Bowl (simple, deep, compound, or carinated) motifs include the following: scroll (sinuous or undifferentiated), slanted scroll, 


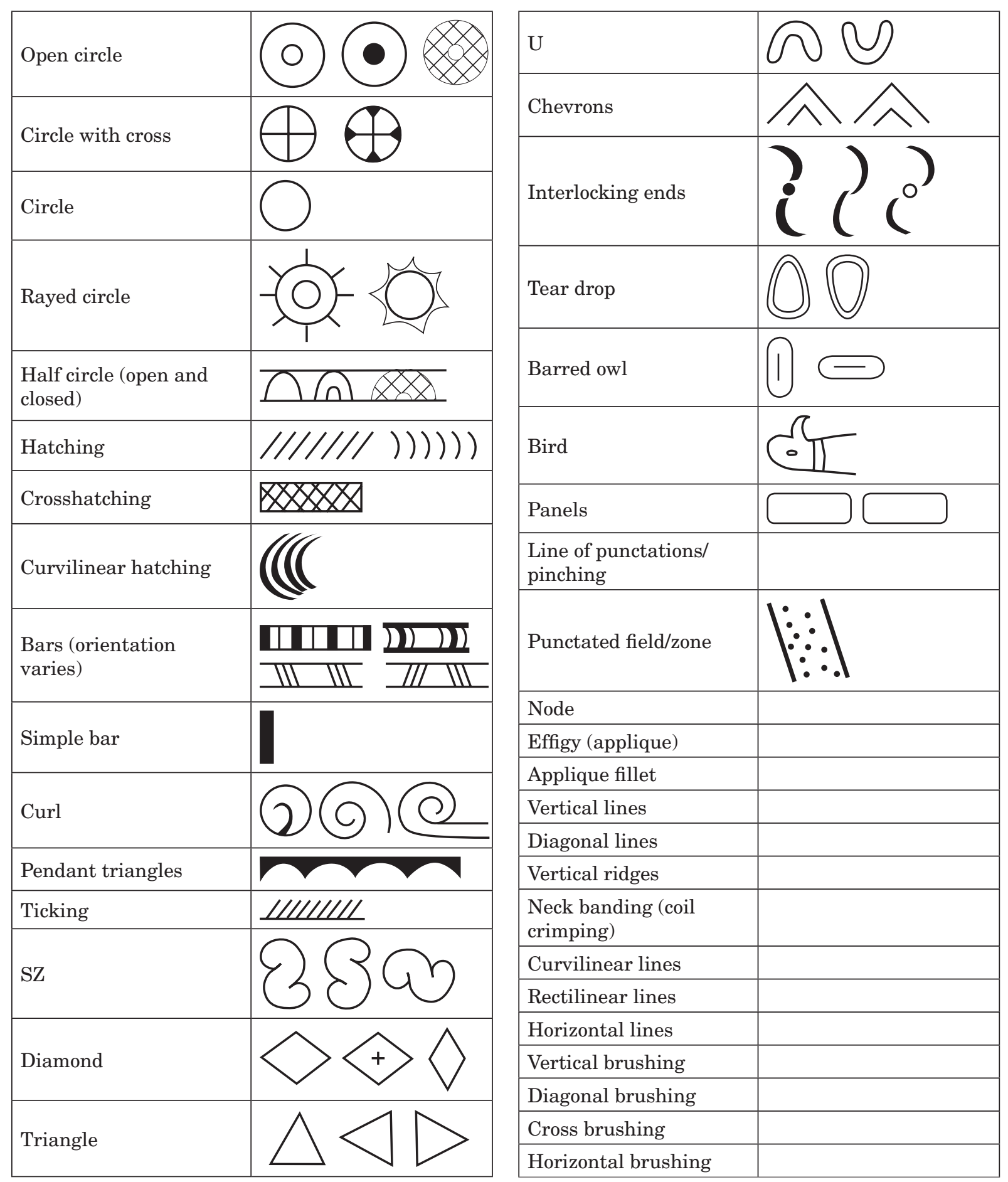

Figure 3.9. Ceramic design elements. Elements without illustrations are considered self-explanatory. 
straight scroll, opposed scroll, slanted/opposed scroll, band of alternating elements, band of repeating elements, effigy, horizontal lines at the rim, and unique. Jar and beaker motifs include the following: scroll, slanted scroll, medallions, body panels, rim panels, band of alternating elements, ridged body, zone of punctations at the rim, diagonal lines at the rim, alternating parallel lines, horizontal rows of punctations at the rim, vertical parallel lines at the rim, horizontal lines at the rim, and unique.

Ceramic type definitions were drawn mainly from Suhm and Jelks (1962) supplemented by the work of Turner (1978), Webb (1959), and Krieger (1946). Types identified or suggested include Ripley Engraved, Wilder Engraved, Johns Engraved, Sanders Engraved, Maydelle Incised, Weches Fingernail Impressed, Pease Brushed-Incised, Harleton Appliqué, Killough Pinched, Bullard Brushed, La Rue Neck Banded, and Belcher Ridged.

\section{Special Studies}

Ceramic special studies included instrumental neutron activation analysis (INAA) and petrography for selected vessels and sherds from the George Richey, William Ford, and James Richey sites. Fifteen samples from each site were chosen for study. In previous studies of this nature, sample selection often has included a variety of vessel forms, decorative modes, and ceramic types in an attempt to address local vs. nonlocal origins. The results are often muddied by the fact that clays within northeast Texas are part of the same depositional unit, making it hard to isolate discrete elemental constituents. Added to this difficulty is the possibility that different vessel forms and ceramic types had different potentials for trade and, thereby, movement out of the communities where they were manufactured. There is even the possibility that certain clays were imported for the manufacture of certain vessel types, such as large fine bottles.

This study attempted a more-focused approach by selecting only utility wares or jars to try to identify a local ceramic fingerprint unmuddied by vessels or clays that were brought in. The rationale is that it seems likely that large to medium-sized jars found at these sites were made using local clays (as opposed to more-easily transported small jars) and that similar clay sources were used, given that the three sites are close to one another.

Both typed and untyped jars and jar sherds were used. Untyped ones included a medium-sized to large jar form decorated with horizontal rows of punctations around the rim and having a plain or brushed body/rim. These decorated jars are prominent at the William Ford and James Richey sites and are likely related to the types Bullard Brushed and Mockingbird Punctated, though type assignments were not made because the distinction between the two, i.e., a brushed vs. plain body, was not discernible on rim sherds alone. Typed jars or jar sherds include Maydelle Incised, Harleton Appliqué, Pease Brushed-Incised, and Killough Pinched. The INAA samples were analyzed by Dr. Jeffrey R. Ferguson and Dr. Michael D. Glascock of the MURR research lab, and the petrographic analysis was undertaken by Dr. Leslie Cecil of Stephen F. Austin State University.

\section{Lithic Analysis}

Lithic analysis began by categorizing artifacts by techno-functional attributes as projectile points, nonprojectile point bifaces, flake tools (including unifacial tools, flake tools, and core tools), ground stone tools, cores, and debitage. These categories were further analyzed to identify attributes such as tool type, size (size categories for debitage and metric attributes for all other types), lithic material, and weight (measured in grams).

Lithic material type was recorded for all stone artifacts. Categories consist of local and nonlocal coarse- and fine-grained chert, novaculite, quartzite, silicified wood, ferruginous sandstone, hematite or ocher, and a few other materials. Principal sources for identification and understanding of the rock and mineral resources of northeast Texas and adjacent areas include Shafer (1973), Banks (1984, 1990), Studer (1982), Perttula (1984), and Fischer (1965). Banks (1990), Perttula (1984), and Shafer (1973) provide a regional perspective on the distribution and prehistoric use of lithic materials in east and northeast Texas.

By far, most of the lithic artifacts recovered are of locally available materials. These consist primarily of Ogallala chert, quartzite, silicified wood, ferruginous sandstone, hematite, and ochre. The local cherts are yellowish 
brown, brown, brown with red, reddish brown, red, tan and red, tan and gray, tan, and grayish brown and are opaque. Local materials also include Ogallala and other quartzites that range from yellowish brown to reddish brown in color and include coarse- and fine-grained varieties. Silicified wood also was utilized and is common in the area. The silicified wood is usually coarse grained, but a few fine-grained examples were noted. The local materials derive from the Eocene Wilcox Group (undivided), Reklaw Formation, and Carrizo Sands, as well as Quaternary alluvial and terrace deposits and the upland Uvalde Gravels.

The nonlocal materials include novaculite; jasper; varieties of Edwards chert; varieties of gray, black, and white chert; Stanley or Jackfork sandstone; rhyolite; andesite; diorite; and probably limestone. The most likely sources for the novaculite are near Hot Springs, Arkansas, or the Little River and Glover Creek areas of southeast Oklahoma (Perttula 1984). The jasper could be from Red River gravels. The black chert may be from gravels in the Ouachita Mountain drainages, in the Red River, and in the Stanley Shale in Oklahoma and Arkansas. Black chert also occurs in central Texas (Banks 1990; Trierweiler 1994). The white chert probably is from multiple sources. A variety with brown specks is associated with the Keokuk-Burlington formations (Boone and Elsey are also grouped with this variety) and likely is from the Ozark Mountains of Oklahoma, Arkansas, or Missouri (Banks 1990). Perttula (1999:176-177) notes that white chert could have come from Red River gravels, having been transported downstream from sources in the Ouachita Mountains in southeastern Oklahoma. The gray chert could be from the Ouachita Mountains as well as central Texas (Perttula 1984; Trierweiler 1994). Other cherts that could be from central Texas are light to medium brown or gray and shades of brown (mottled) (Trierweiler 1994).

Stanley and Jackfork sandstone are quartzitic sandstones that crop out in the Stanley Shale and Jack Fork Sandstone Formations in the Ouachita Mountains in southeast Oklahoma and southwest Arkansas. Indistinguishable when removed from their parent formation, these materials are common in drainages trending south from the Ouachitas and in Red River gravel deposits (Banks 1990; Perttula 1984). Diorite crops out in the Arbuckle Mountains in south-central Oklahoma, the Potato Hills and the Broken Bow
Uplift in southeastern Oklahoma, and smaller uplifts in the southeastern part of the Ouachita Mountains (Ham et al. 1964; U.S. Geological Survey, Mineral Resources On-line Spatial Data 2011). Rhyolite is a major subsurface component from the south-central portion of Oklahoma west through the Texas panhandle. Outcrops of this igneous rock are found in the Arbuckle and Wichita Mountains in south-central and southwest Oklahoma (Denison 1959; Ham et al. 1964). Diorite and rhyolite are present in gravel deposits along the Red River and in many of its tributaries. Andesite occurs at Iron Mountain in southeast Missouri and in west Texas and New Mexico. The few pieces of limestone identified might have come from the Upper Cretaceous Pecan Gap Chalk or Annona Chalk Formations, which crop out $50 \mathrm{~km}$ north of the project area, or perhaps gravel beds in the Sulphur River downstream from those outcrops.

\section{Projectile Points}

Projectile points were subdivided into arrow points and dart points. Where possible, formal type names following Turner and Hester (1999) and other sources were employed. Projectile point attributes coded in this analysis include completeness, fragment type, breakage type, breakage cause, base shape, stem shape, blade shape, weight, and several metric attributes (measured in $\mathrm{cm}$ ) that include maximum length, maximum width, maximum thickness, blade length, blade width, blade thickness, stem length, stem thickness, neck width, and neck thickness. In presentation of the metric data (Appendix E), asterisks mark measurements that reflect incomplete dimensions. For points that do not have well-defined stems, i.e., triangular or lanceolate arrow or dart points, stem length was measured from the uppermost edge of the hafted portion as indicated by edges that are smoothed or lack blade serration or reworking.

Completeness categories are whole, broken, and indeterminate. Fragment types are proximal, medial, distal, proximo-medial, medio-distal, stem/haft, wedge, lateral, barb only, barb/stem, barb(s) missing, radial break(s), other, and indeterminate. Breakage types are bending, overshot, perverse, step/snap fracture, hinge fracture, distal crushing/impact, lateral fracture/impact, and indeterminate. Breakage causes are manufacture, use, recycling, general postdepositional, 
thermal, excavation, and unknown. Base shape categories are straight, concave, convex, irregular, and indeterminate. Stem shape categories are straight, expanding, contracting, irregular, and indeterminate. Blade shape categories are triangular, oval/ovate, lanceolate, bipointed/diamond, trapezoidal, rectangular, square, round, irregular, and indeterminate.

\section{Nonprojectile Point Bifaces}

This category incorporates all bifaces that are not projectile points. These were categorized into biface types consisting of early stage, middle stage, late stage, knife, drill, adze, gouge, hafted scraper, hafted knife, gunflint, and indeterminate. These types are defined by the morphology and characteristic patterns of use. No use wear analysis, other than examination with hand lens, was conducted, and functions are based on these characteristics or are assumed based on shape.

Early-stage bifaces are thick (roughly twice as wide as they are thick) and crude with sinuous edges and wide flake scars (Odell 2004:100; Whittaker 1994:201). They reflect an early step in the manufacture, or roughing out, of chipped stone bifacial tools and are often referred to as blanks (Inizan et al. 1999; Odell 2004; Whittaker 1994). Middle-stage bifaces reflect early thinning of the blank but are still relatively thick (usually three or four times wider than they are thick) with a biconvex or lenticular cross section and less sinuous edges that are centered (Odell 2004:100; Whittaker 1994:202). These are also considered preforms or quarry blanks. Latestage bifaces are thin and fairly regular with straight edges and have flattened cross sections, usually four times or more wider than they are thick (Odell 2004:100, Whittaker 1994: 203). This stage is near the final stage of manufacture.

Knives (hafted and unhafted) are bifaces with acute edge retouch on one or more lateral edge and were most likely used for cutting. These can have poorly shaped or well-made proximal ends, hafts (indicated by the shape of the proximal end), and bevels (moderately steep edge retouch). Drills have a bit or protrusion used for perforating. These are believed to have been used for hide and wood working. They tend to have a long narrow rodlike distal end, the drill bit, which is well prepared and often has alternate edge retouch. Bifacial hafted scrapers have edges shaped with very steep retouch that were used for scraping and have evidence for a haft. Adze or celt bifaces are thick with a biconvex distal (working) end. They are typically triangular or subtriangular in shape. Gouges are triangular to rectangular tools with a steep working bit. Gunflints are square in shape and have fairly steep edge retouch on the working edge. Indeterminate bifaces include fragments of indeterminate stage or function.

Bifaces were also coded for completeness, fragment type, breakage type, breakage cause, and outline shape, all similar to projectile points and described above. Metric attributes recorded are weight, maximum length, maximum width, maximum thickness, and, when appropriate, basal width, basal thickness, stem width, and stem thickness.

\section{Flake Tools}

This category consists of all tools made on flakes and, for convenience sake, on cores as well. The one exception is unifacial projectile points, which were included under projectile points. The flake tools include unifacial, edge modified, and utilized artifacts. The unifacial artifacts are considered formal tools that required a certain amount of time to prepare, and edge-modified and utilized flake tools are considered informal tools that required very little time investment, since they lack deliberate shaping and exhibit only slight retouch or modification. The formally prepared unifaces are subcategorized by morphology and function into end scraper, side scraper, end/side scraper, hafted knife, spokeshave (notched uniface), drill, graver, gunflint, multifunctional tool, and indeterminate. Tool types for informally prepared flake tools include scraper, knife, multifunctional tool, graver, spokeshave, and utilized flake (unretouched flake with use wear). All functional assessments are based on shape and the location and morphology of the functional edge(s) and characteristics of use wear. Unifacial scrapers typically have very steep edge retouch, and unifacial and flake tool knives (tools used for cutting or sawing) have retouch along one or more edge and typically have an acute tool edge. Small pointed implements with edge rounding, polish, or crushing along the tip and flakes with small projections are interpreted as drills or gravers.

The core tools are cores that have retouch or use wear on one or more edges. Core tools likely 
were used for tasks requiring tool mass and a durable edge, such as chopping or scraping dense material, but were also used for other functions (scrapers or knives). Core tools are considered expedient or informal technology, similar to edge-modified and utilized flakes. Additional attributes recorded for these artifacts include completeness, maximum length, maximum width, maximum thickness, weight, and, when appropriate, basal width, basal thickness, stem width, and stem thickness.

\section{Ground, Pecked, and Battered Stone Tools}

Ground, pecked, and battered stones were classified into the following general categories: grinding slabs; anvils; abraders; grooved stones; incised stones; manos; hammerstones; pitted hammerstones; pestles; polishing stones; celts; axes; adzes; pigment stones; possible pipe; and indeterminate fragments. These artifacts were separated according to their basic functional positions for descriptive purposes when possible. This involved distinguishing between handheld artifacts (e.g., hammerstones, manos) and foundation or base-position artifacts (e.g., grinding slabs, anvils). Certain artifacts may have been used interchangeably between these positions, whereas the functional positions of other artifacts are equivocal or unknown. The basic types of modification and use wear recorded include grinding and abrasion-derived smoothing, abrasion-derived channeling (i.e., grooves), battering, pitting, pecking, incising (both intentional and inadvertent), surface polishing, and flaking. Specimens may exhibit a single type of wear derived from a specific use (e.g., battering on a hammerstone) or combinations of wear stemming from multiple functions (e.g., grinding-derived smoothing and percussion-derived pitting on grinding slabs/anvils). An attempt was made to classify multifunctional tools according to the most prominent wear type exhibited. The primary mechanical operations associated with ground stone tool use, the types of wear derived from each, and the tool types on which they occur are described below.

Wear is defined as the progressive, cumulative loss of material from the surface of an object through relative motion (Adams 1988:310, 1996:4). Wear processes that may occur when two surfaces come into contact include abrasion, adhesion, fatigue, and tribochemical interaction. Abrasion produces scratches, grooves, or striations on individual grains and the intergrain matrix. Particles detached from one or both tool surfaces are found in the interstices between individual grains. Adhesion produces surface heating through the breakdown of molecular bonds, which causes plastic deformation of uneven surfaces and leaves cones, flakes, and pits derived from material transfer between surfaces. Surface fatigue is the breakdown of a material's structural integrity due to repeated stresses. This type of wear is characterized by cracking and pitting that may have a frosted appearance due to crushing and step fracturing of individual grains. Detached particles are present in the spaces between grains. The tribochemical wear process is an interaction between friction, heat, and the surrounding environment that results in the deposition of films or oxides on worn surfaces. This process is only noticeable if tool surfaces are sufficiently worn to allow the buildup of these deposits (Adams 1988, 1996; Ellis 2009).

The two basic forms of motion associated with ground stone tool use include rubbing and pounding (Ellis 2009:306). Pressure and friction are key components of the former, and the latter is typified by forceful impact. In accordance with the general wear processes presented above, various kinds of rubbing or friction-based wear result in morphologically distinct wear patterns that can be used to infer tool functions.

A common type of friction-based wear stems from grinding one stone implement against another (i.e., mano and grinding slab) to reduce vegetal and nonvegetal materials such as corn kernels, plant seeds, ochre, and ceramic sherds. Such grinding surfaces are degraded by fatigue resulting from repeated compression and friction stresses generated during use. Ground surfaces are smooth and may exhibit rounding of individual grains and use-derived striations. Well-ground surfaces show no asperities; individual grains are flattened and interstices are obliterated.

Striations, incisions, and grooves are rubbing- or friction-derived features that appear on many of the artifacts in this assemblage. Smaller marks such as striations and small incisions may be inadvertently created by grinding coarse materials, asperities or individual grains in the surface of the opposing tool, detached grains 
(loose wear particles or grit), or a combination of these. These marks range from micro- to macroscopic, may occur in clusters or cover an entire working facet, and may be generated while shaping an unfinished object or while using a finished tool. Use-derived striations and incisions are instrumental in determining the direction and manner of use (Adams 1996, 1999).

Many incisions and grooves are the result of intentional abrasion of bone, antler, wood, or stone. The incisions and grooves in this collection vary considerably in size and depth, and no specific set of characteristics clearly separates one kind of mark from another (i.e., some large incisions could be described as narrow grooves). However, the incisions observed on tools in this assemblage typically have narrow, V- to U-shaped cross sections, and they are often found in spatially associated groups of similarly oriented marks. Cuts on the edges of a working facet or on narrow margins have been referred to as notches (Ellis 2009; Fields et al. 1991); these are similar to the incisions in section but are shorter by virtue of their location. Grooves are broader in section and are typically much shallower relative to their maximum width than the incisions and notches. These features are found alone, paired but differently aligned, or in similarly oriented groups. Cross sections are typically parabolic with curved walls and floor, but at least one flat-bottomed groove with an angular cross section was observed in the assemblage. Most grooves retain consistent cross sections along their lengths but have somewhat irregular, poorly smoothed walls and floors.

Lastly, friction-based wear can generate highly polished surfaces that have shiny, glossy, or greasy appearances. Polished surfaces may result from tool friction against soft materials (e.g., hide processing), the buildup of fats or oils on the grinding surface, or the abrasion of two types of lithic material with varying crystalline structures (Adams 1988; Ellis 2009). In this collection, polished surfaces are retained on axes, several celt fragments, some quartzite pebbles, and a cylindrical piece of hematite.

Pounding is a process of forceful impact used to pulverize, crush, or otherwise reduce vegetal (e.g., seeds and nuts) and nonvegetal material (e.g., lithic reduction, crushing sherds for temper). The same basic process can be used to shape tools, rejuvenate tool facets, or soften materials (e.g., hide working) (Ellis 2009:307).
Rocks used as percussors or pulverizers exhibit battering damage, which is characterized by crushing or indentation of the rock surface that sometimes coincides with flake detachment. Pecking is a percussive process that entails striking the surface of one stone with another stone (of preferably harder material) to remove small bits of rock from the struck surface. Pecking leaves small divots and minute pits on the impacted surface. This process was instrumental in shaping a wide range of ground stone tools and was also important for restoring the efficiency of overly smoothed grinding facets (Adams 1999; Barnett 1973). However, using a tool to crush or pulverize resistant materials (i.e., hammer and anvil) also may create peck marks and slightly larger percussion-derived voids on a tool surface. Pitting is derived from targeted forceful impact in a localized area, which results in the removal of larger fragments of a tool's surface than is characteristic of pecking. Pits can be intentionally and inadvertently created. These features may result from direct impact with a percussor, indirect impact associated with crushing or pulverizing resistant material (i.e., hard-shelled nuts, bipolar reduction of lithic material), mortar use (i.e., crushing vegetal material, pulverizing/mixing pigment), or a combination of these processes (Bell and Cross 1980). Pits in this collection range from subtle depressions to well-defined, rough-walled divots, to cups with partly or completely smoothed margins. Although variations in pit morphology and size probably reflect differences in function, at least some of the morphological and dimensional variation may be from variable use intensities along monofunctional and multifunctional use trajectories.

The grinding slabs in this collection typically are tabular with grinding wear on at least one flat to slightly concave face. Peck marks are common on these facets, and some retain use-derived striations. Grinding slabs presumably were used in conjunction with handheld grinding implements to process vegetal matter or other relatively soft materials. Most grinding slabs/anvils are thick tabular quartzite cobbles, usually with one ground face with scattered or targeted percussion marks, percussion-derived pits and incipient pits, smooth-walled pits, or a combination of these in or on the margins of the grinding facets. They probably were used to grind vegetal materials and cradle vegetal 
or nonvegetal materials that were crushed with a stone hammer or other handheld tool. The anvils are mostly tabular to blocky quartzite and ferruginous sandstone cobbles with one or more pits that held materials to be crushed; many also have surface smoothing suggesting use for grinding, often localized around individual pits or pitted areas.

The abraders, grooved stones, and incised stones consist almost exclusively of tabular pieces of ferruginous sandstone and hematite. Some served as base-position artifacts, others were definitely handheld items, and others probably were used interchangeably. All exhibit some form of wear derived from reciprocal motion. Almost all of the abraders have only one smoothed face. Likewise, the few grooved stones only exhibit abrasion wear on only one surface. The incised stones have at least one worked facet with one or more incisions or narrow grooves that vary considerably in dimension between artifacts.

The hammerstones, manos/hammerstones, and pitted hammerstones consist of naturally rounded, tabular, and irregularly shaped cobbles and pebbles of a variety of materials. Some hammerstones exhibit battering wear only on their ends, but most show various combinations of battering damage on ends, narrow ridges, and one or more margins or facets; some were used in conjunction with anvils to crush or pulverize materials and also were used as abraders or polishing stones. Manos/hammerstones have at least one face smoothed by grinding, as well as battering damage mostly on the tool margins; some of these also were used as abraders. Size variation within the manos/hammerstones indicates that some were manipulated with the palm like true manos, while others were manipulated with the fingers like the mullers classified by Ellis (2009). Pitted hammerstones have at least one flat to slightly concave facet with focused percussion or pecking, incipient pitting, percussion-derived pits, or intentionally ground depressions or pits, often surrounded by surface smoothing, in addition to battering wear mostly on the edges. The pits typically are smaller than, and not as well-defined as, the pits on the anvils and grinding slabs/anvils.

The manos consist of two gritty subangular ferruginous sandstone cobbles with at least one grinding facet and an oval nonferruginous sandstone cobble with two grinding surfaces; none has battering damage. The polishing stones are ovoid quartzite pebbles with at least one well-smoothed, highly polished facet and a small cylindrical piece of hematite with smoothed, polished ends.

The stone axes and celt fragments were shaped by extensive pecking and grinding. The axes have battering damage along the bits. Most of the celt fragments exhibit impact-derived crushing damage or flake detachment from their poll ends. The pigment stone category includes small fragments of ochre, hematite, and ferruginous sandstone that exhibit cultural modification. The term ochre is reserved for soft items that appear to be fragments of hematite-rich clay or processed/refined and reconsolidated hematite. Modification in this category typically consists of grinding/abrasion-derived facets with striations. Most facets are flat or nearly so.

Various other tools include a pecked and ground adze with a retouched edge and a possible stone pipe fragment. Artifacts identified as indeterminate ground, pecked, battered stones have wear consistent with that observed on ground stone tools in the remainder of the assemblage, but for various reasons, they cannot be identified or classified into one of the above tool categories.

Other attributes recorded for the ground, pecked, and battered stone artifacts are overall tool shape, whether the artifact was intentionally shaped, tool completeness, the degree of thermal alteration, dimensions (length, width, and thickness in millimeters), and weight (in grams). Overall tool shape was recorded as round, ovate, cylindrical, rectangular, trapezoidal, triangular, pentagonal, bipointed, irregular, or indeterminate; tool fragments typically were classified as having an irregular or indeterminate shape unless enough of the tool remained to allow for a confident estimation of the overall shape of the complete tool. Evidence of intentional shaping was coded as yes, no, or indeterminate, and the type of modification was described. Tool completeness was used to record whether an artifact is whole or fragmentary. Thermal modification was coded as absent, light (minor to moderate oxidation or surface cracking), or heavy (severe oxidation, extensive surface cracking, heat spalls or pot lids, angular fracturing, or a combination of these). 


\section{Cores}

A core is a mass of lithic material (cobble or tabular in shape) that has had flakes removed from it. The cores in this analysis were subdivided into flake core, bipolar core, bifacial core, core fragment, and tested cobble/pebble. The majority of the core categories are associated with freehand hard-hammer percussion. Flake cores are cores with platforms on one or multiple sides and can be prepared or unprepared (Whittaker 1994). Bipolar cores are created by placing a core on an anvil and striking the core with a percussor, which causes the cone of force to be shattered (Crabtree 1972:16; Johnson 1987:195; Shott 1989). Bipolar reduction has also been described as an example of amorphous technology, characterized by crude, uncontrolled freehand techniques, and often regarded as an indicator of low levels of lithic material availability (Amick and Mauldin 1997; Parry and Kelly 1987; Shott 1989:2). Some analysts contest bipolar cores as actually representing wedges used to split wood or bone (Andrefsky 1998:120; Gramly and Rutledge 1981; Lothrop and Gramly 1982; MacDonald 1968), while others argue pieces esquilles or wedges are bipolar cores (Odell 2000:195).

Core fragments are the remnants of flake cores either removed during the preparation of a new platform on a core or the discard of a core at the end of its use life. Tested cobbles/pebbles are source materials that exhibit only a few flake removals, leaving most of the cobble, pebble, or tabular material intact. Attributes recorded for each core type include weight, maximum length, maximum width, and maximum thickness.

The generalized core reduction strategies apparent in the flake and bipolar cores from these sites conform with the current understanding of Caddo lithic technology. The cores indicate that the Caddo did not produce flakes of a specific morphology and that core preparation was not planned or deliberate. Debris best suited to the task was chosen and often not prepared ahead of time.

\section{Debitage}

Debitage consists of the debris removed during chipped stone reduction and retouch. This includes flakes, shatter, and blocky debris. Debitage was subcategorized by size: $<3.0 \mathrm{~mm}$ (Size Grade 1), 3.0-7.0 mm (Size Grade 2), 7.0-12.5 mm (Size Grade 3), 12.5-19.0 mm (Size Grade 4), 19.0-25.0 mm (Size Grade 5), 25.0-38.0 mm (Size Grade 6), 38.0-50.0 mm (Size Grade 7), and $>50 \mathrm{~mm}$ (Size Grade 8). Size grading provides a very rough measure of reduction stages and very general assessments of reduction and production.

\section{Bone Tools, Daub, Burned Clay, and Thermally Altered Rocks}

Bone tools were very rare with only a handful of faunal remains modified into tools. Analytical attributes included taxon (and common name), element, portion, side, weathering, breakage, and burning, as well as a description of the modification.

Daub and burned clay are small to medium-sized pieces of clayey sediment that have been altered by heat, either through exposure to the sun or fire. Daub is distinguished from burned clay by wattle (grass and stick) impressions. Some of the daub is probably from sundried mud from structure walls. Burned clay has no such impressions and is usually round or oval in shape. Thermally altered rocks were also analyzed. Analysis of these three artifact categories included only weight and count. 


\section{RESULTS OF EXCAVATIONS IN SUBAREA 1 OF THE GEORGE RICHEY SITE, 41TT851}

Virginia L. Hatfield, Damon Burden, Eloise Frances Gadus, and Ross C. Fields

\section{4}

This chapter focuses on the results of the data recovery excavations in one part, Subarea 1, of the George Richey site (41TT851). Incorporated into the discussion, though, are features and artifacts found in earlier auger and intensive testing.

\section{WORK ACCOMPLISHED IN DATA RECOVERY}

The data recovery investigations in Subarea 1 began with backhoe excavation of 72 sample units that ranged from 1.3 to $2.8 \mathrm{~m}$ in length (mean $=2.2 \mathrm{~m}$ ), 0.9 to $1.1 \mathrm{~m}$ in width $($ mean $=1.0 \mathrm{~m})$, and 0.15 to $0.88 \mathrm{~m}$ in depth $($ mean $=0.36 \mathrm{~m})($ Figure 4.1$)$. These consisted of 57 units placed more-or-less systematically across the area to complement 1x1-m units dug during testing and 15 units placed within four areas demarcated for trackhoe swath excavations where Caddo houses were considered most likely. Of these, Sample Unit 66 turned out to be within Test Units 3 and 6 and therefore was not screened. Sample Units 1, 2, and 23 were screened completely or nearly so $(30,35$, and 30 five-gallon buckets, respectively). Most of the other sample units $(n=59)$ had approximately 50 percent of their matrix screened (15 buckets). Differing quantities of screened fill are as follows: 5 buckets for 1 unit; 6 buckets for 1 unit; 8 buckets for 2 units; 11 buckets for 1 unit; 12 buckets for 1 unit; 13 buckets for 1 units; and 14 buckets for 2 units.

Four trackhoe swaths were excavated in two areas to try to identify Caddo houses or other concentrations of features. These were $13.3-19.0 \mathrm{~m}$ long $($ mean $=15.9 \mathrm{~m}), 2.9-3.3 \mathrm{~m}$ wide $($ mean $=3.0 \mathrm{~m})$, and $0.35-0.42 \mathrm{~m}$ deep
$($ mean $=0.37 \mathrm{~m})$. The walls and floors of these swaths were shovel skimmed and hand troweled to look for cultural features. While some features were found, they did not form patterns clearly indicative of houses. Hence, manual excavations using fine provenience controls were considered unwarranted.

Then, the full extent of the data recovery investigation area was stripped down to the sandy clay Bt horizon contact (removing the $\mathrm{A}$ and $\mathrm{E}$ horizons) using a trackhoe. The stripped area was approximately $83 \mathrm{~m}$ north-south by $33 \mathrm{~m}$ east-west at its widest point, approximately $2,218 \mathrm{~m}^{2}$. The stripped area was cleaned by hand troweling and shovel skimming, except for one area where dense roots prevented cleaning. This area measured ca. $14 \times 7 \mathrm{~m}$ and was on the west side of the north end of Subarea 1. It was visually examined and appeared to contain no soil disturbances other than the roots, though it is possible that some subtle cultural features could remain undetected there.

All soil disturbances that had the potential to be cultural were assigned numbers, mapped using a total data station, and manually excavated. Disturbances that clearly were not cultural (small linear or circular ones resulting from recent root and rodent activity) were not assigned feature numbers or investigated. Since excavation of the features occurred over several weeks, they were covered with plastic to keep soil moisture in and rainwater out.

The final task involved excavating just outside the data recovery investigation area to ensure that no burials were missed along the margins of Subarea 1. This additional trackhoe stripping consisted of 18 trenches that were 3.5-15.7 $\mathrm{m}$ long $($ mean $=9.5 \mathrm{~m})$ and $2.0-3.1 \mathrm{~m}$ 


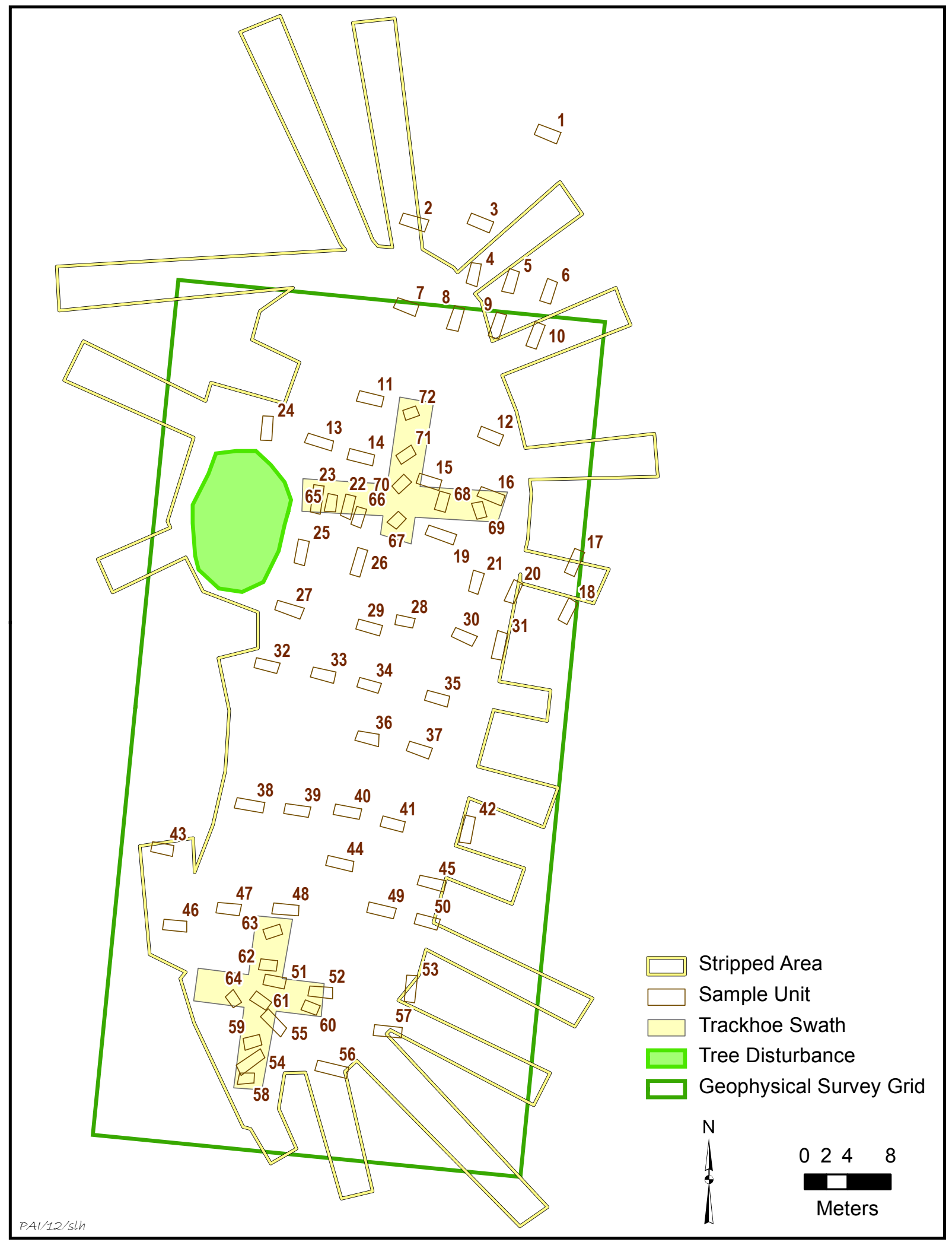

Figure 4.1. Map of Subarea 1 at the George Richey site showing the data recovery excavations. 
wide $($ mean $=2.5 \mathrm{~m})$, exposing about $428 \mathrm{~m}^{2}$. They were spaced anywhere from 0.9 to $16.6 \mathrm{~m}$ apart $($ mean $=4.3 \mathrm{~m})$ encircling the stripped data recovery investigation area, except on the southwest side, which is outside the relief route right of way.

\section{CULTURAL FEATURES}

A total of 389 soil disturbances were identified within Subarea 1 during testing and data recovery investigations. The vast majority ( $\mathrm{n}=380 ; 98$ percent) were excavated. Of the 9 that were not, 3 were destroyed by erosion following data recovery stripping and mapping, and 6 were initially identified in sample units but not re-located after stripping and were not mapped. The excavated ones consist of 149 (39 percent) that are interpreted as having Native American origins and 231 (61 percent) that appear to be natural, i.e., the result of bioturbation by rodents or roots. The cultural features are 69 pits, 76 postholes, 2 artifact clusters, 1 burned rock cluster, and 1 area of organically enriched midden sediments (Figure 4.2). The dimensions of the features and their contents are summarized in Table 4.1.

\section{Pits}

Pits make up 46 percent of the cultural features. They are oval to circular in plan view with sloping to vertical walls and rounded to flat bases. They have an average length of $45 \mathrm{~cm}$, ranging from 20 to $110 \mathrm{~cm}$. They are differentiated by size with those having a long axis or diameter greater than or equal to $50 \mathrm{~cm}$ considered large pits and the rest considered small pits. Smudge pits are included within small pits but are distinguished from other small pits by evidence of probable in situ burning.

\section{Large Pits}

The large pits $(n=21)$ are mostly oval in plan view with a long axis that ranges from 50 to $110 \mathrm{~cm}($ mean $=75 \mathrm{~cm})$. They have a mean depth below detection level of $18 \mathrm{~cm}$, ranging from 5 to $55 \mathrm{~cm}$. Nine are relatively deep (greater than $25 \mathrm{~cm}$ ), and 7 of these are in the north-central part of the excavated area. On the other hand, 12 large pits are comparatively shallow $(5-12 \mathrm{~cm})$; 9 of these are in the south part of Subarea 1.
This variation likely reflects differences in the functions of the pits in these two areas.

The large pits are mostly basin shaped or conical in cross section, and most have some irregularity due to bioturbation (Figure 4.3). The fill within them varied somewhat with location, with the pits in the north-central part of the excavation containing a darker matrix reflecting its mixture with the organically enriched deposits overlying this area. In this area, pit fill was dark yellowish brown (10YR $3 / 4$ to $10 \mathrm{YR}$ 4/4), dark reddish brown (5YR 3/2,3/3), dark brown (10YR 3/3), or very dark brown (10YR 2/2) sandy loam. The large pits in the rest of the site contained dark yellowish brown (10YR 4/3) or brown (10YR $5 / 4$ or $7.5 Y R 4 / 4)$ sandy loam. The amount of burned material within these pits and the degree of disturbance affected fill color. Bioturbation was noted within the fill of most of the large pits.

The large pits contained a wide range of cultural materials in moderate quantities (Table 4.2). The large pits yielded more of almost all classes of materials (as measured by counts or weights and as percentages of the total site assemblage) than did the small pits and postholes, which is not surprising given the differences in size and hence fill volume. Notably, two of the three bone tools from the site were recovered from large pits. The faunal recovery represents 60 percent of the total faunal remains from the site and is fairly diverse, with 1,452 specimens from 19 different taxa (Appendix G). The vast majority are identified only to the vertebrate subphylum, but 15 percent $(\mathrm{n}=216)$ are identified as mammals ranging from shrew/rabbit sized to deer/bison sized, less than 1 percent $(n=7)$ are birds, 3 percent $(n=38)$ are turtles, and 1 specimen is a fish bone.

The macrobotanical remains from the large pits account for 74 percent of the site total. The identified macrobotanical remains are mostly charred wood (29.38 g of buckeye, catalpa, hickory, maple, mulberry, oak, red oak, white oak, slippery elm, and sweetgum) and nutshells (30.81 g of hickory, hickory/walnut, and acorn), with small amounts of seeds $(0.31 \mathrm{~g}$ from corn, goosefoot, grape, grass, knotweed, maygrass, purslane, and sumac), corn rachis $(0.31 \mathrm{~g})$, bulb scales $(0.03 \mathrm{~g})$, and cane stem $(0.07 \mathrm{~g})$. The densities of macrobotanical remains from those with flotation samples range from 0.001 to $1.114 \mathrm{~g} /$ liter, averaging $0.126 \mathrm{~g} /$ liter (or 0.072 


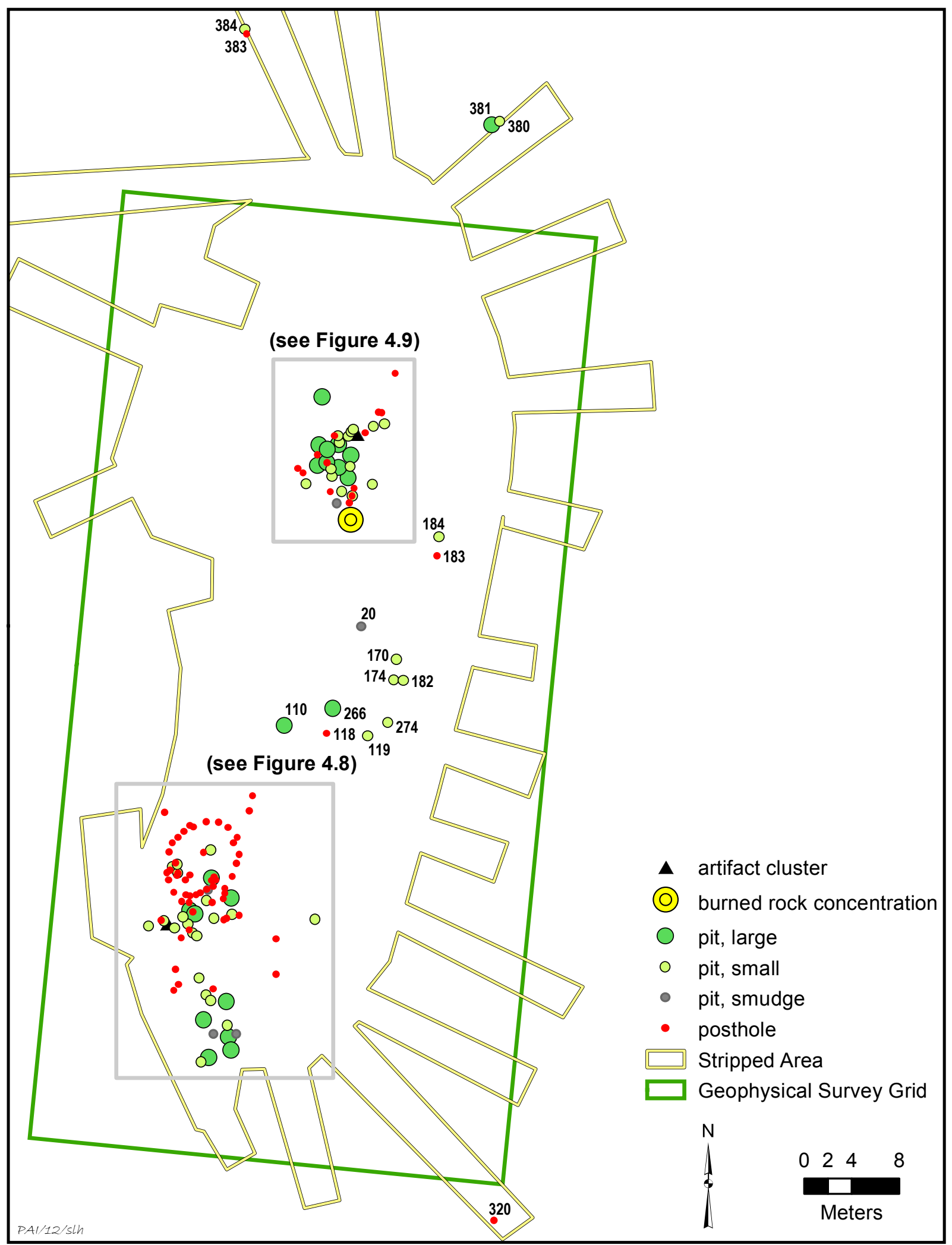

Figure 4.2. Map of Subarea 1 at the George Richey site showing the distribution of cultural features. 
Table 4.1. Summary of the cultural features in Subarea 1 at the George Richey site

\begin{tabular}{|c|c|c|c|c|}
\hline Feature & Type & Size $(\mathrm{cm})$ & Depth $(\mathrm{cm})$ & Contents \\
\hline 9 & pit, large & $110 \times 74$ & $35-68$ & $\begin{array}{l}65 \text { sherds }(937.4 \mathrm{~g}), 1 \text { Bonham point, } 1 \text { biface, } 23 \text { debitage, } \\
1 \text { ground stone, } 1 \text { bone tool, } 318 \text { faunal remains, } 27 \text { shell } \\
\text { fragments, } 6.61 \mathrm{~g} \text { macrobotanical remains, } 2.9 \mathrm{~g} \text { daub, } \\
2.6 \mathrm{~g} \text { burned clay, } 22.4 \mathrm{~g} \text { thermally altered rocks }\end{array}$ \\
\hline 17 & pit, large & $77 \times 40$ & $35-63$ & $\begin{array}{l}37 \text { sherds }(204.9 \mathrm{~g}), 1 \text { flake tool, } 1 \text { core, } 24 \text { debitage, } 1 \\
\text { abrader, } 322 \text { faunal remains, } 14 \text { shell fragments, } 2.01 \mathrm{~g} \\
\text { macrobotanical remains, } 10.0 \mathrm{~g} \text { burned clay, } 13.3 \mathrm{~g} \text { daub, } \\
641.0 \mathrm{~g} \text { thermally altered rocks }\end{array}$ \\
\hline 28 & pit, large & $93 \times 84$ & 29 & $\begin{array}{l}25 \text { sherds }(102.3 \mathrm{~g}), 1 \text { biface, } 1 \text { flake tool, } 1 \text { core, } 15 \\
\text { debitage, } 1 \text { antler tool, } 130 \text { faunal remains, } 11 \text { shell } \\
\text { fragments, } 5.23 \mathrm{~g} \text { macrobotanical remains, } 7.8 \mathrm{~g} \text { burned } \\
\text { clay, } 300.3 \mathrm{~g} \text { thermally altered rocks }\end{array}$ \\
\hline 46 & pit, large & $52 \times 46$ & 8 & $\begin{array}{l}1 \text { sherd }(0.3 \mathrm{~g}), 16 \text { debitage, } 4 \text { faunal remains, } 0.03 \mathrm{~g} \\
\text { macrobotanical remains, } 1.0 \mathrm{~g} \text { burned clay }\end{array}$ \\
\hline 75 & pit, large & $53 \times 27$ & 27 & 1 biface, $0.17 \mathrm{~g}$ macrobotanical remains \\
\hline 78 & pit, large & $60 \times 36$ & 6 & $\begin{array}{l}20 \text { debitage, } 2 \text { faunal remains, } 1 \text { shell fragment, } 0.37 \mathrm{~g} \\
\text { macrobotanical remains, } 350.5 \mathrm{~g} \text { thermally altered rocks }\end{array}$ \\
\hline 79 & pit, large & $77 \times 42$ & 7 & $\begin{array}{l}1 \text { sherd }(2.2 \mathrm{~g}), 9 \text { debitage, } 3 \text { faunal remains, } 0.55 \mathrm{~g} \\
\text { macrobotanical remains }\end{array}$ \\
\hline 110 & pit, large & $67 \times 52$ & 8 & $\begin{array}{l}1 \text { sherd }(0.5 \mathrm{~g}), 2 \text { debitage, } 2 \text { faunal remains, } 12.58 \mathrm{~g} \\
\text { macrobotanical remains }\end{array}$ \\
\hline 137 & pit, large & $97 \times 70$ & 10 & 4 sherds (16.4 g), 4 debitage \\
\hline 188 & pit, large & $90 \times 70$ & 26 & $\begin{array}{l}18 \text { sherds }(94.9 \mathrm{~g}), 28 \text { debitage, } 1 \text { arrow point fragment, } \\
160 \text { faunal remains, } 17 \text { shell fragments, } 19.19 \mathrm{~g} \\
\text { macrobotanical remains, } 47.4 \mathrm{~g} \text { burned clay, } 10.4 \mathrm{~g} \text { daub }\end{array}$ \\
\hline 189A & pit, large & $90 \times 89$ & 30 & $\begin{array}{l}36 \text { sherds (115.8g), } 1 \text { biface, } 16 \text { debitage, } 1 \text { anvil, } 190 \\
\text { faunal remains, } 17.52 \mathrm{~g} \text { macrobotanical remains, } 21 \text { shell } \\
\text { fragments, } 546.3 \mathrm{~g} \text { burned clay, } 25.5 \mathrm{~g} \text { daub }\end{array}$ \\
\hline $205 / 16$ & pit, large & $65 \times 48$ & $35-90$ & $\begin{array}{l}73 \text { sherds ( } 1889.1 \mathrm{~g}), 30 \text { debitage, } 1 \text { hammerstone, } 1 \text { bone } \\
\text { tool, } 228 \text { faunal remains, } 38 \text { shell fragments, } 7.22 \mathrm{~g} \\
\text { macrobotanical remains, } 29.9 \mathrm{~g} \text { burned clay, } 55.3 \mathrm{~g} \\
\text { thermally altered rocks }\end{array}$ \\
\hline 233 & pit, large & $65 \times 45$ & 25 & $\begin{array}{l}10 \text { sherds }(59.9 \mathrm{~g}), 1 \text { flake tool, } 15 \text { debitage, } 67 \text { faunal } \\
\text { remains, } 12 \text { shell fragments, } 5.12 \mathrm{~g} \text { macrobotanical } \\
\text { remains, } 9.0 \mathrm{~g} \text { burned clay }\end{array}$ \\
\hline 266 & pit, large & $62 \times 62$ & 25 & 4 sherds (7.8 g), $6.9 \mathrm{~g}$ burned clay \\
\hline $271 \mathrm{~A}$ & pit, large & $55 \times 48$ & 11 & $\begin{array}{l}3 \text { sherds }(12.7 \mathrm{~g}), 1 \text { core, } 5 \text { debitage, } 14 \text { faunal remains, } \\
2.55 \mathrm{~g} \text { macrobotanical remains }\end{array}$ \\
\hline 291 & pit, large & $85 \times 73$ & 8 & 7 debitage, 0.07 g macrobotanical remains \\
\hline 300 & pit, large & $104 \times 51$ & 7 & $0.12 \mathrm{~g}$ macrobotanical remains \\
\hline 316 & pit, large & $50 \times 30$ & 12 & 2 sherds $(1.9 \mathrm{~g}), 5$ debitage, $2.0 \mathrm{~g}$ burned clay \\
\hline 352 & pit, large & $80 x 60$ & 5 & 2 debitage, $0.07 \mathrm{~g}$ macrobotanical remains \\
\hline 359 & pit, large & $90 \times 70$ & 8 & $\begin{array}{l}9 \text { sherds }(62.4 \mathrm{~g}), 1 \text { flake tool, } 9 \text { debitage, } 0.52 \mathrm{~g} \\
\text { macrobotanical remains }\end{array}$ \\
\hline 381 & pit, large & $61 \times 53$ & $30-38$ & 4 sherds (20.8 g), $0.01 \mathrm{~g}$ macrobotanical remains \\
\hline 20 & pit, smudge & $28 \times 28$ & $28-42$ & 1 sherd $(0.4 \mathrm{~g}), 2$ debitage, $1.72 \mathrm{~g}$ macrobotanical remains \\
\hline 76 & pit, smudge & $25 \times 24$ & 16 & 1 sherd $(2.8 \mathrm{~g}), 4$ debitage \\
\hline 80 & pit, smudge & $25 \times 24$ & 5 & $\begin{array}{l}1 \text { flake tool, } 5 \text { debitage, } 2 \text { faunal remains, } 0.06 \mathrm{~g} \\
\text { macrobotanical remains }\end{array}$ \\
\hline 165 & pit, smudge & $24 \times 18$ & 19 & $\begin{array}{l}4 \text { sherds }(7.8 \mathrm{~g}), 2 \text { debitage, } 3 \text { faunal remains, } 5.69 \mathrm{~g} \\
\text { macrobotanical remains }\end{array}$ \\
\hline 319 & pit, smudge & $25 \times 25$ & 16 & $6.03 \mathrm{~g}$ macrobotanical remains \\
\hline
\end{tabular}


Table 4.1, continued

\begin{tabular}{|c|c|c|c|c|}
\hline Feature & Type & Size $(\mathrm{cm})$ & Depth $(\mathrm{cm})$ & Contents \\
\hline 19 & pit, small & $32 \times 20$ & $36-67$ & $\begin{array}{l}6 \text { sherds ( } 48.6 \mathrm{~g}), 6 \text { debitage, } 48 \text { faunal remains, } 6 \text { shell } \\
\text { fragments, } 1.36 \mathrm{~g} \text { macrobotanical remains, } 4.4 \mathrm{~g} \text { burned } \\
\text { clay }\end{array}$ \\
\hline 27 & pit, small & $32 \times 21$ & 19 & $\begin{array}{l}1 \text { sherd ( } 1.2 \mathrm{~g}), 13 \text { faunal remains, } 0.19 \mathrm{~g} \text { macrobotanical } \\
\text { remains }\end{array}$ \\
\hline 47 & pit, small & $27 \times 19$ & 7 & 2 debitage, 0.03 g macrobotanical remains \\
\hline 51 & pit, small & $23 \times 17$ & 3 & 2 sherds (11.5 g), 5 debitage, 0.43 macrobotanical remains \\
\hline 54 & pit, small & $35 \times 28$ & 5 & 2 sherds (17.5 g), 3 debitage, 1 faunal remain \\
\hline 55 & pit, small & $34 \times 30$ & 16 & $\begin{array}{l}1 \text { sherd }(0.2 \mathrm{~g}), 2 \text { debitage, } 0.16 \mathrm{~g} \text { macrobotanical remains, } \\
0.8 \mathrm{~g} \text { burned clay }\end{array}$ \\
\hline 58 & pit, small & $36 \times 36$ & 14 & $\begin{array}{l}1 \text { debitage, } 36 \text { faunal remains, } 1 \text { shell fragment, } 0.17 \mathrm{~g} \\
\text { macrobotanical remains, } 0.6 \mathrm{~g} \text { burned clay }\end{array}$ \\
\hline 64 & pit, small & $34 \times 26$ & 12 & 7 debitage, $0.4 \mathrm{~g}$ burned clay \\
\hline 77 & pit, small & $29 x 28$ & 9 & 17 debitage \\
\hline 119 & pit, small & $28 \times 28$ & 8 & 2 debitage, 1 faunal remain \\
\hline 145 & pit, small & $30 \times 30$ & 32 & $\begin{array}{l}14 \text { sherds }(120.3 \mathrm{~g}), 8 \text { debitage, } 40 \text { faunal remains, } 1.14 \mathrm{~g} \\
\text { macrobotanical remains, } 4.4 \mathrm{~g} \text { burned clay }\end{array}$ \\
\hline 147 & pit, small & $48 \times 38$ & 18 & $\begin{array}{l}9 \text { sherds ( } 43.2 \mathrm{~g}), 4 \text { debitage, } 2 \text { faunal remains, } 0.15 \mathrm{~g} \\
\text { macrobotanical remains }\end{array}$ \\
\hline 159 & pit, small & $43 \times 28$ & 14 & $\begin{array}{l}3 \text { sherds (12.9 g), } 2 \text { debitage, } 2 \text { faunal remains, } 0.24 \mathrm{~g} \\
\text { macrobotanical remains, } 1.5 \mathrm{~g} \text { burned clay }\end{array}$ \\
\hline 164 & pit, small & $35 \times 35$ & 10 & $\begin{array}{l}3 \text { sherds }(24.5 \mathrm{~g}), 7 \text { debitage, } 46 \text { faunal specimens, } 0.16 \mathrm{~g} \\
\text { macrobotanical remains, } 1.4 \mathrm{~g} \text { burned clay }\end{array}$ \\
\hline $166 \mathrm{~A}$ & pit, small & $40 \times 31$ & 10 & $\begin{array}{l}4 \text { sherds }(7.8 \mathrm{~g}), 6 \text { debitage, } 38 \text { faunal specimens, } 1.24 \mathrm{~g} \\
\text { macrobotanical remains, } 6.9 \mathrm{~g} \text { burned clay }\end{array}$ \\
\hline 170 & pit, small & $37 \times 35$ & 3 & $0.6 \mathrm{~g}$ burned clay \\
\hline 174 & pit, small & $36 \times 28$ & 7 & \\
\hline 182 & pit, small & $28 \times 26$ & 9 & 1 debitage \\
\hline 184 & pit, small & $20 x 9$ & 4 & 1 debitage, 4 faunal remains \\
\hline 190 & pit, small & $25 \times 24$ & 8 & $\begin{array}{l}1 \text { debitage, } 2 \text { faunal remains, } 0.75 \mathrm{~g} \text { macrobotanical } \\
\text { remains }\end{array}$ \\
\hline 198 & pit, small & $28 \times 25$ & 23 & $\begin{array}{l}3 \text { debitage, } 26 \text { faunal remains, } 1 \text { shell fragment, } 1.03 \mathrm{~g} \\
\text { macrobotanical remains }\end{array}$ \\
\hline 199 & pit, small & $23 \times 23$ & 6 & $\begin{array}{l}1 \text { sherd }(5.0 \mathrm{~g}), 12 \text { faunal remains, } 0.02 \mathrm{~g} \text { macrobotanical } \\
\text { remains, } 0.2 \mathrm{~g} \text { burned clay }\end{array}$ \\
\hline 200 & pit, small & $26 \times 17$ & 7 & $\begin{array}{l}1 \text { sherd }(0.2 \mathrm{~g}), 2 \text { debitage; } 48 \text { faunal specimens, } 0.09 \\
\text { macrobotanical remains, } 2.4 \mathrm{~g} \text { burned clay }\end{array}$ \\
\hline 201 & pit, small & $31 \times 26$ & 7 & $\begin{array}{l}1 \text { sherd }(0.1 \mathrm{~g}), 16 \text { faunal remains, } 0.09 \mathrm{~g} \text { macrobotanical } \\
\text { remains, } 0.6 \mathrm{~g} \text { burned clay }\end{array}$ \\
\hline 202 & pit, small & $26 \times 20$ & 9 & $\begin{array}{l}3 \text { debitage, } 9 \text { faunal remains, } 0.07 \mathrm{~g} \text { macrobotanical } \\
\text { remains }\end{array}$ \\
\hline 243 & pit, small & $22 \times 18$ & 9 & $\begin{array}{l}91 \text { debitage, } 6 \text { faunal remains, } 21 \text { shell fragments, } 0.37 \mathrm{~g} \\
\text { macrobotanical remains }\end{array}$ \\
\hline 274 & pit, small & $30 \times 29$ & 4 & 1 sherd $(0.5 \mathrm{~g})$ \\
\hline 282 & pit, small & $32 \times 25$ & 14 & 1 debitage, $1.38 \mathrm{~g}$ macrobotanical remains \\
\hline 284 & pit, small & $45 \times 40$ & 12 & \\
\hline 290 & pit, small & $30 \times 30$ & 4 & $0.01 \mathrm{~g}$ macrobotanical remains \\
\hline 317 & pit, small & $48 \mathrm{x} 40$ & 6 & 2 sherds $(10.1 \mathrm{~g}), 2$ debitage \\
\hline 331 & pit, small & $42 \times 38$ & 6 & $0.01 \mathrm{~g}$ macrobotanical remains \\
\hline 332 & pit, small & $23 \times 23$ & 6 & \\
\hline 335 & pit, small & $30 \times 24$ & 9 & 2 sherds $(2.1 \mathrm{~g}), 1$ debitage, $0.53 \mathrm{~g}$ macrobotanical remains \\
\hline 337 & pit, small & $30 \times 18$ & 11 & 1 debitage \\
\hline 338 & pit, small & $40 \times 30$ & 29 & 0.12 g macrobotanical remains \\
\hline
\end{tabular}


Table 4.1, continued

\begin{tabular}{|c|c|c|c|c|}
\hline Feature & Type & Size $(\mathrm{cm})$ & Depth $(\mathrm{cm})$ & Contents \\
\hline 347 & pit, small & $42 \times 63$ & 28 & $\begin{array}{l}6 \text { sherds }(33.0 \mathrm{~g}), 1 \text { core, } 7 \text { debitage, } 1.79 \mathrm{~g} \text { of } \\
\text { macrobotanical remains }\end{array}$ \\
\hline 348 & pit, small & $26 \times 20$ & 10 & $0.03 \mathrm{~g}$ macrobotanical remains \\
\hline 368 & pit, small & $23 \times 23$ & 3 & \\
\hline $371 \mathrm{~A}$ & pit, small & $32 \times 24$ & 8 & $0.01 \mathrm{~g}$ macrobotanical remains \\
\hline 376 & pit, small & $24 \times 23$ & 4 & \\
\hline 380 & pit, small & $32 \times 20$ & $25-37$ & $0.05 \mathrm{~g}$ macrobotanical remains \\
\hline 384 & pit, small & $25 \times 25$ & 15 & $0.01 \mathrm{~g}$ macrobotanical remains \\
\hline 1 & posthole & $18 \times 16$ & $58-74$ & \\
\hline 10 & posthole & $19 \times 19$ & $70-79$ & \\
\hline 12 & posthole & $24 \times 18$ & $42-56$ & 1 debitage \\
\hline 15 & posthole & $14 \times 14$ & $50-60$ & \\
\hline 18 & posthole & $24 \times 24$ & $40-56$ & \\
\hline 34 & posthole & $27 \times 16$ & 8 & $0.02 \mathrm{~g}$ macrobotanical remains \\
\hline 38 & posthole & $20 \times 18$ & 8 & 1 sherd $(0.1 \mathrm{~g}), 5$ debitage \\
\hline 39 & posthole & $21 \times 18$ & 20 & 1 debitage, $0.7 \mathrm{~g}$ burned clay \\
\hline 43 & posthole & $14 \times 12$ & 20 & 1 debitage \\
\hline 50 & posthole & $16 \times 15$ & 4 & \\
\hline 56 & posthole & $14 \times 12$ & 6 & $\begin{array}{l}1 \text { sherd }(2.2 \mathrm{~g}), 1 \text { debitage, } 0.01 \mathrm{~g} \text { macrobotanical remains, } \\
1.5 \mathrm{~g} \text { burned clay }\end{array}$ \\
\hline 57 & posthole & $16 \times 14$ & 14 & $0.11 \mathrm{~g}$ macrobotanical remains, $0.4 \mathrm{~g}$ burned clay \\
\hline 59 & posthole & $17 \times 16$ & 6 & $0.02 \mathrm{~g}$ macrobotanical remains, $0.1 \mathrm{~g}$ burned clay \\
\hline 73 & posthole & $18 \times 18$ & 17 & 3 debitage, 1 faunal remain \\
\hline 84 & posthole & $24 \times 24$ & 30 & 59 debitage, 5 faunal remains, $0.5 \mathrm{~g}$ burned clay \\
\hline 101 & posthole & $18 \times 16$ & 8 & $\begin{array}{l}5 \text { debitage, } 41 \text { faunal remains, } 0.12 \mathrm{~g} \text { macrobotanical } \\
\text { remains }\end{array}$ \\
\hline 104 & posthole & $14 \times 13$ & 7 & 1 debitage, $0.02 \mathrm{~g}$ macrobotanical remains \\
\hline 106 & posthole & $14 \times 14$ & 8 & $\begin{array}{l}1 \text { sherd }(0.1 \mathrm{~g}), 0.01 \mathrm{~g} \text { macrobotanical remains, } 0.3 \mathrm{~g} \\
\text { burned clay }\end{array}$ \\
\hline 107 & posthole & $16 \times 15$ & 8 & 1 debitage, 1 faunal remain \\
\hline 118 & posthole & $11 \times 10$ & 8 & \\
\hline 143 & posthole & $25 \times 17$ & 5 & 10 faunal remains \\
\hline 144 & posthole & $26 \times 17$ & 9 & 1 debitage, 13 faunal remains, $0.9 \mathrm{~g}$ of burned clay \\
\hline 154 & posthole & $30 \times 20$ & 16 & $\begin{array}{l}1 \text { debitage, } 5 \text { faunal remains, } 0.31 \mathrm{~g} \text { macrobotanical } \\
\text { remains }\end{array}$ \\
\hline 163 & posthole & $20 \times 14$ & 15 & $\begin{array}{l}2 \text { sherds }(8.5 \mathrm{~g}), 1 \text { biface, } 2 \text { debitage, } 10 \text { faunal remains, } \\
0.13 \mathrm{~g} \text { macrobotanical remains, } 5.7 \mathrm{~g} \text { burned clay }\end{array}$ \\
\hline 166B & posthole & $12 \times 11$ & 26 & see Feature $166 \mathrm{~A}$ \\
\hline 167 & posthole & $18 \times 18$ & 12 & \\
\hline 180 & posthole & $19 \times 18$ & 11 & 7 debitage, $0.02 \mathrm{~g}$ macrobotanical remains \\
\hline 183 & posthole & $23 \times 23$ & 13 & 2 debitage \\
\hline 225 & posthole & $15 \times 13$ & 10 & 1 debitage, 3 faunal remains \\
\hline 234 & posthole & $26 \times 23$ & 5 & 4 faunal remains, $1.9 \mathrm{~g}$ burned clay \\
\hline 236 & posthole & $14 \times 10$ & 20 & 1 debitage, 1 faunal remain \\
\hline 240 & posthole & $14.5 \times 12$ & 5 & \\
\hline 260 & posthole & $12 \times 12$ & 10 & $0.01 \mathrm{~g}$ macrobotanical remains \\
\hline 263 & posthole & $12 \times 12$ & 7 & $0.01 \mathrm{~g}$ macrobotanical remains, $0.4 \mathrm{~g}$ burned clay \\
\hline 264 & posthole & $15 \times 15$ & 10 & 1 debitage \\
\hline 269 & posthole & $16 \times 16$ & 3 & 1 debitage \\
\hline 270 & posthole & $16 \times 15$ & 2 & 1 debitage \\
\hline $271 \mathrm{~B}$ & posthole & $18 \times 18$ & 12 & see Feature 271A \\
\hline
\end{tabular}


Table 4.1, continued

\begin{tabular}{|c|c|c|c|c|}
\hline Feature & Type & Size $(\mathrm{cm})$ & Depth $(\mathrm{cm})$ & Contents \\
\hline 273 & posthole & $14 \times 14$ & 4 & $0.03 \mathrm{~g}$ macrobotanical remains \\
\hline 275 & posthole & $23 \times 23$ & 8 & $0.01 \mathrm{~g}$ macrobotanical remains \\
\hline 276 & posthole & $16 \times 16$ & 4 & 1 faunal remains, $0.01 \mathrm{~g}$ macrobotanical remains \\
\hline 278 & posthole & $16 \times 16$ & 5 & \\
\hline 279 & posthole & $15 \times 15$ & 8 & $0.03 \mathrm{~g}$ macrobotanical remains \\
\hline 280 & posthole & $16 \times 16$ & 18 & 2 debitage, $0.08 \mathrm{~g}$ macrobotanical remains \\
\hline 285 & posthole & $15 \times 15$ & 16 & 1 arrow point preform, $0.01 \mathrm{~g}$ macrobotanical remains \\
\hline 286 & posthole & $22 \times 17$ & 11 & $1.11 \mathrm{~g}$ macrobotanical remains \\
\hline 287 & posthole & $18 \times 18$ & 14 & 1 sherd (3.8 g), $0.07 \mathrm{~g}$ macrobotanical remains \\
\hline 288 & posthole & $18 \times 17$ & 15 & $0.18 \mathrm{~g}$ macrobotanical remains \\
\hline 293 & posthole & $16 \times 16$ & 12 & $2.2 \mathrm{~g}$ burned clay \\
\hline 294 & posthole & $22 \times 20$ & 25 & $0.03 \mathrm{~g}$ macrobotanical remains \\
\hline 295 & posthole & $24 \times 24$ & 17 & $0.01 \mathrm{~g}$ macrobotanical remains \\
\hline 296 & posthole & $18 \times 18$ & 11 & 1 sherd (7.8 g), 1 debitage, $0.02 \mathrm{~g}$ macrobotanical remains \\
\hline 297 & posthole & $18 \times 18$ & 16 & $0.01 \mathrm{~g}$ macrobotanical remains \\
\hline 298 & posthole & $12 \times 12$ & 14 & 1 faunal remain, $0.01 \mathrm{~g}$ macrobotanical remains \\
\hline 299 & posthole & $14 \times 14$ & 11 & $0.02 \mathrm{~g}$ macrobotanical remains \\
\hline 320 & posthole & $21 \times 20$ & 15 & \\
\hline 323 & posthole & $22 \times 20$ & 14 & \\
\hline 333 & posthole & $15 \times 15$ & 14 & $0.10 \mathrm{~g}$ macrobotanical remains \\
\hline 334 & posthole & $25 \times 25$ & 12 & 4 sherds (3.5 g), $0.18 \mathrm{~g}$ macrobotanical remains \\
\hline 336 & posthole & $22 \times 21$ & 8 & 1 debitage, $0.12 \mathrm{~g}$ macrobotanical remains \\
\hline 340 & posthole & $18 \times 16$ & 5 & 2 sherds $(9.7 \mathrm{~g})$ \\
\hline 341 & posthole & $18 \times 18$ & 8 & $0.01 \mathrm{~g}$ macrobotanical remains \\
\hline 349 & posthole & $16 \times 16$ & 4 & 1 debitage \\
\hline 355 & posthole & $21 \times 20$ & 12 & $\begin{array}{l}5 \text { sherds ( } 11.5 \mathrm{~g}), 0.01 \mathrm{~g} \text { macrobotanical remains, } 10.5 \mathrm{~g} \\
\text { burned clay }\end{array}$ \\
\hline 369 & posthole & $45 \times 23$ & 6 & $0.04 \mathrm{~g}$ macrobotanical remains \\
\hline 370 & posthole & $19 \times 18$ & 10 & $0.02 \mathrm{~g}$ macrobotanical remains \\
\hline $371 \mathrm{~B}$ & posthole & $18 \times 18$ & 16 & see Feature 371A \\
\hline 372 & posthole & $14 \times 14$ & 14 & \\
\hline 373 & posthole & $13 \times 13$ & 8 & \\
\hline 374 & posthole & $11 \times 11$ & 13 & $0.04 \mathrm{~g}$ macrobotanical remains \\
\hline 375 & posthole & $23 \times 23$ & 4 & \\
\hline 377 & posthole & $16 \times 16$ & 12 & \\
\hline 383 & posthole & $20 \times 20$ & $22-36$ & \\
\hline 36 & probable posthole & $14 \times 14$ & 18 & \\
\hline 189B & probable posthole & ind. & ind. & see Feature 189A \\
\hline $189 \mathrm{C}$ & probable posthole & ind. & ind. & see Feature 189A \\
\hline 29 & artifact cluster & $12 \times 9$ & 2 & $\begin{array}{l}5 \text { sherds }(29.3 \mathrm{~g}), 1 \text { debitage, } 1 \text { bone tool, } 6 \text { faunal remains, } \\
3.6 \mathrm{~g} \text { burned clay }\end{array}$ \\
\hline 52 & artifact cluster & $25 \times 24$ & 3 & 25 sherds ( $48.8 \mathrm{~g}), 1$ core, 3 debitage, $1.9 \mathrm{~g}$ burned clay \\
\hline 8 & $\begin{array}{l}\text { burned rock } \\
\text { concentration }\end{array}$ & $220 \times 200$ & $18-40$ & $\begin{array}{l}3 \text { sherds }(34.5 \mathrm{~g}), 1 \text { dart preform, } 1 \text { core tool, } 11 \text { debitage, } \\
1 \text { mano/hammerstone, } 5 \text { faunal remains, } 15.5 \mathrm{~kg} \text { thermally } \\
\text { altered rocks }\end{array}$ \\
\hline 11 & $\begin{array}{l}\text { area of organically } \\
\text { enriched deposit }\end{array}$ & $110 \times 76$ & $25-40$ & 2 sherds ( $16.3 \mathrm{~g}), 1$ ground stone, 2 debitage, 11 faunal remains \\
\hline
\end{tabular}

Note: Single number for depth indicates depth below detection level (the scraped surface); range indicates depth below ground surface. 


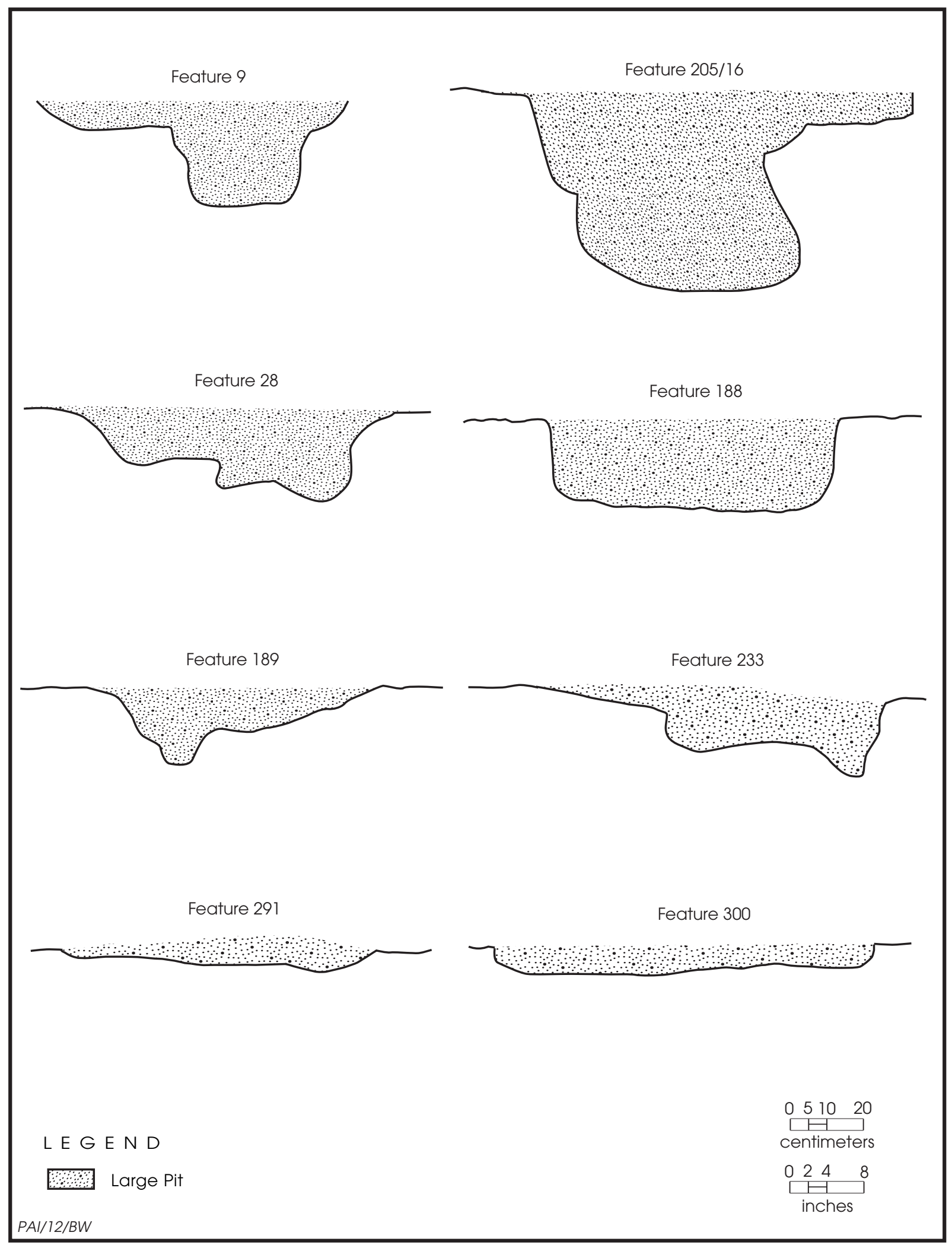

Figure 4.3. Cross sections of selected large pits in Subarea 1 at the George Richey site. 
Excavations along the U.S. Highway 271 Mount Pleasant Relief Route

Table 4.2. Cultural materials from pits and postholes in Subarea 1 at the George Richey site

\begin{tabular}{l|c|c|c|c|c|c}
\hline & \multicolumn{2}{|c|}{ Large Pits } & \multicolumn{2}{c}{ Small Pits } & \multicolumn{2}{c}{ Postholes } \\
\hline & No./Wt. (g) & $\begin{array}{c}\text { \% of Site } \\
\text { Total }\end{array}$ & No./Wt. (g) & $\begin{array}{c}\text { \% of Site } \\
\text { Total }\end{array}$ & \multicolumn{2}{c}{ No./Wt. (g) } \\
Total \\
\hline Ceramics & $299 / 3582.5$ & $11 / 23$ & $56 / 295.9$ & $2 / 2$ & $19 / 51.4$ & $1 /<1$ \\
\hline Chipped stone tools & 10 & 8 & 1 & 1 & 1 & 1 \\
\hline Ground stone tools & 4 & 11 & 0 & 0 & 0 & 0 \\
\hline Bone tools & 2 & 67 & 0 & 0 & 0 & 0 \\
\hline Cores & 3 & 5 & 1 & 2 & 0 & 0 \\
\hline Debitage & $228 / 78.3$ & $13 / 3$ & $198 / 77.0$ & $11 / 3$ & $101 / 18.0$ & $6 / 1$ \\
\hline $\begin{array}{l}\text { Macrobotanical } \\
\text { remains }\end{array}$ & 79.79 & 74 & 25.29 & 23 & 2.96 & 4 \\
\hline Faunal remains & 1452 & 60 & 355 & 15 & 96 & 4 \\
\hline Mussel/snail shells & 125 & 58 & 8 & 4 & 0 & 0 \\
\hline $\begin{array}{l}\text { Thermally altered } \\
\text { rocks }\end{array}$ & 1395.0 & 7 & 0 & 0 & 0 & 0 \\
\hline Daub & 26.6 & 25 & 0 & 0 & & 0 \\
\hline Burned clay & 657.2 & 71 & 17.8 & 2 & 31.1 & 0 \\
\hline
\end{tabular}

$\mathrm{g} /$ liter excluding the anomalously high value for Feature 110). This low average is comparable to that for the small pits discussed below, much lower than the one for smudge pits, and much higher than the average for postholes. The low densities in general suggest that most of these remains are in secondary context, and this probably is true as well for the other classes of materials in these pits. There is a high likelihood that most of the cultural materials were introduced into these pits from general scatters of debris present when the pits were dug or deposited there during and after pit use. The difference compared to the smudge pits also may indicate that these large pits were cleaned out for reuse more often.

A few of the large pits warrant individual discussion. In the north-central part of Subarea 1, Features 9 and 17 first appeared as a large amorphous but somewhat circular dark area between 20 and $30 \mathrm{~cm}$ below the ground surface. These features were better defined at contact with the Bt horizon, $35 \mathrm{~cm}$ below the surface. Feature 9 is a large $(110 \times 74 \mathrm{~cm})$ irregular oval pit with a shallow $(11 \mathrm{~cm})$ basin incorporating a smaller $(36 \times 28 \mathrm{~cm})$ and deeper $(33 \mathrm{~cm}$ deep) portion in the southeast quadrant of the pit (see Figure 4.3). Feature 17, which measured $77 \times 40 \mathrm{~cm}$ and was $28 \mathrm{~cm}$ deep, overlapped on the east side with Feature 9 and on the north side with Feature 19. Feature 19 was identified at $36 \mathrm{~cm}$ below the surface and may have been a deeper portion of Feature 17, similar to Feature 9 , or it may have been a cylindrical small pit that Feature 17 intruded into. Feature 19 continued to $67 \mathrm{~cm}$ below the ground surface; it is further described below with the small pits.

Feature $205 / 16$ is a large $(65 \times 48 \mathrm{~cm})$ conical pit west of Feature 9. It had two fill zones, which could reflect two periods of use but more likely represent two fill events following disuse or abandonment of the site. Among the other cultural materials from the fill were a hammerstone, a bone tool, and a significant portion of a large ceramic jar with three rows of punctations around the rim and an undecorated body (see Table 4.1).

Feature 28 is unusual in that it has an irregular 15-cm-deep basin with a smaller $(50 \times 41 \mathrm{~cm})$ and deeper $(22 \mathrm{~cm})$ portion on the southwest side, shown on Figure 4.3. This pit has two fill zones and abundant rodent disturbance. The two zones may reflect periods of use or periods of infilling of refuse from the general area following disuse. The smaller, deeper portion of the pit is similar to Feature 9 and may reflect a change in the use of this feature over time.

Another two large deep oval pits that are fairly close to each other are in the north-central part of the excavation area. Feature 188 had fairly homogenous fill and abundant cultural 
materials (see Table 4.1). Similar in shape, Feature 189A had two vertical posthole-like discolorations in the dark yellowish brown (10YR $3 / 6$ ) sandy loam fill. Noted only in profile, the probable postholes are Feature 189B filled with dark yellowish brown (10YR 3/4) sandy loam and Feature 189C filled with strong brown (7.5YR 4/6) sandy loam fill. These may be postholes dug into the pit after it was no longer in use. An irregularity in the base of the pit correlates with the bottom of one of the possible postholes and supports the excavation of a posthole here. The fill of Feature 189A contained a bifacial knife, a pitted stone or anvil along the wall sitting flat but above the floor, much burned clay, and daub, among other things (see Table 4.1). Also within the fill were discrete clumps of ash suggesting in situ burning, perhaps for cooking.

Feature 233 is a large oval pit with an irregular basin-shaped bottom (see Figure 4.3). Some of the irregularity in the base of the pit may reflect one or two postholes that intruded into this feature and that correlate with different fill zones within the pit. However, this pit exhibits notable disturbance by bioturbation, and this could explain the basal irregularities as well. Feature $271 \mathrm{~A}$ is a pit with a posthole (Feature 271B) on its south side. Bioturbation (both root and rodent) prevented clear definition between the pit and posthole, however. The pit basin extended $11 \mathrm{~cm}$ below the stripped surface. The posthole extended to $21 \mathrm{~cm}$ and had vertical walls and an irregular rounded to pointed base.

In the south part of the excavation area, two large shallow pits contain possible postholes. Feature 291 measures $85 \times 73 \mathrm{~cm}$ and incorporates a $32 \times 28-\mathrm{cm}$ circular central zone with very dark grayish brown (10YR 3/2) sandy loam surrounded by brown (10YR 4/3) sandy loam fill. Feature 300 included two postholes (Features 333 and 334) discovered in the floor of the pit after it was excavated. These postholes were not visible in the fill.

\section{Small Pits}

The 48 small pits (including 5 smudge pits) make up 32 percent of the features. These range in length from 20 to $48 \mathrm{~cm}($ mean $=31 \mathrm{~cm})$ and in depth below detection level from 3 to $32 \mathrm{~cm}$ $($ mean $=11 \mathrm{~cm})$. Just 4 are deeper than $25 \mathrm{~cm}$. The small pits have sloping sides with flat or rounded bottoms and some irregularity in shape due to bioturbation (Figure 4.4). Determining the function of most of these small pits is difficult since their content likely is the result mostly of infilling following disuse. The fill was predominantly sandy loam, and color variations include brown (7.5YR 5/4), dark brown (10YR 2/2; 7.5YR $3 / 2,3 / 4,4 / 4)$, dark yellowish brown (10YR $3 / 4$, 4/4, 4/6), dark reddish brown (10YR 4/3; 5 YR 3/2, $3 / 3,3 / 4)$, and dark grayish brown (10YR $4 / 2$ ). The amount of burned material within them and the degree of disturbance affected fill color. Rodent and root disturbance was common.

Most categories of cultural materials are sparse or absent in the assemblage from small pits, with debitage, faunal remains, and charred plant remains being the only ones to occur in even moderate percentages (see Table 4.2). Most of the 355 faunal remains were identified only to the vertebrate subphylum. The 21 identifiable fragments consist of mammals ranging from shrew/rabbit to deer/pronghorn in size (see Appendix G).

The macrobotanical remains from small pits make up only 23 percent of the site sample. The identified remains consist of wood charcoal (16.22 $\mathrm{g}$ of American elm, ash, hickory, holly, mulberry, oak, pecan, plum/cherry, red group oak, white group oak, sweetgum, and willow), burned nutshells (5.30 g of hickory, hickory/ walnut, black walnut, and acorn), seeds ( $0.12 \mathrm{~g}$ of corn, little barley/wildrye, maygrass, grass, purslane, and verbena), corn rachis (0.12 g), and fruit $(0.01 \mathrm{~g})$. A significant portion of these remains (53 percent) are from smudge pits, even though flotation samples came from far fewer smudge pits than other small pits (4 vs. 28). Excluding the smudge pits (and two other small pits whose flotation samples contained no charcoal at all), the small pits have an average macrobotanical remains density of $0.069 \mathrm{~g} /$ liter (or $0.055 \mathrm{~g} /$ /iter excluding Feature 51 with an unusually high value), ranging from 0.001 to $0.430 \mathrm{~g} / \mathrm{liter}$. As with the large pits, this low value implies that most of the charred materials are not related directly to the functions of the small pits, instead reflecting general debris in the vicinity that was mixed over time.

In contrast, the four smudge pits with flotation samples (Features 20,80, 165, and 319) have a higher density of macrobotanical remains $($ mean $=0.608 \mathrm{~g} /$ liter, range $=0.03-1.264 \mathrm{~g} /$ liter), consistent with the idea that they represent primary contexts. Recovery by feature was 


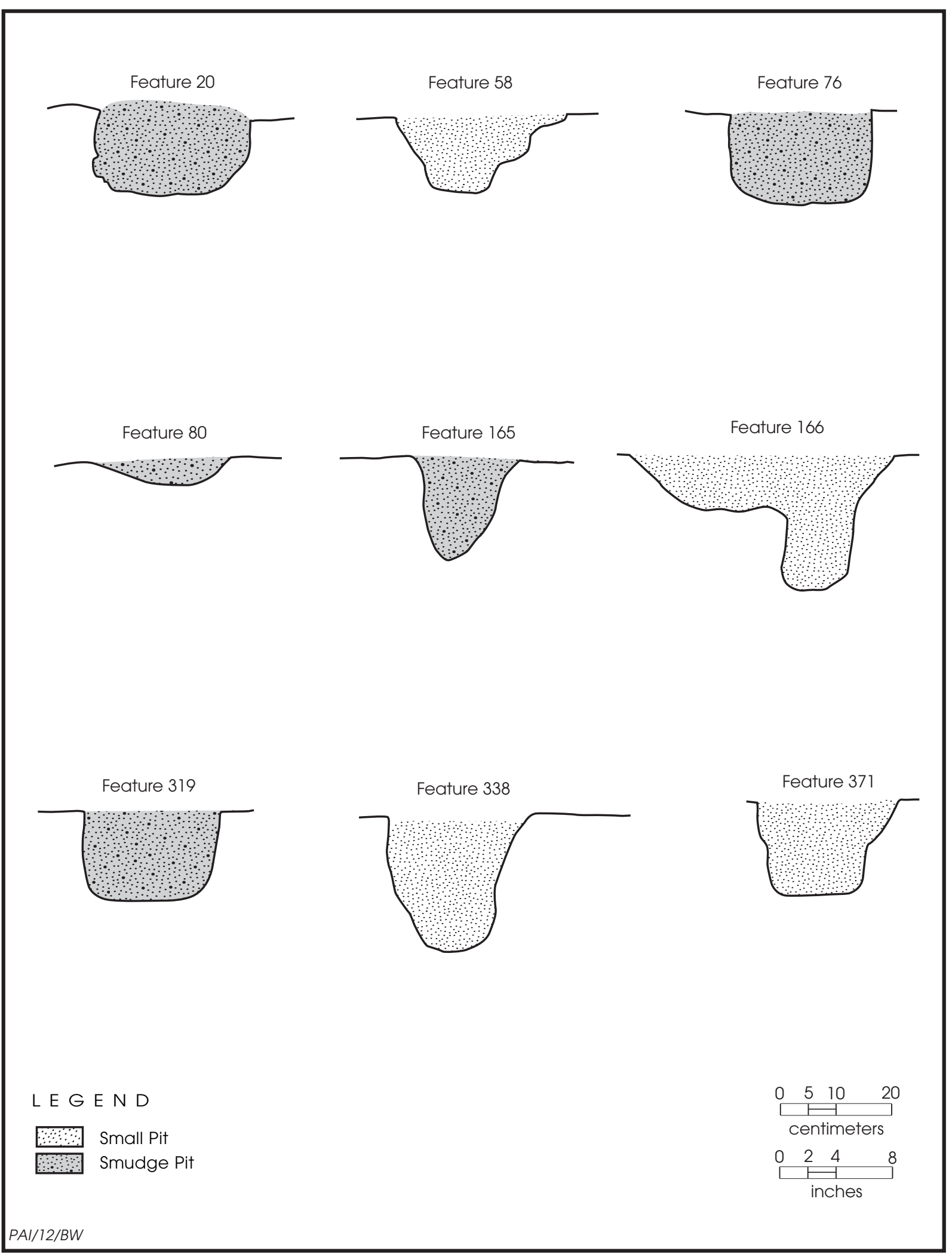

Figure 4.4. Cross sections of selected small pits in Subarea 1 at the George Richey site. 
highly variable, but as a group they are mostly wood charcoal (11.07 g including hickory, oak, and sweetgum) with only small amounts of nutshells ( $0.26 \mathrm{~g}$ including hickory, hickory/walnut, and acorn), corn rachis (0.09 g), and grass seeds $(0.02 \mathrm{~g})$. Apparently, various woods were the fuel of choice in creating smoky fires. Not surprisingly, faunal remains are very limited with only five specimens from two features, as are other classes of cultural materials ( 1 sherd, 13 pieces of debitage, and a flake tool).

All five smudge pits had evidence of in situ burning. Feature 20 had yellowish brown (10YR 5/6) sandy loam fill with some charcoal above a dense layer of black (10YR 2/1) silty loam; Feature 76 contained very dark gray (10YR 3/1) sandy loam fill; Feature 80 had greasy black (5YR 2.5/1) silt loam within dark reddish brown (5YR 2.5/2) silt loam fill; Feature 165 had a dense 2 -cm-thick charcoal layer within dark yellowish brown (10YR 3/4) sandy loam fill; and Feature 319 had dark yellowish brown (10YR 3/4) sandy loam fill with a dense black (10YR 2/1) band of charred remains. These are presumed to have contained smoky fires used for insect control or hide and meat processing.

A few of the other small pits warrant individual discussion. Feature 19, mentioned above with the large pits, is a small pit that overlaps Feature 17. It occurred lower than most of the other pits at this site and was conical in shape. Three small pits had postholes within the fill. Feature 166A had a posthole (Feature 166B) on its eastern side. The posthole extended $16 \mathrm{~cm}$ below the pit floor (see Figure 4.4). Feature 371A is a small pit with a smaller circular posthole (Feature 371B) within it. The posthole has vertical walls and a flat base and cut through the bottom of the pit (see Figure 4.4). Feature 58 had a possible posthole defined by the irregular base of the pit (see Figure 4.4). The pit bottom extended to $8 \mathrm{~cm}$ below the stripped surface, and the possible posthole, measuring $20 \times 16 \mathrm{~cm}$, extended to $12 \mathrm{~cm}$ below the stripped surface.

\section{Postholes}

The 76 postholes make up 51 percent of the features. They typically are circular with straight to slightly sloping walls and rounded to flat bottoms (Figure 4.5). Three are considered probable postholes. Two of these (Features 189B and 189C) are within a pit feature, and designa- tion as postholes is tenuous. The third, Feature 36 , was initially identified as noncultural, but it falls within the arc of a possible house and thus may be the remnant of a posthole that was badly disturbed. The postholes range from 11 to $25 \mathrm{~cm}$ in diameter (mean $=17 \mathrm{~cm})$, and the depths below detection level range from 2 to $30 \mathrm{~cm}($ mean $=11 \mathrm{~cm})$.

Fill generally consisted of brown (10YR 4/3, 4/4; 7.5YR 4/4), dark yellowish brown (10YR 4/6, 4/4), dark grayish brown (10YR 4/2), and dark brown (10YR 3/3, 7.5YR 3/4) sandy and silty sandy loam surrounded by strong brown (7.5YR 5/6) sandy clay. Some contained charcoal flecking, but these materials were in low densities, and no posthole had evidence of in situ burning. One, Feature 369, appears to be two overlapping postholes.

Postholes generally contained little in the way of cultural materials (see Table 4.2). Macrobotanical remains from 40 postholes with flotation samples total $2.96 \mathrm{~g}$, or 3 percent of the site total. The identified remains consist mostly of wood charcoal ( $2.49 \mathrm{~g}$ ) dominated by oak and hickory but also including maple, catalpa, ash, mulberry, and plum/cherry. Also present are hickory, hickory/walnut, and acorn nutshells $(0.28 \mathrm{~g})$; corn rachis $(0.02 \mathrm{~g})$; and grass seed $(0.01 \mathrm{~g})$. These remains occur in very low densities in the 35 postholes that contained charcoal (mean $=0.023 \mathrm{~g} /$ liter [or $0.016 \mathrm{~g} /$ liter excluding Feature 286], range $=0.001-0.278 \mathrm{~g}$ liter), and none of these materials actually relate to the posts these features once held. Faunal recovery consists of 96 specimens, 1 from a deer/pronghorn-sized ungulate and the rest identified only to the vertebrate subphylum (see Appendix G).

As discussed below (see Distribution), many of the postholes are in the southern part of the excavated area, and some of these appear to be parts of one or more houses. The other postholes likely represent additional small structures like drying racks, and it is possible that a few belong to modern or historic fence lines. There are no posthole patterns suggesting structures such as ramadas or granaries.

\section{Artifact Clusters}

Two artifact clusters were recorded as features. Feature 29 is most likely the result of rodent disturbance. It consists of a bone tool, a flake, $3.6 \mathrm{~g}$ of burned clay, three canid/deer-sized 


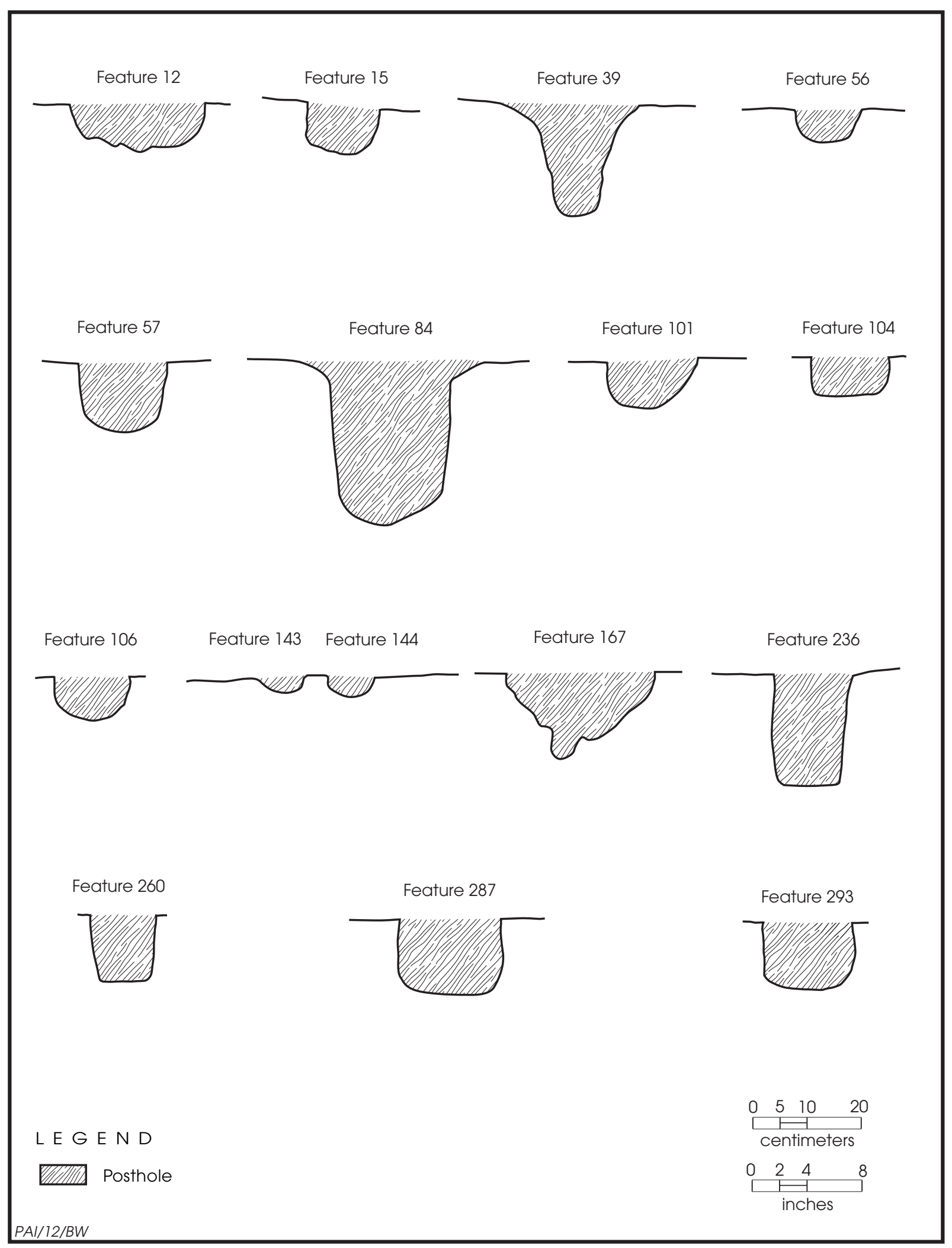

Figure 4.5. Cross sections of selected postholes in Subarea 1 at the George Richey site. 
bone fragments, two deer/pronghorn ungulate bones (a calcined carpal and an unburned middle phalange fragment), and an unidentified bone fragment that were clustered together in dark yellowish brown sandy loam that extended, in a linear shape measuring $12 \times 9 \mathrm{~cm}$, between two pit features.

Feature 52 consists of a few fire-cracked rock fragments, a core, three pieces of debitage, and $1.9 \mathrm{~g}$ of burned clay mixed with unmodified gravels within mottled brown, reddish brown, and yellowish red (7.5YR 4/4, 5YR 5/4, 5YR 5/8) sandy clay fill over an area of $25 \times 24 \mathrm{~cm}$ in the south part of the excavation area. Given the location and gravels and mixed fill, it may be a badly disturbed posthole or a result of bioturbation.

\section{Burned Rock Cluster}

The single burned rock cluster, Feature 8 , is a fairly large $(220 \times 200 \mathrm{~cm})$, disarticulated scatter of $85(15.5 \mathrm{~kg})$ burned and fire-cracked ferruginous sandstone, hematite, and quartzite cobbles (Figure 4.6). The feature extended from 18 to $40 \mathrm{~cm}$ below the ground surface. Most of the rocks were within dark yellowish brown sandy loam sediments toward the bottom of the $\mathrm{A} / \mathrm{E}$ horizon and resting on or near the strong brown sandy clay Bt horizon. There was no staining or charcoal associated with the rocks, with the exception of the sediment brought in by roots and rodents, noted as linear soil disturbances. The rocks were clustered in a few places, but overall they were scattered. Artifacts recovered in the immediate vicinity include a dart point, a flake tool, a mano/hammerstone, 11 flakes, 3 ceramics, and 5 faunal specimens; none are clearly associated with use of the feature. This feature appears to be a disturbed cooking feature that probably predates the Caddo occupation.

\section{Organically Enriched Midden Sediments}

Organically enriched midden sediments are characterized as dark brown to black deposits, typically with relatively high densities of cultural materials. There is one such area within Subarea 1. It is in the north-central part of the excavation area, covering most, but not all, of the features there. It represents the amalgamation of organic residue from the processing and use of plants and animals during the primary occupations at the site. A small portion of the western edge of this area was excavated (as Feature 11) during testing. It extended east, north, and south from Feature 11 and also was identified during testing in Trenches 40 and 41, parts of Trenches 32 and 33, and Test Units 3, 5,6 , and BHT 40 south-extension.

In the profiles of these trenches and test units, the A horizon extended from the ground surface to between 3 and $6 \mathrm{~cm}$ and was consisted of dark grayish brown, dark brown, or dark yellowish brown (10YR 3/2,3/3,3/4) sandy loam (Figure 4.7). Below the A horizon, between 3 and $35 \mathrm{~cm}$ below the surface, the organically enriched sediments consisted of dark yellowish brown (10YR 3/4) very fine loamy sand.

During data recovery, Sample Units 22, 23, $26,65,66,67$, and 70 and two trackhoe swaths were excavated in this area. The midden sediments were also noted during data recovery stripping, at which time they were removed and cultural features, as well as a plethora of rodent and root intrusions, were exposed in the Bt horizon. Based on evidence from both testing and data recovery, these organically enriched sediments extended over an area of 9 by $11 \mathrm{~m}$.

\section{Distributions}

Consistent with expectations based on testing data, most of the cultural features $(\mathrm{n}=132$, 89 percent) are in two concentrations in the southern and northern parts of the Subarea 1 excavation (see Figure 4.2). The remaining 17 features are between these two areas $(n=11)$ and on the outskirts of the excavated area $(\mathrm{n}=6)$

\section{Southern Feature Concentration}

The southern concentration has 60 percent of the features, mostly postholes $(\mathrm{n}=57)$ but also small pits $(\mathrm{n}=20)$, smudge pits $(\mathrm{n}=3)$, large pits $(\mathrm{n}=9)$, and an artifact cluster (Figure 4.8). These features occur over an area of $23 \mathrm{~m}$ north-south by $15 \mathrm{~m}$ east-west. The postholes (including 1 probable posthole) have a mean diameter of $17 \mathrm{~cm}$ (ranging from 11 to $25 \mathrm{~cm}$ ) and a mean depth of $11 \mathrm{~cm}$ (ranging from 2 to $30 \mathrm{~cm}$ ). Sixteen of the postholes form an arc that appears to be most of a house; 14 or 15 other postholes form two much shorter arcs that could 


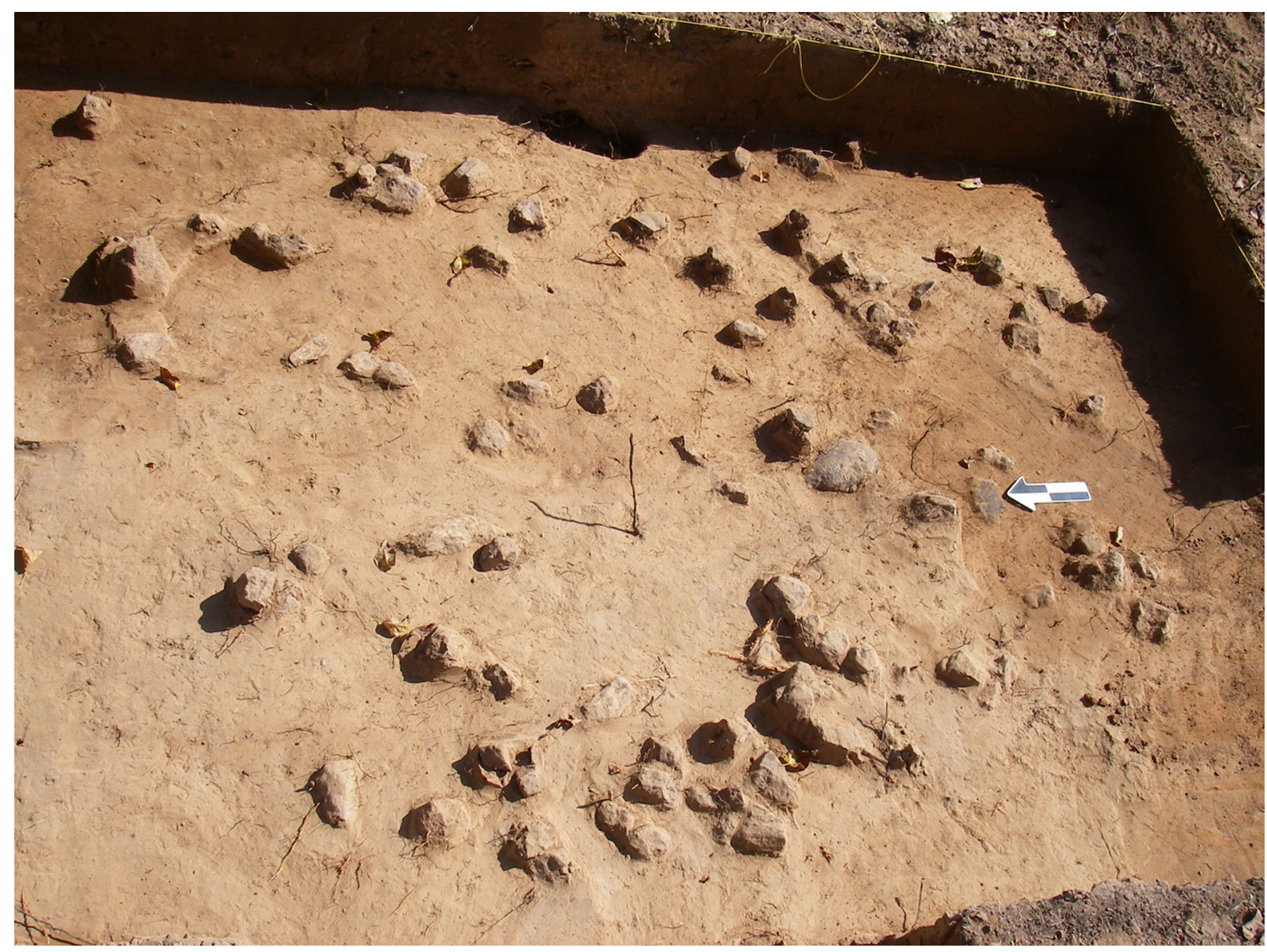

Figure 4.6. Photograph of burned rock cluster Feature 8 in Subarea 1 at the George Richey site.

represent houses, though they are too incomplete to be sure. Houses were difficult to identify in this area due to overprinting of features and postdepositional factors such as bioturbation. Most of the radiocarbon dates indicate that the main occupation, and presumably the house(s), here date to the late A.D. 1200 s-early 1300 s, though some dates indicate earlier and later occupations as well (see Chronology).

The most-complete arc of postholes appears to represent a slightly oval structure measuring $6.0 \times 6.4 \mathrm{~m}$. The 16 postholes making up House 1 (Features 36, 38, 39, 104, 106, 260, 263, 264, $269,270,276,278,279,297,369$, and 377) are somewhat irregular in alignment and spacing, ranging from 0.7 to $1.4 \mathrm{~m}$ apart with an average of $1.0 \mathrm{~m}$ and modes at 0.8 and $1.2 \mathrm{~m}$. Defining about 80 percent of the structure, the postholes range from 12 to $23 \mathrm{~cm}$ in diameter, with an average of $16 \mathrm{~cm}$, and they are $2-20 \mathrm{~cm}$ deep $($ mean $=9 \mathrm{~cm})$. There is no clear center post, although posthole Feature 355 , which is $20-21 \mathrm{~cm}$ in diameter and thus larger than the average wall posthole, is $0.4 \mathrm{~m}$ north of the center and may be an interior support post. A large shallow pit (Feature 300), a smudge pit (Feature 319), 4 small pits (Features 290, 371, 376, and 376), and 13 postholes (Features 43, 275, 293, 333, 334, $341,355,372,373,374,375,285$, and 287) are within the projected house outline, but it is unknown if they are associated interior features or predate or postdate the house. The fact that the site has multiple components certainly increases the chances they are not directly associated (see Chronology). In fact, the smudge pit is so close to the projected wall $(30 \mathrm{~cm})$ that it is unlikely it was inside the house, and 4 of the postholes in the south part of the structure are part of an 
arc that could represent a different house, as discussed below.

The two posthole arcs that could represent very incomplete house patterns both overlap House 1. One consists of eight postholes that could be about 20 percent of a structure that is nearly the same size as House 1. Four of the eight postholes (Features 285, 287, 294, and 341) are within the House 1 outline; three postholes (Features 273,298 , and 299) are outside it; and one posthole (Feature 297) is part of the House 1 pattern. Most of these postholes are fairly regularly and closely spaced at $0.4-0.6 \mathrm{~m}$. They are $12-18 \mathrm{~cm}$ in diameter $($ mean $=16 \mathrm{~cm})$ and $4-16 \mathrm{~cm}$ deep $($ mean $=12 \mathrm{~cm})$. There is no center post.

Another 9 or 10 postholes could be about one-third of a large structure (ca. $8.0 \mathrm{~m}$ in diameter) that would have extended east and south of House 1. The best part of the arc extends for a distance of $5.0 \mathrm{~m}$ and contains Feature 36 in the west wall of House 1 and Features 34, 370, 273, 296 , and 294 to the south and southeast; these are $0.6-1.3 \mathrm{~m}$ apart, with most being $1.0-1.3 \mathrm{~m}$ and thus similar to the spacing in House 1. Features 56,57 , and 59 could be part of the southeast wall; the first two are close together, and the latter is about $1.2 \mathrm{~m}$ to the east-northeast. Feature 373 is an isolated posthole that could be part of the north wall. These postholes are $12-27 \mathrm{~cm}$ in diameter $($ mean $=17 \mathrm{~cm})$ and $4-25 \mathrm{~cm}$ deep $($ mean $=11 \mathrm{~cm})$. There is no clear center post, but posthole Feature 334, which is $25 \mathrm{~cm}$ in diameter and thus fairly large, is only $0.4 \mathrm{~m}$ south of the projected center and thus a candidate.

As with House 1, determining which features within these projected house outlines could

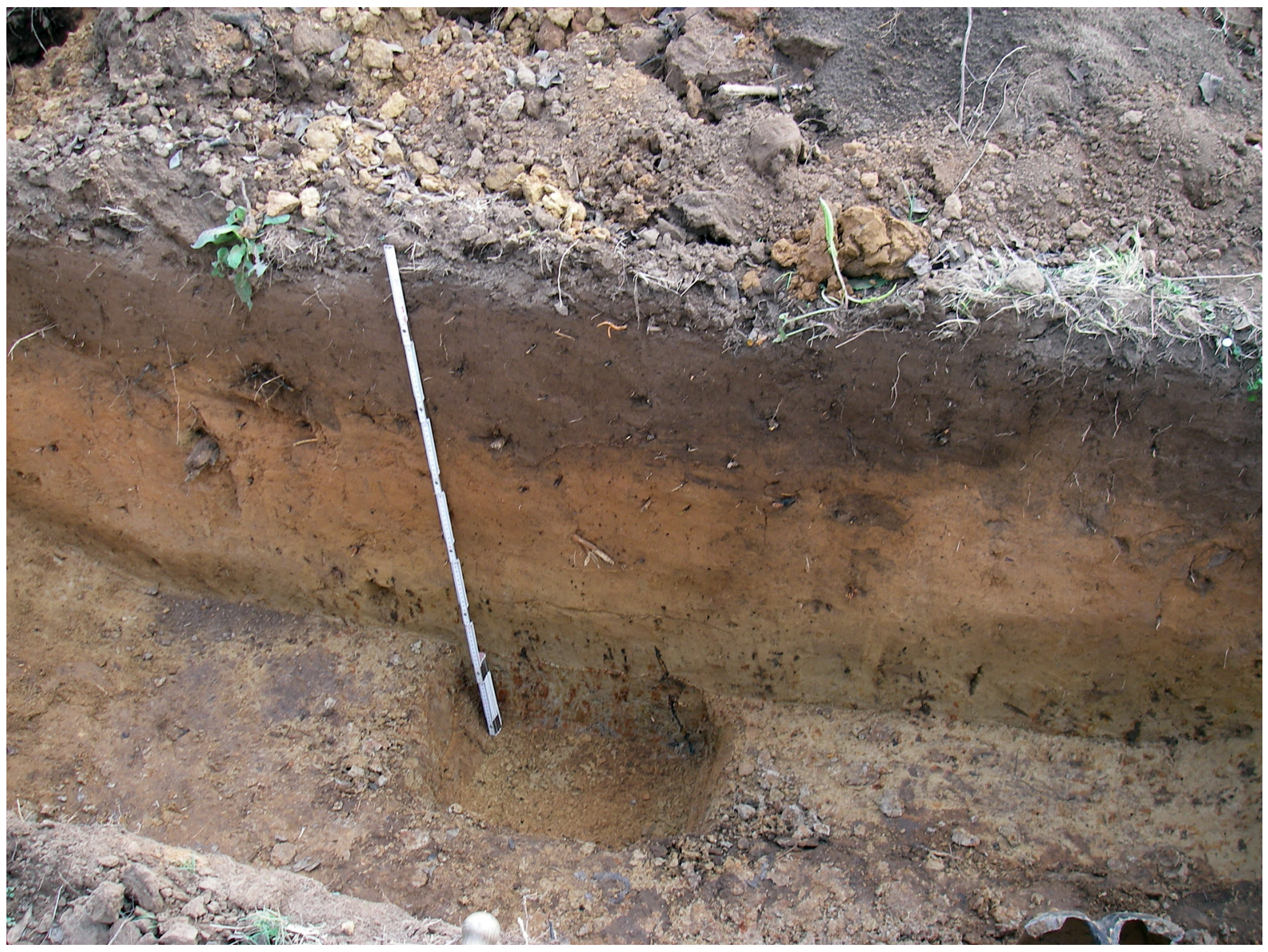

Figure 4.7. Photograph of a section of the east wall of Trench 40 in Subarea 1 at the George Richey site showing organically enriched midden sediments in the upper part of the profile. 


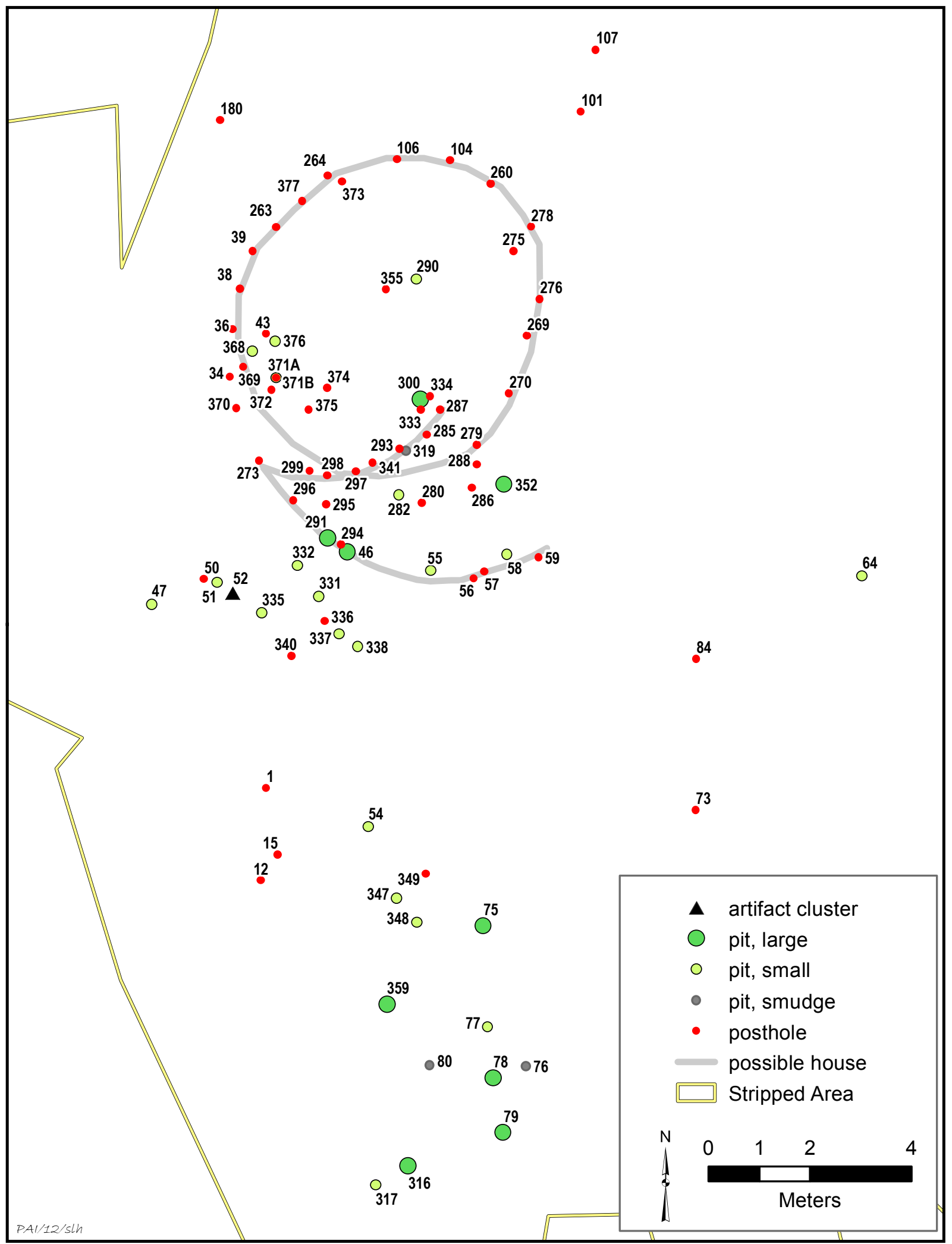

Figure 4.8. Plan of the southern feature concentration in Subarea 1 at the George Richey site. 
have been associated with them is problematical because of multicomponency and the extent of overlap with House 1. There are a number of pits that surely were not within any of these structures, though. Two large pits (Features 46 and 291) and nine small pits (Features 47, 51, $55,58,331,332,335,337$, and 338) are within a $7 \times 3-\mathrm{m}$ area about $2 \mathrm{~m}$ south of House 1, and five large pits (Features 75, 78, 79, 316, and 359), two smudge pits (Features 76 and 80), and five other small pits (Features 54, 77, 317, 347, and 348) occupy a $7 \times 3-\mathrm{m}$ area about $3 \mathrm{~m}$ farther to the south. Though some of these features may well predate and postdate the one to three houses in this area, many probably relate to outside activities, such as cooking and food preparation, contemporaneous with the houses. There are small numbers of clearly extramural postholes as well; these occur singly or in small clusters and probably represent drying racks or other such structures. None of the postholes form small circular patterns suggestive of granaries or rectangular patterns indicative of ramadas.

\section{Northern Feature Concentration}

The northern concentration has 28 percent of the features, mostly large $(n=9)$ and small pits ( $\mathrm{n}=15$, including 1 smudge pit) but also postholes and probable postholes $(\mathrm{n}=15)$, a burned rock cluster, and an artifact cluster (Figure 4.9). Most are in an area of about $10 \mathrm{~m}$ north-south by $8 \mathrm{~m}$ east-west, with 2 more features (a large shallow pit Feature 137 and posthole Feature 18) lying 2-3 $\mathrm{m}$ to the north of the others. Most of this area has organically enriched midden sediments reflecting intensive activities associated with use of many of these features. Judging from the radiocarbon dates, much but not all of this use was contemporaneous with the late A.D. 1200 searly 1300s main occupation represented by the houses in the southern feature concentration. The assemblage of features suggests that a different set of activities was performed in the northern area, though, and most of it appears to be an area of outside activities for processing and cooking food, preparing hides, etc.

The organically enriched sediments extend a few meters beyond the feature concentration on the west and northwest sides and to a lesser extent the east side. This may be the result of plowing or other mixing processes, or it may reflect purposeful deposition of organic materials adjacent to but outside the pit area. The burned rock feature on the south edge (Feature 8) also is outside the midden area and, as mentioned above, is most likely related to an earlier nonCaddo occupation and thus only coincidentally located near the other features.

The 13 postholes and 2 probable postholes are very similar in size to those in the southern feature concentration, having an average diameter of $18 \mathrm{~cm}$ (ranging from 12 to $25 \mathrm{~cm}$ ) and an average depth of $13 \mathrm{~cm}$ (ranging from 5 to $26 \mathrm{~cm}$ ). This excludes probable posthole Features 189B and $189 \mathrm{C}$ discussed above, since they were within the fill of a pit and the dimensions were indistinct. They occur singly or in pairs (e.g., Features 143 and 144 and Features 236 and 240) throughout the feature concentration, and their distribution reflects no patterns indicative of structures such as granaries or ramadas; hence, they probably represent less-substantial structures such as drying racks or shade supports in and around outdoor cooking and processing features.

The nine large pits (Features 9, 16/205, $17,28,137,188,189 \mathrm{~A}, 233$, and 271A), most of which are relatively deep (greater than $25 \mathrm{~cm}$ ) compared to most of the other large pits at the site, probably relate to communal processing activities that contributed to the midden staining in this area. They have a restricted distribution, with all but Feature 137 being in the central part of the concentration. The single smudge pit (Feature 165) is off on the south edge of the concentration. The small pits here are no different than the ones in the southern feature concentration, with those in both areas probably reflecting a variety of generalized activities. They are distributed widely without any apparent patterning.

\section{Other Features}

Within the 26-m area that separates the northern and southern concentrations are two large pits (Features 110 and 266), a smudge pit (Feature 20), seven small pits (Features 119, 170, $174,182,184,274$, and 284), and two postholes (Features 118 and 183). All but two of these are concentrated in a 10x9-m area. The large pits and one of the postholes are on the west side of this cluster, the smudge pit is on the north side, and the small pits are along the east side. Another small pit and a posthole are north of 
this cluster, about $6 \mathrm{~m}$ southeast of the northern concentration. Similar to the northern concentration, these features are likely associated with general camp activities. The scarceness of features here is distinctive and probably reflects a mostly open middle area that may have functioned as a plaza.

Along the northern edge of the data recovery area are two small pits, a large pit, and a posthole. An isolated posthole was also identified on the southeastern edge of the site. These scant features indicate some, although infrequent, use of the periphery of this site.

\section{CERAMIC ARTIFACTS}

The ceramic artifacts recovered from Subarea 1 number 2,702 (15,495 g). Of these, $1,347(12,893 \mathrm{~g})$, or 50 percent by count and 83 percent by weight, are large enough for analysis. Two of these are smoking pipe fragments, and the rest are from ceramic vessels. Included in the latter are large sections of two deep bowls. The sample is described below in relation to sherd characteristics, vessel form, and decoration. The pipe fragments are described separately.

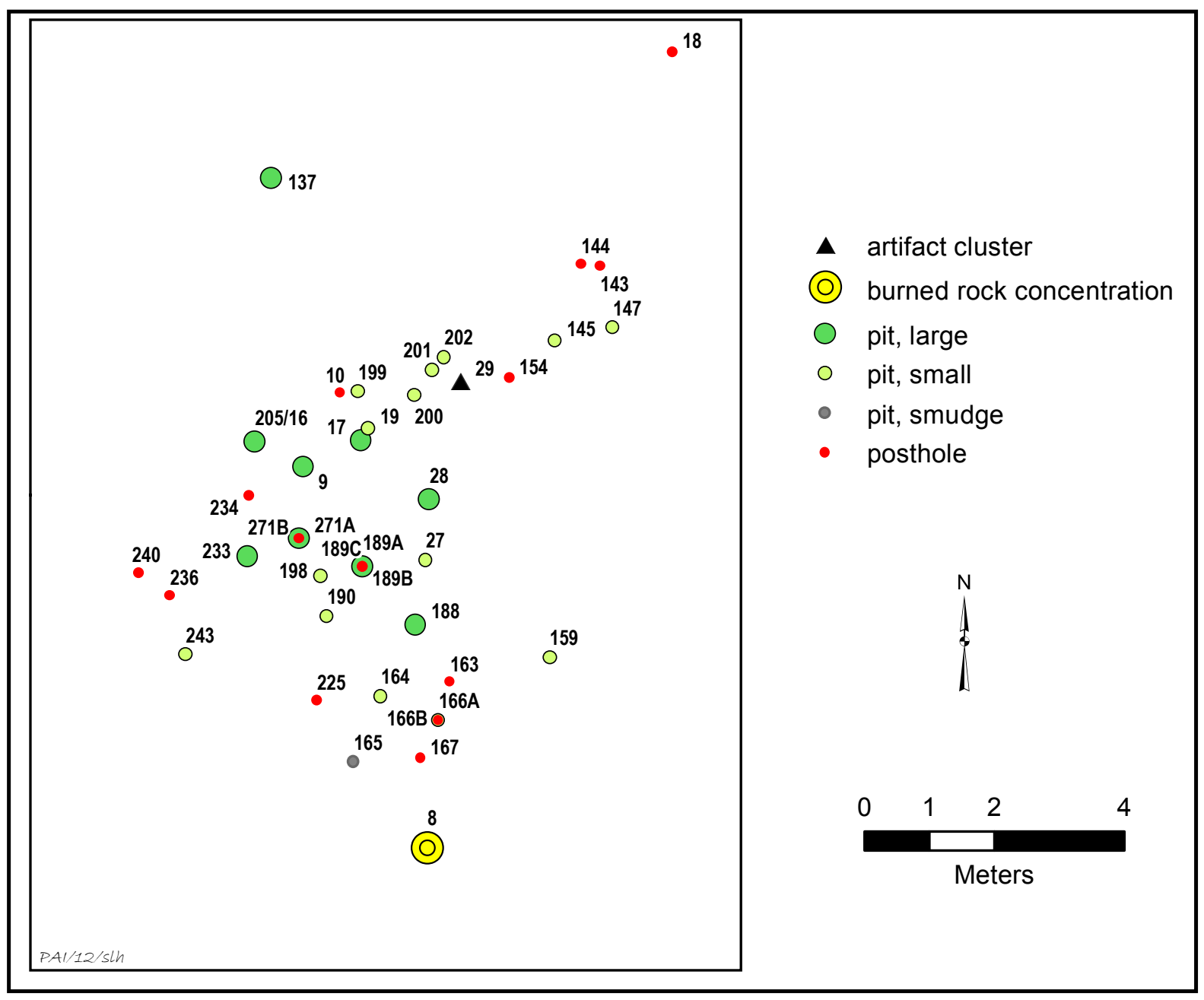

Figure 4.9. Plan of the northern feature concentration in Subarea 1 at the George Richey site. 


\section{Vessel Sherd Characteristics}

The vessel sherd sample consists of body sherds $(n=1,101)$, carinated body sherds $(\mathrm{n}=19)$, rim sherds $(\mathrm{n}=121), \mathrm{rim} /$ carination sherds, $(n=5)$, neck sherds $(n=25)$, base sherds $(\mathrm{n}=71)$, and 3 indeterminate sherds. These are mainly tempered with grog alone, though grogbone is well represented and some bone temper by itself is also present (Table 4.3). The voids that occur with grog or bone may represent leached bone. The only other tempering agent identified is sand, and it is minimal.

Table 4.3. Tempering agents in the ceramic sherd sample from the George Richey site

\begin{tabular}{l|c|c}
\multicolumn{1}{c|}{ Temper } & No. & $\%$ \\
\hline Grog & 857 & 63.7 \\
\hline Grog-bone & 331 & 24.6 \\
\hline Bone & 105 & 7.8 \\
\hline Bone-voids & 33 & 2.5 \\
\hline Grog-bone-voids & 10 & 0.7 \\
\hline Voids & 1 & 0.3 \\
\hline Sand & 4 & 0.1 \\
\hline Indeterminate & 4 & 0.3 \\
\hline Total & 1,345 & 100.0 \\
\hline
\end{tabular}

Sherd characteristics indicate that most vessels had everted rims ( $\mathrm{n}=90,71$ percent of the rims and rims/carinations). Straight rims $(\mathrm{n}=14)$ make up 11 percent of the sample while inverted rims $(n=6)$ are 5 percent. The number of rims of indeterminate orientation $(n=16$, 13 percent) reflects the small size of some of the sherds. Fifty percent of the rims have flat lips $(\mathrm{n}=63)$, and 22 percent have rounded lips $(n=28)$. Exterior rolled lips, common on Ripley Engraved bowls and late utility wares, are found on just 16 percent $(n=20)$ of the rims. Tapered lips ( $\mathrm{n}=10,8$ percent) are few, as are indeterminate lip forms $(\mathrm{n}=5,4$ percent). Rim thickness ranges from 3.51 to $9.67 \mathrm{~mm}$ with a mean of $6.54 \mathrm{~mm}(\mathrm{sd}=1.38)$. This range suggests that the assemblage contains small to large vessels. Base thickness, which ranges from 5.87 to $18.21 \mathrm{~mm}$ with a mean of $11.30 \mathrm{~mm}$ $(\mathrm{sd}=2.35)$, supports this conclusion. Most of the base sherds are flat $(\mathrm{n}=49,69$ percent) rather than rounded ( $\mathrm{n}=6,8$ percent) or of indeterminate form ( $\mathrm{n}=16,23$ percent).

Weathering of the surfaces of the sherds made it difficult to determine surface finish. Most were considered to have smoothed surfaces (both exterior and interior), as it was obvious that they were well finished but evidence of polish or tool marks that would indicate burnishing was not apparent (Table 4.4). True burnishing was noted for only 6 percent of the exterior surfaces and 2 percent of the interior surfaces. Floating, achieved using a tool on the wet clay to bring to the surface a fine layer of clay particles, was distinguishable on almost twice as many interior as exterior surfaces (23 vs. 13 percent; see Table 4.4). This may indicate that this was the main method employed to finish the interiors of bowls and jars. Three percent of the interior surfaces are scraped but otherwise unfinished, providing a crucial clue for identifying restricted-orifice vessels such as ollas and bottles. Slipping was noted on small numbers of both finished exterior and interior surfaces; the slip commonly used was red, but there are a few instances of reddish brown slips. Red pigment was found in the engraved lines on seven sherds, one of which could be identified as a bottle sherd. White pigment was seen in the engraved lines on only one bowl sherd.

Decorated sherds constitute only 30 percent of the sample (see Table 4.4). Most display punctations or pinching ( $\mathrm{n}=174,43$ percent of those with decoration). Engraved sherds ( $\mathrm{n}=95$, 23 percent) and incised sherds ( $\mathrm{n}=74,18$ percent) are the next most prevalent decorative modes. Sherds with brushing or a combination of brushing with other decorative modes make up only 12 percent $(n=50)$ of the decorated sherds and only 4 percent of all sherds. An additional 3 percent of the decorated sherds display appliqué (without brushing). Coil crimping is present on only two sherds.

\section{Vessel Form}

Vessel forms identified within the sherds are based on a combination of characteristics such as vessel part, rim orientation, and lip form as well as a few distinctive surface treatments. These characteristics reflect production decisions that relate to particular vessel forms. For instance, Caddo bottles and ollas have constricted orifices 
Table 4.4. Surface treatment and decorative attributes for the ceramic sherd sample from Subarea 1 of the George Richey site

\begin{tabular}{|c|c|c|}
\hline & No. & $\%$ \\
\hline \multicolumn{3}{|l|}{ Exterior Surface Finish } \\
\hline Smoothed & 1,000 & 74 \\
\hline Floated & 181 & 13 \\
\hline Burnished & 76 & 6 \\
\hline Slipped & 13 & 1 \\
\hline Scraped & 4 & 0 \\
\hline Indeterminate & 71 & 5 \\
\hline Totals & 1,345 & 100 \\
\hline \multicolumn{3}{|l|}{ Interior Surface Finish } \\
\hline Smoothed & 908 & 68 \\
\hline Floated & 314 & 23 \\
\hline Burnished & 29 & 2 \\
\hline Slipped & 11 & 1 \\
\hline Scraped & 34 & 3 \\
\hline Indeterminate & 49 & 4 \\
\hline Totals & 1,345 & 100 \\
\hline \multicolumn{3}{|l|}{ Decorative Mode } \\
\hline None & 937 & 70 \\
\hline Engraved & 95 & 7 \\
\hline Incised & 74 & 6 \\
\hline Fingernail punctated & 73 & 5 \\
\hline Stick puntated & 67 & 5 \\
\hline Brushed & 47 & 3 \\
\hline Brushed-punctated & 2 & 0 \\
\hline Brushed-appliquéd & 1 & 0 \\
\hline Appliquéd, linear & 8 & 1 \\
\hline Appliquéd, nodes & 2 & 0 \\
\hline Appliquéd-punctated & 3 & 0 \\
\hline Punctated-incised & 11 & 1 \\
\hline Pinched & 23 & 2 \\
\hline Coil crimped & 2 & 0 \\
\hline Totals & 1,345 & 100 \\
\hline \multicolumn{3}{|l|}{ Decorative Element } \\
\hline Punctated field/zone & 112 & 38 \\
\hline Horizontal lines & 37 & 12 \\
\hline Hatching & 31 & 10 \\
\hline Curvilinear lines & 24 & 8 \\
\hline Rectilinear lines & 22 & 7 \\
\hline Diagonal lines & 15 & 5 \\
\hline Vertical lines & 21 & 7 \\
\hline Lines of punctations or pinching & 18 & 6 \\
\hline Appliquéd fillet & 9 & 3 \\
\hline Node(s) & 2 & 1 \\
\hline Neck banding & 2 & 1 \\
\hline Diamond & 1 & 0 \\
\hline Half circle & 3 & 1 \\
\hline Totals & 295 & 100 \\
\hline
\end{tabular}

\begin{tabular}{l|c|c}
\hline & No. & $\%$ \\
\hline Main Motif & & \\
\hline Horizontal lines at rim & 13 & 38 \\
\hline Diagonal lines at rim & 5 & 15 \\
\hline Vertical lines at rim & 6 & 18 \\
\hline Zoned punctations at rim & 4 & 12 \\
\hline Scroll & 4 & 12 \\
\hline $\begin{array}{l}\text { Horizontal rows of punctations at } \\
\text { rim }\end{array}$ & 2 & 6 \\
\hline Totals & 34 & 100 \\
\hline
\end{tabular}


that limited the ability of the potter to finish the interior of the vessels, such that sherds will have a rough or scraped interior surface. Sherds with carinations indicate that carinated bowls are represented, as are simple deep bowls. In addition, sherds with engraved decoration are likely to have been parts of bowls or bottles. Neck sherds represent restricted-orifice vessels, and, if they are thick sherds, they likely represent utility vessels such as jars or ollas. Jars and jar rims tend to be decorated with some combination of incising, brushing, punctations, or appliqué. The 9 percent of the sample that can be identified confidently with particular vessel forms consists of 23 bottle sherds, 48 bowl sherds, 26 deep bowl sherds, 22 jar sherds, and 3 olla sherds. It is presumed that these relative frequencies provide a general indication of the proportions of the kinds of vessels used at the site.

Only 11 rim sherds are large enough to provide a measure of orifice diameter and thereby address vessel size. The nearly complete deep bowl described below has a rim diameter of $35 \mathrm{~cm}$. Other rims indicate bowls or deep bowls with diameters of $25 \mathrm{~cm}$ or greater. Rim sherds that could be from either bowls or jars suggest diameters of 10 to $25 \mathrm{~cm}$. One olla rim has a diameter of $10 \mathrm{~cm}$. This scant evidence appears to confirm the rim and base thickness data, which suggest a range of vessel sizes were utilized at the site, albeit with medium-sized to large vessels perhaps predominating.

\section{Decorative Elements, Motifs, and Ceramic Types}

In all, 13 decorative elements were recognized on 72 percent $(n=295)$ of the decorated sherds (see Table 4.4). The most common one is zone or field of punctations at 38 percent of those with identifiable elements (Figure $4.10 \mathrm{a}-\mathrm{c})$. In contrast, lines of punctations or pinching (Figure 4.10d) are found on only 6 percent, and appliquéd elements, both linear and nodes, occur on only 4 percent (Figure $4.10 \mathrm{e}-\mathrm{f}$ ). Five linear elements formed by engraving or incising-horizontal lines, curvilinear lines, rectilinear lines, vertical lines, and diagonal lines-were identified on 40 percent of the sample (Figure 4.11). The main element in this group is simple horizontal lines. Hatching is also fairly well represented at 10 percent. Some of the hatching is fine and appears to decorate the arms of scrolls or surround other elements within a design (Figure 4.12a-b). Other elements of minimal occurrence, but that may be associated with the scroll motif, are the half circle and the diamond. A diamond element is found within a half circle on one rim sherd (Figure 4.12c).

Only 8 percent of the decorated sherds could be related to specific motifs based on combinations of elements or position on the vessel part (see Table 4.4). Using these motifs to define associated ceramic types was problematic, with small sherd sizes often forcing the analyst to make a mental leap to decide how a motif played out across the entire vessel. Still, some type associations can be made. For instance, utility wares such as jars or deep bowls with incised horizontal lines on the rim $(\mathrm{n}=13)$ could be associated with types such as Kiam Incised, Crockett Curvilinear Incised, or Davis Incised (see Figure $4.11 \mathrm{a}-\mathrm{b}$ ), but these rims are not distinctive enough to be typed with certainty. Five sherds with incised diagonal lines at the rim may be associated more confidently with Maydelle Incised (see Figure 4.11c). Jars with zoned punctations at the rim $(n=4)$ also could be related to Maydelle Incised or possibly Canton Incised (see Figure 4.10a). At least one sherd with zoned fingernail punctations represents Weches Fingernail Impressed (see Figure 4.10b). Two jar sherds with horizontal rows of punctations on the rim likely represent an untyped utility ware that is more common at the other two excavated sites.

The nine sherds with appliquéd fillets, which in this sample occur as curvilinear lines of appliqué on the body (see Figure 4.10f), could represent Harleton Appliqué. Harleton vessels can be decorated with appliquéd scrolls, concentric diamonds, and triangular motifs (Suhm and Jelks 1962:Plate 33). Unfortunately, these sherds are not large enough to identify specific motifs or to rule out the possibility that some might be from Pease Brushed-Incised vessels.

Ripley Engraved is represented by 4 sherds that display sections of scroll arms (see Figure 4.12a), and a few others have primary and secondary elements such as half circles and diamonds that are common to the type (see Figure 4.12b-c). Also, 2 bottle sherds have engraved curvilinear lines that could be parts of Ripley motifs, and red pigment is present in some of these engraved designs, which is also 


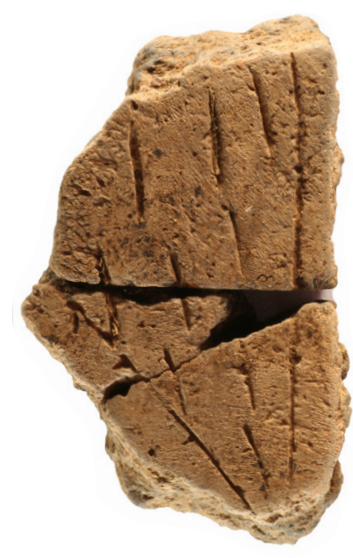

a
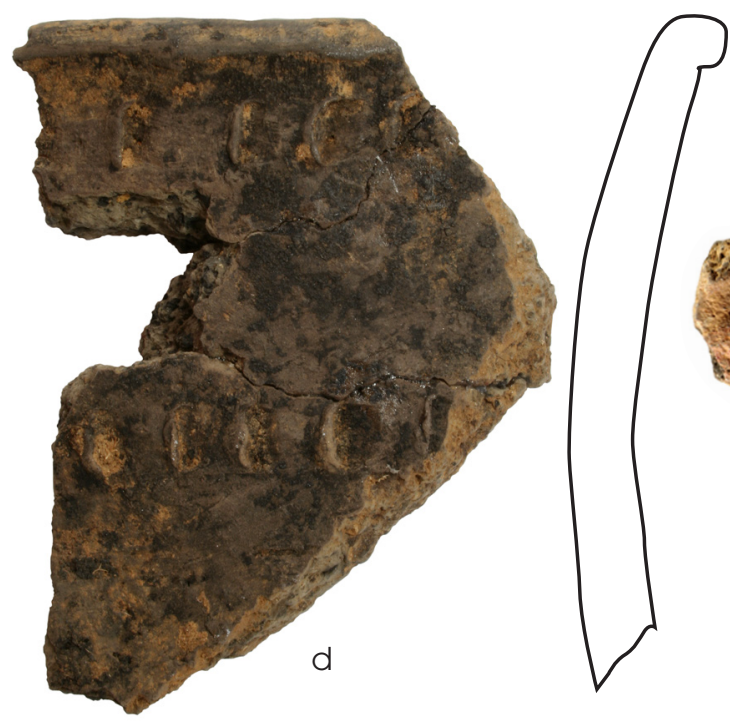

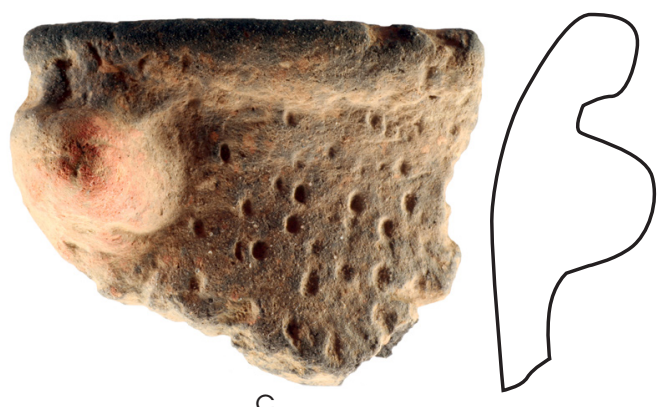

C
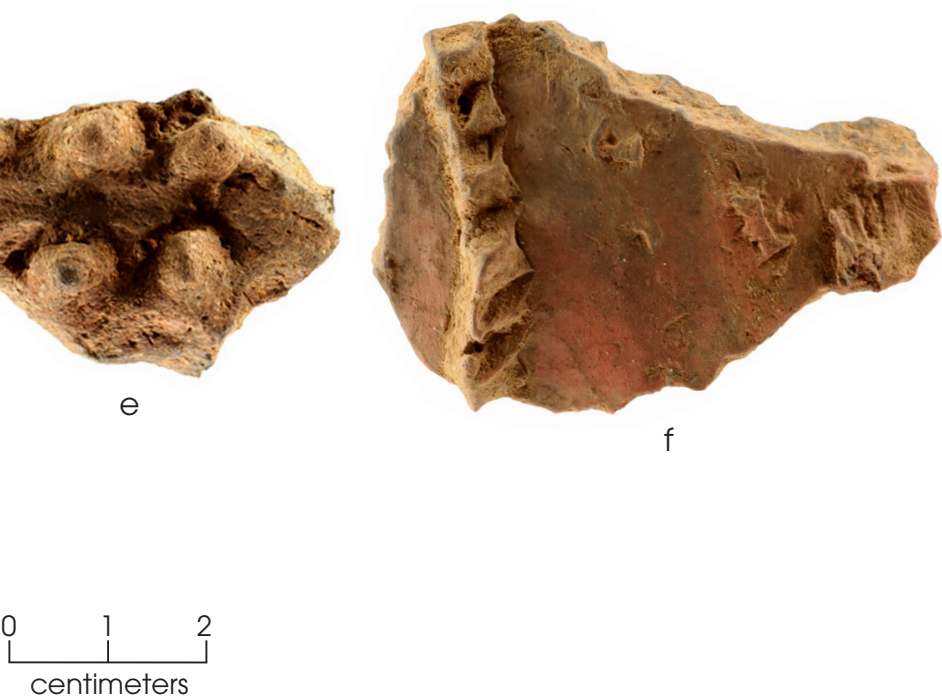

Figure 4.10. Bowl and jar sherds with punctations, appliqué, and incising from Subarea 1 at the George Richey site. (a-c) Rim and neck sherds with zone or field of punctations; (d) jar rim with lines of punctations; (e) body sherd with appliquéd nodes; (f) body sherd with linear appliquéd fillets.

common for the type (Figure 4.12d-e). In all, 10 sherds can be called Ripley Engraved with confidence, though it is likely the many of the other engraved sherds are from Ripley vessels.

Lastly, there are a few sherds that can be classed as a noded bowl and effigy bowls. A small body sherd covered by two lines of closely spaced appliquéd nodes represents the noded bowl (see Figure 4.10e). Each node is approximately $8.5 \mathrm{~mm}$ in diameter with four complete and two partial nodes still adhering to the sherd. The exterior of the sherd is brown, but it has a black interior and core. Color is mentioned because often these bowls were found to hold pigment and are thought to be ceremonial paraphernalia (Suhm and Jelks 1962:51). The effigy bowls are represented by two rim/body sections that have a straight or everted rim with a flat lip. The rims are engraved with four or five encircling horizontal lines that curve or bend downward 


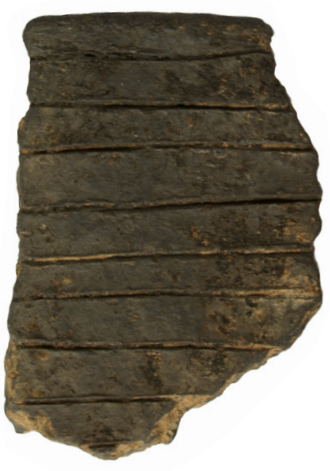

a

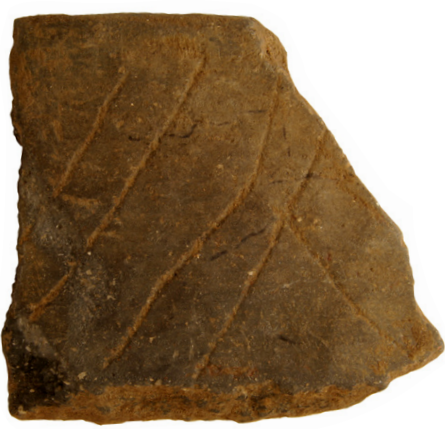

C
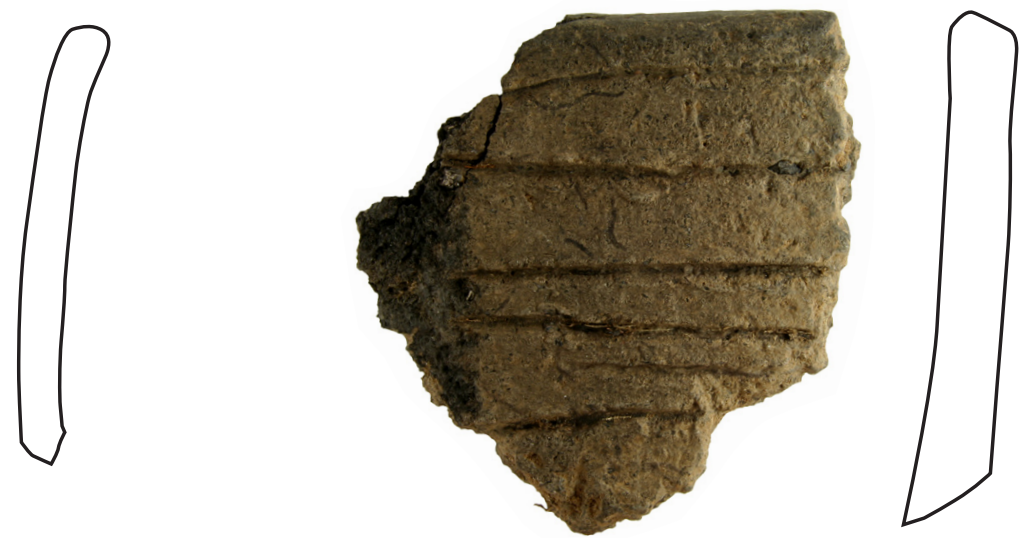

b
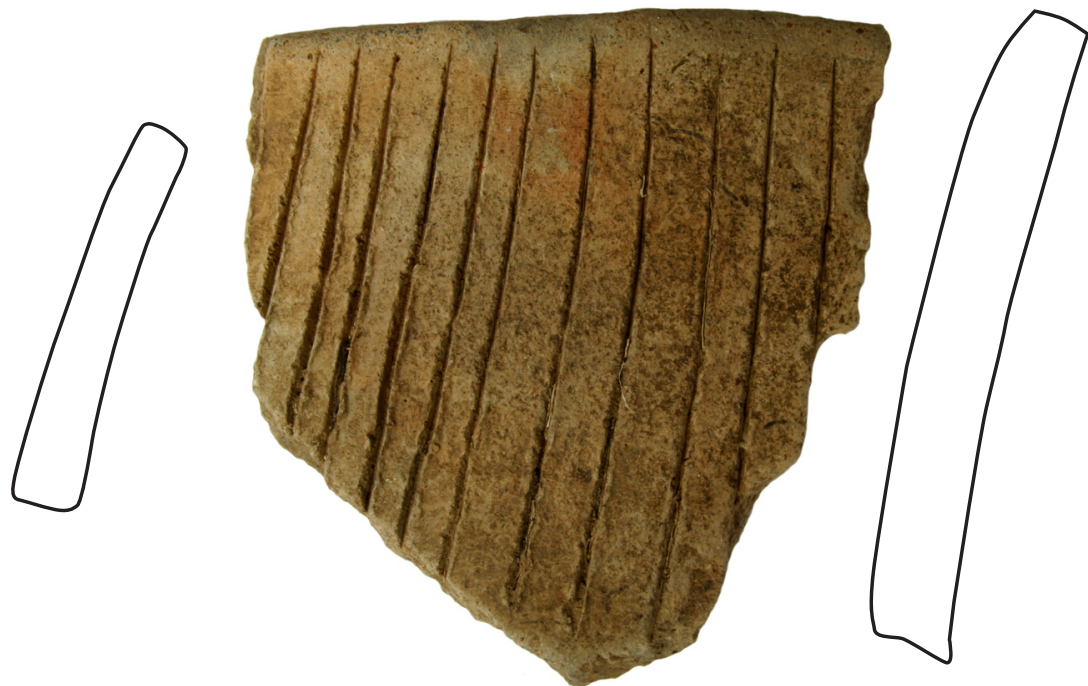

d

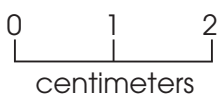

Figure 4.11. Incised jar sherds from Subarea 1 at the George Richey site. (a-b) Rim sherds with horizontal lines; (c) rim sherd with opposed diagonal lines; (d) rim sherd with vertical lines.

below what would have been the attachment point for an effigy head or tail (Figure 4.12f). While not associated with a ceramic type, these unique bowls form a class of vessels that may have had ritual significance.

\section{Vessel Sections}

Several sections representing two vessels were recovered from Features 9 and 205/16. One appears to be a large deep bowl; it is undecorated. The second, also maybe a deep bowl, has incised horizontal lines at the rim and a plain body.

Several sections of the undecorated large deep bowl were recovered from two adjacent features in the northern feature concentration. Feature 9 produced 11 sherds that refit to form part of the rim and body wall of the vessel along with 2 sherds that do not refit but that, based on color and temper, are likely part of the vessel. This vessel section and sherds weigh $738.4 \mathrm{~g}$. 


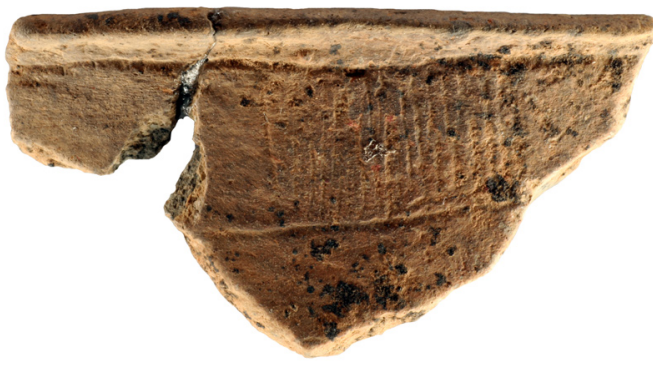

a

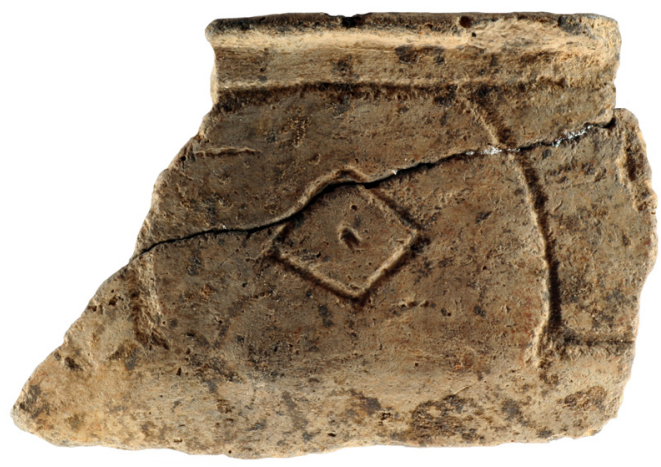

C

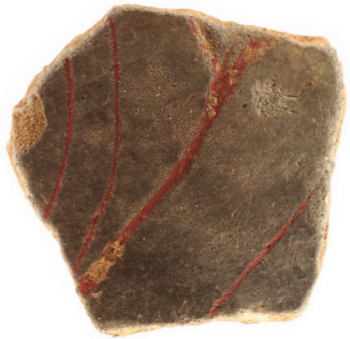

e
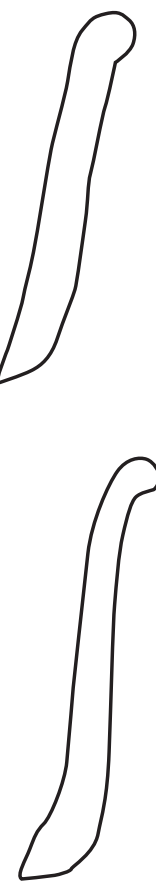

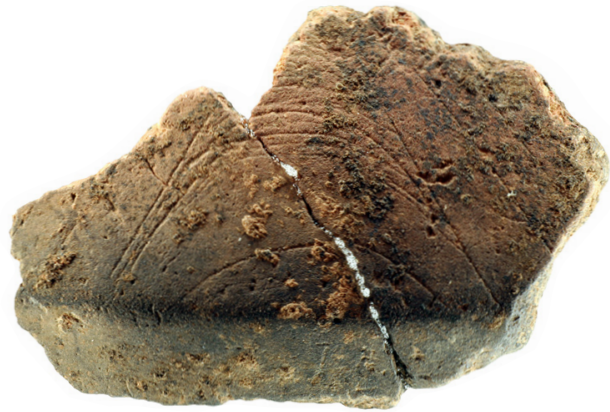

b

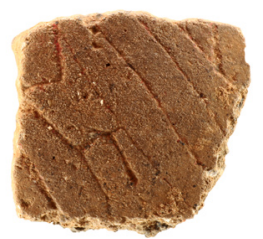

d
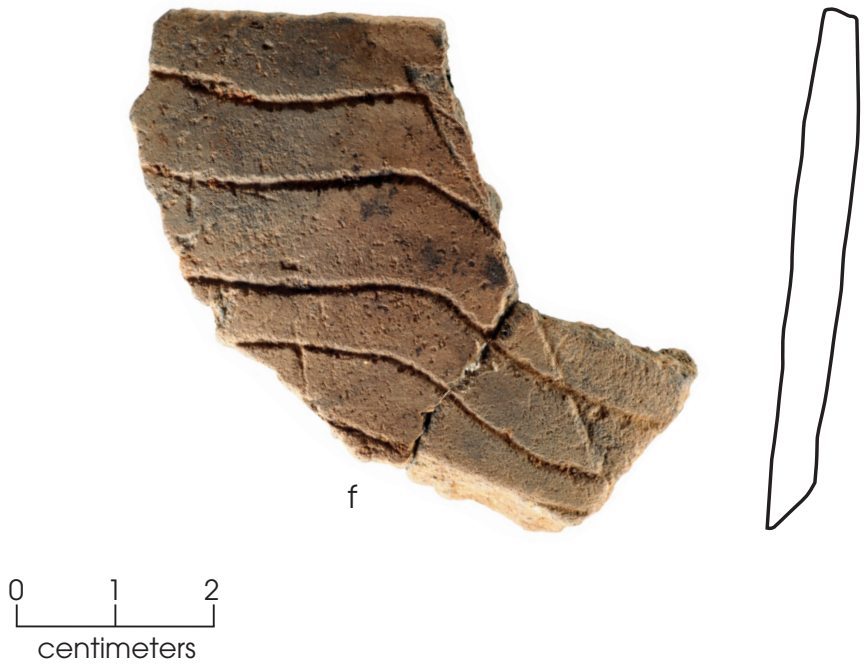

Figure 4.12. Engraved bowl and bottle sherds from Subarea 1 at the George Richey site. (a-c) Bowl sherds with elements associated with scroll motifs; (d-e) bottle sherds with curvilinear elements; (f) rim fragment of possible effigy bowl.

Feature 205/16 produced another large rim/body section composed of 16 refitted sherds, along with 5 body sherds that refit to form another wall section and 5 small sherds that do not refit but are likely part of the vessel; these weigh $505.6 \mathrm{~g}$.
Some of the rim/wall sections from both features refit, confirming this was the same vessel, which is about 45 percent complete (Figure $4.13 \mathrm{a}$ ).

The transition from the rim to the body wall on this vessel is gradual without the obvious con- 
striction of a jar neck. Because of this lack of a neck and the vessel's apparent height, it appears to be a deep bowl or conical bowl. The exterior surface is burnished, with the tool marks being horizontal on the rim and vertical on the body; the interior surface is smoothed. Neither surface has any burned encrustations. The vessel has grog temper, a dark brown exterior, and a light brown interior surface and core. It has a slightly everted rim with a flat lip. Rim thickness is $0.81 \mathrm{~cm}$, and body thickness is $0.79 \mathrm{~cm}$. The estimated orifice diameter is $32.0 \mathrm{~cm}$; the vessel height is unknown. The vessel is untyped, but vessels with a similar form are associated with Canton Incised, Avery Engraved, and possibly Maydelle Incised (Suhm and Jelks 1962:Plates 2, 12, and 52b). Its size, the flat rim lip, and the lack of decoration but with obvious tool marks on the exterior suggest greater similarity to Canton Incised.

The second vessel, only about 5 percent complete, is represented by a single rim sherd and two refitted sherds (weighing $126.8 \mathrm{~g}$ ) forming part of the base and body wall, all from Feature 205/16 (Figure 4.13b). This vessel also appears to be a deep bowl. The exterior surface is burnished, and the interior surface is smoothed. Neither surface has any burned encrustations. The vessel has grog temper and gray exterior and interior surfaces and core. It has a slightly everted rim with a round lip and a flat base. Rim thickness is $0.73 \mathrm{~cm}$, body thickness is $0.71 \mathrm{~cm}$, and base thickness is $1.04 \mathrm{~cm}$. The estimated orifice diameter is $25.0 \mathrm{~cm}$; the vessel height is unknown. Decoration consists of horizontal incised lines on the rim. It is untyped. Its decoration and form are suggestive of Kiam Incised, although the plain body is not (Suhm and Jelks 1962:89).

\section{Nonvessel Artifacts}

The two smoking pipe fragments consist of a possible bowl fragment and a stem fragment. Both are suggestive of Red River-style pipes, which have long thin stems and short flaring bowls with thin walls (Hoffman 1967). The pipe stem fragment is $35.0 \mathrm{~mm}$ long with an outer diameter of $10.2 \mathrm{~mm}$ and a draw hole diameter of $4.3 \mathrm{~mm}$. It is not decorated but has a smoothed exterior surface; it is tempered with grog-bone. This stem broke close to the bowl as a bit of bowl still adheres to it. The second pipe fragment, recovered from Feature 9, appears to be a small fragment of a bowl rim that was decorated with a field of fine stick punctations. It is bone tempered, and the wall of the bowl is $3.85 \mathrm{~mm}$ thick. The bowl appears to be flaring and tapered to the lip, but not enough remains to determine bowl diameter or height. Still, based on the thinness of the bowl wall, it is more likely from a Red River-style pipe than an elbow pipe.

\section{CHIPPED STONE ARTIFACTS}

The chipped stone assemblage consists of 26 arrow points, 16 dart points, 43 bifaces, 30 flake tools, 3 core tools, 56 cores, and 1,764 pieces of debitage. Appendix E lists the metric attributes of all the tools. The assemblage reflects periodic use from the Middle Archaic period to the Late Caddo period, a distinct reliance on local lithic materials, and knapping activities consisting mostly of late reduction, tool production, and tool maintenance.

\section{Projectile Points}

Seventy-one percent of the 42 projectile points are of materials that could have been obtained locally, mostly chert and quartzite. Silicified wood is uncommon, probably because of its coarse-grained nature. None of the arrow points are of silicified wood, and nonlocal materials are far more common in the arrow points (35 percent are of nonlocal black chert, gray chert, and Edwards chert) than in the dart points (19 percent are of nonlocal gray chert and Edwards chert). Chert dominates both arrow points and dart points, making up 61 percent of the former and 69 percent of the latter.

A little over half ( 55 percent) of the projectile points are complete. Of the 19 that are fragments, 47 percent are proximal, 26 percent are medial, 21 percent are distal, and 5 percent are lateral. The fairly high frequencies of complete points and proximal point fragments support retooling activities at this site. Most points were reworked, also indicating retooling and tool maintenance. There are several preforms and several points with only slightly modified edges, more so in arrow points than dart points, which supports some tool manufacturing.

\section{Arrow Points}

The 26 arrow points consist of 2 Alba, 3 Bassett, 4 Bonham, 1 Colbert, 3 Friley, 1 Maud, 1 


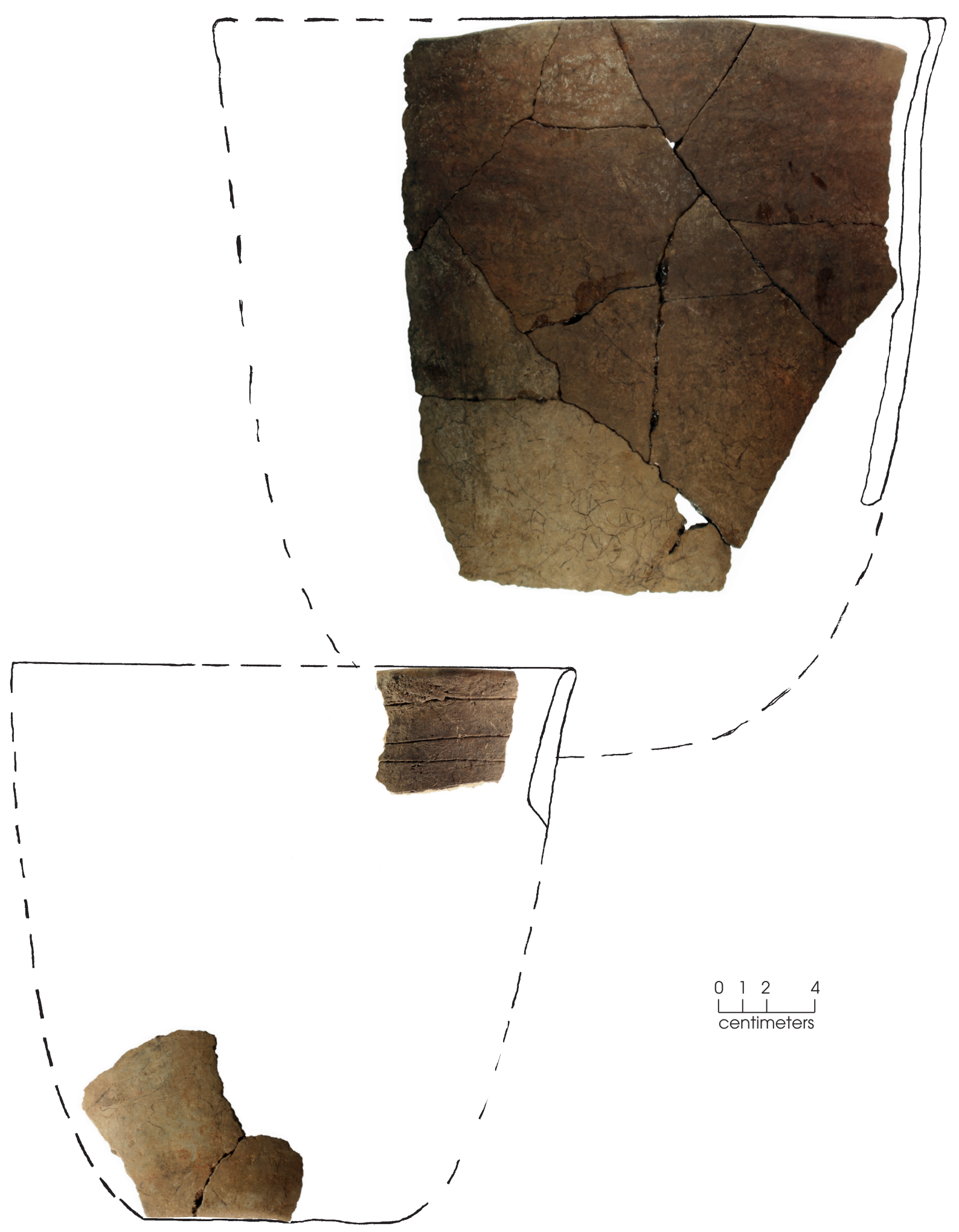

Figure 4.13. Vessel sections from Subarea 1 at the George Richey site. (a) Undecorated large deep bowl from Features 9 and 205/16; (b) incised large deep bowl from Feature 205/16. 
Talco, and 1 possible Talco. There are also 3 preforms and 7 untyped fragments. Collectively, they suggest use throughout the Caddo period and perhaps in the late part of the Woodland period.

Alba points are characterized by recurved blade edges (sometimes with serration), a straight base, and a straight stem (Turner and Hester 1999:200). One is of nonlocal black chert (Figure 4.14a). It has a triangular blade with heavily serrated edges, the stem is slightly expanding, and the base edge and barbs are broken and missing. The second Alba is made of tan Edwards chert and is mostly complete (Figure 4.14b). It has a triangular blade with heavily serrated edges and a slightly expanding stem. The base is straight but is missing one corner. Small portions of the tip are also missing. Pot lid fractures was burned.

Bassett points have a short broad blade, long barbs, a contracting stem, and a pointed base (Turner and Hester 1999:201). The three from the George Richey site include one made on a flake with minimal retouch to create a slight bevel and serrated blade and to shape the stem and base (Figure 4.14c). The point has a pointed base, a contracting stem, and a wide triangular blade and is made of nonlocal banded black chert. The other two Bassetts are made of nonlocal mottled gray and brown chert. One has a convex base, a contracting stem, and an irregular blade shape due to breakage and reworking (Figure 4.14d). The other is very thick, is missing its barbs, and has a convex base, contracting stem, and an irregular reworked triangular blade (Figure 4.14e).

Bonham points have narrow triangular blades, small barbs, straight stems, and straight bases (Turner and Hester 1999:202; Suhm et al. 1954:496). One finely flaked and relatively large specimen is of tan Edwards chert; it is complete with a straight base, straight stem, square shoulders, and slightly reworked concave blade (Figure 4.14f). Another is made of dark yellowish brown local chert. It has a straight base, straight stem, and triangular blade with one irregular edge from reworking (Figure $4.14 \mathrm{~g}$ ). The third Bonham is complete and has a straight base, straight stem, and triangular blade; it is made of yellowish brown local chert (Figure $4.14 \mathrm{~h}$ ). The fourth one has a straight to slightly convex base, straight stem, and triangular blade (Figure 4.14i). It is complete and made of yellowish brown Edwards chert.
Colbert points typically have recurved to convex blade edges with serration, wide shoulders and barbs, expanding stems, and straight bases. The single example is complete and is made of locally available Ogallala quartzite that appears to have been heat treated or burned (Figure 4.14j). It has a convex base, expanding stem, and slightly irregular triangular blade that has been reworked. Due to the reworking, the blade is not as wide and the barbs not as pronounced as in the typical Colbert point.

Friley points are characterized by a straight base, expanding stem, and well-defined shoulders that recurve toward the distal end of the point (Turner and Hester 1999: 214). One is made of heat-treated yellowish brown quartzite and is complete with a straight base, an expanding stem, and a triangular blade with straight to concave edges and heavy serration (Figure $4.14 \mathrm{k})$. Another Friley has recurved blade edges, a straight base, and an expanding stem; it is missing parts of the base, tip, and barbs (Figure 4.141). This Friley is also made of yellowish brown quartzite. The third Friley is complete with the tip recurved from extensive retouch; the blade is very long and narrow and triangular and has heavy serration (Figure $4.14 \mathrm{~m}$ ). It is made of Ogallala chert. The contracting stem and convex base are unusual and likely the result of reworking following a break.

Maud points are slender stemless points with concave to V-shaped bases (Turner and Hester 1999:223). The single specimen has a concave base and a triangular blade with retouch and moderate serration (Figure 4.14n). It is made of heat-treated (discolored pink) local chert.

Talco points are defined by serrated and recurved blade edges and a concave base (Turner and Hester 1999:233). The single Talco is nearly complete, missing only the distal tip and part of the base; made of Ogallala quartzite, it has a concave base, and the remaining portion of the blade is triangular with heavy serration (Figure 4.140). Another specimen may be an extensively reworked Talco point (Figure 4.14p). It is made of Ogallala quartzite. It is a proximo-medial fragment with a concave base and triangular, although incomplete, blade that was extensively reworked. The base is also fractured. If it is a Talco, it has been retouched extensively, creating the recurved blade edge and causing the stem to recurve toward the distal tip of the point. 


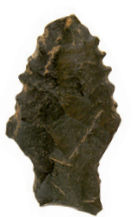

a

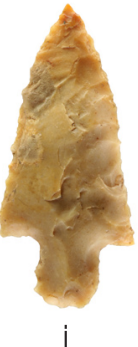

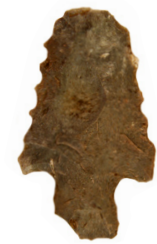

$\mathrm{b}$

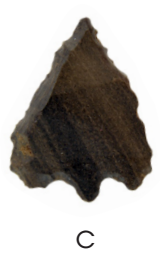

C

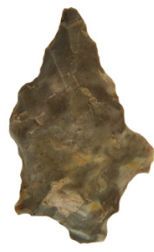

d
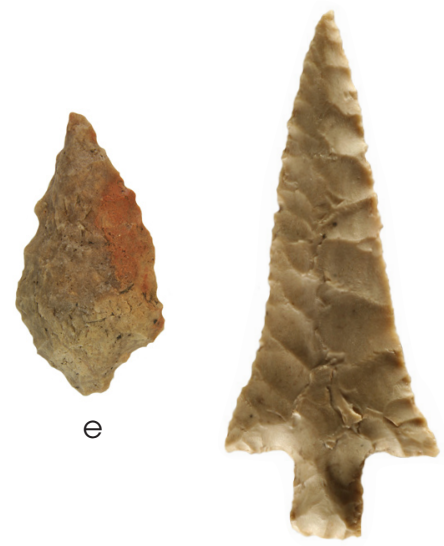

$f$

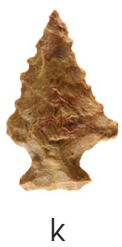

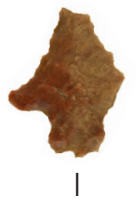

I

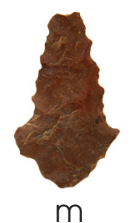

$\mathrm{m}$

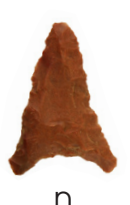

$\mathrm{n}$

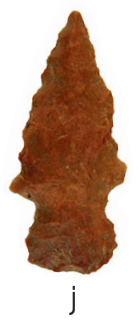

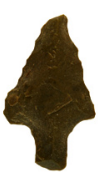

g

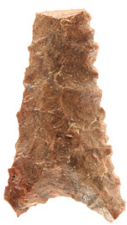

$\mathrm{O}$

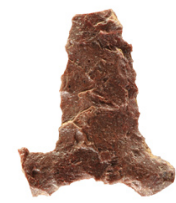

$\mathrm{P}$

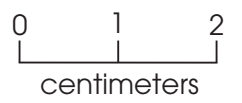

Figure 4.14. Arrow points recovered from Subarea 1 at the George Richey site. (a-b) Alba; (c-e) Bassett; (f-i) Bonham; (j) Colbert; (k-m) Friley; (n) Maud; (o) Talco; (p) possible Talco.

Of the three arrow preforms, one is complete, made on a quartzite flake blank with an unfinished base, and has an expanding stem and an irregular blade. The second is a proximal fragment made of local brown chert; it has an expanding stem with a straight base. The third is a medio-distal fragment made of gray chert and is mottled with patination.

The seven untypeable arrow fragments consist of the following: four medial fragments of olive brown local chert, reddish brown local chert, medium gray chert, and local Ogallala quartzite; a proximo-medial fragment with a convex base and expanding stem made on a retouched flake of local olive chert with dark speckles, which may be an unfinished point; a distal triangular blade fragment of local Ogallala quartzite; and a proximal fragment of yellowish brown local quartzite with a straight base and expanding stem.

\section{Dart Points}

The 16 dart points include specimens identified as the following types: Edgewood, Ellis, Gary and possible Gary, Kent and possible Kent, and Wells. There also are one untyped point, three untypeable fragments, a possible Gary preform, and an untyped preform.

Edgewood dart points tend to be short with short barbs, an expanding stem, and a concave to straight base (Turner and Hester 1999:111). The single Edgewood point is of yellowish brown local chert; it is complete with a convex base, expanding stem, and triangular blade (Figure 4.15a). Similar to Edgewood points, Ellis are 
short and thick with shallow corner notching, squared barbs, expanding stems, and straight bases (Turner and Hester 1999:113). The single Ellis is made of light gray nonlocal chert; it is a proximal fragment with a slightly convex base, expanding stem, and indeterminate blade shape (Figure 4.15b).

The Gary type incorporates great variation in morphology. The first Gary is made of local quartzite and is mostly complete but has hinge fractures on the blade faces and is missing a small part of the tip and base (Figure 4.15c). It has a contracting stem and triangular blade that has been reworked. The second Gary is a proximal fragment of reddish brown local chert; it has a convex base and contracting stem, and the haft looks pointed (Figure 4.15d). The possible Gary is unifacial, made of dark reddish brown local chert, and very small; it is complete with a convex base, contracting stem, and triangular but somewhat irregular blade (Figure 4.15e). A Gary preform is made of local dark yellowish brown chert (Figure 4.15f). It is missing a portion of the stem but appears to have a convex base, a contracting stem, and an irregularly shaped blade. It is patinated and, although unfinished, shows some reworking and probably was used as a knife.

Kents are poorly made, asymmetrical points with squared to indistinct shoulders, a straight stem (although it may be contracting or slightly expanding as well), and a flat to concave base. Both identified Kent points are proximal fragments. One is made of local light yellowish brown chert with a straight base and a slightly expanding stem (Figure $4.15 \mathrm{~g}$ ). The other is made of local quartzite and has a straight base, a slightly expanding stem, and an irregular blade that is missing the distal tip but does show some reworking (Figure $4.15 \mathrm{~h}$ ). One possible Kent point is made of tan to olive gray Edwards chert; it is complete with a straight stem, an irregular reworked blade and an irregular reworked base (Figure 4.15i). The blade was extensively and asymmetrically reworked, and the asymmetrical retouch suggests it was used as a knife. The other possible Kent is made of quartzite; it is complete and has an irregularly shaped base, expanding stem, and triangular blade with a tip that has been fractured and reworked symmetrically (Figure 4.15j).

Wells are characterized by long contracting to straight stems with edges that are often ground, blades that are often serrated, and a base that varies from convex to straight (Suhm and Jelks 1962:257-258; Turner and Hester 1999:193). This type has square to round shoulders depending on the amount of reworking. A single possible Wells point is made of banded nonlocal dark gray chert (Figure 4.15k). It has an extensively reworked blade with the tip reworked into a possible gouge. It has a concave base and very long contracting stem.

An untyped complete but crude, narrow dart point made of silicified wood has a convex base, irregular stem, and indeterminate blade shape (Figure 4.15l). The three untyped dart point fragments consist of distal, lateral, and medial sections. The distal fragment is made of brown and reddish brown local chert. A lateral fragment of a triangular blade is made of light olive brown local chert. The medial fragment is made of Ogallala quartzite and has evidence of burning including pot lids and discoloration. A triangular unstemmed dart point preform is made of banded gray chert (Figure $4.15 \mathrm{~m}$ ). It has a convex base and an oval blade.

\section{Bifaces}

Most of the bifaces are finished or nearly finished tools with indications of use and consist of an adze, a drill, 2 hafted knives, and 20 knives without hafts. The rest are early $(\mathrm{n}=3)$, middle $(n=5)$, and late $(n=5)$ reduction bifaces, as well as indeterminate specimens $(n=6)$. Most are made of local chert ( $\mathrm{n}=29,70$ percent), with silicified $\operatorname{wood}(\mathrm{n}=3)$ and quartzite $(\mathrm{n}=1)$ also represented. Nonlocal materials consist of Edwards chert $(n=1)$, gray chert $(n=7)$, white $\operatorname{chert}(n=1)$, and red and pink banded chert $(\mathrm{n}=1)$.

These artifacts reflect mostly retooling, along with discard of broken tools, some manufacture, and perhaps loss of some stilluseful knives. Ten of the bifaces are complete, 3 are mostly complete, and 30 are fragments (9 proximal/proximo-medial, $12 \mathrm{distal} /$ mediodistal, 6 medial, and 3 indeterminate). The proximal and distal fragments are associated with both manufacture and use. The lateral fragments are more commonly associated with breakage during manufacture. Based on the kinds of fractures represented, a third of the fragments are the result of manufacture failures and include lateral impacts, overshot, and step fractures. The rest of the fragments are from use or unknown causes. 


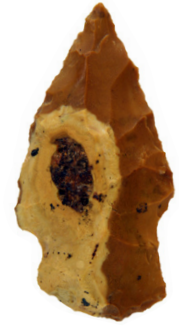

a

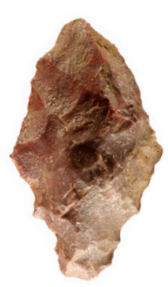

e
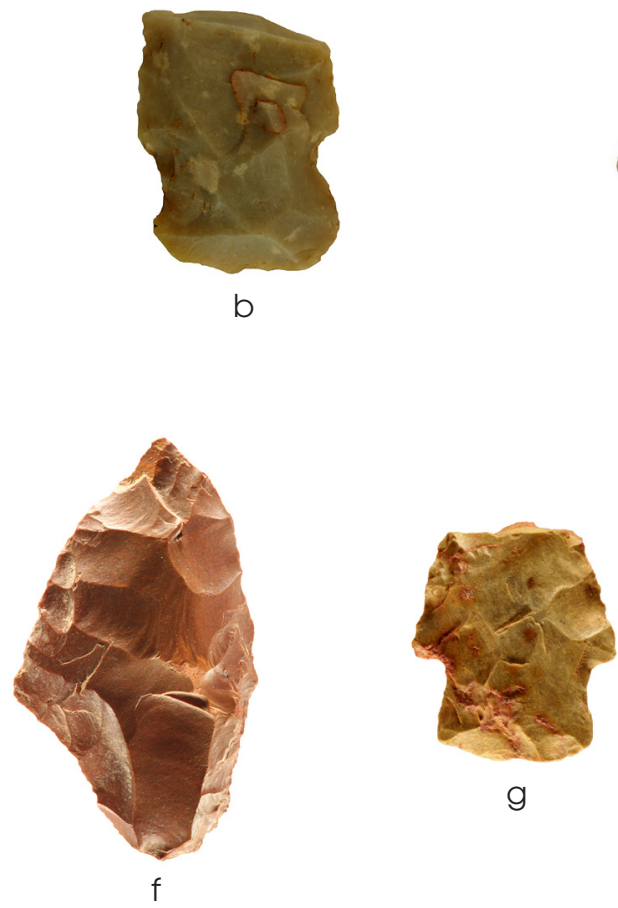

9

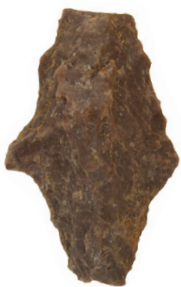

C
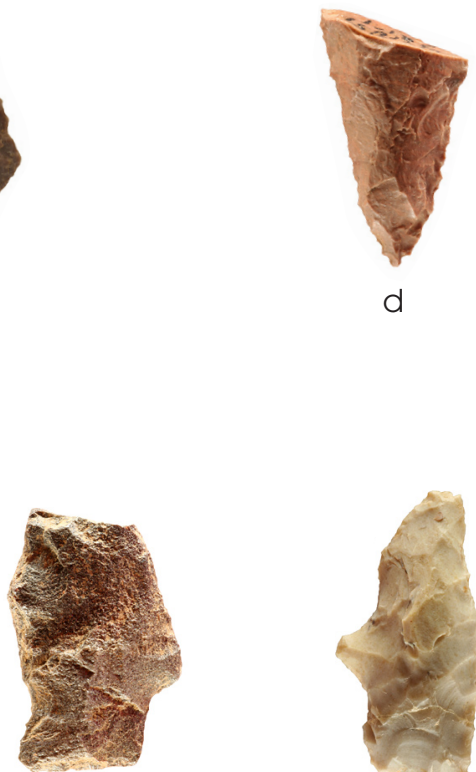

$\mathrm{h}$

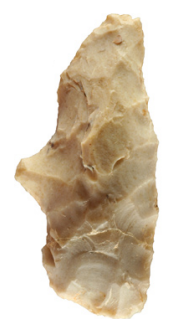

i
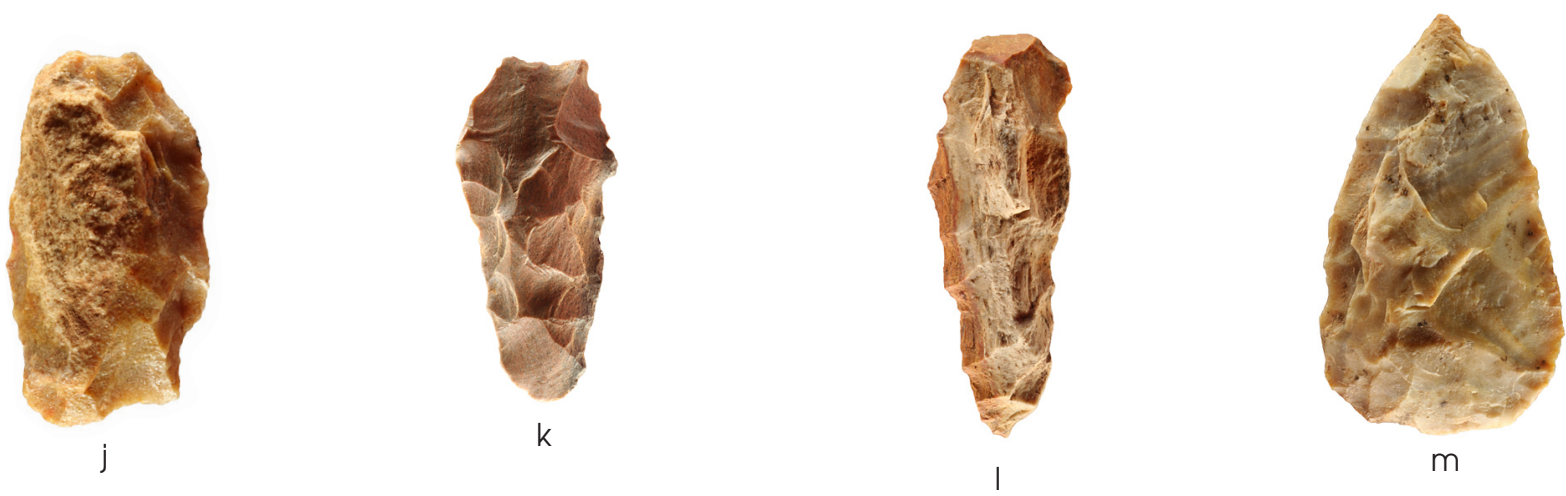

$\mathrm{m}$

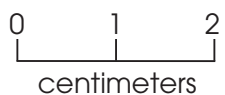

Figure 4.15. Dart points and point fragments from Subarea 1 at the George Richey site. (a) Edgewood; (b) Ellis; (c-e) Gary and possible Gary; (f) Gary preform; (g, h) Kent; (i-j) possible Kent; (k) possible Wells; (l) untyped complete point; $(\mathrm{m})$ untyped dart point preform.

The single adze fragment is made of banded and mottled gray and brown nonlocal chert, possibly from the Ouachita Mountains (Figure 4.16a). It is very well made, with evenly beveled edges on the sides and the distal end and an impact fracture on the hafted end. The bifacial drill has fractures on both the distal and prox- imal ends and is irregularly shaped (Figure $4.16 \mathrm{~b})$. The bit end looks unfinished, has rough alternate edge beveling, and is fairly thin. It is made of Ogallala quartzite.

Both hafted knives are asymmetrical (Figure 4.16c-d). One is a distal fragment made of coarse-grained medium to dark gray 
chert that has brown mottles. A remnant of the proximal end indicates it was hafted. The blade edge has been reworked and used. The fracture appears to be due to manufacture. The other hafted knife is complete and made of gray chert with red bands. Its asymmetrical blade has been reworked and used.

The 20 bifacial knives without hafts consist of 6 complete specimens and 14 fragments and include some that are thick and irregular as well as finely flaked and symmetrical specimens. All have some use wear or retouch indicating they were used for cutting. The complete knives consist of 4 made of local red, reddish brown, or tan chert and 2 of silicified wood. One of the complete knives is very small with several hinge fractures on one face (Figure 4.16e). The 14 knife fragments consist of 6 distal specimens, 1 lateral-distal piece, 4 proximal fragments, 2 lateral specimens, and 1 other piece. Most of the distal fragments are small, with 5 of local red to reddish brown chert and 1 of nonlocal gray chert; 1 has retouch on the fractured edge, suggesting it was used after it was broken. The single lateral-distal fragment, of local yellowish brown chert with red bands, is missing one side extending from the proximal end to the distal end and may have been fractured by a radial impact. The 4 proximal fragments are all made of locally available red, reddish brown, and brownish red chert. One of the 2 lateral fragments is made of local tan chert, and the other dark reddish brown chert. Another knife fragment of nonlocal gray chert has an odd fracture that removed part of one face and probably occurred during manufacture but did not inhibit its ability to function as a knife.

Two of the three earlystage bifaces are complete; one middle-stage biface is complete, two are distal fragments, one is a lateral piece, and one is a proximal fragment; two late-stage bifaces are complete, one is a distal fragment, one is a lateral fragment, and one is a proximal fragment. A single stemmed biface fragment probably is part of a tool but is of indeterminate function; it is very small and thin and is made of local reddish brown chert. Five biface fragments could not be further categorized due to their small fragmentary nature or irregular shape.

\section{Flake and Core Tools}

Thirty tools are made on flakes and 3 on cores. Only 5 are formally prepared unifacial tools, and 28 are informal tools. The formal tools are all made of chert, 2 of nonlocal gray chert and 3 of local chert. The informal tools are predominantly (89 percent) of local material, mostly chert, but also silicified wood, quartzite, a

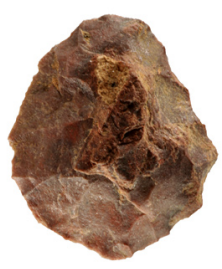

e

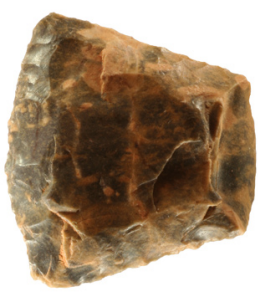

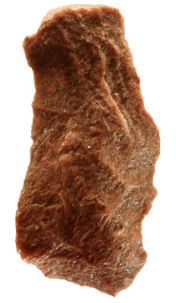

b
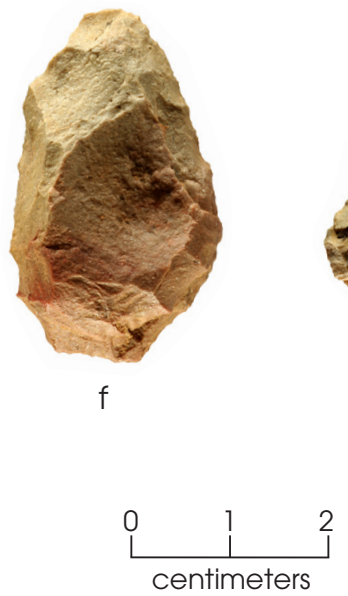

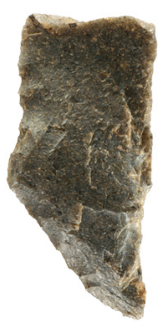

C

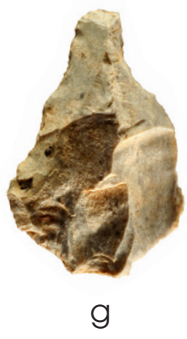

g

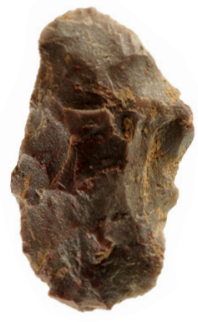

d

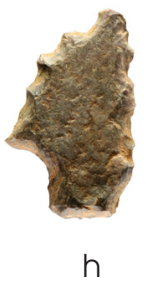

h
Figure 4.16. Bifaces and flake tools recovered from Subarea 1 at 41TT851. (a) adze; (b) bifacial drill; (c-d) hafted bifaces; (e) complete bifacial knife; (f) flake side scraper; (g) flake drill; (h) flake hafted knife. 
and hematite. Eleven percent are of nonlocal materials that include Edwards chert, gray chert, and novaculite. The greater variety in material types among informal, expedient tools probably correlates with lighter-duty tasks (based on the fragile nature of their working edges) and the expectation that these tools would not be curated as much as formal tools.

\section{Formal Tools}

The formal tools consist of a side scraper, a drill, a hafted knife, a graver, and a multifunctional tool. The side scraper, of light tan and reddish brown local chert, has retouch on three edges, but only one edge was formally prepared and used as a scraper (Figure 4.16f). The drill is made of nonlocal light gray chert with tan inclusions; the bit, part of which is missing, reflects formal preparation, whereas the rest of this tool is an unmodified flake (Figure $4.16 \mathrm{~g}$ ).

The hafted knife has heavy serration and could be a crude arrow point made on a flake blank; it is of nonlocal gray chert (Figure 4.16h). The graver is unifacially worked with a protrusion on one edge. It has steep edge retouch on one end and also may have been used as a scraper; it is made of local reddish brown chert. The multifunctional tool has formal retouch on one edge and use wear on the other edges. It is made of yellowish brown chert.

\section{Informal Tools}

The 28 informal tools consist of 25 edge-modified or utilized flakes and 3 edge-modified cores. The 8 edge-modified knives have light retouch indicative of light-duty expedient cutting. Five are local chert, and 2 are silicified wood. The eighth is a large novaculite flake fragment. It has retouch on three edges but not on the broken edge. Four edge-modified flakes have light retouch indicative of scraping; 2 are of local chert, 1 is of nonlocal gray chert, and 1 is of hematite. The single edge-modified graver has light retouch, creating a small protrusion with wear indicative of use as a graver or a perforator. This specimen is made of local chert. The three spokeshaves are all of local chert and are flakes with retouch that created or exploited a notch.

Nine tools are simple utilized flakes. They most likely were used as cutting tools. Six are local chert, one is Edwards chert, and two are silicified wood.

The core tools are all edge modified and consist of one with retouch and use indicative of a knife and two with steep retouch and wear typical of scrapers. The knife is made from local quartzite, and the scrapers are made of local chert and silicified wood.

\section{Cores}

Twenty-six cores, 10 core fragments, and 20 tested cobbles were recovered (Table 4.5). These are all of locally available materials, predominantly chert and silicified wood, with some quartzite. Most had flakes removed using hard-hammer percussion and were reduced in an unpatterned way (unlike rotated or unidirectional cores). The hard-hammer technique was used to create flakes of suitable size for tool blanks and also to shape and refine larger bifaces.

All three of the bipolar cores are chert. Bipolar percussion could have been used primarily to reduce small nodules to produce usable flake blanks that could not be reduced by hard-hammer percussion. Bipolar percussion would have been used here not because of resource scarcity but because of the small size of source materials (see Shafer 1973; Studer 1982). All 10 of the core fragments are chert. They most likely are remnants of irregular flake cores and represent rejuvenation, manufacture errors, or exhaustion of the material. The tested cobbles also are mostly chert. They have only a few flake scars (no more than three).

\section{Debitage}

The Subarea 1 excavations yielded 1,764 pieces of debitage. They are predominantly (84 percent) locally available materials, with chert best represented (56 percent), quartzite (13 percent) and silicified wood (11 percent) in modest numbers, and ferruginous sandstone (1 percent), other sandstone ( $<1$ percent), and hematite ( 2 percent) least frequent. The sandstone and hematite debitage is likely the byproduct of manufacturing and use of ground or battered stone tools such as hammerstones, celts, and manos.

Nonlocal materials are mostly a variety of gray cherts (16 percent), along with a few flakes of black chert, white chert, Edwards chert, and 
Table 4.5. Cores from Subarea 1 at the George Richey site

\begin{tabular}{|c|c|c|c|c|c|c|}
\hline Provenience & Core Type & Lithic Material & $\begin{array}{c}\text { Maximum } \\
\text { Length }(\mathrm{cm})\end{array}$ & $\begin{array}{c}\text { Maximum } \\
\text { Width }(\mathrm{cm})\end{array}$ & $\begin{array}{c}\text { Maximum } \\
\text { Thickness } \\
(\mathrm{cm})\end{array}$ & Weight (g) \\
\hline Backdirt & bipolar & chert, local & 2.61 & 2.13 & 1.38 & 11.9 \\
\hline Backdirt & bipolar & chert, local & 2.93 & 1.36 & 8.90 & 3.4 \\
\hline Feature 271 & bipolar & chert, local & 2.11 & 1.58 & 9.68 & 3.1 \\
\hline AT 37 & core & silicified wood & 7.51 & 3.50 & 1.09 & 31.8 \\
\hline Backdirt & core & chert, local & 3.18 & 2.84 & 1.57 & 13.3 \\
\hline Backdirt & core & chert, local & 4.89 & 3.18 & 1.61 & 24.5 \\
\hline Backdirt & core & chert, local & 8.43 & 5.15 & 3.06 & 137.3 \\
\hline Backdirt & core & quartzite & 4.83 & 4.54 & 2.35 & 45.7 \\
\hline Backdirt & core & silicified wood & 4.14 & 3.34 & 0.82 & 13.2 \\
\hline Backdirt & core & silicified wood & 6.95 & 5.34 & 1.80 & 80.1 \\
\hline Backdirt & core & silicified wood & 7.10 & 2.06 & 1.09 & 19.2 \\
\hline BT 1 & core & chert, local & 6.70 & 5.45 & 4.04 & 133.7 \\
\hline BT 17 & core & chert, local & 3.93 & 3.37 & 1.92 & 25.2 \\
\hline BT 32 & core & silicified wood & 23.62 & 6.83 & 2.15 & 368.8 \\
\hline BT 40 & core & chert, local & 6.56 & 5.48 & 3.68 & 163.7 \\
\hline BT 45 & core & chert, local & 4.89 & 3.08 & 1.77 & 26.8 \\
\hline Feature 156 & core & silicified wood & 7.88 & 3.51 & 1.42 & 26.8 \\
\hline SU 7 & core & chert, local & 5.04 & 3.66 & 2.51 & 26.1 \\
\hline$\overline{\text { SU } 23}$ & core & chert, local & 5.64 & 3.85 & 2.01 & 45.4 \\
\hline SU 58 & core & chert, local & 4.07 & 3.51 & 2.96 & 38.4 \\
\hline SU 67 & core & silicified wood & 6.03 & 3.57 & 1.80 & 31.1 \\
\hline SU 71 & core & chert, local & 5.15 & 4.97 & 2.76 & 47.4 \\
\hline TU 3, Lev. 3A & core & chert, local & 5.48 & 4.35 & 3.59 & 87.5 \\
\hline TU 3, Lev. 3A & core & silicified wood & 9.28 & 3.72 & 2.32 & 79.8 \\
\hline TU 40, Lev. 2 & core & chert, local & 7.49 & 4.67 & 2.66 & 90.6 \\
\hline TU 44, Lev. 3 & core & chert, local & 4.01 & 3.33 & 1.76 & 21.1 \\
\hline Backdirt & core fragment & chert, local & 3.01 & 2.20 & 1.78 & 11.2 \\
\hline Backdirt & core fragment & chert, local & 3.19 & 1.83 & 1.53 & 10.3 \\
\hline Backdirt & core fragment & chert, local & 4.03 & 2.42 & 1.56 & 12.0 \\
\hline Backdirt & core fragment & chert, local & 6.27 & 4.72 & 2.63 & 59.6 \\
\hline BT 1 & core fragment & chert, local & 4.89 & 2.61 & 2.52 & 34.8 \\
\hline BT 40 & core fragment & chert, local & 2.53 & 2.01 & 2.05 & 13.2 \\
\hline Feature 17 & core fragment & chert, local & 3.37 & 2.15 & 2.15 & 15.9 \\
\hline Feature 28 & core fragment & chert, local & 3.73 & 3.20 & 1.89 & 19.6 \\
\hline Feature 52 & core fragment & chert, local & 5.25 & 3.45 & 2.62 & 44.8 \\
\hline SU 15 & core fragment & chert, local & 5.51 & 4.58 & 2.18 & 48.0 \\
\hline Backdirt & core (tested) & chert, local & 4.08 & 3.35 & 1.57 & 20.9 \\
\hline Backdirt & core (tested) & chert, local & 5.12 & 4.06 & 3.30 & 88.2 \\
\hline Backdirt & core (tested) & chert, local & 5.45 & 5.60 & 1.52 & 49.7 \\
\hline Backdirt & core (tested) & chert, local & 5.55 & 4.60 & 3.29 & 96.6 \\
\hline Backdirt & core (tested) & chert, local & 6.01 & 4.72 & 3.12 & 78.9 \\
\hline Backdirt & core (tested) & chert, local & 9.41 & 6.02 & 5.72 & 393.9 \\
\hline Backdirt & core (tested) & chert, local & 9.21 & 7.29 & 5.59 & 427.0 \\
\hline Backdirt & core (tested) & quartzite & 5.32 & 3.41 & 1.83 & 38.8 \\
\hline Backdirt & core (tested) & quartzite & 6.20 & 5.39 & 5.12 & 215.5 \\
\hline Backdirt & core (tested) & quartzite & 8.40 & 7.33 & 5.22 & 365.3 \\
\hline Backdirt & core (tested) & silicified wood & 2.46 & 1.54 & 1.43 & 5.1 \\
\hline
\end{tabular}


Table 4.5, continued

\begin{tabular}{l|l|l|c|c|c|c}
\hline \multicolumn{1}{c|}{ Provenience } & \multicolumn{1}{|c|}{ Core Type } & \multicolumn{1}{|c|}{ Lithic Material } & $\begin{array}{c}\text { Maximum } \\
\text { Length }(\mathrm{cm})\end{array}$ & $\begin{array}{c}\text { Maximum } \\
\text { Width }(\mathrm{cm})\end{array}$ & $\begin{array}{c}\text { Maximum } \\
\text { Thickness } \\
(\mathrm{cm})\end{array}$ & Weight (g) \\
\hline BT 17 & core (tested) & quartzite & 13.96 & 11.33 & 9.14 & 1821.0 \\
\hline BT 24 & core (tested) & silicified wood & 8.10 & 4.91 & 3.25 & 130.7 \\
\hline BT 24 & core (tested) & silicified wood & 9.83 & 6.11 & 2.75 & 151.8 \\
\hline Feature 347 & core (tested) & chert, local & 3.87 & 2.80 & 1.06 & 10.4 \\
\hline SU 30 & core (tested) & chert, local & 4.36 & 2.51 & 1.84 & 20.1 \\
\hline TU 7, Lev. 2 & core (tested) & chert, local & 5.63 & 4.15 & 2.59 & 55.6 \\
\hline TU 7, Lev. 3 & core (tested) & chert, local & 2.70 & 1.90 & 1.50 & 7.6 \\
\hline TU 18, Lev. 4 & core (tested) & ferruginous sandstone & 3.82 & 3.34 & 2.16 & 27.0 \\
\hline TU 22, Lev. 5 & core (tested) & quartzite & 5.11 & 4.14 & 3.75 & 93.5 \\
\hline
\end{tabular}

chalcedony (less than 1 percent each). Given that the cores are entirely of local materials, the nonlocal debitage most likely came from finished artifacts or tool blanks (bifaces or flakes) that were further manufactured into tools, resulting in retouch and other debitage.

The debitage is mostly small: 29 percent is smaller than $7.0 \mathrm{~mm}, 26$ percent is $7.0-12.5 \mathrm{~mm}, 22$ percent is $12.5-19.0 \mathrm{~mm}$, 11 percent is $19.0-25.0 \mathrm{~mm}, 9$ percent is 25.0 $38.0 \mathrm{~mm}$, and 2 percent is larger than $38.0 \mathrm{~mm}$. This pattern, which is the same for both local and nonlocal materials, is consistent with the conclusion that most reduction on-site focused on small source materials, i.e., local pebbles and cobbles and tool blanks or finished tools of nonlocal materials.

\section{GROUND, PECKED, AND BATTERED STONE ARTIFACTS}

Thirty-six ground, pecked, and battered stones were collected from Subarea 1, consisting of 1 axe, 2 hammerstones, 3 manos/ hammerstones, 4 pitted hammerstones, 6 anvils, 1 grinding slab/anvil, 2 grinding slabs, 4 abraders, 2 grooved stones, 3 pigment stones, and 8 indeterminate (see Appendix E for metric and provenience information). Approximately 40 percent of the assemblage consists of pitted stones (both anvils and handheld hammers). If items with interchangeable, equivocal, or indeterminate functions are excluded, then base-position artifacts (anvils, grinding slabs, etc.) account for 28 percent of the assemblage, and handheld items make up 39 percent. Only 11 percent exhibit clear evidence of intentional shaping, and 53 percent show no indication of such treatment (a confident determination was not possible for the remainder). Some kind of thermal alteration is evident in 42 percent, and heat-derived modification is heavy or severe on two-thirds of that group.

This collection shows little lithic material variability. Only five basic material types are represented, and two of these account for more than 80 percent of the inventory. The majority $(n=20 ; 56$ percent) are of quartzite. Other materials are ferruginous sandstone $(\mathrm{n}=10$; 28 percent), hematite and ocher $(\mathrm{n}=2$ each; 5 percent), and silicified wood and ferruginous sandstone-hematite conglomerate $(\mathrm{n}=1$ each; 3 percent).

The single pecked and ground ferruginous sandstone axe head is elliptical in cross section and has a well-smoothed and polished bit end, a semirounded poll, a full groove, and an additional groove across the poll that gives the proximal end a bi-lobed appearance (Figure 4.17). The bit end is the only area where smoothing and subsequent polishing completely obliterated the original peck marks. The remainder of the axe is variably smoothed, and parts of the groove and poll show minor polish. Blade width decreases from the primary groove to the bit's edge, which has minor impact damage. Parts of the edge are crushed, and small flake scars are visible on both sides of the bit. Morphologically, this axe is analogous to the Aberdeen-style axes noted by Turner (2006:6, Figures 7 and 8 ). 
Nine cobbles were used as hammerstones, with three also having been used as manos and four having pits indicating use in conjunction with anvils. Eight are quartzite, and one is ferruginous sandstone. The two artifacts classed simply as hammerstones consist of an ovoid cobble and a vaguely ovoid cobble fragment with battering damage on the ends and along thin edges. The larger of these has severe thermal discoloration. Two of the manos/hammerstones are oblong rocks with varying degrees of surface smoothing and end-localized battering damage. Peck marks are visible across the surface of the thermally fractured ferruginous sandstone specimen. The morphology of one mano/hammerstone fragment suggests that the complete specimen was roughly pyramidal or subconical in shape. This artifact has one slightly convex, smoothed facet remnant; the other facet remnant is slightly concave with percussion marks

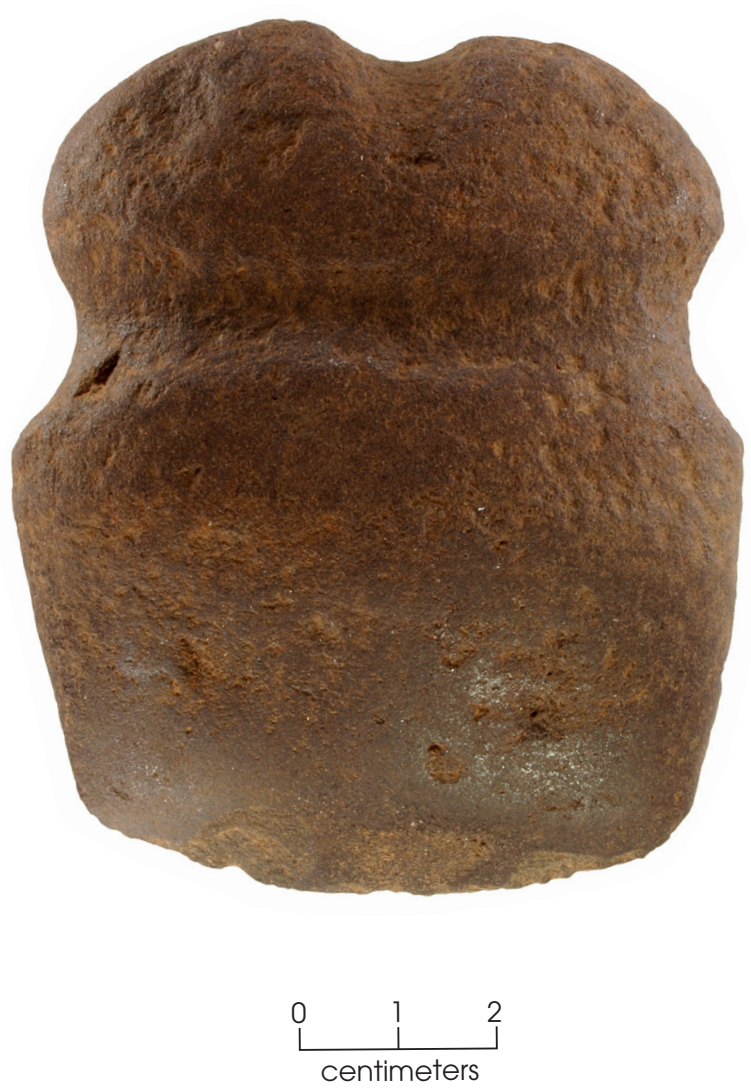

Figure 4.17. Full-grooved ferruginous sandstone axe from Subarea 1 at the George Richey site. in the depression and battering wear along the edges of the concavity. Percussion marks are also present on the artifact's narrow margins. Characteristics of the concave facet indicate that this specimen also was used in conjunction with an anvil for crushing/pulverizing/splitting activities. The size of this artifact is indicative of the finger-manipulated mullers that Ellis (2009:Table 13-1) classifies as a distinct tool type in the ground stone assemblage from the Ear Spool site.

The pitted hammerstones range from ovate cobbles with rounded edges to angular pieces of rock. Three have one flat to slightly concave face with focused percussion/peck marks on the facet and battering damage on the edges of that face. Only one of these three has a shallow pit. Incipient pitting is visible in two parts of a roughly convex face on the fourth artifact. The location and extent of battering wear vary considerably among these artifacts. On one, battering damage is limited to the edges of the crushing/pulverizing facet. The other artifacts show some combination of battered ends, margins, and convex facets.

Four of the six anvils and fragments were fashioned from tabular or near-tabular blanks of quartzite, and one is a piece of ferruginous sandstone-hematite conglomerate. The sixth is a thick subtriangular quartzite cobble with irregular facets. Two complete artifacts and one fragment have pits on a single facet. The other three (one complete and two fragmentary) have pits on two facets. Two anvil fragments have only one pit per facet remnant. The others have two or more pits or incipient pits per work surface. Surface smoothing on one complete anvil suggests it also was used for grinding (Figure 4.18a). Battering along the margins and ends of this artifact suggest limited shaping, and impact/ abrasion-derived smoothing on one end may indicate use as a pestle. The largest artifact in the anvil category is a thick tabular fragment found along the wall of a large pit (Feature 189A) (Figure $4.18 \mathrm{~b})$. It has two well-smoothed facets with multiple percussion-derived pits in each. The degree of surface smoothing on both facets and battering damage along the fractured edges strongly suggest this is a recycled grinding slab/anvil.

The single artifact classified as a grinding slab/anvil is a large ovate hematite cobble fragment with grinding/abrasion-derived smoothing and occasional peck marks on one face and pit- 
ting on the opposite face. While there may be as many as three pits, only one is clearly anthropogenic. The others are likely attributable to lithic material degradation through weathering and exfoliation (Turner 2006:16, 18-19). Battering damage on the rounded cobble margins suggests that it also was used as a hammer or maul.

One of two grinding slabs is a small, tabular, roughly rectilinear piece of ferruginous sandstone with one moderately smoothed face. Smoothing is variable across the face, but rounded crystals and occasional short discontinuous striations are visible under magnification. This item is probably a fragment of a larger artifact. The other grinding slab is a large thin tabular fragment of vesicular ferruginous sandstone, which contrasts with the much thicker tabular cobbles more commonly used as grinding platforms (Figure 4.19). It is either an end or corner fragment of an intentionally shaped artifact. The working face is slightly concave and well smoothed. Abrasion wear on the opposite face may or may not be derived from use of that side of the slab. The rough bottom side and its outside margin remnants exhibit differential thermal discoloration.

Recovered abraders consist of three ferruginous sandstone specimens and a hematite artifact. Each is a thin tabular stone (the thickest is approximately $10.3 \mathrm{~mm}$ ) with one worked surface and wear patterns consistent with reciprocal motion. The largest may be complete, but the other three are fragments. A series of barely perceptible, shallow, roughly parallel grooves trend across the length of the largest one (Figure 4.20a). Under magnification, the work surface exhibits multiple, very fine, overlapping striations that have V- to narrow U-shaped cross sections. Abrasion wear on the other artifacts is visible but much subtler. The hematite abrader might have been used in pigment production (Figure $4.20 \mathrm{~b}$ ). This artifact has three short, narrow, parallel incisions on its rough side; these slightly curved cuts extend off the fragment edge.

A small tabular pebble and an irregular medial fragment of a larger artifact are grooved. Both are ferruginous sandstone. The smaller item has a 14.0 -mm-long groove on one face that is widest and deepest at the edge (5.0 and $3.0 \mathrm{~mm}$, respectively). The groove's cross section varies from V- to U-shaped over its length. The other artifact was fashioned on a narrow piece of stone with a roughly V-shaped cross section. A wide groove with gently sloping sides and a broad gently curved base follow the central axis of the fragment (Figure 4.20c). The groove surface is relatively rough, but one side is more pronounced than the other. The differential wear suggests that abrasion was concentrated on one side of the channel. The top of the groove is $27.1-33.7 \mathrm{~mm}$ wide, and it has a maximum depth of $6.1 \mathrm{~mm}$. The surfaces on either side were pecked and ground/abraded to a uniform level.

Recovered pigment stones consist of a dense, well-cemented piece of ferruginous sandstone and two pieces of ochre. The sandstone artifact has two adjacent facets with abrasion marks that trend in different directions. Six abrasion facets are visible on a wedge-shaped piece of ochre, and three facets are visible on the other ochre fragment.

Seven artifacts are classified as indeterminate fragments. They retain clear indications of use wear but are too fragmentary to allow confident assignment to one of the other artifact categories. Five, four of quartzite and one of silicified wood, exhibit considerable thermal discoloration. Two of these are derived solely from thermal fracture, and the other three bear characteristics of both thermal and percussion-derived fracture. Percussion/peck marks are visible on the facet remnants of three of these items, and two may be pitted stone fragments. The other two show variable surface smoothing on single facet remnants. The other indeterminate fragments are an irregular piece of quartzite and a tabular quartzite cobble fragment. Characteristics of the facet remnant on the irregular fragment suggest it is part of a pitted stone. The tabular fragment is split longitudinally in two planes. The slightly concave facet remnant and part of the curved margin are smooth from grinding wear. The ends are relatively rough, and one is clearly battered. The morphology of the smoothed surface suggests this is part of a small grinding slab or anvil.

An eighth specimen is included in the indeterminate category because it could be part of a ground stone tool, but is not clearly so. It is a medial cobble fragment separated from a larger piece by intentional percussion. Percussion marks are visible on both facet remnants. One relatively flat facet is smooth, 
Chapter 4: Excavations at the George Richey Site, $41 T T 851$
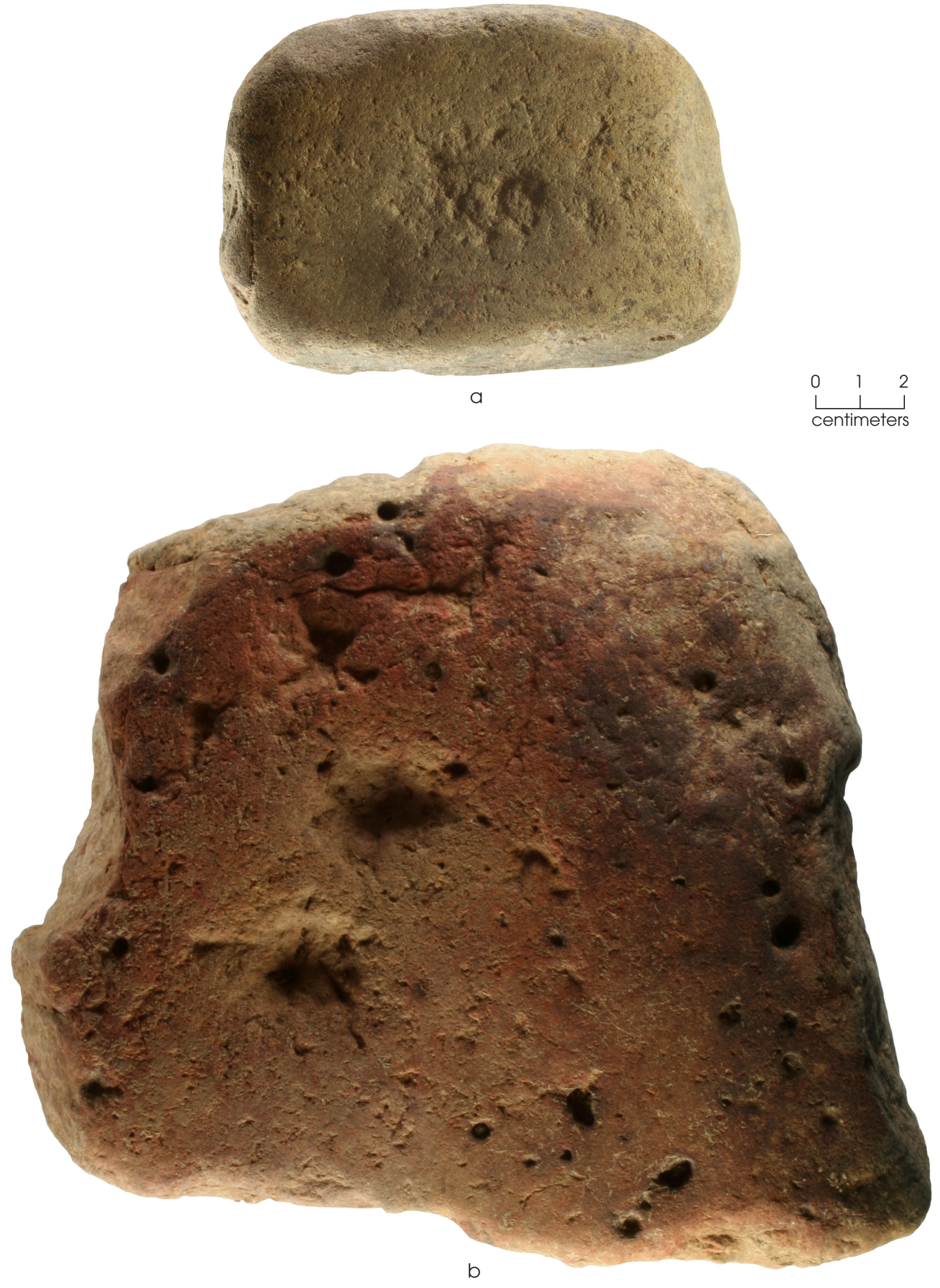

Figure 4.18. Quartzite anvils from Subarea 1 at the George Richey site. (a) Complete anvil with surface smoothing; (b) anvil fragment with multiple pits. 


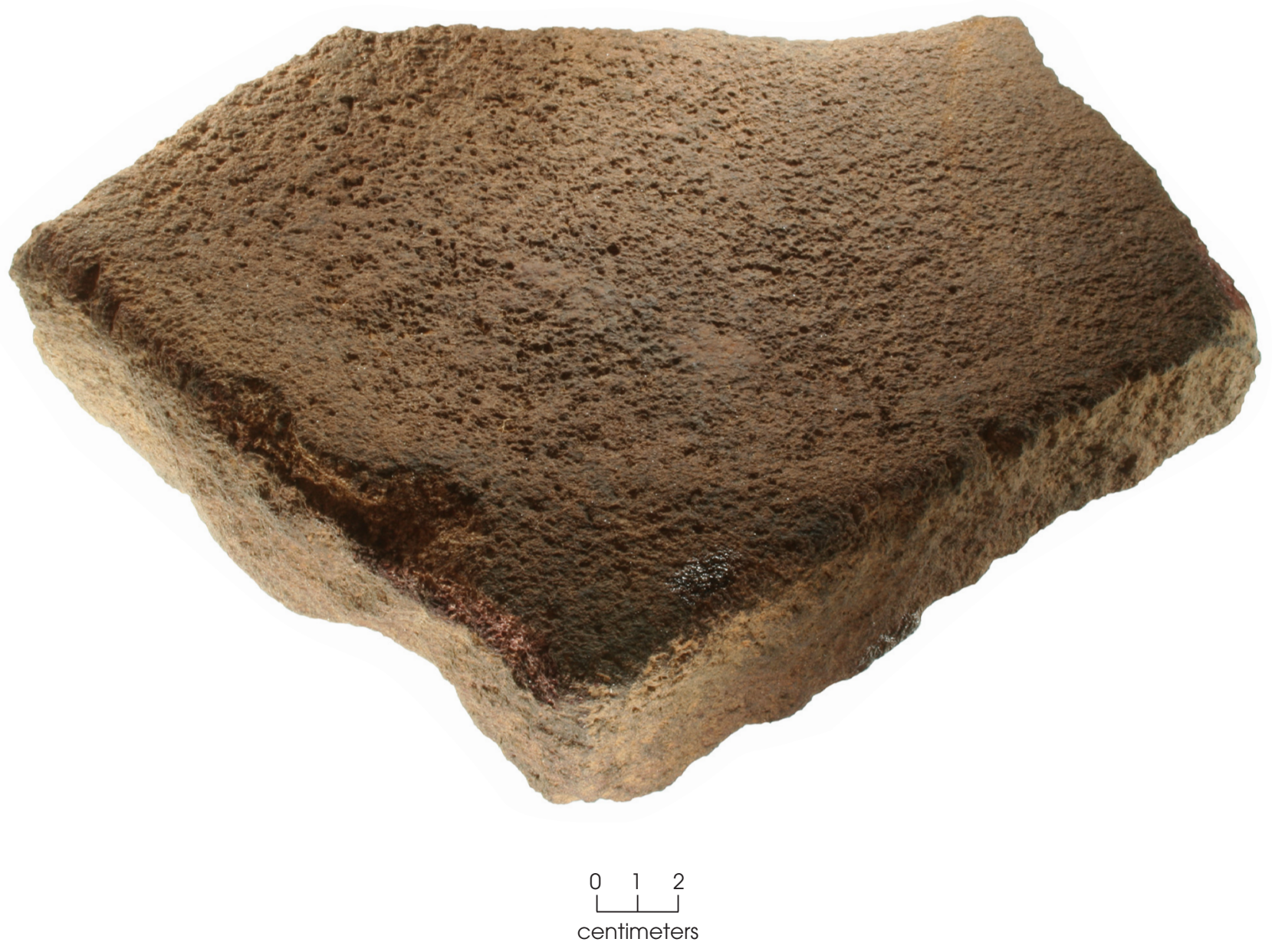

Figure 4.19. Vesicular ferruginous sandstone grinding slab fragment from Subarea 1 at the George Richey site.

but it is not clear if this is from use or a natural cortical surface. Some very fine multidirectional striations are discernible on this surface under magnification, but individual grains do not exhibit smoothing.

\section{BONE TOOLS}

Three bone tools were recovered. The distal end of a calcined antler tip was recovered from a large pit, Feature 28 (Figure 4.21a). Use-derived smoothing is evident on the surface of the distal fracture plane, and longitudinal striations are present on the antler shaft. This suggests it was used for polishing or abrading. The distal end of an unburned rib fragment recovered from Feature 29 was bifacially modified through abrasion and pressure flaking to create a wedge-shaped bit
(Figure 4.21b). Cultural modification removed any indication of the original fracture on this element, and the lateral and medial surfaces of the shaft segment exhibit varying degrees of polish. This tool was probably used as a wedge. The third bone tool, from Feature 205/16, is a short horn core/cranial segment from a bison (Bison bison) and has surface rounding and smoothing on the convex side of the spatulate-shaped cranial end (Figure 4.21c). Based on the morphology and wear, the proximal end was used as a tool for scraping, burnishing, and/or abrading.

\section{DAUB, BURNED CLAY, AND MUD DAUBER NESTS}

A modest amount of wattle-impressed daub (107.4 g) was recovered, mostly from test 

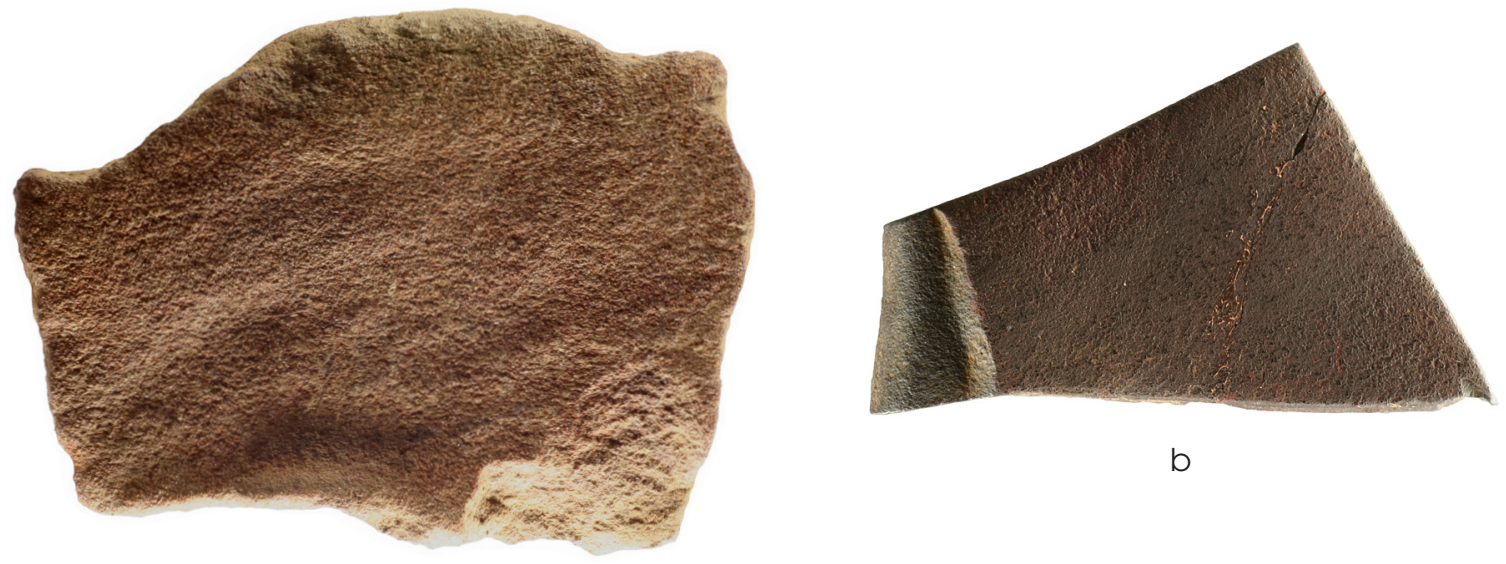

b

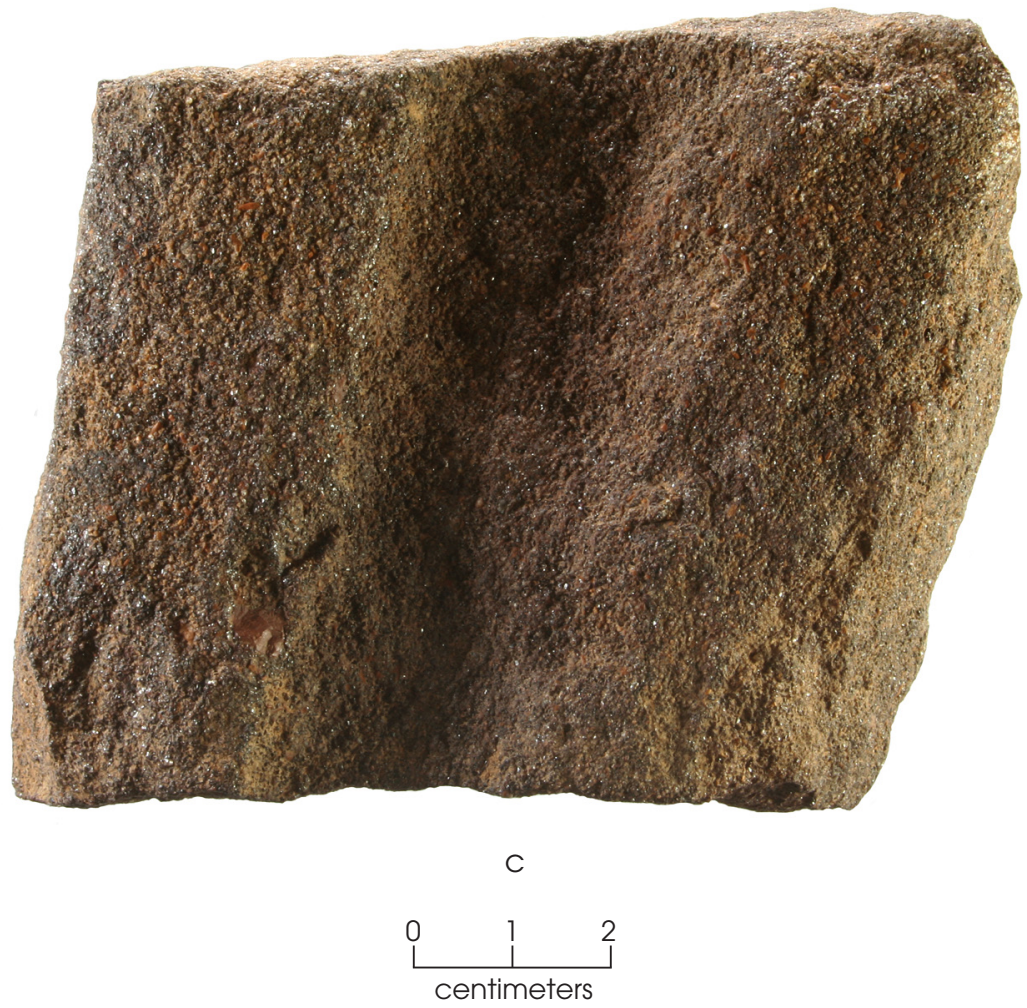

Figure 4.20. Tabular abraders and grooved stone from Subarea 1 at the George Richey site. (a) Ferruginous sandstone abrader fragment; (b) hematite abrader fragment; (c) grooved stone.

units but also from some features, and was distributed chiefly in the north-central part of Subarea 1 (Table 4.6). Most of the $922.3 \mathrm{~g}$ of burned clay also was from the north-central area, with Feature 189 yielding most of it
(546.3 g). Fragments of two burned mud dauber nests were recovered from the same area. The larger of the two $(72.8 \mathrm{~g})$ was from Test Unit 6, and the smaller piece (3.5 g) was within the fill of Feature 16. 


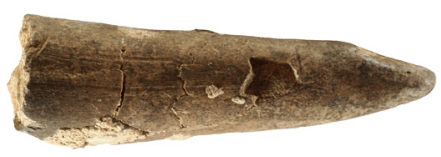

a

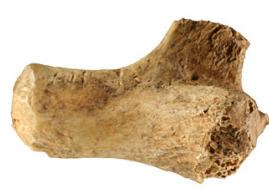

b
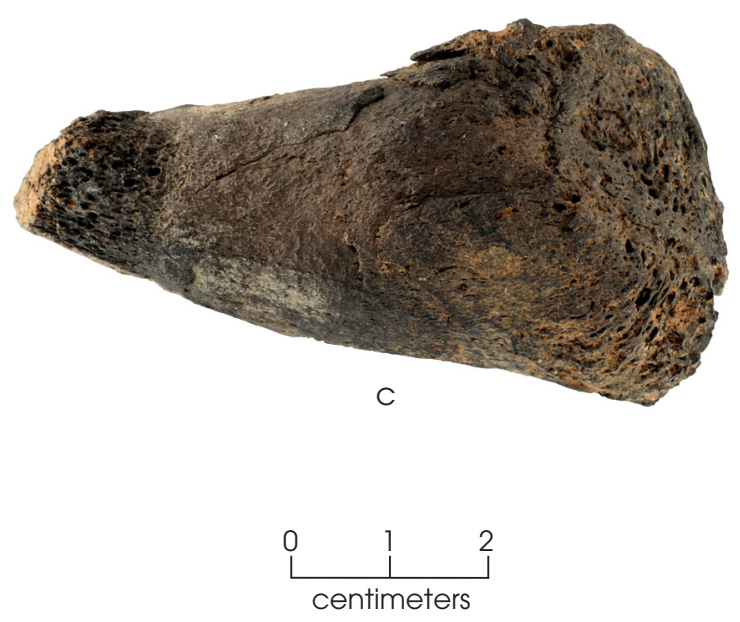

Figure 4.21. Bone tools from Subarea 1 at the George Richey site. (a) Antler abrader; (b) modified rib used as a wedge; (c) modified horn core/cranial segment.

by flotation differs somewhat, with 81 percent from pits of uncertain function, 14 percent from postholes, and only 1 percent from smudge pits. The 12 nonflotation samples consist of 10 from large pits, 1 from a small pit, and 1 from a smudge pit.

The bulk of the analyzed material is from secondary contexts and represents the generalized scatter of plant remains created by occupation of the site. The samples from smudge pits, however, more likely represent primary contexts. The remains from these pits indicate that hickory nutshells and hickory, oak (both white and red), and sweetgum wood were used to create smoky fires. Corn rachis, grass seed, and hickory and acorn nutshells also were recovered from the smudge pits. Feature 189A, a large pit, may in part reflect primary context and contained mostly hickory nutshells and oak wood; however, it is possible that these materials were mixed in from surrounding deposits.

From all of the flotation samples, 15 kinds of wood charcoal were identified (excluding general catego-

\section{MACROBOTANICAL REMAINS}

The excavations recovered macrobotanical remains from numerous contexts. About $108 \mathrm{~g}$ are analyzed and reported in Appendix F. The analyzed materials are from 104 flotation samples from 93 features and 12 samples collected by hand from 9 features. Selection of flotation samples for study was primarily guided by context and included all large pits, small pits, and smudge pits, but only a sample from the postholes. Forty samples were collected and floated but not sorted or analyzed; most of these are postholes. Features whose fill appeared to be in primary context, such as smudge pits with evidence of in situ burning based on large quantities of burned macrobotanical remains, were prime candidates for analysis. Most flotation samples are from pits of uncertain function (57 percent) and postholes (39 percent), with a small number (3 percent) from smudge pits and 1 from a noncultural feature. Volumetrically, the breakdown of the 1,092.5 liters processed ries like diffuse-porous hardwoods, hardwoods, and indeterminate), with oak (both white and red) and hickory being the dominant types. These fuels were likely collected from on or near the site, reflecting the oak-hickory forest that the area supported. Wood charcoal representing deciduous and riparian environments includes American elm, buckeye, catalpa, holly, mulberry, pecan, plum/cherry, slippery elm, sweetgum, and willow. Charred cane stem is present in small amounts and is likely representative of baskets and mats rather than fuel materials.

Corn is the only cultigen identified. Corn kernels $(0.06 \mathrm{~g})$ were identified in 4 features (Features 16, 198, 233, and 271), all in the northern part of the site, and corn cupules and glumes $(0.31 \mathrm{~g})$ were identified within 11 features (Features 9, 17, 27, 28, 154, 165, 188, 189, 198,233 , and 271) in the north part of the site and 4 features (Features 279, 282, 319, and 359) in the south part. Small numbers of maygrass, Chenopodium, little barley or wildrye, and knotweed seeds were recovered as well and indicate 
Table 4.6. Burned clay, daub, and mud dauber nests from Subarea 1 at the George Richey site (weights in grams)

\begin{tabular}{|c|c|c|c|}
\hline Provenience & $\begin{array}{c}\text { Burned } \\
\text { Clay }\end{array}$ & Daub & $\begin{array}{c}\text { Mud } \\
\text { Dauber } \\
\text { Nest }\end{array}$ \\
\hline Feature 9 & 2.6 & 2.9 & \\
\hline Feature 16 & 29.9 & & 3.5 \\
\hline Feature 17 & 10.0 & 13.3 & \\
\hline Features $17 \& 19$ & 1.2 & & \\
\hline Feature 19 & 4.4 & & \\
\hline Feature 28 & 7.8 & & \\
\hline Feature 29 & 3.6 & & \\
\hline Feature 30 & 0.2 & & \\
\hline Feature 39 & 0.7 & & \\
\hline Feature 46 & 1.0 & & \\
\hline Feature 52 & 1.9 & & \\
\hline Feature 55 & 0.8 & & \\
\hline Feature 56 & 1.5 & & \\
\hline Feature 57 & 0.4 & & \\
\hline Feature 58 & 0.6 & & \\
\hline Feature 59 & 0.1 & & \\
\hline Feature 64 & 0.4 & & \\
\hline Feature 68 & 0.1 & & \\
\hline Feature 84 & 0.5 & & \\
\hline Feature 86 & 0.2 & & \\
\hline Feature 91 & 1.1 & & \\
\hline Feature 106 & 0.3 & & \\
\hline Feature 109 & 0.2 & & \\
\hline Feature 114 & 1.9 & & \\
\hline Feature 116 & 0.3 & & \\
\hline Feature 144 & 0.9 & & \\
\hline Feature 145 & 4.4 & & \\
\hline Feature 149 & 0.1 & & \\
\hline Feature 151 & 17.4 & & \\
\hline Feature 159 & 1.5 & & \\
\hline Feature 163 & 5.7 & & \\
\hline Feature 164 & 1.4 & & \\
\hline Feature 166 & 6.9 & & \\
\hline Feature 170 & 0.6 & & \\
\hline Feature 188 & 47.4 & 10.4 & \\
\hline Feature 189 & 546.3 & & \\
\hline Feature 199 & 0.2 & & \\
\hline Feature 200 & 2.4 & & \\
\hline Feature 201 & 0.6 & & \\
\hline Feature 210 & 0.4 & & \\
\hline Feature 226 & 0.8 & & \\
\hline Feature 228 & 0.2 & & \\
\hline Feature 233 & 9.0 & & \\
\hline Feature 234 & 1.9 & & \\
\hline
\end{tabular}

\begin{tabular}{l|r|r|r}
\hline \multicolumn{1}{c|}{ Provenience } & $\begin{array}{c}\text { Burned } \\
\text { Clay }\end{array}$ & Daub & $\begin{array}{c}\text { Mud } \\
\text { Nest }\end{array}$ \\
\hline Feature 256 & 3.8 & & \\
\hline Feature 262 & 1.0 & & \\
\hline Feature 263 & 0.4 & & \\
\hline Feature 265 & 4.3 & & \\
\hline Feature 268 & 0.1 & & \\
\hline Feature 293 & 2.2 & & \\
\hline Feature 316 & 2.0 & & \\
\hline Feature 355 & 10.5 & & \\
\hline Feature 378 & 2.8 & & \\
\hline TU 3 & 10.3 & 27.9 & \\
\hline TU 6 & 21.1 & 14.1 & 72.8 \\
\hline TU 7 & 11.2 & & \\
\hline TU 11 & 18.9 & & \\
\hline TU 14 & & 12.1 & \\
\hline TU 16 & & 2.8 & \\
\hline TU 18 & 11.2 & & \\
\hline TU 26 & 3.3 & 5.0 & \\
\hline TU 36 & 0.8 & & \\
\hline TU 37 & 3.8 & 2.4 & \\
\hline TU 42 & 1.3 & & \\
\hline TU 44 & & 13.6 & \\
\hline TU BHT 40 South Ext. & 7.9 & & \\
\hline SU 67 & & 0.5 & \\
\hline SU 70 & 1.8 & & \\
\hline Tetals & 2.6 & 2.4 & \\
\hline
\end{tabular}


use of starchy-seeded annuals along with corn cultivation.

Hardwood nuts, especially hickory but also acorn and black walnut, dominate the rest of the macrobotanical remains that represent foods (or in some cases perhaps medicines); these were present in 62 percent of the flotation samples. Much less frequent are grape, verbena, sumac, purslane, and grass family seeds and the remains of unidentified fruit as well as bulb scales that could be from plants such as wild garlic or camas.

\section{FAUNAL REMAINS}

A total of 2,413 faunal elements were recovered (Appendix G). All but 1 of these, a carnivore tooth from Auger Test 127 in the eastern part of the site, are from Subarea 1. Eighty-one percent $(\mathrm{n}=1,958)$ are classifiable only as vertebrate, and 12 percent $(n=277)$ are identifiable only as mammalian skeletal material ranging in size from micro/small to large/very large. Medium to large mammalian remains are the most numerous in this generalized group $(\mathrm{n}=265)$. The next most-common taxon is deer/pronghorn-sized ungulates (Artiodactyla [medium]), which is represented by 54 specimens ( 2 percent of the site assemblage). Other mammalian taxa identified in the remaining 5 percent of the collection include members of the families Leporidae (rabbits and hares), Cervidae (deer), and Bovidae (bison, cattle, antelope) and members of the orders Carnivora and Rodentia. The assemblage also includes elements from the orders Anura (toads and frogs) and Testudinata (tortoises and turtles) and the classes Aves (birds) and Osteichthyes (bony fishes).

Deer remains consist of 20 elements that are classifiable at the genus level (Odocoileus sp.). Identified elements are the tips of 2 antler tines, 9 teeth, a mandible fragment, an atlas vertebra, 6 limb bones (a radius, fibula, and 4 phalanges), and a pelvic fragment. The mandible fragment is spirally fractured; 13 other elements exhibit angular fracture patterns. Burning is limited to an antler tine, a tooth, and a phalange. Cultural modification is evidenced by numerous stone tool cut marks on an unburned radius fragment. Identified deer specimens account for less than 1 percent of the total assemblage, but if they are combined with specimens of size grades that likely represent deer (Artiodactyla [medium] and Mammalia [medium/large and large/very large]), then the combined group accounts for 14 percent of the assemblage $(\mathrm{n}=341)$.

The 54 bones categorized as deer/pronghorn-sized ungulates primarily consist of limb bones ( $\mathrm{n}=45$; 83 percent), and more than a quarter of those are long bone fragments $(n=12)$. Almost sixty percent of the medium-sized artiodactyl bones are spirally fractured $(n=31)$. Ten of the long bone fragments exhibit this breakage pattern. Additionally, 14 metapodial fragments (primarily metatarsals), 6 foot/ankle bones, and a thoracic vertebra show spiral fractures. Impact points are visible on a spirally fractured tibia and phalange. Twenty-one of the medium-sized artiodactyl elements exhibit angular fractures, and 2 specimens are unbroken. The majority are unburned $(\mathrm{n}=48)$.

The 267 elements categorized as Mammalia (medium/large $[\mathrm{n}=265]$ and large/very large $[n=2])$ are primarily indeterminate fragments $(\mathrm{n}=238)$. The remainder of this group is composed of 2 teeth, a mandible fragment, 20 axial skeletal elements (including 14 rib fragments), and 6 limb bones (includes 4 long bone fragments). About 60 percent of the medium/large and large/very large mammal bones exhibit spiral fractures $(n=157)$. This fracture group contains the following identifiable elements: 3 long bone fragments, a metatarsal, 2 rib segments, and a mandible fragment. An impact point is evident on 1 of the spirally fractured long bone segments. All but 1 of the remaining medium/large and large/very large mammal elements show angular fractures $(n=109)$. Thirtysix percent of the medium/large and large/very mammal remains $(\mathrm{n}=95)$ are calcined, and 14 percent $(n=37)$ are charred.

Bovid remains consist of four fragmented teeth, part of a phalange, and a partially calcined horn core/cranial fragment. The unburned teeth and phalange were recovered from nonfeature contexts and likely are derived from historic or modern cattle ranching. The modified horn core/cranial segment was recovered from a prehistoric cultural feature (Feature 9) that also contained cultigens (corn), goosefoot and knotweed seeds, gathered nuts (acorn, hickory, and hickory/walnut), cane, and a variety of wood charcoal; hence, it is linked with indigenous site occupation and is most likely derived from a bison rather than a domesticated cow. 
Leporid specimens consist of 20 cottontail rabbit (Sylvilagus sp.) elements and 2 specimens (a humerus fragment and a tooth) that are identifiable only at the family level. The tooth is derived from either a swamp rabbit (Sylvilagus aquaticus) or a black-tailed jackrabbit (Lepus californicus). Both of the Leporidae elements are unburned and have angular fractures. The cottontail elements consist of 7 teeth, 4 cranial/ mandibular bones, a scapula, a pelvic fragment, and 7 limb bones. Three long bone fragments exhibit spiral fractures, and 16 specimens have angular fracture patterns. A phalange is the only complete Sylvilagus sp. element. Burned specimens are limited to a tooth, cranial bone, metatarsal, and calcaneus.

There are 14 carnivore elements. Eleven teeth and a mandible fragment are identifiable only at the order level, but almost all of this material is raccoon sized. Other specimens from this order are a cranial fragment from a member of the Mustelidae family and a raccoon (Procyon lotor) vertebra fragment. The cranial fragment is likely derived from a skunk or a mink. All carnivore elements are fragmentary and unburned.

Rodent bones consist of eight squirrel/probable squirrel elements (Sciurus sp., Sciuridae family [squirrels and chipmunks]) and two specimens that are identifiable only as medium-sized and large rodent remains (an incisor fragment and a pelvic fragment). The squirrel/probable squirrel elements are five teeth, a cranial fragment, and two limb bones. The latter consist of a calcined calcaneus and an unburned spirally fractured humerus fragment. The calcaneus is the only complete specimen in the rodent assemblage that exhibits evidence of thermal modification, and other than teeth, is the only complete element in this group.

Two micro/small elements are from shrew/ rabbit-sized mammals, and eight small/medium-sized elements are from rabbit/canid-sized mammals. Three are indeterminate fragments, three are teeth, two are rib fragments, one is part of a femur, and one is a complete metacarpal. Two of the indeterminate fragments exhibit spiral fractures, whereas all other broken bones show angular fractures. None is burned.

Bird elements consist of four specimens that are identifiable only at the class level (Aves), two humeri fragments from the Columbidae family (pigeons and doves), and three turkey/probable turkey (Meleagris gallapavo, cf. Meleagris gallapavo) leg bone fragments. The four Aves bones are part of a rib, a long bone fragment from a medium-sized bird, and a complete phalange and humerus fragment from a large bird (the humerus is duck-sized). The turkey/probable turkey elements are spirally fractured; the five other fragmentary specimens have angular breaks. None is burned.

Reptilian remains (order Testudinata [tortoises and turtles]) consist of 33 specimens that cannot be classified beyond the order level, 2 elements from the Emydidae family (water and box turtles), and 4 elements from the Kinosternidae family (mud and musk turtles). As a group, turtle remains account for 1.6 percent of the total assemblage and are the third most-common taxon after canid/deer-sized mammals and deer/pronghorn-sized ungulates. Recovered Testudinata elements consist of 14 specifically identifiable carapace bones, 24 shell fragments, and a part of a long bone. All of this material is fragmentary and exhibits angular fracture patterns. Burned elements are 4 calcined shell fragments and 13 charred shell and carapace bone fragments.

Amphibian elements (order Anura [toads and frogs]) consist of humerus, radioulnar, and long bone fragments. The one fish specimen is part of a dental-bearing element from a small bony fish (class Osteichthyes); it is unburned.

Complete or unbroken bones make up less than 1 percent $(n=15)$ of the assemblage, which is dominated by specimens with angular fractures $(n=2,067 ; 86$ percent). Spirally fractured elements $(\mathrm{n}=329)$ constitute slightly less than 14 percent. The majority of the spirally fractured specimens ( $n=281 ; 85$ percent) are too fragmented to allow for element determination. Ninety percent of the 48 identifiable specimens are limb bones $(n=43)$, and fused third and fourth metatarsals from medium-sized artiodactyls and canid/deer-sized mammals $(\mathrm{n}=11)$ account for just over a quarter of that group. Spirally fractured limb bones are almost evenly divided between long bones ( $n=21 ; 49$ percent) and foot bones ( $\mathrm{n}=22 ; 51$ percent). The remaining identifiable spirally fractured specimens are axial skeletal elements ( 2 ribs and a vertebra) and 2 mandible fragments.

Almost half of the assemblage is unburned $(\mathrm{n}=1,168)$. Burned elements consist of 919 calcined specimens (38 percent) and 326 charred 
specimens (14 percent). Almost 90 percent of the calcined specimens $(\mathrm{n}=809)$ and more than 80 percent of the charred specimens $(n=272)$ are identifiable only as vertebrate skeletal material. A little more than 11 percent of the calcined bone $(n=106)$ represents various mammalian taxa; the 4 remaining elements are reptilian (Testudinata). Mammalian taxa account for 13 percent of the charred specimens $(\mathrm{n}=42)$. The only other identifiable taxa in the charred inventory are Testudinata $(n=11)$ and Kinosteridae $(n=2)$. None of the bird specimens is thermally modified.

The small collection of invertebrate remains contains 17 fragments of mussel shell (Appendix H). These include Lampsilis hudiana, Lampsilis sp. Lampsilis teres, Leptodea fragilis, and Leptodea sp. Snail shell includes 4 fragments of Mesodon thyroidus, Mesodon sp., and Rabdotus dealbatus. In addition there are 193 unidentified shell fragments.

\section{CHRONOLOGY}

\section{Radiocarbon Dates}

Forty-five radiocarbon dates were obtained from charred nutshells, seeds, corn, and wood as a result of the 2007-2008 testing and 2010 data recovery excavations (Tables 4.7 and 4.8). All are from smudge pits, large pits, small pits, and postholes. Only 4 are from smudge pits, which are preferable for dating since their contents are more likely to represent in situ burning than are charred remains in other kinds of features. One large pit (Feature 189) contained discrete ash pockets, which could indicate in situ burning, but there is no other evidence to indicate this, and the dated material could well have been introduced after the pit was used.

The remaining dates almost certainly are from secondary contexts: 17 from large pits, 20 from small pits, and 3 from postholes. The carbonized materials occur in low densities in these features, and most probably were dumped or swept into open pits during cleaning episodes. Other charred remains probably accumulated on the surface and incidentally made their way into open features, for example, when posts were pulled and postholes left open. The dated materials from most, if not all, of these do not relate to the functions of the features. They may be contemporaneous or predate actual use of the features, and they could even postdate them if rodent burrowing or roots translocated later charcoal into the fill of older features. In addition to limitations imposed by the scarceness of primary contexts, the data set suffers because some of the assays fall within spans when calibration yields multiple or long date ranges due to wiggles in the calibration curve.

The discussion of radiocarbon dating below relies on the calibrated results as determined by CALIB Rev 6.0 (Stuiver et al. 2005) using the IntCal09 data set, since it gives probabilities associated with the possible intervals (the intervals determined by the Beta Analytic calibrations are included on Table 4.7 as well), and focuses on the two-sigma ranges. The data can be interpreted in multiple ways. For example, one could look at Figure 4.22 and conclude that Subarea 1 was occupied periodically during two intervals, first between about A.D. 800 and 1000 and more intensively later from about 1150 to at least 1500 and maybe even the mid 1600s. Presented below is a different interpretation that accounts for the clear multicomponency indicated by the dates while at the same time being consistent with the feature evidence. This interpretation hinges on the idea that the features point to a single primary residential occupation no more than a generation or two in length, with the site used both before and after this main occupation but not for sustained residential purposes.

The main residential occupation appears to be represented by 33 dates overlapping chiefly between about A.D. 1250 and 1325 . Their ranges all extend either earlier or later than this as well, but the overlap suggests that the one- or two-generation main occupation, almost certainly lasting no more than 40 years, was sometime in the decades flanking 1300. All 4 of the smudge pit dates are in this group, as is the single large pit date that could be from a primary context. Not surprisingly, the dates are split between the two main feature areas, with 19 in the northern concentration and 13 in the southern concentration; 1 date is from the sparsely populated area between the two feature concentrations.

A single date, from Feature 19 in the northern concentration, has a low-probability interval of A.D. 1231-1252 that could go with the early end of the main occupation span but is more likely to represent some ephemeral use at $1147-1229$, or less likely at 1119-1142 or 1045-1095. 
Chapter 4: Excavations at the George Richey Site, $41 T T 851$

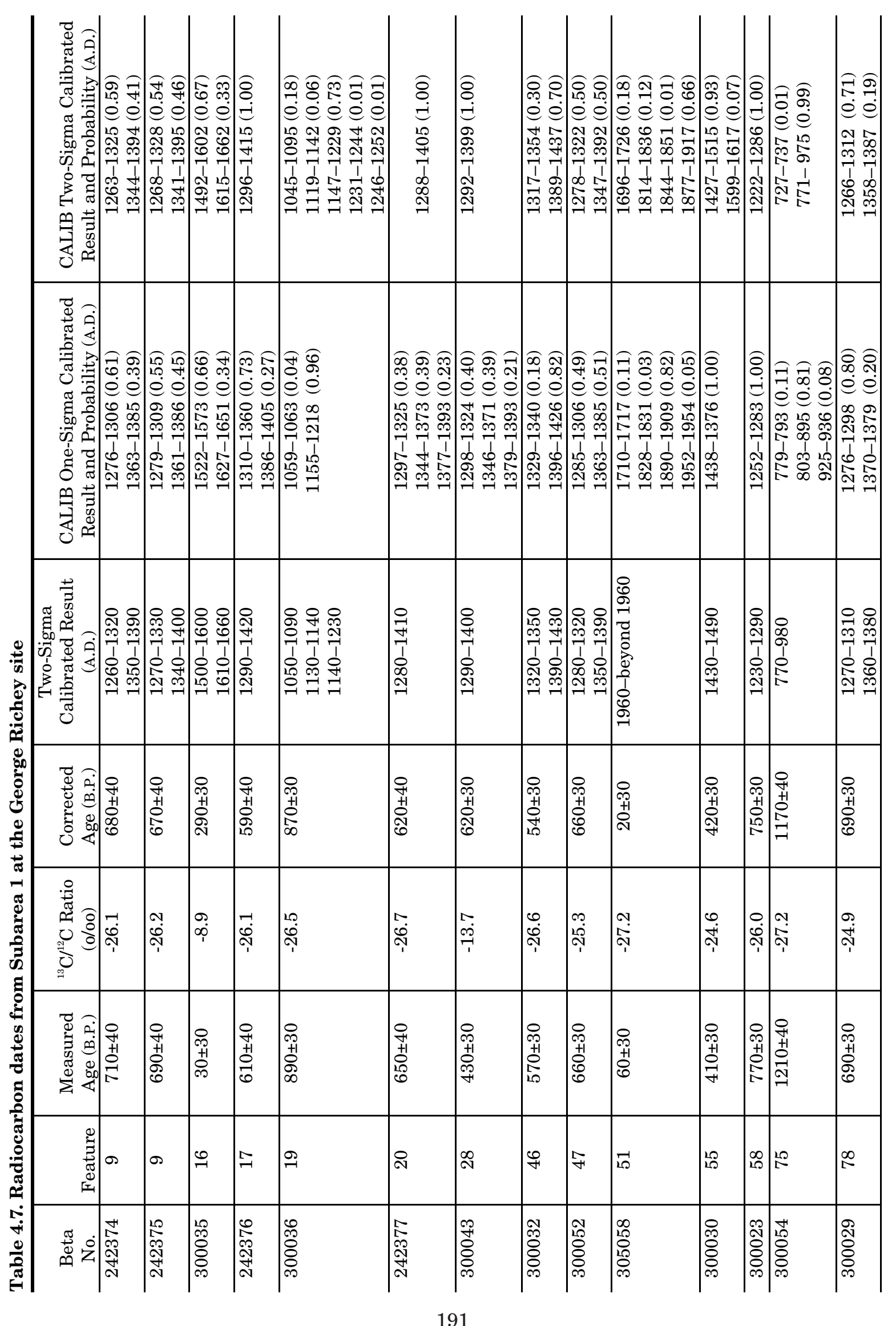


Excavations along the U.S. Highway 271 Mount Pleasant Relief Route

\begin{tabular}{|c|c|c|c|c|c|c|c|c|c|c|c|c|c|c|c|c|c|}
\hline 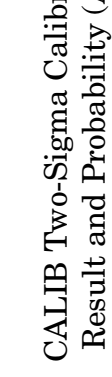 & 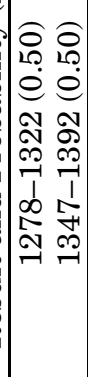 & 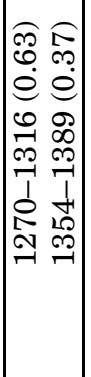 & 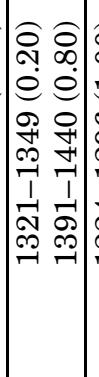 & 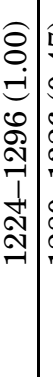 & 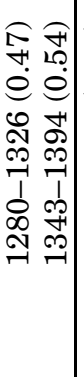 & 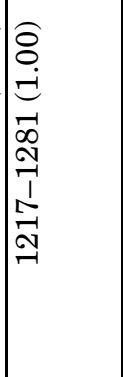 & 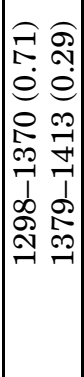 & 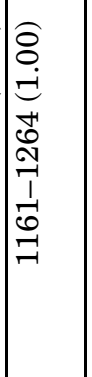 & 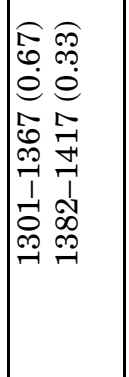 & 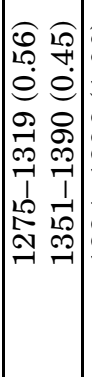 & 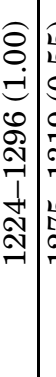 & 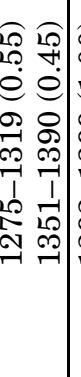 & 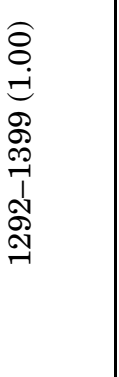 & 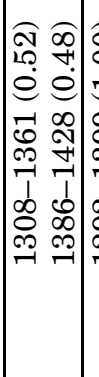 & 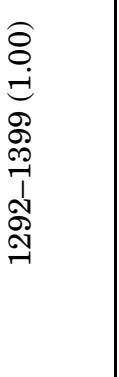 & 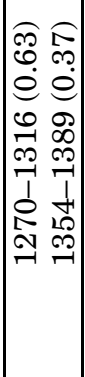 & 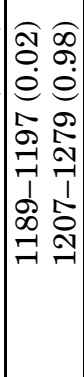 \\
\hline 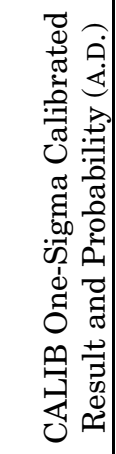 & 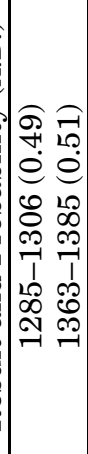 & 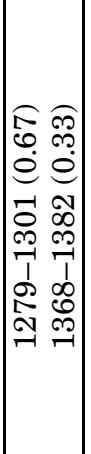 & 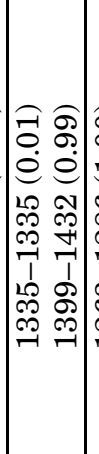 & 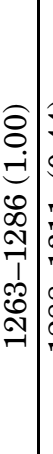 & 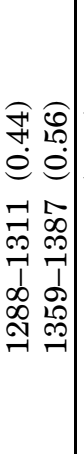 & 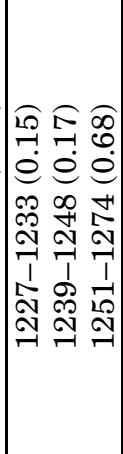 & 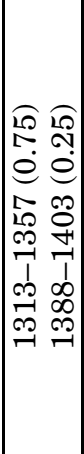 & 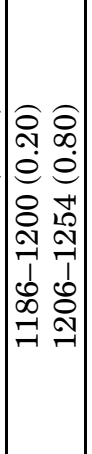 & 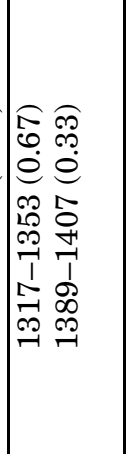 & 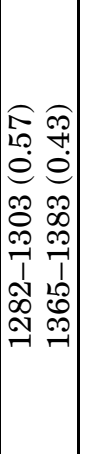 & 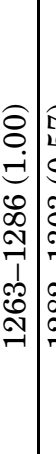 & 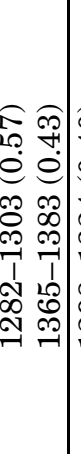 & 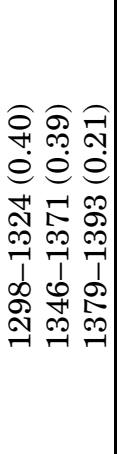 & 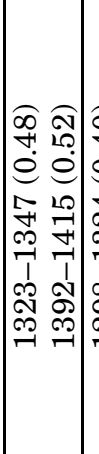 & 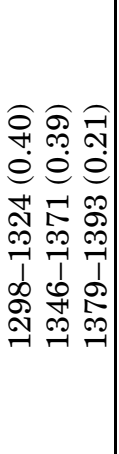 & 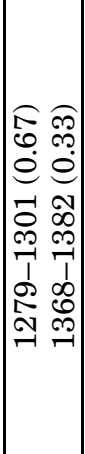 & 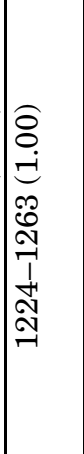 \\
\hline 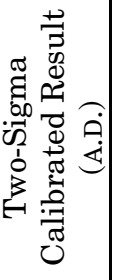 & 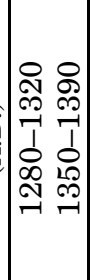 & 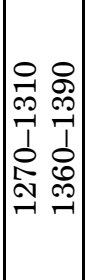 & 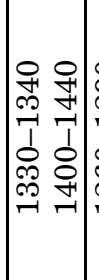 & 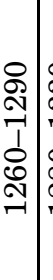 & 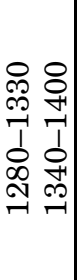 & 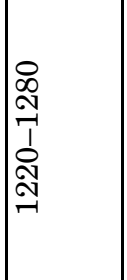 & 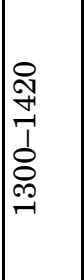 & \begin{tabular}{l}
0 \\
0 \\
$\stackrel{2}{1}$ \\
7 \\
0 \\
0 \\
\hdashline \\
-1
\end{tabular} & 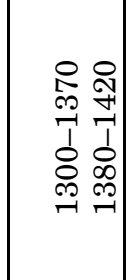 & 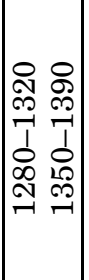 & 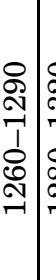 & 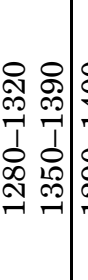 & 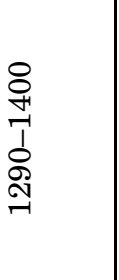 & 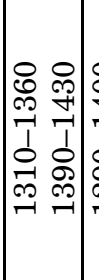 & 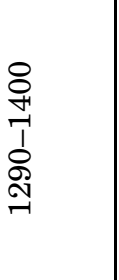 & 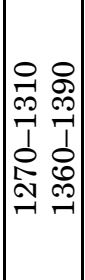 & 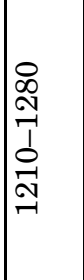 \\
\hline 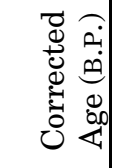 & $\begin{array}{l}0 \\
\infty \\
+1 \\
0 \\
0 \\
0\end{array}$ & $\begin{array}{l}0 \\
\infty \\
0 \\
+1 \\
0 \\
\infty \\
0\end{array}$ & $\begin{array}{l}0 \\
0 \\
0 \\
0 \\
0 \\
0 \\
i n\end{array}$ & 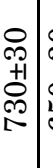 & $\begin{array}{l}0 \\
0 \\
1 \\
0 \\
0 \\
0 \\
0\end{array}$ & 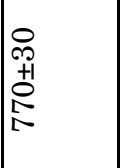 & 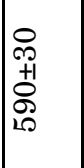 & 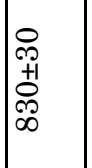 & $\begin{array}{l}0 \\
\infty \\
0 \\
+1 \\
\infty \\
\infty \\
10\end{array}$ & $\begin{array}{l}0 \\
0 \\
0 \\
+1 \\
0 \\
0 \\
0\end{array}$ & 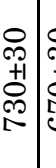 & $\begin{array}{c}0 \\
0 \\
+1 \\
0 \\
0 \\
0\end{array}$ & 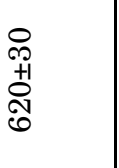 & $\begin{array}{l}0 \\
0 \\
+1 \\
0 \\
0 \\
0 \\
10\end{array}$ & 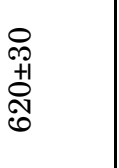 & $\begin{array}{l}0 \\
i \\
+1 \\
0 \\
\infty \\
0 \\
0\end{array}$ & 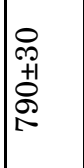 \\
\hline 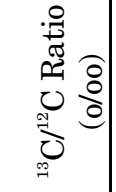 & . & 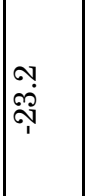 & 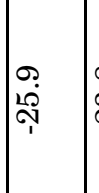 & 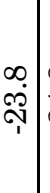 & $\begin{array}{l}\infty \\
\underset{\sim}{+}\end{array}$ & $\stackrel{0}{\dot{p}}$ & $\mid \begin{array}{c}-1 \\
\stackrel{0}{0} \\
\text { iv }\end{array}$ & 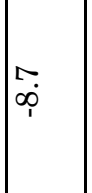 & $\begin{array}{l}\infty \\
\stackrel{+}{+} \\
\text { i }\end{array}$ & $\begin{array}{l}\infty \\
\stackrel{\infty}{+} \\
\text { ஸे }\end{array}$ & 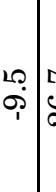 & 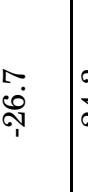 & & $\begin{array}{l}-1 \\
\stackrel{-}{\circ} \\
\text { ஸे }\end{array}$ & $\stackrel{0}{\dot{p}}$ & 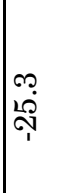 & 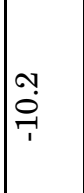 \\
\hline 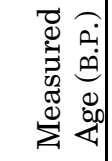 & $\begin{array}{l}0 \\
0 \\
+1 \\
0 \\
0 \\
0\end{array}$ & $\begin{array}{l}0 \\
i \infty \\
+1 \\
0 \\
0 \\
0 \\
0\end{array}$ & $\begin{array}{l}0 \\
0 \\
0+1 \\
0 \\
0 \\
10\end{array}$ & 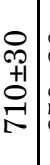 & 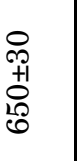 & $\begin{array}{l}0 \\
\infty \\
+1 \\
0 \\
10 \\
10\end{array}$ & 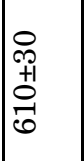 & $\mid \begin{array}{l}0 \\
\infty \\
+1 \\
0 \\
0 \\
0 \\
20\end{array}$ & $\mid \begin{array}{l}\infty \\
\infty \\
+1 \\
0 \\
\infty \\
10\end{array}$ & $\mid \begin{array}{c}0 \\
⿱ ㇒ \\
+1 \\
0 \\
0 \\
0\end{array}$ & 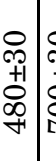 & 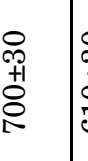 & $\begin{array}{l}0 \\
\text { r } \\
+1 \\
0 \\
0 \\
0\end{array}$ & $\begin{array}{l}0 \\
\infty \\
+1 \\
+1 \\
\infty \\
0 \\
10\end{array}$ & $\begin{array}{l}0 \\
0 \\
+1 \\
+1 \\
0 \\
0 \\
\infty\end{array}$ & $\begin{array}{l}0 \\
0 \\
+1 \\
0 \\
0 \\
0 \\
0\end{array}$ & $\begin{array}{l}0 \\
0 \\
0 \\
+1 \\
0 \\
0 \\
10 \\
10\end{array}$ \\
\hline 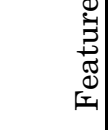 & 2 & $\infty$ & 突 & 号 & ङ્ & ְ. & 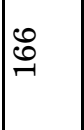 & $\mid \begin{array}{l}\infty \\
\infty \\
-1\end{array}$ & 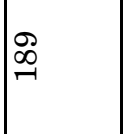 & 号 & $\stackrel{\infty}{\stackrel{\infty}{-}}$ & 尺. & ڤి & 尺े & ๙ึ & $\stackrel{\text { }}{\text { N }}$ & 촛 \\
\hline$\stackrel{\sigma}{\mathbb{0}} \dot{0}$ & 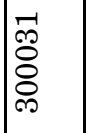 & 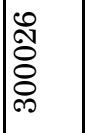 & 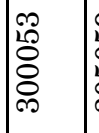 & \begin{tabular}{l|l}
0 \\
2 \\
0 \\
0 \\
2 \\
0 \\
0
\end{tabular} & 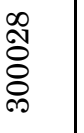 & 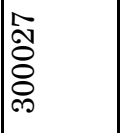 & 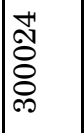 & 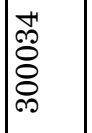 & 苟 & $\begin{array}{l}\text { o } \\
\text { क्ष } \\
8 \\
0 \\
0\end{array}$ & 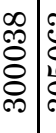 & $\begin{array}{l}8 \\
0 \\
0 \\
0 \\
0 \\
0 \\
\text { co }\end{array}$ & $\begin{array}{l}4 \\
0 \\
0 \\
0 \\
0 \\
0\end{array}$ & 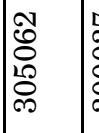 & 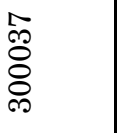 & 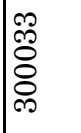 & 命 \\
\hline
\end{tabular}




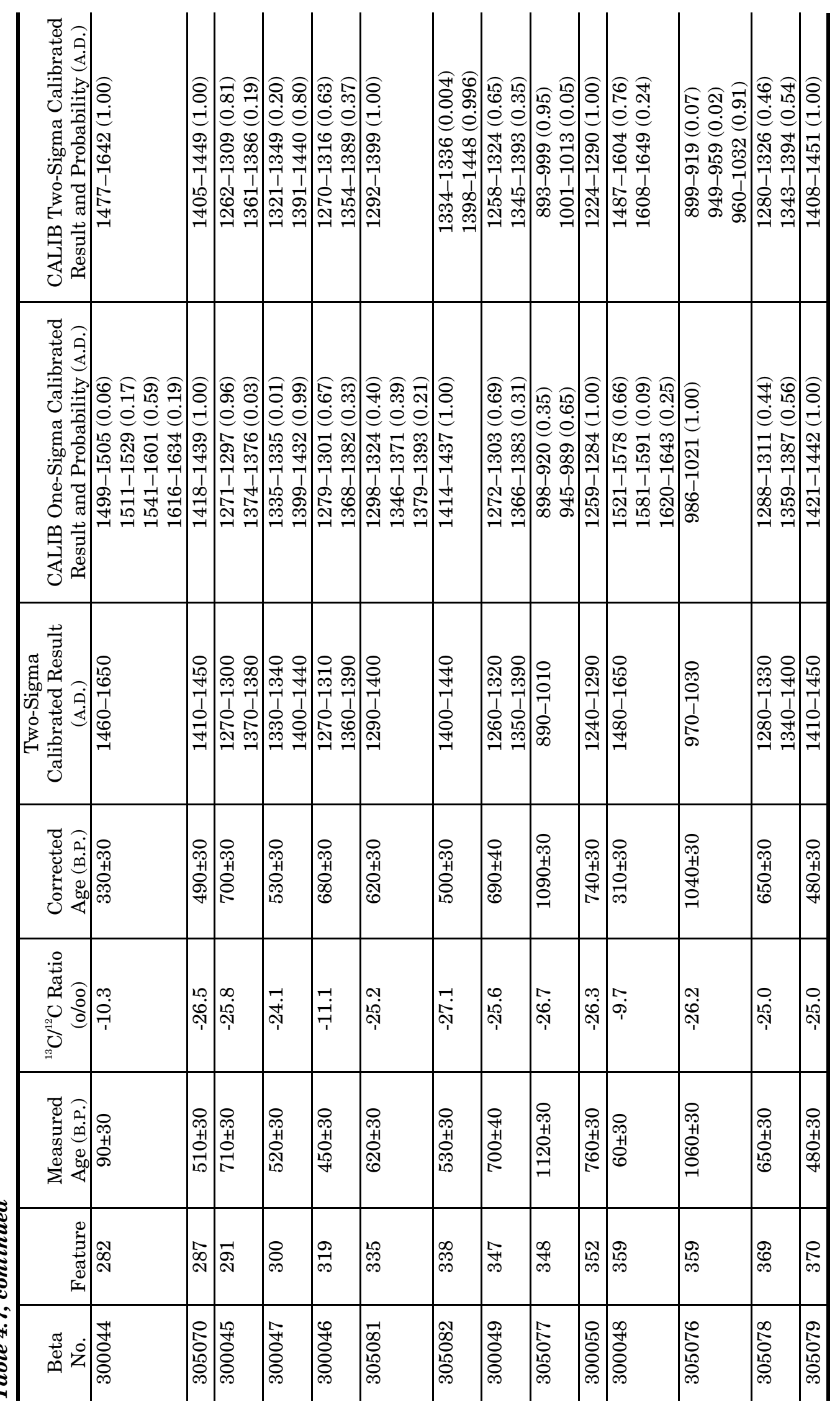


Table 4.8. Radiocarbon-dated contexts in Subarea 1 at the George Richey site

\begin{tabular}{|c|c|c|c|c|}
\hline Beta No. & Feature & $\begin{array}{c}\text { Feature } \\
\text { Type }\end{array}$ & Material & Weight (g) \\
\hline 242374 & 9 & large pit & White oak (Quercus subg. Quercus) wood & 0.94 \\
\hline 242375 & 9 & large pit & White oak (Quercus subg. Quercus) wood & 0.97 \\
\hline 300035 & 16 & large pit & Corn (Zea mays) seed & 0.01 \\
\hline 242376 & 17 & large pit & Hickory (Carya sp.) nutshell & 0.24 \\
\hline 300036 & 19 & small pit & Cane (Arundunarua gigantean) stem & 0.01 \\
\hline 242377 & 20 & smudge pit & Indeterminable - probable nut husk & 1.72 \\
\hline 300043 & 28 & large pit & Corn (Zea mays) rachis & 0.04 \\
\hline 300032 & 46 & large pit & Hickory (Carya sp.) nutshell & 0.02 \\
\hline 300052 & 47 & small pit & Hickory (Carya sp.) nutshell & 0.02 \\
\hline 305058 & 51 & small pit & indeterminable & 0.03 \\
\hline 300030 & 55 & small pit & Hickory (Carya sp.) nutshell & 0.04 \\
\hline 300023 & 58 & small pit & Hickory (Carya sp.) nutshell & 0.06 \\
\hline 300054 & 75 & large pit & Cane (Arundunarua gigantean) stem & 0.01 \\
\hline 300029 & 78 & large pit & Hickory (Carya sp.) nutshell & 0.10 \\
\hline 300031 & 79 & large pit & Hickory (Carya sp.) nutshell & 0.28 \\
\hline 300026 & 80 & smudge pit & Hickory (Carya sp.) nutshell & 0.03 \\
\hline 300053 & 147 & small pit & Hickory (Carya sp.) nutshell & 0.04 \\
\hline 305059 & 159 & small pit & Hickory (Carya sp.) nutshell & 0.15 \\
\hline 300028 & 164 & small pit & Hickory (Carya sp.) nutshell & 0.14 \\
\hline 300027 & 165 & smudge pit & Corn (Zea mays) rachis & 0.08 \\
\hline 300024 & 166 & small pit & Hickory (Carya sp.) nutshell & 0.80 \\
\hline 300034 & 188 & large pit & Corn (Zea mays) rachis & 0.01 \\
\hline 300041 & 189 & large pit & Hickory (Carya sp.) nutshell & 3.70 \\
\hline 300040 & 190 & small pit & Hickory (Carya sp.) nutshell & 0.62 \\
\hline 300038 & 198 & small pit & Corn (Zea mays) seed & 0.01 \\
\hline 305063 & 199 & small pit & Hickory/Walnut (Juglandaceae) nutshell & 0.01 \\
\hline 305064 & 200 & small pit & Hickory (Carya sp.) nutshell & 0.07 \\
\hline 305062 & 202 & small pit & Hickory (Carya sp.) nutshell & 0.02 \\
\hline 300037 & 233 & large pit & Corn (Zea mays) rachis & 0.02 \\
\hline 300033 & 243 & small pit & Hickory (Carya sp.) nutshell & 0.26 \\
\hline 300039 & 271 & large pit & Corn (Zea mays) rachis & $<0.01$ \\
\hline 300044 & 282 & small pit & Corn (Zea mays) rachis & 0.01 \\
\hline 305070 & 287 & posthole & Oak (Querus sp.) wood & 0.02 \\
\hline 300045 & 291 & large pit & Hickory/Walnut (Juglandaceae) nutshell & $<0.01$ \\
\hline 300047 & 300 & large pit & Hickory (Carya sp.) nutshell & 0.03 \\
\hline 300046 & 319 & smudge pit & Corn (Zea mays) rachis & 0.01 \\
\hline 305081 & 335 & small pit & Red group oak (Quercus subg. Lobatae) wood & 0.12 \\
\hline 305082 & 338 & small pit & White group oak (Quercus subg. Quercus) wood & 0.02 \\
\hline 300049 & 347 & small pit & Hickory (Carya sp.) nutshell & 0.20 \\
\hline 305077 & 348 & small pit & White group oak (Quercus subg. Quercus) wood & 0.01 \\
\hline 300050 & 352 & large pit & Hickory/Walnut (Juglandaceae) nutshell & 0.03 \\
\hline 300048 & 359 & large pit & Corn (Zea mays) rachis & 0.01 \\
\hline 305076 & 359 & large pit & Oak (Quercus sp.) wood & 0.30 \\
\hline 305078 & 369 & posthole & Acorn (Quercus sp.) nutshell & 0.30 \\
\hline 305079 & 370 & posthole & White group oak (Quercus subg. Quercus) wood & 0.02 \\
\hline
\end{tabular}


More certainly marking use of Subarea 1 before the main occupation are three dates from Features 75, 348, and 359, all in the south part of the southern feature concentration. Their ranges cover the period from A.D. 771 to 1032 , but they all overlap in the late 900 s. Given their proximity to one another, it is likely they are from a single episode of nonresidential use in the late tenth century.

Eight dates appear to reflect activities after the main occupation, i.e., after the early A.D. 1300s. One of these, from Feature 51 in the southern concentration, probably does not relate to Native American use of the site. Its highest-probability interval is 1877-1917, and while it does have two intervals in the early 1700 s and early 1800 s, there are no gunflints or other historic materials to indicate Native occupation this late. Of the other seven late dates, three from Features 287, 338, and 370 (all in the southern concentration) overlap at 1408-1448, one from Feature 55 (southern concentration) has a range of 1427-1515, one from Feature 282 (southern concentration) has a range of 1477-1642, and two from Feature 16 (northern concentration) and Feature 359 (southern concentration) overlap at 1492-1649. Minimally, these would seem to indicate an occupation in the early 1400s and another later one between 1492 and 1642 , but more likely sometime in the 1500s. Of course, it is possible they represent more than two use episodes. Whether just two or more, it seems likely this use was not intensive and not for residential purposes.

In sum, the interpretation of the radiocarbon dates that is most consistent with the feature evidence involves a primary occupation between A.D. 1250 and 1325 and minor occupations in the late $900 \mathrm{~s}$, perhaps the late 1100 s or early $1200 \mathrm{~s}$, the early 1400 s, and sometime in the 1500 s. The main-occupation dates are well represented in both feature concentrations, indicating the same occupation is responsible for the concentrations. The single date that slightly predates the main occupation is from the northern concentration. Six of the post- 1325 dates are from the southern concentration and two are from the northern concentration, showing both parts of the site were used then. Ephemeral use during the 900s may have been restricted to the southern area.

\section{The Artifact Evidence}

The lithic artifacts that convey some chronological information are generally consistent with the radiocarbon evidence. The six arrow points typed as Alba and Bonham probably are associated with the main occupation, while the four Frileys and Colberts and six Bassetts, Mauds, and Talcos relate to earlier and later episodes of use. All three groups were concentrated in and around the northern feature concentration, with only one Bonham and one Friley coming from the southern concentration. The single examples of Edgewood, Ellis, and Wells points and the eight Garys and possible Garys and Kents and possible Kents probably relate to periodic lowintensity episodes of use in the Archaic and Woodland periods.

It is hard to relate particular groups of ceramics to the proposed A.D. 1250-1325 main occupation. The Maydelle Incised sherds are one candidate, though Maydelle also occurs in later contexts, as are the untyped deep bowls. The Ripley Engraved and possible Harleton Appliqué sherds would seem later, most likely relating to minor occupations in the 1400 s and 1500 s. At the other end of the spectrum, the single Weches Fingernail Impressed sherd and the sherds with horizontal engraved lines suggestive of types like Crockett Curvilinear Incised, Kiam Incised, or Davis Incised could go with the minor occupations suggested for the late 900 s and late 1100 s-early $1200 \mathrm{~s}$. What may be most telling is the comparative infrequency of brushing (12 percent of the decorated sherds vs. 34-48 percent at the William Ford and James Richey sites and the high frequency of punctating unassociated with brushing ( 37 percent of decorated sherds vs. 15-20 percent at the other two sites). Lacking a better handle on what a late 1200 s-early 1300 s ceramic assemblage should look like typologically, measures such as these may be key in making chronological comparisons.

\section{PATTERNING IN THE HORIZONTAL DISTRIBUTION OF MATERIALS}

Patterning in the horizontal distributions of artifacts can be explored to address questions relating to the arrangement of activities, i.e., activity areas, and trash disposal. Given the thinness of the deposits and the clear multicomponency, this is a poor place to look for finegrained patterns, for example, specific activity areas within houses. It is amenable to study of 


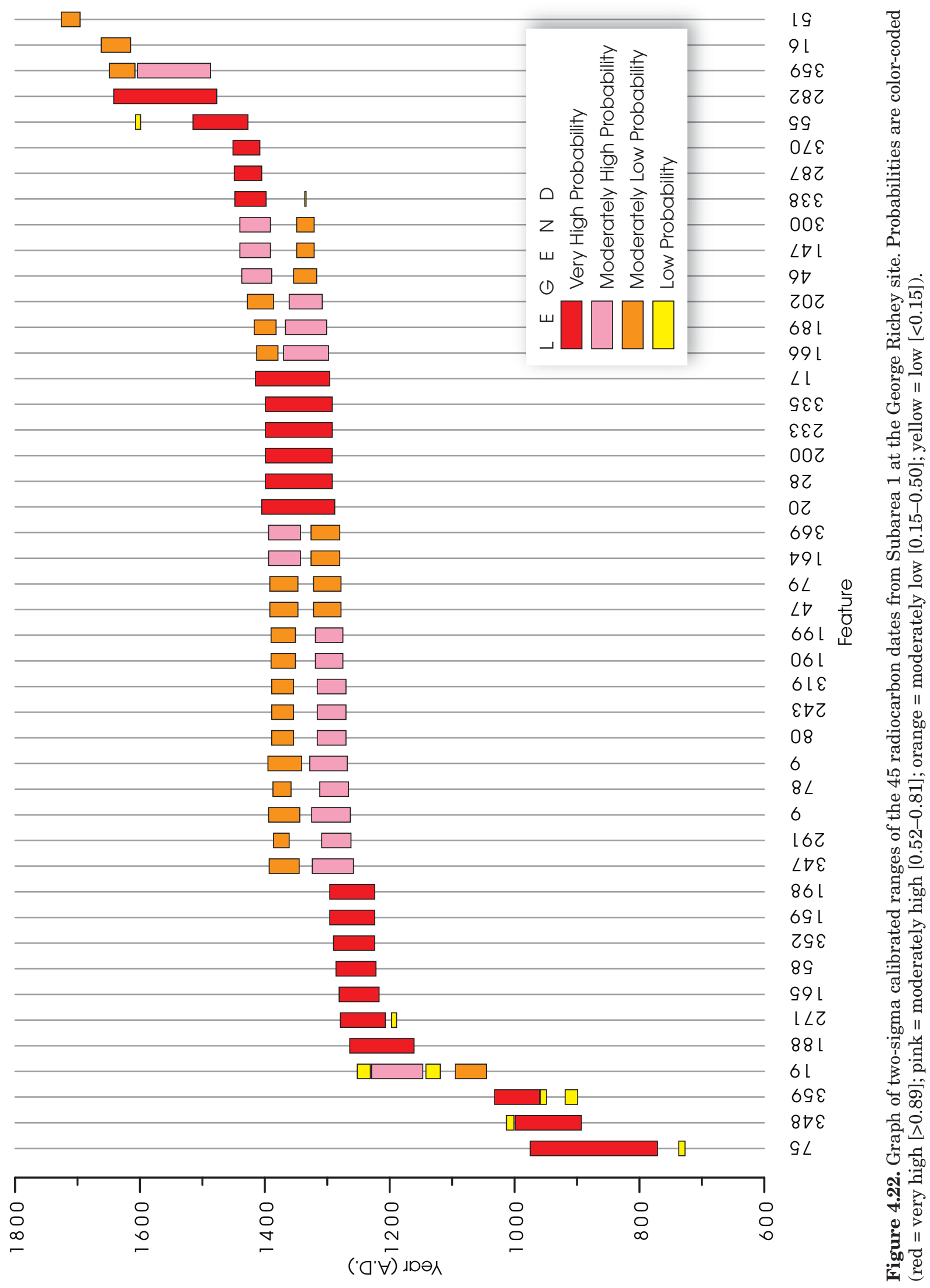


coarser-grained patterns, however. The artifact samples available for this are from the following contexts: 41 test units $(1 \times 1 \mathrm{~m})$ dug during testing in the part of the site that subsequently saw data recovery work; and 70 machine-dug sample units (averaging $2.2 \times 1.0 \mathrm{~m}$ ) placed across the data recovery area. Because the sizes of the excavations and the amounts of fill screened varied, the densities of materials recovered from them were calculated based on the number of five-gallon buckets of screened fill.

In initial analysis of the test unit data, it was assumed that each level excavated would have yielded five buckets of fill $\left(0.10 \mathrm{~m}^{3}\right.$ per level divided by a bucket volume of $0.022 \mathrm{~m}^{3}$ ), as with the other two data recovery sites. Unlike at the other sites, however, this resulted in very different overall artifact density figures for the test units compared to the sample units (2.46 vs. 0.72 artifacts per bucket), implying some bias in one data set or the other. The only obvious bias is that, during data recovery, freezing weather hampered sample unit screening, with frozen dirt clods translating into buckets that were underfilled and hence artifact densities that were artificially depressed. To compensate for this, the artifact frequencies in the test units were decreased (to 29 percent of the actual counts) to make the two data sets comparable. While these adjusted values are the ones used below in looking at distributions, it is worth noting that the overall patterns are the same regardless of whether actual or adjusted counts are employed (i.e., we looked at it both ways and saw only minor differences).

Densities were calculated for the two most abundant kinds of occupational debris-ceramic sherds (from 95 of 111 proveniences; nonzero range $=0.03-3.20$, mean $=0.38 \pm 0.48$, median $=0.21$ ) and all lithics combined (from 101 proveniences; nonzero range $=0.02-1.13$, mean $=0.27 \pm 0.24$, median $=0.20$ - - and these data were used to create isopleth maps (with ArcGIS Spatial Analyst using the inverse-distance method to grid the data and the Jenks natural breaks method to define intervals) for distributional analysis. Attempts were made to look at the distributions of subsets of the artifacts and other classes of materials, but small frequencies made this problematical.

Figure 4.23 shows that the ceramics are concentrated in two areas. The main concentration overlaps the northern feature concentration, extending beyond it in all directions, especially to the north. Ceramics are also relatively common in a much smaller area at the north and northeast edges of the southern feature concentration, within and just outside the posthole arcs representing one or more houses. The lithic artifact distribution is similar, with one concentration overlapping the northern feature concentration and another at the north edge of the southern feature concentration. Unlike the ceramics, though, lithics also are relatively abundant in the south part of the southern feature concentration. The similarities indicate that most of the lithics relate to Caddo occupations, even though some part of the collection surely goes with earlier occupations indicated by the 16 dart points. A few dart points were recovered in or near the south part of the southern feature concentration, but they are not numerous enough to explain the high density of total lithics there.

These patterns led to three main conclusions. First, the bulk of the artifacts represent a general rain of debris resulting from activities in and immediately around houses and outdoor activity areas represented by clusters of features. Second, the Caddo who lived here did not consistently dispose of trash, resulting in high artifact densities, in areas away from houses and activity areas within the area sampled, with the possible exception of the area north of the northern feature concentration. Third, the fact that the distributions of lithics and especially ceramics are mostly well bounded suggests that the area chosen for data recovery captured the full extent of the occupation area. The only distribution that is not well bounded is the concentration of lithics in the south part of the southern feature concentration. The isopleths suggest it continues west of the area investigated, but based on landform extent, it cannot go far in this direction.

\section{SUMMARY AND CONCLUSIONS}

Approximately 2,646 $\mathrm{m}^{2}$ of Subarea 1 was excavated, resulting in the discovery of 69 pits, 76 postholes, 2 artifact clusters, 1 burned rock cluster, and 1 area of organically enriched midden sediments. Eighty-nine percent of the cultural features are in two concentrations in the southern and northern parts of the area. The southern concentration has 60 percent of the features, including 16 postholes forming an 
arc that represents most of a house that was 6.0-6.4 $\mathrm{m}$ in diameter, and 14 or 15 other postholes forming two much shorter arcs that could represent earlier or later houses, though they are too incomplete to be sure. Other features here relate to outside activities, such as cooking and food preparation, contemporaneous with the houses, while still others are likely to predate or postdate the houses.

The northern feature concentration has 28 percent of the features, mostly large and small pits. Most of this area has organically enriched midden sediments reflecting intensive activities associated with use of many of these features. The assemblage of features suggests that this area was used for outside activities such as processing and cooking food, preparing hides, etc. The 26-m-wide area that separates the northern and southern concentrations contains a small number of pits and postholes, but the scarceness of features here indicates this was mostly an open area that may have functioned as a plaza.

The ceramic artifacts recovered number 2,702 , of which 1,347 are large enough for analysis. Two of these are smoking pipe fragments, and the rest are from ceramic vessels. Included in the latter are large sections of two deep bowls. The vessel ceramics are mainly tempered with grog alone, though grog-bone is well represented and some bone temper by itself is also present. Decorated sherds constitute only 30 percent of the sample. Most of the decorated sherds have punctations or pinching (43 percent of those with decoration). Engraved sherds (23 percent) and incised sherds (18 percent) are the next most prevalent decorative modes. Sherds with brushing or a combination of brushing with other decorative modes make up only 12 percent of the decorated sherds and only 4 percent of all sherds. An additional 3 percent of the decorated sherds display appliqué without brushing. Coil crimping is present on only two sherds. Most of the ceramics cannot be identified typologically, but a small number bear similarities to types such as Crockett Curvilinear Incised, Kiam Incised, Davis Incised, and Weches Fingernail Impressed and are suggestive of Early Caddo occupation, while others appear to relate to types such as Maydelle Incised, Harleton Appliqué, and Ripley Engraved, which are consistent with later occupations in the Middle and Late Caddo periods.
The chipped stone assemblage consists of 26 arrow points, 16 dart points, 43 bifaces, 30 flake tools, 3 core tools, 56 cores, and 1,764 pieces of debitage. Identified arrow point types are Alba, Bassett, Bonham, Colbert, Friley, Maud, and Talco, and the dart point types are Edgewood, Ellis, Gary, Kent, and Wells. The 36 ground, pecked, and battered stones consist of 1 axe, 2 hammerstones, 3 manos/hammerstones, 4 pitted hammerstones, 6 anvils, 1 grinding slab/ anvil, 2 grinding slabs, 4 abraders, 2 grooved stones, 3 pigment stones, and 8 indeterminate. Approximately 40 percent of the assemblage consists of pitted stones (both anvils and handheld hammers). Excluding items with interchangeable, equivocal, or indeterminate functions, base-position artifacts (anvils, grinding slabs, etc.) account for 28 percent of the assemblage, and handheld items make up 39 percent.

Three bone tools and 2,413 faunal elements were recovered. Medium to large mammalian faunal remains are most numerous, followed by deer/pronghorn-sized ungulates. Other identified taxa include rabbits and hares; deer; bison, cattle, or antelope; toads and frogs; tortoises and turtles; birds; and bony fishes.

Fifteen kinds of wood charcoal were identified from flotation samples, with oak (both white and red) and hickory being the dominant types. These fuels were collected from on or near the site, reflecting the oak-hickory forest that the area supported. Other wood charcoal includes American elm, buckeye, catalpa, holly, mulberry, pecan, plum/cherry, slippery elm, sweetgum, and willow. Charred cane stems probably represent baskets and mats rather than fuel materials. Corn is the only cultigen identified. Small numbers of maygrass, Chenopodium, little barley or wildrye, and knotweed seeds were recovered as well and indicate use of starchy-seeded annuals. Hardwood nuts, especially hickory but also acorn and black walnut, dominate the rest of the macrobotanical remains that represent foods (or in some cases perhaps medicines). Much less frequent are grape, verbena, sumac, purslane, and grass family seeds and the remains of unidentified fruit as well as bulb scales that could be from plants such as wild garlic or camas.

Forty-five radiocarbon dates were obtained. The interpretation of the radiocarbon dates that is most consistent with the feature evidence involves a primary farmstead occupation by a 


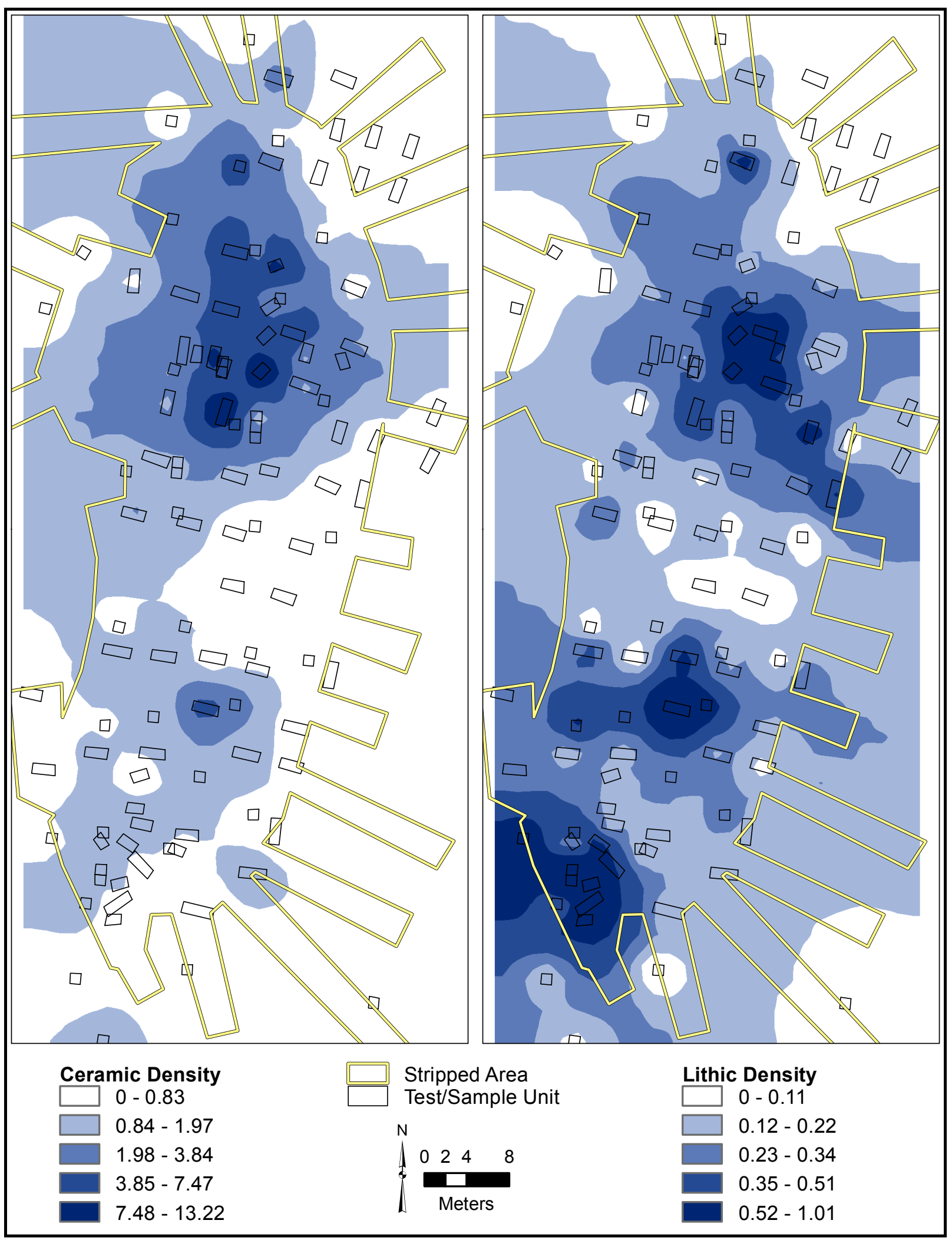

Figure 4.23. Distribution of ceramic sherds (left) and total lithic artifacts (right) across the data recovery area in Subarea 1 at the George Richey site. 
single family between A.D. 1250 and 1325 and minor shorter-term occupations in the late $900 \mathrm{~s}$, perhaps the late 1100 s or early 1200 s, the early $1400 \mathrm{~s}$, and sometime in the $1500 \mathrm{~s}$. The main-occupation dates are well represented in both feature concentrations, indicating that the same occupation is responsible for most of the features there. The single date that slightly predates the main occupation is from the northern concentration. Six of the post- 1325 dates are from the southern concentration and 2 are from the northern concentration, showing both parts of the site were used then. Ephemeral use during the 900s may have been restricted to the southern area.
Analysis of the distributions of the artifacts suggests three main conclusions: (1) the bulk of the materials represent a general rain of debris resulting from activities in and immediately around houses and outdoor activity areas; (2) the Caddo who lived there did not consistently dispose of trash in areas away from houses and activity areas within the area sampled, with the possible exception of the area north of the northern feature concentration; and (3) the fact that the distributions of lithics and especially ceramics are mostly well bounded suggests that the area chosen for data recovery captured the full extent of the occupation area. 


\section{RESULTS OF EXCAVATIONS IN SUBAREA 1 OF THE WILLIAM FORD SITE, 41TT852}

Virginia L. Hatfield, Damon Burden, Eloise Frances Gadus, and Ross C. Fields

This chapter focuses on the results of the data recovery excavations in one part, Subarea 1, of the William Ford site (41TT852). Incorporated into the discussion, though, are features and artifacts found in earlier auger and intensive testing.

\section{WORK ACCOMPLISHED IN DATA RECOVERY}

Data recovery investigations began with backhoe excavation of 75 sample units, which ranged from 1.1 to $3.5 \mathrm{~m}$ in length $($ mean $=1.9 \mathrm{~m})$, 0.9 to $1.1 \mathrm{~m}$ in width $($ mean $=1.0 \mathrm{~m})$, and 0.14 to $0.55 \mathrm{~m}$ in depth $($ mean $=0.32 \mathrm{~m})$ (Figure 5.1). Seven units were within the area designated for trackhoe swath excavations where Caddo houses were considered most likely, and the remainder were placed across the full extent of the data recovery area. None of the sample units were screened in their entirety. For most $(n=57)$, about half the fill (15 five-gallon buckets) was screened. Differing quantities of screened fill are as follows: 8 buckets for 1 unit; 10 buckets for 6 units; 11 buckets for 1 unit; 12 buckets for 5 units; 13 buckets for 2 units; 14 buckets for 1 unit; and 18 buckets for 1 unit. Five sample units were inadvertently placed on the eastern part of the site outside the relief route right of way; artifacts recovered from these were reburied in their respective units per the landowner's request.

Two trackhoe swaths were excavated in the southeast part of Subarea 1. A northwest-southeast swath measured $16.9 \mathrm{~m}$ long and $3.7 \mathrm{~m}$ wide, and extending southeast from the end of this was a second swath that was $6.0 \mathrm{~m}$ long by $4.5 \mathrm{~m}$ wide. Both were ca. $0.40 \mathrm{~m}$ deep. Several soil disturbances were identified, but no clear house arc was evident (Figure 5.2). Hence, manual excavations using fine provenience controls were considered unwarranted.

Following excavation of sample units and trackhoe swaths, the data recovery investigation area was stripped using a trackhoe down to the sandy clay Bt horizon surface, removing the A and $\mathrm{E}$ horizons. The stripped area measured $51 \mathrm{~m}$ long by $32 \mathrm{~m}$ wide, for an area of $1,754 \mathrm{~m}^{2}$. The stripped area was cleaned by hand troweling and shovel skimming, except for several areas with disturbance from tree stumps. In one area with organically enriched anthropogenic deposits, only the upper 5-10 cm was stripped off, leaving the rest for hand excavation. This area (labeled Feature 90) measured $3.7 \mathrm{~m}$ long and $2.4 \mathrm{~m}$ wide (Figure 5.3).

Almost all soil disturbances that had the potential to be cultural were assigned numbers, mapped using a total data station, and manually excavated. Six were given feature numbers but not excavated for various reasons (see Cultural Features). Disturbances that clearly were not cultural (small linear or circular ones resulting from recent root and rodent activity) were not assigned feature numbers or investigated. Since excavation of the features occurred over several weeks, they were covered with plastic to keep soil moisture in and rainwater out.

The final task involved stripping areas around the data recovery investigation area to be sure no prehistoric burials were missed. This additional stripping consisted of 11 trenches that ranged in length from $9.0 \mathrm{~m}$ to $28.0 \mathrm{~m}$ (mean $=16.2 \mathrm{~m})$, in width from 2.1 to $4.9 \mathrm{~m}($ mean $=3.4 \mathrm{~m})$, and in depth from 0.25 to $0.60 \mathrm{~m}($ mean $=40 \mathrm{~cm})$, totaling $606 \mathrm{~m}^{2}$. The 


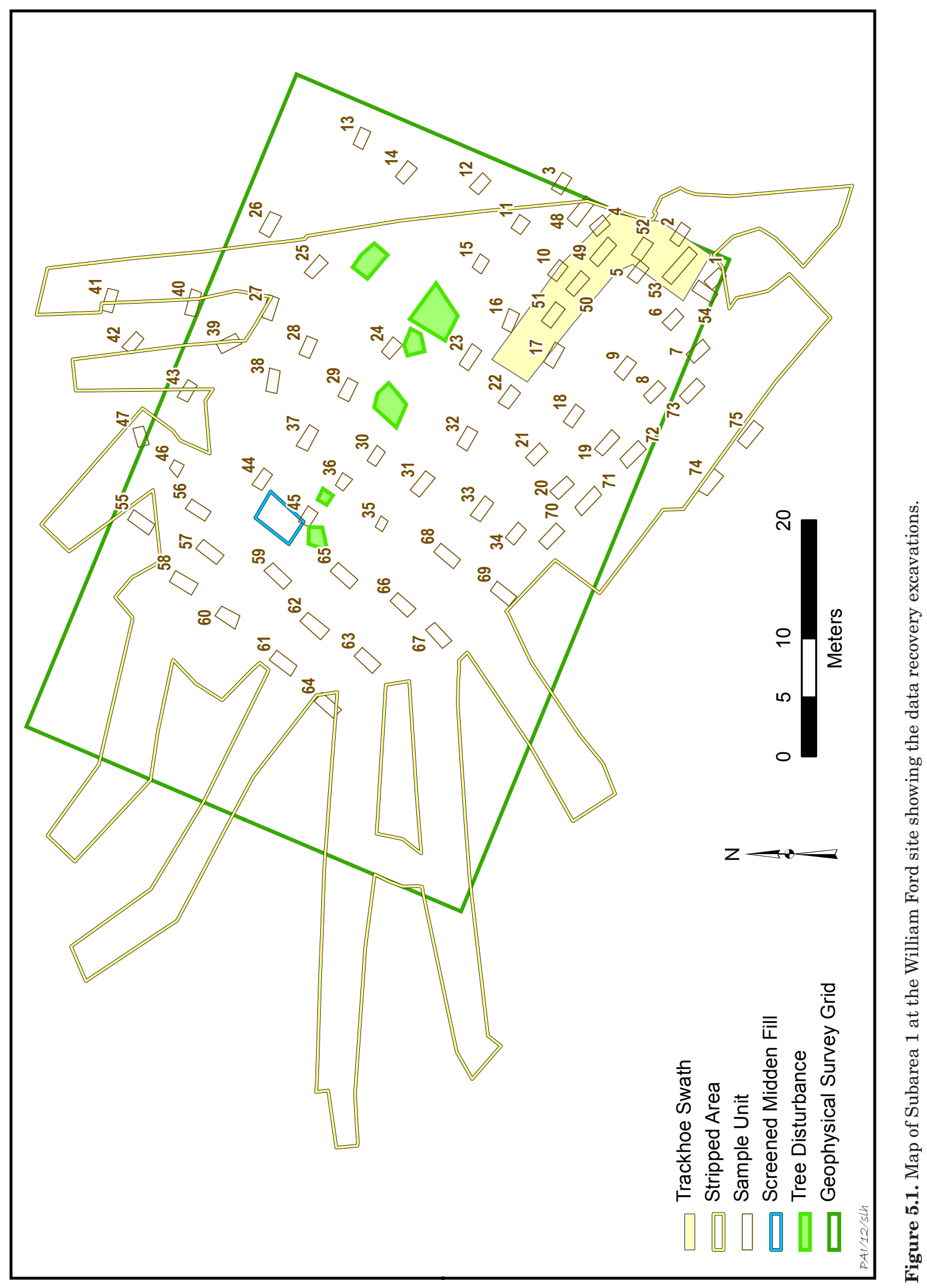




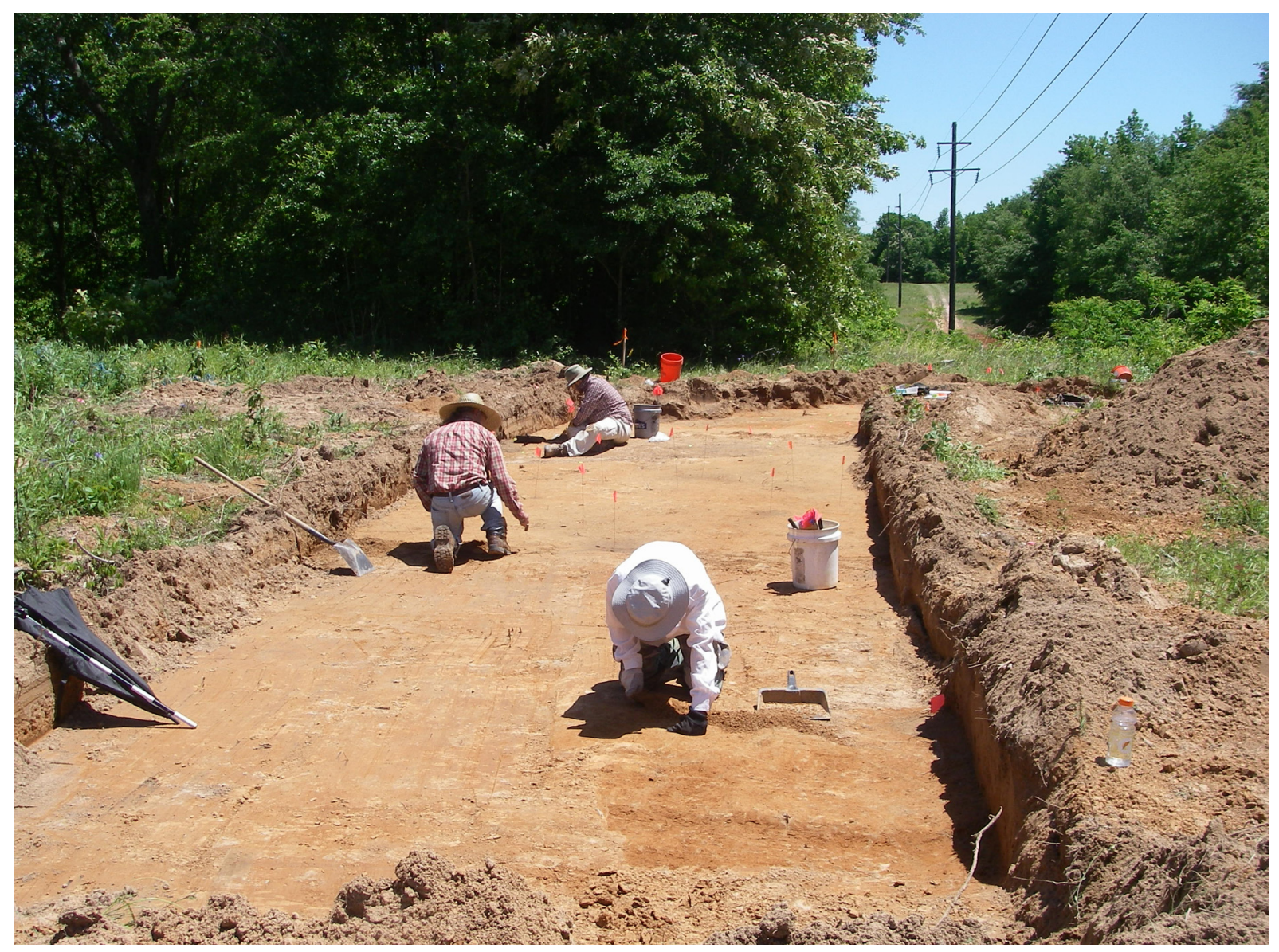

Figure 5.2. View to the east of excavation of the larger trackhoe swath in Subarea 1 at the William Ford site.

spacing between strips ranged from 3.0 to $6.0 \mathrm{~m}$ $($ mean $=3 \mathrm{~m})$.

\section{CULTURAL FEATURES}

Five hundred fifty-nine soil disturbances were identified in Subarea 1 during the testing and data recovery investigations. The vast majority ( $\mathrm{n}=553,99$ percent) were excavated. Four of the 6 that were not excavated were destroyed by erosion following data recovery stripping; the other 2 , both pockets of an organically enriched anthropogenic deposit, remained unexcavated due to time constraints. The excavated ones consist of 158 (29 percent) that are interpreted as having Native American origins and 395 (71 percent) that appear to be natural, i.e., the result of bioturbation by rodents or roots. The cultural features are 2 burials,
69 pits, 81 postholes, 1 artifact cluster, and 5 soil disturbances that correlate with 2 areas of organically enriched midden sediments (Figure 5.4). The feature dimensions and contents are summarized in Table 5.1.

\section{Burials}

One burial and one probable burial were identified. Caddo burials in east Texas exhibit some variation but typically consist of a pit that contains complete ceramic vessels, sometimes projectile points or other inclusions, and occasionally human remains. The probable burial is atypical in size.

Feature 164 was in the central portion of Subarea 1 and was discovered during data recovery stripping when the rim of a jar was exposed. The burial pit was small $(84 \times 42 \mathrm{~cm})$ 


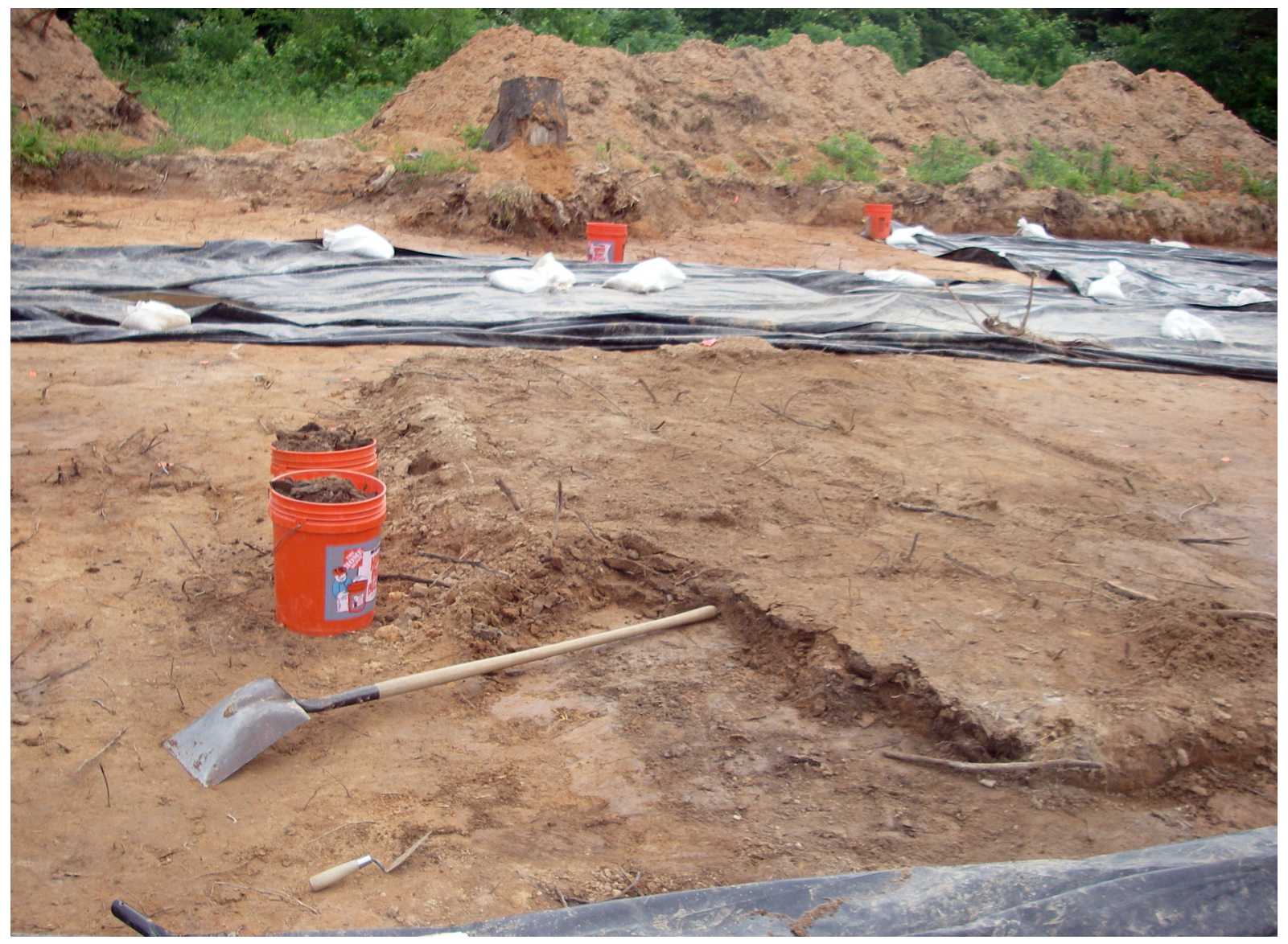

Figure 5.3. View to the northeast showing Feature 90, the organically enriched anthropogenic deposit, in Subarea 1 at the William Ford site.

and extended just $17 \mathrm{~cm}$ into the Bt horizon; its long axis was oriented northwest-southeast. The pit had vertical walls but was somewhat bean shaped in plan (Figures 5.5 and 5.6). The outline was subtle and difficult to discern in plan but was defined easily during hand excavation based on the textural difference between the loose sandy loam fill and the much more compact sandy clay Bt horizon. The burial fill was dark yellowish brown (10YR 4/6) sandy loam and contained small amounts of charcoal flecking, a few very small burned (nonhuman) bone slivers, a flake, and a little burned clay, all of which are incidental inclusions (see Table 5.1). There were no human remains preserved. Given the small size of the pit, it most likely represents the burial of a juvenile.

Burial offerings consist of a Ripley Engraved carinated bowl, a small to medium-sized untyped jar, a partial large undecorated jar, and a clump of dark reddish brown (2.5YR 3/4) clay. The bowl was situated on the east side of the pit, and the two jars and clay clump were on the west side with the smaller jar sitting on top of the larger one.

Feature $542 \mathrm{~A}$ is a probable burial and consists of a small pit $(24 \times 22 \mathrm{~cm})$ containing a single complete vessel (Figures 5.7 and 5.8). It was in the southeast part of Subarea 1 among many other features and may be a subfloor interment of an infant, fetus, or umbilical cord. The pit is circular with sloping walls and a rounded base and is only slightly larger than the vessel; it extended only $12 \mathrm{~cm}$ into the Bt horizon. The fill within the pit surrounding the vessel was strong brown (7.5YR 5/6) and reddish yellow (7.5YR 6/6) silty sand with occasional charcoal flecks, one flake, three animal bone fragments, and a small amount of charred white oak wood, all of which are incidental inclusions. The wood 


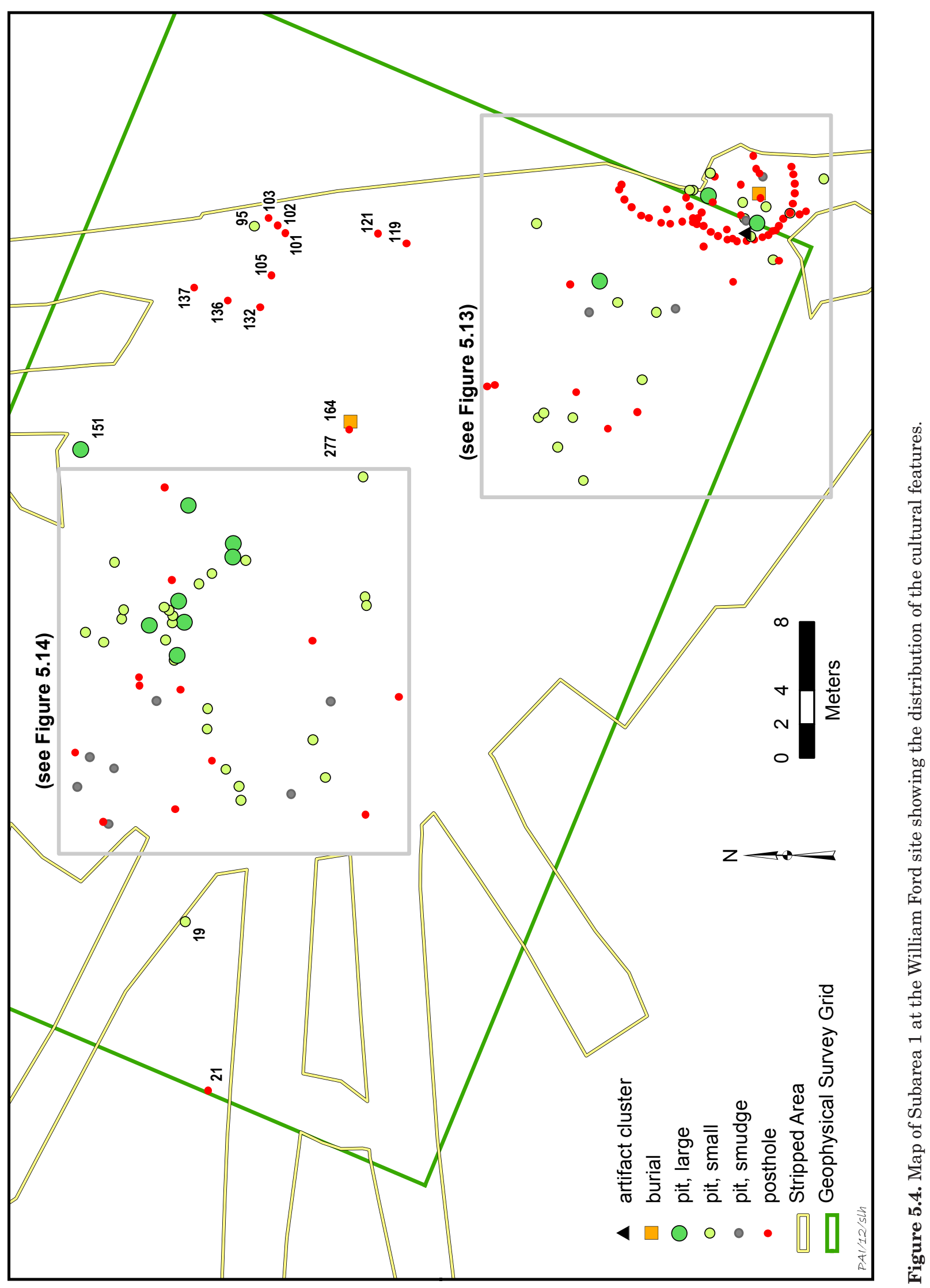


Table 5.1. Summary of cultural features in Subarea 1 at the William Ford site

\begin{tabular}{|c|c|c|c|c|}
\hline Feature & Type & \begin{tabular}{|c|}
$\begin{array}{c}\text { Dimensions } \\
(\mathrm{cm})\end{array}$ \\
\end{tabular} & $\begin{array}{l}\text { Depth } \\
(\mathrm{cm})\end{array}$ & Contents \\
\hline 164 & burial & $84 \times 42$ & 17 & $\begin{array}{l}\text { Ripley Engraved carinated bowl ( } 346.8 \mathrm{~g}) \text {, untyped small to } \\
\text { medium-sized jar ( } 823.1 \mathrm{~g}) \text {, untyped partial large jar } \\
(351.6 \mathrm{~g}), 0.3 \mathrm{~g} \text { burned clay }\end{array}$ \\
\hline $542 \mathrm{~A}$ & burial & $24 \times 22$ & 12 & $\begin{array}{l}\text { small untyped jar ( } 450.0 \mathrm{~g}), 1 \text { debitage, } 3 \text { faunal remains, } \\
0.01 \mathrm{~g} \text { macrobotanical remains }\end{array}$ \\
\hline 13 & pit, large & $100 \times 69$ & $30-37$ & $\begin{array}{l}3 \text { sherds }(4.0 \mathrm{~g}), 1 \text { point fragment, } 10 \text { debitage, } 1.63 \mathrm{~g} \\
\text { macrobotanical remains, } 6.6 \mathrm{~g} \text { burned clay, } 56.8 \mathrm{~g} \text { daub }\end{array}$ \\
\hline 55 & pit, large & $90 \times 60$ & $20-35$ & $\begin{array}{l}6 \text { sherds }(37.4 \mathrm{~g}), 4 \text { debitage, } 5 \text { faunal remains, } 1.25 \mathrm{~g} \\
\text { macrobotanical remains, } 5.3 \mathrm{~g} \text { burned clay, } 11.7 \mathrm{~g} \text { daub }\end{array}$ \\
\hline 79 & pit, large & $85 \times 50$ & 12 & 11 debitage \\
\hline 151 & pit, large & $50 \times 30$ & 27 & \\
\hline 189 & pit, large & $113 \times 95$ & 27 & $\begin{array}{l}16 \text { sherds }(79.8 \mathrm{~g}), 1 \text { Maud point, } 1 \text { flake tool, } 13 \text { debitage, } \\
4.44 \mathrm{~g} \text { macrobotanical remains, } 2.9 \mathrm{~g} \text { burned clay, } 1.3 \mathrm{~g} \\
\text { daub, } 5345.2 \mathrm{~g} \text { thermally altered rocks }\end{array}$ \\
\hline 191B & pit, large & $76 x 50$ & 18 & $\begin{array}{l}23 \text { sherds }(68.1 \mathrm{~g}), 1 \text { core tool, } 1 \text { flake tool, } 9 \text { debitage, } 3.5 \mathrm{~g} \\
\text { daub, } 4.4 \mathrm{~g} \text { burned clay, } 0.47 \mathrm{~g} \text { macrobotanical remains }\end{array}$ \\
\hline 193 & pit, large & $77 \times 70$ & 18 & $\begin{array}{l}\text { (also Feature 194) } 25 \text { sherds }(116.7 \mathrm{~g}), 1 \text { arrow point } \\
\text { fragment, } 1 \text { Kent or Gary point, } 1 \text { biface, } 12 \text { debitage, } 1 \\
\text { faunal remain, } 22.94 \mathrm{~g} \text { macrobotanical remains }\end{array}$ \\
\hline 199 & pit, large & $58 \times 44$ & 13 & $\begin{array}{l}8 \text { sherds }(29.7 \mathrm{~g}), 8 \text { debitage, } 0.58 \mathrm{~g} \text { macrobotanical } \\
\text { remains, } 7.9 \mathrm{~g} \text { daub }\end{array}$ \\
\hline 484 & pit, large & $50 \times 44$ & 11 & $\begin{array}{l}4 \text { sherds }(19.4 \mathrm{~g}), 6 \text { debitage, } 12 \text { faunal remains, } 2.42 \mathrm{~g} \\
\text { macrobotanical remains, } 29.5 \mathrm{~g} \text { burned clay, } 3.0 \mathrm{~g} \text { daub, } 1 \\
\text { thermally altered rock not recovered }\end{array}$ \\
\hline 490 & pit, large & $58 \times 55$ & 15 & $\begin{array}{l}9 \text { sherds }(50.6 \mathrm{~g}), 4 \text { debitage, } 6 \text { faunal remains, } 2.97 \mathrm{~g} \\
\text { macrobotanical remains, } 14.7 \mathrm{~g} \text { burned clay, } 12.2 \mathrm{~g} \text { daub }\end{array}$ \\
\hline 518 & pit, large & $120 \times 60$ & 12 & $\begin{array}{l}6 \text { sherds ( } 10.6 \mathrm{~g}), 1 \text { flake tool, } 1 \text { debitage, } 3 \text { faunal remains, } \\
3.23 \mathrm{~g} \text { macrobotanical remains }\end{array}$ \\
\hline 526 & pit, large & $73 \times 38$ & 35 & 1 sherd ( $7.6 \mathrm{~g}), 2$ debitage, $1.35 \mathrm{~g}$ macrobotanical remains \\
\hline 14 & pit, smudge & $22 \times 15$ & $28-40$ & $\begin{array}{l}4 \text { sherds }(9.5 \mathrm{~g}), 9.84 \mathrm{~g} \text { macrobotanical remains, } 3.0 \mathrm{~g} \\
\text { burned clay, } 0.6 \mathrm{~g} \text { daub }\end{array}$ \\
\hline 15 & pit, smudge & $26 \times 20$ & $23-47$ & 1 debitage, $3.29 \mathrm{~g}$ macrobotanical remains, $8.3 \mathrm{~g}$ daub \\
\hline 82 & pit, smudge & $33 \times 32$ & 6 & $0.05 \mathrm{~g}$ macrobotanical remains \\
\hline 232 & pit, smudge & $37 \times 37$ & 5 & 2 debitage, 2.12 g macrobotanical remains \\
\hline 233 & pit, smudge & $27 \times 22$ & 9 & $3.14 \mathrm{~g}$ macrobotanical remains, $6.6 \mathrm{~g}$ burned clay \\
\hline 259 & pit, smudge & $24 \times 18$ & 6 & 1.08 g macrobotanical remains \\
\hline 364 & pit, smudge & $37.5 \times 31$ & 22 & $0.05 \mathrm{~g}$ macrobotanical remains \\
\hline 423 & pit, smudge & $33 \times 33$ & 20 & $\begin{array}{l}5 \text { sherds }(90.7 \mathrm{~g}), 8 \text { debitage, } 26 \text { faunal remains, } 28.36 \mathrm{~g} \\
\text { macrobotanical remains }\end{array}$ \\
\hline 507 & pit, smudge & $35 \times 27$ & 16 & 1 sherd $(9.0 \mathrm{~g}), 2$ debitage, $1.11 \mathrm{~g}$ macrobotanical remains \\
\hline 508 & pit, smudge & $21 \times 20$ & 7 & 1 debitage, 3.28 g macrobotanical remains \\
\hline 546 & pit, smudge & $20 \times 16$ & 6 & 1 debitage, $5.79 \mathrm{~g}$ macrobotanical remains \\
\hline 4 & pit, small & $33 \times 31$ & $36-46$ & \\
\hline 19 & pit, small & $39 \times 26$ & $25-35$ & 1 sherd $(0.8 \mathrm{~g})$ \\
\hline 23 & pit, small & $33 \times 32$ & $35-53$ & also Feature $50 ; 1$ sherd ( $3.9 \mathrm{~g}), 1$ flake tool \\
\hline 95 & pit, small & $32 \times 30$ & 14 & $0.07 \mathrm{~g}$ macrobotanical remains \\
\hline 96 & pit, small & $32 \times 30$ & 18 & \\
\hline 112 & pit, small & $23 \times 22$ & 6 & \\
\hline 191A & pit, small & $36 \times 32$ & 16 & $\begin{array}{l}1 \text { pipe stem fragment }(1.3 \mathrm{~g}), 13 \text { sherds }(70.0 \mathrm{~g}), 1 \text { debitage, } \\
4.9 \mathrm{~g} \text { daub, } 0.99 \mathrm{~g} \text { macrobotanical remains }\end{array}$ \\
\hline
\end{tabular}


Table 5.1, continued

\begin{tabular}{|c|c|c|c|c|}
\hline Feature & Type & $\begin{array}{c}\text { Dimensions } \\
(\mathrm{cm})\end{array}$ & $\begin{array}{c}\text { Depth } \\
(\mathrm{cm})\end{array}$ & Contents \\
\hline 198 & pit, small & \begin{tabular}{|l|}
$28 \times 20$ \\
\end{tabular} & 16 & $\begin{array}{l}3 \text { sherds }(10.2 \mathrm{~g}), 4 \text { debitage, } 0.67 \mathrm{~g} \text { macrobotanical } \\
\text { remains, } 2.8 \mathrm{~g} \text { burned clay }\end{array}$ \\
\hline 203 & pit, small & $48 \times 34$ & 24 & $\begin{array}{l}21 \text { sherds }(107.1 \mathrm{~g}), 2 \text { debitage, } 1.09 \mathrm{~g} \text { macrobotanical } \\
\text { remains }\end{array}$ \\
\hline 204 & pit, small & $42 \times 41$ & 21 & 9 sherds (47.8 g), 2 debitage, 1.68 g macrobotanical remains \\
\hline 240 & pit, small & $30 \times 26$ & 12 & $\begin{array}{l}2 \text { sherds }(2.1 \mathrm{~g}), 2 \text { debitage, } 3 \text { faunal remains, } 1.77 \mathrm{~g} \\
\text { macrobotanical remains }\end{array}$ \\
\hline 243 & pit, small & $25 \times 22$ & 11 & 2 sherds (2.8 g), $1.62 \mathrm{~g}$ macrobotanical remains \\
\hline 245 & pit, small & $25 \times 20$ & 19 & 1 sherd (4.0 g), 4 faunal remains \\
\hline 264 & pit, small & $40 \times 36$ & 5 & \\
\hline 271 & pit, small & $28 \times 20$ & 4 & \\
\hline 315 & pit, small & $32 \times 30$ & 14 & 4 debitage, 0.07 g macrobotanical remains \\
\hline 316 & pit, small & $36 \times 30$ & 8 & 2 debitage \\
\hline 318 & pit, small & $35 \times 22$ & 14 & 1 sherd (27.7 g), 1 debitage \\
\hline 321 & pit, small & $45 \times 40$ & 9 & 1 debitage, $0.67 \mathrm{~g}$ macrobotanical remains \\
\hline 326 & pit, small & $42 \times 26$ & 22 & $0.54 \mathrm{~g}$ macrobotanical remains \\
\hline 344 & pit, small & $31 \times 27$ & 6 & 1 sherd (1.6 g), 1 debitage, $0.08 \mathrm{~g}$ macrobotanical remains \\
\hline 365 & pit, small & $39 \times 24$ & 10 & $0.36 \mathrm{~g}$ macrobotanical remains \\
\hline 368 & pit, small & $22 \times 21$ & 5 & \\
\hline 388 & pit, small & $41 \times 31$ & 39 & 2 sherds $(6.1 \mathrm{~g}), 4$ debitage, $0.67 \mathrm{~g}$ macrobotanical remains \\
\hline 407 & pit, small & $29 \times 26$ & 16 & $\begin{array}{l}5 \text { sherds }(23.5 \mathrm{~g}), 1 \text { debitage, } 0.06 \mathrm{~g} \text { macrobotanical } \\
\text { remains, } 1.3 \mathrm{~g} \text { burned clay }\end{array}$ \\
\hline 420 & pit, small & $42 \times 26$ & 15 & $\begin{array}{l}4 \text { sherds }(399.4 \mathrm{~g}), 6 \text { debitage, } 1.65 \mathrm{~g} \text { macrobotanical } \\
\text { remains, } 0.9 \mathrm{~g} \text { daub }\end{array}$ \\
\hline 421 & pit, small & $26 \times 24$ & 12 & 1 sherd (1.5 g), 2 debitage, $0.14 \mathrm{~g}$ macrobotanical remains \\
\hline 435 & pit, small & $25 \times 23$ & 10 & 1 sherd (2.3 g), 1 debitage, $0.99 \mathrm{~g}$ macrobotanical remains \\
\hline 437 & pit, small & $40 \times 34$ & 15 & 1 sherd ( $4.5 \mathrm{~g}), 1$ debitage, $0.67 \mathrm{~g}$ macrobotanical remains \\
\hline 442 & pit, small & $40 \times 36$ & 36 & 1 core, 2 debitage, 1.25 g macrobotanical remains \\
\hline 456 & pit, small & $25 \times 24$ & 11 & \\
\hline 472 & pit, small & $26 \times 21$ & 7 & $16.8 \mathrm{~g}$ burned clay, $0.19 \mathrm{~g}$ macrobotanical remains \\
\hline 481 & pit, small & $36 \times 26$ & 35 & $\begin{array}{l}4 \text { sherds }(13.3 \mathrm{~g}), 2 \text { debitage, } 10 \text { faunal remains, } 1.37 \mathrm{~g} \\
\text { macrobotanical remains, } 1 \text { thermally altered rock }\end{array}$ \\
\hline 487 & pit, small & $22 \times 20$ & 11 & $0.3 \mathrm{~g}$ macrobotanical remains \\
\hline 488 & pit, small & $40 \times 35$ & 38 & $\begin{array}{l}1 \text { sherd ( } 14.6 \mathrm{~g}), 1 \text { debitage, } 32 \text { faunal remains, } 1.23 \mathrm{~g} \\
\text { macrobotanical remains }\end{array}$ \\
\hline 492 & pit, small & $32 \times 28$ & 15 & $\begin{array}{l}2 \text { sherds }(5.2 \mathrm{~g}), 6 \text { faunal remains, } 5.79 \mathrm{~g} \text { macrobotanical } \\
\text { remains, } 1.4 \mathrm{~g} \text { burned clay }\end{array}$ \\
\hline $496 \mathrm{~A}$ & pit, small & $28 \times 27$ & 6 & 1 debitage, $0.16 \mathrm{~g}$ macrobotanical remains \\
\hline 496B & pit, small & $29 \times 24$ & 6 & 1 sherd (13.5 g), $0.12 \mathrm{~g}$ macrobotanical remains \\
\hline 515 & pit, small & $27 \times 24$ & 12 & $\begin{array}{l}12 \text { sherds (46.3), } 2 \text { debitage, } 7 \text { faunal remains, } 0.77 \mathrm{~g} \\
\text { macrobotanical remains, } 14.8 \mathrm{~g} \text { burned clay, } 3.2 \mathrm{~g} \text { daub }\end{array}$ \\
\hline 524 & pit, small & $28 \times 23$ & 5 & $0.21 \mathrm{~g}$ macrobotanical \\
\hline $534 \mathrm{~A}$ & pit, small & $32 \times 31$ & 6 & 1 sherd $(3.1 \mathrm{~g}), 3$ debitage, $0.1 \mathrm{~g}$ macrobotanical remains \\
\hline 539 & pit, small & $25 \times 21$ & 15 & \\
\hline 544 & pit, small & $38 \times 36$ & 16 & $\begin{array}{l}3 \text { sherds }(5.1 \mathrm{~g}), 2 \text { flake tools, } 1 \text { faunal remains, } 1.66 \mathrm{~g} \\
\text { macrobotanical remains, } 6.6 \mathrm{~g} \text { burned clay, } 9.4 \mathrm{~g} \text { daub }\end{array}$ \\
\hline 547 & pit, small & $29 \times 27$ & 9 & $\begin{array}{l}1 \text { sherd (12.2 g), } 2 \text { debitage, } 0.39 \mathrm{~g} \text { macrobotanical, } 2.0 \mathrm{~g} \\
\text { daub }\end{array}$ \\
\hline 557 & pit, small & $33 \times 27$ & 18 & \\
\hline 565 & pit, small & $26 \times 22$ & 9 & 0.31 macrobotanical remains, $0.5 \mathrm{~g}$ burned clay, $0.7 \mathrm{~g}$ daub \\
\hline
\end{tabular}


Table 5.1, continued

\begin{tabular}{|c|c|c|c|c|}
\hline Feature & Type & \begin{tabular}{|c|}
$\begin{array}{c}\text { Dimensions } \\
(\mathrm{cm})\end{array}$ \\
\end{tabular} & $\begin{array}{c}\text { Depth } \\
(\mathrm{cm})\end{array}$ & Contents \\
\hline 21 & posthole & $13 \times 10$ & $23-42$ & \\
\hline 24 & posthole & $25 \times 18$ & $30-54$ & also Feature 338 \\
\hline 25 & posthole & $27 \times 28$ & $35-43$ & 6 sherds $(50.7 \mathrm{~g}), 2.9 \mathrm{~g}$ burned clay, $2.6 \mathrm{~g}$ daub \\
\hline 30 & posthole & $20 \times 20$ & 37-62 & also Feature 339 \\
\hline 31 & posthole & $22 \times 19$ & $39-56$ & \\
\hline 32 & posthole & $16 \times 16$ & $30-42$ & \\
\hline 33 & posthole & $23 \times 23$ & $42-53$ & also Feature 59 \\
\hline 34 & posthole & $13 \times 13$ & $43-54$ & \\
\hline 35 & posthole & $21 \times 15$ & $40-58$ & 1 Gary point \\
\hline 36 & posthole & $19 \times 14$ & $40-56$ & \\
\hline 37 & posthole & $18 \times 15$ & $37-44$ & also Feature 58 \\
\hline 38 & posthole & $25 \times 23$ & $32-47$ & also Feature 52 \\
\hline 39 & posthole & $21 \times 16$ & $32-50$ & also Feature $51 ; 4$ sherds $(41.0 \mathrm{~g}), 4.3 \mathrm{~g}$ daub \\
\hline 40 & posthole & $15 x ?$ & $15-37$ & \\
\hline 41 & posthole & $20 \times 20$ & $42-62$ & \\
\hline 53 & posthole & $19 \times 17$ & 14 & 1 debitage \\
\hline 56 & posthole & $28 \times 20$ & 16 & \\
\hline 57 & posthole & $16 \times 16$ & 12 & 1 debitage \\
\hline 61 & posthole & $20 \times 17$ & 6 & \\
\hline 64 & posthole & $18 \times 16$ & 11 & $0.05 \mathrm{~g}$ macrobotanical remains \\
\hline 65 & posthole & $17 \times 17$ & 8 & $0.07 \mathrm{~g}$ macrobotanical remains \\
\hline 66 & posthole & $21 \times 18$ & 20 & 1 sherd (1.6 g), 2 debitage \\
\hline 83 & posthole & $12 \times 10$ & 19 & \\
\hline 88 & posthole & $20 \times 19$ & 4 & 1 debitage \\
\hline 101 & posthole & $16 \times 16$ & 24 & \\
\hline 102 & posthole & $19 \times 16$ & 12 & \\
\hline 103 & posthole & $15 \times 13$ & 19 & \\
\hline 105 & posthole & $24 \times 20$ & 8 & \\
\hline 106 & posthole & $26 \times 20$ & 25 & $0.04 \mathrm{~g}$ macrobotanical remains \\
\hline 107 & posthole & $14 \times 12$ & 15 & $0.06 \mathrm{~g}$ macrobotanical remains \\
\hline 108 & posthole & $12 \times 10$ & 18 & $0.02 \mathrm{~g}$ macrobotanical remains \\
\hline 117 & posthole & $18 \times 17$ & 4 & 1 sherd $(1.9 \mathrm{~g})$ \\
\hline 119 & posthole & $19 \times 18$ & 11 & 3 debitage \\
\hline 121 & posthole & $19 \times 18$ & 10 & 1 debitage \\
\hline 132 & posthole & $22 \times 19$ & 9 & \\
\hline 136 & posthole & $22 \times 20$ & 24 & 2 debitage \\
\hline 137 & posthole & $16 \times 16$ & 15 & \\
\hline 166 & posthole & $18 \times 18$ & 16 & 1 debitage, $0.13 \mathrm{~g}$ macrobotanical remains \\
\hline 234 & posthole & $17 \times 16$ & 9 & 1 sherd $(15.3 \mathrm{~g})$ \\
\hline 239 & posthole & $22 \times 18$ & 12 & 1 debitage \\
\hline 261 & posthole & $15 \times 14$ & 8 & \\
\hline 277 & posthole & $21 \times 20$ & 13 & 2 debitage \\
\hline 280 & posthole & $15 \times 15$ & 17 & 1 debitage, $2.6 \mathrm{~g}$ burned clay \\
\hline 317 & posthole & $21 \times 19$ & 13 & 1 debitage \\
\hline 324 & posthole & $20 \times 17$ & 22 & 2 debitage \\
\hline 325 & posthole & $24 \times 22$ & 8 & 1 debitage \\
\hline 336 & posthole & $18 \times 16$ & 11 & $0.08 \mathrm{~g}$ macrobotanical remains \\
\hline
\end{tabular}


Table 5.1, continued

\begin{tabular}{|c|c|c|c|c|}
\hline Feature & Type & $\begin{array}{l}\text { Dimensions } \\
(\mathrm{cm})\end{array}$ & $\begin{array}{l}\text { Depth } \\
(\mathrm{cm})\end{array}$ & Contents \\
\hline 337 & posthole & $16 \times 16$ & 14 & 1 debitage, $0.03 \mathrm{~g}$ macrobotanical remains \\
\hline 346 & posthole & $22 \times 19$ & 7 & $4.7 \mathrm{~g}$ daub \\
\hline 351 & posthole & $27 \times 22$ & 6 & \\
\hline 369 & posthole & $17 \times 16$ & 10 & \\
\hline 400 & posthole & $12 \times 12$ & 6 & \\
\hline 413 & posthole & $17 \times 14$ & 6 & \\
\hline 426 & posthole & $20 \times 17$ & 11 & $\begin{array}{l}1 \text { sherd }(2.0 \mathrm{~g}), 4 \text { faunal remains, } 0.22 \mathrm{~g} \text { macrobotanical } \\
\text { remains }\end{array}$ \\
\hline 430 & posthole & $24 \times 13$ & 16 & 3 faunal remains, $0.77 \mathrm{~g}$ macrobotanical remains \\
\hline 497 & posthole & $26 \times 26$ & 28 & $\begin{array}{l}7 \text { sherds }(30.0 \mathrm{~g}), 1 \text { flake tool, } 8 \text { debitage, } 42 \text { faunal } \\
\text { specimens, } 1.1 \mathrm{~g} \text { macrobotanical remains, } 61.7 \mathrm{~g} \text { burned } \\
\text { clay, } 45.7 \mathrm{~g} \text { daub }\end{array}$ \\
\hline 498 & posthole & $10 \times 8$ & 20 & Homan point \\
\hline 533 & posthole & $17 \times 16$ & 16 & 2 debitage, $0.15 \mathrm{~g}$ macrobotanical remains \\
\hline $534 \mathrm{~B}$ & posthole & $15 \times 12$ & 8 & see Feature 534A \\
\hline 535 & posthole & $14 \times 14$ & 4 & $0.01 \mathrm{~g}$ macrobotanical remains, $34.2 \mathrm{~g}$ burned clay \\
\hline 536 & posthole & $12 \times 11$ & 2 & \\
\hline 537 & posthole & $18 \times 17$ & 20 & $0.02 \mathrm{~g}$ macrobotanical remains \\
\hline 538 & posthole & $15 \times 14$ & 10 & \\
\hline 548 & posthole & $20 \times 18$ & 7 & \\
\hline 550 & posthole & $19 \times 17$ & 6 & \\
\hline 551 & posthole & $18 \times 16$ & 21 & $0.04 \mathrm{~g}$ macrobotanical remains \\
\hline 553 & posthole & $17 \times 16$ & 18 & 1 debitage, $0.24 \mathrm{~g}$ macrobotanical remains \\
\hline 555 & posthole & $14 \times 14$ & 17 & \\
\hline 558 & posthole & $28 \times 26$ & 32 & $\begin{array}{l}2 \text { debitage, } 4 \text { faunal remains, } 17.2 \mathrm{~g} \text { burned clay, } 13.1 \mathrm{~g} \\
\text { daub }\end{array}$ \\
\hline 560 & posthole & $17 \times 16$ & 19 & \\
\hline 561 & posthole & $15 \times 14$ & 12 & \\
\hline 564 & posthole & $15.5 \times 13$ & 6 & \\
\hline 570 & posthole & $14 \times 14$ & 13 & $\begin{array}{l}0.43 \mathrm{~g} \text { macrobotanical remains, } 2.5 \mathrm{~g} \text { burned clay, } 4.3 \mathrm{~g} \\
\text { daub }\end{array}$ \\
\hline 572 & posthole & $16 \times 16$ & 10 & 2 debitage, $0.48 \mathrm{~g}$ macrobotanical remains \\
\hline 573 & posthole & $15 \times 15$ & 25 & \\
\hline 574 & posthole & $16 \times 16$ & 26 & 2 debitage, $0.36 \mathrm{~g}$ macrobotanical remains \\
\hline 575 & posthole & $16 \times 16$ & 23 & $\begin{array}{l}0.41 \mathrm{~g} \text { macrobotanical remains, } 1.6 \mathrm{~g} \text { burned clay, } 0.3 \mathrm{~g} \\
\text { daub }\end{array}$ \\
\hline 62 & $\begin{array}{l}\text { probable } \\
\text { posthole }\end{array}$ & $21 \times 17$ & & \\
\hline 67 & $\begin{array}{l}\text { probable } \\
\text { posthole }\end{array}$ & $22 \times 18$ & & \\
\hline 68 & $\begin{array}{l}\text { probable } \\
\text { posthole }\end{array}$ & $20 \times 15$ & 4 & \\
\hline 552 & $\begin{array}{l}\text { probable } \\
\text { posthole }\end{array}$ & $18 \times 18$ & 5 & \\
\hline 1 & $\begin{array}{l}\text { artifact } \\
\text { cluster }\end{array}$ & $40 \times 27$ & $19-39$ & $\begin{array}{l}208 \text { sherds ( } 1862.6 \mathrm{~g} ; 632.8 \mathrm{~g} \text { of which make up } 20 \text { percent } \\
\text { of a large utility jar), } 2 \text { bifaces, } 2 \text { flake tools, } 53 \text { debitage, } 12 \\
\text { faunal remains }\end{array}$ \\
\hline
\end{tabular}


Table 5.1, continued

\begin{tabular}{|c|c|c|c|c|}
\hline Feature & Type & \begin{tabular}{|c|} 
Dimensions \\
$(\mathrm{cm})$
\end{tabular} & $\begin{array}{l}\text { Depth } \\
\text { (cm) }\end{array}$ & Contents \\
\hline 90 & $\begin{array}{l}\text { area of } \\
\text { organically } \\
\text { enriched } \\
\text { deposit }\end{array}$ & $400 \times 400$ & $5-35$ & $\begin{array}{l}361 \text { sherds }(2418.11 \mathrm{~g}), 1 \text { spindle whorl fragment, } 1 \\
\text { Catahoula point, } 1 \text { biface, } 3 \text { flake tools, } 2 \text { cores, } 2 \text { celts, } 1 \\
\text { mano/hammerstone, } 1 \text { pigment stone, } 40 \text { debitage, } 1 \text { turtle } \\
\text { shell game piece, } 18 \text { faunal remains, } 4.26 \mathrm{~g} \text { macrobotanical } \\
\text { remains, } 82.2 \mathrm{~g} \text { burned clay, } 68.6 \mathrm{~g} \text { daub, } 152.4 \mathrm{~g} \text { thermally } \\
\text { altered rocks }\end{array}$ \\
\hline 477 & $\begin{array}{l}\text { area of } \\
\text { organically } \\
\text { enriched } \\
\text { deposit }\end{array}$ & $140 \times 65$ & $25-43$ & $\begin{array}{l}12 \text { sherds }(99.0 \mathrm{~g}), 1 \text { Maud point, } 1 \text { flake tool, } 2 \text { cores, } 16 \\
\text { debitage, } 5 \text { faunal specimens, } 1.72 \mathrm{~g} \text { macrobotanical } \\
\text { remains, } 33.7 \mathrm{~g} \text { burned clay, } 39.8 \mathrm{~g} \text { daub }\end{array}$ \\
\hline 478 & $\begin{array}{l}\text { area of } \\
\text { organically } \\
\text { enriched } \\
\text { deposit } \\
\end{array}$ & $32 \times 30$ & $30-34$ & $\begin{array}{l}1 \text { sherd ( } 1.2 \mathrm{~g}), 1 \text { faunal remains, } 0.21 \mathrm{~g} \text { macrobotanical } \\
\text { remains, } 3.2 \mathrm{~g} \text { burned clay, } 2.7 \mathrm{~g} \text { daub }\end{array}$ \\
\hline 543 & $\begin{array}{l}\text { area of } \\
\text { organically } \\
\text { enriched } \\
\text { deposit }\end{array}$ & $30 \times 20$ & 5 & $\begin{array}{l}\text { artifacts from Features } 543 \text { and } 545 \text { were combined in the } \\
\text { field; } 2 \text { sherds }(8.1 \mathrm{~g}), 2 \text { debitage, } 8.7 \mathrm{~g} \text { burned clay, } 2.0 \mathrm{~g} \\
\text { daub }\end{array}$ \\
\hline 545 & $\begin{array}{l}\text { area of } \\
\text { organically } \\
\text { enriched } \\
\text { deposit }\end{array}$ & $30 \times 35$ & 5 & \\
\hline
\end{tabular}

Note: Single number for depth indicates depth below detection level (the scraped surface); range indicates depth below ground surface.

charcoal yielded a two-sigma calibrated date of A.D. 720-944, but this does not relate to the age of the probable burial. The single vessel is a small undecorated and untyped jar.

\section{Pits}

The 69 pits make up 43 percent of the cultural features. Pits are typically oval to circular in plan view with sloping walls and rounded to flat bottoms. They range in length from 20 to $120 \mathrm{~cm}($ mean $=40 \mathrm{~cm})$, in width from 15 to $95 \mathrm{~cm}($ mean $=32 \mathrm{~cm})$, and in depth from 4 to $39 \mathrm{~cm}($ mean $=14 \mathrm{~cm})$. The pits are differentiated by size with those having a long axis greater than or equal to $50 \mathrm{~cm}$ considered large pits and the rest considered small pits. Included within the small pits are smudge pits, which have evidence of probable in situ burning.

\section{Large Pits}

The large pits $(n=12)$ are predominantly oval in plan view and range in length from 50 to
$120 \mathrm{~cm}($ mean $=86 \mathrm{~cm})$, in width from 30 to $95 \mathrm{~cm}$ $($ mean $=55 \mathrm{~cm})$, and in depth below detection level from 7 to $35 \mathrm{~cm}$ (mean $=16 \mathrm{~cm})$. In cross section, they are basin shaped with sloping walls and rounded bases (Figure 5.9). Bioturbation intruded into many of these pits and impacted the shape of the walls and floors of some. The fill within the large pits included brown (7.5YR 5/4; 10YR 4/3, 4/4), strong brown (7.5YR 4/4), yellowish brown (10YR 5/8), and dark yellowish brown (10YR 3/6) sandy loam or silty sandy loam.

Cultural materials were generally infrequent in the large pits, which yielded less than 15 percent of the total assemblage in almost all categories (Table 5.2). One exception is thermally altered rocks, of which 63 percent came from Feature 189. Faunal remains consist of just 27 elements. These are predominantly identified only to the vertebrate subphylum, but 6 are canid/deer-sized to deer/pronghorn-sized mammal bone fragments, and 2 are turtle shell fragments (see Appendix G).

The macrobotanical remains make up 31 percent of the total site assemblage. 


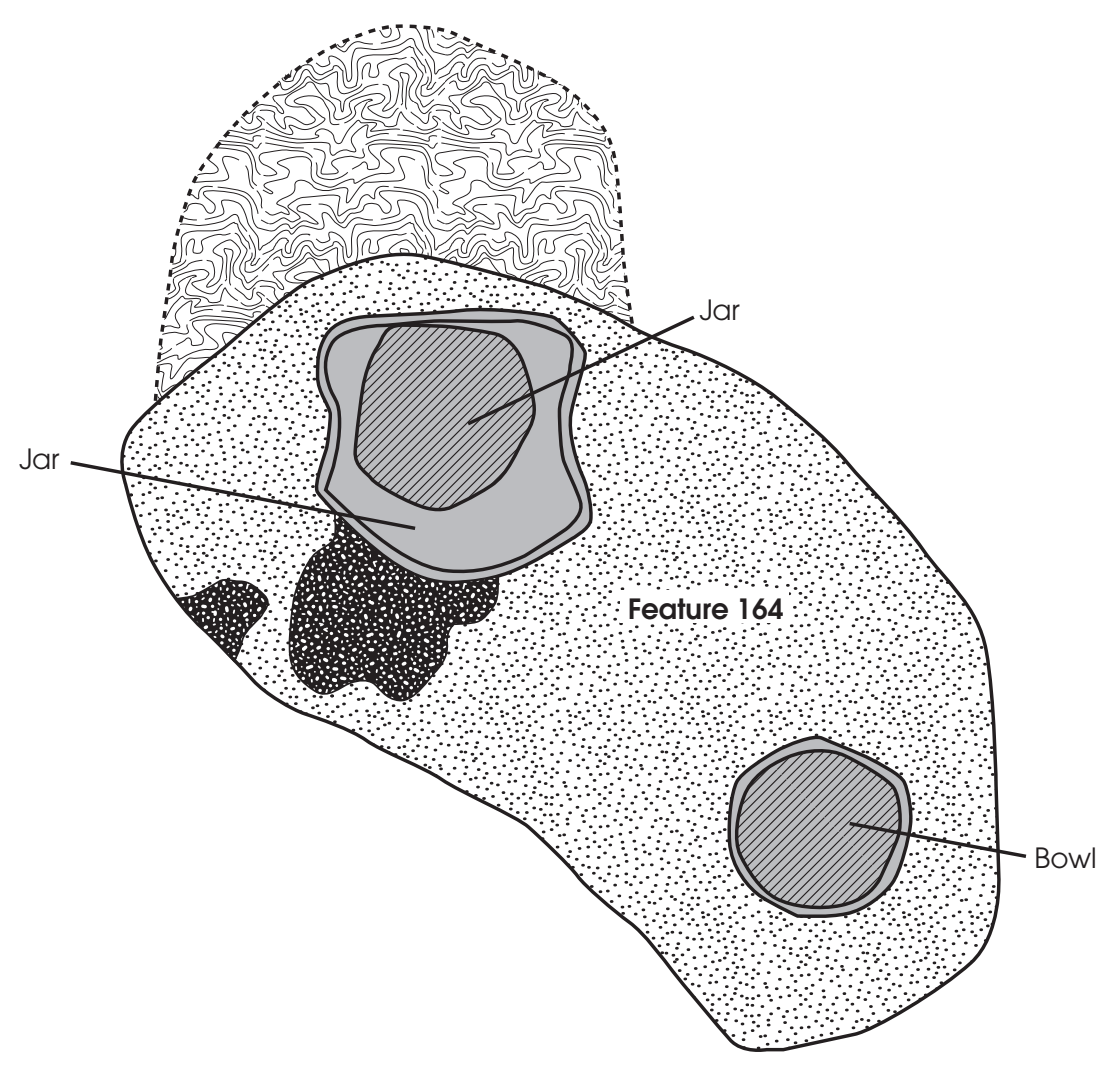

$L E G E N D$

Red Clay

Bioturbated Area

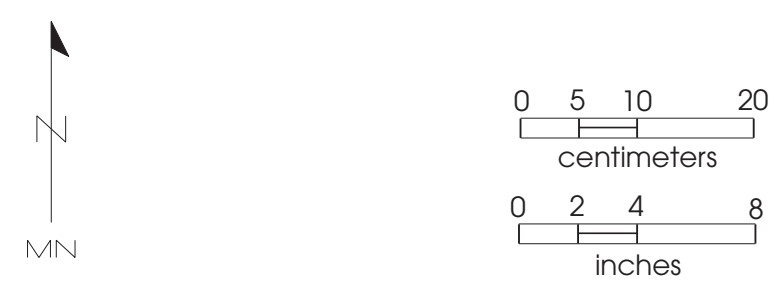

PAI/12/BW

Figure 5.5. Plan of burial Feature 164 in Subarea 1 at the William Ford site.

The identified remains consist mostly of wood charcoal (14.54 g of American elm, ash, elderberry, hickory, maple, oak, persimmon, willow, and sweetgum) and burned nutshells (7.20 g of hickory, hickory/walnut, and acorn), with small amounts of corn rachis $(0.83 \mathrm{~g})$, cane stem $(0.01 \mathrm{~g})$, and a variety of seeds $(0.23 \mathrm{~g}$ of bean/persimmon, corn, erect knotweed, maygrass, panicgrass, persimmon, purslane, and sticktight). The density of macrobotanical remains in the 10 features with flotation samples ranges from 0.025 to $0.612 \mathrm{~g} /$ liter, averaging $0.172 \mathrm{~g} /$ liter (or just $0.087 \mathrm{~g} /$ liter excluding Features 193 and 518 with the highest 
values). This low average is comparable to that for the small pits discussed below, much lower than the one for smudge pits, and higher than the average for postholes. The low densities in general suggest that most of these remains are in secondary context, and this probably is true as well for the other classes of materials in these pits. There is a high likelihood that most of the cultural materials were introduced into these pits from general scatters of debris present when the pits were dug or deposited there during and after pit use. The difference compared to the smudge pits also may indicate that these large pits were cleaned out for reuse more often.

Although most of the large pits are fairly nondescript, a handful warrant discussion. Feature 189 is $27 \mathrm{~cm}$ deep with a scatter of burned rocks on one side (Figure 5.10; see Figure 5.9). Within the pit were $5.3 \mathrm{~kg}$ of burned rocks, including a fairly tight concentration of burned silicified wood weighing $2.7 \mathrm{~kg}$. The remaining burned rocks were ferruginous sandstone and were more dispersed. The concentration of rocks measured $30 \mathrm{~cm}$ in diameter and $13 \mathrm{~cm}$ deep, with dark gray ash, charcoal flecking, and charcoal staining around the rocks. This pit may have served as a hearth or perhaps was used to heat-treat lithic materials, like silicified wood. This pit may reflect some primary context, given the tight concentration of burned rocks, but most of the fill likely reflects deposition of refuse or infilling following disuse.

Feature 199 is just west of, and connected via bioturbation to, Feature 189 (see Figures 5.9 and 5.10). It had three fill zones including a pocket of carbon-stained sediment toward the base. The upper zone and most of the fill is dark yellowish brown (7.5YR 4.4), and the lower zone is mottled

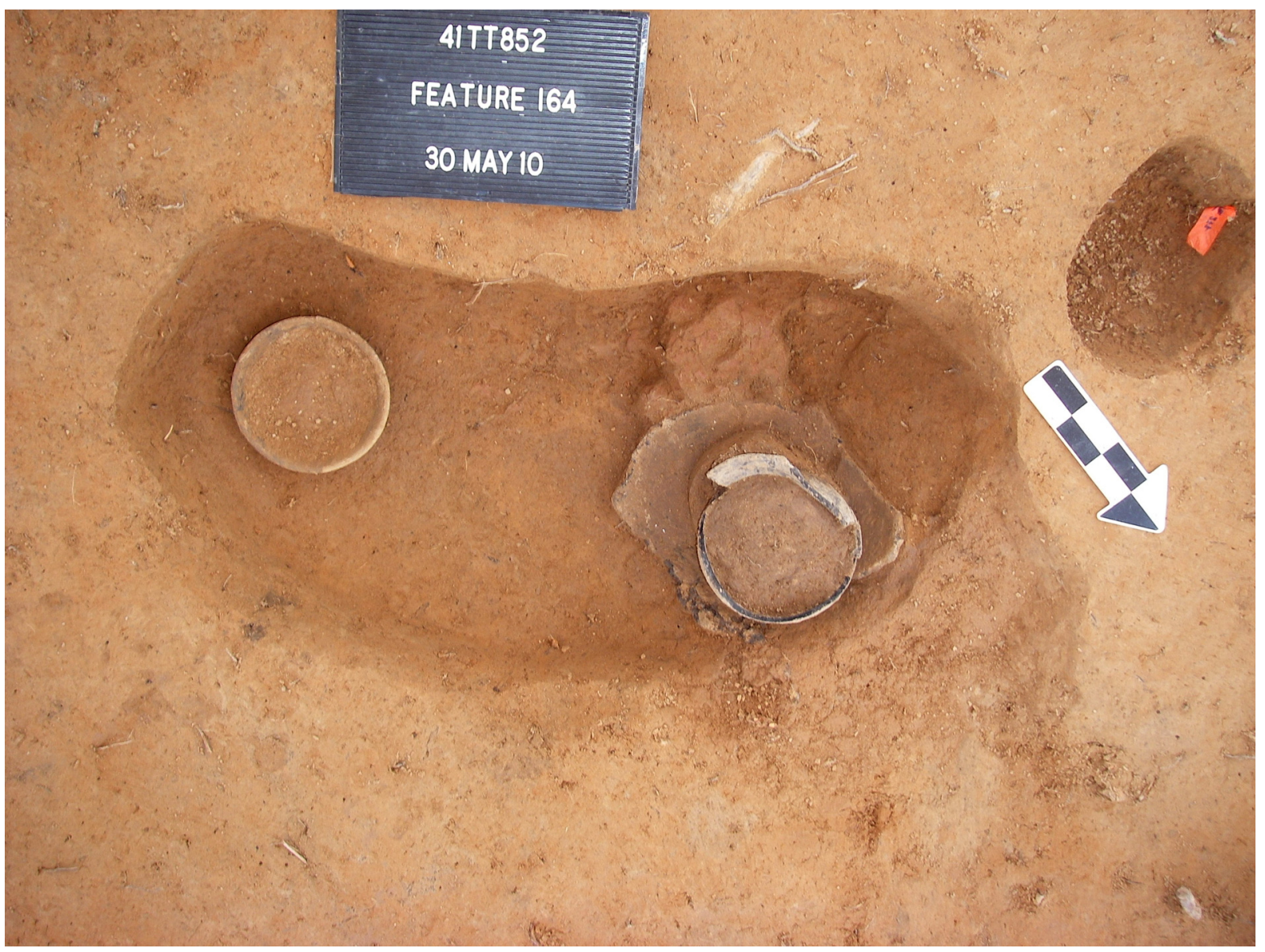

Figure 5.6. Photograph of burial Feature 164 in Subarea 1 at the William Ford site. 
strong brown (7.5YR 5/6 and 5/7) sandy loam with sandy clay inclusions. Both of these are probably the result of infilling of refuse from the general area, with only the pocket of carbon-stained sediment potentially reflecting a primary context.

Features 191A (a small pit) and 191B (a large pit) are near Features 189 and 199. Although Feature 191A is a small pit, it is described here because of its close association with Feature 191B (see Figure 5.10). Initially, Features 191A and 191B appeared to be the same pit and designated Feature 191. Excavation revealed two distinct features separated by a rise in the floor that defined two basin-shaped pits. The fill within both pits is brown (10YR 4/3) silty sand loam. Feature 191A is smaller $(36 \times 32 \mathrm{~cm})$ and slightly shallower $(16 \mathrm{~cm})$ than Feature $191 \mathrm{~B}(76 \times 50 \times 18 \mathrm{~cm})$ and is on the west side.

Feature 484 had three distinct fill zones and indications of possible in situ burning (see Figure 5.9). The northwest zone may be an intrusive cultural feature or possibly a posthole, but the other two zones included dark sandy loam with charcoal flecks and fragments, a fire-cracked rock, burned macrobotanical and faunal remains, and burned clay and daub (see Table 5.1). In addition, the base of the pit was oxidized, and the walls were carbon stained. This feature was probably used for cooking.

\section{Small Pits}

The 57 small pits (including 11 smudge pits) represent 36 percent of the features. They range from 20 to $48 \mathrm{~cm}$ in length (mean $=32 \mathrm{~cm}), 15$ to $41 \mathrm{~cm}$ in width $($ mean $=27 \mathrm{~cm})$, and 4 to $39 \mathrm{~cm}$ in depth below detection level $($ mean $=14 \mathrm{~cm})$. Only 4 have depths greater than $25 \mathrm{~cm}$. The small pits are predominantly basin shaped in cross section with some variability due to bioturbation (Figure 5.11). The fill in these pits includes strong brown (7.5YR 5/6,4/6), yellowish brown (10YR 5/4), grayish brown (10YR 5/2), brown (10YR 4/3, 7.5YR4/4), dark yellowish brown (10YR 4/6, 4/4, 3/4), dark gray (10YR 4/1), dark brown (10YR 3/3), very dark yellowish brown (10YR 3/2), dark reddish brown (5YR 3/2 and 3/3), and dark brown (10YR 3/2 and 3/1) sandy loam. Some have charcoal flecking, and a few have multiple fill zones.

Cultural materials are generally similar to those from large pits, except that the former had slightly more faunal remains, far more macrobotanical remains, and no burned rocks (see Table 5.2). The faunal remains $(\mathrm{n}=89)$ are slightly more diverse than those from the large pits, though most are identified only to the vertebrate subphylum with 1 being deer/pronghorn-sized mammal, 6 being canid/deer-sized mammal, 1 being cottontail rabbit, and 9 being turtle.

The macrobotanical remains make up 61 percent of the total from the site. Identified remains 


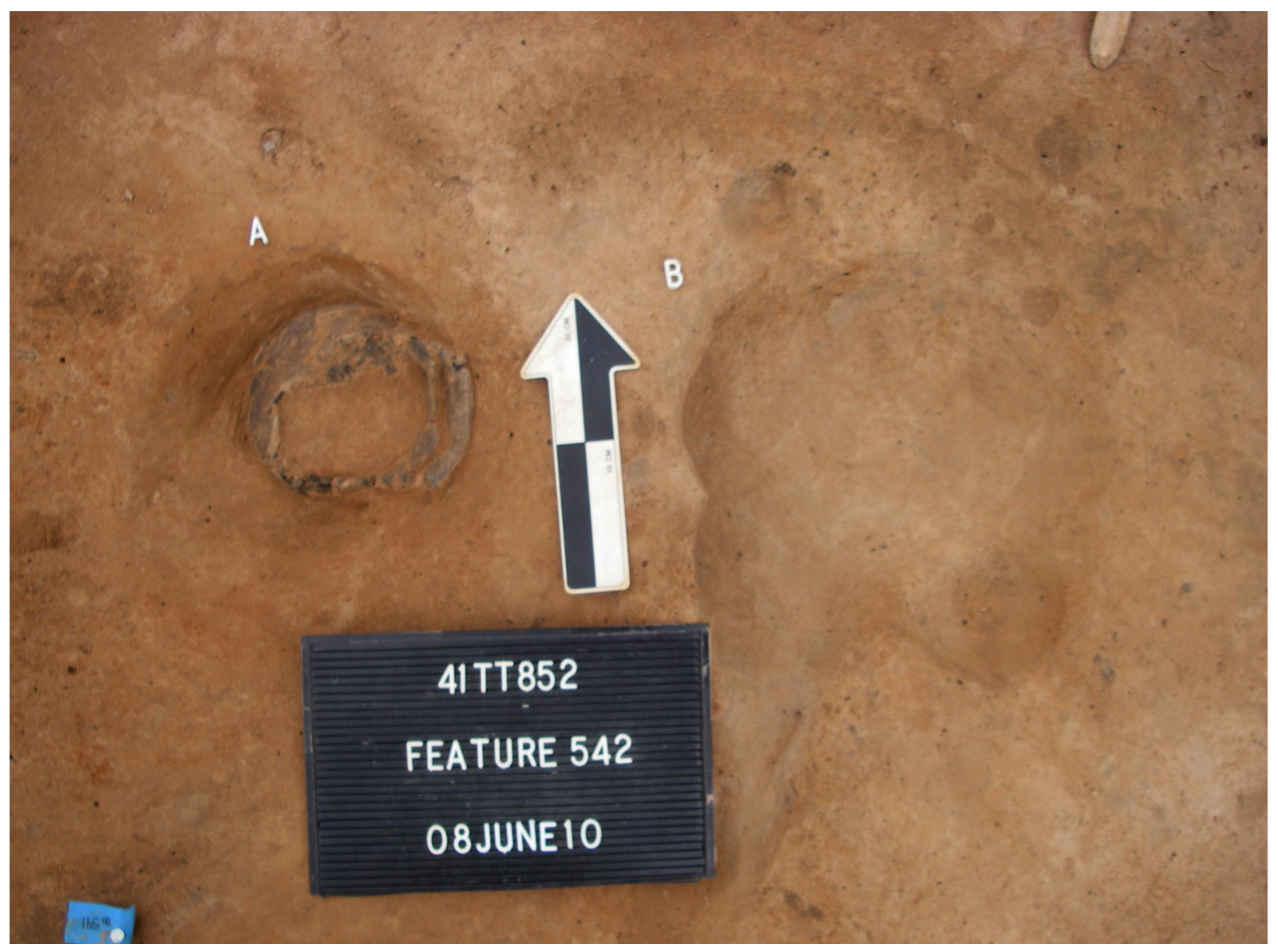

Figure 5.8. Photograph of probable burial Feature 542A in Subarea 1 at the William Ford site.

consist of $64.55 \mathrm{~g}$ of wood charcoal (American elm, ash, black walnut, buckeye, elm, hickory, maple, mulberry, oak, plum/cherry, sycamore, and willow/ cottonwood), $16.50 \mathrm{~g}$ of burned nutshells (hickory/ walnut, hickory, and acorn), $0.07 \mathrm{~g}$ of hickory/ walnut family nutmeat, $3.12 \mathrm{~g}$ of corn rachis, $0.03 \mathrm{~g}$ of cane stem, $0.01 \mathrm{~g}$ of grass stem, and $0.77 \mathrm{~g}$ of seeds (goosefoot, maygrass, purslane, bean/persimmon, common bean, corn, daisy family, grape, grass family, legume, little barley, panicgrass, smartweed, stick-tight, and sumac). A significant portion of the remains (68 percent) are from smudge pits, even though flotation samples came from far fewer smudge pits than other small pits (11 vs. 32). Excluding the smudge pits, the small pits have an average macrobotanical remains density of $0.106 \mathrm{~g} /$ liter, ranging from 0.005 to $0.608 \mathrm{~g} /$ liter. As with the large pits, this low value implies that most of the charred materials are not related directly to the functions of the small pits, instead reflecting general debris in the vicinity that was mixed over time.

Small pits that exhibit in situ burning are interpreted as smudge pits, which are presumed to have contained smoky fires for insect control or hide and meat processing. Feature 14 was filled with dark yellowish brown sandy loam with a 2-cm-thick lens of charred remains. Feature 15 has a central zone of dark brown sandy loam with charcoal flecking and charcoal pieces surrounded by mottled yellowish brown and strong brown sandy clay; the outer zone may reflect the initial excavation of the pit or bioturbation, while the inner zone most likely pertains to use as a smudge pit. Feature 82 , the very bottom of a smudge pit, had brown to strong brown (7.5YR 4/4-4/6) sandy loam fill with very dark gray (7.5YR 3/0) mottles and 


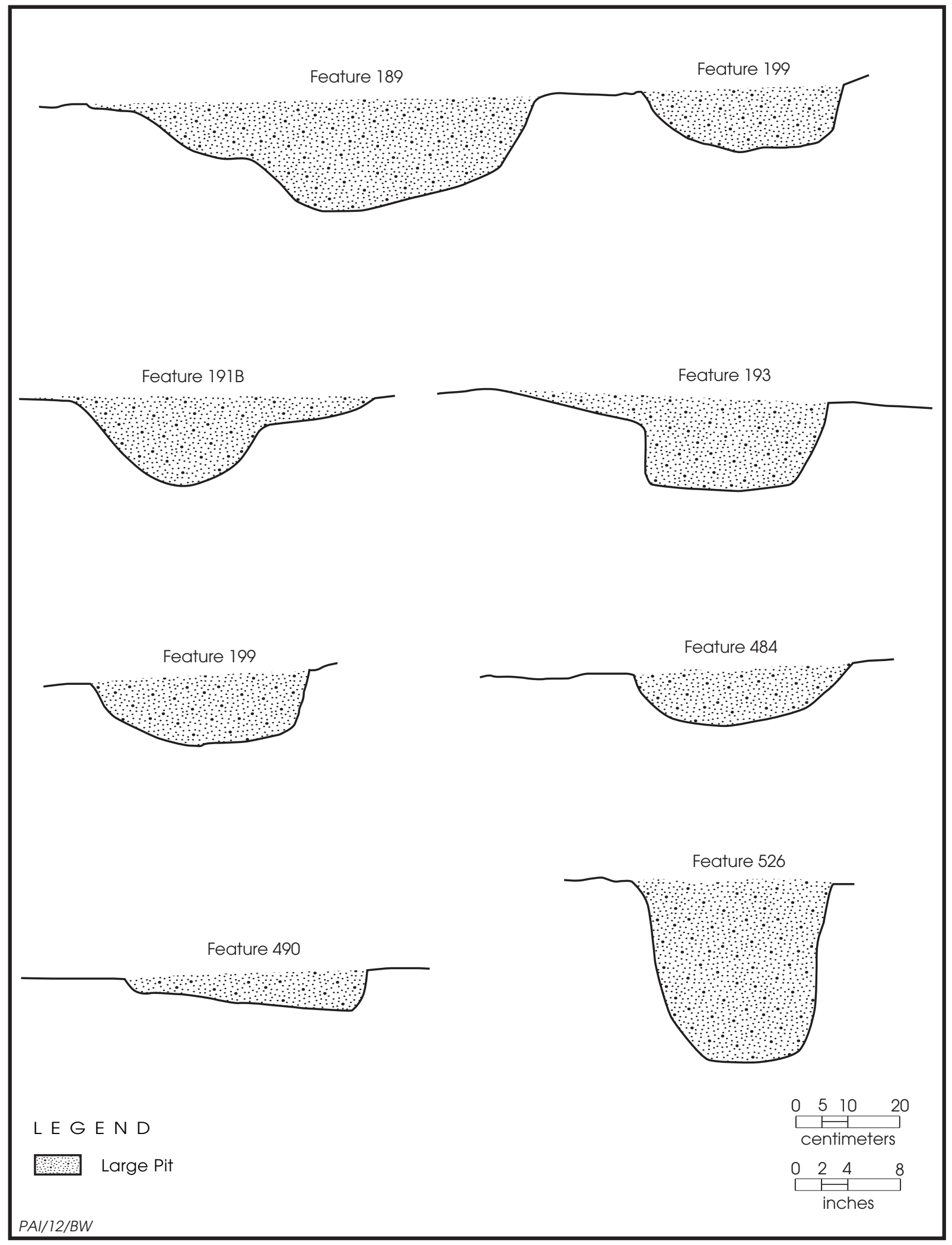

Figure 5.9. Cross sections of selected large pits in Subarea 1 at the William Ford site. 
Excavations along the U.S. Highway 271 Mount Pleasant Relief Route

Table 5.2. Cultural materials from pits and postholes in Subarea 1 at the William Ford site

\begin{tabular}{l|c|c|c|c|c|c}
\hline & \multicolumn{2}{|c|}{ Large Pits } & \multicolumn{2}{c}{ Small Pits } & \multicolumn{2}{c}{ Postholes } \\
\hline & No./Wt. (g) & $\begin{array}{c}\text { \% of Site } \\
\text { Total }\end{array}$ & No./Wt. (g) & $\begin{array}{c}\text { of Site } \\
\text { Total }\end{array}$ & No./Wt. (g) & $\begin{array}{c}\text { Total } \\
\text { Tote }\end{array}$ \\
\hline Ceramics & $101 / 423.9$ & $2 / 1$ & $115 / 623.4$ & $2 / 2$ & $27 / 194.8$ & $1 / 1$ \\
\hline Chipped stone tools & 9 & 5 & 3 & 2 & 3 & 2 \\
\hline Ground stone tools & 0 & 0 & 0 & 0 & 0 & 0 \\
\hline Bone tools & 0 & 0 & 0 & 0 & 0 & 0 \\
\hline Cores & 0 & 0 & 1 & 2 & 0 & 0 \\
\hline Debitage & $44 / 26.4$ & $2 / 1$ & $59 / 29.2$ & $3 / 1$ & $38 / 13.1$ & $2 /<1$ \\
\hline Macrobotanical remains & 43.05 & 30 & 86.08 & 61 & 4.71 & 3 \\
\hline Faunal remains & 27 & 7 & 89 & 23 & 49 & 13 \\
\hline Mussell/snail shells & 0 & 0 & 0 & 0 & 3 & 100 \\
\hline Thermally altered rocks & 5345.2 & 63 & 0 & 0 & 0 & 0 \\
\hline Daub & 111.9 & 7 & 16.8 & 1 & 83.3 & 5 \\
\hline Burned clay & 67.1 & 5 & 51.0 & 4 & 122.7 & 9
\end{tabular}

small amounts of ash, charcoal staining, and charred remains. Feature 232 had two fill zones; the west half was charcoal-stained black to dark yellowish brown (10YR 2/1 to 3/2) silty sand, and the east half was dark yellowish brown (10YR 3/3 to 4/3) sandy loam. Feature 233 had dark grayish brown (10YR 3/2) silty sand fill mottled with dark yellowish brown (10YR 4/4), brown (10YR 3/3), and very dark grayish brown (10YR 2/2) silty sand and common charcoal flecking. Feature 259 was filled mostly with charcoal-stained black (10YR 2/1) sand, dense charcoal, and occasional strong brown (7.5YR 5/8) sandy loam inclusions; at the base was red (2.5YR 4/6) and reddish brown (2.5YR 4/3) clay loam that appeared oxidized. Feature 364 was filled with very dark gray (10YR 3/1) sandy loam and pockets of darker charcoal-rich loam. Feature 423 is another smudge pit with two zones of fill-an upper one of very dark grayish brown (10YR 3/2) sandy loam and a lower one of slightly darker very dark grayish brown (10YR 3/1) sandy loam with charcoal flecking and fragments - and the base of the pit was oxidized. Feature 507 also had evidence for in situ burning; the fill included an upper zone of loose brown (7.5YR 4/4) sandy loam with some mottling, charcoal flecking, and charred botanical remains, and the lower fill was compact brown (7.5YR 4/4) and dark brown (7.5YR 3/4) sandy clay with dense charcoal staining, flecking, and fragments, as well as ashy patches. Feature 508 was filled with black (10YR 2/1) charcoal-dense sandy loam. Feature 546 had yellowish brown (10YR 5/4) sandy loam fill with relatively dense charred macrobotanical remains.

The 11 smudge pits within Subarea 1 make up 20 percent of the small pits. The identified macrobotanical remains among the $58.49 \mathrm{~g}$ recovered are dominated by wood charcoal $(51.38 \mathrm{~g}$ of buckeye, elm, hickory, maple, oak, plum/cherry, and other wood), with some nutshells (4.57 $\mathrm{g}$ of hickory/walnut, hickory, and acorn), seeds ( $0.15 \mathrm{~g}$ of corn, goosefoot, maygrass, purslane, and indeterminable), and $1.9 \mathrm{~g}$ of corn rachis. Apparently, various woods were the fuel of choice in creating smoky fires. Macrobotanical remains are relatively abundant within the smudge pits, ranging from 0.002 to $5.79 \mathrm{~g} /$ liter and averaging $1.153 \mathrm{~g} /$ liter (or 0.689 g/liter excluding Feature 546 with an unusually high value), consistent with the idea that they represent primary contexts. The only other cultural materials within them were debitage $(\mathrm{n}=13)$, sherds $(\mathrm{n}=10)$, and burned clay (6.6 g).

Only one other small pit warrants individual discussion. Feature 204 contained ash, charred remains, and charcoal flecking that may be the result of in situ burning; it had two fill zones (see Figure 5.11).

\section{Postholes}

The 81 postholes make up 51 percent of the cultural features. Postholes are circular to 


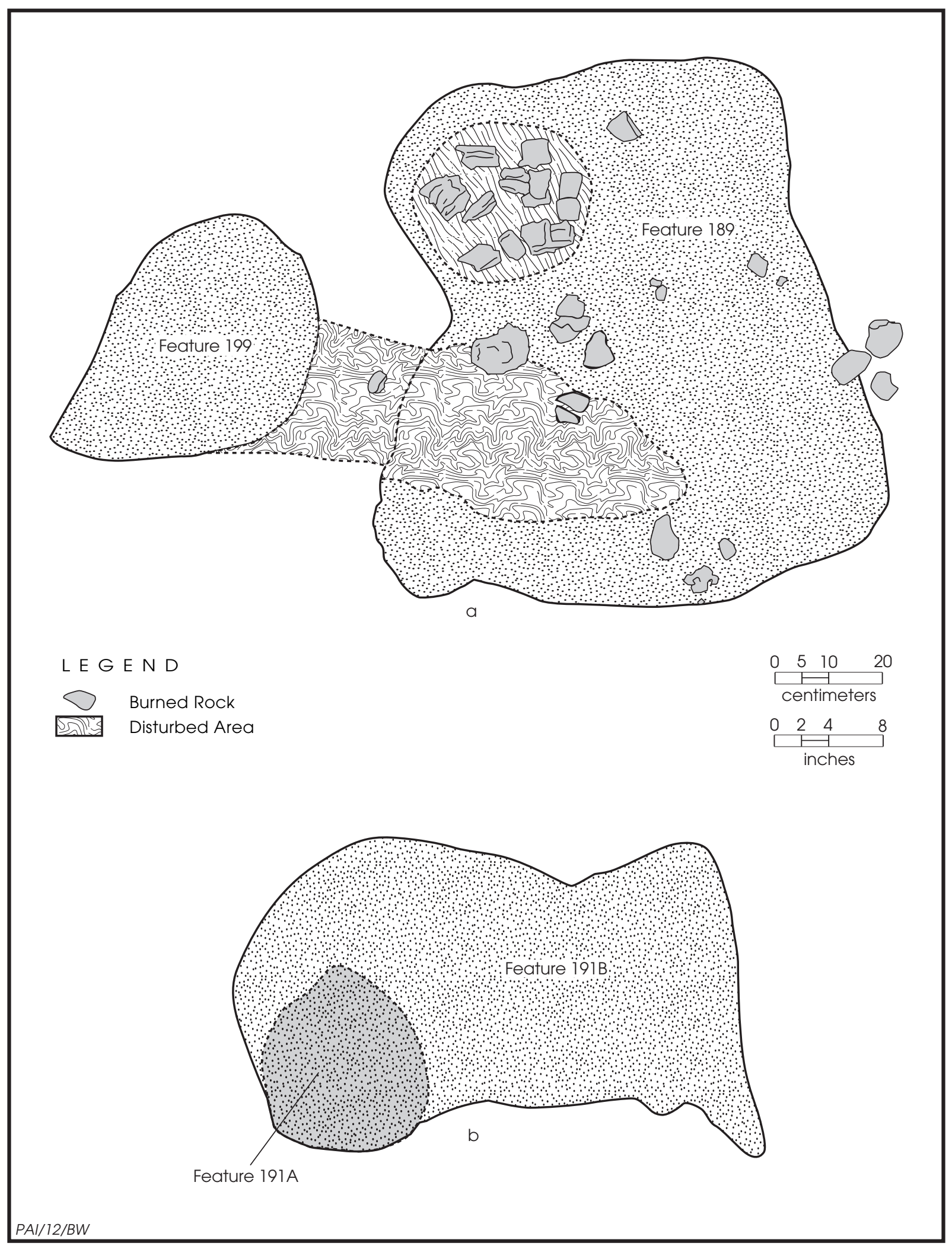

Figure 5.10. Plans of three large pits in Subarea 1 at the William Ford site. (a) Features 189 and 199; (b) Feature 191B and small pit Feature 191A. 


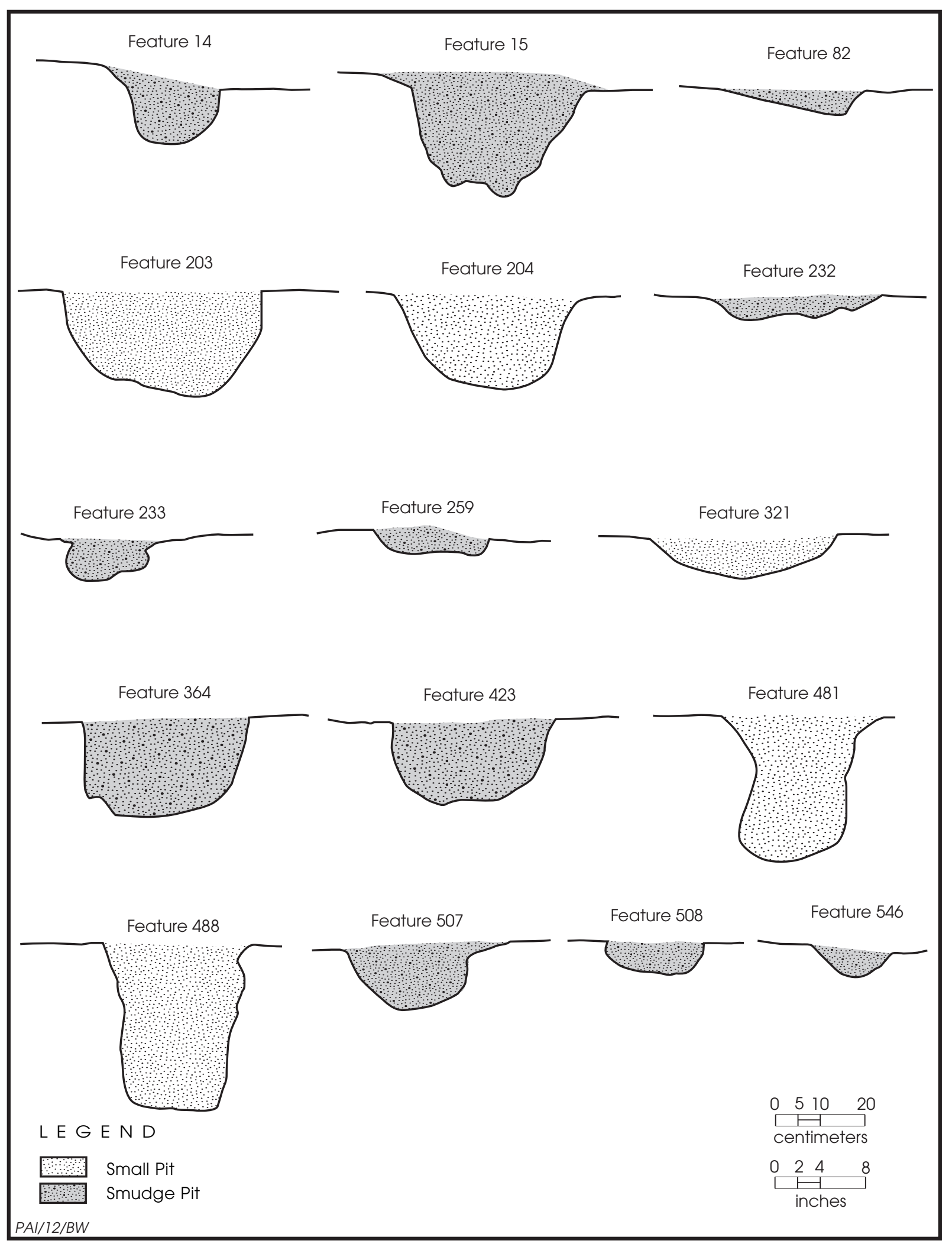

Figure 5.11. Cross sections of selected small pits in Subarea 1 at the William Ford site. 


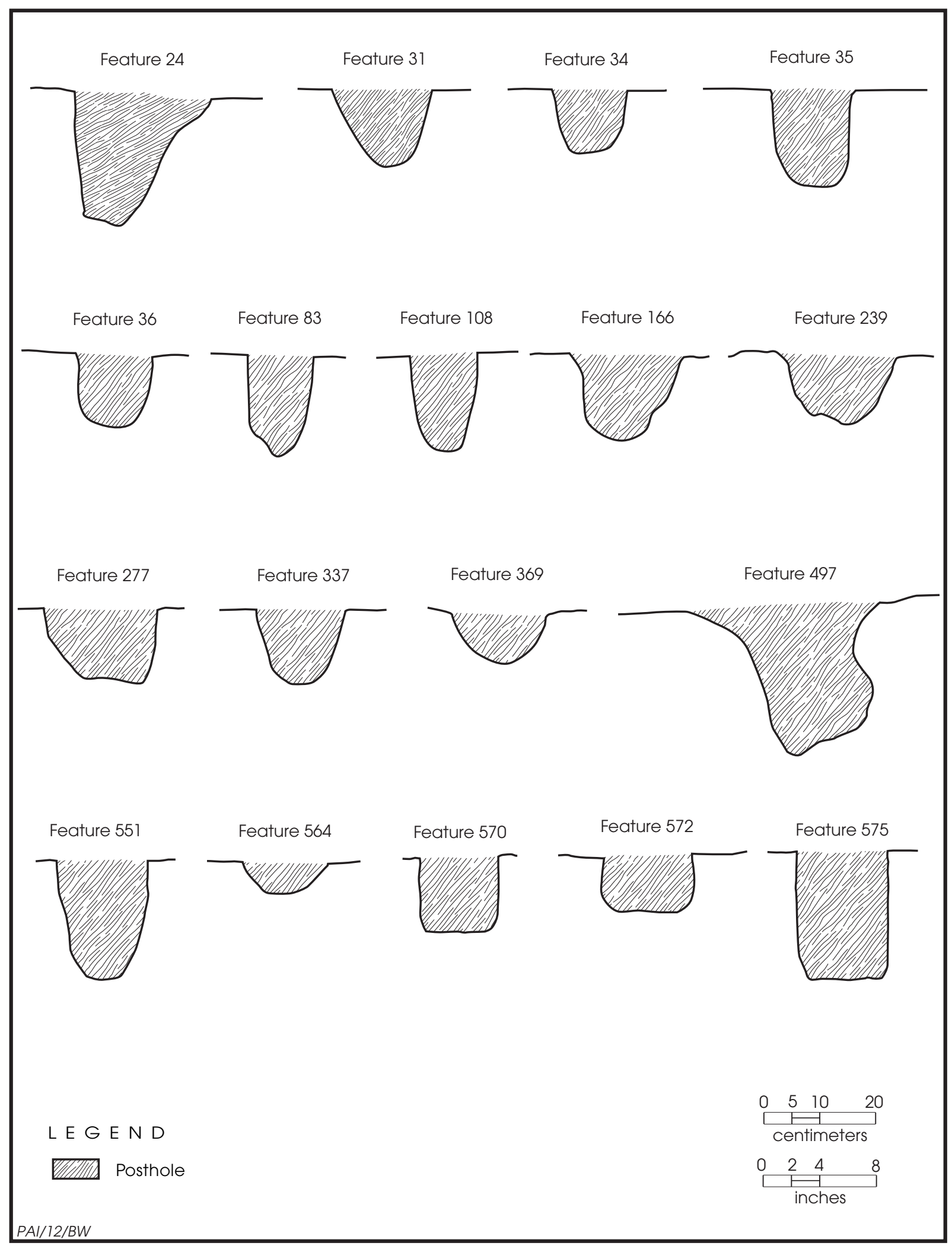

Figure 5.12. Cross sections of selected postholes in Subarea 1 at the William Ford site. 
slightly oval in plan view with straight to slightly sloping walls and rounded to flat bases. They have a mean diameter of $17 \mathrm{~cm}$ (ranging from 9 to $27 \mathrm{~cm}$ ) and a mean depth below detection level of $14 \mathrm{~cm}$ (ranging from 2 to $32 \mathrm{~cm}$ ). Figure 5.12 shows the cross sections of a sample of them. Four are considered probable postholes, even though they initially were considered noncultural disturbances, because they are within arcs representing houses; their locations within the arcs suggest they are badly disturbed postholes.

The fill generally was brown (10YR 4/3), dark brown (7.5YR 4/4, 10YR 3/3), dark yellowish brown (10YR $4 / 4,4 / 3$, and yellowish brown (10YR 5/4,5/8) sandy loam and sandy silty loam. Some contained charcoal flecking, but these materials were in low densities, and no posthole had evidence of in situ burning.

Very few artifacts were recovered from the postholes (see Table 5.2). Identified macrobotanical remains among the $4.71 \mathrm{~g}$ recovered are wood charcoal (2.35 g of elm, hackberry, hickory, mulberry, oak, and plum/cherry), nutshells (0.94 g of mostly hickory with some hickory/walnut), grass family stem $(0.02 \mathrm{~g})$, and a variety of seeds ( $0.94 \mathrm{~g}$ of bean/persimmon, common bean, corn, erect knotweed, goosefoot, grass family, legume maygrass, panicgrass, persimmon, purslane, and sumac). None of these materials actually relate to the posts these features once held, though. The density of macrobotanical remains in the 20 postholes with flotation samples is low, ranging from 0.003 to $0.128 \mathrm{~g} /$ liter $($ mean $=0.04 \mathrm{~g} /$ liter). The very small assemblage of faunal remains $(\mathrm{n}=49)$ is identified mostly to the vertebrate subphylum with a few canid/deer-sized mammals.

As discussed below (see Distributions), many of the postholes are in the southeast part of the excavated area and appear to be parts of two houses. Most of the other postholes likely represent additional small structures like drying racks, although one cluster could represent a 4-m-diameter square structure such as a ramada.

\section{Artifact Cluster}

The single artifact cluster, Feature 1, includes 208 sherds weighing $1,862.6 \mathrm{~g}$. One large vessel section was reconstructed out of these sherds. It is a large jar with three rows of punctations on the rim and an undecorated body. It appears to be the remains of a discarded utilitarian jar (see Ceramic Artifacts). Two bifaces, 2 flake tools, 53 pieces of debitage, and 12 faunal remains also were recovered. The discrete cluster covered an area of 40x27 cm at $19-39 \mathrm{~cm}$ below the ground surface at the end of Trench 4. It probably reflects trash deposition that contributed to formation of the organically enriched anthropogenic deposit that occurs in this part of the site.

\section{Organically Enriched Midden Sediments}

Organically enriched midden sediments are characterized as dark brown to black deposits, typically with relatively high densities of artifacts. Two such areas were identified and represent the amalgamation of organic residue from the processing and use of plants and animals during the primary occupations at the site. One marked by dark brown to dark yellowish brown (10YR 3/3, 3/6) sandy loam coincided with a concentration of other features in the northwest part of the excavated area and was labeled Feature 90. It measured $18 \times 11 \mathrm{~m}$ and covered 31 other features. During data recovery stripping, a 5x3-m area of Feature 90 was left for hand excavation. After the upper $10 \mathrm{~cm}$ was stripped off by trackhoe, this area was excavated by shovel down to the Bt horizon, approximately $35 \mathrm{~cm}$ below the ground surface; all the sediment was screened, except for 9.0 liters of fill that was processed by flotation. These midden-stained sediments were noted initially in Trenches 29, 30 , and 34 and Test Unit 7. During data recovery, they were noted in Sample Units 44, 45, 57, 58, and 59 and in subsequent stripping.

The second area with organically enriched sediments covered a $34 \times 17-\mathrm{m}$ section of the east side of the excavation, including the main concentration of features in the southeast part and extending north from there. It also continued outside the project area to the east and north, based on the profiles in the testing trenches and test units and the profile at the edge of the data recovery excavations. It was first identified in Test Units 1-6, 13, 16, 22, and 25 and Trenches 2-4, 7-12, and 16. Sample Units $2-6,10-12,15,16$, and $48-54$ and the trackhoe swaths dug during data recovery also sampled this area. These excavations exposed a dark yellowish brown (10YR 3/6) sandy loam A horizon 
extending to as much as $18 \mathrm{~cm}$ below the ground surface overlying organically enriched dark yellowish brown (10YR 3/4 to 10YR 4/4) mottled sandy loam and an irregular lower boundary to ca. $30 \mathrm{~cm}$, with a strong brown (7.5YR 4/6) sandy loam $\mathrm{E}$ horizon and lighter strong brown (7.5YR 5/8) sandy clay Bt horizon below. Six feature numbers were assigned to disturbances that extended slightly into the Bt horizon but that turned out to be nothing more than irregular pockets of this midden (excavated Features 477, 478, 543, and 545 and unexcavated Features $569 \mathrm{~A}$ and 569B).

\section{Distributions}

Most of the cultural features $(n=134$, 88 percent, excluding the 7 areas of organically enriched sediment recorded as features) are in two concentrations in the southeastern and northwestern parts of the Subarea 1 excavation (see Figure 5.4). The remaining 19 features are between these two areas $(n=3)$ and on the outskirts of the excavated area $(n=16)$.

\section{Southeastern Feature Concentration}

The southeastern concentration has 56 percent of the features, mostly postholes $(n=57)$ but also small pits $(\mathrm{n}=19)$, smudge pits $(\mathrm{n}=4)$, large pits $(\mathrm{n}=3)$, a burial, and an artifact cluster (Figure 5.13). These features occur over an area of $20 \mathrm{~m}$ east-west by $19 \mathrm{~m}$ north-south, virtually all of which has organically enriched midden sediments. The postholes (including 4 probable postholes) have a mean diameter of $18 \mathrm{~cm}$ (ranging from 10 to $28 \mathrm{~cm}$ ) and a mean depth of $14 \mathrm{~cm}$ (ranging from 2 to $32 \mathrm{~cm}$ ). Thirty-one of the postholes form two arcs that represent parts of two overlapping houses at the southeast edge of the concentration. Most of the radiocarbon dates indicate that the main occupation, and presumably the two houses, here dates to A.D. 1425-1500, though a number of dates indicate earlier and later occupations as well (see Chronology).

Nineteen postholes (Features 24, 25, 30, 33, $35,39,53,56,57,336,337,533,534 \mathrm{~B}, 537,538,551$, and 573-575) and 1 probable posthole (Feature 552) make up the southwestern half of the House $1 \mathrm{arc}$; the northeastern half is outside the project area and thus remains unexcavated. Feature
552 was originally designated a noncultural soil disturbance, but its location with respect to the arc suggests it may be a posthole that was severely impacted by bioturbation. Two other postholes (Features 31 and 560) could be part of the house wall but are not so designated here because they lie just outside the 6.3-m-diameter projected house outline. The mean diameter of the 20 House 1 postholes is $18 \mathrm{~cm}$ (ranging from 12 to $28 \mathrm{~cm}$ ), and the mean depth was $17 \mathrm{~cm}$ (ranging from 5 to $26 \mathrm{~cm}$ ). The postholes are spaced fairly closely and consistently, averaging $0.5 \mathrm{~m}$ apart (ranging from 0.4 to $0.6 \mathrm{~m}$ ). Feature 497, which is a relatively large ( $26 \mathrm{~cm}$ in diameter) and deep $(26 \mathrm{~cm})$ posthole with angled walls, probably held the center post.

Other potential interior features include two smudge pits, four other small pits, one large pit, seven postholes, and one burial. Three other small pits, one large pit, and one posthole are in the area where Houses 1 and 2 overlap and could be associated with either. Like the other potential interior features, though, the likelihood of multiple components (see Chronology) means that some probably predate or postdate the houses. In addition, small pit Features 23, $496 \mathrm{~A}$, and $496 \mathrm{~B}$ are so close to the walls that they are poor candidates for interior facilities. Those caveats aside, six pits cluster west and southwest of the center of House 1 and could represent a locus of interior activities; these consist of one smudge pit (Feature 14), four other small pits (Features 23, 539, 544, and 557), and one large shallow pit (Feature 13). Also in this area were Feature 1, a discarded broken jar, and probable burial Feature 542A; the latter could be a subfloor interment of an infant, fetus, or umbilical cord. East of this concentration in the southeast quadrant of the structure are a smudge pit (Feature 546) and three postholes. Large pit Feature 55 and small pit Feature 565, each with a single posthole nearby, may mark another area of interior activities in the north part of the house.

House 2 is indicated by eight postholes (Features 34, 36, 64-66, 107, 108, and 561) and three probable postholes (Features 62,67 , and 68). The latter initially were considered noncultural but subsequently were noted to be in line with the House 2 arc; they probably are badly disturbed postholes. These 11 features represent the western third of a 6.3-m-diameter house (like House 1), the rest of which extends 


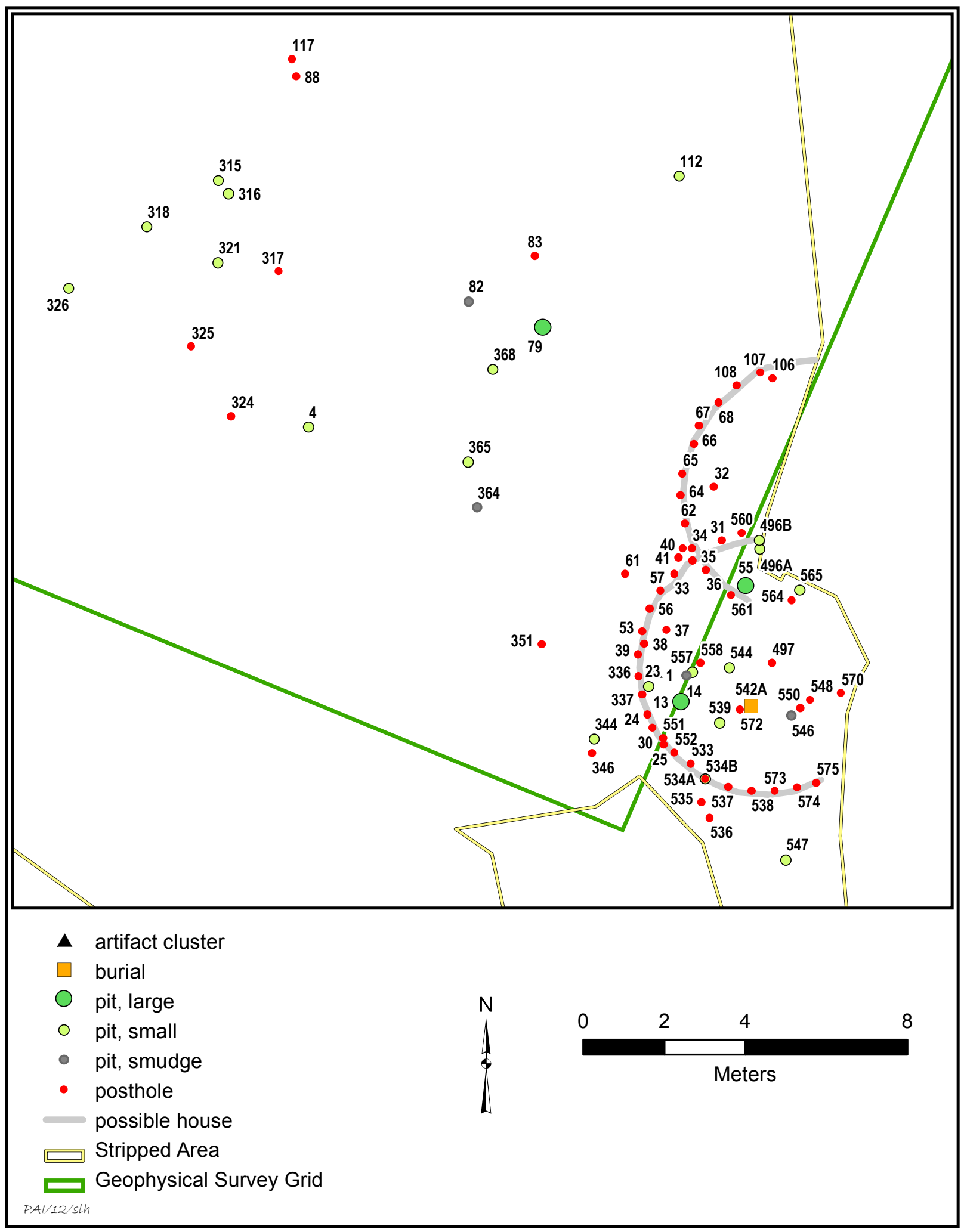

Figure 5.13. Plan of the southeastern feature concentration in Subarea 1 at the William Ford site. 
east outside the project area and thus remains unexcavated. The mean diameter of the postholes is $16 \mathrm{~cm}$ (ranging from 11 to $22 \mathrm{~cm}$ ), and the mean depth is $13 \mathrm{~cm}$ (ranging from 4 to $20 \mathrm{~cm}$ ). There are more gaps than in the House 1 arc, and the postholes are not spaced quite as regularly $(0.5-0.9 \mathrm{~m})$, but on average they are fairly closely spaced $(0.6-0.7 \mathrm{~m})$. If a center post exists, it is outside the area excavated.

Too little of the house was exposed to say much about potential interior features, although small pit Features 496A and 496B and posthole Features 31 and 560 nearby are more likely to go with House 2 than House 1 and could represent a locus of activities in the southwest quadrant. Large and small pit Features 55 and 565, noted above as possibly being interior to House 1 , could just as easily have been inside the south wall of House 2 (though not with the symmetry of both having associated postholes nearby).

The other features in the southeastern concentration are scattered mainly to the northwest of the houses. Many probably represent nearby outdoor activity areas, though the likelihood of multiple components means that some could predate or postdate the houses. Seven postholes (Features 40, 41, $61346,351,535$, and 536) occur singly or in pairs with a few meters of Houses 1 and 2 and could represent marker poles or racks, with two small pits nearby (Features 344 and 547). Slightly farther from the houses, ca. 5-6 m, are two smudge pits (Features 82 and 364), three other small pits (Features 112, 365 , and 368), one large pit (Feature 79), and a lone posthole (Feature 83). Westward from this group across a span of $4-5 \mathrm{~m}$ where there are no features is a group of six small pits (Features 4, $315,316,318,321$, and 326) and five postholes (Features 88, 117, 317, 324, and 325). The postholes occur by themselves or in pairs and not in patterns indicating structures such as granaries or ramadas.

\section{Northwestern Feature Concentration}

The northwestern concentration has 32 percent of the features, mostly small pits $(\mathrm{n}=30$, including 7 smudge pits) but also postholes $(\mathrm{n}=12)$, and large pits $(\mathrm{n}=8)$ (Figure 5.14). Features are most concentrated in an area measuring $11 \mathrm{~m}$ northwest-southeast by 3-7 m northeast-southwest, but others are scattered to the north, west, and south such that the concentration covers an area about $20 \mathrm{~m}$ across. Most of the northern part of this area has organically enriched midden sediments (Feature 90) reflecting intensive activities presumably associated with feature use. Only Feature 90 was identified in the $\mathrm{E}$ horizon, with the other features found at the top of the reddish brown to strong brown sandy clay Bt horizon; the Bt horizon surface below Feature 90 was riddled with bioturbation, having 88 soil disturbances reflecting rodent activity. Based on the radiocarbon dates, much of this use was contemporaneous with the A.D. 1425-1500 main occupation represented by the houses in the southeastern feature concentration, but earlier and later occupations are represented as well. As at the George Richey site, the assemblage of features suggests that a different set of nondomiciliary outside activities including processing and cooking food, preparing hides, etc., was performed here.

The 12 postholes are very similar in size to those in the southeastern feature concentration, having an average diameter of $16 \mathrm{~cm}$ (ranging from 8 to $24 \mathrm{~cm}$ ) and an average depth of $13 \mathrm{~cm}$ (ranging from 6 to $20 \mathrm{~cm}$ ). They occur singly or, in one instance, as a pair (Features 426 and 430) distributed throughout the feature concentration, and hence they appear to represent structures such as drying racks or shade supports rather than granaries or ramadas. Interpreting them is difficult, though, since the extensive bioturbation in this area probably obscured or destroyed many small features such as postholes.

The large pits, 67 percent of the total found in Subarea 1, probably relate to communal processing activities that contributed to the midden staining in this area. The smudge pits, 64 percent of the total, also played a role. The small pits are very similar to those in the southeastern feature concentration and probably reflect a variety of generalized camp activities; they are common here but not as predominant as the large pits and smudge pits ( 48 percent of the site total). The large pits have a relatively restricted distribution, with all eight (Features 189, 191B, $193,199,484,490,518$, and 526) being in the northeastern part of the concentration. The seven smudge pits (Features 15, 232, 233, 259, 423,507 , and 508) are distributed more widely, but only across the western and southern parts of the concentration, i.e., differently than the 


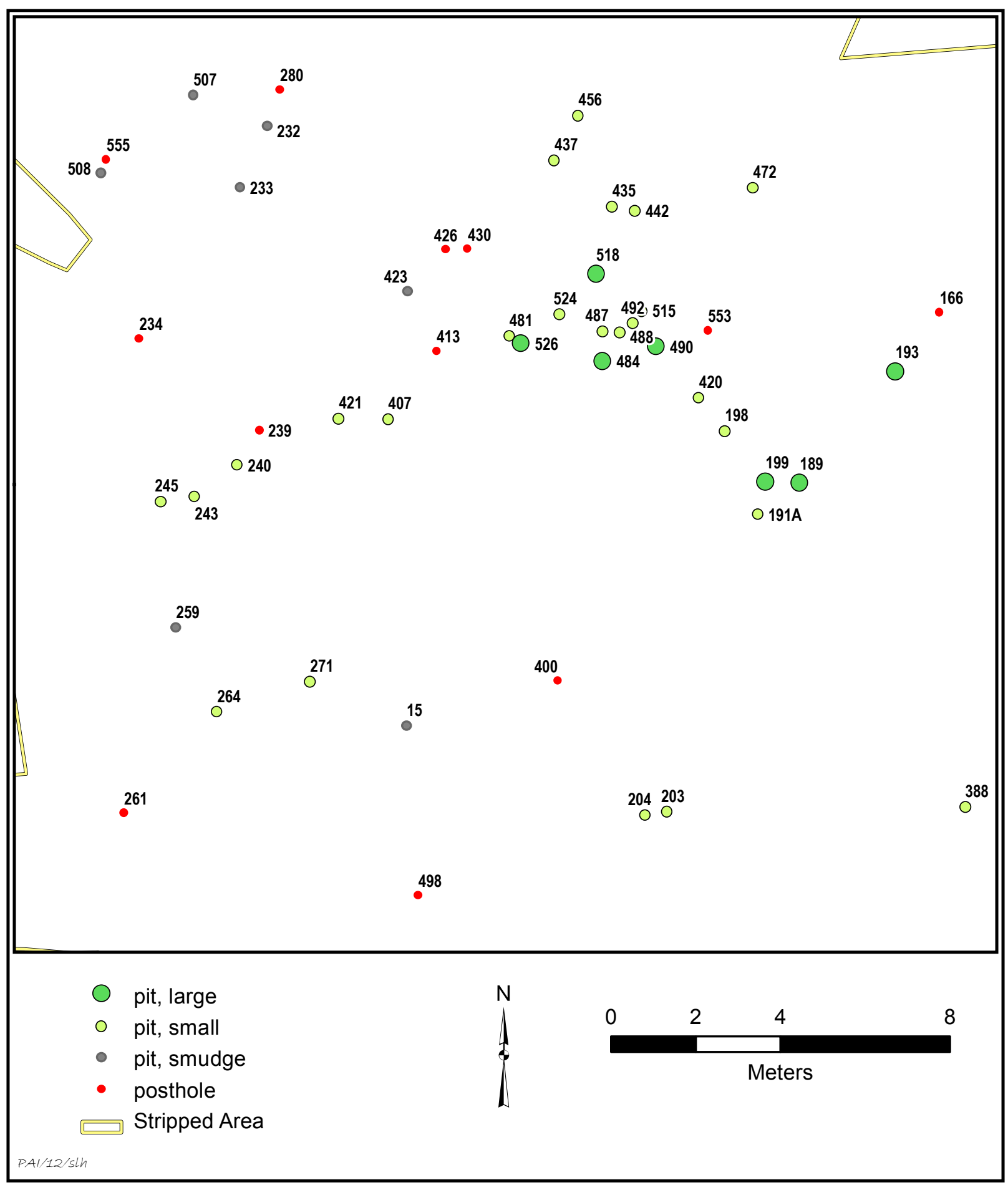

Figure 5.14. Plan of the northwestern feature concentration in Subarea 1 at the William Ford site. 
large pits. Not surprisingly given their numbers, the small pits have the broadest distribution.

\section{Other Features}

In the northeast corner of the data recovery area are seven postholes (Features 101, 102, 103, $105,132,136$, and 137) and a single small pit (Feature 95) that may reflect an activity area or perhaps a ca. 4-m-diameter square structure such as a ramada, with Features 102, 105, 132, 136 , and 137 indicating its southern and western sides (see Figure 5.4). Interpreting this cluster is difficult because it is at the edge of the excavation area and could be associated with what we suspect are abundant archeological remains just outside the project area to the east. The organically enriched midden sediments that occur across the southeast feature concentration to the south extend into this area and to the east outside the excavations. Between this cluster and the main concentration to the south are two postholes sitting about $1.7 \mathrm{~m}$ apart that may be a structure such as a drying rack.

The ca. 14-m-wide expanse between the two main site areas is devoid of features, except for one small pit (Feature 388), one posthole (Feature 277), and probable juvenile burial Feature 164. The posthole and pit probably are unrelated to the burial. This open area may have functioned as a plaza.

The remaining features are individual outliers. One is a large pit (Feature 151) on the north edge. Two are postholes (Features 21 and 369 ) on the west edge and west of the southeast concentration. And two are small pits (Features 19 and 96), one west of the northwest concentration and the other north of the southeastern concentration.

\section{CERAMIC ARTIFACTS}

The ceramic artifacts recovered from Subarea 1 number 5,058 (33,448 g). Of these, $2,677(28,025 \mathrm{~g})$, or 53 percent by count and 81 percent by weight, are large enough for analysis. Ten of these are nonvessel ceramics (1 ear spool fragment, 1 spindle whorl fragment, 1 possible ceramic waster, and 7 smoking pipe fragments), and the rest are from ceramic vessels. Included in the latter are a complete miniature bottle, a small carinated bowl, 2 mostly complete medium/small jars, and 2 probable large jars. The vessel sample is described below in relation to sherd characteristics, vessel form, and decoration. The nonvessel artifacts are described separately below.

\section{Vessel Sherd Characteristics}

The vessel sherd sample consists of 6 complete or nearly complete vessels, 2,225 body sherds, 64 carinated body sherds, 166 rim sherds, $7 \mathrm{rim} /$ carination sherds, 103 neck sherds, 72 base sherds, and 24 sherds of indeterminate form. These show a fairly even split between use of grog by itself as temper and grog and bone (Table 5.3). The voids that occur with grog-bone and bone likely represent leached bone. Just 8 percent have bone as the sole tempering agent. The only other tempering agent identified is sand, and it too is minimal.

Rim and base characteristics indicate that, while a range of vessel sizes and forms were used, containers with flat bases and everted rim were most common. Everted rims $(\mathrm{n}=75)$ make up 43 percent of the rims and rims/carinations. Just 12 percent are straight $(n=21)$, and 3 percent are inverted $(n=5)$. Due to their small size, a substantial number ( $\mathrm{n}=73,42$ percent) could not be distinguished by form. Forty-five percent of the rims have rolled lips $(\mathrm{n}=79)$, and 24 percent are rounded $(\mathrm{n}=42)$. Less frequent are flat lips ( $n=20,11$ percent), folded lips $(n=15,9$ percent $)$, tapered lips ( $\mathrm{n}=11,6$ percent), and indeterminate lip forms ( $\mathrm{n}=7,4$ percent). Rim thickness ranges from 3.96 to $9.49 \mathrm{~mm}$ with a mean of $6.55 \mathrm{~mm}(\mathrm{sd}=1.19)$ indicating that small to large vessels are represent in the sample. Base thick-

Table 5.3. Tempering agents in the ceramic vessel sample from Subarea 1 at the William Ford site

\begin{tabular}{l|c|c}
\hline Temper & No. & $\%$ \\
\hline Grog & 1,195 & 45.0 \\
\hline Grog-bone & 896 & 33.6 \\
\hline Grog-bone-voids & 329 & 12.3 \\
\hline Bone & 141 & 5.2 \\
\hline Bone-voids & 80 & 3.0 \\
\hline Sand & 17 & 0.6 \\
\hline Indeterminate & 9 & 0.3 \\
\hline Total & 2,667 & 100 \\
\hline
\end{tabular}


ness, which ranges from 6.79 to $16.16 \mathrm{~mm}$ with a mean of $10.77 \mathrm{~mm}(\mathrm{sd}=2.11)$, also indicates that vessels of various sizes are represented. Most of the base sherds are flat $(n=46,64$ percent) rather than rounded ( $n=5,7$ percent) or are of indeterminate form ( $\mathrm{n}=21,29$ percent).

Floating and smoothing are the main finishes recorded for both interior and exterior surfaces on the sherds (Table 5.4). Floated surfaces, with a fine finish made while the clay was still plastic, were noted most often on interiors. However, chemical and mechanical weathering made it difficult to distinguish between these two finishes, and the smoothed category was often used simply because the surface had even texture but with no evidence of polish or other tool marks. True burnished surfaces are few as they were noted for only 4 percent of the exterior surfaces and 5 percent of the interior surfaces. Scraped surfaces were noted mostly on interiors, but only on 2 percent of the sample. Scraping also provides a crucial clue for identifying restricted-orifice vessels such as ollas and bottles. A very few interiors are roughened and are similar to scraped surfaces in that they appear unfinished, but they do not show the striations of scraping. One percent of the exteriors are roughened; this may have been a means of giving a nonslip texture to a vessel similar to brushing. Finishing of the vessel surface by use of a slip or adding pigment to engraved lines is rare in this sample (see Table 5.4). A slip was noted on 18 exterior and 8 interior surfaces; slips are most commonly red, but some are orange or reddish brown. Red pigment was found in the engraved lines on only 3 sherds, and white pigment was seen on another 3 sherds.

Decorated sherds constitute 28 percent of the sample. Most display brushing or some combination of brushing with punctations or appliqué ( $\mathrm{n}=259,35$ percent of those with decoration). Engraving ( $\mathrm{n}=163,22$ percent) and incising ( $\mathrm{n}=132,18$ percent) also are common decorative modes, as is punctating or a combination of punctating and incising $(\mathrm{n}=151,20$ percent). Sherds with appliqué but no brushing are minimally represented $(n=29,4$ percent), along with sherds with pinching or coil crimping $(\mathrm{n}=11,1$ percent $)$.

\section{Vessel Form}

Vessel forms identified within the sherds are based on rim and body forms along with decorative mode and surface finish. For instance, Caddo bowls and bottles are unlikely to be brushed, display linear appliqué on the body, or have zones and fields of pinching or punctations on the rim. Sherds with such decorations or obvious necks or thick everted rims were coded as jars. Carinated rim or body sherds were coded as bowls, and sherds with scraped interiors were considered bottles or ollas. The identification of an olla vs. a bottle was based on the curvature of the vessel body and sometimes the size and form of the rim or neck. The 6 percent of the sample that can be identified confidently with particular vessel forms consists of 20 bottle sherds, 67 bowl sherds, 64 jar sherds, and 6 olla sherds. It is presumed that these relative frequencies provide a general indication of the proportions of the kinds of vessels used at the site.

The vessels represented range from very small to very large. This is based on rim thicknesses and the six complete or nearly complete vessel fragments described below. These vessels consist of a miniature bottle, a small bowl with a rim diameter of $16.2 \mathrm{~cm}$, and small to medium-sized jars and large jars with diameters ranging from 12.0 to $26.3 \mathrm{~cm}$. Rims within the sherd sample that are large enough to provide diameter data indicate bowls with diameters as large as $25 \mathrm{~cm}$ and jars up to $34 \mathrm{~cm}$ across. A few bottle sherds indicate rim diameters of $4-5 \mathrm{~cm}$, indicating fairly large vessels probably greater than $15 \mathrm{~cm}$ in height. Olla rim diameters range from 7 to $10 \mathrm{~cm}$.

\section{Decorative Elements, Motifs, and Ceramic Types}

Twenty-two decorative elements were recognized on 61 percent $(\mathrm{n}=455)$ of the decorated sherds (see Table 5.4). From combinations of these and their association with particular vessel parts, 11 specific motifs were identified on 53 sherds, not including unique motifs on 3 (see Table 5.4). Some of these motifs are simplified from ones defined from more-complete vessels in this study, because the small sherds provide only glimpses of how motifs were structured across entire vessels. Still, these elements and motifs suggest that most sherds in the sample represent types associated with Middle to Late Caddo period occupations.

Common and readily identifiable elements are lines of punctations at 16 percent of those 
Table 5.4. Surface treatment and decorative attributes for the ceramic vessel sample from Subarea 1 at the William Ford site

\begin{tabular}{|c|c|c|}
\hline & No. & $\%$ \\
\hline \multicolumn{3}{|l|}{ Exterior Surface Finish } \\
\hline Smoothed & 1,247 & 47 \\
\hline Floated & 1,154 & 43 \\
\hline Burnished & 113 & 4 \\
\hline Slipped & 18 & 1 \\
\hline Scraped & 4 & 0 \\
\hline Roughened & 22 & 1 \\
\hline Indeterminate & 109 & 4 \\
\hline Totals & 2,667 & 100 \\
\hline \multicolumn{3}{|l|}{ Interior Surface Finish } \\
\hline Smoothed & 825 & 31 \\
\hline Floated & 1,500 & 56 \\
\hline Burnished & 129 & 5 \\
\hline Slipped & 8 & 0 \\
\hline Scraped & 57 & 2 \\
\hline Roughened & 9 & 0 \\
\hline Indeterminate & 139 & 5 \\
\hline Totals & 2,667 & 100 \\
\hline \multicolumn{3}{|l|}{ Decorative Mode } \\
\hline None & 1,909 & 72 \\
\hline Engraved & 163 & 6 \\
\hline Incised & 132 & 5 \\
\hline Fingernail punctated & 44 & 2 \\
\hline Stick puntated & 88 & 3 \\
\hline Brushed & 243 & 9 \\
\hline Brushed-punctated & 11 & 0 \\
\hline Brushed-appliquéd & 5 & 0 \\
\hline Appliquéd, linear & 19 & 1 \\
\hline Appliquéd, nodes & 3 & 0 \\
\hline Appliquéd-punctated & 5 & 0 \\
\hline Punctated-incised & 19 & 1 \\
\hline Appliquéd-incised & 2 & 0 \\
\hline Pinched & 9 & 0 \\
\hline Coil crimped & 2 & 0 \\
\hline Indeterminate & 13 & 0 \\
\hline Totals & 2,667 & 100 \\
\hline \multicolumn{3}{|l|}{ Decorative Element } \\
\hline Punctated field/zone & 66 & 15 \\
\hline Horizontal lines & 43 & 9 \\
\hline Hatching/crosshatching & 14 & 3 \\
\hline Curvilinear lines & 47 & 10 \\
\hline Rectilinear lines & 30 & 7 \\
\hline Diagonal lines & 52 & 11 \\
\hline Vertical lines & 32 & 7 \\
\hline Lines of punctations & 74 & 16 \\
\hline Lines of pinching & 3 & 1 \\
\hline
\end{tabular}

\begin{tabular}{|c|c|c|}
\hline & No. & $\%$ \\
\hline Appliquéd fillet & 21 & 5 \\
\hline $\operatorname{Node}(\mathrm{s})$ & 2 & 0 \\
\hline Neck banding & 2 & 0 \\
\hline Vertical brushing & 36 & 8 \\
\hline Horizontal brushing & 11 & 2 \\
\hline Diagonal brushing & 5 & 1 \\
\hline Cross brushed & 3 & 1 \\
\hline Ridging & 2 & 0 \\
\hline Circle & 4 & 1 \\
\hline Curl & 3 & 1 \\
\hline Half circle & 2 & 0 \\
\hline Pendant triangles & 2 & 0 \\
\hline SZ & 1 & 0 \\
\hline Totals & 455 & 100 \\
\hline \multicolumn{3}{|l|}{ Main Motif } \\
\hline Horizontal lines at rim & 2 & 4 \\
\hline Diagonal lines at rim & 4 & 7 \\
\hline Vertical lines at rim & 2 & 4 \\
\hline Zoned punctations at rim & 2 & 4 \\
\hline Alternating parallel lines & 9 & 16 \\
\hline Body panels & 7 & 12 \\
\hline Scroll, slanted & 12 & 21 \\
\hline Scroll, straight & 2 & 4 \\
\hline Scroll, unidentified & 3 & 5 \\
\hline $\begin{array}{l}\text { Horizontal rows of } \\
\text { punctations at rim }\end{array}$ & 10 & 18 \\
\hline Rim panel & 1 & 2 \\
\hline Unique & 3 & 5 \\
\hline Totals & 57 & 100 \\
\hline
\end{tabular}


with identifiable elements and zone or field of punctations at 15 percent (Figure 5.15). These elements appear to be associated with jars, but most examples could not be associated with a particular motif or type. Ten examples with lines of punctations are assigned to the horizontal rows of punctations at the rim motif, which may represent an untyped utility ware akin to Mockingbird Punctated (Figure 5.15a) or, when they occur with brushing $(\mathrm{n}=7)$, represent Bullard Brushed jars (Figure 5.16a-c) (Suhm and Jelks 1962:21). Three of the mostly complete jars recovered from the site display this motif, and two of these have plain bodies (see Figures 5.20 and 5.22). Jars with horizontal lines of punctations on the rim and plain or brushed bodies make up 29 percent of all jars from the nearby Thomas B. Caldwell cemetery, although three of these jars have lines of punctations alternating with incised lines at the rim, which is a variation not seen at the William Ford site.

The numerous sherds with vertical brushing, horizontal brushing, diagonal brushing, and cross brushing attest to the variability in the use of this decorative mode at this site. Jar motifs that may include brushing are body panels and rim panels, which may be associated with the type Pease Brushed-Incised $(n=8)$. Certainly, body panels consisting of sections of brushed body set off by vertical appliquéd fillets or incised lines are common to this type (Figure 5.16d).

The element appliquéd fillet is fairly common and could include fillets associated with both body and rim panel motifs. However, 13 sherds have fillets that appear to be sinuous or curving (Figure 5.16e), and though no specific motif could be discerned on these, it is likely they are associated with the type Harleton Appliqué. Less common is the line of pinching element $(\mathrm{n}=3)$, which appears to represent the type Killough Pinched (Figure 5.16f). The few ridged body sherds $(n=2)$ may point to the occurrence of a few Belcher Ridged jars at the site. Also presented in a limited way is the element neck banding, based on the recovery of 2 coil crimped sherds. These sherds are small and could not be used to define a motif, but they may represent La Rue Neck Banded jars.

Five linear elements formed by engraving or incising-horizontal lines, curvilinear lines, rectilinear lines, vertical lines, and diagonal lines-were identified on 51 percent of the sample. The most common element in this group is diagonal lines, which occurs in several motifs-diagonal lines at the rim $(n=4)$, alternating parallel lines $(n=9)$, and zoned punctations at the rim $(n=2)$-suggesting that Maydelle Incised jars are well represented (see Figure 5.15e).

Engraved curvilinear and rectilinear elements, as well as half circle, circle, curl, pendant triangle, and SZ elements, indicate the presence of engraved wares such as Ripley Engraved bowls, bottles, and ollas (see Table 5.4). These are associated with the slanted scroll $(\mathrm{n}=12)$ and straight scroll $(\mathrm{n}=2)$ motifs, as well as scrolls of indeterminate form $(\mathrm{n}=3)$ (Figure 5.17). Curl elements at the ends of scroll arms are common (see Figure 5.17b, f), occurring, for example, with a slanted scroll motif on two rims from a large carinated bowl with a reconstructed diameter of 20-25 cm. Similar scrolls with curl elements are known from the Thomas B. Caldwell cemetery nearby (see Chapter 7), as well as from Grave 4 (Vessel 8) and Grave 41 (Vessel 2) at the Tuck Carpenter site (Turner (1992), where bowls with this motif are typed as Ripley Engraved. There is some similarity between this particular motif and the scroll motifs common to Taylor Engraved, but the Ripley Engraved curl does not appear to interlock around a common center as the Taylor Engraved elements do (Suhm and Jelks 1962:Plate 75i, 1, o).

Two other common Ripley Engraved elements found on a few of the sherds are pendant triangles and the SZ element. One sherd has pendant triangles as part of the arms of a straight scroll on a carinated bowl (see Figure 5.17d). Ripley Engraved bowls from the Tuck Carpenter site also displayed pendant triangles, and Turner (1978) and Thurmond (1990:36) considered this a motif in its own right. Here, however, pendant triangles are considered a secondary element modifying the scroll. The single sherd with an SZ element is on an apparent olla body sherd (Figure 5.18a). This often is a primary element within Ripley Engraved scrolls (Suhm and Jelks 1962:Plate 64f), but it also appears isolated in other contexts, suggesting that it may have held meaning that was recognized outside of its occurrence in a scroll or an association with other elements.

Two sherds that likely came from the same straight-rim bowl were recorded as having a unique motif (Figure 5.18c-e). This bowl has 


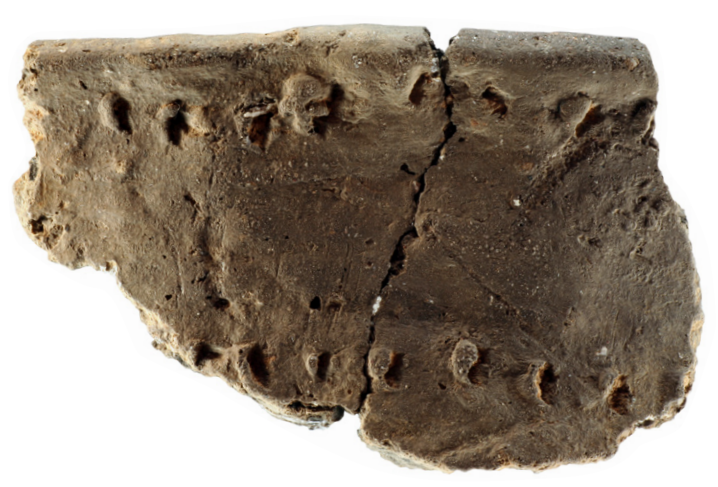

a
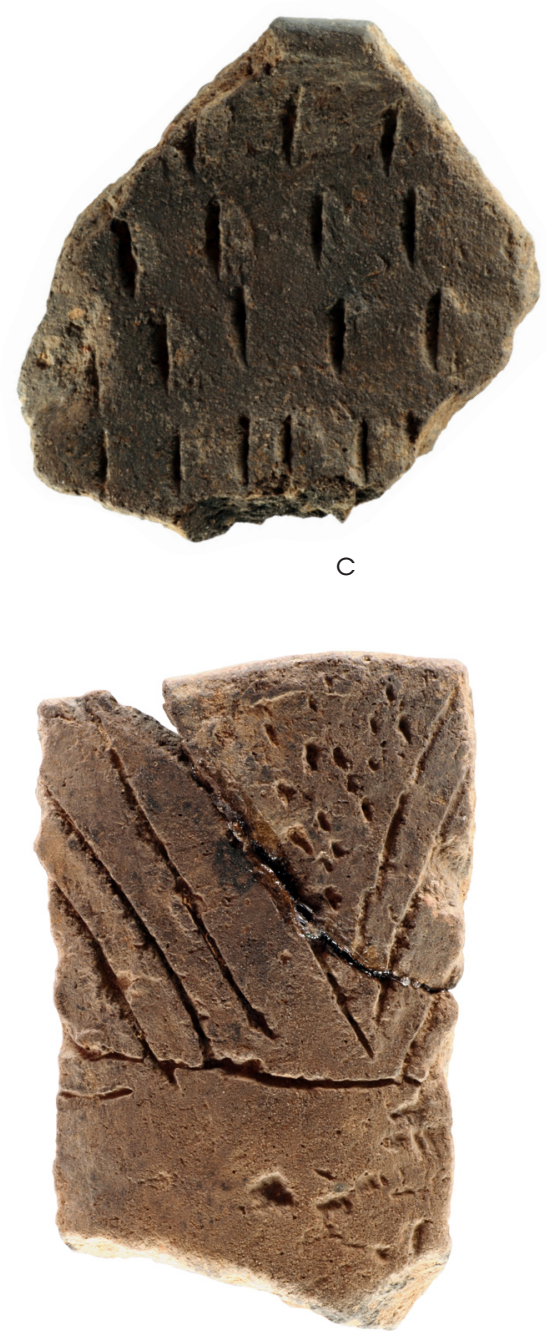

e
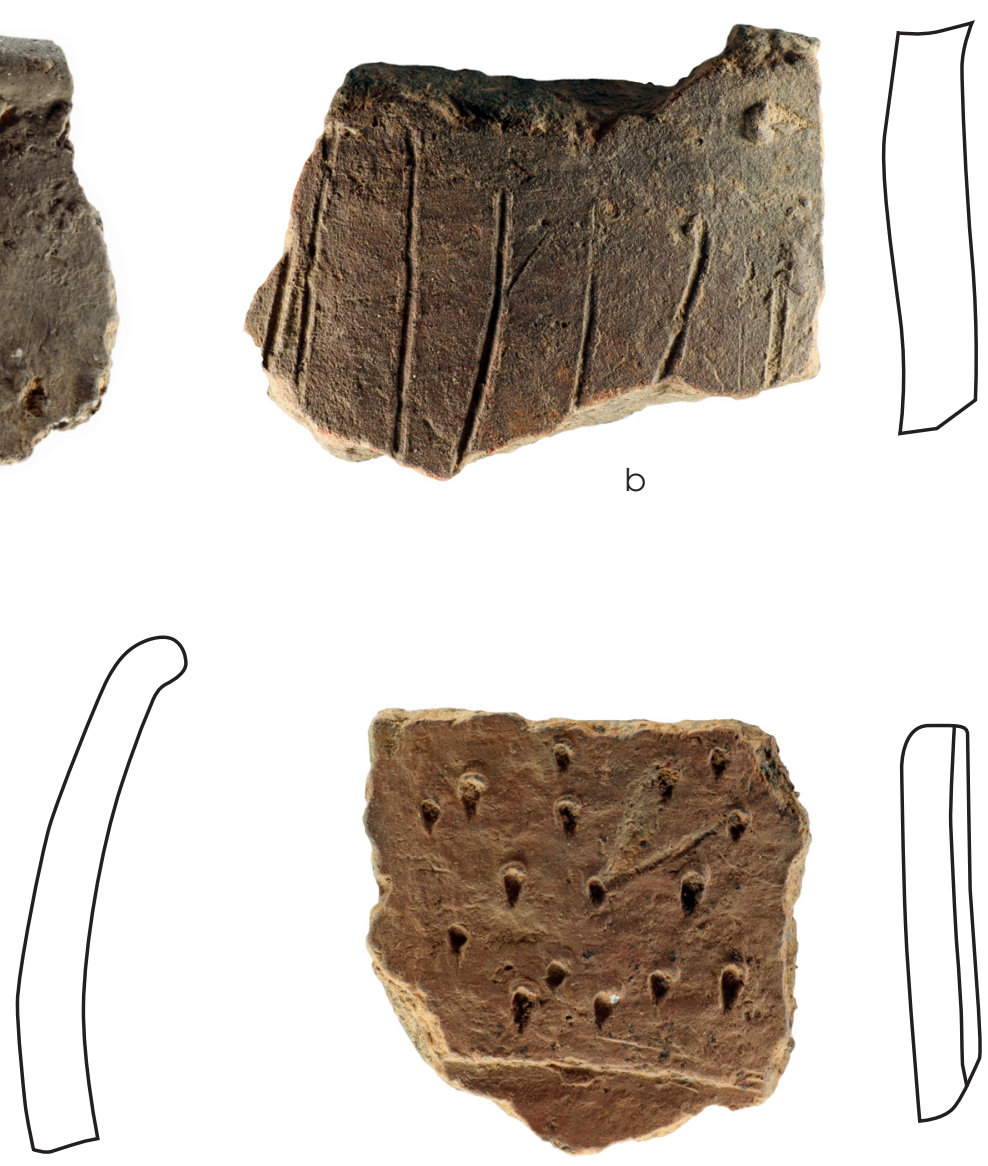

d
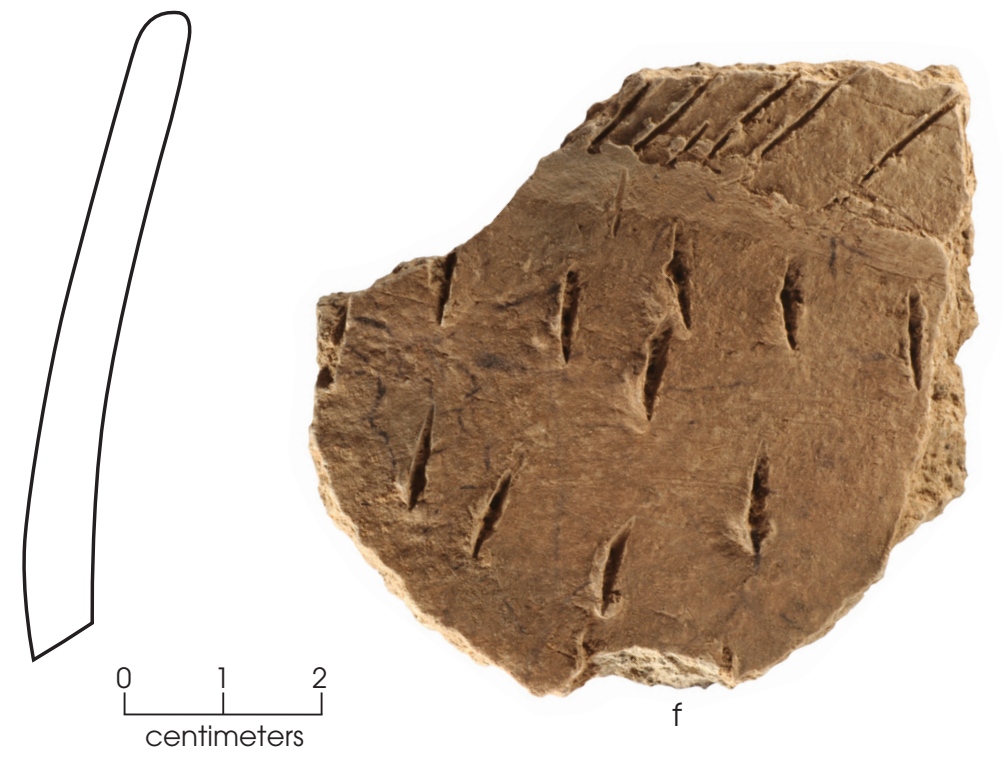

Figure 5.15. Jar sherds with punctations and incising from Subarea 1 at the William Ford site. (a) Rim sherd with rows of punctations; (b) sherd with row of punctations at the bottom of the neck and vertical incising on the body; (c-e) rim sherds with fields or zones of punctations; (f) sherd with field of punctations on the body and diagonal incising on the neck. 

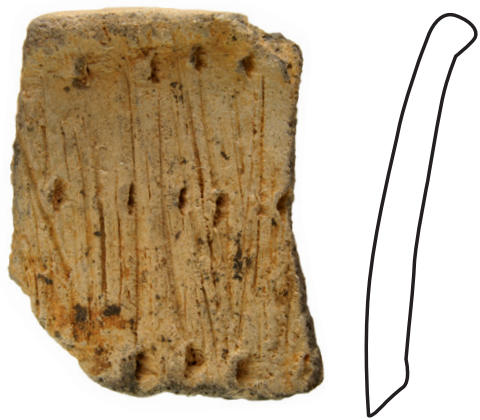

a

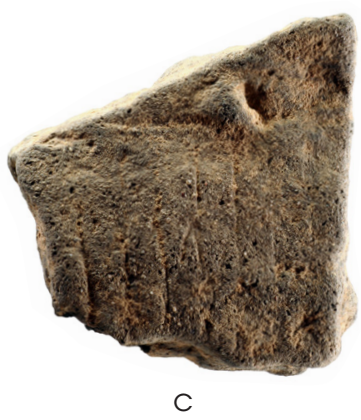

C

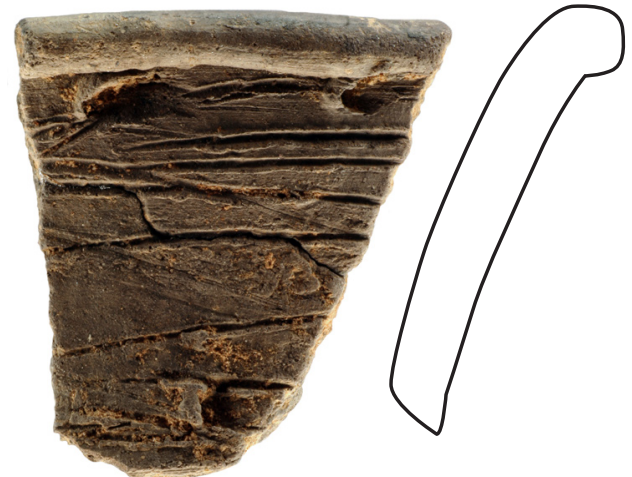

$\mathrm{b}$

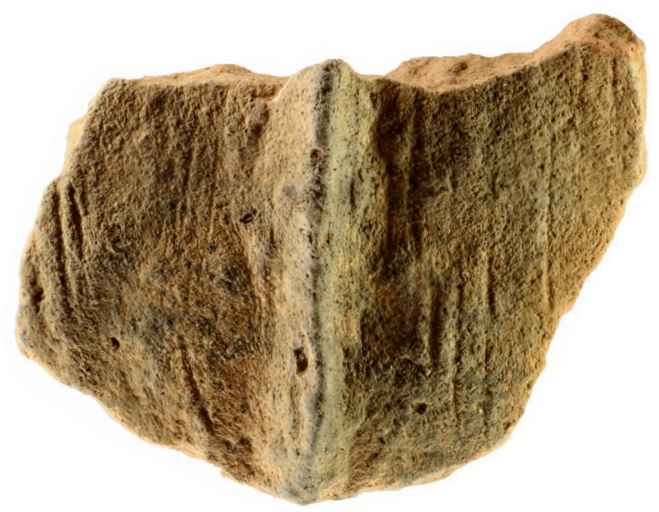

d

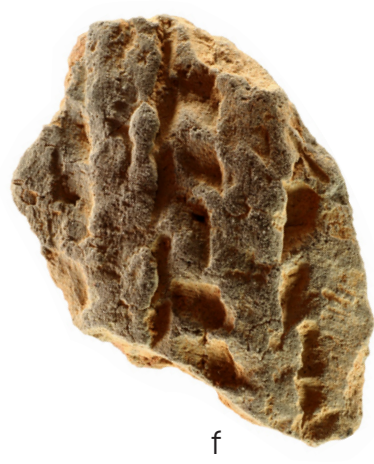

e

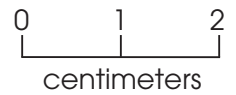

Figure 5.16. Jar sherds with brushing, punctations, appliqué, and pinching from Subarea 1 at the William Ford site. (a-c) Rim sherds with rows of punctations and brushing; (d) brushed body sherd with vertical appliqué fillets; (e) body sherd with curving appliqué fillet; (f) body sherd with vertical lines of pinching. 


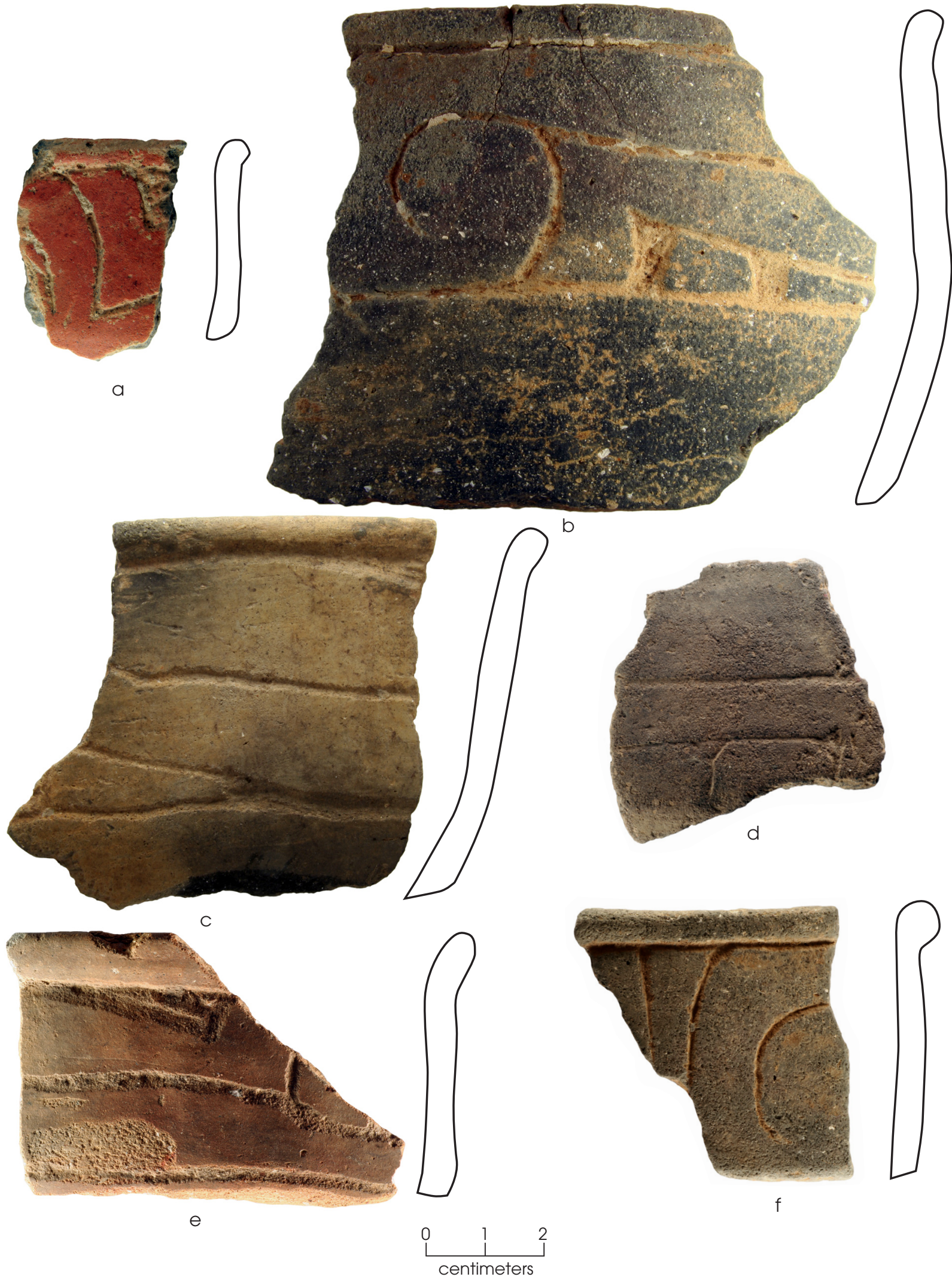

Figure 5.17. Engraved rim and body sherds likely representing Ripley Engraved bowls from Subarea 1 at the William Ford site. (a-c) Slanted scroll motif; (d-e) straight scroll motif; (f) unidentified scroll motif. 
inward-projecting tabs on a flat lip, and these tabs are engraved with short parallel lines. Not enough of the rim was recovered to determine a vessel diameter, but the vessel appears to be a well-made small bowl. Some Coles Creek types such as French Fork Incised have flattened lips with inward projecting elaboration and decoration (Ford 1951:62-65); this unique bowl could be related to one of these early types. In addition, there are a small number of flat-lipped rims $(n=20)$ and folded rims $(n=15)$ that may be related to Early Caddo types such as Holly Fine Engraved (Suhm and Jelks 1962:77-79). Most of these rims are undecorated, but in a few instances folded rims display a field of stick punctations. Also, two body sherds with finely engraved, closely spaced parallel lines or hatching could be from a Holly Fine Engraved bowl. These sherds cannot be firmly typed, however.

\section{Vessels and Vessel Sections}

Six complete or nearly complete vessels were recovered. These range in size from a miniature bottle to a large utility jar with rim diameter approaching $30 \mathrm{~cm}$, with most being small to medium in size.

\section{Test Unit 9}

This is a miniature bottle, ca. 99 percent complete with a broken neck and rim, weighing
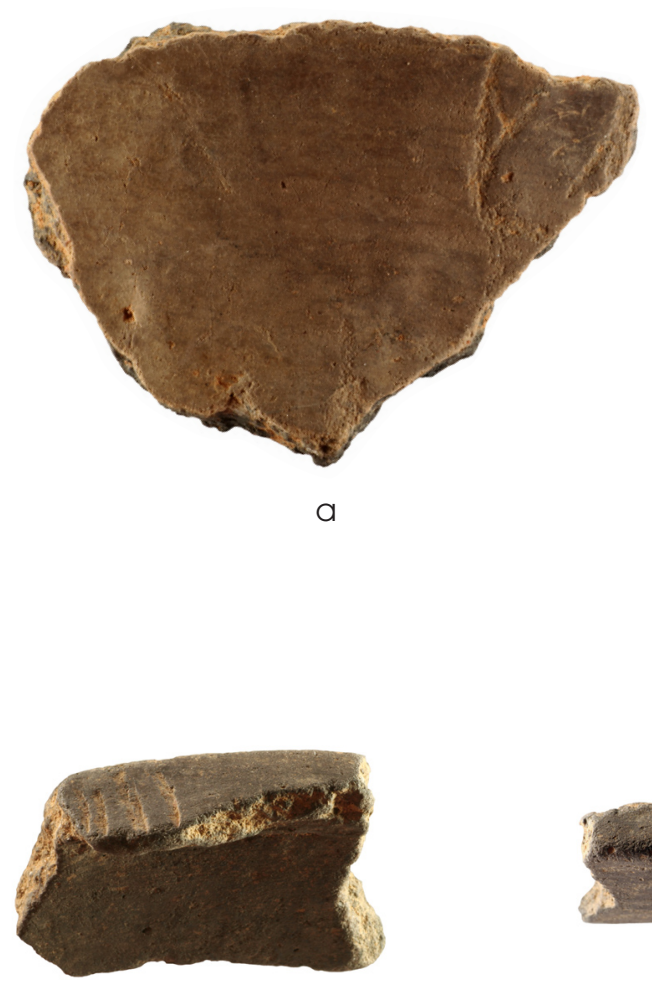

C

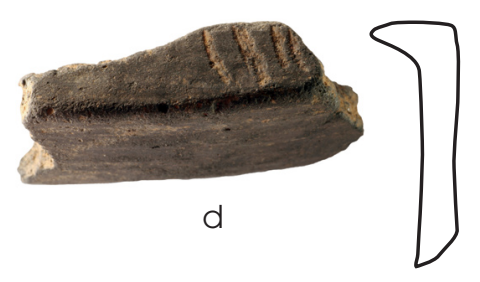

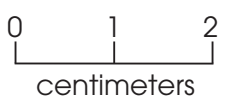
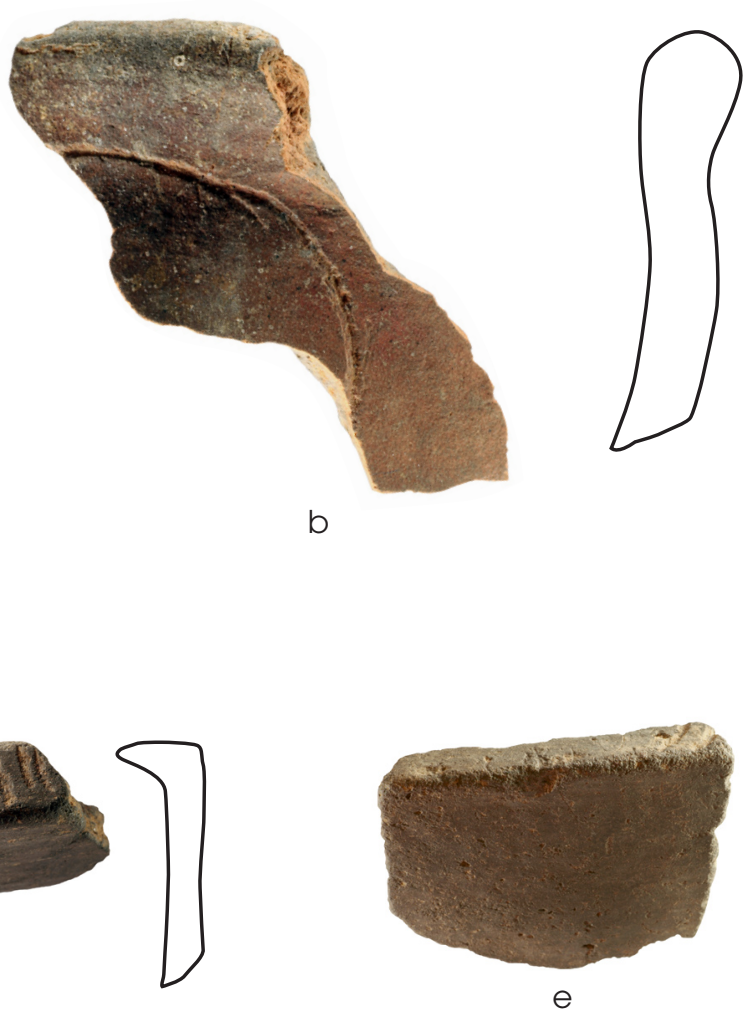

e

Figure 5.18. Engraved olla and unique bowl sherds from Subarea 1 at the William Ford site. (a) Possible olla body sherd with small engraved SZ element; (b) engraved olla rim with rolled lip; (c-e) two sherds from a bowl with straight rim and flat lip with inward-oriented tabs engraved with short parallel lines (c-d are interior view and top-down view of exterior of sherd with lip tab; e is exterior view of sherd with flat lip and no tab). 


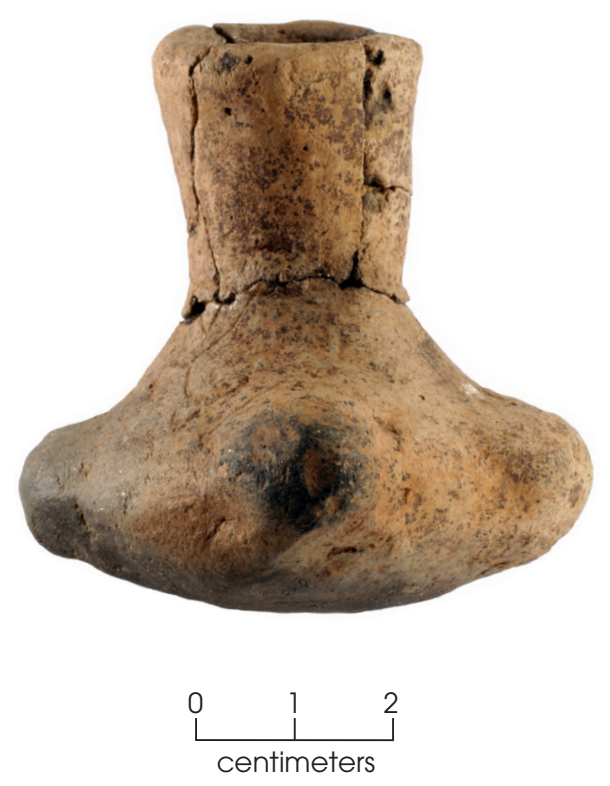

Figure 5.19. Miniature square bottle from Test Unit 9 in Subarea 1 at the William Ford site.

$47.0 \mathrm{~g}$ (Figure 5.19). It has an everted rim, rounded lip, and flat base. It is not decorated, but it has four large appliquéd node-like corners that give it a square body shape. The exterior surface is smoothed, and the finish of the interior surface is unknown. No burned encrustations are evident on the exterior. The vessel has grog and bone temper, a light brown exterior, and a black core; the interior surface color is unknown. The bottle is only $5.5 \mathrm{~cm}$ high with a body diameter of $4.4 \mathrm{~cm}$ and a neck diameter of $2.2 \mathrm{~cm}$. The neck is $2.7 \mathrm{~cm}$ tall, and the orifice diameter is $2.5 \mathrm{~cm}$. The base is $2.6 \mathrm{~cm}$ across. It has a volume of just $10 \mathrm{ml}$. This vessel is untyped, though the square vessel form is common in Ripley Engraved bottles.

\section{Feature 1}

This is a large utility jar represented by a rim/shoulder fragment weighing $632.8 \mathrm{~g}$, about 20 percent of the vessel (Figure 5.20). The rim is everted and has a rolled lip. The fragment is decorated with three lines of rectangular stick punctations that encircle the tall neck from below the lip to the neck/body juncture. The body is not decorated. The exterior and interior surfaces are smoothed. Slight burned encrusta- tions are evident on the rim interior. The vessel has grog and bone temper, light brown to gray exterior and interior surfaces, and a gray core. It has an orifice diameter of $29.5 \mathrm{~cm}$ and an estimated height of $30 \mathrm{~cm}$. The rim is $7.0 \mathrm{~cm}$ tall, and the diameter at the neck is $26.3 \mathrm{~cm}$. Rim thickness is $0.66 \mathrm{~cm}$, and body thickness is $0.70 \mathrm{~cm}$. This utility jar is untyped, although it is consistent with what Perttula (2005:277-278) calls Mockingbird Punctated.

\section{Feature 164, Vessel 1}

This is a small complete Ripley Engraved carinated bowl weighing $346.8 \mathrm{~g}$. It is engraved with a slanted scroll motif on the rim (Figure 5.21), and the body is not decorated. It has an everted rim, rolled lip, and flat base. The exterior surface is burnished, while the interior surface is smoothed; neither surface has any evidence of encrustations. The vessel has bone temper, as well as voids probably representing leached bone. Both the exterior and interior surfaces are dark brown; the core color is unknown. The bowl is $6.7 \mathrm{~cm}$ tall with an orifice diameter of $16.2 \mathrm{~cm}$. The rim is $3.1 \mathrm{~cm}$ tall; the maximum body diameter is $14.0 \mathrm{~cm}$. The base diameter is $6.6 \mathrm{~cm}$. Rim thickness is $0.57 \mathrm{~cm}$. It has a volume of $550 \mathrm{ml}$.

The motif repeats four times with two repetitions focused on an open circle as a primary element to the scroll (Figure 5.21a). The open circle elements alternate with two repetitions that have interlocking scroll arms instead of circles (Figure 5.21b). A similar scroll motif with alternating primary elements is known from graves at both the Thomas B. Caldwell cemetery (see Chapter 7) and the Tuck Carpenter site (Vessel 3 in Grave 5 and Vessel 1 in Grave 11; Turner 1992:16-17, 28-29). This bowl also has an engraved line that encircles the bowl following the carination on the bowl's interior. This interior line is present on several Ripley Engraved bowls from the Caldwell cemetery.

\section{Feature 164, Vessel 2}

This is a medium-sized jar, ca. 70 percent complete, weighing $823.1 \mathrm{~g}$ (Figure 5.22a). It has an everted rim, rolled lip, and flat base. The exterior and interior surfaces are smoothed; both surfaces have slight burned encrustations. The vessel has grog and bone temper. The exterior surface is black and yellow, while the interior 


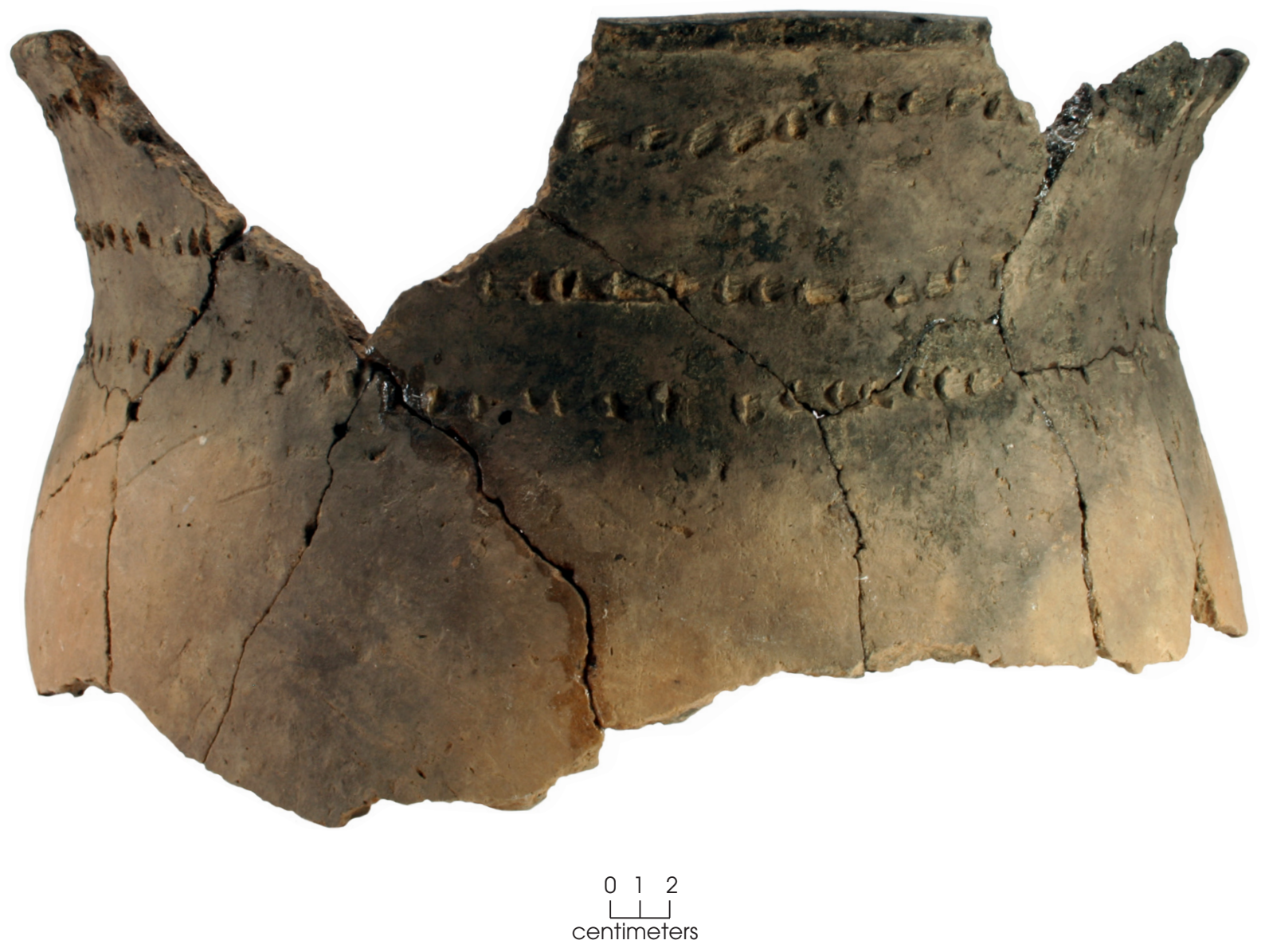

Figure 5.20. Rim section from a large punctated jar from Feature 1 in Subarea 1 at the William Ford site.

surface is black; the core is also black. The jar is $17.8 \mathrm{~cm}$ tall with an orifice diameter of $15.0 \mathrm{~cm}$. The rim is $4.0 \mathrm{~cm}$ tall, and the diameter at the neck is $13.8 \mathrm{~cm}$; the maximum body diameter is $15.7 \mathrm{~cm}$. The base diameter is $7.0 \mathrm{~cm}$. Rim thickness is $0.38 \mathrm{~cm}$, and body thickness is $0.42 \mathrm{~cm}$. Its volume could not be determined.

Two horizontal lines of stick punctations encircle the rim, one below the lip and the other at the neck/body junction. The punctations were made from the right using a tool with a flat rectangular end. Striations in the punctations visible under magnification suggest a split piece of cane was used. The body is decorated with sets of five evenly and closely spaced incised vertical lines extending from the neck to the base. The evenness of the lines gives the impression that they were made with a comblike tool. Similar jars with two or more lines of punctations around the rim and a plain or decorated body are common at the Thomas B. Caldwell cemetery (see Chapter 7). This vessel is not typed.

\section{Feature 164, Vessel 3}

This vessel consists of two undecorated body sections from what appears to be a large jar similar to the one from Feature 1 described above, though its rim treatment is unknown; it is only about 10 percent complete, weighing $351.6 \mathrm{~g}$. The exterior and interior surfaces are smoothed and show no evidence of burned encrustations. The vessel has grog and bone temper, dark to light brown exterior and interior surfaces, and a black core. The body diameter is $25.0 \mathrm{~cm}$; body thickness is $0.84 \mathrm{~cm}$. This utility jar is untyped. 


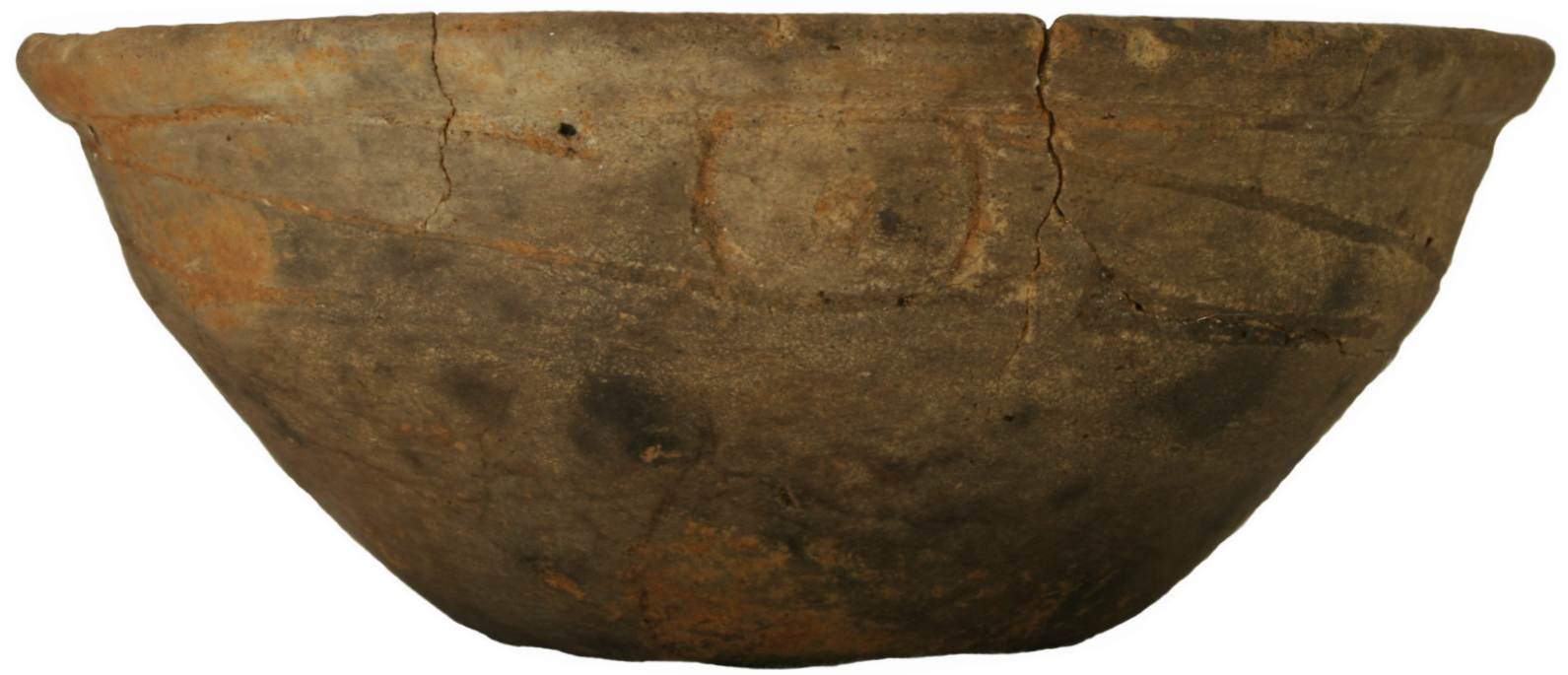

a

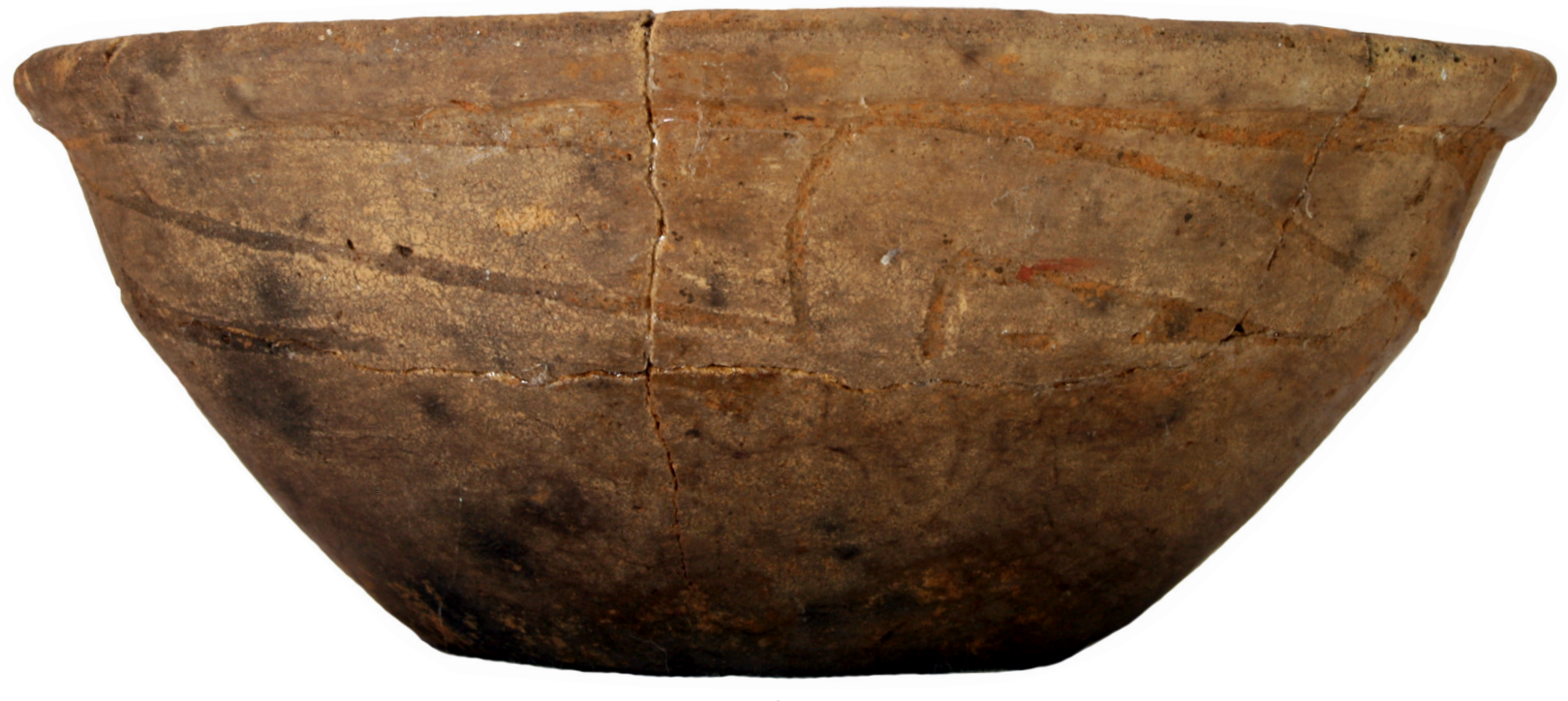

$\mathrm{b}$

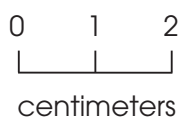

Figure 5.21. Two views of a small Ripley Engraved bowl from Feature 164 in Subarea 1 at the William Ford site. (a) Scroll with open circle as primary element; (b) scroll with interlocking arms and no primary element. 


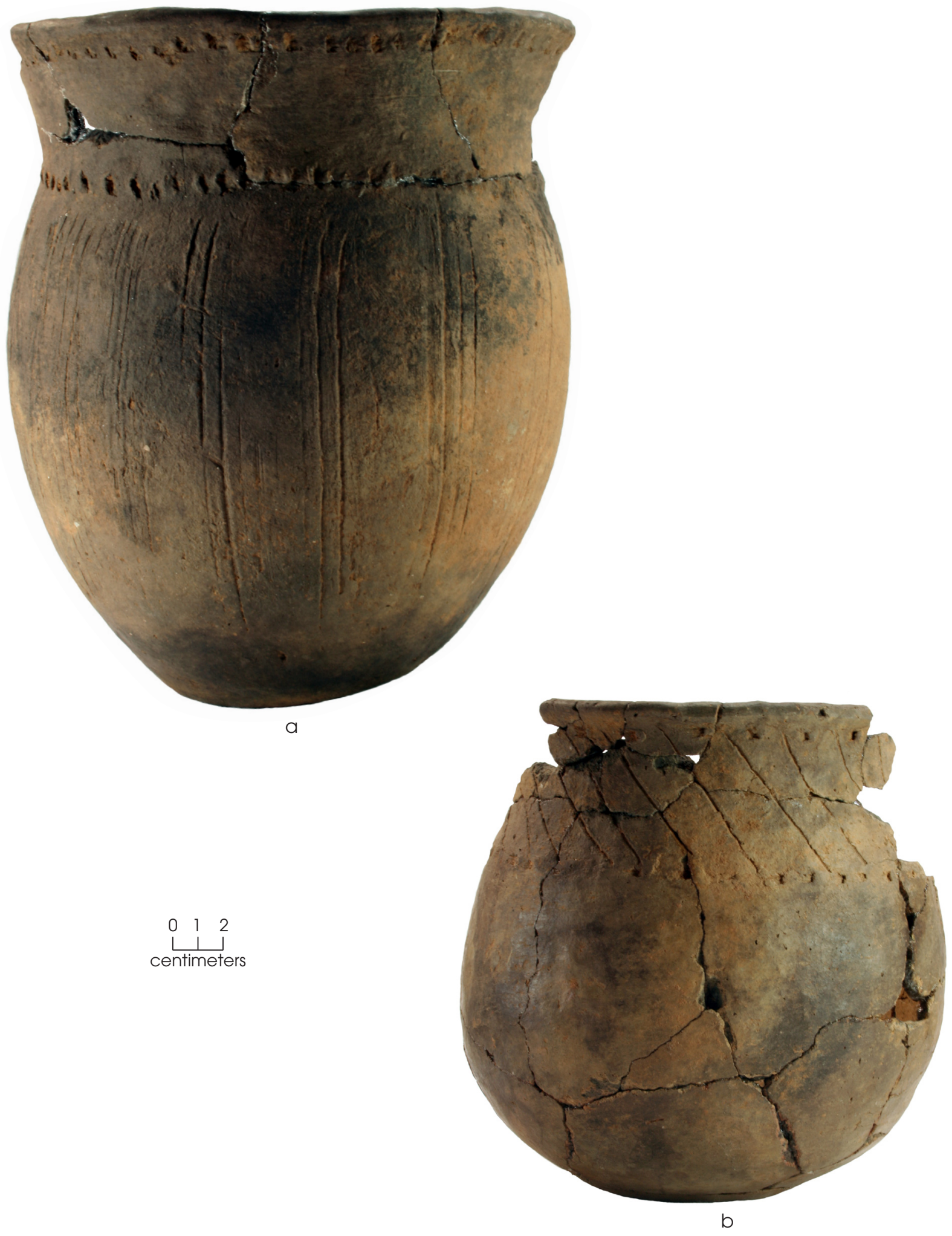

Figure 5.22. Punctated-incised jars from Subarea 1 at the William Ford site. (a) Feature 164; (b) Feature 542A. 


\section{Feature 542A}

This is a small jar, ca. 80 percent complete, weighing $450.0 \mathrm{~g}$ (Figure 5.22b). It has an everted rim, rolled lip, and flat base. The exterior surface is burnished and light to dark brown, while the interior surface is smoothed and yellow; neither has evidence of burned encrustations. The core is black. The vessel has grog temper. The jar is $12.7 \mathrm{~cm}$ tall with a rim height of $4.0 \mathrm{~cm}$ and an orifice diameter of $12.0 \mathrm{~cm}$. The neck diameter could not be measured due to breakage. The maximum body diameter is $12.5 \mathrm{~cm}$. The base diameter is $6.1 \mathrm{~cm}$. Rim thickness is $0.53 \mathrm{~cm}$, and body thickness is $0.55 \mathrm{~cm}$. Its volume could not be determined. It has two horizontal lines of stick punctations encircling the rim, one below the lip and the other at the neck/body junction. Diagonal incised lines extend between the lines of punctations. The body is not decorated. This jar is untyped, but it is similar in form and decorative mode to other jars from the site.

\section{Nonvessel Artifacts}

Ten nonvessel ceramic artifacts were recovered: an ear spool fragment from Feature 439 (a noncultural feature [rodent disturbance] with organically enriched anthropogenic fill), a possible spindle whorl fragment from Feature 90, 7 smoking pipe fragments recovered from various proveniences, and a ceramic waster from Test Unit 19. The ear spool fragment is approximately a quarter of a circular pulley-shaped ear spool with a central perforation (Figure 5.23a). The inner and outer flanges are made from slight thickening of the spool ends and have the same configuration. The reconstructed outer diameter for both flanges is $2.4 \mathrm{~cm}$, and the inner diameter of the perforation is $1.4 \mathrm{~cm}$. The length of the specimen is $1.57 \mathrm{~cm}$, and its wall thickness is $0.65 \mathrm{~cm}$. This specimen was tempered with grog.

The possible spindle whorl fragment consists of approximately half of a whorl, which is $8.0 \mathrm{~cm}$ in diameter and $1.24 \mathrm{~cm}$ thick at the central hole and $0.93 \mathrm{~cm}$ thick at the outer edge (Figure 5.23b). The central hole is well finished while the outer edges are roughly finished. The central hole flares out at the surface of the specimen; its minimum diameter is $0.72 \mathrm{~cm}$. In cross section, it has one flat side and one convex side, with some circular striations on the convex side around the central hole. This specimen is tempered with grog and bone; it has a gray core and light brown to gray surfaces. Similar ceramic specimens are known, though infrequent, at many Caddo sites in northeast Texas. Identification of this specimen as a spindle whole is based on Alt's (1999) work on ones from early Cahokian settlements.
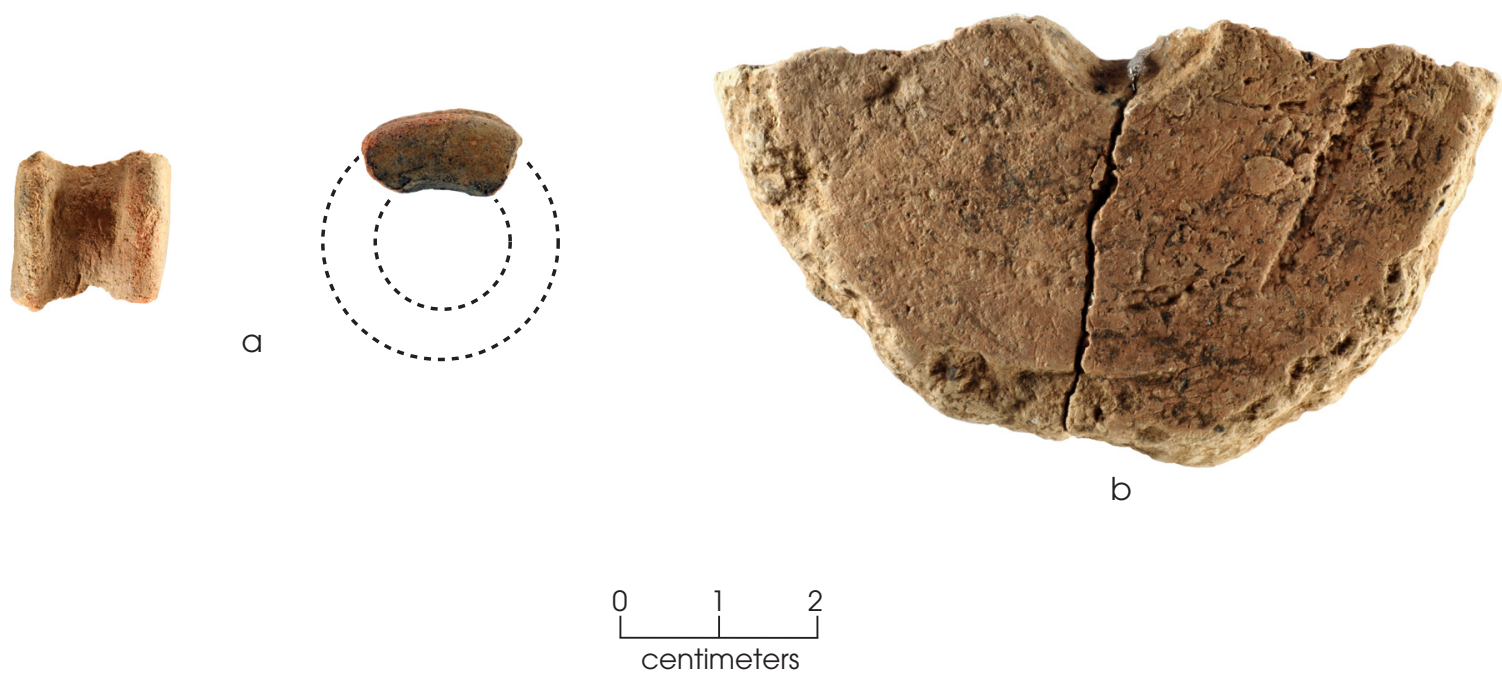

Figure 5.23. Nonvessel ceramic artifacts from Subarea 1 at the William Ford site. (a) Ear spool fragment; (b) spindle whorl fragment. 
The seven smoking pipe fragments consist of two stem pieces and five bowl pieces. The stem fragments, from Features 191A and 429, are small but appear to represent Red River-style pipes (Hoffman 1967). The stem from Feature $191 \mathrm{~A}$ is $1.47 \mathrm{~cm}$ in length and $0.92 \mathrm{~cm}$ in diameter and has a draw hole that is $0.37 \mathrm{~cm}$ in diameter; it is tempered with bone. The stem from noncultural Feature 429 is grog tempered and appears to be from the stem-bowl juncture; it is $1.65 \mathrm{~cm}$ in length, but other measurements could not be made. Because of their small sizes, it is difficult to determine what style of pipe the five bowl fragments may represent. They range in thickness from 0.31 to $0.62 \mathrm{~cm}$, which is more consistent with the bowl thickness range of $0.30-0.58 \mathrm{~cm}$ for several elbow pipes from burial contexts at the Pine Tree Mound site (Fields and Gadus 2012:539) than the extremely thin bowls on Red River-style pipes (Hoffman 1967:7). Two of these have grog temper, two have grog and bone, and one has bone with voids. One is decorated with engraved horizontal lines, while the others are undecorated; one of the latter is burnished.

An indication that ceramic vessel manufacture may have occurred at the site is provided by the recovery of a single waster or ceramic lump. It has a flattened side and a convex side. It is approximately $3.0 \mathrm{~cm}$ long by $2.5 \mathrm{~cm}$ wide and is $0.5 \mathrm{~cm}$ thick. It is tempered with grog and bone.

\section{CHIPPED STONE ARTIFACTS}

The chipped stone assemblage from Subarea 1 consists of 23 arrow points, 24 dart points, 1 dart or arrow point fragment, 3 gunflints, 33 bifaces, 5 unifaces, 73 flake tools, 7 core tools, 65 cores, and 2,172 pieces of debitage. Appendix E lists the metric attributes of all the tools. Excluded from this analysis are a small number of artifacts (19 flakes from various proveniences, a Gary dart point from Auger Test 114, and a Dalton dart point from Auger Test 103) found during auger testing but left at the site because the landowner had not granted permission for artifact collection (other items left at the site during auger testing subsequently were collected when they were exposed in the data recovery excavations). The assemblage reflects periodic use from the Early Archaic period to the Late Caddo period, a distinct reliance on local lithic materials, and knapping activities consist- ing mostly of late reduction, tool production, and tool maintenance.

\section{Projectile Points}

The 48 projectile points consist of 23 arrow points and fragments, 24 dart points and fragments, and 1 that is from either a dart or arrow point; the latter is a barb or distal tip of locally available chert. Eighty-one percent $(\mathrm{n}=39)$ are of locally available materials. The entire arrow point assemblage is of local material, with 65 percent $(\mathrm{n}=15)$ of quartzite and 35 percent $(n=8)$ of chert. The dart points are mostly (88 percent) of local materials, with 38 percent $(n=9)$ chert, 38 percent quartzite $(n=9)$, and 13 percent silicified wood $(\mathrm{n}=3)$. Two untyped dart points are nonlocal gray chert, and a San Patrice or Dalton is of nonlocal jasper.

Fifty-two percent $(\mathrm{n}=25)$ are complete and reflect curation, retooling, discard, or loss. Only a few of the points indicate manufacture failures, seen in the preforms and aborted tools $(\mathrm{n}=5,10$ percent). Additional indications of retooling are seen in the proximal projectile point fragments $(n=6,14$ percent). Fractures from use were noted on 19 percent $(n=9)$ of the projectile points. Reworking or retouch was identified on 73 percent, supporting retooling and tool maintenance. The moderately high frequency of complete points combined with the proximal point fragments and the degree of reworking suggest more retooling and loss than manufacturing, although some manufacturing is evident.

\section{Arrow Points}

The 23 arrow points consist of 2 Bassett, 1 Bonham, 2 Catahoula, 2 Colbert, 1 Homan, 5 Maud, 1 Steiner, 1 possible Steiner, 1 preform, and 7 untypeable fragments. Collectively, they span the Caddo period.

Bassett points have short broad blades, long barbs, contracting stems, and pointed bases (Turner and Hester 1999:201). Both Bassetts are complete and made of quartzite. One is Ogallala quartzite and has a convex base, contracting stem, and triangular but reworked blade (Figure 5.24a). The other, of yellowish brown quartzite, has a straight base, contracting stem, and irregular blade edges with a needle-like distal tip (Figure 5.24b). 

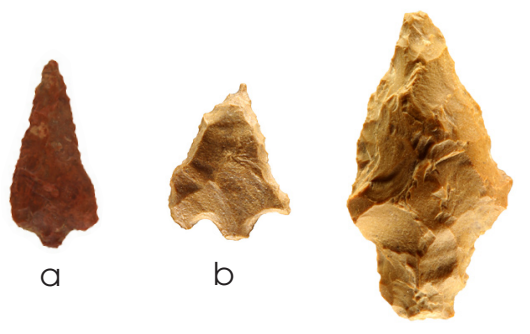
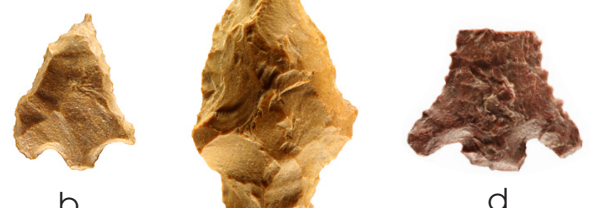

d

C
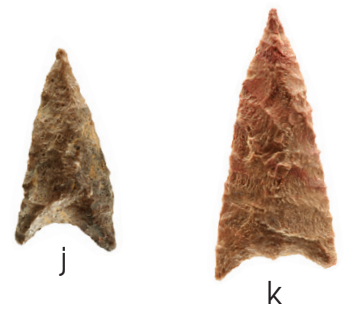

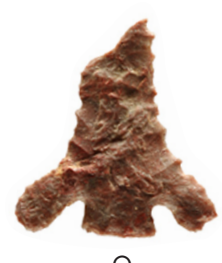

e

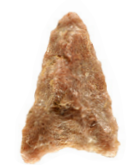

$\mathrm{m}$

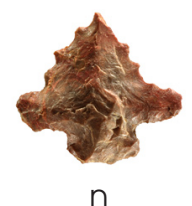

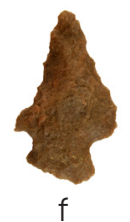
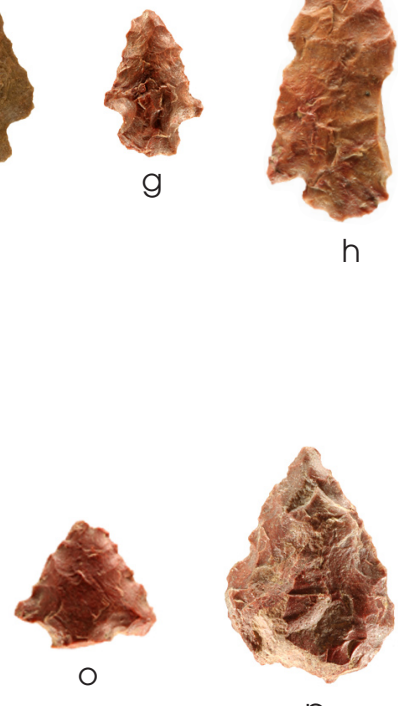

$\mathrm{P}$

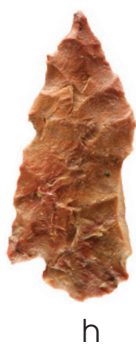

h

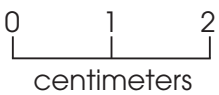

Figure 5.24. Arrow points and preforms from Subarea 1 at the William Ford site. (a-b) Bassett; (c) Bonham; (d-e) Catahoula; (f-g) Colbert; (h) Homan; (i-m) Maud; (n) Steiner; (o) possible Steiner; (p) preform.

Bonham points are characterized by narrow triangular blades, small barbs, straight stems, and straight bases (Suhm et al. 1954:496; Turner and Hester 1999:202). The single Bonham is complete but missing its barbs (Figure $5.24 \mathrm{c}$ ). It is made of chert and is very thick. It has a straight base, contracting stem, and triangular but reworked blade.

Catahoula points have long flared shoulders with squared barbs, expanding to straight stems and straight bases (Turner and Hester 1999:206). One of the two Catahoulas is a proximo-medial fragment made of red chert (Figure 5.24d). It has a straight base (with a fracture on the corner), a straight stem, and a recurved heavily serrated blade. Basal notching created long barbs. The second Catahoula is also a proximo-medial fragment (Figure 5.24e) It is made of quartzite and has a straight base and straight stem. The blade is recurved and has heavy serration.

Colbert points have recurved to convex blade edges with serration, wide shoulders and barbs, expanding stems, and straight bases (Turner and Hester 1999:209). Both Colberts are of quartzite. One, made on a flake blank, has a convex base, expanding stem, and irregular serrated blade that has been extensively reworked (Figure 5.24f). The second Colbert is complete with a convex base, expanding stem, and blade that is extensively reworked and serrated (Figure 5.24g).

Homan points are characterized as having recurved, sometimes serrated, blade edges, a flared to fan-shaped stem, and a convex base (Turner and Hester 1999: 219). The single Homan, made of quartzite, has a convex base, an expanding stem, and a triangular blade that is missing a barb (Figure 5.24h). The distal tip is needle-like. A lateral fracture removed part of one side, including the barb and part of the stem.

Mauds are slender stemless points with concave to V-shaped bases (Turner and Hester 1999:223). One of the five Mauds is a proximo-medial fragment made of dark brown and reddish brown chert (Figure 5.24i). It has a 
concave base; the blade is serrated, but the distal tip and part of one side are missing. The second Maud is complete and made of dark brown chert (Figure 5.24j). It has a concave base and triangular, but reworked, blade. The remaining three Maud points, all of quartzite, are complete and have concave bases and triangular blades. One has a needle-like distal tip from blade edge retouch and also has a small projection on the base (Figure 5.24k). Another has an extensively retouched blade with heavy serration and may be exhausted (Figure 5.24l). The third also has extensive retouch on the blade and is very small (Figure $5.24 \mathrm{~m}$ ).

Steiners are small serrated points with recurved blades, expanding to straight stems, and straight bases (Turner and Hester 1999:232). One Steiner and one possible Steiner were recovered. The Steiner, made of quartzite, has a straight base, an expanding stem, and a triangular blade with heavy serration; it was made on a flake blank (Figure 5.24n). The possible Steiner is nearly complete, missing the tip and base (Figure 5.24o). It has moderate to heavy serration on the blade.

One arrow point preform of reddish brown chert has an irregular base, expanding stem, and triangular blade (Figure 5.24p). Of the seven untyped arrow point fragments, three are chert (one dark brown and two reddish brown) and four are quartzite. The fragments include four distal, two medial, and one lateral.

\section{Dart Points}

The 24 dart points consist of 1 Dalton and 1 possible Dalton, 1 Dalton or San Patrice, 1 Edgewood, 3 Garys, 1 Godley, 1 Johnson, 1 Kent and 1 possible Kent, 1 Kent or Gary, 1 Marshall, 1 Yarbrough, 1 Yarbrough or Kent, 7 untyped points and fragments, and 2 preforms.

Dalton points are characterized by parallel-sided stems, grinding on the stem and base edges, deep concave bases, and basal thinning or fluting, and they often exhibit beveled and serrated blade edges (Turner and Hester 1999:99). The single Dalton, of chert, is a proximo-medial fragment with a concave base and slightly expanding stem; although missing the distal tip, the remaining portion appears to be triangular and has moderate serration, and the stem and basal edges are ground (Figure 5.25a). The possible Dalton is a proximal portion with the distal end reworked into either a drill or a knife, probably after the point broke (Figure 5.25b). A portion of the base is missing, but the remaining part of the base is concave. It has a straight stem and is made of reddish brown chert.

One specimen is either a Dalton or San Patrice. San Patrice points have fairly deep concave bases, basal and stem edge grinding, rounded shoulders, and basal thinning or fluting (Turner and Hester 1999:181-182). This specimen is complete, made of jasper, and has a concave base, slightly expanding stem, and triangular blade (Figure 5.25c). The blade has moderate serration, and the base and stem are ground.

Edgewood points tend to be short with short barbs, an expanding stem, and concave to straight base (Turner and Hester 1999:111). One Edgewood is made of pink quartzite (Figure $5.25 \mathrm{~d})$. It is complete with a straight base, expanding stem, and triangular blade. The blade has been reworked symmetrically.

Garys are thick points with square shoulders and contracting stems and incorporate great variation in morphology (Turner and Hester 1999:123). One Gary is complete with a convex base, contracting stem, and irregular blade due to extensive reworking (Figure 5.25e); it is made of dark gray and red chert. Another Gary, made of reddish brown local chert, is complete with a convex base, contracting stem, and an extensively reworked blade; given the shape of the blade, it was possibly used as a hafted scraper (Figure 5.25f). The third Gary point is nearly complete, is of Ogallala quartzite, and has a convex base, contracting stem, and very crude irregular blade (Figure 5.25g).

Godleys are small triangular points with prominent shoulders, expanding stems, and convex bases (Turner and Hester 1999:125). The single Godley is complete with a convex base, expanding stem, and triangular blade (Figure $5.25 \mathrm{~h}$ ). It is made of highly siliceous silicified wood.

Johnson points are characterized by broad blades with square shoulders, straight stems, and slightly concave bases (Turner and Hester 1999:132). The single Johnson is complete with a concave base, straight stem, and triangular blade. It is a broad point with basal and stem edge grinding and basal thinning (Figure 5.25i). It is made of reddish brown local chert.

Kents are poorly made asymmetrical points with squared to indistinct shoulders, a straight stem (although it may be contracting or slightly 


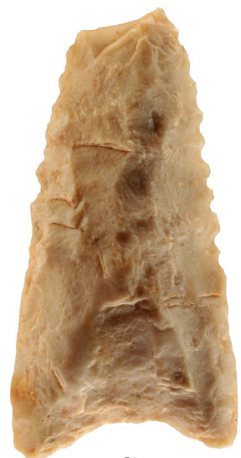

a

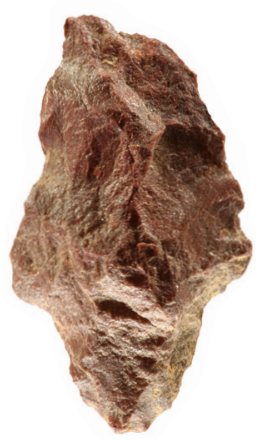

g

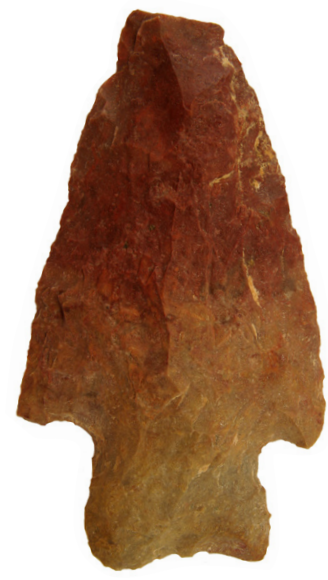

m

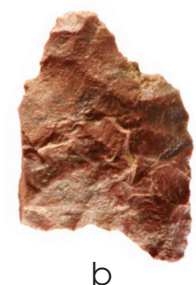

b

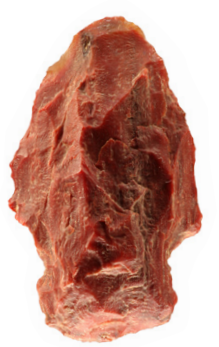

h

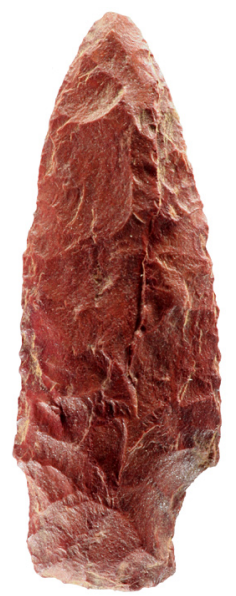

$\mathrm{n}$
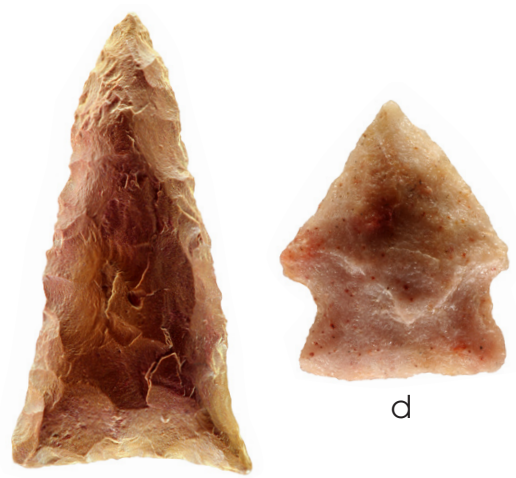

d

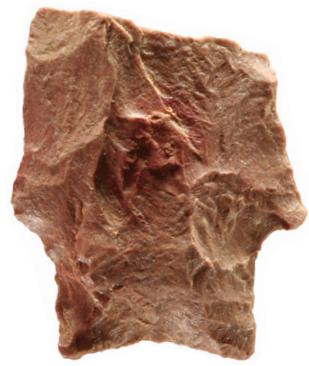

i

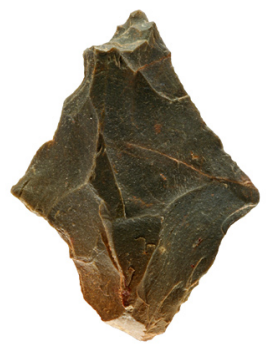

e
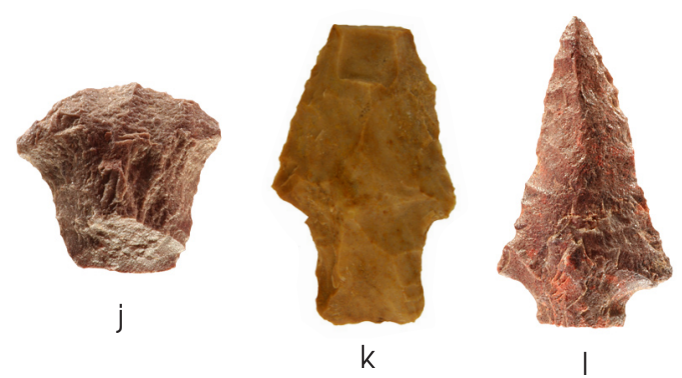

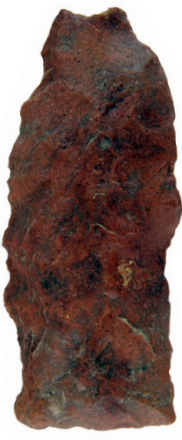

○

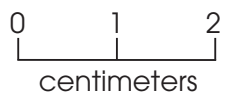

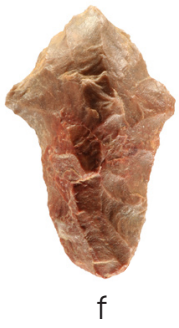

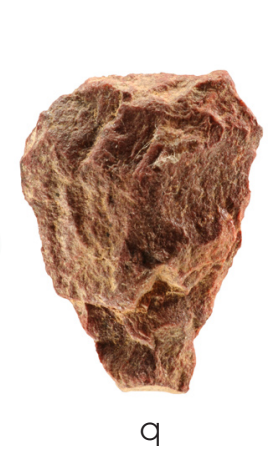

a

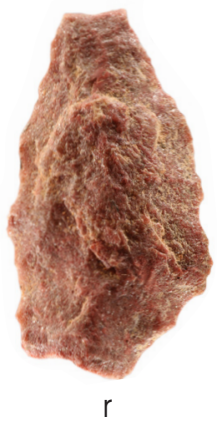

$\mathrm{P}$

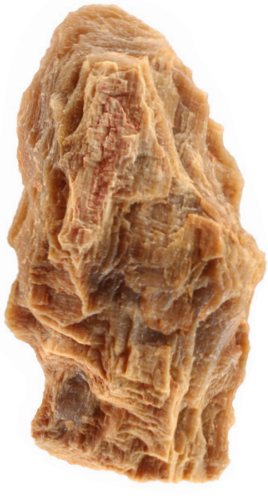

Figure 5.25. Dart points and preforms from Subarea 1 at the William Ford site. (a) Dalton; (b) possible Dalton; (c) Dalton or San Patrice; (d) Edgewood; (e-g) Gary; (h) Godley; (i) Johnson; (j) Kent; (k) possible Kent; (l) Kent or Gary; (m) Marshall; (n) Yarbrough; (o) Yarbrough or Kent; (p) untyped; (q-r) preforms. 
expanding as well), and a flat to concave base. The Kent point from Subarea 1 at 41TT852 is complete with a straight base, contracting stem, and irregular blade that has been reworked into a scraper (Figure 5.25j). It is made of quartzite. Another specimen is a possible Kent. Made of local chert, it has a straight base and straight stem, and the blade is triangular with alternate beveling and an impact fracture on the tip (Figure 5.25k). A possible Kent or Gary has a straight stem and triangular blade but is missing part of the base (Figure 5.25l). The base is indeterminate since it is fractured. It is very well made, with extensive reworking and moderate serration on the blade. It is made of very dark brown with red chert.

Marshall points have broad triangular blades with convex edges, long barbs, deep corner notching, concave bases, and straight to expanding stems (Suhm and Jelks 1962; Turner and Hester 1999:149). The single Marshall is made of red and gray quartzite and is complete except for a small portion of the distal tip; it has a concave base and expanding stem, and the blade is triangular and slightly serrated (Figure $5.25 \mathrm{~m}$ ).

Yarbroughs are slender elongated points with prominent shoulders, straight to expanding stems, straight bases, and stem and basal edge grinding (Turner and Hester 1999:197). The single Yarbrough has a straight base and straight stem (Figure 5.25n). The blade has been asymmetrically reworked, probably used as a knife, and has moderate serration. A point that could be a Yarbrough or Kent, of Ogallala quartzite, has a straight base, straight stem, and irregular blade due to an impact fracture on the tip, which was retouched after the fracture (Figure 5.250).

Seven untyped dart points were recovered. One complete one, of silicified wood, is very crude with some cortex on both faces (Figure 5.25p). The other six are fragments. One is a medio-distal piece of local olive gray/green chert; the tip has been reworked but it is basically triangular. Another is a distal portion of local yellowish brown chert. A medial fragment is of nonlocal medium gray chert. A proximal fragment of nonlocal gray banded chert has a straight base and straight stem. A medio-distal fragment of Ogallala quartzite has heavy serration on the blade. Another medio-distal fragment is very crude but has evidence that it was used and resharpened in an irregular way.
Both dart preforms are of Ogallala quartzite. One is missing its tip and has a convex base, an expanding stem, and a triangular blade (Figure $5.25 \mathrm{q})$. The second is missing the tip and the corner of the base (Figure 5.25r).

\section{Gunflints}

One of the three gunflints is made of dark gray nonlocal chert (Figure 5.26a). It is diamond shaped, bifacially worked, beveled on two edges, and retouched on four edges with wear indicative of use as a gunflint on three edges. The second gunflint is an oval complete biface made of Ogallala quartzite with retouch on four edges and wear indicative of use as a gunflint on two edges (Figure 5.26b). The third gunflint is made on a flake (Figure 5.26c). It has cortex on the dorsal side, unifacial retouch on one edge of the ventral side, bifacial retouch on two edges, and wear indicative of use as a gunflint on two edges. It is made of dark yellowish brown Edwards chert and is square to oval in shape.

\section{Bifaces}

Excluding the 2 bifacial gunflints, 33 bifaces were recovered. Nine are knives, 2 are indeterminate tools, 5 are early-stage bifaces, 9 are middle-stage bifaces, and 8 are late-stage bifaces. Most are of local materials, consisting of chert (76 percent; $\mathrm{n}=25)$, quartzite (9 percent; $\mathrm{n}=3$ ), silicified wood (6 percent; $\mathrm{n}=2$ ), and quartz (3 percent; $\mathrm{n}=1$ ). Only 2 are of nonlocal chert.

Only 7 are complete. Of the fragments, 11 are proximal, 1 is medial, 4 are distal, 7 are lateral, and 3 are indeterminate. The abundance of proximal and distal fragments is associated with breakage during manufacture or use as knives. The lateral fragments indicate breakage during manufacture. Most of the fracture types (60 percent) are the result of manufacture failure and include lateral impact, overshot, and step fractures. The rest of the fragments are from use or unknown causes.

Only two of the nine knives are complete. Both are crudely worked pieces of silicified wood. Only retouch on the edges suggests they were used as knives. Of the knife fragments, three are distal, one is medial, and three are proximal portions. The distal and medial fragments are all of reddish brown or brown local chert (Figure 5.26d-e). Two of the proximal fragments are of local chert (one 


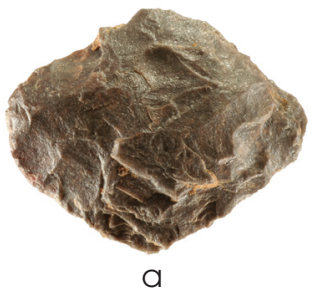

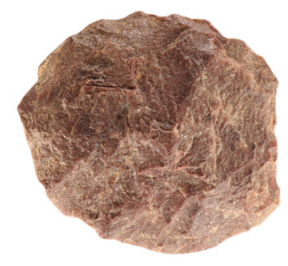

$\mathrm{b}$

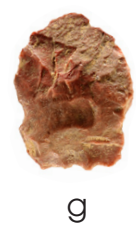

g

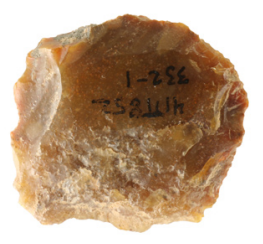

C

h

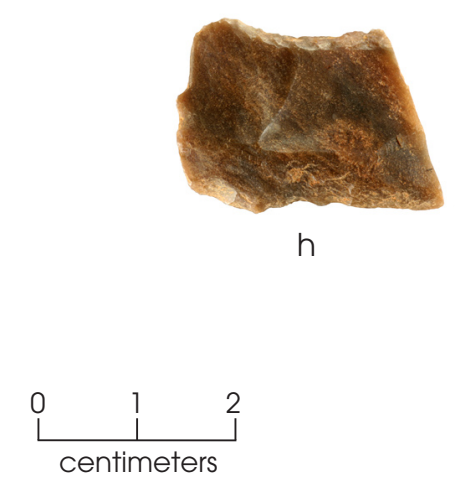

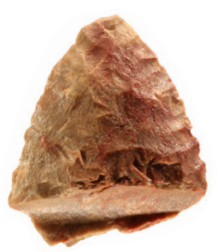

d

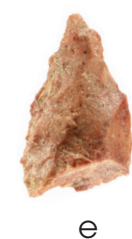

e
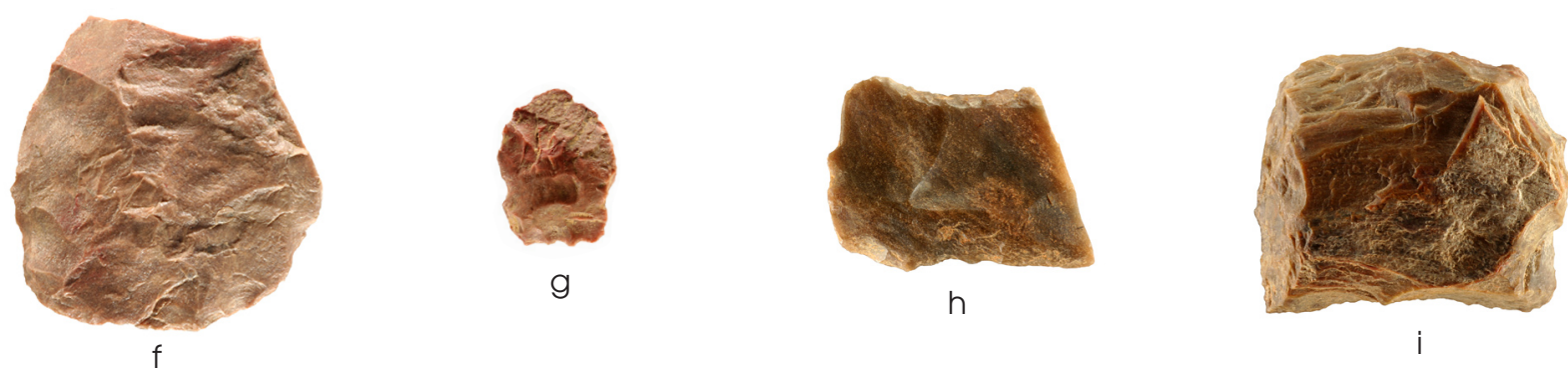

centimeters

Figure 5.26. Gunflints, bifaces, and flake tools from Subarea 1 at the William Ford site. (a-b) Bifacial gunflints; (c) unifacial gunflint; (d-f) bifacial knife fragments; (g) indeterminate bifacial tool; (h) flake side scraper; (i) flake end and side scraper.

yellowish brown and one dark reddish brown), and one is of quartzite (Figure 5.26f).

Both indeterminate bifacial tools are unstemmed. One is a very small, thin, well-flaked, proximal fragment of reddish brown chert (Figure 5.26g). The other is a small irregular fragment that has been retouched and used.

The early-stage bifaces include one complete one of red chert, two lateral fragments of local chert, a proximal fragment of brown local chert, and an indeterminate (probable lateral) fragment of reddish brown chert. Four of the middle-stage bifaces are complete; they are of local chert $(n=3)$ and quartz $(n=1)$. The middle-stage bifaces also include a distal fragment, three lateral fragments, and a proximal fragment. The distal fragment, of reddish brown chert with cortex on one side, is thinned fairly well and was broken in manufacture. The lateral fragments are thick and made of local chert. The proximal fragment is made of reddish and yellowish brown chert and was broken during manufacture. The late-stage bifaces consist of two lateral and six proximal fragments. Five are of local chert, two are of quartzite, and one is of nonlocal gray chert.

\section{Flake and Core Tools}

There are 85 tools made on flakes or cores, excluding the gunflint described above that is made on a flake. Five are formal tools, and 80 are informal. Four of the formal tools are made of chert, of which 2 are nonlocal and 2 are local. The fifth is made of very fine-grained silicified wood. The informal tools are predominantly (91 percent) of local materials (mostly chert, silicified wood, and quartzite), with the other 9 percent of nonlocal Edwards and varieties of white, gray, and black chert.

\section{Formal Tools}

The formal unifacial tools consist of a side scraper, an end and side scraper, two spoke- 
shaves, and an indeterminate tool. The side scraper has steep retouch on one lateral edge and is made of banded brown nonlocal chert (Figure 5.26h). The end and side scraper is made of highly silicified wood and has retouch on all four edges (Figure 5.26i). One spokeshave is a tertiary flake of nonlocal gray chert with a notched lateral edge, and the other, of reddish brown local chert, has a notched distal edge and also may have been used as a graver since the edge curves out and creates a projection, though no definite traces of wear were observed. The indeterminate tool is a very small lateral fragment that may actually be part of a biface. It has a notch on one side and is made of local yellowish green to gray chert.

\section{Informal Tools}

The informal flake tools consist of include 5 multifunctional tools, 37 edge-modified flake knives, 9 edge-modified flake scrapers, 22 utilized flakes, 3 edge-modified core knives, and 4 edge-modified core scrapers. The multifunctional tools include a flake with steep edge retouch (for use as a scraper), oblique edge retouch on another edge (for use as a knife), and another side with retouch that created a slight bevel and two curved edges. The curved edges include two projections that also may have been a used as gravers. This specimen is made of very light gray, probably local, chert with white cortex. Another multifunctional flake tool has an edge with even, beveled, somewhat steep retouch and another edge with more irregular and minimal bilateral and bifacial retouch on the ventral surface. It is made of reddish brown to red chert with some cortex on the dorsal surface. The third multifunctional tool has steep retouch on one edge and use wear on another; it is made of reddish brown chert with tan cortex on the dorsal side. The fourth has irregular retouch on the distal end that probably was used for cutting and another edge with protrusions that may have been used as gravers; it is of reddish brown chert. The last multifunctional tool has retouch on the distal end, creating a projection that probably was used as a graver, and retouch on another end, which probably was used as a knife; it is also of reddish brown chert.

The 37 edge-modified knives are flakes with light retouch and wear typical of light-duty expedient cutting. These are mostly chert $(n=23)$ with 10 of silicified wood and 4 of quartzite. The chert includes a few nonlocal varieties ( 1 white, 1 gray, and 1 black) but is mostly local red, reddish brown, yellowish brown, light brown, and dark brown varieties. Four of the edge-modified scrapers are of chert, 3 are of silicified wood, and 2 are of quartzite; only 1 of the chert specimens is of a nonlocal material, dark brown Edwards chert with white patina.

The 22 utilized flakes have evidence of use based on microflakes removed from one or more edges. These were most likely used as cutting tools. They are predominantly of local materials (1 quartzite, 3 silicified wood, and 17 local chert), with only 1 of gray chert that is probably nonlocal.

The three edge-modified core knives are all made of silicified wood and exhibit retouch and use wear on one or more edges. The four edge-modified core scrapers consist of one of chert and three of silicified wood.

\section{Cores}

Two bipolar cores, 33 flake cores, 17 core fragments, and 13 tested cobbles were recovered (Table 5.5). With the exception of 2 core fragments of nonlocal gray chert, all are locally available lithic materials, predominantly chert and silicified wood with some quartzite and hematite as well. Flake cores are cores with flakes removed, often in more than one direction, using hard-hammer percussion; 19 are of silicified wood, 10 are of local chert, and 4 are of quartzite.

Both bipolar cores are of local chert. Bipolar percussion is often used to reduce small nodules to produce usable flake blanks that could not be reduced by hard-hammer percussion. The tested cobbles are of local chert $(n=6)$, quartzite $(\mathrm{n}=4)$, silicified wood $(\mathrm{n}=1)$, and hematite $(\mathrm{n}=2)$; they have only a few flake scars (no more than three).

\section{Debitage}

The Subarea 1 excavations yielded 2,136 pieces of debitage. They are predominantly (94 percent) locally available materials, mostly chert (55 percent) but also quartzite (22 percent) and silicified wood (14 percent), as well as small amounts of ferruginous sandstone (1 percent), ocher (less than 1 percent), and hematite ( 2 percent). The sandstone, ocher, and hematite 
Table 5.5. Cores from Subarea 1 at the William Ford site

\begin{tabular}{|c|c|c|c|c|c|c|}
\hline Provenience & Core Type & Lithic Material & $\begin{array}{l}\text { Maximum } \\
\text { Length } \\
(\mathrm{cm})\end{array}$ & \begin{tabular}{|l|} 
Maximum \\
Width $(\mathrm{cm})$ \\
\end{tabular} & $\begin{array}{c}\text { Maximum } \\
\text { Thickness } \\
(\mathrm{cm})\end{array}$ & $\begin{array}{c}\text { Weight } \\
\text { (g) }\end{array}$ \\
\hline Feature 442 & bipolar & chert, local & 2.51 & 1.31 & 0.79 & 2.4 \\
\hline SU 57 & bipolar & chert, local & 2.39 & 2.02 & 0.74 & 3.4 \\
\hline Backdirt & core & chert, local & 3.59 & 2.44 & 2.05 & 20.3 \\
\hline Backdirt & core & chert, local & 4.41 & 2.95 & 2.80 & 39.7 \\
\hline Backdirt & core & chert, local & 5.26 & 3.48 & 2.57 & 44.5 \\
\hline Backdirt & core & chert, local & 5.56 & 4.78 & 3.32 & 98.3 \\
\hline Backdirt & core & chert, local & 4.06 & 2.16 & 1.91 & 14.0 \\
\hline Backdirt & core & chert, local & 5.56 & 3.22 & 2.51 & 63.3 \\
\hline Backdirt & core & quartzite & 4.92 & 4.18 & 2.13 & 46.3 \\
\hline Backdirt & core & quartzite & 6.19 & 4.77 & 2.94 & 60.8 \\
\hline Backdirt & core & silicified wood & 3.74 & 2.29 & 1.54 & 21.7 \\
\hline Backdirt & core & silicified wood & 4.46 & 2.84 & 0.69 & 17.0 \\
\hline Backdirt & core & silicified wood & 4.84 & 4.23 & 0.89 & 21.0 \\
\hline Backdirt & core & silicified wood & 5.22 & 5.13 & 1.19 & 50.2 \\
\hline Backdirt & core & silicified wood & 8.34 & 5.33 & 4.65 & 200.3 \\
\hline BT 10 & core & silicified wood & 11.19 & 5.85 & 2.77 & 268.4 \\
\hline BT 23 & core & silicified wood & 8.02 & 5.98 & 2.11 & 164.6 \\
\hline BT 24 & core & silicified wood & 7.05 & 4.80 & 1.63 & 57.2 \\
\hline BT 49 & core & silicified wood & 11.33 & 4.57 & 1.82 & 108.6 \\
\hline Feature 90 & core & silicified wood & 17.09 & 6.18 & 3.41 & 405.0 \\
\hline Feature 477 & core & chert, local & 3.86 & 2.47 & 2.36 & 28.2 \\
\hline Feature 477 & core & Ogallala quartzite & 5.35 & 4.31 & 2.17 & 63.1 \\
\hline SU 1 & core & silicified wood & 3.12 & 2.89 & 2.51 & 25.8 \\
\hline SU 10 & core & chert, local & 5.26 & 4.00 & 2.16 & 36.2 \\
\hline SU 10 & core & silicified wood & 5.53 & 4.45 & 1.25 & 49.6 \\
\hline SU 31 & core & silicified wood & 6.99 & 3.22 & 1.10 & 26.4 \\
\hline SU 53 & core & silicified wood & 4.30 & 3.66 & 2.19 & 35.2 \\
\hline SU 54 & core & silicified wood & 4.90 & 3.44 & 1.10 & 18.6 \\
\hline SU 60 & core & chert, local & 3.99 & 3.17 & 2.25 & 26.7 \\
\hline SU 72 & core & silicified wood & 4.35 & 3.57 & 0.84 & 13.1 \\
\hline SU 75 & core & silicified wood & 8.77 & 4.82 & 1.94 & 104.9 \\
\hline TU 15, Lev. 2 & core & silicified wood & 7.84 & 3.95 & 2.22 & 87.7 \\
\hline TU 24, Lev. 2 & core & quartzite & 6.03 & 4.40 & 2.23 & 72.2 \\
\hline TU 24, Lev. 3 & core & silicified wood & 6.40 & 2.27 & 1.61 & 39.1 \\
\hline TU 46, Lev. 3 & core & chert, local & 6.20 & 3.78 & 3.13 & 74.3 \\
\hline Backdirt & core fragment & chert, local & 2.96 & 2.94 & 2.93 & 21.3 \\
\hline Backdirt & core fragment & chert, local & 5.61 & 4.02 & 2.76 & 53.5 \\
\hline Backdirt & core fragment & chert, local & 2.19 & 1.82 & 0.71 & 3.2 \\
\hline Backdirt & core fragment & chert, local & 3.70 & 2.28 & 2.22 & 11.4 \\
\hline Backdirt & core fragment & chert, local & 5.19 & 3.38 & 1.86 & 30.3 \\
\hline Backdirt & core fragment & gray chert & 3.10 & 2.68 & 1.42 & 11.5 \\
\hline Backdirt & core fragment & quartzite & 3.57 & 3.19 & 2.43 & 30.2 \\
\hline Backdirt & core fragment & quartzite & 6.52 & 4.94 & 2.35 & 71.0 \\
\hline Backdirt & core fragment & silicified wood & 2.83 & 2.49 & 2.35 & 11.7 \\
\hline Backdirt & core fragment & silicified wood & 4.38 & 2.82 & 0.92 & 16.5 \\
\hline BT 49 & core fragment & gray chert & 4.54 & 4.45 & 2.48 & 42.5 \\
\hline
\end{tabular}


Table 5.5, continued

\begin{tabular}{l|l|l|c|c|c|c}
\hline \multicolumn{1}{c|}{ Provenience } & \multicolumn{1}{|c|}{ Core Type } & \multicolumn{1}{c|}{ Lithic Material } & $\begin{array}{c}\text { Maximum } \\
(\mathrm{cm})\end{array}$ & $\begin{array}{c}\text { Maximum } \\
\text { Width }(\mathrm{cm})\end{array}$ & $\begin{array}{c}\text { Thickness } \\
(\mathrm{cm})\end{array}$ & $\begin{array}{c}\text { Weight } \\
(\mathrm{g})\end{array}$ \\
\hline Feature 90 & core fragment & chert, local & 5.63 & 4.31 & 1.98 & 41.8 \\
\hline SU 53 & core fragment & chert, local & 2.76 & 2.07 & 1.55 & 7.3 \\
\hline SU 72 & core fragment & quartzite & 5.34 & 3.39 & 2.86 & 35.3 \\
\hline TU 6, Lev. 1 & core fragment & quartzite & 4.13 & 3.81 & 3.32 & 53.6 \\
\hline TU 12, Lev. 2 & core fragment & silicified wood & 5.57 & 5.13 & 2.88 & 42.9 \\
\hline TU 17, Lev. 1 & core fragment & chert, local & 4.46 & 4.01 & 1.90 & 46.8 \\
\hline Backdirt & core (tested) & chert, local & 4.07 & 3.37 & 1.63 & 30.9 \\
\hline Backdirt & core (tested) & chert, local & 4.61 & 3.45 & 2.02 & 36.7 \\
\hline Backdirt & core (tested) & chert, local & 4.72 & 3.18 & 1.02 & 19.0 \\
\hline Backdirt & core (tested) & chert, local & 8.99 & 5.77 & 4.98 & 314.6 \\
\hline Backdirt & core (tested) & Ogallala quartzite & 4.46 & 3.91 & 3.32 & 64.7 \\
\hline Backdirt & core (tested) & Ogallala quartzite & 7.83 & 4.91 & 4.22 & 197.6 \\
\hline BT 3 & core (tested) & silicified wood & 3.99 & 2.43 & 1.39 & 11.2 \\
\hline BT 36 & core (tested) & hematite & 2.68 & 1.97 & 1.18 & 7.9 \\
\hline CMS 1 & core (tested) & quartzite & 5.06 & 4.21 & 2.97 & 81.1 \\
\hline SU 21 & core (tested) & Ogallala quartzite & 4.69 & 4.32 & 1.54 & 38.8 \\
\hline SU 57 & core (tested) & hematite & 3.58 & 2.27 & 1.22 & 12.5 \\
\hline SU 66 & core (tested) & quartzite & 7.01 & 6.27 & 4.55 & 238.7 \\
\hline TU 6, Lev. 2 & core (tested) & chert, local & 4.12 & 2.80 & 2.79 & 46.3 \\
\hline
\end{tabular}

debitage is likely the byproduct of manufacturing or use of ground or battered stone tools such as hammerstones, celts, and manos, as well as pigment stones.

Nonlocal materials account for only 6 percent of the assemblage and are mostly Edwards chert and gray chert, with smaller numbers of black chert, white chert, jasper, and limestone. Given that all but two of the cores are of local materials, the nonlocal debitage is mostly from finished artifacts or tool blanks (bifaces or flakes) that were further manufactured into tools, resulting in retouch and other debitage.

The debitage is predominantly small to medium in size: 9 percent is smaller than $7.0 \mathrm{~mm}, 28$ percent is $7.0-12.5 \mathrm{~mm}, 31$ percent is $12.5-19.0 \mathrm{~mm}, 17$ percent is $19.0-25.0 \mathrm{~mm}$, 12 percent is $25.0-38.0 \mathrm{~mm}$, and 3 percent is larger than $38.0 \mathrm{~mm}$. The scarcity of large pieces of debitage suggests much initial reduction was done away from the site, and it also is consistent with the conclusion that the reduction that was done there focused on small locally available materials and tool blanks or finished tools of nonlocal materials.

\section{GROUND, PECKED, AND BATTERED STONE ARTIFACTS}

Fifty-nine ground, pecked, and battered stone artifacts were recovered from Subarea 1: 6 celts, 7 hammerstones, 6 manos/hammerstones, 1 polishing stone/hammerstone, 10 pitted hammerstones, 3 manos, 1 mano/pitted hammerstone, 4 anvils, 3 grinding slabs/anvils, 1 grinding slab, 2 abraders, 1 abrader/anvil, 3 grooved and grooved/incised stones, 1 pigment stone, 1 possible unfinished pipe, 1 pestle, 1 pestle/hammerstone/mano/anvil, and 7 indeterminate (see Appendix E for metric and provenience information). Thirty-six percent of the assemblage consists of pitted stones (both anvils and handheld hammers). If items with interchangeable, equivocal, or indeterminate functional positions are excluded, then base-position artifacts (anvils, grinding slabs, etc.) account for 19 percent of the assemblage, and handheld items compose 63 percent. Eighteen percent exhibit clear evidence of intentional shaping, while 58 percent show no evidence of such treatment (confident determination was not possible for the 
remainder). Over half, 53 percent, exhibit some degree of thermal alteration, and heat-derived modification is heavy or severe on 17 percent of that group.

Eleven lithic material types are represented. Forty-two percent are of quartzite. Ferruginous and nonferruginous sandstone artifacts account for 24 and 12 percent of the collection, respectively. The remainder consists of five Stanley or Jackfork sandstone artifacts, two pieces of limestone, and one artifact each of rhyolite, diorite, chert, silicified wood, hematite, and ochre.

Four of the six celt fragments were fashioned from Stanley or Jackfork sandstone, and the other two were made of diorite and ferruginous sandstone. Two are distal-medial segments with bifacial bit ends, one is a medial fragment, and three are proximal/proximal-medial segments. These artifacts are elliptical in cross section. All retain well-smoothed and polished surfaces, but the conditions of the different artifact surfaces vary considerably.

The proximal/proximal-medial celt fragments are conical to roughly conical in shape. The poll ends of two exhibit impact damage; the end of the third was intentionally modified from its original form. The two smallest pieces have the roughest surfaces of the recovered celts. Wear indicates that at least some of the apparent surface degradation occurred after the artifact surfaces were ground smooth. The proximal end of one of these pieces has a flat abraded facet that is oblique to the artifact's long axis (Figure 5.27a). Coarse striations are visible on this circular facet, and three short shallow striations are present on a smoothed surface remnant adjacent to the facet. The largest fragment is fashioned from diorite and is more nearly conical than the other end fragments (Figure 5.27b). It has a wellsmoothed and polished surface around most of its circumference. The medial fragment has a wellsmoothed and polished surface remnant around its circumference (Figure 5.27c). The distal end of this artifact was minimally reworked.

Both distal-medial celt fragments retain well-ground and polished bit ends with few visible peck marks (Figure 5.27d-e). Fine striations derived from grinding and shaping are visible at the distal ends of both. The remaining artifact surfaces are covered with peck marks and exhibit varying degrees of smoothing. One has a narrow bifacially worked bit edge that is intact save for a few small nicks (see Figure 5.27d). Several incisions are present on a flattened face segment, and several short cuts are present at the edge of the curved blade margin. The largest incisions are parabolic in cross section and oriented in the same approximate direction. The opposite side of the blade is convex and rougher than the flat face. One short incision is present on this face, at the transition between the rough marginally smoothed surface and the polished bit end. The other distal-medial fragment includes part of a curved blade margin, about $1.5 \mathrm{~cm}$ of the bit, and corresponding segments of each blade face (see Figure 5.27e). This wedgeshaped fragment is wider in transverse section than the other celt fragments. The well-polished bit end has noticeable facet lines between the bit edge and coarser surfaces of the celt head. Impact-derived damage is evident along the bit edge. Flake scars emanating from the transverse fracture plane may be derived from an intentional reworking effort.

Seven hammerstones, 6 manos/hammerstones, 1 polishing stone/hammerstone, and 10 pitted hammerstones were recovered. Eighteen (75 percent) are quartzite, 3 are nonferruginous sandstone, and 1 each are chert, rhyolite, and silicified wood. The hammerstones typically are oval in plan and usually have battered ends and one or more battered margins and narrow ridges. Three are also battered on one or two faces; the same number of artifacts exhibit minor to moderate surface smoothing in places. Facet morphology on one small hammerstone suggests that the tool also was used in conjunction with an anvil to crush or pulverize material. The presence of incisions or narrow grooves on one hammerstone fragment suggests it also was used as an abrader.

Manos/hammerstones, which tend to be larger than plain hammerstones, include subangular and rounded cobbles. Outline shapes range from nearly circular to teardrop-shaped. The larger ones typically exhibit grinding/abrasion wear on one large, relatively flat face, though the primary work surface on one is apparently on its margin. The smoothness of these surfaces and the size and densities of associated percussor marks vary between artifacts. Back-and-forth motion on one specimen produced two sets of rough, differently oriented striations on its working facet. Battering damage is most common on the margins of these artifacts but is also 


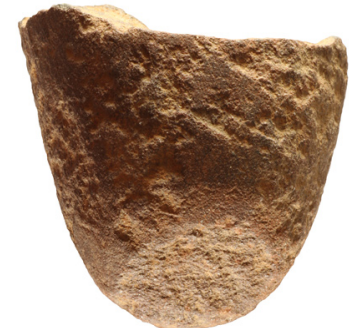

a

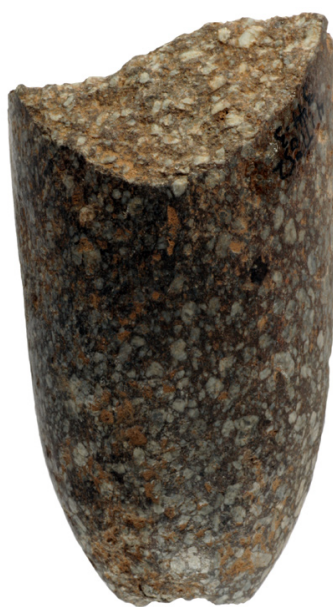

b
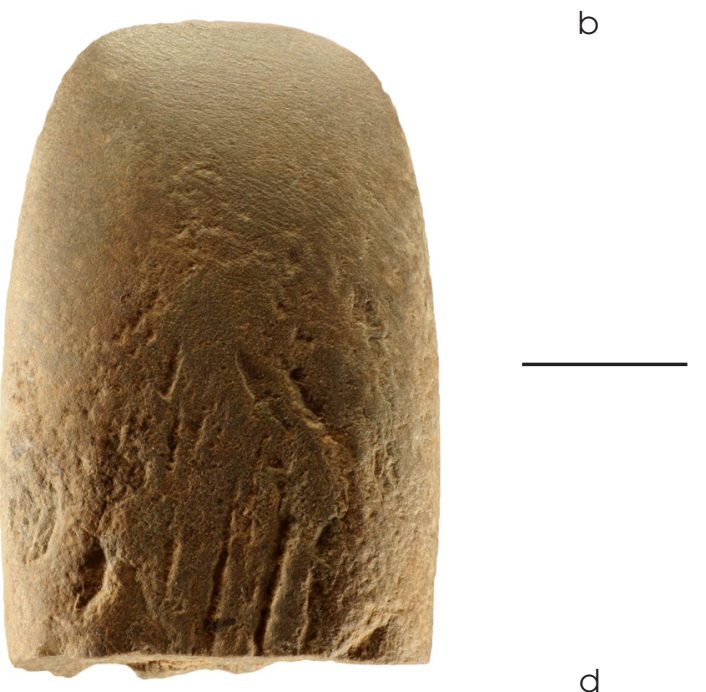
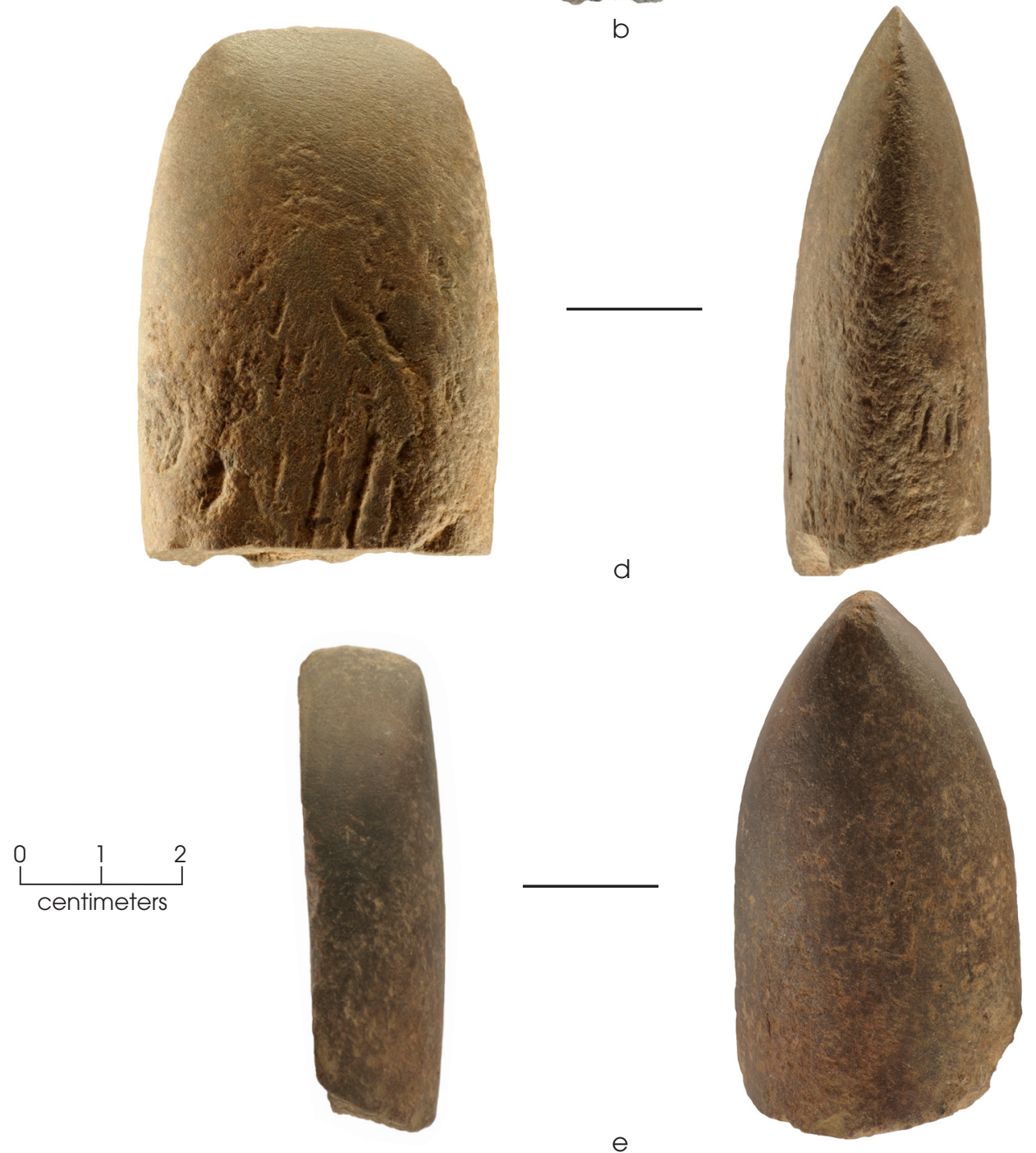

Figure 5.27. Celt fragments from Subarea 1 at the William Ford site. (a) Ferruginous sandstone proximal fragment with abraded end facet; (b) diorite proximal-medial fragment with impact damage at the proximal end; (c) Stanley or Jackfork sandstone medial fragment with minimally reworked distal end; (d-e) Stanley or Jackfork sandstone distal-medial fragments. 
present on the convex upper surfaces of several. Prominent points and ridges on the faces opposite the primary grinding surfaces also exhibit varying degrees of grinding/abrasion-derived smoothing. One of the two smallest ones has smoothing on a side margin and limited battering damage on its widest facets and its ends. The other has variable smoothing in several places, but the smoothest area spans a curved surface. Battering damage is apparent on numerous facets of that subangular artifact. Unlike the other artifacts in the mano/hammerstone group, the size of these two artifacts indicates they were manipulated with the fingers rather than the palm, like the mullers identified in the ground stone assemblage from the Ear Spool site (Ellis 2009:306).

An ovoid, subangular, thermally discolored quartzite pebble was utilized primarily as a polishing stone and secondarily as a hammerstone. One convex face is extremely smooth and slightly polished. Minor battering damage is apparent on the ends.

The 10 pitted hammerstones are roughly ovate to angular pebbles and cobbles that have at least one relatively flat to slightly concave facet with some degree of targeted wear. Two complete ones and 2 fragments have two or three facets. In most instances, facet wear consists of focused percussion/pecking, incipient pitting, or both. Shallow pits are present on 4 specimens. Natural depressions were utilized for pit locations on one artifact. Working facets often exhibit smoothing around concentrated percussion marks or pits, which is consistent with using the hammer to crush/pulverize material on an anvil. Battering wear is common on the margins and ends and is often present on protruding or convex surfaces opposite the working facets. Some of the battered surfaces are also smoothed.

Two of the three manos are subangular cobbles of poorly consolidated, gritty, striated ferruginous sandstone. One is roughly ovate and has as many as four grinding facets, though only one slightly convex surface is well smoothed. The other is irregular and has one slightly convex well-smoothed face. The third mano is an oval tabular cobble of nonferruginous sandstone. It has a marginally smoothed face with numerous percussion marks. Smoothing is also apparent on the outside edge of the opposite face, which indicates that at least part, if not all, of this surface was also utilized. Wear on the margins-smoothed surfaces with clear percussion/ peck marks-indicates intentional shaping. An oblong depression on a lower portion of a margin is derived from an expanded vesicle. This feature suggests that the mano also was used in conjunction with an anvil to crush/pulverize material.

A dense subrectangular tabular piece of ferruginous sandstone exhibits some end shaping and has two smoothed faces (Figure 5.28a). Percussion marks and percussion-derived pits are present in the center of each face and on both ends. Use-derived flake/fragment removal is apparent at one end. This artifact was utilized as a mano and a pitted hammerstone.

The four anvil fragments consist of two tabular pieces of quartzite, an irregular piece of ferruginous sandstone, and a tabular piece of Stanley or Jackfork sandstone. The smallest fragments (pieces of quartzite and ferruginous sandstone) are only tentatively classified as anvils and could be pieces of pitted hammerstones. Each has a smoothed facet remnant with at least one apparent pit and percussion marks. Remnants of two other pits are present on one. The larger quartzite cobble fragment has two smoothed facet remnants with percussion marks on each. The smaller facet retains part of an incipient pit. The wide cobble margins are battered and exhibit minimal smoothing. Percussion-derived pitting is visible on two margin facets. Although some thermal discoloration is apparent, fracture of this cobble was from use. The elongated fragment of Stanley or Jackfork sandstone has smooth faces with rounded edges (Figure 5.28b). Although some of this smoothing may be attributable to natural processes and intentional shaping, most is derived from use. Surface smoothing may predate the smooth-walled pit on one facet. However, the fact that the facet surface slopes down toward the pit suggests that the pit and surrounding face were used in tandem. Pit morphology suggests it served as a mortar for crushing or pulverizing materials. The opposite face slopes similarly downward toward the cobble interior. Peck marks on both faces are small, thin, and more linear than oval in shape. Battering damage is apparent on the artifact's outside margin and on its fractured interior edge. Localized percussion marks are present in a depressed portion of the margin. A small flat facet on the interior fracture plane is roughly 

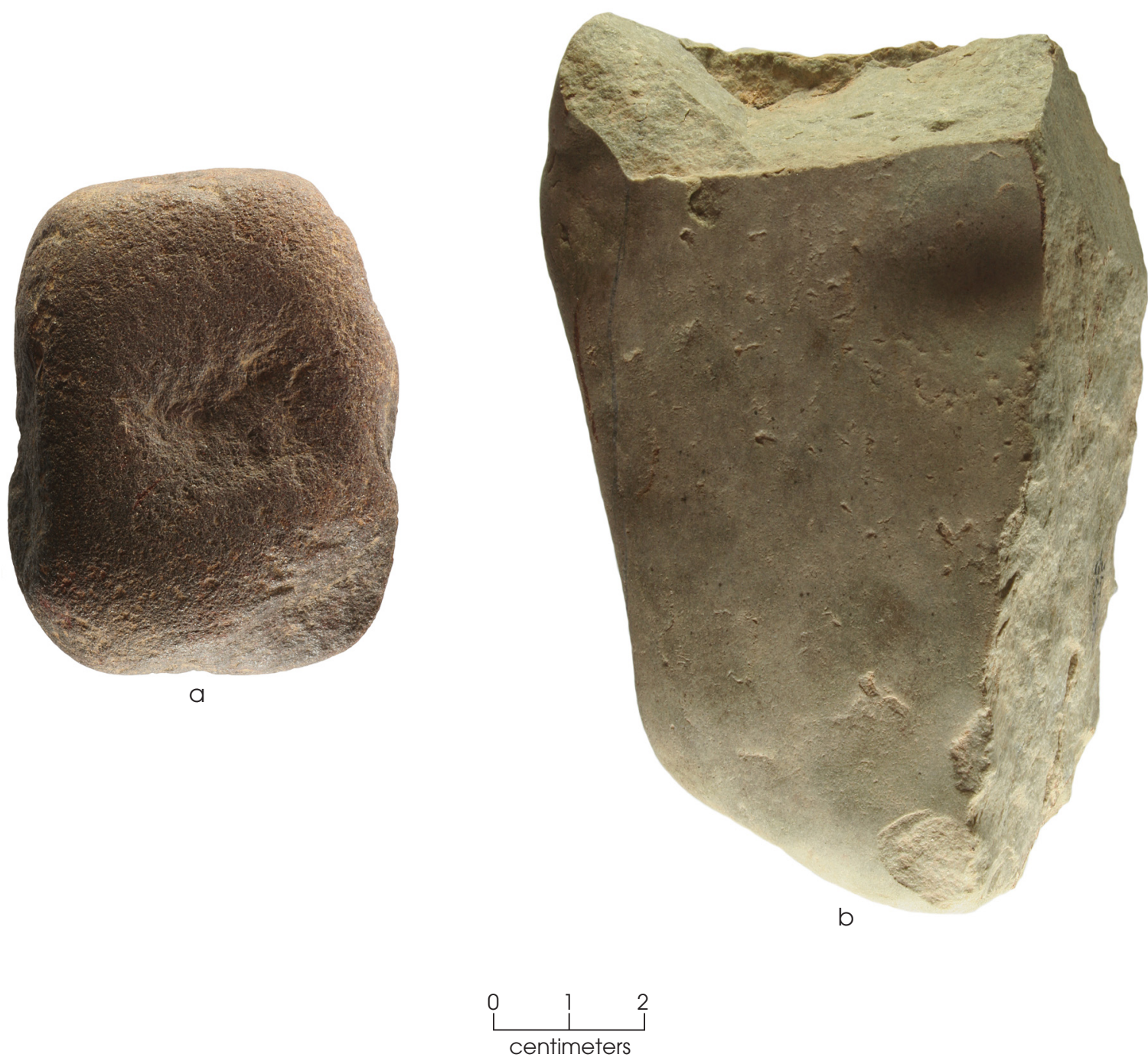

Figure 5.28. Mano/pitted hammerstone and anvil from Subarea 1 at the William Ford site. (a) Ferruginous sandstone mano/pitted hammerstone; (b) Stanley or Jackfork sandstone anvil fragment.

smoothed. This facet is a remnant of a larger ground/abraded surface that was used after the smooth-walled pit was split by material fracture.

The three grinding slabs/anvils consist of a shaped nonferruginous sandstone fragment and two thick tabular quartzite cobbles. The latter have broad circular to oval ground/abraded depressions with percussion/peck marks and incipient pitting on one face and large, well-developed pits on the otherwise unmodified opposite faces. The large pit remnant on one cobble is $38 \mathrm{~mm}$ deep, and its location with respect to the fracture plane indicates that the break was use related. In addition to the large pit, natural depressions in one rock surface were utilized to cradle material that was crushed, pulverized, or split. The sandstone grinding slab/anvil was either oval or circular in shape when complete. In section, it is thickest along its outside edge (Figure 5.29). The nearly flat base, steeply sloped margin, rounded rim, and concave upper surface give the fragment a bowl-like appearance. Two very shallow abrasion marks are visible in the thermally discolored upper face. Only the larger one has definable edges, and it has a maximum length of $50.9 \mathrm{~mm}$ and approximate maximum 

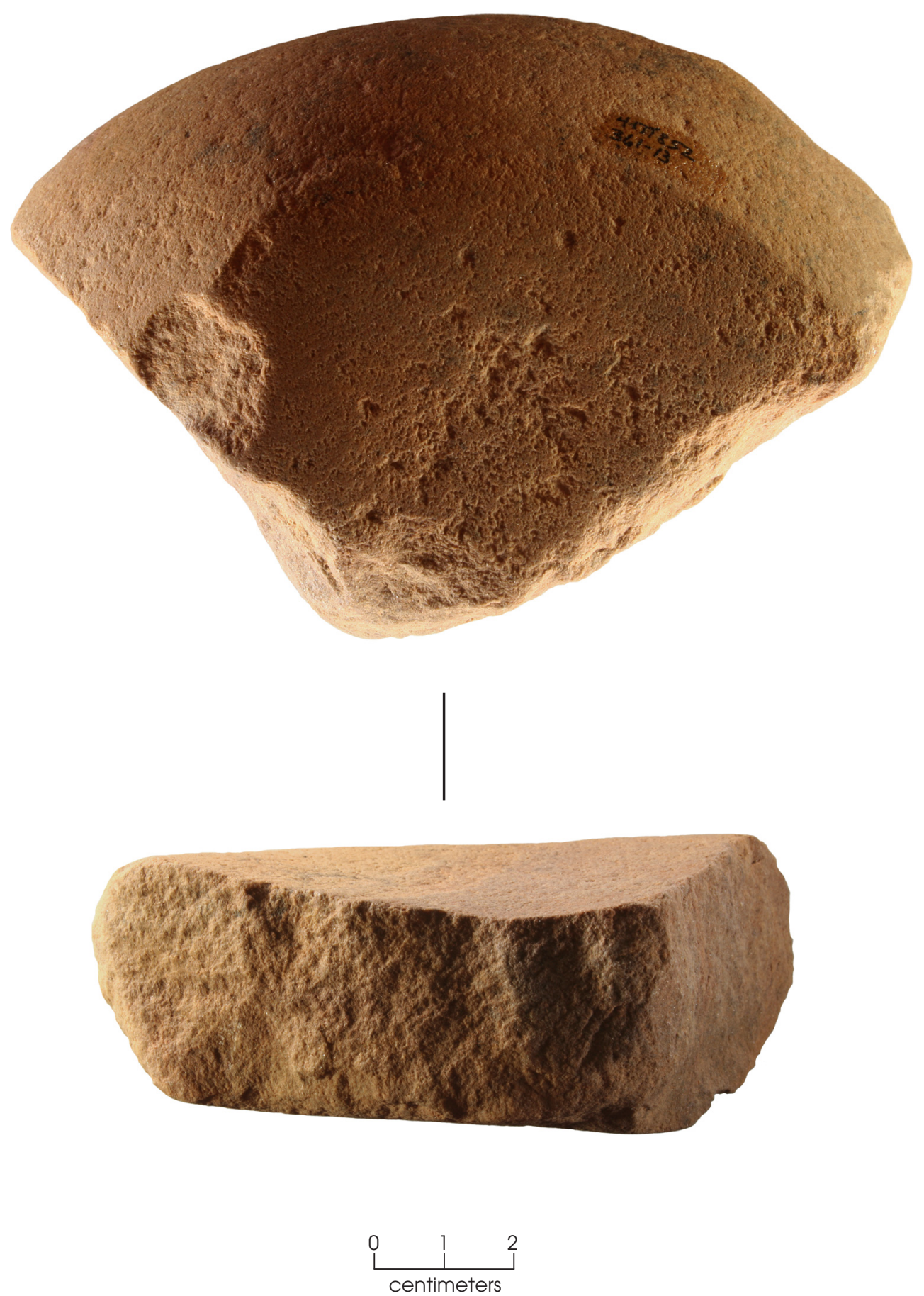

Figure 5.29. Grinding slab/anvil from Subarea 1 at the William Ford site.

width of $9.5 \mathrm{~mm}$; it is less than $1.0 \mathrm{~mm}$ deep. Color variation on this facet suggests that the abrasion marks postdate the heat-derived color change. The relatively flat bottom facet slopes down toward the center of the artifact. Percussion/peck marks are more common and more clearly visible on this facet, and a possible pit remnant is at the artifact's innermost edge. 
A ferruginous sandstone grinding slab fragment has a slightly curved outer margin with minimal battering wear. Peck marks and smoothing on part of the outside edge suggest this artifact was intentionally shaped. It has two concave smoothed working facets with percussion/peck marks on each. In section, the wedge-shaped piece is thickest along its outside edge. The fractured ends exhibit light battering/ impact damage, which suggests it was used as a hammerstone after its fracture.

Two artifacts are abraders. An irregular hematite fragment with a slightly convex smoothed face is classified as an abrader because of its surface wear characteristics (Figure 5.30a). Numerous striations and fine incisions are visible on its abraded surface. The majority follow two partially overlapping alignments. Small Vto U-shaped incisions or notches are present on the edges of the working facet and on the sides of the fragment. This hematite fragment also could have been used for pigment production. The other abrader is an angular piece of dense, well-cemented, tabular ferruginous sandstone. Two margins are clearly battered, and one face is flat and slightly smoothed from abrasion. The opposite face is rounded and pecked and ground relatively smooth. A wide shallow depression in the center of this face is derived from reciprocal abrasion in two slightly different directions. One side of this depression is well smoothed; the other is rougher with vague peck marks. Abrasion wear does not appear to extend to the facet edges, suggesting that this item is a complete artifact.

A thick tabular sandstone cobble fragment has one slightly concave and minimally smoothed face remnant. Part of this surface remnant is missing due to battering and associated flake detachment at one corner. Visible wear marks are oriented roughly parallel to the cobble's long axis. Subtle grooving on this face suggests this cobble was used as an abrader. A pit on the cobble margin indicates it also served as an anvil. A second possible pit is close to the cobble's corner. Despite intense thermal discoloration, flake scarring suggests the cobble was fractured during use of the pitted side. The fact that the scarring originates at a natural declivity on the rock surface suggests that these natural voids were used to cradle material that was crushed/pulverized/split.

A thin tabular fragment of ferruginous sandstone has two clearly defined grooves and two subtle grooves on one face (Figure 5.30b). These differ in width and depth, but they follow the same approximate orientation. The widths of the grooves also vary across their individual lengths. The bottom of the largest groove is essentially flat and varies in depth. The second-largest groove is parabolic in cross section. The widest groove has an approximate maximum width of $7.2 \mathrm{~mm}$, and the deepest groove (the one with the parabolic cross section) has a maximum depth of $2.0 \mathrm{~mm}$. In addition to the obvious features, there are numerous smaller poorly defined shallow grooves. Flake scars and other percussion damage on one margin may represent minimal shaping of the outer edges of the intact artifact.

An irregular tabular piece of ferruginous sandstone is classified as a grooved/incised stone. It has one smooth face covered with peck marks, which suggests that the artifact was used as an abrader. A shallow groove and a pair of short grooves or notches are present on opposite edges of the smooth facet. The shallow groove is less than a millimeter deep and has a maximum length and width of 10.1 and $5.1 \mathrm{~mm}$, respectively. A slightly curved incision in the central part of the facet may be recent.

The second grooved/incised stone is a fragment of soft pale gray limestone with a flat smooth facet that curves into a smoothed slightly rounded side. The curved edge is charcoal gray, possibly from thermal alteration or carbon staining. Parts of two incisions and a third discontinuous one are visible on the flat surface. The longest is about $18.6 \mathrm{~mm}$, with an approximate maximum width of $3.0 \mathrm{~mm}$ and a depth of a millimeter or less. These cuts are oriented in essentially the same direction. Surface uniformity suggests that the smoothing is not accidental. While the incisions are tentatively considered to be intentional, the softness of this material raises the possibility they are incidental.

Two conjoinable ocher fragments are classified as a pigment stone. When fit together, they form a triangular fragment with a relatively smooth, slightly concave grinding facet. This fine-grained material may be processed (refined) and reconsolidated hematite.

One ferruginous sandstone artifact may be an unfinished pipe (Figure 5.30c). It is a roughly circular pecked, ground, and shaped object with a flat base and hollowed-out interior that gives it the appearance of a miniature cup. Some 

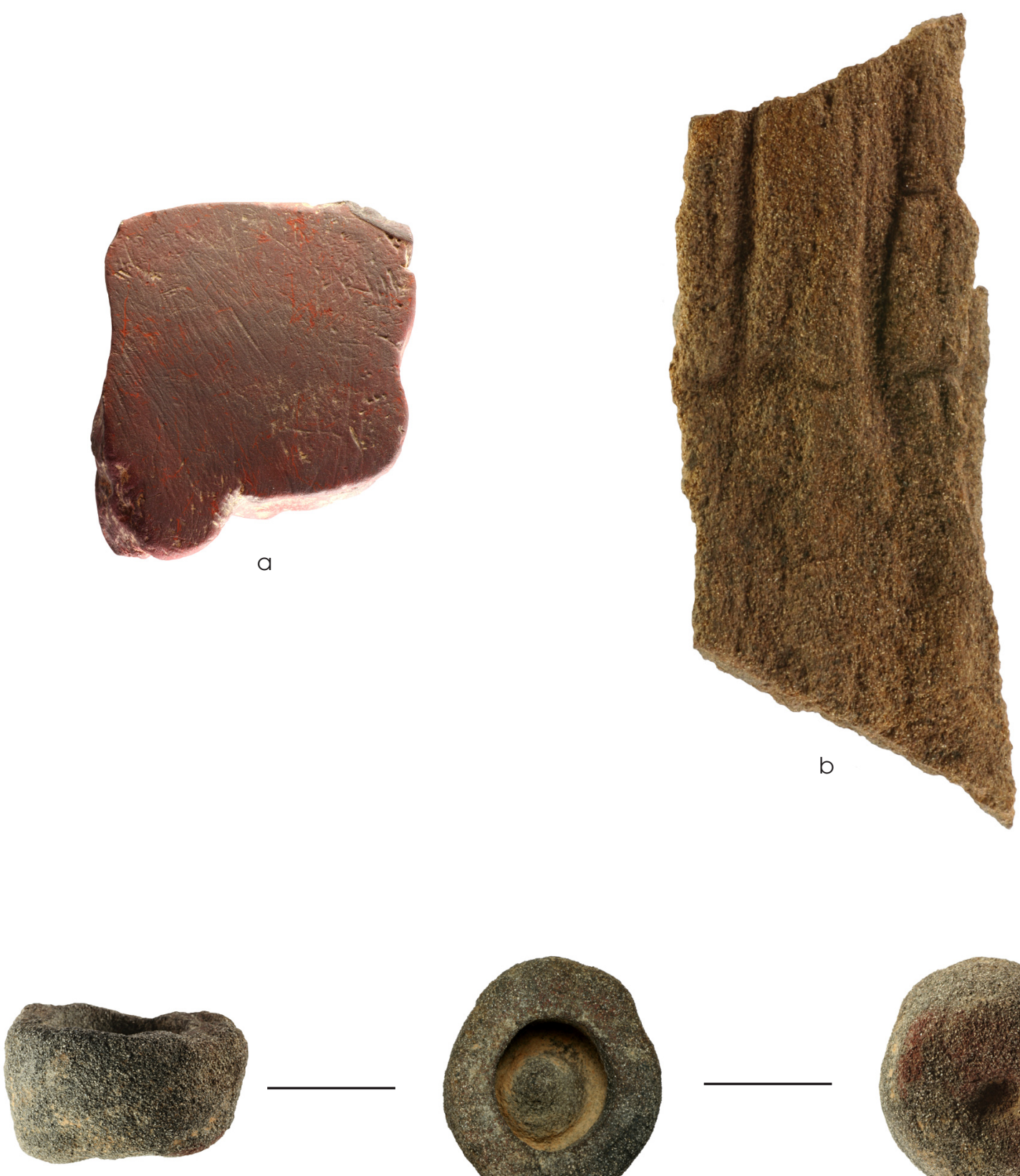
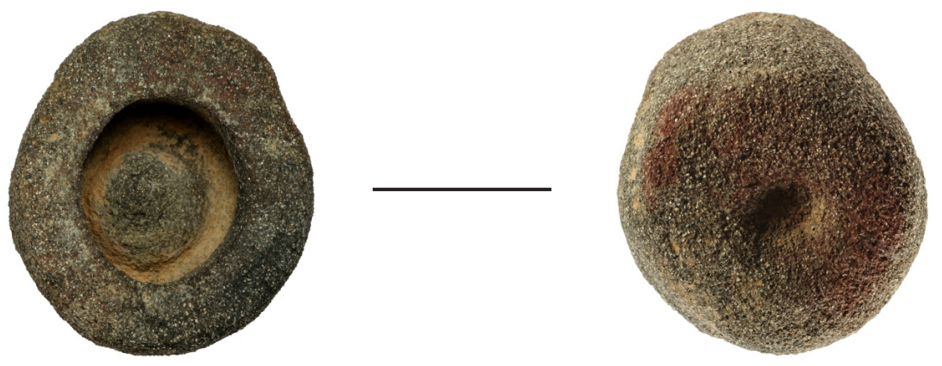

C

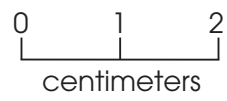

Figure 5.30. Abrader, grooved stone, and possible unfinished stone pipe from Subarea 1 at the William Ford site. (a) Hematite abrader; (b) a grooved fragment of ferruginous sandstone; (c) possible unfinished pipe (side, top, and bottom views). 
striations are visible on the hollowed-out cavity. A nipple at the base of the cavity and a small divot located on the exterior opposite the nipple suggest that a hole was to be drilled through the base. The interior walls at the base of the cavity are slightly undercut, which probably is the result of moving the reamer or hand drill around the nipple at the cavity base.

An elongated ferruginous sandstone fragment with a battered, slightly smoothed flat end was probably used as a pestle. Smoothing on the high points of its flattest margin also indicates that it was used for grinding/pulverizing material. An oval nonferruginous sandstone cobble was used as a pestle, a hammer, a mano, and anvil or pitted hammerstone. This artifact has wear-derived smoothing at both ends and along one margin, battering damage on one end, grinding-derived smoothing on portions of both faces, and incipient pitting on three facets.

Seven artifacts are classified as indeterminate as to function. Three are quartzite, three are ferruginous sandstone, and one is limestone. Two small quartzite edge fragments retain smoothed surface remnants, and a small quartzite flake has a smooth facet remnant pocked with percussion/peck marks. Two ferruginous sandstone fragments have flat facet remnants with visible percussion/peck marks. The larger piece has a flat well-smoothed facet segment at one side of a curved marginally smoothed surface. An adjacent facet with numerous percussion marks may be part of another work surface. Several flake scars are on the ventral side of this fragment. The smaller wedge-shaped fragment retains a well-smoothed, slightly convex surface remnant with peck marks. The third ferruginous sandstone fragment is thermally fractured; wear and incipient pitting suggest it could have been used in conjunction with an anvil for crushing/ pulverizing material.

The seventh item in this group is a piece of soft gray limestone and is not a ground stone artifact per se but is included here because the material is so similar to one of the grooved/incised stones described above. Some smoothing is apparent on prominent parts of the fragment, but this could be derived from recent handling.

\section{BONE TOOL}

A modified turtle shell fragment was recovered from Feature 90. It is an oval fragment that is abraded and beveled and has slightly rounded edges (Figure 5.31). Brian Shaffer (personal communication 2011) suggests it might be a game piece.

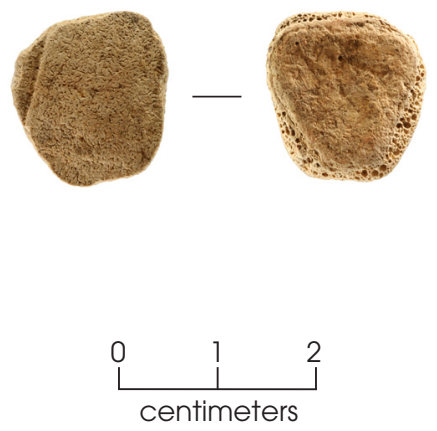

Figure 5.31. Modified turtle shell from Subarea 1 at the William Ford site (ventral and dorsal views).

\section{DAUB AND BURNED CLAY}

The wattle-impressed daub (1,610.3 g) from Subarea 1 was mostly from features, as well as test units and sample units, and was distributed most heavily in the southeast area (Table 5.6). The burned clay $(1,388.4 \mathrm{~g})$ was mostly from features and sample units and similarly densest in the southeast feature concentration.

\section{MACROBOTANICAL REMAINS}

The excavations recovered macrobotanical remains from numerous contexts. About $138 \mathrm{~g}$ are analyzed and reported in Appendix F. The analyzed materials are from 83 flotation samples (from 74 features) and 17 samples collected by hand from 13 features. Selection of flotation samples for study was primarily guided by context and included all large pits, small pits, and smudge pits, but only from a sample of the postholes. Fifty-nine samples were collected and floated but not sorted or analyzed; most of these are from postholes. Features whose fill appeared to be in primary context, such as smudge pits with evidence of in situ burning based on large quantities of burned macrobotanical remains, were prime candidates for analysis. 
Chapter 5: Excavations at the William Ford Site, $41 T T 852$

Table 5.6. Burned clay and daub from Subarea 1 at the William Ford site (weights in grams)

\begin{tabular}{|c|c|c|}
\hline Provenience & Burned Clay & Daub \\
\hline Feature 1 & 56.8 & 312.3 \\
\hline Feature 13 & 2.6 & 51.8 \\
\hline Feature 15 & & 8.3 \\
\hline Feature 25 & & 2.6 \\
\hline Feature 39 & & 4.3 \\
\hline Feature 55 & 5.3 & 11.7 \\
\hline Feature 75 & 2.2 & 3.8 \\
\hline Feature 80 & 1.7 & \\
\hline Feature 90 & 82.2 & 68.6 \\
\hline Feature 145 & 3.0 & \\
\hline Feature 164 & 0.3 & \\
\hline Feature 171 & 4.0 & \\
\hline Feature 189 & 2.9 & 1.3 \\
\hline Feature 191A & 4.4 & 3.5 \\
\hline Feature 191B & & 4.9 \\
\hline Feature 198 & 2.8 & \\
\hline Feature 199 & & 7.9 \\
\hline Feature 220 & 0.7 & 0.9 \\
\hline Feature 233 & 6.6 & \\
\hline Feature 280 & 2.6 & \\
\hline Feature 343 & 4.7 & 2.3 \\
\hline Feature 346 & & 4.7 \\
\hline Feature 352 & 25.0 & 4.9 \\
\hline Feature 381 & 9.4 & \\
\hline Feature 387 & 3.1 & \\
\hline Feature 407 & 1.3 & \\
\hline Feature 414 & 0.8 & \\
\hline Feature 419 & 12.0 & 6.6 \\
\hline Feature 420 & & 0.9 \\
\hline Feature 422 & 0.7 & \\
\hline Feature 438 & 5.6 & \\
\hline Feature 465 & 8.2 & 8.9 \\
\hline Feature 466 & 0.9 & 10.6 \\
\hline Feature 470 & 6.0 & \\
\hline Feature 472 & 16.8 & \\
\hline Feature 477 & 33.7 & 39.8 \\
\hline Feature 478 & 3.2 & 2.7 \\
\hline Feature 482 & 3.5 & \\
\hline Feature 483 & 16.8 & 28.0 \\
\hline Feature 484 & 29.5 & 3.0 \\
\hline Feature 489 & 0.3 & 1.0 \\
\hline Feature 490 & 14.7 & 12.2 \\
\hline Feature 491 & & 4.5 \\
\hline Feature 492 & 1.4 & \\
\hline Feature 494 & 8.0 & 7.3 \\
\hline Feature 497 & 61.7 & 45.7 \\
\hline
\end{tabular}

\begin{tabular}{|c|c|c|}
\hline Provenience & Burned Clay & Daub \\
\hline Feature 501 & 12.1 & \\
\hline Feature 515 & 14.8 & 3.2 \\
\hline Feature 527 & & 2.0 \\
\hline Feature 529 & & 8.4 \\
\hline Feature 535 & 34.2 & \\
\hline Feature 542B & $\overline{7.2}$ & 5.5 \\
\hline Feature 544 & 6.6 & 9.4 \\
\hline Feature 547 & & 2.0 \\
\hline Feature 558 & 17.2 & 13.1 \\
\hline Feature 565 & 0.5 & 0.7 \\
\hline Feature 570 & 2.5 & 4.3 \\
\hline Feature 575 & 1.6 & 0.3 \\
\hline Features $543 \& 545$ & 8.7 & 2.0 \\
\hline TU 6 & 7.4 & 46.1 \\
\hline TU $6 \& 9$ & 1.7 & 0.6 \\
\hline TU 9 & 9.6 & 67.4 \\
\hline TU 12 & 11.2 & 45.9 \\
\hline TU 13 & 17.1 & 12.0 \\
\hline TU 14 & & 7.6 \\
\hline TU 21 & & 19.7 \\
\hline TU 22 & 5.6 & 107.5 \\
\hline TU 24 & & 4.2 \\
\hline TU 25 & & 4.7 \\
\hline TU 46 & 2.1 & 24.9 \\
\hline BHT 2 & 92.7 & 22.1 \\
\hline BHT 4 & & 17.6 \\
\hline BHT 8 & & 11.3 \\
\hline$\overline{\text { SU } 1}$ & 24.0 & 22.6 \\
\hline SU 2 & 284.4 & 190.2 \\
\hline SU 3 & 2.1 & 16.4 \\
\hline$\overline{\text { SU } 4}$ & 12.6 & 2.5 \\
\hline$\overline{\text { SU } 5}$ & 5.7 & \\
\hline SU 6 & 6.8 & 1.0 \\
\hline SU 8 & & 4.3 \\
\hline SU 9 & 4.5 & \\
\hline SU 11 & & 2.9 \\
\hline$\overline{\text { SU } 13}$ & & 2.5 \\
\hline SU 16 & & 2.9 \\
\hline$\overline{\text { SU } 18}$ & 5.8 & \\
\hline SU 19 & 0.9 & 3.5 \\
\hline SU 21 & 2.4 & \\
\hline$\overline{\text { SU } 23}$ & 1.3 & \\
\hline SU 24 & 1.4 & \\
\hline SU 27 & 17.4 & \\
\hline SU 30 & 6.3 & 4.1 \\
\hline SU 34 & 5.6 & \\
\hline SU 37 & 1.2 & 5.8 \\
\hline$\overline{\text { SU } 44}$ & 44.5 & 53.9 \\
\hline$\overline{\text { SU } 45}$ & 8.7 & 35.0 \\
\hline
\end{tabular}


Table 5.6, continued

\begin{tabular}{l|c|c}
\hline Provenience & Burned Clay & Daub \\
\hline SU 48 & 6.1 & \\
\hline SU 52 & 12.1 & 14.2 \\
\hline SU 53 & 15.7 & 45.1 \\
\hline SU 54 & 1.4 & 4.7 \\
\hline SU 56 & 2.3 & 4.3 \\
\hline SU 57 & 0.5 & 1.9 \\
\hline SU 65 & 2.1 & 2.1 \\
\hline SU 70 & & \\
\hline SU 71 & 2.9 & 1.0 \\
\hline SU 72 & & \\
\hline SU 74 & 7.7 & \\
\hline CMS 1 & 203.8 & 79.0 \\
\hline General Site & $1,388.4$ & $1,610.3$ \\
\hline Totals & &
\end{tabular}

Most of the flotation samples are from pits of uncertain function (54 percent) and postholes (25 percent), with a small number (13 percent) from smudge pits and even fewer from organically enriched midden sediments ( 6 percent) and the fill of a burial ( 1 percent). Volumetrically, the breakdown of the 861.5 liters processed by flotation differs somewhat, with 70 percent from pits of uncertain function, 11 percent from postholes, 9 percent from smudge pits, 9 percent from midden sediments, and less than 1 percent from burial fill. The 17 nonflotation samples consist of 7 from large pits, 3 from small pits, 3 from smudge pits, and 4 from midden sediments.

The bulk of the analyzed material is from secondary contexts and represents the generalized scatter of plant remains created by occupation of the site. The samples from smudge pits, however, more likely represent primary contexts. Six kinds of wood (red and white oak, hickory, elm, buckeye, maple, and plum/cherry) charcoal were recovered from smudge pits as well as Chenopodium, maygrass, purslane, and stick-tight seeds and corn kernels and cupules and glumes. The three nonflotation samples from smudge pits (Features 14, 15, and 423) contained white oak and hickory wood and hickory nutshells. Other features that may be in primary context are Feature 484, a large pit with mostly hickory nutshells and wood as well as oak, ash, and persimmon wood and corn cupules and glumes, and Feature 204, a small pit with hickory nutshells, oak and hickory wood, corn cupules and glumes, and grass and purslane seeds.

From all of the features, 17 kinds of wood charcoal (excluding general categories like diffuse-porous hardwoods, hardwood, and indeterminate) were identified, with oak (both white and red) and hickory dominant. These fuels were collected from on or near the site, reflecting the oak-hickory forest that the area supported. Wood charcoal representing deciduous and riparian environments includes American elm, buckeye, mulberry, plum/cherry, slippery elm, sycamore, sweetgum, and willow/cottonwood. Charred cane stem is present in small amounts and is likely representative of baskets and mats rather than fuel materials.

Cultigens are present in small amounts and include corn and common bean. Corn kernels $(0.22 \mathrm{~g})$ and cupules and glumes (5.07 g) were identified in 38 features. Common beans ( $0.28 \mathrm{~g})$ and bean or persimmon ( $0.27 \mathrm{~g}$ bean/persimmon) were identified in 8 features. Generally small numbers of amaranth, maygrass, Chenopodium, little barley, panicgrass, erect knotweed, persimmon, legume, stick-tight, smartweed, purslane, sumac, daisy family, grass family, sedge family, and grape seeds were recovered as well, with some of these indicating use of starchy-seeded annuals along with corn cultivation. The remainder of the macrobotanical remains that represent foods is dominated by hardwood nuts, especially hickory but also acorn; these were present in 76 percent of the flotation samples.

\section{FAUNAL REMAINS}

The excavations in Subarea 1 recovered 391 animal bones, with 3 others (an artiodactyl tibia and 2 bones identifiable only as vertebrate) found in Subarea 3 during testing (Appendix G). Seventy-one percent of the specimens $(\mathrm{n}=281)$ are identifiable only as vertebrate. The remains of deer (Odocoileus sp.; $\mathrm{n}=8$ ), deer/pronghorn-sized ungulates (Artiodactyla [medium], cf. Artiodactyla [medium]; n = 16), and canid/deer-sized mammals (Mammalia [medium/large]; $\mathrm{n}=64$ ) account for 22 percent of the assemblage. Other identifiable mammalian remains are a tooth fragment (only classifiable as Mammalia), 5 fragments of a cow/bison (Bos / Bison) tooth, a cottontail rabbit (Silvilagus 
sp.) tooth, and 4 elements from a nine-banded armadillo (Dasypus novemcinctus). The rest of the assemblage consists of a bone fragment from a large bird (Aves) and 13 turtle (Testudinata) elements, including 12 shell fragments.

Aside from the previously noted teeth and turtle shell fragments, the assemblage includes only 33 identifiable elements. The 24 elements categorized as deer or deer/pronghorn-sized ungulates consist of 10 foot bones, 6 long bone fragments, 2 mandible fragments, and 6 teeth fragments. Identifiable canid/deer-sized mammal elements are 2 mandible fragments and 2 rib shaft segments. The remaining classifiable elements are a bird coracoid, a turtle carapace bone fragment, and armadillo limb bones.

The fragments of Bos / Bison tooth enamel could be derived from a bison or a cow and thus may or may not be associated with indigenous occupation of the site. Since armadillo is a newcomer to the region, those elements are not associated with the Caddo occupation.

The only complete bones are an armadillo astragalus and a medium-sized artiodactyl carpal and phalange. Almost 90 percent have angular fractures $(\mathrm{n}=351)$. Ten percent are spirally fractured $(n=40)$, and most of these are indeterminate elements classifiable only as vertebrate $(n=8)$ or bone from canid/deersized mammals $(n=23)$. Identifiable elements in the spirally fractured group are eight deer/ pronghorn-sized ungulate limb bones and the armadillo femur. The spiral break in the latter is not considered to be the result of intentional human action. The artiodactyl/probable artiodactyl elements include a femur, three radii, two tibiae, and two metapodia. Deep cut marks are present on one of the tibia fragments and a metatarsal.

Fifty percent of the assemblage is calcined $(\mathrm{n}=196)$, whereas only 4 percent exhibit characteristics of less intensive burning $(n=16)$. Eighty-four percent of the calcined elements $(n=164)$ and 63 percent of the charred specimens $(n=10)$ are identifiable only as vertebrate. Artiodactyls (medium) and canid/deer-sized mammals account for 15 percent of the calcined bone $(n=29)$; three elements are calcined turtle shell fragments. The six charred elements that are classifiable below the vertebrate level are the previously noted artiodactyl femur, two canid/ deer-sized mammal elements, and three turtle shell fragments.
Invertebrate remains are very scarce. They consist of just three unidentifiable shell fragments.

\section{CHRONOLOGY}

\section{Radiocarbon Dates}

Fifty-six radiocarbon dates from charred nutshells, corn seeds and rachis, cane, bean/persimmon seed, and wood charcoal were obtained as a result of the 2007-2008 testing and 2010 data recovery excavations (Tables 5.7 and 5.8). All are from smudge pits, large pits, small pits, postholes, burial fill, and midden sediments. Only 9 are from smudge pits, which are preferable for dating since their contents are more likely to represent in situ burning than are charred remains in other kinds of features. One small pit (Feature 204) and one large pit (Feature 484) also have attributes suggesting in situ burning and thus may represent primary contexts.

The remaining dates almost certainly are from secondary contexts: 10 from large pits, 29 from small pits, 4 from postholes, 1 from possible burial fill, and 1 from the Feature 90 organically enriched midden. The carbonized materials generally occur in low densities in these features, and most probably were dumped or swept into them during cleaning episodes. Other charred remains probably accumulated on the surface and incidentally made their way into open features, for example, when posts were pulled and postholes left open. The dated materials from most, if not all, of these do not relate to the functions of the features. They may be contemporaneous or predate actual use of the features, and they could even postdate them if rodent burrowing or roots translocated later charcoal into the fill of older features. In addition to limitations imposed by the scarceness of primary contexts, the data set suffers because some of the assays fall within spans when calibration yields multiple or long date ranges due to wiggles in the calibration curve.

The discussion of radiocarbon dating below relies on the calibrated results as determined by CALIB Rev 6.0 (Stuiver et al. 2005) using the IntCal09 data set, since it gives probabilities associated with the possible intervals (the intervals determined by the Beta Analytic calibrations are included on Table 5.7 as well), and focuses on the two-sigma ranges. The data can be interpreted 


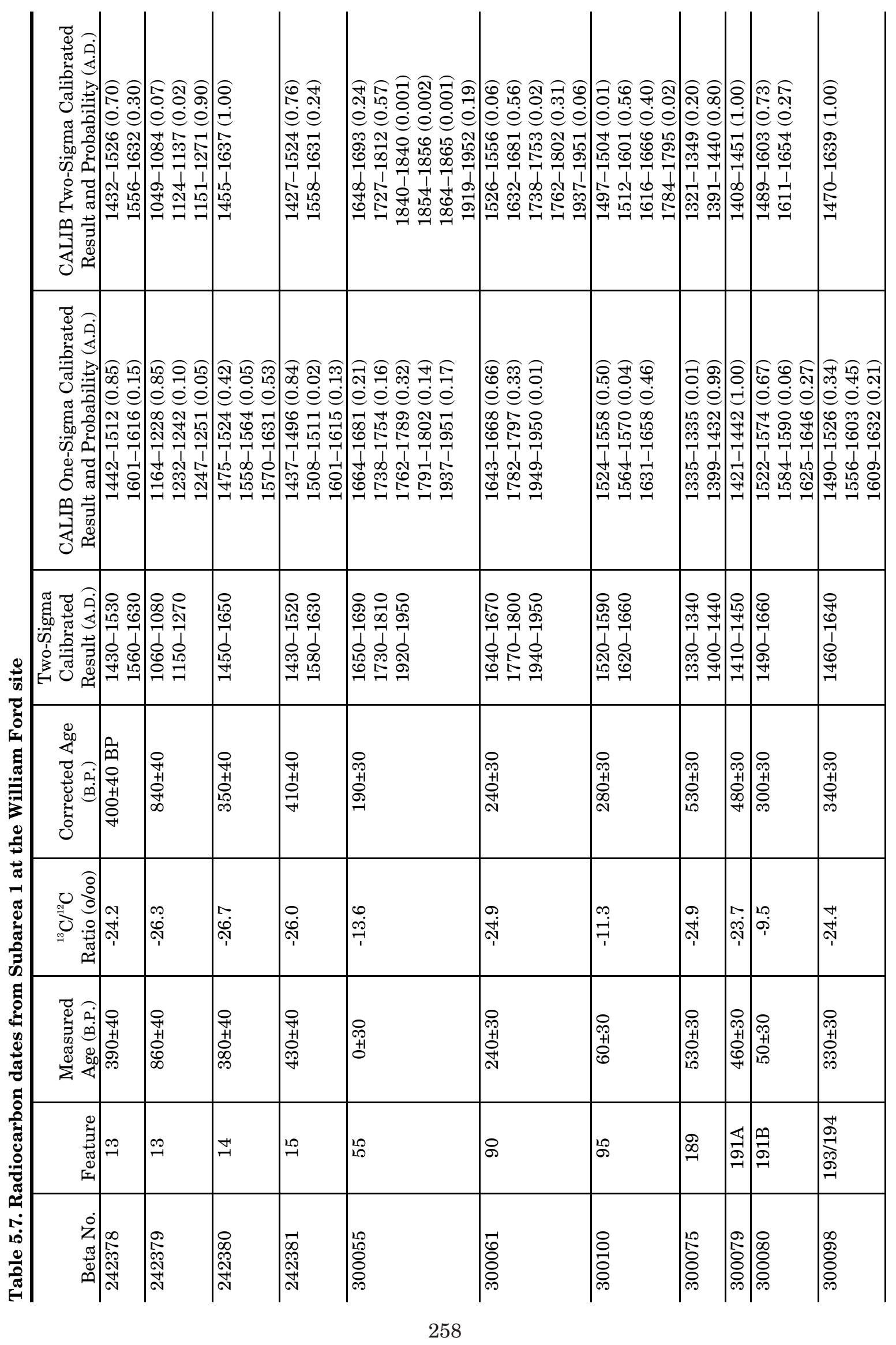




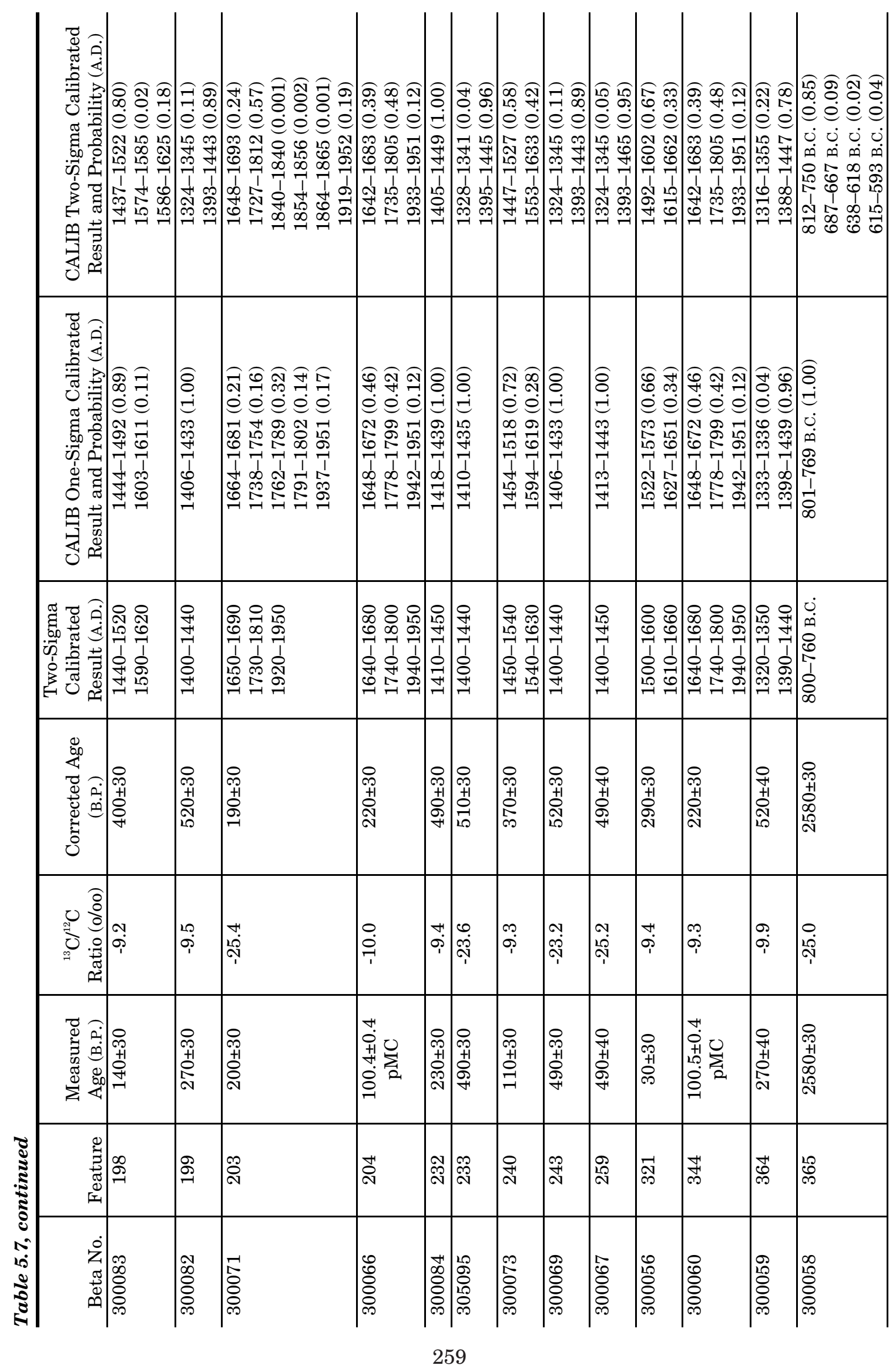




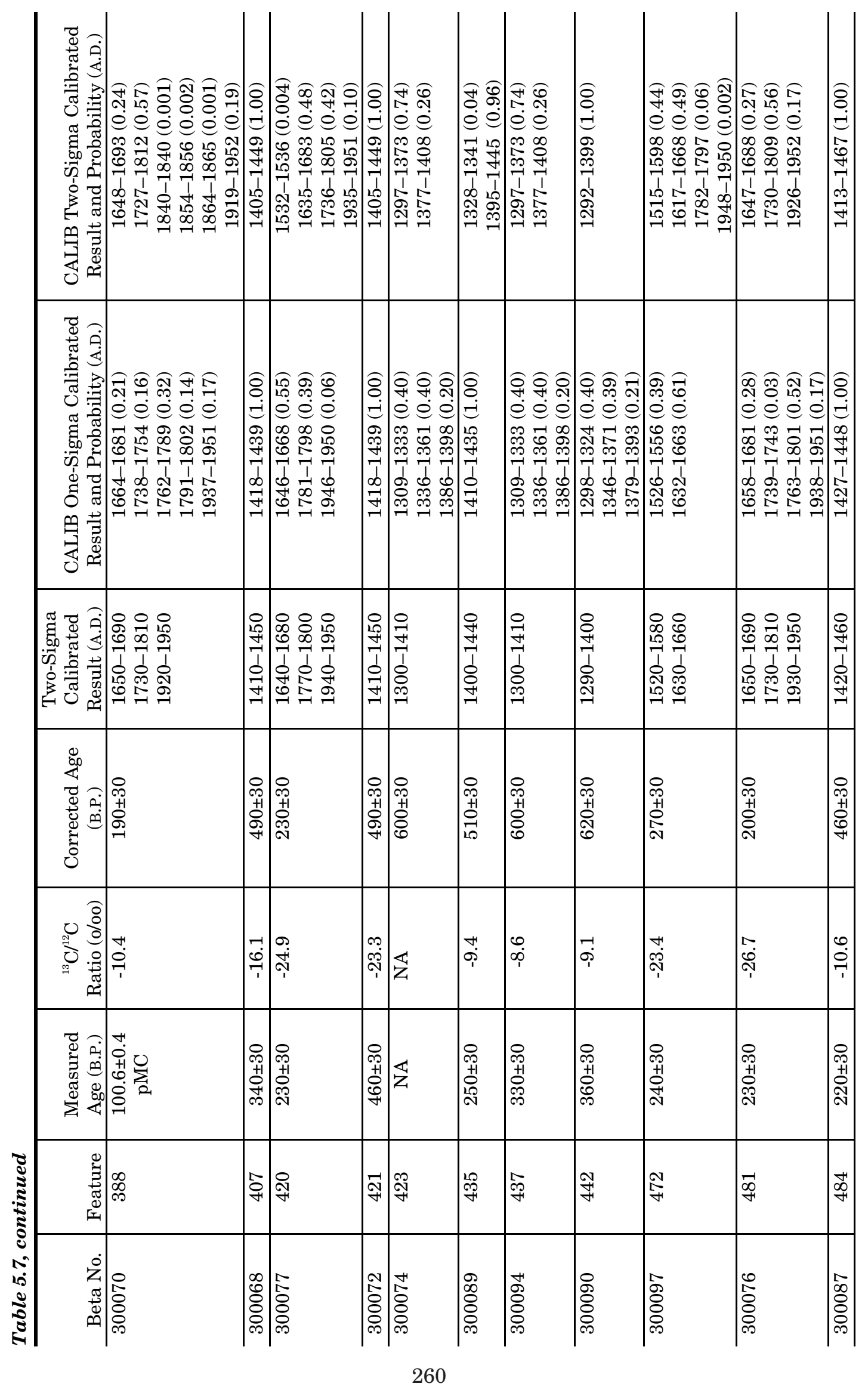




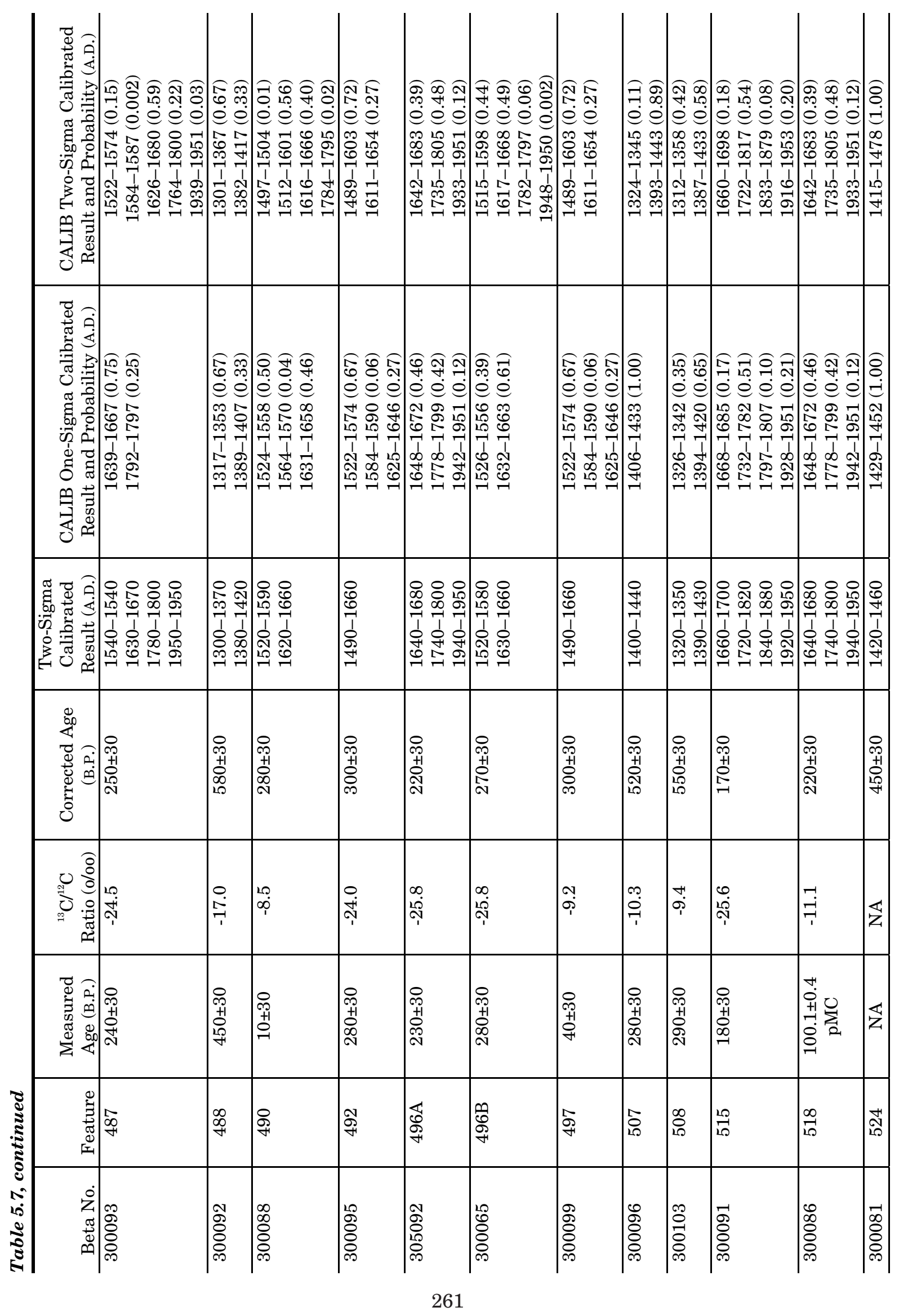




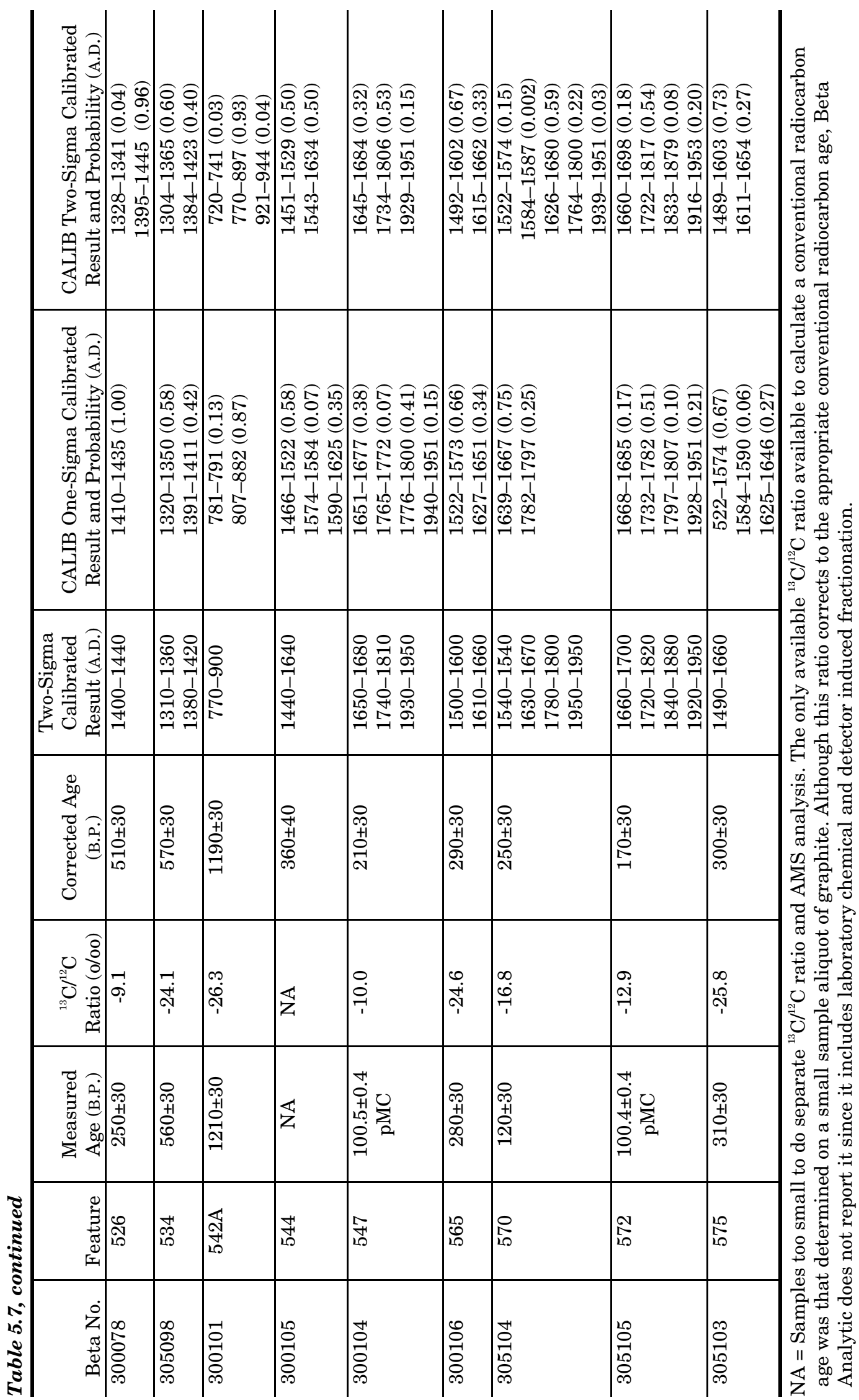


Table 5.8. Radiocarbon-dated contexts in Subarea 1 at the William Ford site

\begin{tabular}{|c|c|c|c|c|}
\hline Beta No. & Feature & Feature Type & Materials & Weight $(\mathrm{g})$ \\
\hline 242378 & 13 & large pit & Oak (Quercus spp.) wood & 0.28 \\
\hline 242379 & 13 & large pit & Hickory (Carya sp.) nutshell & 1.02 \\
\hline 242380 & 14 & smudge pit & White oak (Quercus subg. Quercus) wood & 2.32 \\
\hline 242381 & 15 & smudge pit & Hickory (Carya sp.) nutshell & 0.87 \\
\hline 300055 & 55 & large pit & Corn (Zea mays) rachis & 0.14 \\
\hline 300061 & 90 & midden & Hickory (Carya sp.) nutshell & 0.27 \\
\hline 300100 & 95 & small pit & Corn (Zea mays) rachis & 0.01 \\
\hline 300075 & 189 & large pit & Hickory (Carya sp.) nutshell & 0.27 \\
\hline 300079 & $191 \mathrm{~A}$ & small pit & Hickory (Carya sp.) nutshell & 0.05 \\
\hline 300080 & 191B & large pit & Corn (Zea mays) rachis & $<0.01$ \\
\hline 300098 & $193 / 194$ & large pit & Hickory (Carya sp.) nutshell & 1.19 \\
\hline 300083 & 198 & small pit & Corn (Zea mays) rachis & $<0.01$ \\
\hline 300082 & 199 & large pit & Corn (Zea mays) rachis & 0.01 \\
\hline 300071 & 203 & small pit & Hickory (Carya sp.) nutshell & 0.49 \\
\hline 300066 & 204 & small pit & Corn (Zea mays) rachis & 0.05 \\
\hline 300084 & 232 & smudge pit & Corn (Zea mays) rachis & 0.01 \\
\hline 305095 & 233 & smudge pit & Hickory/Walnut (Juglandaceae) nutshell & 1.13 \\
\hline 300073 & 240 & small pit & Corn (Zea mays) rachis & 0.01 \\
\hline 300069 & 243 & small pit & Hickory (Carya sp.) nutshell & 1.39 \\
\hline 300067 & 259 & smudge pit & Hickory (Carya sp.) nutshell & 0.58 \\
\hline 300056 & 321 & small pit & Corn (Zea mays) rachis & 0.02 \\
\hline 300060 & 344 & small pit & Corn (Zea mays) rachis & 0.02 \\
\hline 300059 & 364 & smudge pit & Corn (Zea mays) rachis & 0.01 \\
\hline 300058 & 365 & small pit & Hickory (Carya sp.) nutshell & 0.07 \\
\hline 300070 & 388 & small pit & Corn (Zea mays) seed & 0.01 \\
\hline 300068 & 407 & small pit & Corn (Zea mays) rachis & 0.01 \\
\hline 300077 & 420 & small pit & Hickory (Carya sp.) nutshell & 1.24 \\
\hline 300072 & 421 & small pit & Hickory (Carya sp.) nutshell & 0.06 \\
\hline 300074 & 423 & smudge pit & Corn (Zea mays) rachis & 0.01 \\
\hline 300089 & 435 & small pit & Corn (Zea mays) rachis & 0.94 \\
\hline 300094 & 437 & small pit & Corn (Zea mays) seed & 0.01 \\
\hline 300090 & 442 & small pit & Corn (Zea mays) seed & $<0.01$ \\
\hline 300097 & 472 & small pit & Hickory (Carya sp.) nutshell & 0.11 \\
\hline 300076 & 481 & small pit & Cane (Arundunarua gigantean) stem & 0.02 \\
\hline 300087 & 484 & large pit & Corn (Zea mays) rachis & 0.03 \\
\hline 300093 & 487 & small pit & Hickory (Carya sp.) nutshell & 0.15 \\
\hline 300092 & 488 & small pit & Corn (Zea mays) rachis & 0.02 \\
\hline 300088 & 490 & large pit & Corn (Zea mays) seed & 0.04 \\
\hline 300095 & 492 & small pit & Corn (Zea mays) rachis & 0.02 \\
\hline 305092 & $496 \mathrm{~A}$ & small pit & Red group oak (Quercus subg. Lobatae) wood & 0.12 \\
\hline 300065 & $496 \mathrm{~B}$ & small pit & Bean/persimmon (Phaseolus/Diospyros) seed & 0.04 \\
\hline 300099 & 497 & posthole & Corn (Zea mays) rachis & 0.01 \\
\hline 300096 & 507 & smudge pit & Corn (Zea mays) rachis & 0.05 \\
\hline 300103 & 508 & smudge pit & Corn (Zea mays) rachis & 0.34 \\
\hline 300091 & 515 & small pit & Hickory (Carya sp.) nutshell & 0.47 \\
\hline 300086 & 518 & large pit & Corn (Zea mays) rachis & 0.62 \\
\hline 300081 & 524 & small pit & Corn (Zea mays) rachis & $<0.01$ \\
\hline 300078 & 526 & large pit & Corn (Zea mays) seed & 0.01 \\
\hline
\end{tabular}


Excavations along the U.S. Highway 271 Mount Pleasant Relief Route

Table 5.8, continued

\begin{tabular}{l|c|l|l|c}
\hline Beta No. & Feature & \multicolumn{1}{|c|}{ Feature Type } & \multicolumn{1}{|c}{ Materials } & Weight (g) \\
\hline 305098 & $534 \mathrm{~A}$ & small pit & Oak (Quercus sp.) wood & 0.05 \\
\hline 300101 & $542 \mathrm{~A}$ & burial fill & White oak (Quercus subg. Quercus) wood & 0.01 \\
\hline 300105 & 544 & small pit & Corn (Zea mays) rachis & $<0.01$ \\
\hline 300104 & 547 & small pit & Corn (Zea mays) rachis & 0.01 \\
\hline 300106 & 565 & small pit & Bean/persimmon (Phaseolus / Diospyros) seed & 0.05 \\
\hline 305104 & 570 & posthole & Common bean (Phaseolus vulgaris) seed & 0.08 \\
\hline 305105 & 572 & posthole & Corn (Zea mays) rachis & 0.12 \\
\hline 305103 & 575 & posthole & Common bean (Phaseolus vulgaris) seed & 0.11 \\
\hline
\end{tabular}

in multiple ways. For example, one could look at Figure 5.32 and conclude that Subarea 1 was occupied from the late A.D. 1200 s all the way up through the 1700s (not counting two earlier occupations not reflected on the graph). Presented below is a different interpretation that accounts for the clear multicomponency indicated by the dates while at the same time being consistent with the feature evidence. Similar to the George Richey site, this interpretation hinges on the idea that the features point to a primary residential occupation no more than a generation or two in length, with the site used both before and after this as well. The situation here is more complicated than the one at the George Richey site, though, for two reasons. First, both the testing and data recovery excavations indicate that substantial associated archeological deposits remain unexcavated immediately outside the project area, which suggests that Subarea 1 at the William Ford site had a more-complex, and longer, history of use than Subarea 1 at the George Richey site. This appears to have involved at least one substantial occupation after the primary one, judging from the radiocarbon evidence. Second, more of the dates from William Ford are in spans where calibration yields multiple intervals and long date ranges, making it harder to pin down actual occupation dates.

Six dates clearly indicate occupation in the first half of the A.D. 1400s, overlapping at 1415-1449, and seven more almost certainly do, with overlapping high-probability intervals at 1395-1443. These appear to be the core set of dates relating to the primary residential occupation of Subarea 1. Three dates with moderately high-probability ranges overlapping at 1391-1443 probably go with this group as well, though they have moderately low-probability ranges in the early-mid 1300 s as well. Thirteen more dates can be added to this group by extending its terminus to ca. 1500 . Though all 13 have ranges extending much later than 1500 , their partial overlap with the other 16 dates is consistent with the idea that the oneor two-generation main occupation indicated by the two overlapping houses, probably lasting no more than 40 years, was sometime between about 1425 and 1500 . Four of these 13 have moderately high-probability ranges that overlap at 1447-1552 and later moderately low-probability ranges in the late 1500 s-early 1600 s. A single date has moderately low-probability ranges in both of these intervals, and 2 more have single high-probability ranges spanning 1455-1639. The final 6 have moderately high-probability ranges that overlap at 1492-1602 and moderately low-probability ranges in the early-mid 1600s. Together, these 29 dates are considered to indicate the primary residential occupation. Eight of the 9 smudge pit dates are in this group, 2 from the southeastern feature concentration and 5 from the northwestern concentration. The other 21 dates are likely from secondary contexts, 6 in the southeastern concentration and 15 in the northwestern concentration.

The second core set of dates consists of 11 that clearly indicate occupation in the latter half of the A.D. $1600 \mathrm{~s}$ or last three-quarters of the 1700 s into the early 1800 s. For 7 of these, the later intervals have higher probabilities than the earlier ones, and the recovery of a few gunflints indicates that some of the eighteenth-century spans could be accurate. However, the facts that gunflints are so scarce and there are no other artifacts pointing to substantial Historic Caddo 


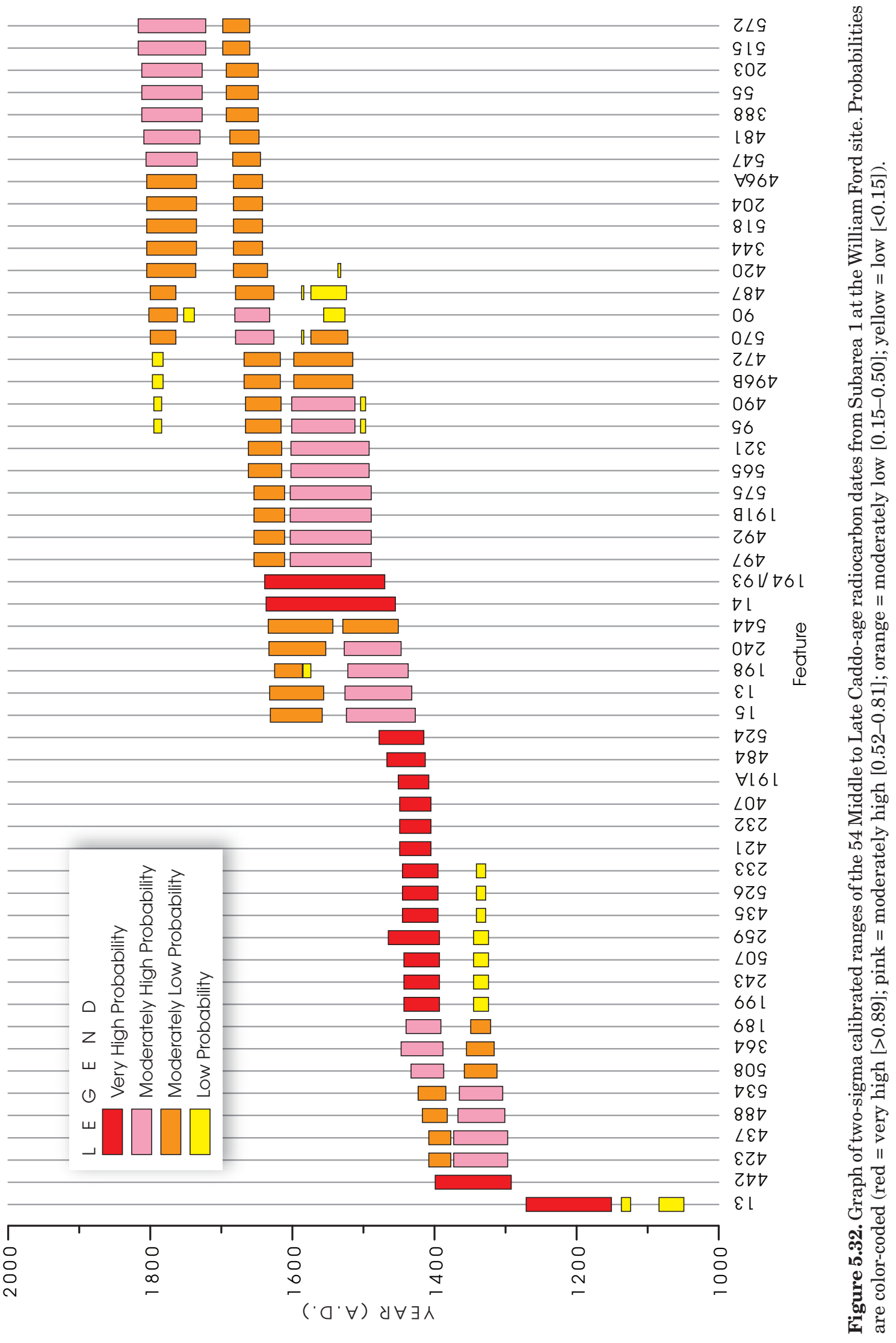


occupation imply that the sixteenth-century intervals tend to be more accurate. Six other dates probably can be added to this group, even though all have moderately low- or low-probability ranges that are earlier, i.e., the 1500s. Two have moderately low-probability ranges overlapping at 1636-1680 and 1764-1800, with low-probability ranges between 1524 and 1587 . Two have moderately high-probability ranges that overlap at 1632-1680, with moderately low-probability ranges between 1762 and 1802 and low-probability ranges at 1526-1556 and 1584-1587; 1 also has a moderate-probability range at 1522-1574. The final two have moderately low-probability ranges at 1515-1598 and 1617-1668, with much later low-probability ranges at 1782-1797. The primary rationale for lumping these with the mostly 1600 s group, in addition to the fact that all have moderate-probability intervals in that century, is that it allows us to terminate the primary occupation at 1500 . Of course, pushing that to ca. 1525 would mean that 3-5 of the later-group dates could be reassigned to the primary occupation. Two dates not assigned to either the earlier primary occupation or the later secondary, but still substantial, occupation suggest an alternative explanation, though. These two have moderately high-probability ranges at 1512-1601 and moderately low-probability ranges at 1616-1666, with both earlier and later low-probability ranges (1497-1504 and 1784-1795). They suggest some low-intensity use of Subarea 1 during the $1500 \mathrm{~s}$, and at least 3 and maybe all 6 of the dates provisionally added above to the group of late dates could actually belong here. Ignoring this wrinkle, 7 of the late dates are from the southeastern feature concentration, 9 are from the northwestern concentration, and 1 is from the area in between; only the 1 from small pit Feature 204 in the northwestern concentration may be from a primary context. These 17 dates are interpreted as reflecting a secondary, probably residential, occupation, perhaps mostly between 1650 and 1700 , and a minor occupation after 1725 .

Five dates indicate some occupation in the A.D. 1300s. Though four of these have moderately low-probability ranges that end not long before the proposed 1425 start date for the main occupation (1408-1423), all four have higherprobability ranges that overlap between 1304 and 1365 . The fifth has a single high-probability range at $1292-1399$. One of these five is from the southeastern feature concentration, and four (one from primary context in smudge pit Feature 423) are from the northwestern concentration.

Three dates are outliers. One, from large pit Feature 13 in the southeastern feature concentration has a high-probability range of A.D. 1151-1271; it appears to reflect some ephemeral use in the twelfth or thirteenth centuries. Another, from the fill of probable juvenile burial Feature 542A between the two main concentrations, has a high-probability range at 770-897; it does not relate to the actual interment, and instead reflects ephemeral activities during the late part of the Woodland period or the Early Caddo period. The third is from small pit Feature 365 in the southeastern concentration; with a high-probability interval at 812-750 B.C., it appears to relate to ephemeral use during the Late Archaic period.

In sum, the radiocarbon dates are interpreted as indicating the following: (1) a primary residential occupation responsible for many of the features, including the two known houses, between A.D. 1425 and 1500; (2) a secondary, probably residential, occupation responsible for a smaller number of features, and conjecturally including an undocumented house or two immediately outside the project area to the east, between 1650 and 1700; and (3) several minor occupations during the Late Archaic period and at 770-897, 1151-1271, the 1300s, the 1500s, and after 1725 . The primary- and secondary-occupation dates are well represented in both feature concentrations, indicating some continuity in use of the landscape during occupations widely separated in time.

\section{The Artifact Evidence}

The lithic artifacts that convey some chronological information are generally consistent with the radiocarbon evidence. The seven arrow points typed as Bassett and Maud probably are associated with one or more of the occupations after A.D. 1400, while the eight Bonham, Catahoula, Colbert, Homan, and Steiner points more likely go with occupations in the mid 1100 s-mid 1200s and the 1300s. Both groups were found in and around both main feature concentrations, supporting the radiocarbon dates indicating multicomponency in both. All three gunflints were recovered from the northwest part of the site, which suggests that the 
Historic Caddo occupation was focused there. The recovery of single Gary and Kent points from in and near the northwest concentration and two Garys and one Kent from the southeast concentration suggests they could be associated with the Caddo components, but most of the other dart points (single examples of Dalton or San Patrice, Edgewood, Godley, Yarbrough, Yarbrough or Kent, Johnson, Marshall, and two Dalton points) more likely relate to periodic use during the late Paleoindian and Archaic periods, including the Late Archaic as indicated by one of the radiocarbon dates.

The ceramic assemblage is mostly consistent with a primary occupation in the A.D. 1400 s, as well as later Caddo use. Among the typed ceramics, Ripley Engraved dominates with scroll motifs consistent with those seen at the nearby Thomas B. Caldwell and A. P. Williams cemeteries as well as at the Tuck Carpenter site. Other types identified or suggested, i.e., Harleton Appliqué, Maydelle Incised, Pease BrushedIncised, Killough Pinched, La Rue Neck Banded, and Bullard Brushed, also would fit comfortably, as does the percentage of brushing (34 percent) among the decorated wares. This is similar to the 30 percent brushed sherds seen in Component I at the Ear Spool site, which appears to date mostly to the 1400s (Perttula and Sherman 2009:178-182). The few ridged body sherds that are likely from Belcher Ridged jars may reflect the proposed secondary occupation in the 1600s. The only possible evidence in the ceramic assemblage for occupation prior to 1400 are 2 sherds from a straight-rimmed bowl, 20 flat-lipped rims, 15 folded rims, and 2 stem fragments from Red River-style pipes. The rim sherds are similar in form to some Coles Creek types or Early Caddo Holly Fine Engraved bowls (Ford 1951:55-89; Suhm and Jelks 1962:77-79), though they are not distinctive enough to be typed as such. If they do relate to early occupations, they may go with the radiocarbon dates indicating minor occupations at 770-897 or 1151-1271. The pipe fragments also could reflect such occupations or maybe later ones in the 1300 s.

\section{PATTERNING IN THE HORIZONTAL DISTRIBUTION OF MATERIALS}

Patterning in the horizontal distributions of artifacts can be explored to address questions relating to the arrangement of activities, i.e., activity areas, and trash disposal. Given the thinness of the deposits and the clear multicomponency, this is a poor place to look for fine-grained patterns, for example, specific activity areas within houses. It is amenable to study of coarser-grained patterns, however. The artifact samples available for this are from the following contexts: 25 test units $(1 \mathrm{x} 1 \mathrm{~m}) \mathrm{dug}$ during testing in the part of Subarea 1 that subsequently saw data recovery work; and 74 machine-dug sample units (averaging $1.9 \times 1.0 \mathrm{~m}$ ) placed across the data recovery area. Because the sizes of the excavations and the amounts of fill screened varied, the densities of materials recovered from them were calculated based on the number of five-gallon buckets of screened fill. For the test units, which were completely screened, it was assumed that each level excavated would have yielded five buckets of fill $\left(0.10 \mathrm{~m}^{3}\right.$ per level divided by a bucket volume of $0.022 \mathrm{~m}^{3}$ ); the fact that the overall density of artifacts from the test units calculated in this manner (3.22 per bucket) is close to that from the sample units (3.41 per bucket) indicates that this is a reasonable assumption.

Densities were calculated for the two most abundant kinds of occupational debrisceramic sherds (from 97 of 99 proveniences; nonzero range $=0.07-6.47$, mean $=1.96 \pm 1.53$, median $=1.47$ ) and all lithics combined (from 98 proveniences; nonzero range $=0.07-4.15$, mean $=1.07 \pm 0.87$, median $=0.80)$ - and these data were used to create isopleth maps (with ArcGIS Spatial Analyst using the inverse-distance method to grid the data and the Jenks natural breaks method to define intervals) for distributional analysis. Attempts were made to look at the distributions of subsets of the artifacts and other classes of materials, but small frequencies made this problematical.

Figure 5.33 shows that, while ceramics are distributed widely across the data recovery area, they are notably concentrated in three areas. One overlaps the northwestern feature concentration. Another overlaps the southeastern feature concentration, including both the eastern part with the two house patterns and the western part with scattered features. Though the isopleth map shows this concentration of ceramics extending eastward outside the area excavated, the landform drops off steeply in this direction, providing a natural boundary. The 


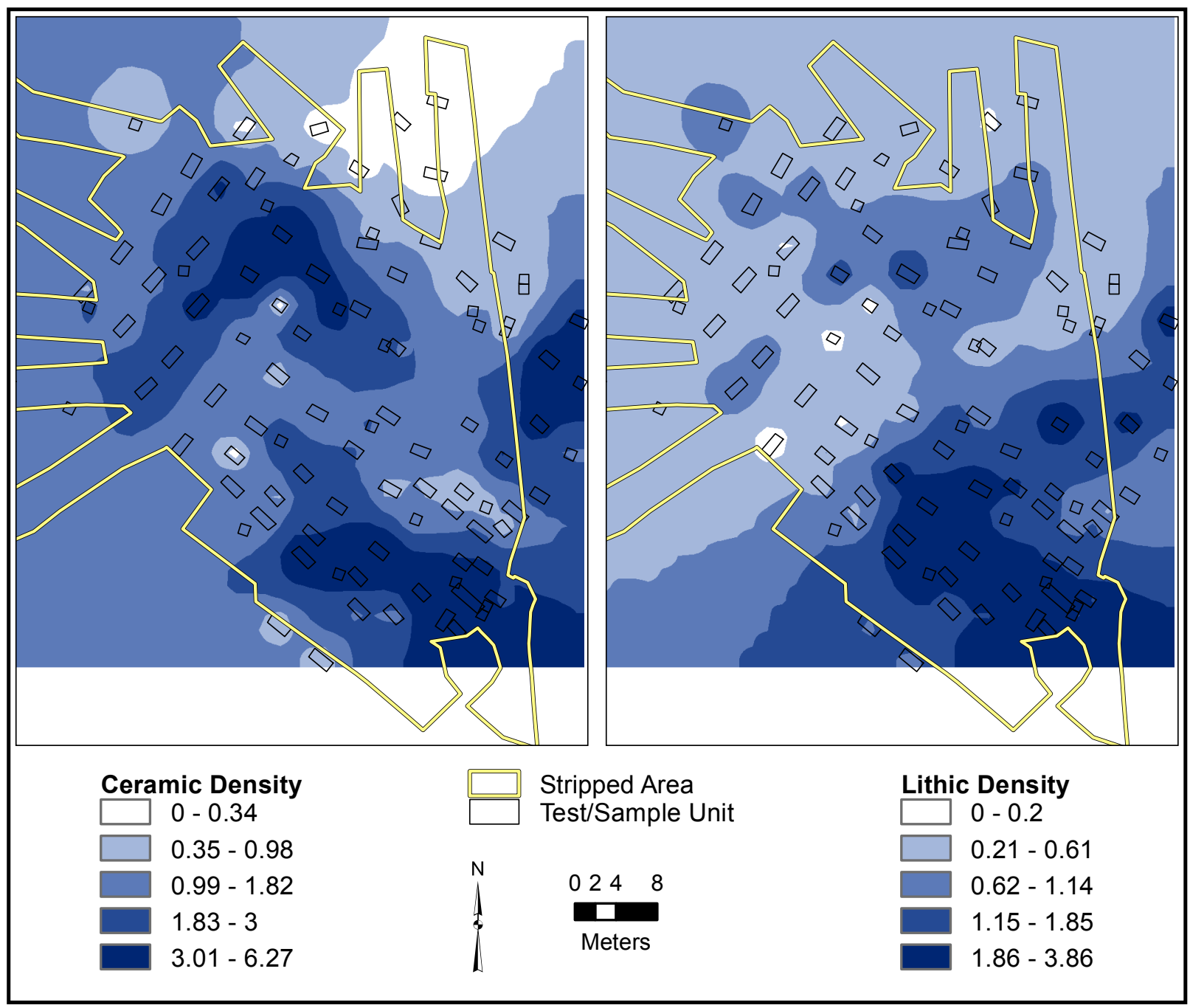

Figure 5.33. Distribution of ceramic sherds (left) and total lithic artifacts (right) across the data recovery area in Subarea 1 at the William Ford site.

third concentration is north of the southeastern feature concentration along the east edge of Subarea 1. It suggests that substantial cultural deposits, speculatively including at least one more house, are present just outside the project area. The landform extends another 25-30 m beyond the investigated area in this direction, ample room for another structure.

The lithic artifact distribution is similar to that of the ceramics, although skewed toward a relative concentration in the southeastern part of the area. Lithics are frequent in and around the northwestern feature concentration, but also extending eastward from it. They also are fre- quent along the east edge of the excavation area overlapping the third ceramic concentration, but their distribution here appears more continuous with the main southeast lithic concentration than is the case with the ceramics. The differences notwithstanding, the lithic distribution is similar enough to that of the ceramics to suggest that most of the lithics relate to Caddo occupations, even though some part of the collection surely goes with earlier occupations indicated by the 24 dart points recovered.

These patterns led to three main conclusions. First, the bulk of the artifacts represent a general rain of debris resulting from activities 
in and immediately around houses and outdoor activity areas represented by clusters of features. Second, the Caddo who lived here did not consistently dispose of trash, resulting in high artifact densities, in areas away from houses and activity areas (at least, not within the area sampled). Third, the fact that the very east edge of the investigated area has high densities of both ceramics and lithics suggests that an undiscovered house or activity area could lie just outside the project area here.

\section{SUMMARY AND CONCLUSIONS}

Approximately 2,360 $\mathrm{m}^{2}$ of Subarea 1 was excavated, resulting in the discovery of 2 burials, 69 pits, 81 postholes, 1 artifact cluster, and 5 soil disturbances that correlate with 2 areas of organically enriched midden sediments. Eighty-eight percent of the cultural features are in two concentrations in the southeastern and northwestern parts of the area. The southeastern concentration has 56 percent of the features, including 31 postholes forming two arcs that represent parts of two overlapping houses, both of which were $6.3 \mathrm{~m}$ in diameter. Other features here relate to outside activities, such as cooking and food preparation, contemporaneous with the houses, while still others are likely to predate or postdate the houses.

The northwestern feature concentration has 32 percent of the features, mostly small pits. Most of the northern part of this area has organically enriched midden sediments reflecting intensive activities presumably associated with feature use. The assemblage of features suggests that mostly nondomiciliary outside activities, including processing and cooking food, preparing hides, etc., were performed here. The ca. 14-mwide expanse between the two main site areas is almost devoid of features, suggesting it may have functioned as a plaza. In the northeast corner of the data recovery area are seven postholes and a single small pit that may reflect an activity area or perhaps a ca. 4-m-diameter square structure such as a ramada. It is hard to interpret this cluster because it is at the edge of the excavation area and could be associated with what are likely to be abundant archeological remains, perhaps representing an undiscovered house, just outside the project area to the east.

The ceramic artifacts recovered number 5,058 , of which 2,677 are large enough for analysis. Ten of these are nonvessel ceramics (1 ear spool fragment, 1 spindle whorl fragment, 1 possible ceramic waster, and 7 smoking pipe fragments), and the rest are from ceramic vessels. Included in the latter are a complete miniature bottle, a small carinated bowl, 2 mostly complete medium/small jars, and 2 probable large jars. These show a fairly even split between use of grog by itself as temper and grog and bone, with bone by itself being much less frequent. Decorated sherds make up 28 percent of the sample. Many have brushing or some combination of brushing with punctations or appliqué (34 percent of those with decoration). Engraving (22 percent) and incising (17 percent) also are common decorative modes, as is punctating or a combination of punctating and incising (20 percent). Sherds with appliqué but no brushing are minimally represented (4 percent), along with sherds with pinching or coil crimping (1 percent). Types represented include Ripley Engraved, Harleton Appliqué, Maydelle Incised, Pease BrushedIncised, Killough Pinched, La Rue Neck Banded, and Bullard Brushed and are consistent with Middle to Late Caddo occupations. The incidence of brushing among the decorated sherds (34 percent) supports this temporal assessment.

The chipped stone assemblage consists of 23 arrow points, 24 dart points, 1 dart or arrow point fragment, 3 gunflints, 33 bifaces, 5 unifaces, 73 flake tools, 7 core tools, 65 cores, and 2,172 pieces of debitage. Identified arrow point types are Bassett, Bonham, Catahoula, Colbert, Homan, Maud, and Steiner, and the dart point types are Dalton, Dalton or San Patrice, Edgewood, Gary, Godley, Johnson, Kent, Marshall, and Yarbrough. The 59 ground, pecked, and battered stone artifacts consist of 6 celts, 7 hammerstones, 6 manos/hammerstones, 1 polishing stone/ hammerstone, 10 pitted hammerstones, 3 manos, $1 \mathrm{mano} /$ pitted hammerstone, 4 anvils, 3 grinding slabs/anvils, 1 grinding slab, 2 abraders, 1 abrader/anvil, 3 grooved and grooved/incised stones, 1 pigment stone, 1 possible unfinished pipe, 1 pestle, 1 pestle/hammerstone/mano/anvil, and 7 indeterminate. Thirty-six percent of the assemblage consists of pitted stones (both anvils and handheld hammers). Excluding items with interchangeable, equivocal, or indeterminate functional positions, base-position artifacts (anvils, grinding slabs, etc.) account for 19 percent of the assemblage, and handheld items compose 63 percent. 
A single modified bone (gaming piece?) and 391 faunal elements were recovered. The remains of deer, deer/pronghorn-sized ungulates, artiodactyls, and canid/deer-sized mammals account for most of the identifiable remains. Also represented are cow/bison, cottontail rabbit, armadillo, a large bird, and turtle.

Seventeen kinds of wood charcoal were identified from flotation samples, with oak (both white and red) and hickory dominant. These fuels were collected from on or near the site, reflecting the oak-hickory forest that the area supported. Other wood charcoal includes American elm, buckeye, mulberry, plum/cherry, slippery elm, sycamore, sweetgum, and willow/ cottonwood. Charred cane stems likely represent baskets and mats rather than fuel materials. Cultigens are present in small amounts and include corn and common bean. Generally small numbers of amaranth, maygrass, Chenopodium, little barley, panicgrass, erect knotweed, persimmon, legume, stick-tight, smartweed, purslane, sumac, daisy family, grass family, sedge family, and grape seeds were recovered as well, with some of these indicating use of starchy-seeded annuals. The remainder of the macrobotanical remains that represent foods is dominated by hardwood nuts, especially hickory but also acorn.

Fifty-six radiocarbon dates were obtained. The interpretation of the radiocarbon dates that is most consistent with the feature evidence involves the following: (1) a primary farmstead occupation by a single family between A.D. 1425 and 1500; (2) a secondary, probably farmstead, occupation responsible for a smaller number of features and conjecturally including an undocumented house or two immediately outside the project area to the east between 1650 and 1700; and (3) several minor shorter-term occupations during the Late Archaic period and at 770-897, 1151-1271, the 1300 s, the 1500 s, and after 1725 . The primary- and secondary-occupation dates are well represented in both feature concentrations, indicating some continuity in use of the landscape during occupations widely separated in time.

Analysis of the distributions of the artifacts suggests three main conclusions: (1) the bulk of the artifacts represent a general rain of debris resulting from activities in and immediately around houses and outdoor activity areas; (2) the Caddo who lived there did not consistently dispose of trash, resulting in high artifact densities, in areas away from houses and activity areas (at least, not within the area sampled); and (3) the fact that the very east edge of the investigated area has high densities of both ceramics and lithics suggests that an undiscovered house or activity area could lie just outside the project area. 


\section{RESULTS OF EXCAVATIONS AT THE JAMES RICHEY SITE, 41TT853}

Virginia L. Hatfield, Damon Burden, Eloise Frances Gadus, and Ross C. Fields

6

This chapter focuses on the results of the data recovery excavations at the James Richey site (41TT853). Incorporated into the discussion, though, are features and artifacts found in earlier auger and intensive testing.

\section{WORK ACCOMPLISHED IN DATA RECOVERY}

Data recovery investigations began with backhoe excavation of 69 sample units ranging in length from 1.3 to $2.9 \mathrm{~m}$ (mean $=2.0 \mathrm{~m})$, in width from 0.9 to $1.1 \mathrm{~m}($ mean $=1.0)$, and in depth from 0.03 to $0.91 \mathrm{~m}($ mean $=0.39 \mathrm{~m})$ (Figure 6.1). Six of the units were within the area designated for trackhoe swath excavations where Caddo houses were considered most likely; the remainder were placed more-or-less systematically across the area to complement 1x1-m units dug during testing. One sample unit (SU 44) was screened in its entirety (40 five-gallon buckets). For 22 units, 15 buckets were screened, while 10 units had 18 buckets. Differing quantities of screened fill are as follows: 1 bucket for 8 units; 2 buckets for 6 units; 5 buckets for 1 unit; 9 buckets for 1 unit; 10 buckets for 4 units; 11 buckets for 1 unit; 12 buckets for 2 units; 13 buckets for 2 units; 20 buckets for 5 units; 21 buckets for 1 unit; and 25 buckets for 2 units. Three units were so shallow that there essentially was no screenable fill; shallow unit depth also explains the 14 units with 1-2 buckets of screened fill.

Two swaths were excavated by trackhoe in one area. They were 17.8 to $18.0 \mathrm{~m}$ long, 4.1 to $4.4 \mathrm{~m}$ wide, and 0.55 to $0.63 \mathrm{~m}$ deep. Some features were found, but they did not form patterns clearly indicative of houses, and thus manual excavations using fine provenience controls were considered unwarranted.

Following excavation of sample units and trackhoe swaths, the $\mathrm{A}$ and $\mathrm{E}$ horizon sediments above the sandy clay Bt horizon were stripped using a trackhoe. The stripped area was approximately $52 \mathrm{~m}$ north-south by $36 \mathrm{~m}$ east-west at its widest point, or approximately $1,334 \mathrm{~m}^{2}$. The stripped area was cleaned by hand troweling and shovel skimming, except for several areas with disturbance from tree stumps. Almost all soil disturbances that had the potential to be cultural were assigned numbers, mapped using a total data station, and manually excavated. Two features were not excavated because they were lost after mapping, and one was mapped incorrectly due to an error in the total data station setup. Disturbances that clearly were not cultural (small linear or circular ones resulting from recent root and rodent activity) were not assigned feature numbers or investigated. Since excavation of the features occurred over several weeks, they were covered with plastic to keep soil moisture in and rainwater out.

The final task consisted of additional stripping to be sure no burials were missed around the data recovery investigation area. This was done over an area of ca. $24 \times 27 \mathrm{~m}\left(535 \mathrm{~m}^{2}\right)$ extending north and uphill. Final stripping was not done in other directions because the landform drops off sharply there, and burials were considered unlikely.

Unlike at the George Richey and William Ford sites, the surface sands varied substantially in thickness, from 5 to over $70 \mathrm{~cm}$, adding a significant obstacle to effective stripping and feature identification. Deep sands occur in the central and southeastern portions of the site, 


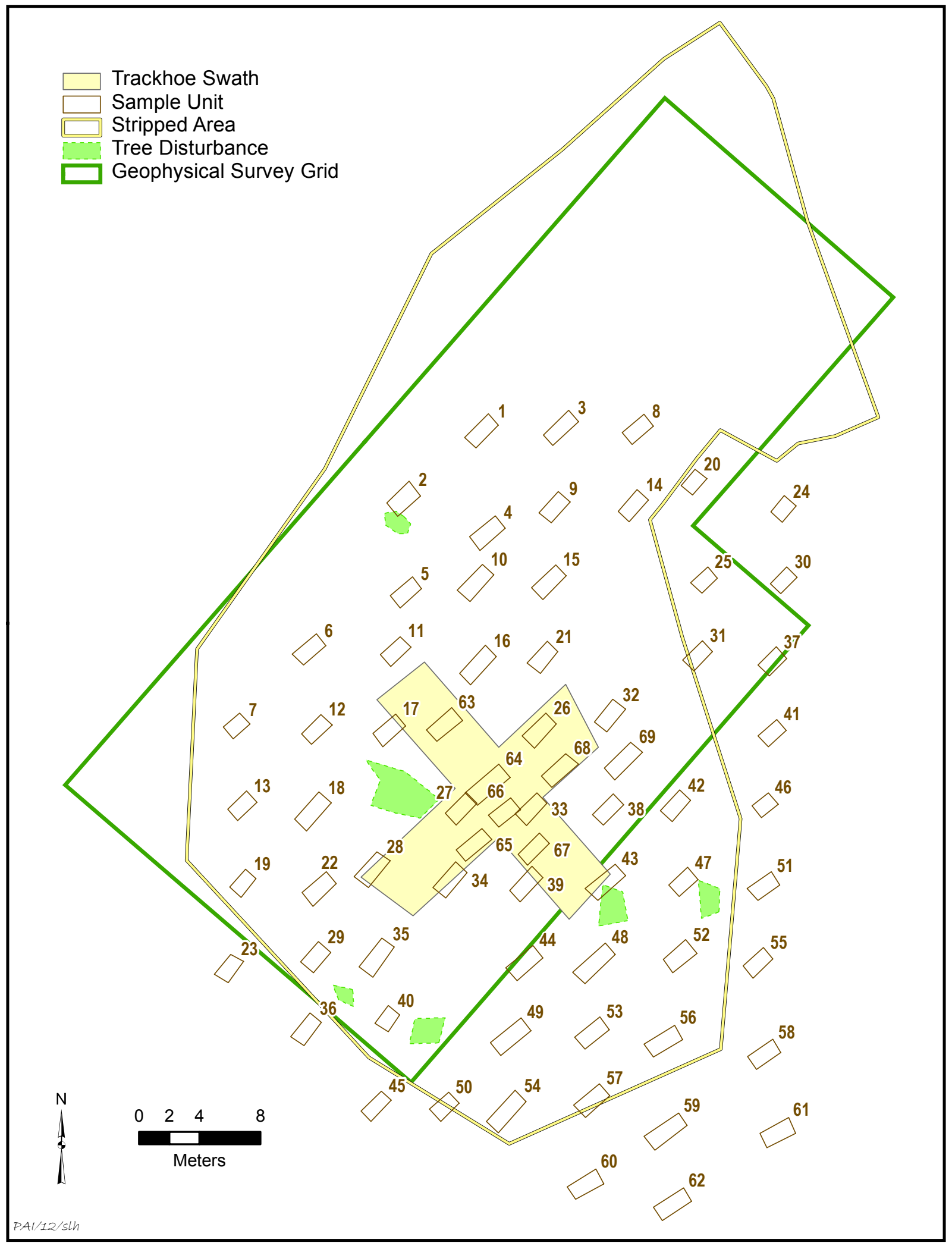

Figure 6.1. Map of the James Richey site showing the data recovery excavations. 
while the western, eastern, and northern edges generally have much thinner sands. Though an attempt was made to identify features as stripping progressed, bioturbation and the minimal contrast between the $\mathrm{A} / \mathrm{E}$ horizon sediments and possible feature fill made it nearly impossible to identify features with confidence in areas where the sands were thick, since possible features rarely extended into the $\mathrm{Bt}$ horizon. Hence, it is likely that the features identified here represent only a sample of the total once present.

\section{CULTURAL FEATURES}

One hundred seventy-eight soil disturbances were identified during the testing and data recovery investigations. The vast majority ( $\mathrm{n}=176,99$ percent) were excavated. The 2 that were not were destroyed by erosion after data recovery stripping. The excavated ones consist of 60 (34 percent) that are interpreted as having Native American origins and 116 (66 percent) that appear to be natural, i.e., the result of bioturbation by rodents or roots. The cultural features are 3 burials, 30 pits, 24 postholes, 2 burned rock clusters, and 1 artifact cluster (Figure 6.2). The feature dimensions and contents are summarized in Table 6.1. In addition, one area of organically enriched midden sediments was observed but not designated as a feature.

\section{Burials}

Three burials were identified. Burials typically are oval to subrectangular in plan view with vertical walls and flat bottoms and contain complete or near-complete ceramic vessels and sometimes other offerings. Feature 2 fits this characterization and is interpreted as an adult burial. Features 18 and 25 are small and may represent child burials. Feature 25 was in the northwestern part of the site, and Features 2 and 18 were in the central and southeastern parts. All are isolated graves and not parts of a cemetery.

Feature 2 is a likely adult burial discovered in the east wall of Trench 7 during testing when the backhoe removed a portion of a complete ceramic vessel. Test Units 1-3 were excavated on the east side of the trench to further reveal this feature. An oval disturbance measuring $180 \times 63 \mathrm{~cm}$ and oriented lengthwise to magnetic north-south was exposed in the E horizon at a depth of $40 \mathrm{~cm}$ (Figures 6.3 and 6.4). The burial pit extended $54 \mathrm{~cm}$ below detection level and did not go down into the Bt horizon. Very large tree roots in the test units above it obscured its level of origin along the southern end, but most of the feature was distinct. The fill was dark yellowish brown (10YR4/4, 4/6) mottled sandy loam. No human remains were preserved. Offerings consist of a grooved stone tool and two complete ceramic vessels, a Maydelle Incised jar and an effigy bowl. The effigy bowl was placed along the north wall on the east side; the Maydelle jar was about $60 \mathrm{~cm}$ from the north end on the west side; and the grooved stone was on the east side about $50 \mathrm{~cm}$ from the north end.

Also recovered from the pit were 13 sherds not refitting to the damaged vessel, 2 cores, 39 pieces of debitage, 1 animal bone fragment, and some charred botanical remains (see Table 6.1). These are probably incidental inclusions, and some of the sherds were in clusters as if in rodent caches. A piece of burned hickory nutshell yielded a calibrated two-sigma radiocarbon date with ranges of A.D. 1430-1530 and 1560-1630, but this does not date the interment.

Feature 18 is a probable child burial identified during testing in Test Units 4, 6, 9, and 12 in the deep sands of the south-central portion of the site (Figures 6.5 and 6.6). The $98 \times 44-\mathrm{cm}$ pit is oval and oriented lengthwise to magnetic north-south. It was identified at a depth of $20 \mathrm{~cm}$ in the $\mathrm{E}$ horizon and extended $46 \mathrm{~cm}$ below this, going a few centimeters into the Bt horizon. No human remains were preserved. Offerings consist of two small bowls and one small jar. The bowls are both carinated; one is decorated and typed as Ripley Engraved, and the other is undecorated. The jar is tentatively typed as Harleton Appliqué. The bowls were along the west-central wall of the burial, close together. The southern one, the Ripley bowl, was $52 \mathrm{~cm}$ from the north end of the burial. The untyped bowl was $42 \mathrm{~cm}$ from the north end of the burial. The Harleton Appliqué small jar was on the east edge of the burial, about $40 \mathrm{~cm}$ from the north end. The small size of these vessels is consistent with this being a child's grave, as is the fact that nine other features were found in the immediate area, four of which are postholes. Though the postholes did not form an arc indicative of a house wall, a house may well have been present here (see Distributions below), and Feature 18 may have been a subfloor interment. Also included in the feature fill were three sherds 


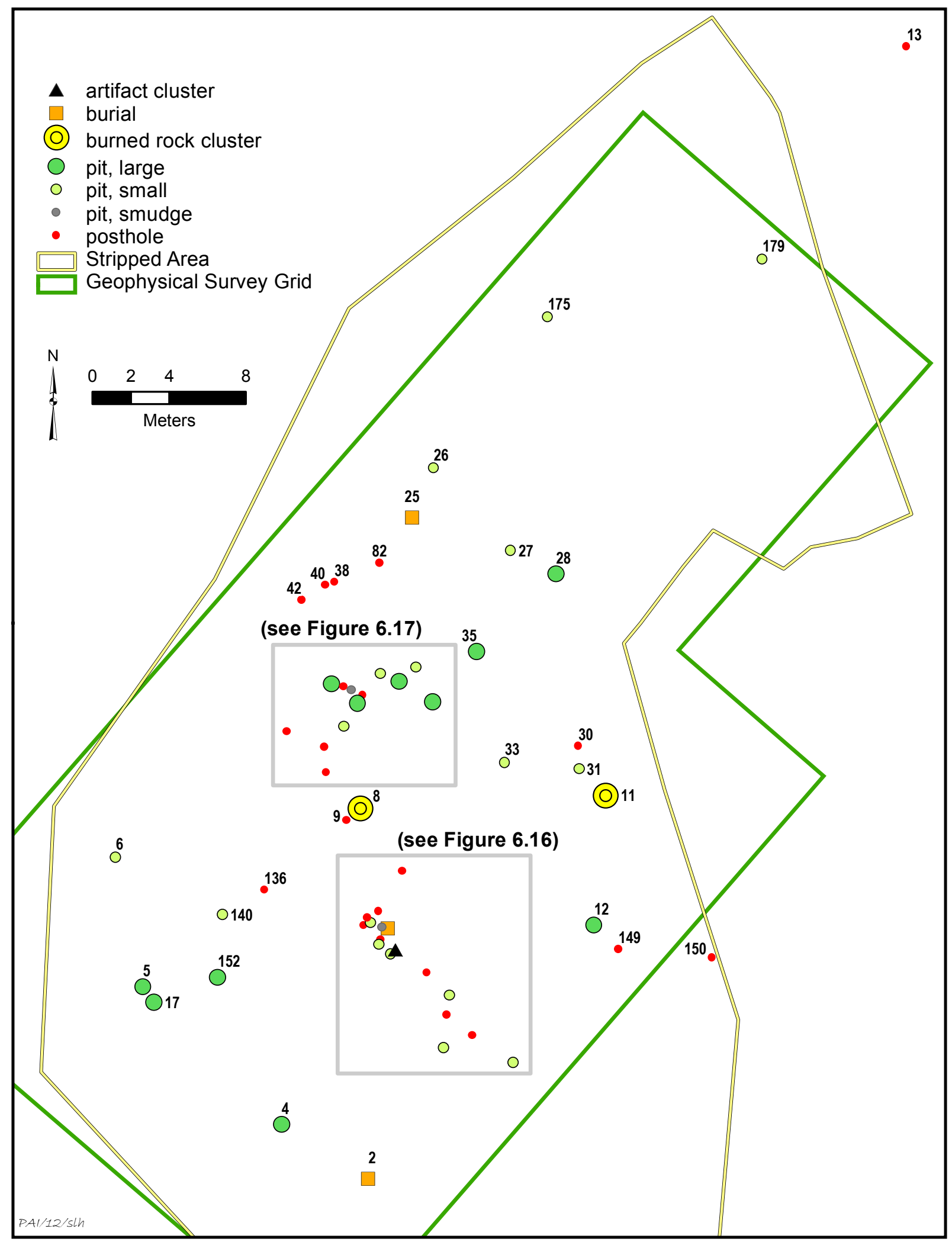

Figure 6.2. Map of the James Richey site showing the distribution of cultural features. 
Table 6.1. Summary of cultural features at the James Richey site

\begin{tabular}{|c|c|c|c|c|}
\hline Feature & Type & $\begin{array}{c}\text { Dimensions } \\
(\mathrm{cm})\end{array}$ & $\begin{array}{l}\text { Depth } \\
(\mathrm{cm})\end{array}$ & Contents \\
\hline 2 & burial & $180 \times 63$ & 14 & $\begin{array}{l}1 \text { Maydelle Incised jar, } 1 \text { effigy bowl, } 13 \text { sherds }(73.3 \mathrm{~g}), 2 \\
\text { cores, } 39 \text { debitage, } 1 \text { grooved/incised stone, } 1 \text { faunal } \\
\text { remain, } 2.34 \text { g macrobotanical remains }\end{array}$ \\
\hline 18 & burial & $98 \times 44$ & $40-46$ & $\begin{array}{l}3 \text { sherds (14.9 g), } 2 \text { small bowls (1 possible Ripley } \\
\text { Engraved, } 1 \text { undecorated and untyped), } 1 \text { small jar } \\
\text { (possible Harleton Appliqued), } 3 \text { debitage }\end{array}$ \\
\hline 25 & burial & $90 \times 45$ & 20 & $\begin{array}{l}1 \text { small jar (possible Pease Brushed-Incised), } 1 \text { engraved } \\
\text { bowl (possible Sanders Engraved), } 22 \text { sherds, } 1 \text { Yarbrough } \\
\text { point, } 8 \text { flake tools, } 33 \text { debitage, } 1 \text { daub, } 11 \text { ironstone } \\
\text { pebbles, } 6 \text { silicifed wood pebbles }\end{array}$ \\
\hline 4 & pit, large & $138 \times 84$ & $50-77$ & 3 sherds (18.6 g), 2 flake tools, 106 debitage \\
\hline 5 & pit, large & $60 x 60$ & $20-38$ & \\
\hline 12 & pit, large & $64 \times 41$ & $18-28$ & 9 sherds $(53.2 \mathrm{~g}), 9.76 \mathrm{~g}$ macrobotanical remains \\
\hline 17 & pit, large & $120 \times 120$ & $29-175$ & $\begin{array}{l}91 \text { sherds }(410.6 \mathrm{~g}), 1 \text { godley point, } 1 \text { Yarbrough point, } 1 \\
\text { point fragment, } 4 \text { flake tools, } 107 \text { debitage, } 10.93 \mathrm{~g} \\
\text { macrobotanical remains }\end{array}$ \\
\hline 28 & pit, large & $90 \times 77$ & 17 & $\begin{array}{l}1 \text { sherd }(3.3 \mathrm{~g}), 10 \text { debitage, } 0.17 \mathrm{~g} \text { macrobotanical remains, } \\
2.4 \mathrm{~g} \text { burned clay }\end{array}$ \\
\hline 35 & pit, large & $54 \times 53$ & 7 & $\begin{array}{l}1 \text { sherd }(10.0 \mathrm{~g}), 2 \text { debitage, } 2 \text { faunal remains, } 6.05 \mathrm{~g} \\
\text { macrobotanical remains }\end{array}$ \\
\hline 45 & pit, large & $74 \times 52$ & 25 & $\begin{array}{l}9 \text { sherds }(74.1 \mathrm{~g}), 7 \text { debitage, } 34 \text { faunal remains, } 3.68 \mathrm{~g} \\
\text { macrobotanical remains, } 7.3 \mathrm{~g} \text { burned clay, } 25.7 \mathrm{~g} \text { daub }\end{array}$ \\
\hline 48 & pit, large & $68 \times 35$ & 8 & $\begin{array}{l}16 \text { sherds ( } 70.6 \mathrm{~g}), 1 \text { debitage, } 1 \text { flake tool, } 0.09 \mathrm{~g} \\
\text { macrobotanical remains, } 19.3 \mathrm{~g} \text { burned clay, } 48.3 \mathrm{~g} \text { daub }\end{array}$ \\
\hline 53 & pit, large & $88 \times 55$ & 25 & 16 debitage, $0.02 \mathrm{~g}$ macrobotanical remains \\
\hline 56 & pit, large & $90 \times 90$ & 11 & 1 biface, 12 debitage, $0.02 \mathrm{~g}$ macrobotanical remains \\
\hline 152 & pit, large & $70 \times 56$ & 18 & $\begin{array}{l}1 \text { sherd }(4.8 \mathrm{~g}), 1 \text { core, } 19 \text { debitage, } 1 \text { flake tool, } 1 \text { pitted } \\
\text { hammerstone, } 0.03 \mathrm{~g} \text { macrobotanical remains }\end{array}$ \\
\hline 16 & pit, smudge & $36 \times 14$ & $29-40$ & 2 sherds (18.3 g), $1.34 \mathrm{~g}$ macrobotanical remains \\
\hline 47 & pit, smudge & $32 \times 29$ & 14 & $8.04 \mathrm{~g}$ macrobotanical remains \\
\hline 6 & pit, small & $37 \times 37$ & $10-36$ & $\begin{array}{l}2 \text { sherds }(6.9 \mathrm{~g}), 1 \text { debitage, } 23 \text { faunal remains, } 6.21 \mathrm{~g} \\
\text { macrobotanical remains, } 2.8 \mathrm{~g} \text { burned clay, } 7.5 \mathrm{~g} \text { daub }\end{array}$ \\
\hline 14 & pit, small & $42 \times 42$ & $37-50$ & $\begin{array}{l}1 \text { sherd }(5.9 \mathrm{~g}), 1 \text { debitage, } 1 \text { mano/hammerstone, } 0.91 \mathrm{~g} \\
\text { macrobotanical remains }\end{array}$ \\
\hline 15 & pit, small & $32 \times 30$ & $39-53$ & $0.20 \mathrm{~g}$ macrobotanical remains \\
\hline 20 & pit, small & $40 \times 34$ & $23-41$ & $0.24 \mathrm{~g}$ macrobotanical remains \\
\hline 24 & pit, small & $35 \times 42$ & 8 & $\begin{array}{l}\text { Also Feature } 98 ; 1 \text { sherd (16.6 g), } 1 \text { pitted hammerstone, } 1 \\
\text { other ground stone, } 0.89 \mathrm{~g} \text { macrobotanical remains }\end{array}$ \\
\hline 26 & pit, small & $46 \times 30$ & 7 & 1 debitage, $0.02 \mathrm{~g}$ macrobotanical remains \\
\hline 27 & pit, small & $42 \times 18$ & 6 & \\
\hline 31 & pit, small & $40 \times 30$ & 9 & 2 debitage, $0.15 \mathrm{~g}$ macrobotanical remains \\
\hline 33 & pit, small & $40 \times 32$ & 6 & $0.01 \mathrm{~g}$ macrobotanical remains \\
\hline 51 & pit, small & $28 \times 28$ & 7 & $\begin{array}{l}4 \text { sherds ( } 18.2 \mathrm{~g}), 3 \text { debitage, } 1 \text { flake tool, } 0.15 \mathrm{~g} \\
\text { macrobotanical remains, } 3.3 \mathrm{~g} \text { burned clay, } 5.0 \mathrm{~g} \text { daub }\end{array}$ \\
\hline 55 & pit, small & $38 \times 48$ & 20 & $0.01 \mathrm{~g}$ macrobotanical remains \\
\hline 58 & pit, small & $46 \times 27$ & 12 & 2 debitage, $2.18 \mathrm{~g}$ macrobotanical remains \\
\hline 87 & pit, small & $44 \times 40$ & 7 & 0.07 g macrobotanical remains \\
\hline 92 & pit, small & $32 \times 32$ & 6 & $0.08 \mathrm{~g}$ macrobotanical remains \\
\hline 140 & pit, small & $39 \times 32$ & 8 & \\
\hline 175 & pit, small & $40 \times 32$ & 5 & $1.29 \mathrm{~g}$ macrobotanical remains \\
\hline
\end{tabular}


Table 6.1, continued

\begin{tabular}{|c|c|c|c|c|}
\hline Feature & Type & \begin{tabular}{|c|} 
Dimensions \\
$(\mathrm{cm})$
\end{tabular} & $\begin{array}{l}\text { Depth } \\
\text { (cm) }\end{array}$ & Contents \\
\hline 179 & pit, small & $26 \times 24$ & 4 & 4 debitage \\
\hline 7 & posthole & $9 \times 9$ & $20-23$ & \\
\hline 9 & posthole & $25 \times 25$ & $51-66$ & \\
\hline 13 & posthole & $25 \times 20$ & $59-67$ & \\
\hline 19 & posthole & $15 \times 15$ & $29-34$ & 1 debitage, 1 flake tool \\
\hline 21 & posthole & $18 \times 17$ & $23-33$ & \\
\hline 22 & posthole & $17 \times 14$ & $23-33$ & \\
\hline 23 & posthole & $24 \times 22$ & $23-37$ & \\
\hline 30 & posthole & $18 \times 14$ & 13 & \\
\hline 38 & posthole & $20 \times 16$ & 6 & \\
\hline 40 & posthole & $20 \times 14$ & 9 & $0.01 \mathrm{~g}$ macrobotanical remains \\
\hline 42 & posthole & $20 \times 20$ & 10 & 1 debitage \\
\hline 46 & posthole & $16 \times 13$ & 4 & 1 debitage, $0.97 \mathrm{~g}$ macrobotanical remains \\
\hline 63 & posthole & $18 \times 16$ & 12 & 3 sherds $(20.6 \mathrm{~g})$ \\
\hline 67 & posthole & $23 \times 17$ & 6 & \\
\hline 82 & posthole & $20 \times 16$ & 8 & \\
\hline 89 & posthole & $24 \times 22$ & 4 & \\
\hline 96 & posthole & $21 \times 16$ & 6 & \\
\hline 100 & posthole & $19 x 17$ & 6 & \\
\hline 104 & posthole & $16 \times 16$ & 6 & \\
\hline 136 & posthole & $22 \times 22$ & 14 & 1 debitage, $1.43 \mathrm{~g}$ macrobotanical remains \\
\hline 149 & posthole & $20 \times 18$ & 4 & \\
\hline 150 & posthole & $22 \times 20$ & 19 & \\
\hline 153 & posthole & $15 \times 15$ & 4 & \\
\hline 171 & posthole & $22 \times 20$ & 8 & 0.03 g macrobotanical remains \\
\hline 8 & $\begin{array}{l}\text { burned rock } \\
\text { cluster }\end{array}$ & $190 \times 124$ & $20-30$ & $\begin{array}{l}5 \text { sherds }(279.5 \mathrm{~g}), 11 \text { debitage, } 7100 \mathrm{~g} \text { thermally altered } \\
\text { rocks }\end{array}$ \\
\hline 11 & $\begin{array}{l}\text { burned rock } \\
\text { cluster }\end{array}$ & $100 \times 80$ & $20-28$ & \\
\hline 10 & $\begin{array}{l}\text { artifact } \\
\text { cluster }\end{array}$ & $17 \times 13$ & $22-26$ & 61 refitting sherds, 1 debitage, $1.4 \mathrm{~g}$ daub \\
\hline
\end{tabular}

Note: Single number for depth indicates depth below detection level (the scraped surface); range indicates depth below ground surface.

and three pieces of lithic debitage, which were probably incidental inclusions.

Feature 25 was in the northwestern part of the site, on a slope, where the sands are very shallow. It was identified in the Bt horizon after data recovery stripping below sands that were only 5 to $8 \mathrm{~cm}$ thick. Initially, the feature appeared as an elongated $2.9 \times 1.2-\mathrm{m}$ oval sandy area with the rim of two vessels slightly visible at the north end. The fill was yellowish brown (10YR 5/4) sandy loam. The long axis was oriented north-northeast to south-southwest, in line with the slope. The larger disturbance was only 2-3 cm thick, and Sample Unit 1 impacted its southeast corner. Within this larger disturbance was a deeper (ca. $20 \mathrm{~cm}$ ) and smaller (90x45) oval pit with a complete bowl tentatively typed as Sanders Engraved and a mostly complete jar tentatively typed as Pease Brushed-Incised (Figures 6.7 and 6.8). The vessels were placed close together on the northwest side of the smaller pit. The smaller pit appears to be a remnant of the grave pit, and the larger elongated oval is probably a naturally eroded depression in the $\mathrm{Bt}$ 


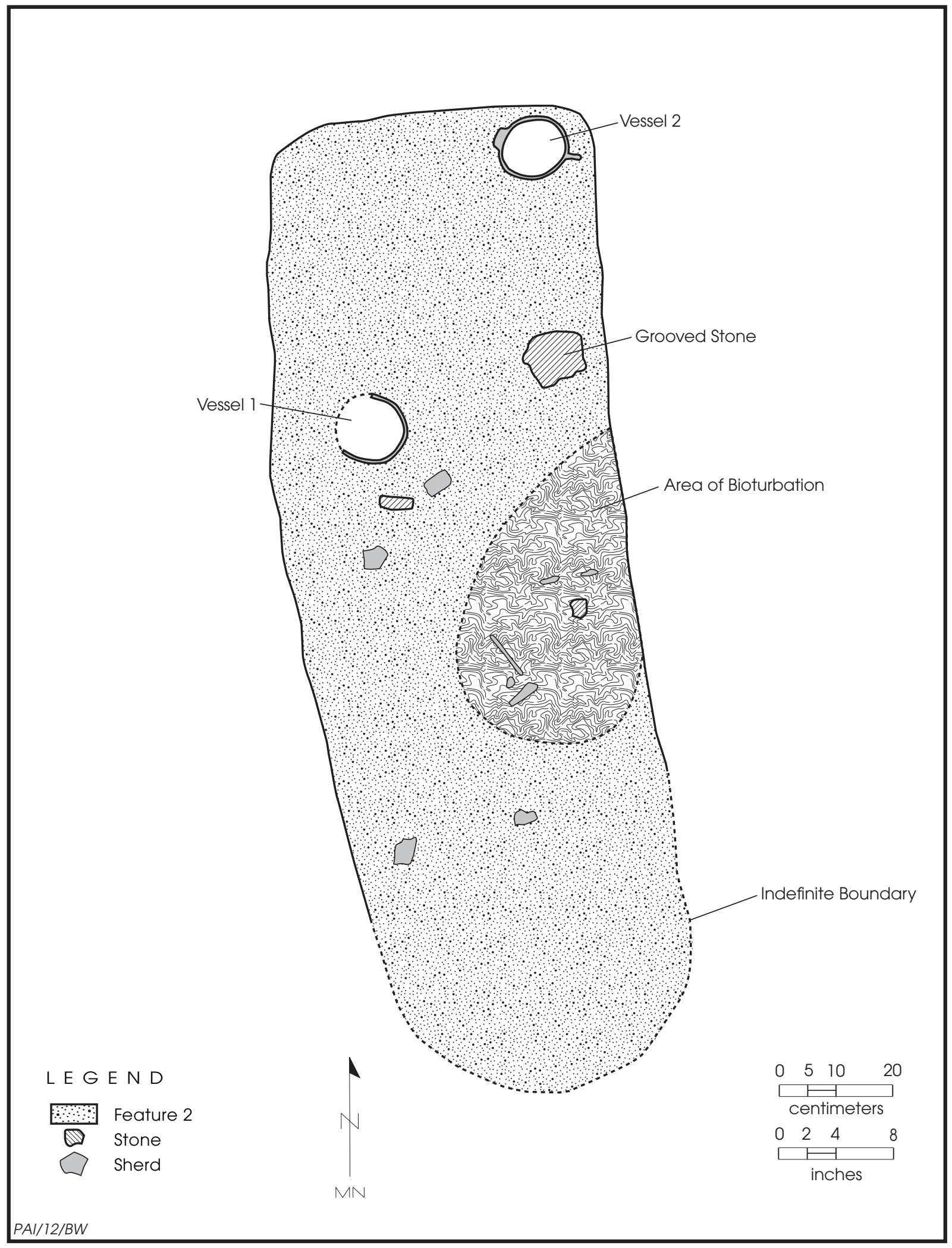

Figure 6.3. Plan of burial Feature 2 at the James Richey site. 


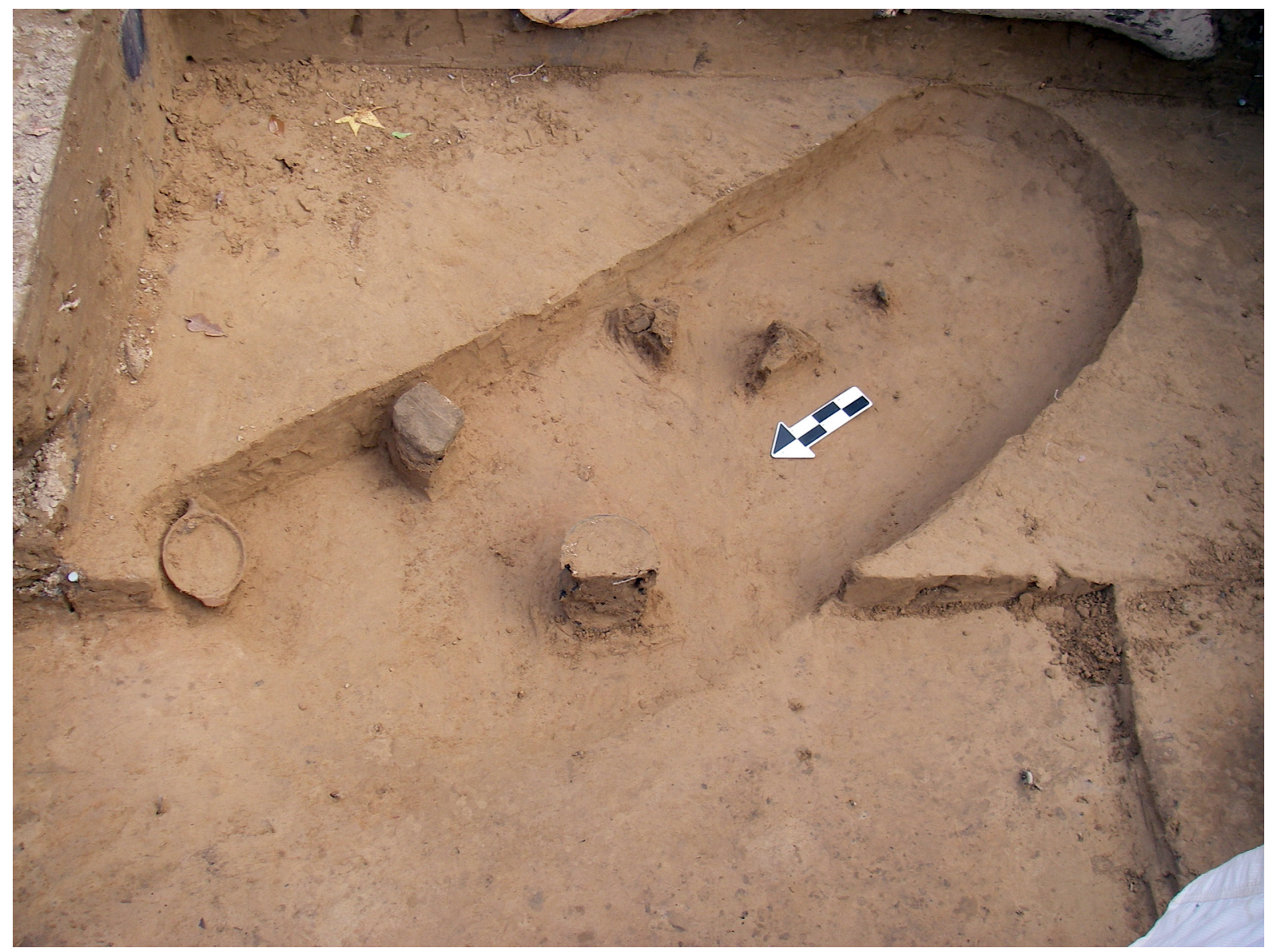

Figure 6.4. Photograph of burial Feature 2 at the James Richey site.

horizon. The erosion that caused the depression may have removed the upper part of the burial. If the original burial was larger, it did not intrude into the Bt horizon, except for the small pit containing the vessels. The poor condition of this feature precludes a confident assessment of its original shape, size, and orientation, although the long axis of the part that remains is oriented north-northwest-south-southeast. Feature 25 may be a child burial, however, the vessels are very well made compared to the crudely decorated small bowls in Feature 18. Instead, they are more similar to the inclusions in Feature 2, the adult burial, as well as to mortuary offerings from other adult Late Caddo burials in that they are not diminutive.

Other items recovered consist of 22 sherds, a Yarbrough dart point, 8 flake tools, 33 pieces of debitage, 11 ironstone pebbles, 6 pieces of silicified wood, and a small piece of daub. They represent incidental inclusions brought in by bioturbation, with some in a linear alignment indicating a rodent run.

\section{Pits}

Pits are oval to circular in plan view with sloping walls and rounded to flat bases. The 30 pits make up 50 percent of the cultural features. They range in length from 26 to $138 \mathrm{~cm}$ $($ mean $=54 \mathrm{~cm})$, in width from 14 to $120 \mathrm{~cm}$ $($ mean $=44 \mathrm{~cm})$, and in depth from 4 to $136 \mathrm{~cm}$ $($ mean $=17 \mathrm{~cm})$. The pits are differentiated by size with those having a long axis greater than or equal to $50 \mathrm{~cm}$ considered large pits and the rest considered small pits. Smudge pits, a subset of small pits, have evidence of probable in situ burning. 


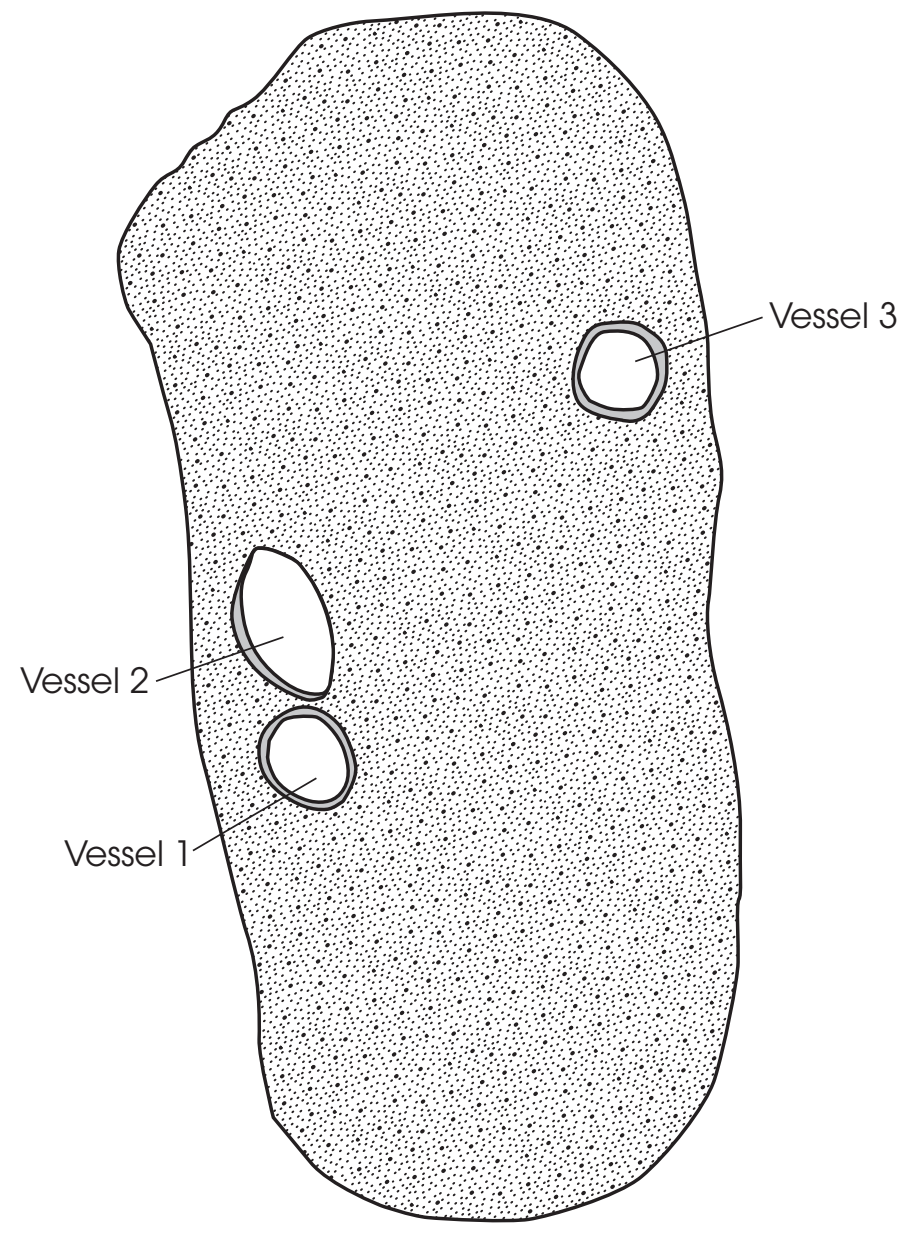

LE GEN D

Feature 18

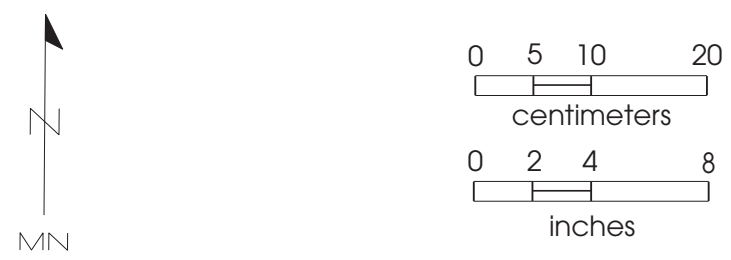

PAI/12/BW

Figure 6.5. Plan of burial Feature 18 at the James Richey site.

\section{Large Pits}

The large pits $(\mathrm{n}=11)$ are oval or circular in plan view with long axes ranging from 54 to $138 \mathrm{~cm}$ (mean $=83 \mathrm{~cm})$, widths ranging from 35 to $120 \mathrm{~cm}($ mean $=66)$, and depths below detection level ranging from 7 to $136 \mathrm{~cm}$
$($ mean $=27 \mathrm{~cm})$. One, Feature 17, is exceptionally deep $(136 \mathrm{~cm})$, and excluding it reduces the average depth of the large pits to $17 \mathrm{~cm}$. Most are basin shaped in cross section with sloping walls and rounded bases (Figure 6.9). The large pits were filled with dark reddish brown (5YR 3/3, 3/4), brown (7.5YR 4/4), brownish yellow (10YR 
6/6), yellowish brown (10YR 5/4), light yellowish brown (10YR 6/4), or pinkish gray (7.5YR 6/2) sandy to silty sandy loam.

The large pits generally contained more cultural materials than the small pits and postholes (Table 6.2). The faunal remains consist of just 36 bone fragments, all identified to the vertebrate subphylum. The $30.60 \mathrm{~g}$ of macrobotanical remains make up 53 percent of the site total; identified remains consist of $0.01 \mathrm{~g}$ catkin, $0.01 \mathrm{~g}$ pine cone scales, $0.01 \mathrm{~g}$ fruit, $0.01 \mathrm{~g}$ fungus, $13.00 \mathrm{~g}$ nutshells (acorn, hickory, and hickory/ walnut), $0.45 \mathrm{~g}$ corn rachis, $0.16 \mathrm{~g}$ seeds (corn, daisy, elderberry, grass, maygrass, nightshade, strawberry, and verbena), $0.04 \mathrm{~g}$ cane and grass stems, and $16.08 \mathrm{~g}$ wood charcoal (ash, elm, hickory, oak, persimmon, plum/cherry, red oak, and white oak). The densities of macrobotanical remains from those with flotation samples range from 0.001 to $0.894 \mathrm{~g} /$ liter, averaging $0.200 \mathrm{~g} /$ liter (or $0.035 \mathrm{~g} /$ liter excluding the anomalously high values for Features 12 and 35). This low average is comparable to those for the small pits and postholes discussed below and much lower than the one for smudge pits. The low densities in general suggest that most of these remains are in secondary context, and this probably is true as well for the other classes of materials in these pits. There is a high likelihood that most of the cultural materials were introduced into these pits from general scatters of debris present when the pits were dug or deposited there during and after pit use. The difference compared to the smudge pits also may indicate that these large pits were cleaned out for reuse more often.

Most of the large pits are nondescript, but a few are unusual in shape or fill content. The most unusual one is Feature 17, a very large

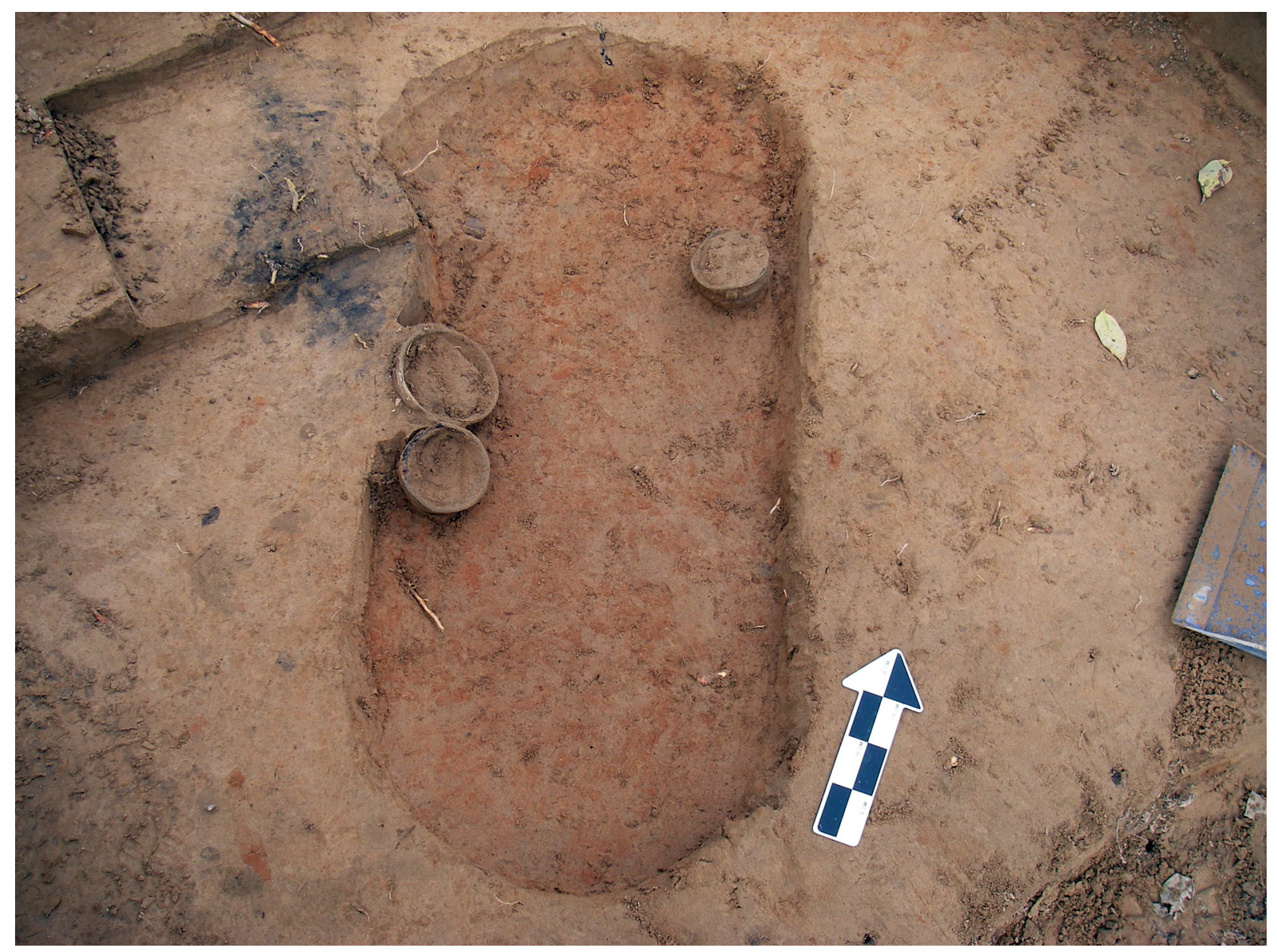

Figure 6.6. Photograph of burial Feature 18 at the James Richey site. 


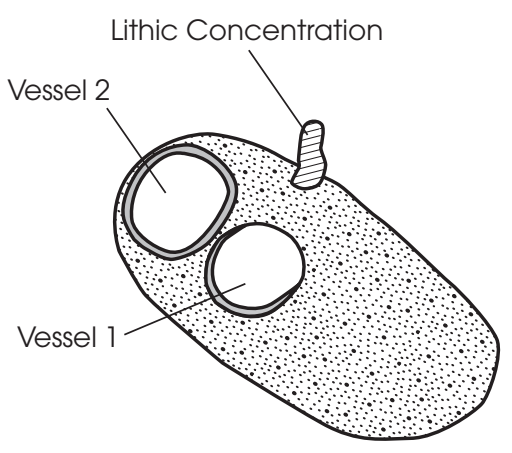

L E E N D

Feature 25
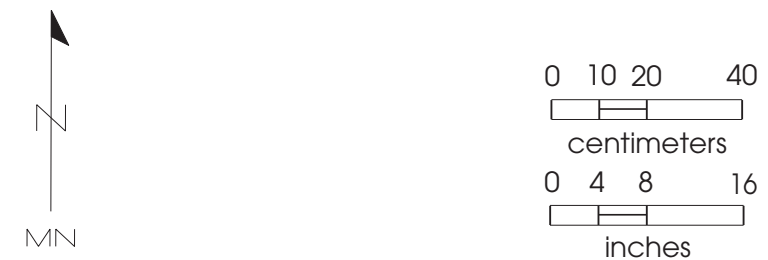

PAI/12/BW

Figure 6.7. Plan of burial Feature 25 at the James Richey site.

$(120 \times 120 \mathrm{~cm})$, deep $(165 \mathrm{~cm})$ pit with a flat floor and irregular walls that were vertical in some places and sloping in others (Figures 6.10 and 6.11). Identified at the top of the Bt horizon, it was partially excavated during testing, in Test Units 8 and 13, and was completely excavated during data recovery. Feature 17 was first noted at $29 \mathrm{~cm}$ below the ground surface and extended to $175 \mathrm{~cm}$. The west wall had an abrupt transition between the fill and the surrounding sediment marked by an increase in compaction and clay content. The east side was more gradual, and a 50x65-cm section was excavated transecting the east wall to confirm the feature boundary there. This exploratory unit was excavated from 110 to $175 \mathrm{~cm}$ below ground surface and extended $40 \mathrm{~cm}$ beyond the east wall. There were several 3-4-cm-thick lamellae in the fill at various depths reflecting natural accumulation of fine-grained sediments. The fill contained a typical assortment of cultural materials, including burned corn and cane (see Table 6.1), but not in any great abundance. As with most other large pits, it seems likely that most or all of the contents are unrelated to actual use of the pit. The size and shape of this feature suggest it may have been used for storage, although probably not of perishable materials such as foodstuffs, which probably would not have survived well underground.

The other large pits at 41TT853 are much smaller, and only a few are distinctive. Feature 12 is unusual because of the relative abundance of macrobotanical remains ( $0.69 \mathrm{~g} /$ liter) recovered from the floated fill. It is basin shaped with charcoal-rich dark brown (10YR 3/3) sandy loam fill containing mostly burned hickory and hickory/walnut nutshells but also hickory wood, white oak wood, and some indeterminate remains. It may have been used to hold refuse from cleaning 
out of a hearth or cooking feature nearby.

Feature 28 has four fill zones that may reflect use and reuse or a complicated taphonomic history. The lowermost zone is mottled dark grayish brown (10YR 4/2) and brown (10YR 4/3) sandy loam with oxidized sandy clay at the base. Above this is a small area of brown (10YR 4/3) sandy loam surrounded by dark grayish brown (10YR 4/2) sandy loam. These three zones are within a larger oval of brownish yellow (10YR $6 / 6)$ sandy loam. In plan, a small circular area $(26 \times 24 \mathrm{~cm})$ with the brown sandy loam is within the larger oval area $(58 \times 32 \mathrm{~cm})$ within the overall feature outline $(90 \times 77 \mathrm{~cm})$. These differing fills may be the result of reuse and multiple infilling episodes. The oxidization at the base suggests it was used for cooking at one time.

Feature 53 had pinkish gray (7.5YR 6/2) sandy loam fill with dense burned clay in the lower $5-6 \mathrm{~cm}$ indicating in situ thermal activity; hence, it may have functioned as a cooking feature. Debitage and a little charred hickory/walnut nutshell and unexamined wood are the only materials recovered in flotation,

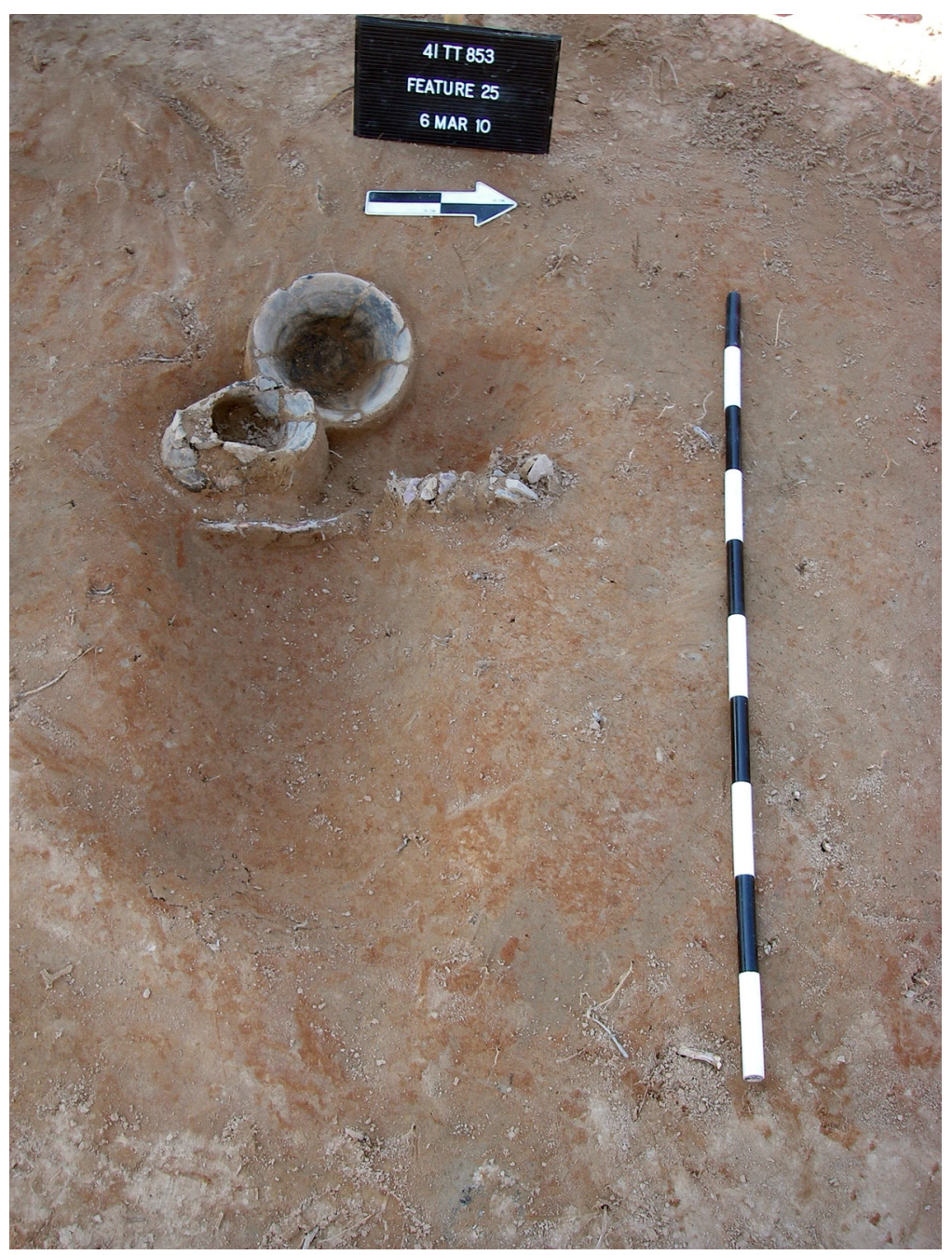

Figure 6.8. Photograph of burial Feature 25 at the James Richey site. however (see Table 6.1).

\section{Small Pits}

The 19 small pits, including 2 smudge pits, represent 32 percent of the cultural features. They range in length from 26 to $46 \mathrm{~cm}$ $($ mean $=38 \mathrm{~cm})$, in width from 14 to $48 \mathrm{~cm}$ $($ mean $=31 \mathrm{~cm})$, and in depth below detection level from 4 to $26 \mathrm{~cm}($ mean $=11 \mathrm{~cm})$. They are basin shaped in cross section, with some variability due to bioturbation (Figure 6.12). Pit fills were dark yellowish brown (10YR 3/4, 3/6, 4/4), light yellowish brown (10YR 6/4), pale brown (10YR 6/4), or pale beige (7.5YR 4/4) sandy loam.

The small pits yielded sparse cultural materials (see Table 6.2). The did contain moderate amounts of faunal remains (all indeterminate vertebrate bone fragments) and botanical remains ( $22.16 \mathrm{~g}, 39$ percent of the site total). Identified macrobotanical remains consist of $4.04 \mathrm{~g}$ hickory and hickory/walnut nutshells, $0.81 \mathrm{~g}$ corn rachis, $0.01 \mathrm{~g}$ cane stem, $0.03 \mathrm{~g}$ seeds (daisy, purslane, and spiderwort), and $14.4 \mathrm{~g}$ wood charcoal (ash, elm, hardwood, hickory, live oak, oak, red oak, and white oak). A little under half of these remains (44 percent) are from the two smudge pits, with the remainder from 14 other small pits. Excluding the smudge pits, the small pits have an average macrobotanical remains density of $0.074 \mathrm{~g} /$ liter, ranging from 0.001 to $0.323 \mathrm{~g} /$ liter. As with the large pits, this low value implies that most of the charred materials 


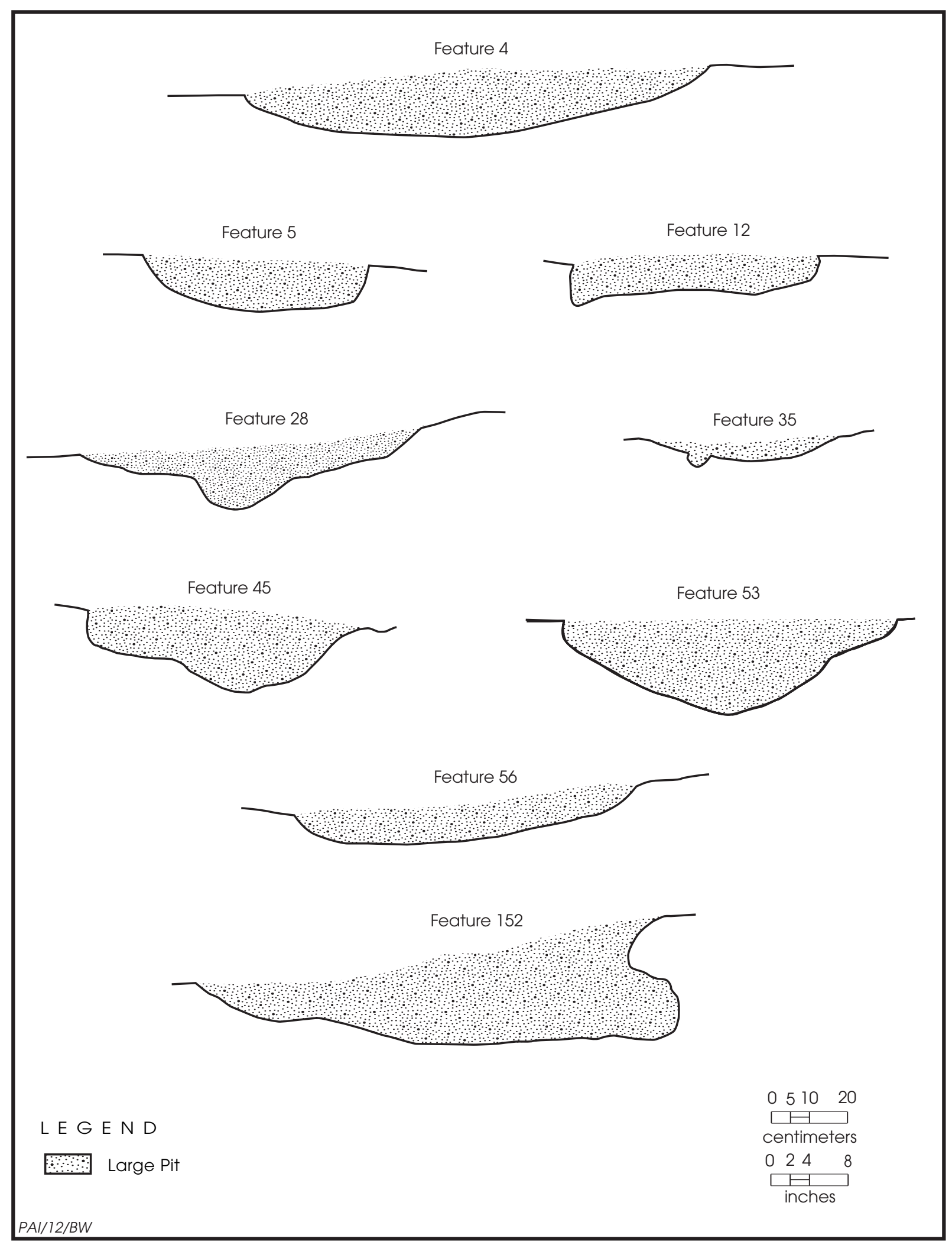

Figure 6.9. Cross sections of large pits at the James Richey site. 
Excavations along the U.S. Highway 271 Mount Pleasant Relief Route

Table 6.2. Cultural materials from pits and postholes at the James Richey site

\begin{tabular}{l|c|c|c|c|c|c}
\hline & \multicolumn{2}{|c|}{ Large Pits } & \multicolumn{2}{c|}{ Small Pits } & \multicolumn{2}{c}{ Postholes } \\
\hline & No./Wt. & $\begin{array}{c}\text { \% of Site } \\
\text { Total }\end{array}$ & No./Wt. & $\begin{array}{c}\text { \% of Site } \\
\text { Total }\end{array}$ & \multicolumn{2}{c}{$\begin{array}{c}\text { No./Wt. } \\
\text { Total }\end{array}$} \\
\hline Ceramics & $131 / 645.2$ & $4 / 3$ & $22 / 200.9$ & $1 / 1$ & $3 / 20.6$ & $<1 /<1$ \\
\hline Chipped stone tools & 12 & 4 & 1 & $<1$ & 1 & $<1$ \\
\hline Ground stone tools & 2 & 2 & 0 & 0 & 0 & 0 \\
\hline Bone tools & 0 & 0 & 0 & 0 & 0 & 0 \\
\hline Cores & 1 & 1 & 0 & 0 & 0 & 0 \\
\hline Debitage & $280 / 459.3$ & $11 / 8$ & $14 / 7.3$ & $1 /<1$ & $3 / 16.5$ & $<1 /<1$ \\
\hline Macrobotanical remains & 30.60 & 53 & 22.16 & 39 & 2.44 & 4 \\
\hline Faunal remains & 36 & 31 & 23 & 20 & 0 & 0 \\
\hline Mussell/snail shells & 0 & 0 & 0 & 0 & 0 & 0 \\
\hline Thermally altered rocks & 0 & 0 & 0 & 0 & 0 & 0 \\
\hline Burned clay & 74.0 & 24 & 12.5 & 4 & 0 & 0 \\
\hline
\end{tabular}

are not related directly to the functions of the small pits, instead reflecting general debris in the vicinity that was mixed over time.

In contrast, both smudge pits (Features 16 and 47) have higher densities of macrobotanical remains ( 0.428 and $0.804 \mathrm{~g} /$ /iter), consistent with the idea that they represent primary contexts. Feature 16 was identified during test excavations in the E horizon of Test Unit 6 and extended slightly into the Bt horizon. It contained charcoal-enriched, mottled, dark yellowish brown (10YR 3/6) sandy loam. The primary fuel was oak wood. Feature 47 had relatively abundant charred botanical remains and charcoal staining in the lower half of the pit. There were also red clay inclusions and light gray ash in pockets just above the base, and the walls and base were stained with charcoal and appeared oxidized. Wood (ash, hickory, and oak) and nutshells (hickory and hickory/walnut) were the primary fuels.

Two other small pits are distinctive in that their bases were oxidized indicating in situ burning; they probably are cooking features. One, Feature 20, is a small oval pit with straight but slightly irregular walls and a flat bottom and two fill zones. Feature 58 also had two fill zones with charcoal flecking that extended up the walls.

\section{Postholes}

The 24 postholes make up 40 percent of the cultural features. They generally are circular to slightly oval in plan view with straight to slightly sloping walls and rounded to flat bases (Figure 6.13). They range from 9 to $25 \mathrm{~cm}$ in diameter $($ mean $=18 \mathrm{~cm})$ and from 3 to $19 \mathrm{~cm}$ in depth below detection level (mean $=8 \mathrm{~cm}$ ). The postholes were filled with strong brown (7.5YR 5/6), light yellowish brown (10YR 6/4), yellowish brown (10YR 5/4), dark yellowish brown (10YR $3 / 4,4 / 4,4 / 6$ ), or reddish brown (5YR 3/2) sandy loam. Some contained charcoal flecking, but these materials were in low densities and no posthole had evidence of in situ burning.

Cultural materials within these postholes consist of just three sherds, one flake tool, three flakes, and $2.44 \mathrm{~g}$ of macrobotanical remains, including $0.77 \mathrm{~g}$ of nutshells (hickory and hickory/ walnut) and $0.48 \mathrm{~g}$ of wood charcoal (oak, red oak, and white oak). None of these materials actually relate to the posts these features once held, though. The four postholes with processed flotation samples had low densities of macrobotanical remains, ranging from 0.003 to 0.286 g/liter and averaging $0.089 \mathrm{~g} /$ liter (or $0.023 \mathrm{~g} /$ liter excluding Feature 136 with an unusually high value).

As discussed below (see Distributions), none of the postholes form arcs indicative of house walls. This does not mean none represent houses, though, since there are other indications for houses, such as the child burial near four postholes in the south-central part of the site and a midden-like deposit in the same area. 


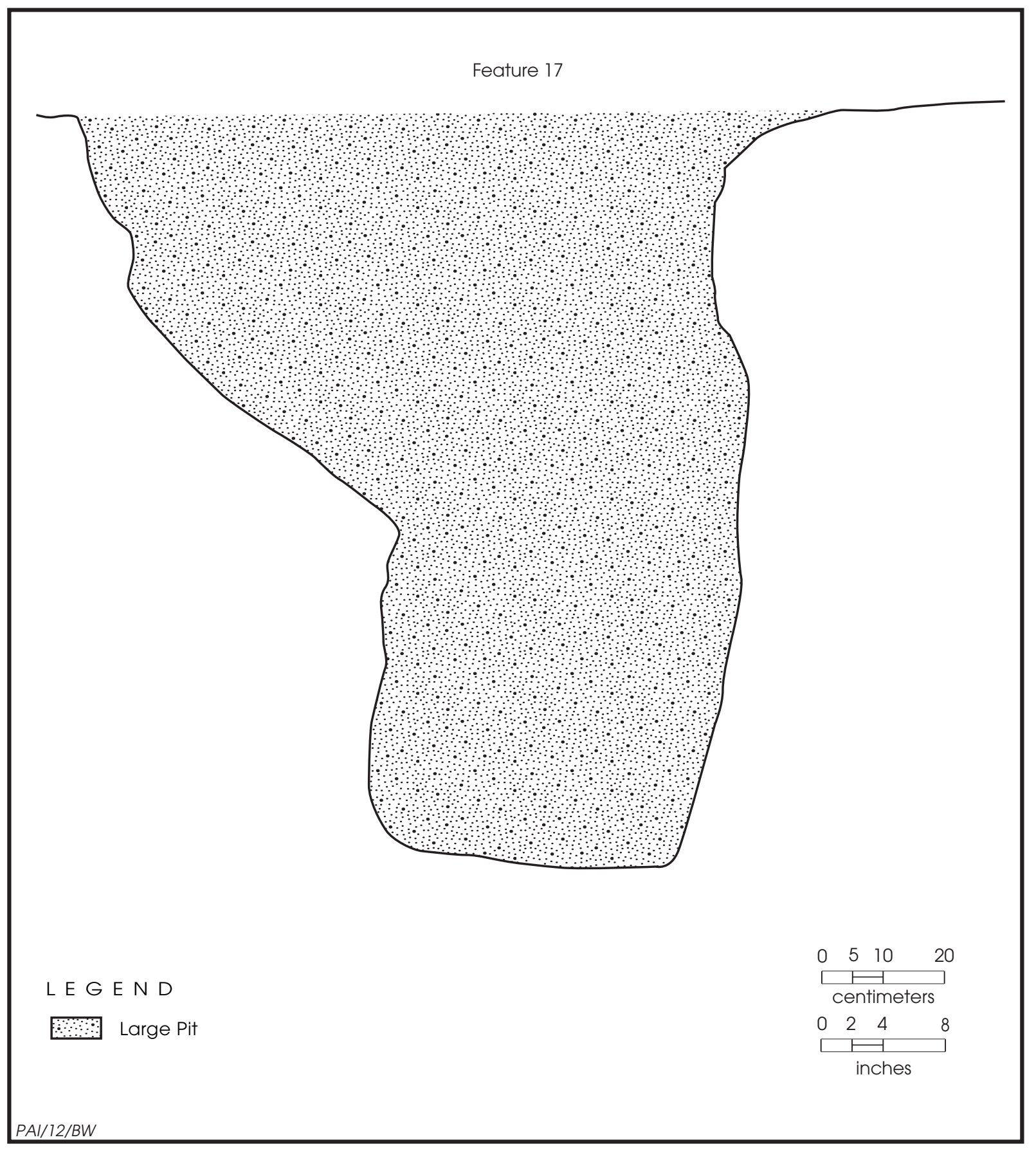

Figure 6.10. Cross section of large pit Feature 17 at the James Richey site.

\section{Artifact Cluster}

The single artifact cluster, Feature 10, consists of a concentration of sherds identified at a depth of $22-26 \mathrm{~cm}$ in the A horizon at the south end of Trench 15 (Figure 6.14). Test Unit 7 further exposed the $17 \times 13$-cm cluster revealing 61 sherds and a single piece of debitage. The sherds were refit into part of the bottom of a small bowl (see Ceramic Artifacts). It is a discarded piece of utility ware. 


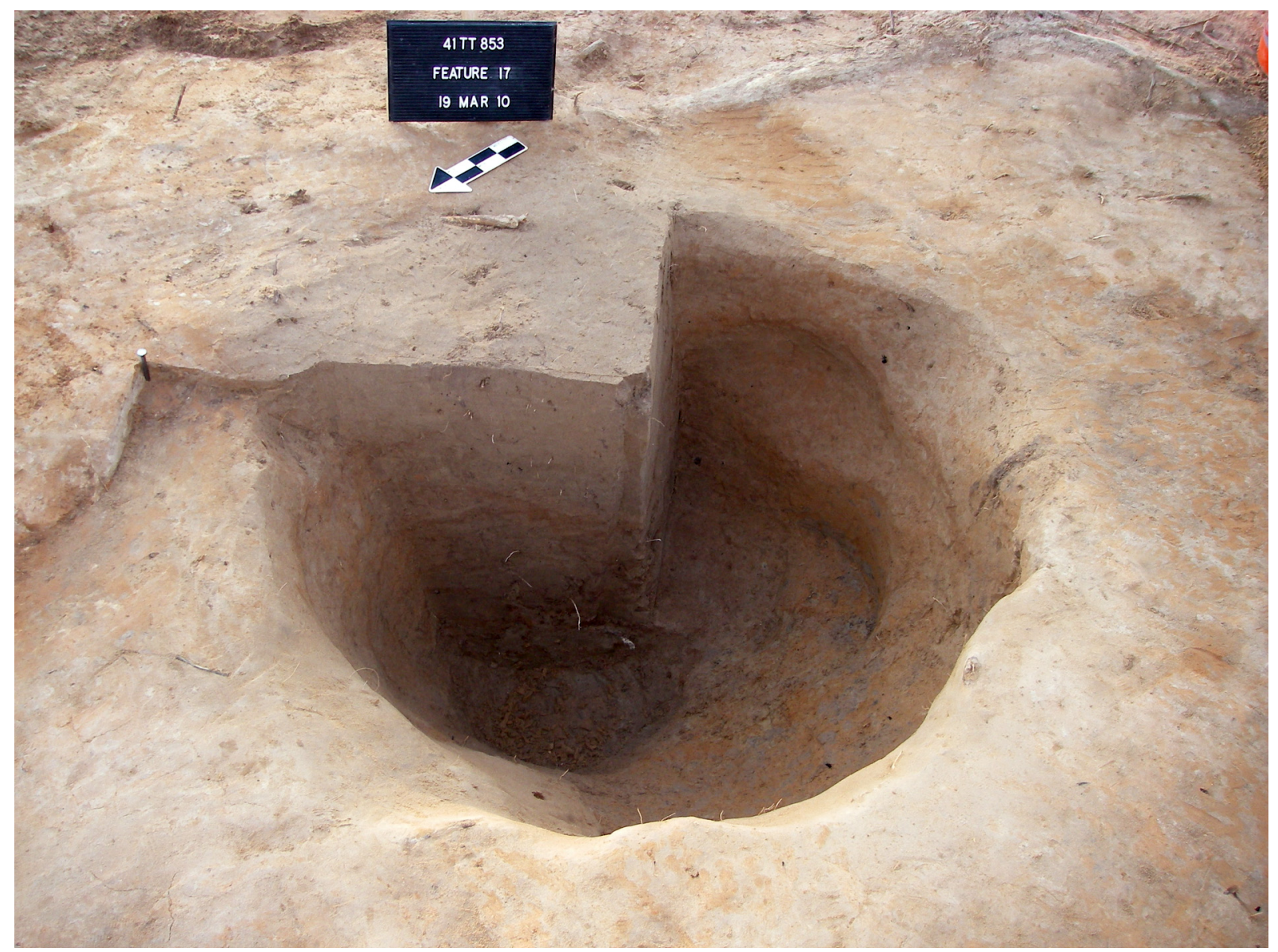

Figure 6.11. Photograph of large pit Feature 17 at the James Richey site. Three-quarters of the pit has been excavated.

\section{Burned Rock Clusters}

Two burned rock clusters were identified. Feature 8 was found at a depth of $20-30 \mathrm{~cm}$ in the A horizon in Trench 14 and Test Unit 21 (Figure 6.15). The rocks covered an area of $190 \times 124 \mathrm{~cm}$ and extended slightly into the south and north walls of Test Unit 21. There were 41 fire-cracked ferruginous sandstone rocks, weighing $7.1 \mathrm{~kg}$, which were disarticulated and scattered. Found in the vicinity, though not necessarily associated with use of the feature, were 11 pieces of lithic debitage and 5 sherds. This probably is a disturbed cooking feature and may predate the Caddo occupation.

Feature 11 was identified at a depth of 20-28 cm below the surface in Trench 18 and Test Unit 23. The scatter of rocks was within the dark yellowish brown sandy loam of the thin A horizon and resting on the Bt horizon at $28 \mathrm{~cm}$ below the ground surface. It did not continue into Test Unit 20. The cluster of burned rocks consisted of a disarticulated grouping of about 20 pieces of fire-cracked ferruginous sandstone over an area of 100x80 cm. It was not fully documented during testing due to weather conditions and was destroyed by data recovery excavations. This probably also is a disturbed cooking feature and may predate the Caddo occupation.

\section{Organically Enriched Midden Sediments}

Organically enriched midden sediments are characterized as dark brown to black deposits, typically with relatively high densities of arti- 


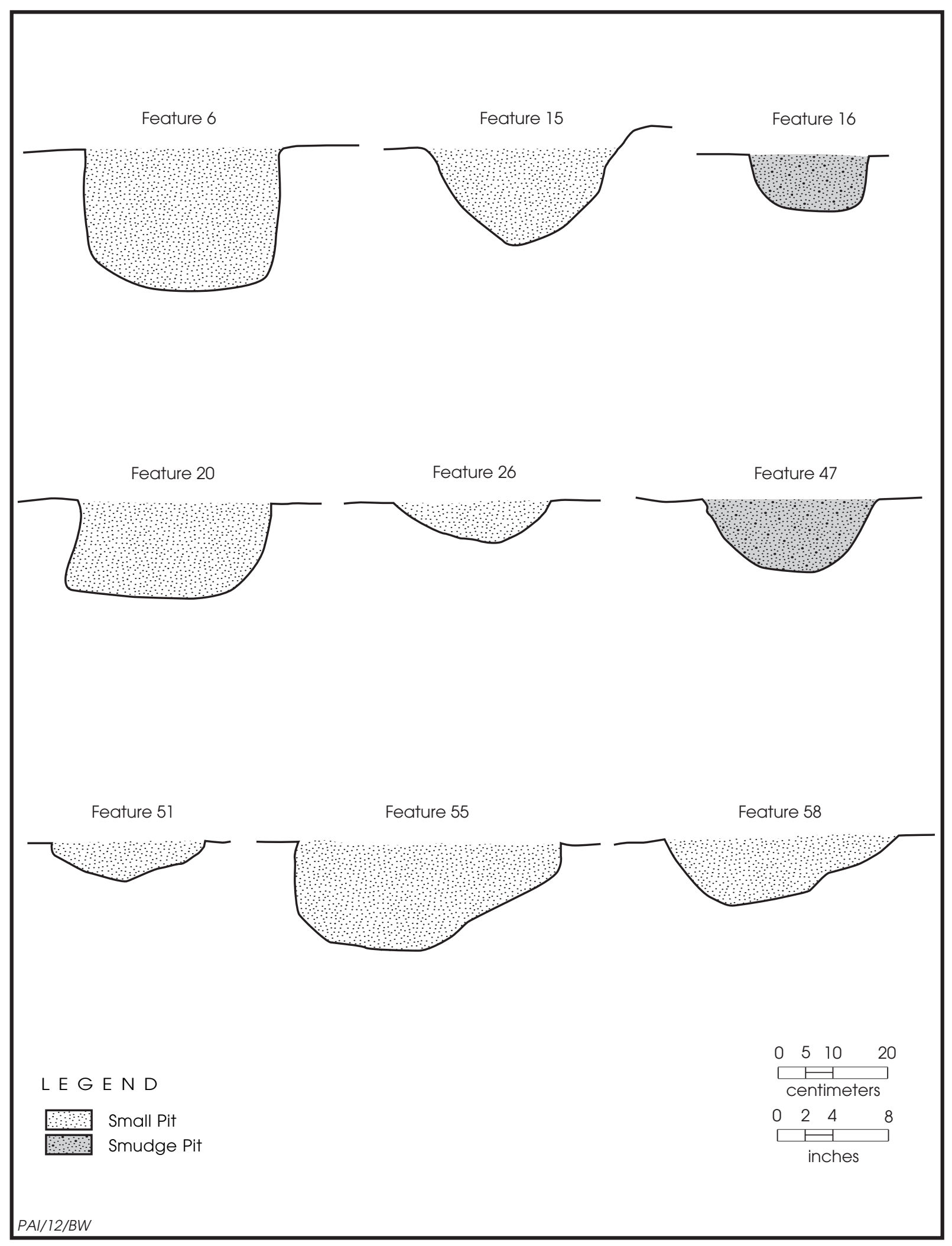

Figure 6.12. Cross sections of selected small pits at the James Richey site. 


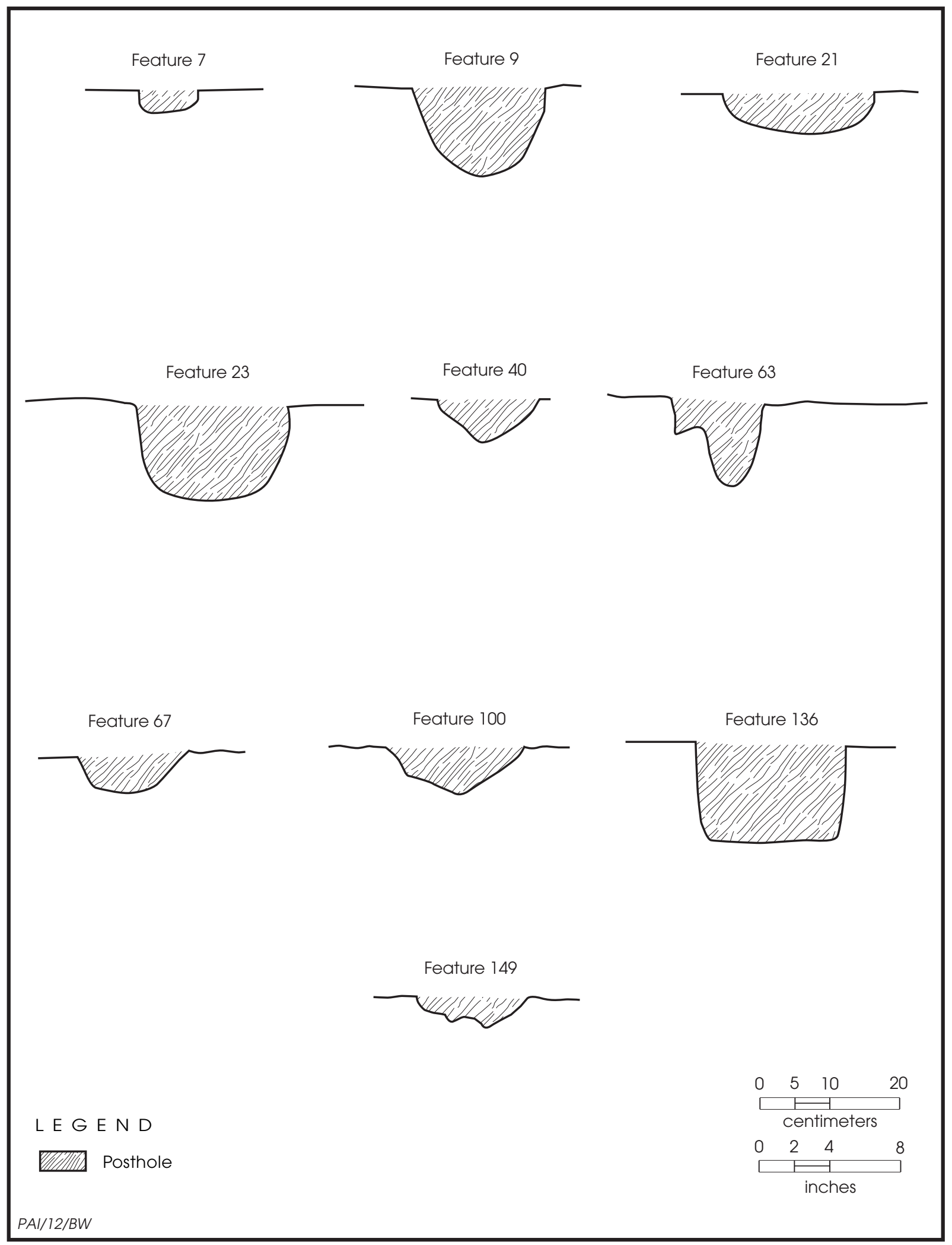

Figure 6.13. Cross sections of selected postholes at the James Richey site. 


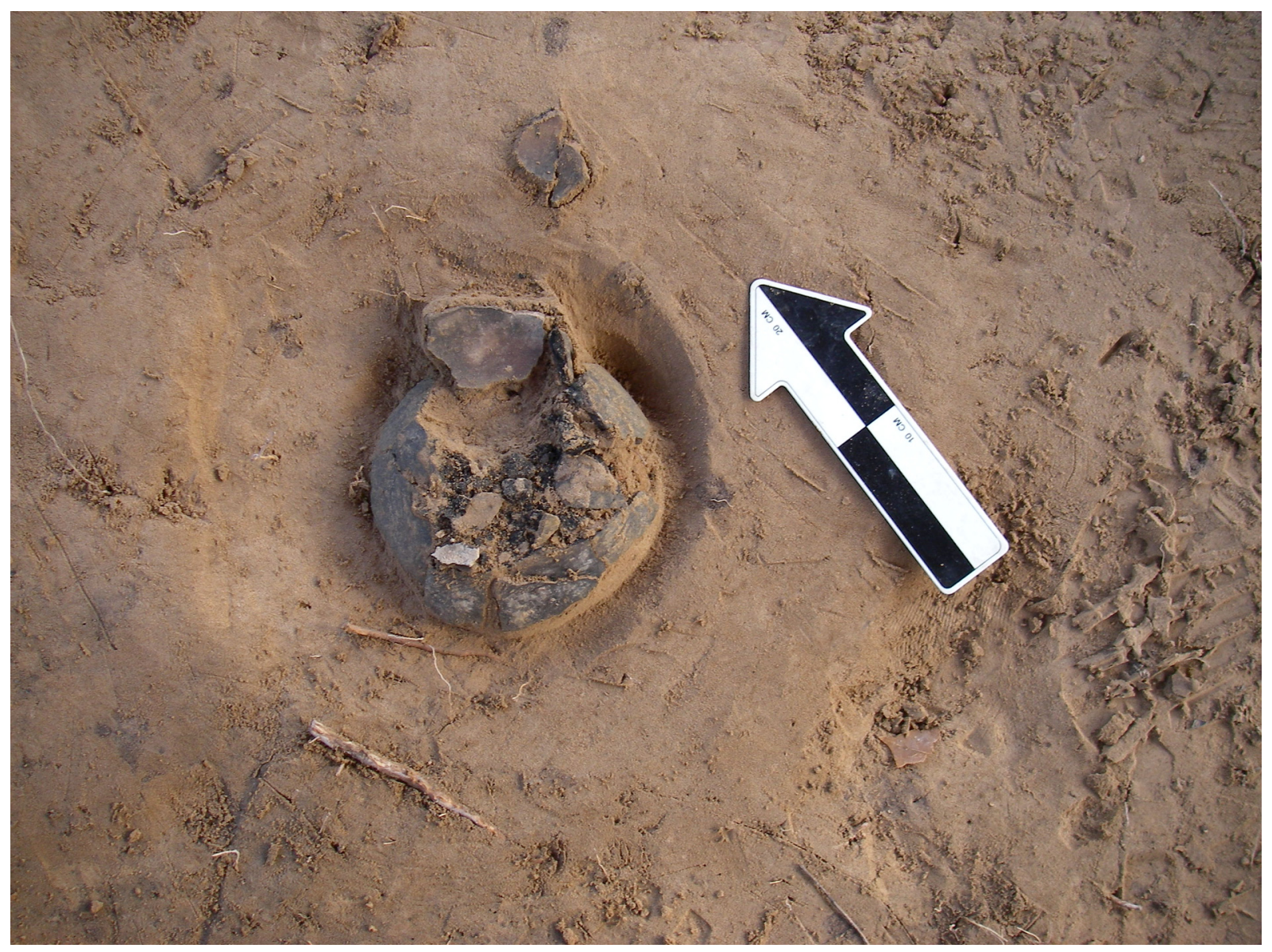

Figure 6.14. Photograph of artifact cluster Feature 10 at the James Richey site.

facts. One such area stood out from the rest of the site and represents the amalgamation of organic residue from the processing and use of plants and animals during the primary occupations at the site. It was in the central portion of the site and was noted during testing investigations in Trenches 7, 8, 15, and 16 over an area 8-9 $\mathrm{m}$ in diameter. It may have been more extensive than was observed, but the presence of large trees and extensive root activity inhibited its identification. The east wall of Trench 15 shows the enriched sediments as dark yellowish brown (10YR 3/3) sandy loam, extending from the ground surface to 35 or $40 \mathrm{~cm}$, with possible features or an undulating lower boundary extending to as much as $50 \mathrm{~cm}$. The dark yellowish brown (10YR 4/4) sandy loam E horizon was between 40 and $65 \mathrm{~cm}$, and the yellowish red (5YR 4/6) sandy clay Bt horizon was at $65+\mathrm{cm}$. Sample
Units 27 and 64-68 dug during data recovery also sampled these deposits.

\section{Distributions}

As noted, this site did not have the same kind of feature evidence preserved as the George Richey and William Ford sites, with the thick sands blanketing part of it translating into few features there penetrating the Bt horizon. Based on the features that were found and the other evidence, though, it is surmised that one Caddo house was present. It probably was in the central part of the excavation area, where organically enriched sediments extended over an area at least 8-9 $\mathrm{m}$ across (Figure 6.16). Within this area of darker sediments were three postholes (Features 89, 96, and 100) and three small pits (Features 14, 24, and 92), and immediately 


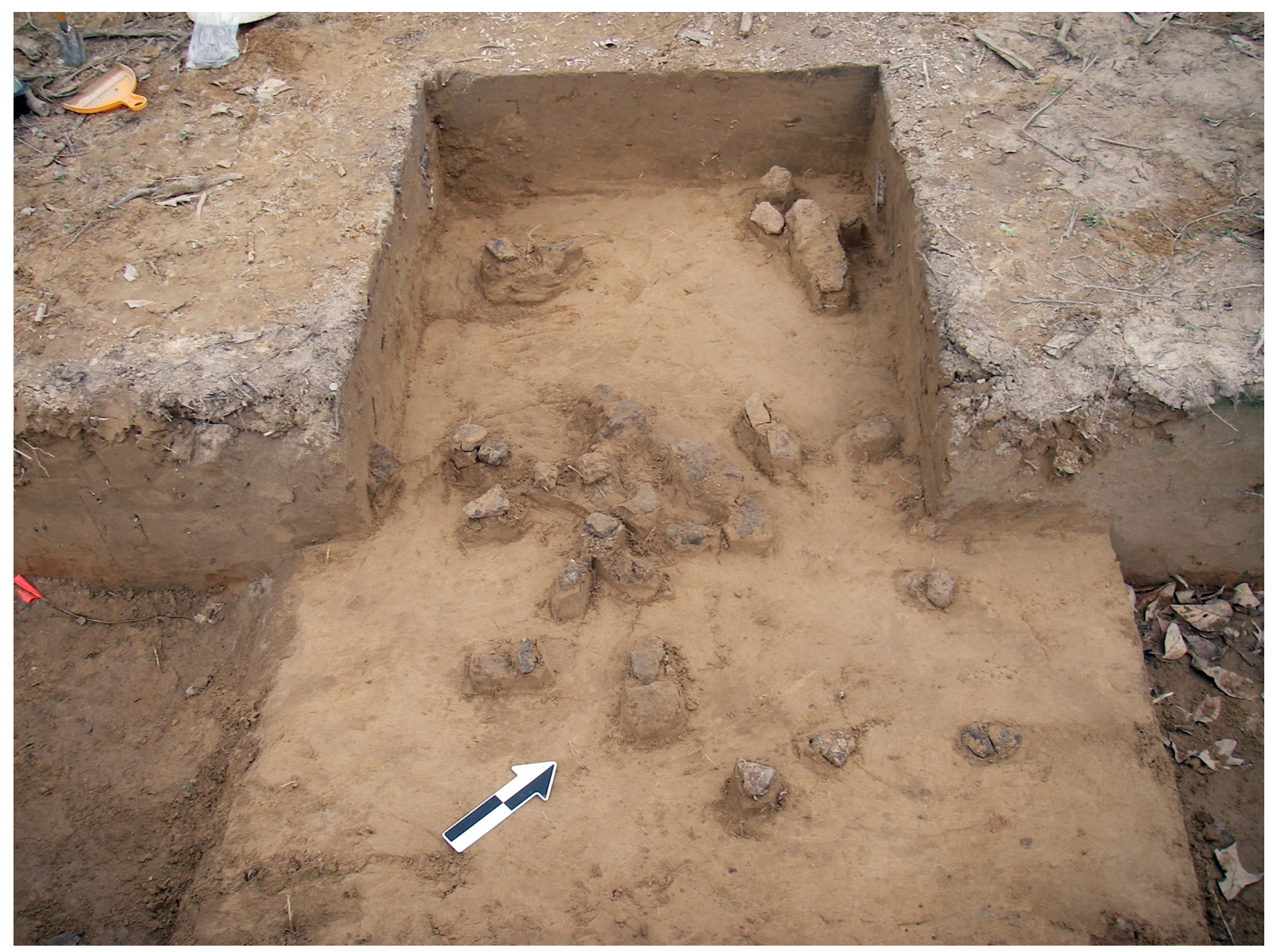

Figure 6.15. Photograph of burned rock cluster Feature 8 at the James Richey site.

northwest of it were four postholes (Features 19 and 21-23), a smudge pit (Feature 16), two other small pits (Features 15 and 20), and the probable child burial (Feature 18). The postholes do not form any convincing arcs indicative of house walls, but the burial does suggest a house could have stood here.

Other than the possible house area, there is not much that stands out in the feature distributions that looks interpretable, with one exception (see Figure 6.2). Notably, the other two burials, Features 2 and 25, are on the south and north sides of the excavation at the edges of the main occupation area. For the most part, the other features are scattered about singly or in groups of a few, mostly to the northwest, north, and northeast of the possible house area. These likely represent various outdoor activities, with only one area having a sufficient concentration of features to suggest it may have been a structured or consistently reused activity area. This area, lying 7-12 $\mathrm{m}$ north of the possible house (Figure 6.17), contains four large pits (Features $45,48,53$, and 56), three small pits (Features 51, 55, and 58), a smudge pit (Feature 47), and five postholes (Feature 7, 46, 63, 67, and 153). Several of the pits have evidence of thermal activity, suggesting this could be a cooking area. The postholes are not in a circular or rectangular pattern suggesting a granary or ramada, and thus they probably represent less-substantial structures such as drying racks.

\section{CERAMIC ARTIFACTS}

The ceramic artifacts recovered number 3,105 (24,963 g). Of these, 1,906 (22,343 g), or 61 percent by count and 90 percent by weight, 


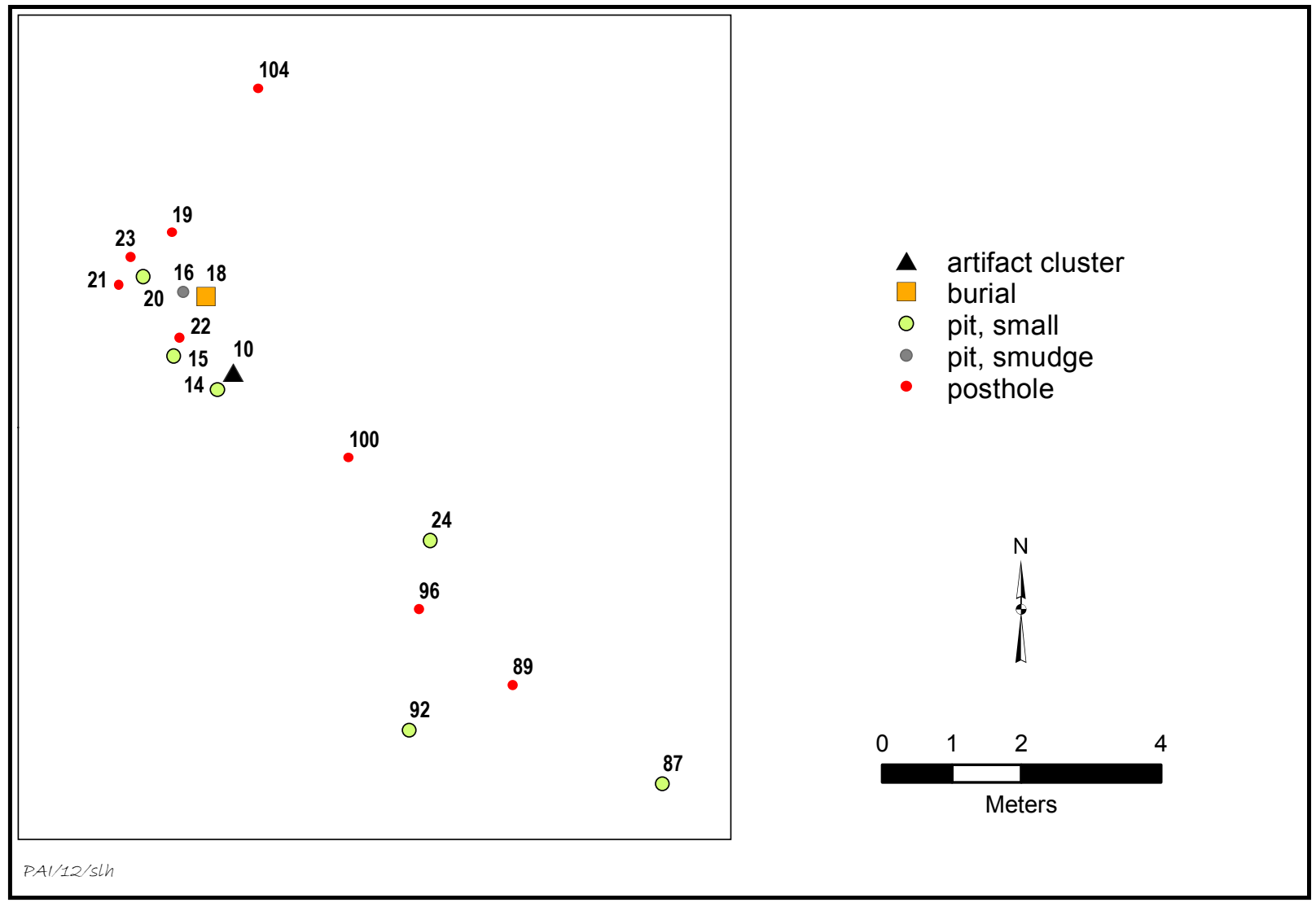

Figure 6.16. Plan showing features in the central possible house area the James Richey site.

are large enough for analysis. Three of these are smoking pipe fragments, and the rest are from ceramic vessels. The latter includes 3 complete or nearly complete small jars, 1 partial medium-sized jar, and 4 complete small bowls. The vessel sample is described below in relation to sherd characteristics, vessel form, and decoration. The pipe fragments are described separately.

\section{Vessel Sherd Characteristics}

The ceramic vessel sample consists of 8 complete or nearly complete vessels, 1,491 body sherds, 62 carinated body sherds, 141 rim sherds, $8 \mathrm{rim} /$ carination sherds, 108 neck sherds, 83 base sherds, and 2 sherds of indeterminate form. Ninety-eight percent have grog temper, with 33 percent also having bone (Table 6.3). Just 2 percent have bone temper alone. The voids that occur with grog or bone may represent leached bone. The only other tempering agent identified is sand, and it is minimal.

Sherd characteristics indicate that, while a range of vessel sizes and forms were used at the site, everted-rim containers with flat bases predominated. Everted rims constitute 70 percent $(n=104)$ of the sample. Straight rims make up 9 percent $(\mathrm{n}=13)$ while inverted rims are 5 percent $(n=8)$. Twenty-four rims are of indeterminate form (16 percent). Most rims have rolled $(n=67,45$ percent) or rounded $(n=32$, 21 percent) lips. Both of these lip forms are common on Ripley Engraved bowls and jars associated with Ripley Engraved vessels. Other lip forms are flat ( $\mathrm{n}=27,18$ percent), folded $(\mathrm{n}=6$, 4 percent), and tapered ( $\mathrm{n}=12,8$ percent); five have lips of indeterminate form (3 percent). Rim thickness ranges from 3.62 to $9.33 \mathrm{~mm}$ with a mean of $6.36 \mathrm{~mm}(\mathrm{sd}=1.15)$, indicating that small to large vessels are represented. Base thickness, which ranges from 4.83 to $17.94 \mathrm{~mm}$ 


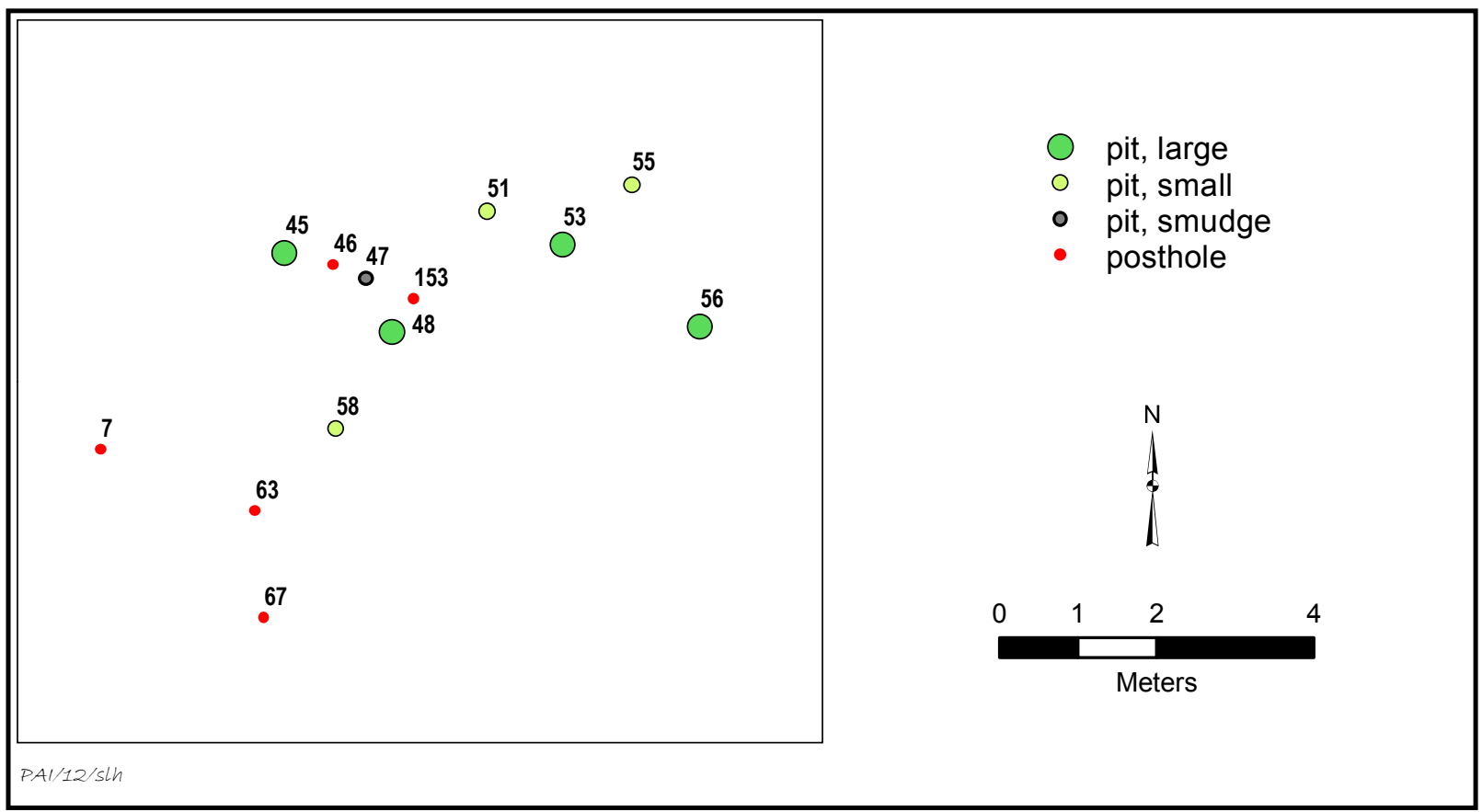

Figure 6.17. Plan showing features in the possible outdoor activity area at the James Richey site.

Table 6.3. Tempering agents in the ceramic sherd sample from the James Richey site

\begin{tabular}{l|c|c}
\hline \multicolumn{1}{c|}{ Temper } & No. & $\%$ \\
\hline Grog & 1,241 & 65.2 \\
\hline Grog-bone & 548 & 28.8 \\
\hline Grog-bone-voids & 73 & 3.8 \\
\hline Bone & 30 & 1.6 \\
\hline Bone-voids & 6 & 0.3 \\
\hline Voids & 2 & 0.1 \\
\hline Sand & 2 & 0.1 \\
\hline Indeterminate & 1 & 0.1 \\
\hline Total & 1,903 & 100.0 \\
\hline
\end{tabular}

with a mean of $10.37 \mathrm{~mm}(\mathrm{sd}=2.33)$, also indicates a range of vessels sizes. Most of the base sherds are flat ( $\mathrm{n}=62,75$ percent) rather than rounded ( $n=5,6$ percent) or are of indeterminate form ( $\mathrm{n}=16,19$ percent).

Floating and smoothing are the main finishes recorded for both interior and exterior surfaces on the sherds (Table 6.4). Floated surfaces, done while the clay is still plastic and with a fine-textured finish, are most common on interior surfaces. Burnishing was noted on only 11 percent of the exterior surfaces and 16 percent of the interior surfaces. Scraping was noted almost exclusively on interior surfaces. Scraping, which thins and strengthens the vessel wall during manufacture, also provides a crucial clue for identifying restricted-orifice vessels such as ollas and bottles. The limited number of scraped sherds in the sample suggests that bottles and ollas are not as frequent as bowls and jars. Roughened surfaces are also few, occurring mainly on the exterior of utility vessels such as jars, possibly to provide a nonslip surface. Finishing of the vessel surface by use of a slip or adding pigment to engraving is also limited. Slipping was noted on 3 percent of the exteriors of sherds and 2 percent of the interiors. Slip color is commonly red, but reddish brown and a single instance of a black slip are present. One red-slipped sherd also has white pigment in the engraved lines that decorated its surface. Red pigment was found in the engraved lines on only one sherd. Two sherds have red pigment adher- 
Table 6.4. Surface treatment and decorative attributes for the ceramic vessel sample from the James Richey site

\begin{tabular}{|c|c|c|}
\hline & No. & $\%$ \\
\hline \multicolumn{3}{|l|}{ Exterior Surface Finish } \\
\hline Smoothed & 723 & 38 \\
\hline Floated & 856 & 45 \\
\hline Burnished & 211 & 11 \\
\hline Slipped & 56 & 3 \\
\hline Scraped & 1 & 0 \\
\hline Roughened & 6 & 0 \\
\hline Indeterminate & 50 & 3 \\
\hline Totals & 1,903 & 100 \\
\hline \multicolumn{3}{|l|}{ Interior Surface Finish } \\
\hline Smoothed & 433 & 23 \\
\hline Floated & 1,067 & 56 \\
\hline Burnished & 306 & 16 \\
\hline Slipped & 47 & 2 \\
\hline Scraped & 30 & 2 \\
\hline Roughened & 1 & 0 \\
\hline Indeterminate & 19 & 1 \\
\hline Totals & 1,903 & 100 \\
\hline \multicolumn{3}{|l|}{ Decorative Mode } \\
\hline None & 1,110 & 58 \\
\hline Engraved & 132 & 7 \\
\hline Incised & 118 & 6 \\
\hline Fingernail punctated & 36 & 2 \\
\hline Stick puntated & 49 & 3 \\
\hline Brushed & 340 & 18 \\
\hline Brushed-punctated & 21 & 1 \\
\hline Brushed-appliquéd & 20 & 1 \\
\hline Appliquéd, linear & 4 & 0 \\
\hline Appliquéd, nodes & 1 & 0 \\
\hline Appliquéd-punctated & 3 & 0 \\
\hline Punctated-incised & 36 & 2 \\
\hline Appliquéd-incised & 1 & 0 \\
\hline Pinched & 21 & 1 \\
\hline Coil crimped & 4 & 0 \\
\hline Rim notched & 1 & 0 \\
\hline Indeterminate & 6 & 0 \\
\hline Totals & 1,903 & 100 \\
\hline \multicolumn{3}{|l|}{ Decorative Element } \\
\hline $\begin{array}{l}\text { Punctated or pinched } \\
\text { field/zone }\end{array}$ & 38 & 7 \\
\hline Horizontal lines & 38 & 7 \\
\hline Hatching/crosshatching & 46 & 8 \\
\hline Curvilinear lines & 20 & 4 \\
\hline Rectilinear lines & 50 & 9 \\
\hline Diagonal lines & 73 & 13 \\
\hline Vertical lines & 26 & 5 \\
\hline
\end{tabular}

\begin{tabular}{|c|c|c|}
\hline & No. & $\%$ \\
\hline Lines of punctations & 87 & 16 \\
\hline Lines of pinching & 15 & 3 \\
\hline Appliquéd fillet & 28 & 5 \\
\hline $\operatorname{Node}(\mathbf{s})$ & 1 & 0 \\
\hline Neck banding & 4 & 1 \\
\hline Vertical brushing & 48 & 9 \\
\hline Horizontal brushing & 24 & 4 \\
\hline Diagonal brushing & 12 & 2 \\
\hline Cross brushed & 18 & 3 \\
\hline Bars & 3 & 1 \\
\hline Chevron & 2 & 0 \\
\hline Circle & 6 & 1 \\
\hline Curl & 1 & 0 \\
\hline Half circle & 5 & 1 \\
\hline Interlocking ends & 1 & 0 \\
\hline Open circle & 1 & 0 \\
\hline Pendant triangles & 8 & 1 \\
\hline Ticking & 1 & 0 \\
\hline Triangle & 1 & 0 \\
\hline Totals & 557 & 1 \\
\hline \multicolumn{3}{|l|}{ Main Motif } \\
\hline Diagonal lines at rim & 1 & 1 \\
\hline Zoned punctations at rim & 1 & 1 \\
\hline Alternating parallel lines & 13 & 13 \\
\hline Body panels & 13 & 13 \\
\hline Scroll, slanted & 21 & 21 \\
\hline Scroll & 2 & 2 \\
\hline Swirl & 1 & 1 \\
\hline $\begin{array}{l}\text { Band of alternating } \\
\text { elements }\end{array}$ & 1 & 1 \\
\hline $\begin{array}{l}\text { Band of repeating } \\
\text { elements }\end{array}$ & 2 & 2 \\
\hline $\begin{array}{l}\text { Horizontal rows of } \\
\text { punctations at rim }\end{array}$ & 38 & 38 \\
\hline Rim panel & 1 & 1 \\
\hline Medallions & 1 & 1 \\
\hline Effigy & 1 & 1 \\
\hline Unique & 2 & 2 \\
\hline Totals & 98 & 100 \\
\hline
\end{tabular}


ing to their inner surfaces, suggesting they may have held the pigment. Weathering is not much of a factor in the preservation of surface finish, as only 3 percent of the exterior surfaces and 1 percent of the interior surfaces are classified as indeterminate in terms of finish.

Decorated sherds make up 41 percent of the sample (see Table 6.4). Most common are sherds with brushing or some combination of brushing with punctations or appliqué ( $\mathrm{n}=381$, 48 percent of those with decoration). Engraving $(\mathrm{n}=132,17$ percent $)$ and incising $(\mathrm{n}=118$, 15 percent) also are common decorative modes, as is punctating or a combination of punctating and incising ( $\mathrm{n}=121,15$ percent). Sherds with appliqué but no brushing are minimally represented ( $n=9,1$ percent), along with sherds with pinching, coil crimping, and rim notching ( $\mathrm{n}=26,3$ percent).

\section{Vessel Form}

Vessel forms identified within the sherds are based on rim and body form and to a lesser extent surface finish and decorative mode. For instance, Caddo bowls and bottles are unlikely to be brushed, display linear appliqué on the body, or have zones and fields of pinching or punctations on the rim. Sherds with such decorations or obvious necks or thick everted rims were coded as jars. Carinated rim or body sherds were coded as bowls, and sherds with scraped interiors were considered bottles or ollas. The identification of an olla vs. a bottle was based on the curvature of the vessel body and sometimes the size and form of the rim or neck. The 11 percent of the sample that can be identified confidently with particular vessel forms consists of 12 bottle sherds, 96 bowl sherds, 99 jar sherds, and 11 olla sherds. It is presumed that these relative frequencies provide a general indication of the proportions of the kinds of vessels used at the site.

The vessels represented range from small to large. This is based on rim thicknesses and the complete and nearly complete vessels described below, most of which are small jars and bowls. The three small jars range in rim diameter from 8.6 to $13.3 \mathrm{~cm}$, while the four bowls range from 9.1 to $19.3 \mathrm{~cm}$, with the upper end of the range approaching what could be called a medium-sized bowl. Few rims within the sherd sample are large enough to provide diameter data, but jar rims that could be measured range from 12 to $25 \mathrm{~cm}$ in diameter while bowl rims range from 15 to $25 \mathrm{~cm}$. No data on bottle rim diameter was obtained, but the thicknesses of the rim/neck and body sherds suggest that medium-sized and large bottles were present at the site. Only one olla neck could be measured at $11 \mathrm{~cm}$ in diameter.

\section{Decorative Elements, Motifs, and Ceramic Type}

Twenty-six different elements were recognized on 71 percent $(n=557)$ of the decorated sherds (see Table 6.4). These elements and their positions on the sherds form the basis for identifying 13 particular motifs on 96 sherds, not including unique motifs on 2 (see Table 6.4). Some of these motifs are simplified from ones defined from more-complete vessels in this study, because the small sherds provide only glimpses of how motifs were structured across entire vessels. Still, these elements and motifs suggest that most sherds in the sample represent types associated with Middle to Late Caddo period occupations.

The most common decorative element is lines of punctations at 16 percent of those with identifiable elements. Most sherds that display this element could not be associated with a particular motif or type, but at least 38 are jar rim sherds that have one or more horizontal lines of stick or fingernail punctations encircling the rim between the vessel neck and lip (Figure 6.18). Some sherds with this motif are also decorated with incised lines or crosshatching (Figure $6.19 \mathrm{a}-\mathrm{c}$ ), and these, along with those just with punctations, appear to represent untyped utility vessels common to the site. Nine rims with horizontal lines of punctations are also brushed, and these may be typed as Bullard Brushed or Pease Brushed-Incised (see below). Clearly, there was great variety in how these jars were decorated.

Another common element is incised diagonal lines at 13 percent. Fifteen sherds with this element are further associated with three motifs consisting of diagonal lines at the rim, alternating parallel lines, and zoned punctations at the rim (Figure 6.19d-f). These motifs may be associated with the type Maydelle Incised. These are, however, simplifications of another motif-band of alternating elements - that also distinguishes the type. This band motif, reminiscent of a basket weave, is on the rim of a small complete Maydelle Incised jar with undecorated body recovered from Feature 2 (see description 

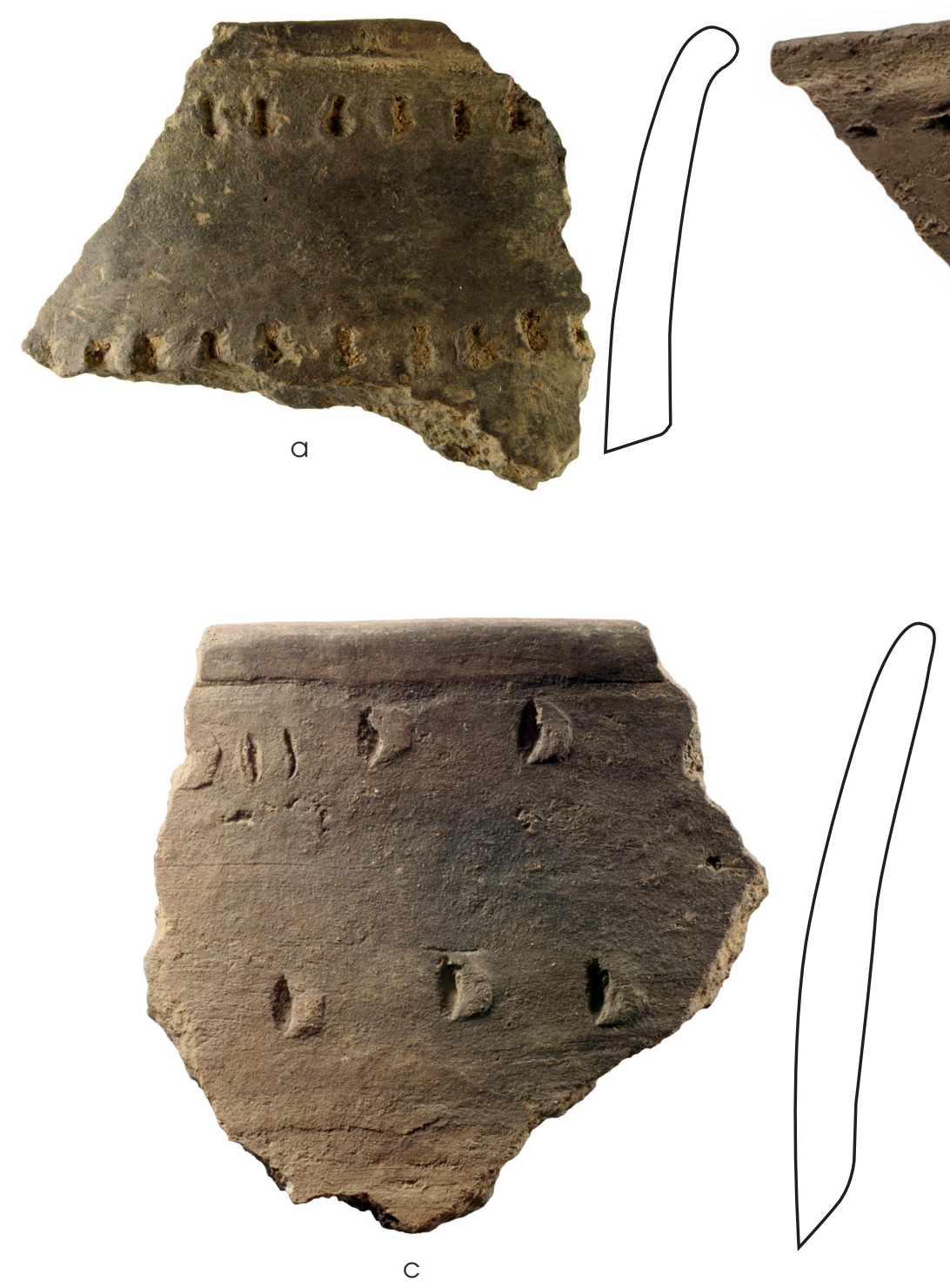
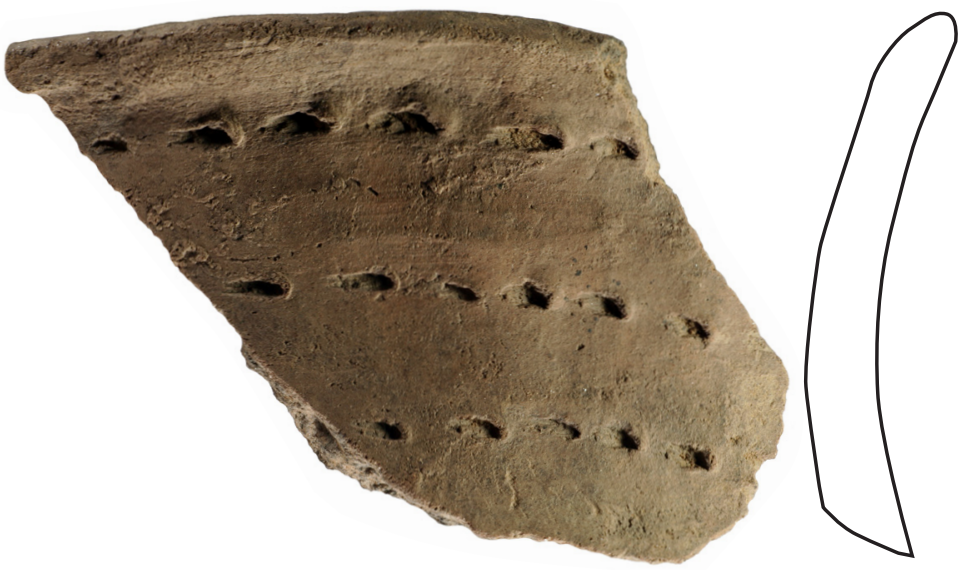

$\mathrm{b}$

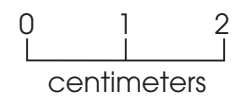

Figure 6.18. Jar rims with horizontal rows of stick and fingernail punctations from the James Richey site.

below). Some Maydelle Incised jars have brushed bodies or zones of punctations in the rim band (Suhm and Jelks 1962:103), and a single sherd shows both of these treatments (Figure 6.19f).

Brushed elements-vertical brushing, horizontal brushing, diagonal brushing, and cross brushing-together make up 18 percent of the recognized decorative elements (see Table 6.4). As noted above, brushing on some punctated rims may be associated with Bullard Brushed,
Pease Brushed-Incised, or an untyped utility ware (Figure 6.20a). One sherd with a vertically brushed body and horizontally brushed rim and no other decorative elements may be from a Bullard Brushed jar (Figure 6.20b). Pease Brushed-Incised jars can have both brushed rims and bodies and rims decorated with rows of punctations, but what distinguishes this type are motifs involving body panels and rim panels. The former consists of sections of brushed, incised, 

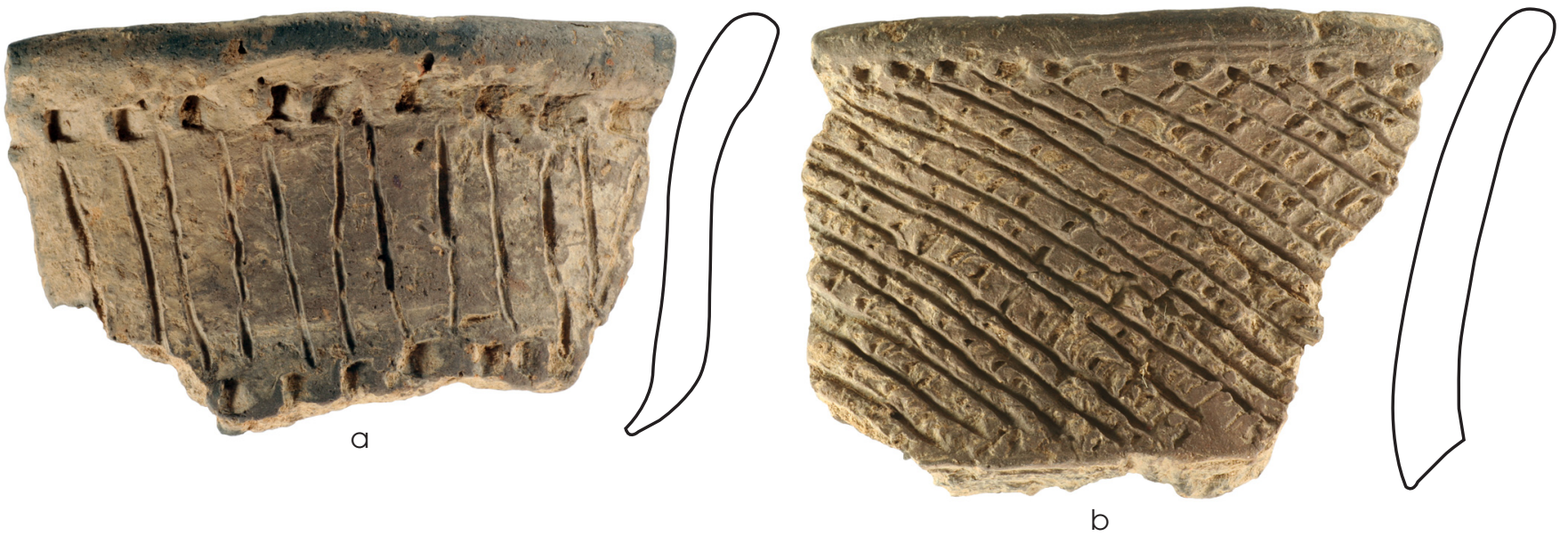

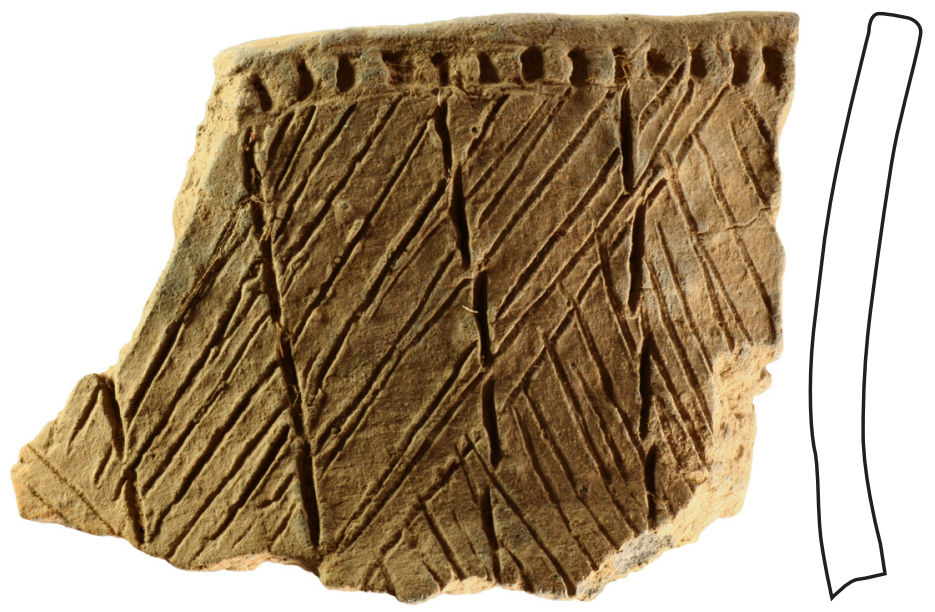

C

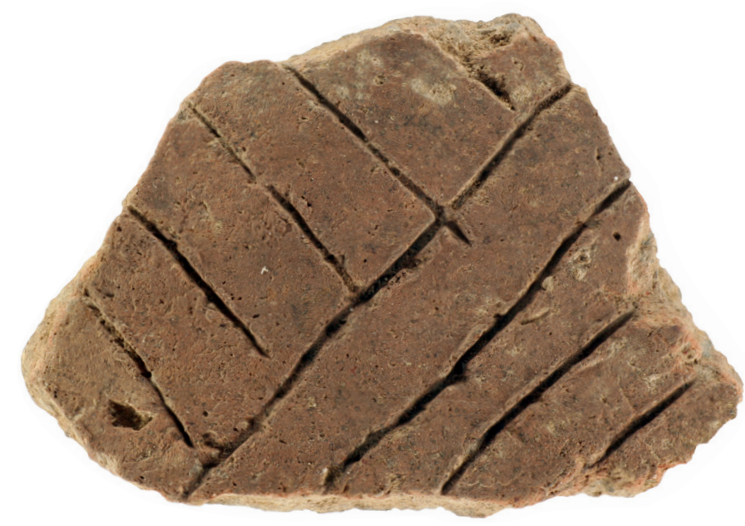

e

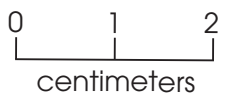

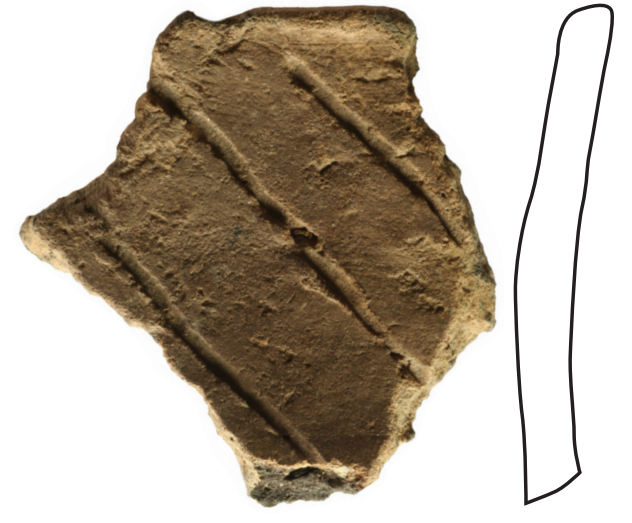

d

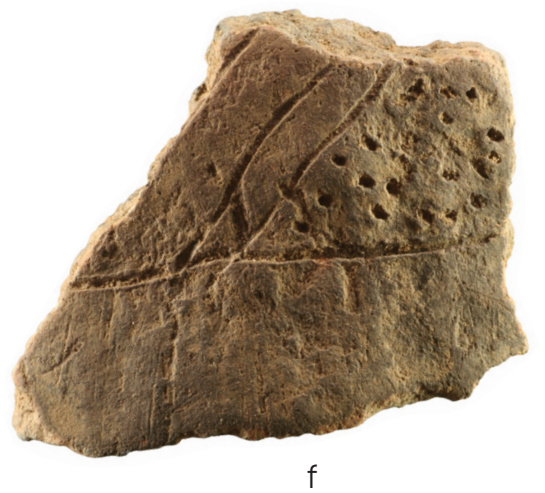

Figure 6.19. Jar rims and necks with punctations and incising from the James Richey site. (a) Rim sherd with horizontal rows of punctations and vertical incised lines; (b) rim sherd with horizontal row of punctations and incised crosshatching; (c) rim sherd with horizontal and vertical rows of punctations and sets of alternating parallel incised lines; (d) rim sherd with parallel diagonal incised lines; (e) neck sherd with alternating parallel incised lines; (f) neck sherd with zone of punctations and diagonal incised lines on the rim and vertical brushing on the body. 
or plain vessel body set off by appliqué fillets (Figure 6.20c-d). Incised vertical lines instead of fillets can also be used to form the panels. The only instance of this in this assemblage is the mostly-complete jar from Feature 25, which has rim panels created by incising (see description below). That jar's overall form, extended neck, and punctated rim support its identification as Pease Brushed-Incised.

Some sherds with linear appliqué can be associated with Pease Brushed-Incised body panels, but most cannot be related to a particular motif or type. However, at least one of these appliquéd sherds shows a hint of a more-elaborate body design like that on a Harleton Appliqué jar from the Thomas B. Caldwell cemetery (Figure 6.21a; see Chapter 7). In addition, a small complete jar that does not have body fillets but that still can be typed as Harleton based on its appliqué handles and rim peaks was recovered from Feature 18 (see description below). Another element from which a particular motif could not be defined is pinched lines, though these sherds may well represent the type Killough Pinched (Figure 6.21b-d). Neck banding was also considered a decorative element based on the recovery of four small coil-crimped sherds; these could be from La Rue Neck Banded jars.

The elements of horizontal lines, curvilinear lines, rectilinear lines, vertical lines, and diagonal lines make up 41 percent of the sample, and on the examples that are engraved, the lines typically compose the bodies of scrolls and other motifs, such as swirls, bands of repeating elements, concentric bands, and medallions. Circles, half circles, chevrons, pendant triangles, bars, curls, triangles, open circles, interlocking ends, and hatching/crosshatching occur as primary or secondary elements in these motifs. Together, these elements represent the engraved fine-ware bowls, including at least one compound bowl, and bottles used at the site.

Scroll motifs with these elements are common to the type Ripley Engraved (Suhm and Jelks 1962:127). Several carinated bowl sherds display scroll arms that abut to create a zigzag effect, such that there is no primary element to the scroll (Figure 6.22a-d). This is similar to the scroll on the small complete carinated bowl from Feature 18, where a simple bar is the primary element between the scroll arms (see description below). These motifs are a variation of Ripley Engraved motifs that is common in the graves at the Tuck Carpenter site (Turner 1992:17, 31, 33, $37,39,41,43,51,55,59,71,75,85,91)$ and also at the Thomas B. Caldwell and A. P. Williams cemeteries (see Chapter 7). Ripley Engraved scrolls with primary elements of circles, open circles, and half circles are also common at the above-mentioned sites. Two examples of scrolls or probable scrolls with open circle and half circle primary elements from James Richey show further enhancement of the circular element with pendant triangles creating a rayed or scalloped (feathered) effect (Figure 6.22e-f). One of these is from a compound bowl that is red slipped both inside and out. Similar use of pendant triangles occurs within scroll motifs at the A. P. Williams cemetery (see Chapter 7).

Less common here but well represented at the Tuck Carpenter and Thomas B. Caldwell cemeteries is the curl element used to form the end of a scroll on some Ripley Engraved bowls (Figure 6.23a). Two bowl sherds that stand out as different have a medallion motif with zoned punctations and chevrons and a unique motif with engraved vertical lines, half circles, and a curious pattern of hatching (Figure 6.23b-c). It is unclear what ceramic types these motifs may be associated with. Also exceptional is a single bowl rim sherd that has patterned engraved lines extending from the lip on the interior of the vessel (Figure 6.23d). This is similar to the hatched and opposed triangles on a small simple bowl from Feature 25 (see description below). The decorations on both are reminiscent of decoration on Sanders Engraved vessels (Suhm and Jelks 1962:137).

Few bottle and olla sherds were identified in the sample, and fewer still have recognizable elements or motifs. One bottle body sherd is large enough to show what appears to be part of the interlocking end element of a Wilder Engraved swirl motif (Figure 6.24a). Another bottle body sherd displays linear and hatched elements forming some sort of unique motif (Figure 6.24b); it is reminiscent of some Caddo bottles with "crazy" engraved patterns. The size and thickness of these sherds suggest that these bottles were fairly large. An undecorated bottle rim/neck suggests a vessel form with a long flaring neck and bell-shaped body common to both Wilder and Ripley Engraved (Figure 6.24c). The olla sherds recovered have little decoration and therefore cannot be associated with any particular type. One possible olla rim has a single horizontal engraved line (Figure 6.24d). 


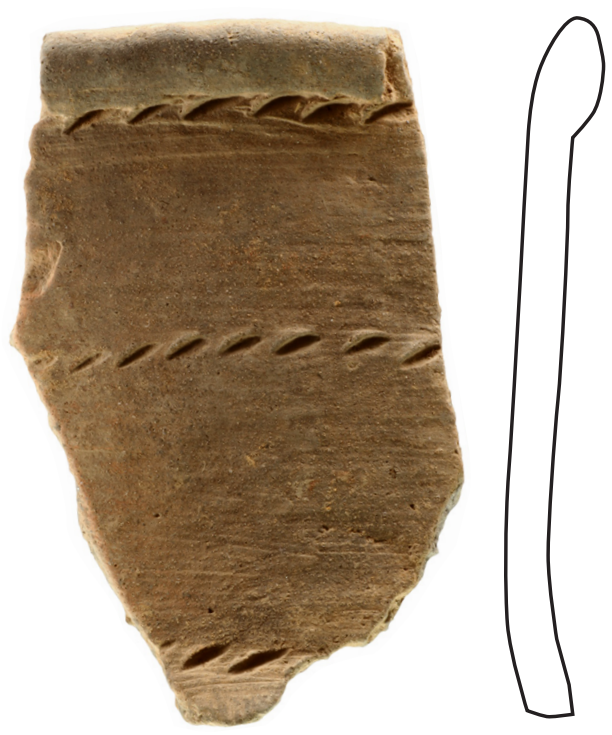

a
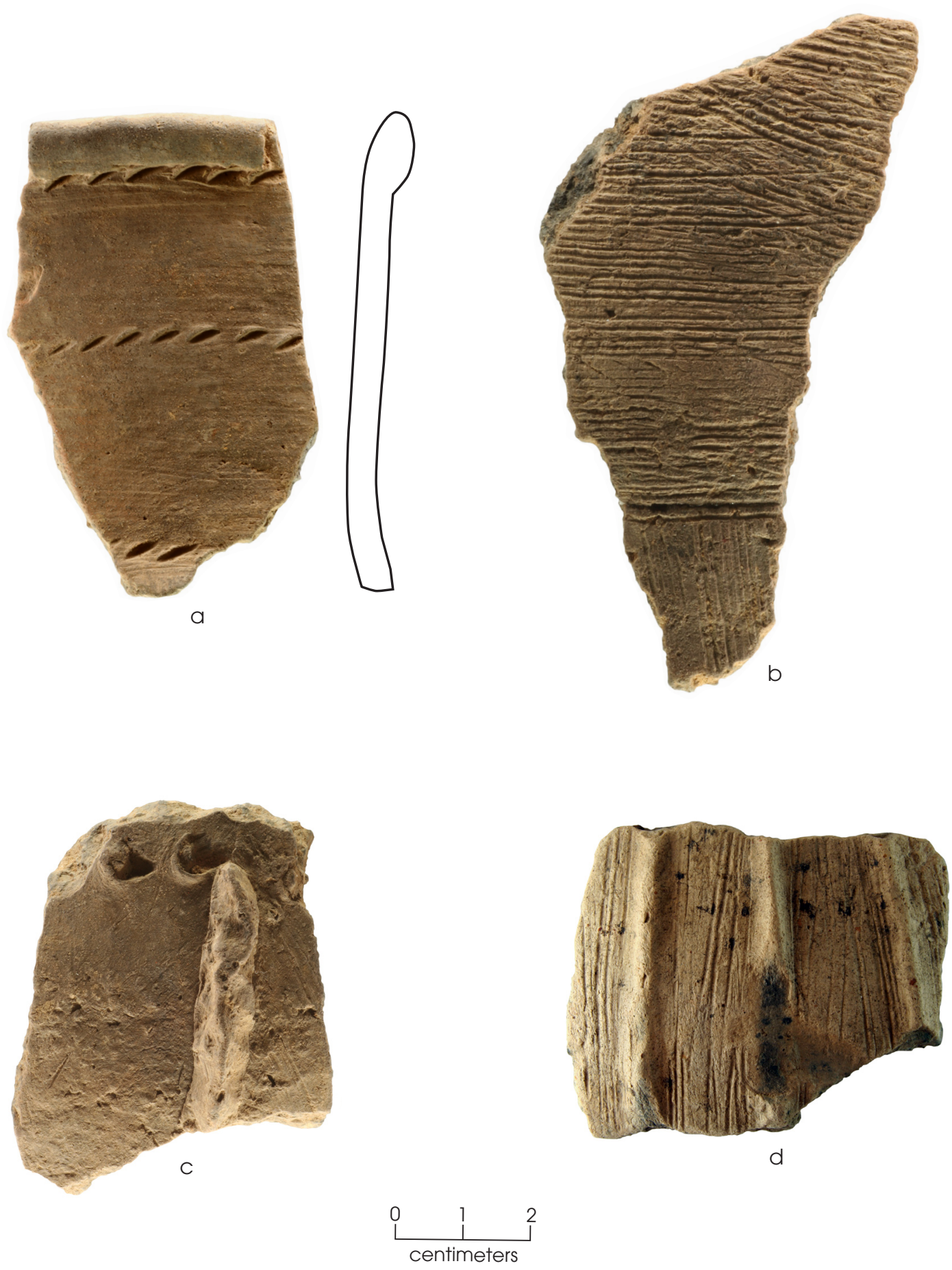

Figure 6.20. Jar sherds with brushing, punctations, and appliqué from the James Richey site. (a) Rim sherd with horizontal lines of punctations and brushing; (b) neck sherd with horizontal brushed rim and vertical brushed body; (c) neck sherd with horizontal line of punctations at the rim-body juncture and brushed body panels created by vertical appliqué fillets; (d) brushed body sherd with panels created by vertical appliqué fillets. 


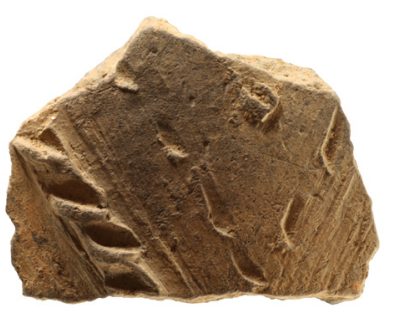

a
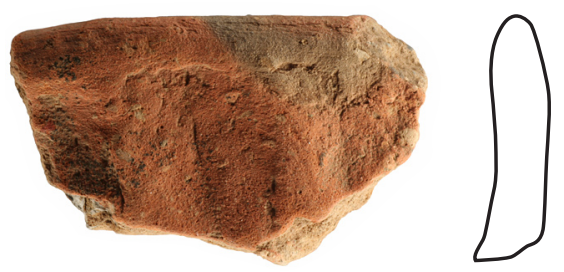
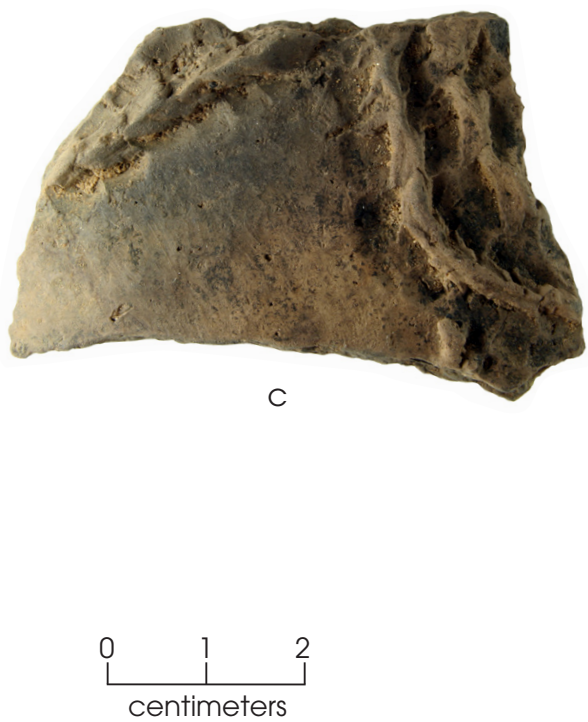

Figure 6.21. Probable jar sherds with appliqué and pinching from the James Richey site. (a) Body sherd with diagonal appliqué fillet, punctations, and brushing; (b) body sherd with horizontal lines of pinching; (c) body sherd with curvilinear lines of pinching; (d) rim sherd with vertical ridges formed by pinching.

\section{Vessels and Vessel Sections}

Eight vessels were recovered from features. Seven are complete or nearly so, and one is represented by what appears to be part of the base and lower wall of a medium-sized jar. Other than this jar and the medium-sized simple bowl from Feature 25, the vessels are small, with rim diameters ranging from 8.6 to $13.3 \mathrm{~cm}$.

\section{Feature 2, Vessel 1}

This is a small Maydelle Incised jar, about 70 percent complete, weighing $484 \mathrm{~g}$ (Figure 6.25a). It has a globular body, everted rim with rolled lip, and flat base. Decoration is restricted to the rim and consists of sets of opposing diagonal incised lines forming a band of alternating elements motif. The exterior and interior surfaces are burnished and gray and yellowish brown in color; the core is gray. Burned encrustations are present on the exterior surface near the base. The vessel has grog temper. The jar is $14.3 \mathrm{~cm}$ tall with a $5.3-\mathrm{cm}$-tall tall rim and an orifice diameter of $13.3 \mathrm{~cm}$. The maximum body diam- eter is $13.3 \mathrm{~cm}$, and the diameter at the neck is $10.4 \mathrm{~cm}$. The base diameter is $6.3 \mathrm{~cm}$. Rim thickness is $0.57 \mathrm{~cm}$, body thickness is $1.15 \mathrm{~cm}$, and base thickness is $0.70 \mathrm{~cm}$. Its volume could not be determined.

\section{Feature 2, Vessel 2}

This is a small simple effigy bowl, 99 percent complete, weighing $232.8 \mathrm{~g}$ (Figure 6.25b). It has an everted rim with rolled lip and a flat base. The effigy head may be of a bird or snake. Other than its sinuous form, there are no distinguishing features. The tip of the "beak" is slightly broken. The tail on the opposite side is rounded and flat. The length of the head is $3.2 \mathrm{~cm}$, and the tail is $1.8 \mathrm{~cm}$. Two engraved horizontal lines encircle the rim, curving below the head and tail and continuing unbroken around the vessel. The exterior and interior surfaces are floated and yellow and red in color; the core is gray. There are no burned encrustations. The vessel is tempered with grog. The bowl is $5.5 \mathrm{~cm}$ tall with an orifice diameter of $11.5 \mathrm{~cm}$. The base diameter is $6.0 \mathrm{~cm}$. Rim thickness is $0.50 \mathrm{~cm}$. It has a volume of $250 \mathrm{ml}$. 


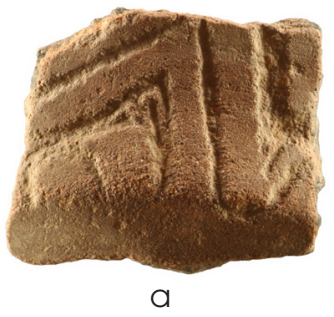

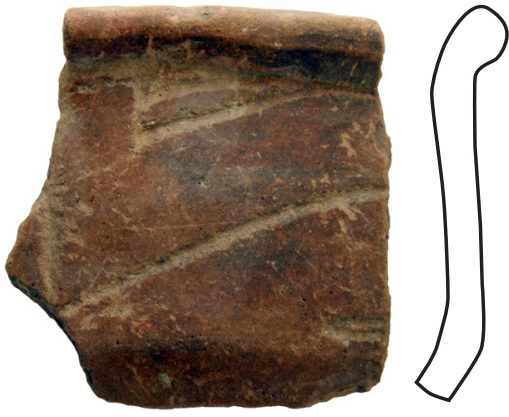

$\mathrm{b}$

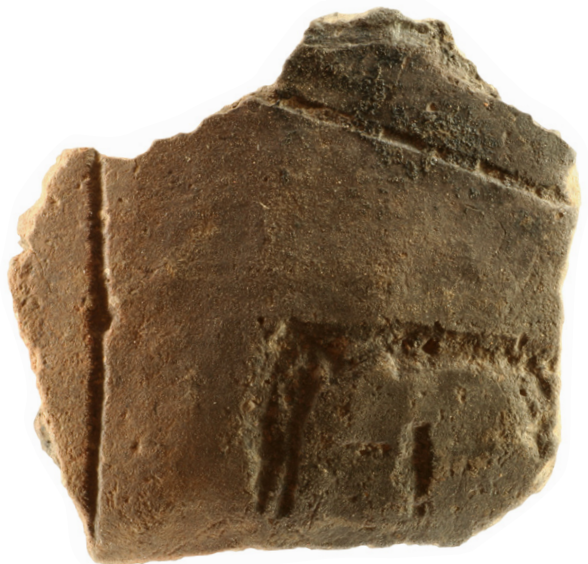

C
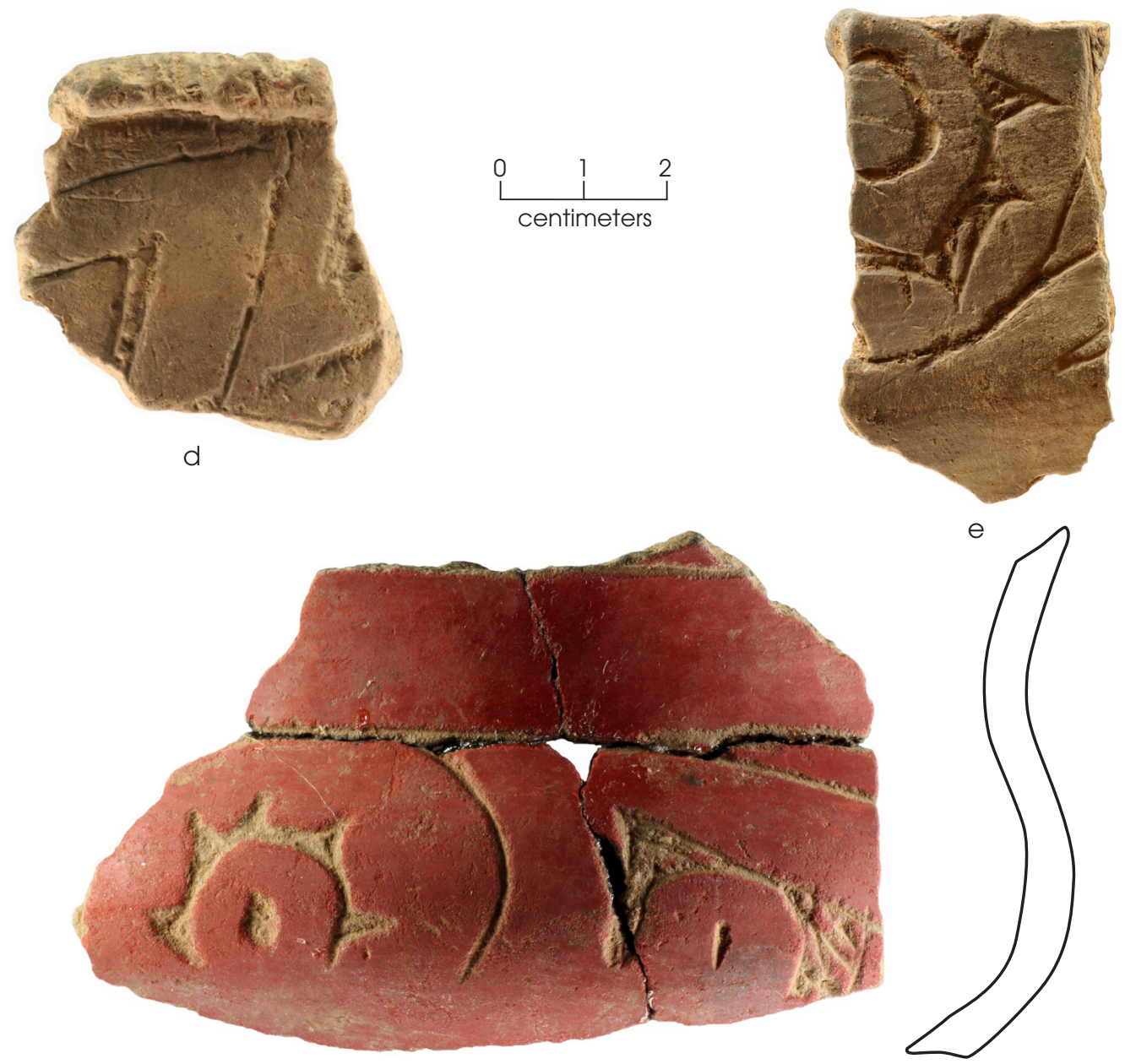

$f$

Figure 6.22. Ripley Engraved carinated and compound bowl sherds from the James Richey site. (a-d) Scroll motif with no primary element between scroll arms; (e) scroll open circle primary element surrounded by pendant triangle secondary elements; (f) compound bowl sherd with scroll half circle primary element surrounded by pendant triangle secondary elements along with secondary circular elements in the arms of the scroll and horizontal lines around the rim. 


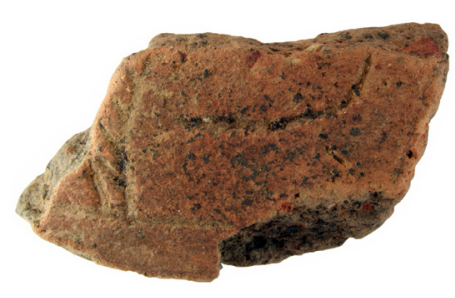

a

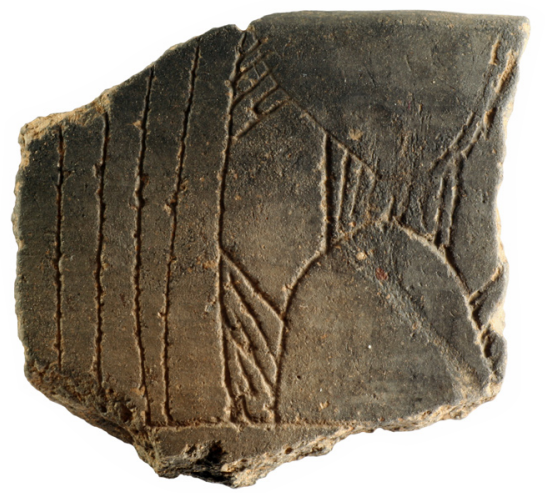

C

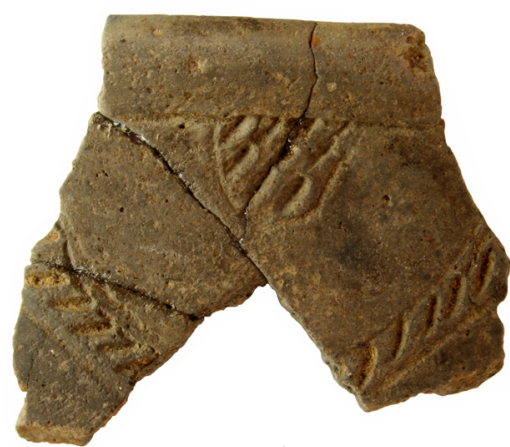

b
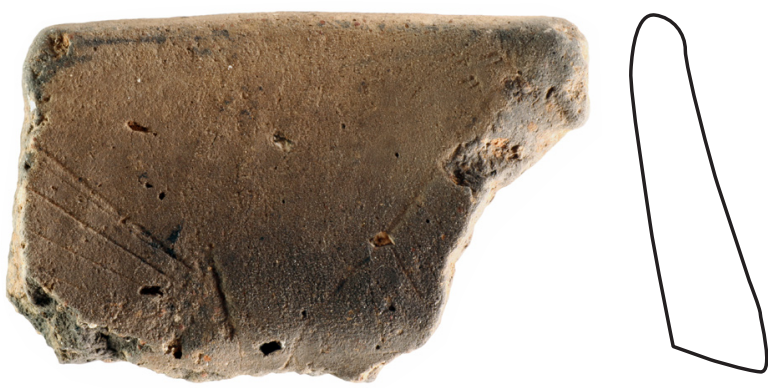

d

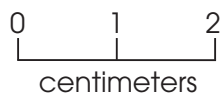

Figure 6.23. Engraved bowl sherds with uncommon motifs and elements from the James Richey site. (a) Ripley Engraved motif with curl scroll element; (b) rim with a medallion motif involving zoned punctations and chevrons; (c) rim with unique motif involving engraved vertical lines, half circles, and hatching; (d) possible Sanders Engraved rim with engraved linear decoration on the interior.

\section{Feature 10}

The single vessel from Feature 10 consists of 16 refitted sherds that make up the basal section of what appears to be a medium-sized jar with a flat base. The vessel is about 20 percent complete and weighs $229.7 \mathrm{~g}$. The vessel section is not decorated, and no type association can be made. The exterior and interior surface are both burnished and dark brown in color; the core is black. There are no burned encrustations. The vessel is tempered with grog. Body thickness is $0.65 \mathrm{~cm}$. The diameter of the base, which is $1.06 \mathrm{~cm}$ thick, $7.3 \mathrm{~cm}$.

\section{Feature 18, Vessel 1}

This is a small carinated bowl, ca. 98 percent complete, weighing $170.3 \mathrm{~g}$ (Figure 6.26a). 


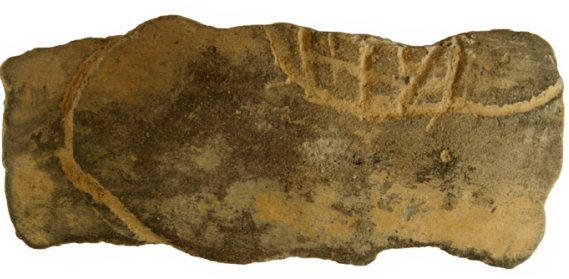

a

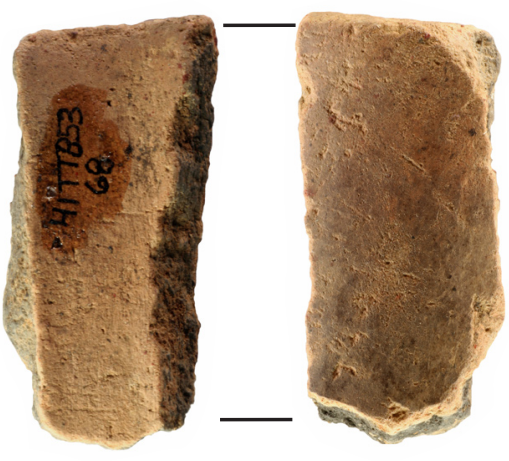

C
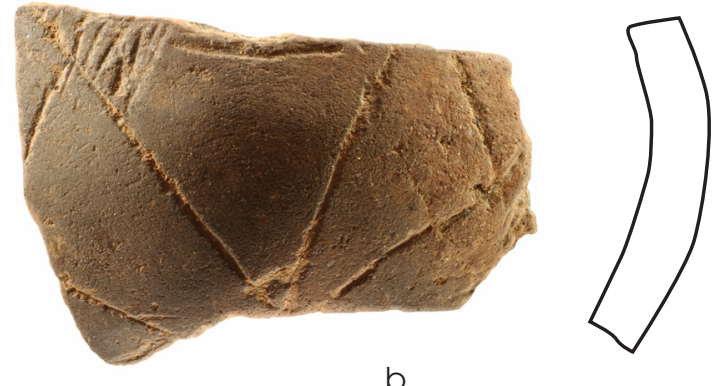

b
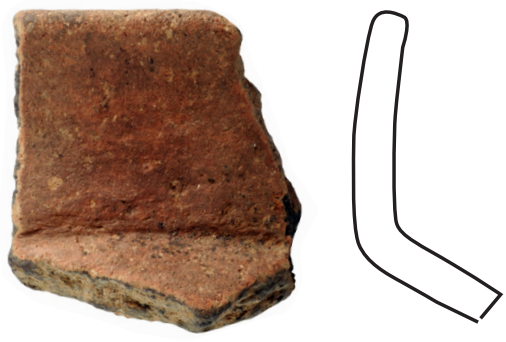

d

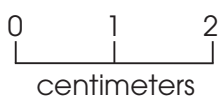

Figure 6.24. Bottle and olla sherds from the James Richey site. (a) Bottle body sherd with interlocking end element of swirl motif; (b) bottle body sherd with linear and hatched elements of unique motif; (c) plain rim of bottle with long flaring neck; (d) olla rim sherd with horizontal engraved line at neck-body juncture.

It has a straight rim with flat lip and a flat base. It has an engraved slanted scroll motif that repeats six times around the rim and is typed as Ripley Engraved. The motif has bars as primary elements between the scroll arms and hatching as secondary elements within the scroll arms. This variation produces an effect similar to the zigzag created by a slanted scroll where the scroll arms abut with no primary element in between. These scroll variations are common to Ripley Engraved and are especially well represented at the Tuck Carpenter site (Turner 1992). The exterior surface is floated, and the interior surface is smoothed; both are dark brown, and the core is black. Neither surface has burned encrustations. The vessel is tempered with grog and bone. The bowl is $5.7 \mathrm{~cm}$ tall with a $3.0-\mathrm{cm}-$ high rim and an orifice diameter of $9.1 \mathrm{~cm}$. The base diameter is $5.9 \mathrm{~cm}$. Rim thickness is $0.50 \mathrm{~cm}$. It has a volume of $175 \mathrm{ml}$.

\section{Feature 18, Vessel 2}

This is a small complete carinated bowl weighing $199.1 \mathrm{~g}$ (Figure 6.26b). It is undecorated and has no type association. It has a straight rim with flat lip and a flat base. The exterior surface is burnished, and the interior surface is floated; both surfaces are light brown and gray in color and lack burned encrustations. The vessel is tempered with grog. The bowl is $4.4 \mathrm{~cm}$ tall with a 1.8-cm-high rim and an orifice diameter of $11.6 \mathrm{~cm}$. The base diameter is $5.4 \mathrm{~cm}$. Rim thickness is $0.50 \mathrm{~cm}$. It has a volume of $200 \mathrm{ml}$. 


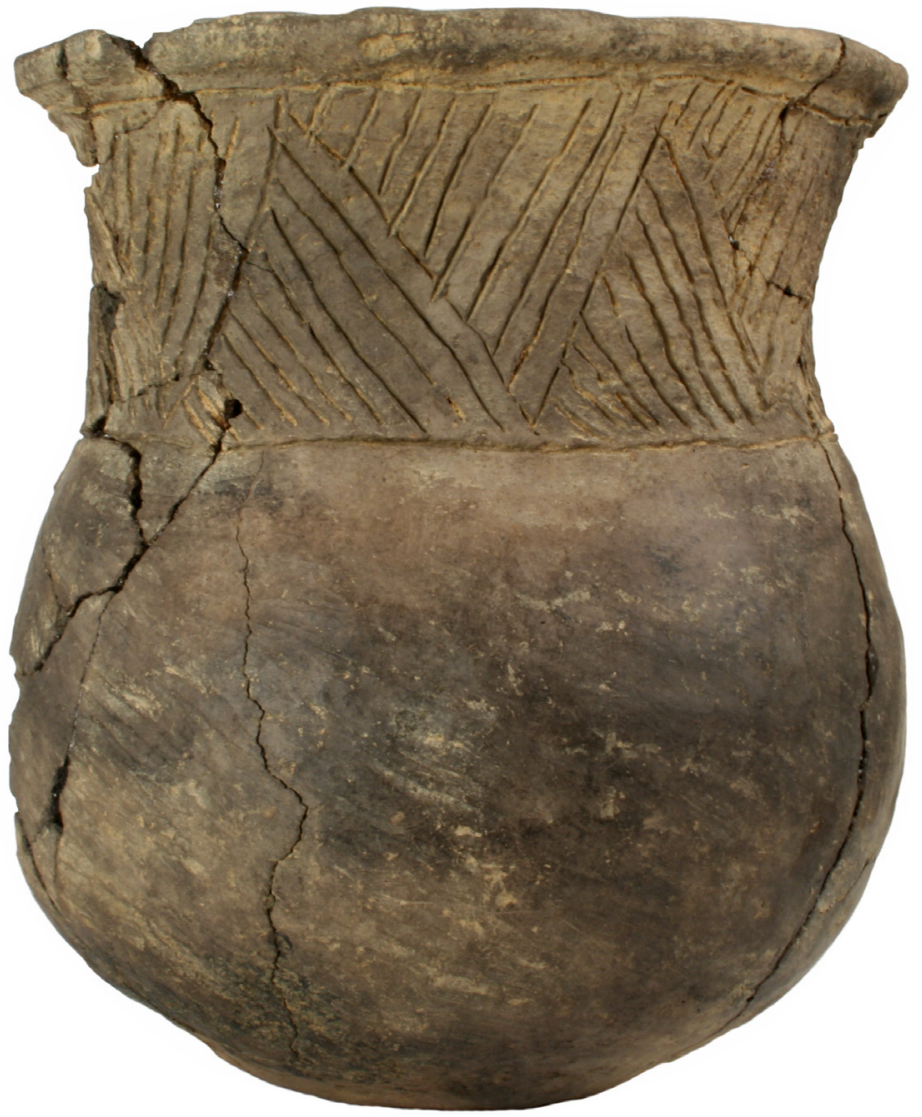

a

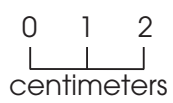

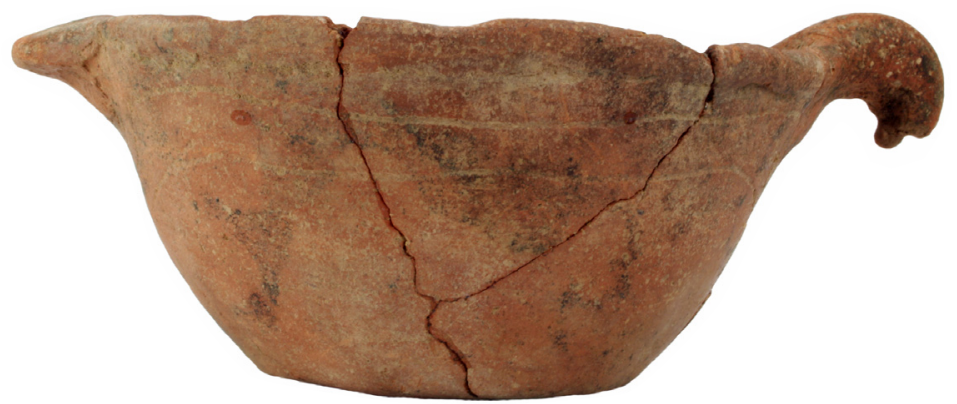

b

Figure 6.25. Vessels from Feature 2 at the James Richey site. (a) Maydelle Incised jar; (b) effigy bowl. 

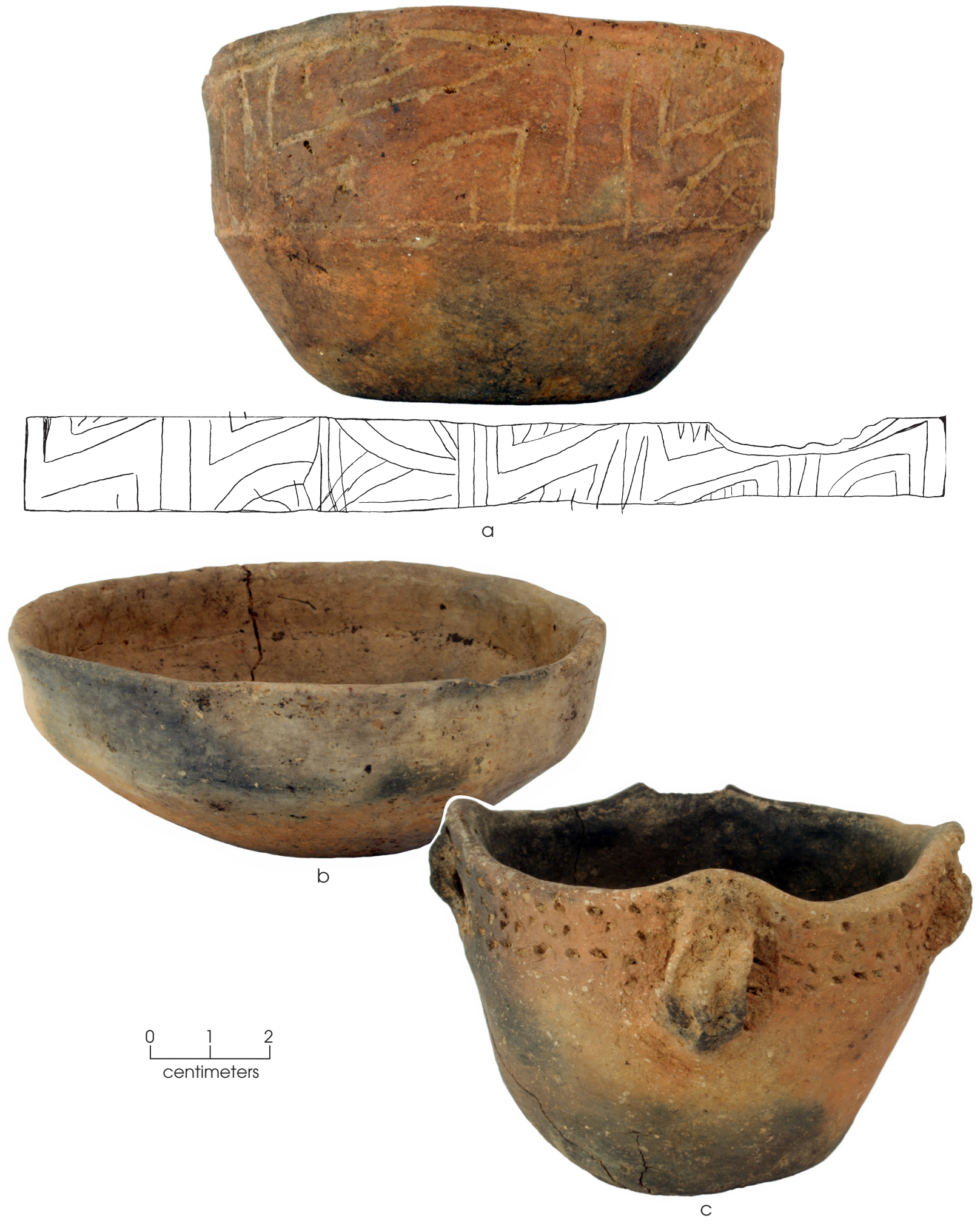

Figure 6.26. Vessels from Feature 18 at the James Richey site. (a) Ripley Engraved carinated bowl; (b) plain carinated bowl; (c) possible Harleton Appliqué jar. 


\section{Feature 18, Vessel 3}

This is a small jar that has a four-peaked rim with a handle beneath each peak, 98 percent complete and weighing $163.5 \mathrm{~g}$ (Figure 6.26c). The rim is everted with a rounded lip; the base is flat. One handle is broken away, but the remaining handles show enhancement with three fine vertical appliqué lines. In addition, lines of stick punctations encircle the vessel below the lip and at the neck/body juncture. Between the punctated lines are scattered stick punctations that form a field effect. Because of the rim peaks and handles with appliqué, this vessel is tentatively typed as Harleton Appliqué. The exterior surface is burnished, and the interior surface is smoothed; both are yellow and gray in color and lack burned encrustations. The vessel is tempered with grog. The jar is $6.2 \mathrm{~cm}$ tall with a $1.8-\mathrm{cm}$-high rim and an orifice diameter of $8.6 \mathrm{~cm}$. The diameter at the neck is $8.2 \mathrm{~cm}$, and the maximum body diameter is $8.4 \mathrm{~cm}$. The base diameter is $5.3 \mathrm{~cm}$. Rim thickness is $0.48 \mathrm{~cm}$. It has a volume of $175 \mathrm{ml}$.

\section{Feature 25, Vessel 1}

This is a small jar with an everted rim with rolled lip, a globular body, and a flat base, about 70 percent complete and weighing $643.6 \mathrm{~g}$ (Figure 6.27a). It is decorated with four evenly spaced lines of stick punctations that encircle the vessel neck between the lip and the neck/ body juncture. Between the punctated lines are a series of incised diagonal lines extending out on both sides from short vertical lines. This pattern repeats seven or eight times around the neck and gives the impression of the Pease BrushedIncised panel motif, although here the panels are on the rim rather than the body. The body of this jar is not decorated. The globular body and tall neck of this vessel are also characteristic of some Pease Brushed-Incised jars (Suhm and Jelks 1962:Plate 60). This vessel has a floated exterior surface and burnished interior surface; both are yellow and gray in color, with the exterior having slight burned encrustations. It has grog temper. The jar is $16.2 \mathrm{~cm}$ tall with a 7.5 -cm-high rim and an orifice diameter of $12.0 \mathrm{~cm}$. The diameter at the neck is $11.7 \mathrm{~cm}$, and the maximum body diameter is $13.1 \mathrm{~cm}$. The base diameter is $6.5 \mathrm{~cm}$. Rim thickness is $0.56 \mathrm{~cm}$, body thickness is $0.61 \mathrm{~cm}$, and base thickness is $1.37 \mathrm{~cm}$. Its volume could not be determined.

\section{Feature 25, Vessel 2}

This is a complete small to medium-sized simple bowl weighing $663 \mathrm{~g}$ (Figure 6.27b). It has an everted rim with rounded lip and a flat base It is not decorated on the exterior, but there is a band of decoration on the interior just below the lip. This band is $2.5 \mathrm{~cm}$ wide and consists of lightly engraved pairs of opposed triangles that are filled with hatching. These primary triangle elements repeat 21 times around the vessel. This motif is similar to decoration that occurs on the exteriors of some Sanders Engraved carinated bowls (Suhm and Jelks 1962:Plate 69e), and the type does include bowls with interior engraving (Suhm and Jelks 1962:Plate 69f). A similarly decorated bowl recovered from the Spoonbill site (41WD109) was called Spoonbill Engraved (Perttula et al. 2009). The burnished exterior surface is light brown and black, and the gray interior is smoothed; neither surface has burned encrustations. The core is black. The vessel has grog temper. The bowl is $9.6 \mathrm{~cm}$ tall with an orifice diameter of $19.3 \mathrm{~cm}$. The base diameter is $8.5 \mathrm{~cm}$. Rim thickness is $0.50 \mathrm{~cm}$. It has a volume of $1,350 \mathrm{ml}$.

\section{Nonvessel Artifacts}

The three nonvessel ceramic artifacts are smoking pipe fragments. One pipe bowl fragment recovered from SU 44 is from a short flaring bowl with a rounded lip typical of the Red River pipe style (Hoffman 1967:Figure 4). This bowl fragment has a height of $16.72 \mathrm{~mm}$ from its rim to its attachment point to the stem and has a reconstructed outer diameter of $3.0 \mathrm{~cm}$. This bowl fragment is $4.23 \mathrm{~mm}$ thick, and its clay body is tempered with grog.

A second pipe bowl fragment was recovered from general site backdirt. This fragment also represents a flaring bowl with a rounded lip, but the bowl is taller at $34.24 \mathrm{~mm}$ or more and is $4.79 \mathrm{~mm}$ thick. This bowl fragment is tempered with grog. It is difficult associate this fragment with a particular pipe style as only about a fifth of the bowl remains and attachment to the stem is not present.

The third pipe fragment is a stem fragment recovered from SU 27 that appears to be from an elbow style pipe (Hoffman 1967:Figure 6). About a fourth of the proximal end of the stem is intact; it has a flat lip and a reconstructed draw hole diameter of $15.5 \mathrm{~mm}$. This stem frag- 


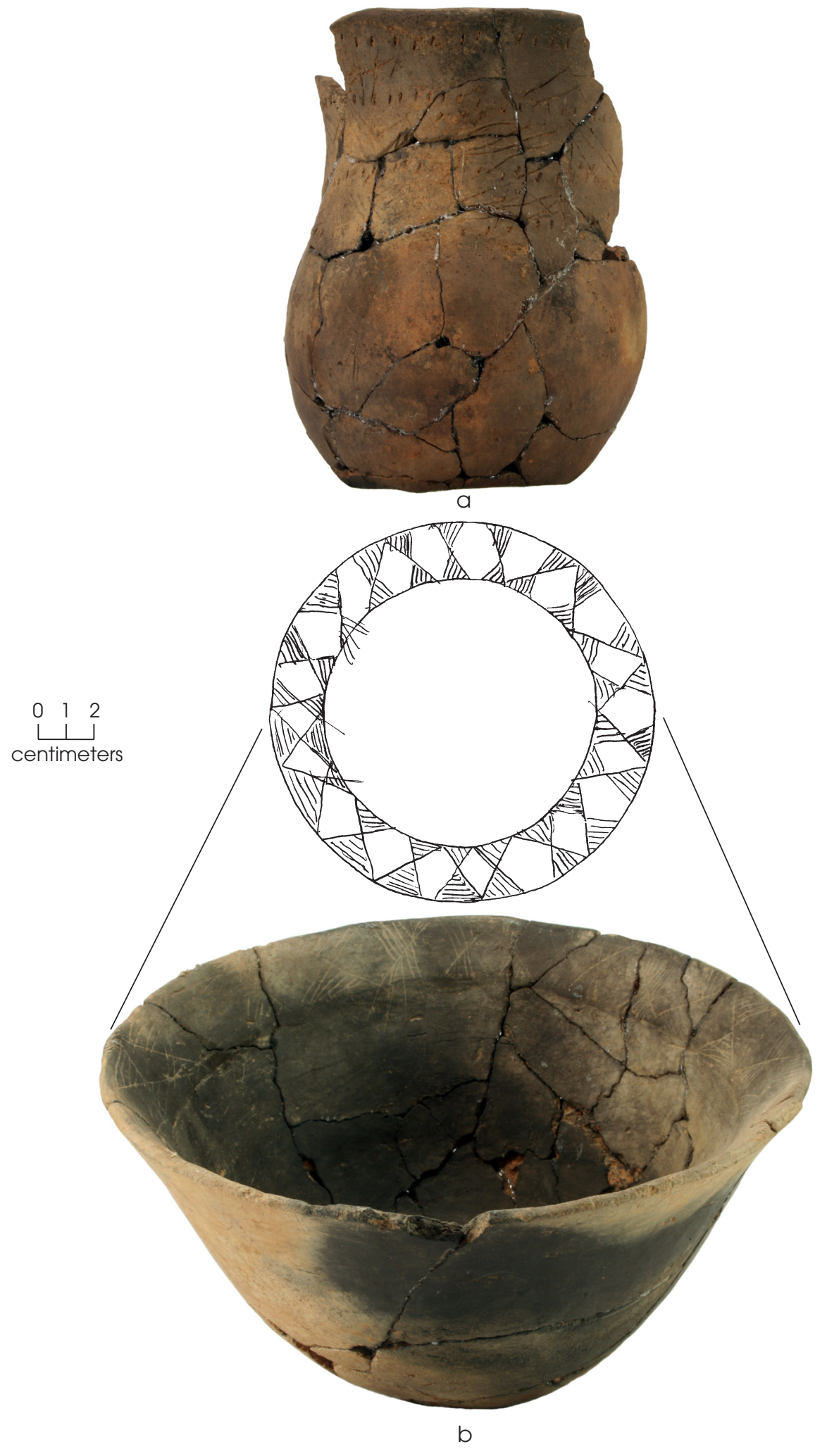

Figure 6.27. Vessels from Feature 25 at the James Richey site. (a) Possible Pease Brushed-Incised jar; (b) possible Sanders Engraved simple bowl. 
ment is $4.31 \mathrm{~mm}$ thick and is tempered with grog and bone.

\section{CHIPPED STONE ARTIFACTS}

The chipped stone assemblage consists of 35 projectile points, 2 gunflints, 51 bifaces, 4 unifaces, 153 edge-modified and utilized flake tools, 14 edge-modified core tools, 78 cores, and 2,495 pieces of debitage. Appendix $\mathrm{E}$ lists the metric attributes of all the tools. The projectile points reflect periodic use during the Paleoindian, Middle to Late Archaic, Woodland, and Early to Late Caddo periods, and the gunflints indicate some use in the late seventeenth century or later. The assemblage demonstrates a strong reliance on local lithic materials and knapping activities focusing on late reduction, tool production, and tool maintenance.

\section{Projectile Points}

The projectile points consist of 6 arrow points, 28 dart points, and 1 distal fragment that could be from either an arrow or dart. The vast majority (83 percent) are of local materials, mostly chert with some of quartzite and only 2 of silicified wood. Only 6 are of nonlocal materials: a Wells dart point and 2 Yarbrough dart points are of Edwards chert; and a Godley or Lone Oak dart point, a Colbert arrow point, and the unclassifiable distal fragment are of gray chert.

Sixty-six percent of the projectile points are complete. Of the 13 fragments, 31 percent are proximal, 8 percent are medial, 31 percent are distal, and the rest are mostly complete missing significant segments of the bases or blades. The complete points and proximal fragments support retooling activities at this site. Reworking indicative of tool maintenance was identified on all of the dart points and most of the arrow points. Some manufacture is reflected in the breakage patterns and the preforms. There are several points with only slightly modified edges or no evidence of reworking, more so in the dart points than arrow points, which supports some tool manufacturing. The complete specimens also may reflect loss rather than retooling.

\section{Arrow Points}

The six arrow points and fragments consist of one possible Catahoula, two Colbert, one Maud, and two preforms. These span the Caddo period.
Catahoula points have long flared shoulders with squared barbs, expanding to straight stems, and straight bases (Turner and Hester 1999:206). The possible Catahoula is missing most of the stem and base and has heavy blade serration; it is reddish brown chert (Figure 6.28a).

Colbert points have recurved to convex blade edges with serrations, wide shoulders, barbs, expanding stems, and straight bases (Turner and Hester 1999: 209). The two from this site are complete with straight bases, straight stems, and triangular blades. One has slight blade serration and is made of local reddish brown chert (Figure 6.28b). The other was asymmetrically reworked and has slight blade serration and beveling; it is made of gray, probably Edwards, chert (Figure 6.28c).

Mauds are slender triangular points with a concave to V-shaped base and no stem (Turner and Hester 1999:223). The single example is complete and has a heavily serrated blade and needle-like tip; it was made of dark red chert and has a thermal (pot lid) fracture on one side (Figure 6.28d).

One arrow preform is mostly complete with a fracture on the lateral edge and some thermal fracturing (Figure 6.28e). It is oval with a concave base and no stem and is made of Ogallala quartzite. The other preform is very crude. It was made on a silicified wood flake blank and has a straight base (the platform of the flake) with a contracting stem (Figure 6.28f). The distal end is irregular and extensively reworked.

\section{Dart Points}

The 28 dart points consist of 1 Edgewood, 1 Ellis, 4 Garys, 2 Godleys, 1 Godley or Lone Oak, 2 Kents or Garys, 1 possible Motley, 2 San Patrices, 3 Wells, 9 Yarbroughs, and 2 untyped.

Edgewood points tend to be short points with short barbs, expanding stems, and concave to straight bases (Turner and Hester 1999:111). The single Edgewood, missing part of its base, has a concave base, an expanding stem, some blade reworking, moderate serration, and grinding on the basal edge; it is made of reddish brown chert (Figure 6.29a). Ellis points are short and thick with shallow corner notching, squared barbs, expanding stems, and straight bases. A nearly complete specimen has an expanding stem with straight base and a triangular blade 


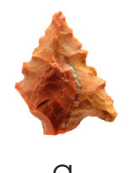

a
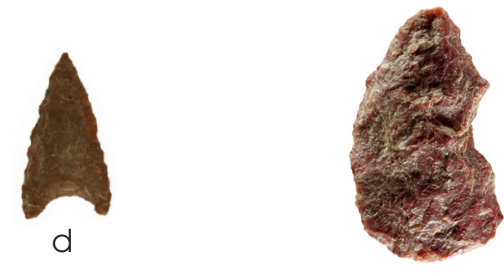

e

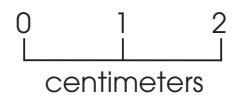

Figure 6.28. Arrow points from the James Richey site.

(a) Possible Catahoula; (b-c) Colbert; (d) Maud; (e-f) preforms.

with moderate serration; it is missing part of the distal tip as well as the basal tangs and is made of quartzite (Figure 6.29b).

Gary points, with square shoulders and contracting stems, incorporate great morphological variation (Turner and Hester 1999:123). Two of the Garys have convex bases and contracting stems. One is of local dark brown chert (Figure $6.29 \mathrm{c}$ ); the blade is serrated and one shoulder is missing. The second, of brown chert with cortex on one side, has one corner missing and could be a preform (Figure 6.29d). The third Gary has a crude irregular base and contracting stem (Figure 6.31e). It has a hinge fracture on the haft and is made of reddish brown chert. The fourth Gary, of yellowish brown chert with red inclusions, has a convex base, a straight stem, and an extensively reworked triangular blade (Figure 6.29f).

Godleys are small triangular points with prominent shoulders, expanding stems, and convex bases (Turner and Hester 1999:125). One Godley is complete with a slightly concave base
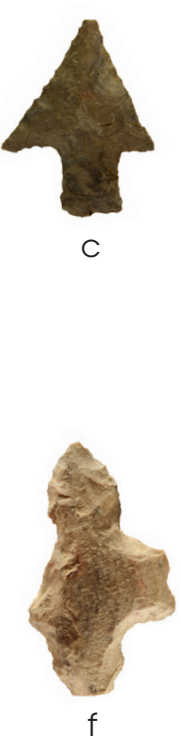

and expanding stem (Figure 6.29g). It has an asymmetrically reworked blade and slight grinding on the base and stem edges. The other Godley is a tan chert proximo-medial fragment retaining part of the distal end (Figure $6.29 \mathrm{~h}$ ). It has a convex base and expanding stem. The base and stem edges are ground, and there is moderate to heavy blade serration. The blade was broken during use. Another dart point, of gray chert, is either a Godley or Lone Oak (Figure 6.29i). It has an expanding stem with ground edges and a straight base. The blade is irregular in shape and has steep edge beveling. The blade may have been worked into a drill, since it is narrow and pointed.

Kents are poorly made asymmetrical points with squared to indistinct shoulders, straight stems (although they may be contracting or slightly expanding as well), and flat to concave bases (Turner and Hester 1999:136). Two dart points are either Kents or Garys. One is complete with an irregular base, contracting stem, and irregular blade (Figure 6.29j). It is made of quartzite, and the blade has a hinge fracture along one side from retouch. The other, of dark reddish brown chert, is a medial fragment with a contracting stem but a broken, indeterminate base (Figure $6.29 \mathrm{k}$ ). There is an impact fracture on the blade.

Motleys are well-made, long points, with an expanding stem, a straight to convex base, and deep corner notching that produces barbs (Turner and Hester 1999:162). One possible Motley has a straight base, an expanding stem, and a triangular reworked blade; it has stem and basal edge grinding and is made of reddish brown chert (Figure 6.291).

San Patrice points have fairly deep concave bases, basal and stem edge grinding, rounded shoulders, and basal thinning or fluting (Turner and Hester 1999:181-182). Both San Patrice points are complete. One has a triangular blade with moderate to heavy blade serration (Figure $6.29 \mathrm{~m}$ ). It has a slightly concave base and ground stem edges and an impact fracture on the blade edge. It is made of a pinkish white quartzite. The second was extensively reworked into a drill (Figure $6.29 \mathrm{n}$ ). The drill bit is somewhat 


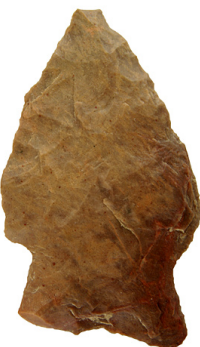

a

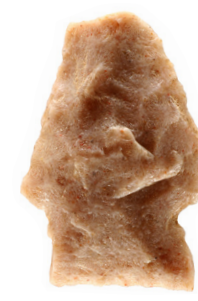

$\mathrm{b}$

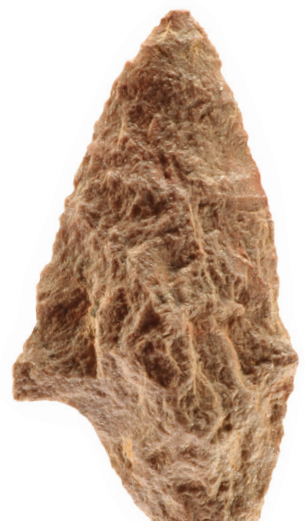

C

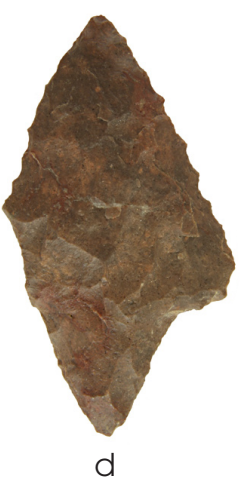

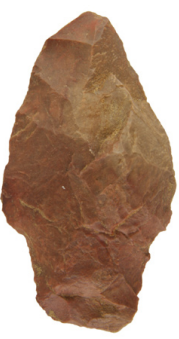

e

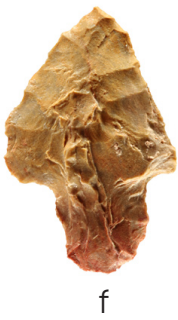

d
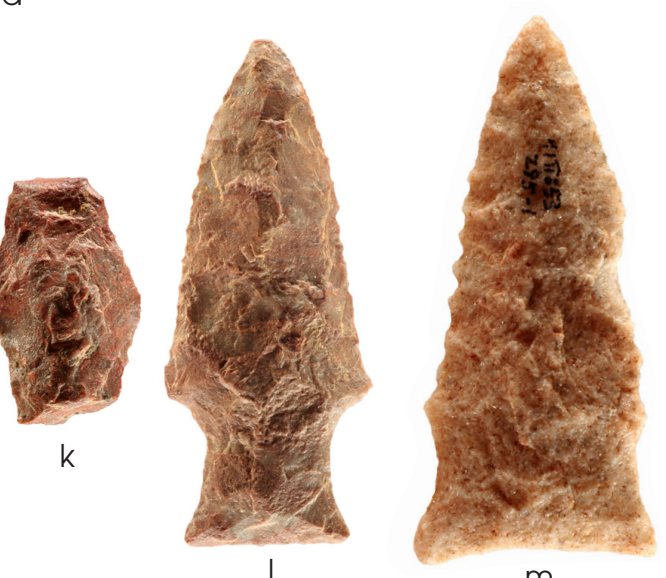

$\mathrm{m}$

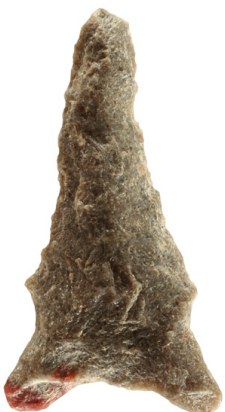

$\mathrm{n}$

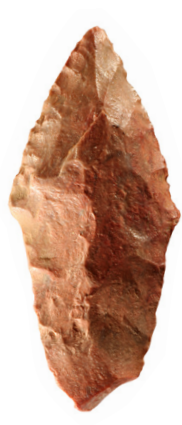

○
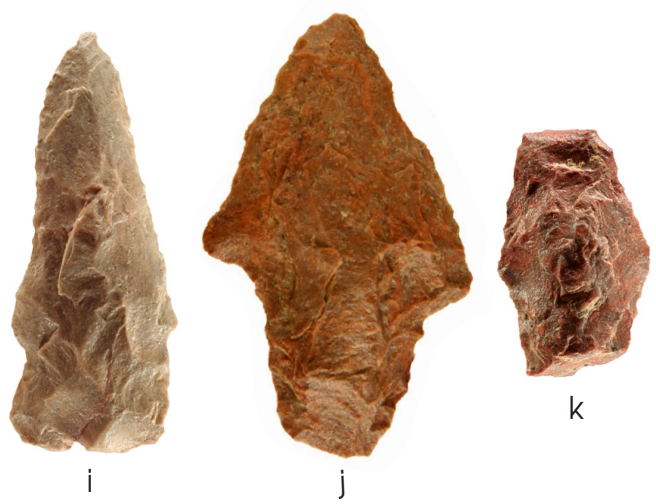

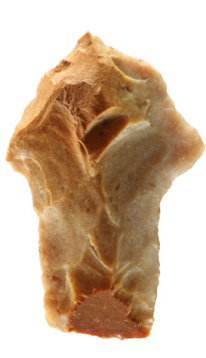

P

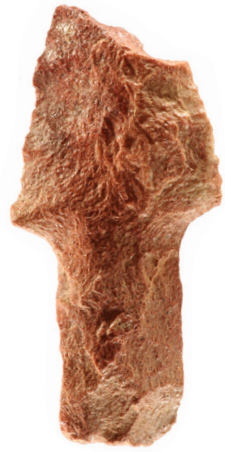

9

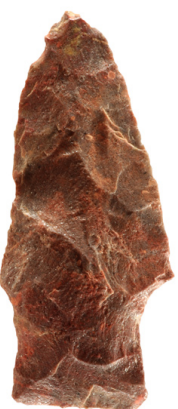

u

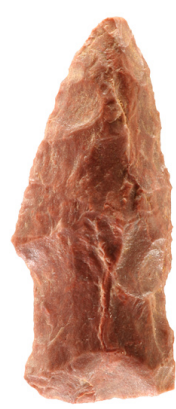

V

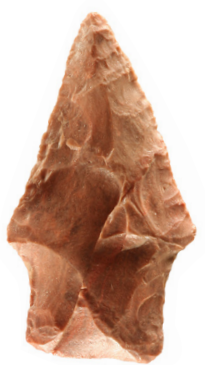

w
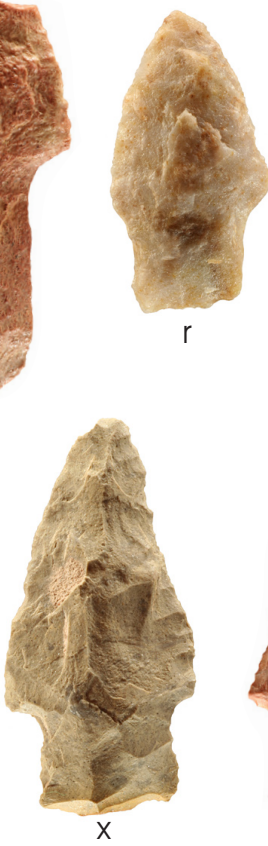

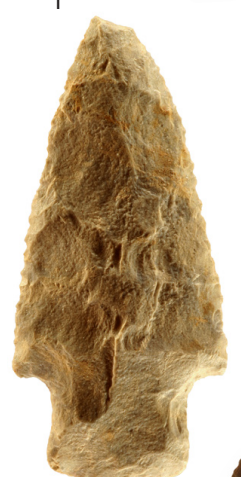

S
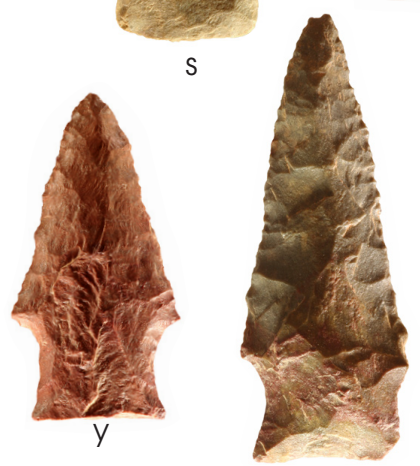

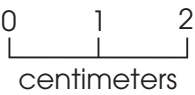

Figure 6.29. Dart points from the James Richey site. (a) Edgewood; (b) Ellis; (c-f) Gary; (g-h) Godley; (i) Godley or Lone Oak; (j-k) Kent or Gary; (1) possible Motley; (m-n) San Patrice; (o-q) Wells; (r-z) Yarbrough. 
irregular in shape and has alternate blade edge beveling. This specimen has a concave base and ground stem edges and is made of medium to dark gray quartzite with some red inclusions.

Wells points are characterized by long contracting to straight stem edges that are often ground, blade edges that are often serrated, and a base that varies from convex to straight (Suhm and Jelks 1962:257-258; Turner and Hester 1999:193). This type has square to round shoulders depending on the amount of reworking. One Wells is of reddish brown chert and has a contracting stem with ground edges, moderate blade serration, and steep blade edge beveling; it is missing part of the base (Figure 6.29o). The second Wells is made of tan Edwards chert and has a straight base, a straight stem, and an extensively reworked blade; there is cortex on one side of the base (Figure 6.29p). The third Wells is a quartzite proximo-medial fragment with a straight base and straight stem (Figure 6.29q). The remaining part of the blade has moderate serration. It has alternate blade and stem edge beveling and stem and basal edge grinding.

Yarbrough points are slender, elongated points with prominent shoulders, straight to expanding stems, and straight bases, with stem and basal edge grinding (Turner and Hester 1999:197). Eight of the nine Yarbroughs are complete. One, of quartzite, has a straight base and straight stem with ground edges; the blade is slightly serrated, has alternate edge beveling, and is extensively reworked to the point that it was exhausted and discarded (Figure 6.29r). The second Yarbrough is made of yellowish tan Edwards chert and has a straight base and straight stem (Figure 6.29s). There is moderate blade serration and slight blade beveling. The stem and base edges are ground. This specimen is missing a small part of the tip. The third Yarbrough, of reddish brown local chert, has a straight stem and an indeterminate base with a small portion missing; the blade has moderate serration (Figure 6.29t). The fourth Yarbrough, of reddish dark brown chert, has a straight base and straight stem; the blade has been extensively reworked, and there is slight stem and basal edge grinding (Figure $6.29 \mathrm{u}$ ). The fifth Yarbrough, of reddish brown chert, has a convex base and straight to slightly expanding stem. The blade has alternate edge beveling and moderate serration (Figure 6.29v). The sixth Yarbrough, made of reddish brown locally available chert, has a straight base and a straight stem with basal and stem edge grinding; the blade has slight serration and alternate edge beveling (Figure 6.29w). The seventh Yarbrough, made of light tan Edwards chert, has a straight base and a straight to slightly expanding stem; the blade has been reworked somewhat asymmetrically, and the blade has moderate serration (Figure 6.29x). The eighth Yarbrough is typed tentatively since the base is missing (Figure 6.29y). It has a straight to expanding stem with ground edges, and the blade has symmetrical retouch with some serration. This point is made on a flake blank of reddish brown chert. The ninth Yarbrough is made of dark gray quartzite with red bands and has an expanding stem and a straight base (Figure $6.29 \mathrm{z}$ ). The blade was reworked and has moderate serration, and the stem and base edges are ground.

An untyped dart point is a proximal fragment with a straight base and straight stem; it is of dark reddish brown chert. Another untyped fragment is bifacially worked but missing the corners; it is made of highly siliceous dark brown silicified wood.

\section{Gunflints}

There are two gunflints. One is a small, irregular square gunflint that is bifacially worked but retains cortex on part of one side (Figure 6.30a). Three of the edges are bifacially retouched, although one edge is thick, poorly worked, and has hinge fractures. The other two edges are finely worked. Wear indicating use as a gunflint is present on three edges. It is made of yellowish brown local chert. The other gunflint, made on a flake, has unilateral retouch on two edges and some bifacial retouch on two edges, with wear indicating use as a gunflint on at least three edges (Figure 6.30b). It is made of reddish brown local chert.

\section{Bifaces}

Excluding the bifacial gunflint mentioned above, 50 bifaces were recovered. The 29 tools consist of an adze, a drill, 4 gouges, 17 knives, and 6 indeterminate tools. In addition, there are 21 tool blanks or preforms that consist of 9 early-stage bifaces, 8 middle-stage bifaces, and 4 late-stage bifaces. Eighty-six percent are of local lithic materials, mostly chert $(\mathrm{n}=33,66$ percent) 
but also silicified wood ( $n=4)$, quartzite $(n=5)$, and hematite $(\mathrm{n}=1)$. Nonlocal materials are Edwards chert $(n=2)$, gray chert $(n=3)$, and white chert $(n=2)$. All of the bifaces made of nonlocal materials are tools, except for a latestage tool blank of gray chert.

Thirty bifaces are broken, and 20 are complete. Of the fragments, 13 are distal pieces, 10 are proximal, and the rest are a medial, 3 lateral, and 3 indeterminate fragments. The distal fragments are almost entirely tools, and the proximal fragments include more early- and late-stage bifaces. The abundance of proximal and distal fragments is associated with breakage during manufacture or use as knives. The lateral fragments and common step fractures (50 percent) indicate breakage during manufacture. The rest of the fragments are fractured from use or unknown causes.

The adze is mostly complete with a small portion of one end missing (Figure 6.30c). It is made of red chert. The drill is made of nonlocal white chert and is very well made (Figure 6.30d). It has an expanding stem with ground edges, a concave base, and basal thinning; it may be a reworked Dalton point. The gouges are all made of local reddish and yellowish brown chert. Three are complete, and one is a distal fragment (Figure 6.30e-h). One of the complete specimens may have been used as a scraper and a knife as well as a gouge (see Figure 6.30e).

The 17 bifacial knives consist of 6 that are complete and 11 that are fragments. Eight are made of local chert, 4 are of quartzite, and 2 are of silicified wood. Two are made of Edwards chert, and 1 is of nonlocal gray chert. One of the complete knives, of local red chert, is very well made. The broken knives consist of 7 distal fragments, a medial fragment, a proximo-medial fragment, and 2 indeterminate fragments.

Two indeterminate biface fragments have evidence for stems but are of unknown function. These consist of a lateral fragment of white chert that has an indentation possibly from a haft and a proximal fragment of local brown chert with grinding on the edges of what may be a stem. There were also four unstemmed biface fragments that appear to be tools but are of unknown function. One is a distal fragment with enough retouch to obscure the break and has retouch on the blade edges. It is made of reddish brown chert. Another is a lateral fragment of nonlocal gray chert with evidence for tool use. A proximal fragment with reworking on the break was possibly used as a wedge. It was made of yellowish brown chert. The final unstemmed bifacial tool fragment is a proximal fragment narrowing toward the distal end and made of reddish brown chert. It has some retouch suggesting use as a tool but is of unknown function.

The nine early-stage bifaces include three proximal fragments of locally available red, reddish brown, and dark reddish brown chert. The rest of the early-stage bifaces are complete, with three of yellowish or reddish brown chert, one of hematite, and two of silicified wood. One complete specimen may be a bifacial core.

The eight middle-stage bifaces, all of local materials, consist of three complete ones made of chert, two distal fragments of chert, a distal fragment of quartzite, and two indeterminate fragments of chert and reddish brown chert. The four late-stage biface fragments consist of a distal fragment of gray chert, two proximal fragments of local chert and nonlocal pinkish white chert, and a proximo-medial fragment of red chert.

\section{Flake and Core Tools}

There are 171 tools made on flakes or cores, excluding the unifacial gunflint. Only 4 of these are formally prepared tools (a hafted knife, an end scraper, a multifunctional tool, and an indeterminate uniface), and the rest are informally prepared (55 edge-modified flake tools, 98 utilized flake tools, and 14 edge-modified core tools). These are mostly ( 88 percent) made of local lithic materials, with 55 percent of chert, 20 percent of silicified wood, 11 percent of quartzite, and a few of ferruginous sandstone and hematite. The 12 percent that are made of nonlocal materials include Edwards chert, gray chert, white chert, and novaculite. All of the formal tools are made of local materials. This assemblage is unusual in that formally prepared tools are infrequent and expedient tools are numerous.

\section{Formal Tools}

The single hafted knife is complete, made of reddish brown local chert (Figure 6.30i). The end scraper is made of yellowish brown and red chert and has steep retouch on one end and use wear on another edge (Figure 6.30j). A multifunctional unifacial tool made on a long thick flake of reddish brown chert has steep retouch on one edge 


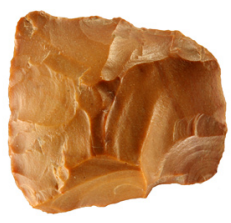

a

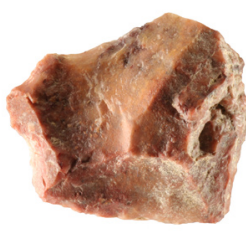

b
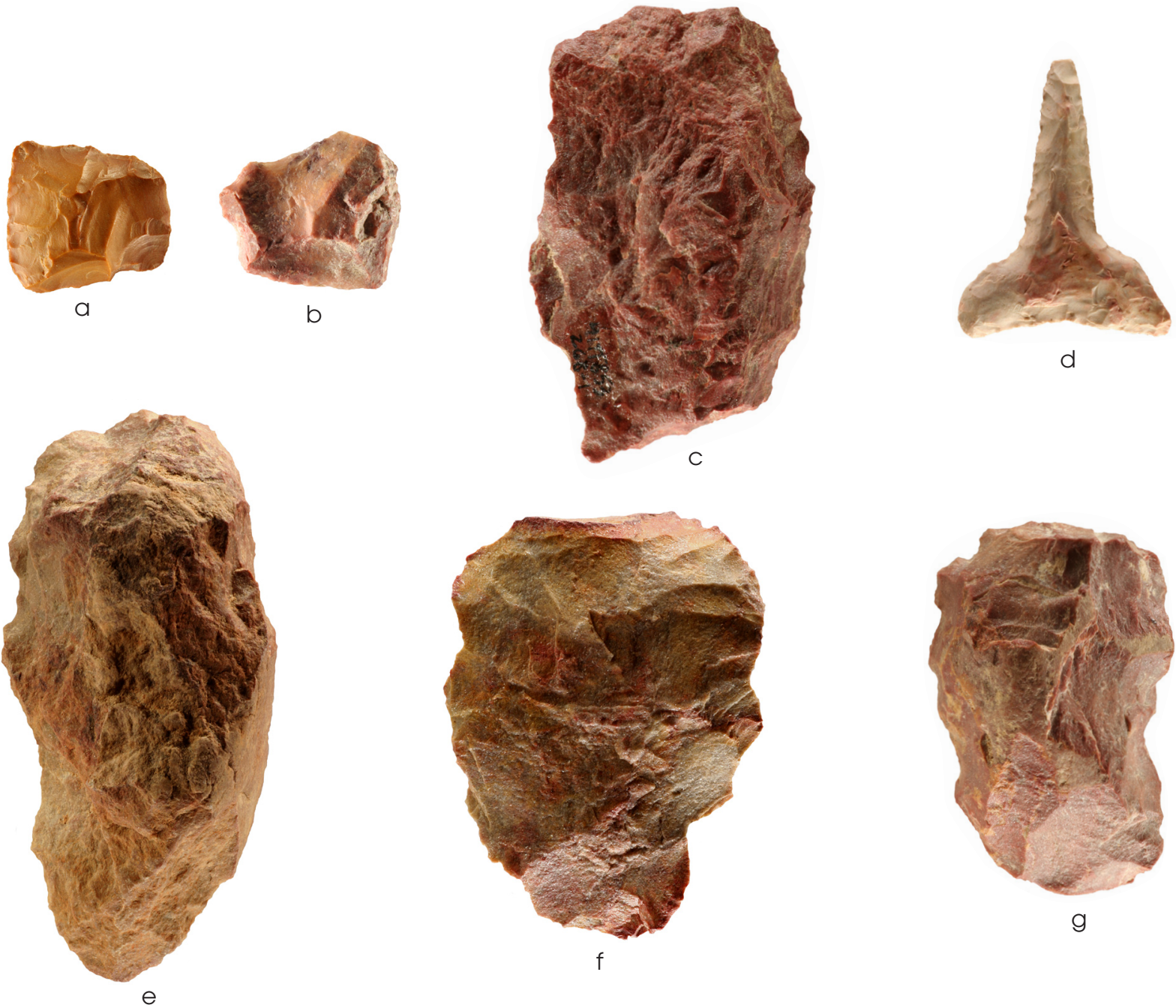

d
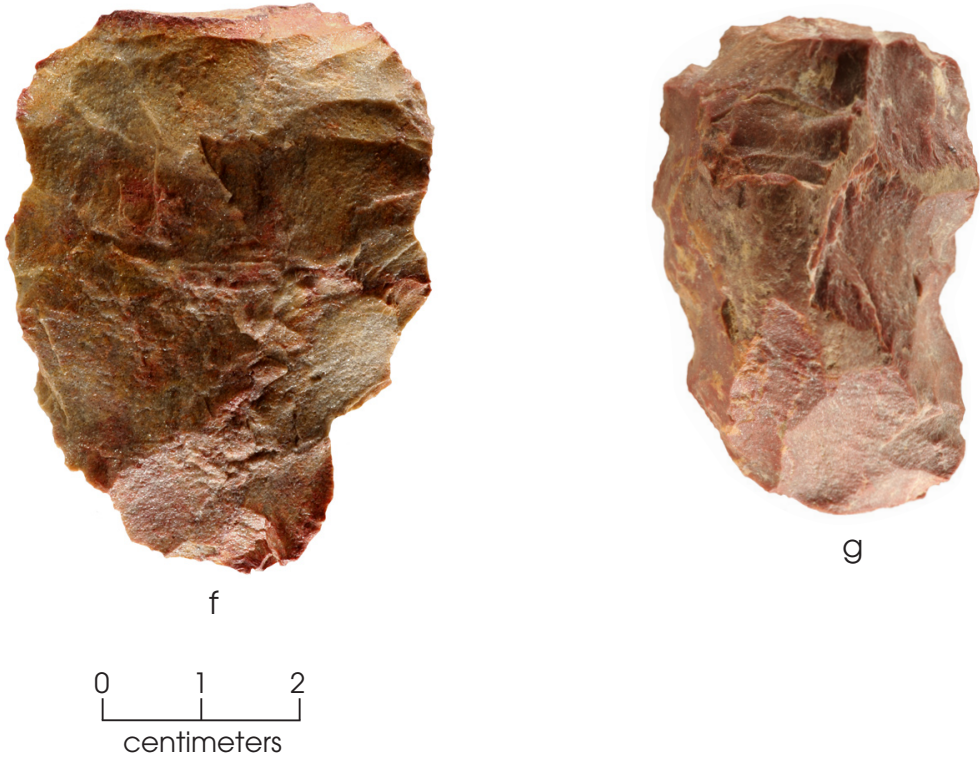

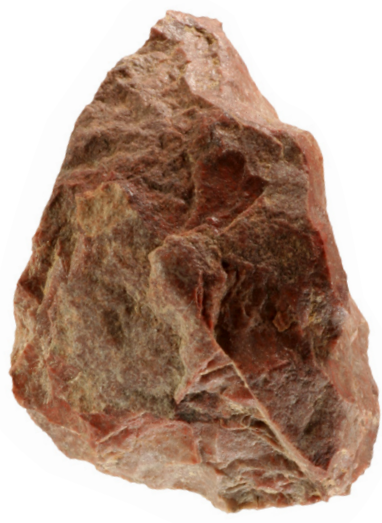

h

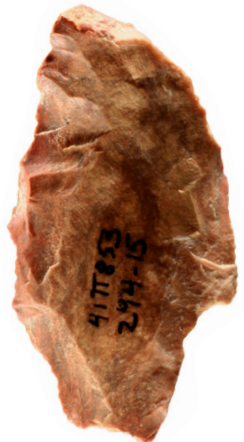

i

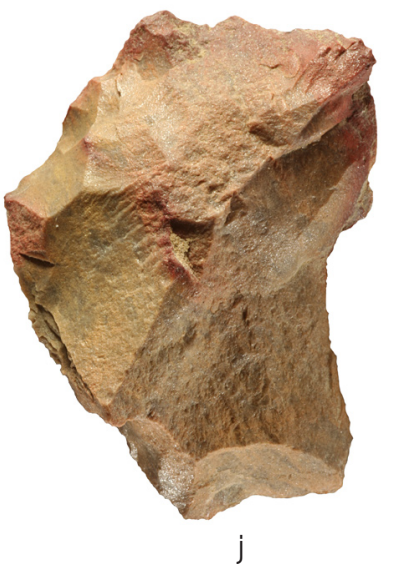

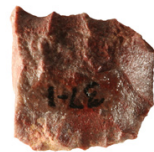

k

Figure 6.30. Gunflints, bifaces, and flake tools from the James Richey site. (a) Bifacial gunflint; (b) gunflint with unifacial and bifacial retouch; (c) adze; (d) bifacial drill; (e-h) gouges; (i) hafted flake knife; (j) flake end scraper; (k) indeterminate flake uniface. 
that was used as a scraper, less-formal retouch and use wear on another edge that was used as a knife, and retouch along a curved edge that was used as a gouge. An indeterminate uniface fragment is made of quartzite and may have been part of a hafted tool (Figure 6.30k).

\section{Informal Tools}

The informal flake tools consist of 5 multifunctional edge-modified tools, 36 edge-modified knives, 15 edge-modified scrapers, 3 edge-modified gravers, and 102 utilized flakes. The edge-modified core tools consist of 3 choppers, 2 knives, 8 scrapers, and a multifunctional tool.

The five edge-modified flakes that are multifunctional tools include one that has slight retouch and use wear on three edges indicating use as a scraper, a knife, and a graver. It is made of reddish brown chert. Another has three edges with retouch and wear indicating it was used as a knife, and it has a protrusion that may have been used as a graver. It is made of tan and brown chert. A third flake tool has retouch that is irregular and rough but creates two curved areas that meet to form a protrusion suggesting it was used as a graver, gouge, and knife. The fourth was used as a gouge and scraper and is made of reddish brown chert. The last multifunctional tool has two retouched edges indicating use as a scraper and knife; it is made of yellowish brown chert.

The 36 edge-modified flake knives have light retouch indicative of light-duty expedient cutting and are mostly (92 percent) made of local material, dominated by chert but also including silicified wood, quartzite, and one made of hematite. Two are of Edwards chert, and 1 is of novaculite. The 15 edge-modified flake scrapers have light retouch and wear indicative of scraping; they are mostly of local materials with only 1 of nonlocal chert. Three edge-modified gravers have light retouch creating small utilized protrusions. The 102 utilized flakes have evidence of use based on microflakes removed from one or more edges. They likely were cutting tools.

Three modified cores have use wear and some retouch indicative of chopping. Two are of silicified wood, and one is of local chert. The two core knives have light retouch and use wear typical of light-duty expedient cutting. One is silicified wood, and the other is chert. The eight core scrapers have light retouch on steep edges and wear indicative of scraping. Five are silicified wood, two are ferruginous sandstone, and one is local chert. One edge-modified core tool, of silicified wood, has three retouched edges that have light retouch and wear indicative of scraping, cutting, and engraving/perforating.

\section{Cores}

Seventy-eight cores, core fragments, and tested cobbles were recovered (Table 6.5). Over half (54 percent) are of local chert, 22 percent are silicified wood, 15 percent are quartzite, 5 percent are ferruginous sandstone, and 4 percent are hematite. There are 37 flake cores (irregular, rotated, and bifacial), 19 core fragments, and 22 tested cobbles. Irregular flake cores are the most common $(\mathrm{n}=34)$. These are cores with flakes removed using hard-hammer percussion and reduced in an unpatterned way to produce lithic materials of suitable size to serve as tool blanks and to shape and refine larger bifaces.

There is one rotated core of local chert and two bifacial cores of local chert and local quartzite. Rotated cores are turned or rotated in one main direction to remove flakes, and bifacial cores have edges used as platforms to remove flakes to be worked into tools (Andrefsky 1998:14). Both rotated and bifacial cores reflect removal of flakes using hard-hammer percussion in a patterned way.

The core fragments are remnants of flake cores and may represent rejuvenation or exhaustion. All are of local materials, mostly chert $(\mathrm{n}=13)$ but also quartzite $(\mathrm{n}=3)$, silicified wood $(\mathrm{n}=2)$, and hematite $(\mathrm{n}=1)$. Tested cobbles have only a few flake scars (no more than three). Most are chert $(\mathrm{n}=11)$ and quartzite $(\mathrm{n}=7)$, with a few of silicified wood ( $\mathrm{n}=1$ ), ferruginous sandstone $(n=1)$, and hematite $(n=2)$.

\section{Debitage}

There are 2,495 pieces of debitage recovered from all phases of work. Locally available materials dominate, making up 95 percent of the collection. Local chert is most common (69 percent), with silicified wood (17 percent) and quartzite ( 8 percent) present in moderate amounts. Ferruginous sandstone, hematite, ocher, and quartz together account for 2 percent; these flakes are likely the byproducts of manufacturing and use of ground or battered stone tools such as hammerstones, celts, manos, and pigment stones. 
Table 6.5. Cores from the James Richey site

\begin{tabular}{|c|c|c|c|c|c|c|}
\hline Provenience & Core Type & Lithic Material & $\begin{array}{l}\text { Maximum } \\
\text { Length } \\
(\mathrm{cm})\end{array}$ & \begin{tabular}{|c|}
$\begin{array}{c}\text { Maximum } \\
\text { Width } \\
(\mathrm{cm})\end{array}$ \\
\end{tabular} & $\begin{array}{c}\text { Maximum } \\
\text { Thickness } \\
(\mathrm{cm})\end{array}$ & Weight $(\mathrm{g})$ \\
\hline BT 14 & rotated & chert, local & 7.26 & 6.17 & 3.20 & 122.1 \\
\hline TU 2, Lev. 5 & bifacial & quartzite & 7.43 & 5.94 & 3.13 & 137.2 \\
\hline TU 11, Lev. 4 & bifacial & chert, local & 6.56 & 3.95 & 1.81 & 60.7 \\
\hline Backdirt & core & chert, local & 3.80 & 3.56 & 2.26 & 30.1 \\
\hline Backdirt & core & chert, local & 4.59 & 4.03 & 2.03 & 36.6 \\
\hline Backdirt & core & chert, local & 5.65 & 4.91 & 4.71 & 134.3 \\
\hline Backdirt & core & chert, local & 4.87 & 4.05 & 2.26 & 47.2 \\
\hline Backdirt & core & chert, local & 5.47 & 3.53 & 3.34 & 46.9 \\
\hline Backdirt & core & chert, local & 6.14 & 4.64 & 2.45 & 75.7 \\
\hline Backdirt & core & chert, local & 6.55 & 4.35 & 2.04 & 45.3 \\
\hline Backdirt & core & ferruginous sandstone & 5.93 & 4.90 & 4.41 & 161.2 \\
\hline Backdirt & core & silicified wood & 3.97 & 3.92 & 1.53 & 23.1 \\
\hline Backdirt & core & silicified wood & 5.07 & 4.43 & 3.03 & 101.0 \\
\hline Backdirt & core & silicified wood & 6.10 & 5.29 & 4.04 & 153.1 \\
\hline Backdirt & core & silicified wood & 6.55 & 6.00 & 5.63 & 189.0 \\
\hline Backdirt & core & silicified wood & 9.23 & 6.92 & 5.38 & 460.0 \\
\hline Backdirt & core & silicified wood & 10.37 & 5.96 & 4.85 & 397.0 \\
\hline Backdirt & core & silicified wood & 17.01 & 7.04 & 6.90 & 977.0 \\
\hline BT 4 & core & silicified wood & 14.55 & 10.77 & 4.57 & 910.0 \\
\hline BT 8 & core & chert, local & 5.63 & 3.87 & 2.04 & 53.3 \\
\hline BT 9 & core & silicified wood & 9.60 & 4.06 & 2.00 & 73.6 \\
\hline BT 14 & core & Ogallala quartzite & 6.77 & 4.36 & 3.88 & 126.7 \\
\hline BT 21 & core & chert, local & 5.10 & 3.17 & 2.64 & 50.0 \\
\hline BT 30 & core & chert, local & 5.34 & 5.19 & 2.85 & 66.0 \\
\hline BT 30 & core & ferruginous sandstone & 5.11 & 4.89 & 3.15 & 80.1 \\
\hline CMS 1 & core & silicified wood & 9.13 & 4.00 & 2.14 & 115.0 \\
\hline CMS 2 & core & silicified wood & 10.07 & 2.73 & 2.71 & 134.8 \\
\hline SU 8 & core & chert, local & 5.69 & 4.32 & 3.10 & 66.8 \\
\hline SU 9 & core & chert, local & 4.13 & 3.15 & 2.29 & 39.2 \\
\hline SU 28 & core & silicified wood & 4.41 & 3.43 & 1.60 & 28.2 \\
\hline SU 39 & core & ferruginous sandstone & 10.22 & 4.66 & 3.01 & 166.9 \\
\hline SU 44 & core & chert, local & 4.61 & 3.27 & 2.25 & 38.4 \\
\hline SU 69 & core & chert, local & 10.00 & 8.69 & 4.99 & 455.0 \\
\hline TU 10, Lev. 4 & core & silicified wood & 8.17 & 4.51 & 2.29 & 113.9 \\
\hline TU 10, Lev. 5 & core & silicified wood & 6.18 & 3.50 & 2.75 & 71.2 \\
\hline TU 11, Lev. 4 & core & chert, local & 4.14 & 3.54 & 1.89 & 32.3 \\
\hline TU 18, Lev. 4 & core & chert, local & 5.08 & 3.98 & 2.79 & 64.6 \\
\hline Backdirt & core fragment & chert, local & 3.43 & 2.21 & 1.82 & 9.8 \\
\hline Backdirt & core fragment & chert, local & 4.52 & 3.08 & 2.30 & 33.7 \\
\hline Backdirt & core fragment & chert, local & 4.04 & 2.54 & 2.54 & 25.1 \\
\hline Backdirt & core fragment & silicified wood & 2.87 & 2.84 & 1.98 & 19.1 \\
\hline BT 8 & core fragment & chert, local & 3.46 & 2.67 & 1.98 & 16.7 \\
\hline$\overline{\mathrm{BT}} 20$ & core fragment & chert, local & 2.77 & 2.03 & 1.94 & 7.0 \\
\hline BT 21 & core fragment & quartzite & 3.79 & 2.71 & 2.21 & 24.6 \\
\hline Feature 2 & core fragment & quartzite & 4.38 & 3.11 & 2.31 & 22.4 \\
\hline Feature 2 & core fragment & silicified wood & 3.20 & 2.60 & 2.04 & 10.5 \\
\hline
\end{tabular}


Table 6.5, continued

\begin{tabular}{|c|c|c|c|c|c|c|}
\hline Provenience & Core Type & Lithic Material & $\begin{array}{l}\text { Maximum } \\
\text { Length } \\
(\mathrm{cm})\end{array}$ & $\begin{array}{c}\text { Maximum } \\
\text { Width } \\
(\mathrm{cm})\end{array}$ & $\begin{array}{c}\text { Maximum } \\
\text { Thickness } \\
(\mathrm{cm})\end{array}$ & Weight $(\mathrm{g})$ \\
\hline Feature 152 & core fragment & chert, local & 3.77 & 3.06 & 1.86 & 16.0 \\
\hline SU 17 & core fragment & hematite & 5.17 & 4.06 & 2.14 & 42.0 \\
\hline SU 28 & core fragment & chert, local & 3.01 & 2.17 & 1.60 & 10.0 \\
\hline$\overline{\text { SU } 32}$ & core fragment & chert, local & 3.71 & 2.52 & 2.25 & 22.1 \\
\hline SU 39 & core fragment & chert, local & 3.16 & 2.79 & 1.30 & 9.4 \\
\hline$\overline{\text { SU } 40}$ & core fragment & chert, local & 3.64 & 2.38 & 1.28 & 12.1 \\
\hline$\overline{\text { SU } 66}$ & core fragment & chert, local & 2.58 & 1.49 & 1.31 & 3.8 \\
\hline TU 3, Lev. 4 & core fragment & chert, local & 3.28 & 3.07 & 2.37 & 14.4 \\
\hline TU 11, Lev. 5 & core fragment & chert, local & 6.20 & 5.29 & 1.84 & 58.2 \\
\hline TU 21, Lev. 4 & core fragment & quartzite & 3.09 & 3.09 & 1.71 & 15.4 \\
\hline Backdirt & core (tested) & chert, local & 3.83 & 2.95 & 2.13 & 27.6 \\
\hline Backdirt & core (tested) & chert, local & 4.66 & 3.93 & 3.47 & 72.8 \\
\hline Backdirt & core (tested) & chert, local & 4.72 & 4.31 & 2.80 & 80.3 \\
\hline Backdirt & core (tested) & chert, local & 5.86 & 4.33 & 1.45 & 40.3 \\
\hline Backdirt & core (tested) & hematite & 6.75 & 6.27 & 4.84 & 222.3 \\
\hline Backdirt & core (tested) & hematite & 3.79 & 2.56 & 2.06 & 20.2 \\
\hline Backdirt & core (tested) & quartzite & 6.77 & 4.85 & 3.04 & 101.3 \\
\hline Backdirt & core (tested) & quartzite & 7.04 & 5.66 & 4.99 & 202.0 \\
\hline Backdirt & core (tested) & quartzite & 8.40 & 6.19 & 3.11 & 241.4 \\
\hline Backdirt & core (tested) & quartzite & 8.44 & 6.95 & 3.63 & 247.3 \\
\hline Backdirt & core (tested) & quartzite & 2.82 & 2.41 & 2.17 & 14.2 \\
\hline BT 4 & core (tested) & chert, local & 5.39 & 3.58 & 2.86 & 70.2 \\
\hline BT 4 & core (tested) & quartzite & 5.84 & 2.81 & 2.52 & 62.2 \\
\hline BT 6 & core (tested) & ferruginous sandstone & 6.63 & 6.39 & 4.49 & 205.3 \\
\hline BT 7 & core (tested) & chert, local & 5.45 & 2.93 & 2.57 & 70.1 \\
\hline BT 30 & core (tested) & chert, local & 6.38 & 3.05 & 3.91 & 106.3 \\
\hline BT 30 & core (tested) & chert, local & 6.74 & 4.71 & 3.83 & 213.4 \\
\hline BT 30 & core (tested) & chert, local & 3.92 & 2.83 & 1.39 & 14.6 \\
\hline CMS 2 & core (tested) & chert, local & 4.58 & 4.22 & 2.75 & 52.1 \\
\hline SU 34 & core (tested) & quartzite & 3.79 & 2.38 & 1.66 & 16.3 \\
\hline SU 59 & core (tested) & chert, local & 9.56 & 7.11 & 4.83 & 405.0 \\
\hline TU 16, Lev. 5 & core (tested) & silicified wood & 9.20 & 6.12 & 3.26 & 228.2 \\
\hline
\end{tabular}

Nonlocal materials are mostly gray cherts (3 percent) as well as some black chert, white chert, Edwards chert, other odd cherts, and chalcedony (together accounting for 1 percent). Given that the cores are entirely of local materials, the nonlocal debitage most likely came from finished artifacts or tool blanks (bifaces or flakes) that were further manufactured into tools, resulting in retouch and other debitage.
The debitage is predominantly small to medium in size: 4 percent is less than $7.0 \mathrm{~mm}$, 26 percent is $7.0-12.5 \mathrm{~mm}, 30$ percent is $12.5-$ $19.0 \mathrm{~mm}, 19$ percent is $19.0-25.0 \mathrm{~mm}, 15$ percent is $25.0-38.0 \mathrm{~mm}$, and 5 percent is larger than $38.0 \mathrm{~mm}$. The scarcity of large pieces of debitage suggests much initial reduction was done away from the site, and it also is consistent with the conclusion that the reduction that was done there focused on small locally available 
materials and tool blanks or finished tools of nonlocal materials.

\section{GROUND, PECKED, AND BATTERED STONE ARTIFACTS}

A total of 104 ground, pecked, and battered stone artifacts were recovered: 1 axe, 1 celt, 1 adze, 22 hammerstones, 15 manos/hammerstones, 21 pitted hammerstones, 5 anvils, 4 grinding slabs/anvils, 4 grinding slabs, 4 grooved and grooved/incised stones, 1 mano/anvil/abrader, 1 polishing stone, 3 pigment stones, and 21 indeterminate (see Appendix $\mathrm{E}$ for metric and provenience information). A third $(\mathrm{n}=35)$ have some form of pit or depression used in crushing/ splitting/pulverizing activities. If items with interchangeable, equivocal, or indeterminate functional positions are excluded, then base-position artifacts (anvils, grinding slabs, etc.) account for 15 percent of the assemblage, and handheld items make up 63 percent. Eight percent exhibit clear evidence of intentional shaping, and 62 percent show no indication of such treatment. The presence/absence of deliberate surface modification was not determinable for almost a third of the assemblage, but nearly two-thirds of this group are indeterminate fragments. Almost half (48 percent) show some level of thermal alteration; heat-derived modification is heavy or severe on 36 percent of that group.

Seven material types are represented. Over half are quartzite (52 percent). Ferruginous and nonferruginous sandstone account for 17 and 14 percent, respectively. Hematite artifacts compose 11 percent. Small amounts of Stanley or Jackfork sandstone $(n=2)$, chert $(n=1)$, and ochre $(n=2)$ account for the remainder.

A pecked and ground fully grooved hematite axe is roughly trapezoidal in outline and elliptical in cross section and has a semirounded poll (Figure 6.31). Numerous peck marks are visible across its surface. Much of the surface is only marginally smoothed and still relatively rough, though the friable nature of the material suggests that at least some of the surface irregularities may be derived from material exfoliation. One side of the blade (from groove to bit end) is very well smoothed and polished and is likely a better representation of how the axe looked when new. The opposite side of the blade and the curved blade margins also retain very smooth and highly polished surface remnants.
The bit end was destroyed by unifacial impact fracturing, and blunt force damage removed material from both sides of the poll and one of its rounded corners. Inadvertent modern impact with a shovel sent fracture lines through the length of the artifact and removed a large fragment from one side of the poll. This blow also exposed concentric bands of iron oxides known as Liesegang rings, which are derived from chemical weathering of a once-homogenous piece of ferruginous sandstone (Turner 2006:18-19).

The single celt fragment is made of Stanley or Jackfork sandstone (Figure 6.32a). Segments of the original pecked and ground surface are present on this battered proximal fragment. Focused percussion marks are not associated with initial shaping of the artifact. In addition, the proximal end shows impact-derived flake removals around most of its diameter. Ridges created by flake scars and material fracture at the snapped distal end trend longitudinally relative to the artifact's elliptical cross section.

An exhausted quartzite adze has a curved top, incurved sides, and well-smoothed dorsal surface above the flake scars along the bit edge (Figure 6.32b). Consistent use and retouch of the unifacial bit modified its edge angle to such a degree that it was no longer useable as a planing tool. A flake scar on the ventral surface emanates from the proximal end, and several prominent percussion marks are in the immediate vicinity of the scar's initiation point. These attributes suggest that the proximal end of the exhausted adze was used as a hammerstone after it was removed from its haft.

Twenty-two hammerstones, 15 manos/hammerstones, and 21 pitted hammerstones were recovered (Figure 6.32c-e). Thirty-five (60 percent) are quartzite. Ferruginous and nonferruginous sandstone are evenly represented with 9 artifacts each. The remainder consist of 3 hematite specimens and 1 each of chert and Stanley or Jackfork sandstone. Hammerstones include a variety of naturally rounded ovoid pebbles and cobbles, irregular pebbles, and an irregular tabular cobble. Five are battered on the ends only, whereas 5 others have battering damage on their ends, margins, and multiple facets. The remaining hammerstones show battering damage in numerous places and in a variety of combinations, including ends, margins, raised ridges, and faces. Six specimens exhibit slight battering/abrasion-derived smoothing on one or 


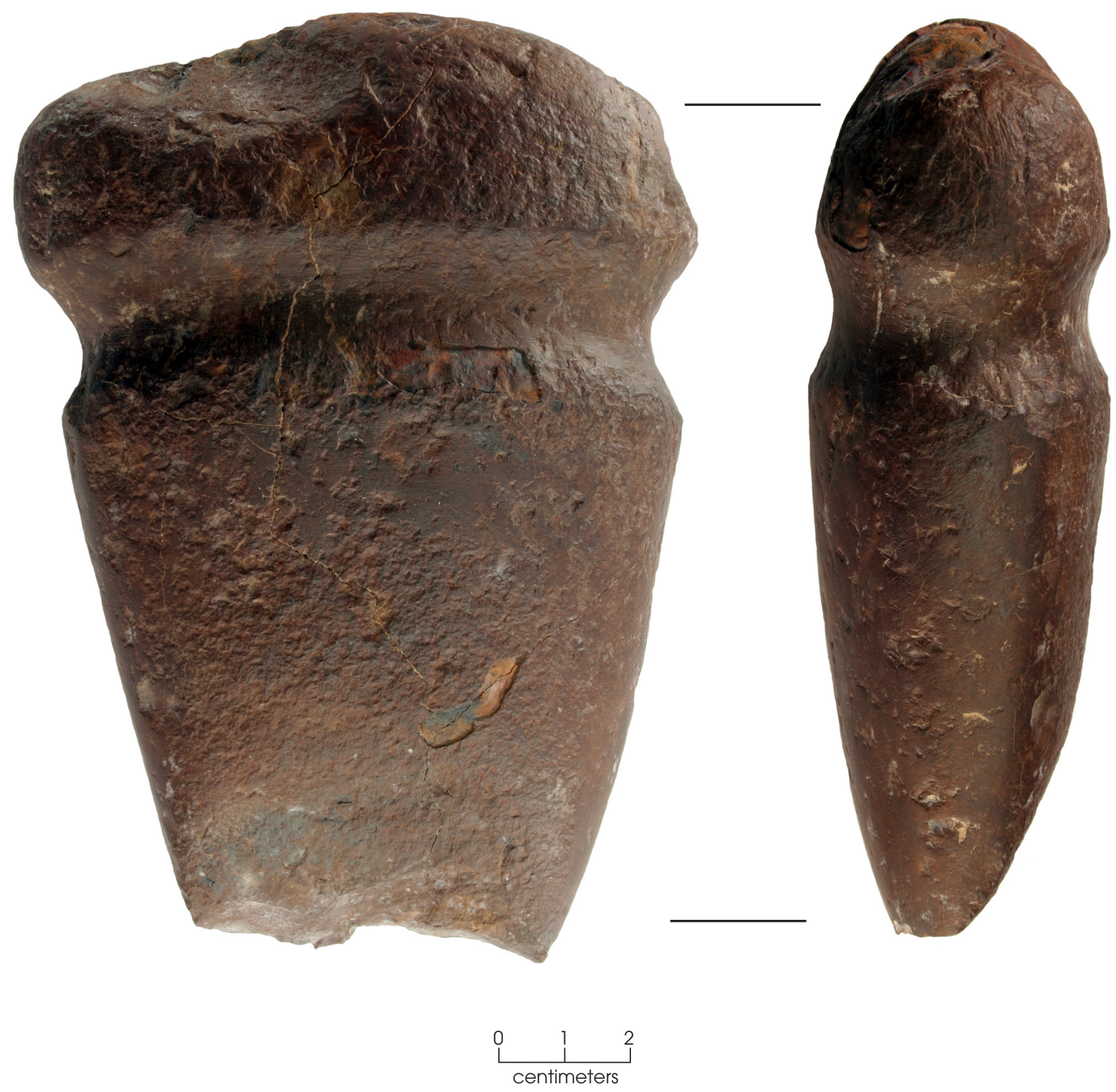

Figure 6.31. Full-grooved hematite axe from the James Richey site.

more faces or on the margins, indicating that the faces were used in conjunction with anvils to crush or pulverize material. Impact-derived flake removal is evident on 3 hammerstones, and 4 are fragments of larger artifacts. A naturally rounded quartzite cobble was used primarily as a hammerstone and secondarily as a polishing stone (see Figure 6.32c). Small percussion marks are on its ends, one margin, and on both faces; most of these are concentrated in five places. The slightly convex face is well polished.

Naturally rounded pebbles and cobbles typically were utilized as manos/hammerstones. These tend to be larger than the plain hammerstones. Some exhibit intentional modification. The size variation within this group indicates 


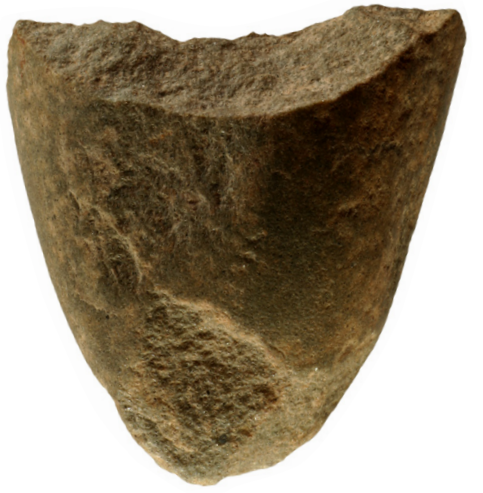

a

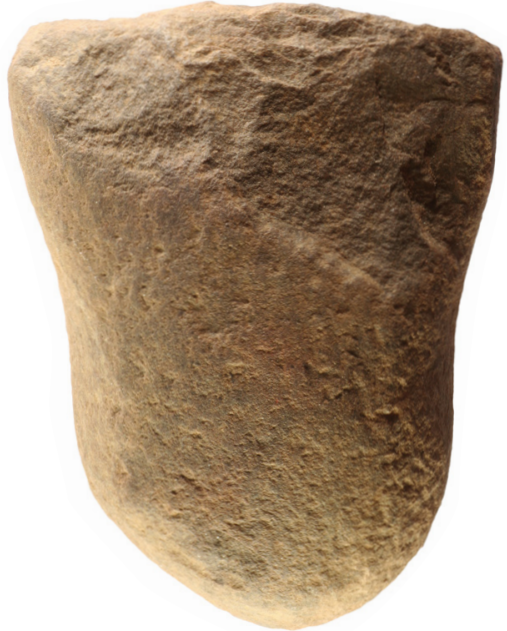

b

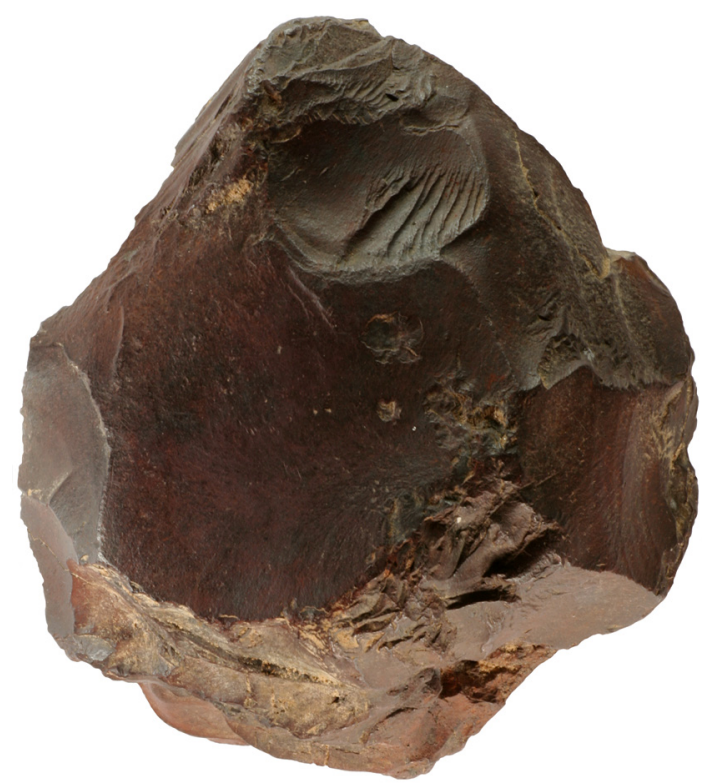

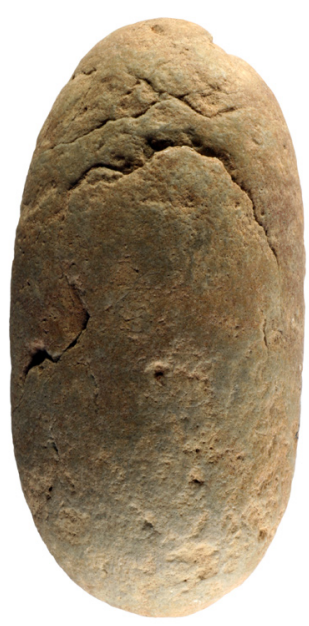

e

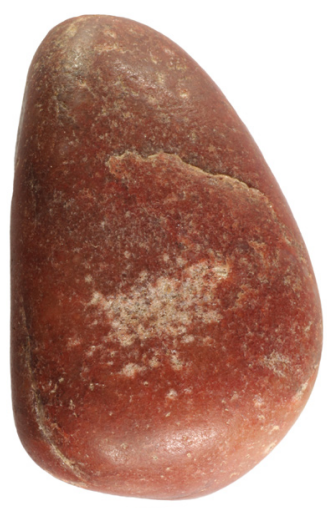

C

d

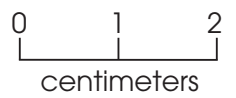

Figure 6.32. Celt, adze, hammerstones, and mano/hammerstone from the James Richey site. (a) Battered celt fragment; (b) exhausted adze; (c) quartzite hammerstone/polishing stone; (d) hematite hammerstone; (e) Stanley or Jackfork sandstone mano/hammerstone.

that 10 were manipulated with the palm (like true manos), whereas 4 were manipulated with the fingers like the mullers noted by Ellis (2009); one fragment is too small to make a confident determination. Manos/hammerstones exhibit varying degrees of grinding/abrasion-derived smoothing on one or two faces, or in one instance, on a wide cobble margin. Battering 
damage is most common on ends and margins and often present on unsmoothed faces. As with hammerstones, battering damage occurs in a variety of locations. Percussion/peck marks are common on smoothed facets, and in 6 instances, these are primarily restricted to the center of a facet or localized around shallow depressions or incipient pits centered on grinding/abrading facets. Thus, smoothing on some of these artifacts is derived from a variety of activities (i.e., grinding/abrasion, crushing, pulverizing). The largest could have been used as a hammer or an anvil. Although naturally striated along bedding planes, fine striations derived from grinding wear are present on multiple working facets, and most are oriented at acute angles to the bedding planes. In addition, ocher is lodged in vesicles on the edge of one smoothed face. A naturally rounded cobble has a series of narrow, discontinuous, roughly parallel incisions/grooves on one smoothed face that appear to be caused by hard material trapped between the mano and the grinding surface. In addition, a series of short incisions is on the outer edge of the opposite, less-used grinding facet, and two short sets of incisions are on a smoothed segment of the cobble margin. The two largest and deepest incisions (on the rougher facet) may be derived from intentional abrasion. Targeted percussion on the same facet also indicates that the cobble was used to crush/pulverize/split material. A small, battered ferruginous sandstone cobble has two marginally smoothed facets and a wide shallow groove created by reciprocal abrasion on a third facet. Several incisions or angular cuts are visible within the larger groove. In addition to other uses, this mano/hammerstone was used as a handheld abrader. One mano/hammerstone is of Stanley or Jackfork sandstone (see Figure 6.32e). Given the material type, this small (ca. $62 \mathrm{~mm}$ long), elongated, ovoid artifact could be a recycled celt fragment. Percussion/peck marks are scattered across the entire surface of the artifact and concentrated on one wide face. The opposite face is well smoothed from grinding/ abrasion wear, suggesting use as a mano/muller. However, if this artifact is a recycled celt fragment, then the smooth surface may be derived from original celt manufacture.

Pitted hammerstones are mostly subangular and angular tabular cobbles but also include naturally rounded ovoid pebbles and cobbles and irregular subangular and angular pieces of rock.
Wear on some indicates they were multifunctional tools. Several might be recycled ground stone tools. Five have surfaces that were smoothed (at least in part) by grinding, and one of these could be a multifunctional tool or a recycled mano/muller. Four others are either recycled anvil fragments or pieces that were used interchangeably as pitted hammers and anvils. Two of the pitted hammerstones were intentionally shaped. Battering damage is commonly located on ends, corners, margins, and thin facet edges. These artifacts typically have at least one relatively flat to slightly concave facet with targeted wear consisting of one or a combination of the following: focused percussion/pecking, incipient pitting, percussion-derived pits, and ground/ abraded depressions or pits. In general, the pits are smaller and less well defined than those on anvils. Natural cavities or depressions were utilized for pit locations on at least 5 artifacts. Surfaces surrounding these often show minimal to moderate abrasion-derived smoothing from use of the hammer to crush/pulverize material on an anvil. In some instances, facet edges exhibit considerable impact-derived damage. The pitted hammers are almost evenly divided between single- and double-facet artifacts (9 and 10, respectively). Another has localized percussion on three variably smoothed facets. An irregular subangular cobble has pits on three facets and targeted percussion on a fourth. A relatively large natural depression on one of those facets was utilized as a pit. Percussion marks are visible in this pit, and the surrounding surface is well battered. Although this relatively large cobble is considered to have served primarily as a hammer, it also might have been utilized as an anvil.

There are two complete anvils, an anvil fragment, and two probable anvil fragments. The complete artifacts are thick, angular, tabular to blocky quartzite and ferruginous sandstone cobbles with two work surfaces. In both instances, shallow natural depressions on the cobble faces were utilized to crush, pulverize, and/or split material. Scattered percussion marks and incipient pitting are present within each, and some degree of battering/abrasion-derived smoothing is apparent in or on the outside edges of these depressions. Some of the smoothing on the working facets is likely the result of abrasion by the surface that the artifact was resting on while in use. The tabular quartzite cobble has a natural 
shallow depression on one face and a well-defined, relatively deep pit at the edge of the same face. The depression is 100-120 mm across and $17 \mathrm{~mm}$ deep. Percussion marks within this feature are indicative of incipient pitting. The well-defined pit may be a natural declivity that was expanded by targeted percussion. The opposite side of this artifact has a shallow concavity that is roughly 120-150 mm across. The other large anvil was fashioned from a block of ferruginous sandstone. The edges of the top and bottom work surfaces were intentionally smoothed and rounded by battering and pecking. The primary working facet is a shallow depression with smoothing and percussion marks that is approximately $100-120 \mathrm{~mm}$ across. Smoothing is most obvious around a rough-surfaced central area defined by numerous large percussion marks. The uneven bottom face exhibits evidence of less-intensive use.

A tabular anvil fragment of very loosely consolidated ferruginous sandstone has smoothed upper and lower faces and intentionally smoothed and rounded margins (Figure 6.33a). The rougher facet retains numerous percussion/ peck marks with incipient pitting in the center. The well-smoothed opposite face retains approximately half of a pit on the roughest facet edge. The pit is derived from a combination of percussion and grinding/abrasion wear. Its location at the edge of the facet and the morphology of the adjacent margin suggest this is a fragment of a larger artifact that was modified after an earlier fracture. While lithic material degradation may be responsible for the poorly consolidated condition of this specimen, it is also possible that this loosely consolidated material was intentionally selected and used for pigment production. Two angular fragments are tentatively classified as anvils on the basis of morphology and visible wear. A thermally fractured piece of quartzite appears to be a medial fragment of a tabular cobble. Percussion/peck marks are present on top and bottom facet remnants, and incipient pitting is apparent on the largest of these surfaces. A thick nonferruginous sandstone fragment has a relatively flat, roughly smoothed face with peck marks and part of a pit, which may be a utilized and expanded natural vesicle. Artifact fracture may be derived from the use of that feature.

The assemblage includes four grinding slabs/anvils and four grinding slab fragments. The former were fashioned on thick, blocky, tabular quartzite cobbles and have one flat to concave face smoothed to varying degrees by grinding/abrasion-derived wear. One also has a marginally smoothed second facet. One blocky artifact has an elongated smooth pit and a rough-sided pit within a smoothed concave facet. The rough pit is an expanded and utilized natural void. The other grinding slabs/anvils have either concentrated percussion/peck marks or incipient pitting on the smooth work surfaces, typically outside the smoothest facet segments. A natural depression on the side of one artifact and natural vesicles on the bottom of another were used in conjunction with a hammer for crushing/pulverizing activities. The shape of one grinding slab/anvil was intentionally modified by flake removal, and its top and bottom edges were purposefully smoothed. Thermal color alteration is evident on three specimens, and heat spalling is apparent on one of those.

The grinding slab fragments are tabular pieces of ferruginous sandstone and hematite and a thick angular fragment of thermally fractured quartzite. The latter has one well-smoothed, very flat facet remnant with peck marks and several narrow deep striations. Ferruginous sandstone artifacts include a rectilinear fragment with one smoothed face and an irregular fragment with two smoothed faces. Peck marks are present on the smoothed surfaces. The work surface on the irregular hematite fragment consists of a thin veneer of solid material on an otherwise extensively honeycombed fragment. The degraded veneer has a rough, pitted, crumbly appearance, though very smooth surface remnants are still present. Under magnification, a multitude of narrow overlapping striations is visible on intact segments of the grinding surface. The majority of these trend along the same or closely similar alignments, but wear is apparent in two other directions as well.

A rectilinear tabular piece of ferruginous sandstone is classified as a grooved/incised stone because of wear on both faces (Figure 6.33b). One side consists of a concave, very smooth, ground/ abraded facet remnant derived from reciprocal motion. This linear depression parallels the fragment's long axis. This feature appears to have been part of a larger groove. Under magnification, the smooth surface is composed of numerous overlapping striations that follow the same alignment. These minute cuts are $\mathrm{V}$-shaped and broadly V-shaped in cross section. The opposite facet has a rough, minimally smoothed 

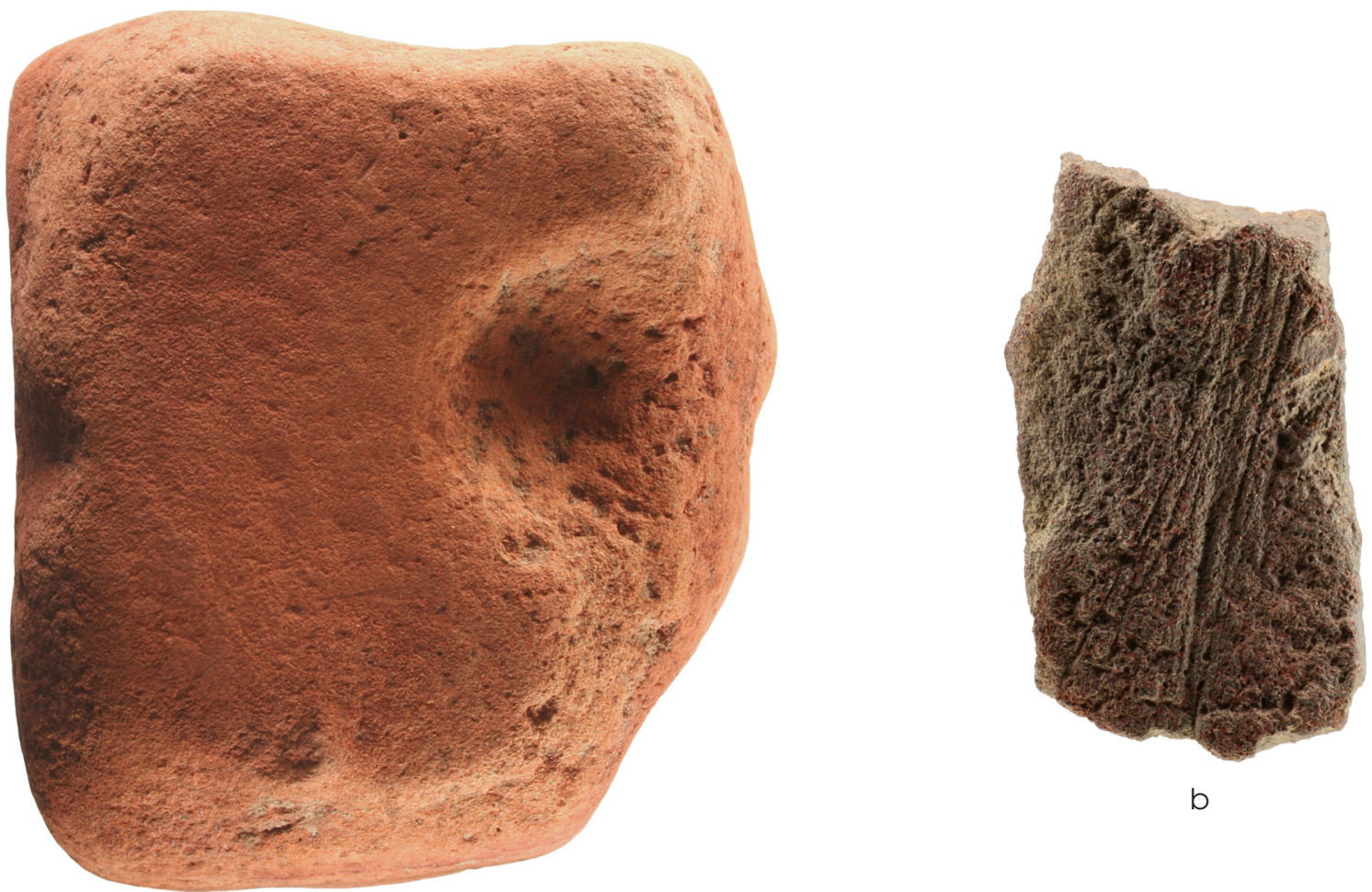

b

a
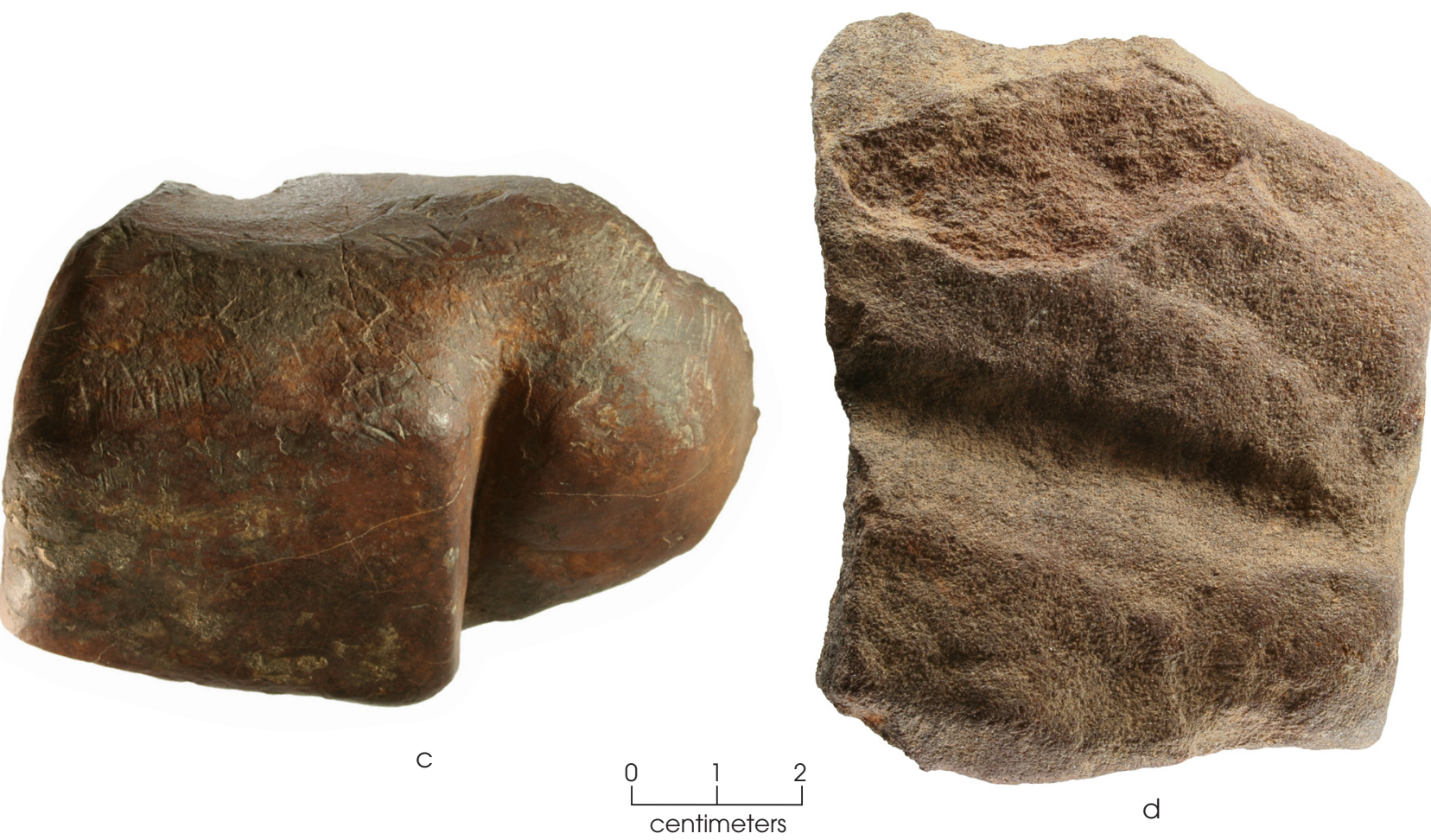

Figure 6.33. Anvil and grooved or incised stones from the James Richey site. (a) Ferruginous sandstone anvil fragment with smooth pit; (b) grooved/incised tabular ferruginous sandstone; (c) incised hematite cobble; (d) grooved tabular ferruginous sandstone. 
surface remnant that is slightly concave. A series of incisions trend across the length of the facet on various alignments. These have a maximum width and depth of 2.8 and $1.0 \mathrm{~mm}$, respectively. The incisions have steeply angled walls and narrow curved bases. In addition, several short incisions on the edge of the facet remnant are oriented transverse to the longer cuts.

The second grooved/incised stone is a thick tabular fragment of ferruginous sandstone with three parallel narrow grooves/incisions on one facet remnant. These have maximum widths of 3.4 and $4.1 \mathrm{~mm}$, and the longest is $61.5 \mathrm{~mm}$. The two clearest grooves are U-shaped in cross section. In addition, a short downward-trending groove or notch is on the outer edge of the grooved/incised face. Several parts of this facet are smoothed. Two small oval areas are particularly smooth. A bisected pit remnant on the same face indicates this specimen was part of a larger pitted artifact.

An irregular, relatively thick subangular hematite cobble also is classified as a grooved/ incised stone, but this artifact also exhibits wear characteristic of several other functions (Figure 6.33c). In addition to serving as an abrader, it was also used as a pitted hammerstone, an anvil, a hammerstone, and possibly a pestle. Incipient, percussion-derived pitting is apparent on one cobble margin. Part of a shallow, circular, smooth-faced depression is in the center of the relatively flat ventral face, and several narrow percussion marks are in and around the smoothed area. About half of the surrounding surface remnant is rough because of concentrated percussion and battering damage. Approximately 40 percent of the depression was removed by battering-derived flake detachment. This flake and others were removed from a relatively flat cobble end. The edges of this facet are clearly battered, but the facet surface is smoothed and exhibits some polish. This kind of damage and wear could be derived from using the flat cobble end as a pestle. Use-derived flake scars also emanate in two different directions from the narrower opposite end. Numerous short incisions or notches are present in clusters at the edges of the dorsal and ventral surfaces and the flat cobble end, but most are along one margin segment. Some of the most prominent incisions are along the top edge of a flake scar at the cobble's narrow end. In general, these narrow cuts are parallel or oriented on closely similar alignments, but incisions cross each other at nearly perpendicular angles on the narrow rounded cobble end. Many of the incisions may be natural or inadvertent, but at least one well-entrenched incision and surrounding marks were derived from intentional abrasion. In the latter instance, a natural crease in the cobble's dorsal surface was utilized for abrasion, which in turn created a slightly expanded, entrenched incision or narrow groove. Aligned roughly perpendicular to the cobble's long axis, the groove is relatively straight, slightly undercut on one side, and about $40 \mathrm{~mm}$ long. Use-derived incision marks are present at either end of this cut.

A tabular fragment of ferruginous sandstone has two acutely oriented, rough-walled grooves on one face (Figure 6.33d). The largest is parabolic in cross section, has an approximate maximum width of $15 \mathrm{~mm}$, and varies from 5.2 to $5.7 \mathrm{~mm}$ in depth. The subtle second groove is uneven in section (one wall steeper than the other) and has an approximate maximum width of $10.6 \mathrm{~mm}$. A flake scar truncates the smaller groove. Although the margins of these grooves are uneven (because of natural declivities in the rock, uneven wear, or both), the cross section of each is consistent over its length.

A small, thin piece of ferruginous sandstone served several functions. Variable grinding-derived smoothing is apparent on both faces, and the slightly convex face might have been used as a mano. A shallow pit with percussion/peck marks is in the center of the same face. This feature indicates the artifact was used as either a light pitted hammerstone or a small anvil or both. A broad, shallow depression at one end of the convex face suggests that the specimen was used as an anvil. In addition, wear on the sides and opposite face indicate it also was used as a handheld abrader. Numerous fine incisions are present on one thin rounded margin. Most of these are oriented perpendicular to the artifact's edge, but others meet the edge at oblique angles. Some of these features extend around the margin. Under magnification, the largest incision is V-shaped in cross section. Two subtle, narrow, shallow grooves are apparent on the opposite margin, and at least that many are visible on the rougher artifact face.

A cylindrical piece of hematite is tentatively classified as a polishing stone. The ends of the thin, elongated piece are angled relative to the object's 
long axis and worn smooth and polished. Similarly oriented striations are present on one end.

The three pigment stones are a small piece of hematite and two sizable ochre fragments. The irregular elongated hematite fragment has a relatively hard angular end and a soft rounded end. Two ground/abraded facets are present on the soft side of the artifact, and the morphology of the now-fractured end suggests it too probably was abraded. Numerous striations are visible on the softest two-thirds of the artifact. One of the ochre fragments is roughly triangular with a large curved and rounded edge. Two flat smooth grinding/abrasion facets are present on one side of this curved face. Striations are visible on each facet. The narrow width of one grinding surface and its location with respect to a rough unused face suggests that this specimen is a fragment of a larger piece. The third pigment stone is a tabular roughly ovoid piece with smoothing on both faces. Numerous striations and fine incisions are present along the smoother face; these are multidirectional, but most follow the same general alignment. In addition, a broad groove is cut into the narrowest portion of the same facet, and several short incisions are cut into one edge. Approximately 10 narrow grooves or notches are cut into the opposite edge, most of which extend around and onto the opposite face, giving the edge a faceted bifacial appearance. Paired or multiple partially overlapping narrow incisions are visible at the bases of these broad notches. Under magnification, the cross sections of individual incisions are steep-walled parabolas. In some instances, one side of the incision is flatter or not as steeply angled as the other; this morphology is likely derived from reuse of the large grooves on the side of the fragment, which resulted in incision overlap. Offset incisions on both faces of the grooved edge indicate bifacial wear. The change in incision orientation from one side to the other suggests that the fragment was flipped as it was rubbed against an object. While the notches appear to be culturally derived, paired shallow striations/grooves on one edge segment are probably the result of rodent gnawing.

Twenty-one artifacts are indeterminate fragments. Eleven are quartzite, 5 are nonferruginous sandstone, 1 is ferruginous sandstone, and 4 are hematite. Four quartzite fragments and 2 pieces of nonferruginous sandstone are thermally fractured. The quartzite artifacts are primarily irregular cobble and pebble edge fragments that retain a facet with some degree of use-derived smoothing and percussion/peck marks. In some instances, facet segments are naturally smoothed cortical surfaces. One cobble edge fragment has two smoothed facet remnants. Percussion-derived pitting is apparent on 2 of the quartzite fragments, and 2 specimens are battered on margins adjacent to the smoothed facet remnants. One of the quartzite fragments is a wide flake that was detached from the edge of a curved artifact; this specimen retains a flat pockmarked facet remnant. The quartzite tool fragments are derived from various grinding implements, primarily manos, hammerstones, and pitted stones.

Four of the nonferruginous sandstone fragments have battered margin segments and wellsmoothed facet remnants. General morphology and wear patterns on a rounded cobble fragment suggest it may have been used as a mano/hammerstone and a pitted hammerstone. A tabular piece of fossiliferous sandstone with a smooth slightly concave facet could be part of a small anvil. The other two items are cobble edge or end fragments with small facet remnants; one is slightly concave, and the other is convex. The orientation and morphology of three facet remnants on the fifth nonferruginous sandstone artifact suggest it could be a grinding slab fragment.

A tabular ferruginous sandstone fragment has a well-smoothed face that is slightly concave across its length. A curved segment on the smoothed facet remnant could represent an artifact edge, the side of a groove, or part of a smooth-walled pit. Surface striations are oriented in at least two opposing directions. Although confident functional assessment is not possible, the morphology of the ground/abraded surface suggests it is not part of a handheld artifact.

The hematite specimens are rectilinear and wedge-shaped fragments that retain one to two smoothed facet remnants. The largest fragment has two opposing, variably smoothed, friable, concave surface remnants with numerous percussion/peck marks. The depths of some of the percussion marks are suggestive of pitting. The smaller fragments each have one well-smoothed facet remnant. Peck marks, micropitting, and short shallow incisions are present in various combinations on these surfaces, and magnification revealed that each retains fine, multidirectional striations. Striation densities vary considerably between the two facet remnants. 


\section{DAUB AND BURNED CLAY}

The wattle-impressed daub (305.9 g) was recovered predominantly from sample units (36 percent), features ( 28 percent), and test units (23 percent), mostly (65 percent) on the west side of the site in the shallow deposits, and all but 5 percent of this is in the northwest part (Table 6.6). Burned clay totals $798.3 \mathrm{~g}$.

\section{MACROBOTANICAL REMAINS}

The excavations recovered macrobotanical remains from numerous contexts. About $58 \mathrm{~g}$ are analyzed and reported in Appendix F. The analyzed materials are from 29 flotation samples (from 25 features) and 17 samples collected by hand from 12 features. Selection of flotation samples for study was primarily guided by context and included most of the large and small pits and all of the smudge pits, but only a few of the postholes. Features whose fill appeared to be in primary context, such as smudge pits with evidence of in situ burning based on large quantities of burned macrobotanical remains, were prime candidates for analysis. Twentyseven samples were collected and floated but not sorted or analyzed.

Most of the samples are from pits of uncertain function (83 percent), with only 14 percent from postholes, and 3 percent from smudge pits. Volumetrically, the breakdown of the 377 liters processed by flotation is even more skewed to pits of uncertain function (94 percent), with 3 percent from smudge pits and 3 percent from postholes. The 17 nonflotation samples are from large pits $(n=9)$, small pits $(\mathrm{n}=4)$, smudge pits $(\mathrm{n}=2)$, burial fill $(\mathrm{n}=1)$, and a soil disturbance that was determined to be noncultural $(\mathrm{n}=1)$.

The bulk of the analyzed material is from secondary contexts and represents the generalized scatter of plant remains created by occupation of the site. The samples from the smudge pits, however, more likely represent primary contexts. The remains from these samples indicate that corn cobs, hickory nutshells, and mostly oak wood were used to create smoky fires. One large pit (Feature 53) potentially reflects primary context based on some evidence for thermal activity, but the scant remains $(0.01 \mathrm{~g}$ hickory nutshell and $0.01 \mathrm{~g}$ wood not examined) provide little support for this supposition.
Table 6.6. Burned clay and daub from the James Richey site (weights in grams)

\begin{tabular}{|c|c|c|}
\hline Provenience & Burned Clay & Daub \\
\hline Feature 28 & 2.4 & \\
\hline Feature 44 & 9.6 & 7.3 \\
\hline Feature 45 & 7.3 & 25.7 \\
\hline Feature 48 & 19.3 & 48.3 \\
\hline Feature 51 & 3.3 & 5.0 \\
\hline Feature 113 & & 0.6 \\
\hline Feature 142 & 6.1 & \\
\hline AT 16 & & 1.1 \\
\hline TU 2 & & 4.5 \\
\hline TU 3 & 1.7 & \\
\hline TU 5 & 2.3 & \\
\hline TU 9 & 1.3 & 7.3 \\
\hline TU 10 & & 16.6 \\
\hline TU 14 & & 13.8 \\
\hline TU 17 & & 21.0 \\
\hline TU 19 & & 6.6 \\
\hline TU 21 & 5.1 & \\
\hline BHT 10 & 1.6 & 6.8 \\
\hline BHT 21 & & 1.5 \\
\hline SU 4 & 4.7 & 37.1 \\
\hline SU 5 & & 16.1 \\
\hline SU 10 & 4.6 & 21.8 \\
\hline SU 15 & & 7.2 \\
\hline SU 16 & & 2.5 \\
\hline SU 39 & 2.1 & \\
\hline SU 43 & & 9.7 \\
\hline SU 53 & 1.8 & 2.5 \\
\hline$\overline{\text { SU } 66}$ & 0.6 & \\
\hline SU 67 & & 4.5 \\
\hline SU 68 & & 8.4 \\
\hline SU 69 & 3.7 & \\
\hline CMS 2 & 4.1 & \\
\hline General site & 716.7 & 30.0 \\
\hline Totals & 798.3 & 305.9 \\
\hline
\end{tabular}

From all of the features, seven kinds of wood charcoal (excluding general categories like hardwoods and indeterminate) were identified, with oak (white and red) and hickory dominant. These fuels were collected from on or near the site, reflecting the oak-hickory forest that the area supported. Wood charcoal representing deciduous and riparian environments is represented by ash, elm, persimmon, and plum/cherry. 
Charred cane stem is present in small amounts and is likely representative of baskets and mats rather than fuel materials.

Corn is the only cultigen identified. The corn kernels $(0.07 \mathrm{~g})$ were recovered from Feature 17 , the very large pit, and corn cupules and glumes $(1.26 \mathrm{~g})$ were recovered from four large pits (including Feature 17), two small pits, and one smudge pit (Feature 47). Small numbers of maygrass, nightshade, purslane, spiderwort, verbena, elberberry, strawberry, daisy family, and grass family seeds were recovered as well. The remainder of the macrobotanical remains that represent foods is dominated by hardwood nuts, especially hickory but also acorn; these were present in 83 percent of the flotation samples.

\section{FAUNAL REMAINS}

The excavations yielded a small collection of 117 faunal bone fragments (Appendix G). Ninety-five percent $(n=111)$ are classifiable only as vertebrate skeletal material. The other 6 specimens are 3 canid/deer-sized mammal elements, a medium-sized artiodactyl tibia fragment, and 2 fragments of dermal armor plate from a nine-banded armadillo (Dasypus novemcinctus). The armadillo's range did not expand into this region until historic times, so these remains are likely unassociated with indigenous use of this location.

Eighty-four percent of the elements $(\mathrm{n}=98)$ are calcined. Burned elements include a calcined rib shaft fragment from a canid/deer-sized mammal and indeterminate fragments of vertebrate skeletal material. The artiodactyl tibia fragment is unburned and is the only element in the collection that exhibits spiral fracture. All of the other faunal elements show angular fractures.

\section{CHRONOLOGY}

\section{Radiocarbon Dates}

Twenty-six radiocarbon dates were obtained from charred nutshells, corn, and wood as a result of the 2007-2008 testing and 2010 data recovery excavations; a twenty-seventh assay, from Feature 136, yielded a modern age (Tables 6.7 and 6.8). All are from smudge pits, large pits, small pits, postholes, and the fill of a burial. Only 2 are from smudge pits, which are preferable for dating since their contents are more likely to represent in situ burning than are charred remains in other kinds of features. Three dates are from 2 large pits, Features 12 and 35, that may be large versions of smudge pits, and thus these may be primary contexts as well.

The remaining 21 dates almost certainly are from secondary contexts: 5 from large pits, 13 from small pits, 2 from postholes, and 1 from burial fill. The carbonized materials occur in low densities in these features, and most probably were dumped or swept into open features during cleaning episodes. Other charred remains probably accumulated on the surface and incidentally made their way into open features, for example, when posts were pulled and postholes left open. The dated materials from most, if not all, of these do not relate to the functions of the features. They may be contemporaneous or predate actual use of the features, and they could even postdate them if rodent burrowing or roots translocated later charcoal into the fill of older features. In addition to limitations imposed by the scarceness of primary contexts, the data set suffers because some of the assays fall within spans when calibration yields multiple or long date ranges due to wiggles in the calibration curve. The discussion of radiocarbon dating below relies on the calibrated results as determined by CALIB Rev 6.0 (Stuiver et al. 2005) using the IntCal09 data set, since it gives probabilities associated with the possible intervals (the intervals determined by the Beta Analytic calibrations are included on Table 6.7 as well), and focuses on the two-sigma ranges.

This site does not have the same kind of feature evidence that the George Richey and William Ford sites do and thus is harder to interpret, but assuming it had a similar kind of history, the dates can be interpreted as representing a single main Caddo residential component and several minor earlier and later components. The main occupation appears to be represented by 21 dates overlapping chiefly in the A.D. 1400s (Figure 6.34). Three dates have ranges that extend substantially earlier, and 16 have ranges extending much later, but such a long span (several hundred years for this group of dates) would not be consistent with the presumed nature of the main occupation, i.e., a residential settlement lasting a generation or two. One of the smudge pit dates is in this group, as are all 3 large pit dates that could be from primary contexts. 


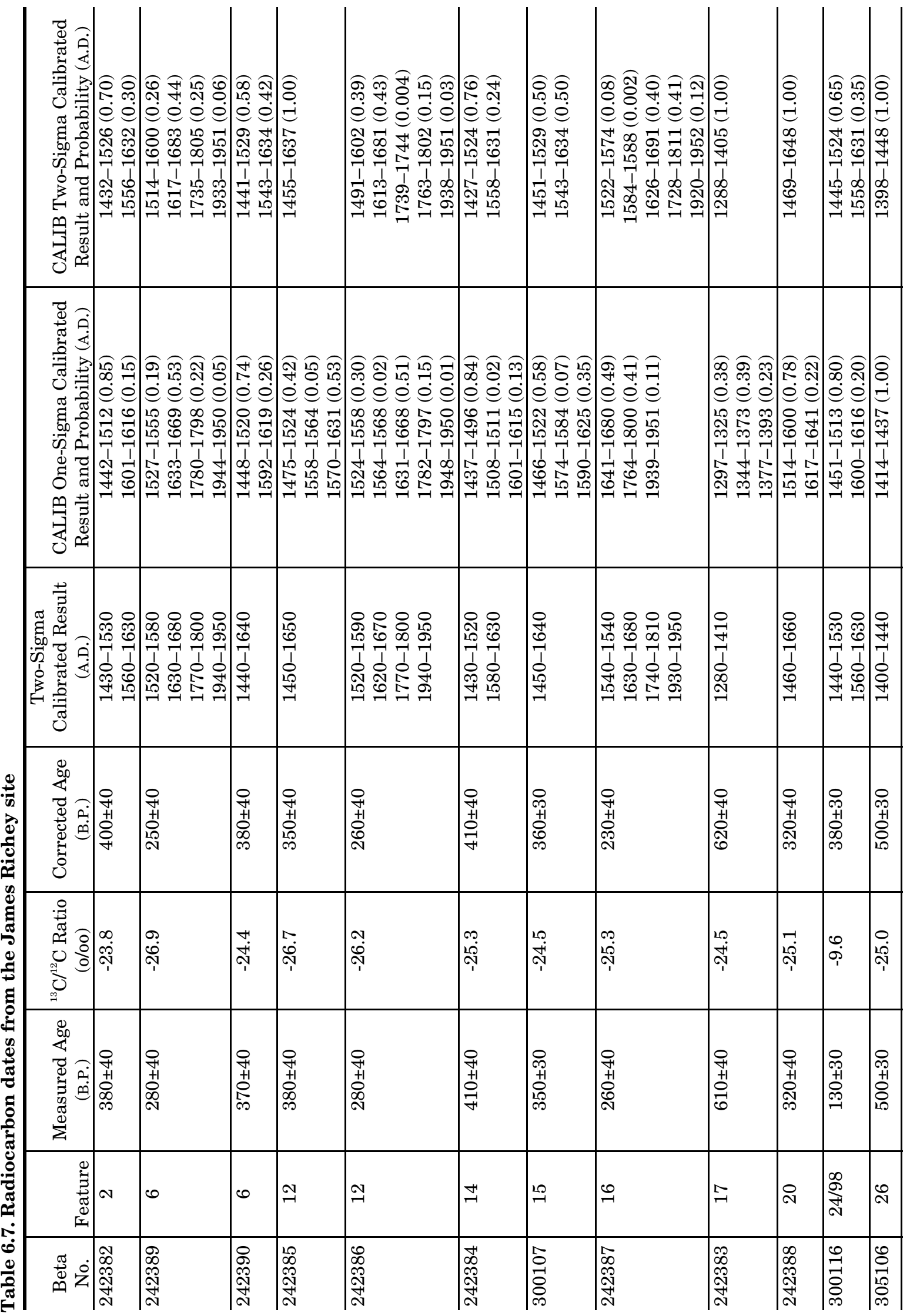




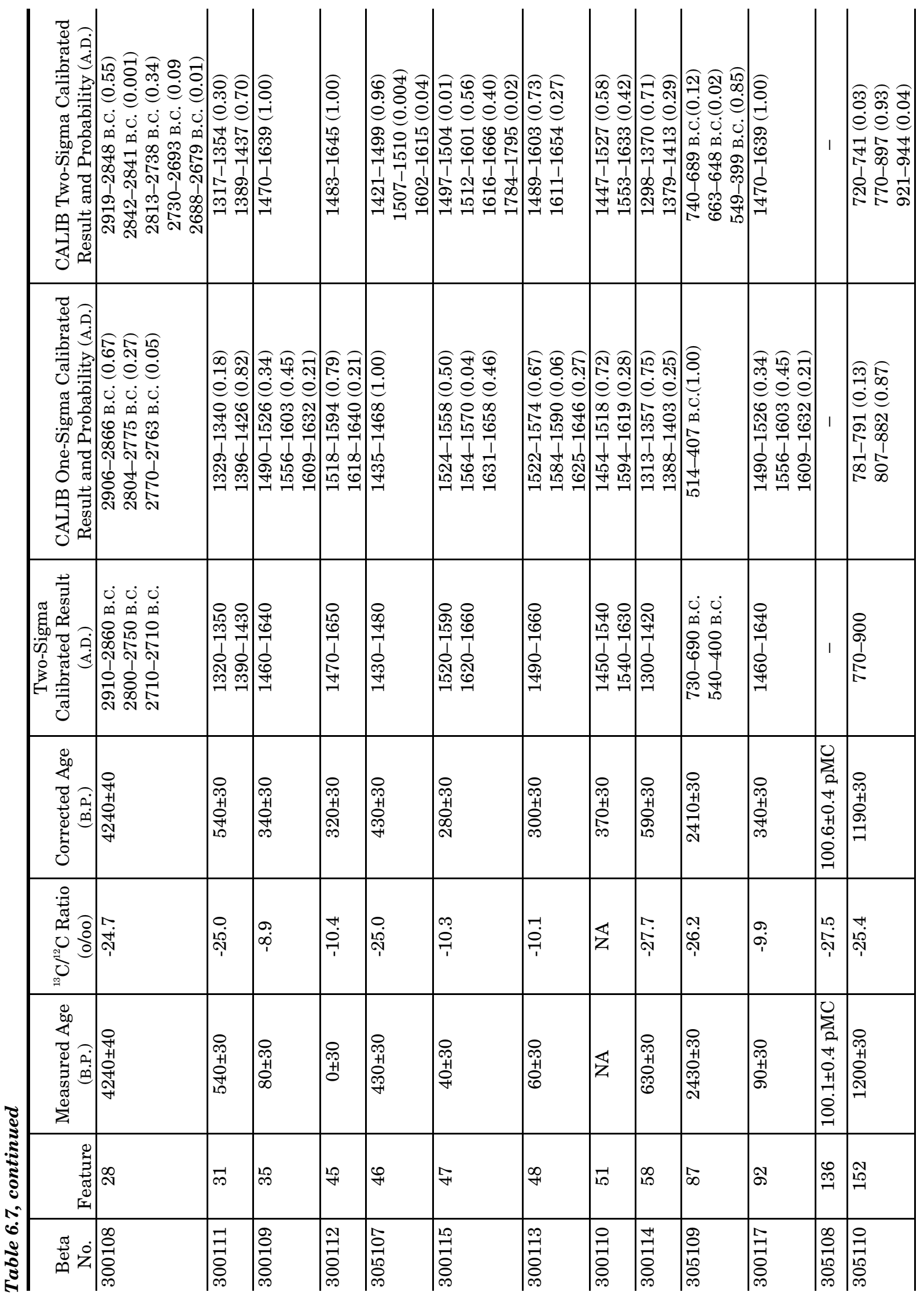




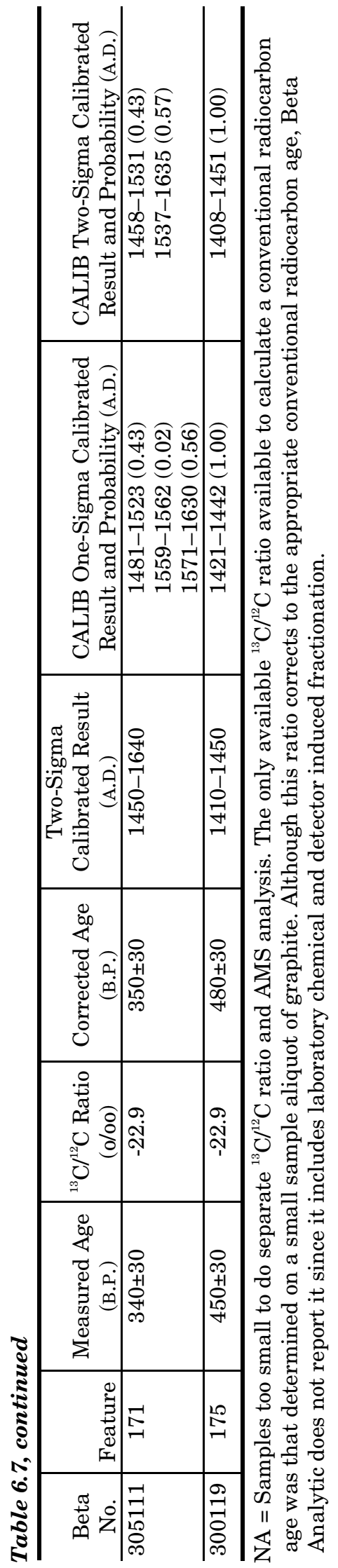


Table 6.8. Radiocarbon-dated contexts at the James Richey site

\begin{tabular}{|c|c|c|c|c|}
\hline Beta No. & Feature & $\begin{array}{l}\text { Feature } \\
\text { Type }\end{array}$ & Material & $\begin{array}{l}\text { Weight } \\
(\mathrm{g})\end{array}$ \\
\hline 242382 & 2 & burial fill & Hickory (Carya sp.) nutshell & 0.07 \\
\hline 242389 & 6 & small pit & Hickory (Carya sp.) nutshell & 0.91 \\
\hline 242390 & 6 & small pit & Hickory (Carya sp.) nutshell & 0.91 \\
\hline 242385 & 12 & large pit & Hickory (Carya sp.) nutshell & 4.41 \\
\hline 242386 & 12 & large pit & Hickory (Carya sp.) nutshell & 0.68 \\
\hline 242384 & 14 & small pit & Live oak (Quercus virginiana) wood & 0.12 \\
\hline 300107 & 15 & small pit & Hickory (Carya sp.) nutshell & 0.14 \\
\hline 242384 & 16 & smudge pit & Oak (Quercus sp.) wood & 0.18 \\
\hline 242383 & 17 & large pit & Hickory (Carya sp.) nutshell & 0.20 \\
\hline 242388 & 20 & small pit & Hickory (Carya sp.) nutshell & 0.24 \\
\hline 300116 & 24 & small pit & Corn (Zea mays) rachis & 0.01 \\
\hline 305106 & 26 & small pit & White group oak (Quercus subg. Quercus) wood & 0.01 \\
\hline 300108 & 28 & large pit & Hickory (Carya sp.) nutshell & 0.06 \\
\hline 300111 & 31 & small pit & Hickory (Carya sp.) nutshell & 0.13 \\
\hline 300109 & 35 & large pit & Corn (Zea mays) rachis & 0.08 \\
\hline 300112 & 45 & large pit & Corn (Zea mays) rachis & 0.01 \\
\hline 305107 & 46 & posthole & Hickory (Carya sp.) nutshell & 0.72 \\
\hline 300115 & 47 & smudge pit & Corn (Zea mays) rachis & 0.76 \\
\hline 300113 & 48 & large pit & Corn (Zea mays) rachis & 0.01 \\
\hline 300110 & 51 & small pit & Hickory (Carya sp.) nutshell & 0.01 \\
\hline 300114 & 58 & small pit & Hickory (Carya sp.) nutshell & 0.06 \\
\hline 305109 & 87 & small pit & Hickory (Carya sp.) wood [not nutshell] & 0.06 \\
\hline 300117 & 92 & small pit & Corn (Zea mays) rachis & 0.01 \\
\hline 305108 & 136 & posthole & White group oak (Quercus subg. Quercus) wood & 0.26 \\
\hline 305110 & 152 & large pit & Red group oak (Quercus subg. Lobatae) wood & 0.01 \\
\hline 305111 & 171 & posthole & $\begin{array}{l}\text { White group oak (Quercus subg. Quercus) wood } \\
\text { [not Carya nutshell] }\end{array}$ & 0.01 \\
\hline 300119 & 175 & small pit & Corn (Zea mays) rachis & 0.01 \\
\hline
\end{tabular}

At least two dates appear to indicate one or more minor occupations after A.D. 1500 (some of those assigned above to the main occupation could as well, of course). One from smudge pit Feature 16 has moderate-probability ranges of 1626-1691 and 1728-1811, the latter of which would be consistent with the few gunflints recovered. The other late date, from small pit Feature 6, has three moderate-probability ranges spanning much of the 1500 s-1700s; it also may relate to a Historic Caddo occupation, or it could go with some episode of minor use in the sixteenth or seventeenth centuries.

One date from large pit Feature 152 has a high-probability range of A.D. 770-897 and would appear to indicate late Woodland or Early Caddo occupation. The final dates appear to relate to Middle and Late Archaic occupations, which are well supported by the various dart points. Both dates are on nutshells surely from secondary contexts. One from Feature 28 has moderate-probability ranges of 2919-2848 and 2813-2738 B.C., and the other, from Feature 87, has a higher-probability range of 549-399 B.C.

In sum, the radiocarbon dates are interpreted as indicating a primary occupation between A.D. 1400 and 1500 and one or more minor occupations after 1500 and in the late Woodland/ Early Caddo and Middle and Late Archaic periods. Not surprisingly, the dates that appear to go with the main occupation are well scattered 


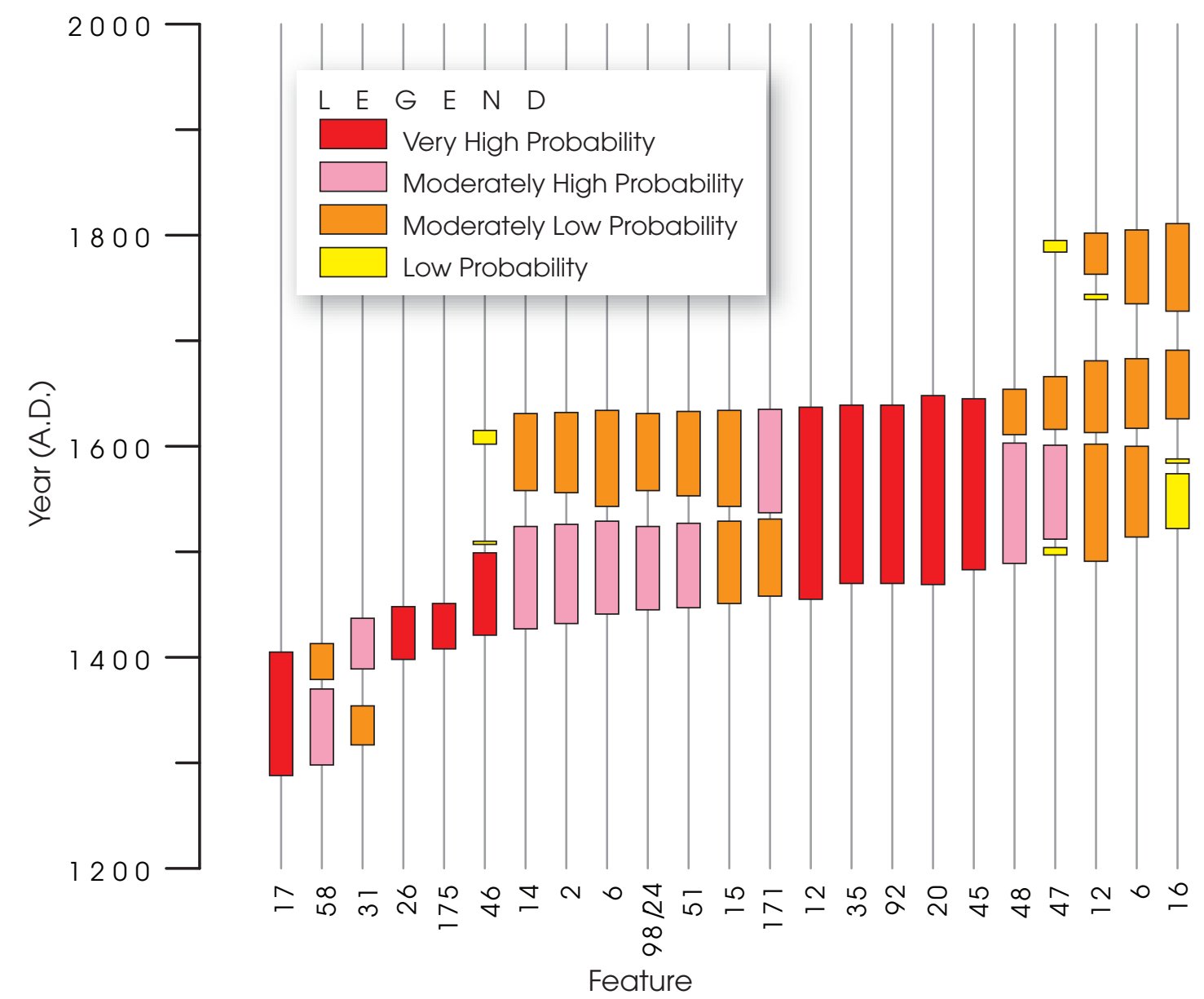

Figure 6.34. Graph of two-sigma calibrated ranges of the 23 Late to Historic Caddo-age radiocarbon dates from the James Richey site. Probabilities are color-coded (red = very high [>0.89]; pink = moderately high [0.52-0.81]; orange $=$ moderately low $[0.15-0.50]$; yellow $=$ low $[<0.15])$.

across the excavation area, though many are in the proposed house area $(n=5)$ and the possible activity area north of the house area $(n=7)$. The two proveniences with later Caddo dates are not particularly close to one another (14 $\mathrm{m}$ apart), which may suggest the dates relate to different occupations. The two Archaic dates are from contexts even farther apart $(25 \mathrm{~m})$, consistent with their substantially different ages.

\section{The Artifact Evidence}

Most of the lithic artifacts that convey some chronological information are consistent with the picture given by the radiocarbon dates. The single Maud point is consistent with the primary Late Caddo component, and the two gunflints fit well with use in the A.D. 1700s. Most of the various dart points (one Edgewood, one Ellis, two Godley, one Godley or Lone Oak, one possible Motley, eight Yarbrough, and three Wells) probably go with use during the Middle and Late Archaic periods, although there are others (three Gary, one Kent, and two Kent or Gary) that more likely relate to Woodlandperiod use that is not represented well, if at all, in the dates. Also not represented by dates are very early occupations, as suggested by the two San Patrice points. Finally, two Colbert arrow points and a possible Catahoula point hint at Early Caddo occupations, for which there are no clear dates. 
The distributions of these artifacts are not particularly enlightening, since most were found scattered across the data recovery excavation area. Exceptions include the following: (1) the Colbert points, both of which came from the south edge; (2) the San Patrice points, both of which came from near the southeast edge; and (3) two of the Gary points, one Wells, and one Yarbrough, which came from the north part; all are outside the main feature area, supporting inferences based on their presumed ages that they do not go with the main site occupation.

The ceramic sherds and vessels support the primary occupation of the site as defined by the radiocarbon dates. For utility wares, brushed sherds are especially common at 48 percent of all decorated sherds, which is between the 30 and 52 percent values for Components I and II at the Ear Spool site; the former appears to date mostly to the A.D. $1400 \mathrm{~s}$, and the latter dates mostly after 1500 (Perttula and Sherman 2009:178185). Utility ware types in the assemblage, i.e., Bullard Brushed, Pease Brushed-Incised, Maydelle Incised, La Rue Neck Banded, Harleton Appliqué, and Killough Pinched, fit well with this scenario. Ripley Engraved dominates the fine ware, with only a single sherd attributable to a Wilder Engraved bottle. This too conforms to expectations for an occupation postdating 1400 . The variations of the Ripley slanted scroll motif without a primary element or with a simple primary bar element between the scroll arms, which are most recognizable in this assemblage, connect this site to several Titus phase cemeteries such as those at the Thomas B. Caldwell, A. P. Williams, and Tuck Carpenter sites. For Tuck Carpenter, Turner (1978:74-75) called these scroll motifs a "triangular motif" and suggested that they were common in the earlier graves (ca. 1400-1500) (Perttula 1992:Figure 16).

The only possible evidence in the ceramics of earlier Middle Caddo use consists of a single possible Sanders Engraved sherd and the possible Sanders Engraved bowl. There is no radiocarbon evidence of such an occupation, though, and the fact that the bowl was found in a burial in association with a Pease Brushed-Incised jar suggests that these are not out of place in this Titus phase assemblage. No ceramic evidence supports the possible Woodland-Early Caddo occupation indicated by the A.D. 770-897 date from Feature 152.

\section{PATTERNING IN THE HORIZONTAL DISTRIBUTION OF MATERIALS}

Patterning in the horizontal distributions of artifacts can be explored to address questions relating to the arrangement of activities, i.e., activity areas, and trash disposal. Given that no houses or other structures were identified and the site clearly has multiple components, it is a poor place to look for fine-grained patterns, for example, specific activity areas within houses. It is amenable to study of coarser-grained patterns, however. The artifact samples available for this are from the following contexts: 22 test units $(1 \mathrm{x} 1 \mathrm{~m})$ dug during testing in the part of the site that subsequently saw data recovery work; and 66 machine-dug sample units (averaging 2.0x1.0 m) placed across the data recovery area. Because the sizes of the excavations and the amounts of fill screened varied, the densities of materials recovered from them were calculated based on the number of five-gallon buckets of screened fill. For the test units, which were completely screened, it was assumed that each level excavated would have yielded five buckets of fill $\left(0.10 \mathrm{~m}^{3}\right.$ per level divided by a bucket volume of $0.022 \mathrm{~m}^{3}$ ); the fact that the overall density of artifacts from the test units calculated in this manner (2.56 per bucket) is close to that from the sample units (2.47 per bucket) indicates that this is a reasonable assumption.

Densities were calculated for the two most abundant kinds of occupational debrisceramic sherds (from 72 of 88 proveniences; nonzero range $=0.04-4.17$, mean $=0.97 \pm 0.97$, median $=0.65$ ) and all lithics combined (from 74 proveniences; nonzero range $=0.07-3.17$, mean $=0.91 \pm 0.78$, median $=0.83$ - - and these data were used to create isopleth maps (with ArcGIS Spatial Analyst using the inverse-distance method to grid the data and the Jenks natural breaks method to define intervals) for distributional analysis. Attempts were made to look at the distributions of subsets of the artifacts and other classes of materials, but small frequencies made this problematical.

Figure 6.35 shows that there are two concentrations of ceramics. One is in the south-central part of the data recovery area, slightly overlapping the hypothesized house area but extending mostly south of it. The other concentration is about $8 \mathrm{~m}$ to the north, overlapping the cluster of features that is interpreted as a consistently 
reused outdoor activity area. Though the isopleth map shows this concentration extending northwestward outside the area investigated, the landform drops off steeply in this direction providing a natural boundary. The lithic artifact distribution is very similar to that of the ceramics. There is a southern concentration, offset slightly to the west from the ceramic concentration but also south of the proposed house area, and there is a northern concentration that coincides with the second ceramic concentration. As with the ceramics, the northern concentration is bounded by the extent of the landform to the northwest. The similarities in the distributions indicate that most of the lithics relate to Caddo occupations, even though some part of the collection surely goes with earlier occupations indicated by the 28 dart points. Not reflected on Figure 6.35 because it is outside the data recovery area to the north (in Test Unit 16) is a third concentration of lithics on the crest of the landform; it may relate mostly to Archaic occupations, given the paucity of ceramics in that area.

These patterns led to three main conclusions. First, the bulk of the artifacts represent a general rain of debris resulting from activities probably in and immediately around a house and outdoor activity areas represented by clusters of features. Second, assuming that the hypothesized house area has been identified correctly, it appears that a particular discard pattern may be evident here that is not evident at the George Richey and William Ford sites. Specifically, both ceramics and lithics are notably frequent just outside of and downslope (south) from the proposed house area, suggesting consistent disposal of trash in this direction. Third, the fact that the distributions of both ceramics and lithics are well bounded indicates that the area chosen for data recovery captured the full extent of the occupation area, which is not surprising given that the landform is well defined topographically.

\section{SUMMARY AND CONCLUSIONS}

Approximately $1,869 \mathrm{~m}^{2}$ of the James Richey site was excavated, resulting in the discovery of 3 burials, 30 pits, 24 postholes, 2 burned rock clusters, and 1 artifact cluster. This site did not have the same kind of feature evidence preserved as the other two excavated sites, but based on the features that were found and the other evidence, it is surmised that one Caddo house was present, probably in the central part of the excavation area where organically enriched sediments extended over an area at least 8-9 $\mathrm{m}$ across. Within this area of darker sediments were three postholes and three small pits, and immediately northwest of it were four postholes, a smudge pit, two other small pits, and a probable child burial. The postholes do not form arcs indicative of house walls, but the burial suggests a house could have stood here. Other than the possible house area, the only notable feature patterning relates to the positioning of the other two burials on the edges of the main occupation area and the presence of a concentration of features 7-12 m north of the possible house that may represent a structured or consistently reused activity area. Several pits in this concentration have evidence of thermal activity, suggesting this could be a cooking area.

The ceramic artifacts recovered number 3,105 , of which 1,906 are large enough for analysis. Three of these are smoking pipe fragments, and the rest are from ceramic vessels. The latter includes 3 complete or nearly complete small jars, 1 partial medium-sized jar, and 4 complete small bowls. Almost two-thirds have grog by itself as temper, and one-third have grog and bone; bone by itself is much less frequent. Decorated sherds make up 42 percent of the sample. Most display brushing or some combination of brushing with punctations or appliqué (48 percent of those with decoration). Engraving (17 percent) and incising (15 percent) also are common decorative modes, as is punctating or a combination of punctating and incising (15 percent). Sherds with appliqué but no brushing are minimally represented (1 percent), along with sherds with pinching, coil crimping, and rim notching (3 percent). Types represented include Ripley Engraved, Wilder Engraved, Harleton Appliqué, Maydelle Incised, Pease Brushed-Incised, Killough Pinched, La Rue Neck Banded, Bullard Brushed, and possibly Sanders Engraved; all are consistent with Middle to Late Caddo occupations. The incidence of brushing among the decorated sherds (48 percent) supports this temporal assessment.

The chipped stone assemblage consists of 6 arrow points, 28 dart points, 1 distal fragment that could be from either an arrow or dart, 2 gunflints, 51 bifaces, 4 unifaces, 153 edge-modified and utilized flake tools, 14 edge-modified core tools, 78 cores, and 2,495 pieces of debitage. Identified arrow point types are possible 


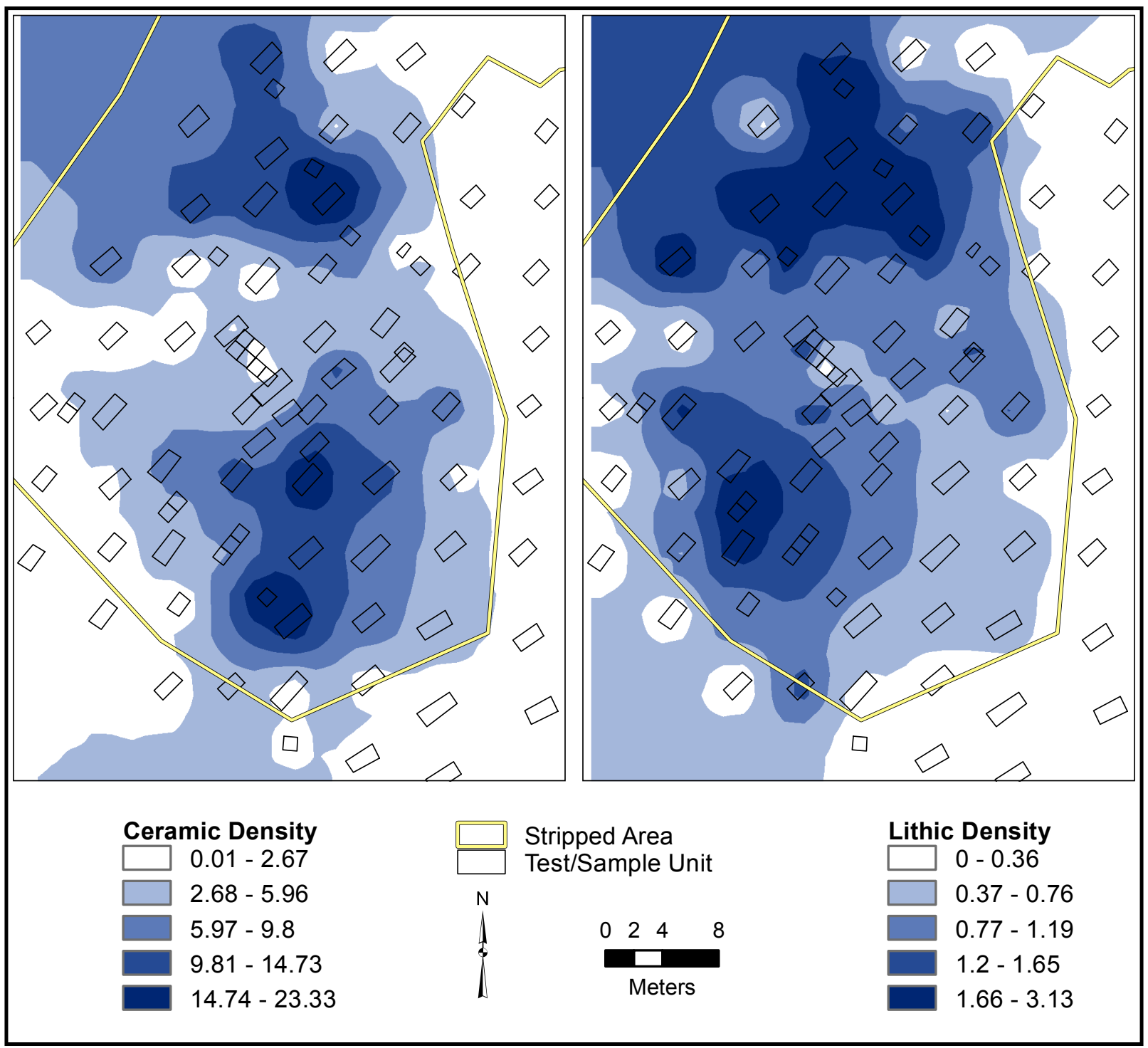

Figure 6.35. Distribution of ceramic sherds (left) and total lithic artifacts (right) across the data recovery area at the James Richey site.

Catahoula, Colbert, and Maud, and the dart point types are Edgewood, Ellis, Gary, Godley, Godley or Lone Oak, Kent or Gary, possible Motley, San Patrice, Wells, and Yarbrough. The 104 ground, pecked, and battered stone artifacts consist of 1 axe, 1 celt, 1 adze, 22 hammerstones, 15 manos/hammerstones, 21 pitted hammerstones, 5 anvils, 4 grinding slabs/anvils, 4 grinding slabs, 4 grooved and grooved/incised stones, 1 mano/anvil/abrader, 1 polishing stone, 3 pig- ment stones, and 21 indeterminate. A third have some form of pit or depression used in crushing/ splitting/pulverizing activities. Excluding items with interchangeable, equivocal, or indeterminate functional positions, base-position artifacts (anvils, grinding slabs, etc.) account for 15 percent of the assemblage, and handheld items make up 63 percent.

One hundred seventeen faunal elements were recovered. Ninety-five percent are classi- 
fiable only as vertebrate skeletal material. The other 6 specimens are canid/deer-sized elements, an artiodactyl tibia fragment, and 2 fragments of armadillo dermal armor plate.

Seven kinds of wood charcoal were identified in the flotation samples, with oak (white and red) and hickory dominant. These fuels were collected from on or near the site, reflecting the oak-hickory forest that the area supported. Other wood charcoal includes ash, elm, persimmon, and plum/cherry. Charred cane stems likely represent baskets and mats rather than fuel materials. Corn is the only cultigen identified. Small numbers of maygrass, nightshade, purslane, spiderwort, verbena, elberberry, strawberry, daisy family, and grass family seeds were recovered as well. The remainder of the macrobotanical remains that represent foods is dominated by hardwood nuts, especially hickory but also acorn.

Twenty-six radiocarbon dates were obtained. Lacking the kind of feature evidence that the other excavated sites have, the dates are harder to interpret. But assuming it had a similar kind of history, the dates can be seen as representing a single main Caddo farmstead component between A.D. 1400 and 1500 and several minor shorter-term occupations after 1500 and in the late Woodland/Early Caddo and Middle and Late Archaic periods. The main-occupation dates are scattered across the excavation area, with many in the proposed house area and the possible activity area north of the house area.

Analysis of the distributions of the artifacts suggests three main conclusions: (1) the bulk of the artifacts represent a general rain of debris resulting from activities probably in and immediately around a house and outdoor activity areas; (2) assuming that the hypothesized house area has been identified correctly, it appears that a particular discard pattern may be evident here that is not evident elsewhere, with artifacts notably frequent just outside of and downslope (south) from the proposed house area suggesting consistent disposal of trash in this direction; and (3) the fact that the distributions of both ceramics and lithics are well bounded indicates that the area chosen for data recovery captured the full extent of the occupation area, which is not surprising given that the landform is well defined topographically. 


\section{THE THOMAS B. CALDWELL AND A. P. WILLIAMS CEMETERIES AND TITUS PHASE MORTUARY BEHAVIOR}

Damon Burden, Ross C. Fields, Eloise Frances Gadus, and Virginia L. Hatfield

This chapter discusses two Late Caddo cemeteries that are just outside the current project area, and hence potentially associated with the George Richey, William Ford, and James Richey sites, and that were excavated in 1934. It describes the work done at these two sites and the overall character of the cemeteries, and it summarizes the grave goods recovered; detailed descriptions of the burial offerings are not included, since they (or most of them) are housed at the Texas Archeological Research Laboratory (TARL) and have been partially analyzed previously (Thurmond 1990:177-183). The chapter closes with sections addressing how these cemeteries might relate to the residential occupations within the U.S. Highway 271 project area and to Titus phase mortuary behavior overall.

\section{THE THOMAS B. CALDWELL CEMETERY}

Between June 14 and 27, 1934, a crew from the University of Texas at Austin excavated a prehistoric Caddo cemetery located on the Thomas B. Caldwell plantation. The site was located when the property owner (Mr. Caldwell) noticed "pottery in a small wash in an old road track" adjacent to a fence line (Goldschmidt 1934a:1). This find was eventually brought to the attention of A. T. Jackson, who was a field foreman with the Department of Anthropology at the University of Texas. Mr. Jackson selected the site for investigation and developed an excavation plan. Walter E. Goldschmidt and an eight-man crew carried out the plan during a two-week field period, excavating 10 burials and investigating the surrounding area for additional mortuary features.
Goldschmidt notes that the cemetery was on the eastern margin of the Thomas B. Caldwell plantation, 2.5 miles $(4.0 \mathrm{~km})$ southwest of Mount Pleasant and about 0.5 miles $(0.8 \mathrm{~km})$ north of Tankersley Creek. He goes on to say that the site was on a previously wooded slope, "about 100 yards below the crest of the highest terrace" (Goldschmidt 1934a:1). An east-west fence line crossed the excavation area. The recently cleared parcel north of the fence was under cultivation at the time of the investigation, and the previously cultivated property south of the fence was fallow.

The Caldwell cemetery was eventually assigned the trinomial 41TT6, and many years later it was plotted based on the verbal description on modern USGS topographic maps at TARL. This plotting was on an upland interfluve on the eastern valley margin of Tankersley Creek, southeast of FM 127, and, according to Perttula et al. (2002), was derived from a map provided by Thurmond (1990:Figure 23). The plotted location put the cemetery within the corridor of the proposed U.S. Highway 271 relief route.

Following survey of the proposed corridor by Archeological and Environmental Consultants, LLC (AEC), in 2002, Perttula et al. (2002; Perttula and Nelson 2005:52-53) noted that the plotted location of 41TT6 conflicts with the description provided in the 1934 excavation report (Goldschmidt 1934a, 1935). That work suggested that the cemetery actually was at 41TT846 about $300 \mathrm{~m}$ west of 41TT6. Subsequent auger testing supported this conclusion but could not verified it, since post-2002 design changes to the proposed highway right of way excluded that part of 41TT846 from investigation (see Chapter 2). 
In 2007, Prewitt and Associates, Inc., conducted archival research and performed informant interviews as part of a historic landscape study in an attempt to confirm the location of the Caldwell cemetery (see Appendix D). Although this investigation failed to reveal irrefutable evidence about its location, information provided by various interviewees and revealed through examination of property ownership history suggest that the cemetery was indeed on the west edge of the 41TT846 site boundary, about $90 \mathrm{~m}$ outside the final U.S. Highway 271 relief route right of way. In addition, examination of a 1935 aerial photograph revealed a disturbance approximating the size of the 1934 excavation area on an east-west fence line in the same general location as that indicated by an informant. The same fence line now marks the property boundary between a Priefert Development Corporation parcel to the north and the Charles S. Caldwell et al. parcel to the south. Thomas Caldwell owned both of these tracts at the time of the 1934 excavation.

\section{Excavation Methodology and General Results}

Goldschmidt's report (1934a) provides relatively detailed information about each of the excavated burials but only briefly describes the methodology employed during this investigation. The report does note that excavations began in the fallow field south of the east-west fence line that later was determined to split the cemetery roughly in half (Figure 7.1). Fieldwork began with a trench that was started in the vicinity of the previous surface find. Trench excavation continued parallel to the fence until the first burial was exposed. Investigators dug to the A-B horizon interface, which ranged from less than a foot $(0.30 \mathrm{~m})$ below the surface on the east side of the excavation block to three feet $(0.90 \mathrm{~m})$ below the surface on its west side. By all indications, the field crew removed or stripped surface soils without the aid of draft animals or mechanical equipment.

The old road where ceramics were first observed on the surface was immediately south of the fence. Burials were numbered in the order in which they were exposed, so the location of Burial 2 with respect to Burial 1 indicates that initial trenching progressed from east to west. No information concerning the width of the initial trench or its location with respect to the road is provided in the report. However, the fact that the excavators missed Burial 6 as they moved west suggests that the trench was likely several feet south of the fence, perhaps along the south side of the road. Trench excavation was abandoned for wholesale stripping of the surface sediments after the discovery of Burial 2 provided some indications as to feature orientation and distribution. The progression of feature numbers indicates that fill removal proceeded south and southwest of Burial 2.

Following the discovery and excavation of Burials 3-5, the surface sediments were stripped in a large broadcast that extended $7.6 \mathrm{~m}$ south and west of Burial 5 in an attempt to identify additional mortuary features. Broad trenches were excavated in these directions at varying intervals. These were approximately 4.6-9.1 $\mathrm{m}$ in length and $0.9-1.5 \mathrm{~m}$ in width. In addition, several narrow trenches (some as long as $14 \mathrm{~m}$ ) were excavated off the block's southeast corner.

Manual stripping continued north underneath the fence and into the adjacent field where five additional burials were exposed. Block excavation extended 8-9 m north of Burials 9 and 10 and 9-11 m east and west of those features. Trenches excavated off the north and west sides of the excavation block varied from about 4.0 to $7.6 \mathrm{~m}$ in length and were roughly $0.6-1.2 \mathrm{~m}$ wide. No mortuary features were identified outside the cluster of 10 burials located in the central portion of the stripped block, and thus it appears that all of the cemetery was removed.

Individual graves were identified by changes in sediment composition, consistency, and color within the A horizon; vessels protruding above the A-B horizon interface; and well-defined pit margins preserved in the more-compact $\mathrm{B}$ horizon sediments. All mortuary features except for Burial 5 were excavated, drawn in plan, photographed, and removed within 24 hours of discovery; Burial 5 was discovered late on a Saturday and excavated the following Monday. The report provides little direct information about the process followed for individual burial excavation. However, it appears that burial pit edges were completely or at least partially defined at the top of the B horizon, and excavation proceeded from one end of the pit to the other. Vessel fill was cleaned out prior to the removal of the surrounding pit fill. 


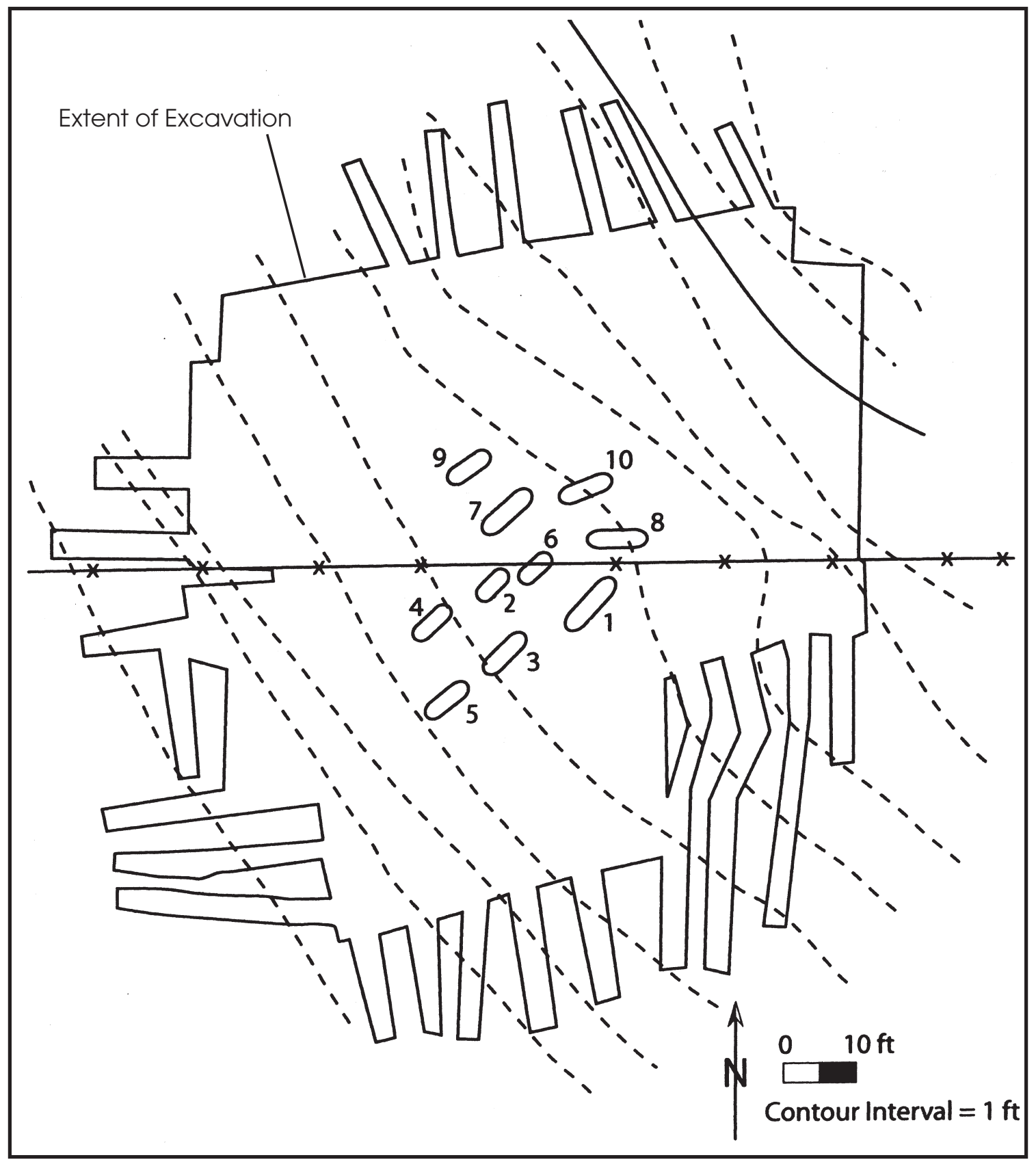

Figure 7.1. Plan of the 1934 excavation at the Thomas B. Caldwell cemetery (from Perttula and Nelson 2005:Figure 6).

Horizontal dimensions were documented for each of the grave pits, but individual pit depths were not dutifully recorded. Pit dimensions (most likely recorded at the top of the $\mathrm{B}$ horizon) ranged from 50 to 108 inches
$(127-244 \mathrm{~cm})$ in length and 24 to 42 inches $(61-107 \mathrm{~cm}$ ) in width (Table 7.1$)$. The report states that "The Graves...varied in depth from a few inches to three feet" (Goldschmidt 1934a:48). All of the burial pits were excavated down into B 
horizon, and examination of feature photographs suggests that the deepest of these bottomed out at about $30 \mathrm{~cm}$ below the top of the B horizon. The general depth measurements provided by Goldschmidt probably refer to the maximum range at which burials were encountered below the surface. It is not clear if the shallower depth in the above statement refers to the top of a pit exposed in the B horizon, or the tops of mortuary vessels that protruded above the B horizon in several burials, though the report suggests the latter. For instance, the top of a jar that the excavators associated with Burial 1 was only a few inches below the surface. The greater depth noted in the above statement probably refers to the below-surface depth of the grave pit floor in either Burial 7 or 8 , as both were deeper than the other burials (Goldschmidt 1934a:29, 33). This suggests that the A horizon was thicker in the vicinity of these features than elsewhere, perhaps because of an undulating A-B horizon contact.

The cemetery was in an area that was subjected to repeated disturbance from plowing, which probably was at least partly responsible for the variability in topsoil thickness across the excavation area. Plowing negatively impacted the upper portions of the burials and probably reached deep enough to impact mortuary inclusions in some cases. Burial 6 had been disturbed by surface erosion, and it was suggested that some of the vessels in that feature had been directly impacted by the plow (Goldschmidt

Table 7.1. Thomas B. Caldwell cemetery burial pit orientations and dimensions

\begin{tabular}{c|c|c|c|c}
\hline $\begin{array}{c}\text { Burial } \\
\text { No. }\end{array}$ & $\begin{array}{c}\text { Head } \\
\text { Orientation } \\
\text { degrees E } \\
\text { of N) }\end{array}$ & $\begin{array}{c}\text { Length } \\
(\mathrm{m})\end{array}$ & $\begin{array}{c}\text { Width } \\
(\mathrm{m})\end{array}$ & $\begin{array}{c}\text { Depth } \\
(\mathrm{m})\end{array}$ \\
\hline 1 & 45 & 2.44 & 0.61 & 0.46 \\
\hline 2 & 50 & 1.52 & 0.69 & shallow \\
\hline 3 & 43 & 1.68 & 1.07 & 0.74 \\
\hline 4 & 45 & 1.27 & 0.81 & $?$ \\
\hline 5 & 55 & 1.83 & 0.86 & 0.46 \\
\hline 6 & 45 & 1.52 & 0.61 & shallow \\
\hline 7 & 52 & 2.18 & 0.84 & $?$ \\
\hline 8 & 90 & 2.44 & 0.81 & $?$ \\
\hline 9 & 56 & 1.83 & 0.84 & $?$ \\
\hline 10 & 70 & 1.96 & 0.76 & $?$ \\
\hline
\end{tabular}

1934a:26). In addition, the east-west fence that crossed the cemetery at the time of the excavation formerly had been several feet to the south, and installation of the two fences certainly could have impacted several burials. Use of the road that paralleled the fence also could have disturbed mortuary features. Additionally, there is some evidence to suggest that at least one shallowly buried burial had been destroyed by recent disturbance. A jar, well-made biface fragment, and two pieces of silicified wood recovered just southwest of Burial 1 were resting about 8 inches $(20 \mathrm{~cm})$ above the level of the burial pit floor. Goldschmidt (1934a:4) associated these materials with Burial 1 for the sake of convenience, but he could not rule out the possibility that they were associated with a different, higher burial.

Goldschmidt (1934a:44) notes that the 10 extended burials in this small cemetery were within $25 \mathrm{ft}(7.6 \mathrm{~m})$ of where prehistoric ceramics were exposed by erosion in the old road. The graves were within 1.5-1.8 $\mathrm{m}$ of each other and were arranged in two to three rows within a 12-m-diameter area (see Figure 7.1). The longitudinal axes of 9 of the burials were oriented from $43^{\circ}$ to $70^{\circ}$ east of north; the long axis of Burial 8 was oriented due east. Excluding the latter, the graves had an average orientation of about $50^{\circ}$.

The determination of head orientation was hampered by the fact that none of the graves retained human remains. However, Goldschmidt felt that similarities in the grave pit alignments were indicative of similarities in cranial orientation. Based on an assumed correlation between bottle and head locations and the consistent location of bottles at the northeast end of similarly aligned graves at other sites in the vicinity, he suggests that the individuals in the Caldwell cemetery were buried with their heads to the northeast, though he suggests in one place that Burial 4 may have been oriented to the southwest (Goldschmidt 1934a:16, 44).

Goldschmidt (1934a:48) identified 95 ceramic vessels as having come from the graves, consisting of " 55 bowls, 27 pots (including jars), 9 bottles, and four unclassifiable objects." An inventory of the ceramic assemblage performed by TARL personnel in the 1980s determined that 53 bowls, 31 jars, 8 bottles, and 1-2 other vessels had been collected (Table 7.2); 5 of these were listed as missing or lost at that time. This assemblage is characterized more fully below. 
Table 7.2. Burial offerings in the Thomas B. Caldwell cemetery graves

\begin{tabular}{c|c|c|l}
\hline $\begin{array}{c}\text { Burial } \\
\text { No. }\end{array}$ & $\begin{array}{c}\text { Ceramic } \\
\text { Vessels }\end{array}$ & $\begin{array}{c}\text { Arrow } \\
\text { Points }\end{array}$ & \multicolumn{1}{|c}{ Other } \\
\hline 1 & 8 & 25 & $\begin{array}{l}\text { limonite, 1 mass of glauconitic clay, kaolinitic clay, 1 biface, 2 pieces of } \\
\text { silicified wood }\end{array}$ \\
\hline 2 & 6 & & hematitic clay \\
\hline 3 & 13 & 11 & ash bed with charcoal \\
\hline 4 & 9 & 25 & ochre fragments, 1 mass of kaolinitic clay, unidentifed stone (?) \\
\hline 5 & 11 & 12 & 1 celt, 3 ochre fragments, 1 mass of hematitic clay \\
\hline 6 & 10 & & \\
\hline 7 & 9 & 1 & hematitic clay \\
\hline 8 & 10 & 3 & \\
\hline 9 & 9 & & hematitic clay \\
\hline 10 & 10 & 8 & hematitic clay \\
\hline Totals & 95 & 85 &
\end{tabular}

According to Goldschmidt, 85 chert arrow points were recovered from seven burials. Four interments had from 11 to 25 arrow points each. Many of these specimens were clustered in a manner suggesting that quivers of arrows were included in some of the burials. Identified point styles include Bassett, Maud, and Talco (Thurmond 1990:Table 40). In addition, a celt, 1 biface, 2 pieces of silicified wood, an ash bed, limonite, ochre, and hematitic, kaolinitic, and glauconitic clays were found in some of the burials.

Some artifacts were recovered from nonburial or unprovenienced contexts during the excavations. The 1934 report mentions some but not all of these. A specimen inventory in the TARL files prepared more than 50 years after the excavation provides a more comprehensive list. According to that inventory, the investigators recovered 374 ceramic sherds, 6 Gary dart points/point fragments (includes a possible arrow point), a possible Gary point preform, a possible Yarbrough dart point fragment, 5 bifaces/biface fragments, a flake, an abraded stone, and a modified red ochre fragment. In his analysis of this collection, Thurmond (1990:180) identified 357 sherds, which he classified as follows:
21 Ripley Engraved bowl rims, 1 Canton Incised bowl rim, 20 miscellaneous engraved bowl rims, 8 plain bowl rims, 1 Maydelle Incised jar rim, 2 miscellaneous incised jar rims, 13 punctated jar rims, 1 Harleton Appliqué jar body sherd and 3 miscellaneous appliquéd body sherds, 97 plain body sherds, 13 brushed body sherds and 1 brushed and appliquéd sherd, 4 red-slipped body sherds, 2 engraved body sherds, 7 incised body sherds, 6 punctated body sherds, 7 plain bases, 98 unclassified Caddo sherds, 48 Williams Plain sherds, and 4 sandy paste sherds. These materials are excluded from the descriptions of the burial-associated grave goods below. The point styles indicate ephemeral Late Archaic and Woodland components at this location, with the latter supported by the Williams Plain and possibly the sandy paste pottery.

\section{Burial Descriptions}

In addition to listing accompaniments for each burial, Goldschmidt (1934a) offers varying amounts of detail for each, ranging from comments on pit morphology to locations or arrangements of burial offerings within a pit.

\footnotetext{
${ }^{1}$ Examination of some of the sherds at TARL in November 2012 confirmed that some of the pottery classified as Williams Plain represents thick-walled, flowerpot-shaped vessels, i.e., classic Williams Plain, although Thurmond was less restrictive in making this identification (particularly with body sherds) than we would be. In contrast, his sandy paste pottery appears to be just very sandy Caddo pottery rather than true early sandy paste ware.
} 
Included below are burial-specific details not provided in Tables 7.1 and 7.2.

\section{Burial 1}

The limits of the burial pit were clearly visible at the $B$ horizon contact, and the pit's walls and floor were obvious. A bottle (\#1), a biface fragment (\#37), and two pieces of silicified wood (\#11) that were of equivocal provenience are included in the pit boundary on the Burial 1 plan (Figure 7.2). Pit length is listed as $9 \mathrm{ft}$ $(2.74 \mathrm{~m})$ with these items and $8 \mathrm{ft}(2.44 \mathrm{~m})$ without them. This vessel and the other materials are clearly outside the burial pit in a photograph of the feature, though, and hence they my not have been associated with this grave (Goldschmidt 1934a:5). Hence, the shorter dimension is probably the more accurate one.

Most of the vessels and vessel fragments in Burial 1 were on or near the pit's longitudinal axis. A small bowl (\#2) was near the pit's southwest end, a jar (\#5) and crushed bowl (\#6) were at and just east of the pit's center, and an unidentifiable vessel fragment (\#8) was near the northeast end; the unidentifiable fragment was missing during a 1983 inventory of the ceramic assemblage, and notes suggest that it might have been part of a small crushed bowl (\#7) found toward the northeast side of the grave, though Items 7 and 8 were not very close to one another. Lastly, a medium-sized bottle (\#4) and a large jar (\#3) were placed next to each other between the interment and the northwest pit wall, just southwest of the pit's transverse axis.

Four of the 25 arrow points were next to one another near the northeast end of the grave with their distal ends to the northeast. The remaining arrow points were scattered throughout the pit and pointing in various directions. The statement that most were on the pit floor indicates that some were recovered from burial fill instead. This placement could be derived from placing items (presumably tipped arrows in this instance) in the grave as it was filled (Goldschmidt 1934a:4). Alternately, the unpatterned distribution of arrow points in Burial 1 may be the result of bioturbation. Thurmond (1990:Table 40) identified 9 Bassett points, 9 Maud points, and 3 Talco points during his review of the Burial 1 assemblage; he listed 4 points as lost or stolen at that time. Other materials recovered from Burial 1 include a limonite fragment (\#9) and a mass of glauconitic clay (\#10), both near the southwest end. The kaolinitic clay noted in Table 7.2 was observed in various places during the burial excavation; this too might have been added as the pit was backfilled.

\section{Burial 2}

As the mapped length of Burial $2(122 \mathrm{~cm})$ does not match its length reported in two places in the 1934 report $(152 \mathrm{~cm})$, it is difficult to be certain about the placement of the grave goods. Nonetheless, most of the ceramic vessels probably were in the central part of the burial pit (see Figure 7.2). An undecorated jar (\#38), a large bowl (\#41), and a large jar (\#43) were along the sides of the pit at a slightly higher level than the pit floor (Goldschmidt 1934a:9). The undecorated jar was almost half full of soft hematitic clay. A large bowl (\#39) was placed on the pit's longitudinal axis, just southwest of its center and likely atop the interment. According to a photograph of the feature, a medium-sized bowl (\#40) was just east of the pit's center, between the large bowl and the vessels set along the southeast pit wall (Goldschmidt 1934a:10). A small effigy bowl (\#42) was northwest of the pit's longitudinal axis, where it was partially overlain by the large jar (\#43) along the pit wall; this bowl apparently was placed alongside the deceased. Burial 2 had no offerings other than the ceramic vessels and the mass of hematitic clay.

\section{Burial 3}

Most of the 13 ceramic vessels in Burial 3 were on or immediately adjacent to the burial pit's long axis, which suggests that they were placed on or alongside the interment (see Figure 7.2). According to a photograph of the feature, the vessels were grouped in two roughly linear arrangements (some of the vessel locations depicted on the burial plan are not completely accurate). The vessel alignment northwest of the centerline consists of a bowl (\#50), a bottle (\#48) flanked by 2 small jars (\#49 and \#47), and a bowl (\#46). The vessel alignment on or just southeast of the centerline consists of 2 jars (\#51 and \#52) and 3 bowls (\#54, \#58, and \#55); 2 of the bowls were stacked. A large jar (\#53) and large bowl (\# 56) were between this vessel group and the southeast pit wall. In addition, an isolated jar (\#57) was along the northwest pit wall; this 

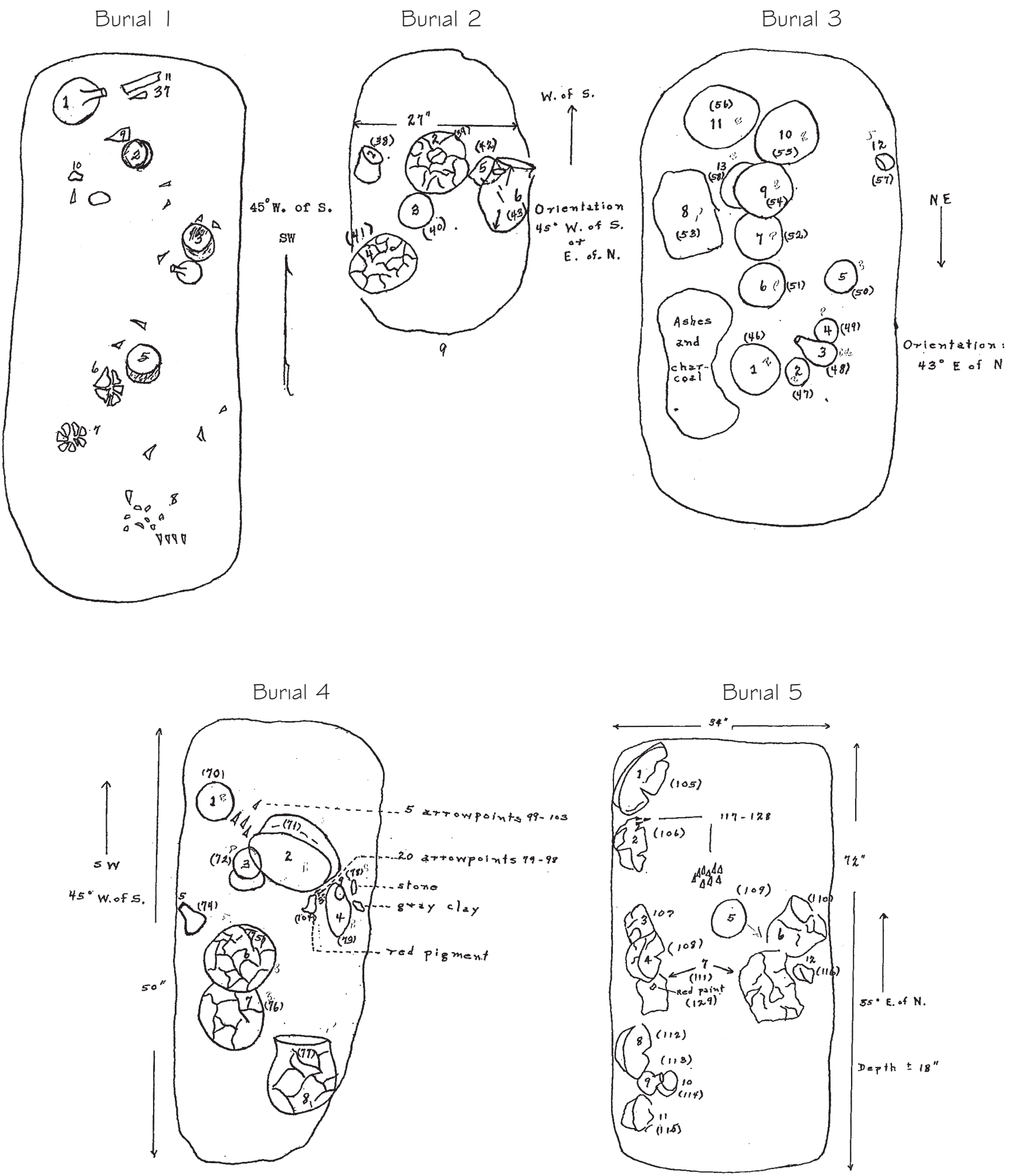

Figure 7.2. Plans of Burials 1-5 at the Thomas B. Caldwell cemetery (from Goldschmidt 1934a; burials are scaled correctly relative to one another, but their placement on this page does not reflect their positions on the ground). 
vessel was resting on loose burial fill about 8 inches $(20 \mathrm{~cm})$ above the floor of the pit. No vessels were in the northeast quarter of the pit.

Eleven small arrow points were grouped next to Item 58 , below Item 54 . No comment is made about distal end orientations. Two points were lost or stolen by the time Thurmond reviewed the collection. Thurmond (1990:Table 40) identified the remaining specimens as 2 Bassetts, 4 Mauds, and 3 Talco points.

A large bed of "white, gummy [burned] material" and charcoal fragments, suggested to represent an ash deposit, was just above the floor on the northeast side of the pit (Goldschmidt 1934a:12). The vertical provenience of this material suggests that it may relate to ritual activities performed as the pit was being backfilled.

\section{Burial 4}

Although the photograph and plan of this feature show some differences in vessel locations, the photograph suggests that the nine ceramic vessels were on or along the burial pit's longitudinal axis, as if placed on or immediately next to the interment. A large jar (\#77) was along the northwest pit wall, near the northeast end (see Figure 7.2). Two partly overlapped bowls (\#75 and \#76) were on the southeast side of the longitudinal axis, at and just north of its center. A miniature bottle (\#74) was immediately south of Item 75. A large bowl (\#71) was on the central axis south of the pit's center, and a jar (\#72) was at its east side. Another bowl (\#70) was set slightly apart from the central vessel group between the large bowl and the southeast pit wall. A fifth bowl (\#73) was immediately north of the Item 71; it covered a tiny bowl (\#78). Item 71 was missing during the 1983 inventory of the ceramic assemblage.

Twenty-five arrow points were recovered from Burial 4. Goldschmidt (1934a:17) states that these points were fashioned from red chert, but it is not clear if their color is attributable to a particular raw material type, heat treatment, or the transfer of ferrous minerals to the siliceous lithic material from surrounding iron-rich sediments. Five points just over $5 \mathrm{~cm}$ in length were grouped together and pointing west between Items 70 and 71 . Twenty shorter points were clustered below Item 73; no comment is made about their orientations. These points appear to be pointed west on the burial plan, but 1 visible in a photograph is pointing in more of a southerly direction. Thurmond (1990:Table 40) identified 16 Maud and 2 Talco points in the assemblage; 7 specimens were listed as lost or stolen. Other items recorded in the vicinity of Item 73 include a mass of kaolinitic clay, several ochre fragments (\#104), and an unidentified stone.

Goldschmidt (1934a:16) notes that the northeast end of the pit appeared to be the foot of the grave. This inference was apparently based on the presence of the large jar (\#77) near that end of the pit. This statement runs counter to a subsequent discussion about head orientation in the Caldwell cemetery burials, where he suggests that the people were buried with their heads to the northeast (Goldschmidt 1934a:44).

\section{Burial 5}

Burial 5 is the southernmost interment in the cemetery (see Figure 7.1). Feature photographs show a well-defined burial pit with several vessels set along one wall. The feature plan indicates that this was the northwest wall (see Figure 7.2), but the 1934 report text indicates clearly that the drawing is mislabeled and that the directions should be reversed. Hence, most vessels were along the southeast wall.

Eight vessels and half of a ninth were along the length of the southeast pit wall. From southwest to northeast, these consist of four bowls (\#105-108), half of a large jar (\#111), a bowl (\#112), a small bottle (\#113) and miniature bowl (\#114), and a jar (\#115). Most of the vessel orifices were tilted to the northwest. A bowl (\#109), a jar (\#110), and the opposite half of the large jar above (\#111) were in the central third of the pit, separate from the vessels on the southeast wall. In photographs, Item 109 appears closer to Item 110 and the adjacent half of Item 111 than is depicted in the plan, suggesting that it was placed on the right side of the interred. Item 110 is close to the pit's northwest wall, and the other half of Item 111 is just northeast of Item 110 . The nearly equal halves of the intentionally divided jar were placed parallel to each other on opposite sides of the burial pit, likely flanking the deceased. The vessel fragment northwest of the longitudinal axis held a mass of hematitic clay; the fragment southeast of the center line contained three small pieces of ochre. 
Burial 5 held the only celt (\#116) recovered from the cemetery. It was between the northwest pit wall and Item 110 and half of Item 111, but at a higher elevation than the $\mathrm{B}$ horizon contact (Goldschmidt 1934a:22). Goldschmidt (1934a:20, 24) states that it was found at a "height equivalent to the high portions of neighboring pottery" and that "it is made of the gray stone typical of Texas celts"; it appears to be of andesite. According to Goldschmidt (1934a), 12 arrow points were recovered from this burial. Thurmond (1990:Table 40) lists 14 points: 12 Maud and 2 Talco.

The points in Burial 5 were made of red chert. As in Burial 4, it is unclear if this is attributable to a particular chert type, heat treating, or pedological processes in iron-rich sediments. Nine points were grouped together on the pit's longitudinal axis, south of Item 109. All distal ends were aligned to the southwest. The other three points were along the southeast pit wall below Item 106. The report states that the distal ends of these three points were oriented to the southwest. In plan, however, the points are shown pointing to the northwest (Goldschmidt 1934a:21, $24)$. Given their proximity to the southeast pit wall, the former orientation makes more sense if these were on arrows included as offerings.

\section{Burial 6}

Burial 6 was under the east-west fence line that bisected the cemetery (see Figure 7.1). The southwest part of the grave was disturbed by surface erosion and possibly by fence construction. In addition, some of the vessels in this grave may have been impacted by agricultural activities. However, the northeast portion of the burial pit was undisturbed. This burial's 10 ceramic vessels were on and northwest of the pit's longitudinal axis, which suggests that the interment was southeast of that line (Figure 7.3). A small, badly fractured jar (\#139) was isolated near the pit's southwest end. The other vessels were clustered together in the central third of the pit. Most of this vessel group was composed of 3 bowls and 3 jars (\#132-137). Another jar (\#138) was at the southwest end of this vessel group. A small cup-shaped vessel with a flared rim (\#140) was under Item 135, and two pieces of a possible miniature jar or pipe (\#141) were found in the southern portion of the central vessel group. No other mortuary offerings were identified in Burial 6. Item 140 was missing during a 1983 inventory of the assemblage.

\section{Burial 7}

Burial 7 was in a well-defined pit north of the east-west fence line. This interment was noted to be "at a greater depth than the others," but no depth measurement is provided (Goldschmidt 1934a:29). General grave depths provided elsewhere in the report suggest that the Burial 7 pit floor probably was at or close to $3 \mathrm{ft}(90 \mathrm{~cm})$ below the surface (Goldschmidt 1934a:48). Seven ceramic vessels were on or immediately northwest of the pit's longitudinal axis (see Figure 7.3). From southwest to northeast, these consist of a group of three bowls (\#142-144); a beaker (\#145), bowl (\#146), and bottle (\#147) clustered together on the pit's transverse axis; and a jar (\#150) on the long axis near the pit's northeast end. Two other vessels-a bowl reworked from a larger vessel (\#148) and a large jar (\# 149) —were set against the southeast pit wall just northeast of the pit's transverse axis; these two were noted to be "on a somewhat higher level," and a photograph confirms that they were not resting directly on the pit floor (Goldschmidt 1934a:29, 31). Item 148 was filled with hematitic clay. No vessels were at the ends of the pit. The only other offering was a Bassett point immediately east of Item 146 ; its distal end was oriented west-southwest.

\section{Burial 8}

Burial 8 was the easternmost interment (see Figure 7.1). It was unique because it was aligned due east-west rather than northeast-southwest. The length of this pit is identical to that of Burial 1 located $1.52 \mathrm{~m}$ to the south; these two interments had the longest pits in the cemetery. Like Burial 7, the Burial 8 pit floor was said to be "at a rather great depth compared to the others," which suggests that it was at or close to $3 \mathrm{ft}(90 \mathrm{~cm})$ below the surface. Ceramic vessels were on or adjacent to the pit's long axis in all but the westernmost 20 percent of the grave (see Figure 7.3). According to the feature photograph, the vessels were in three groups. A bowl (\#152) and a jar (\#153) were next to each other at the east end of the pit. The second group, centered north of the longitudinal axis and just east of the pit's transverse axis, consisted of a large bowl 
Burial 6

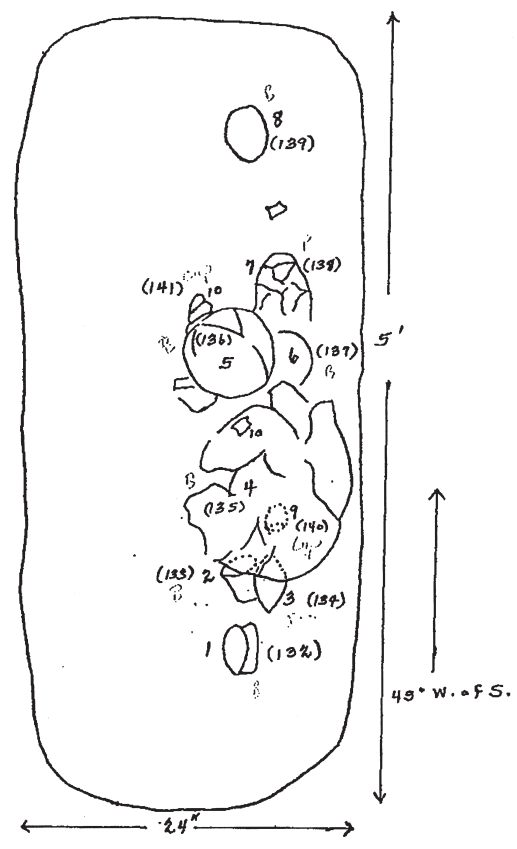

Burial 9

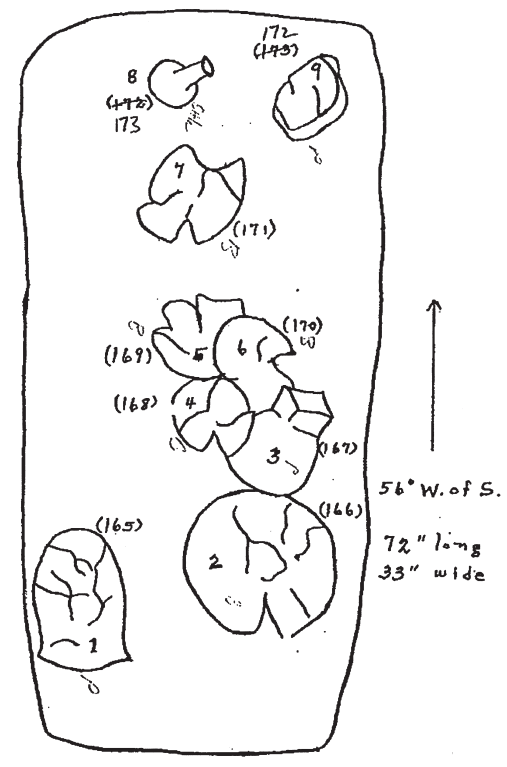

Burial 7

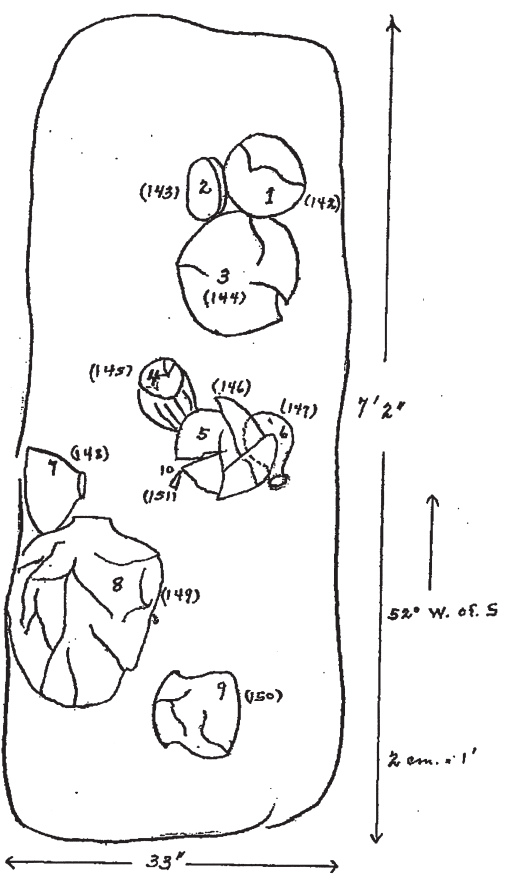

Burial 10

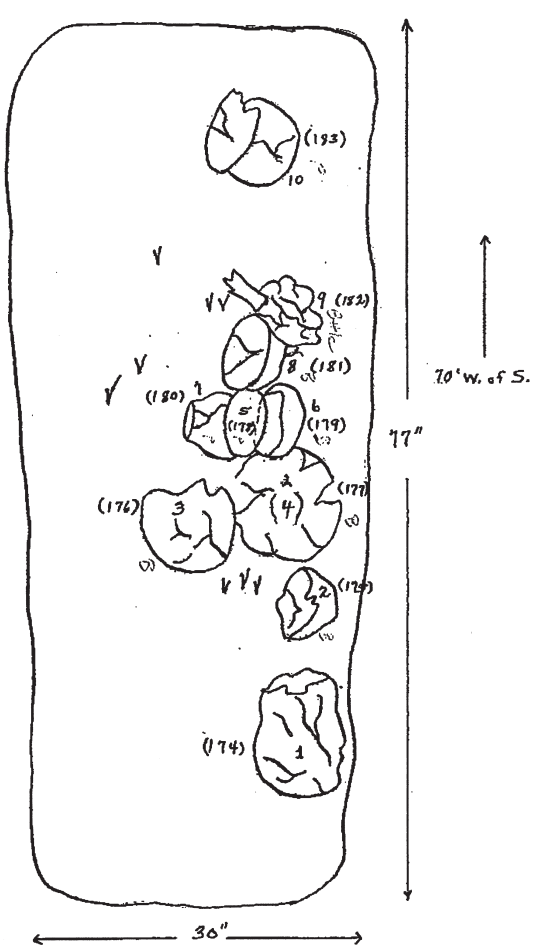

Burial 8

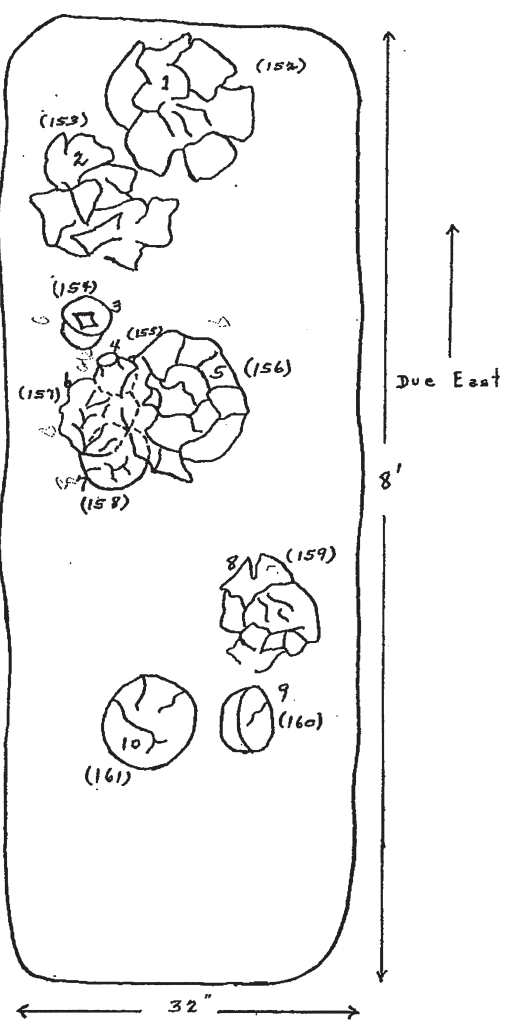

Figure 7.3. Plans of Burials $6-10$ at the Thomas B. Caldwell cemetery (from Goldschmidt 1934a; burials are scaled correctly relative to one another, but their placement on this page does not reflect their positions in the ground). 
(\#156), three smaller bowls (\#154, \#157, and \#158), and a bottle (\#155). The large bowl, which partially overlapped three of the vessels in this group, probably was placed on the interment. The other vessels probably sat to the right of the body. The westernmost cluster consisted of a jar and two bowls (\#159-161) set next to each other on and south of the longitudinal axis. If the cranium was at the east end of the pit, then these bowls were placed on or next to the legs of the interred. Three arrow points were found on the grave pit floor, but their locations are not specified in the text or depicted on the feature plan (Goldschmidt 1934a; Thurmond 1990:Table 40). One of these (\#152) was missing during a 1983 inventory of the assemblage. In 1964, Item 153 was loaned out for a museum exhibit; the vessel was reported lost in 1985.

\section{Burial 9}

Burial 9 was the northernmost interment (see Figure 7.1). Ceramic vessels were placed along nearly the full length of the burial pit, with only the northeast end free of pots (see Figure 7.3). The two largest vessels were closest to the pit's northeast end. Seven of nine vessels were on or just northwest of the pit's longitudinal axis. From northeast to southwest, these consist of a vessel cluster composed of a large bowl (\#166), a jar (\#167), and three bowls (\#168-170); an isolated bowl (\#171); and an isolated bottle (\#173) near the pit's southwest end. A small jar (\#172) partially filled with hematitic clay was in the southwest corner, and a medium-sized jar (\#165) was along the southeast pit wall near the northeast corner. The feature photograph suggests that the deceased was placed between Items 165 and 166 . The other vessels on or just northwest of the long axis would have been placed on or alongside the interred. No other artifacts were identified in this burial, and no unusual characteristics were noted.

\section{Burial 10}

Numerous roots impeded the excavation of Burial 10, and all of the vessels in this bioturbated feature were broken (Goldschmidt 1934a:40). The overall arrangement of vessels in this burial is very similar to that in Burial 6 , with vessels on and primarily northwest of the longitudinal axis, and most clustered in the central third of the pit (see Figure 7.3). This vessel group consisted of five bowls (\#175-177, \#179 and \#181), two jars (\#178 and \#180), and a bottle (\#182). The latter was at the southwest end of the vessel group. The bowl at the northeast end of the group (\#175) was about a quarter full of hematitic clay. Isolated jars (\#174 and \#183) were northeast and southwest of the central cluster. The larger of the two (\#174) was along the pit's northwest wall, near its north corner. Item 183 was just northwest of the longitudinal axis, about $46 \mathrm{~cm}$ southwest of the central group. Most of these vessels probably were located along the interment's right side.

Eight arrow points of varying lengths were recovered from Burial 10. One was found at an elevation equivalent to the tops of the ceramic vessels. The others were found on the floor of the pit. Goldschmidt (1934a:42, 43) notes that the points were found in two different groups, and eight small $\mathrm{V}$ shapes depicted on the plan are believed to represent projectile points, but no differentiation is made between those found on the pit floor and the one found in pit fill. Three points are indicated between Items 175 and 176 at the northeast edge of the central vessel group. These are in a closely spaced row and pointing to the northeast. The five other points are dispersed across the pit's longitudinal axis to the south and south-southwest of the central vessel group. All are pointing to the northeast. Four of these points may be grouped in pairs. Thurmond (1990:Table 40) classified the five remaining projectiles as Maud points, and the other three were listed as lost or stolen.

\section{The Ceramic Assemblage}

Ninety-five vessels and a possible pipe were recovered from the 10 graves. Five vessels are marked as missing in the TARL inventory, leaving 91 items for description and analysis: 9 bottles, 44 carinated bowls, 6 simple bowls, 30 jars, 1 beaker, and 1 possible pipe (Table 7.3 ; includes 1 vessel of unknown provenience). These vessels had been identified typologically by Thurmond (1990:182). They were reexamined at TARL for this study to record additional details, including information on decorative motifs. Some of the typological identifications made here differ from those made by Thurmond, reflecting a reticence in this analysis to type vessels when motifs or vessel forms vary greatly from 
established definitions. The descriptions below are presented by vessel form and ceramic type. Many of the vessels ( $\mathrm{n}=40,44$ percent) can be associated with the type Ripley Engraved. Other types identified, accounting for 14 percent of the assemblage, are Wilder Engraved ( $\mathrm{n}=4)$, Johns Engraved ( $\mathrm{n}=1)$, Bullard Brushed $(\mathrm{n}=4)$, Pease Brushed-Incised ( $\mathrm{n}=3$ ), and Harleton Appliqué $(n=1)$. The remainder (40 percent) are 1 effigy bowl and 36 other untyped vessels.

\section{Bottles}

The nine bottles are all mostly complete. Five are typed as Ripley Engraved and four as Wilder Engraved. Bottle height, which gives a measure of overall size, ranges from 8.4 to $30.0 \mathrm{~cm}$. This wide range can be broken into three groups that cross types, with three bottles in each group. Large to medium-sized bottles have heights of 30.0, 22.5, and $19.7 \mathrm{~cm}$ (Figure 7.4a-c). Small bottles have heights of 15.0, 13.5 and 12.3 (Figure 7.4d-f). Miniature bottles have heights of 8.8, 8.5, and $8.4 \mathrm{~cm}$ (Figure $7.4 \mathrm{~g}-\mathrm{i}$ ).

\section{RIPLEY ENGRAVED}

The five Ripley Engraved bottles (Items $4,48,113,147$, and 155) are medium-sized, small, and miniature vessels. The largest has an overall height of $19.7 \mathrm{~cm}$. Its body is round, and it has a slightly flaring neck (see Figure 7.4c). It is decorated with three iterations of a concentric circle motif with a cross-in-circle as a primary element and pendant triangles, closed circles, and hatching as secondary elements. The cross-in-circle elements are made from four inward-pointing pendant triangles connected by two engraved lines. Pendant triangles pointing outward accent the second innermost circles of the motif and give the impression of a rayed circle. Hatching and closed circles are present in the surrounds between the motif iterations.

The small Ripley Engraved bottles, 15.0 and $13.5 \mathrm{~cm}$ tall, have bell-shaped bodies and flaring necks. One is decorated with a concentric band motif composed of four horizontal lines encircling the vessel from the neck-body juncture to the carination (see Figure 7.4d). Pendant triangles accent two of the lines, and red pigment is visible in the engraving. The other displays the classic Ripley circles and diamonds motif (see Figure 7.4e). Here, alternating open circles and diamonds are the primary elements with pendant triangle surrounds as secondary elements. This bottle may have had a red slip that has been eroded away. White pigment is still visible in some of its engraved lines.

The two miniature Ripley Engraved bottles are 8.8 and $8.5 \mathrm{~cm}$ tall. One has a bell-shaped body with a short flaring neck and is decorated with what may be a medallion motif, as an engraved line extends down the body from the neck-body juncture and curves back up to end as a curl (see Figure 7.4g). The decoration is faint, but the motif appears to occur only once on the bottle. The second miniature bottle has a round body with a short straight neck and is decorated with a concentric circle motif that repeats four times around the body (see Figure 7.4h). This motif has an open circle primary element not enhanced by secondary elements. Red pigment is present in its engraved lines.

\section{WILDER ENGRAVED}

The two largest Wilder Engraved bottles (Items 1 and 182) are of 30.0 and $22.5 \mathrm{~cm}$ tall. Both are decorated with the classic Wilder Engraved swirl motif that repeats four times around the body (see Figure $7.4 \mathrm{a}-\mathrm{b}$ ). In each case, the primary element of the swirl consists of interlocking ends around a central circle or point. The bottles differ in shape, with Item 1 having an elongated body with a short flaring neck that gives the impression of an olla and Item 182 having the bell-shaped body characteristic of Ripley Engraved bottles. The neck body-juncture on the latter also has a slight shoulder that is also found on some Ripley Engraved bottles, and it has traces of red pigment in its engraved lines.

Item 173 is a small Wilder Engraved bottle with a height of $12.2 \mathrm{~cm}$, and Item 74 is a miniature Wilder Engraved bottle with a height of $8.4 \mathrm{~cm}$ (see Figure 7.4f, i). Like the larger Wilder bottles, both display the swirl motif, though on these the motif repeats just three times. Item 173 has a cross within its central circle, and Item 74 has secondary open circles in its shoulder surrounds. The body shape also differs on these two. The miniature bottle has a straight-sided body while the other one has a bell-shaped body. Remnants of red pigment are present within the engraved lines on the latter. 
Chapter 7: The Thomas B. Caldwell and A. P. Williams Cemeteries

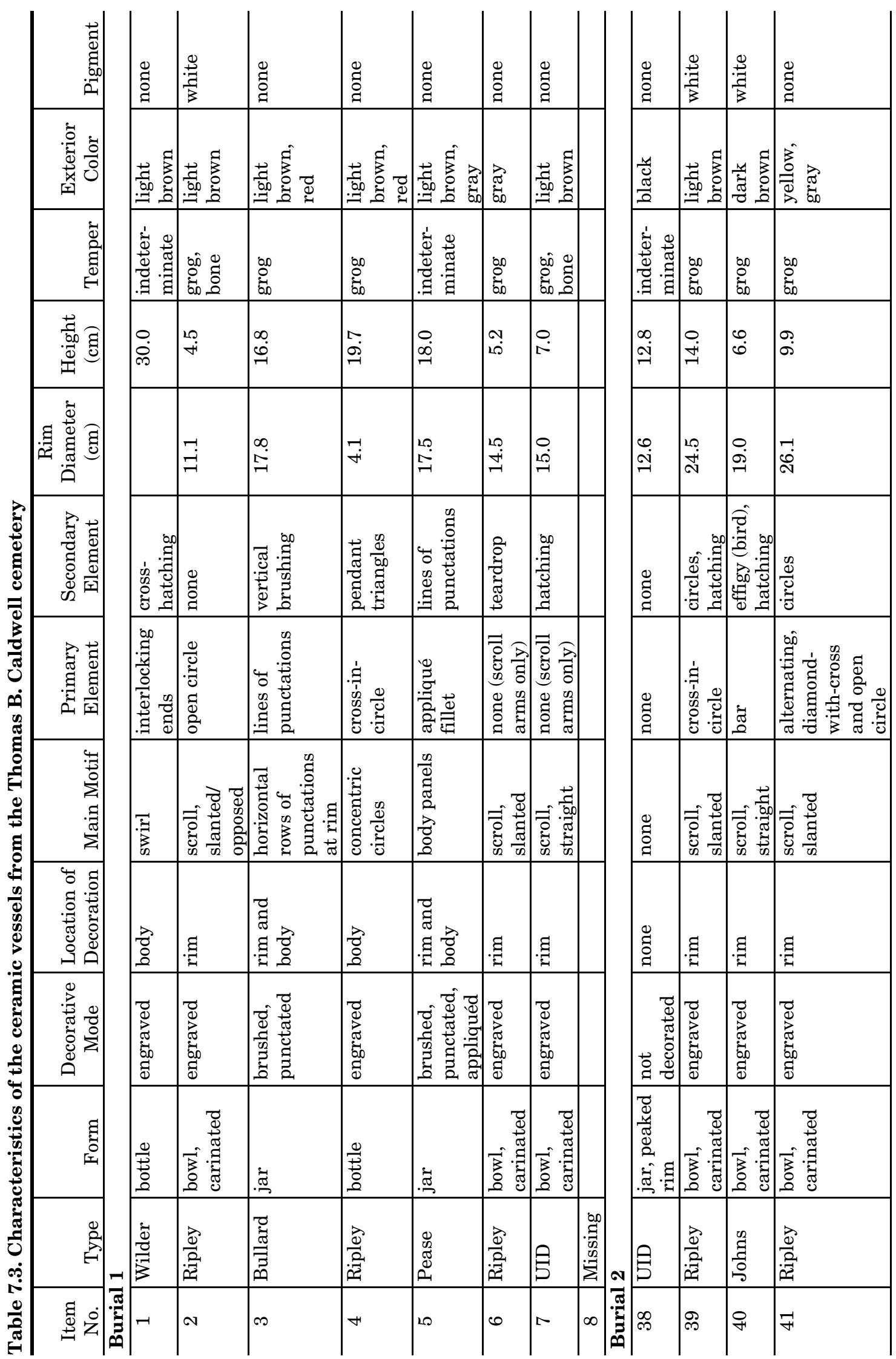


Excavations along the U.S. Highway 271 Mount Pleasant Relief Route

\begin{tabular}{|c|c|c|c|c|c|c|c|c|c|c|}
\hline 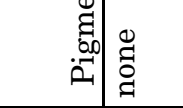 & 窇 & 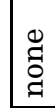 & 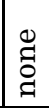 & $\bar{d}$ & 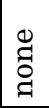 & 崩 & 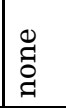 & 苟 & 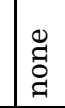 & 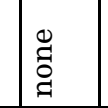 \\
\hline 离謧 & 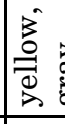 & $\widetilde{\pi}$ & & & & & 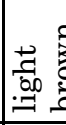 & 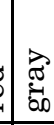 & 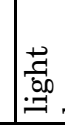 & 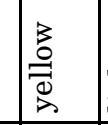 \\
\hline $\mathrm{F}$ & 要 & 然 & 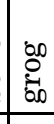 & 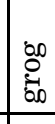 & \begin{tabular}{|cc}
0 \\
$\vdots$ \\
0 \\
0
\end{tabular} & 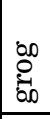 & 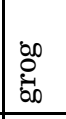 & & 递 & \\
\hline 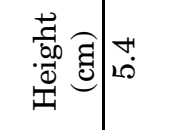 & 趈 & تُ & $\stackrel{\leftrightarrow}{\stackrel{9}{9}}$ & 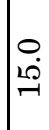 & 10 & 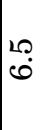 & 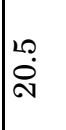 & $\stackrel{8}{j}$ & : & 露 \\
\hline 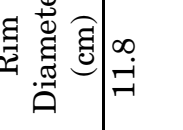 & 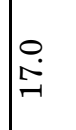 & $\mid \overrightarrow{\vec{N}}$ & 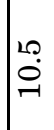 & 品 & $\overbrace{\circ}^{\circ}$ & $\vec{F}$ & $\vec{D}$ & 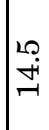 & 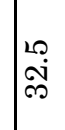 & 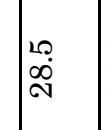 \\
\hline 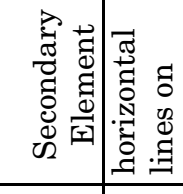 & 哥 & $1 \Xi$ & $\mathbb{E}$ & 音 & I气 & 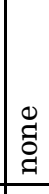 & 莺 & 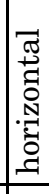 & 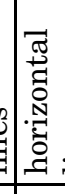 & \\
\hline & 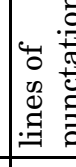 & 芯 & & & & 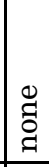 & 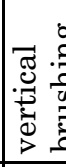 & 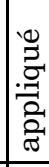 & & N \\
\hline 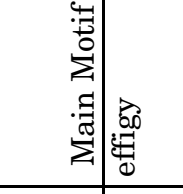 & & $\mid$ & & 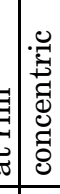 & & 吠 & 莺 & 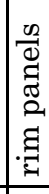 & 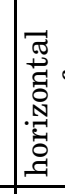 & 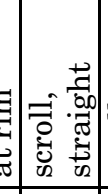 \\
\hline 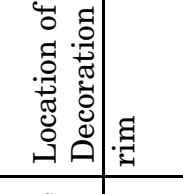 & 具 & 苞 & . & 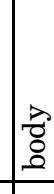 & 目 & 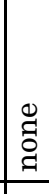 & : & 县 & 貝 & 音 \\
\hline 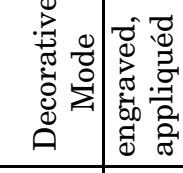 & 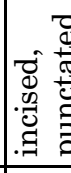 & 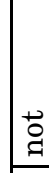 & 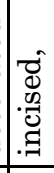 & 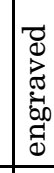 & 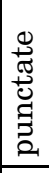 & ¿ & & & 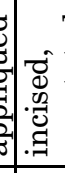 & 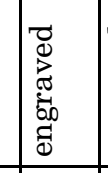 \\
\hline 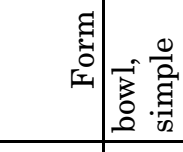 & . & $\vec{\xi}$ &.$\tilde{\omega}$ & 曾 & .ّ & 离 &.$\tilde{\Xi}$ & 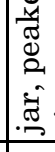 &.$\tilde{\omega}$ & \\
\hline 鳃罗 & 言 & 咅 & 5 & 零 & E & 官 & 官 & $\underline{E}$ & S & 苞 \\
\hline 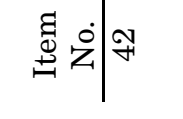 & \% & 0 & 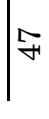 & 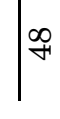 & fi & $\frac{18}{10}$ & |ت & & 足 & it \\
\hline
\end{tabular}


Chapter 7: The Thomas B. Caldwell and A. P. Williams Cemeteries

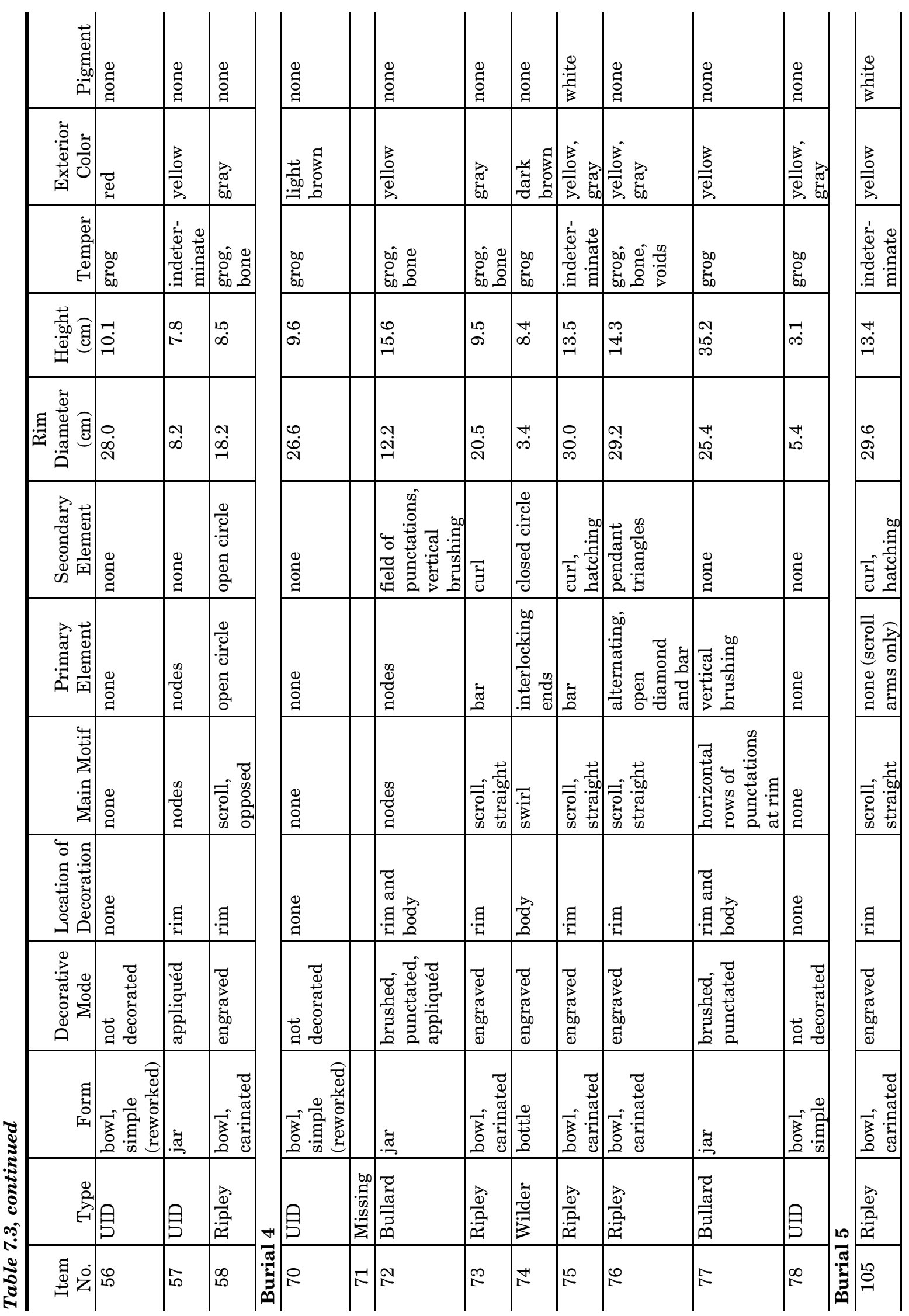




\begin{tabular}{|c|c|c|c|c|c|c|c|c|c|c|c|c|c|}
\hline ind & $\frac{\pi}{\frac{\pi}{3}}$ & $\frac{\pi}{\frac{\pi}{3}}$ & $\frac{0}{\frac{\pi}{3}}$ & \begin{tabular}{|l}
$\frac{9}{7}$ \\
$\frac{7}{B}$
\end{tabular} & ‡ & 离 & 苋 & 苈 & : & 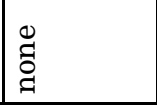 & 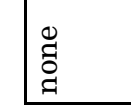 & 总 & 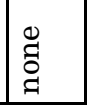 \\
\hline 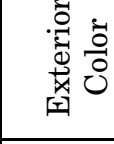 & & 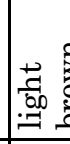 & $\hat{\sigma}_{\Rightarrow}^{0}$ & 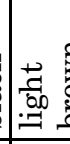 & ? & 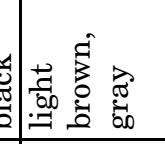 & 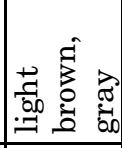 & 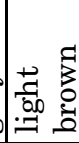 & $\frac{3}{3}$ & 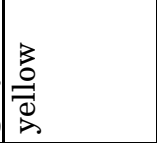 & 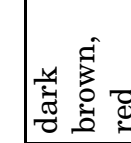 & 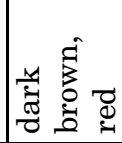 & 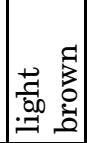 \\
\hline 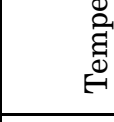 & & 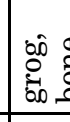 & 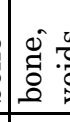 & 离 & 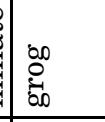 & 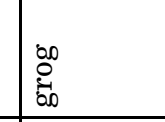 & 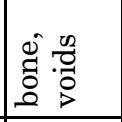 & 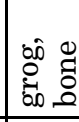 & 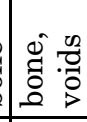 & $\begin{array}{l}0 \\
\\
\end{array}$ & 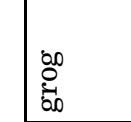 & $\mid \begin{array}{l}0 \\
\vdots \\
\vdots \\
\vdots\end{array}$ & 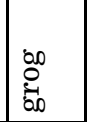 \\
\hline 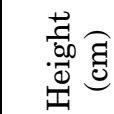 & & $\stackrel{?}{\stackrel{P}{\sim}}$ & $\stackrel{\circ}{\stackrel{\circ}{-}}$ & $\stackrel{L}{\leftrightarrow}$ & $\mid \begin{array}{l}\infty \\
\infty \\
-\infty \\
-1\end{array}$ & 嗵 & $\begin{array}{l}\stackrel{L}{0} \\
\text { İ } \\
\end{array}$ & $\mid \begin{array}{l}\infty \\
\infty \\
\infty\end{array}$ & $\mathscr{C}_{\infty}^{\circ}$ & $\mid \begin{array}{l}\dot{0} \\
\dot{\theta} \\
-1\end{array}$ & $\stackrel{0}{0}$ & $\underset{+}{\stackrel{P}{+}}$ & ${ }_{\infty}^{+4}$ \\
\hline 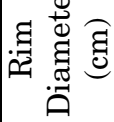 & & 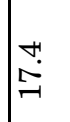 & $\begin{array}{l}0 \\
\stackrel{\text { I }}{N}\end{array}$ & 年 & 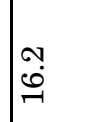 & i̊ & |ro & $\underset{+}{\stackrel{P}{*}}$ & : & 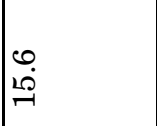 & $\vec{\exists}$ & $\underset{\nexists}{\stackrel{\sim}{ت}}$ & $\mid \begin{array}{l}\infty \\
\vdots \\
0\end{array}$ \\
\hline 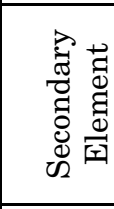 & & $\bar{\Xi}$ & $\vec{\xi}$ & 离 & 芯 & 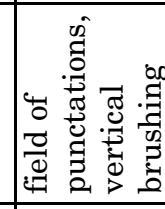 & : & 苋 & 音 & 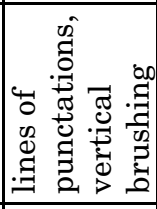 & 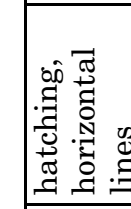 & $\begin{array}{l}0 \\
0 \\
0 \\
0 \\
0 \\
0\end{array}$ & : \\
\hline 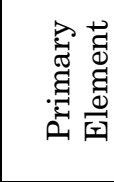 & 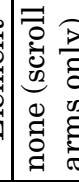 & జే & 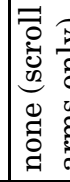 & 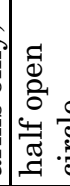 & 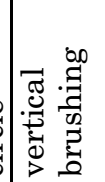 & 造 & 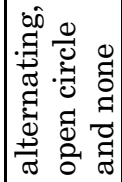 & $\bar{\Xi}$ & : & 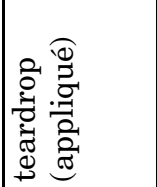 & 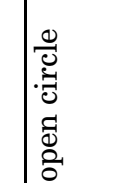 & 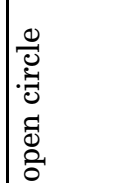 & 芵 \\
\hline 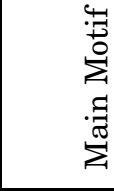 & & 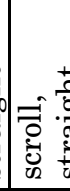 & & 每 & ğ & 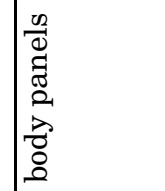 & 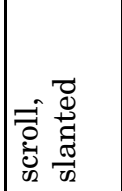 & 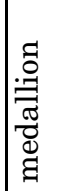 & 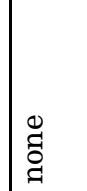 & 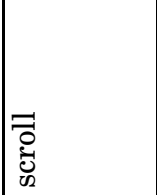 & 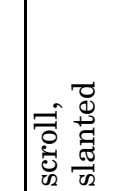 & 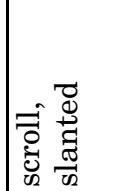 & 童 \\
\hline 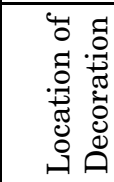 & 蕞 & घี & gี & 踪 & $\begin{array}{l}8 \\
0 \\
0\end{array}$ & 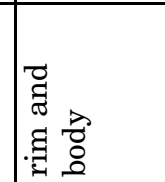 & 清 & $\begin{array}{l}8 \\
0 \\
0 \\
0\end{array}$ & 竜 & 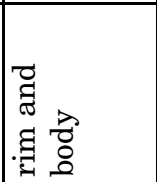 & 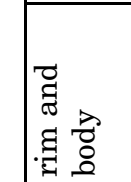 & 䑰 & 离 \\
\hline 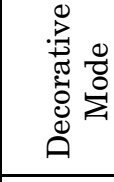 & 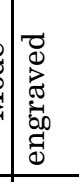 & 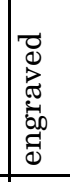 & 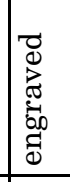 & $\mid$ & 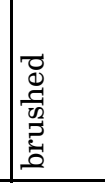 & 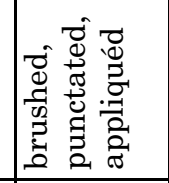 & 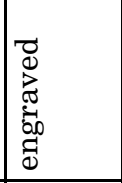 & 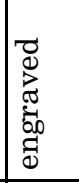 & 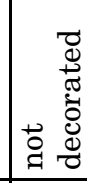 & 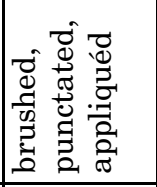 & 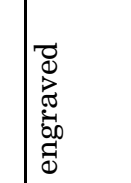 & 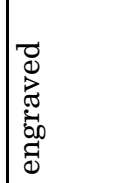 & 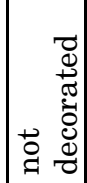 \\
\hline & 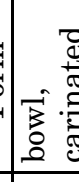 & $\vec{B}$ & 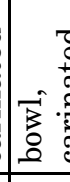 & $\vec{B}$ & : & . & 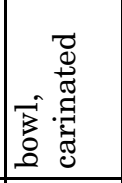 & 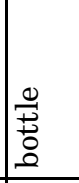 & 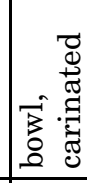 & 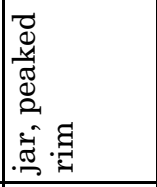 & 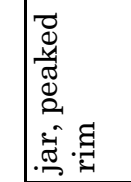 & 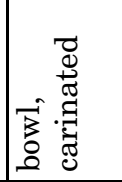 & . .ّ \\
\hline & 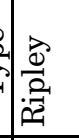 & $\mid \begin{array}{l}\overrightarrow{2} \\
\frac{\overrightarrow{2}}{2} \\
\overrightarrow{2}\end{array}$ & 官 & 离 & 崄 & 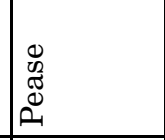 & 卷 & 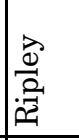 & 会 & 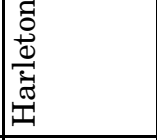 & 㺃 & 卷 & 目 \\
\hline 焉宫 & 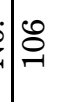 & 흠 & $\stackrel{\infty}{\stackrel{\infty}{-1}}$ & 8 & 윽 & $\exists$ & 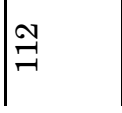 & 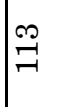 & 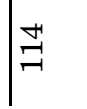 & 10 & 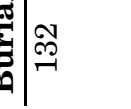 & חָ & 罕 \\
\hline
\end{tabular}


Chapter 7: The Thomas B. Caldwell and A. P. Williams Cemeteries

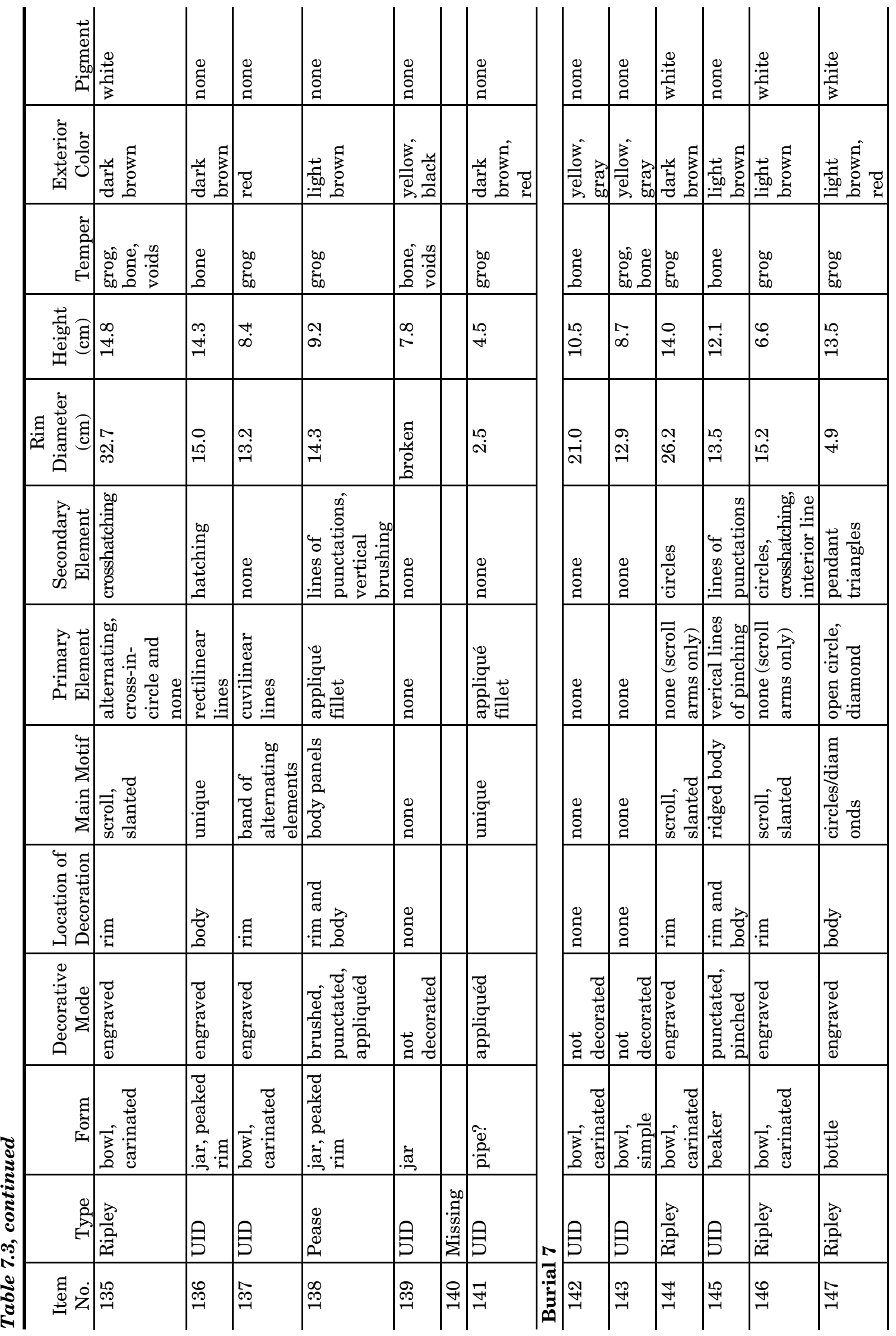




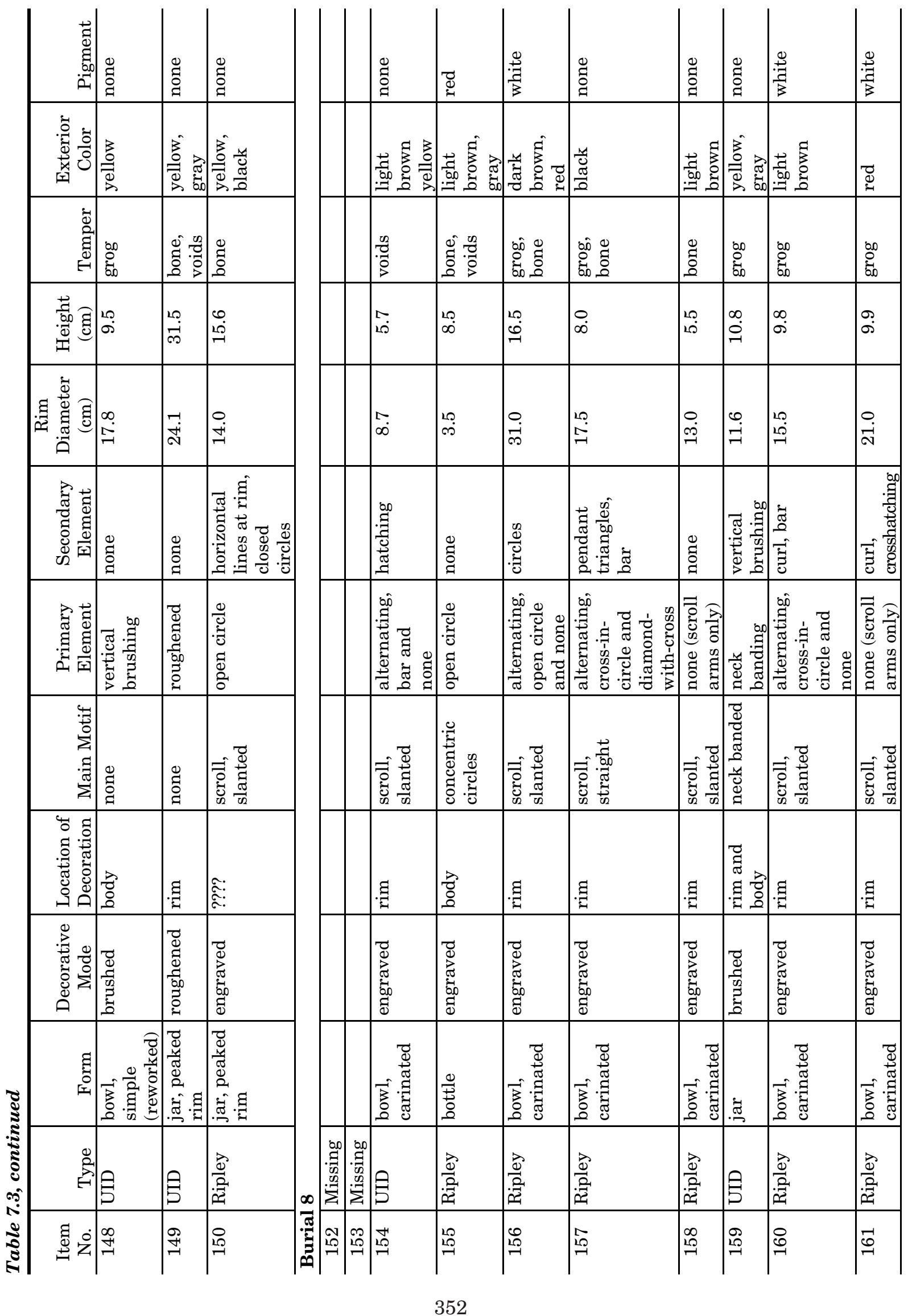


Chapter 7: The Thomas B. Caldwell and A. P. Williams Cemeteries

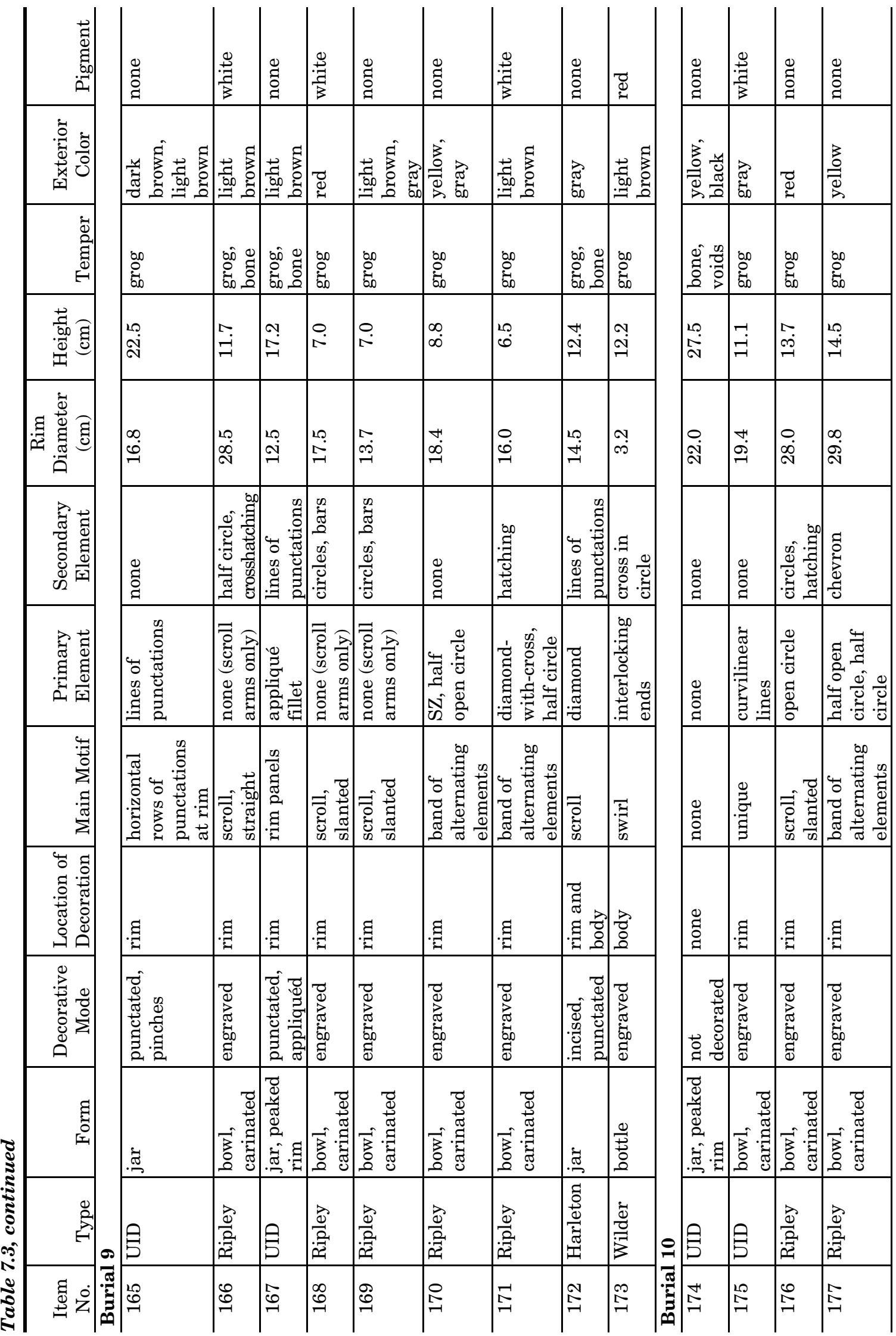


Excavations along the U.S. Highway 271 Mount Pleasant Relief Route

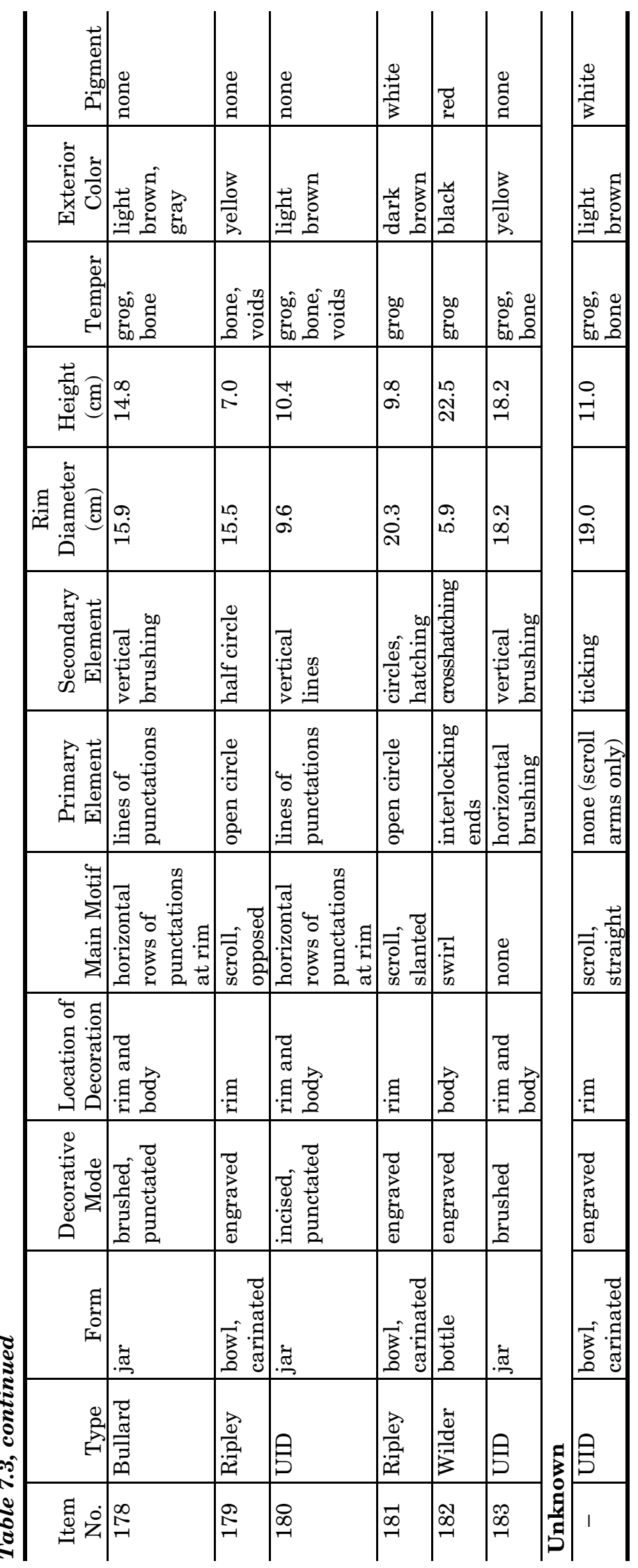




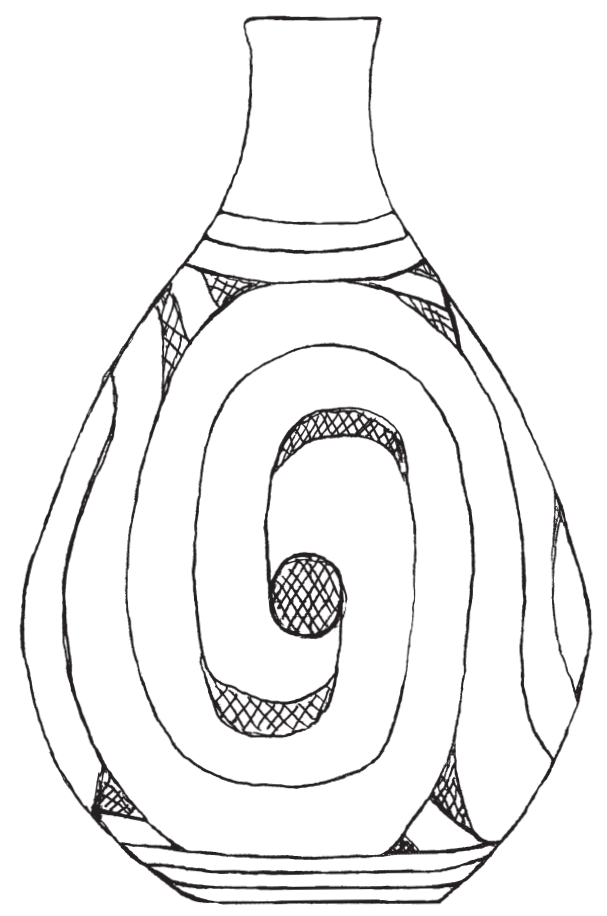

a
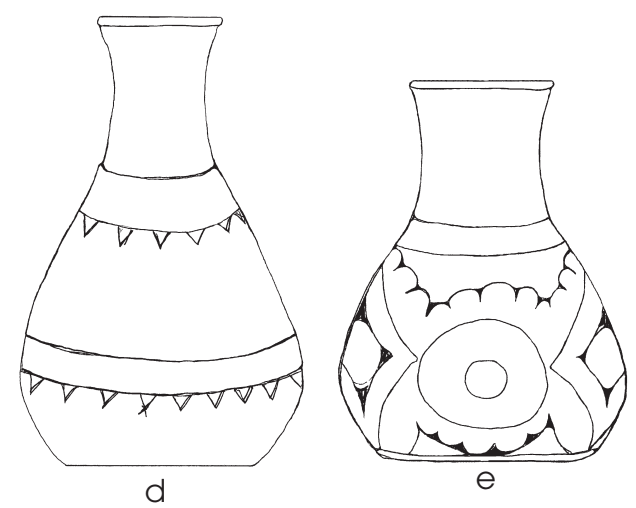

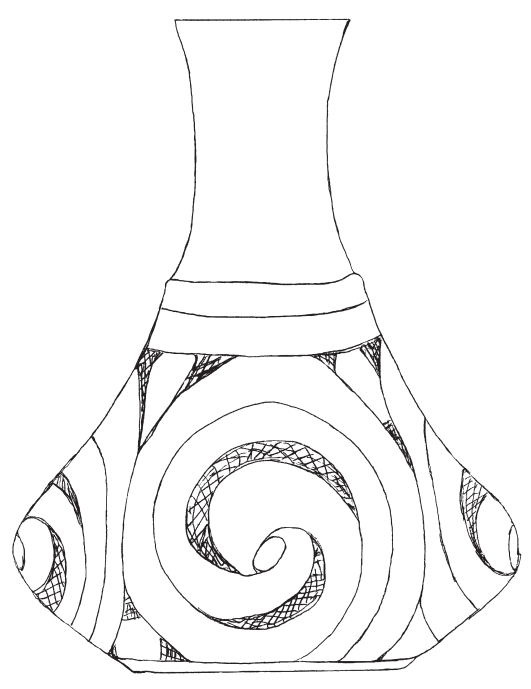

b
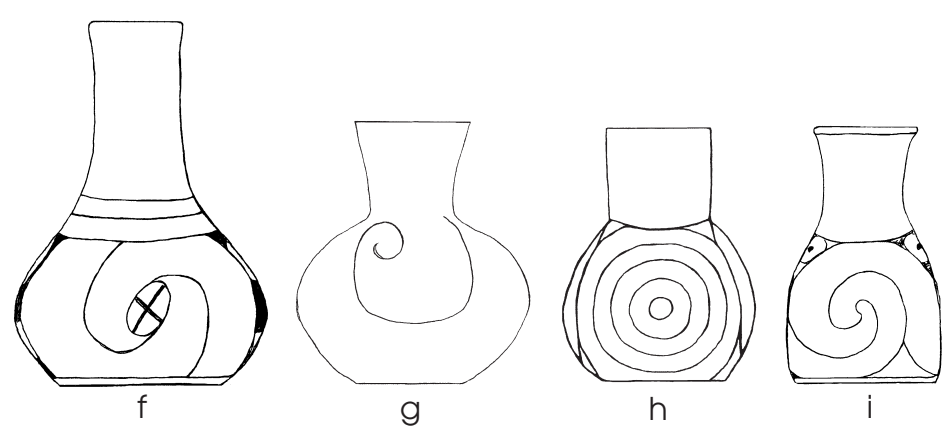

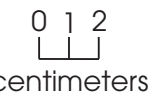

Figure 7.4. Bottles from the Thomas B. Caldwell cemetery arranged by vessel height. (a) Burial 1, Item 1, Wilder Engraved; (b) Burial 10, Item 182, Wilder Engraved; (c) Burial 1, Item 4, Ripley Engraved; (d) Burial 3, Item 48, Ripley Engraved; (e) Burial 7, Item 147, Ripley Engraved; (f) Burial 9, Item 173, Wilder Engraved; (g) Burial 5, Item 113, Ripley Engraved; (h) Burial 8, Item 155, Ripley Engraved; (i) Burial 4, Item 74, Wilder Engraved. 


\section{Bowls}

The 50 bowls consist of 44 carinated bowls and 6 simple bowls. The carinated bowls have a rim diameter range of 6.0 to $32.7 \mathrm{~cm}$ and a mean of $20.1 \mathrm{~cm}$. With 26 bowls (59 percent) at or below the mean, most carinated bowls are small to medium-sized vessels. Simple bowls have a rim diameter range of 3.1 to $10.1 \mathrm{~cm}$, and hence they are small vessels. The majority of the carinated bowls can be typed as Ripley Engraved $(\mathrm{n}=33,75$ percent). There is also a single Johns Engraved carinated bowl. Ten carinated bowls are untyped; 4 of these are not decorated.

\section{RIPLEY ENGRAVED CARINATED BOWLS}

The 33 Ripley Engraved carinated bowls have straight $(n=19)$, everted $(n=13)$, or inverted $(n=1)$ rims with rolled $(n=30)$, rounded $(n=2)$, or tapered $(n=1)$ lips. Other rim treatments such as scalloping, peaking, and punctating are not present on these vessels. These bowls have rim diameters that span the range of all the carinated bowls, $7.9-32.7 \mathrm{~cm}$. White pigment was noted within the engraved lines on 17 of these vessels.

The motifs that decorate the bowls are slanted scroll $(n=17)$, straight scroll $(n=10)$, opposed scroll $(n=2)$, a combination of opposed and slanted scroll $(\mathrm{n}=1)$, and band of alternating elements $(n=3)$ (Figures 7.5-7.7). The primary element most often associated with these motifs is some form of circle. Open circles, that is a circle within a circle, are most common $(n=8)$, but there are also open half circles $(\mathrm{n}=3)$, half circles $(n=2)$ and cross-in-circle $(n=4)$ elements. Less-frequent primary elements are bar $(\mathrm{n}=4), \mathrm{SZ}(\mathrm{n}=3)$, diamond-with-cross $(\mathrm{n}=3)$, and diamond $(\mathrm{n}=1)$.

Secondary elements that appear in the arms of the scroll include circles, half circles, pendant triangles, and crosshatching. In addition, one secondary element, curl, seems to flow out of the structure of the scroll arm itself (see Figure $7.6 \mathrm{a}-\mathrm{c}$ ). This element can be defined as the scroll arm folding or curling around itself as it abuts the adjoining arm, with or without an intervening primary element. In three cases, a bar as a simple line separates the scroll arms rather than a primary element, and in two cases there is no bar. Use of this curl element, with or without a primary element, is restricted to cari- nated bowls from Burials 3, 4, and 5. One form of curl seen on Item 106 from Burial 5 (see Figure $7.6 \mathrm{c}$ ) is quite similar to the interlocking ends associated with Taylor Engraved scrolls (Suhm and Jelks 1962:Plate 75 i, 1, o). Though the ends on the Item 106 scroll do appear to interlock as they do with Taylor Engraved, its overall structure is closer to the other Ripley Engraved scrolls with curled arms. The Ripley Engraved curl and the Taylor Engraved interlocking scroll likely represent some cross influences between potters concerning motif construction.

Another way scroll arms were depicted on Ripley Engraved bowls was to leave out primary elements and set the scroll arms end to end. This structure is common $(\mathrm{n}=14)$ in this assemblage and is noted in Table 7.3 as "none (scroll arms only)" in the primary element column. Thurmond (1990:Figure 6f) called one particular depiction of this scroll (see Figure 7.5e) a continuous scroll, and it is common at the Tuck Carpenter site where Turner (1978:75) called it a triangular motif. Definition of this motif is expanded here to include scroll arms that are both slanted and straight (see Figure 7.5d-f, Figure 7.6c, f), and the ends of the arms that usually abut the primary element can be straight or curving (see Figure 7.5d, e). As a result, the motif Thurmond (1990:Figure $6 \mathrm{~g})$ calls interlocking horizontal scroll also falls within the straight scroll motif with scroll arms only and no primary element as used here.

Yet another variation of the scroll motif structure that is common to Ripley Engraved bowls from the Thomas B. Caldwell and Tuck Carpenter cemeteries is the use of alternating primary elements within the scroll (see Figure 7.5f, Figure 7.6d, e). There are seven bowls with this variation from the Caldwell site. Some of the elements that alternate are cross-in-circle and diamond-with-cross, cross-in-circle and scroll arms only, open circle and scroll arms only, and diamond-with-cross and bar. There are some 21 instances of this kind of scroll variation at Tuck Carpenter (Graves 1, 3, 5, 10, 11, 19, 21, 25, 27, 31-34, 36, and 38 [Turner 1992]), most of which are modified by pendant triangle secondary elements and would be classed under Thurmond's (1990:Figure 6a) pendant triangle motif. Only two scrolls on bowls from the Caldwell cemetery display pendant triangle elements. Both are straight scrolls with alternating primary elements of cross-in-circle and diamond-with-cross or open diamond and bar (see Figure 7.6d, e). 


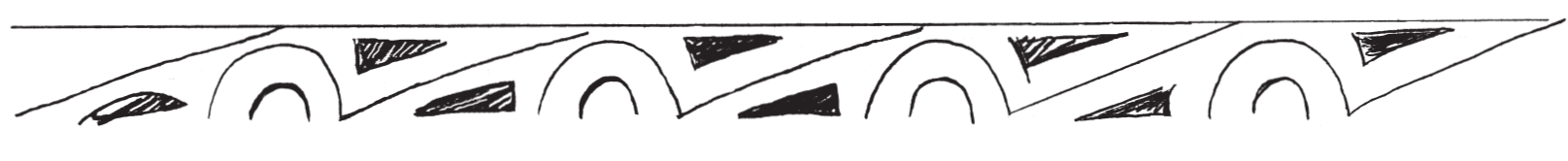

a

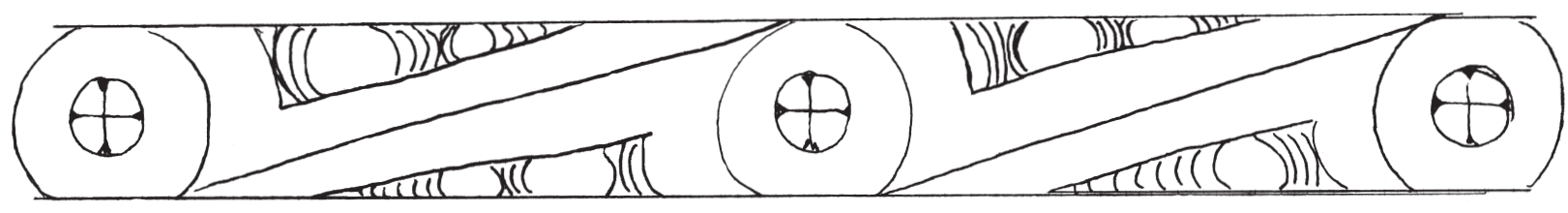

b
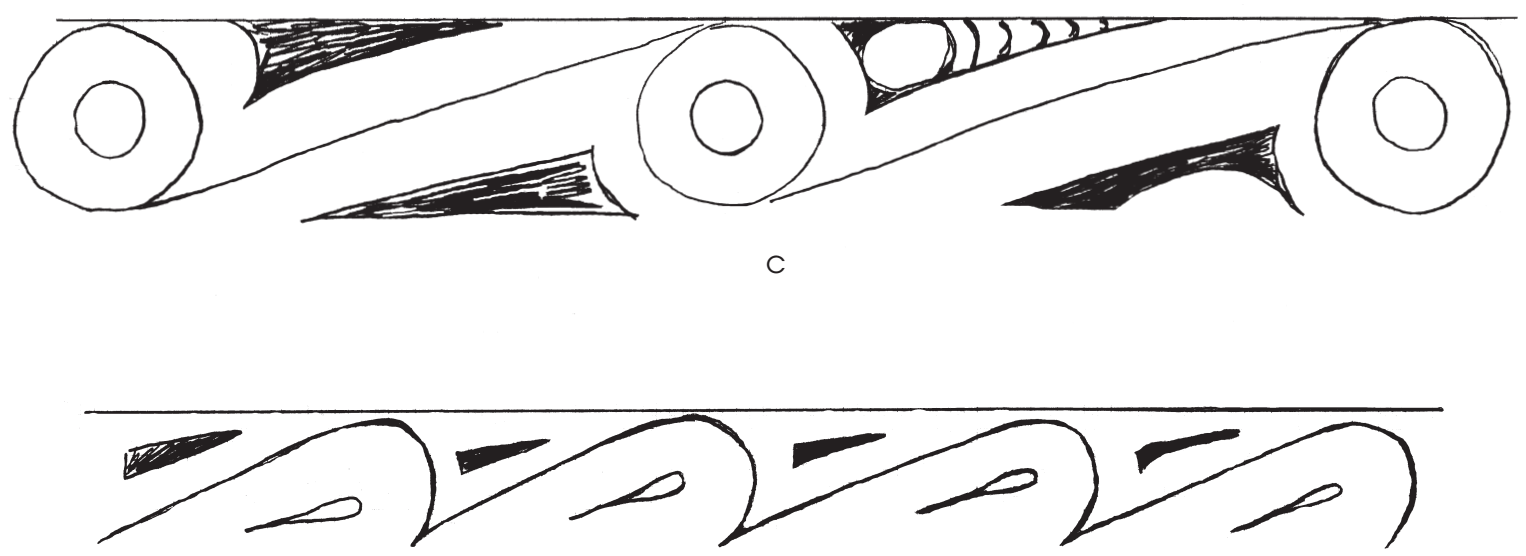

d

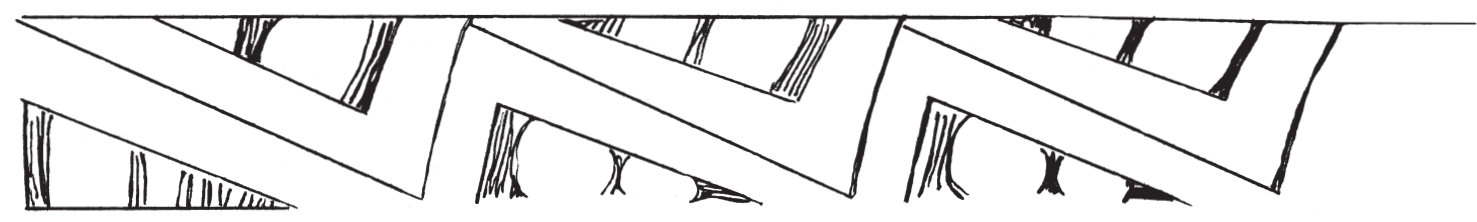

e

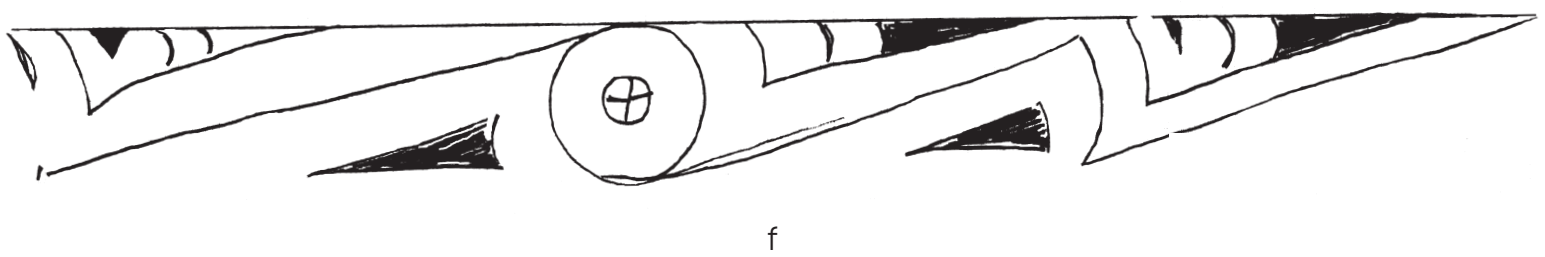

Figure 7.5. Ripley Engraved slanted scroll motifs on carinated bowls from the Thomas B. Caldwell cemetery. (a) Burial 5, Item 109, with half open circle primary element; (b) Burial 2, Item 39, with cross-in-circle primary element; (c) Burial 10, Item 181, with open circle primary element; (d) Burial 1, Item 6, with no primary element; (e) Burial 7, Item 146, with no primary element; (f) Burial 8, Item 160, with alternating cross-in-circle and no primary element. 


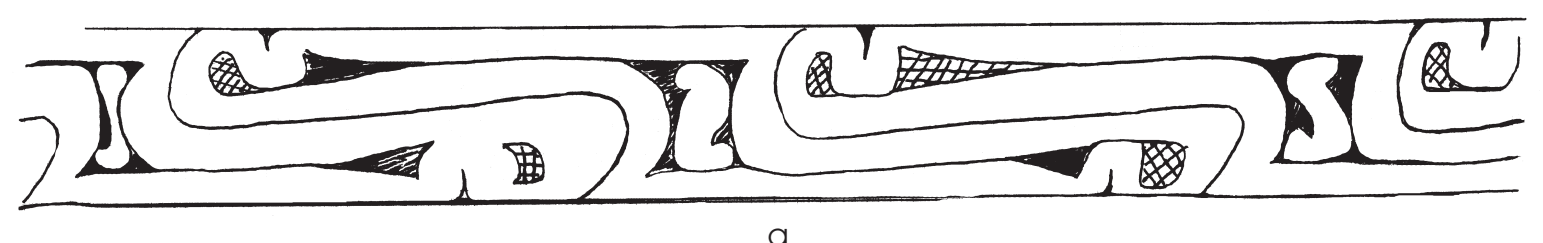

a

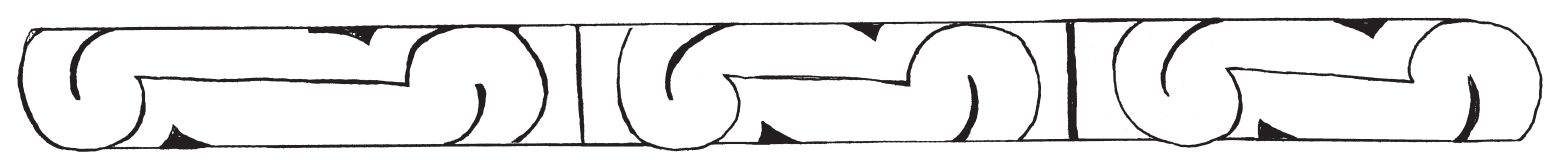

b

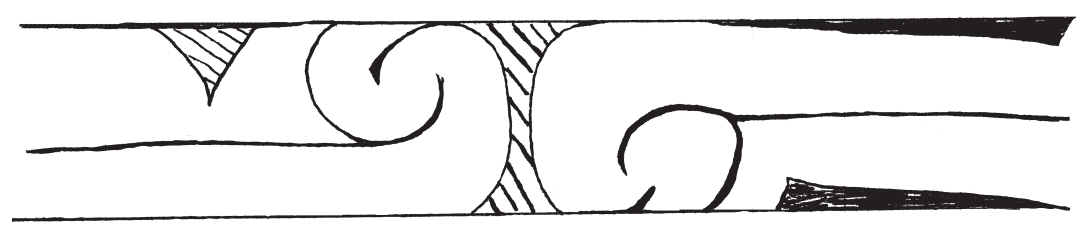

C

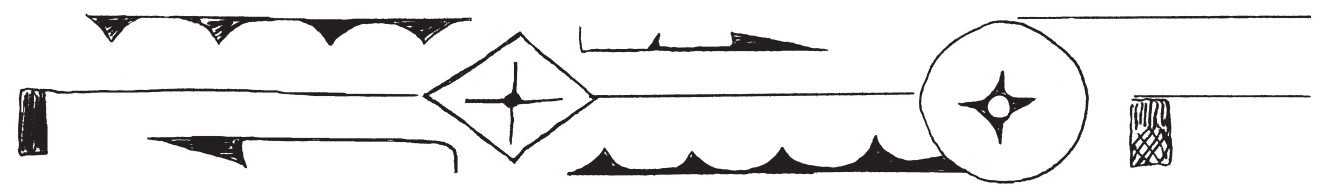

d

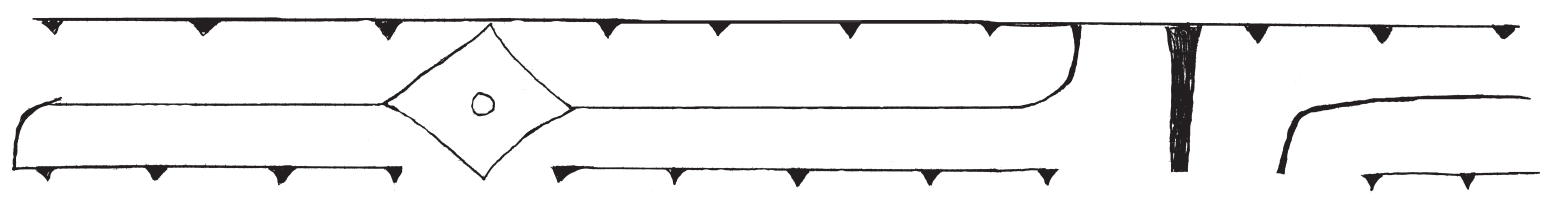

e

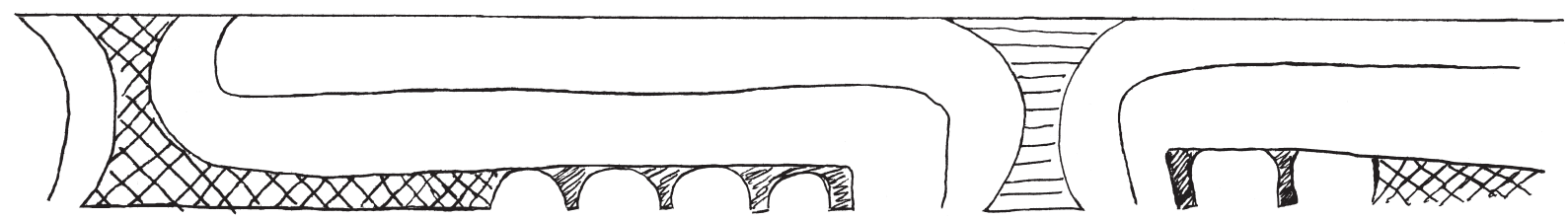

Figure 7.6. Ripley Engraved straight scroll motifs on carinated bowls from the Thomas B. Caldwell cemetery. (a) Burial 3, Item 54, with SZ primary element and curled scroll arms; (b) Burial 5, Item 107, with bar primary element and curled scroll arms; (c) Burial 5, Item 106, with no primary element and curled scroll arms; (d) Burial 8, Item 157, with alternating cross-in-circle and diamond-with-cross primary elements and pendant triangles; (e) Burial 4, Item 76, with alternating open diamond and bar primary elements and pendant triangles; (f) Burial 9, Item 166, with no primary element. 

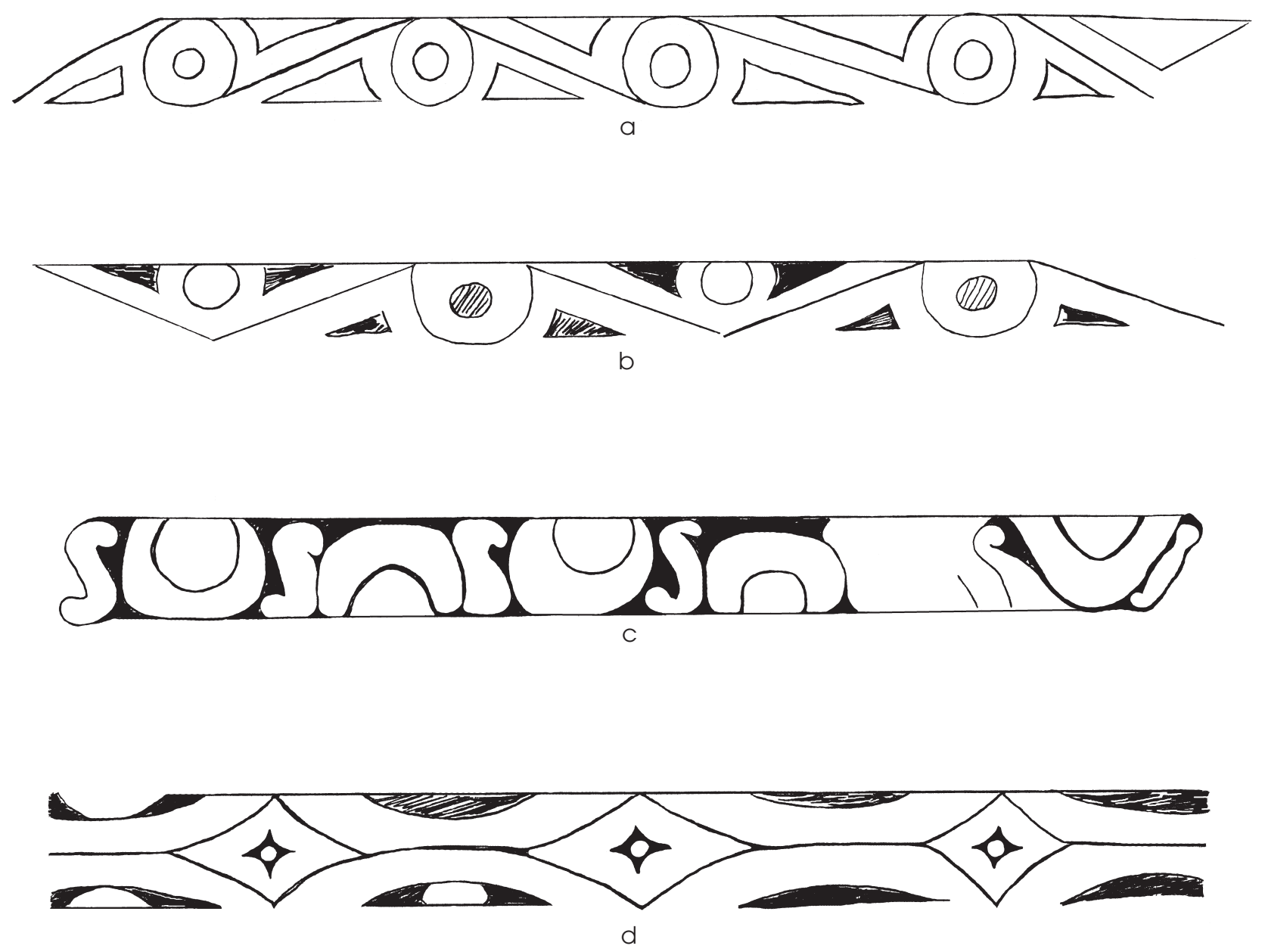

Figure 7.7. Ripley Engraved opposed scroll and band of alternating elements motifs on carinated bowls from the Thomas B. Caldwell cemetery. (a) Burial 1, Item 2, opposed scroll alternating with slanted scroll motif; (b) Burial 3, Item 58, opposed scroll motif; (c) Burial 9, Item 170, band of alternating elements with SZ and half open circle elements; (d) Burial 9, Item 171, band of alternating elements with diamond-with-cross and half circle elements.

\section{JOHNS ENGRAVED CARINATED BOWL}

The single Johns Engraved carinated bowl, Item 40 from Burial 2, has a straight rim with a rolled lip. With a rim diameter of $19.0 \mathrm{~cm}$, it is a medium-sized vessel. There is white pigment remaining in the engraved lines. The motif is emblematic of the type (Turner 1978:86-88). It is reminiscent of a straight scroll with the scroll arms configured as bird heads that abut hatched bar primary elements (Figure 7.8a). This bird motif repeats six times around the vessel. A hooked beak, a circular eye, and a line at the neck mark the bird head. The tail is wedge shaped with an internal patch of hatching. As scroll arms around the central bar element, one bird faces up and the other faces down, a configuration similar to the scroll with curl ends discussed above. Variations on Ripley Engraved motifs using representational bird elements occur on both bottles and bowls; however, this particular motif appears restricted to the upper Big Cypress Creek drainage, with most examples coming from the Johns site itself in Camp County (Turner 1978:86-88). A small simple bowl with a similar bird head in a medallionlike motif is known from Grave 17 at the Tuck Carpenter site (Turner 1992:Figure 19). 


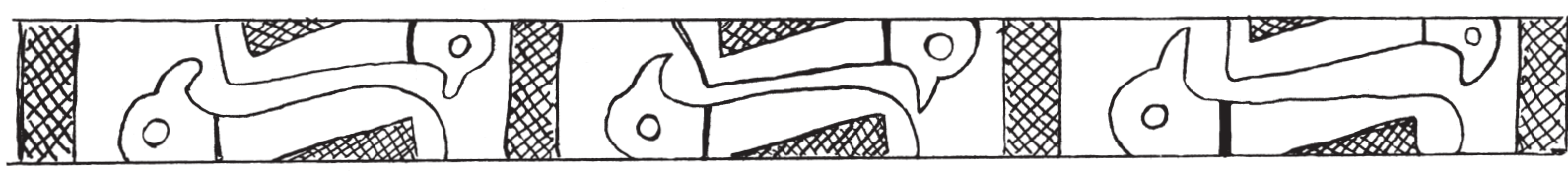

a
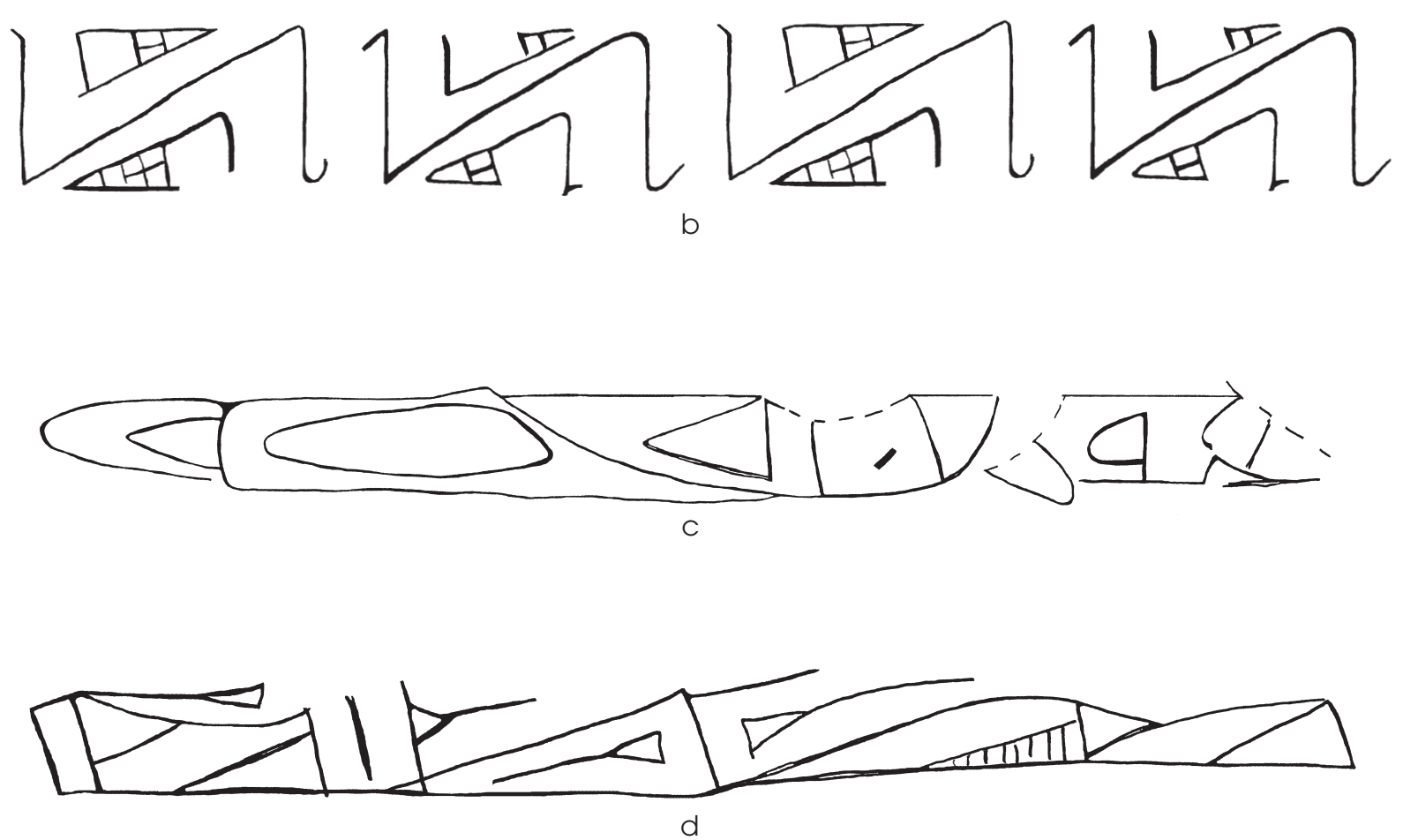

Figure 7.8. Johns Engraved and untyped carinated bowl motifs from the Thomas B. Caldwell cemetery. (a) Burial 2, Item 40, Johns Engraved with straight scroll motif and bar primary element with bird as scroll arms; (b) Burial 5, Item 108, untyped slanted scroll with no primary element; (c) Burial 10, Item 175, untyped idiosyncratic band motif with unique curvilinear elements; (d) Burial 8, Item 154, untyped idiosyncratic slanted scroll motif with alternating bar and no primary element.

\section{UNIDENTIFIED CARINATED BOWLS}

Ten carinated bowls cannot be confidently typed, though they have many characteristics that are similar to the Ripley Engraved bowls described above. Four are not decorated. Six are engraved with what may be called a straight scroll, a slanted scroll, or a band motif, but appear idiosyncratic and do not easily fit a type designation (Figure 7.8b-d). Three of these bowls, most likely the ones with the motifs illustrated here, were typed as Ripley Engraved by Thurmond 1990:182).

\section{UNTYPED SIMPLE BOWLS}

All six simple bowls are untyped. One is an effigy bowl with a broken head (possibly of a bird), a tail, and three horizontal lines around the rim. Four bowls are not decorated, and two of those appear to be the reworked near-base sections of larger vessels. The sixth bowl also appears to be reworked. It is decorated with vertical brushing and may be the bottom of a brushed jar. 


\section{Beaker}

The single beaker, Item 145 from Burial 7, also remains unidentified as to ceramic type. A beaker is defined here as a small vessel that is similar in height and width and has no body or rim inflections. This example has an everted rim and flat base and is relatively small with a rim diameter of $13.5 \mathrm{~cm}$ and a height of $12.1 \mathrm{~cm}$. It is decorated with close vertical rows of pinching that extend from the rim to the base and continue around the body. A line of fingernail punctations encircles the rim just below the lip. The decoration is reminiscent of Killough Pinched, and Thurmond (1990:182) typed this vessel as such and called it a jar, but the vessel form is not commonly associated with that type (Suhm and Jelks 1962:91-92).

\section{Jars}

The 30 jars recovered include 4 that can be typed as Bullard Brushed, 3 Pease BrushedIncised, 2 Ripley Engraved, and 1 Harleton Appliqué. The other 20 are not identified to type. Overall, these jars are mostly small to medium in size, ranging in height range from 7.8 to $35.2 \mathrm{~cm}$ with a mean of $16.8 \mathrm{~cm}$. Most ( $\mathrm{n}=18,60$ percent) fall at or below the mean, and only 6 (20 percent) are large vessels over $20 \mathrm{~cm}$ in height.

\section{BULLARD BRUSHED}

The four Bullard Brushed jars are so identified because they have a main motif of horizontal rows of punctations at the rim, sometimes with nodes, along with brushed rims or bodies (Suhm and Jelks 1962:21). Item 72 from Burial 4 is decorated with four sets of two nodes. Each set has one node at the lip and another at the neck-body juncture. Three jars are medium in size with a height range of $14.8-16.8 \mathrm{~cm}$ and a rim diameter range of $12.2-17.8 \mathrm{~cm}$. The fourth jar is larger, with a height of $35.2 \mathrm{~cm}$ and a rim diameter of $25.4 \mathrm{~cm}$. All of these jars have tall everted rims with rolled lips. One of the smaller jars (Item 3, Burial 1) was called an untyped utility jar by Thurmond (1990:182).

\section{PEASE BRUSHED-INCISED}

The three Pease Brushed-Incised jars have panel motifs defined by vertical appliqué fillets on a plain or brushed body, along with lines of punctations and brushing around the rim. The fillets are evenly spaced and demarcate the simple vertical brushed or plain body panels. These three jars range in height from 9.3 to $24.5 \mathrm{~cm}$ and have rim diameters of $14.3-21.5 \mathrm{~cm}$. The smallest one, Item 138 from Burial 6, has a four-peaked rim with sets of two nodes below two opposite peaks and one below the remaining peaks. The peaks, nodes, and vertical appliqué on the brushed body are aligned. One of these vessels (Item 5, Burial 1), a jar with vertical appliqué marking plain body panels, was considered an untyped utility jar by Thurmond (1990:182).

\section{RIPLEY ENGRAVED}

Two jars, Items 132 and 150 from Burials 6 and 7, are typed as Ripley Engraved because they are decorated with slanted scrolls with open circle primary elements. Each has a four-peaked rim with two horizontal engraved lines encircling the rim/neck. These jars are small with rim diameters of 11.1 and $14.0 \mathrm{~cm}$ and vessel heights of 10.0 and $15.6 \mathrm{~cm}$. These jars are similar in form and decoration to a Ripley Engraved jar from the Russell site in Titus County as illustrated by Suhm and Jelks (1962:Plate 65g). Thurmond (1990:182) typed one of these as a Ripley jar and one (Item 132, Burial 6) as a Ripley compound bowl.

\section{HARLETON APPLIQUÉ}

Item 115 from Burial 5 is a Harleton Appliqué jar that has a four-peaked rim without handles. The form is similar to a Harleton jar from the Russell site in Titus County that is illustrated by Suhm and Jelks (1962:Plate 33d). The body is decorated with diagonal appliqué fillets connecting four large appliqué teardrops that extend from the bottom of the rim almost to the base as primary elements of the scroll (Figure 7.9). Lines of stick punctations follow the appliqué, and three horizontal lines of punctations encircle the four-peaked rim. All of the decorations, body and rim, are on surfaces with fine, even vertical brushing. This jar has a rim diameter of $15.6 \mathrm{~cm}$ and an overall height of $16.0 \mathrm{~cm}$.

\section{UNTYPED JARS}

The 20 jars that remain untyped consist of small, medium, and large vessels. Four are not 

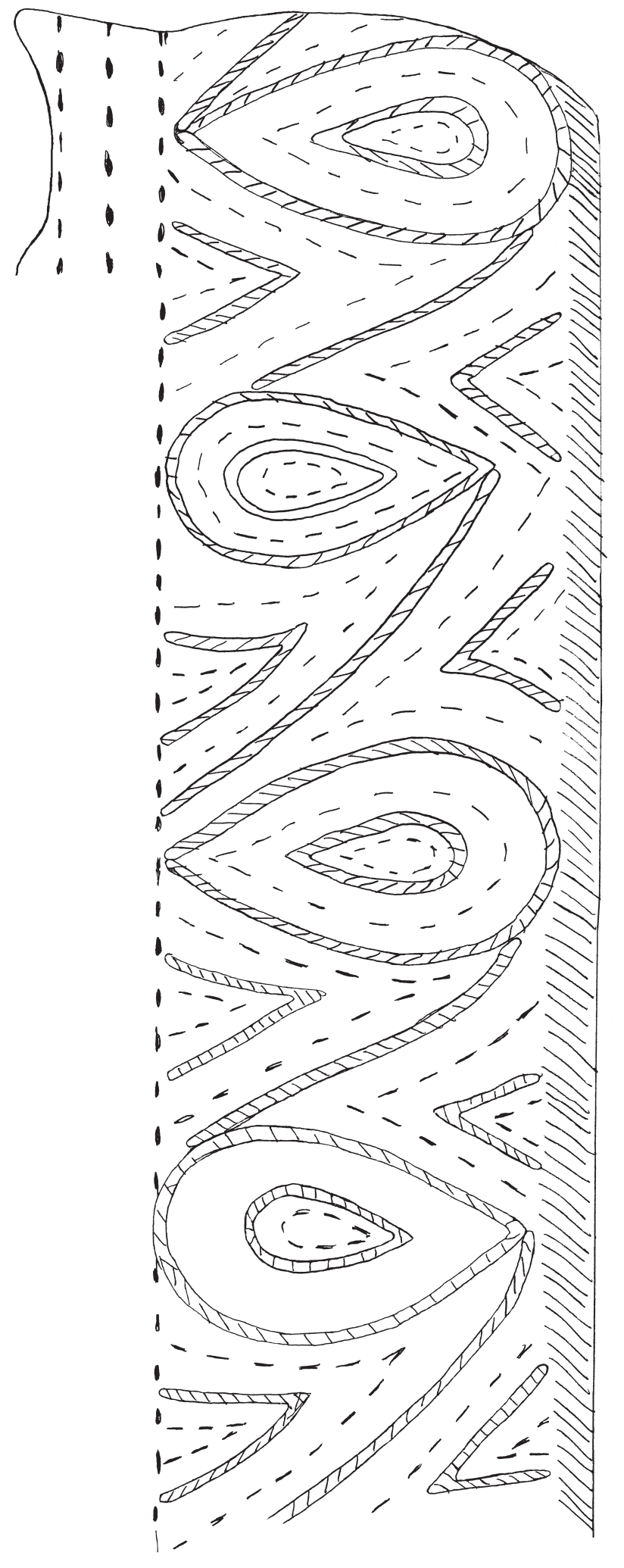

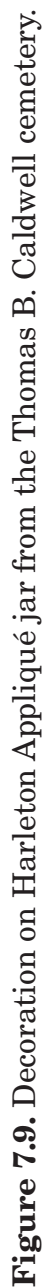


decorated, 10 have decorated rims and plain bodies, 4 have both decorated rims and bodies, and 2 have plain rims and decorated bodies. Three of the plain jars are small with heights of $7.8-8.4 \mathrm{~cm}$. One displays four lip nodes that are suggestive of a four-peaked rim. The fourth plain jar is medium in size (height $=27.5 \mathrm{~cm}$ ) and has a classic four-peaked rim. One large plain jar (Item 174, Burial 10) appears to have been typed as La Rue Neck Banded by Thurmond (1990:182), but neck banding was not apparent during the inspection of this vessel.

The 10 jars with decorated rims and plain bodies consist of 3 small jars (height $=9.5-$ $12.8 \mathrm{~cm}$ ), 5 medium jars (height $=14.0-23.0 \mathrm{~cm}$ ), and 2 large jars (height $=30+\mathrm{cm}$ ). Five are decorated with three or four horizontal rows of stick punctations at the rim, sometimes separated by a horizontal incised line. None of these punctated and incised rims is peaked. This rim decoration is similar to that seen on the Bullard Brushed jars described above, but the examples here lack brushed bodies. This rim decoration also is similar to what Perttula (2005:277-278) has called Mockingbird Punctated, but the amount of variation that can occur within this proposed type is still unclear, making it hard to use. Thurmond (1990:180) relates these to McKinney Plain but does not type them as such. A medium-sized jar and a small jar have horizontal lines of stick punctations or incised lines between four vertical appliqué fillets that are positioned below the peaks of four-peaked rims. This decoration may be considered rim panels and may have some association with the type Pease Brushed-Incised, though the panel fill of punctations and incising is not executed in a way that is consistent with that type. A medium-sized jar and a large jar have brushed rims only with the large jar also displaying a four-peaked rim. The larger jar with rim peaks (Item 149, Burial 7) was typed as La Rue Neck Banded by Thurmond (1990:182), but the neck and rim appear to have been textured by brushing rather than banding, and La Rue jars are not known to be peaked. The tenth vessel in this group is a small jar with a four-peaked rim and a single incised line below the lip as its only decoration.

The four jars that have both decorated rims and bodies consist of thee small vessels (height $=10.4-12.4 \mathrm{~cm}$ ) and one medium-sized vessel (height $=18.2 \mathrm{~cm}$ ) vessel. The latter has a horizontally brushed rim and a vertically brushed body. The three small jars are variously decorated. One has deep, evenly spaced vertical incisions around the body and three horizontal rows of stick punctations around the rim. Another has three horizontal rows of stick punctations around the rim while the body is decorated with an incised scroll motif with large nested diamonds as the primary element (Figure 7.10). The motif structure is similar to that on the Harleton Appliqué jar described above, but, unlike the Harleton jar, this one is incised and its rim is not peaked. The third small jar is a neck banded vessel with a vertically brushed body. It is not typed as La Rue Neck Banded, though Thurmond (1990:182) called it so, because the globular body and only slightly everted rim are uncharacteristic for the type.

Lastly, the jars with decorated bodies and plain rims consist of one medium-sized vessel and one small one. The former (height $=18.8 \mathrm{~cm}$ ) has a vertically brushed body. The small jar (height $=14.3 \mathrm{~cm}$ ), which has a four-peaked rim, has an engraved body design that is eroded and difficult to discern, but what can be seen consists of hatched patches and rectilinear lines that emerge from two horizontal lines encircling the neck. This design is vaguely reminiscent of Ripley Engraved scroll motifs. The vessel form is similar to the Ripley Engraved jars described above.

\section{Possible Ceramic Pipe}

Though the TARL inventory lists them as the remains of a possible miniature jar that Thurmond (1990:182) typed as Killough Pinched, the fragments of Item 141 from Burial 6 may be a smoking pipe. These fragments are highly friable and hard to orient, but it appears that several might be part of a pipe bowl that has an orifice diameter of $2.5 \mathrm{~cm}$ and a height of $4.5 \mathrm{~cm}$. The stem is completely broken away, but attachment points on the broken bowl suggest that the stem extended out from both sides of the bowl, much like a Poole or Red River-style pipe (Hoffman 1967). Unlike that pipe style, however, this specimen is decorated with appliqué ridges that curl down and around the bowl from what is projected to be the bowl rim. In addition, a 2.3-cm-diameter cylindrical section that may be part of the stem is present, though it does not refit to the bowl fragment and shows no evidence of a draw hole. There is no evidence of burning on the possible bowl fragment as might 

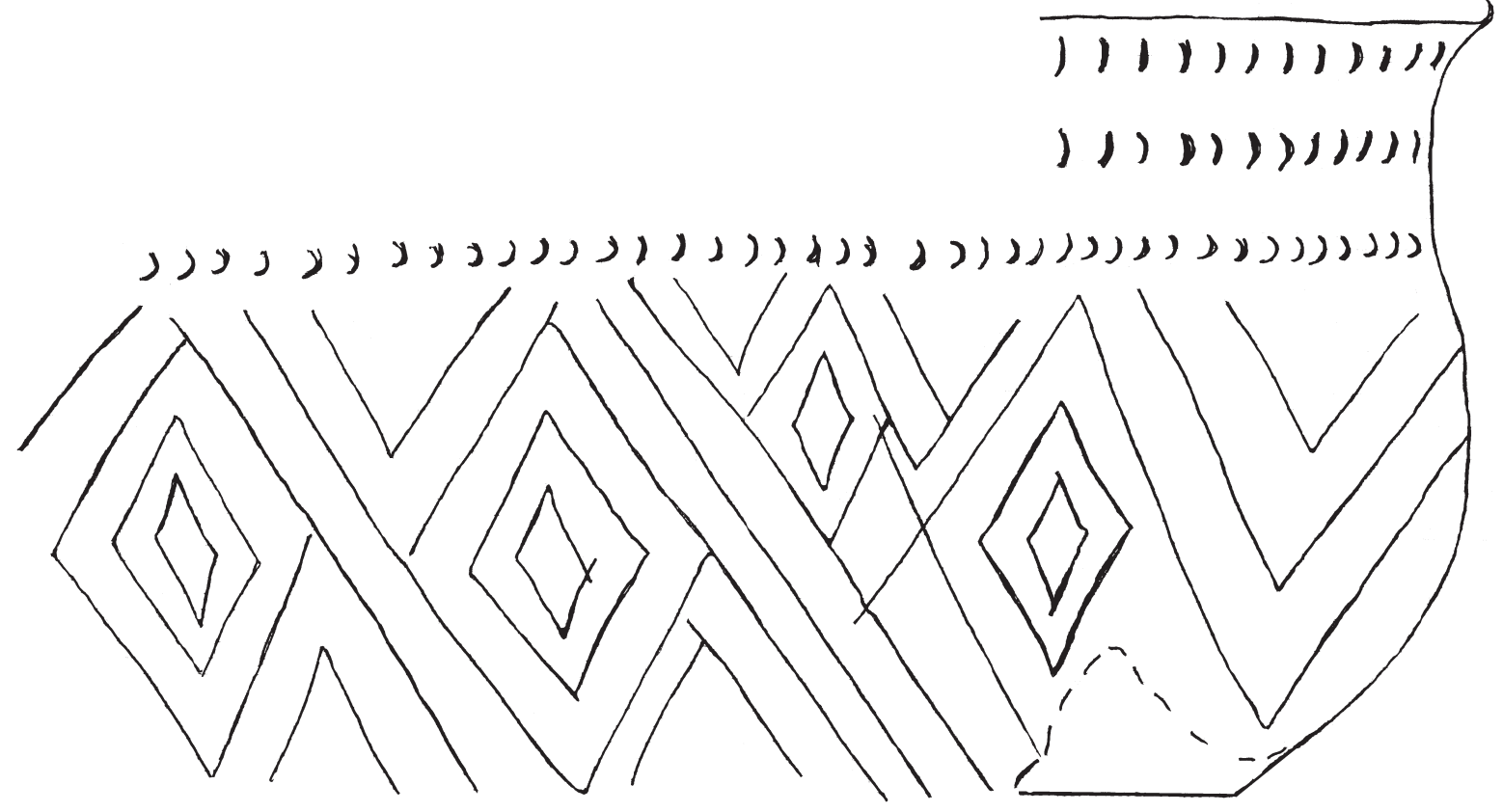

Figure 7.10. Decoration on untyped jar with rows of punctations on the rim and incised scroll on the body from the Thomas B. Caldwell cemetery.

be expected with a pipe that was used. If this is not a pipe, it is a small and curious vessel that, given its friable nature, may have been made specifically as a burial offering.

\section{Conclusions and Impressions}

The 9 bottles, 44 carinated bowls, 6 simple bowls, 30 jars, 1 beaker, and 1 possible pipe from the Thomas B. Caldwell cemetery likely represent vessels manufactured for the most part by the local group that used the cemetery. Given the consistency of motifs and decorative elements from one grave to another, it is likely that the cemetery was in use for a fairly short interval.

Fifty-one vessels (56 percent; including the 2 engraved jars) constitute the engraved fine wares. Most can be typed as Ripley Engraved $(\mathrm{n}=40)$ and secondarily Wilder Engraved $(\mathrm{n}=4)$. The Ripley Engraved scroll motifs on carinated bowls show a strong affinity to bowls from the Tuck Carpenter cemetery in Camp County. The slanted scroll motif with open circle primary element is common at both. The Caldwell cemetery bowls also display the curl element at scroll ends, a straight scroll with diamonds and pendant triangle elements, and scrolls with no primary elements, which are also common at Tuck Carpenter. Even the presence of the single Johns Engraved bowl at the Caldwell cemetery is mirrored by a Johns Engraved bowl from Burial 17 at Tuck Carpenter (Turner 1978:87). Curiously, there are no compound bowls from the Caldwell graves; carinated and simple bowls predominate, unlike at Tuck Carpenter and the A. P. Williams cemetery.

The nine engraved bottles also are similar to those from Tuck Carpenter. The large Wilder Engraved bottle from Burial 1 has a very similar vessel body and motif construction as a bottle from Grave 30 at Tuck Carpenter (Turner 1992:64). These nine bottles are interesting because most $(n=6)$ are small, with the two largest being Wilder Engraved. Unlike at the A. P. Williams cemetery, none have unique motifs.

\section{The Lithic Assemblage}

As noted, Goldschmidt (1934a) reported that 85 arrow points, 1 biface, 1 piece of limonite, 2 pieces of silicified wood debitage, and 1 celt were recovered from the graves. When 
Thurmond inventoried the collection for his 1981 thesis, he found all of these except for 14 arrow points. A later (1986) TARL inventory identified everything but 4 arrow points. This study was able to re-locate the full collection, minus 12 arrow points (4 from Burial 1, 6 from Burial 4 , and 3 from Burial 10, minus 1 extra point from Burial 5; of the 2 extra points Thurmond recorded from Burial 5, 1 with a poorly written label actually was associated with Burial 1, while the other likely belongs to one of the other burials). The biface, from Burial 1, is a distal fragment made of nonlocal yellowish-white chert (probably Keokuk-Burlington); it is fairly long $(6.7 \mathrm{~cm})$ and narrow $(2.6 \mathrm{~cm})$ with retouch and use evident on the blade edges; it has a maximum thickness of $0.6 \mathrm{~cm}$ and weighs $11.2 \mathrm{~g}$. Also from Burial 1 are 3 pieces of debitage: a large $(>50 \mathrm{~mm})$ primary flake of limonite, probably part of some pigment source; and 2 very large, irregular pieces of silicified wood that have no apparent use wear or retouch. The celt, from Burial 5 , is of petaloid form and made of greenish-gray andesite with tan inclusions that may be basalt. It is complete and has battering on the proximal end and a nicely polished distal end. Weighing $176.2 \mathrm{~g}$, it has an overall length of $8.1 \mathrm{~cm}$, a maximum width of $4.4 \mathrm{~cm}$, and a maximum thickness of $3.3 \mathrm{~cm}$.

The 73 arrow points consist of 61 triangular specimens typed here as Maud (includes those typed as Talco by Thurmond) and 12 points typed as Bassett. Table 7.4 presents metric data for them. The Mauds are slender triangular points with concave to V-shaped bases. All but 1 are complete or nearly so; the broken Maud is a distal fragment and thus is typed tentatively. All but 1 has some degree of blade serration, and most $(n=51)$ have some retouch; this retouch resulted in a needle-like tip on several, which is a common characteristic of this type. A little over half $(n=37)$ were made of cherts that appear to be local, including varieties that are dark to light brown, brown with red, grayish brown, yellowish brown, reddish brown, tan, tan and gray, tan and red, and red. A few of these may actually be nonlocal. Fourteen Mauds are made of Ogallala quartzite, and 6 are of other quartzite; all are considered local materials. Nonlocal materials consist of 1 made of translucent dark yellowish brown Edwards chert and 3 of gray chert. The Maud points are from the following graves: Burial 1, $\mathrm{n}=14$; Burial 3, $\mathrm{n}=7$; Burial
$4, \mathrm{n}=19 ;$ Burial 5, $\mathrm{n}=13 ;$ Burial $8, \mathrm{n}=3 ;$ and Burial 10, $\mathrm{n}=5$.

The Bassett points have short contracting stems with pointed bases. Eight are complete, three are proximo-medial fragments, and one is missing the barbs. All but one have blade serration, and four are retouched. Seven are made of local chert (brown, red, reddish brown, or tan), and five are of Ogallala quartzite. Seven are from Burial 1, four are from Burial 3, and one is from Burial 7.

\section{THE A. P. WILLIAMS SITE}

A crew from the Department of Anthropology at the University of Texas at Austin excavated a prehistoric Caddo cemetery and conducted test excavations nearby on the A. P. Williams farm between July 20 and August 1, 1934, one month after they excavated the Thomas B. Caldwell cemetery. The farm was 3 miles $(4.8 \mathrm{~km})$ west of the town of Mount Pleasant, on the north and south sides of the Winfield Road. Field investigations were south of the road and the adjacent Cotton Belt railroad tracks, just south of the original channel of Dragoo Creek. In addition to removing 10 burials from the cemetery, the crew sampled a midden a short distance east of the cemetery (Goldschmidt 1934b:1, 43).

The property owner (Mr. Williams) and a renter (O. A. Qualls) discovered six ceramic vessels while digging an artificial channel south of the Dragoo Creek streambed. Discovery of the vessels was eventually related to Walter R. Goldschmidt, field foreman with the Department of Anthropology, who visited the property on July 17. Goldschmidt interviewed Mr. Qualls and Mr. Williams, was shown the exact location of the discovery, obtained permission to conduct excavations, and purchased the vessels that Mr. Qualls had in his possession for \$5. Department Chairman J. E. Pearce and A. T. Jackson were taken to the site a few days later, and they concurred that the site was worth further investigation.

The site was eventually assigned the trinomial designation 41TT4. Archeologists with Espey, Huston and Associates, Inc. (EH\&A), revisited it in the early 1980s in connection with work at the Monticello-Winfield Mine and identified the previously excavated cemetery about $650 \mathrm{~m}$ southeast of the plotted cemetery location in the TARL files (Espey, Huston and 


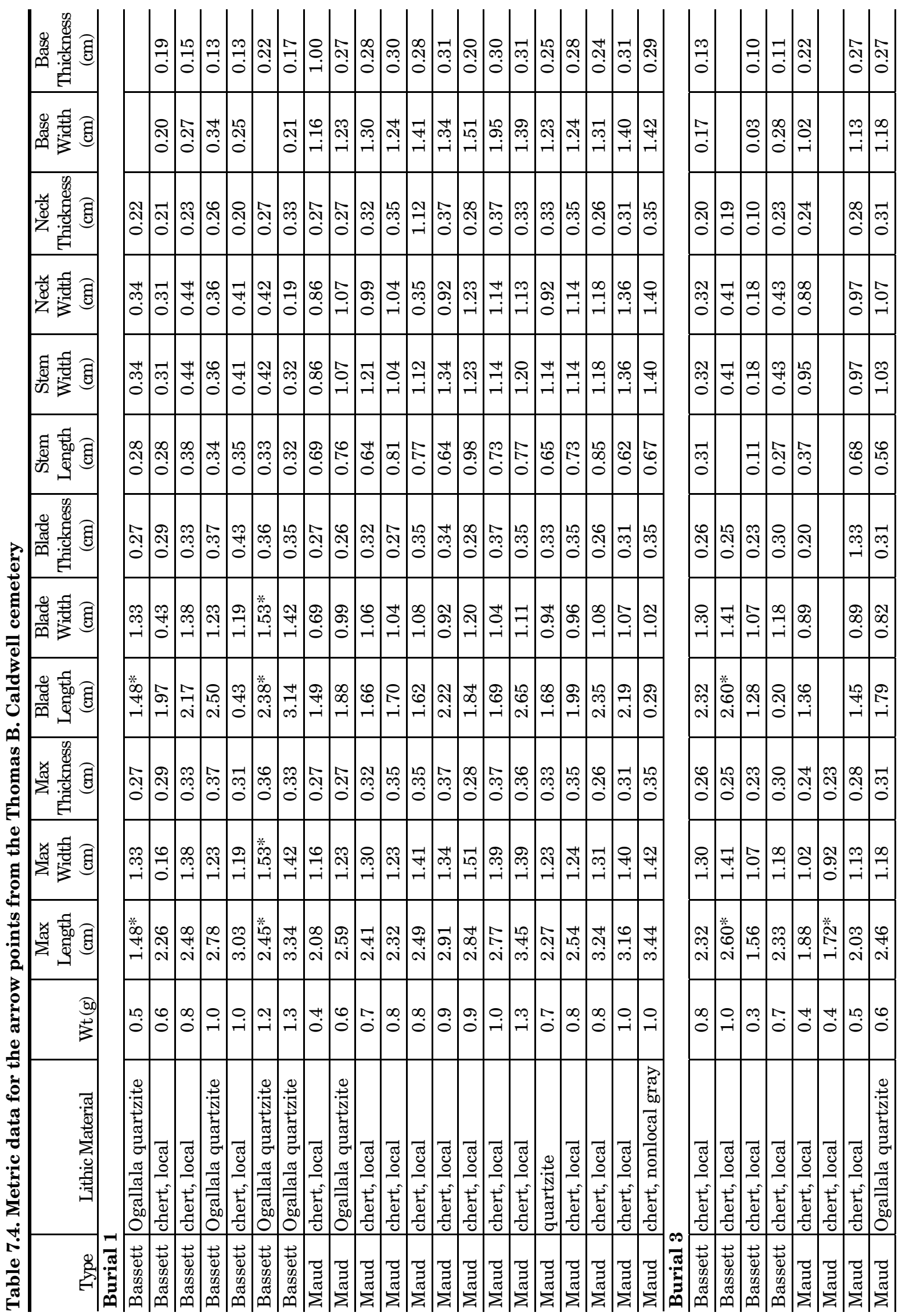




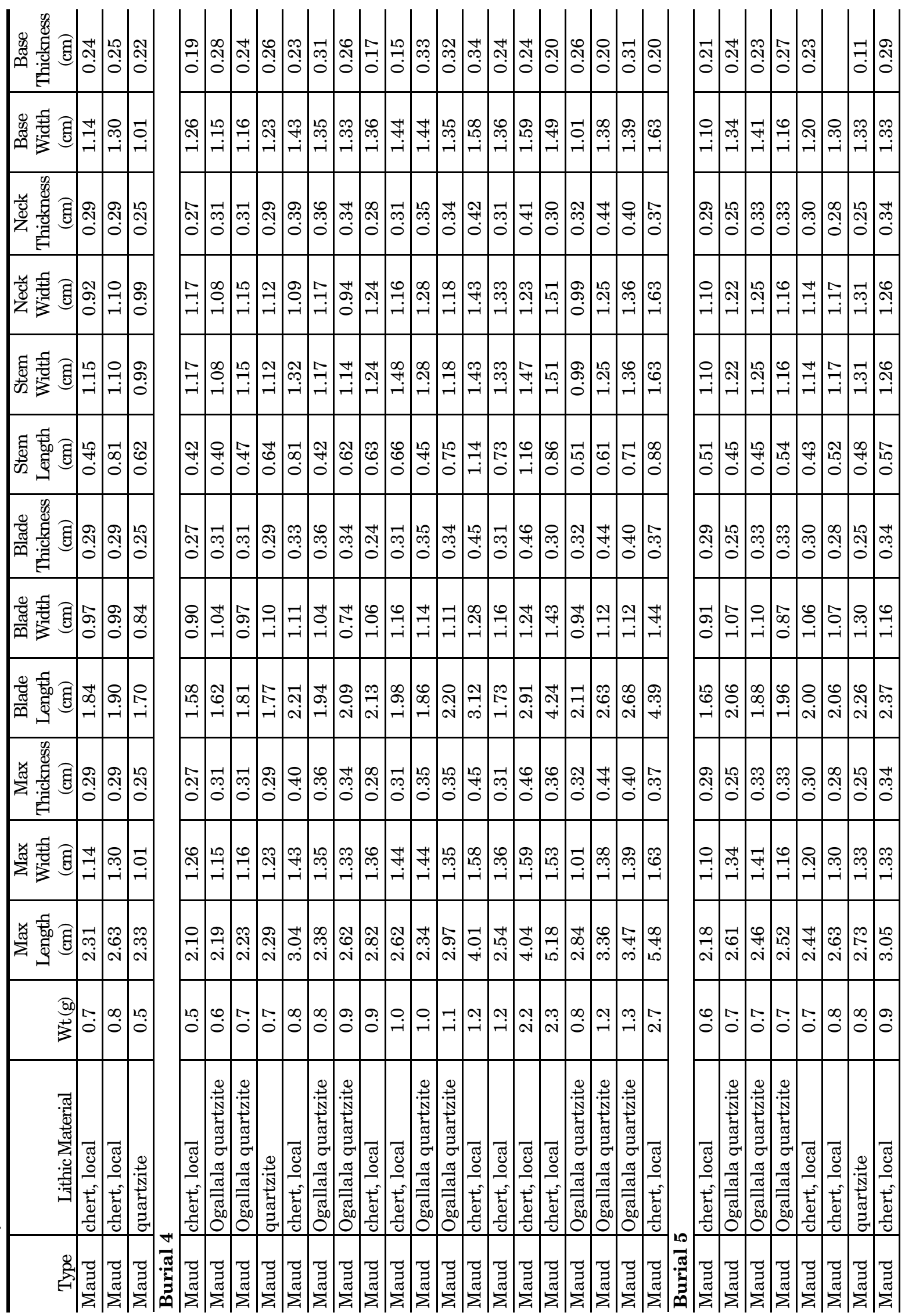


Excavations along the U.S. Highway 271 Mount Pleasant Relief Route

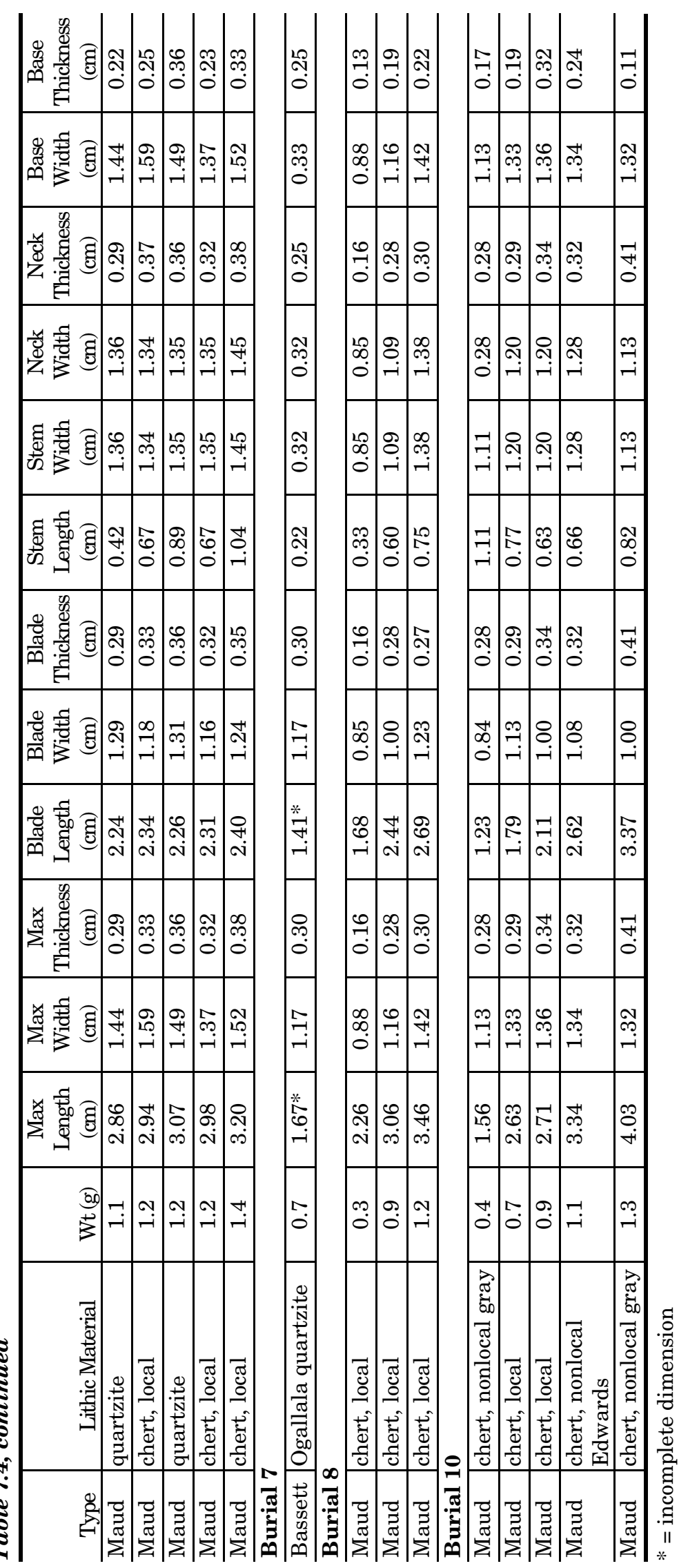


Associates, Inc. 1984:22). Shallow depressions and backdirt piles marked the locality, which was apparently disturbed by the excavation of a "more recent drainage ditch" (Espey, Huston and Associates, Inc. 1984:22). A hammerstone was recovered from this area during shovel testing, but no artifacts were visible on the surface. The EH\&A crew did not identify any evidence of the sampled midden but noted that the upland locality reported to contain this feature was badly degraded by agricultural disturbance and surface erosion. Based on the extent of Goldschmidt's previous investigations and the findings of their field evaluation, EH\&A concluded that the A. P. Williams site (41TT4) did not contain additional research potential and did not retain elements that would make it eligible for inclusion in the National Register of Historic Places.

\section{Excavation Methodology and General Results}

A field crew started work at this location on July 20,1934, and commenced excavation "about 100 yards to the west of where the [cemetery] was finally located" (Goldschmidt 1934b:2). This is presumably the rectangular excavation area labeled "Original Trench" on the south side of the artificial stream channel on the site sketch map (Figure 7.11). This area is briefly referenced in the report, but no further information is provided. Since the sketch map has only a verbal scale, which appears to be incorrect, there is no way to know how large this initial excavation was.

Excavation in the cemetery area started on the morning of July 24. The investigators identified and excavated 10 Caddo burials and opened a large enough excavation block to confidently establish the limits of the cemetery (Figure 7.12) (Thurmond 1990:177, 180). The field crew also tested two other locations in the vicinity of the cemetery where individual ceramic sherds were reported or observed. One was northwest of the cemetery on the south bank of Dragoo Creek, and the other was in the artificial stream channel southeast of the cemetery block ("1" and "2" on Figure 7.11). Limited work in both areas revealed recently redeposited or disturbed sediments and no ceramics. The crew also observed and sampled what Goldschmidt (1934b:43, 46) described as a "shallow midden" located "on the southeast face of a hill" about a quarter to a third of a mile $(0.4-0.5 \mathrm{~km})$ east of the cemetery. Efforts at the midden consisted of the excavation of a single trench, and "work was continued only long enough to get a fair sample" (Goldschmidt 1934b:43). According to Thurmond (1990:177, Figure 22), the roughly circular, 15-20-m-diameter midden was on an upland projection roughly 170 m east-southeast of the cemetery.

The cemetery was in a field with few trees on a floodplain dissected by the small, deeply entrenched, meandering channel of Dragoo Creek. Goldschmidt (1934b:2) states that the field "was not under cultivation," which suggests that the field had been used for crop production prior to the archeological investigation. The condition of the cemetery area is only speculative, however, since no general site photographs are included in the original report. According to available field maps (see Figures 7.11 and 7.12), the artificial channel paralleled an existing fence line on a northwest-southeast alignment. The ditch truncated the south edge of the cemetery, passing between Burials 2 and 9. Thurmond's (1990:177) suggestion that the six vessels purchased from Mr. Qualls probably were derived from Burial 2 is reasonable given Goldschmidt's description of the feature.

Goldschmidt (1934b:2) notes that Dragoo Creek was completely dry at the time of the field investigation due to an ongoing drought, and that the "hardness of the earth" made digging difficult. Sediment in the cemetery area was described as a hard-packed sandy clay, and a "hard red clay substratum" noted to be common at other sites in the region was not encountered (Goldschmidt 1934b:46).

Little information is provided with respect to excavation methodology in the cemetery area or in the other tested or sampled parts of the Williams property. The report does state that narrow "feeler" trenches were recommended to expedite fill removal and burial discovery in the cemetery area, but this approach was turned down in favor of "broadcast" excavation after the rapid discovery of two burials (Goldschmidt 1934b:2). The investigators may have used the depth of the first burials exposed as a general gauge for excavation depth in the absence of a well-defined substratum. Over the course of the cemetery investigation, the crew excavated an irregular block that straddled the artificial channel and extended northeastward beyond the adjacent fence line. The block had approximate 


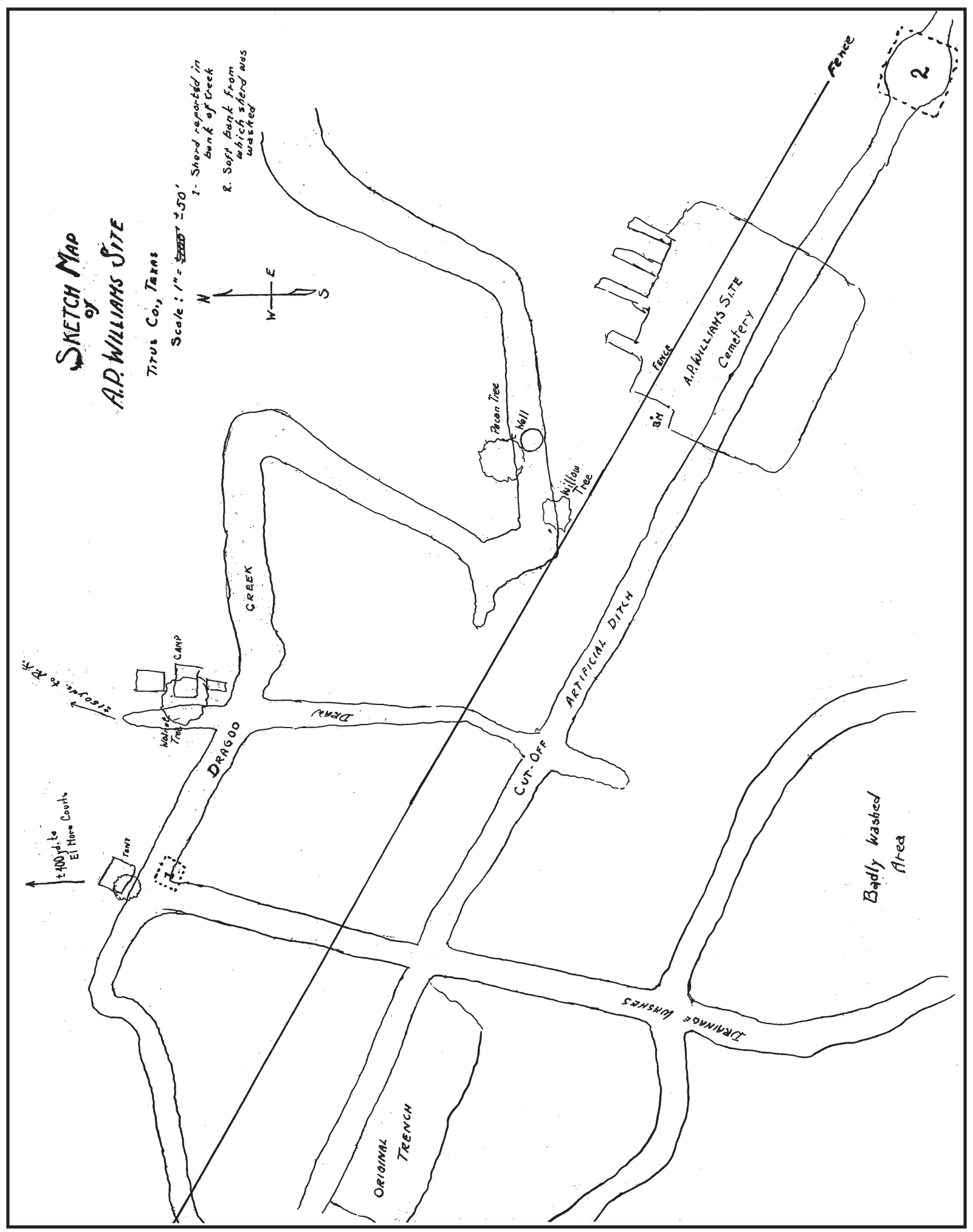

Figure 7.11. Sketch map of the A. P. Williams site depicting the natural and artificial channels of Dragoo Creek and the locations of the cemetery excavation and nearby tested areas (from Goldschmidt 1934b). 


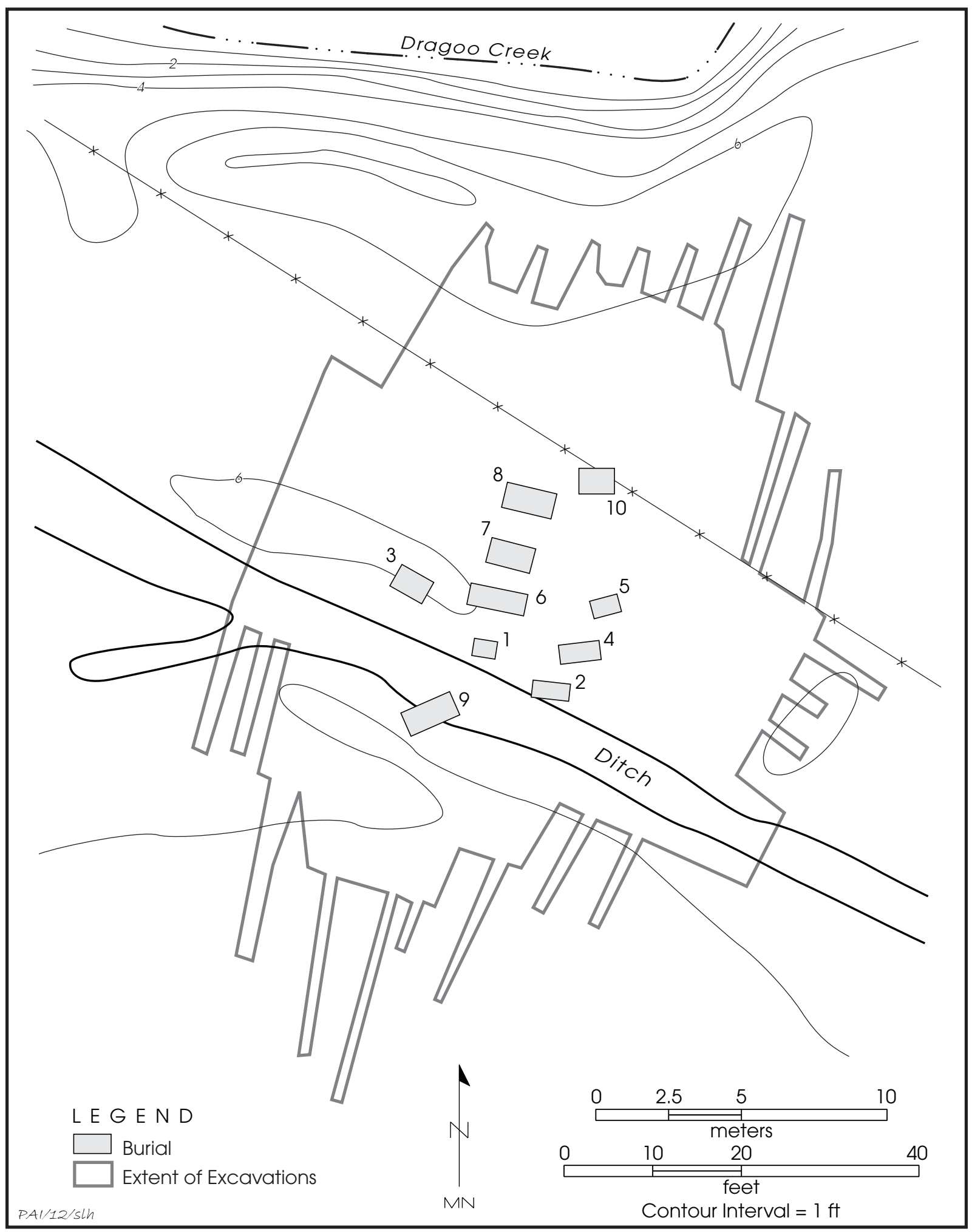

Figure 7.12. Plan of the 1934 excavation at the A. P. Williams cemetery (adapted from Goldschmidt 1934b). 
maximum dimensions of $20 \mathrm{~m}$ northwest-southeast by $21 \mathrm{~m}$ northeast-southwest. Exploratory trenches were excavated off the block's north, east, and south sides at roughly evenly spaced intervals. The longest of these was approximately $8 \mathrm{~m}$.

The report provides no information concerning the process followed for burial excavation, but with Goldschmidt as field foreman, it is likely that the methodology was similar to that followed during the Caldwell cemetery excavation. Apparently, the dry conditions hindered determination of grave pit boundaries. Early in the report, Goldschmidt (1934b:5) states that the dimensions recorded for each burial represent the area covered by the included ceramic vessels and so should not be used as an indicator of pit size. He later notes that at least the length measurements "indicate the actual size of the grave only in those cases where the disturbed earth could be determined," but he does not specify where that was the case (Goldschmidt 1934b:45). With lengths ranging from 32 to 78 inches $(81-198 \mathrm{~cm})$ and widths from 24 to 36 inches $(61-91 \mathrm{~cm})$ (Table 7.5), though, the dimensions recorded are not dramatically smaller than those of the Caldwell cemetery graves, suggesting that some of them are representative of complete pit floor dimensions.

The small cemetery consisted of 10 closely spaced burials arranged mostly in two rows (Thurmond 1990:177) covering an area of

Table 7.5. A. P. Williams cemetery burial pit orientations and dimensions

\begin{tabular}{c|c|c|c|c}
\hline $\begin{array}{c}\text { Burial } \\
\text { No. }\end{array}$ & $\begin{array}{c}\text { Head } \\
\text { Orientation } \\
\text { degrees E } \\
\text { of } \mathrm{N})\end{array}$ & $\begin{array}{c}\text { Length } \\
(\mathrm{m})\end{array}$ & $\begin{array}{c}\text { Width } \\
(\mathrm{m})\end{array}$ & $\begin{array}{c}\text { Depth } \\
\text { from } \\
\text { Surface } \\
(\mathrm{m})\end{array}$ \\
\hline 1 & 97 & 0.81 & 0.61 & 0.76 \\
\hline 2 & 262 & 1.35 & $?$ & 0.76 \\
\hline 3 & 114 & 1.22 & 0.91 & 0.89 \\
\hline 4 & 85 & 1.42 & 0.61 & 0.97 \\
\hline 5 & 78 & 0.91 & 0.61 & 0.71 \\
\hline 6 & 280 & 1.98 & 0.76 & 1.04 \\
\hline 7 & 105 & 1.52 & 0.91 & 0.81 \\
\hline 8 & 103 & 1.68 & 0.91 & 0.74 \\
\hline 9 & 69 & 1.83 & 0.91 & 0.91 \\
\hline 10 & 90 & 1.22 & 0.76 & 0.87 \\
\hline
\end{tabular}

$11 \mathrm{x} 8 \mathrm{~m}$. Most of the graves had orientations close to east-west, although Burial 3 was more east-southeast to west-northwest and Burial 9 was more east-northeast to west-southwest. Burials 8 and 9 had preserved cranial elements indicating the individuals were buried with their heads to the east, and it is presumed this was the case in most of the other graves as well. However, Burials 2 and 6 may have been exceptions. The cranium in Burial 2 was at the westerly end of the feature, though Goldschmidt (1934b:9) noted the potential for inaccuracy in this instance. In Burial 6, a long bone fragment toward the east end suggested head placement toward the west (Goldschmidt 1934b:21, 24). Excluding Burials 2 and 6 , the burials had an average presumed head orientation of $93^{\circ}$.

The excavators recorded surface contour height or elevation (apparently relative to a datum located at the northwest corner of the cemetery block) and depth from the surface for each grave. Listed surface contours vary from 2.9 to $3.6 \mathrm{ft}(0.9-1.1 \mathrm{~m})$. Comparison of the contours depicted on the original excavation map with the surface elevations recorded at each burial suggest that the cemetery was on a slight rise (or series of rises) on the Dragoo Creek floodplain. Listed pit depths range from 28 to 41 inches (71-104 cm). The shallowest ones generally were on the highest surface contours, which suggests that historic activities such as land clearing and plowing had modified the surface topography.

Fragmentary human remains were identified in half of the graves (Burials 2, 6, and $8-10$ ). Skeletal material ranged from a trace of bone in Burial 10 to much of the postcranial skeleton in Burial 9. As noted, skeletal elements indicated or suggested interment orientation in four of the five burials with human remains (all except Burial 10).

According to Goldschmidt, 81 ceramic vessels were recovered from the 10 burials, excluding the 6 vessels probably from Burial 2 that he purchased from Mr. Qualls and a seventh purchased vessel not associated with the cemetery. The vessels excavated by the crew consisted of "54 bowls, 20 pots, and 7 bottles," while the 6 purchased ones were classified as 1 bowl, 1 pot, 2 probable pots, and 2 bottles (Goldschmidt 1934b:2-4, 47). An inventory of the ceramic assemblage by TARL personnel in the 1980s identified 83 vessels in the excavated burial assemblage: 54 bowls, 20 jars, 
Chapter 7: The Thomas B. Caldwell and A. P. Williams Cemeteries

Table 7.6. Burial offerings in the A. P. Williams cemetery graves

\begin{tabular}{c|c|c|l}
\hline $\begin{array}{c}\text { Burial } \\
\text { No. }\end{array}$ & $\begin{array}{c}\text { Ceramic } \\
\text { Vessels }\end{array}$ & $\begin{array}{c}\text { Arrow } \\
\text { Points }\end{array}$ & Other \\
\hline 1 & 10 & & \\
\hline 2 & 8 & 1 & \\
\hline 3 & 9 & & 1 celt, lithic debitage \\
\hline 4 & 10 & & \\
\hline 5 & 9 & & \\
\hline 6 & 14 & 16 & 1 celt, lithic debitage (later counted as 1 offering) \\
\hline 7 & 8 & 11 & \\
\hline 8 & 6 & & 1 celt, 1 battered cobble, mass of kaolinitic clay \\
\hline 9 & 6 & 5 & 1 polished pebble, 2 hematite fragments \\
\hline 10 & 9 & 6 & 1 drill, cache of lithic debitage (later counted as 1 offering) \\
\hline Totals & 89 & 39 & \\
\hline
\end{tabular}

and 9 bottles (Table 7.6). In addition, 5 of the 6 vessels purchased from Qualls are listed in the inventory as 2 bottles and 3 bowls. The sixth vessel is listed as missing. This assemblage is characterized more fully below.

A total of 39 arrow points were recovered from five burials (see Table 7.6). Nearly 70 percent were in Burials 6 and 7, which contained 16 and 11 points, respectively. The arrangement of 15 points in Burial 6, grouped together and pointing to the west-northwest, suggests they were part of a quiver of arrows. Seven of the points in Burial 7 were grouped together, but all were oriented in different directions. Identified point styles include Scallorn, Perdiz, and Bonham (Thurmond 1990:Table 39). Other items found in the graves were 3 celts, a chipped stone drill, a battered cobble, three groups of lithic debitage, two hematite pigment fragments, a polished pebble, and a mass of kaolinitic clay. Those artifacts that might be considered incidental inclusions - the battered cobble, debitage, and hematite fragments, for example-were grouped or arranged with other grave items in a manner that strongly suggests they were intentional mortuary offerings.

As noted, Goldschmidt only briefly references the original excavation area and the two test excavation localities near the cemetery excavation block, and he makes no mention of artifact recovery in those areas aside from the statement that ceramics were not found in the two tested localities. Goldschmidt is almost as vague in his discussion of the sampled midden at some distance from the cemetery. He notes that "very little of significance was found" there, but does note the recovery of a celt fragment, a crude chert knife (later identified as a Gary dart point preform), and an expanding-stem dart point (Goldschmidt 1934b:43). Thurmond (1990:177) lists 388 Caddo sherds as having come from the midden and identifies them as follows: 13 Ripley Engraved bowl rims, 19 miscellaneous engraved bowl rims, 3 Maydelle Incised jar rims, 17 punctated jar rims, 1 punctated and appliquéd jar rim, 5 brushed jar rims, 3 brushed and punctated jar rims, 1 combed and appliquéd jar rim, 5 Pease Brushed-Incised jar body sherds, 148 plain body sherds, 39 brushed body sherds, 4 red-slipped body sherds, 5 engraved body sherds, 6 incised body sherds, 1 incised and punctated body sherd, 1 punctated body sherd, 4 appliquéd body sherds, 2 combed body sherds, 6 plain base sherds, and 105 unclassified sherds. Thurmond (1991:180) concluded that the midden was probably associated with the cemetery. These materials are excluded from the descriptions of the burial-associated grave goods below.

\section{Burial Descriptions}

In addition to listing accompaniments for each burial, Goldschmidt (1934b) offers varying amounts of detail for each feature, ranging from comments on sediment characteristics to locations or arrangements of burial offerings within a pit. Included below are burial-specific details not provided in Tables 7.5 and 7.6. 


\section{Burial 1}

Burial 1 was at the north edge of the artificial ditch that truncated the cemetery but apparently was undamaged by ditch excavation and subsequent erosion. This feature was definable only by the ceramic vessel alignments on the pit floor (Figure 7.13). Three bowls (\#8, \#11, and \#12), a jar (\#10), and a bottle (\#9) were on the north side, and three bowls (\#13, \#14, and \#16) and one jar (\#15) were along the south edge. A small bowl (\#7) was centrally located at the east end of the grave.

\section{Burial 2}

Burial 2 was partially within the ditch that initially exposed the site, and thus it had been directly impacted by that excavation and later erosion. Skull remnants discernible to the west-northwest of the two remaining vessels strongly suggest that this individual was interred with the head at the westerly end of the grave (see Figure 7.13). Goldschmidt (1934b:9) states that no other skeletal material was identifiable, probably in part because they would have been exposed in the ditch cut or removed during ditch excavation. The spatial relationship between what remained in the grave and the posited grave orientation suggests that more of the feature was in the ditch than is indicated on the map of the cemetery. The two in situ vessels (\#17 and \#18) were both bowls, and the identified offering was an arrow point (\#19) found between the vessels and the skull. Thurmond (1990:Table 39) classified this artifact as a Scallorn point. The six purchased vessels that may have come from Burial 2 consist of two bottles, one bowl, one jar, and two incomplete jars or bowls. The plan of the feature shows what appear to be some sherds north of the skull and intact offerings that could be parts of these vessels.

\section{Burial 3}

Most of the nine vessels in Burial 3 were grouped along the south and west sides of the pit floor (see Figure 7.13); these consist of four bowls (\#20, \#21, \#23, and \#25) and two jars (\#22 and \#24); all of them were broken. The three vessels on the north side of the grave consist of two bowls (\#26 and \#28) and one jar (\#27). A celt set on its poll end was at the northwest corner of the pit, and several pieces of lithic debitage and a fragment of silicified wood were grouped on the pit floor immediately southeast of the celt.

\section{Burial 4}

The 10 vessels associated with Burial 4 were mostly grouped at each end of the grave (see Figure 7.13). At one end (it is uncertain which) were two bowls (\#38 and \#39) and two jars (\#36 and \#37). Four bowls (\#31-34) and a jar (\#30) were near the other end. A small bottle (\#35) was near the second group but closer to the center of the grave. No other grave goods were found.

\section{Burial 5}

Goldschmidt (1934b:18) noted that Burial 5 was "more shallow than most" and that the vessels were grouped in a small area (see Figure 7.13). Three bowls (\#46-48) were at one end, next to a bottle (\#45), a bowl (\#43), and a jar (\#44) that were more centrally placed. A small bowl (\#42) was by itself on one side of the grave. Near the end opposite the three bowls were two small bowls (\#40 and \#41). No other offerings were found.

\section{Burial 6}

An extremely friable long bone fragment in the eastern portion of Burial 6 suggests that the cranium was at the west-northwest end of the grave. Most of the 14 vessels were "badly smashed" (Goldschmidt 1934b:21). Many were on the longitudinal axis of the grave (Figure 7.14). The distribution of these ceramics is probably representative of the actual dimensions of the original pit floor. A large bowl (\#59), a large jar (\#60), and a medium-sized jar (\#58) were near the west end of the grave. To the east along the midline was a large bottle (\#57), and farther east, probably on the north side of the interment, were a jar (\#55) and a number of sherds possibly representing a badly broken large bottle (\#56). Across the grave were a large bowl (\#51), a small straight-sided bowl (\#52), a small noded bowl (\#52A), two other bowls (\#53 and \#54), and a small jar (\#53A). Two bowls (\#49 and \#50) were near the east end. Other offerings included 15 arrow points grouped together and pointing west-northwest below a crushed 
Chapter 7: The Thomas B. Caldwell and A. P. Williams Cemeteries

Burial |

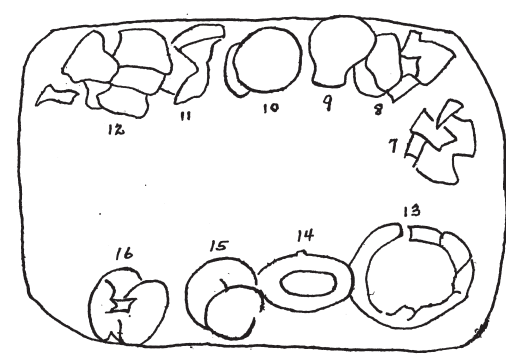

Burial 2

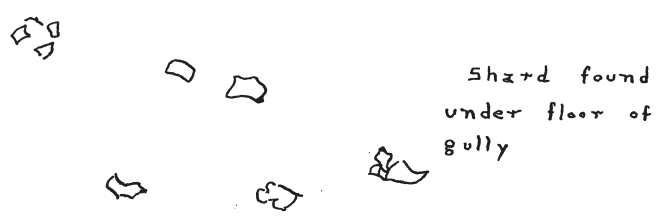

$82^{\circ} \mathrm{W}$. of $\mathrm{S}$ SKULL
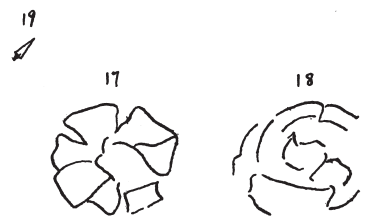

$I^{\prime \prime}=I^{\prime}$
Burial 3

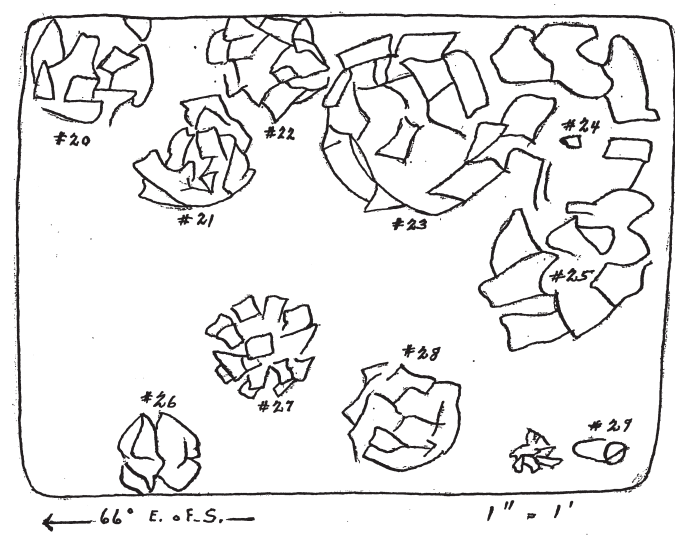

Burial 4

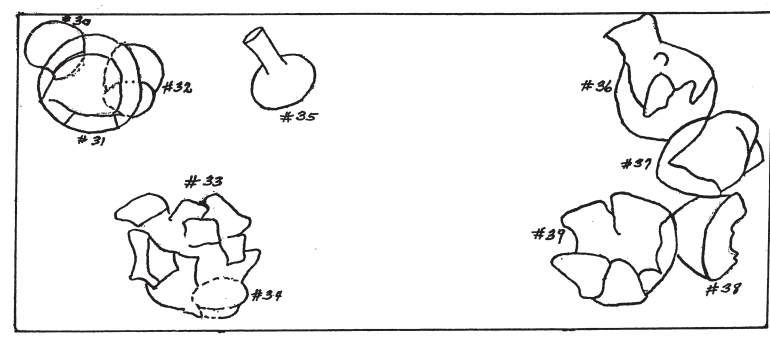

Burial 5

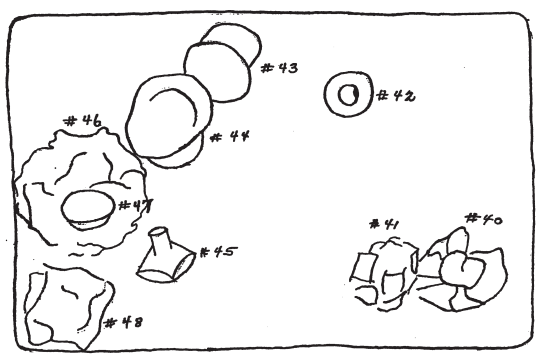

Figure 7.13. Plans of Burials $1-5$ at the A. P. Williams cemetery (from Goldschmidt 1934b; burials are scaled correctly relative to one another, but their placement on this page does not reflect their positions on the ground). 

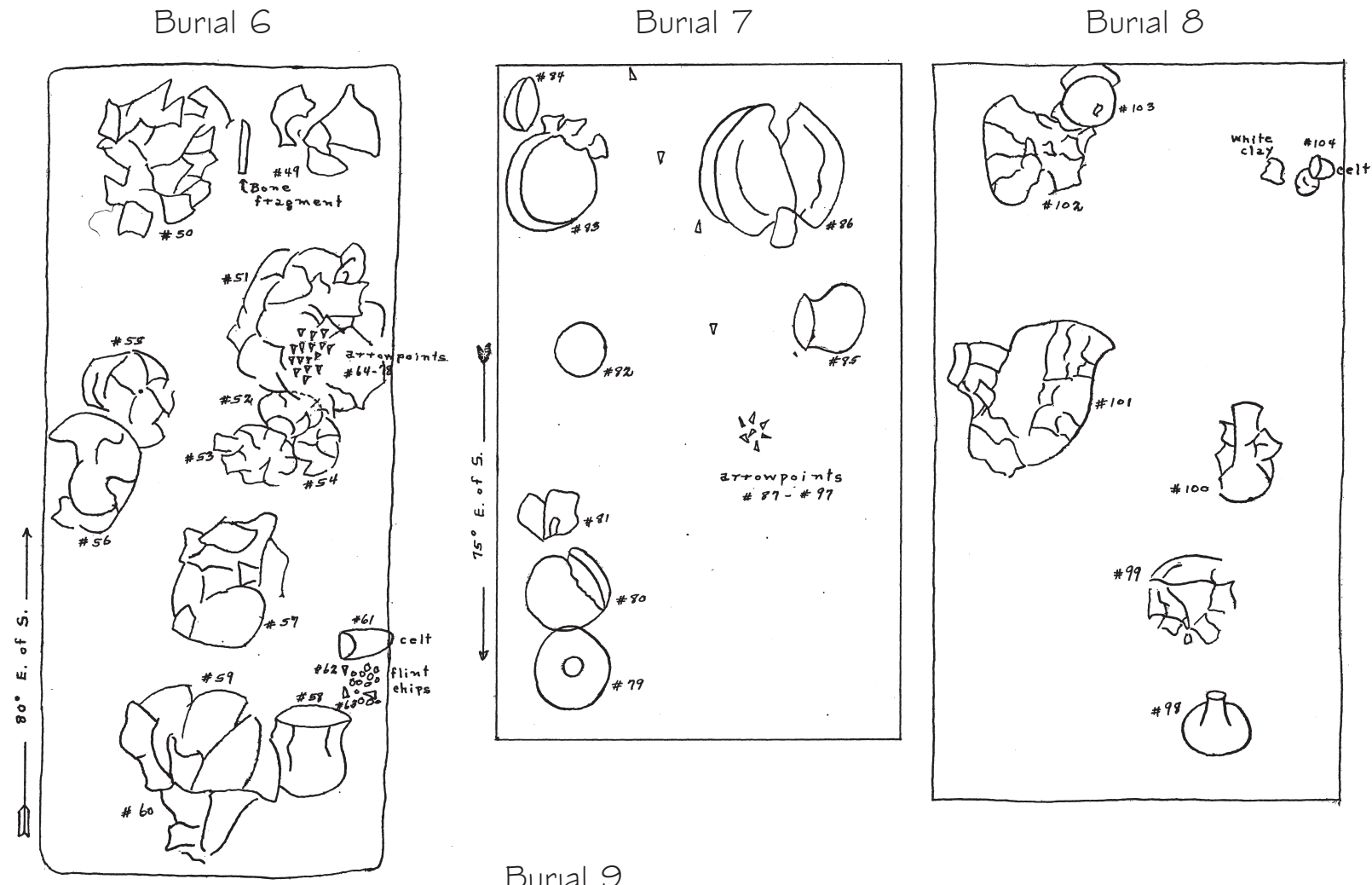

Burial 9

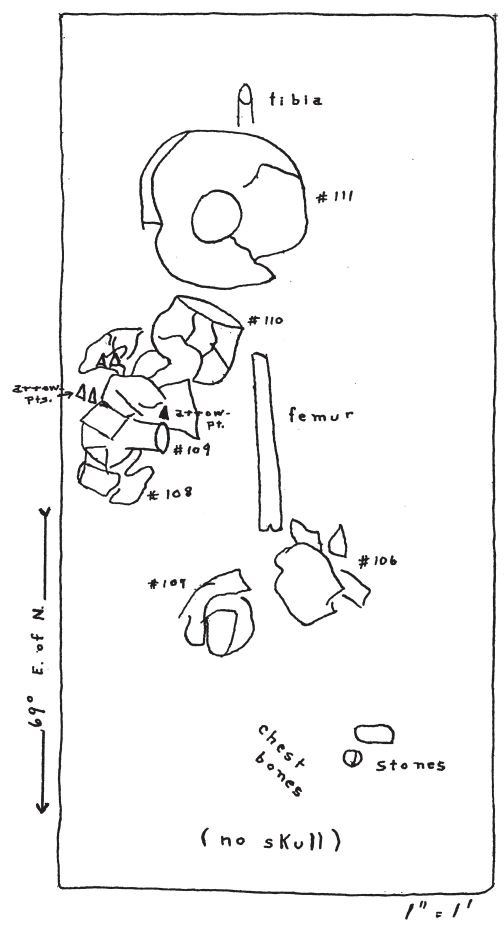

Burial 10

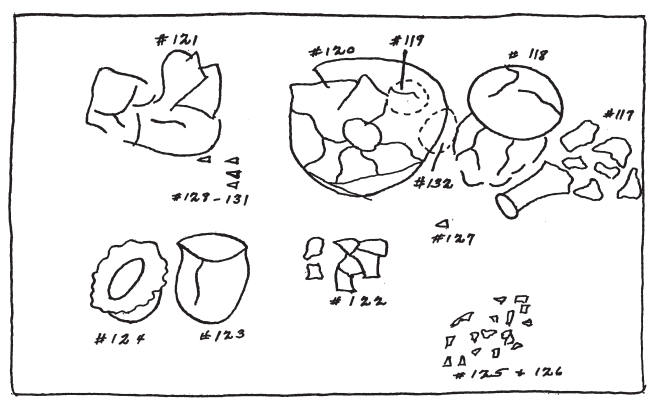

Figure 7.14. Plans of Burials $6-10$ at the A. P. Williams cemetery (from Goldschmidt 1934b; burials are scaled correctly relative to one another, but their placement on this page does not reflect their positions on the ground). 
vessel in the southeast quadrant; all were wellmade points fashioned from thin flakes. A celt was along the south edge, close to the feature's southwest corner. As in Burial 3, the celt was resting on its poll end. A cache of unmodified and modified lithic debitage, an arrow point fragment, and a "crude arrow or dart head of coarse chert" were immediately west of the celt (Goldschmidt 1934b:23). The cache of debitage was said to include "spoke shaves" (Goldschmidt 1934b:21, 23).

A 1960s inventory lists 12 of the arrow points as missing, and Thurmond only identified 5 during a subsequent review of the assemblage: a Scallorn, a Bonham, and three Perdiz points (Thurmond 1990:Table 39).

\section{Burial 7}

Burial 7 was in softer sand than the other burials, and Goldschmidt (1934b:26) speculated that this explained the excellent condition of the associated ceramic vessels. Six of the eight vessels-a bottle (\#79) and five bowls (\#80-84) _ were in a row along the south side of the grave (see Figure 7.14); the remaining two-a jar (\#85) and a large bowl (\#86) - were near the northwest corner. Seven arrow points were clustered together but oriented in different directions in the north-central portion of the grave. Four other projectile points were scattered along the longitudinal axis in the west half of the feature. The points apparently were poorly made, though many had serrated blades (Goldschmidt 1934b:28). Thurmond (1990:Table 39) identified a Scallorn, a Perdiz, and two Bonham points in the remaining assemblage; seven specimens were listed as lost or stolen.

\section{Burial 8}

This interment was noted to be "shallower than most of the others, and...poorer in artifacts" (Goldschmidt 1934b:31). Remnant skeletal elements include the fragments of two long bones near the west end and a skull outline. The latter was presumably at the east end of the feature in the vicinity of a large bottle (\#98), but the exact location of the cranial remnant is not detailed in the site report. The bottle was one of six ceramic vessels placed throughout the grave, and all but two of these were isolated one from another (see Figure 7.14). Not far west of the bottle near the center line of the grave was a small bowl (\#99), and farther west near the center of the grave but on the north side was a small jar (\#100). Opposite this on the south side of the grave was a bowl (\#101). A bowl (\#102) and a jar (\#103) were in the southwest corner. According to Goldschmidt (1934b:31, 32), the vessels that accompanied this interment were of coarse or "crude" wares that were generally poorly made with decorative elements crudely executed. As with Burial 7, the distribution of the artifacts probably was closely representative of the actual dimensions of the grave floor. Other artifacts consisted of a reworked celt with the poll end broken (\#104), a battered stone, and a mass of kaolinitic clay. These items were grouped together in the northwest corner of the grave, with the celt on top of the battered stone.

\section{Burial 9}

The southernmost grave in the cemetery, Burial 9 was along the southwest edge of the artificial ditch. This burial contained the most complete set of skeletal elements. A large, relatively well-preserved femur fragment was in the center of the grave, and a tibia fragment was at the west-southwest end. Vertebrae, ribs, and arm bone remnants were discernible at the opposite end of the feature, but no cranial elements were preserved, perhaps because of proximity to the eroded ditch excavation. Four of the six vessels were grouped in the southwest quadrant of the grave (see Figure 7.14). These included a crushed large bowl (\#108) inverted over an upright bottle with a roughly squared body (\#109). Goldschmidt (1934b:37) noted the unusual position of these vessels and speculated that the bowl might have been intentionally fractured on the neck of the underlying bottle. The two other vessels in this area, a jar (\#110) and a large bowl (\#111), were nearer the feature's longitudinal axis. The remaining two vessels, both small bowls (\#106 and \#107), were along the longitudinal axis in the east-central part of the grave. Five arrow points made of "fine red flint" were found below the crushed large bowl. All were oriented westward. Three were later lost or stolen. Thurmond (1990:Table 39) classified the remaining two as Perdiz points. A smooth pebble and an adjacent scored hematite fragment were in the northeast quadrant of the grave, to the right of the rib cage. 


\section{Burial 10}

Burial 10 was close to Burial 8 at the north edge of the cemetery. Skeletal material in Burial 10 was limited to a trace of bone found beneath a crushed bottle (\#117) at the east end. In addition to the bottle, eight other ceramic vessels were included with this interment. A large jar (\#118), a small jar (\#132), and three bowls (\#119-121) were along the north side west of the bottle. A jar (\#123) and two small bowls (\#122 and \#124) were along the south side from the middle of the grave westward. Four chert arrow points were clustered together in the northwest quadrant, just north of the longitudinal axis. All of these pointed to the west. Another chert arrow point was found along the long axis in the east half. A cache of chert and silicified wood debitage was near the southeast corner. This pile of material also included an arrow point fragment, a chipped stone drill, a spokeshave, and a sandstone fragment (Goldschmidt 1934b:42-43). Thurmond (1990:Table 39) identified two Scallorn and three Perdiz points in the remaining assemblage; the sixth projectile was listed as lost or stolen.

\section{The Ceramic Assemblage}

Ninety ceramic vessels are listed in the TARL inventory as associated with the A. P. Williams cemetery. These include the 7 vessels purchased at the time of the 1934 site excavations, 1 of which (Item 105 in the TARL records) reportedly was not from the cemetery at all. This vessel is not considered here, although it does appear in Thurmond's (1990:179) discussion as a Harleton Appliqué jar. Eliminating this jar brings the number of associated vessels down to 89. Also, one of the other purchased vessels (Item 6 ) is listed as missing in the TARL inventory. This vessel was likely a bowl, but since there is no other information concerning it, it is not given further consideration in this study. As such, 88 vessels are described here, including 2 vessels not noted in the 1934 site report (Table 7.7); it appears that Items 52A and 53A from Burial 6 were recognized only after additional work on the collection took place at TARL. The vessel descriptions presented below were compiled from existing drawings and notes at TARL, with spot checks of the vessels themselves. Hence, some information that was recorded for the Caldwell cemetery vessels (i.e., temper) was not recorded for the Williams cemetery ceramics. In addition, some vessel characteristics, such as rim and lip treatments, were not consistently recorded in the TARL notes and were not checked for every vessel. As such, they do not appear in the descriptions below, which are presented by vessel form and ceramic type. As with the Caldwell cemetery assemblage, some of the typological identifications made here differ from those made by Thurmond (1990:179), reflecting a reticence in this analysis to type vessels when motifs or vessel forms vary greatly from established definitions.

The assemblage consists of 10 bottles, 28 carinated bowls, 19 compound bowls, 9 simple bowls, 19 jars, 2 beakers, and 1 olla. Most vessels ( $n=45$, 51 percent) cannot be associated with a ceramic type. Otherwise, Ripley Engraved ( $\mathrm{n}=39,44$ percent) predominates. Other identified types are Wilder Engraved ( $\mathrm{n}=1)$, Maydelle Incised $(\mathrm{n}=2)$, Bullard Brushed ( $\mathrm{n}=2)$, La Rue Neck Banded $(\mathrm{n}=1)$, and Pease Brushed-Incised $(\mathrm{n}=3)$.

\section{Bottles}

Of the 10 bottles, 5 complete ones and 1 fragment are typed as Ripley Engraved, 1 is typed as Wilder Engraved, and 3 are unidentified as to type. Two of the untyped ones have form and motif characteristics that are similar to classic Ripley Engraved bottles, however, the third untyped one (Item 79, Burial 7) has a unique motif.

\section{RIPLEY ENGRAVED}

Two complete Ripley Engraved bottles (Items 35 and 57) have bell-shaped bodies with elongated necks that terminate in a straight or flaring rim. The three other complete ones (Items 1,45 , and 109) have square bodies with prominent corners and elongated necks with everted rims. The sixth Ripley bottle is a large base/body fragment (Item 56) that appears to be part of a large bell-shaped vessel. Thurmond (1990:179) classified this fragmentary bottle as a Ripley Engraved bowl with a concentric circle motif. Using height as a measure of size, Item 57 is the largest at $27.0 \mathrm{~cm}$. Item 35 is medium-sized at $16.8 \mathrm{~cm}$. The three square-bodied are smaller, ranging in height from 14.0 to $15.0 \mathrm{~cm}$.

All of the complete bottles are decorated with either a medallion or circle/diamond main motif irrespective of body shape (Figure 7.15). 
Chapter 7: The Thomas B. Caldwell and A. P. Williams Cemeteries

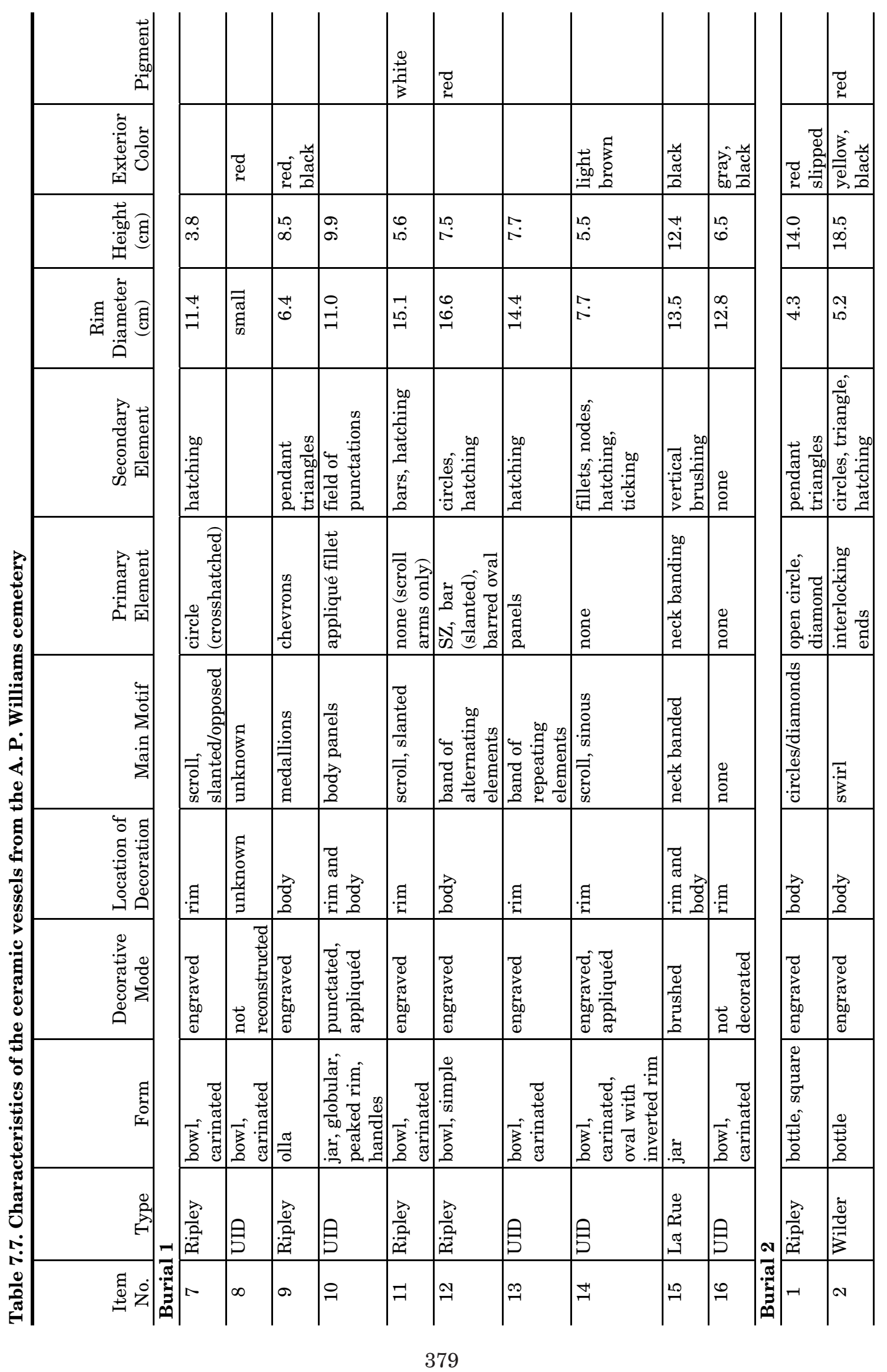




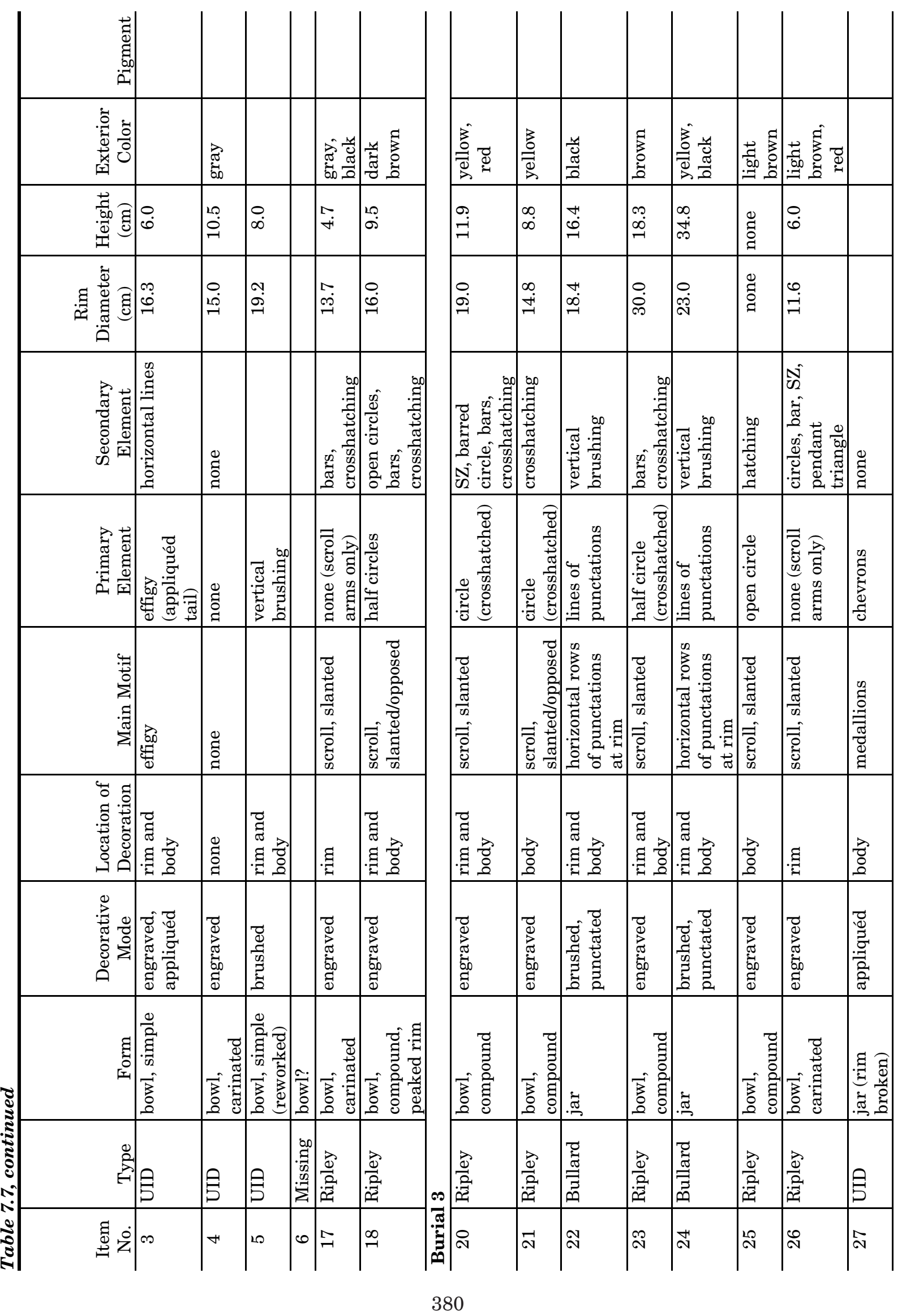


Chapter 7: The Thomas B. Caldwell and A. P. Williams Cemeteries

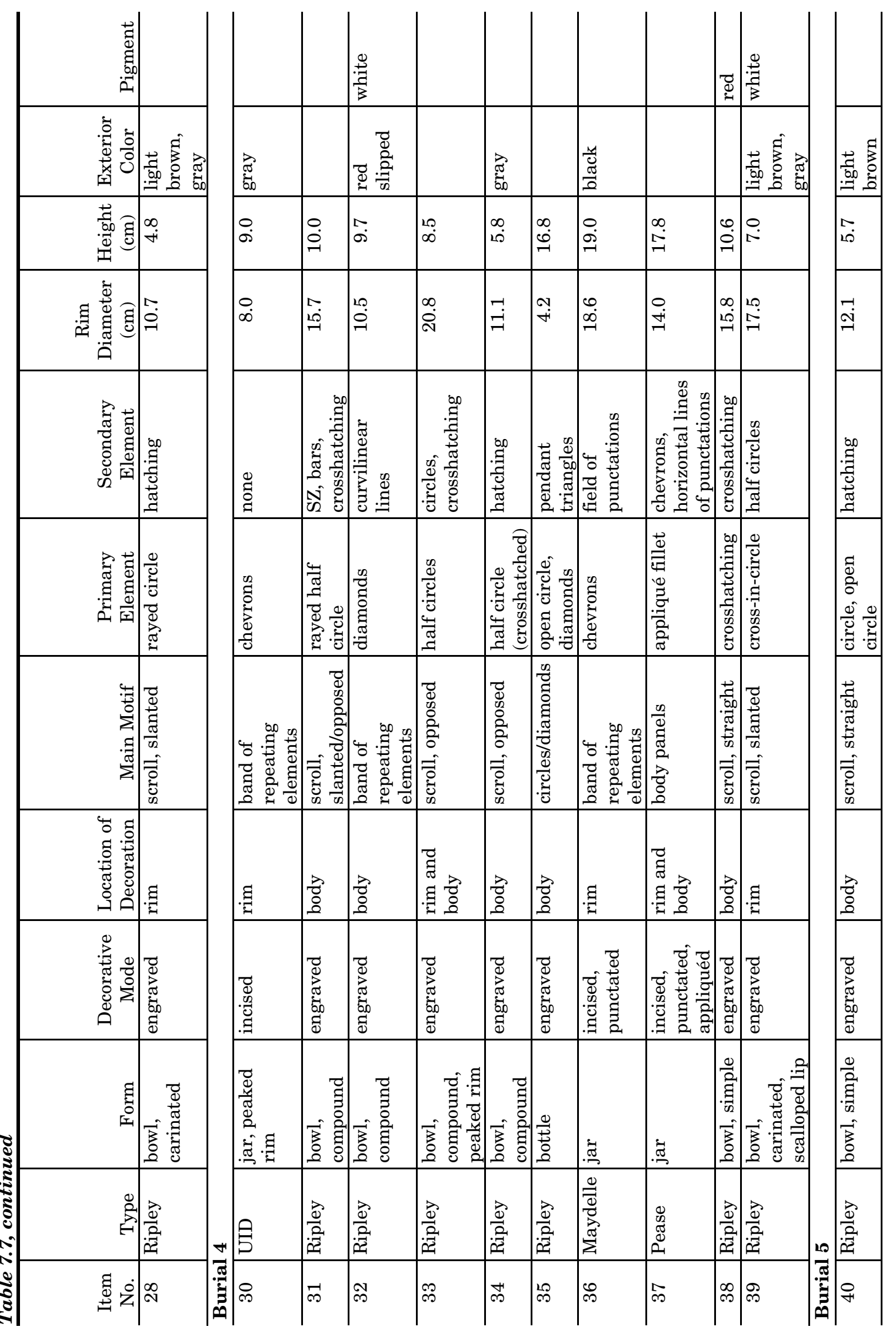




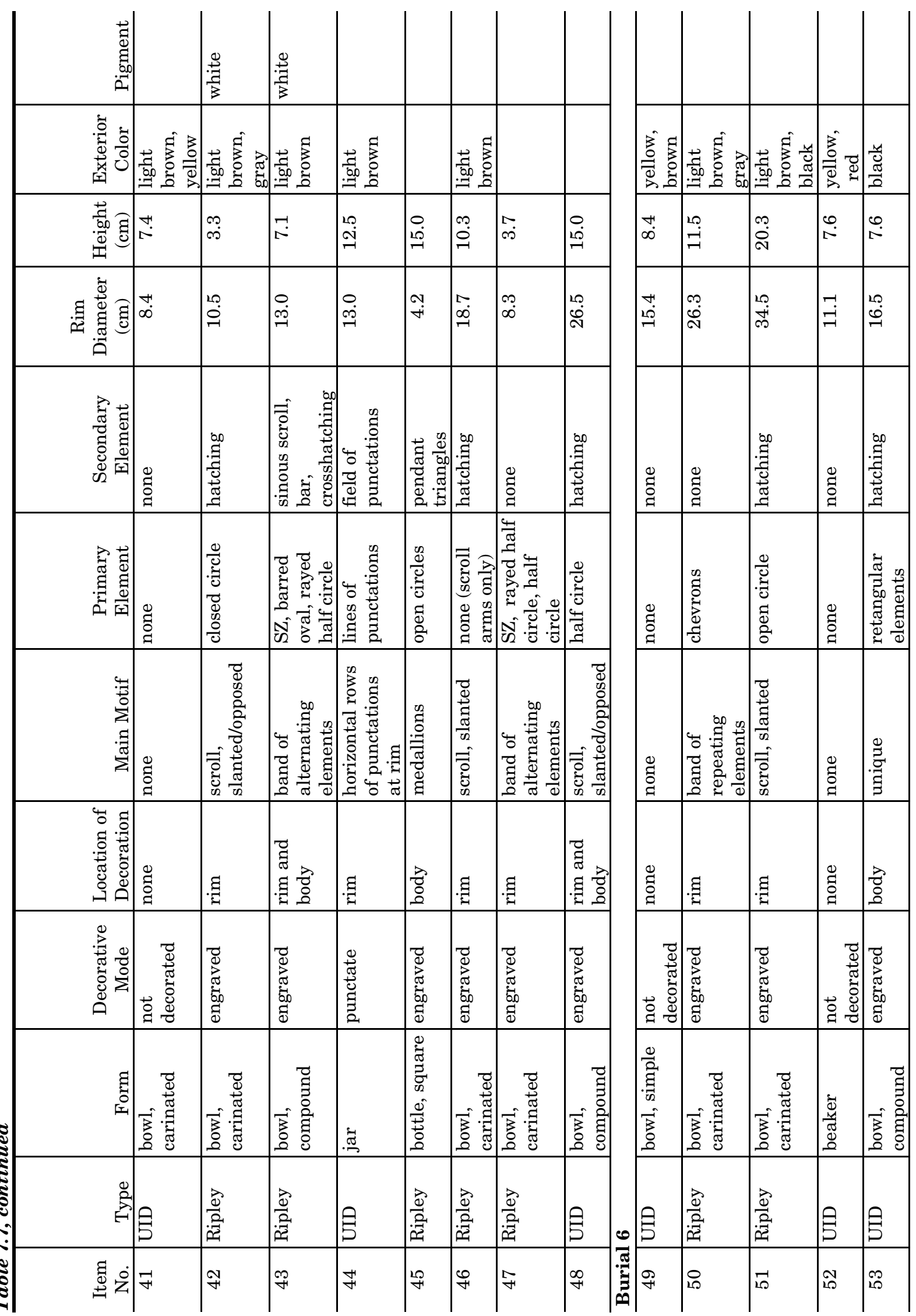




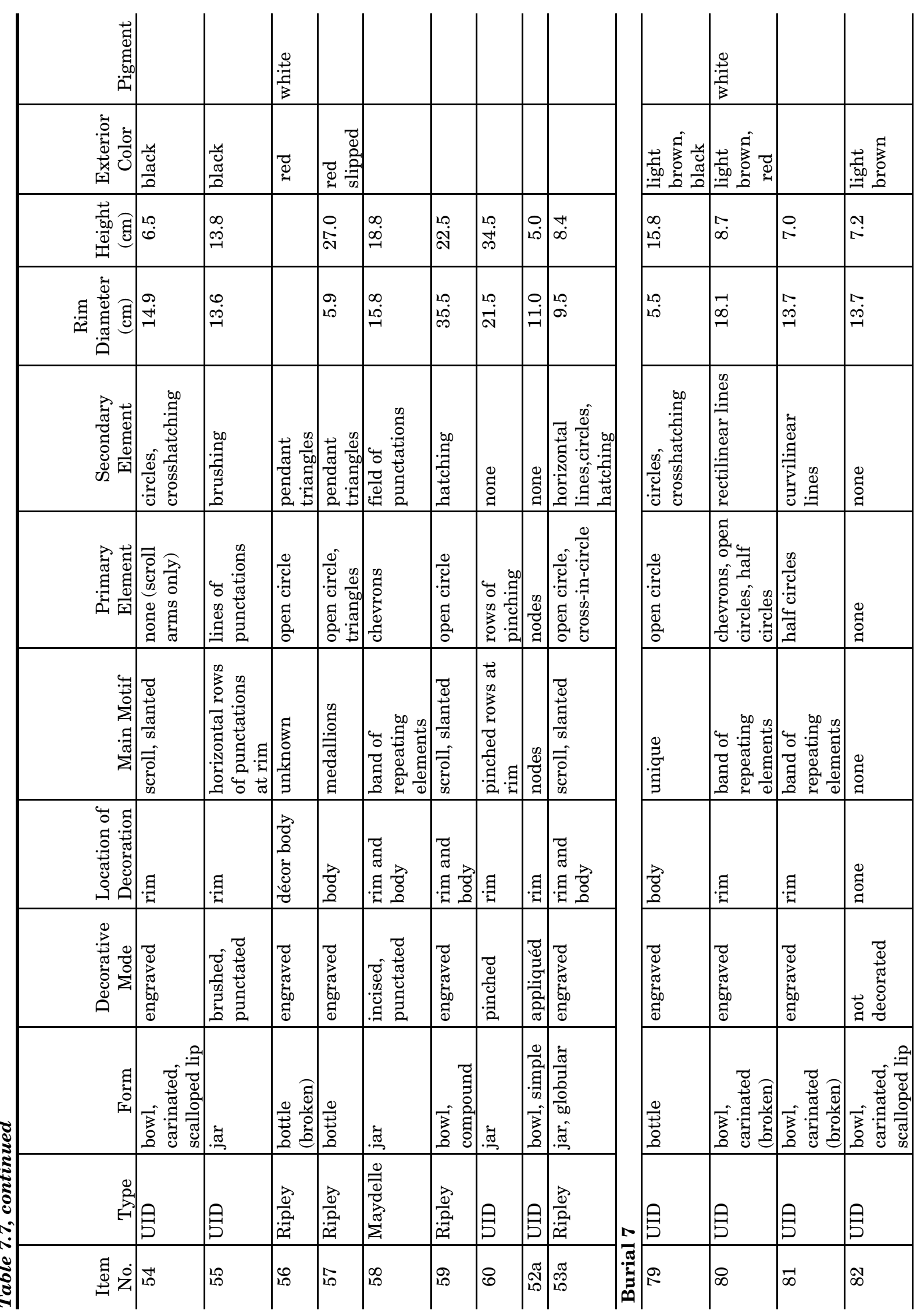




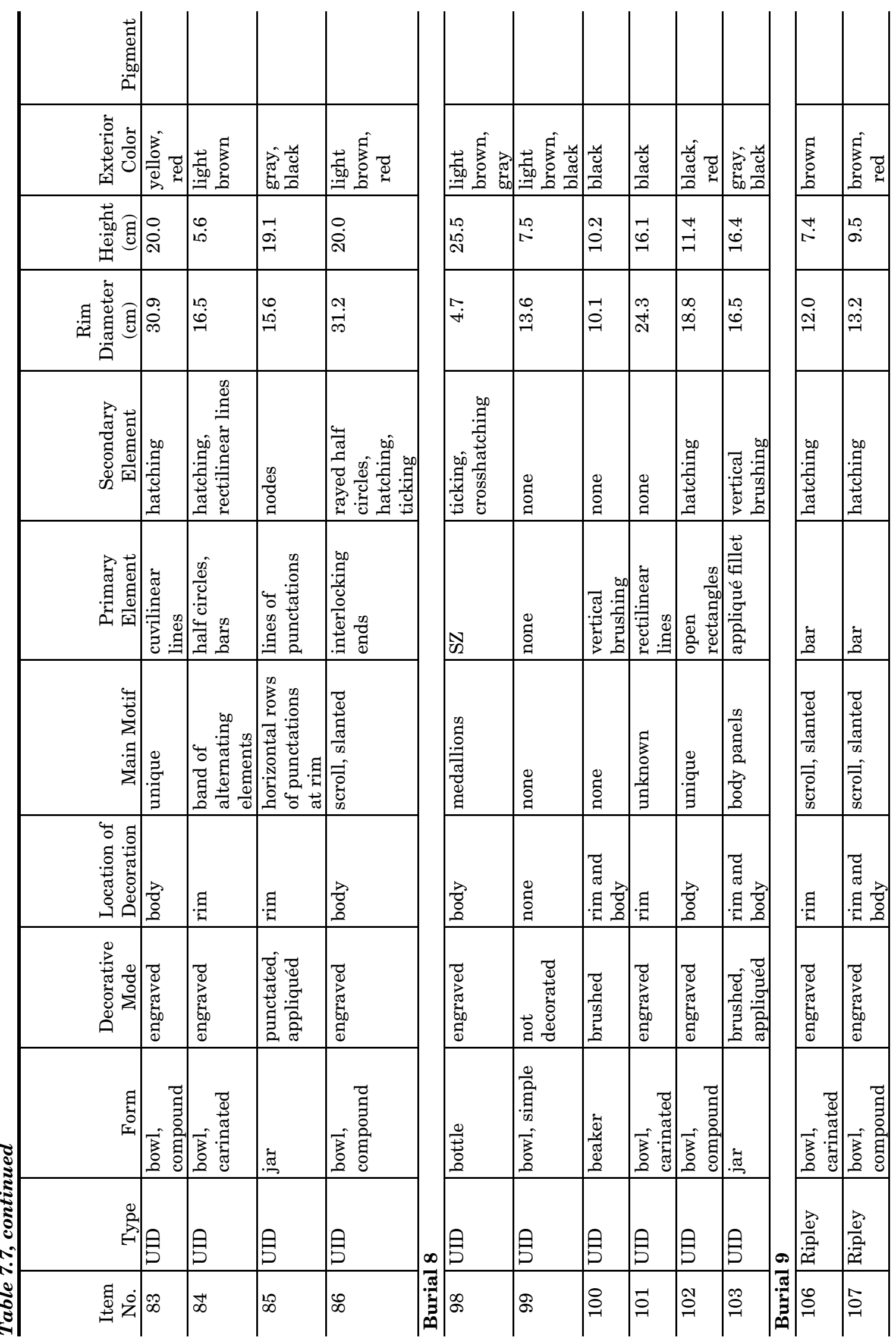


Chapter 7: The Thomas B. Caldwell and A. P. Williams Cemeteries

\begin{tabular}{|c|c|c|c|c|c|c|c|c|c|c|c|c|c|c|}
\hline 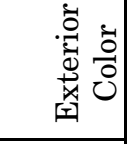 & 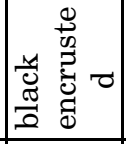 & \begin{tabular}{|l}
$\frac{y}{0}$ \\
$\frac{\pi}{3}$ \\
3
\end{tabular} & & 蛋 & & \begin{tabular}{|l}
0 \\
0 \\
\end{tabular} & & 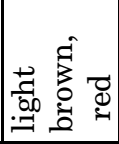 & 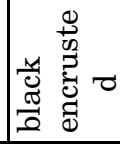 & 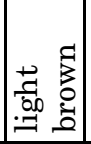 & & & 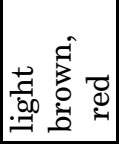 & \begin{tabular}{|l}
$y$ \\
0 \\
$\frac{\pi}{3}$ \\
0
\end{tabular} \\
\hline 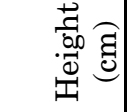 & $\stackrel{10}{\circ}$ & $\stackrel{\infty}{\underset{+}{+}}$ & $\mid \begin{array}{l}\infty \\
1 \\
\stackrel{\rho}{-1}\end{array}$ & 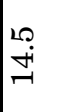 & & ه̊ & & 0 & $\begin{array}{l}\infty \\
10 \\
10\end{array}$ & 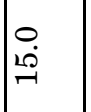 & 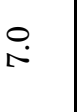 & 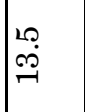 & $\mid \begin{array}{l}0 \\
\dot{0}\end{array}$ & 吕 \\
\hline 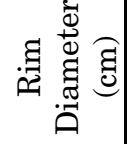 & $\stackrel{\leftrightarrow}{\mathscr{N}}$ & $\stackrel{\vec{H}}{\vec{H}}$ & $\underset{\sim}{10}$ & 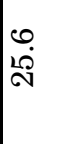 & & $\stackrel{\leftrightarrow H}{\rightarrow}$ & & 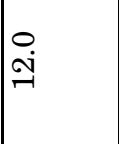 & कृ & 官 & $\begin{array}{l}0 \\
\stackrel{0}{0} \\
-1\end{array}$ & $\begin{array}{l}0 \\
\stackrel{0}{ } \\
\end{array}$ & |l & $\stackrel{\stackrel{\sim}{f}}{=}$ \\
\hline 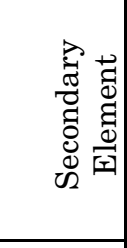 & 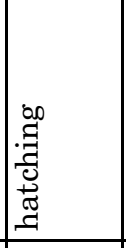 & 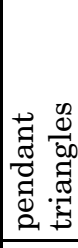 & 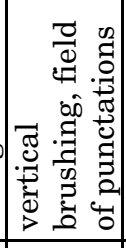 & قِ & & 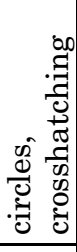 & 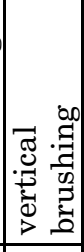 & 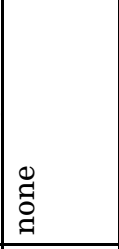 & 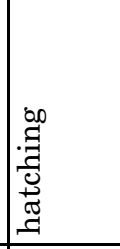 & 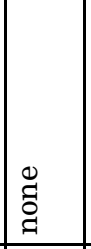 & 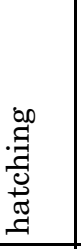 & 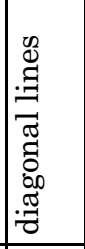 & 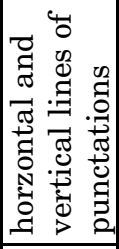 & 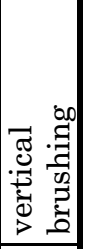 \\
\hline 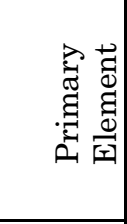 & 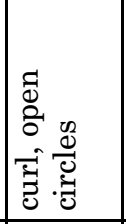 & 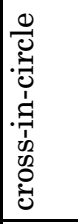 & 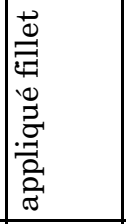 & $\vec{\Xi}$ & & 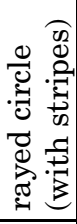 & 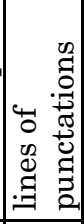 & 竎 & 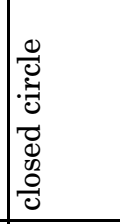 & 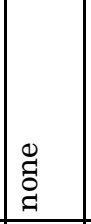 & 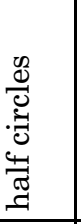 & 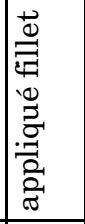 & 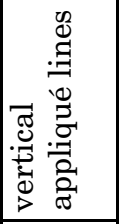 & 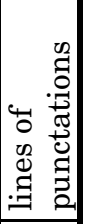 \\
\hline 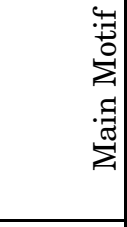 & 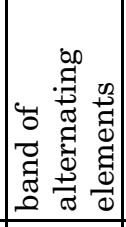 & 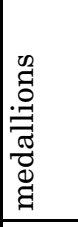 & 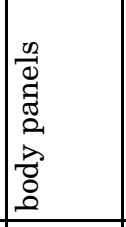 & 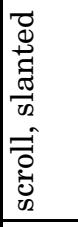 & & 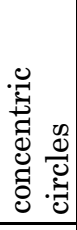 & \begin{tabular}{|l}
0 \\
0 \\
0 \\
$\tilde{\sigma}$ \\
0 \\
2 \\
2 \\
0 \\
8 \\
8 \\
\end{tabular} & 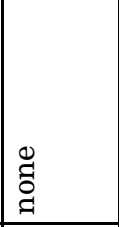 & 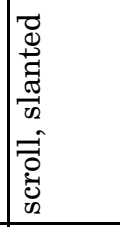 & 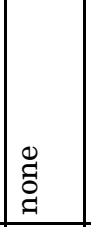 & 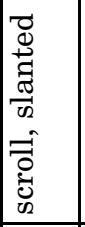 & 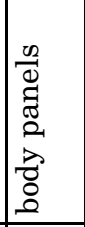 & 童 & \begin{tabular}{|l}
0 \\
0 \\
0 \\
$\approx$ \\
$\approx$ \\
0 \\
0 \\
0 \\
0 \\
0 \\
0
\end{tabular} \\
\hline 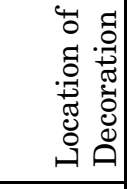 & g्च & $\begin{array}{l}3 \\
8 \\
\end{array}$ & 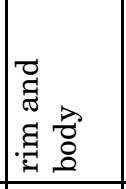 & (ี) & & : & 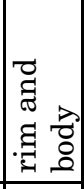 & : & Iี & 总 & 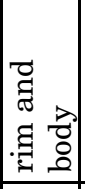 & 8 & 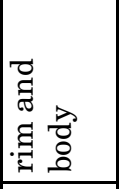 & 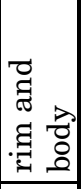 \\
\hline 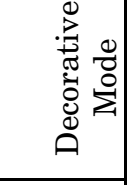 & 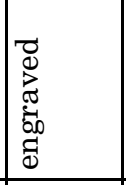 & 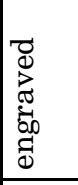 & 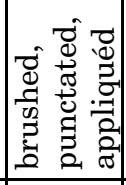 & \begin{tabular}{|l}
0 \\
0 \\
0 \\
0 \\
0 \\
0 \\
0 \\
0 \\
\end{tabular} & & $\begin{array}{l}8 \\
0 \\
2 \\
0 \\
50 \\
0 \\
0 \\
\end{array}$ & 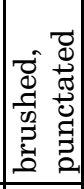 & 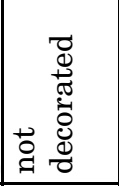 & 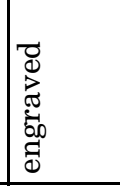 & 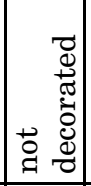 & 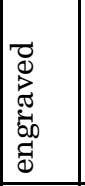 & 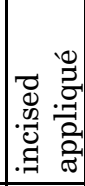 & 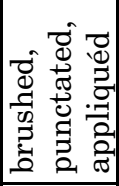 & 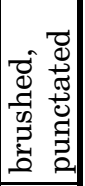 \\
\hline $\begin{array}{c}\text { च्ञ్ } \\
0 \\
\text { | }\end{array}$ & 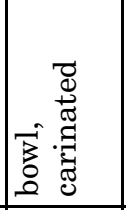 & 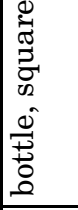 & 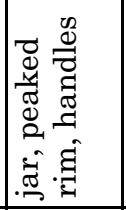 & 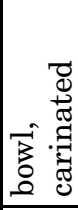 & & 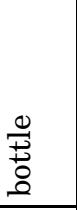 & 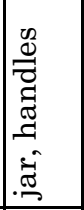 & 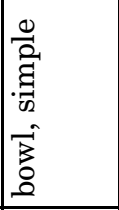 & 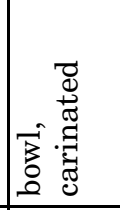 & 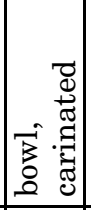 & 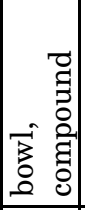 & 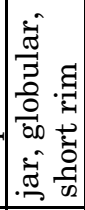 & 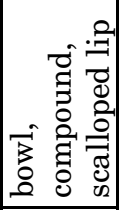 & . \\
\hline 蛋 & 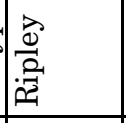 & 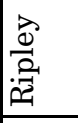 & 同 & 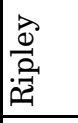 & 음 & 今 & \begin{tabular}{|l}
0 \\
0 \\
0 \\
0 \\
0 \\
\\
\end{tabular} & 合 & 常 & 同 & 总 & 貝 & 同 & 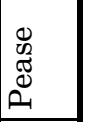 \\
\hline 焉 & $\stackrel{\infty}{\circ}$ & $\stackrel{\ominus}{\circ}$ & $\stackrel{\varrho}{=}$ & $\exists$ & 吾 & $\stackrel{ }{\beth}$ & $\stackrel{\infty}{=}$ & $\exists$ & స్త్ & $\stackrel{\vec{N}}{\sim}$ & 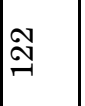 & 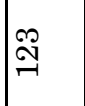 & 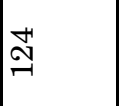 & $\stackrel{\widetilde{N}}{\stackrel{\sim}{\rightarrow}}$ \\
\hline
\end{tabular}


These motifs have an open circle or diamond as primary elements with pendant triangles as prominent secondary elements. The main motif on the square bottles repeats four times around the body with the circular elements on the corners. On Item 109, a square bottle, pendant triangles are found within the centermost circle of the primary element giving the impression of a cross (Figure 7.15a). In this motif on Ripley Engraved bottles and bowls from other sites, pendant triangles such as these often are connected by engraved lines to form a cross. On Items 1 and 57, the pendant triangles extend out from the central circle giving the impression of a rayed circle or rayed diamond (Figure $7.15 \mathrm{~b}-\mathrm{c}$ ). The extensive use of pendant triangles can be viewed as a way in which Caddo ceramic artists created scalloped edges to the primary elements, which may have had iconic association with the representation of feathers (Gadus and Fields 2012:509-512).

Item 57 displays another interesting structural feature of Ripley Engraved motifs, which is the combination of elements in a manner that is reminiscent of more than one main motif on a single vessel. On this vessel, medallions extend down from the neck and repeat three times around the bell-shaped body. This leaves wide gaps at the base of the vessel that are filled with concentric circles (see Figure 7.15b). The concentric circle motif, with or without pendant triangles as secondary elements, is a common Ripley Engraved motif, especially on square bottles. The concentric circles on this bottle repeat six times around the widest part of the body.

Though the main motif on Item 56, the bottle fragment, could not be distinguished in full, it too appears to have either medallions or concentric circles modified with pendant triangles. This motif repeats at least four times around the body. The likely motif along with the fragment's reported size (maximum diameter of $17.5 \mathrm{~cm}$ ), body shape, and color (red) suggest that it may have been part of a large bottle similar in size, color, and motif to Item 57 (see Figure $7.15 \mathrm{~b}$ ). Both of these bottles are from Burial 6, which had more vessels than any other grave.

\section{WILDER ENGRAVED}

Item 2, possibly from Burial 2, is typed Wilder Engraved, though its motif appears to be a combination of both Ripley and Wilder elements. It is a large bottle with a height of $18.5 \mathrm{~cm}$ and a bell-shaped body with an extended and flaring neck and rim. The Wilder Engraved association is based on two repetitions of a swirl motif with interlocking ends as primary elements (Figure 7.16). One repetition of the main motif, however, is more of a curl that ends in a small central circle. The curl element is found on various Ripley Engraved vessels and some Taylor Engraved bottles (Suhm and Jelks 1962:Plate $76 \mathrm{~b}, \mathrm{c}, \mathrm{f})$. The curl on Item 2 is juxtaposed with a rectangular band decorated with a chevron element, and closed circles and bars are seen in the areas surrounding the curl and swirls. All of these secondary elements are common to Ripley Engraved motifs. A similar configuration of secondary elements with the curl element within a band motif is present on Item 108, a Ripley Engraved carinated bowl from Burial 9. The presence of both Wilder and Ripley motifs on the same bottle are not uncommon at Titus phase sites. One such bottle from the Riley site in Upshur County is illustrated by Suhm and Jelks (1962:Plate 78c), and another comes from the Tuck Carpenter site (Turner 1978:Figure 27c). Both of these examples are double bottles. An example from the Pine Tree Mound site shows the combination of Wilder and Ripley elements on the common bell-shaped bottle form as well (Fields and Gadus 2012:Figure 6.11).

\section{UNTYPED}

The three bottles that are untyped are Item 79 from Burial 7, Item 98 from Burial 8, and Item 117 from Burial 10 (Figure 7.17). The bodies of Items 98 and 117 have a round or globular form in the style of Taylor Engraved (Suhm and Jelks 1962:Plate 76h), though both have tall necks and slightly everted rims common to Ripley and Wilder Engraved bottles. Item 79 has a bell-shaped body with a tall neck and everted rim common to Ripley Engraved. These are medium to large bottles at 15.8, 25.5, and $20.5 \mathrm{~cm}$ in height.

The motifs are similar to but not quite the same as the medallion and concentric circle motifs on the Ripley Engraved bottles described above. However, the primary elements used, such as SZ, hatched circle, and rayed circle, are found on other vessels from the cemetery. For instance, Item 79 has a unique motif with a crosshatched circle primary element (see 


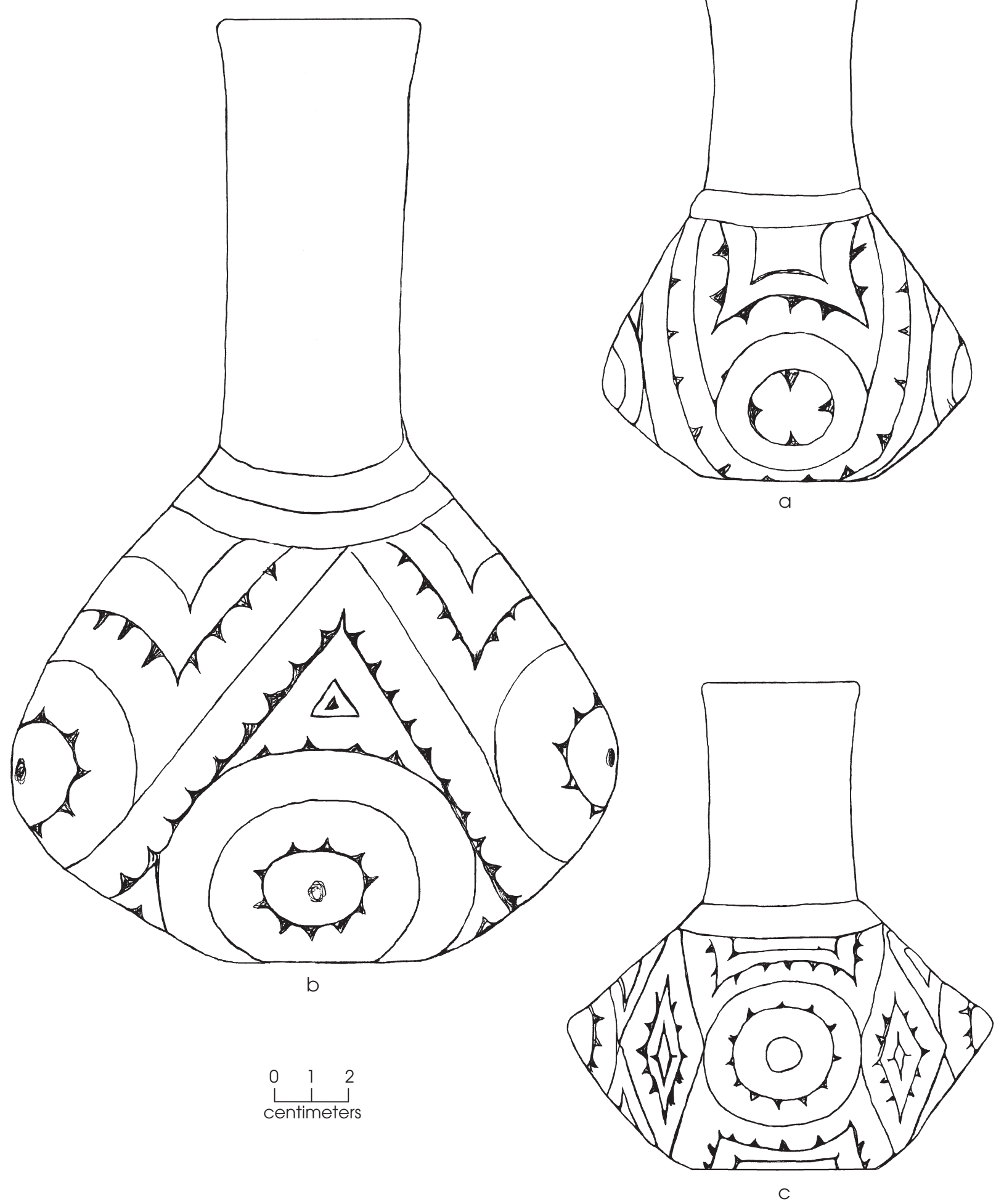

Figure 7.15. Ripley Engraved bottles from the A. P. Williams cemetery. (a) Burial 9, Item 109, square body with medallion motif; (b) Burial 6, Item 57, red-slipped bell-shaped body with medallion motif; (c) Burial 2(?), Item 1, square body with circles/diamonds motif. 

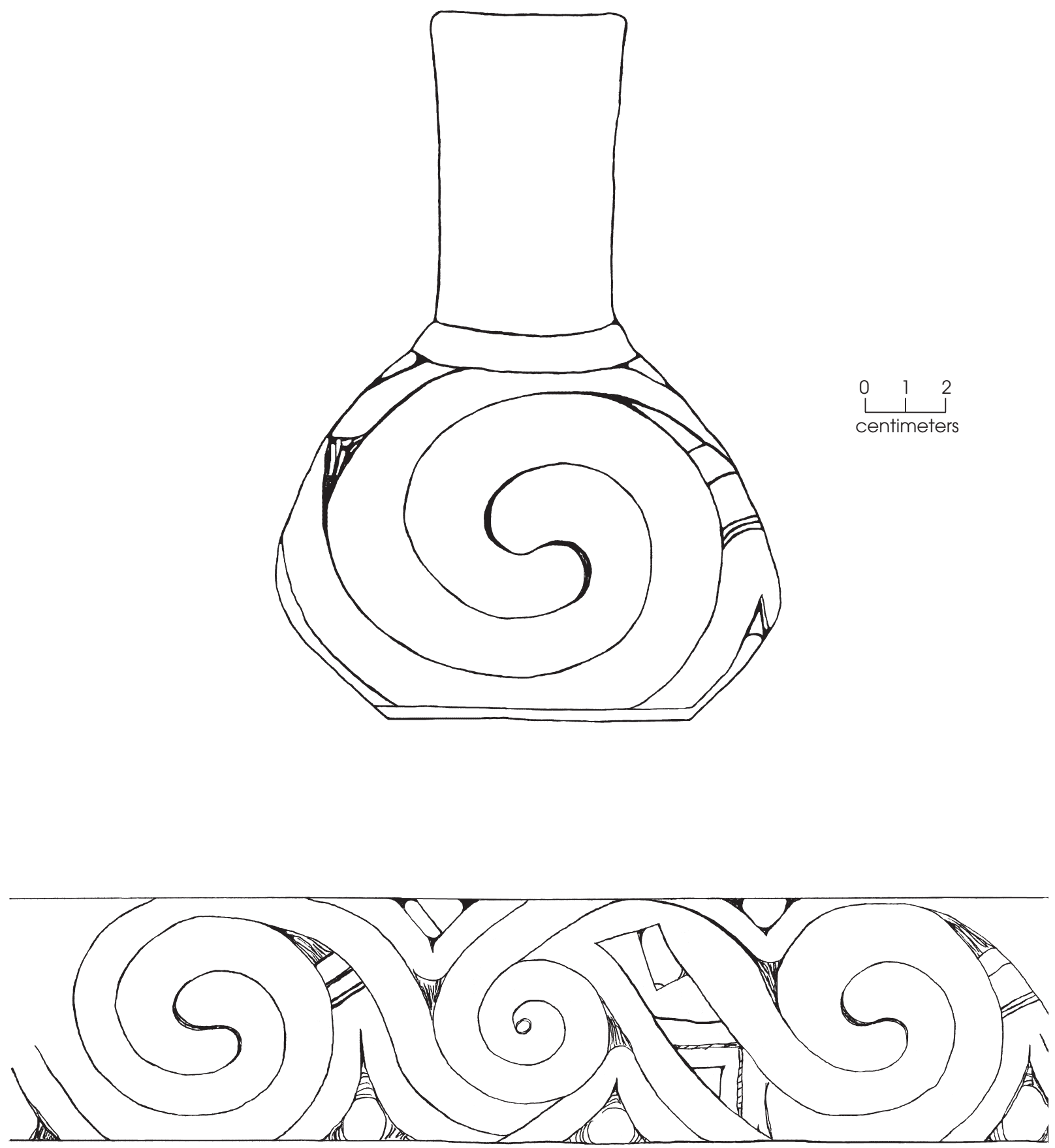

Figure 7.16. Wilder Engraved bottle from the A. P. Williams cemetery.

Figure 7.17a). The same crosshatched circle also appears on a number of bowls with Ripley Engraved scroll motifs from other graves at the site. However, the crosshatched surrounds that extend down the bottle body from the neck to the carination and enclose the primary circle form a motif structure that is not common to classic Ripley Engraved bottles. Still, four bottles from the Mockingbird site with a similar motif structure were typed as Ripley Engraved, while one without a primary element was not given a type classification (Perttula et al. 1998:Figures 26, 38, 
51. 57, 87). Thurmond (1990:179) called Item 79 an Avery Engraved bottle. While the bottle form has affinities to Avery bottles, the crosshatched surrounds within the motif do not.

Item 98 displays a horizontal SZ element with a central line as a primary element within a concentric half circle (see Figure 7.17b). This primary element is also present on Items 43 and 107 from Burials 5 and 9. This bottle also has ticking and crosshatched surrounds that are reminiscent of Taylor, Hodges, or even Hatchel Engraved. Thurmond (1990:179) typed this bottle as Ripley Engraved. The third untyped bottle, Item 117, displays a concentric circle motif with a rayed circle as a primary element (see Figure $7.17 \mathrm{c}$ ). At the center of the rayed circle are opposed curving elements reminiscent of Hatchel Engraved bottles (Suhm and Jelks 1962:Plate 34). In addition, the intensive hatching surrounding small closed circles that themselves surround the primary elements are reminiscent of the type Avery Engraved (Suhm and Jelks:Plate 2). Thurmond (1990:179) typed this bottle as Ripley Engraved. Given these combinations of elements, it appears that these three bottles incorporate influences from a number of Caddo ceramic types.

\section{Bowls}

The 56 bowls consist of 28 carinated bowls, 19 compound bowls, and 9 simple bowls. Ripley Engraved is the main ceramic type, accounting for 15 of the carinated bowls (54 percent), 13 of the compound bowls (68 percent), and 3 of the simple bowls (33 percent). The remainder are untyped, with 2 of the simple bowls being effigy vessels. The carinated bowls have a rim diameter range of 7.7 to $34.5 \mathrm{~cm}$ and a mean of $16.7 \mathrm{~cm}$. With 18 bowls (64 percent) at or below the mean, most are small to medium-sized vessels. The typed carinated bowls have a rim diameter range of $8.3-34.5 \mathrm{~cm}($ mean $=18.1 \mathrm{~cm})$ and a height range of $3.8-20.3 \mathrm{~cm}$ (mean $=8.6 \mathrm{~cm})$, while the untyped ones have smaller ranges but very similar means $(14.5-24.3 \mathrm{~cm}$, mean $=18.1 \mathrm{~cm}$; $5.6-16.1 \mathrm{~cm}$, mean $=8.9 \mathrm{~cm}$ ).

The compound bowls also range widely in terms of rim diameter $(10.5-35.5 \mathrm{~cm}$, mean $=19.3 \mathrm{~cm}$ ) and are mostly small to medium-sized vessels; just 6 are larger than the mean. The 12 typed ones that could be measured have a rim diameter range of
$11.1-35.5 \mathrm{~cm}($ mean $=17.9 \mathrm{~cm})$ and a vessel height range of $5.8-22.5 \mathrm{~cm}($ mean $=10.8 \mathrm{~cm})$, while the values for the untyped ones are $13.5-31.2 \mathrm{~cm}$ (mean $=22.9 \mathrm{~cm})$ and $6.6-20.0 \mathrm{~cm}$ $($ mean $=13.4 \mathrm{~cm})$. Compared to the carinated bowls, the compound bowls overall are a bit larger.

All simple bowls are small to medium sized, with a rim diameter range of 11.0 to $19.2 \mathrm{~cm}$ $($ mean $=14.7 \mathrm{~cm})$. They range in height from 5.0 to $10.6($ mean $=7.2 \mathrm{~cm})$.

\section{RIPLEY ENGRAVED CARINATED BOWLS}

The 15 Ripley Engraved carinated bowls have mostly everted rims $(n=10)$, though straight rims do occur $(n=5)$. Special rim treatments are infrequent. Only Item 39 from Burial 4 has a scalloped rim with ticking below the lip. White pigment was noted within the engraved lines on 5 of these vessels. One (Item 47 from Burial 5) has evidence of red pigment on the interior.

The slanted scroll motif is most common, occurring on 10 vessels (Figure 7.18a-b). Two have slanted scrolls alternating with opposed scrolls, the arms of which are oriented in the same direction, either up or down, in relation to the primary element. Item 42 is a small bowl that has the slanted/opposed scroll motif with a closed circle primary element (Figure 7.18c). Three other bowls have band motifs. One is a band of repeating elements with the elements being chevrons; the other two have a band of alternating elements motif (Figure 7.18d).

Eleven primary elements are associated with these scroll and band motifs, most of which are forms of the circle. They are open circle, closed circle, cross-in-circle, rayed circle, and crosshatched circle. Other primary elements include half circle, rayed half circle, SZ, curl, bar, and chevron. Given the variety of primary elements used, it is interesting that four vessels lack primary elements other than the scroll arms themselves. Item 26 from Burial 3 is one example of this slanted scroll motif with no primary elements but the scroll arms (see Figure 7.18b). On this vessel, elements such as the bar, SZ, and closed circle, which are often used as primary elements, are placed in a secondary position within the arms of the scroll. On the three other examples of slanted scrolls with no primary elements, secondary elements in 

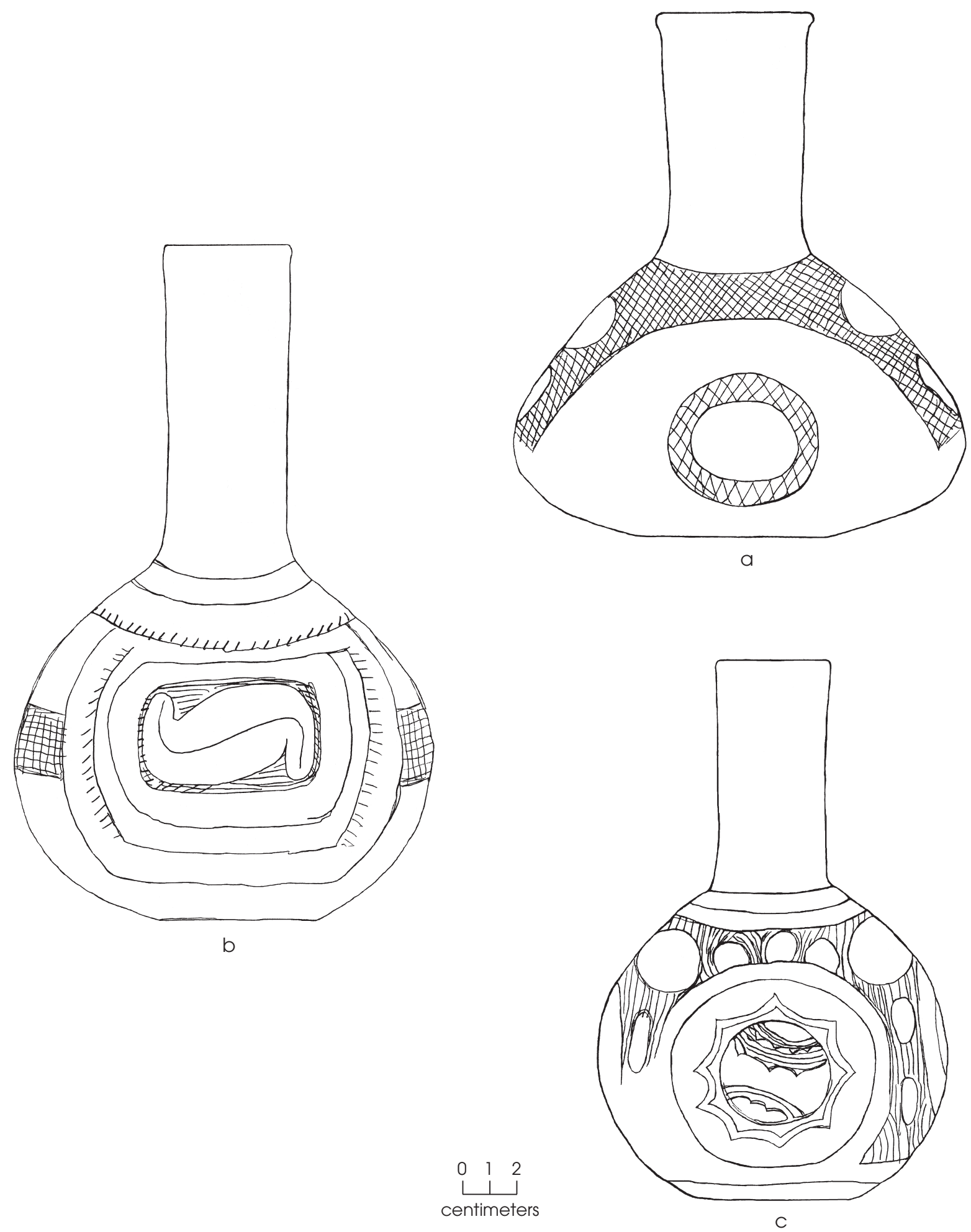

Figure 7.17. Untyped bottles from the A. P. Williams cemetery. (a) Burial 7, Item 79; (b) Burial 8, Item 98; (c) Burial 10, Item 117. 


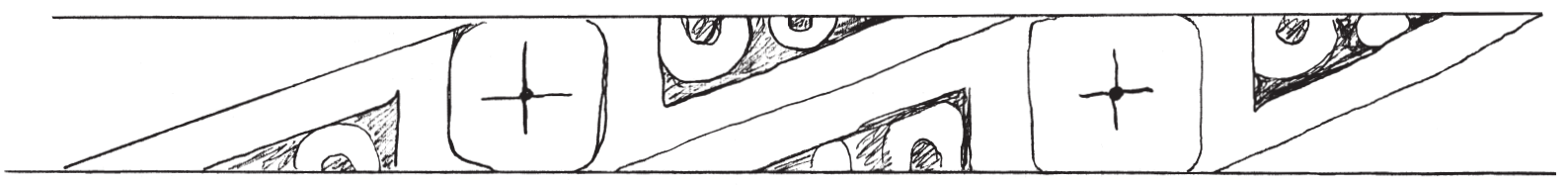

a

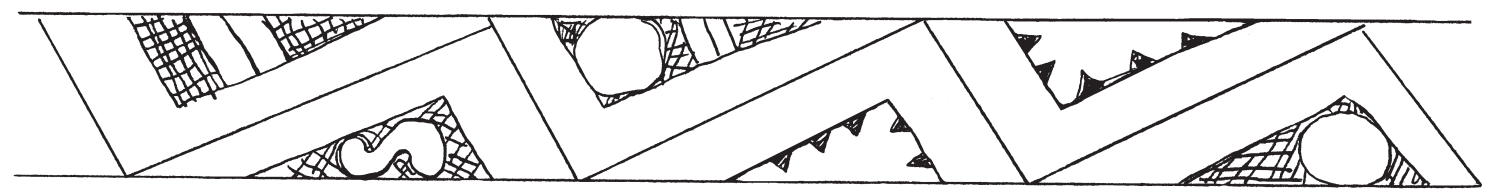

b
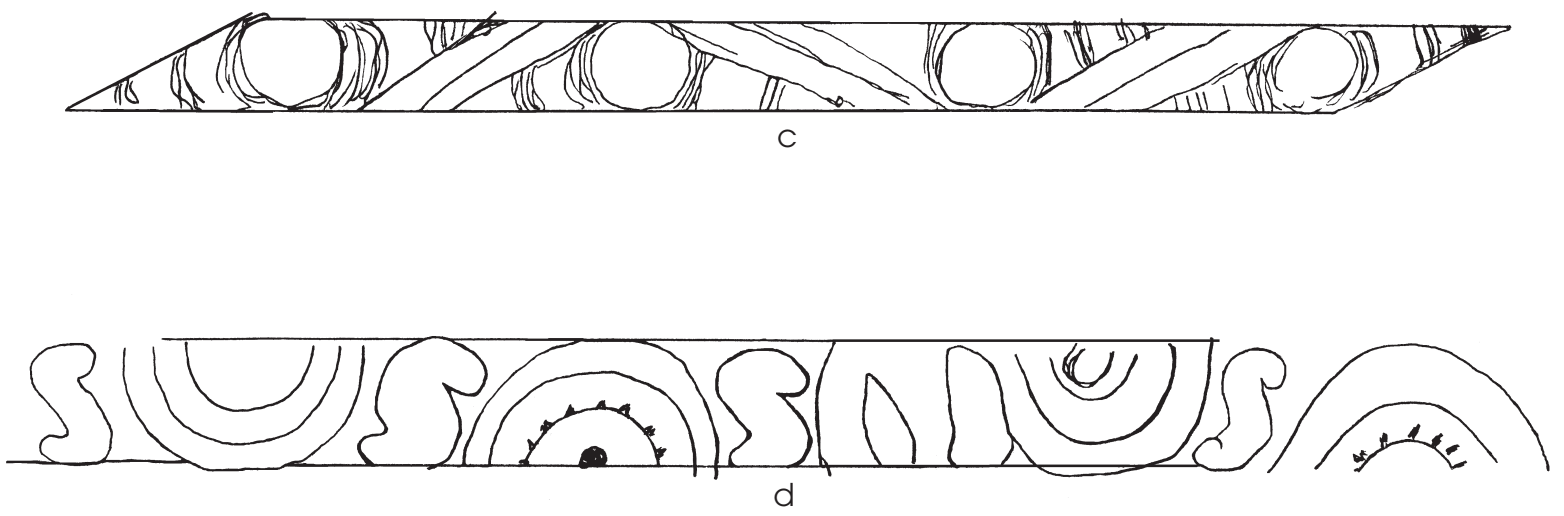

Figure 7.18. Ripley Engraved scroll motifs and band of alternating elements motif on carinated bowls from the A. P. Williams cemetery. (a) Burial 4, Item 39, slanted scroll with cross-in-circle primary element; (b) Burial 3, Item 26, slanted scroll with no primary element; (c) Burial 5, Item 42, slanted/opposed scroll with closed circle primary element; (d) Burial 5, Item 47, band of alternating elements with half circles, rayed half circles, and SZ primary elements.

the arms are simply bars or hatching. Similar arms-only slanted scrolls are common on carinated bowls $(\mathrm{n}=33)$ from the graves at the Tuck Carpenter site.

It is also interesting to note how the use of the same primary element within different motifs may alter motif structure. For instance, the curl is used both as a primary element on a slanted scroll on Item 11 from Burial 9 and within a band with alternating elements on Item 108 from Burial 9. For the slanted scroll, curls extend from the ends of the scroll arms with the adjoining arms fitted to the side of the curl (Figure 7.19a). In the band of alternating elements, the curls are centered within circles with hatched surrounds (Figure 7.19b). In both of these motifs, one of four iterations of the curl is engraved in the opposite direction. These renditions of the curl differ from the continuous spiral or swirl with interlocking ends that is often associated with Wilder or Taylor Engraved vessels (Suhm and Jelks 1962:Plates 75, 76, 78).

Almost any primary element, except for cross-in-circle and rayed circle, was used in a secondary position within scrolls. However, the most common secondary elements on these 
carinated bowls are hatching or crosshatching $(\mathrm{n}=10)$ and bars $(\mathrm{n}=4)$. Pendant triangles, which are common on the bottles, occur only once as a secondary element on the bowls (Item 26).

\section{UNTYPED CARINATED BOWLS}

Thirteen carinated bowls remain untyped. Of the 10 where rim form could be discerned from the TARL notes, 5 have everted rims and 5 have straight rims. Three carinated bowls have no decoration and are not typed, though one (Item 82) does have a scalloped rim, which is often associated with Ripley Engraved. Ten carinated bowls are decorated with motifs that are not well executed, making it difficult to unquestionably associate them with Ripley Engraved or any other type. Some elements on these bowls are similar to those associated with Ripley motifs. For instance, Item 54 from Burial 6 appears to have a slanted scroll with no primary element, but with closed circles and crosshatching in what could be taken as the scroll arms (Figure 7.19c). Item 13 from Burial 1 displays a version of the band of repeating elements motif with repeating panels marked by hatching (Figure 7.19d). Panel elements are not generally associated with Ripley Engraved bowls, however.

One untyped carinated bowl stands out, as it has a unique oval body shape with an inverted rim; the inflection of the inverted rim is the carination. It is Item 14 from Burial 1. This is a small bowl with a rim diameter of $7.7 \mathrm{~cm}$ and a height of $5.5 \mathrm{~cm}$. It is decorated with a scroll motif that repeats four times around the body with hatched surrounds, ticking on the lip, and pendant triangles below the carination. It also has vertical appliqué fillets on the elongated end of the body with suspension holes where the fillets meet the rim. Two nodes are set central to the body between the fillets, giving the bowl a four-fold symmetry even though it has an oval shape. All of these design features give the impression of an effigy vessel. Thurmond (1990:179) typed it as Ripley Engraved.

\section{RIPLEY ENGRAVED COMPOUND BOWLS}

Thirteen compound bowls can be typed as Ripley Engraved; 1 has a straight rim, and the others have everted rims. As on the carinated bowls, the slanted scroll $(\mathrm{n}=6)$ is the most common motif (Figure 7.20a, d). Three display slanted scrolls that alternate with opposed scrolls (Figure 7.20b), and 2 bowls have only opposed scrolls (Figure 7.20c). Thus, opposed scrolls appear more on compound bowls than carinated bowls. One compound bowl displays a band of alternating elements motif (Figure $7.20 \mathrm{e}$ ), while another has a band of repeating diamonds. Eight of the Ripley Engraved compound bowls were recovered from Burials 3 and 4 , with 4 coming from each grave. Seven of these are decorated with a variation of a scroll motif. The one that differs (Item 32 from Burial 4) has the band of repeating diamonds.

The common primary elements on these bowls are the open circle, half circle, SZ, and bar; as on the carinated bowls, some form of circle predominates. There are four instances of crosshatched circles or half circles as primary elements within scrolls on compound bowls but only one such occurrence on a carinated bowl. This crosshatched circle or half circle might be a local variation, an interpretation supported by the prominent crosshatched circle on Item 79 , an untyped bottle from Burial 7 (see Figure $7.17 \mathrm{a}$ ). In contrast, there are only two slanted scroll motifs with hatched half circles as primary elements in the large Tuck Carpenter site assemblage, and both are from the same grave (Turner 1992:93).

The single example of a band of alternating elements motif demonstrates a correspondence between the SZ element, which often is engraved upright but can occur on its side, and what may be called a sinuous slanted scroll. The difference is that the sinuous slanted scroll has an interior line running its length while the SZ element does not (see Figure 7.20e). There is also some difference in overall usage, as the sinuous slanted scroll only appears as a primary element, whereas the SZ can be used both as primary and secondary elements, as in the arms of a scroll (see Figure $7.20 \mathrm{a}, \mathrm{b}$ ). It is also possible that a sinuous slanted scroll can be used in place of a scroll motif, with at least one instance of this appearing on a bowl from the A. P. Williams site (Figure 7.20d).

One other element used both in primary and secondary fashion on these bowls, but not seen commonly if at all in other assemblages of Ripley Engraved vessels, is the barred oval (see Figure $7.20 \mathrm{a}, \mathrm{e})$. This element has great antiquity and can be found on the Spiro site shell engravings, where it often has serpent associations (Phillips 


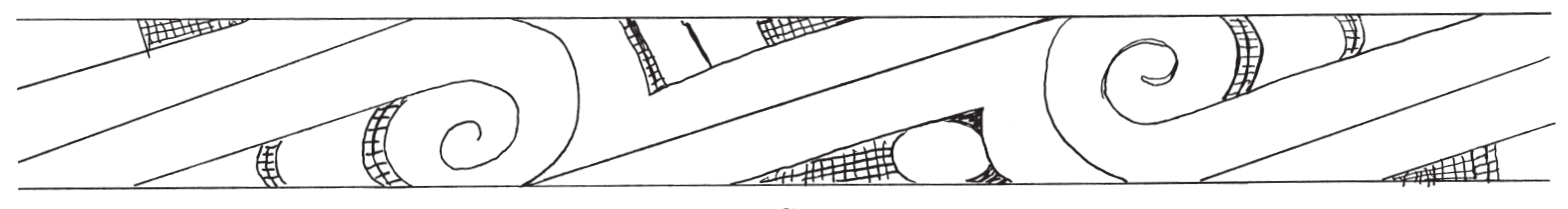

a
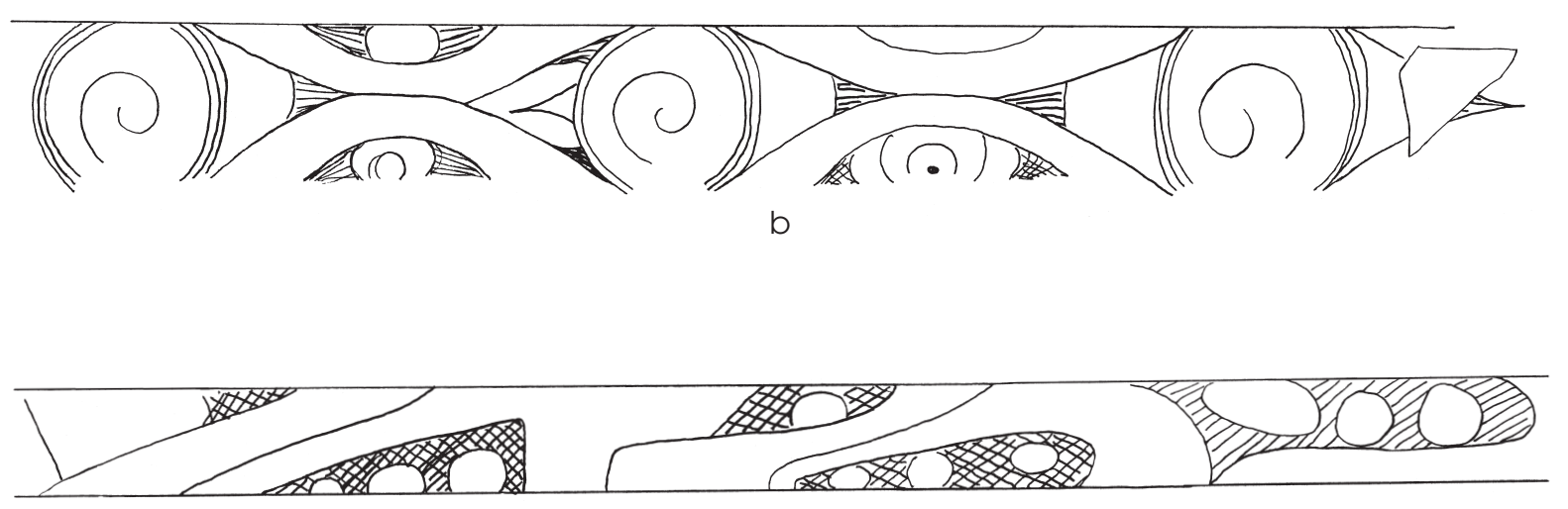

C

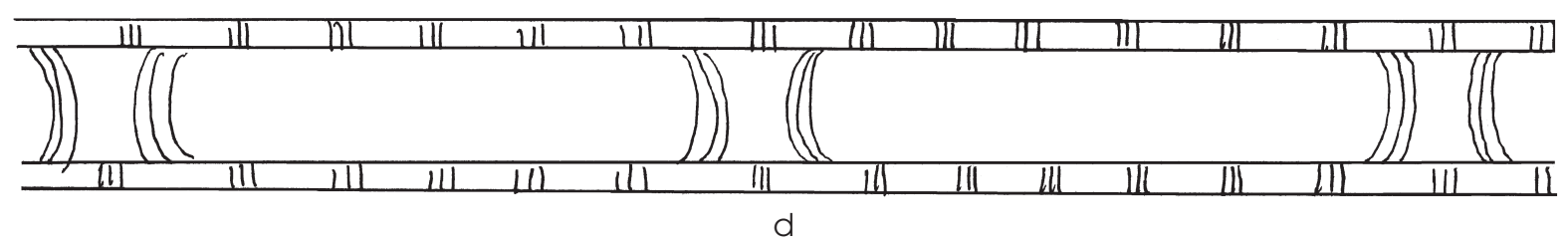

Figure 7.19. Ripley Engraved motifs and untyped carinated bowl motifs from the A. P. Williams cemetery. (a) Burial 9, Item 111, Ripley Engraved slanted scroll with curl as primary element; (b) Burial 9, Item 108, Ripley Engraved band of alternating elements motif with curl and open half circle as primary elements; (c) Burial 6, Item 54, untyped possible slanted scroll motif; (d) Burial 1, Item 13, untyped band of repeating elements motif with panels.

and Brown 1978:147). The association between barred ovals and SZs in the A. P. Williams assemblage, where the two are used in a similar fashion, strengthens the serpent association for the latter (see Figure 7.21a below).

Lastly, eight of the Ripley Engraved compound bowls have an additive or subtractive decoration or both. This consists mainly of one or more horizontal lines engraved between the lip and the first carination (Items 20,23, 33, 43, 59,107 , and 122). Two bowls have four-peaked rims (Items 18 and 33). Item 18 is decorated with a slanted/opposed scroll motif and has an open circle in each of its peaks. Item 33 is decorated with an opposed scroll motif and has an engraved horizontal line around the rim; closed circles and hatching decorate each peak.

\section{UNTYPED COMPOUND BOWLS}

Six compound bowls, all with everted rims, could not be typed. Two are decorated with scrolls that are haphazardly executed making type identification difficult, and four 


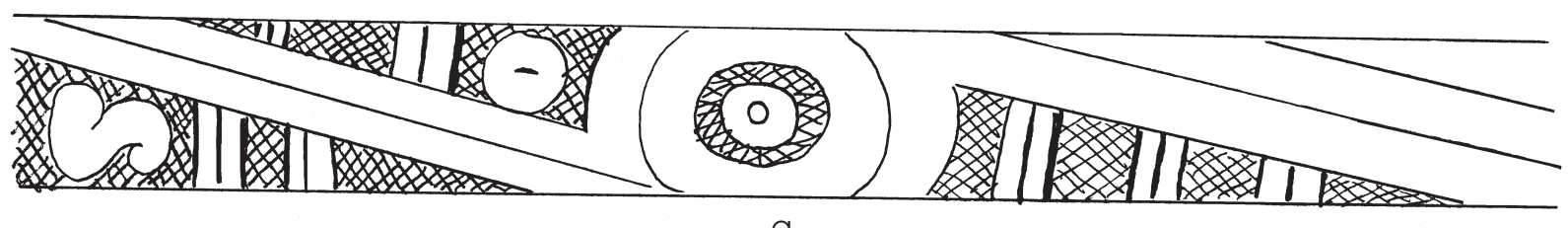

a
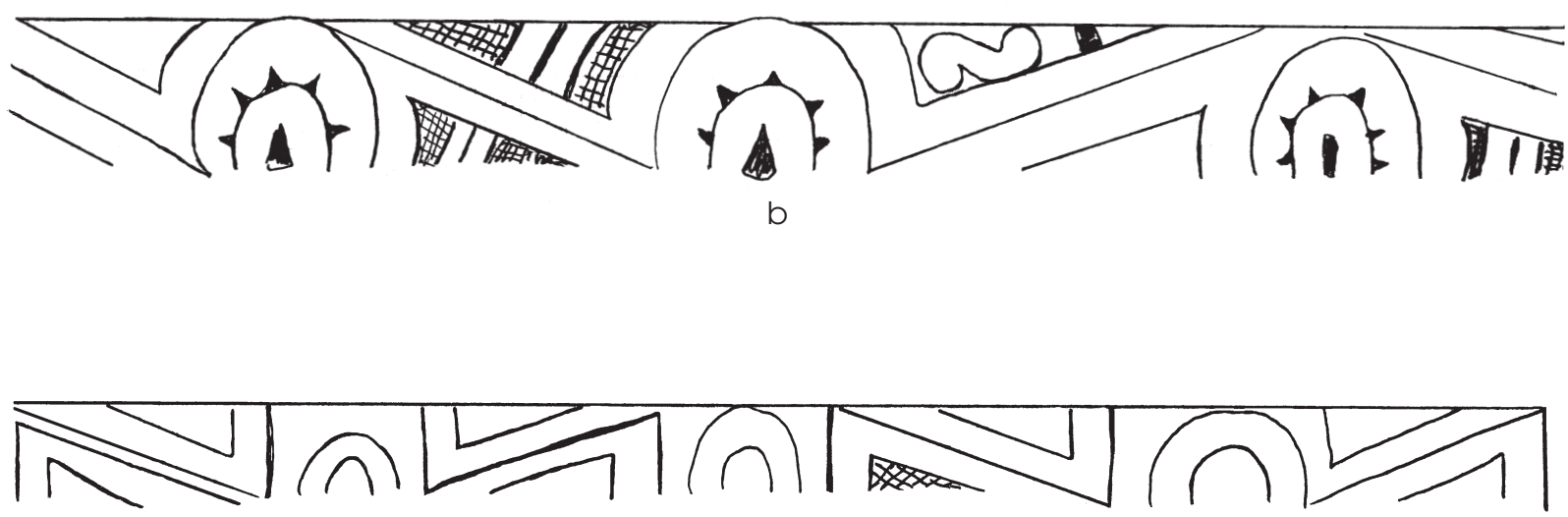

C

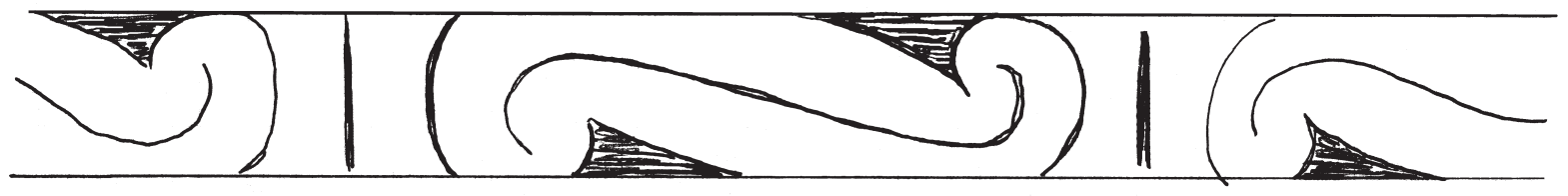

d

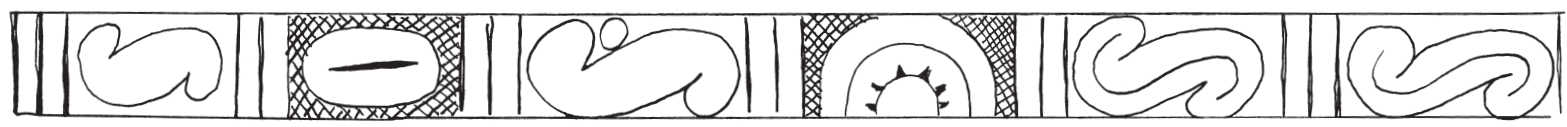

e

Figure 7.20. Ripley Engraved motifs on compound bowls from the A. P. Williams cemetery. (a) Burial 3, Item 20, slanted scroll with crosshatched circle primary element; (b) Burial 4, Item 31, slanted/opposed scroll with rayed half circle primary element; (c) Burial 2, Item 18, slanted/opposed scroll with half circle primary element; (d) Burial 9, Item 107, slanted scroll with bar primary element; (e) Burial 5, Item 43, band of alternating elements with barred oval, SZ, and rayed half circle primary elements. 
have unique motifs that resist type definition. The most unusual is Item 124 from Burial 10. This small compound bowl, with a rim diameter of $13.5 \mathrm{~cm}$, has many design elements that are usually associated with jars, as it is decorated with brushing, vertical appliqué fillets, and lines of stick punctations. Its everted rim is brushed vertically between the lip and the first carination, while two horizontal lines of punctations made though the brushing encircle the rim. Its rim is also scalloped. In addition, seven vertical appliqué fillets decorate the body of the vessel and alternate around it with vertical lines of punctations. A third horizontal line of punctations circles the vessel at the body carination (i.e. the second carination below the lip). Thurmond (1990:179) lumped this vessel with the Pease Brushed-Incised jars from Burial 10, but the vessel is clearly a compound bowl.

Another unique motif is on the body of Item 83 from Burial 7. It consists of a series of sinuous horizontal lines marked with hatching that encircle the body to create a chevron effect. Item 86, also from Burial 7, displays a sinuous slanted scroll with interlocking ends. This motif is similar to Taylor Engraved, except for the hatching that decorates the scrolls and the rayed half circles that are positioned above and below the encircling line of scrolls. On a third unique compound bowl, Item 53 from Burial 6, much of the motif is not distinguishable, except for a set of open rectangles, decorated with hatching, prominent on the vessel body. Such rectangles, while not a common east Texas ceramic element, are known from a few Spiro engraved shell cups (Phillips and Brown 1978:153).

\section{RIPLEY ENGRAVED SIMPLE BOWLS}

As far as can be discerned from the TARL notes, all three Ripley Engraved simple bowls have everted rims. Thurmond (1990:179) calls these conoidal bowls. Item 12 from Burial 1 is decorated with a band of alternating elements motif (Figure 7.21a). The primary elements are SZ, barred oval, and bar, while secondary elements consist of small closed circles and hatching. In many respects, this is similar to the Ripley Engraved band motif on Item 43 from Burial 5 (see Figure 7.20e). The other two bowls have straight scrolls (Figure 7.21b-c). These are similar in execution and style to straight scroll motifs on Ripley Engraved vessels from the
Mockingbird site (Perttula et al. 1998:149-150). They do not fit the classic examples of Ripley Engraved scroll motifs, and they may represent local variation on the type.

\section{UNTYPED SIMPLE BOWLS}

The six untyped simple bowls also appear to have everted rims. Three are undecorated, one is vertically brushed and appears to be the reworked bottom of a jar, one is an effigy bowl, and one is a noded bowl. The effigy bowl is Item 3, possibly from Burial 2. It is likely similar to ones illustrated by Suhm and Jelks (1962:Plate 24). The effigy head is missing, but the tail is intact and two horizontal lines encircle the rim. Item $52 \mathrm{a}$ from Burial 6is a noded bowl similar to a rattle bowl from the Hatchel site in Bowie County as illustrated by Suhm and Jelks (1962:Plate 26g).

\section{Olla}

The single olla, Item 9 from Burial 1, is small with a squat body and a short, slightly everted rim. The rim diameter is $6.4 \mathrm{~cm}$, and overall height of this vessel is $8.5 \mathrm{~cm}$. It can be typed as Ripley Engraved, as it has four repetitions of a chevron element with pendant triangles suspended from a line below the vessel neck as a medallion motif. This is reminiscent of the motif surrounds, less the concentric circles, seen on the Ripley Engraved olla illustrated by Suhm and Jelks (1962:Plate 65k).

\section{Beakers}

The two beakers are small, with rim diameters of 10.1 and $11.1 \mathrm{~cm}$ and heights of 7.6 and $10.2 \mathrm{~cm}$. They have straight sides and no rim constriction. Item 52 from Burial 6 is undecorated and has a slightly rolled lip on the interior. Item 100 from Burial 8 has vertical brushing on its exterior. Thurmond (1990:179) classed both as miscellaneous untyped vessels.

\section{Jars}

\section{RIPLEY ENGRAVED JAR}

One of the three globular jars (Item 53a) is typed as Ripley Engraved, as it is similar in form to a Ripley jar illustrated by Suhm 

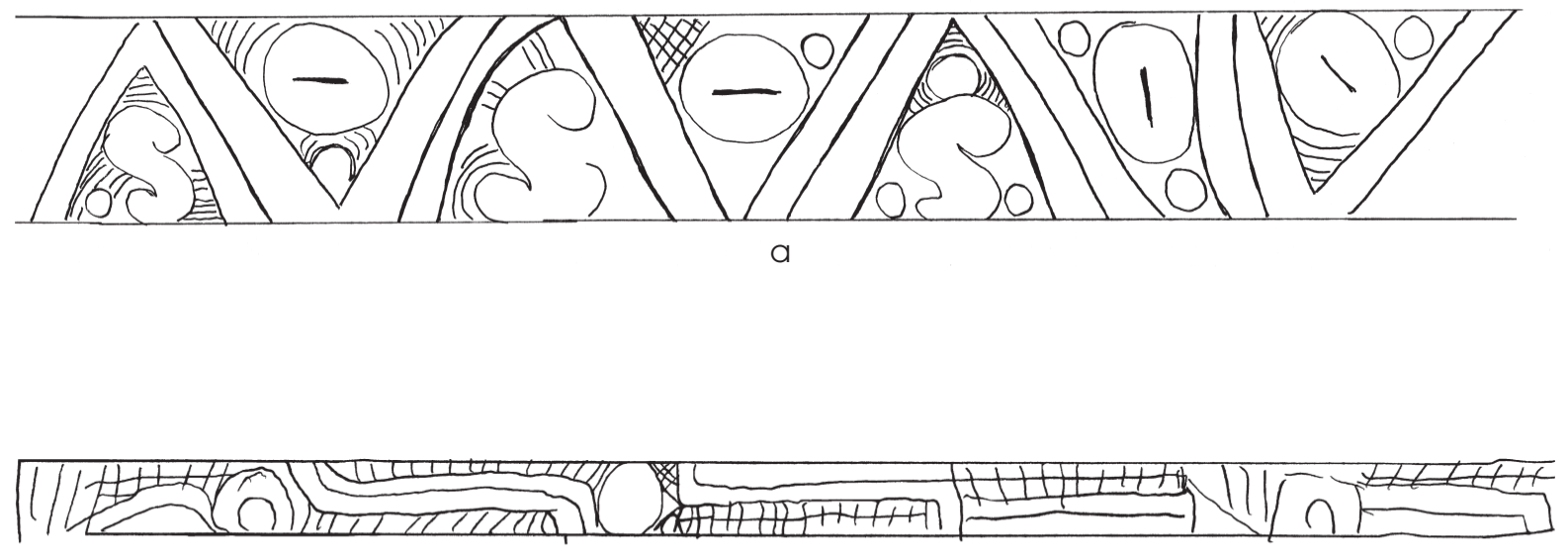

b

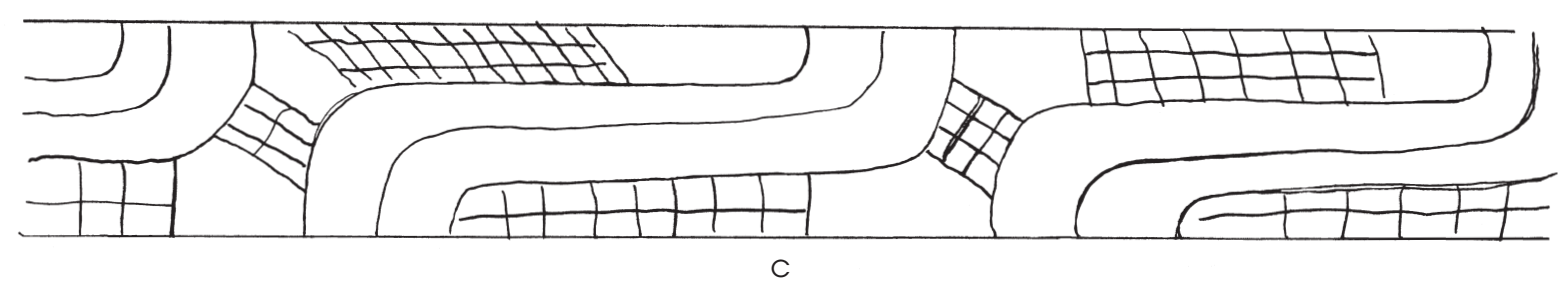

Figure 7.21. Ripley Engraved motifs on simple bowls from the A. P. Williams cemetery. (a) Burial 1, Item 12, band of alternating elements motif; (b) Burial 5, Item 40, straight scroll motif with open and closed circle primary elements and crosshatching; (c) Burial 4, Item 38, straight scroll motif with crosshatching.

and Jelks (1962:Plate 65a). Unlike that jar, which has a concentric circles motif, Item $53 \mathrm{a}$ displays a slanted scroll with open circle and cross-in-circle primary elements. Item $53 \mathrm{a}$ is small, with a rim diameter of $9.5 \mathrm{~cm}$ and a height of $8.4 \mathrm{~cm}$.

\section{UNTYPED GLOBULAR JARS}

The other two globular jars (Items 10 and 123) are small with rim diameters ranging of 11.0 and $12.6 \mathrm{~cm}$ and vessel heights of 9.9 and $13.5 \mathrm{~cm}$. They have body panels marked by vertical appliqué fillets, one with undecorated panels and the other with diagonal incised lines in the panels. Item 10 has a four-peaked rim with handles and a field of punctations, and Item 123 has a short undecorated rim. Their various rim characteristics do not seem consistent with the classic definition of Pease Brushed-Incised, as is suggested by the body panels; hence, they are untyped here. However, Thurmond (1990:179) did type Item123 as Pease Brushed-Incised.

\section{PEASE BRUSHED-INCISED JARS}

Three elongated jars have body panels defined by vertical appliqué fillets $(n=1)$ or vertical lines of punctations $(n=2)$; the former has incised chevrons in the panels, and the latter have vertical brushing. All three have horizontal lines of punctations and incising on the rims, which is characteristic of Pease Brushed-Incised (Suhm and Jelks 1962:Plate $60 \mathrm{c}, \mathrm{e}, \mathrm{g})$. These vary in size. The smallest, Item 132 , has a rim diameter of $11.2 \mathrm{~cm}$ and a height of $12.0 \mathrm{~cm}$. The largest, Item 118, has a rim diameter of $21.0 \mathrm{~cm}$ and a height of $24.7 \mathrm{~cm}$. Item 37 has a rim diameter of $14.0 \mathrm{~cm}$ and a height of $17.8 \mathrm{~cm}$. 


\section{BULLARD BRUSHED JARS}

Two jars with elongated bodies have horizontal rows of punctations at the rim and vertical brushing on the body. They are typed as Bullard Brushed. Both are from Burial 3. Item 24 is the larger of the two, with a rim diameter of $23.0 \mathrm{~cm}$ and an overall height of $34.8 \mathrm{~cm}$. Item 22 has a rim diameter of $18.4 \mathrm{~cm}$ and a height of $16.4 \mathrm{~cm}$.

\section{MAYDELLE INCISED JARS}

Two elongated jars (Items 36 and 58) have bands of repeating elements on the rims, with the bands consisting of incised chevrons demarcating zones of stick punctations; these vessels are typed as Maydelle Incised. One also has incised diagonal lines on its body, while the other has a plain body (Suhm and Jelks: 1962:Plate 52e). Both are medium sized, with rim diameters of 15.8 and $18.6 \mathrm{~cm}$ and heights of 18.8 and $19.0 \mathrm{~cm}$. Thurmond (1990:179) called Item 58, which has diagonal lines on the body, Pease Brushed-Incised.

\section{LA RUE NECK BANDED JAR}

One elongated jar (Item 15) is neck banded and has a vertically brushed body; it is typed as La Rue Neck Banded (Suhm and Jelks 1962:Plate 47c). It is a moderately small vessel with a rim diameter of $13.5 \mathrm{~cm}$ and an overall height of $12.4 \mathrm{~cm}$.

\section{UNTYPED ELONGATED JARS}

Eight jars with elongated bodies cannot be typed, though they generally resemble the ones that are typed. Like many of the vessels from these graves, most are small to medium-sized. Six have rim diameters of $8.0-16.5 \mathrm{~cm}$ with a mean of $13.5 \mathrm{~cm}$ and heights of $9.0-19.1 \mathrm{~cm}$ with a mean of $14.4 \mathrm{~cm}$. One is considerably larger with a rim diameter of $21.5 \mathrm{~cm}$ and an overall height of $34.5 \mathrm{~cm}$. The eighth has a broken rim and was not measured. All are decorated with brushing, incising, punctating, or appliqué (see Table 7.7).

Two jars have body panels defined by vertical appliqué fillets and vertical brushing in the panels. They were not typed because of unique rim decorations. One has a peaked rim with four small handles on a field of fingernail punctations. The other has four short appliqué fillets on a field of vertical brushing that appears to extend the body panels onto the rim. Three jars have horizontal rows of punctations on the rims and plain bodies, comparable to what Perttula (2005:277-278) calls Mockingbird Punctated. However, the amount of variation that can occur within this proposed type is still unclear, and each of these jars has other decoration on the rim as well, consisting of brushing, a field of punctations, and appliqué nodes. One jar has a band of repeating incised chevrons on a peaked rim and a plain body; it is untyped because the motif appears haphazardly executed.

The seventh jar with an elongated body has pinched rows at the rim and a plain body; the TARL notes specifically mention that this vessel is not neck banded; however, some Nash Neck Banded jars look as if they have close pinching at the rim (Suhm and Jelks 1962:Plate 56j). Still, this vessel has none of the appliqué attributed to Nash and as such remains untyped. Thurmond (1990:179) did type this vessel as La Rue Neck Banded, though. The final elongated jar is decorated with appliquéd chevron elements on an otherwise undecorated body. These chevrons extend from the vessel neck as a medallion motif; rim decoration is unknown, as most of it is missing. The chevrons are composed of thick appliqué with punctations within and are unlike the fine appliquéd fillets associated with the type Harleton Appliqué; thus, this jar remains untyped. Thurmond (1990:179) did call it Harleton, though.

\section{Conclusions and Impressions}

The 10 bottles, 28 carinated bowls, 19 compound bowls, 9 simple bowls, 19 jars, 2 beakers, and 1 small olla from the A. P. Williams cemetery likely represent vessels manufactured for the most part by the local group that used the cemetery. Given the consistency of motifs and decorative elements from one grave to another, it seems that the cemetery was in use for a relatively short interval.

Fifty-six (64 percent) of the vessels have engraved motifs (excluding the effigy bowl). Of these, 70 percent are Ripley Engraved, and a substantial number (29 percent) are unidentified as to type. This is a much higher percentage of untyped engraved vessels than at the Thomas B. Caldwell cemetery (10 percent), 
which suggests that the potters who contributed to the A. P. Williams assemblage, while borrowing heavily from the classic formula of Ripley Engraved elements and motifs, added quite a bit of variation into how they expressed these common decorative themes. Ideas, and maybe even vessels, appear to have come from such sites as Mockingbird not far to the northeast and Tuck Carpenter farther away to the southeast, as well as from Caddo groups living to the north in the Red River basin.

Six of the bottles are classic Ripley Engraved in terms of form and motifs, while a seventh has a Wilder Engraved motif. These seven bottles would fit well with bottles from other sites in the Big Cypress Creek drainage, such as Tuck Carpenter. The three untyped bottles are different in form and especially motifs. The motifs on two of them incorporate elements that are reminiscent of types that occur along the Great Bend of the Red River, such as Avery and Hatchel Engraved, while the third is similar to a bottle from the Mockingbird site located to the northeast of the project area in the Hart Creek drainage. The juxtaposition of graves containing these clearly different bottles (Burials 7, 8, and 10 ) and graves with typical bottles (Burials 2?, $4,5,6$, and 9) suggests a degree of outside influence or introduction of vessels that is not seen at the Thomas B. Caldwell cemetery, where all the bottles were typed as either Ripley or Wilder Engraved.

\section{The Lithic Assemblage}

Goldschmidt (1934b) reported that 39 arrow points, 3 celts, 1 piece of kaolinitic clay, 1 battered stone (hammerstone), 1 polished pebble, 2 hematite (ocher) pieces, a drill, a spokeshave, a sandstone fragment, and debitage were recovered from the graves. When Thurmond inventoried the collection for his 1981 thesis, he was unable to find 22 of the arrow points. This study was able to re-locate most of the collection, except for 17 points, the sandstone fragment, and the debitage. These items are presumed lost or stolen.

The andesite celt from Burial 3 is $11.4 \mathrm{~cm}$ long, $4.4 \mathrm{~cm}$ wide, and $3.3 \mathrm{~cm}$ thick and weighs $269.1 \mathrm{~g}$. The distal end is well polished and beveled. The proximal end has battering suggesting it also may have been used as a hammerstone. There is some polish around the sides that may be the result of wear from hafting. Burial 6 has an andesite celt with a polished and beveled distal end. The proximal hafted end has battering suggesting use as a hammerstone. It is $12.9 \mathrm{~cm}$ long, $4.9 \mathrm{~cm}$ wide, and $3.3 \mathrm{~cm}$ thick and weighs $390.0 \mathrm{~g}$. The third celt, from Burial 8 , is a proximal end, also of andesite; it is $6.4 \mathrm{~cm}$ long, $4.6 \mathrm{~cm}$ wide, and $3.6 \mathrm{~cm}$ thick and weighs $139.6 \mathrm{~g}$.

The hammerstone (described in the report as a battered cobble), from Burial 8, is of sandstone and is $5.4 \mathrm{~cm}$ long, $5.2 \mathrm{~cm}$ wide, and $4.7 \mathrm{~cm}$ thick; it weighs $180.9 \mathrm{~g}$. The kaolinitic clay from Burial 8 is irregular in shape and has a rough texture. Cuts and incisions on this piece suggest it was used as an abrader. It is $5.6 \mathrm{~cm}$ long, $5.3 \mathrm{~cm}$ wide, and $2.9 \mathrm{~cm}$ thick and weighs $66.6 \mathrm{~g}$. The polished pebble from Burial 9 is of quartzite and is $6.2 \mathrm{~cm}$ long, $3.3 \mathrm{~cm}$ wide, and $2.6 \mathrm{~cm}$ thick; it weighs $79.4 \mathrm{~g}$. The ocher from Burial 9 includes one with polish on one face, measuring $3.9 \mathrm{~cm}$ long, $3.3 \mathrm{~cm}$ wide, and $2.2 \mathrm{~cm}$ thick and weighing $29.3 \mathrm{~g}$, and another that is rounded with wear and that measures $2.9 \mathrm{~cm}$ long, $1.9 \mathrm{~cm}$ wide, and $0.9 \mathrm{~cm}$ thick and that weighs $5.6 \mathrm{~g}$. These were used as pigment sources.

Two unifacial tools were recovered from Burial 10. One is a drill or perforator of silicified wood. It is made on a flake with bilateral retouch that shaped the distal (drill bit) end. The proximal end shows very little shaping. It weighs $1.7 \mathrm{~g}$ and is $3.4 \mathrm{~cm}$ long, $1.7 \mathrm{~cm}$ wide, and $0.5 \mathrm{~cm}$ thick. The spokeshave/scraper, of white Keokuk-Burlington chert, is formally prepared with moderately steep edge retouch on both sides. One side is curved and may have been used as a spokeshave. The other edge was more likely used as a scraper. Retouch on the proximal end is typical of use as a knife. It weighs $18.6 \mathrm{~g}$ and is $6.3 \mathrm{~cm}$ long, $3.8 \mathrm{~cm}$ wide, and $0.6 \mathrm{~cm}$ thick.

The 22 re-located arrow points consist of 3 Alba, 11 Bonham, 4 Perdiz, a possible Scallorn, an untyped specimen, and 2 preforms. Table 7.8 presents metric data for them. The Alba points have slightly expanding stems and straight to rounded bases, and they all have barbs. Two are of a local chert and 1 is of nonlocal black chert. Two of the Albas are complete, and one is missing part of the side. Two have serrations on the blade edges, and they all have some retouch. One Alba is from Burial 6, and two are from Burial 10.

Ten of the Bonham points are complete, and 1 is missing part of the stem. Those that 


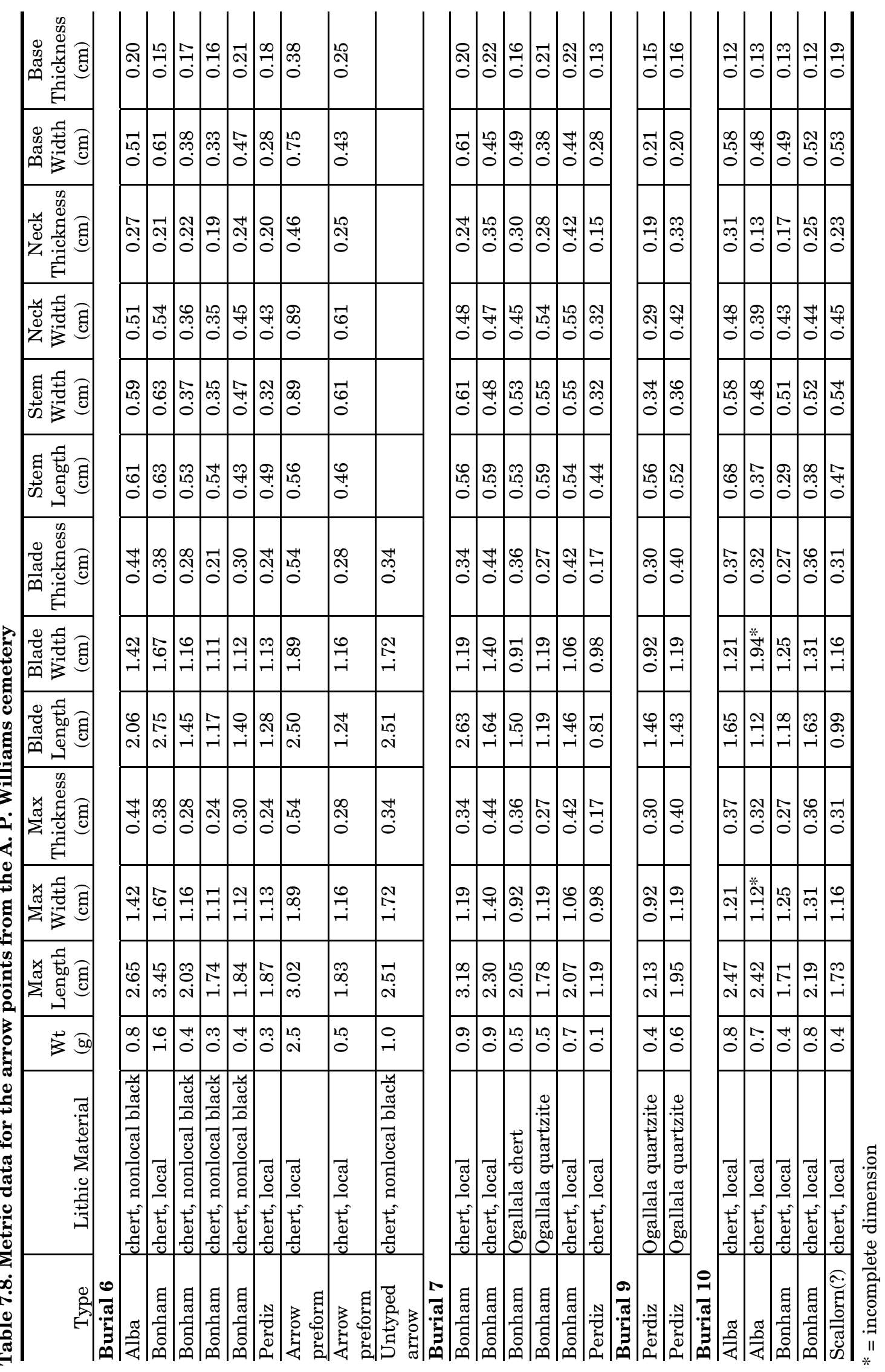


are complete have straight to expanding stems and straight to rounded bases. All have barbs. Seven are made of local chert, 1 is of Ogallala quartzite, and 3 are of nonlocal black chert. All have some blade serration, and half have some retouch. Four are from Burial 6, 5 are from Burial 7, and 2 are from Burial 10. The Perdiz points have contracting stems that narrow to pointed bases, and the blades are serrated and have barbs. All 4 are complete, and 3 have some reworking. One is from Burial 6, 1 is from Burial 7, and 2 are from Burial 9. The possible Scallorn point is of yellowish brown local chert with pieces of the tip and base missing. It has a straight base, expanding stem, and heavy serration. This specimen is from Burial 10.

The untyped arrow point is probably a Bonham or Alba but is missing the stem, making type association impossible. It has heavy blade serration and is from Burial 6. Also from Burial 6 are two preforms, both complete and made on flake blanks. One is of local dark brown and gray chert with a rounded base and an expanding stem. It has serration on one blade edge and cortex on one face. The other is of local dark brown chert with an expanding stem and irregular broken base. The blade has some serration and some reworking.

\section{RELATIONSHIPS TO THE GEORGE RICHEY, WILLIAM FORD, AND JAMES RICHEY SITES}

Although there is no particular reason to think that the people buried at the Thomas B. Caldwell and A. P. Williams cemeteries actually lived at the George Richey (41TT851), William Ford (41TT852), and James Richey (41TT853) sites, there are reasons to think that all of these sites were created by a single group of Caddo people. The evidence for this is based on geography, chronology, and decorations on pottery. A sixth site, the Duncan Anderson site (41TT18), is added to this discussion because it is a cemetery much like Caldwell and Williams and is close by; Appendix $\mathrm{K}$ describes some of the materials from 41TT18.

\section{Geography}

The geographical evidence that these three cemeteries and three residential sites are closely associated consists of the fact that all are near one another within the middle Tankersley Creek drainage (Figure 7.22). All but A. P. Williams are on the main stem of Tankersley Creek, with the Duncan Anderson site at the north end on the west bank, the William Ford site ca. $1.3 \mathrm{~km}$ to the southeast on the east bank, the James Richey site ca. $0.4 \mathrm{~km}$ farther to the south, and the George Richey site ca. $0.6 \mathrm{~km}$ beyond James Richey to the south-southeast. The Thomas B. Caldwell cemetery, also on the east side of the creek, is $0.9 \mathrm{~km}$ south-southeast of the George Richey site. A. P. Williams is on Dragoo Creek, a tributary of Tankersley Creek, $1.3 \mathrm{~km}$ due west of the William Ford site and $1.2 \mathrm{~km}$ southwest of the Duncan Anderson site.

\section{Chronology}

The chronological evidence for association starts with the radiocarbon dates obtained from the George Richey, William Ford, and James Richey sites. As discussed in Chapters 4-6, the dates indicate a primary residential occupation between A.D. 1250 and 1325 at George Richey; primary and secondary residential occupations at 1425-1500 and 1650-1700, respectively, at William Ford; and a primary residential occupation between 1400 and 1500 at James Richey (Figure 7.23). All three sites also have other minor, probably nonresidential (or maybe very short-term residential), Middle-Late Caddo components dating to the mid 1100 s-mid 1200s (George Richey and William Ford), 1300s (William Ford), early 1400s (George Richey), 1500s (George Richey, William Ford, and maybe James Richey), and perhaps the 1600s (James Richey). Omitted from this list are components pre- and postdating the Middle-Late Caddo period at all three sites, which are indicated by radiocarbon dates or diagnostic artifacts. The radiocarbon dates indicate that William Ford and James Richey are mostly contemporaneous, mostly Late Caddo sites, while George Richey is predominantly earlier, i.e., Middle Caddo. George Richey clearly continued to be used during the Late Caddo period, though, and its many similarities to the other sites indicate that the farmstead there was an early residential component of the Tankersley Creek community.

There are no radiocarbon dates from the three cemetery sites to correlate with those from the three residential sites, but the diagnostic artifacts certainly are similar, implying general 


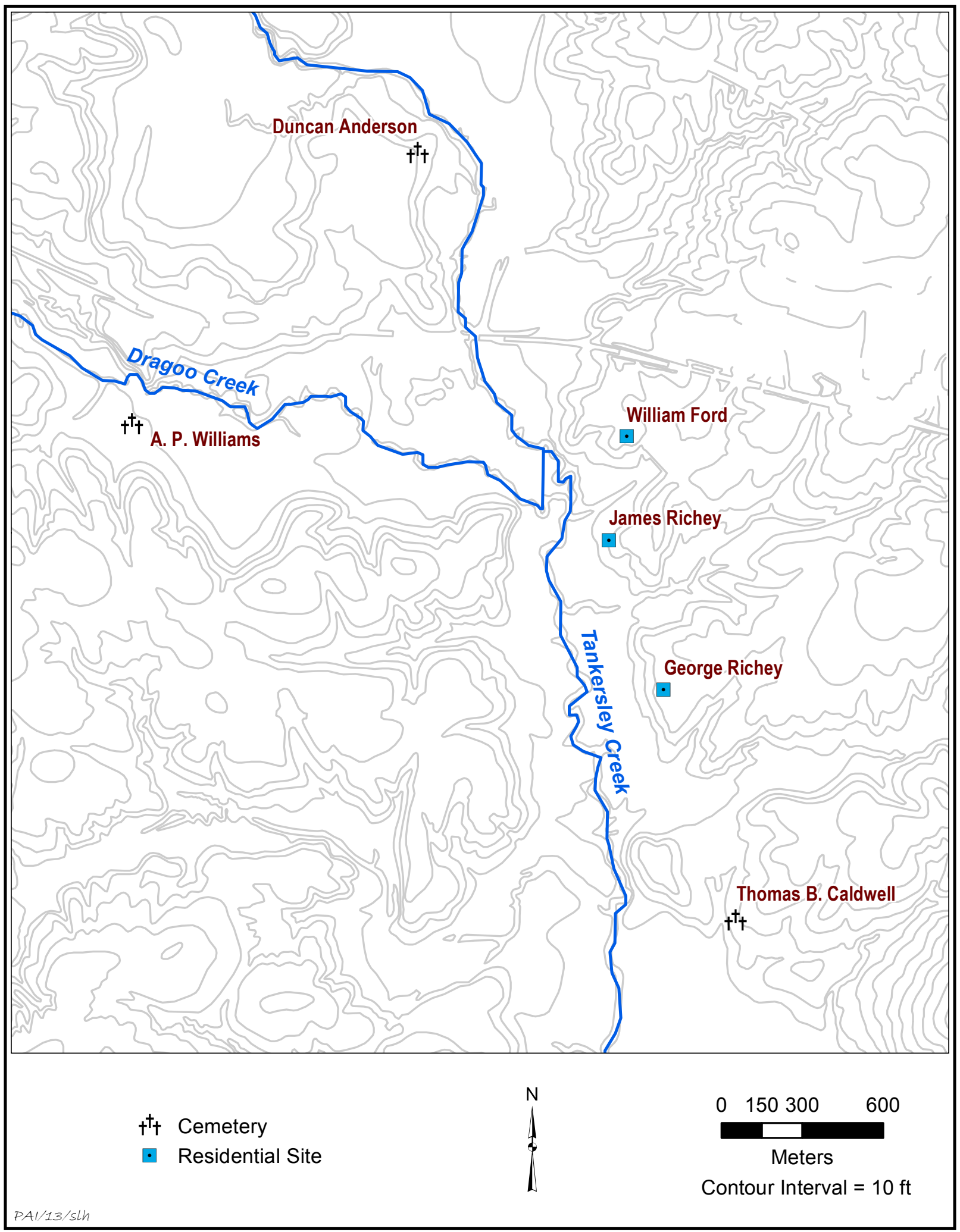

Figure 7.22. Map showing the locations of residential sites George Richey (41TT851), William Ford (41TT852), and James Richey (41TT853) and the cemeteries at Thomas B. Caldwell (41TT6/846), A. P. Williams (41TT4), and Duncan Anderson (41TT18). 


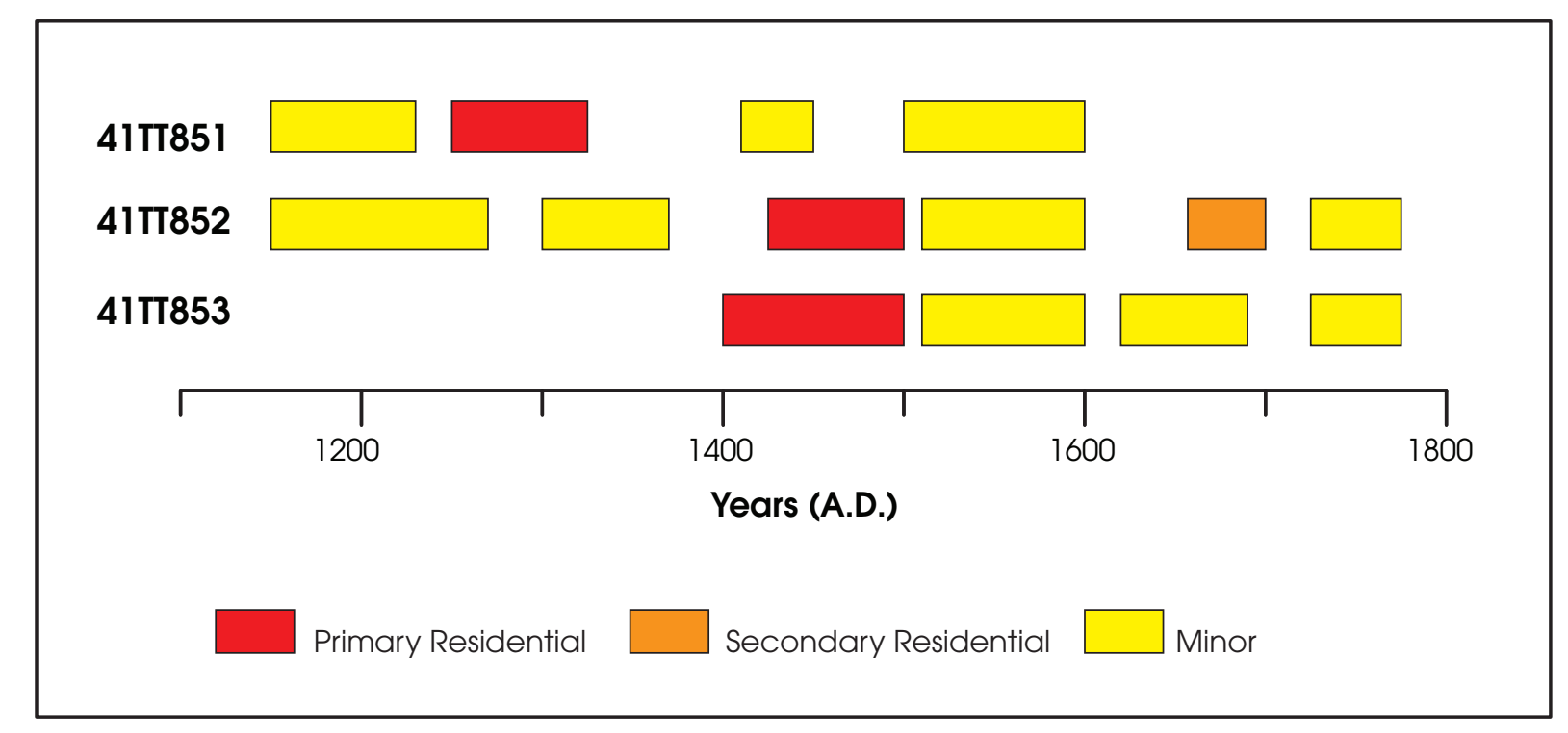

Figure 7.23. Graphs showing Middle-Late Caddo component chronologies indicated by radiocarbon dates from the George Richey (41TT851), William Ford (41TT852), and James Richey (41TT853) sites.

contemporaneity. Most of the arrow points from the Caldwell cemetery are stemless Mauds or Talcos, with Bassett being the only other type represented. Together, these styles make up 38 percent of the typed arrows from George Richey, 47 percent of those from William Ford, and 25 percent of those from James Richey (with the latter yielding only 4 typed points, though, the sample is too small to be very meaningful). Most of the arrow points from the Williams cemetery are of styles typically considered earlier (14 of the 19, or 74 percent, are Bonham or Alba), although 21 percent are Perdiz and could be equivalent temporally to Bassett and the stemless styles. Bonham and Alba points make up 50 percent of the arrows from George Richey but are scarcely represented at William Ford (7 percent) and absent at James Richey. Hence, the arrow points are consistent with a sequence of Middle-Late Caddo components at both kinds of sites, with George Richey and perhaps the Williams cemetery being at least in part earlier than the William Ford and James Richey sites and the Caldwell cemetery. The cemetery at the Duncan Anderson site cannot be evaluated in this regard because no arrow points were recovered.
The ceramics also indicate contemporaneity between the sites, albeit over a lengthy span of time. Between 38 and 59 percent of the vessel assemblage from each cemetery can be typed, with Ripley Engraved accounting for 69-81 percent of the typed vessels at all three (Table 7.9). Other fine wares are small numbers of Wilder Engraved bottles from the Caldwell and Williams cemeteries and a single Johns Engraved bowl from the former. All three have a range of utility wares, no one type dominating. Bullard Brushed and Pease Brushed-Incised are present at all three cemeteries. Maydelle Incised and La Rue Neck Banded occur at A. P. Williams and Duncan Anderson. Killough Pinched and Belcher Ridged jars came from Duncan Anderson, and a small beaker that might be Killough Pinched was found at Caldwell, though it was not so typed because of its uncharacteristic vessel form. A particular style of untyped decorated jar is present at all three cemeteries. It is a tall jar with a flaring rim with three or more horizontal lines of punctations between the lip and neck. Often, there is one or more horizontal incised lines between the lines of punctations and two or more sets of appliquéd nodes on the rim. The fact that the vessel body is not brushed is what 
distinguishes it from Bullard Brushed. Perttula et al. (2012:273, 324) classify two of these from Duncan Anderson as Mockingbird Punctated. The Caldwell and Williams cemeteries yielded similar vessels, though they were not typed.

These same styles dominate the small samples of typed ceramics from the residential occupations at the George Richey, William Ford, and James Richey sites, although percentages vary between them and the cemetery sites because they represent different kinds of contexts (see Table 7.9). Ripley Engraved is the most common fine ware type, with a single example of Wilder Engraved from James Richey. For utility wares, Maydelle Incised and Harleton Appliqué are represented at all three, and Pease Brushed-Incised, La Rue Neck Banded, Killough Pinched, and Bullard Brushed are present at both William Ford and James Richey. Also represented at all three sites are jar rims decorated with two or more horizontal rows of stick punctations, which probably are related to Perttula's (2005:277278) Mockingbird Punctated but that are hard to type because body treatment usually cannot be determined on sherds. William Ford yielded two sherds that could be typed as Belcher Ridged.

On a nontypological level, the fact that all six sites have some amounts of brushed pottery indicates some degree of contemporaneity. There is some variability, however. Most notable are the low frequencies of brushing among the decorated sherds from George Richey (12 percent) compared to those from William Ford and James Richey (34 and 48 percent) and among the decorated vessels from Duncan Anderson (9 percent) compared to those from Caldwell and Williams (17 and 14 percent). The former is consistent with the radiocarbon evidence that the primary occupation at George Richey predates those at the other two residential sites. It is hard to see the latter (the low incidence of brushing at Duncan Anderson) as a function of chronology, though, given the typological similarities between the three cemetery collections, which also argue against the Williams cemetery being significantly earlier than Caldwell, as suggested by the different arrow point styles.

\section{Motifs and Elements on Decorated Pottery}

Given the predominance of a single fine ware type, Ripley Engraved, at all three cemeteries, it is reasonable to ask whether there is any variability between them in how that type is expressed that relates to how the sites are associated. Table 7.10 shows that the main motif on the Ripley bowls from all three sites is the slanted scroll, occurring on 52-53 percent

Table 7.9. Middle-Late Caddo ceramic types from the cemeteries at Thomas B. Caldwell, A. P. Williams, and Duncan Anderson and from residential sites George Richey, William Ford, and James Richey

\begin{tabular}{|c|c|c|c|c|c|c|c|c|c|c|c|c|}
\hline \multirow[t]{2}{*}{ Ceramic Type } & \multicolumn{2}{|c|}{$\begin{array}{c}\text { Thomas B. } \\
\text { Caldwell }\end{array}$} & \multicolumn{2}{|c|}{$\begin{array}{c}\text { A. P. } \\
\text { Williams }\end{array}$} & \multicolumn{2}{|c|}{$\begin{array}{c}\text { Duncan } \\
\text { Anderson }\end{array}$} & \multicolumn{2}{|c|}{$\begin{array}{l}\text { George } \\
\text { Richey }\end{array}$} & \multicolumn{2}{|c|}{$\begin{array}{l}\text { William } \\
\text { Ford }\end{array}$} & \multicolumn{2}{|c|}{$\begin{array}{l}\text { James } \\
\text { Richey }\end{array}$} \\
\hline & No. & $\%$ & No. & $\%$ & No. & $\%$ & No. & $\%$ & No. & $\%$ & No. & $\%$ \\
\hline Ripley Engraved & 41 & 76 & 39 & 81 & 25 & 69 & 10 & 42 & 17 & 25 & 28 & 32 \\
\hline Wilder Engraved & 4 & 7 & $\overline{1}$ & 2 & 0 & 0 & $\overline{0}$ & 0 & $\overline{0}$ & 0 & 1 & 1 \\
\hline Johns Engraved & 1 & 2 & 0 & 0 & 0 & 0 & 0 & 0 & 0 & 0 & 0 & 0 \\
\hline Maydelle Incised & 0 & 0 & 2 & 4 & 4 & 11 & 5 & 21 & 15 & 22 & 15 & 17 \\
\hline Pease Brushed-Incised & 3 & 6 & 3 & 6 & 1 & 3 & 0 & 0 & 8 & 12 & 14 & 16 \\
\hline Harleton Appliqué & 1 & 2 & 0 & 0 & 0 & 0 & 9 & 38 & 13 & 19 & 2 & 2 \\
\hline Killough Pinched & 0 & 0 & 0 & 0 & 1 & 3 & 0 & 0 & 3 & 4 & 15 & 17 \\
\hline La Rue Neck Banded & 0 & 0 & 1 & 2 & 1 & 3 & 0 & 0 & 2 & 3 & 4 & 5 \\
\hline Belcher Ridged & 0 & 0 & 0 & 0 & 1 & 3 & 0 & 0 & 2 & 3 & 0 & 0 \\
\hline Bullard Brushed & 4 & 7 & 2 & 4 & 1 & 3 & 0 & 0 & 7 & 10 & 9 & 10 \\
\hline Mockingbird Punctated & $\mathrm{X}$ & - & $\mathrm{X}$ & - & 2 & 6 & $\mathrm{X}$ & - & $\mathrm{X}$ & - & $\mathrm{X}$ & - \\
\hline Totals & 54 & & 48 & & 36 & & 24 & & 67 & & 88 & \\
\hline
\end{tabular}

$\mathrm{X}=$ Ceramics similar to Mockingbird Punctated are present but not formally identified as such. 
Table 7.10. Motifs and primary elements on Ripley Engraved bowls from the Thomas B. Caldwell, A. P. Williams, and Duncan Anderson sites

\begin{tabular}{|c|c|c|c|c|c|c|}
\hline & \multicolumn{2}{|c|}{ Thomas B. Caldwell } & \multicolumn{2}{|c|}{ A. P. Williams } & \multicolumn{2}{|c|}{ Duncan Anderson } \\
\hline & No. & $\%$ & No. & $\%$ & No. & $\%$ \\
\hline \multicolumn{7}{|l|}{ Motif: } \\
\hline Slanted scroll & 18 & 53 & 16 & 52 & 12 & 52 \\
\hline Straight scroll & 10 & 29 & 2 & 6 & 5 & 22 \\
\hline Opposed scroll & 3 & 9 & 7 & 23 & 0 & 0 \\
\hline Band of elements & 3 & 9 & 6 & 19 & 6 & 26 \\
\hline Totals & 34 & & 31 & & 23 & \\
\hline \multicolumn{7}{|l|}{ Primary Element: } \\
\hline Circle & 0 & 0 & 3 & 8 & 0 & 0 \\
\hline Hatched circle & 0 & 0 & 3 & 8 & 2 & 11 \\
\hline Open circle & 9 & 29 & 5 & 14 & 4 & 21 \\
\hline Open half circle & 4 & 13 & 0 & 0 & 0 & 0 \\
\hline Half circle & 2 & 6 & 4 & 11 & 0 & 0 \\
\hline Hatched half circle & 0 & 0 & 2 & 6 & 0 & 0 \\
\hline Rayed circle & 0 & 0 & 2 & 6 & 0 & 0 \\
\hline Rayed half circle & 0 & 0 & 3 & 8 & 0 & 0 \\
\hline Cross-in-circle & 4 & 13 & 1 & 3 & 1 & 5 \\
\hline Cross-in-diamond & 3 & 9 & 0 & 0 & 0 & 0 \\
\hline Diamond & 1 & 3 & 1 & 3 & 0 & 0 \\
\hline Bar & 5 & 16 & 3 & 8 & 2 & 11 \\
\hline Sinuous Scroll & 0 & 0 & 1 & 3 & 0 & 0 \\
\hline $\mathrm{SZ}$ & 3 & 10 & 3 & 8 & 2 & 11 \\
\hline Chevron & 1 & 9 & 1 & 3 & 3 & 16 \\
\hline Barred Oval & 0 & 0 & 2 & 6 & 0 & 0 \\
\hline Curl & 0 & 0 & 1 & 3 & 1 & 5 \\
\hline Crosshatched zone & 0 & 0 & 1 & 3 & 3 & 16 \\
\hline Diamond-in-circle & 0 & 0 & 0 & 0 & 1 & 5 \\
\hline Totals & 32 & & 36 & & 19 & \\
\hline
\end{tabular}

*Totals for primary element do not match those for motif because some motifs have multiple primary elements, some have one, and some have none.

of the vessels. Straight scrolls are moderately prominent at Caldwell and Duncan Anderson, with the latter also having moderate numbers of bowls with the band of elements motif. Band of elements and opposed scrolls are moderately prominent at A. P. Williams. So, what variability there is between sites is in the relative frequencies of the less-prominent motifs.

The breakdown of the primary elements associated with these scroll and band motifs, i.e. those found between the scroll arms or as the main repeating or alternating elements in band motifs, also shows some similarities and difference between sites (see Table 7.10). Five primary elements-open circle, cross-incircle, bar, curl, SZ, and chevron-are present at all three sites, accounting for 69 (Caldwell), 36 (Williams), and 63 (Anderson) percent of primary elements. Another nine elements are restricted to single sites: (1) cross-in-diamond, accounting for 9 percent of the Caldwell assemblage; (2) circle, hatched half circle, rayed circle, rayed half circle, sinuous scroll, and barred oval, accounting for 36 percent of the Williams assemblage; and (3) diamond-in-circle, accounting for 5 percent of the Anderson assemblage. Two 
elements (half circle and diamond) occur only at Caldwell and Williams, and three elements (hatched circle, curl, and crosshatched zone) occur only at Williams and Anderson. No primary elements are restricted to Caldwell and Anderson. At all three cemeteries, there also are Ripley bowls with scrolls that lack primary elements between the scroll arms. This configuration is most prominent at the Caldwell site, where it occurs on 29 percent of the Ripley bowls, and least common at the A. P. Williams site (13 percent); Duncan Anderson has a moderate value ( 22 percent).

In sum, the overall similarities in the motifs used and their structure suggest that the Caddo potters who made these vessels were participants in a shared ceramic tradition expressed within a limited time span. Hence, these cemeteries apparently were created at roughly the same time by related peoples. The assemblages are not identical, however, and the differences between them suggest that they represent the work of particular, possibly family, potters operating within a larger community.

Expanding this discussion to include the residential sites is hard because there we are dealing mostly with sherds, only small numbers of which display recognizable Ripley Engraved motifs or elements. For example, a single bowl rim from George Richey has a distinctive diamond-in-circle primary element, although the associated motif cannot be determined; a single example of this element also occurs at Duncan Anderson. The single complete Ripley Engraved bowl from William Ford has a slanted scroll with an open circle primary element alternating with no primary element, a configuration also seen at the Caldwell cemetery. This small bowl also has a single engraved line following the carination on the interior of the vessel; six Ripley bowls from the Caldwell cemetery have a similar interior line. Other carinated bowl sherds from William Ford have curled scroll ends that appear to be configured with no primary element; similar curled ends were noted on bowls from all three cemeteries, though they are mainly at Caldwell. At least four sherds and one small carinated bowl from James Richey have slanted scrolls with no primary element, a configuration common at both the Caldwell and Williams cemeteries. Also present at James Richey are at least two bowl sherds with rayed circle primary elements, which also occur at the Williams cemetery, and a single rim with decoration resembling a straight scroll with a hatched primary element, which is also known from Duncan Anderson.

These correspondences are few in number, but they indicate that the Ripley Engraved bowls used at the three habitation sites are similar to those found at all three Tankersley Creek cemeteries. These correspondences link the individuals who resided at these sites to those who were buried short distances away, supporting the idea that all of the sites relate to a single local community.

\section{TITUS PHASE MORTUARY BEHAVIOR}

Based on the information Perttula (2005:371376) presents in his report on the Pilgrim's Pride site, plus that obtained more recently from a few other sites, there are at least 146 known places in the Cypress Creek, Sabine River, and Sulphur River basins where Titus phase peoples buried their dead (excludes the few isolated burials at the William Ford and James Richey sites). These 146 sites reportedly contain the remains of more than 3,000 people. Despite this wealth of information, there are some significant gaps in our understanding of Titus mortuary behavior. The main reason for this is that only a handful of cemeteries have been excavated and documented completely and carefully enough to provide a clear picture of the mortuary practices they represent. Many of the burial sites, including the largest and most complex ones, are known only from looters' reports or excavations in the 1930s; most of these are inadequately documented at best. For 8 sites, all we know is that unstated numbers of graves supposedly were present. Almost a third of the sites with burials $(n=45)$ have fewer than 4 graves and may not actually be cemeteries, consisting instead of isolated graves in and around residential areas (this is based solely on the number of graves and hence may erroneously include small sections of partially excavated cemeteries; on the other hand, just because a site had more than 3 burials does not necessarily mean it contained a cemetery, and any such sites are excluded from the count above).

Two types of Titus phase cemeteries have been identified. They are the family cemetery, typically containing 10-40 individuals interred near a habitation area, and the community 
cemetery, which has numerous interments (70-200 or more) with generally limited evidence of habitation in the immediate area of the cemetery. Individuals buried in family cemeteries usually show little distinction in burial offerings that may indicate differences in status (Perttula 2005b:383), and Thurmond (1990:235-236) notes that offering associations in family cemeteries appear to be determined by age and sex rather than status.

The 13 known community cemeteries apparently were used by multiple villages and likely represent "broad communitywide participation in ceremonial and mortuary rituals" (Perttula and Sherman 2009:394). It has been suggested that community cemeteries more often contain burials of high-status people than family cemeteries, with such graves identified based on one or more of the following characteristics (Perttula et al. 1998:381): (1) interment in shaft tombs or earthen mounds; (2) graves with multiple bodies; (3) large quantities of diverse grave offerings; and (4) rare kinds of offerings made of exotic materials. Based on these criteria, Perttula (2005:385-386) lists 18 sites with what appear to be notable, presumably high-status burials, most of which were at the community cemetery sites of Pleasure Point, Shelby/Tracy,
H. R. Taylor, Spider Lilly, Tuck Carpenter, and Harold Williams; smaller numbers were at a handful of family cemeteries, including Thomas B. Caldwell, and sites that are hard to classify because they are not well documented.

In a recent analysis comparing what was found at the Pine Tree Mound site in Harrison County with published Titus phase mortuary data, Fields and Gadus (2012:372-377) concluded that identifying status and patterns in status across large areas is a tricky matter, however. For example, they showed that the two small cemeteries at Pine Tree Mound have low average numbers of offerings, measured by both the numbers of ceramic vessels and total numbers of offerings per grave, compared to other Titus phase cemeteries (Table 7.11). On this criterion (mean values), the people buried at Pine Tree would appear to have been of relatively low status, and Titus family and community cemeteries do not look much different from each other. This does not square with other evidence from some of the Pine Tree graves, however, which had multiple high-status markers, including multiple interments, large grave pits, offerings that are both numerous and varied, highly visible offerings made nonlocally of exotic materials, and inclusion of grave furniture in the form of

Table 7.11. Comparison between the Pine Tree Mound site and selected other Titus phase cemetery sites in terms of frequencies of offerings per grave and grave size

\begin{tabular}{|c|c|c|c|c|c|c|c|}
\hline \multirow[t]{2}{*}{ Site } & \multirow[t]{2}{*}{$\begin{array}{c}\text { No. of } \\
\text { Burials }\end{array}$} & \multicolumn{2}{|c|}{$\begin{array}{c}\text { Ceramic Vessels Per } \\
\text { Grave }\end{array}$} & \multicolumn{2}{|c|}{$\begin{array}{c}\text { Total Offerings Per } \\
\text { Grave }\end{array}$} & \multicolumn{2}{|c|}{ Grave Size $\left(\mathrm{m}^{2}\right)$} \\
\hline & & Mean & Range & Mean & Range & Mean & Range \\
\hline \multicolumn{8}{|l|}{ All Graves: } \\
\hline $\begin{array}{l}\text { Titus Phase, Family } \\
\text { Cemeteries }\end{array}$ & 210 & 7.6 & - & 12.2 & - & - & - \\
\hline $\begin{array}{l}\text { Titus Phase, } \\
\text { Community Cemeteries }\end{array}$ & 234 & 8.2 & - & 13.6 & - & - & - \\
\hline Pine Tree Mound, Total & 27 & 5.4 & - & 8.0 & - & - & - \\
\hline \multicolumn{8}{|c|}{ Adult and Adolescent Graves Only: } \\
\hline Tuck Carpenter & 39 & 9.0 & $3-17$ & 15.0 & $6-46$ & 2.0 & $1.3-3.5$ \\
\hline Mockingbird & 9 & 9.1 & $3-16$ & 12.1 & $3-23$ & 2.3 & $1.1-4.8$ \\
\hline Pilgrim's Pride & 11 & 8.5 & $4-13$ & 19.4 & $5-105$ & 2.0 & $1.2-3.8$ \\
\hline Pine Tree Mound, Total & 20 & 6.9 & $2-27$ & 10.5 & $2-37$ & 2.4 & $0.9-4.8$ \\
\hline
\end{tabular}

Note: Titus phase family and community cemetery data are from Perttula and Sherman (2009:394). Family cemeteries are the R. L. Cason, W. A. Ford, Thomas P. Caldwell, Alex Justiss, J. M. Riley, J. E. Galt, Ben McKinney, Goldsmith, B. J. Horton, A. P. Williams, Spoonbill, P. S. Cash, Mattie Gandy, Mockingbird, Joe Justiss, W. O. Reed, Pilgrim's Pride, Harold Nix, Turquoise, Culpepper, and Ear Spool sites. Community cemeteries are the Tuck Carpenter, H. R. Taylor, and W-S sites. 
litters. That discrepancy prompted a harder look at how to define status archeologically.

The lower half of Table 7.11 illustrates an attempt to do that by excluding graves of juveniles to sidestep problems created by variable mixes of adult/adolescent vs. juvenile interments, since the latter tend to be small, have few offerings, and never have markers for high status; focusing on just three of the better-analyzed and reported Titus phase sites, the community cemetery at Tuck Carpenter and the family cemeteries at Mockingbird and Pilgrim's Pride (Perttula 2005; Perttula et al. 1998; Turner 1992), to try to decrease site-averaging effects; and adding grave size as a variable, since as a reflection of energy expenditure it may be a better marker of vertical social position than the number of offerings (Carr 1995:165, 169). With these adjustments, the Pine Tree Mound graves still have fewer vessels and total offerings than the Titus sites, but on average they are larger than the graves at two of the other sites (Tuck Carpenter and Pilgrim's Pride). This could mean that the people buried at Pine Tree were of higher status, or at least comparable in status, to the people interred at those three sites. This apparent comparability presents a problem, though, because Tuck Carpenter, with multiple-individual interments and large numbers of offerings in some graves, is the only one of the three interpreted by the excavators as containing high-status graves. In fact, all three Titus sites have graves that are large enough to have contained multiple individuals, but there is no evidence that the large ones at Mockingbird and Pilgrim's Pride did (neither contained preserved skeletons, though, so we will never be sure).

Focusing on the ranges of these measures rather than the means is instructive. The Pine Tree Mound site has the highest and lowest numbers of ceramic vessels as offerings, with all three other examples having moderate maximum counts. In terms of total offerings, Mockingbird has the lowest maximum, Pine Tree and Tuck Carpenter have moderate values, and Pilgrim's Pride has by far the highest maximum. However, in several cases, these figures are influenced dramatically by high-frequency occurrences of certain kinds of things, such as the 26 arrow points in Feature 8.1091 at Pine Tree, the 84 pieces of lithic debris in two clusters in Feature 504 at Pilgrim's Pride, and the 25 arrow points from Grave 19 and 22 from Grave
23 at Tuck Carpenter. In these cases and others, it is appropriate to question how burial offerings should be quantified. Is a cluster of 26 arrow points probably representing a quiver of arrows best counted as 26 items, or would it be better to consider it a single offering? And of course, this does not even begin to address offerings that are no longer represented in the archeological record because they have decayed away.

Fields and Gadus (2012:372-377) ultimately concluded that it is hard to get at status when using site- or cemetery-wide summary statistics such as these. Instead, this is something that must be determined grave by grave using multiple criteria.

As a follow-up to the Pine Tree Mound site study, we compiled data on 238 burials from 14 Titus phase sites with burials (Table 7.12). These consist of 3 sites with community cemeteries (Tuck Carpenter, H. R. Taylor, and Peanut Patch [also known as Patton]) and 11 sites with family cemeteries or just scattered graves (A. P. Williams, Alex Justiss, Ben McKinney, Ear Spool, J. M. Riley, Joe Justiss, Mockingbird, P. S. Cash, Pilgrim's Pride, Pine Tree Mound, and Thomas B. Caldwell). The data are derived from the following sources: Bell (1981), Davis and Golden (1960), Fields and Gadus (2012), Goldschmidt (1934a, 1934b), Jackson (1930, 1931a, 1931b, 1931c), Jones (n.d.), Perttula (2005), Perttula et al. (1998), Perttula and Sherman (2009), Rogers et al. (2003), and Turner (1992). Eleven of these are scattered along nearly the full southeast-northwest length of the Titus phase heartland, with 2 others being at the Mockingbird and Ear Spool sites just north of the heartland and the final one at the Pine Tree Mound site in the Sabine River basin about $30 \mathrm{~km}$ southeast of the heartland (Figure 7.24). Those closest to the U.S. Highway 271 Mount Pleasant relief route project area are the Thomas B. Caldwell site immediately outside it and the A. P. Williams site on Dragoo Creek just west of it. Site selection was based mainly on the ready availability (in published reports or at TARL) of information on grave size and contents, starting with the list of sites presented by Perttula (2005:371-376). Most of the excluded sites are those known only from looters' accounts or early excavations with inadequate documentation. Even within the better-documented sites included in the compilation, though, some burials and apparent burials were excluded because 


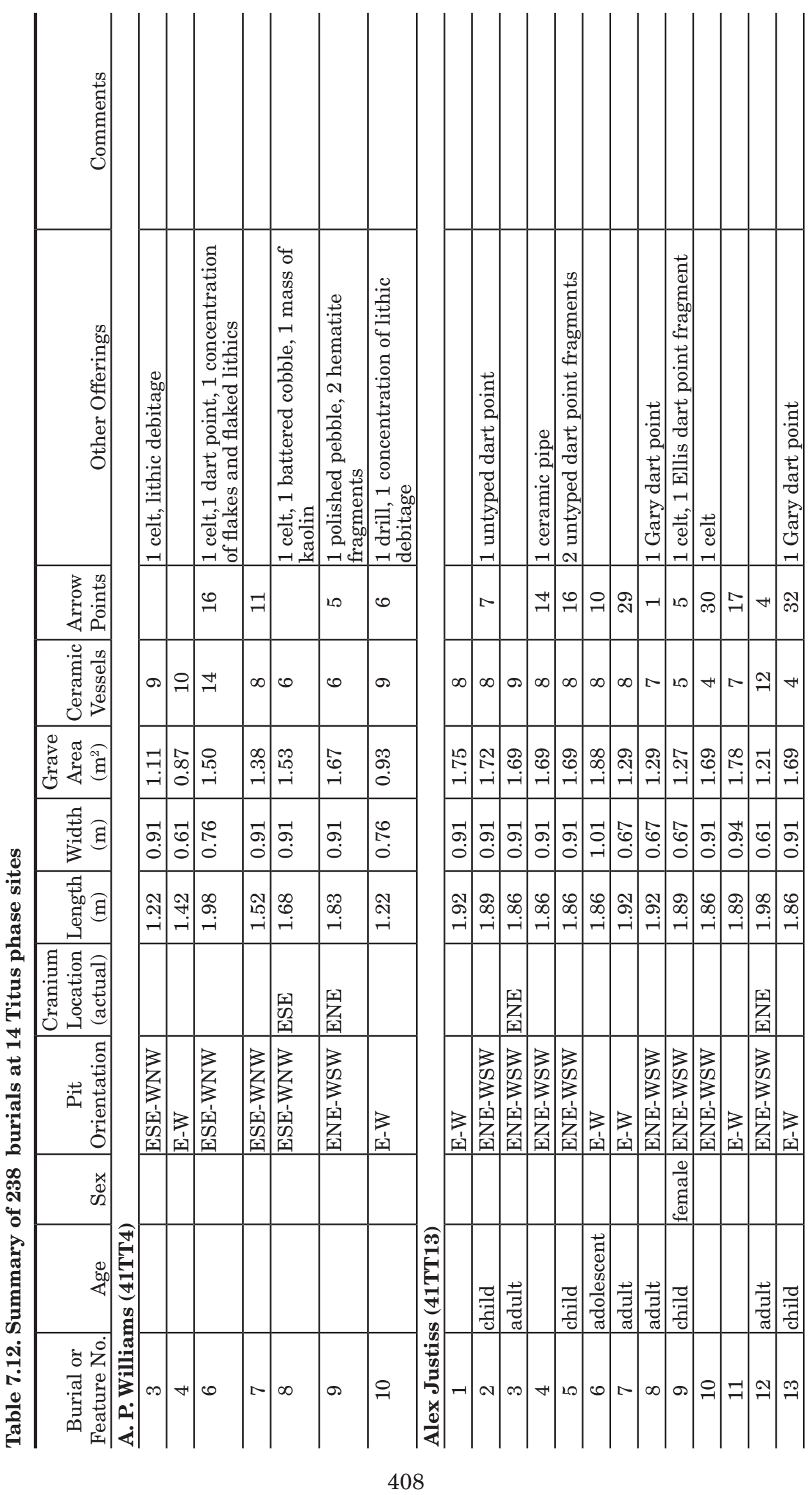


Chapter 7: The Thomas B. Caldwell and A. P. Williams Cemeteries

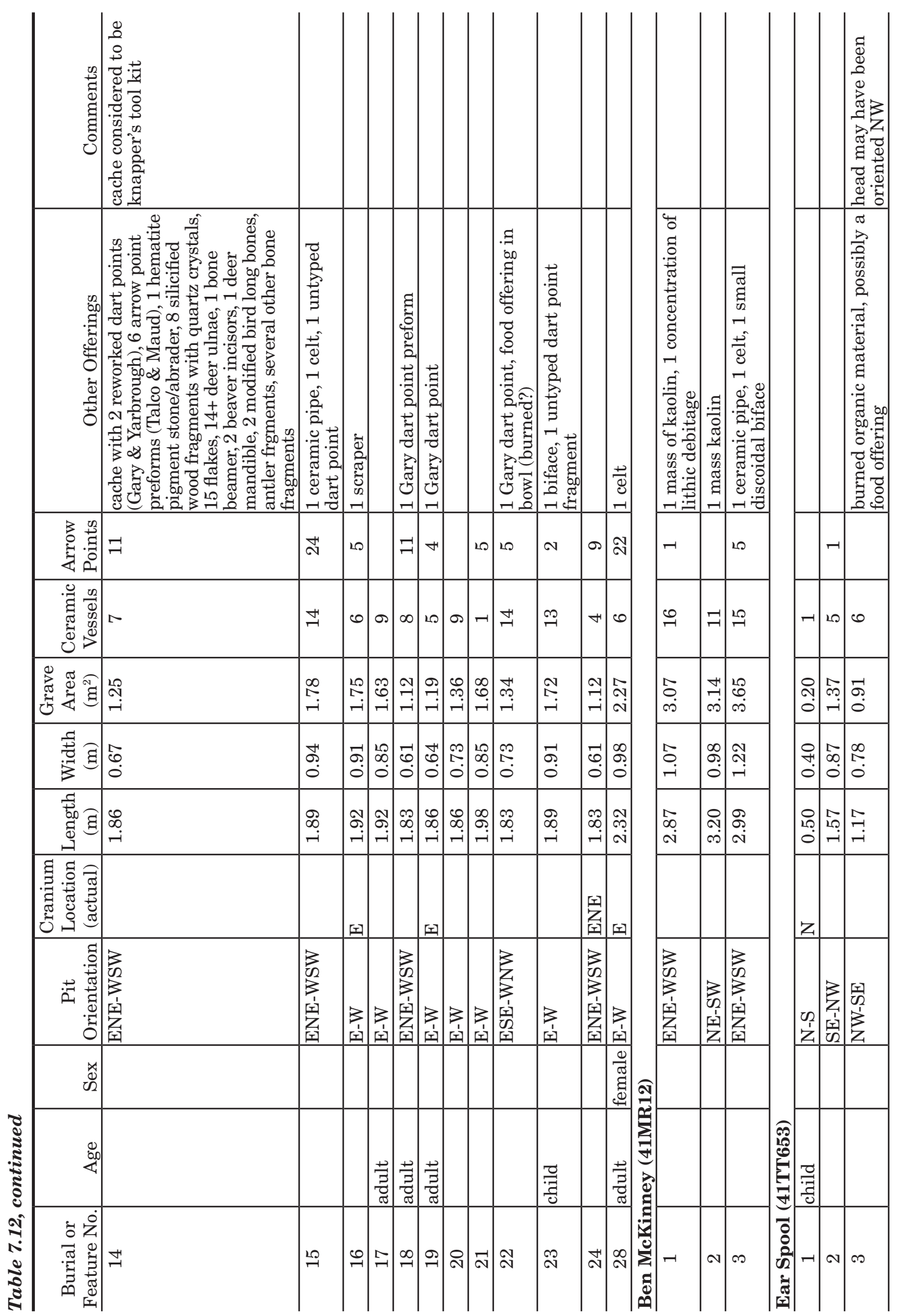




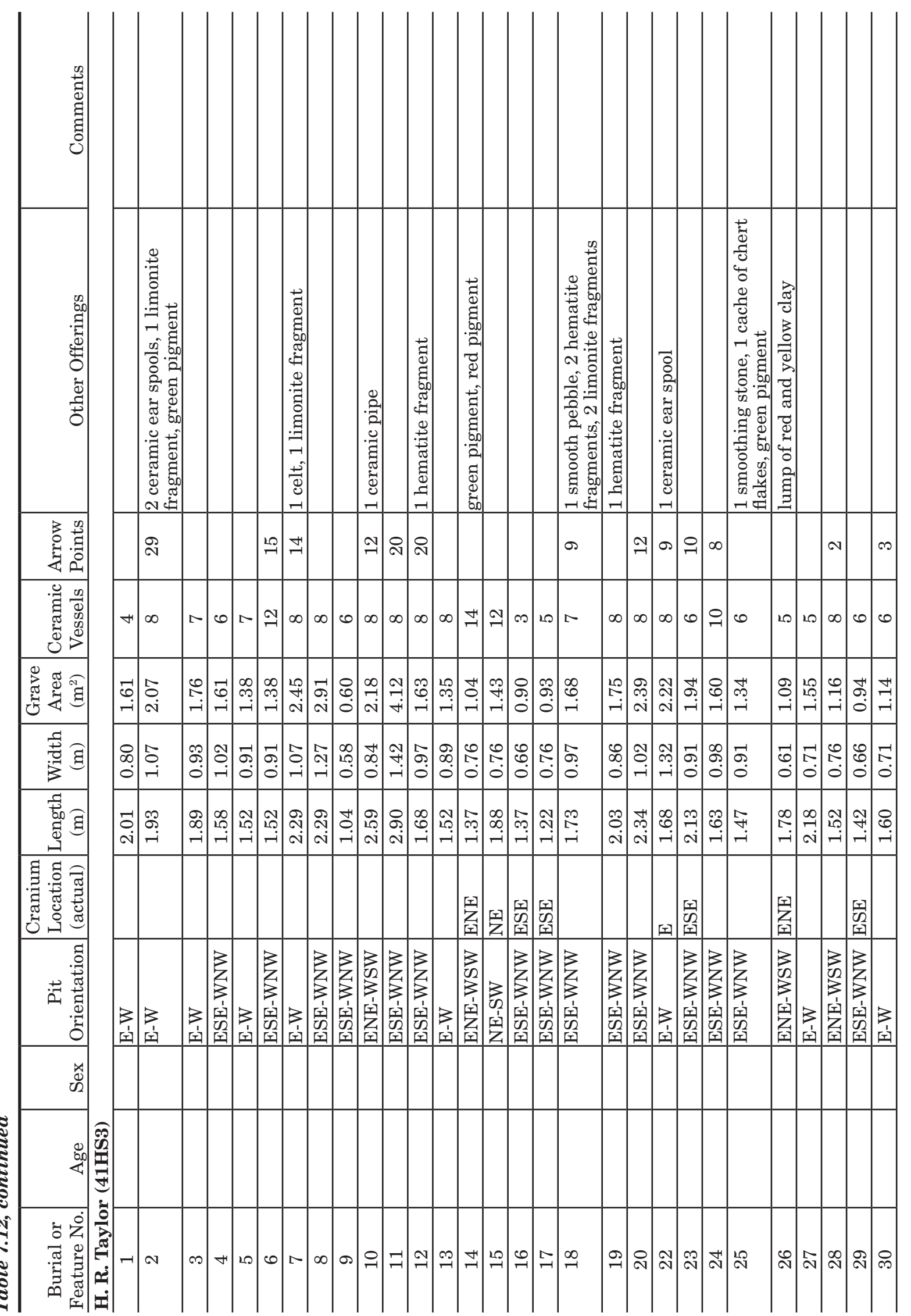


Chapter 7: The Thomas B. Caldwell and A. P. Williams Cemeteries

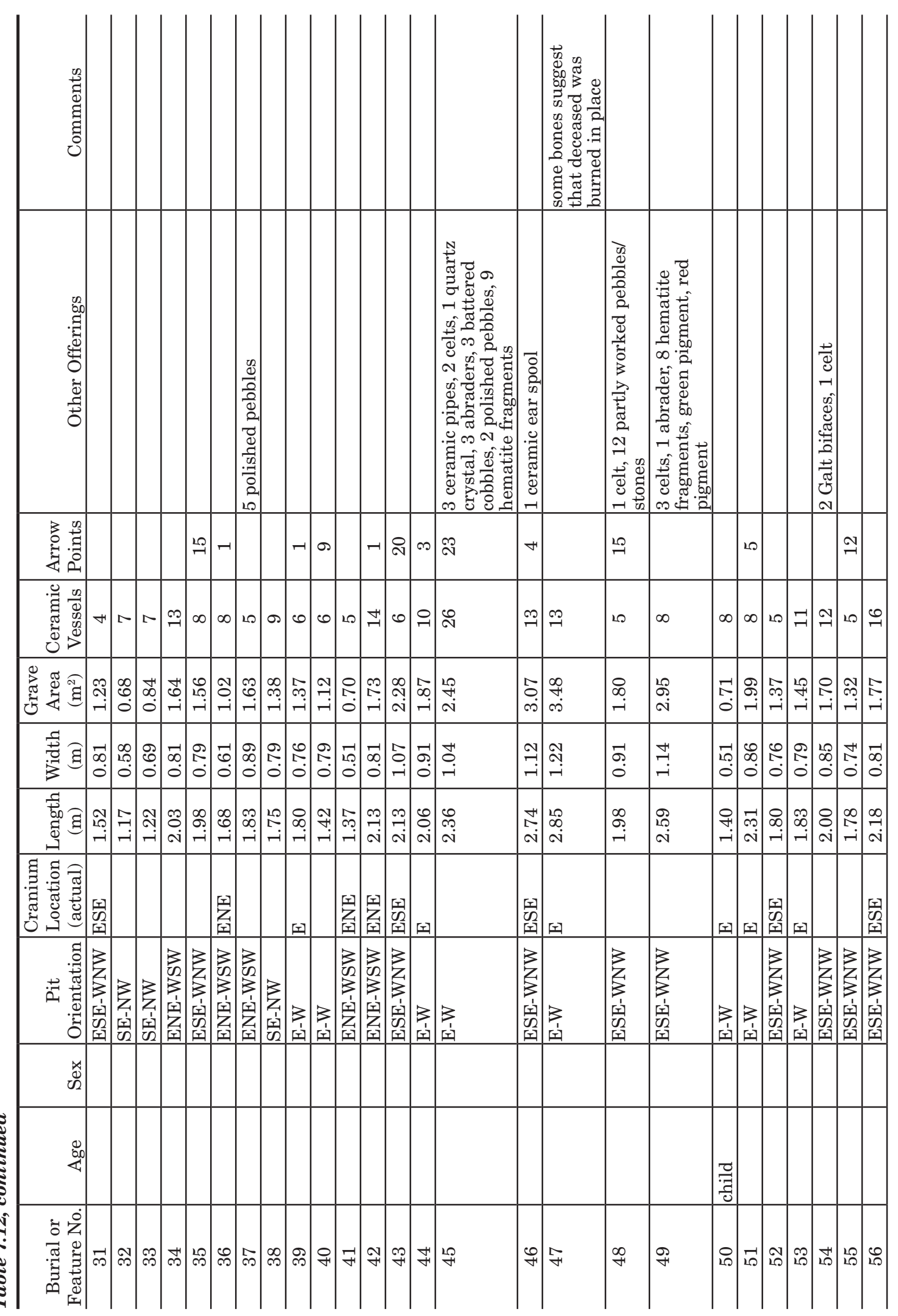




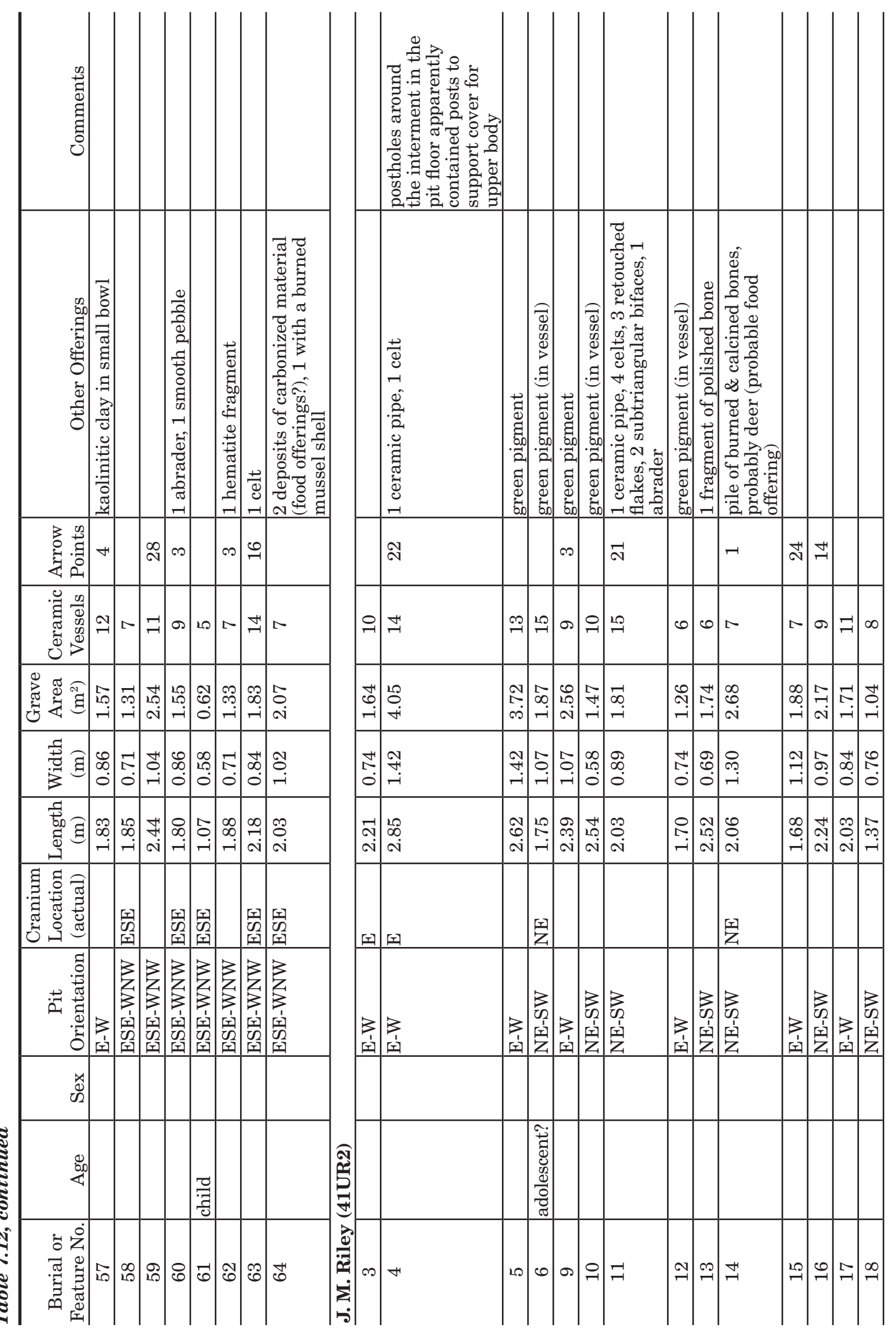


Chapter 7: The Thomas B. Caldwell and A. P. Williams Cemeteries

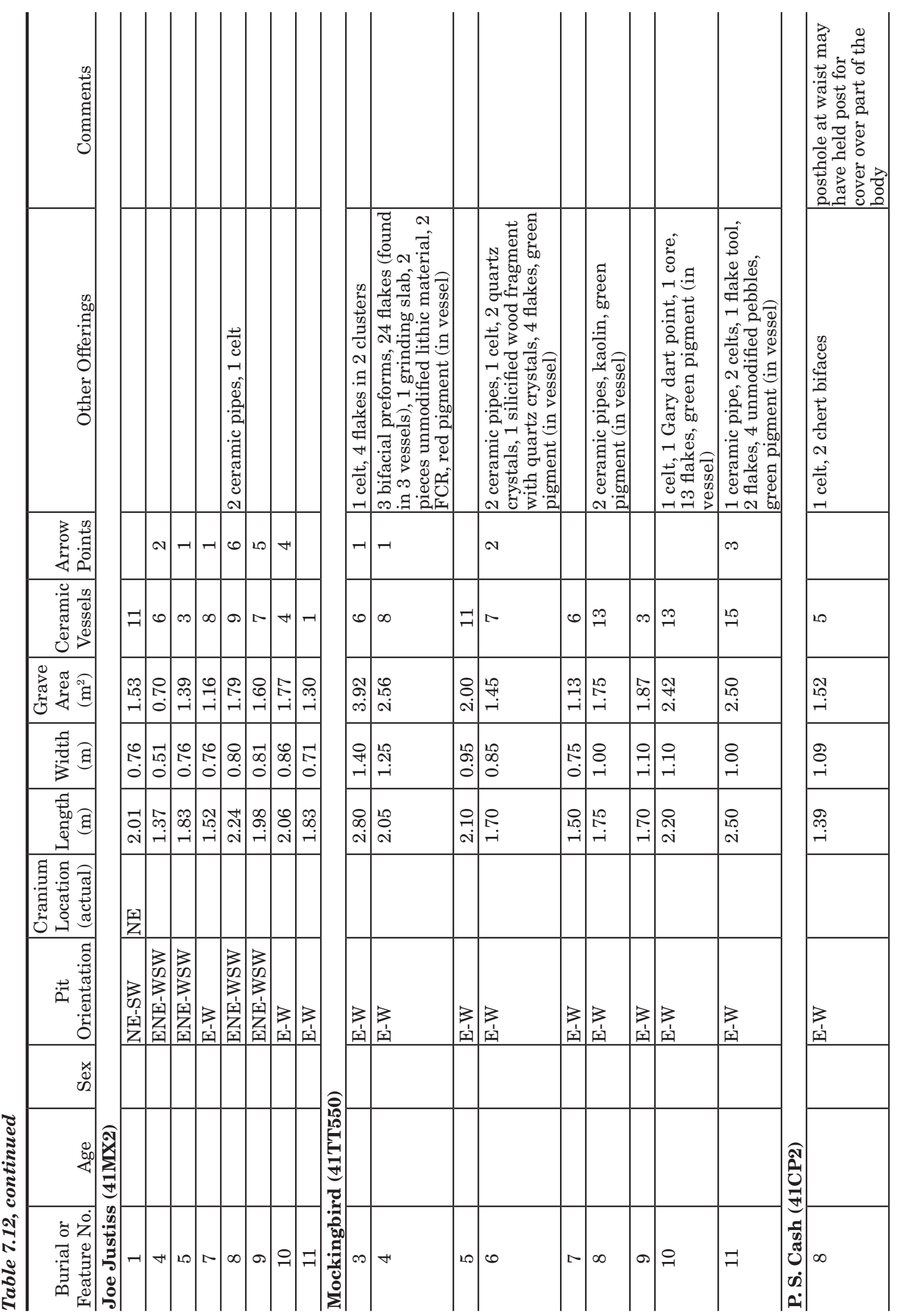




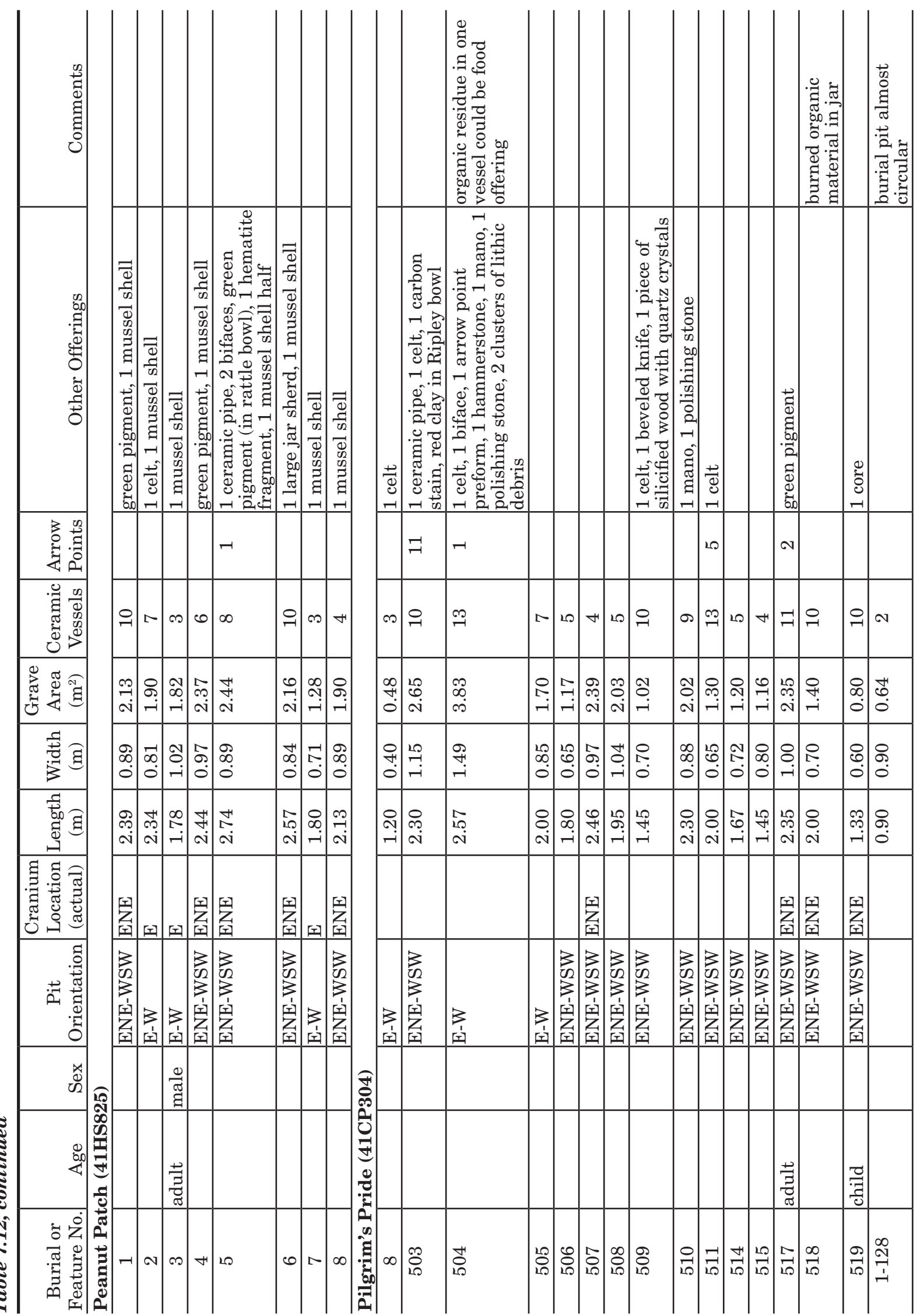


Chapter 7: The Thomas B. Caldwell and A. P. Williams Cemeteries

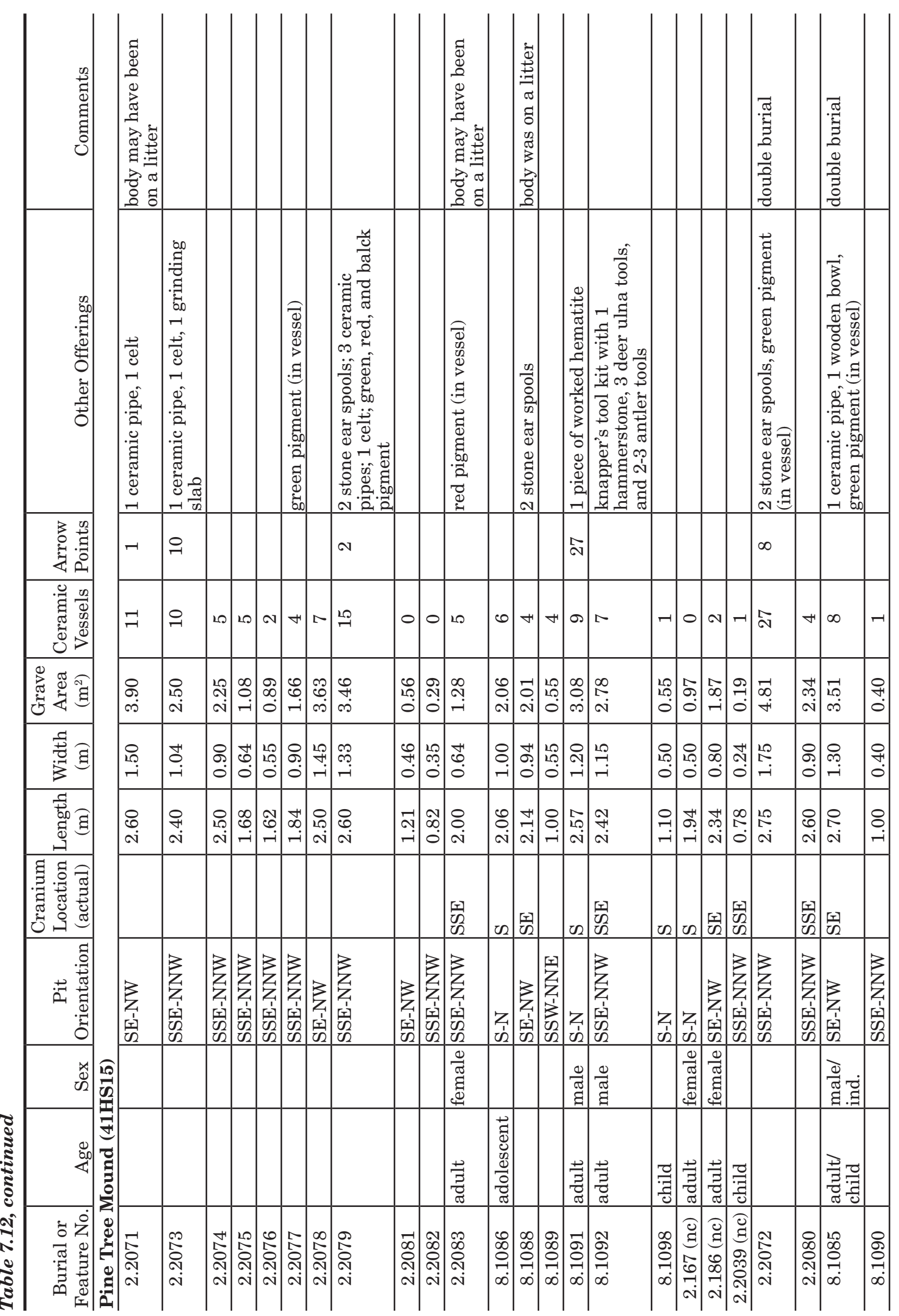




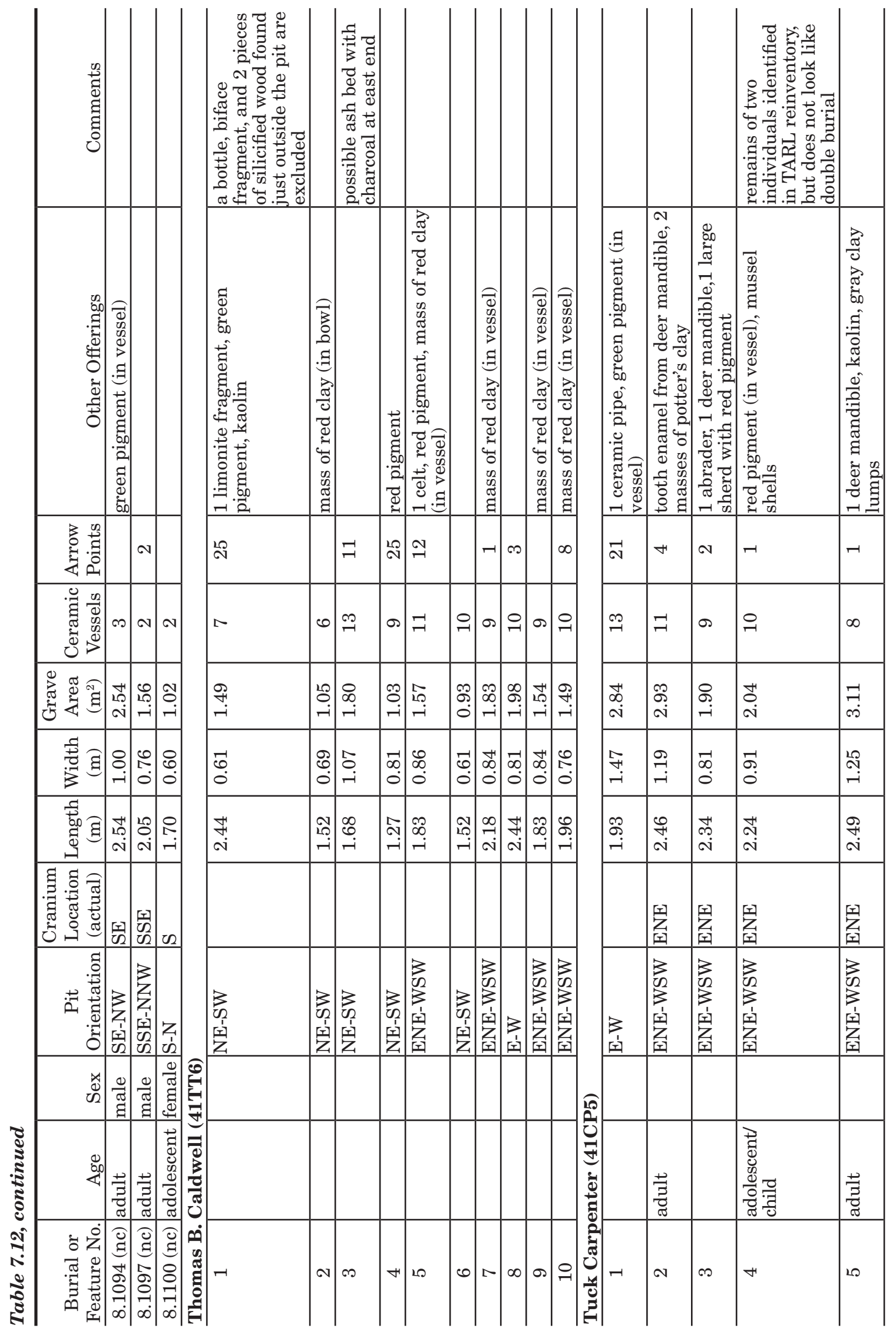




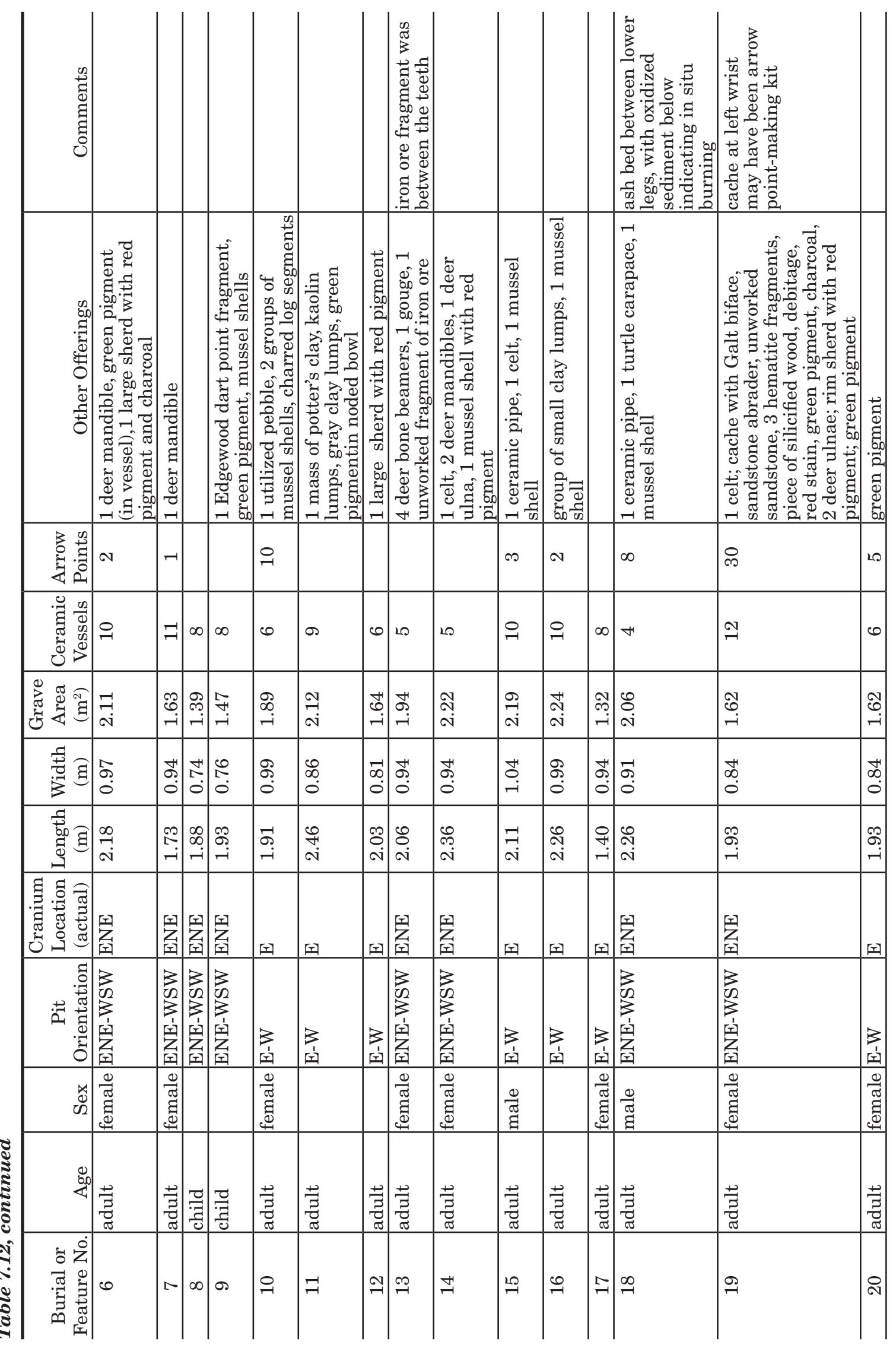




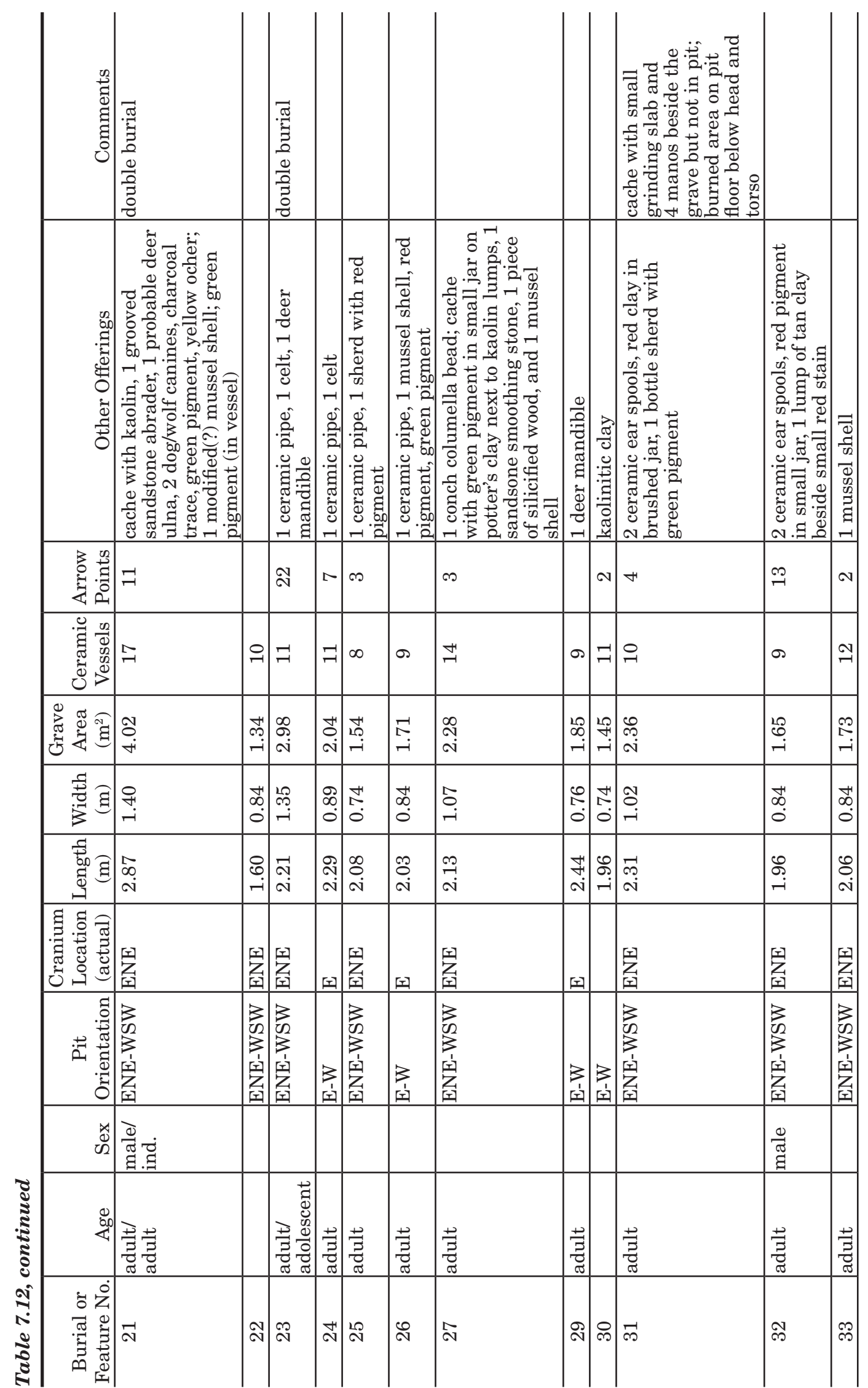


Chapter 7: The Thomas B. Caldwell and A. P. Williams Cemeteries

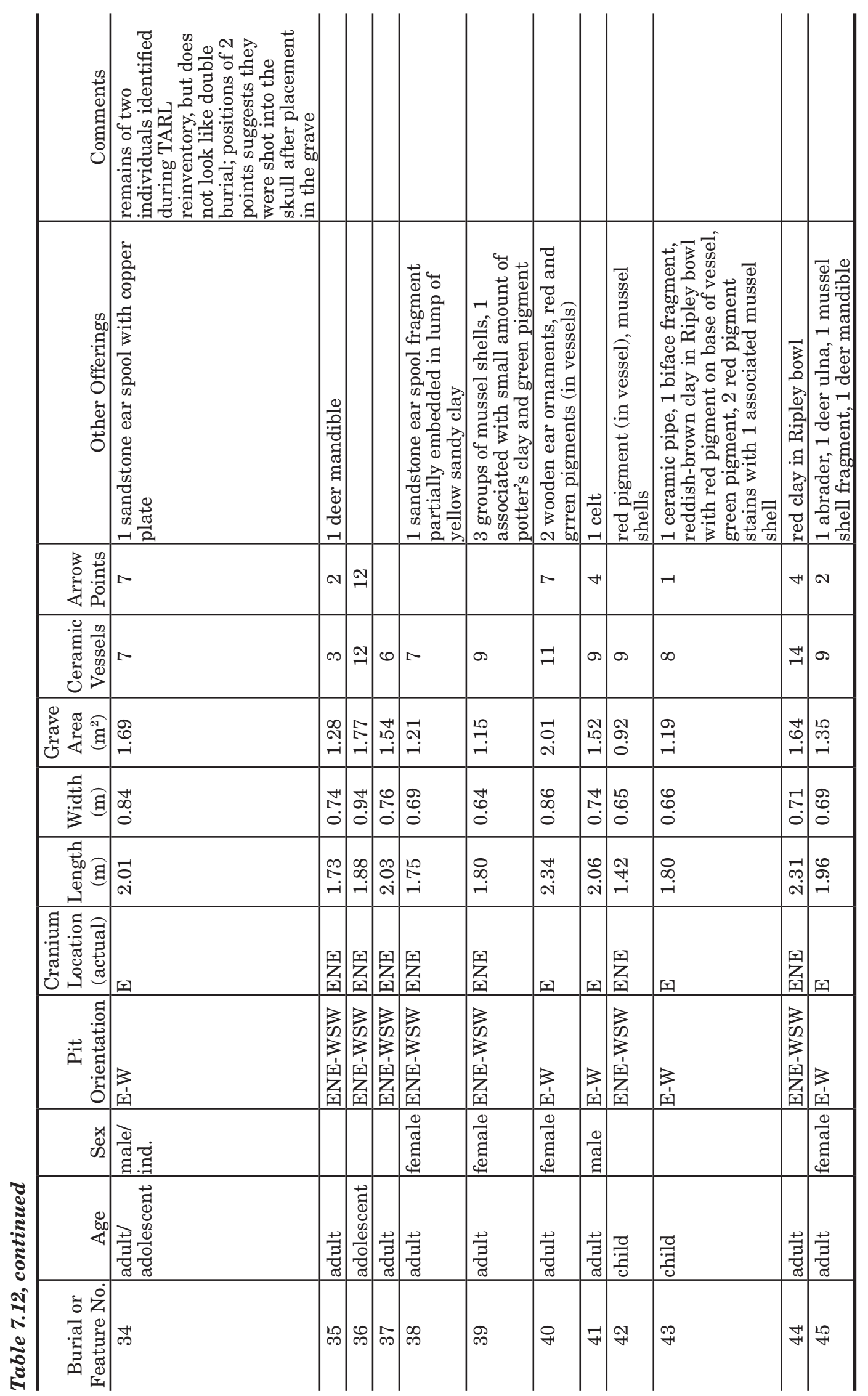




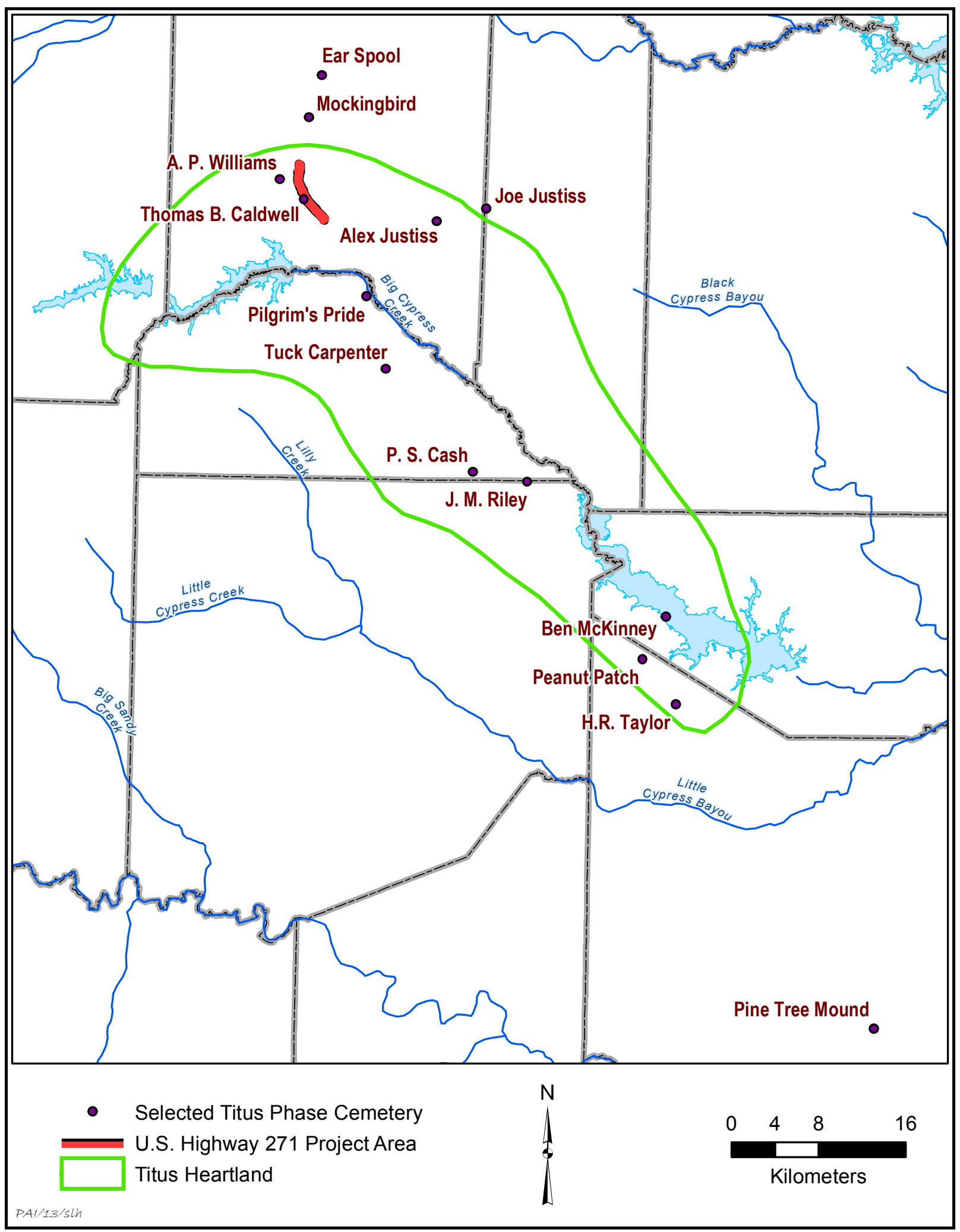

Figure 7.24. Map showing the locations of the Titus phase sites with compiled burial data. 
they were so badly disturbed that it is doubtful that what could be recorded of their dimensions or contents is fully accurate.

Most of the information presented in Table 7.12 is directed at allowing analysis of grave size and contents to get at issues of status and potentially social complexity. Also included is information on the age and sex of the interred where this is known (based on osteological analysis or in-field observation of skeletal remains), grave pit orientation, and body orientation (based on preserved skeletal remains or rarely the position of offerings such as ear spools). That human remains tend to be poorly preserved in northeast Texas sites such as these is attested to by the fact that over half the graves $(\mathrm{n}=129)$ lack direct information on body orientation. It also plays a large role in the high incidences of graves without information on the age and sex of the interred (69 and 87 percent, respectively). Of the 79 individuals (in 74 graves) where age could be determined, 18 are children (23 percent), 8 are adolescents (10 percent), and 53 are adults (67 percent). Of the 30 individuals where sex could be determined, 18 are female, and 12 are male.

The 109 graves where body orientation is known with certainty break down into two groups accompanied by a single outlier. The majority by far ( 86 percent) follow the predominant Titus phase pattern of having their heads oriented to the northeast, east-northeast, east, or east-southeast, with most falling in the middle of this range. The second group consists of 14 graves (13 percent) with heads to the southeast, south-southeast, and south. All of these are at the Pine Tree Mound site, and it is this unusual orientation that Fields and Gadus (2012:675) rely on to suggest that the Titus group who lived there was distinct from those who lived to the north and northwest in the Cypress Creek basin. The outlier consists of a single child burial with its head to the north; it is at the Ear Spool site at the far north edge of the study area.

The much larger data set of grave pit orientations, which incorporates assumptions about body orientation where human remains are missing, follows the same general pattern, with 86 percent in the northeast to east-southeast range and 13 percent in the southeast to south-southwest range. Outliers consist of the north-oriented grave mentioned above, a single grave at Ear Spool that may have been oriented to the northwest, and a single grave at Pilgrim's Pride that was circular. As with the graves with known body orientations, grave pits with southeast to southerly orientations are peculiar to the Pine Tree Mound site, except for 1 possible case at Ear Spool and 3 possible cases at the H. R. Taylor site. The ones at the latter site appear to be a slight variation from the predominant east-southeast to east pattern at that site (79 percent of the graves there). It is hard to know what to make of the one at Ear Spool, since that site contained only 3 scattered graves, all oriented differently.

The information in Table 7.12 that could relate to status has to do with the sizes of the grave pits, the numbers and kinds of things included as offerings, and a few cases where the deceased were afforded some sort of special treatment. These variables are discussed first individually below, but patterns evident in looking at them all together probably are most meaningful, and that is done at the end of this section.

Grave pit size is indicated by length, width, and area. A fourth variable, depth, certainly could be informative, but it is too inconsistently reported and too variable between sites, probably in part because of differences in the depth to the Bt horizon, to be useful in this study. Grave pit area (length $\mathrm{x}$ width) is used here to look at variability in the data set. The figures given are considered generally reliable, if not always precise. The less-precise data come from some of the sites excavated long ago or by looters, with imprecision coming from two sources: (1) some dimensions were taken from site-wide plan maps where burials are shown in a semi-schematic fashion; and (2) at some sites, some burials were defined based on concentrations of grave goods rather than visible grave pits. Though obvious problem cases arising from both sources were excluded from the analysis, it is possible that some of the included ones suffer from errors of these sorts. If so, however, it is likely that the errors are small enough that they do not make much difference in this analysis.

The 238 graves range from 0.19 to $4.81 \mathrm{~m}^{2}$ in area, with a mean and standard deviation of $1.75 \pm 0.76 \mathrm{~m}^{2}$ and a median and mode of 1.65 and $1.69 \mathrm{~m}^{2}$ (Figure 7.25). Most of the 27 smallest graves (less than $0.99 \mathrm{~m}^{2}$, or more than one standard deviation below the mean), are probably those of children. Seven can be identified as 

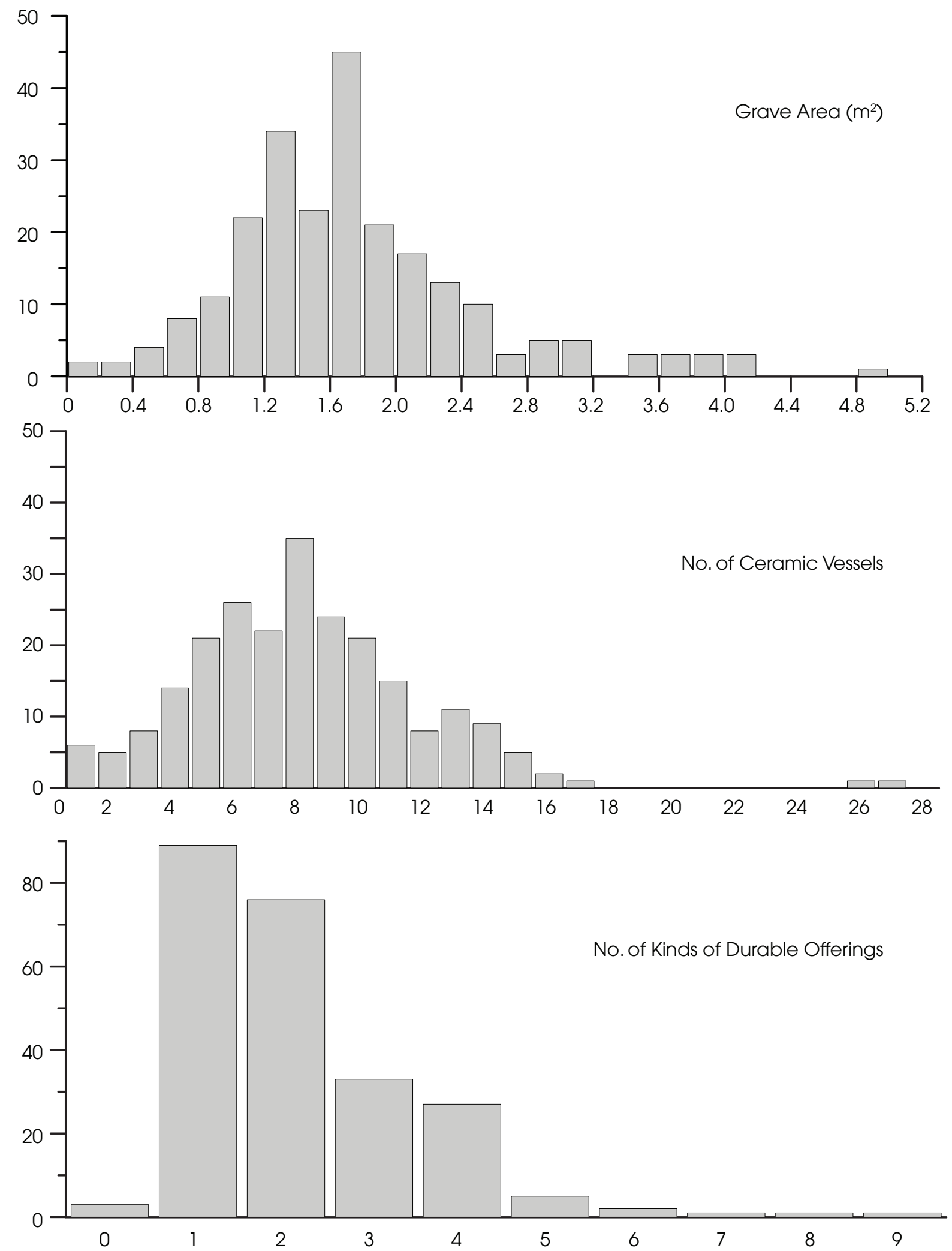

Figure 7.25. Histograms showing frequency distributions for grave size, number of ceramic vessel offerings, and number of kinds of durable offerings for 238 analyzed Titus phase burials. 
such based on the human remains present, and only 1 is known to have contained an adult; the grave of this adult, a female (Feature 2.167 at the Pine Tree Mound site), is the largest of these small burial pits. There are 8 graves larger than $0.99 \mathrm{~m}^{2}$ that are reported to contain the remains of children. Three are at the Tuck Carpenter site (Burials 8, 9, and 43). Though skeletal remains were not well preserved in any of them, there is no reason to doubt the age assessments or that the remains were in situ. They appear to be children who were placed in oversized, but still moderately small, grave pits ranging from 1.19 to $1.47 \mathrm{~m}^{2}$ in size. The sizes of the pits may have been related to the fact that all three contained moderate numbers of ceramic vessels (eight or nine).

The other 5 large children's graves were at the Alex Justiss site (Burials 2, 5, 9, 13, and 23). For 4 of these, though, there are reasons to doubt whether they actually contained children: (1) the human remains were recovered in the 2001 reexcavation of graves that had been looted many years before, opening up the possibility that the remains actually came from other graves; (2) only teeth were recovered, in at least two cases (Burials 13 and 23) from places suggesting they were not in situ; (3) all 4 contained arrow points, which are uncommon in the graves of children at other sites (only 3 of the 29 other graves containing the remains of children or thought likely to be children's graves based on size contained arrow points); and (4) these 4 are all larger than any other known or likely children's graves (1.69-1.72 $\mathrm{m}^{2}$ ). The fifth grave at Alex Justiss (Burial 9) may actually have contained a child. It is much smaller than the other $4\left(1.27 \mathrm{~m}^{2}\right)$, comparable to the 3 large examples at Tuck Carpenter, and it contained more bone (postcranial elements as well as teeth); on the other hand, the presence of arrow points could argue that the bones recovered in 2001 originated elsewhere.

From the standpoint of identifying graves that may have held people who were of high status or considered important for other reasons, it is the large graves that are most interesting, since these are the ones representing the greatest investment of effort. Thirty graves are larger than $2.51 \mathrm{~m}^{2}$, or more than one standard deviation above the mean. They were at 7 of the 14 sites analyzed: Ben McKinney $(\mathrm{n}=3), \mathrm{H}$. R. Taylor ( $\mathrm{n}=6)$, J. M. Riley $(\mathrm{n}=4)$, Mockingbird,
( $\mathrm{n}=2)$, Pilgrim's Pride $(\mathrm{n}=2)$, Pine Tree Mound $(n=8)$, and Tuck Carpenter $(n=5)$. Included in this group are all four of the known double burials, two at Pine Tree Mound and two at Tuck Carpenter.

The abundance of offerings has been used often to try to gauge status, and Table 7.12 lists all the things known to have been included in the graves as offerings. As noted, however, an approach using gross counts can be criticized based on uncertainties about how to tabulate certain kinds of things. In addition, some of the graves contained things that, in some cases, are more likely to be incidental inclusions (e.g., occasional flakes, dart points, and pieces of unworked hematite), but it is usually hard to tell given the level of documentation. Further, given the fact that the fill from most of the graves was not screened, there is no way to ensure consistent recovery of small items such as arrow points. For these reasons, we chose to use the total number of ceramic vessels, which were less likely to be missed than small offerings (though multiple examples at the Alex Justiss site indicate that this can happen), as a measure of offering frequency.

The frequency of ceramic vessels ranges from 0 to 27, with a mean and standard deviation of $8.1 \pm 3.8$ and a median and mode of 8 (see Figure 7.25). The three graves that contained no vessels were all at Pine Tree Mound. One of these is Feature 2.167, the small adult female grave mentioned above; Fields and Gadus (2012:314) speculate that vessel offerings may have been removed from this grave in antiquity and redeposited in a nearby large pit feature, but there is no way to be sure. The other two (Features 2.2081 and 2.2082) are presumed to be child burials based on their small sizes, but neither contained any human remains or offerings at all, so it is possible they are unused grave pits. At the other end of the scale, ceramic vessels are supernumerous in Burial 45 at H. R. Taylor and Feature 2.2072 at Pine Tree Mound. The latter is one of the two double burials there.

The variety of offerings also has been used to try to identify the graves of important people. This is an even more complex issue than the abundance of offerings, however. Complicating factors, some of which also relate to quantifying total offerings, include the following: (1) variable preservation of organic materials; (2) uncertainty about how to account for things such as a knapper's toolkit (is it one thing, or do you 
tabulate the various kinds of things within it?); (3) uncertainty about how to account for things like ceramic vessels, which occur in various forms used for different functions; (4) discriminating incidental inclusions from offerings; (5) lack of consistent screening, raising the possibility of small items being missed; and (6) the likelihood that the inclusion of some kinds of things relates more to an individual's role in that group than status (e.g., a large number of arrow points may mean that individual was known for his hunting prowess, which may have no relation to his status).

Because of these complications, this study adopted a generally conservative approach looking only at items of durable inorganic materials and excluding ones about which there might be some doubt about whether they actually were offerings (e.g., dart points, debitage not noted as being in concentrations or caches). Ceramic vessels were counted only once (not by vessel form), as were ceramic pipes and celts. Pigments and clay masses, though common, were not counted because of uncertainty about how consistently they were identified. Concentrations of artifacts identified as toolkits or caches were counted as single things, whereas similar assemblages of materials in other graves not so identified were counted as multiple things. Because this variable is considered to be a relatively poor indicator of status, it is given comparatively little weight in the analysis below.

Offering variety ranges from 0 to 9 , with a mean and standard deviation of $2.1 \pm 1.3$, a median of 2, and a mode of 1 (see Figure 7.25). Ceramic vessels are nearly ubiquitous, missing only in the 3 graves at Pine Tree Mound discussed above. Eighty-nine graves (37 percent) contain only ceramic vessels. Sixty-one of the 76 graves with two kinds of offerings contain arrow points along with the vessels. Four have celts, 3 have ceramic pipes, 2 have stone ear spools, 2 have large sherds that apparently served as pigment palettes, 1 has a core, 1 has a piece of unworked hematite, 1 has 5 polished pebbles, and 1 has a knapper's tool kit. Thirty-three graves (14 percent) have three kinds of durable offerings. Most common in addition to ceramic vessels are arrow points (29 graves); celts (8 graves); ear spools (6 graves); unworked pieces of hematite, limonite, or iron ore (5 graves); and ceramic pipes (4 graves). Bifaces occur in three graves; polishing or smoothing stones, debitage concentrations, and clusters apparently representing tool kits each occur in two; and an abrader, pigment palette, mano, scraper, modified pebble, and gouge each occur in one.

Twenty-seven graves (11 percent) have four kinds of offerings. Once again, arrow points are common, occurring in 23 of these. Other offerings include celts (16 graves); ceramic pipes (11 graves); unworked limonite or hematite (5 graves); flake concentrations (4 graves); abraders (3 graves); pigment palettes (3 graves); polishing or smoothing stones (3 graves); bifaces (2 graves); ear spools (2 graves); and single occurrences of a battered cobble, beveled knife, piece of silicified wood with quartz crystals, core, conch columella bead, tool kit cluster, drill, and worked pebbles.

All 10 graves (4 percent) that have more than four kinds of offerings have arrow points in addition to ceramic vessels. Nine have celts, and 7 have ceramic pipes. Other offerings are bifaces (4 graves), quartz crystals or silicified wood with crystals (2 graves), grinding slabs (2 graves), debitage concentrations ( 2 graves), unmodified lithic raw materials (2 graves), flake tools (2 graves), abraders (2 graves), hammerstones (2 graves), polishing stones (2 graves), a knapper's toolkit (1 grave), a pigment palette (1 grave), ear spools (1 grave), a mano (1 grave), and unworked hematite (1 grave).

Inclusion of exotic offerings also has been used as an indicator of status. Most commonly in Titus phase graves, this has meant large bifaces of nonlocal materials, i.e., Galt bifaces (Perttula 2005:385). Other obvious examples are the finely crafted stone ear spools from Pine Tree Mound (Fields and Gadus 2012:596-601), a copper-covered stone ear spool from Burial 34 at Tuck Carpenter (Turner 1992:72), and quartz crystals from Burial 45 at H. R. Taylor and Burial 6 at Mockingbird. Also included in this category, though not necessarily exotic or imported, are ceramic, sandstone, and wooden ear spools from 10 sites; quartz crystals embedded in pieces of silicified wood at 3 sites; and a conch columella bead from Burial 27 at Tuck Carpenter. In all, 19 sites have graves with such items. Of course, this may well undercount the things considered exotic and unusual by the Caddo involved in these interments. Most conspicuously missing are ceramic vessels that were judged special because of their size, craftsmanship, far-off origins, or symbolic or iconographic importance. It is virtually certain that some vessels were included 
as offerings for these reasons, but identifying them is beyond the scope of this study.

The final criterion used here is for other characteristics that make a burial stand out, of which there are just seven cases. Four are graves known to have contained two individuals each: Features 2.2072 and 8.1085 at Pine Tree Mound and Graves 21 and 23 at Tuck Carpenter. Two others are Features 2.2071 and 8.1088 at Pine Tree Mound, where the bodies appear to have been placed on litters. The seventh case is Burial 4 at J. M. Riley, which apparently had five posts set into the bottom of the pit around the upper torso, perhaps to support some sort of superstructure or cover over the grave.

The five criteria described above can be used to separate the 238 burials into five groups (Table 7.13). Group 1 consists of 144 burials that have no indicators of high status, accounting for 61 percent of the sample; two burials in this group (Burials 3 and 43 at Tuck Carpenter) do have high, but not very high, scores for offering variety, but, as noted above, this criterion is given less weight than the others. Group 2 consists of 29 graves (12 percent) that have high values for grave area $(0.5-1.0$ standard deviation above the mean) or number of vessels (11-12, but not more than 12), but not both; none of these has a very high value for variety of offerings (though 4 have high values) or contained exotic offerings. The third group includes 32 graves with the following characteristics: 12 with very high values for grave size (more than 1 standard deviation above the mean); 12 with very high values for number of vessels (13+); and 7 with exotic offerings. None of these has high values for more than one criterion, and none has a very high value for offering variety (though 5 have high values). Also included in this third group is 1 grave (Feature 517 at Pilgrim's Pride) with high (but not very high) values for both grave size and number of ceramic vessels. The third group accounts for 14 percent of the sample. The fourth group consists of 19 graves (8 percent) with two markers potentially indicating people of high status. Eight have high or very high values for grave size and number of vessels. Four are characterized by very high values for offering diversity ( 5 or more), plus high or very high values for grave size or number of vessels or presence of exotic offerings. Another has a high value for offering diversity and a very high value for number of vessels. Four have exotic offerings and high values for grave size or number of vessels. One of the final 2 in this group is a very large double burial, and the other is a burial on a litter with exotic offerings. The fifth group consists of 13 graves (5 percent) with multiple potential status markers. All but 1 have high to very high values for grave size. All have high to very high values for number of vessels. Six have very high values for offering variety. Six contained exotic offerings. And five are either double burials or have other special characteristics.

This scheme provides one way of ordering these burials according to the status (or wealth, importance, or power) of the people interred in them. At one end (Group 1) are the 144 people who appear to have been the common members of the society. At the other end (Group 5 and probably Group 4) are 13-32 people who were special. The 62 graves in the middle (Groups 2 and 3) are harder to interpret, though overall they seem more like Group 1 than Group 5. Patterns among the groups are enlightening about the nature of the society that created these burial sites, sometimes confirming conclusions other researchers have offered. According to the measures used here, children generally were not buried with indicators of status. The only graves documented as containing children that are not in Group 1 are Burial 23 at Alex Justiss (Group 3 ) and Feature 8.1085 at Pine Tree Mound (Group 4). As noted above, the former may not actually have been a child's grave, as the scant dental remains were found in the middle of the burial pit (i.e. perhaps out of context) and may have been introduced into the feature when it and many others at the site were first excavated by looters. The latter was one of two individuals in that grave, and it is surmised that it was the death of the other, an adult male, that precipitated the interment.

Analysis of breakdowns by sex is hampered by woefully inadequate sample sizes, but it probably is significant that males and females are identified in all five groups, with Groups 4 and 5 containing two of each sex. This implies that acquisition of status was not gender specific, contrary to what others have suggested. As noted by Fields and Gadus (2012:374), it appears there were avenues to status or social position open to some women within Titus groups. Though the hierarchical political structure was male dominated, the Caddo were matrilineal, and at 
Table 7.13. Burials at 14 Titus phase sites grouped according to potential status indicators Group 1

\section{Site Name}

Age Sex

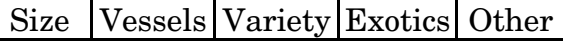

A. P. Williams (41TT4)

A. P. Williams (41TT4)

A. P. Williams (41TT4)

A. P. Williams (41TT4)

A. P. Williams (41TT4)

A. P. Williams (41TT4)

Alex Justiss (41TT13)

Alex Justiss (41TT13)

Alex Justiss (41TT13)

Alex Justiss (41TT13)

Alex Justiss (41TT13)

Alex Justiss (41TT13)

Alex Justiss (41TT13)

Alex Justiss (41TT13)

Alex Justiss (41TT13)

Alex Justiss (41TT13)

Alex Justiss (41TT13)

Alex Justiss (41TT13)

Alex Justiss (41TT13)

Alex Justiss (41TT13)

Alex Justiss (41TT13)

Alex Justiss (41TT13)

Alex Justiss (41TT13)

Alex Justiss (41TT13)

Alex Justiss (41TT13)

Ear Spool (41TT653)

Ear Spool (41TT653)

Ear Spool (41TT653)

H. R. Taylor (41HS3)

H. R. Taylor (41HS3)

H. R. Taylor (41HS3)

H. R. Taylor (41HS3)

H. R. Taylor (41HS3)

H. R. Taylor (41HS3)

H. R. Taylor (41HS3)

H. R. Taylor (41HS3)

H. R. Taylor (41HS3)

H. R. Taylor (41HS3)

H. R. Taylor (41HS3)

H. R. Taylor (41HS3)

H. R. Taylor (41HS3)

H. R. Taylor (41HS3)

H. R. Taylor (41HS3)

H. R. Taylor (41HS3)

H. R. Taylor (41HS3)

H. R. Taylor (41HS3)

H. R. Taylor (41HS3)

H. R. Taylor (41HS3)

\begin{tabular}{|r|r}
\hline & 3 \\
\hline & 7 \\
\hline & 8 \\
\hline & 10 \\
\hline & \multicolumn{1}{|c|}{3} \\
\hline & 4 \\
\hline & 6 \\
\hline & 8 \\
\hline & 9 \\
\hline & 10 \\
\hline
\end{tabular}
No.

\begin{tabular}{c|l}
\hline 3 & \\
\hline 4 & \\
\hline 7 & \\
\hline 8 & \\
9 & \\
10 & \\
\hline 1 & \\
\hline 2 & child/adolescent \\
\hline 3 & subadult \\
\hline 4 & \\
\hline 5 & child \\
\hline 6 & adolescent \\
\hline 7 & adult \\
\hline 8 & adult \\
\hline 9 & child \\
\hline
\end{tabular}

9 child

10

11

\begin{tabular}{|l|l|} 
child & female \\
\hline & \\
\hline
\end{tabular}

\begin{tabular}{|c|c|c|c|c|c|}
\hline & $\bar{L}$ & $\mathrm{MH}$ & $\bar{L}$ & & \\
\hline & VL & $\mathrm{MH}$ & VL & & \\
\hline & $\mathrm{L}$ & $\bar{L}$ & $\mathrm{~L}$ & & \\
\hline & $\mathrm{L}$ & $\bar{L}$ & $\mathrm{H}$ & & \\
\hline & $\mathrm{L}$ & $\mathrm{L}$ & $\mathrm{H}$ & & \\
\hline & VL & $\mathrm{MH}$ & $\mathrm{H}$ & & \\
\hline & $\mathrm{L}$ & $\mathrm{L}$ & VL & & \\
\hline & $\mathrm{L}$ & $\bar{L}$ & $\mathrm{~L}$ & & \\
\hline & $\mathrm{L}$ & $\mathrm{MH}$ & VL & & \\
\hline & $\bar{L}$ & $\bar{L}$ & MH & & \\
\hline & $\mathrm{L}$ & $\mathrm{L}$ & $\mathrm{L}$ & & \\
\hline & MH & $\bar{L}$ & $\mathrm{~L}$ & & \\
\hline & $\bar{L}$ & $\bar{L}$ & $\bar{L}$ & & \\
\hline & $\mathrm{L}$ & $\bar{L}$ & $\mathrm{~L}$ & & \\
\hline female & $\mathrm{L}$ & $\mathrm{L}$ & $\mathrm{L}$ & & \\
\hline & $\bar{L}$ & VL & $\mathrm{MH}$ & & \\
\hline & MH & $\mathrm{L}$ & $\mathrm{L}$ & & \\
\hline & $\mathrm{L}$ & VL & $\mathrm{L}$ & & \\
\hline & $\mathrm{L}$ & $\bar{L}$ & $\mathrm{MH}$ & & \\
\hline & $\mathrm{L}$ & $\mathrm{MH}$ & VL & & \\
\hline & $\mathrm{L}$ & $\mathrm{L}$ & $\mathrm{L}$ & & \\
\hline & $\mathrm{L}$ & $\bar{L}$ & $\mathrm{~L}$ & & \\
\hline & $\mathrm{L}$ & $\mathrm{MH}$ & VL & & \\
\hline & $\mathrm{L}$ & VL & $\mathrm{L}$ & & \\
\hline & $\mathrm{L}$ & VL & $\mathrm{L}$ & & \\
\hline & VL & VL & VL & & \\
\hline & $\mathrm{L}$ & $\mathrm{L}$ & $\mathrm{L}$ & & \\
\hline & VL & $\bar{L}$ & VL & & \\
\hline & $\mathrm{L}$ & VL & VL & & \\
\hline & MH & $\mathrm{L}$ & VL & & \\
\hline & $\mathrm{L}$ & $\mathrm{L}$ & VL & & \\
\hline & $\mathrm{L}$ & $\mathrm{L}$ & VL & & \\
\hline & VL & L & VL & & \\
\hline & $\mathrm{L}$ & $\mathrm{L}$ & MH & & \\
\hline & $\mathrm{L}$ & $\mathrm{L}$ & VL & & \\
\hline & VL & VL & VL & & \\
\hline & VL & $\bar{L}$ & VL & & \\
\hline & $\mathrm{L}$ & $\mathrm{L}$ & $\mathrm{H}$ & & \\
\hline & $\mathrm{L}$ & $\mathrm{L}$ & $\mathrm{L}$ & & \\
\hline & $\mathrm{MH}$ & $\mathrm{L}$ & $\mathrm{L}$ & & \\
\hline & $\mathrm{L}$ & $\mathrm{MH}$ & $\mathrm{L}$ & & \\
\hline & $\mathrm{L}$ & $\mathrm{L}$ & MH & & \\
\hline & $\mathrm{L}$ & $\mathrm{L}$ & VL & & \\
\hline & $\mathrm{L}$ & $\mathrm{L}$ & VL & & \\
\hline & $\mathrm{L}$ & $\mathrm{L}$ & $\mathrm{L}$ & & \\
\hline & VL & $\mathrm{L}$ & VL & & \\
\hline & $\mathrm{L}$ & $\mathrm{L}$ & $\mathrm{L}$ & & \\
\hline & $\mathrm{L}$ & VL & VL & & \\
\hline
\end{tabular}

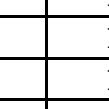

16

17 adult

18 adult

19 adult

20

21

1 child

\begin{tabular}{|c|c|}
\hline & 1 \\
\hline & 2 \\
\hline
\end{tabular}

3

1

3

4

5

9

12

13

16

18

19

19

23

24

25

26

27

28

29

30

31 
Table 7.13, continued

\begin{tabular}{|c|c|c|c|c|c|c|c|c|}
\hline Site Name & $\begin{array}{c}\text { Burial or } \\
\text { Feature } \\
\text { No. }\end{array}$ & Age & Sex & Size & Vessels & Variety & Exotics & Other \\
\hline H. R. Taylor (41HS3) & 32 & & & $\mathrm{VL}$ & $\mathrm{L}$ & VL & & \\
\hline H. R. Taylor (41HS3) & 33 & & & $\mathrm{VL}$ & $\mathrm{L}$ & $\mathrm{VL}$ & & \\
\hline H. R. Taylor (41HS3) & 35 & & & $\mathrm{~L}$ & $\mathrm{~L}$ & $\mathrm{~L}$ & & \\
\hline H. R. Taylor (41HS3) & 36 & & & $\mathrm{~L}$ & $\mathrm{~L}$ & $\mathrm{~L}$ & & \\
\hline H. R. Taylor (41HS3) & 37 & & & $\mathrm{~L}$ & $\mathrm{~L}$ & $\mathrm{~L}$ & & \\
\hline H. R. Taylor (41HS3) & 38 & & & $\mathrm{~L}$ & $\mathrm{MH}$ & $\mathrm{VL}$ & & \\
\hline H. R. Taylor (41HS3) & 39 & & & $\mathrm{~L}$ & $\mathrm{~L}$ & $\mathrm{~L}$ & & \\
\hline H. R. Taylor (41HS3) & 40 & & & $\mathrm{~L}$ & $\mathrm{~L}$ & $\mathrm{~L}$ & & \\
\hline H. R. Taylor (41HS3) & 41 & & & $\mathrm{VL}$ & $\mathrm{L}$ & VL & & \\
\hline H. R. Taylor (41HS3) & 44 & & & $\mathrm{MH}$ & MH & $\mathrm{L}$ & & \\
\hline H. R. Taylor (41HS3) & 48 & & & $\mathrm{MH}$ & $\mathrm{L}$ & $\mathrm{H}$ & & \\
\hline H. R. Taylor (41HS3) & 50 & child & & $\mathrm{VL}$ & $\mathrm{L}$ & $\mathrm{VL}$ & & \\
\hline H. R. Taylor (41HS3) & 51 & & & $\mathrm{MH}$ & $\mathrm{L}$ & $\mathrm{L}$ & & \\
\hline H. R. Taylor (41HS3) & 52 & & & $\mathrm{~L}$ & $\mathrm{~L}$ & $\mathrm{VL}$ & & \\
\hline H. R. Taylor (41HS3) & 55 & & & $\mathrm{~L}$ & $\mathrm{~L}$ & $\mathrm{~L}$ & & \\
\hline H. R. Taylor (41HS3) & 58 & & & $\mathrm{~L}$ & $\mathrm{~L}$ & $\mathrm{VL}$ & & \\
\hline H. R. Taylor (41HS3) & 60 & & & $\mathrm{~L}$ & $\mathrm{MH}$ & $\mathrm{H}$ & & \\
\hline H. R. Taylor (41HS3) & 61 & child & & $\mathrm{VL}$ & $\mathrm{L}$ & $\mathrm{VL}$ & & \\
\hline H. R. Taylor (41HS3) & 62 & & & $\mathrm{~L}$ & $\mathrm{~L}$ & $\mathrm{MH}$ & & \\
\hline H. R. Taylor (41HS3) & 64 & & & $\mathrm{MH}$ & $\mathrm{L}$ & VL & & \\
\hline J. M. Riley (41UR2) & 3 & & & $\mathrm{~L}$ & $\mathrm{MH}$ & VL & & \\
\hline J. M. Riley (41UR2) & 10 & & & $\mathrm{~L}$ & $\mathrm{MH}$ & $\mathrm{VL}$ & & \\
\hline J. M. Riley (41UR2) & 12 & & & $\mathrm{~L}$ & $\mathrm{~L}$ & $\mathrm{VL}$ & & \\
\hline J. M. Riley (41UR2) & 13 & & & $\mathrm{~L}$ & $\mathrm{~L}$ & $\mathrm{VL}$ & & \\
\hline J. M. Riley (41UR2) & 15 & & & $\mathrm{MH}$ & $\mathrm{L}$ & $\mathrm{L}$ & & \\
\hline J. M. Riley (41UR2) & 18 & & & $\mathrm{~L}$ & $\mathrm{~L}$ & $\mathrm{VL}$ & & \\
\hline Joe Justiss (41MX2) & 4 & & & VL & $\mathrm{L}$ & $\mathrm{L}$ & & \\
\hline Joe Justiss (41MX2) & 5 & & & $\mathrm{~L}$ & VL & $\mathrm{L}$ & & \\
\hline Joe Justiss (41MX2) & 7 & & & $\mathrm{~L}$ & $\mathrm{~L}$ & $\mathrm{~L}$ & & \\
\hline Joe Justiss (41MX2) & 8 & & & MH & $\mathrm{MH}$ & $\mathrm{H}$ & & \\
\hline Joe Justiss (41MX2) & 9 & & & $\mathrm{~L}$ & $\mathrm{~L}$ & $\mathrm{~L}$ & & \\
\hline Joe Justiss (41MX2) & 10 & & & $\mathrm{MH}$ & $\mathrm{VL}$ & $\mathrm{L}$ & & \\
\hline Joe Justiss (41MX2) & 11 & & & $\mathrm{~L}$ & $\mathrm{VL}$ & VL & & \\
\hline Mockingbird (41TT550) & 7 & & & $\mathrm{~L}$ & $\mathrm{~L}$ & VL & & \\
\hline Mockingbird (41TT550) & 9 & & & $\mathrm{MH}$ & $\mathrm{VL}$ & VL & & \\
\hline Peanut Patch (41HS825) & 1 & & & $\mathrm{MH}$ & $\mathrm{MH}$ & VL & & \\
\hline Peanut Patch (41HS825) & 2 & & & MH & $\mathrm{L}$ & $\mathrm{L}$ & & \\
\hline Peanut Patch (41HS825) & 3 & adult & male & $\mathrm{MH}$ & VL & VL & & \\
\hline Peanut Patch (41HS825) & 7 & & & $\mathrm{~L}$ & $\mathrm{VL}$ & $\mathrm{VL}$ & & \\
\hline Peanut Patch (41HS825) & 8 & & & $\mathrm{MH}$ & $\mathrm{VL}$ & $\mathrm{VL}$ & & \\
\hline Pilgrim's Pride (41CP304) & 8 & & & $\mathrm{VL}$ & VL & $\mathrm{L}$ & & \\
\hline Pilgrim's Pride (41CP304) & 505 & & & $\mathrm{~L}$ & $\mathrm{~L}$ & VL & & \\
\hline Pilgrim's Pride (41CP304) & 506 & & & $\mathrm{~L}$ & $\mathrm{~L}$ & VL & & \\
\hline Pilgrim's Pride (41CP304) & 508 & & & $\mathrm{MH}$ & $\mathrm{L}$ & VL & & \\
\hline Pilgrim's Pride (41CP304) & 510 & & & $\mathrm{MH}$ & MH & $\mathrm{MH}$ & & \\
\hline Pilgrim's Pride (41CP304) & 514 & & & $\mathrm{~L}$ & $\mathrm{~L}$ & VL & & \\
\hline Pilgrim's Pride (41CP304) & 515 & & & $\mathrm{~L}$ & VL & VL & & \\
\hline Pilgrim's Pride (41CP304) & 518 & & & $\mathrm{~L}$ & $\mathrm{MH}$ & VL & & \\
\hline Pilgrim's Pride (41CP304) & 519 & child & & $\mathrm{VL}$ & $\mathrm{MH}$ & $\mathrm{L}$ & & \\
\hline Pilgrim's Pride (41CP304) & $1-128$ & & & $\mathrm{VL}$ & VL & $\mathrm{VL}$ & & \\
\hline
\end{tabular}


Table 7.13, continued

\begin{tabular}{|c|c|c|c|c|c|c|c|c|}
\hline Site Name & $\begin{array}{c}\text { Burial or } \\
\text { Feature } \\
\text { No. }\end{array}$ & Age & Sex & Size & Vessels & Variety & Exotics & Other \\
\hline Pine Tree Mound (41HS15) & 2.2075 & & & $\mathrm{~L}$ & $\mathrm{~L}$ & $\mathrm{VL}$ & & \\
\hline Pine Tree Mound (41HS15) & 2.2076 & & & VL & VL & VL & & \\
\hline Pine Tree Mound (41HS15) & 2.2077 & & & $\mathrm{~L}$ & VL & VL & & \\
\hline Pine Tree Mound (41HS15) & 2.2081 & & & $\mathrm{VL}$ & VL & VL & & \\
\hline Pine Tree Mound (41HS15) & 2.2082 & & & $\mathrm{VL}$ & $\mathrm{VL}$ & VL & & \\
\hline Pine Tree Mound (41HS15) & 2.2083 & adult & female & $\mathrm{L}$ & $\mathrm{L}$ & $\mathrm{VL}$ & & \\
\hline Pine Tree Mound (41HS15) & 8.1086 & adolescent & & $\mathrm{MH}$ & $\mathrm{L}$ & $\mathrm{VL}$ & & \\
\hline Pine Tree Mound (41HS15) & 8.1089 & & & $\mathrm{VL}$ & VL & VL & & \\
\hline Pine Tree Mound (41HS15) & 8.1098 & juvenile & & $\mathrm{VL}$ & VL & VL & & \\
\hline Pine Tree Mound (41HS15) & 2.167 & adult & female & $\mathrm{VL}$ & VL & VL & & \\
\hline Pine Tree Mound (41HS15) & 2.186 & adult & female & $\mathrm{MH}$ & $\mathrm{VL}$ & $\mathrm{VL}$ & & \\
\hline Pine Tree Mound (41HS15) & 2.2039 & juvenile & & $\mathrm{VL}$ & $\mathrm{VL}$ & $\mathrm{VL}$ & & \\
\hline Pine Tree Mound (41HS15) & 8.1090 & & & $\mathrm{VL}$ & $\mathrm{VL}$ & $\mathrm{VL}$ & & \\
\hline Pine Tree Mound (41HS15) & 8.1097 & adult & male & $\mathrm{L}$ & $\mathrm{VL}$ & $\mathrm{L}$ & & \\
\hline Pine Tree Mound (41HS15) & 8.1100 & adolescent & female & $\mathrm{L}$ & VL & VL & & \\
\hline Thomas B. Caldwell (41TT6) & 1 & & & $\mathrm{~L}$ & $\mathrm{~L}$ & $\mathrm{MH}$ & & \\
\hline Thomas B. Caldwell (41TT6) & 2 & & & $\mathrm{~L}$ & $\mathrm{~L}$ & VL & & \\
\hline Thomas B. Caldwell (41TT6) & 4 & & & $\mathrm{~L}$ & $\mathrm{MH}$ & $\mathrm{L}$ & & \\
\hline Thomas B. Caldwell (41TT6) & 6 & & & $\mathrm{VL}$ & $\mathrm{MH}$ & VL & & \\
\hline Thomas B. Caldwell (41TT6) & 7 & & & $\mathrm{MH}$ & $\mathrm{MH}$ & $\mathrm{L}$ & & \\
\hline Thomas B. Caldwell (41TT6) & 8 & & & $\mathrm{MH}$ & $\mathrm{MH}$ & $\mathrm{L}$ & & \\
\hline Thomas B. Caldwell (41TT6) & 9 & & & $\mathrm{~L}$ & $\mathrm{MH}$ & VL & & \\
\hline Thomas B. Caldwell (41TT6) & 10 & & & $\mathrm{~L}$ & $\mathrm{MH}$ & $\mathrm{L}$ & & \\
\hline Tuck Carpenter (41CP5) & 3 & & & $\mathrm{MH}$ & $\mathrm{MH}$ & $\mathrm{H}$ & & \\
\hline Tuck Carpenter (41CP5) & 4 & adolescent/child & & $\mathrm{MH}$ & $\mathrm{MH}$ & $\mathrm{L}$ & & \\
\hline Tuck Carpenter (41CP5) & 6 & adult & female & $\mathrm{MH}$ & $\mathrm{MH}$ & $\mathrm{MH}$ & & \\
\hline Tuck Carpenter (41CP5) & 8 & child & & $\mathrm{L}$ & $\mathrm{L}$ & $\mathrm{VL}$ & & \\
\hline Tuck Carpenter (41CP5) & 9 & child & & $\mathrm{L}$ & $\mathrm{L}$ & $\mathrm{VL}$ & & \\
\hline Tuck Carpenter (41CP5) & 10 & adult & female & $\mathrm{MH}$ & $\mathrm{L}$ & $\mathrm{MH}$ & & \\
\hline Tuck Carpenter (41CP5) & 11 & adult & & $\mathrm{MH}$ & $\mathrm{MH}$ & $\mathrm{VL}$ & & \\
\hline Tuck Carpenter (41CP5) & 12 & adult & & $\mathrm{L}$ & $\mathrm{L}$ & $\mathrm{L}$ & & \\
\hline Tuck Carpenter (41CP5) & 13 & adult & female & $\mathrm{MH}$ & $\mathrm{L}$ & $\mathrm{MH}$ & & \\
\hline Tuck Carpenter (41CP5) & 17 & adult & female & $\mathrm{L}$ & $\mathrm{L}$ & $\mathrm{VL}$ & & \\
\hline Tuck Carpenter (41CP5) & 18 & adult & male & $\mathrm{MH}$ & VL & $\mathrm{MH}$ & & \\
\hline Tuck Carpenter (41CP5) & 20 & adult & female & $\mathrm{L}$ & $\mathrm{L}$ & $\mathrm{L}$ & & \\
\hline Tuck Carpenter (41CP5) & 22 & & & $\mathrm{~L}$ & $\mathrm{MH}$ & VL & & \\
\hline Tuck Carpenter (41CP5) & 25 & adult & & $\mathrm{L}$ & $\mathrm{L}$ & $\mathrm{H}$ & & \\
\hline Tuck Carpenter (41CP5) & 26 & adult & & $\mathrm{L}$ & $\mathrm{MH}$ & $\mathrm{L}$ & & \\
\hline Tuck Carpenter (41CP5) & 29 & adult & & $\mathrm{MH}$ & $\mathrm{MH}$ & $\mathrm{VL}$ & & \\
\hline Tuck Carpenter (41CP5) & 35 & adult & & $\mathrm{L}$ & VL & $\mathrm{L}$ & & \\
\hline Tuck Carpenter (41CP5) & 37 & adult & & $\mathrm{L}$ & $\mathrm{L}$ & $\mathrm{VL}$ & & \\
\hline Tuck Carpenter (41CP5) & 39 & adult & female & $\mathrm{L}$ & $\mathrm{MH}$ & $\mathrm{VL}$ & & \\
\hline Tuck Carpenter (41CP5) & 41 & adult & male & $\mathrm{L}$ & $\mathrm{MH}$ & $\mathrm{MH}$ & & \\
\hline Tuck Carpenter (41CP5) & 42 & child & & $\mathrm{VL}$ & $\mathrm{MH}$ & $\mathrm{VL}$ & & \\
\hline Tuck Carpenter (41CP5) & 43 & child & & $\mathrm{L}$ & $\mathrm{L}$ & $\mathrm{H}$ & & \\
\hline Tuck Carpenter (41CP5) & 45 & adult & female & $\mathrm{L}$ & $\mathrm{MH}$ & $\mathrm{MH}$ & & \\
\hline \multicolumn{9}{|l|}{ Group 2} \\
\hline Alex Justiss (41TT13) & 12 & adult & & $\mathrm{L}$ & $\mathrm{H}$ & $\mathrm{L}$ & & \\
\hline Alex Justiss (41TT13) & 28 & adult & female & $\mathrm{H}$ & $\mathrm{L}$ & $\mathrm{MH}$ & & \\
\hline H. R. Taylor (41HS3) & 6 & & & $\mathrm{~L}$ & $\mathrm{H}$ & $\mathrm{L}$ & & \\
\hline
\end{tabular}


Table 7.13, continued

\begin{tabular}{|c|c|c|c|c|c|c|c|c|}
\hline Site Name & $\begin{array}{c}\text { Burial or } \\
\text { Feature } \\
\text { No. }\end{array}$ & Age & Sex & Size & Vessels & Variety & Exotics & Other \\
\hline H. R. Taylor (41HS3) & 7 & & & $\mathrm{H}$ & $\mathrm{L}$ & $\mathrm{H}$ & & \\
\hline H. R. Taylor (41HS3) & 10 & & & $\mathrm{H}$ & $\mathrm{L}$ & $\mathrm{MH}$ & & \\
\hline H. R. Taylor (41HS3) & 15 & & & $\mathrm{~L}$ & $\mathrm{H}$ & VL & & \\
\hline H. R. Taylor (41HS3) & 20 & & & $\mathrm{H}$ & $\mathrm{L}$ & $\mathrm{L}$ & & \\
\hline H. R. Taylor (41HS3) & 43 & & & $\mathrm{H}$ & $\mathrm{L}$ & $\mathrm{L}$ & & \\
\hline H. R. Taylor (41HS3) & 53 & & & $\mathrm{~L}$ & $\mathrm{H}$ & $\mathrm{VL}$ & & \\
\hline H. R. Taylor (41HS3) & 57 & & & $\mathrm{~L}$ & $\mathrm{H}$ & $\mathrm{L}$ & & \\
\hline J. M. Riley (41UR2) & 16 & & & $\mathrm{H}$ & $\mathrm{MH}$ & $\mathrm{L}$ & & \\
\hline J. M. Riley (41UR2) & 17 & & & $\mathrm{~L}$ & $\mathrm{H}$ & VL & & \\
\hline Joe Justiss (41MX2) & 1 & & & $\mathrm{~L}$ & $\mathrm{H}$ & VL & & \\
\hline Mockingbird (41TT550) & 5 & & & $\mathrm{MH}$ & $\mathrm{H}$ & $\mathrm{VL}$ & & \\
\hline Peanut Patch (41HS825) & 4 & & & $\mathrm{H}$ & $\mathrm{L}$ & $\mathrm{VL}$ & & \\
\hline Peanut Patch (41HS825) & 5 & & & $\mathrm{H}$ & $\mathrm{L}$ & $\mathrm{H}$ & & \\
\hline Peanut Patch (41HS825) & 6 & & & $\mathrm{H}$ & $\mathrm{MH}$ & $\mathrm{L}$ & & \\
\hline Pilgrim's Pride (41CP304) & 507 & & & $\mathrm{H}$ & VL & $\mathrm{VL}$ & & \\
\hline Pine Tree Mound (41HS15) & 2.2074 & & & $\mathrm{H}$ & $\mathrm{L}$ & VL & & \\
\hline Pine Tree Mound (41HS15) & 2.2080 & & & $\mathrm{H}$ & $\mathrm{VL}$ & VL & & \\
\hline Thomas B. Caldwell (41TT6) & 5 & & & $\mathrm{~L}$ & $\mathrm{H}$ & $\mathrm{MH}$ & & \\
\hline Tuck Carpenter (41CP5) & 7 & adult & female & $\mathrm{L}$ & $\mathrm{H}$ & $\mathrm{L}$ & & \\
\hline Tuck Carpenter (41CP5) & 14 & adult & female & $\mathrm{H}$ & $\mathrm{L}$ & $\mathrm{L}$ & & \\
\hline Tuck Carpenter (41CP5) & 15 & adult & male & $\mathrm{H}$ & $\mathrm{MH}$ & $\mathrm{H}$ & & \\
\hline Tuck Carpenter (41CP5) & 16 & adult & & $\mathrm{H}$ & $\mathrm{MH}$ & $\mathrm{L}$ & & \\
\hline Tuck Carpenter (41CP5) & 24 & adult & & $\mathrm{MH}$ & $\mathrm{H}$ & $\mathrm{H}$ & & \\
\hline Tuck Carpenter (41CP5) & 30 & & & $\mathrm{~L}$ & $\mathrm{H}$ & $\mathrm{L}$ & & \\
\hline Tuck Carpenter (41CP5) & 33 & adult & & $\mathrm{L}$ & $\mathrm{H}$ & $\mathrm{L}$ & & \\
\hline Tuck Carpenter (41CP5) & 36 & adolescent & & $\mathrm{MH}$ & $\mathrm{H}$ & $\mathrm{L}$ & & \\
\hline \multicolumn{9}{|l|}{ Group 3} \\
\hline Alex Justiss (41TT13) & 14 & & & $\mathrm{~L}$ & $\mathrm{~L}$ & MH & $\mathrm{X}$ & \\
\hline Alex Justiss (41TT13) & 15 & & & $\mathrm{MH}$ & & $\mathrm{H}$ & & \\
\hline Alex Justiss (41TT13) & 22 & & & $\mathrm{~L}$ & $\mathrm{VH}$ & $\mathrm{L}$ & & \\
\hline Alex Justiss (41TT13) & 23 & child & & $\mathrm{L}$ & $\mathrm{VH}$ & MH & & \\
\hline H. R. Taylor (41HS3) & 2 & & & $\mathrm{MH}$ & $\mathrm{L}$ & $\mathrm{H}$ & $\mathrm{X}$ & \\
\hline H. R. Taylor (41HS3) & 8 & & & $\mathrm{VH}$ & $\mathrm{L}$ & VL & & \\
\hline H. R. Taylor (41HS3) & 11 & & & $\mathrm{VH}$ & $\mathrm{L}$ & $\mathrm{L}$ & & \\
\hline H. R. Taylor (41HS3) & 14 & & & $\mathrm{~L}$ & $\mathrm{VH}$ & $\mathrm{VL}$ & & \\
\hline H. R. Taylor (41HS3) & 34 & & & $\mathrm{~L}$ & $\mathrm{VH}$ & $\mathrm{VL}$ & & \\
\hline H. R. Taylor (41HS3) & 42 & & & $\mathrm{~L}$ & $\mathrm{VH}$ & $\mathrm{L}$ & & \\
\hline H. R. Taylor (41HS3) & 49 & & & $\mathrm{VH}$ & $\mathrm{L}$ & $\mathrm{H}$ & & \\
\hline H. R. Taylor (41HS3) & 56 & & & $\mathrm{MH}$ & $\mathrm{VH}$ & $\mathrm{VL}$ & & \\
\hline H. R. Taylor (41HS3) & 63 & & & MH & $\mathrm{VH}$ & MH & & \\
\hline J. M. Riley (41UR2) & 6 & adolescent? & & $\mathrm{MH}$ & $\mathrm{VH}$ & $\mathrm{VL}$ & & \\
\hline J. M. Riley (41UR2) & 9 & & & $\mathrm{VH}$ & $\mathrm{MH}$ & $\mathrm{L}$ & & \\
\hline J. M. Riley (41UR2) & 14 & & & $\mathrm{VH}$ & $\mathrm{L}$ & $\mathrm{L}$ & & \\
\hline Mockingbird (41TT550) & 3 & & & $\mathrm{VH}$ & $\mathrm{L}$ & $\mathrm{H}$ & & \\
\hline Mockingbird (41TT550) & 8 & & & $\mathrm{~L}$ & $\mathrm{VH}$ & $\mathrm{L}$ & & \\
\hline P. S. Cash (41CP2) & 8 & & & $\mathrm{~L}$ & $\mathrm{~L}$ & $\mathrm{MH}$ & $\mathrm{X}$ & \\
\hline Pilgrim's Pride (41CP304) & 503 & & & $\mathrm{VH}$ & MH & $\mathrm{H}$ & & \\
\hline Pilgrim's Pride (41CP304) & 509 & & & $\mathrm{~L}$ & $\mathrm{MH}$ & $\mathrm{H}$ & $\mathrm{X}$ & \\
\hline Pilgrim's Pride (41CP304) & 511 & & & $\mathrm{~L}$ & $\mathrm{VH}$ & $\mathrm{MH}$ & & \\
\hline Pilgrim's Pride (41CP304) & 517 & adult & & $\mathrm{H}$ & $\mathrm{H}$ & $\mathrm{L}$ & & \\
\hline
\end{tabular}


Table 7.13, continued

\begin{tabular}{|c|c|c|c|c|c|c|c|c|}
\hline Site Name & $\begin{array}{c}\text { Burial or } \\
\text { Feature } \\
\text { No. }\end{array}$ & Age & Sex & Size & Vessels & Variety & Exotics & Other \\
\hline Pine Tree Mound (41HS15) & 2.2078 & & & $\mathrm{VH}$ & $\mathrm{L}$ & $\mathrm{VL}$ & & \\
\hline Pine Tree Mound (41HS15) & 8.1091 & adult & male & $\mathrm{VH}$ & $\mathrm{MH}$ & $\mathrm{MH}$ & & \\
\hline Pine Tree Mound (41HS15) & 8.1092 & adult & male & $\mathrm{VH}$ & $\mathrm{L}$ & $\mathrm{L}$ & & \\
\hline Pine Tree Mound (41HS15) & 8.1094 & adult & male & $\mathrm{VH}$ & $\mathrm{VL}$ & $\mathrm{VL}$ & & \\
\hline Thomas B. Caldwell (41TT6) & 3 & & & $\mathrm{MH}$ & $\mathrm{VH}$ & $\mathrm{L}$ & & \\
\hline Tuck Carpenter (41CP5) & 5 & adult & & $\mathrm{VH}$ & $\mathrm{L}$ & $\mathrm{L}$ & & \\
\hline Tuck Carpenter (41CP5) & 32 & adult & male & $\mathrm{L}$ & $\mathrm{MH}$ & $\mathrm{MH}$ & $\mathrm{X}$ & \\
\hline Tuck Carpenter (41CP5) & 34 & adult/adolescent & male/ind. & $\mathrm{L}$ & $\mathrm{L}$ & $\mathrm{MH}$ & $\mathrm{X}$ & \\
\hline Tuck Carpenter (41CP5) & 38 & adult & female & $\mathrm{L}$ & $\mathrm{L}$ & $\mathrm{L}$ & $\mathrm{X}$ & \\
\hline Tuck Carpenter (41CP5) & 44 & adult & & $\mathrm{L}$ & $\mathrm{VH}$ & $\mathrm{L}$ & & \\
\hline \multicolumn{9}{|l|}{ Group 4} \\
\hline A. P. Williams (41TT4) & 6 & & & $\mathrm{~L}$ & $\mathrm{VH}$ & $\mathrm{H}$ & & \\
\hline Ben McKinney (41MR12) & 2 & & & $\mathrm{VH}$ & $\mathrm{H}$ & $\mathrm{VL}$ & & \\
\hline H. R. Taylor (41HS3) & 22 & & & $\mathrm{H}$ & $\mathrm{L}$ & $\mathrm{MH}$ & $\mathrm{X}$ & \\
\hline H. R. Taylor (41HS3) & 54 & & & $\mathrm{~L}$ & $\mathrm{H}$ & $\mathrm{MH}$ & $\mathrm{X}$ & \\
\hline H. R. Taylor (41HS3) & 59 & & & $\mathrm{VH}$ & $\mathrm{H}$ & $\mathrm{L}$ & & \\
\hline Mockingbird (41TT550) & 10 & & & $\mathrm{H}$ & $\mathrm{VH}$ & $\mathrm{H}$ & & \\
\hline Pine Tree Mound (41HS15) & 2.2073 & & & $\mathrm{H}$ & $\mathrm{MH}$ & $\mathrm{VH}$ & & \\
\hline Tuck Carpenter (41CP5) & 2 & adult & & $\mathrm{VH}$ & $\mathrm{H}$ & $\mathrm{L}$ & & \\
\hline Tuck Carpenter (41CP5) & 31 & adult & & $\mathrm{H}$ & $\mathrm{MH}$ & $\mathrm{H}$ & $\mathrm{X}$ & \\
\hline Tuck Carpenter (41CP5) & 40 & adult & female & $\mathrm{MH}$ & $\mathrm{H}$ & $\mathrm{MH}$ & $\mathrm{X}$ & \\
\hline Ben McKinney (41MR12) & 1 & & & $\mathrm{VH}$ & $\mathrm{VH}$ & $\mathrm{MH}$ & & \\
\hline H. R. Taylor (41HS3) & 47 & & & $\mathrm{VH}$ & $\mathrm{VH}$ & $\mathrm{VL}$ & & \\
\hline J. M. Riley (41UR2) & 5 & & & $\mathrm{VH}$ & $\mathrm{VH}$ & $\mathrm{VL}$ & & \\
\hline J. M. Riley (41UR2) & 11 & & & MH & $\mathrm{VH}$ & $\mathrm{VH}$ & & \\
\hline Mockingbird (41TT550) & 4 & & & $\mathrm{VH}$ & $\mathrm{L}$ & $\mathrm{VH}$ & & \\
\hline Mockingbird (41TT550) & 6 & & & $\mathrm{~L}$ & $\mathrm{~L}$ & $\mathrm{VH}$ & $\mathrm{X}$ & \\
\hline Pine Tree Mound (41HS15) & 8.1088 & & & $\mathrm{MH}$ & VL & $\mathrm{L}$ & $\mathrm{X}$ & $\mathrm{X}$ \\
\hline Pine Tree Mound (41HS15) & 8.1085 & adult/juvenile & male/ind. & $\mathrm{VH}$ & $\mathrm{L}$ & $\mathrm{L}$ & & $\mathrm{X}$ \\
\hline Tuck Carpenter (41CP5) & 1 & & & $\mathrm{VH}$ & $\mathrm{VH}$ & $\mathrm{MH}$ & & \\
\hline \multicolumn{9}{|l|}{ Group 5} \\
\hline Mockingbird (41TT550) & 11 & & & $\mathrm{H}$ & $\mathrm{VH}$ & $\mathrm{VH}$ & & \\
\hline Pine Tree Mound (41HS15) & 2.2071 & & & $\mathrm{VH}$ & $\mathrm{H}$ & $\mathrm{H}$ & & $\mathrm{X}$ \\
\hline Tuck Carpenter (41CP5) & 19 & adult & female & $\mathrm{L}$ & $\mathrm{H}$ & $\mathrm{VH}$ & $\mathrm{X}$ & \\
\hline Tuck Carpenter (41CP5) & 23 & adult/adolescent & & $\mathrm{VH}$ & $\mathrm{H}$ & $\mathrm{H}$ & & $\mathrm{X}$ \\
\hline Tuck Carpenter (41CP5) & 27 & adult & & $\mathrm{H}$ & $\mathrm{VH}$ & $\mathrm{H}$ & $\mathrm{X}$ & \\
\hline Ben McKinney (41MR12) & 3 & & & $\mathrm{VH}$ & $\mathrm{VH}$ & $\mathrm{VH}$ & & \\
\hline H. R. Taylor (41HS3) & 46 & & & $\mathrm{VH}$ & $\mathrm{VH}$ & $\mathrm{MH}$ & $\mathrm{X}$ & \\
\hline J. M. Riley (41UR2) & 4 & & & $\mathrm{VH}$ & $\mathrm{VH}$ & $\mathrm{H}$ & & $\mathrm{X}$ \\
\hline Pilgrim's Pride (41CP304) & 504 & & & $\mathrm{VH}$ & $\mathrm{VH}$ & $\mathrm{VH}$ & & \\
\hline Tuck Carpenter (41CP5) & 21 & adult/adult & male/ind. & $\mathrm{VH}$ & $\mathrm{VH}$ & $\mathrm{MH}$ & & $\mathrm{X}$ \\
\hline H. R. Taylor (41HS3) & 45 & & & $\mathrm{H}$ & $\mathrm{VH}$ & $\mathrm{VH}$ & $\mathrm{X}$ & \\
\hline Pine Tree Mound (41HS15) & 2.2079 & & & $\mathrm{VH}$ & $\mathrm{VH}$ & $\mathrm{VH}$ & $\mathrm{X}$ & \\
\hline Pine Tree Mound (41HS15) & 2.2072 & & & $\mathrm{VH}$ & $\mathrm{VH}$ & $\mathrm{MH}$ & $\mathrm{X}$ & $\mathrm{X}$ \\
\hline
\end{tabular}

Note: Scores for grave size, frequency of vessel offerings, and offering variety are as follows: VL = very low; $\mathrm{L}=$ low; $\mathrm{MH}=$ moderately high; $\mathrm{H}$ = high; $\mathrm{VH}$ = very high. 
least one position in the hierarchy, that of cona, appears to have been an achieved role practiced by both men and women (Carter 1995:126). Having said that, 83 percent of the identified females in this sample are in Groups 1 and 2, while 58 percent of males are in Groups 3-5. This suggests females could and did attain higher status and social positions, but it was more common for males to do so.

These data do support the traditional view that family cemeteries have little indication of variable burial treatment based on status, and that burials of high-status people are relatively common in community cemeteries (Perttula 2005:379, 383). This is evidenced by the following: (1) the two best-sampled community cemeteries (Tuck Carpenter and H. R. Taylor; Peanut Patch, also likely a community cemetery with perhaps 92 graves, is excluded because only 8 graves were documented) have high percentages of burials in Groups 4 and 5 (9-18 percent) compared to the family cemeteries at Alex Justiss, Joe Justiss, and Thomas B. Caldwell (0 percent; the family cemetery at A. P. Williams has one Group 4 burial [14 percent], but only seven graves at this site were analyzed); and (2) Tuck Carpenter and H. R. Taylor have low percentages of burials in Group 1 (52-63 percent) compared to the four family cemeteries (76-88 percent) (Table 7.14). Hence, these data support the idea that social differentiation is reflected in these large cemeteries and that they functioned to integrate the communities that contributed to them.

The two sites with family-size cemeteries at mound sites (Pilgrim's Pride and Pine Tree Mound) have percentages more like community cemeteries than family burial plots, 6-22 percent in Groups 4 and 5 and 56-63 percent in Group 1. This is not surprising, of course, since they too were the centers of ritual and ceremony for their communities.

The figures for most of the other sites in Table 7.14 are hard to interpret because of sampling issues. With just 1 of 9 graves documented and the potential for other unknown burials, little can be said about the cemetery at the P. S. Cash site. All 3 documented graves at the Ben McKinney site have markers for high status, but with 8 known but undocumented graves and the

Table 7.14. Frequencies of burials by potential status group at 14 Titus phase sites

\begin{tabular}{|c|c|c|c|c|c|c|c|c|c|c|c|}
\hline \multirow{2}{*}{$\begin{array}{c}\text { Site } \\
\text { Community Cemetery }\end{array}$} & \multicolumn{2}{|c|}{ Group 1} & \multicolumn{2}{|c|}{ Group 2} & \multicolumn{2}{|c|}{ Group 3} & \multicolumn{2}{|c|}{ Group 4} & \multicolumn{2}{|c|}{ Group 5} & \multirow[t]{2}{*}{ Total } \\
\hline & & & & & & & & & & & \\
\hline Tuck Carpenter (41CP5) & 23 & $52 \%$ & 8 & $18 \%$ & 5 & $11 \%$ & 4 & $9 \%$ & 4 & $9 \%$ & 44 \\
\hline H. R. Taylor (41HS3) & 40 & $63 \%$ & 8 & $13 \%$ & 9 & $14 \%$ & 4 & $6 \%$ & 2 & $3 \%$ & 63 \\
\hline Peanut Patch (41HS825) & 5 & $63 \%$ & 3 & $38 \%$ & 0 & $0 \%$ & 0 & $0 \%$ & 0 & $0 \%$ & 8 \\
\hline Mound Site & & & & & & & & & & & 0 \\
\hline Pilgrim's Pride (41CP304) & 10 & $63 \%$ & 1 & $6 \%$ & 4 & $25 \%$ & 0 & $0 \%$ & 1 & $6 \%$ & 16 \\
\hline Pine Tree Mound (41HS15) & 15 & $56 \%$ & 2 & $7 \%$ & 4 & $15 \%$ & 3 & $11 \%$ & 3 & $11 \%$ & 27 \\
\hline \multicolumn{12}{|l|}{ Family Cemetery } \\
\hline Joe Justiss (41MX2) & 7 & $88 \%$ & 1 & $13 \%$ & 0 & $0 \%$ & 0 & $0 \%$ & 0 & $0 \%$ & 8 \\
\hline A. P. Williams (41TT4) & 6 & $86 \%$ & 0 & $0 \%$ & 0 & $0 \%$ & 1 & $14 \%$ & 0 & $0 \%$ & 7 \\
\hline Thomas B. Caldwell (41TT6) & 8 & $80 \%$ & 1 & $10 \%$ & 1 & $10 \%$ & 0 & $0 \%$ & 0 & $0 \%$ & 10 \\
\hline Alex Justiss (41TT13) & 19 & $76 \%$ & 2 & $8 \%$ & 4 & $16 \%$ & 0 & $0 \%$ & 0 & $0 \%$ & 25 \\
\hline \multicolumn{12}{|l|}{ Unknown Cemetery Type } \\
\hline P. S. Cash (41CP2) & 0 & $0 \%$ & 0 & $0 \%$ & 1 & $100 \%$ & 0 & $0 \%$ & 0 & $0 \%$ & 1 \\
\hline Ben McKinney (41MR12) & 0 & $0 \%$ & 0 & $0 \%$ & 0 & $0 \%$ & 2 & $67 \%$ & 1 & $33 \%$ & 3 \\
\hline Mockingbird (41TT550) & 2 & $22 \%$ & 1 & $11 \%$ & 2 & $22 \%$ & 3 & $33 \%$ & 1 & $11 \%$ & 9 \\
\hline J. M. Riley (41UR2) & 6 & $43 \%$ & 2 & $14 \%$ & 3 & $21 \%$ & 2 & $14 \%$ & 1 & $7 \%$ & 14 \\
\hline \multicolumn{12}{|l|}{ Isolated Graves } \\
\hline Ear Spool (41TT653) & 3 & $100 \%$ & 0 & $0 \%$ & 0 & $0 \%$ & 0 & $0 \%$ & 0 & $0 \%$ & 3 \\
\hline Total & 144 & $61 \%$ & 29 & $12 \%$ & 33 & $14 \%$ & 19 & $8 \%$ & 13 & $5 \%$ & 238 \\
\hline
\end{tabular}


possibility of unknown ones, the significance of this is unclear. Similarly, the Mockingbird and J. M. Riley sites have high percentages of graves in Groups 4 and 5 (44 and 21 percent), but it is likely that the excavations sampled only parts of the cemeteries, and particularly in the case of J. M. Riley only a small part; hence, the information recovered may not be representative. The one site that readily makes sense is Ear Spool, since the 3 graves documented there were isolated and not part of a cemetery, and at least 2 of them and maybe all 3 likely were interments of children or juveniles; it is to be expected that all three would be in Group 1.

Though large cemeteries used by multiple communities and small cemeteries at mound centers do reflect some social differentiation within Titus phase groups, the degree of this differentiation seems not to have been great, on the whole. Fields and Gadus (2012:374-375) suggest that, at least at the Pine Tree Mound site, these high-status individuals were not the people with the highest political or religious authority, but second- or even third-tier leaders. What this reconstruction misses are the first-tier leaders and their family members. These people likely were buried in large, deep shaft tombs, none of which have been fully excavated professionally. It has long been recognized that such shaft tombs exist, with looted examples at the Lower Peach Orchard (41CP17), Pleasure Point (41MR63), and Shelby/Tracy (41CP71) sites (Perttula 2005:385), but it was not until some were documented at the Pine Tree Mound site in 2004 that this component of Titus phase burial practices, and its relationship to social complexity, came into focus.

The shaft graves at Pine Tree Mound appear to be part of a large cemetery that bounds the north side of the plaza there, opposite the largest of the three mounds. Six graves were found in two trenches about $32 \mathrm{~m}$ apart. Though only two were fully exposed horizontally and none were fully excavated, there is no doubt that all six are graves. The five whose horizontal dimensions are known or can be estimated cover areas of 4.4, $4.7(\mathrm{n}=2), 7.1$, and $9.7 \mathrm{~m}^{2}$. Thus, the smallest ones are comparable in size to the largest double burials at this site and Tuck Carpenter, and the largest one is more than twice the size. These graves are 2.5 to 5.5 times the size of the average Titus grave listed in Table 7.12. The single
Pine Tree Mound shaft grave whose depth was determined is about $4 \mathrm{~m}$ deep, or 4.4 times the average for the site. Based on volume, the shaft grave about which we know the most (Feature 136 ) is almost 17 times larger than the average grave associated with residential areas at the Pine Tree Mound site.

Assuming the six graves at the north edge of the plaza represent a single cemetery, Fields and Gadus (2012:130) estimate that at least 67 and perhaps more than 260 burials could be present. With many likely to contain multiple individuals, they speculate that hundreds of people could be interred there. With vastly more effort expended in burying at least some of these people than the average community member, it is clear some of these individuals were very important, i.e., the ultimate political and religious leaders and those associated with them.

Interestingly, the three Titus phase sites reported to contain large shaft graves other than Pine Tree Mound are distributed along Big Cypress Creek such that two (Pleasure Point and Shelby/Tracy) are in two of the five heartland communities defined by Perttula and Sherman (2009:375-377), while the third (Lower Peach Orchard) is well upstream from the others where Perttula and Sherman did not identify communities but where a sixth one surely was present (Perttula, Marceaux, and Nelson 2012:6-7; Figure 7.26). As discussed in Chapter 8, Perttula and Sherman (2009:375-377) describe these communities as consisting of dispersed farmsteads and villages affiliated with a key site or sites marked by public architecture such as mounds, ritual buildings, and community cemeteries.

With cemeteries containing shaft tombs for the elite in three of these areas, it can be argued that each was occupied by a group that was socially differentiated internally, comparable to the Pine Tree Mound community. The absence of known shaft graves in the other three heartland communities could have two main explanations: (1) such graves are (or were) present but remain undetected (in the southeasternmost one, perhaps under the waters of Lake O' the Pines near the Whelan site); or (2) these were not separate and distinct communities at an equivalent level of sociopolitical organization. In any case, these cemeteries with elaborate shaft graves probably are key to understanding Titus phase sociopolitical organization and complexity. 


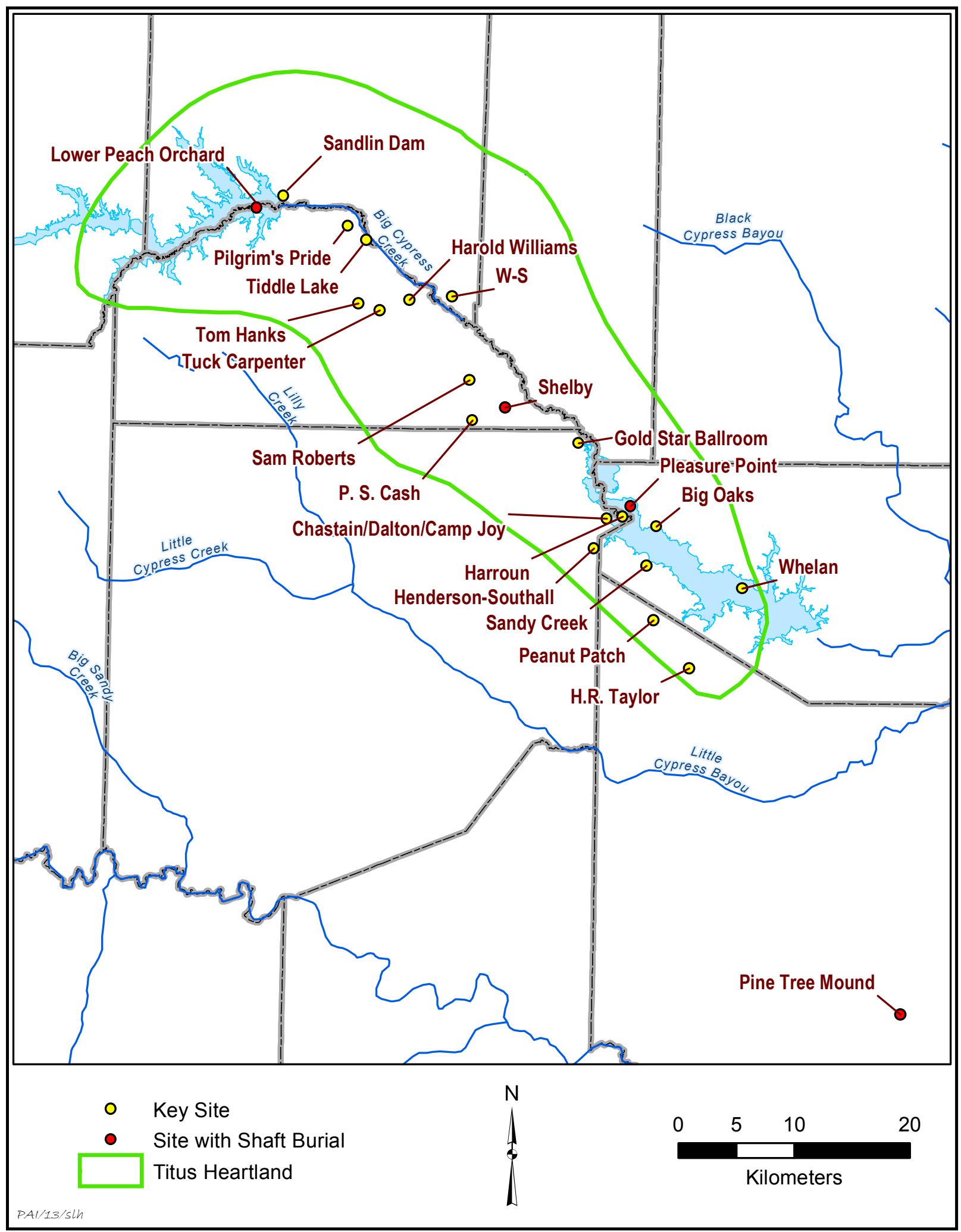

Figure 7.26. Map of the Titus phase area showing sites with shaft graves and key sites. 



\title{
INTERPRETATIONS AND CONCLUSIONS
}

\author{
Ross C. Fields and Eloise Frances Gadus
}

The Middle to Late Caddo Tankersley Creek community, which dominates the archeological record of the U.S. Highway 271 Mount Pleasant relief route project area and was the focus of the excavations reported here, likely had its beginnings in the distant past. Story (1990:323) has argued that, all across northeast Texas and adjoining states, the development of the Caddo tradition was "a culmination of local conditions and processes" with roots reaching back into the Woodland and Archaic periods rather than a result of the influx of new peoples; this portion of the Big Cypress Creek basin likely is no exception. Tankersley Creek is one of several generally south-flowing tributaries in the northern part of the upper reach of Big Cypress Creek, which flows east-southeast to its confluence with the Red River some $130 \mathrm{~km}$ from the current project area near Shreveport, Louisiana. The creek nearest to and east of Tankersley is Hart Creek; these two creeks surround the City of Mount Pleasant, which sits on a ridge between them. To the west of Tankersley is Blundell Creek. These creeks cut though a savanna-like environment (i.e., the Oak Woods and Prairies natural region [Diamond et al. 1987:204]), whereas the rest of the basin south of Big Cypress Creek and east of Hart Creek is in the Piney Woods. This chapter attempts to define the parameters of that community and the place of the Tankersley Creek sites within it. First, though, it is important to discuss the archeology of what preceded that community.

The synthesis presented here, though based on what was found at sites within the U.S. Highway 271 Mount Pleasant relief route project area, benefits from several other intensive archeological efforts in the region. Foremost among these are J. Peter Thurmond's (1981) thorough treatment of what was known of the archeology of the Cypress Creek basin as of 1981. The version that the Texas Archeological Research Laboratory published nine years later contains some new information but was not comprehensively updated from the earlier version (Thurmond 1990:3). Much of the archeological work that has been done in the Titus County area since Thurmond's ambitious effort is the result of expansion of the Monticello-Winfield lignite mine west and north of Mount Pleasant. Some 30 sites have seen test excavations, and 3 have been the scene of intensive work, including the Late Caddo Ear Spool and Mockingbird sites (Figure 8.1; Barnhart et al. 1987; Brown et al. 1986; Espey, Huston and Associates, Inc. 1982, 1984; Galan et al. 1997; Kotter et al. 1991; Nash et al. 1995; Perttula et al. 1998; Perttula and Sherman 2009; Sills and Cliff 2003). Other important work only partly represented in Thurmond's publications includes excavations by the Texas Department of Transportation at 41TT108 (Young 1981) and the Alex Justiss site (Bell 1981; Rogers et al. 2003). Finally, excavation and reporting of the important Pilgrim's Pride site (Perttula 2005) completely postdated Thurmond's work.

\section{NATIVE AMERICAN USE OF THE TANKERSLEY CREEK VALLEY BEFORE THE MIDDLE CADDO PERIOD}

\section{Paleoindian Period}

The traditional view of Native American use of northeast Texas during the Paleoindian 


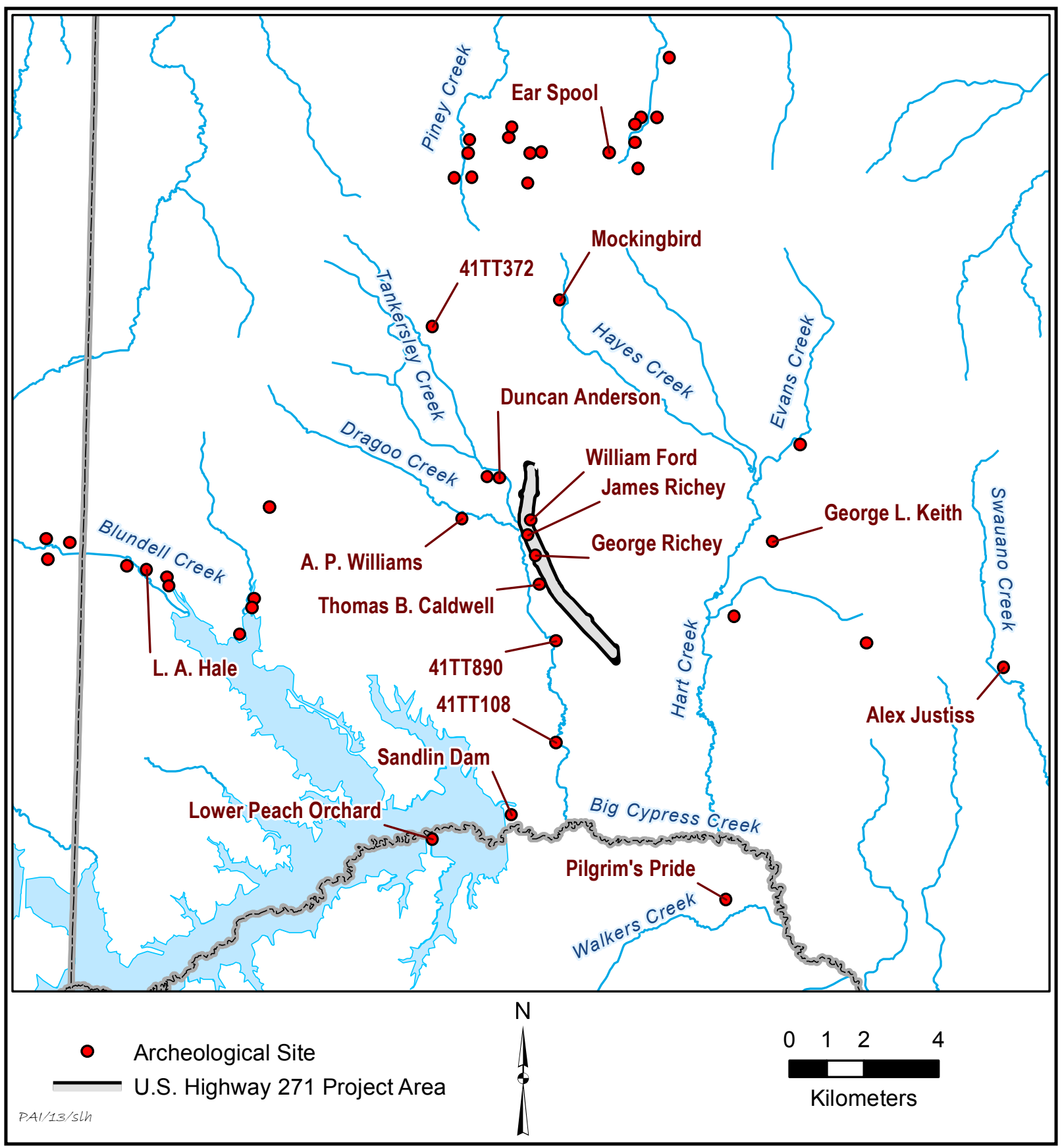

Figure 8.1. Map showing the locations of tested and excavated sites and important unexcavated sites in and near the Tankersley Creek drainage; only particularly notable sites are labeled.

period, ca. 10,000-6,000 B.C., is one of human adaptive strategies involving high residential mobility over large territories (Story 1990:177; Story et al. 1990:425-426). Site occupations were short lived by small social groups, who practiced a generalized subsistence strategy focused on hunting. Population densities were low, and frequent group movement and fluidity of group composition were means of avoiding or resolving stressful economic or social issues. 
Thurmond (1990:102-103) lists 15 sites in the part of the Big Cypress Creek basin west of Hart Creek with Paleoindian components based on the recovery of such early projectile point styles as San Patrice, Meserve/Dalton, Scottsbluff, and Plainview. Most of these $(n=13)$ are on floodplain rises, terraces, or upland projections near Big Cypress Creek, with the other 2 being on the middle to upper reaches of south-flowing tributaries. More-recent archeological investigations have identified a few Paleoindian artifacts at other sites in the area, for example, a San Patrice point and a few fluted stem fragments from 41TT372 on upper Tankersley Creek (Barnhart et al. 1997:71), a possible San Patrice point from 41TT108 on lower Tankersley Creek (Young 1981:36), a Dalton point from 41TT906 on Hart Creek (Burden et al. 2012:27), and a Dalton point from 41FK66 on Blundell Creek (Brown et al. 1986:133). In addition, early projectile points were recovered during excavations at several of the sites reported in this volume (Table 8.1). Two San Patrice points came from the James Richey site and another came from 41TT847, and the William Ford site produced two Dalton points and a Dalton or San Patrice. Three San Patrice points and three Daltons were identified in the private Anderson collection, which was analyzed during the U.S. Highway 271 project (Appendix $\mathrm{K}$ ), from sites just west of Tankersley Creek near the north end of the project area.

These points indicate that Paleoindian groups did utilize the Tankersley Creek drainage and adjacent valleys, but none of these early projectile points can be associated with cultural features, radiocarbon dates, or isolable components, and it appears that these occupations were ephemeral. The fact that many of these early points ( 6 of 12) are fashioned from nonlocal materials supports the long-held view that these early groups were highly mobile (Story 1990:176-177). As Story (1990:210-211) points out, one needs to adopt an extraregional perspective to discern patterns related to these early Native American cultures.

\section{Archaic Period}

Thurmond (1990:214) argues for an increase in Native American population in the Big Cypress drainage during the Archaic period (6000-200 B.C.) based on an increase in the number of sites and components. This likely was coupled with a change in adaptive strategies that included diversification of food resources, with plant foods taking on greater importance than before. Resource exploitation patterns also probably became more geographically focused, with decreasing residential mobility making inter- and intragroup relationships and alliances essential for managing economic and social problems that Paleoindian groups solved simply by moving camp.

Thurmond (1990:104-109) shows that, as of 1981, there were 26 identified Early Archaic components at and west of Hart Creek within the Big Cypress drainage basin, increasing to 36 in the Middle Archaic and 62 in the Late Archaic. Many of these sites clustered near Big Cypress Creek, but many others were along tributaries and in uplands away from the main stem. Thurmond (1990:41) distinguished between sites, calling some "heavy use areas" and others "limited use areas" based on the numbers of projectile points associated with them. While this classification carries with it implications for how intensively sites were used, he acknowledged that it had limited value for understanding settlement strategies and patterns because most sites were so poorly known.

By these parameters, the sites with Archaic materials in the U.S. Highway 271 project area generally can be considered to have seen limited use. All three of the sites with data recovery excavations and four of the tested sites yielded dart points suggestive of Archaic occupations (though some of the darts are Garys and Kents, which may postdate the Archaic), but these points are not particularly numerous (see Table 8.1). The Anderson collection has far more dart points (most classed as Gary), but it is from an unknown number of sites and hence does not represent occupation of any particular place. No features or other deposits isolable to the Archaic period were identified at any of the project area sites, though it is possible that some of the burned rock features could be Archaic. However, several radiocarbon dates from probable secondary contexts in pit feature fill at the William Ford and James Richey sites confirm the Archaic period occupations implied by the dart points. At the former, small pit Feature 365 produced a date with a high-probability range of $812-750$ B.C. At the latter, the date from pit Feature 87 was slightly later at 549-399 B.C., 


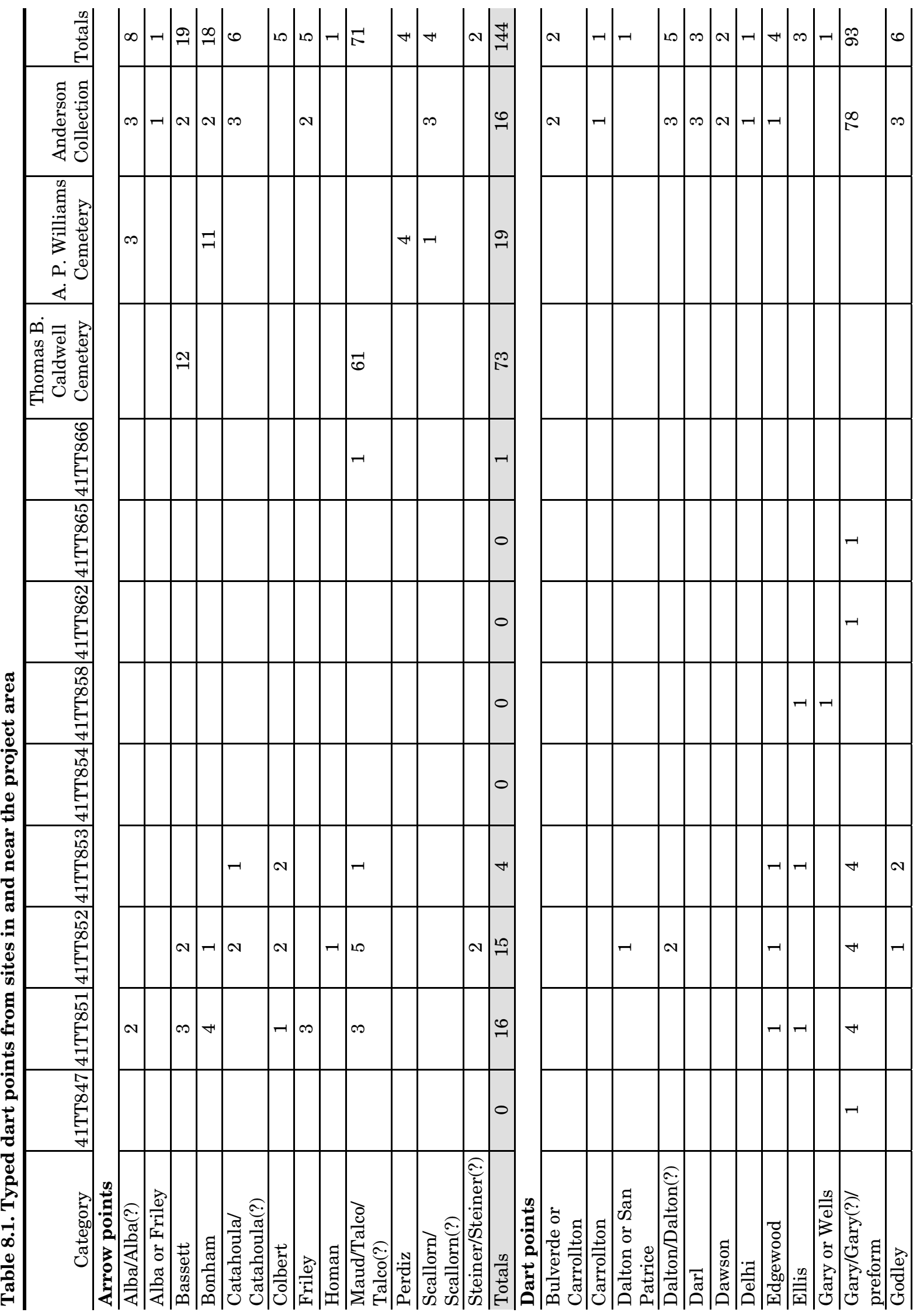




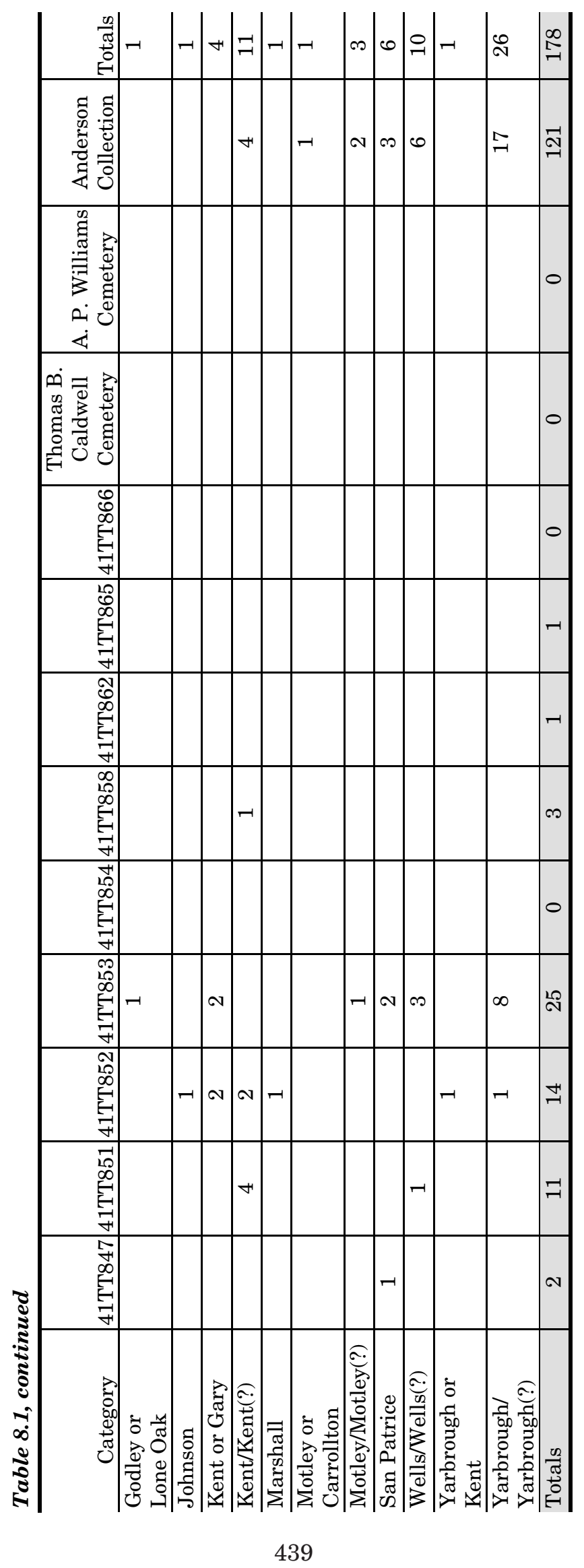


while that from pit Feature 28 was much earlier, with high-probability ranges of 2919-2848 and 2813-2738 B.C.

Looking beyond the immediate project area on the north side of the Big Cypress basin and northward into the White Oak Creek basin, Archaic components apparently representing ephemeral use, as suggested by small numbers of predominantly later dart points, are widespread at sites that have seen more than survey-level work. These include sites such as 41FK65, 41FK66, 41FK70, 41TT12 (L. A. Hale), 41TT135, 41TT145, and 41TT182 in the Blundell Creek drainage (Brown et al. 1986:103, 133, 175; Espey, Huston and Associates, Inc. 1984:43, 58; Kotter et al. 1991:36; Thurmond 1990:187); 41TT11 (George L. Keith), 41TT36 (Tigert), 41TT896, and 41TT906 in the Hart Creek drainage (Burden et al. 2012:vi; Dockall and Fields 2011:4; Thurmond 1990:184); and 41TT440, 41TT577, 41TT591, and 41TT653 (Ear Spool) in the Piney Creek drainage (Perttula and Sherman 2009:285; Galan et al. 1997:54, 65; Sills and Cliff 2003:45). More-substantial Archaic components have been documented at two sites. Excavation of about $80 \mathrm{~m}^{2}$ at $41 \mathrm{TT} 108$ on lower Tankersley Creek yielded 3 Ellis, 81 Gary, 2 Lange, 4 Trinity, 3 Wells, and 15 Yarbrough points (Young 1981:30-36). Three burned rock features, four possible pits, and one flexed burial were found here, though most or all of these, along with at least some of the Gary points, relate to the strong Woodland component here. At $41 \mathrm{TT} 372$ on upper Tankersley Creek, excavation of about $105 \mathrm{~m}^{2}$ yielded 8 Edgewood, 6 Ellis, 17 Gary, 3 Kent, 1 Morrill, 1 Pontchartrain, 8 Yarbrough, 1 Wells, and 1 Williams points (Barnhart et al. 1997:67-70). The eight burned rock features could relate to Archaic occupations, but they also could be later. A wide range of lithic tools such as scrapers, perforators, drills, and gouges were manufactured and used at 41TT372, with blanks and performs transported there for tool manufacture (Barnhart et al. 1997:214-218). Clearly, this site was used during part of the Archaic period for activities relating to more than just occasional resource extraction, unlike the Archaic components in the U.S. Highway 271 project area.

The dart points from the current project area, along with those in the Anderson collection, do convey some other useful information about raw material utilization and mobility. A moder- ate percentage (31 percent, 4 of 13 ) of the handful of points that may relate to earlier types, such as Bulverde, Johnson, and Wells, are of nonlocal raw materials. The percentage decreases to 19 percent (10 of 54) for the plethora of points that are probably mostly Late Archaic (Carrollton, Darl, Dawson, Delhi, Edgewood, Ellis, Godley, Marshall, Motley, and Yarbrough), and it drops to 8 percent (9 of 109) for Gary and Kent points, which may date to both the Late Archaic and Woodland periods. This suggests a strong trend toward decreased mobility though time, which is consistent with increases in both population and regionalization. Most of the nonlocal materials are from central Texas to the southwest, though some are from sources to the north.

\section{Woodland Period}

The Woodland period (ca. 200 B.C.A.D. 800) apparently saw the continuation of adaptive strategies established in the Archaic period. However, important new technologies were introduced, namely manufacture of ceramic vessels and the bow and arrow. Plant food processing is well represented archeologically by numerous ground stone tools. Plant use included the processing of hardwood nuts as well as use and the encouragement of native plants such as sumpweed, Chenopodium, maygrass, knotweed, and sunflower. Tropical cultigens, particularly squash, were introduced into northeast Texas at this time, but the development of true agroecological systems, and hence the adoption of a vastly different subsistence strategy, did not occur until later, probably after A.D. 1200 (Perttula 1993:123; Thurmond 1990:214).

Based on the occurrence of Williams Plain pottery and the absence of Early Caddo pottery, Thurmond (1990:110-111) identified 10 Woodland period components in the upper reach of the Big Cypress basin at or west of Hart Creek. He interpreted most of these as limited-use sites and only 2 as possible small hamlets, both near Big Cypress Creek west of its confluence with Tankersley Creek. This small number of components probably is misleading, though.

There are several reasons to think this. First, Williams Plain pottery may not be ubiquitous on Woodland sites, and thus some sites with only Gary points as diagnostics might be classified erroneously as Archaic. Also, in mul- 
ticomponent Woodland and Caddo sites, it can be difficult to identify Williams Plain against a backdrop of Caddo sherds. Thurmond (1990:185) notes that "the break between Caddoan and Williams Plain body sherds is an arbitrary one. The two intergrade in thickness and paste characteristics."

Third, Thurmond did not identify a Woodland component at the predominantly Titus phase Thomas B. Caldwell cemetery immediately adjacent to the current project area, even though it produced 5 Williams Plain bases, 3 rims, and 40 body sherds (Thurmond 1990:180), because he thought (perhaps correctly, perhaps not) that the Williams Plain pottery reflected an Early Caddo occupation. He reached the same conclusion for the collections of Williams Plain ceramics from two other important sites in the area, George L. Keith and L. A. Hale (41TT11 and 41TT12). The former, which is in the middle reach of Hart Creek, contains a single Caddo (Early Caddo, according to Thurmond [1990:183-184], but as argued later in this chapter, more probably Middle-Late Caddo) mound and a nearby small Titus phase cemetery, but it also yielded 1 rim, 5 base sherds, and 65 body sherds of Williams Plain. The L. A. Hale site, which is on the middle reach of Blundell Creek, is predominantly an Early Caddo site with multiple mounds (Thurmond 1990:185-188), but excavations there in 1934 recovered 149 sherds of Williams Plain pottery including 134 body sherds and 15 bases. The Williams Plain pottery from these mound sites suggests that these may have been places of significant occupation before mound construction began.

In looking at most other tested and excavated sites in the area, Woodland components cannot be identified because early pottery is missing, or maybe unrecognized. There are a number of sites with Gary points but no Williams pottery that could be aceramic Woodland sites, but lacking radiocarbon dates, there is no way to tell. Included are 41FK65, 41FK66, and 41FK70 on Blundell Creek (Brown et al. 1986:103, 133, 175); 41TT896 on Hart Creek (Burden et al. 2012:15); 41TT409, 41TT413, and 41TT593 on Piney Creek (Galan et al. 1997:72; Nash et al.
1995:164, 169); and 41TT372 on Tankersley Creek (Barnhart et al. 1997:67).

One of the more important excavated Woodland components in the vicinity is at 41TT108 on lower Tankersley Creek, where 81 Gary points, 40 Williams Plain sherds, and some Marksville/Troyville pottery that includes Churupa Punctated and Marksville Stamped were found, along with three burned rock features, four possible pits, and one flexed burial (Thurmond 1990:192-196; Young 1981:19-21, 30,32 ). The site also contained abundant Archaic materials and some Early Caddo artifacts, but its Woodland component is notable because it is one of the few sites in the upper Big Cypress drainage that concretely demonstrates extraregional influence from the Lower Mississippi Valley at a time when new technologies and subsistence practices were taking hold.

Mirroring the situation at most other nearby tested and excavated sites, no Williams Plain or other early non-Caddoan pottery was found at any of the sites in the U.S. Highway 271 project area, which is surprising since Williams Plain sherds were collected in 1934 from the adjacent Thomas B. Caldwell cemetery ${ }^{2}$, and a few radiocarbon dates obtained during this project are in the Woodland timeframe. Wood charcoal from Feature 2, a burned rock concentration, at $41 \mathrm{TT} 847$ produced a calibrated two-sigma date range of A.D. 640-770, which along with the single Gary point, certainly implies a late Woodland occupation. Site 41TT865 yielded a date on wood charcoal from a nonfeature context with two-sigma ranges of 360-280 and 260-60 B.C.; combined with the Gary point found in testing and a Kent point recovered previously, this suggests the presence of an early Woodland or very Late Archaic component. The excavations at the George Richey, William Ford, and James Richey sites did not result in any certain Woodland-age dates, but the 22 points classified as Gary or Kent could well reflect some level of Woodland period activity at all three. The 78 Gary and 4 Kent points in the Anderson collection may offer evidence of the same thing, i.e., widespread but not very intensive use of the Tankersley Creek area during Woodland times.

${ }^{2}$ Though not analyzed during this project, the sherds Thurmond (1990:180) called Williams Plain were examined and found to be consistent with that type. 


\section{Early Caddo Period}

Thurmond (1990:112-113) identified 15 Early Caddo (A.D. 800-1200 or 1300) sites on Tankersley Creek, nearby streams, and the adjacent reach of Big Cypress Creek as of 1981, based on ceramic assemblages with types such as Davis Incised, Holly Fine Engraved, Hickory Fine Engraved, Kiam Incised, Carmel Engraved, Weches Fingernail Impressed, Crockett Curvilinear Incised, Pennington Punctated-Incised, Spiro Engraved, Canton Incised, Haley Engraved, Maxey Noded Redware, Sanders Engraved, Sanders Plain, and Coles Creek Incised (Thurmond 1990:39). The number of components, and the fact that they included one multiple-mound center (L. A. Hale [41TT12] on middle Blundell Creek) and another site with a single mound (George L. Keith [41TT11] on middle Hart Creek), implied substantial, aggregated settlement of this part of the basin during that time.

With a better understanding of the chronology of the Caddo period today than was possible more than 30 years ago, however, it now appears that only about a third of these 15 sites are likely to have substantial Early Caddo components, with another third probably having minor Early Caddo components mixed with later materials and the final third perhaps mostly or entirely postdating the Early Caddo period. L. A. Hale (41TT12) is one of the sites in the first group, and it must be the focus of any discussion of Early Caddo occupation in the region, as we know enough about it to be confident that it is a multiple-mound center, and the only known mound site, dating to this time period.

The L. A. Hale site, on the middle reach of Blundell Creek $10 \mathrm{~km}$ west of the U.S. Highway 271 project area, is a cluster of four to six mounds and at least one borrow pit within an area of $325 \times 250 \mathrm{~m}$ on the upland margin ca. $9 \mathrm{~m}$ above the floodplain of the creek (Figure 8.2; Jackson 1934; Thurmond 1990:185-188). Jackson (1934) tested five of the mounds (all but Mound 6) and determined that the two largest ones (Mound 1 , measuring $45 \times 21 \mathrm{~m}$ and $4.3 \mathrm{~m}$ tall; Mound 2, measuring $51 \times 34 \mathrm{~m}$ and $3.2 \mathrm{~m}$ tall) are entirely artificial. He did not document any structural remains within them, but Thurmond (1990:185) suggests that both "likely had been raised as a series of consecutive platforms on which sequent structures were built.” Jackson (1934) concluded that Mounds 3-5 (measuring 13x11, $13 \times 10$, and $14 \times 12 \mathrm{~m}$ and $0.8,0.9$, and $0.9 \mathrm{~m}$ tall) are natural rises modified through the addition of fill, but Thurmond's (1990:185) summary of them suggests that Mound 4 could be entirely natural. Positive evidence of structures was found only in Mound 3, though the other two could have supported structures as well. Very little is known about untested Mound 6, but based on its size $(13 \times 11 \times 1.4 \mathrm{~m})$, it resembles Mounds $3-5$. It is likely that Mounds 1 and 2 define the north and west sides of a plaza, with smaller Mounds 3-5 off its northeast corner. Occupational debris was most abundant around the margins of this presumed plaza and north of Mound 5 (see Figure 8.2), and the overall picture is one of a well-defined, plaza-centered ceremonial landscape. Among the 1,544 Caddo ceramic sherds that Jackson collected were ones typed as Holly Fine Engraved, Hickory Engraved, Spiro Engraved, Weches Fingernail Impressed, and Ripley Engraved (Thurmond 1990:187). The last of these reflects a minor Late Caddo component, but the others, and perhaps the 149 Williams Plain sherds, clearly indicate that the predominant occupation was during the Early Caddo period.

The other mound site that Thurmond considered to have an Early Caddo component is the George L. Keith site (41TT11) on Hart Creek. The ceramic assemblage does have 71 Williams Plain sherds that could go with an Early Caddo or Woodland component, but other than 2 Crockett Curvilinear Incised sherds, it completely lacks types diagnostic of the Early Caddo period (Thurmond 1990:184). Thurmond recognized this, of course, and noting the abundance of types associated with the Sanders phase, he placed the main occupation in the latter part of the Early Caddo period. As discussed below, however, we interpret the mound and the main component as being later, i.e., Middle-Late Caddo.

In addition to the ceremonial center at the L. A. Hale site for the developing Early Caddo community in this part of the basin, there are a few small settlements with Early Caddo burials that are indicative of a rooted lifestyle. One of these is the Tigert site (41TT36) on Hale Creek. Though the sherd assemblage does not look particularly early, a looted grave yielded a vessel resembling Holly Fine Engraved (along with a Canton Incised jar and two plain bowls), sug- 


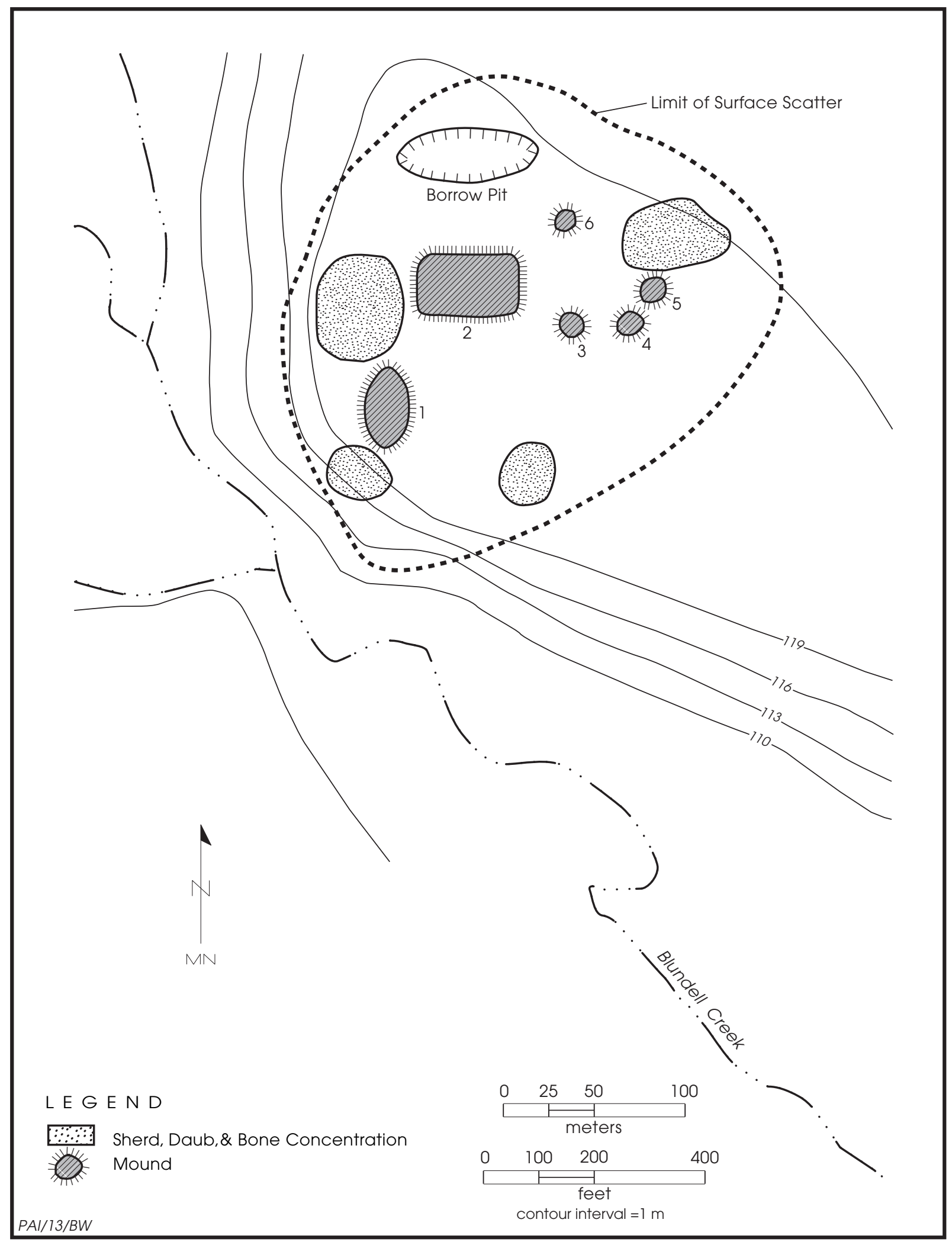

Figure 8.2. Map of the L. A. Hale site, 41TT12 (adapted from Thurmond 1990:Figure 24). 
gesting an Early Caddo component (Brown 1975; Thurmond 1990:191). Another is the R. L. Jaggers site (41FK3) just north of the Big Cypress basin. Three of the four burials there contained Early Caddo vessels (Hickory Fine Engraved, Kiam Incised, and Spiro Engraved), and a Hickory Fine Engraved jar, Spiro Engraved bowl, and Williams Plain-like jar were recovered as isolated finds (Thurmond 1990:155). Settlements with graves suggest that particular groups or families may have frequented certain areas and solidified their identification with these areas by the placement of their dead.

Some tested or excavated sites in the region have yielded small numbers of artifacts suggesting low-intensity use during the Early Caddo period, but it is hard to gauge whether this is an accurate impression or a function of too little data. Included are 41TT135 in the Blundell Creek basin with a single Holly Engraved sherd (Espey, Huston and Associates, Inc. 1984:78); 41FK65 on Blundell Creek with one sherd similar to Davis or Coles Creek Incised (Brown et al. 1986:104); and 41TT372 on upper Tankersley Creek with two Hickory Fine Engraved and three Carmel Engraved sherds and a radiocarbon date of A.D. 1020-1160 (Barnhart et al. 1997:60,151-155). Site 41TT108 on lower Tankersley Creek may belong in this group as well, based on the 14 sherds classed as Crockett Curvilinear Incised or Pennington Punctated-Incised (the single examples identified as Holly Fine Engraved and Weches Fingernail Impressed are less convincing) (Young 1981:24:30). A number of other sites also seem to contain ephemeral Early Caddo components based on the limited occurrence of early arrow point styles such as Friley and Catahoula or sherd assemblages where brushing is absent or very infrequent. These include 41 FK 66 , 41TT137, 41TT140, and 41TT145 on Blundell Creek; 41TT392, 41TT591, and 41TT601 on Piney Creek just north of the Big Cypress basin; and 41TT672 on Tankersley Creek (Brown et al. 1986:140; Dixon et al. 1995:65, 84; Espey, Huston and Associates, Inc. 1984:92, 96, 103; Galan et al. 1997:65; Nash et al. 1995:56, 201).

In a similar vein, Early Caddo remains are not well represented at the sites in the U.S. Highway 271 project area. The best evidence comes from the southern part of the George Richey site, where radiocarbon dates from Features 75, 348, and 359 overlap in the late
A.D. 900 s and appear to represent some limited residential use. A date from Feature 19 in the northern part of the site could indicate ephemeral use at any of several intervals during the Early Caddo period (A.D. 1045-1095, 1119-1142, or 1147-1229). A single Weches Fingernail Impressed sherd and a handful of sherds with decorations suggestive of Crockett Curvilinear Incised, Kiam Incised, or Davis Incised are consistent with Early Caddo occupation here, as are the four Friley and Colbert arrow points.

The William Ford site yielded two radiocarbon dates that could relate to ephemeral use during the Early Caddo period. One is from large pit Feature 13 in the southeastern feature concentration and has a high-probability range of A.D. 1151-1271. The other, from secondary context in the fill of probable juvenile burial Feature 542A, has a high-probability range at A.D. 770-897. There are no typed ceramics to associate with such early occupations, but there are some untyped sherds that could relate. Most are bowl rims with decorated flattened or folded lips that are suggestive of Early Caddo vessel forms associated with types such as Holly Fine Engraved or Coles Creek types. Also, two bowl body sherds have a design reminiscent of Holly Fine Engraved. Arrow points that are likely to go with these occupations are seven Catahoula, Colbert, Homan, and Steiner points.

A single date that could relate to Early Caddo use came from the James Richey site: A.D. 770-897 from large pit Feature 152. No ceramic evidence supports such an occupation, but the two Colbert arrow points and one possible Catahoula might. No early arrow points were found at any of the eight sites in the U.S. Highway 271 project area where only test excavations were done, and even the sizeable Anderson collection contained only eight examples, consisting of two Friley, three Catahoula, and three Scallorn.

The overall picture for the Early Caddo period in and near the project area is sparse but widespread use, probably consisting of small farmsteads, campsites, and procurement and processing locations created by a small local population. However, the L. A. Hale site makes it clear that these Caddo groups were participants in a complex political and religious system akin to those seen elsewhere in the Caddo area at that time, for example, at the George C. Davis site in the Neches River valley; the Hudnall-Pirtle and 
Boxed Springs sites in the Sabine River valley; the Mounds Plantation and Gahagan sites on the Red River in Louisiana; the Bowman, Mineral Springs, and Crenshaw sites in southwestern Arkansas; and perhaps the A. C. Mackin, Wright Plantation, and Fasken sites in the middle Red River valley (Bruseth 1998:63).

\section{THE MIDDLE-LATE CADDO TANKERSLEY CREEK COMMUNITY}

\section{Chronology}

Of the 130 radiocarbon dates obtained from sites along the U.S. Highway 271 Mount Pleasant relief route, 116 entirely postdate A.D. 1200 (at two-sigma) and 4 others partially do, accounting for 92 percent of the total. Combined, these 120 dates form a continuous series spanning the Middle and Late Caddo periods and even the Historic Caddo period (Figure 8.3). This data set provides compelling evidence for dramatically increased use of the middle part of the Tankersley Creek valley after the Early Caddo period, and we equate this with establishment and florescence of a local Caddo community there.

As discussed in Chapters 4-7, though, each location that has been investigated archeologically has its own history. The dates indicate a primary residential occupation at the George Richey site between A.D. 1250 and 1325; primary residential occupation at the William Ford site at 1425-1500 and a secondary one at 1650-1700; and a primary residential occupation at the James Richey site between 1400 and 1500 (Figure 8.4). All three sites also have other minor Middle-Late Caddo components that are probably nonresidential, or perhaps very short-term

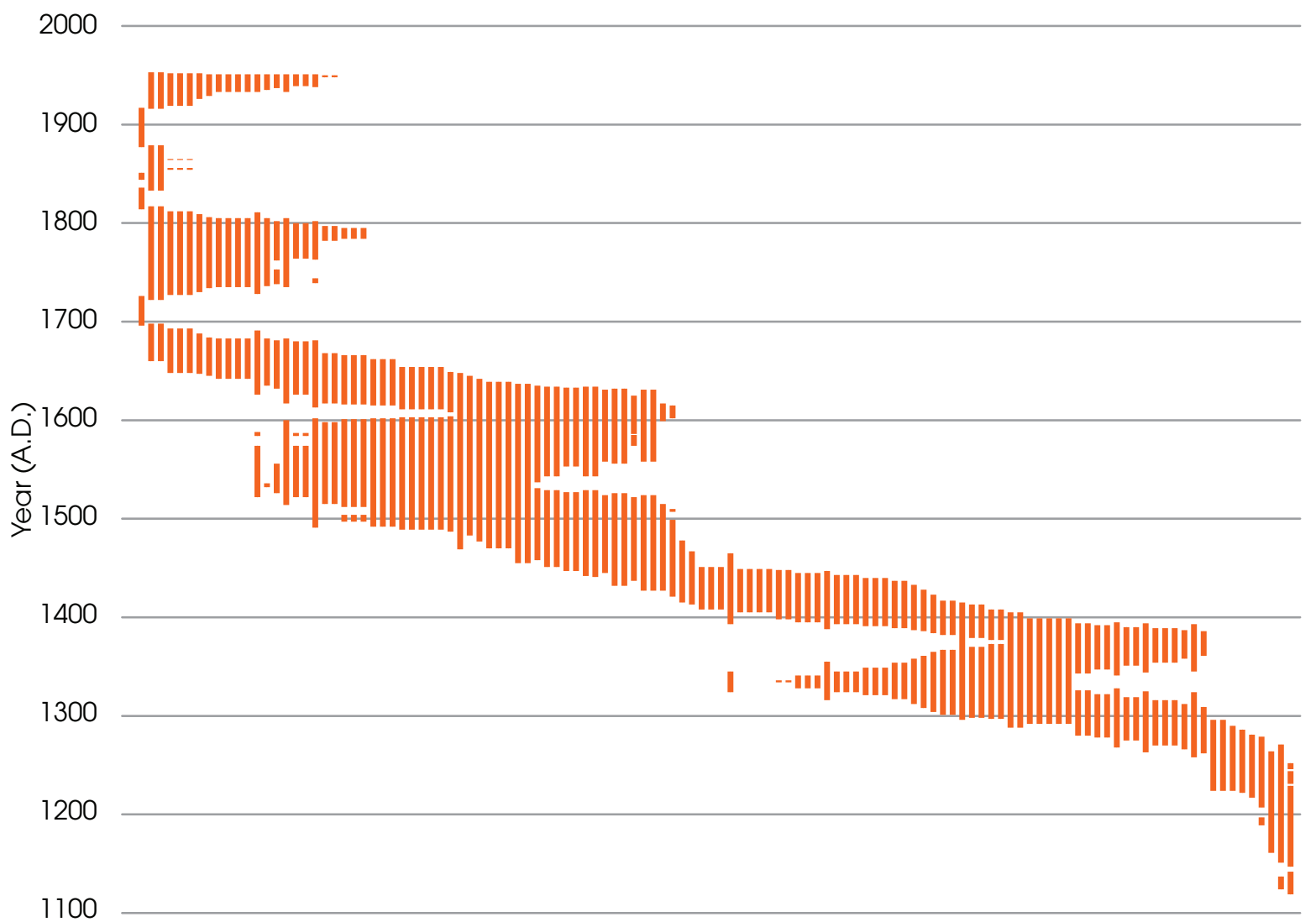

Figure 8.3. Graph of the 120 radiocarbon dates (two-sigma ranges) from the U.S. Highway 271 project area that postdate A.D. 1200 (the two earliest dates also have ranges in the A.D. 1000s that are not shown here). 


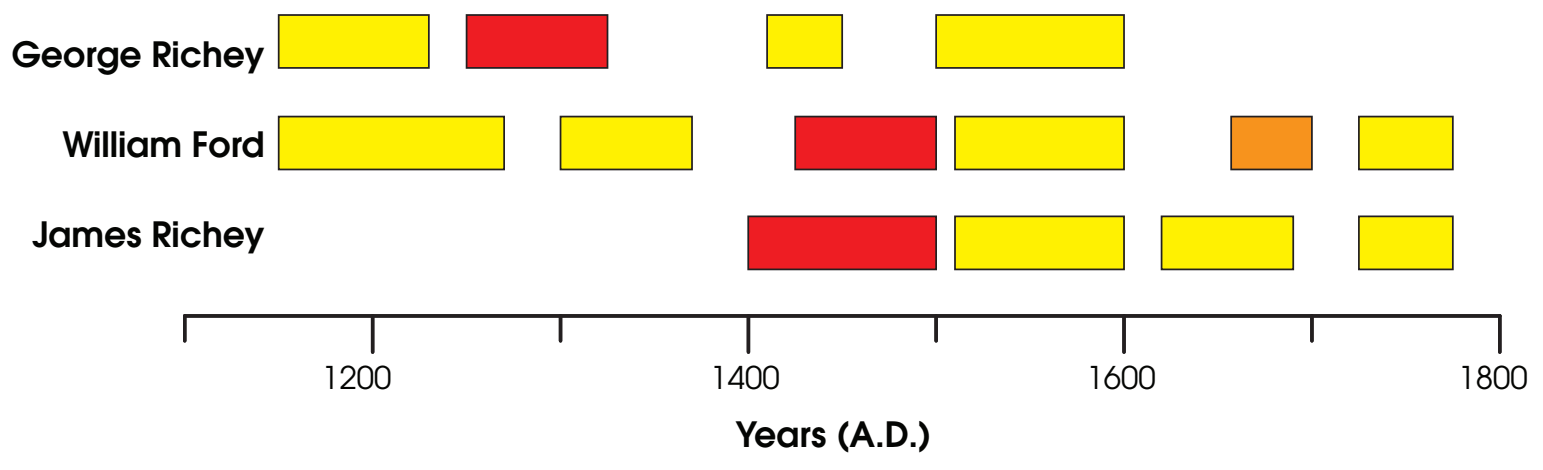

$\square$ Primary Residential $\square$ Secondary Residential $\square$ Minor

Figure 8.4. Graphs showing Middle-Historic Caddo component chronologies indicated by radiocarbon dates from the George Richey, William Ford, and James Richey sites.

residential. These date to the mid $1100 \mathrm{~s}-$ mid 1200s (George Richey and William Ford), 1300s (William Ford), early 1400s (George Richey), 1500s (George Richey, William Ford, and maybe James Richey), and the 1600s (James Richey). In addition, dates and diagnostic artifacts (i.e., gunflints) indicate that both the William Ford and James Richey sites have minor Historic Caddo components dating to the 1700s.

Radiocarbon dates are lacking from the three Caddo cemeteries that are near the project area-Thomas B. Caldwell, A. P. Williams, and Duncan Anderson-but Chapter 7 makes the case that all three are generally contemporaneous based on the kinds of artifacts they contained. With Historic Caddo materials lacking, all three clearly date to the Middle-Late Caddo interval.

Most of the time span indicated by the radiocarbon dates for this Tankersley Creek community falls squarely within the Titus phase interval (A.D. 1430-1680), but it starts earlier (A.D. 1250) and extends later (A.D 1800). The late end of the sequence cannot be correlated with a defined spatio-temporal construct, but there is no reason to think that these relatively minor occupations were by groups other than the Titus phase peoples who had lived here for sev- eral centuries. The traditional end date for the Titus phase is based more on the perception that the Caddo abandoned most of the Big Cypress Creek basin after A.D. 1680-1700 (Perttula and Sherman 2009:37-38) than on radiocarbon dating, but recent evidence, such as that from several cemeteries on Gum Creek in the Little Cypress Creek basin (Perttula, Walters, and Nelson 2012:1), indicates that some Titus groups remained in the region until at least the early 1700 s. This apparently happened in the Tankersley Creek valley as well.

On the early end, the sequence overlaps the Whelan phase, which Perttula and Sherman (2009:26) date to A.D. 1350-1430 and long has been seen as ancestral to the Titus phase. This is a construct that probably should be discarded, however (Davis et al. 2010:45-46, 99-102; Fields and Gadus 2012:673; Perttula 1992:106-107), because it is so poorly defined. Also relevant here is another poorly defined construct, the Sanders phase. Its relevance comes from the fact that a small amount of the pottery from two of the project area sites appears to be related to it, and this ties these sites to the mound at the George L. Keith site not far away (see discussion below). Though centered on the middle Red River valley well north of the project area, the people 
of the Sanders phase, which Bruseth (1998:58) dates to A.D. 1100-1300 based on limited radiocarbon dating, appear to have had some effects, most likely simply through intergroup contact, on early developments in the Tankersley Creek community.

\section{Site Layout and Function and Local Settlement Patterns}

All three sites where data recovery excavations were done are interpreted as single-family farmsteads, and the work at two of them whose main occupations were separated by a century or two-George Richey and William Ford-resulted in a clear picture of what the basic Middle to Late Caddo habitation unit along middle Tankersley Creek looked like (Figure 8.5). It consisted of a domiciliary area with a single house that was rebuilt once or twice separated from a main work area with large pits, small pits, smudge pits, and scattered postholes. The George Richey site had the clearest representation of this pattern with a northern cluster of features marking the main work area and a southern cluster composed of mostly postholes representing a house that was 6.0-6.4 $\mathrm{m}$ in diameter. The southern feature cluster and its house patterns were separated from the northern feature cluster by $23 \mathrm{~m}$. Though there was a scatter of features marking a work area on the east side of this space, it was mostly empty and may have been a plaza. An additional work area represented by small and large pits, smudge pits, and a few postholes was south of the house. Radiocarbon dates indicate that this basic layout was extant during the primary residential occupation, although some features that make up the feature concentrations are from earlier and later minor occupations.

The William Ford site also had two main clusters of features separated by ca. $15 \mathrm{~m}$ of open space that can be interpreted as a plaza. The southeastern feature concentration was mainly domiciliary, with a house that was rebuilt once. This house was $6.3 \mathrm{~m}$ in diameter, the same size as that at the George Richey site. A probable child burial (Feature 542A) appears to have been an interment below the house floor. Small pits, smudge pits, postholes, and a large pit west of the house represent a nearby work area like that south of the house at George Richey. Also like George Richey, the northwestern feature concentration was a work area with large and small pits, smudge pits, and scattered postholes probably representing drying racks or other ancillary structures. As at George Richey, radiocarbon dates indicate that this basic layout was in place during the primary residential occupation. On the northeast side of the possible plaza was a concentration of postholes that could be the remains of a small rectangular structure such as a ramada, but it is not certain that this was contemporaneous with the house area to the south. Instead, it is speculated that the remains in this part of the site may go with a later residential occupation centered just outside the project area to the east.

The layout of the James Richey site was less clear because the thicker sands there precluded small features such as postholes from penetrating deeply into the Bt horizon. As a result, posthole arcs representing houses could not be defined. Still, there was evidence to suggest that a house with a possible subfloor child burial was present generally south of a main work area made up of large pits, small pits, smudge pits, and postholes as at the other two sites. Unlike at the other two sites, a feature-free plaza between the domiciliary and work areas was not apparent. This may be at least partly a function of the unusual topographic setting of this site. In contrast to the other sites, which were on expansive interfluve summits, James Richey was on a relatively confined interfluve slope with less room for activity areas to be spread out.

At all three sites, high densities of lithic and ceramic artifacts and midden-enriched sediments closely followed the feature concentrations, suggesting that most trash disposal occurred at or near the activity areas marked by the features. The bulk of these artifacts represent a general rain of debris resulting from activities in and immediately around the houses and outdoor work areas. In addition at the James Richey site, artifacts were notably frequent just outside of and downslope from the proposed house area, suggesting consistent disposal of trash away from this area; this pattern was not evident at the other two sites.

The houses at George Richey and William Ford are similar in size and construction (e.g., with postholes averaging $15-17 \mathrm{~cm}$ in diameter) to those at the recently reported Pine Tree 


\section{George Richey Site}

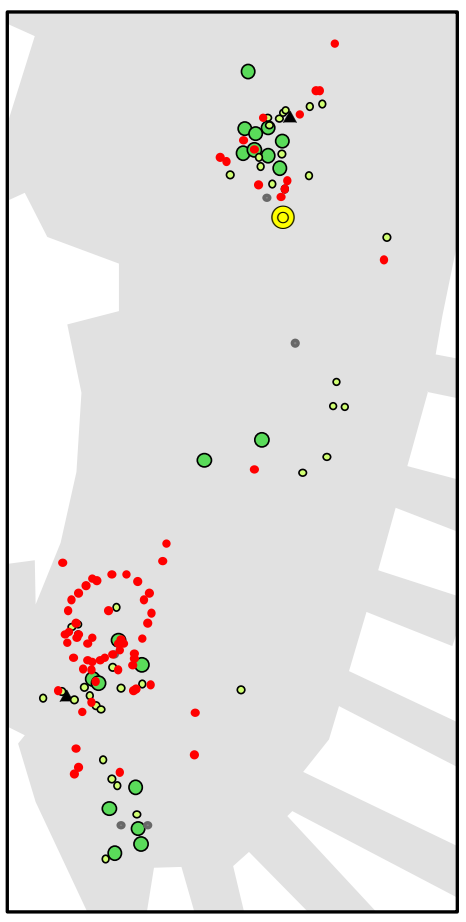

- artifact cluster

() burned rock concentration

- pit, large

- pit, small

- pit, smudge

- posthole

Stripped Area

\section{William Ford Site}
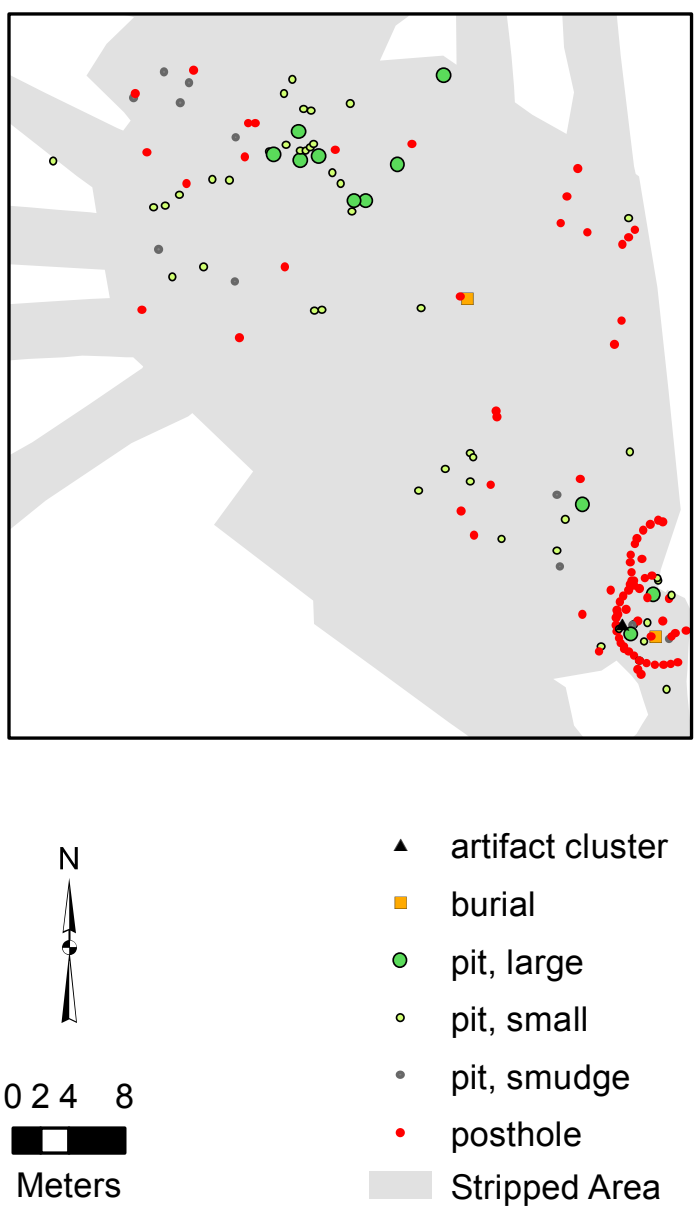

Figure 8.5. Plans of the George Richey and William Ford sites showing farmstead layout.

Mound site in Harrison County (Fields and Gadus 2012). That study argues that houses such as these, which were large enough to shelter a nuclear family or small extended family, had average use lives of perhaps 10 years before decay of support posts made rebuilding necessary (Fields and Gadus 2012:277-280). Extending that argument to this project area would mean that the main occupations of these farmsteads lasted only 20-30 years, i.e., a generation or two, after which the family moved on to occupy another interfluve along Tankersley Creek or a stream nearby.

It is harder to address how these sites were used during the multiple minor occupations that the radiocarbon dates indicate. The fact that there are more than a few dates indicating this suggests that these occupations involved more than just short-term activities, although short stays with very limited archeological visibility certainly are likely as well. Something more substantial seems to be indicated-for example, campsites 
at agricultural fields distant from farmsteads, or locations where quantities of plant or animal foods were processed, or even farmsteads that, for whatever reason, were occupied only very briefly before being abandoned. Such uses probably explain not only the minor components at the three sites where data recovery was done, but also the Caddo components at the tested sites within the project area, including Subarea 3 at 41TT852, 41TT854, 41TT858, 41TT865, and 41TT866.

The overall picture of local settlement patterns during the Middle-Late Caddo period is one of frequent residential moves and reoccupation of elevated landforms along water courses, but for varied activity sets. Farmsteads occupied for a generation or two and family cemeteries are the parts of this system that are most visible and interpretable archeologically, but shorter domestic and nondomestic occupations may be even more common. Certainly, there were no aggregated villages along the middle reach of Tankersley Creek, but it is likely (and probably necessary from a biological perspective) that there were enough occupied farmsteads at any given time along Tankersley Creek, other tributaries, and Big Cypress Creek that in the aggregate they formed the kind of dispersed village that was documented historically for other Caddo groups, for example, the Nondacao or Nadaco of the Sabine River valley in 1542 and 1788 (Fields and Gadus 2012:635, 639) and the Hasinai of the Neches River valley in the late 1600s (Story and Creel 1982:22).

There are three other important points to be noted about this settlement pattern based on the work done on the U.S. Highway 271 project. First, with radiocarbon evidence indicating that the main feature concentrations at the George Richey and William Ford sites reflect not just the main occupations but also some minor earlier and later ones, it appears that some spatial patterns in how these sites were used persisted through time in spite of changes in site function. This implies that the Middle-Late Caddo people who lived there retained longstanding cultural memories that conditioned site layout, or perhaps that there were landscape features, such as clearings in the woods, that affected where activities were performed. We will never know which, but the former explanation is attractive because it is consistent with a scenario in which this area was home to a particular group of people, i.e., a local community, who were intimately familiar with their territory and maintained traditions over centuries about how to use it, even in the face of needing to move farmsteads frequently. In other words, the decisions they made about where to situate their farmsteads, cemeteries, agricultural fields, field-monitoring camps, and procurement and processing locations, and when to move them, were strategic rather than haphazard. This fits well with the level of sociopolitical complexity that we presume these people had.

The issue of sociopolitical complexity is the second point highlighted here. One omission from the discussion of settlement patterns above are sites that served community integrative functions, such as mound sites or community cemeteries. The reason for that is there are no such sites in the U.S. Highway 271 project area. These kinds of sites certainly were important to the people who lived there, though, and they and what they tell us about complexity must be part of the discussion of their settlement system. This topic is important enough that it warrants more-extended examination under its own heading below.

Third, the evidence from the George Richey, William Ford, James Richey, Thomas B. Caldwell, and A. P. Williams sites indicates that the Tankersley Creek Caddo created farmsteads and family cemeteries, but not in the same places. The excavations at the three residential sites were extensive enough to show that no cemeteries were present adjacent to them. Assuming the reconstructed location of the Thomas B. Caldwell cemetery is correct (see Chapter 7), the closest residential sites that could be associated with it are several hundred meters away to the northwest on interfluves along the creek. The A. P. Williams cemetery was separated from a possibly associated midden by a similar distance (see Chapter 7). The Duncan Anderson site could be an exception to this pattern, since "abundant habitation refuse" was found there in addition to the cemetery (Perttula, Marceaux, and Nelson 2012:9), but too little is known about it to be sure.

The fact that farmstead occupations lasted only a generation or two, and that those occupations were by single households, may explain why residential and burial sites were not closely tethered. This conclusion is based on the assumption that structures like those at the George Richey and William Ford sites could have housed seven people (for previous modeling efforts at other Caddo sites, see Fields 
and Gadus [2012:280] and Rogers [2004b:95]) and that a crude death rate of 3 percent per year is reasonable for such agricultural groups (Chamberlain 2006:25,62-68). It would take a group this size 48 years to create a death assemblage like those in the typical family cemetery like Thomas B. Caldwell, A. P. Williams, and probably Duncan Anderson (i.e., 10 individuals). Hence, the cemeteries may have outlived individual farmsteads, unlike at the longer-occupied village areas at the Pine Tree Mound and Pilgrim's Pride sites, for example (Fields and Gadus 2012:313, 338; Perttula 2005:67). If an individual household used a cemetery while they were living at successive farmsteads, then it stands to reason that there would not necessarily be close spatial relationships between them.

\section{Use of Animals and Plants}

Faunal remains were scarce at the William Ford (391 elements) and James Richey (171 elements) sites and only moderately frequent at George Richey (2,413 elements). Still, deer consistently predominated, with other taxa including rabbits and hares, carnivores, rodents, frogs, turtles, birds, and boney fish. A faunal assemblage such as this is consistent with the environmental setting of the project area and suggests exploitation of a range of wild food sources.

Macrobotanical recovery from features at the three excavated sites indicates use of both upland and bottomland plants. Wood charcoal indicates that oak and hickory were the dominant choices for firewood. Other woods used include ash, elm, persimmon, plum/cherry, pecan, sweetgum, and willow, to name a few. Hardwood nuts-hickory, hickory/walnut, and acorn-are ubiquitous at all three sites, present in 62 to 83 percent of all macrobotanical samples analyzed. Cane fragments probably representing basketry or mat construction are also present at all three sites.

Cultigens are dominated by corn in the form of kernels, cupules, and glumes. Though total amounts are low, these remains were present at all three sites. The only other cultigen present, the common bean, was found at the William Ford site. Annual seeds also appear to have been exploited. These include Chenopodium, maygrass, little barley, wild rye, and knotweed. Less common are grape, verbena, sumac, purslane, grass family seeds, and bulb scales that could be from wild garlic or camas.

One of the goals of an early phase of this project was to look for physical evidence of where the Caddo grew their crops. That goal was dropped partway through testing when sponsorship of the project shifted from TxDOT to Titus County. Modern soils mapping likely provides some clues, though. For example, for the ca. 230 acres that encompass the George Richey, William Ford, and James Richey sites, extending from Tankersley Creek ca. $700 \mathrm{~m}$ to the east, the U.S. Department of Agriculture's Web Soil Survey classifies only 13 percent as prime farmland (upland Freestone fine sandy loam). Much of the area (42 percent) is Estes clay loam or Nahatche silty clay loam, which are bottomland soils considered too wet for agriculture today. The remainder is upland Woodtell fine sandy loam, most of which is unsuited to modern agriculture because slopes exceed 5 percent ( 37 percent of the 230 acres) or because of slow permeability or susceptibility to erosion (Roberts 1990:52). Of course, this does not mean the people who lived here did not sometimes plant crops on coarser pockets of Nahatche soils along tributaries to Tankersley Creek or on flatter sections of Woodtell soils, just that their larger fields may have been concentrated in areas with Freestone soils on and near the George Richey and William Ford sites. The limited amount of good farmland may help explain why the family groups who were beginning to rely on cultigens as an important segment of their subsistence economy found it necessary to move their farmsteads as often as they did.

\section{The Ceramic Industry}

There are a few sherds from the George Richey and James Ford sites that appear to relate to Early Caddo use, but the vast majority of the ceramics recovered reflect the MiddleLate Caddo occupations. The paragraphs below characterize these ceramics.

\section{Vessel Forms}

Both the sherd collections from the excavated residential sites and the vessels from the three cemetery sites convey information about the range of vessel forms manufactured and used 
by the Caddo who lived along Tankersley Creek. The two kinds of assemblages are not fully comparable, however, because it is harder to identify some vessel forms, namely specific bowl forms and beakers, based on sherds. The 255 vessels from the cemetery sites - 90 from Thomas B. Caldwell, 88 from A. P. Williams, and 77 from the Duncan Anderson (11 from the Anderson collection [see Appendix K) and 66 from the Margaret Hinton collection [Perttula, Marceaux, and Nelson 2012]) _ are mostly carinated bowls and jars at 37 and 27 percent of the total (Table 8.2). All bowl forms together make up 56-64 percent of each sample, and bottles together with ollas are 10-14 percent. Each site also yielded 1 or 2 beakers. One striking difference between the assemblages is the lack of compound bowls at the Caldwell site, which instead has the highest percentage of carinated bowls. Caldwell also has the highest percentage of jars. These differences suggest that the Caldwell cemetery stands apart from the other two. This implies that there was no single notion of what constituted an appropriate assemblage of vessels to accompany the deceased. Rather, this varied from family to family. One thing that is consistent across all three sites is that the percentage of all bowl forms combined (56-64 percent) is higher and the percentage of utility wares (jars, beakers, and ollas) is lower (25-34 percent) than in the assemblages from the three residential sites (39-44 percent bowls and 41-50 percent utility wares; the unusual deep bowl form found only at George Richey is considered a utility ware for this comparison). This reflects the inclusion of more serving bowls as burial accompaniments. Surprisingly, this pattern does not hold for bottles (10-11 percent of the burial assemblages and 6-19 percent of the residential assemblages), although this may be a function of how bottles are identified in sherd collections (i.e., mostly based on interior surface treatment).

Other than the large range in percentages of bottles at the residential sites, the most notable difference in the assemblages is the presence of deep bowls only at George Richey (see Table 8.2; see Figure 4.13). This probably is due to the fact that the main component at this site is earlier than those at the other two. The deep bowl vessel form is similar to that of Canton Incised, a common Sanders phase type (Suhm and Jelks 1962:Plate 12h), and it is likely that jars supplanted deep bowls as utility vessels by the Late Caddo period.

Vessel sizes ranged from small to large based on the range of rim and base thicknesses, which are comparable for all three sites and generally are between 3.51 and $9.67 \mathrm{~mm}$ for rims and 4.83 and $18.21 \mathrm{~mm}$ for bases. Evidence of

Table 8.2. Breakdown of vessel forms among the ceramic sherds from the George Richey, William Ford, and James Richey sites and the vessels from the Thomas B. Caldwell, A. P. Williams, and Duncan Anderson cemeteries

\begin{tabular}{l|c|c|c|c|c|c|c|c|c|c|c|c}
\hline \multicolumn{1}{c|}{$\begin{array}{c}\text { Vessel } \\
\text { Form }\end{array}$} & \multicolumn{2}{|c|}{$41 \mathrm{TT} 851$} & \multicolumn{2}{c|}{$41 \mathrm{TT} 852$} & \multicolumn{2}{c|}{$41 \mathrm{TT} 853$} & \multicolumn{2}{c|}{$\begin{array}{c}\text { Thomas B. } \\
\text { Caldwell }\end{array}$} & \multicolumn{2}{c|}{$\begin{array}{c}\text { A. P. } \\
\text { Williams }\end{array}$} & \multicolumn{2}{c}{$\begin{array}{c}\text { Duncan } \\
\text { Anderson }\end{array}$} \\
\hline & No. & $\%$ & No. & $\%$ & No. & $\%$ & No. & $\%$ & No. & $\%$ & No. & $\%$ \\
\hline Bottle & 23 & 19 & 20 & 13 & 12 & 6 & 9 & 10 & 10 & 11 & 8 & 10 \\
\hline Bowl & 48 & 39 & 67 & 43 & 96 & 44 & - & - & - & - & - & - \\
\hline Deep bowl & 26 & 21 & - & - & - & - & - & - & - & - & - & - \\
\hline $\begin{array}{l}\text { Carinated } \\
\text { bowl }\end{array}$ & - & - & - & - & - & - & 44 & 49 & 28 & 32 & 23 & 30 \\
\hline $\begin{array}{l}\text { Compound } \\
\text { bowl }\end{array}$ & - & - & - & - & - & - & - & - & 19 & 22 & 9 & 12 \\
\hline $\begin{array}{l}\text { Simple } \\
\text { bowl }\end{array}$ & - & - & - & - & - & - & 6 & 7 & 9 & 10 & 14 & 18 \\
\hline Jar & 22 & 18 & 64 & 41 & 99 & 45 & 30 & 33 & 19 & 22 & 19 & 25 \\
\hline Beaker & - & - & - & - & - & - & 1 & 1 & 2 & 2 & 2 & 3 \\
\hline Olla & 3 & 2 & 6 & 4 & 11 & 5 & - & - & 1 & 1 & 2 & 3 \\
\hline Totals & 122 & & 157 & & 218 & & 90 & & 88 & & 77 & \\
\hline
\end{tabular}


eccentric vessels was recovered from all sites, with sherds from effigy and noded bowls represented at George Richey, a complete miniature square bottle at William Ford, and a complete effigy bowl at James Richey.

\section{Typological Identifications}

As discussed in Chapter 7, 38-59 percent of the vessels from the three cemeteries can be typed, with 69-81 percent being Ripley Engraved (Table 8.3). A few Wilder Engraved bottles came from the Thomas B. Caldwell and A. P. Williams cemeteries, and Caldwell also contained a single Johns Engraved bowl. Among the utility wares, Bullard Brushed and Pease Brushed-Incised came from all three cemeteries, while Maydelle Incised and La Rue Neck
Banded came from A. P. Williams and Duncan Anderson. Killough Pinched and Belcher Ridged jars occurred at Duncan Anderson, and a small beaker similar to Killough Pinched was found at Caldwell. Common to all three is a kind of untyped tall jar with a flaring rim containing three or more horizontal lines of punctations, sometimes with one or more horizontal incised lines between the lines of punctations and two or more sets of appliquéd nodes on the rim. It is similar to Bullard Brushed, except that the body is not brushed. Perttula, Marceaux, and Nelson (2012:273, 324) classify two of these from Duncan Anderson as Mockingbird Punctated.

The small samples of typed ceramics from the George Richey, William Ford, and James Richey sites exhibit mostly the same styles (see

Table 8.3. Middle-Late Caddo ceramic types from the George Richey, William Ford, and James Richey sites and the Thomas B. Caldwell, A. P. Williams, and Duncan Anderson cemeteries

\begin{tabular}{|c|c|c|c|c|c|c|c|c|c|c|c|c|}
\hline \multirow[t]{2}{*}{$\begin{array}{c}\text { Ceramic } \\
\text { Type }\end{array}$} & \multicolumn{2}{|c|}{$\begin{array}{l}\text { George } \\
\text { Richey }\end{array}$} & \multicolumn{2}{|c|}{$\begin{array}{c}\text { William } \\
\text { Ford }\end{array}$} & \multicolumn{2}{|c|}{$\begin{array}{l}\text { James } \\
\text { Richey }\end{array}$} & \multicolumn{2}{|c|}{$\begin{array}{c}\text { Thomas B. } \\
\text { Caldwell }\end{array}$} & \multicolumn{2}{|c|}{$\begin{array}{c}\text { A. P. } \\
\text { Williams }\end{array}$} & \multicolumn{2}{|c|}{$\begin{array}{c}\text { Duncan } \\
\text { Anderson }\end{array}$} \\
\hline & No. & $\%$ & No. & $\%$ & No. & $\%$ & No. & $\%$ & No. & $\%$ & No. & $\%$ \\
\hline $\begin{array}{l}\text { Ripley } \\
\text { Engraved }\end{array}$ & 10 & 42 & 17 & 25 & 28 & 31 & 41 & 76 & 39 & 81 & 25 & 69 \\
\hline $\begin{array}{l}\text { Wilder } \\
\text { Engraved }\end{array}$ & 0 & 0 & 0 & 0 & 1 & 1 & 4 & 7 & 1 & 2 & 0 & 0 \\
\hline $\begin{array}{l}\text { Johns } \\
\text { Engraved }\end{array}$ & 0 & 0 & 0 & 0 & 0 & 0 & 1 & 2 & 0 & 0 & 0 & 0 \\
\hline $\begin{array}{l}\text { Sanders } \\
\text { Engraved }\end{array}$ & 0 & 0 & 0 & 0 & 2 & 2 & 0 & 0 & 0 & 0 & 0 & 0 \\
\hline $\begin{array}{l}\text { Maydelle } \\
\text { Incised }\end{array}$ & 5 & 21 & 15 & 22 & 15 & 17 & 0 & 0 & 2 & 4 & 4 & 11 \\
\hline $\begin{array}{l}\text { Pease } \\
\text { Brushed- } \\
\text { Incised }\end{array}$ & 0 & 0 & 8 & 12 & 14 & 16 & 3 & 6 & 3 & 6 & 1 & 3 \\
\hline $\begin{array}{l}\text { Harleton } \\
\text { Appliqué }\end{array}$ & 9 & 38 & 13 & 19 & 2 & 2 & 1 & 2 & 0 & 0 & 0 & 0 \\
\hline $\begin{array}{l}\text { Killough } \\
\text { Pinched }\end{array}$ & 0 & 0 & 3 & 4 & 15 & 17 & 0 & 0 & 0 & 0 & 1 & 3 \\
\hline $\begin{array}{l}\text { La Rue Neck } \\
\text { Banded }\end{array}$ & 0 & 0 & 2 & 3 & 4 & 4 & 0 & 0 & 1 & 2 & 1 & 3 \\
\hline $\begin{array}{l}\text { Belcher } \\
\text { Ridged }\end{array}$ & 0 & 0 & 2 & 3 & 0 & 0 & 0 & 0 & 0 & 0 & 1 & 3 \\
\hline $\begin{array}{l}\text { Bullard } \\
\text { Brushed }\end{array}$ & 0 & 0 & 7 & 10 & 9 & 10 & 4 & 7 & 2 & 4 & 1 & 3 \\
\hline $\begin{array}{l}\text { Mockingbird } \\
\text { Punctated }\end{array}$ & $\mathrm{X}$ & - & $\mathrm{X}$ & - & $\mathrm{X}$ & - & $\mathrm{X}$ & - & $\mathrm{X}$ & - & 2 & 6 \\
\hline Totals & 24 & & 67 & & 90 & & 54 & & 48 & & 36 & \\
\hline
\end{tabular}

$\mathrm{X}=$ Ceramics similar to Mockingbird Punctated are present but not formally identified as such. 
Chapter 8: Interpretations and Conclusions

Table 8.3). Ripley Engraved is the predominant fine ware, with James Richey also yielding an example of Wilder Engraved (see Figures 4.12, $5.17,5.21,6.22,6.24$, and 6.26). The recovery of a possible Sanders Engraved bowl and sherd from James Richey is intriguing given that this type usually is considered to be earlier than the main component at this site (see Figures 6.23 and 6.27); the significance of its presence here, along with Sanders phase artifacts at other sites in the area, is discussed more below. Maydelle Incised (or maybe Canton Incised) and Harleton Appliqué utility wares came from all three, and Pease Brushed-Incised, La Rue Neck Banded, Killough Pinched, and Bullard Brushed were found at William Ford and James Richey (see Figures 5.15, 5.16, 6.19, 6.20, 6.21, 6.25, 6.26, and 6.27). Also present at all three sites are jars with punctated rims that probably are related to Perttula's (2005:277-278) Mockingbird Punctated (see Figures 5.15, 5.20, 5.22, and 6.18). Unique to William Ford among the residential sites, but also present minimally at the Duncan Anderson cemetery, is Belcher Ridged. One notable characteristic of the assemblages from the residential sites is the low incidence of brushing among the decorated sherds from George Richey (12 percent) compared to William Ford and James Richey (34 and 48 percent); this reflects the earlier age of the main component at George Richey.

Chapter 7 shows that that the main Ripley Engraved bowl motif from the three Tankersley Creek cemeteries is the slanted scroll and that straight scrolls also are prominent at Thomas B. Caldwell and Duncan Anderson. The latter also has moderate numbers of bowls with the band of elements motif, which is also moderately prominent at A. P. Williams, along with the opposed scrolls motif. The similarities in the motifs employed and their structure indicate that the potters who made these vessels were involved in a shared ceramic tradition. There is variability between the sites in terms of how elements were used in Ripley motifs, though, and these differences suggest the assemblages represent the work of particular groups of potters. Because few of the sherds from the residential sites have recognizable Ripley Engraved motifs, it is hard to extend this part of the analysis to these sites. Chapter 7 does note some linkages between them and the cemetery sites, though.

\section{Results of Petrographic and INAA Studies}

Forty-five sherds from the George Richey, William Ford, and James Richey sites (15 from each) were subjected to petrographic study and instrumental neutron activation analysis (INAA). Previous such studies of Caddo pottery (e.g., Cecil 2012; Ferguson and Glascock 2012) often have included a variety of vessel forms, decorative modes, and ceramic types to try to address local vs. nonlocal origins. The results of past INAA studies have often been muddy, probably for a variety of reasons, including the fact that clays across northeast Texas are similar geologically, grog (i.e., crushed sherds from other vessels) is the predominant tempering agent and adds to the INAA signature in unmeasurable ways, the likelihood that different vessel forms and ceramic types had different potentials for trade and movement out of the communities where they were manufactured, and perhaps even the possibility that certain clays for the manufacture of certain vessel types were traded as well.

The study done for this project (reported in Appendixes I and J) involved only large and medium-sized utility wares ( 44 jar sherds and 1 sherd from a deep bowl) in an effort to focus on what is most likely to be local, without adding complications from vessels or clays that were brought in. The sample consists of both typed and untyped vessels. The former are Maydelle Incised, Harleton Appliqué, Pease BrushedIncised, Killough Pinched, and La Rue Neck Banded. Untyped ones include a few undecorated jars and a variety of others decorated mostly with punctations, incising, or brushing; many of these represent Bullard Brushed jars that could not be typed with confidence based on sherds and medium-sized to large jars with horizontal rows of punctations around the rim and a plain body, similar to what Perttula (2005:277-278) calls Mockingbird Punctated.

Dr. Leslie Cecil's petrographic analysis did not provide any dramatic results, but it did yield some insights into choices the Tankersley Creek potters made in selecting and manipulating the clays. She identified five basic groups (three with subgroups) based on paste characteristics and inclusions. Paste Group 1 consists of 23 sherds with grog, bone, and larger angular quartz sand added to a paste containing naturally occurring small quartz sand. Seven of these also have 
angular chert inclusions that may have been introduced along with the larger quartz sand. A single Group 1 sherd has microcline inclusions that probably were natural to the clay; 2 others have natural K-feldspar inclusions; and 3 others have biotite that could be natural. Eight Group 1 sherds have both angular chert and biotite inclusions; as above, the biotite probably is part of the clay matrix, while the chert may have accompanied the large, angular quartz sand when it was introduced as temper. The 6 Group 2 sherds are characterized by grog and larger angular quartz sand as additions to a paste with natural small quartz sand; three subgroups are defined based on variability in the occurrence of biotite, small rounded chert grains, and K-feldspar as natural components of the clay matrix. The 4 Group 3 sherds have bone and larger angular quartz sand added to a paste with natural small quartz sand inclusions. A single sherd makes up Paste Group 4; it has only large angular sand with detrital chert grains as an additive to a sandy clay matrix. Paste Group 5 , with 11 sherds, is characterized by a naturally sandy paste without added large, angular quartz grains; four subgroups are distinguished based on variability in the occurrence of biotite and chert grains as natural components of the clay matrix and grog and bone as added temper, while two others may have sand as an addition to a clayey paste along with grog or bone and with detrital chert and K-feldspar as natural or incidental constituents.

Lacking petrographic data for the local clays, it is hard to guess how much of the variability between the groups and subgroups relates to use of multiple clay sources, but it is easy to see that as a possibility. Otherwise, it is clear that the potters almost always chose to add grog as temper (39 out of 45 samples; although macroscopic and low-power magnification identified grog in the other 6 samples as well) and often added bone (35 samples) and large quartz sand (at least 34 samples) in varying combinations. Multiple sources of sand for use as temper may have been exploited, based on the variable occurrence of detrital chert and K-feldspar that likely accompanied the sand grains.

Only the two smallest paste groups have restricted spatial distributions, with all of the Paste Group 3 sherds and the single Paste Group 4 sherd coming from the William Ford site. The three larger groups are well represented at all three sites: 53, 33, and 67 percent of the samples from George Richey, William Ford, and James Richey are in Paste Group 1; 13 percent from all three sites are in Paste Group 2; and 33, 20, 20 percent are in Paste Group 5. Hence, at least at the aggregate level, the petrographic data do not appear to be very informative about locations of production.

Similarly, among the samples identified to type, only those with single examples are restricted to single groups (La Rue Neck Banded, Paste Group 1; Pease Brushed-Incised, Paste Group 5). The 2 Harleton Appliqué sherds, 2 Killough Pinched sherds, and 4 Maydelle Incised sherds are in two groups each; and the 6 possible Bullard Brushed sherds and 11 possible Mockingbird Punctated sherds each are in four groups. In short, the petrographic data do not appear to be very distinctive in terms of pottery styles as archeologists see them.

Dr. Jeffrey R. Ferguson's and Dr. Michael D. Glascock's INAA analysis found no clear compositional differences between the three sites. The analytical and interpretive difficulties of dealing with INAA in the Caddo area aside, this lack of distinction is not a surprise, since samples were selected to minimize variability and focus on ceramics most likely to have been made locally. About all that can be said about the results of their attempt to compare this data set to the overall data set for northeast Texas is that these samples are consistent with others from the same part of the region (as well as other parts, except the Red River valley to the north).

\section{The Lithic Industries}

It is hard to construct a very precise picture of the lithic industries practiced by the Tankersley Creek Caddo, since most or all of the sites, except for the Thomas B. Caldwell and A. P. Williams cemeteries, have multiple components, and many of the artifacts are not temporally diagnostic. Certainly, the abundance of dart points at the three excavated sites and in the Anderson collection points to substantial use during the Archaic period and probably the Woodland period, and some unknown portions of the nonprojectile point assemblages go with these earlier occupations, as well as the Early Caddo occupations (Table 8.4). A few observations can be made, however. Maud/Talco, Bassett, and Bonham arrow points were the main styles 
produced by the local knappers, judging from their frequencies at both the residential sites and the two cemeteries (see Table 8.1; see Figures 4.14, 5.30, and 6.28). Alba and Perdiz points are less common, but their occurrence at the A. P. Williams cemetery indicates they too were part of the assemblage (see Figure 4.14). Some of this variety in point styles must relate to the long span of time covered by the sites. Other than these categories, only the gunflints and perhaps the celts represent solely Middle-Historic Caddo occupations (see Figures 5.26, 5.27, 6.30, and 6.32), the former because they have to be of historic age and the latter because they are common in Middle-Late Caddo burials, such as at both the Caldwell and Williams cemeteries (though the ones from the William Ford and James Richey sites are not from burials).

The chipped stone tool assemblages are not very diverse, consisting mostly of projectile points, knifes, edge-modified flake tools, and utilized flakes, along with manufacturing failures and rejects. The assemblages of ground, pecked, and battered stone artifacts also have little diversity, with most being grinding slabs, manos, anvils, or hammerstones, and many serving multiple functions. Even without being able to isolate a temporally discrete assemblage, these collections seem to indicate an emphasis on creating multifunctional tools that could be used to satisfy a variety of needs. In addition, it is likely that the Caddo who lived here made many of their tools out of organic materials such as wood, bone, and shell. Among these were implements associated with corn agriculture. Although the grinding slabs and manos could have been used to process agricultural products, these tools occur in a wide variety of contexts in northeast Texas and were not specific to processing corn (Shafer 1975:349-350). Swanton (1942:156) notes that the Hasinai Caddo used certain woods to make agricultural implements as well as mortars and pestles.

Raw materials available locally or nearby were adequate for manufacture of most of the stone tools needed at these sites, regardless of the age of the component. Aggregating all components, 79 percent of the chipped stone tools, 91 percent of the ground/pecked/battered stone tools, and 92 percent of the debitage resulting from tool manufacture are of these materials, most of which are a variety of cherts, quartzite, silicified wood, ferruginous sandstone, and hema- tite (Table 8.5). With nonlocal materials occurring in higher percentages of tools than debitage at the three excavated residential sites, it is clear that many of these tools arrived there in finished or nearly finished form. Subsequent refinishing and repair likely account for most of the debitage.

A notable difference in raw material usage among the three excavated residential sites is that both chipped stone tools and debitage of nonlocal materials are more abundant at the George Richey site (24 and 17 percent) than at the other two sites (12-16 and 5-6 percent). The fact that the pattern holds even when looking just at the arrow points ( 9 of the 26 from George Richey are of nonlocal materials, while none from William Ford and 1 of 6 from James Richey are) indicates this is not a function of the aggregated nature of the collection. This pattern suggests that the Caddo who lived here could have experienced decreased extraregional interaction through time, although the numbers are too small to have a great deal of faith in this interpretation. As for earlier time periods, these nonlocal materials are from both central Texas and sources along and north of the Red River in Oklahoma and Arkansas.

\section{Community Organization and Extent}

To this point, we have talked mostly about the Caddo people who lived along the middle reach of Tankersley Creek after A.D. 1250 as representatives of a local community. We have not been explicit about what this means, though, and we have paid scant attention to how these people were connected to their Caddo neighbors. This section remedies that by trying to fit the sites in the U.S. Highway 271 project area into the bigger Titus phase picture.

\section{Previous Studies of Titus Phase Spatial Organization}

As discussed in Chapter 3, one of the most comprehensive attempts to look at spatial organization among the Titus phase Caddo was J. Peter Thurmond's M.A. thesis (1981, 1990). In it, he associated the Titus phase with the Cypress cluster, a group of similar sites that he considered to represent a third Caddo Indian confederacy comparable to those of the Hasinai and Kadohadacho, both of which were 


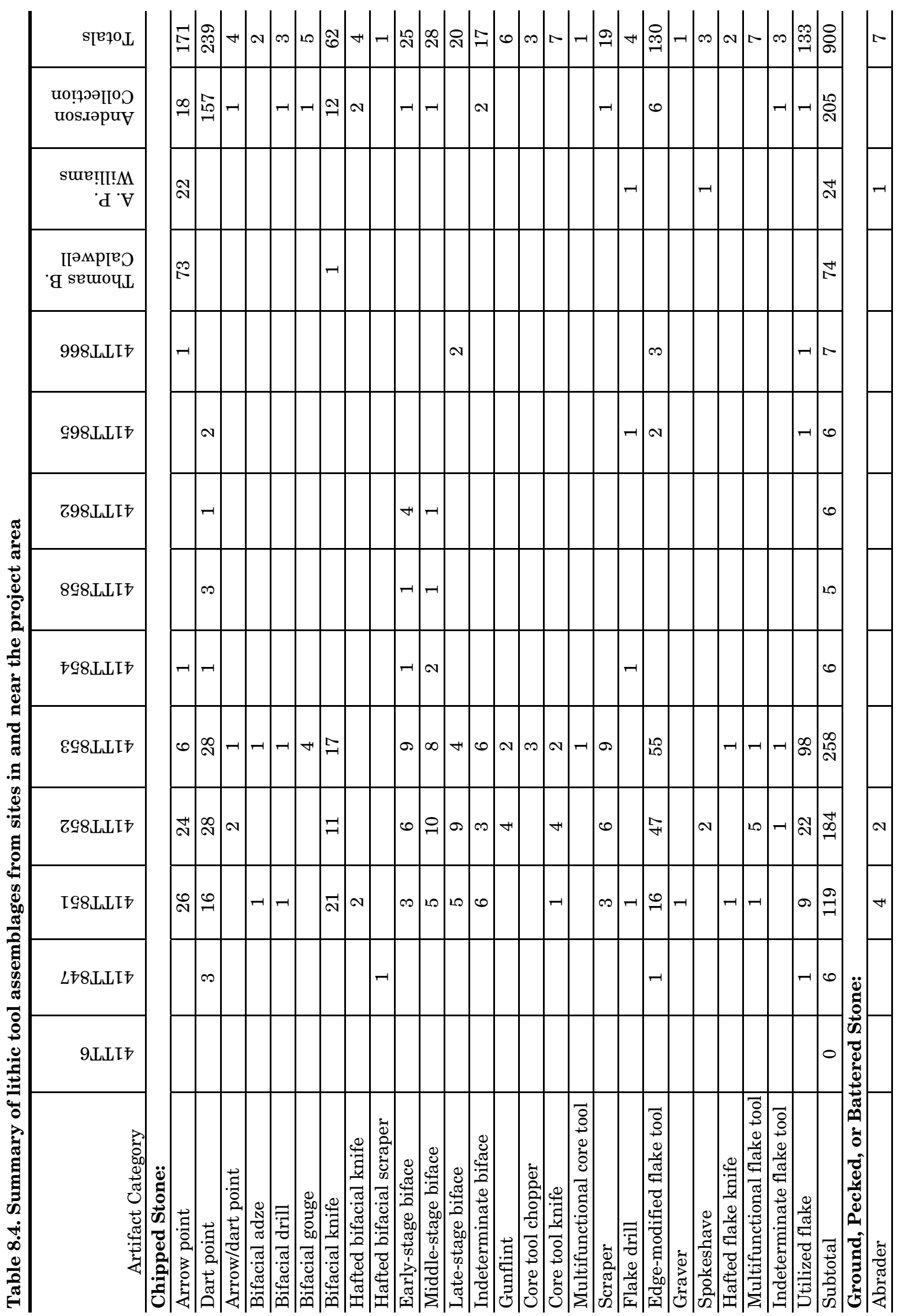




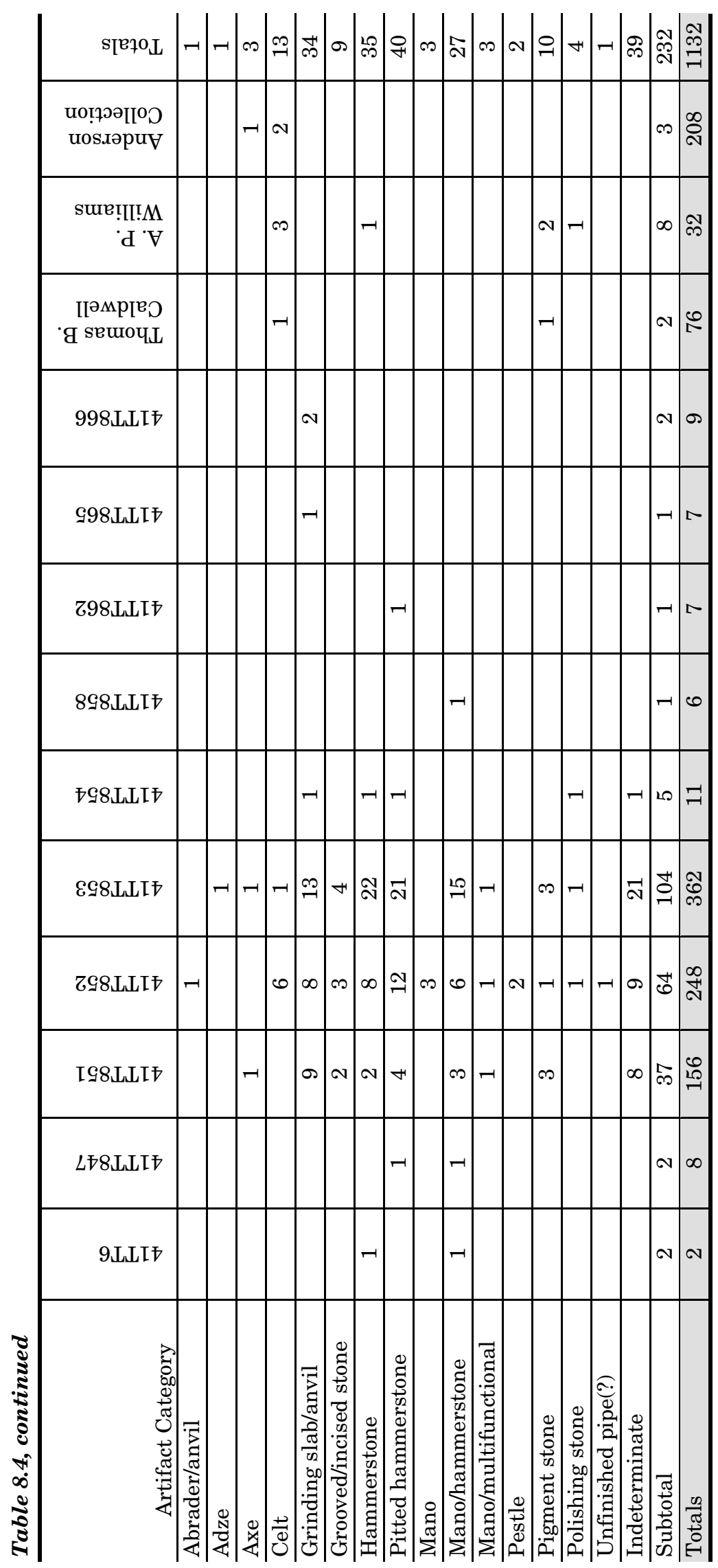


well documented ethnohistorically. Thurmond (1990:232) saw the Cypress cluster as being "centered geographically on the upper Cypress Creek, White Oak Bayou, and Lake Fork Creek basins" and as extending across a large area from the eastern arm of Lake Fork Reservoir on the west to Black Cypress Bayou on the east and from White Oak Creek and the Sulphur River on the north to the Sabine River on the south (Figure 8.6).

Based on burial assemblage variability in this area, which was ca. $100 \mathrm{~km}$ across both east-west and north-south, Thurmond saw four spatial subclusters of sites-which he named Three Basins, Tankersley Creek, Swauano Creek, and Big Cypress Creek-and proposed that they represented contemporaneous sociopolitically integrated tribes or subtribes (Thurmond 1985:191-196). The Three Basins subcluster sites were in the western part in the Lake Fork Creek and Big Sandy Creek drainages, the upper-middle part of the White Oak Creek basin and north to the Sulphur River, and the extreme upper reaches of Big Cypress and Little Cypress Creeks, extending over an area of $45 \mathrm{~km}$ east-west by $90 \mathrm{~km}$ north-south (ca. $3,200 \mathrm{~km}^{2}$ ). The Big Cypress Creek subcluster sites were at the downstream end of the region, mostly on Big Cypress Creek itself but also south of there on Little Cypress Creek and the Sabine River, extending over an area of $30 \mathrm{~km}$ east-west by $55 \mathrm{~km}$ north-south (ca. $1,300 \mathrm{~km}^{2}$ ). The other two much smaller (ca. $550 \mathrm{~km}^{2}$ each) subclusters overlapped each other in the area between the Three Basin and Big Cypress Creek subclusters. Tankersley Creek was the western one, and Swauano Creek was the eastern one. The U.S. Highway 271 project area was in the area of the Tankersley Creek subcluster, at the west edge of the Swauano Creek subcluster.

As Thurmond (1990:214) well knew, the limitations of the data made his interpretations speculative, and he was not able to take his analysis further than just suggesting that the spatial differences in burial assemblages related to different Titus groups. New data acquired since then have allowed more synthetic studies that have led to a better understanding of spatial organization among the Titus phase Caddo. Foremost among the more-recent studies are those of Perttula (1992, 2004, 2005; Perttula and Sherman 2009) and Fields and Gadus (2012).

While agreeing that the four Titus subclusters could represent distinct groups that persisted over time, Perttula (2004:397) goes

Table 8.5. Summary of local vs. nonlocal materials among the lithic artifacts

\begin{tabular}{l|c|c|c|c|c|c|c|c|c}
\hline & \multicolumn{2}{|c|}{ Chipped Stone Tools } & \multicolumn{3}{c|}{ Debitage } & \multicolumn{3}{c}{$\begin{array}{c}\text { Ground, Pecked, and } \\
\text { Battered Stone Tools }\end{array}$} \\
\hline \multicolumn{1}{c|}{ Site } & Local & Nonlocal & Nonlocal & Local & Nonlocal & $\begin{array}{c}\text { \%onlocal } \\
\text { Nocal }\end{array}$ & \multicolumn{2}{c}{ Nonlocal } & Nonlocal \\
\hline 41TT6 & 0 & 0 & 0 & 41 & 0 & 0 & 2 & 0 & 0 \\
\hline 41TT846 & 0 & 0 & 0 & 58 & 0 & 0 & 0 & 0 & 0 \\
\hline 41TT847 & 3 & 1 & 25 & 169 & 4 & 2 & 2 & 0 & 0 \\
\hline 41TT851 & 68 & 24 & 26 & 1449 & 288 & 17 & 36 & 1 & 3 \\
\hline 41TT852 & 101 & 14 & 12 & 2342 & 138 & 6 & 55 & 9 & 14 \\
\hline 41TT853 & 154 & 29 & 16 & 2412 & 116 & 5 & 102 & 2 & 2 \\
\hline 41TT854 & 3 & 0 & 0 & 149 & 17 & 10 & 5 & 0 & 0 \\
\hline 41TT858 & 4 & 0 & 0 & 130 & 1 & 1 & 1 & 0 & 0 \\
\hline 41TT862 & 1 & 0 & 0 & 121 & 0 & 0 & 1 & 0 & 0 \\
\hline 41TT865 & 4 & 0 & 0 & 200 & 9 & 4 & 1 & 0 & 0 \\
\hline 41TT866 & 5 & 0 & 0 & 80 & 2 & 2 & 1 & 0 & 0 \\
\hline Thomas B. Caldwell & 44 & 4 & 8 & 2 & 0 & 0 & 2 & 1 & 33 \\
\hline A. P. Williams & 12 & 2 & 14 & 0 & 0 & 0 & 5 & 3 & 38 \\
\hline Anderson Collection & 127 & 38 & 23 & 8 & 3 & 27 & 9 & 3 & 25 \\
\hline Totals & 526 & 112 & 21 & 7161 & 578 & 8 & 222 & 19 & 9 \\
\hline
\end{tabular}


on to conclude that some of the variability that distinguishes the subclusters might relate to temporal changes rather than geographic differences, echoing Turner's (1978) earlier conclusions. Further, in his analysis of the mortuary ceramics from the Pilgrim's Pride site, he could not get the assemblage to fit well with any of the subclusters, and he concluded that "the Pilgrim's Pride site, and probably other Titus phase sites in the immediate vicinity, apparently represents part of another local but separate Titus phase community from those subsumed under the subcluster groupings proposed by Thurmond" (Perttula 2005:280-281). He reached much the same conclusion in his analysis of the ceramics from the Mockingbird site (Perttula et al. 1998:251-253).

The syntheses of the evidence from the Pilgrim's Pride and Ear Spool sites (Perttula 2005:357-364; Perttula and Sherman 2009:375377) barely mention the four subclusters and instead identify a string of Late Caddo communities along Big Cypress Creek within the Titus heartland. Perttula probably chose to focus on the heartland because of the relatively abundant data from there compared to many other parts of the Titus area. Three of these communities, in the southeast part, are within the northern section of Thurmond's Big Cypress Creek subcluster, and two crosscut both the Swauano Creek and Tankersley Creek subclusters (Figure 8.7). More recently, a sixth community has been suggested at the upstream end of the heartland, in the area of the central part of the Tankersley Creek subcluster not far south of the U.S. Highway 271 project area (Perttula, Marceaux, and Nelson 2012:6-7). ${ }^{3}$ None of these communities was in the area of the Three Basins subcluster, as it is almost entirely outside the heartland.

According to Perttula and Sherman (2009:375-377), these heartland communities consisted of dispersed farmsteads and villages affiliated with key sites that contained public architecture (mounds and ritual buildings) or community cemeteries, i.e., places that were reserved for activities that integrated the community and bound its parts together. They propose that the five communities downstream from Tankersley
Creek were anchored by the following key sites, moving from southeast to northwest: (1) Whelan (41MR2), with four mounds, at the confluence of Arms Creek and Big Cypress Creek, and H. R. Taylor (41HS3) and Peanut Patch (41HS825) nearby, with more than 150 graves as the main cemeteries; (2) in the vicinity of Meddlin Creek, the four mounds at the Harroun (41UR10) site and three mounds at the Chastain/Dalton/Camp Joy (41UR11, 41UR18, and 41UR144) complex, along with community cemeteries at Pleasure Point (41MR63), Henderson-Southall (41UR3), Big Oaks (41MR4), and Sandy Creek (41MR122), which probably contained more than 500 graves; (3) the single-mound Shelby (41CP71), P. S. Cash (41CP2), and Sam Roberts (41CP8) sites on Greasy and Prairie Creeks, with community cemeteries at Shelby and Gold Star Ballroom (41UR107) containing more than 250 graves; (4) the community cemeteries at Tuck Carpenter (41CP5) and Harold Williams (41CP10), with more than 166 graves, on Dry and Swauano Creeks and maybe the community cemetery at the W-S site with 118 graves not far away, perhaps accompanied by the single-mound Tom Hanks site (41CP239); and (5) the single-mound Pilgrim's Pride site (41CP304) on Walkers Creek and perhaps Tiddle Lake (41CP246) with another mound nearby. The proposed key sites for the sixth community, on Big Cypress upstream from Tankersley Creek, are Sandlin Dam (41TT726) and Lower Peach Orchard (41CP17). The former was a community cemetery with more than 150 graves. The latter, with $35+$ known graves, apparently was not large enough to be considered a community cemetery, but with some of graves being large shaft tombs, it clearly was an important place to the Caddo who lived nearby.

All together, there are nine known mound sites in the Titus heartland (considering Chastain, Dalton, and Camp Joy as a single complex) in the list of key sites above (excludes the recently identified probable mound at the Frank Benson site in Titus County [Perttula 2012:83], as well as several others discussed later in this chapter). Six have single mounds, one has 3 mounds, and two have 4 mounds. Though not all are well understood, most of

\footnotetext{
${ }^{3}$ Another recent version combines the fourth and fifth original communities into one, such that the sixth community referenced here becomes the fifth one (Perttula 2012:83).
} 


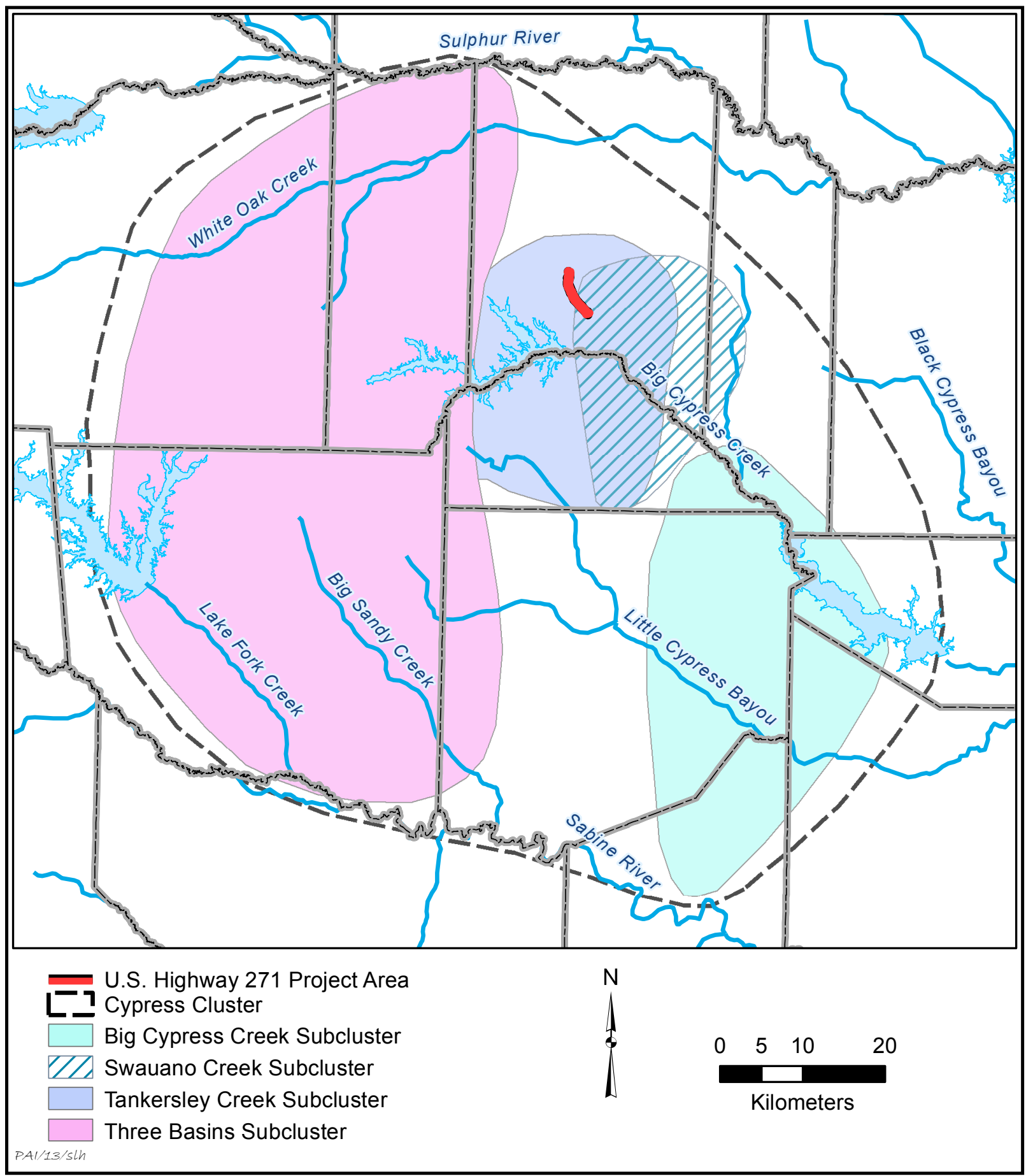

Figure 8.6. Map of Thurmond's (1990) Cypress cluster showing extents of hypothesized Titus phase subclusters. 


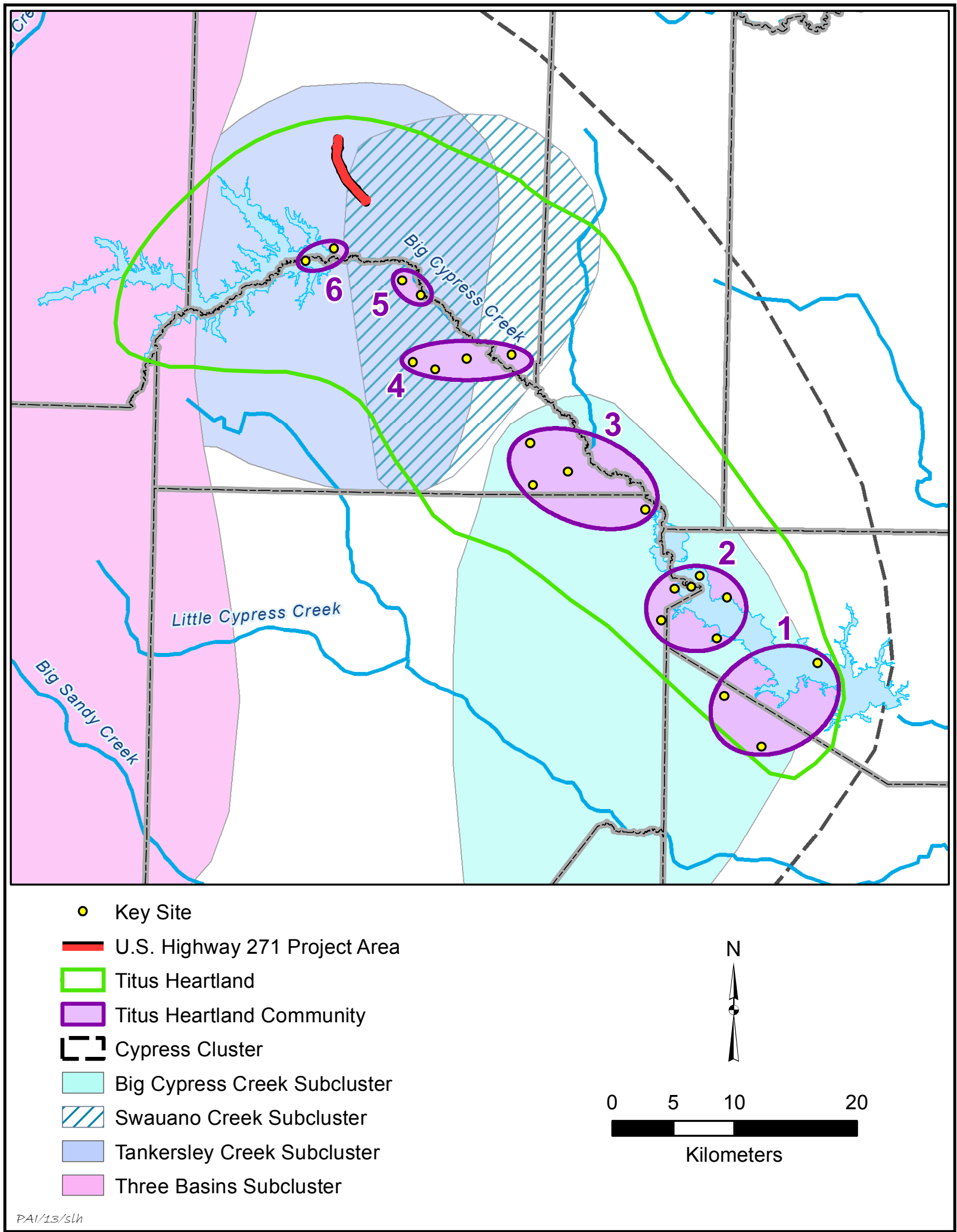

Figure 8.7. Map of the extents of the key sites for the six hypothesized Titus heartland communities and Cypress subclusters. 
the 17 small rounded mounds apparently were erected to cap burned ceremonial structures, some of which had extended entryways ( 1 mound at the Harroun site was put atop a grave). All three of the known multiple-mound sites (Whelan, Harroun, and the Chastain/ Dalton/Camp Joy complex) are in the southeastern part of the heartland, which suggests that not all communities along Big Cypress Creek participated in political and social life in the same way and supports the idea that a hierarchical cultural system prevailed here (Perttula and Sherman 2009:391). Perttula and Sherman (2009:392) also point to the limited residential features at the Whelan and Harroun sites as an indication that the religious and political leaders at these sites maintained separation from the greater population and, in doing so, solidified their authority through regulation of ritual and resources. This does not appear to have been the case at mound sites farther up the Big Cypress, however, where Perttula and Sherman (2009:392) see no separation of the mound sites from the greater communities. Again, this indicates differences between Titus phase communities within an overarching stratified social and political system.

The 12 known community cemeteries listed as key sites above are distributed more equably than the mounds, with only half being in the southeastern two communities where the multiple mound sites are and the other half being upstream from there (Perttula 2004:Figure 13.31). Hence, they may have served more universally to integrate communities, sometimes in the absence of ceremonial landscapes defined concretely by mounds and plazas. As discussed in Chapter 7, the fact that the three Titus phase cemeteries known to contain large shaft graves, which surely held elite members of the society-Pleasure Point, Shelby, and Lower Peach Orchard (excludes Pine Tree Mound, which is outside the heartland)-are distributed such that they are in separate groups of key sites argues that at least some of these truly were distinct communities occupied by groups of people who, though related, considered themselves different than their neighbors.

Perttula's hypothesis of five or six communities within the Titus heartland is appealing because, being based on differences in mound-building activity, cemetery use, and burial assemblages, it posits logically that the heartland contains the archeological expressions of multiple communities with differing degrees of interrelatedness. Further, it can be broadened to include ideas such as that discussed in Chapter 7, i.e., that the Titus phase Caddo established small local communities along tributaries of Big Cypress Creek throughout the basin, but the centers of power and authority that united these local groups into distinct communities were tethered to the main stem of Big Cypress and the lower reaches of particular tributaries. This expanded model is based on much more data than Thurmond's subclusters hypothesis, and it provides a more-robust framework for archeological investigation in the region. As discussed, below, however, this model does not necessarily fit well with all of the archeological evidence and may be too simplistic.

In terms of hierarchical organization, a case can be made for two core communities with a dichotomy of "belief and cultural practices" within the heartland, each covering about $675 \mathrm{~km}^{2}$. The boundary between them was between where Greasy Creek and Dry Creek join Big Cypress Creek, meaning that one encompasses the three downstream groups of key sites, i.e., communities, listed above and the other contains the three upstream ones and the U.S. Highway 271 project area. Perttula and Sherman (2009:397-401) see a split in ceramic traditions between these core communities. Trade wares such as Avery Engraved from McCurtain phase sites on the Red River to the north are more common in burial assemblages of the northwestern core community, along with more La Rue Neck Banded and untyped jars and plain vessels overall. In the southeastern core community, Taylor, Bailey, and Simms Engraved appear as important secondary types along with trade wares from the Belcher phase on the Red River to the east. Utility wares for the southeastern sites include more Harleton Appliqué, Bullard Brushed, and Karnack Brushed-Incised jars. Ripley Engraved dominates the finewares of both subtraditions, though bowl motifs vary some between them (Perttula and Sherman 2009:400).

The latest synthetic treatment of Titus phase spatial organization is not as relevant to the U.S. Highway 271 project area, because it arose from work at the Pine Tree Mound site, which is outside the heartland in the Sabine 
River basin. Its main contribution to this topic is that it hypothesizes a third Titus core community comparable to the two in the heartland (Fields and Gadus 2012:673-677). One difference is that Fields and Gadus did not define any constituent local communities, though this probably relates mostly to a scarcity of data that would make such communities evident. They further suggest, following Thurmond (1985), that Story and Creel's (1982) model of sociopolitical organization and settlement patterning for the Frankston and Allen phases of the Neches-Angelina River basin could be useful in the Titus area as well. That model posits a single major ceremonial center for the "affiliated group," which could equate to a core community in the Titus phase area. This center would have been "the temple-residence complex...associated with a paramount leader, the grand xinesi in the historic accounts" (Story and Creel 1982:32). Positioned around this center would be multiple scattered supporting "constituent groups," each containing a lesser ceremonial center and potentially an array of residential sites ranging from single-house farmsteads to small villages, as well as shortterm use sites. The lesser centers likely would be the residence-ritual complexes of local leaders, i.e., caddis (Story and Creel 1982:32). Using this model, each of the three posited Titus core communities would have a hierarchical arrangement of primary and secondary ceremonial sites.

Another contribution of the Pine Tree Mound project is that it emphasizes how important it is to look beyond the heartland to gain a fuller understanding of what the Titus phase is all about. The maximum extent of the phase as shown by Perttula (2005:358) encompasses about $6,240 \mathrm{~km}^{2}$ beyond the $1,350-\mathrm{km}^{2}$ heartland (i.e., 4.6 times larger), and Fields and Gadus's analysis suggests that in some areas this maximum boundary should be pushed even farther out. These other non-heartland areas may contain few or no communities like that around Pine Tree Mound, with its well-defined ceremonial space (multiple mounds around a plaza) and elite community cemetery all in one place, but they surely contain Titus communities of one sort or another. As appears to be the case in the heartland itself, these likely vary in terms of social complexity and connectedness to other nearby communities.

\section{The Tankersley Creek Sites as a Local Community}

The model developed to this point to help understand the U.S. Highway 271 sites suggests that they are rural farmsteads within a local community near the upstream western end of the Titus heartland. The sections below explore this idea by trying to identify the integrative sites for this community and addressing the extent and boundaries of the community.

\section{POTENTIAL INTEGRATIVE SITES}

Two likely candidates for integrative sites for this community are two cemeteries on Big Cypress Creek about 5-8 km southwest of the current project area (Figure 8.8): the community one at Sandlin Dam with 150+ graves, and another one at Lower Peach Orchard that had fewer graves $(35+)$ but clearly had burials of elite members of the community in large shaft tombs. There are other known sites that could have served integrative functions as well.

\section{Sandlin Dam and Lower Peach}

Orchard Sites

The most concrete information we have about the Sandlin Dam site is its location, which was on a prominent ridge jutting out into the Big Cypress Creek floodplain $1.5 \mathrm{~km}$ west of where Tankersley Creek joins the Big Cypress; this ridge is the first one west of the Tankersley Creek valley. According to the form at the Texas Archeological Research Laboratory, the site, which was mostly destroyed by looters and dam construction, reportedly contained 150 burials with some rumors of up to 300 graves, clearly making it a community cemetery. The graves contained Titus phase pottery and Bassett arrow points, and a variety of dart points and other arrow point styles were found in nonburial contexts. With so little information, it is impossible to address the question of specific ties between this site and those in the U.S. Highway 271 project area, other than to say they likely were contemporaneous and that it would have been an easy trip between the two.

We have a bit more information for Lower Peach Orchard, even though it too was mostly removed by looters and dam construction. Part of it was a large residential site with four low 


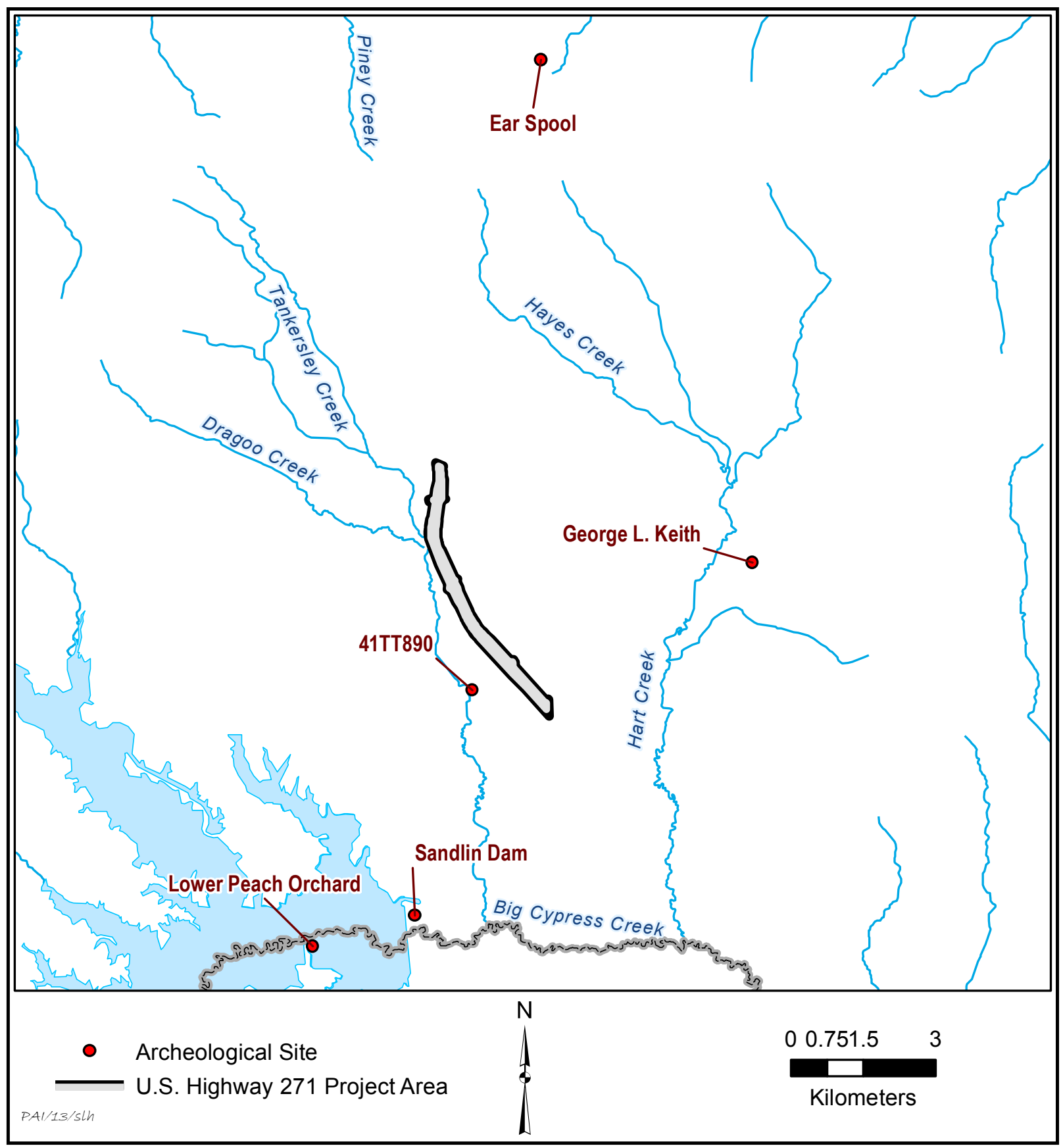

Figure 8.8. Map of the U.S. Highway 271 project vicinity showing possible integrative sites for the Tankersley Creek community.

knolls containing midden debris positioned on a terrace edge above the Big Cypress ca. $2.2 \mathrm{~km}$ west-southwest of Sandlin Dam (Thurmond 1990:148-149). No mounds were reported, but it is possible that special buildings had been erected on the knolls or elsewhere. Based on a collection of sherds, Thurmond (1990:149) suggests that this residential occupation occurred during the Whelan phase. A Titus phase cemetery northwest of the residential area reportedly contained at 
least 35 graves in north-south rows of seven or eight graves each. Most graves contained single individuals and were 1.8-2.4 $\mathrm{m}$ deep. The five or six graves in the row at the edge of the terrace were different, though, because they were much deeper at 3.7-5.5 m and contained multiple individuals (Thurmond 1990:149). One of these graves was ca. $4 \mathrm{~m}$ deep, measured 3.0x2.5 $\mathrm{m}$ at its floor, and contained three bodies side by side. Another grave that also reportedly contained three individuals was $3.7 \mathrm{~m}$ deep and measured $3.7 \times 1.8 \mathrm{~m}$ at the floor. A third shaft grave was $4.3 \mathrm{~m}$ deep and had floor dimensions of 3.1x2.4 m. Grave offerings included Ripley Engraved pots and vessels of other Titus phase types, Maud and Bassett arrow points, celts, ceramic pipes, and large Galt bifaces. The sizes of these graves, the presence of multiple bodies, and the inclusion of high-status offerings such as Galt bifaces clearly mark this as an important place. The pottery and arrow point styles indicate that this site was contemporaneous with those in the U.S. Highway 271 project area, and like Sandlin Dam, it certainly would have been a short trip to this cemetery from middle Tankersley Creek. Fortunately, 20 ceramic vessels reportedly from this site were in the Margaret Hinton collection that Perttula, Marceaux, and Nelson (2012:117-136) analyzed. The 15 that can be typed consist of five Ripley Engraved bowls (varieties Galt, Caldwell, Carpenter, and Gandy), two Turner Engraved bowls, a Wilder Engraved bottle, a Wilder Engraved olla, a Bullard Brushed jar, a Mockingbird Punctated jar, three Harleton Appliqué jars, and a Cass Appliqué jar. All of these types except for Turner Engraved and Cass Appliqué and all four of the Ripley varieties are represented at one or more of the Tankersley Creek sites, implying connections between them and Lower Peach Orchard.

\section{Site $41 \mathrm{TT} 890$}

These two cemeteries are not the only sites in this area that could have served integrative functions, though. In fact, there is a possible mound site, 41 TT 890 , that is only $0.75 \mathrm{~km}$ southwest of the south end of the U.S. Highway 271 project area. Not much is known about it, as it has not been investigated professionally. It is on a high spot on the floodplain of Tankersley Creek, immediately adjacent to the modern channel. According to the site form, the site is large, covering some $200,000 \mathrm{~m}^{2}$, and contains a ca. 2-m-high, 20-m-diameter rise that, when observed by archeologist Bo Nelson in 2002, had a large hole excavated in the center by artifact collectors. Nelson cleaned a wall of that hole in 2004 and, based on the presence of lenses of charcoal staining and soil zones with clay mixed in sandy loam, concluded that the rise likely is a constructed mound (Bo Nelson, personal communication 2011). He also observed artifacts the landowner had collected, including dart and arrow points, debitage, ceramic sherds and vessels, animal bones, and human remains. The human remains and four ceramic vessels reportedly had come from two graves the landowner excavated somewhere off the probable mound. While we do not know anything concrete about the age of the Caddo component at this multicomponent site, there is a good chance that it is Middle-Late Caddo, given the ages of the other Caddo sites nearby and the fact that single mounds are the rule on Titus phase mound sites in the upper half of the Big Cypress Creek basin.

\section{George L. Keith Site}

The George L. Keith Farm, on Hart Creek ca. $6 \mathrm{~km}$ east of the U.S. Highway 271 project area, is another mound site that could be associated with the Middle-Late Caddo sites on Tankersley Creek. Walter Goldschmidt (1934c) of the University of Texas trenched the mound in 1934, and Kenneth Brown, then a student at the University of Texas, performed some limited work there in 1971. Thurmond (1990:183-185) recognized that the site has a substantial Late Caddo component based on the presence of a small Titus phase cemetery with at least 7 graves (Perttula, Walters, and Nelson [2010a:9] report at least 15 graves) containing Ripley Engraved, Wilder Engraved, Cass Appliqué, and La Rue Neck Banded vessels and Talco and Maud arrow points on the upland margin east of the mound, as well as the presence of 23 Ripley Engraved bowl sherds, 2 Ripley/Avery sherds, 41 other mostly Late Caddo engraved body sherds, 7 Pease Brushed-Incised body sherds, 2 Killough Pinched body sherds, 1 Cass or Harleton Appliqué body sherd, and 71 untyped brushed sherds among the 2,112 Caddo sherds collected from the site. However, he concluded that the most intensive use, including most or all of the mound construction, occurred during the Early Caddo period. He based this on the 
following: the high ratio of plain body sherds to brushed body sherds (16 to 1); the presence of 71 Williams Plain sherds; and the presence of 137 sherds he typed as Sanders Engraved, Sanders Plain, or Canton Incised, i.e., styles associated with the Red River valley Sanders phase.

However, there are at least five reasons to think that the predominant component at Keith is later than the Early Caddo period, a conclusion that Perttula, Walters, and Nelson (2010a:10) also reached: (1) the collection contains only two sherds associated with a common early type (Crockett Curvilinear Incised), unlike the Early Caddo ceremonial center at the L. A. Hale site nearby, which yielded Holly Fine Engraved, Hickory Fine Engraved, Spiro Engraved, and Weches Fingernail Impressed sherds; (2) the Williams Plain sherds at Keith could just as easily represent Woodland occupations as Early Caddo ones; (3) though not well dated, the Sanders phase is now thought to have spanned the A.D. 1100-1300 interval and to have immediately preceded the Late Caddo McCurtain phase in the Red River valley (Bruseth 1998:52, 58); (4) the George Richey and James Richey sites both contained small amounts of Sanders phase pottery (deep conical bowls at the former, and a Sanders Engraved bowl and sherd at the latter), suggesting some continued use of these styles into the Middle-Late Caddo period on Tankersley Creek; and (5) the percentage of brushed sherds at Keith (3.9 percent of all sherds, 14.7 percent of decorated sherds) is comparable to that at the George Richey site (3.7 percent of all sherds, 12.3 percent of decorated sherds), implying similarly aged, predominant Middle Caddo components at both.

Further, a radiocarbon date on charcoal obtained in 1971 from the cleaned wall of the 1934 trench into the mound supports this conclusion. Its context is not the best, since it was on a composite sample collected from several layers of fill within the ca. 1.5-m-thick middle part of the mound and probably came from preexisting midden deposits rather than burning on mound surfaces, but the raw one-sigma age $(540 \pm 70 \mathrm{~B}$. P.) and calibrated two-sigma date (A.D. 12851464, assuming a carbon isotope value of -25.0) certainly implies that construction of at least part of the mound occurred in the Middle or Late Caddo period, contemporaneous with occupation of one or all of the Tankersley Creek sites. Review of some of the decorated ceramics from the Keith site at the Texas Archeological Research Laboratory supports this conclusion, since some of the presumably late pottery (15 Ripley sherds and 1 Ripley-Avery sherd) actually came from midden deposits beneath the mound, along with some of the Sanders phase pottery.

The mound at Keith was very large, extending $73 \mathrm{~m}$ north-south and $49 \mathrm{~m}$ east-west and standing at least $4.6 \mathrm{~m}$ tall (Figure 8.9). Thurmond (1990:183) notes that the mound was about a meter taller before it was cleared of vegetation and that it was "rectangular in plan, with steep sides and a broad, flat platform on top." The 1934 excavations cut a ca. 5-m-wide trench across it that extended all the way through the mound into the original ground surface. The mound was built in four major episodes. Each major event probably was associated with the erection of an important building (or maybe more than one, given the size of the mound), though firm evidence of this was found only on the premound surface and on top of the third major fill episode. The structure that preceded the mound was large, ca. $11 \mathrm{~m}$ in diameter, and apparently was within a rectangular perimeter wall that was $17 \mathrm{~m}$ across. Destruction of this building and capping of its remains, probably in the Middle Caddo period, are what started the cycle of events that over a span of maybe as much as several hundred years resulted in the impressive platform mound at Keith.

The mound was on the east edge of the Hart Creek floodplain, over $500 \mathrm{~m}$ from the modern creek channel, though there are two intervening secondary channels that could have been active when the site was occupied. Based on the 1971 site map, the mound likely was on a slightly elevated portion of the floodplain, perhaps a low terrace or colluvial apron from the uplands to the east. The form at the Texas Archeological Research Laboratory shows the site extending over an area at least $300 \mathrm{~m}$ in diameter, with the mound apparently near the center. A borrow pit was just southeast of the mound, at the base of the upland slope; the site map shows it to be within a large marshy area, and it is possible that much of this low area had been used to obtain mound fill. The 1934 work included excavations in a midden ca. $200 \mathrm{~m}$ southwest of the mound, probably on a floodplain rise, and in an occupation area on the uplands about $75-100 \mathrm{~m}$ southeast of the mound. The small Titus phase cemetery excavated in the $1950 \mathrm{~s}$ 

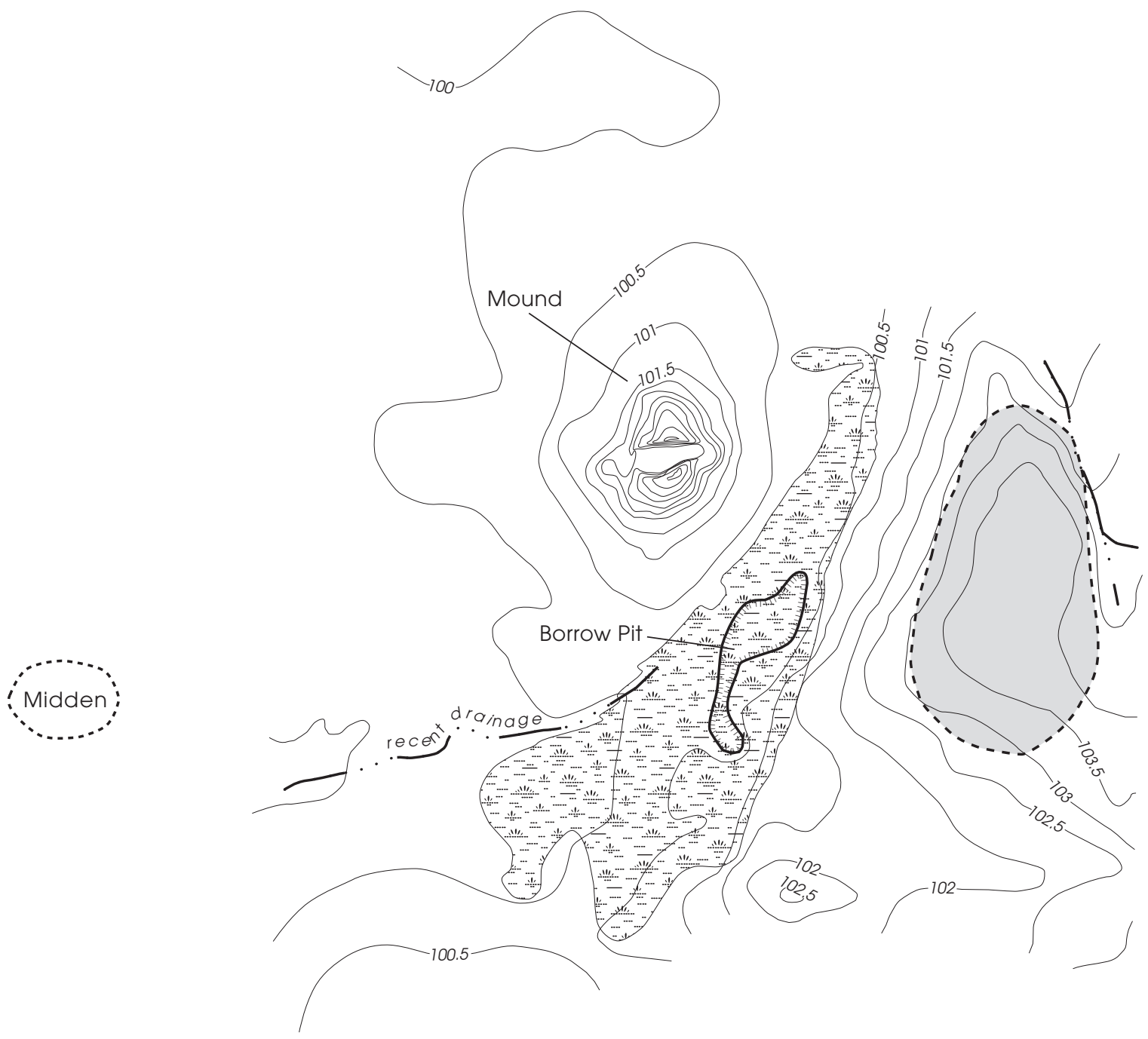

$L E G E N D$

Marshy Area

Occupation Area \& Titus Phase Cemetery
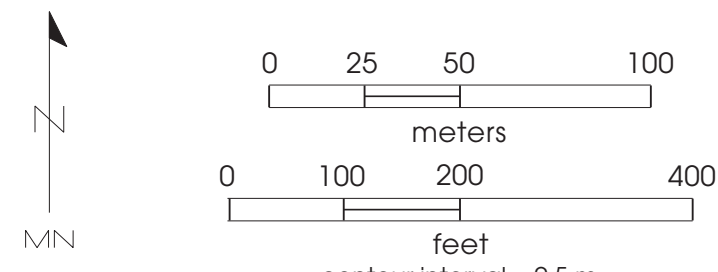

Figure 8.9. Map of the George L. Keith site (adapted from 1971 map in the records at the Texas Archeological Research Laboratory).

by avocational archeologists was in or near the upland occupation area.

Though the picture is far from complete, the Keith site may be best interpreted as a ceremonial site with multiple associated residential areas that was established during the Middle Caddo period and continued to be used during the Late Caddo period. Given its proximity and the impressive and persistent presence on the landscape that the mound provided, it is hard 
to believe that the rituals performed there did not include family groups who lived a short distance to the west on Tankersley Creek. What is intriguing about Keith is that the mound there is far larger than any other Titus phase mound. It covers almost 14 times the area and is 5-6 times taller than the average Titus heartland mound for which size data are known (the 15 mounds at Harroun, Whelan, Chastain, Dalton, Camp Joy, Shelby, Sam Roberts Pilgrim's Pride, and Tiddle Lake are 7-35 $\mathrm{m}$ long, 7-20 $\mathrm{m}$ wide, and $0.6-2.2 \mathrm{~m}$ tall, with average dimensions of $17.1 \times 15.3 \times 1.2 \mathrm{~m}$ ), and it is considerably larger (1.5 times the area and 1.7 times taller) than the temple mound (Mound A) at the Pine Tree Mound site, the large Titus ceremonial center on Potters Creek in the Sabine River valley (Fields and Gadus 2012:35). The size difference relates partly to the fact that the mound at Keith likely served a different function than most Titus phase mounds, i.e., it was a platform built in stages to support important buildings rather than a small tumulus that formed through the destruction and capping of one or two small ritual-associated structures. This implies that the ceremonies performed may have been different than those at other mound sites.

Why this happened along the middle reach of Hart Creek, well up from the Big Cypress Creek valley, is unknown, but it may have something to do with the Sanders phase connections seen at Keith and some other sites in the area. The main reasons to think this are: (1) construction of the mound at Keith probably began at a time when Sanders phase people were building mounds on the Red River and its tributaries to the north; and (2) some of the Sanders ceremonial centers have large, probable temple mounds (Bruseth 1998:60). Among these are Mound $2(88 \times 40 \mathrm{~m}$ and $2-3 \mathrm{~m}$ tall) and maybe Mound 1 (44x20 m and ca. $1 \mathrm{~m}$ tall) at the T. M. Sanders site on Bois d'Arc Creek in Lamar County, perhaps a late component on Mound A (36x48 m and $2.5 \mathrm{~m}$ tall) at the A. C. Mackin site on Nolan Creek in Lamar County, Mound A (90x55 m and $4.3 \mathrm{~m}$ tall) and maybe Mound B (60x40 m and $1.6 \mathrm{~m}$ tall) at the Fasken site on the Red River in Red River County, and perhaps Mound A (55x50 m and $1.8 \mathrm{~m}$ tall) or Mound B (90x50 m and $2.4 \mathrm{~m}$ tall) at the Grobin Davis site on Little River in McCurtain County, Oklahoma (Bruseth 1998:59-60; Krieger 1946:172-174, 195; Mallouf 1976:69; Prikryl 2008:126; Wyckoff and Fisher 1985:25).
We speculate that it was the Keith site's connection to people of the Sanders phase that initially made it a center of political power for this part of the Cypress basin, and that its location away from Big Cypress Creek reflects an effort to be closer to that source of power. Even allowing for these possibilities, though, it seems that at least some of the ideas that led to the mound being built here persisted among the local Titus peoples who lived along Hart Creek, since it appears that at least the upper part of the mound was erected during Titus times, and Titus peoples certainly were living and burying their dead nearby.

\section{Ear Spool Site}

Ear Spool is instructive chiefly because it illustrates that some sites that probably served integrative functions in this region were not made conspicuous by the erection of impressive constructed mounds, such as that at the George L. Keith site, or by use as a community cemetery, such as Sandlin Dam. Ear Spool is farther, ca. $9 \mathrm{~km}$, from the U.S. Highway 271 project area than the other sites discussed above but still within easy walking distance, and while its location north of the project area across the divide in the White Oak Creek basin might make some question the likelihood of its being associated with residential sites along Tankersley Creek, there is no compelling reason to think that the Caddo who occupied the region saw that drainage divide as a boundary.

The excavations at Ear Spool revealed that it "was the product primarily of a domestic occupation during the Titus phase, but one with a special character given the identification of two distinctive structures built within pits and then deliberately burned down" (Perttula and Sherman 2009:1). These two special structures both were associated with the Component I occupation, which dated between A.D. 1400 and 1480 (Perttula and Sherman 2009:371). One had an extended entranceway, and both had characteristics, namely burned structural remains and intentional fill deposits, very similar to what is seen in constructed mounds, even though no mounding was evident on the surface (although Bill Martin [personal communication 2013] of the Texas Historical Commission is of the opinion, based on observations made during a visit to the excavations, that at least one of these had 
a low mound on top of it). This led Perttula and Sherman $(2009: 371,376)$ to conclude that that the "symbolic treatment of Structures 1 and 3 suggests that these structures held a cultural significance beyond that of purely domestic concerns" and that Ear Spool was a key site in a community centered along Piney Creek in the White Oak Creek basin.

\section{Conclusions}

The paragraphs above identify five sites that could be candidates for locales where the Caddo who lived at the George Richey, William Ford, and James Richey sites participated in rituals and ceremonies that helped bind them and their neighbors into a cohesive community. None is more than a half day's walk from the middle reach of Tankersley Creek, and one, 41 TT890, is actually on that stretch of the creek. None of the five is like any of the others, however, and it is hard to see any patterns in the data that make it obvious how they might fit together as ritual components of a local settlement system. The only pattern that might be notable is that the large cemeteries are on Big Cypress Creek, while the mound and mound-like sites are on tributaries well away from the main stem. This would imply spatial segregation of activities associated with these kinds of sites, but the significance of this is unclear. Part of this lack of clarity undoubtedly can be traced to the very fragmentary nature of the archeological record. Given the spottiness of work in the area, even at Lake Bob Sandlin on Big Cypress Creek, it is certain that there are so many unknown sites with mounds and cemeteries that we may never understand the ritual aspect of Titus settlement systems fully. One thing that the existing information does indicate, though, is that the story is liable to be complicated, much more so than a model positing integrative sites tethered to Big Cypress Creek and rural farmsteads scattered up and down tributaries, or local communities with single caddi-associated ceremonial sites as constituents of larger core communities, will allow.

\section{COMMUNITY EXTENT AND BOUNDARIES}

Implicit in the discussion of potential integrative sites above is the notion that the local community that the George Richey, William Ford, and James Richey sites were a part of was larger than just the Tankersley Creek valley. We have suggested that people who lived on Hart Creek to the east, Piney Creek to the north, and Big Cypress Creek to the south-extending over an area of about $220 \mathrm{~km}^{2}$ - could have been part of the same community. This argument is based largely on geography, the small distances between the sites discussed, and general similarities in material culture, but it also stems from the supposition that a community large enough to be viable would have been spread out over a sizeable area, given the short-term nature of the farmstead occupations (a generation or two) and the frequent residential moves. From this perspective, there is no reason to think that the community could not have extended farther east to include the Swauano Creek valley, farther west to include Blundell Creek, or even farther south to include southside tributaries of Big Cypress Creek.

The archeological information collected from the region prior to the U.S. Highway 271 project is robust enough to allow us to characterize the ceramic tradition of the northwestern part of the Big Cypress Creek basin as being partly different than that of the southeastern part (Perttula and Sherman 2009:397-404), thus forming the basis for seeing two core communities there, but those data are not useful for addressing the extent of any local communities within the northwestern part of the basin. Thurmond's (1990:116-119) maps certainly indicate widespread and intensive occupation of the whole upper basin by Late Caddo peoples, but the data are not fine-grained enough to distinguish one community from another. Recent testing and excavation efforts in the project vicinity have succeeded in identifying a number of Middle-Late Caddo residential or ephemeral-use sites that could be associated with the Tankersley Creek sites: 41FK66, 41FK70, 41TT135, 41TT137, and 41TT182 on Blundell Creek (Brown et al. 1986:151, 182; Espey, Huston and Associates, Inc. 1984:43, 48-51; Kotter et al. 1991:38, 40); 41TT906 on Hart Creek and 41TT550 (Mockingbird) on Hayes Creek, a tributary of Hart Creek (Burden et al. 2012:31; Perttula et al. 1998); 41TT392, 41TT396, 41TT399, 41TT400,41TT406, 41TT409, 41TT572, 41TT577, 41TT591, 41TT601, and 41 TT653 (Ear Spool) on Piney Creek (Galan 
et al. 1997:39, 54, 65; Nash et al. 1995:46-47, 68, 90, 107-108, 130, 148-149, 201; Perttula and Sherman 2009); and 41TT372 and 41TT672 on Tankersley Creek (Barnhart et al. 1997; Dixon et al. 1995). With a few notable exceptions, however (e.g., Ear Spool and Mockingbird), the data are too sparse for meaningful comparisons, and even when comparisons can be made, they tend to have ambiguous results. A primary reason for this is that the comparisons mostly involve samples of sherds rather than vessels, and sample sizes often are small. ${ }^{4}$

Ripley Engraved Bowls and Community Extent

Following up on the work of Perttula and Sherman (2009:400), we took another look at the distributions of the various motifs on Ripley Engraved bowls to assess whether they might be informative about local community extent, not just for the vicinity of Tankersley Creek but for the broader Titus phase area as well. There were several reasons to think this might be worth doing. First, there are historical precedents, with motif variation being an important part of what Thurmond used to define his Cypress subclusters and a less-important part of what Perttula and Sherman used to distinguish ceramic subtraditions. Second, Perttula and his colleagues have codified some of the Ripley Engraved bowl variation by assigning motifs to named varieties of the type, and they are using this system in their ongoing efforts to document vessel collections from the region. Third, there has been a persistent feeling among archeologists familiar with Titus phase pottery that some of the extensive variability in designs subsumed under Ripley Engraved must have signified something important, for example, group identity, to the people who made and used the pots.

\section{Sites Included in the Analysis}

We included in this study the vessel assemblages from the three cemeteries in the middle Tankersley Creek valley (Thomas B. Caldwell,
A. P. Williams, and Duncan Anderson); the three other excavated cemeteries closest to the project area at the Mockingbird (Perttula et al. 1998), Alex Justiss (Bell 1981; Rogers et al. 2003), and Pilgrim's Pride (Perttula 2005) sites; two sites, Tuck Carpenter and Johns (Perttula, Walters, and Nelson 2010a, 2010b; Turner 1978), farther south in the Big Cypress basin; three cemeteries in the middle part of the basin at the Lone Star Lake, Rumsey, and Keeling sites (Perttula, Walters, and Nelson 2010a); and four cemeteries at the Henry Williams, Enis Smith, Henry Spencer, and Frank Smith sites in the Little Cypress Creek basin (Perttula, Nelson, and Walters 2012; Perttula, Walters, and Nelson 2012) (Figure 8.10). Also added are two points of comparison in the Sabine River drainage. These are the two family cemeteries at the Pine Tree Mound site (Fields and Gadus 2012) and a collection from sites on Caney Creek southwest of the project area (Perttula et al.2009). Conspicuously missing from this list, because published and illustrated descriptions of sizeable numbers of Ripley Engraved bowls are lacking, are sites in the southeastern part of the Titus phase heartland; this is a significant limitation because it means there are no samples from the two downstream heartland communities proposed by Perttula and Sherman (2009:375-377).

The Mockingbird cemetery (41TT550) is just $4.5 \mathrm{~km}$ north of the U.S. Highway 271 project area. It is at the head of Hayes Creek, an upper tributary of Hart Creek. Perttula and Sherman (2009:376) suggest that it may belong with a community centered on Piney Creek across the divide in the White Oak Creek basin, but as noted above, it is just as plausible that it and the Piney Creek sites, including Ear Spool, are associated with the same community as the Tankersley Creek sites. The Alex Justiss cemetery (41TT13) is $12 \mathrm{~km}$ east of the project area on the middle reach of Swauano Creek. Other than being seen by Thurmond (1990:231) as having associations with both his Tankersley Creek and Swauano Creek subclusters, Alex Justiss has not played a role in previous discussions of Titus spatial organization. Pilgrim's Pride (41CP304) is different than Mockingbird and

${ }^{4}$ Other data sets, e.g., features, lithic artifacts, and botanical remains, sometimes are available for study, but ceramics traditionally have been seen as best for addressing issues such as communities and social groups. 


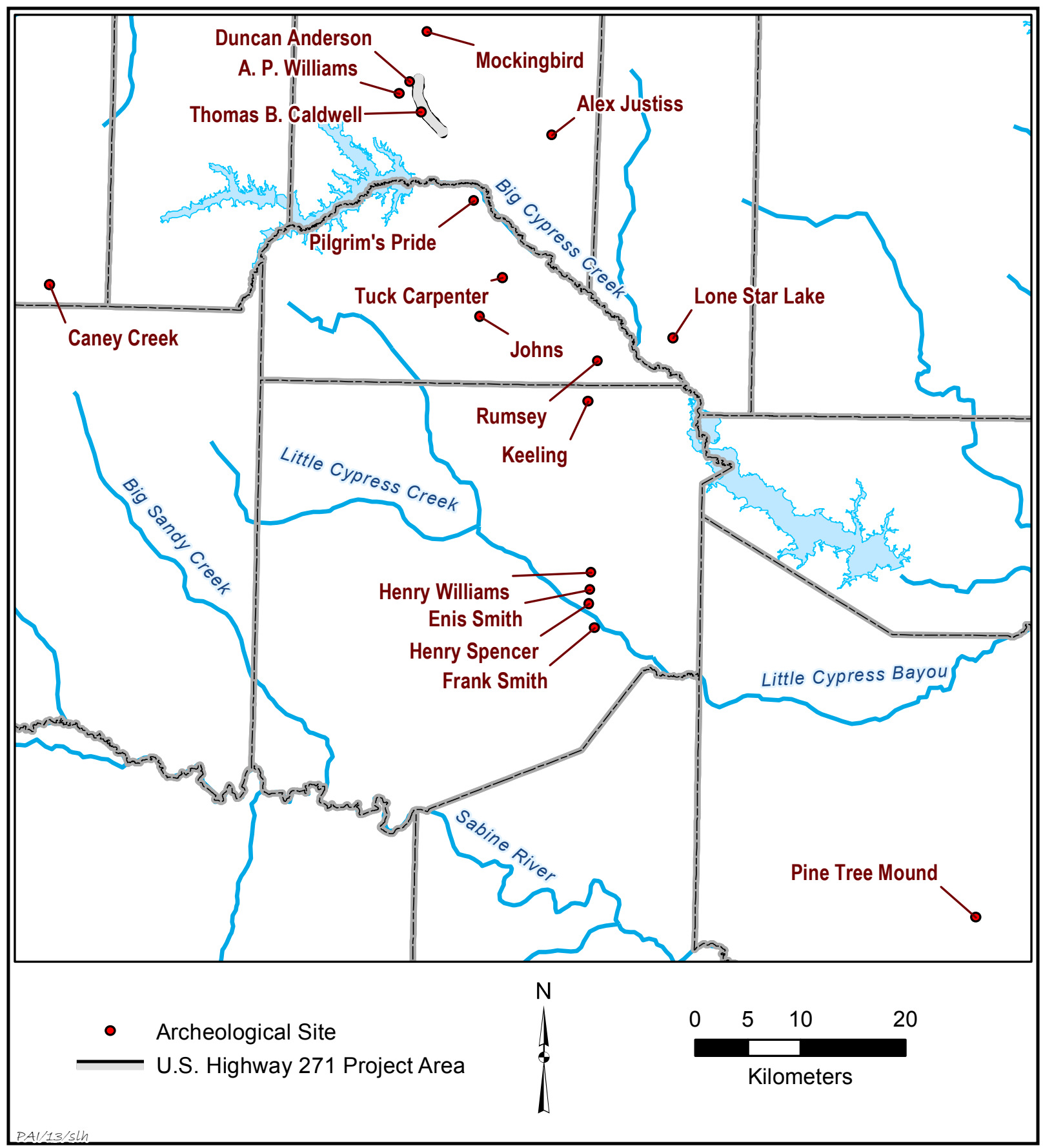

Figure 8.10. Map showing the locations of Titus phase cemeteries used in Ripley Engraved bowl variety comparisons.

Alex Justiss in that the cemetery there is but one aspect of a large habitation site, which also had a single small earthen mound and probable plaza. Perttula (2005:358) considers it to be "the nexus for a local Titus phase community" that encompassed the area in the vicinity of where Walkers and Hart Creeks join Big Cypress Creek. In his scheme, it is the next community 
downstream from the one that was anchored by the Lower Peach Orchard and Sandlin Dam sites. Pilgrim's Pride is on the south side of Big Cypress Creek, $8 \mathrm{~km}$ south-southeast of the U.S. Highway 271 project area.

Moving farther downstream in the Big Cypress drainage, the Tuck Carpenter (41CP5) and nearby Johns (41CP12) sites are 15-17 km south-southeast of the project area. The former, a large community cemetery, is a key site in the next heartland community beyond Pilgrim's Pride (Perttula 2005:360-363), and the latter is a smaller cemetery (30 known graves) that may be associated with the same community. The Lone Star Lake site (41MX65) on Ellison Creek and the G. W. Rumsey (41CP3) and Keeling sites on Greasy Creek are 26-29 km southeast of the project area and may be associated with the next community downstream; not much is known about Lone Star Lake and Rumsey, but with 15 known graves, Keeling is probably a family cemetery. The Rumsey site is just across Greasy Creek from the Shelby site (41CP71), a large community cemetery and mound site.

Not associated with any of the heartland communities because they are in the Little Cypress Creek basin 43-49 km south-southeast of the U.S. Highway 271 project area, the Henry Williams (41UR318), Enis Smith (41UR317), Henry Spencer (41UR315), and Frank Smith (41UR326) sites are on or near Gum Creek. Henry Spencer, which is near the confluence of Gum Creek and Little Cypress Creek, contained a large cemetery (44 graves) and a midden mound. Enis Smith and Henry Williams are just to the north along Gum Creek, and just southeast of Henry Spencer near the mouth of Clear Creek is the Frank Smith site. These cemeteries had from 15 to 37 known graves and, based on proximity to one another, likely were associated with one another.

The Pine Tree Mound site, on Potters Creek in the middle Sabine River basin $90 \mathrm{~km}$ southeast of the project area, is a ceremonial and civic center that is interpreted as the key site in a large Titus core community comparable to the two that have been defined along Big Cypress Creek; the vessels in this study come from two family cemeteries ( 27 graves total) associated with residential areas around the ceremonial part of the site. The final addition to the study consists of Ripley Engraved bowls in the J. A.
Walters collection from the Caney Creek valley, a tributary of Lake Fork Creek, ca. $40 \mathrm{~km}$ southwest of the U.S. Highway 271 project area; the proveniences of these materials are unknown, but they could have come from several sites, including Spoonbill (41WD109, 15 graves), Turquoise (41WD586, 9 graves), 41WD354 (2 graves), and 41WD589 (6 graves). All of these are likely to have been family cemeteries associated with a single community. Other than falling within Thurmond's expansive Three Basins subcluster, these Caney Creek sites have not figured into previous discussions of Titus phase spatial organization.

\section{Ripley Engraved Bowl Varieties}

Eighteen varieties of Ripley Engraved bowls are recognized for this analysis (Table 8.6). These are based on structural differences in the engraved motifs, and as such, this study excludes two previously identified varieties, Walkers Creek and Xena, that are based on characteristics other than motif differences (Perttula 2005:245-255). Nine of the varieties are newly defined here (McKinney-Enis Smith, Gandy-Mockingbird, Gandy-Pine Tree, Richey, Starkey, Pine Tree, Spencer, Harvard, and Tiddle), but the others were defined by Tim Perttula and colleagues (Perttula, Nelson, and Walters 2012; Perttula, Walters, and Nelson (2010a, 2010b, 2012) based on motifs originally illustrated by Thurmond (1990:Figure 6). They have been using these varieties in their efforts to document vessels in various private collections from the region, and it is largely because of their studies that an analysis such as this one is possible.

The variety definitions in Table 8.6 were derived from inspection of many vessel photographs (usually one per vessel), some drawings, and accompanying descriptions; they are an attempt to verbalize the structural elements that the published classifications appear to be based upon. They are considered general in that they rely on basic motif structures and primary elements and exclude other potentially important information, such as secondary elements or how a motif plays out around a vessel, because the latter could not be consistently discerned. Most of the variety classifications made by Perttula, Walters, and Nelson were consistent with the descriptions 
Table 8.6. Ripley Engraved varieties based on bowl motifs

\begin{tabular}{|c|c|}
\hline Variety & Description \\
\hline Galt & $\begin{array}{l}\text { Scroll (generally slanted) with circle as primary element. Circle can be partial, but } \\
\text { more than half is present. Circle can have small circle, cross, or diamond element } \\
\text { within it. Circle may be defined by hatched surounds. No other secondary elements } \\
\text { factor into variety definition. Encompasses Thurmond's scroll and circle motif. }\end{array}$ \\
\hline McKinney & $\begin{array}{l}\text { Straight scroll with pendant triangles secondary element on upper and lower arms } \\
\text { of scroll. Can have open circle, circle with cross, diamond, diamond with cross, or } \\
\text { some combination of these as primary elements. Encompasses Thurmond's pendant } \\
\text { triangle motif. }\end{array}$ \\
\hline $\begin{array}{l}\text { McKinney-Enis } \\
\text { Smith }\end{array}$ & $\begin{array}{l}\text { Version of variety McKinney with simple bar or no primary element between the } \\
\text { scroll arms. Rather, the arm is bent up or down to form rounded abutting scroll } \\
\text { ends. Retains the straight scroll and pendant triangles of McKinney. }\end{array}$ \\
\hline Carpenter & $\begin{array}{l}\text { Slanted scroll with no primary element between the scroll arms. Secondary elements } \\
\text { within scroll arm do not factor into variety definition. Encompasses Thurmond's } \\
\text { continuous scroll motif. }\end{array}$ \\
\hline Gandy & $\begin{array}{l}\text { Straight or slanted scroll with arms making a bisected simple scroll. No primary } \\
\text { element or only a simple line between the scroll arms, which have rounded ends. } \\
\text { This is Thurmond's scroll motif minus the SZ primary element. }\end{array}$ \\
\hline $\begin{array}{l}\text { Gandy- } \\
\text { Mockingbird }\end{array}$ & $\begin{array}{l}\text { Version of variety Gandy with crosshatched zones between and around the scroll } \\
\text { arms. }\end{array}$ \\
\hline Gandy-Pine Tree & $\begin{array}{l}\text { Version of variety Gandy with SZ primary element and slanted or straight scroll } \\
\text { arms. This is true to Thurmond's original scroll motif. }\end{array}$ \\
\hline
\end{tabular}


Table 8.6, continued

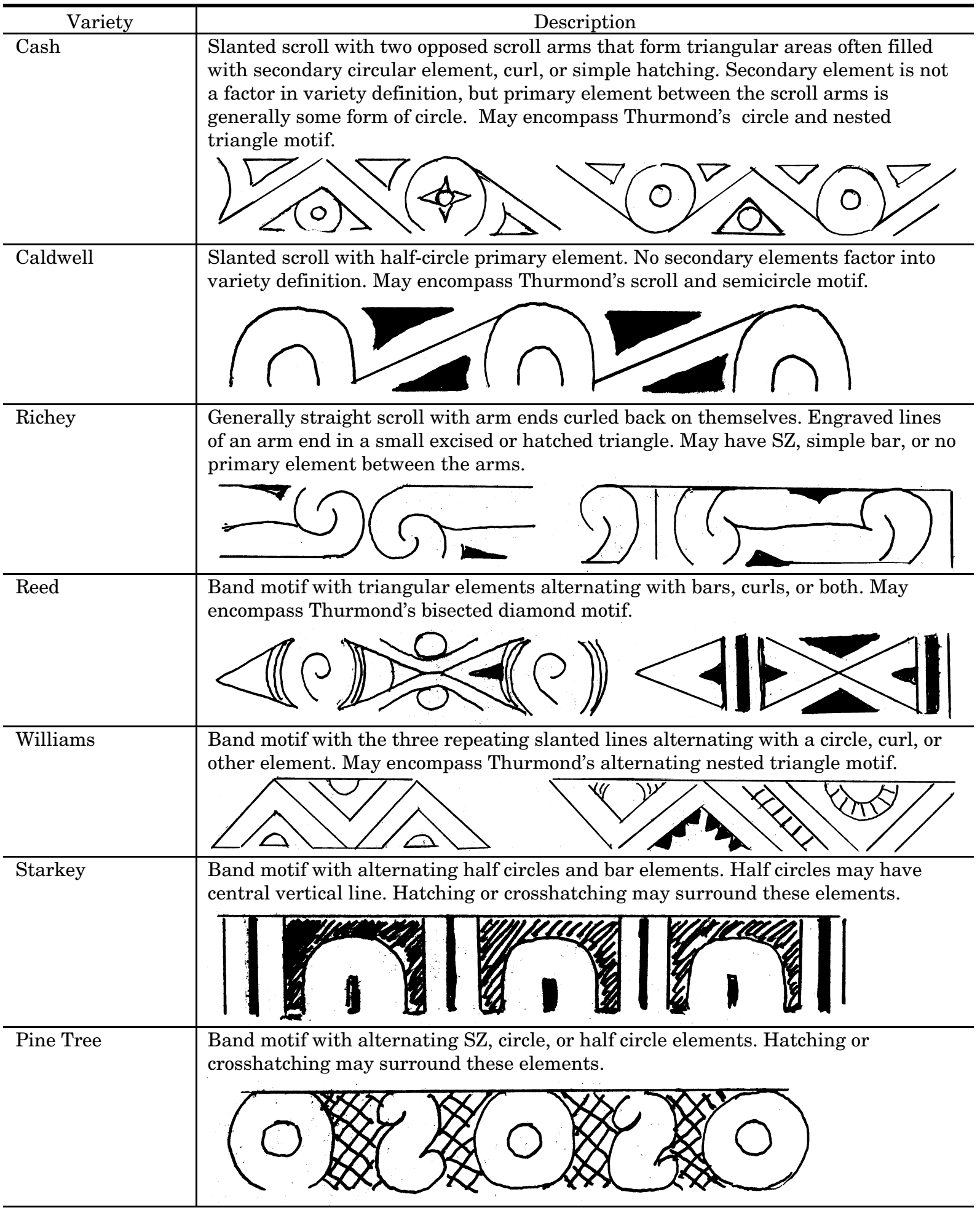


Table 8.6, continued

\begin{tabular}{|c|c|}
\hline Variety & Description \\
\hline Spencer & $\begin{array}{l}\text { Band motif of nested semicircles emerging from lowest carination line and that may } \\
\text { repeat or alternate with straight bars, slanted bars, or semicircle extending down } \\
\text { from upper carination line. Hatching or crosshatching may surround these elements. }\end{array}$ \\
\hline Pilgrim's & $\begin{array}{l}\text { Straight scroll with interlocking arms that may have simple bisecting line. No } \\
\text { primary element between scroll arms. Similar to variety Gandy but more rectilinear. } \\
\text { Similar to Thurmond's interlocking horizontal scroll. }\end{array}$ \\
\hline Harvard & $\begin{array}{l}\text { Sinuous slanted scroll arms that are not broken by primary element, i.e., a } \\
\text { continuous scroll. Scroll arms may be bisected by central line. }\end{array}$ \\
\hline Tiddle & $\begin{array}{l}\text { Rectilinear straight scroll with or without hatched line bisecting the scroll arms. } \\
\text { Arms interlock to form a series of elongated and nested Zs. }\end{array}$ \\
\hline
\end{tabular}

in Table 8.6, but some were not, and in these cases we chose our identifications; in cases where the photographic evidence was unclear, we used their identifications. For sites with published reports containing vessel drawings as well as photographs, i.e., Mockingbird, Pilgrim's Pride, and Tuck Carpenter, there was ample information for assigning vessels to varieties. This also was the case for the collections to which we had direct access, i.e., those from Thomas B. Caldwell, A. P. Williams, Pine Tree Mound, and a small part of Duncan Anderson.

Because not all the varieties have been clearly and fully described, it sometimes was hard to determine what design elements were considered important when the varieties were first defined. Lack of guiding definitions can lead to overly broad or extremely narrow variet- ies, both of which can obscure meaning. One example of an overly broad variety is Galt, which is defined as a slanted scroll with a circle for a primary element based on Thurmond's Motif C (Perttula, Nelson, and Walters 2012:10-11). The kind of circle is not specified, although a cross-in-circle is shown in Thurmond's original figure. Even though there is considerable variation in the treatment of circles within this motif, no attempt was made here to account for that variation because it was not consistently discernible for all the vessels considered here. Hence, any meaning conveyed by whether a circle is open, quartered, accompanied by pendant triangles, or defined by hatching, for example, is lost.

In contrast, differences within variety Gandy could be separated reliably because 
they were observable within the basic motif structures. Gandy originally was defined as Thurmond's Motif B (Perttula, Nelson, and Walters 2012:10-11), which is a straight or slanted, bisected, simple scroll with rounded arm ends and no primary element or only a simple line between the scroll arms. In addition to this, two other versions could be defined: one with an SZ as a primary element within a scroll, here called Gandy-Pine Tree; and one with crosshatched zones between and around the scroll arms, here called Gandy-Mockingbird. In addition, varieties Harvard and Tiddle were separated out of variety Pilgrim's, and a variation of variety McKinney was separated out as McKinney-Enis Smith (see Table 8.6).

Among the proposed new varieties, Starkey is a basic band motif with alternating half circles and bar primary elements, Pine Tree is a band motif with alternating SZ, circle, or half circle elements, and Spencer is a band motif of repeating nested semicircles (see Table 8.6). Band motifs are almost as common on Ripley bowls as scroll motifs. A band motif is composed of alternating or repeating primary elements that are not connected, except by proximity, as they encircle the design field. Thurmond's Motifs H, J, K, and I are all band motifs. Band and scroll motifs share common elements, some of which, such as the cross-incircle and SZ, are found alone on other vessels, suggesting that they have intrinsic meaning that does not rely on their position within either a band or a scroll.

There are some important limitations to this study other than those noted above. First, since many of the collections were not obtained through excavations by professional or trained archeologists, we know very little about their ages and contexts, other than that they came from Titus phase graves. Hence, for sites such as Duncan Anderson, Rumsey, Keeling, Lone Star Lake, the Gum Creek sites, and the Caney Creek sites, we cannot say much about the cemeteries themselves. Second, and perhaps more important for this study, is that for some sites the documented collection is only part of what was found, since multiple collectors excavated at them, and there is no way of knowing how representative the documented part is; this is the case for most, if not all, of the sites listed above and to some extent the Alex Justiss site.

\section{Distributions}

Table 8.7 shows the breakdown of 599 Ripley Engraved bowls in the 15 analyzed collections by variety; the Lone Star Lake, Rumsey, and Keeling collections are lumped together under a Middle Cypress heading because they are small. Excluded from this table are another 92 bowls typed as Ripley that cannot be related to a particular variety, accounting for anywhere from 4 percent (Frank Smith) to 33 percent (Pilgrim's Pride) of the totals. The data in this table provide little support for the idea that variation in Ripley bowl motifs is a productive way to consistently see group identity and local community boundaries, at least not variation as captured by this analytical scheme. For a variety like Galt, which we know is overly inclusive, this conclusion makes sense. It is the only one that occurs in all collections, accounting for 10-29 percent of the assignable bowls by site and 20 percent of the total. This may be true also for 4 varieties that are so widespread that it seems highly unlikely they could be sensitive to this kind of cultural information: Carpenter and Cash, each occurring in 13 collections; Gandy, occurring in 12 collections; and Williams, occurring in 11 collections. Further, none of these 4 occurs in an especially high percentage only in one area, as one might expect for a local style that ended up being widespread because it was traded frequently. Variety Carpenter is most abundant at the Thomas B. Caldwell (39 percent), Tuck Carpenter (37 percent), and Mockingbird (31 percent) sites. Variety Cash is most common at the Johns (14 percent), A. P. Williams (12 percent), and Henry Williams (10 percent) sites. Variety Gandy makes up substantial portions of the Caney Creek (36 percent) and Henry Williams (20 percent) collections. And the highest percentages of variety Williams are in the Duncan Anderson (18 percent), Pine Tree Mound (16 percent), and Henry Spencer (14 percent) collections.

There are some hints that community-level information might be present in some of the less-ubiquitous varieties, but this is not consistently the case. For example, variety GandyPine Tree, though represented widely in eight collections, is notably common only at the Caney Creek sites (23 percent); variety Caldwell, present in seven collections, is common only at the nearby A. P. Williams and Mockingbird sites 


\begin{tabular}{|c|c|c|c|c|c|c|c|c|c|c|c|c|c|c|c|c|c|c|c|c|}
\hline \multirow{2}{*}{ B7OL } & & ลิ & & 10 & 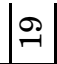 & $\infty$ & -1 & 20 & $\infty$ & 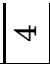 & & & 0 & $-1 \mid$ & -1 & o & o & & -1 & \\
\hline & & $\stackrel{2}{\exists}$ & $\stackrel{N}{\Sigma}$ & ลิ & $\stackrel{0}{=}$ & \& & 10 & $\stackrel{\infty}{\text { N }}$ & Fิ & $\vec{N}$ & $\stackrel{0}{-1}$ & $\stackrel{10}{-1}$ & $\infty$ & 20 & - & $\exists$ & $ㅇ$ & $\infty$ & 10 & \& \\
\hline \multirow{2}{*}{ צәə.х } & $0^{\circ}$ & ล & 0 & 0 & 0 & 粕 & 0 & ล̊ & 0 & 0 & 0 & 0 & 20 & 0 & 0 & 0 & 0 & $\infty$ & 0 & \\
\hline & z & 0 & 0 & 0 & 0 & $\infty$ & 0 & 10 & 0 & 0 & 0 & 0 & -1 & 0 & 0 & 0 & 0 & $N$ & \begin{tabular}{l|l}
0 & 8 \\
\end{tabular} & ลิ \\
\hline \multirow{2}{*}{ 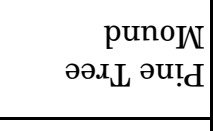 } & $0^{\circ}$ & : & 0 & 0 & 20 & 0 & 0 & 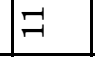 & $\infty$ & $\infty$ & 0 & $\infty$ & $\stackrel{0}{-1}$ & $\stackrel{m}{-1}$ & $\infty$ & 0 & 0 & 0 & $\infty$ & \\
\hline & $z^{\circ}$ & 윽 & 0 & 0 & N & 0 & 0 & A & $\infty$ & $\infty$ & 0 & -1 & 0 & 10 & $\infty$ & 0 & 0 & 0 & $-1 \mid$ & $\begin{array}{l}\infty \\
\infty\end{array}$ \\
\hline \multirow{2}{*}{$\begin{array}{r}\text { surẹ़ा!M } \\
\text { КлиәН }\end{array}$} & $0^{\circ}$ & ลิ & 0 & 20 & 0 & ì & 0 & 은 & 억 & 0 & 10 & 0 & 0 & 0 & 0 & 0 & 0 & 0 & 0 & \\
\hline & $\stackrel{0}{z}$ & + & 0 & 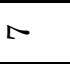 & 0 & H & 0 & a & N & 0 & -1 & 0 & 0 & 0 & 0 & 0 & 0 & 0 & 0 & ลำ \\
\hline \multirow{2}{*}{ ૫ł! } & $0^{\circ}$ & $\stackrel{2}{-1}$ & ఠి & $\stackrel{m}{-}$ & + & $\stackrel{m}{-1}$ & 0 & 0 & $\infty$ & 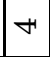 & 0 & 0 & 0 & 0 & 0 & +4 & 0 & 0 & 0 & \\
\hline & $\dot{0}$ & $\infty$ & $\infty$ & $\infty$ & -1 & $\infty$ & 0 & 0 & N & -1 & 0 & 0 & 0 & 0 & 0 & -1 & 0 & 0 & $0 \mid$ & ๙ิ \\
\hline \multirow{2}{*}{ 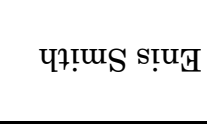 } & $\delta^{\circ}$ & $\ddot{H}$ & $\stackrel{\circ}{\sim}$ & $\stackrel{\leftrightarrow}{N}$ & $\sim$ & ฯ & 0 & 0 & $\sim$ & 0 & 20 & 0 & 10 & 0 & 0 & 0 & 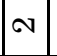 & 0 & 0 & \\
\hline & $\dot{0}$ & 0 & $\exists$ & 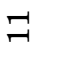 & -1 & مـ & 0 & 0 & $\infty$ & 0 & $\sim$ & 0 & $\sim$ & 0 & 0 & 0 & -1 & 0 & 0 & พิ \\
\hline \multirow{2}{*}{$\begin{array}{r}\text { ләэuәdS } \\
\text { Клuә } \mathrm{H}\end{array}$} & $8^{\circ}$ & จ & $\infty$ & 0 & $\cong$ & $\sigma$ & 0 & 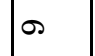 & $\infty$ & 0 & 0 & 0 & $\underset{-}{\Delta}$ & 0 & 0 & $\simeq$ & $\infty$ & 0 & 0 & \\
\hline & $\dot{0}$ & $\triangle$ & -1 & 0 & 0 & $\infty$ & 0 & $\infty$ & -1 & 0 & 0 & o & 10 & 0 & 0 & 0 & -1 & 0 & $\left.0\right|^{2}$ & Lר \\
\hline \multirow{2}{*}{$\begin{array}{r}\operatorname{ss} ә . x d \kappa_{\mathrm{D}} \\
\text { әцрр!ฺN }\end{array}$} & $0^{\circ}$ & $\triangleq$ & $\widehat{\Lambda}$ & 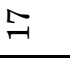 & $\stackrel{ }{\circ}$ & $\stackrel{0}{-}$ & 0 & 10 & $\infty$ & 0 & $\infty$ & 0 & $\Lambda$ & 0 & 0 & 0 & $\triangle$ & 0 & 0 & \\
\hline & $\dot{0}$ & 20 & $\infty$ & مL & $\infty$ & $\infty$ & 0 & 0 & -1 & 0 & -1 & 0 & o & 0 & 0 & 0 & $\sim$ & 0 & 0 & ஓి \\
\hline \multirow{2}{*}{ suyos } & $b^{\circ}$ & $\stackrel{\infty}{*}$ & $\underset{-}{ \pm}$ & N & $\stackrel{0}{-1}$ & $\stackrel{ }{-}$ & 0 & ov & 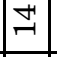 & o & -1 & 10 & 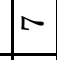 & 0 & 0 & 0 & -1 & 0 & 0 & \\
\hline & $\stackrel{\circ}{z}$ & $\stackrel{\sharp}{\sim}$ & $\stackrel{2}{-1}$ & N & 120 & 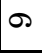 & 0 & 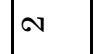 & $\stackrel{\infty}{-1}$ & $\curvearrowright$ & -1 & م & 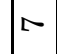 & 0 & 0 & 0 & -1 & 0 & 0 & ठో \\
\hline \multirow{2}{*}{ 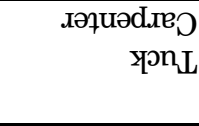 } & $\Delta^{\circ}$ & $\stackrel{2}{-}$ & $\stackrel{10}{-10}$ & $\neg$ & 命 & H & $\neg$ & 0 & 0 & 10 & -1 & o & 10 & 0 & 0 & 0 & 0 & 0 & 0 & \\
\hline & $\dot{z}$ & $\stackrel{\wedge}{\wedge}$ & $\vec{\sim}$ & - & 象 & 20 & -1 & $\infty$ & $\infty$ & 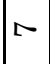 & -1 & $\infty$ & 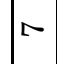 & 0 & 0 & 0 & 0 & 0 & 0 & $\underset{\mathcal{I}}{\mathcal{F}}$ \\
\hline \multirow{2}{*}{ ss!ฺsn ${ }^{2}$ xə[V } & $b^{\circ}$ & $\stackrel{\circ}{-1}$ & 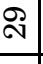 & 0 & $\stackrel{ }{\circ}$ & $\nexists$ & 0 & c & 10 & 0 & $\stackrel{+}{N}$ & 0 & 0 & 0 & 0 & 20 & 20 & 0 & 0 & \\
\hline & $i^{\circ}$ & $\sim$ & 0 & 0 & $\infty$ & $\infty$ & 0 & 0 & -1 & 0 & 20 & 0 & 0 & 0 & 0 & $\neg$ & -1 & 0 & 0 & $\vec{N}$ \\
\hline \multirow{2}{*}{ 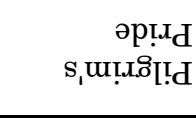 } & $0^{\circ}$ & $\stackrel{m}{-}$ & 0 & 0 & $\infty$ & 0 & 0 & 10 & $\nabla$ & 0 & 0 & 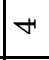 & $\infty$ & 0 & 0 & $\vec{N}$ & $\stackrel{\infty}{-1}$ & $\approx$ & $\stackrel{m}{-}$ & \\
\hline & $\dot{0}$ & $\infty$ & 0 & 0 & $\sim$ & 0 & 0 & 0 & -1 & 0 & 0 & -1 & $\sim$ & 0 & 0 & 10 & $\infty$ & +1 & $\infty$ & $\stackrel{\text { ন }}{ }$ \\
\hline \multirow{2}{*}{ 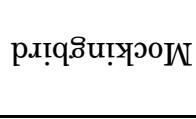 } & 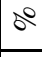 & $\stackrel{10}{-1}$ & 0 & 0 & $\vec{n}$ & テै & $\stackrel{\overbrace{}}{\sim}$ & $\infty$ & 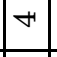 & $\stackrel{\sim}{-}$ & 0 & 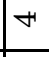 & 0 & 0 & 0 & 0 & $\nabla$ & 0 & 0 & \\
\hline & $\stackrel{0}{z}$ & + & 0 & 0 & $\infty$ & $\infty$ & $\infty$ & ov & -1 & $\infty$ & 0 & -1 & 0 & 0 & 0 & 0 & -1 & 0 & 0 & $\stackrel{\leftrightarrow}{\circ}$ \\
\hline \multirow{2}{*}{$\begin{array}{r}\text { sure!II!M } \\
{ }^{\mathrm{d}}{ }^{\circ} \mathrm{V}\end{array}$} & $0^{\circ}$ & $\stackrel{\leftrightarrow}{\sim}$ & 0 & 0 & $\overrightarrow{\mathrm{N}}$ & 0 & $\infty$ & 0 & $\stackrel{\sim}{\sim}$ & ㄱ & 0 & $\infty$ & 0 & 0 & $\infty$ & $\infty$ & 0 & $\infty$ & 0 & \\
\hline & $\stackrel{0}{z}$ & $\infty$ & 0 & 0 & 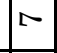 & o & $\neg$ & 0 & + & + & 0 & -1 & $\sim$ & 0 & $\infty$ & $\neg$ & 0 & $\neg$ & 0 & ले \\
\hline \multirow{2}{*}{ 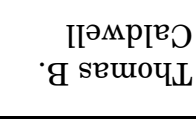 } & $\Delta^{\circ}$ & $\stackrel{\oplus}{-1}$ & 으 & 0 & ని & $\infty$ & 0 & 10 & 0 & $\infty$ & $\stackrel{0}{-}$ & 0 & $\infty$ & 0 & $\infty$ & 0 & 0 & 0 & 0 & \\
\hline & $i^{\circ}$ & 20 & $\infty$ & 0 & $\stackrel{\sim}{\simeq}$ & -1 & 0 & 10 & $\sim$ & -1 & 20 & 0 & -1 & 0 & -1 & 0 & 0 & 0 & 0 & $\vec{\omega}$ \\
\hline \multirow{2}{*}{$\begin{array}{r}\text { uos.səpuV } \\
\text { uøəund }\end{array}$} & $\Delta^{\circ}$ & ล & 0 & 0 & ন & 0 & 0 & $\stackrel{\mathcal{N}}{\sim}$ & 0 & 0 & 0 & 0 & $\stackrel{\infty}{-}$ & 0 & 0 & 0 & 0 & 0 & 0 & \\
\hline & $\dot{8}$ & 20 & 0 & 0 & + & 0 & 0 & $\curvearrowright$ & 0 & 0 & 0 & -1 & $\infty$ & 0 & 0 & 0 & 0 & -1 & -1 & 든 \\
\hline & 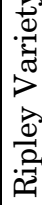 & 营 & 劳 & 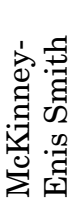 & 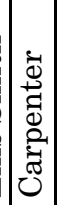 & ซ్రే & 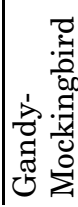 & 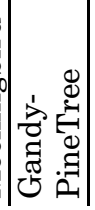 & $\left|\begin{array}{c}-\mathbb{1} \\
\tilde{w} \\
\tilde{J}\end{array}\right|$ & 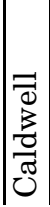 & 胥 & 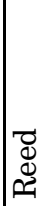 & 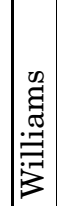 & 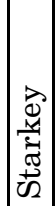 & 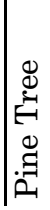 & & 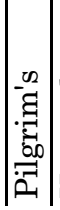 & 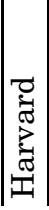 & 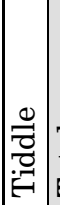 & \\
\hline
\end{tabular}


(12 percent of each); variety Pilgrim's, also present in seven widespread collections, is common only at Pilgrim's Pride (13 percent); and variety McKinney-Enis Smith, present in six collections, makes up large percentages of the collections only from the nearby Henry Williams (35 percent) and Enis Smith (26 percent) sites. In contrast, variety McKinney occurs in eight collections and is common in half of them: Frank Smith (39 percent), Alex Justiss (29 percent), Middle Cypress (27 percent), and Enis Smith (26 percent). Variety Reed also occurs in eight collections, but in uniformly low numbers (2-6 percent). Variety Richey is present in seven widespread collections and common in two that are not particularly close to one another, Alex Justiss (24 percent) and Thomas B. Caldwell (16 percent). And variety Spencer occurs in five collections, most commonly those from Pilgrim's Pride (21 percent) and Henry Spencer (17 percent).

Not surprisingly, some of the more-restricted distributions are among varieties presented by comparatively few vessels. Varieties Harvard and Tiddle are present in four and three collections, respectively, but notably common only at the Pilgrim's Pride site (17 and 13 percent). Variety Gandy-Mockingbird, occurring in three collections, is common only at the Mockingbird site (12 percent). And variety Starkey is present only at the Pine Tree Mound site (13 percent). Contrary to this pattern is variety Pine Tree, which is present in only three collections but common in two widely separated ones, A. P. Williams (9 percent) and Pine Tree Mound (8 percent). For all of the low-frequency varieties, though, it is fair to question whether variations in decoration relate to decisions by individual potters rather than community-wide ideas.

Another way to look at these data is to examine consistency within groups of sites that are close to one another. The three Tankersley Creek cemeteries are one obvious group. Their assemblages are similar in that varieties Galt (1629 percent) and Caldwell (21-39 percent) have the highest or second-highest percentages, but beyond that they look different. The next-most common varieties are: Williams (18 percent) and Gandy-Pine Tree (12 percent) at Duncan Anderson; Richey (16 percent, tied with Galt) at Thomas B. Caldwell; and Cash and Caldwell (12 percent each) at A. P. Williams. The other obvious group consists of the four Little Cypress Creek sites. Two of these are most similar in that variety McKinney is especially common at both, 39 percent at Frank Smith and 26 percent at Enis Smith (tied with variety McKinneyEnis Smith), while varieties Galt, Gandy, and McKinney-Enis Smith (at Frank Smith only) are moderately frequent (12-14 percent). The nearby Henry Williams site is generally similar, with variety McKinney-Enis Smith most common (35 percent) and varieties Galt and Gandy (20 percent each) occurring in moderate numbers. The collection from the Henry Spencer site looks notably different, however. There, varieties Galt, Carpenter, Spencer, and Williams all are moderately abundant (14-20 percent), and varieties McKinney, McKinney-Enis Smith, and Gandy are infrequent or absent. In short, these two groups of collections do not make a very compelling case for assemblages of styles that hang together geographically.

Removing variety Galt from the percentage calculations (because it is overly inclusive) and looking at just the top-ranked varieties in each collection does expose a spatial pattern that relates to Titus communities viewed broadly, but not to communities narrowly defined. Essentially, this may be part of the same pattern that led Perttula and Sherman (2009:401-410) to see southeastern and northwestern ceramic subtraditions in the Titus area. In the data presented here, it can be seen in the fact that 12 of the collections can be placed into two groups, albeit ones that are not very homogeneous, and that most members of these groups have distinct spatial distributions.

The first group consists of collections from the following seven sites: Thomas B. Caldwell, A. P. Williams, Duncan Anderson, Mockingbird, Tuck Carpenter, Johns, and Henry Spencer. In all seven, Carpenter is the predominant variety, with variety Spencer being equally dominant at the Henry Spencer site alone. Beyond this, no two assemblages look exactly alike, though. Variety Gandy-Pine Tree ranks third in four collections (Duncan Anderson, Henry Spencer, Mockingbird, and Tuck Carpenter), and varieties McKinney (Thomas B. Caldwell, Tuck Carpenter, and Johns), Gandy (Henry Spencer, Mockingbird, and Johns), and Cash (A. P. Williams, Tuck Carpenter, and Johns) rank second or third in three each. Four other varieties are in the top three at one or two sites each: Gandy-Mockingbird at the Mockingbird site, Caldwell at A. P. Williams and Mockingbird, Richey at Thomas B. Caldwell, Williams at 
Duncan Anderson and Henry Spencer, and Pine Tree at A. P. Williams. Varieties that show up minimally or not all are McKinney-Enis Smith, Starkey, Pilgrim's, Harvard, and Tiddle.

The second group consists of the following five collections: Frank Smith, Enis Smith, Henry Williams, the Middle Cypress sites, and Alex Justiss. What unites them is that each is dominated by variety McKinney and/or variety McKinney-Enis Smith and that variety Gandy ranks second or third. Variety Cash ranks third at three of them (Frank Smith, Enis Smith, and Henry Williams). The only other high-ranked varieties are Richey (second at Alex Justiss), Gandy-Pine Tree (third at Henry Williams), and Carpenter (third at the Middle Cypress sites). Varieties with minimal or no presence are Gandy-Mockingbird, Caldwell, Williams, Starkey, Pine Tree, Spencer, Pilgrim's, Harvard, and Tiddle.

Three collections are unlike any of the others and are outliers. Their top-ranked varieties are as follows: Starkey, Pine Tree, and Cash at Pine Tree Mound; Gandy, Gandy-Pine Tree, and Harvard at the Caney Creek sites; and Spencer, Harvard, Pilgrim's, and Tiddle at Pilgrim's Pride.

Figure 8.11 shows the spatial distributions of these two groups and three outliers. All of the sites in the first group but one, Henry Spencer, are in the northwestern part of the basin, and all of those in the second group, except Alex Justiss, are in the central part. Not surprisingly, two of the outliers, Pine Tree Mound and the Caney Creek sites, are geographically separated from the other sites. The third, Pilgrim's Pride, is not. These distributions suggest six main conclusions. First, they support the contention that distinct but related core communities occupied the two parts of the Titus heartland. Second, they suggest that Ripley Engraved bowl varieties as used here are not now, and may never be, useful for seeing distinctions between smaller communities within the core ones. Third, they suggest ties between the southeastern heartland core community (represented here by the three Middle Cypress cemeteries at Lone Star Lake, Rumsey, and Keeling) and whatever was going on in the Little Cypress basin to the south. Fourth, with one site in each group being out of place spatially, they suggest that there was movement of potters and people between core communities. Fifth, parts of the Titus phase area outside the Cypress basin supported their own core communities. And sixth, sites like Pilgrim's Pride, which is an outlier ceramically but not spatially, imply that at certain times and places within the heartland there were small local communities that chose to decorate their pottery differently than their neighbors, presumably reflecting different ideas about connections between engraved motifs and a widely held Caddo belief system.

\section{Conclusions}

When all is said and done, it is hard to feel comfortable that we have a good understanding of the extent of the local community of which the Tankersley Creek sites were a part. Notwithstanding certain data limitations that apply to more than just the current project area, including too few professionally excavated sites (especially cemeteries), poor chronological controls that make it hard to distinguish changes that relate to the passage of time as opposed to other factors, and the difficulty of interpreting sherd assemblages from residential sites, it is true that some of the ceramic vessels in the Tankersley Creek mortuary assemblages look different than those from the Alex Justiss and Pilgrim's Pride sites to the east and south, implying boundaries between communities. However, the Tankersley Creek ceramics are similar to those from the Tuck Carpenter and Johns sites even farther south, as well as those from the Mockingbird site to the north, and they are consistent with assemblages across a large area covering much of the upper part of the Big Cypress basin. Some decorations on pottery certainly were expressions of a widely held Caddo cosmology (Fields and Gadus 2012:505-520), and even if potters and groups of potters chose motifs and variable expressions of those motifs in part to reflect social identify, they did that within the context of ideology. Further, Caddo potters could and did inject a high degree of innovation into motif construction, while still using a set number of basic structures and elements, and these motifs were understood and accepted by communities across and beyond the Titus heartland. Thus, vessel trade, shifting community boundaries and centers of political power through time, and group coalescence and splitting would make it extremely difficult to see community associations in the ceramics, even if better data sets were available. 


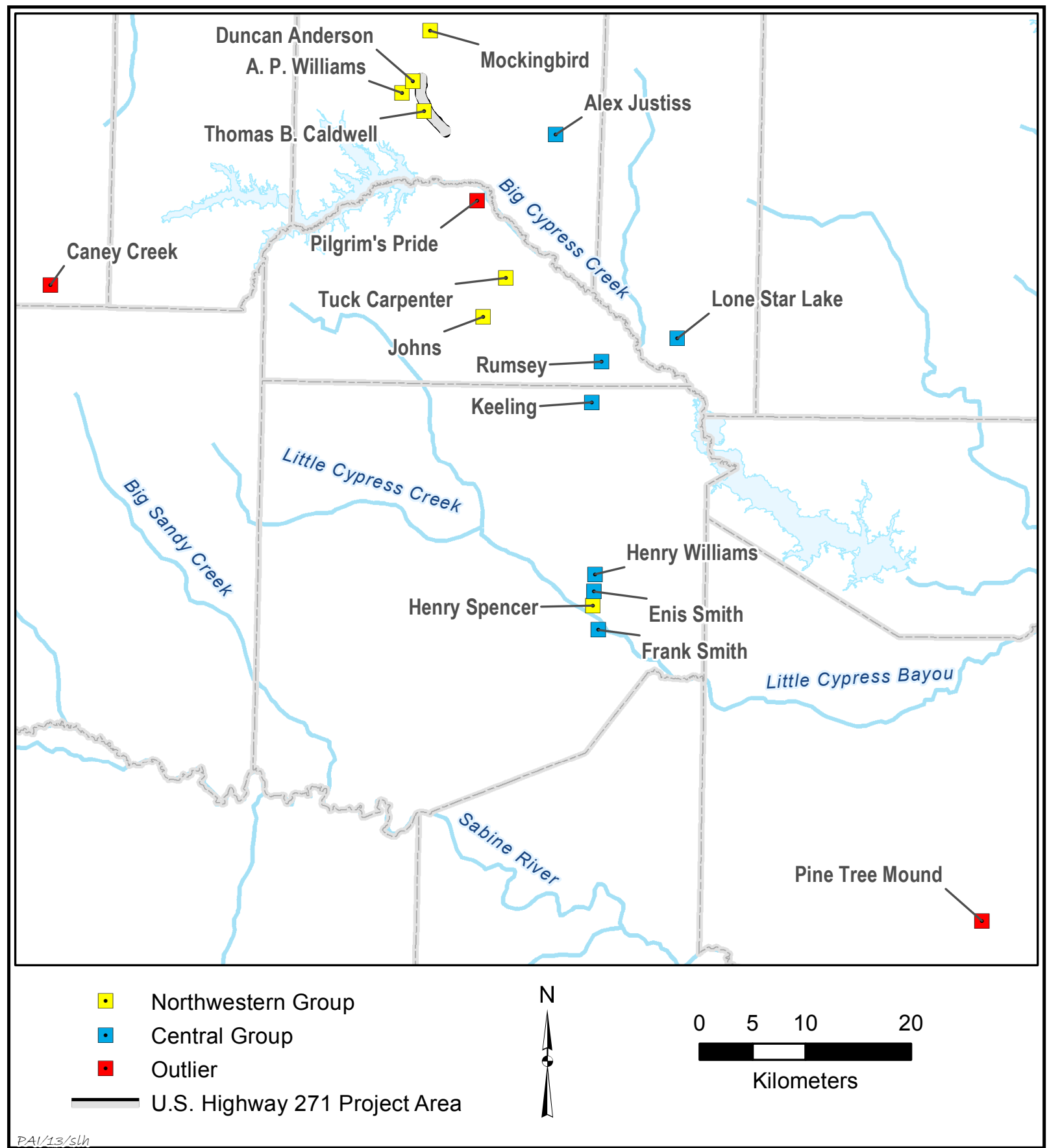

Figure 8.11. Map showing the locations of Titus phase cemeteries grouped according to frequencies of Ripley Engraved bowl varieties.

Of course, just because we cannot use Ripley Engraved bowls to see boundaries between local communities does not mean those communities did not exist. The distributions of mound sites and large cemeteries presented above and of cemeteries with large shaft graves (see Chapter 7) continue to provide compelling evidence for long-term settlement by multiple 
related Caddo groups distributed throughout the Cypress basin and adjoining valleys. One thing that analysis of sites in the Tankersley Creek area tells us, though, is that there likely are (or were) many more mound and large cemetery sites out there than we know about, and that missing information will hamper efforts to define communities based on the distributions of these types of sites. Certainly, the difficulty of deciding how sites such as Sandlin Dam, Lower Peach Orchard, George L. Keith, and 41TT890 relate to the farmsteads and family cemeteries along Tankersley Creek emphasizes how much more there is to know about the archeology of this one part of the Titus phase area before we can say we truly understand the social, religious, and political organization of the Caddo people who lived there.

\section{PROJECT ASSESSMENT}

As befits the amount of effort and money spent on this project, much has been learned about how Native Americans used the Tankersley Creek valley. The contributions to understanding the archeology of the Caddo people in particular are notable, and thus this project was a successful one. If we had the opportunity to do the work over again, we would do most of it the same way. As in any archeological project, though, some things worked better than others.

The overall strategy of zeroing in on the sites and parts of sites with the best information was quite effective. Because of the limitations of survey data, we opted to look at whole sites via intensive auger testing, followed by intensive formal testing (with geophysical surveys, backhoe trenching, and test pits) of selected areas, followed by extensive excavation within parts of the selected areas where warranted. Even though one of the testing-phase investigative techniques, i.e., geophysical surveys, turned out to be not very informative, we still ended up having a great deal of information about the sites going into the data recovery phase. As a result, we were able to craft a research design and data recovery plan that provided solid guidance for the final phase of the project. In the end, we were able to address most of the issues that the research design raised, or at least be clear about why we could not address some. The results of the geophysical work were disappointing but not very surprising. Those techniques work well in some places and not others. Because they did not work well here is not a reason to forgo geophysical surveys on other similar projects in the region.

As the work was unfolding, we did have three slight reservations about the overall zeroing-in strategy and how we implemented it, albeit not ones that make us think we should have done it differently. First, some of the auger testing results did not agree very well with the survey data, making us wonder at times if we were missing something, for example, if excavation with an auger pulverized sherds such that artifact counts were reduced. Ultimately, though, we could not come up with any convincing explanations for why our data might be biased, and, with far more holes in the ground than were dug in survey, we concluded we had to put more faith in the auger testing results than the survey data. Second, on sites where auger testing indicated sparse archeological remains, there was not much to go on when deciding where to put geophysical/testing grids. This meant that the choice was essentially arbitrary. This should not matter, though, since we had good evidence that archeological materials were scarce everywhere on these sites. Third, this strategy may not be a good one for finding Caddo cemeteries, since they can be small and apparently often are well removed from their associated residential sites (see discussion earlier in this chapter). But unless they just happen to be in a place with abundant remains from earlier occupations (as probably was the case with the Thomas B. Caldwell cemetery), they are going to be hard to find no matter the techniques used. This remains an unresolved problem.

Given the archeology present at the sites, focusing on investigating Caddo settlement of the area certainly was the correct choice (although we did also learn a little about the people who lived there before the Caddo period), as was trying to look at household and community organization. This emphasis on looking at site-wide and community-wide issues required extensive excavations that could be done feasibly only with heavy equipment. This approach worked well at the George Richey and William Ford sites, where the surface sands were generally thin, cultural features often extended into the $\mathrm{Bt}$ horizon, and there were no complex use-history or post-use-history questions (as there were at the Ear Spool site, for example). It did not work so well at the James Richey site, where the sands were thicker in places and features often did not 
reach the Bt horizon. It is arguable that manual excavations there would have allowed us to find the house rather than just speculate about it; on the other hand, identifying postholes in the sands there would have been very tricky, and we might never have felt very confident about our interpretations. Further, it is debatable whether results like that would have been worth the extra effort and money that manual excavations would have taken. Focusing on bigger-picture settlement pattern issues still seems like the highest promise of sites like these, but full success with such analyses depends on having the right kinds and amounts of comparative data. We did not achieve all we had hoped for in terms of identifying the community that these sites belonged to or understanding just how that community related to others, but that is not the fault of these sites or how we excavated them. Even where comparative data are abundant (as in this case), there may not be enough information to answer all the questions.

Having said that, one of the better things we did was try to answer them, and to do that by incorporating information from outside the U.S. Highway 271 project area. In addition to using the published data on other excavated sites, that meant including the Thomas B. Caldwell and A. P. Williams cemeteries, and to a lesser extent the cemetery at the Duncan Anderson site, in our analyses. The cemetery data gave us a richer and more-complete view of the Caddo settlement on Tankersley Creek than we would have had from the residential sites alone. We are lucky the Caldwell and Williams cemeteries were excavated in 1934, that they were documented as well as they were, and that the collections are still available for study. We also are lucky that this project coincided partly with our excavations at the Pine Tree Mound site. It is very rare for one team to have two large excavation projects in the same region at the same time. Together, they have shed much light on the archeology of the Titus phase area.

In terms of practical matters, we were satisfied with all of the kinds of heavy equipment we used for the excavations. The auger on the Bobcat worked well as a speedy replacement for shovel tests, given that the sediments are generally thin and we were not concerned about excavating in levels. The backhoe worked well for trenching during testing and excavation of sample units during data recovery, once again partly because we did not need to dig the sample units in levels. One problem we did have with this part of the work, though, was that some of the sample units resulted in so much dirt that we could screen only part of it, accounting for what we screened volumetrically. This led to much consternation and data gyrations to make sure the intrasite distributional analyses worked out; in the end, we believe they did. This problem was caused partly by some units being larger than planned (but also by backdirt piles freezing and becoming unscreenable); in the future, we would exercise more control in keeping such units to a manageable size. Finally, the large trackhoe worked well for stripping large areas at the three data recovery sites. It may not have the finesse of a Gradall, but with a good operator, it can do a good job. Further, it can go just about anywhere and is a more common machine than a Gradall.

The final topic warranting discussion here stems from the unusual history this project had, in particular, the shift from TxDOT to Titus County as the sponsor near the end of fieldwork for the testing phase. This created some uneasiness at the time about whether and how the archeological work would be carried through to completion, but in retrospect, that change was not a bad thing. Up to that point, TxDOT had approached the project in a very ambitious way, which is why the research design we prepared before the testing phase (Appendix A to this report) called for some lines of investigation that many archeologists familiar with the region thought had a very low probability of success. When Titus County took over as project sponsor, those lines of investigation were dropped or scaled back, and the overall focus shifted from a research-driven project to a compliance-driven one. Hence, the project became more straightforward. We will never know whether those other studies would have borne fruit, or how much more costly the project would have been if they had remained a part of the testing plan and been carried forward into data recovery, but it is hard to imagine they would have added much of substance to the story this report tells about the Caddo people who lived along Tankersley Creek. From that perspective, the retrenchment that occurred after the change in sponsor in late 2007, which resulted in a project that was simpler and less expensive (which is not to say inexpensive), was a positive thing. 


\section{REFERENCES CITED}

Adams, Jenny L.

1988 Use-Wear Analyses on Manos and Hide-Processing Stones. Journal of Field Archaeology 15(3):307-315.

1996 Bringing Stone Tools to Life: The People Behind the Rocks. Archaeology in Tucson: Newsletter of the Center for Desert Archaeology 10(3):1-5.

1999 Refocusing the Role of Food-Grinding Tools as Correlates for Subsistence Strategies in the U.S. Southwest. American Antiquity 64(3):475-498.

Ahr, Steven W.

2002 Impact Evaluation WA 57025PD003-Titus County, U.S. 271, Mount Pleasant Bypass (CSJ 1018-02-011). Interim report prepared by Geo-Marine, Inc., Plano.

Alt, Susan

1999 Spindle Whorls and Fiber Production at Early Cahokian Settlements. Southeastern Archaeology 18(2):124-133.

Amick, Daniel S., and Raymond P. Mauldin 1997 Effects of Raw Material on Flake Breakage Patterns. Lithic Technology 22:18-32.

Andrefsky, William, Jr.

1998 Lithics:Macroscopic Approaches to Analysis. Cambridge Manuals in Archaeology, Cambridge University Press, Cambridge, United Kingdom.

Banks, Larry D.

1984 Lithic Resources and Quarries. In Prehistory of Oklahoma, edited by Robert E. Bell, pp. 65-94. Academic Press, Inc., New York.
1990 From Mountain Peaks to Alligator Stomachs: A Review of Lithic Sources in the Trans-Mississippi South, the Southern Plains, and Adjacent Southwest. Memoir No. 4. Oklahoma Anthropological Society, Norman.

Barnett, Franklin

1973 Dictionary of Prehistoric Indian Artifacts of the American Southwest. Northland Press, Flagstaff, Arizona.

Barnhart, Edwin, Boyd Dixon, Stephen Kotter, Michael Nash, Kathryn Reese-Taylor, Elizabeth Skokan, and Rick Taylor

1997 Data Recovery Excavations at Site 41 TT372 in the Tankersley Watershed, Monticello B-2 Surface Mine, Titus County, Texas. Document No. 940608. PBS\&J, Austin.

Bell, Milton

1981 The Alex Justiss Site: A Caddoan Cemetery in Titus County, Texas. Publications in Archaeology, Highway Design Division Report No. 21. Texas State Department of Highways and Public Transportation, Austin.

Bell, Robert E., and George Lynn Cross

1980 Oklahoma Indian Artifacts. Contributions from the Stovall Museum No. 4. Stovall Museum, University of Oklahoma, Norman.

Brown, David, Laura Jones, Juana L. C. Ibanez, Ken White, Thomas Bearden, Sally Victor, Cecilia Green, Wayne Glander, Clay Carruthers, and Joe Lara

1986 Cultural Resources Survey and Testing of the Monticello-Winfield Coal Surface Mine, Titus County, Texas, Volume II, Tract H. Document No. 851200. Espey, Huston and Associates, Inc., Austin. 
Brown, Kenneth M.

1975 The Tigert Site: An Early Caddoan Archeological Site in the Hart Creek Drainage, Northeast Texas. Texas Journal of Science 26(1-2):229-247.

Bruseth, James E.

1998 The Development of Caddoan Polities along the Middle Red River Valley of Eastern Texas and Oklahoma. In The Native History of the Caddo: Their Place in Southeastern Archeology and Ethnohistory, edited by Timothy K. Perttula and James E. Bruseth, pp. 47-68. Studies in Archeology 30. Texas Archeological Research Laboratory, The University of Texas at Austin.

Burden, Damon A., Stephanie L. Katauskas, and Ross C. Fields

2012 National Register Testing at 41TT896 and 41TT906 and Archeological Survey of Three Parcels, FM 1000 Realignment Project (CSJ No. 1226-04-001), Titus County, Texas. Technical Reports No. 91. Prewitt and Associates, Inc., Austin.

Bureau of Economic Geology

1966 Geologic Atlas of Texas, Texarkana Sheet. Bureau of Economic Geology, The University of Texas at Austin.

Carr, Christopher

1995 Determinants of Mortuary Practices: Social Organization, Ideation, and Physical Constraints. Archaeological Method and Theory 2(2):105-200.

Carter, Cecile Elkins

1995 Caddo Indians: Where We Come From. University of Oklahoma Press, Norman.

Cecil, Leslie G.

2012 Petrographic Analysis of Pottery and Clay Samples. In Archeology of the Nadaco Caddo: The View from the Pine Tree Mound Site (41HS15), Harrison County, Texas, Volume II, edited by Ross C. Fields and Eloise Frances Gadus, pp. 797-826. Reports of Investigations No. 164. Prewitt and Associates, Inc., Austin.

Chamberlain, Andrew

2006 Demography in Archaeology. Cambridge Manuals in Archaeology. Cambridge University Press, Cambridge, United Kingdom.
Crabtree, Don E.

1972 An Introduction to Flintworking. Occasional Papers of the Idaho State Museum No. 28, Pocatello.

Crowley, T. J.

2000 Causes of Climate Change Over the Past 1000 Years. Science 289:270-277.

Davis E. Mott, W. A. Davis, Jules R. Gipson, and Bernard Golden

2010 Archeological Investigations at Lake O' the Pines, Marion and Upshur Counties, Texas, 1957-1959. Archival Series 4. Texas Archeological Research Laboratory, The University of Texas at Austin.

Davis, E. Mott, and Bernard Golden

1960 The Ben McKinney Site: A Titus Focus Site in the Ferrell's Bridge Reservoir Area, Northeastern Texas. Report submitted to the National Park Service by the Division of Research in Anthropology, The University of Texas.

Denison, R. E.

1959 The Rhyolites of Oklahoma: Proceedings of the Oklahoma Academy of Science 39:124-126.

Diamond, David D., David H. Riskind, and Steve L. Orzell

1987 A Framework for Plant Community Classification and Conservation in Texas. Texas Journal of Science 39(3):203-221.

Dixon, Boyd, Elizabeth Skokan, Robert Rogers, Steve Kotter, Michael Nash, and Edward Barnhart

1995 Archaeological Testing of Site 41 TT672 and Geomorphological Exploration of the Tankersley and Dragoo Creek Drainages, Titus County, Texas. Document No. 950565. Espey, Huston and Associates, Inc., Austin.

Ellis, Linda W.

2009 Analysis of Ground, Battered, and Polished Stone Artifacts from the Ear Spool Site (41TT653). In Data Recovery Investigations at the Ear Spool Site (41TT653) Titus County, Texas, by Timothy K. Perttula and David L. Sherman, pp. 305-334. Document No. 070205. PBS\&J, Austin.

Espey, Huston and Associates, Inc.

1982 Archaeological Testing of Site 41TT309, Titus County, Texas. Document No. 82404. Espey, Huston and Associates, Inc., Austin. 
1984 Archaeological Site Evaluations, MonticelloWinfield Mine, Titus and Franklin Counties, Texas. Document No. 82532. Espey, Huston and Associates, Inc., Austin.

Ferguson, Jeffrey R., and Michael D. Glascock

2012 Instrumental Neutron Activation Analysis of Ceramic and Clay Samples. In Archeology of the Nadaco Caddo: The View from the Pine Tree Mound Site (41HS15), Harrison County, Texas, Volume II, edited by Ross C. Fields and Eloise Frances Gadus, pp. 773796. Reports of Investigations No. 164 Prewitt and Associates, Inc., Austin.

Fields, Ross C., and Eloise Frances Gadus 2012 Archeology of the Nadaco Caddo: The View from the Pine Tree Mound Site (41HS15), Harrison County, Texas. Reports of Investigations No. 164. Prewitt and Associates, Inc., Austin.

Fields, Ross C., L. Wayne Klement, C. Britt Bousman, Steve A. Tomka, Eloise F. Gadus, and Margaret A. Howard

1991 Excavations at the Bottoms, Rena Branch, and Moccasin Springs Sites, Jewett Mine Project, Freestone and Leon Counties, Texas. Reports of Investigations No. 82. Prewitt and Associates, Inc., Austin.

Fischer, W. L.

1965 Rock and Mineral Resources of East Texas. Reports of Investigations No. 54. Bureau of Economic Geology, The University of Texas at Austin.

Ford, James A.

1951 Greenhouse: A Troyville-Coles Creek Period Site in Avoyelles Parish, Louisiana. Anthropological Papers of the American Museum of Natural History, Volume 44, Part 1. American Museum of Natural History, New York.

Galan, Victor, Robert Rogers, Timothy K. Perttula, and E. S. Switek

1997 National Register Testing of Seven Sites in the Monticello B-2 Surface Mine, Titus County, Texas. Document No. 971085. Espey, Huston and Associates, Inc., Austin.

Goldschmidt, W. R.

1934a Excavation of a Burial Site on Thomas B. Caldwell Plantation in Titus County, Texas. Manuscript on file at the Texas Archeological Research Laboratory, The University of Texas at Austin. 1934b Field Notes: Excavation of a Burial Site on A. P. Williams Farm in Titus County, Texas. Manuscript on file at the Texas Archeological Research Laboratory, The University of Texas at Austin.

1934c Field Report of an Excavation Through the George L. Keith Mound, Titus County, Texas, and Test Trenching on the C.T. Coley Farm, Titus County, Texas. Manuscript on file at the Texas Archeological Research Laboratory, The University of Texas at Austin.

1935 Some Archeological Sites in Titus County and Their Relation to East Texas Prehistory. Master's thesis, Department of Anthropology, The University of Texas at Austin.

Gramly, Richard Michael, and Kerry Rutledge

1981 A New Paleo-Indian Site in the State of Maine. American Antiquity 46:354-360.

Ham, William E., R. E. Denison, and C. A. Merritt

1964 Basement Rocks and Structural Evolution of Southern Oklahoma. Bulletin 95. Oklahoma Geological Survey, University of Oklahoma, Norman.

Hoffman, Michael P.

1967 Ceramic Pipe Style Chronology along the Red River Drainage in Southwestern Arkansas. The Arkansas Archeologist 8(1):4-14.

Inizan, Marie-Louise, Michèle Reduron-Ballinger, Hélène Roche, Jacques Tixier

1999 Technology and Terminology of Knapped Stone. Translated by Jehanne FéblotAugustins. In Préhistoire de la Pierre Taillé, Vol. 5. C.R.E.P., Nanterre.

Jackson, A. T.

1930 Excavation of a Burial Site, Joe Justiss Farm, Morris County, Texas. Manuscript on file at the Texas Archeological Research Laboratory, The University of Texas at Austin.

1931a Excavation of a Burial Site, P. S. Cash Farm, Camp County, Texas. Manuscript on file at the Texas Archeological Research Laboratory, The University of Texas at Austin. 
1931b Notes on Field Work, H. R. Taylor Farm, Harrison County, Texas. Manuscript on file at the Texas Archeological Research Laboratory, The University of Texas at Austin.

1931c Notes on Field Work, J. M. Riley Farm, Upshur County, Texas. Manuscript on file at the Texas Archeological Research Laboratory, The University of Texas at Austin.

1934 Trenching of an Earth Mound, L. A. Hale Farm, Titus County, Texas. Manuscript on file at the Texas Archeological Research Laboratory, The University of Texas at Austin.

Jernigan, E. Wesley

1986 A Non-Hierarchical Approach to Ceramic Decoration Analysis: A Southwestern Example. American Antiquity 51(1):3-20.

Johnson, Jay K.

1987 Cahokia Core Technology in Mississippi: The View from the South. In The Organization of Core Technology, edited by Jay K. Johnson and Carol A. Morrow, pp. 187-206. Westview Press, Boulder, Colorado.

Jones, Buddy Calvin

n.d. Notes on the Patton (Peanut Patch, 41HS825) Site. On file at the Texas Archeological Research Laboratory, The University of Texas at Austin.

Kotter, Steven M., L. Jones, Charles F. Frederick, and Wayne Glander

1991 An Archaeological Investigation of 41TT182 in the Monticello-Winfield South Surface Mine, Titus County, Texas. Document No, 910264. Espey, Huston and Associates, Inc., Austin.

Krieger, Alex D.

1946 Culture Complexes and Chronology in Northern Texas, With Extension of Puebloan Datings to the Mississippi Valley. Publication No. 4640. The University of Texas at Austin.

Lothrop, J. C., and Richard M. Gramly

1982 Piéces Esquillées from the Vail Site. Archaeology of Eastern North America 10:1-22.
MacDonald, George F.

1968 Debert: A Paleoindian Site in Central Nova Scotia. Anthropological Papers 16. National Museum of Canada, Ottawa.

Mallouf, Robert J.

1976 Archeological Investigations at Proposed Big Pine Lake, 1974-1975, Lamar and Red River Counties, Texas. Archeological Survey Report 18. Office of the State Archeologist, Texas Historical Commission, Austin.

Mann, M. E., R. S. Bradley, and M. K. Hughes

1998 Northern Hemisphere Temperatures During the Past Millennium: Inferences, Uncertainties, and Limitations. Geophysical Research Letters 26:759-762.

Nash, Michael A., Steven M. Kotter, and Kathryn V. Reese-Taylor

1995 National Register Testing of Ten Sites in the Monticello B-2 Surface Mine, Titus County, Texas. Document No. 930529. Espey, Huston and Associates, Inc., Austin.

Nass, John P., Jr. and Richard W. Yerkes

1995 Social Differentiation in Mississippian and Fort Ancient Societies. In Mississippian Communities and Households, edited by J. Daniel Rogers and Bruce D. Smith, pp. 58-80. The University of Alabama Press, Tuscaloosa.

Odell, George H.

2000 Stone Tool Research at the End of the Millennium: Procurement and Technology. Journal of Archaeological Research 8(4):269-331.

2004 Lithic Analysis. Kluwer Academic/Plenum Publishers, New York.

Parry, William J., and Robert L. Kelly

1987 Expedient Core Technology and Sedentism. In The Organization of Core Technology, edited by Jay K. Johnson and Carol A. Morrow, pp. 285-305. Westview Press, Boulder, Colorado.

Parsons, Mark

1998 41UR133: A Late Caddo Hamlet at Lake Gilmer. CRM News \& Views 10(1):16-19. Archeology Division, Texas Historical Commission, Austin. 
Perttula, Timothy K.

1984 Patterns of Prehistoric Lithic Raw Material Utilization in the Caddoan Area: The Western Gulf Coastal Plain. In Prehistoric Chert Exploitation: Studies from the Midcontinent, edited by Brian M. Butler and Ernest E. May, pp 129-148. Occasional Paper No. 2. Center for Archaeological Investigations, Southern Illinois University at Carbondale.

1992 "The Caddo Nation": Archaeological and Ethnohistoric Perspectives. University of Texas Press, Austin.

1993 Historic Context: The Development of Agriculture in Northeast Texas Before A.D. 1600. In Archeology of the Eastern Planning Region, Texas: A Planning Document, edited by Nancy Adele Kenmotsu and Timothy K. Perttula, pp. 121-146. Cultural Resource Management Report 3. Department of Antiquities Protection, Texas Historical Commission, Austin.

2004 The Prehistoric and Caddoan Archeology of the Northeastern Texas Pineywoods. In The Prehistory of Texas, edited by Timothy K. Perttula, pp. 370-407. Texas A\&M University Anthropology Series No. 9. Texas A\&M University Press, College Station.

Perttula, Timothy K.

2012 Risky Business: Caddo Farmers Living at the Edge of the Eastern Woodlands. Bulletin of the Texas Archeological Society 83:81-97.

Perttula, Timothy K. (editor)

1999 The Hurricane Hill Site (41HP106): The Archaeology of a Late Archaic/Early Ceramic and Early-Middle Caddoan Settlement in Northeast Texas, Vol. 1. Special Publication No. 4. Friends of Northeast Texas Archaeology.

2005 Archeological Investigations at the Pilgrim's Pride Site (41CP304), a Titus Phase Community in the Big Cypress Creek Basin, Camp County, Texas. Report of Investigations No. 30. Archeological and Environmental Consultants, LLC, Austin.

Perttula, Timothy K., P. Shawn Marceaux, and Bo Nelson

2012 Study of the Margaret Hinton Collection of Pottery Vessels from Northeast Texas Caddo Cemeteries. Archeological and Environmental Consultants, LLC, Austin.
Perttula, Timothy K., and Bo Nelson

2002a Additional Archeological Survey Investigations at 41TT851 for the Proposed U.S. 271 Mt. Pleasant Loop, Titus County, Texas. Interim report prepared by Archeological and Environmental Consultants, LLC, Austin.

2002b Archeological Survey of Lake Bob Sandlin State Park, Titus County, Texas. Report of Investigations No. 48. Archeological and Environmental Consultants, Austin.

2005 Archeological Surveys and Impact Evaluations in the Texas Department of Transportation's Atlanta, Lufkin, and Tyler Districts, 2001-2003 (Contract 572XXSA001). Archeological Studies Program, Report No. 72. Texas Department of Transportation, Environmental Affairs Division, Austin. Report of Investigations No. 61. Archeological and Environmental Consultants, LLC, Austin.

Perttula, Timothy K., Bo Nelson, and LeeAnna Schniebs

2003 Titus Phase Archeology at the S. Stockade Site (41TT865) on Tankersley Creek, Titus County, Texas. Caddoan Archeology Journal 13(1): 7-15.

Perttula, Timothy K., Bo Nelson, and T. Clay Schultz 2002 Archeological Survey of the U.S. 271, Mount Pleasant Loop, Titus County, Texas, for the Texas Department of Transportation. Interim report prepared by Archeological and Environmental Consultants, LLC, Austin.

Perttula, Timothy K., and David L. Sherman

2009 Data Recovery Investigations at the Ear Spool Site (41TT653), Titus County, Texas. Document No. 07025. PBS\&J, Austin.

Perttula, Timothy K., Melinda Tate, Hector Neff, James W. Cogswell, Michael D. Glascock, Elizabeth Skokan, Sue Mulholland, Robert Rogers, and Bo Nelson

1998 Analysis of the Titus Phase Mortuary Assemblage at the Mockingbird Site, "Kahbakayammaahin" (41TT550). Document No. 970849. Espey, Huston and Associates, Inc., Austin.

Perttula, Timothy K., Bo Nelson, and Mark Walters

2012 Caddo Archaeology at the Henry Spencer Site (41UR315) in the Little Cypress Creek Basin of East Texas. Special Publication No. 20. Friends of Northeast Texas Archaeology, Pittsburg and Austin. 
Perttula, Timothy K., Mark Walters, Shawn Marceaux, and Bo Nelson

2009 Caddo Pottery Vessels and Pipes from Sites in the Middle and Upper Sabine and Upper Neches River Basins, Smith and Wood Counties Texas. Special Publication No. 7. Friends of Northeast Texas Archaeology, Pittsburg and Austin.

Perttula, Timothy K., Mark Walters, and Bo Nelson 2010a Caddo Pottery Vessels and Pipes from Sites in the Big Cypress, Sulphur, NechesAngelina, and Middle Sabine River Basins in the Turner and Johns Collections, Camp, Cass, Cherokee, Harrison, Morris, Titus, and Upshur Counties, Texas and Sabine Parish, Louisiana. Special Publication No. 10. Friends of Northeast Texas Archaeology, Pittsburg and Austin.

2010b Caddo Pottery Vessels and Pipes from the Johns Site (41CP12) in the Big Cypress Creek Basin in the Turner and Johns Collections, Camp County, Texas. Special Publication No. 11. Friends of Northeast Texas Archaeology, Pittsburg and Austin.

2012 Little Cypress Creek Basin Archeology: Six Late Caddo Period Cemeteries in Upshur County, Texas. Special Publication No. 22. Friends of Northeast Texas Archeology, Pittsburg and Austin.

Peter, Duane E., S. M. Hunt, R. Reinecke, and J. Hoffman

2001 Environmental Reconnaissance of the Priefert Property, Titus County, Texas. Miscellaneous Reports of Investigations No. 234. Geo-Marine, Inc., Plano.

Phillips, Philip, and James A. Brown

1978 Pre-Columbian Shell Engravings from the Craig Mound at Spiro, Oklahoma, Part I. Peabody Museum of Archaeology and Ethnology, Harvard University, Cambridge, Massachusetts.

Prikryl, Daniel J.

2008 The 1991 and 1992 Texas Archeological Society Field School Excavations at the Fasken Site (41RR14), Red River County, Texas. In Collected Papers from Past Texas Archeological Society Summer Field Schools, edited by Timothy K. Perttula, pp. 125-172. Special Publication No. 5. Texas Archeological Society.
Roberts, Kirthell

1990 Soil Survey of Camp, Franklin, Morris, and Titus Counties, Texas. United States Department of Agriculture, Soil Conservation Service, in cooperation with Texas Agricultural Experiment Station and Texas State Soil and Water Conservation Board.

Rogers, J. Daniel

1995 The Archaeological Analysis of Domestic Organization. In Mississippian Communities and Households, edited by J. Daniel Rogers and Bruce D. Smith, pp. 7-31. The University of Alabama Press, Tuscaloosa.

Rogers, Robert

2004a Summary and Synthesis. In The Oak Hill Village Site (41RK214,) Rusk County, Texas, by Robert Rogers and Timothy K. Perttula, pp. 345-347. Document No. 030083. PBS\&J, Austin.

2004b The Caddoan Village. In The Oak Hill Village Site (41RK214), Rusk County, Texas, by Robert Rogers and Timothy K. Perttula, pp. 49-96. Document No. 030083. PBS\&J, Austin.

Rogers, Robert, Maynard B. Cliff, Timothy K. Perttula, Gary Rutenberg, Sally Victor, Phil Dering, and Mary Malainey

2003 Excavations at the Alex Justiss Site, 41TT13, Titus County, Texas. Archeological Studies Program Report No. 36. Environmental Affairs Division, Texas Department of Transportation, Austin. Document No. 030089. PBS\&J, Austin.

Shafer, Harry J.

1973 Lithic Technology at the George C. Davis Site, Cherokee County, Texas. Ph.D. dissertation, Department of Anthropology, The University of Texas at Austin.

Shott, Michael J.

1989 Bipolar Industries: Ethnographic Evidence and Archaeological Implication. North American Archaeologist 10:1-24.

Sills, Elizabeth, and Maynard Cliff

2003 Results of National Register Testing Conducted on Site 41TT440 and 41TT486. Document No. 02094. PBS\&J, Austin. 
Story, Dee Ann

1990 Cultural History of the Native Americans.

In The Archeology and Bioarcheology of the Gulf Coastal Plain, Volume 1, by Dee Ann Story, Janice A. Guy, Barbara A. Burnett, Martha Doty Freeman, Jerome C. Rose, D. Gentry Steele, Ben W. Olive, and Karl J. Reinhard, pp. 163-366. Research Series No. 38. Arkansas Archeological Survey, Fayetteville.

Story, Dee Ann, and Darrell G. Creel

1982 The Cultural Setting. In The Deshazo Site, Nacogdoches County, Texas, Volume I: The Site, Its Setting, Investigation, Cultural Features, Artifacts of Non-Native Manufacture, and Subsistence Remains, edited by Dee Ann Story, pp. 20-34. Texas Antiquities Permit Series No. 7. Texas Antiquities Committee, Austin.

Story, Dee Ann, Janice Guy, D. Gentry Steele, Barbara Burnett, Martha Doty Freeman

1990 Gulf Coastal Plain Adaptation Types: A Preliminary Statement. In The Archeology and Bioarcheology of the Gulf Coastal Plain, Vol. 1, by Dee Ann Story, Janice A. Guy, Barbara A. Burnett, Martha Doty Freeman, Jerome C. Rose, D. Gentry Steele, Ben W. Olive, and Karl J. Reinhard, pp. 425434. Research Series No. 38. Arkansas Archeological Survey, Fayetteville.

Studer, Joseph Mark

1982 Archaic Pebble Core Reduction Technology in East Texas: The Icy Eye Example. Papers in Anthropology No. 3. Stephen F. Austin State University, Nacogdoches, Texas.

Stuiver, Minze, Paula J. Reimer, and Ron Reimer 2005 CALIB 5.0. Electronic document, http:// calib.qub.ac.uk/calib/calib.html.

Suhm, Dee Ann, and Edward B. Jelks

1962 Handbook of Texas Archeology: Type Descriptions. Texas Archeological Society Special Publications Number 1, Texas Memorial Museum Bulletin 4. Austin.

Suhm, Dee Ann, Alex D. Krieger, and Edward B. Jelks 1954 An Introductory Handbook of Texas Archeology. Bulletin of the Texas Archeological Society 54.

Swanton, John R.

1942 Source Material on the History and Ethnology of the Caddo Indians. Bureau of American Ethnology Bulletin 132. Smithsonian Institution, Washington, D.C.
Thurmond, J. Peter

1981 Archeology of the Cypress Creek Drainage Basin, Northeastern Texas and Northwestern Louisiana. Master's thesis, Department of Anthropology, The University of Texas at Austin.

1985 Late Caddoan Social Group Identifications and Sociopolitical Organization in the Upper Cypress Basin and Vicinity, Northeastern Texas. Bulletin of the Texas Archeological Society 54:185-200.

1990 Archeology of the Cypress Creek Drainage Basin,Northeastern Texas and Northwestern Louisiana. Studies in Archeology 5. Texas Archeological Research Laboratory, The University of Texas at Austin.

Trierweiler, W. Nicholas (editor)

1994 Archeological Investigations on 571 Prehistoric Sites at Fort Hood, Bell and Coryell, Counties, Texas. Research Report No. 31. Archeological Resource Management Series, United States Army Fort Hood.

Turner, Ellen Sue, and Thomas R. Hester

1999 A Field Guide to Stone Artifacts of Texas Indians. Gulf Publishing, Houston.

Turner, Robert L.

1978 The Tuck Carpenter Site and Its Relation to Other Sites Within the Titus Focus. Bulletin of the Texas Archeological Society 49:1-110.

1992 Prehistoric Mortuary Remains at the Tuck Carpenter Site, Camp County, Texas. Studies in Archeology 10. Texas Archeological Research Laboratory, The University of Texas at Austin.

2006 Hematite Axes of Northeast Texas. Bulletin of the Texas Archeological Society 77:1-32.

U. S. Geological Survey, Mineral Resources On-line Spatial Data

2011 Diorite Sill. Electronic document, http:// tin.er.usgs.gov/geology/state/sgmc-unit. php?unit=OKd\%3B0, accessed March 2011.

Webb, Clarence H.

1959 The Belcher Mound, A Stratified Caddoan Site in Caddo Parish, Louisiana. Memoirs No. 16. Society for American Archeology, Salt Lake City, Utah. 
Whittaker, John C.

1994 Flintknapping:Making and Understanding Stone Tools. University of Texas Press, Austin.

Wyckoff, Don G., and Linda Ragland Fisher 1985 Preliminary Testing and Evaluation of the Grobin Davis Archeological Site, 34Mc-253, McCurtain County, Oklahoma. Archeological Resource Survey Report No. 22. Oklahoma Archeological Survey, The University of Oklahoma, Norman.
Young, Wayne C.

1981 Test Excavations at the Tankersley Creek Site, Titus County, Texas. Publications in Archaeology, Highway Design Division Report No. 22. Texas State Department of Highways and Public Transportation, Austin. 